

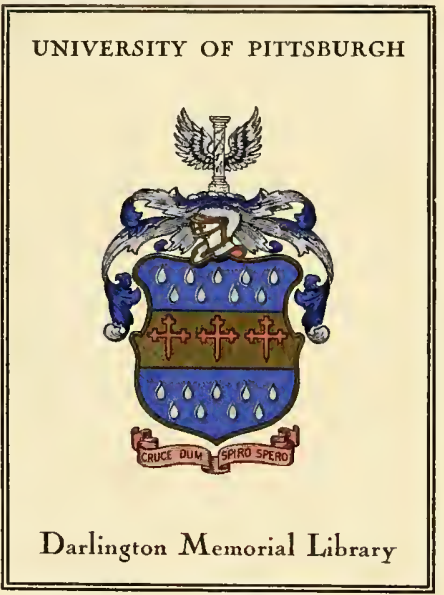



Digitized by the Internet Archive in 2009 with funding from. University of Pittsburgh Library System 




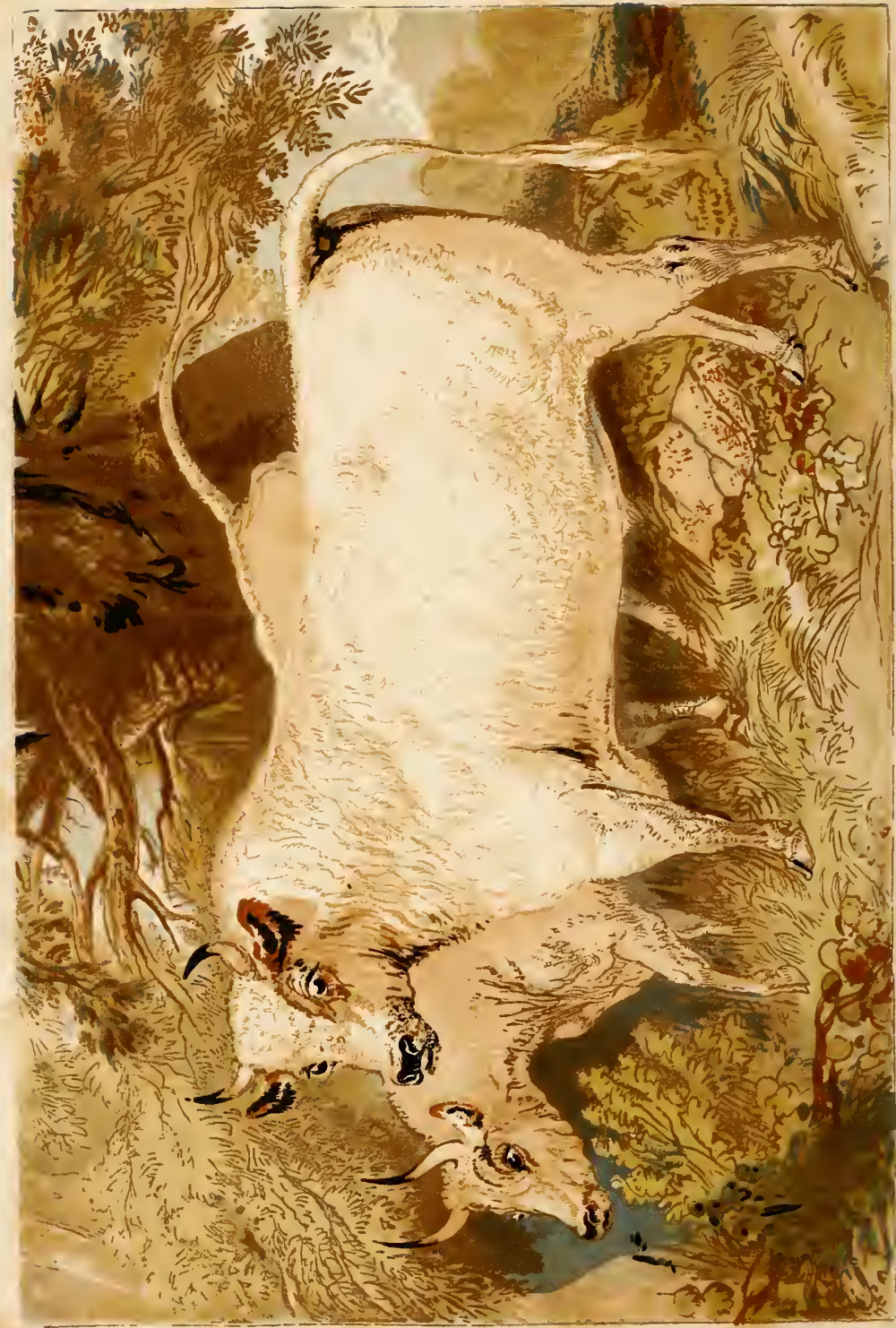




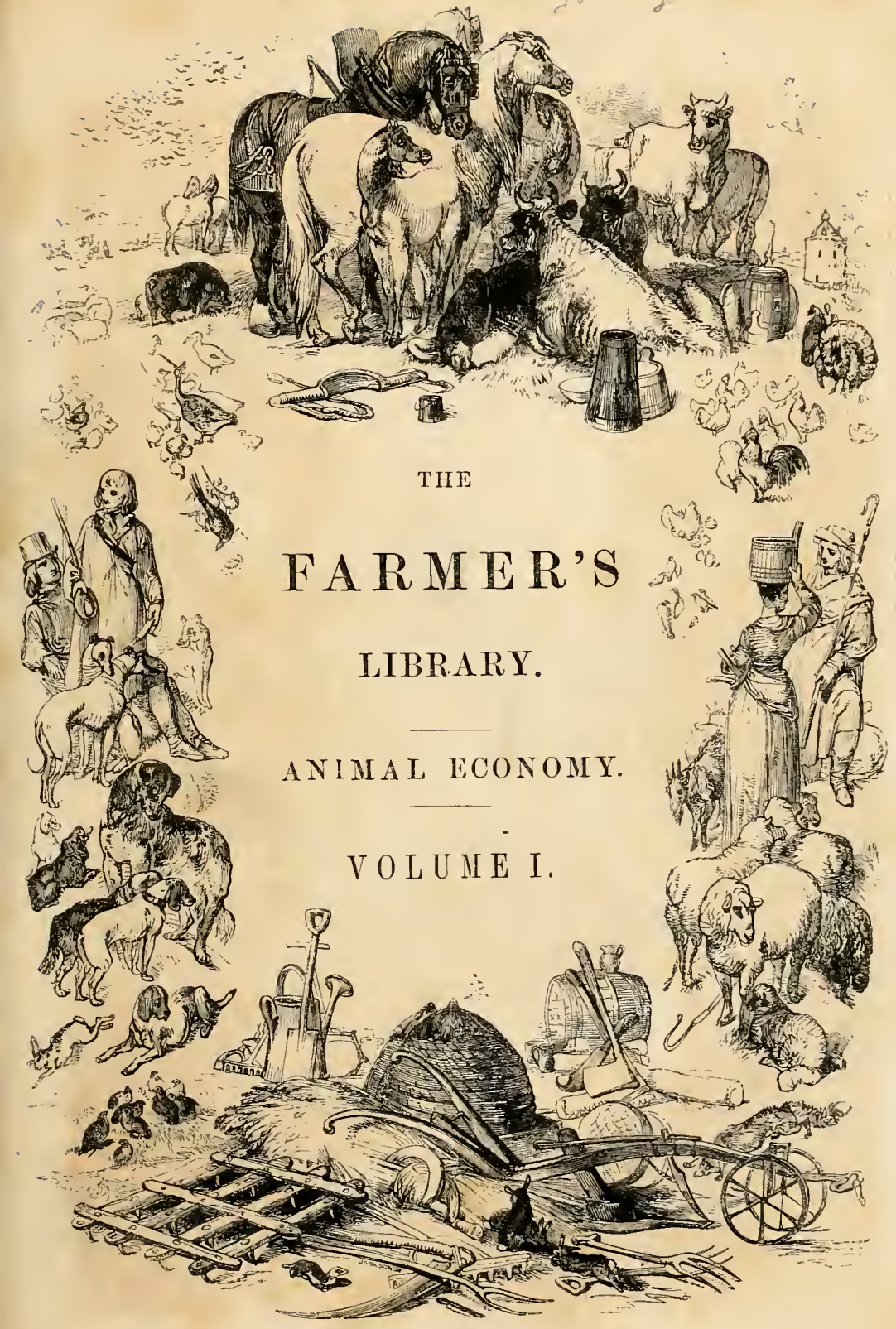

LONDON: CHARLES KINIGHT. 


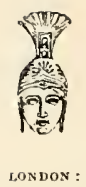

PIZETELLY BROTHERS AND CO, PRINTERS AND ENGRAVERS,

PRTERBOROUGH COURT, FLEET STREET. 


\section{TABLE OF CONTENTS.}

THE OX.

CHAPTER

I.-VARIOUS SPECIES OF THE OX TRIBE

II.-VARIOUS SPECIES OF THE DOMESTICATED OX

PATEE

III-STRUCTURE, SENSES, AND FOOD OF HORNED CATTLE

IV. BPEEDS AND HABITS OF THE EUROPEAN OX

V.-BREEDS AND VARIETIES OF THE ENGLISH HORNED CATTLE 57

VI.-MANAGEMENT OF IIORNED CATTLE

VII.CHEMICAL OBSERVATIONS ON THE FOOD OF CATTLE . . 108

-VIII.DISEASES OF CATTLE, AND THEIR TREATMENT . . . 118

MEDICINES EMPLOYED IN THE TREATMENT OF CATTLE . $17 \%$

THE HORSE.

I.-EARLY HISTORY OF THE HORSE

II.-FOREIGN BREEDS OF HORSES

III.-HISTORY OF THE ENGLISH IIORSE

IV.-DIFFERENT BREEDS OF ENGLISH IIORSES . . . . . . . 233

V.-THE ZOOLOGICAL CLASSIFICATION OF THE HORSE . . . . 262

VI.-THE SENSORIAL FUNCTION

VII.-INJURIES AND DISEASES OF THE SKULI-THE BRAIN-THE EARS-AND THE EYES

261

4

VIII-ANATOMY AND DISEASES OF THE NOSE AND MOUTH

IX.-ANATOMY AND DISEASES OF THE NECK AND NEIGHBOURING PARTS

X.-THE CHEST

n XI.-CONTENTS OF THE CHEST

XII.-THE RESPIRATORY SYSTEM

XIII.-THE ABDOMEN AND ITS CONTENTS . . . . . . . . 389

XIV.-DISEASES OF THE INTESTINES . . . . . . . . 398

XV.-BREEDING; CASTRATION . . . . . . . . . 411

XVI.-THE FORE LEGS . . . . . . . . . . . 417

XVII.THE HIND LEGS . . . . . . . . . . . . 437

XVIII.THE FOOT . . . . . . . . . 451

XIX_-DISEASES OF THE FOOT

XX.-FRACTURES . . . . . . . . . . . 473

XXI.-ON SHOEING . . . . . 483

XXII-SURGICAL OPERATIONS . . . . . . . . . . . 492

XXIII.-VICES . . . . . . . . . . . . . . . 499

XXIV.-GENERAL MANAGEIENT . . . . . . . . . . 510

XXV.-TIIE SKIN AND ITS DISEASES . . . . . . . . . 522

XXVI.-ON SOUNDNESS, AND THE PURCHASE AND SALE OF HORSES 528

XXVII_-MEDICINES-THEIR NATURE AND USES . . . . . . 536

do

A TREATISE ON DRAUGHT

553

N 



\section{ILLUSTRATIONS TO VOIUME I.}

\section{THE OX.}

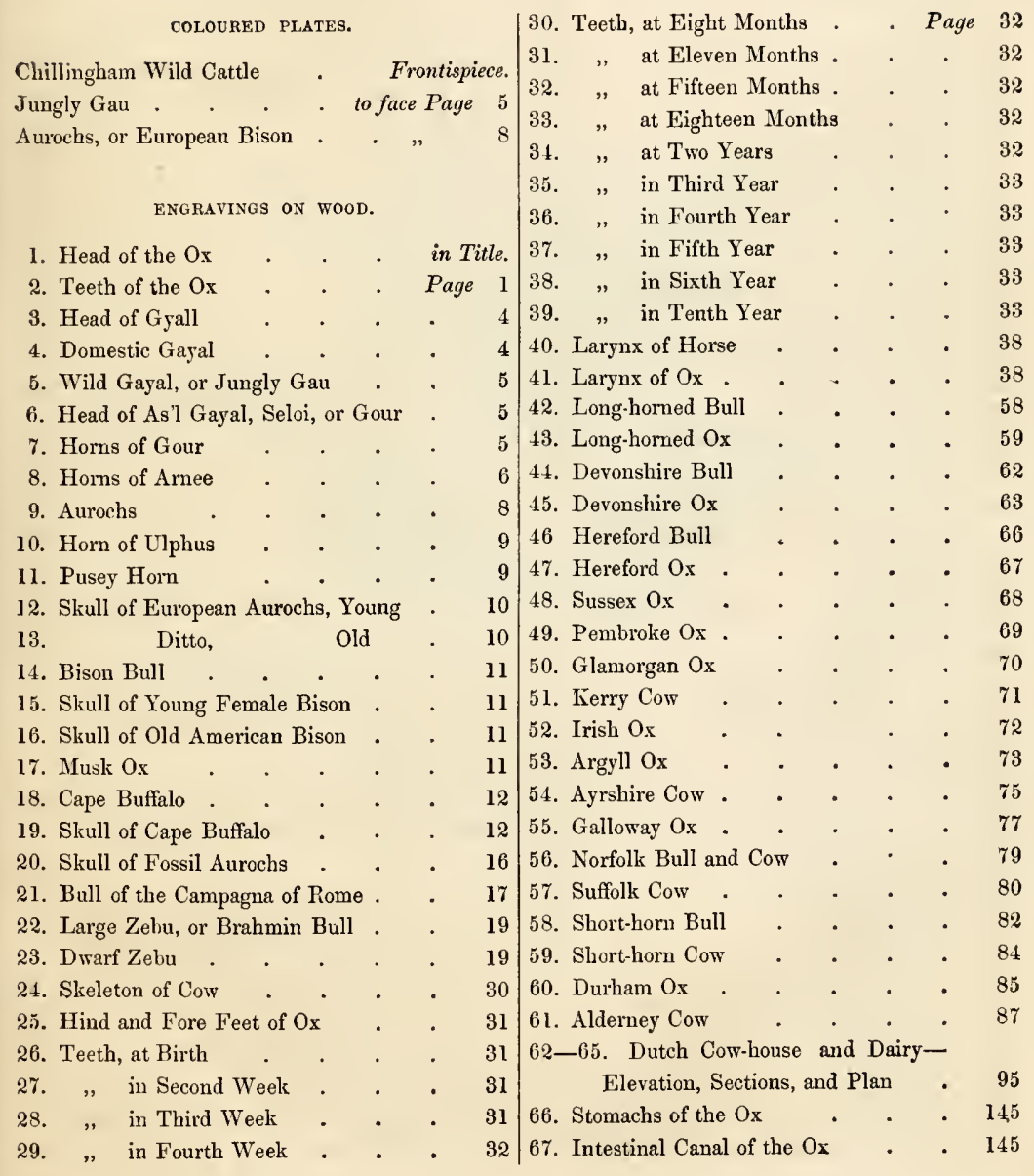


THE HORSE.

1. Head of the Horse

in Title.

2. Horses on the Frieze of the Temple of Minerva

3. The Godolplin Arabian

4. Arab Mare and Foal

5. Bay Arabiau

6. Cossack Horse and Soldier

7. The Colonel

8. Flying Childers

9. Eclipse

10. Fleur-de-lis

11. The Hunter

12. The Hackney

13. The Coach Horse

14. The Suffolk Punch

15. The heary black Horse

16. The Shetland Poney

17. The Skeleton of the Horse

18. Skeleton of the Head

19. Section of the Head

20. Diagram of part of the Temporal Bone

21. Lower part of the Head

22. Nerves of the Spine

23. Section of the Fire

24. Muscles of the Eye

25. Horse suffering from Tetanus

26. Nerves of the Leg

27. Vessels of the Nose

28. The muscles, nerves, and bloodvessels of the head and upper part of the neck

29. The Palate .

30. The Gleuoid Cavity in the Tiger and the Horse

31. Teeth, at Birth

32. " in Sixth Week .

33. " at Twelve Months

34. A Grinder, sawed across

35. Teeth, at Two Years

36. , , at Three Years .

37. " in Fourth Year.

38. " " at Five Years

39. ", at Six Years

40. " at Seven Years.

41. ," at Eight Years .

42. Neck of a Horse

43. The Chest

44. The Stomach

45. The Termination of the Æsophagus

46. Cut of the Bot

47. The Intestines

48. The Coseum .

49. Entanglement of the Bowels.

50. A Straight and Curved Catheter

51. Section showing position of the Shoulder 418
52. Diagram exemplifying the power of the Muscles of the Shoulder
189

199

202

203

221

233

234

235

242

244

249

253

256

258

261

263

266

269

269

270

$2 \pi \cdot 2$

277

282

292

299

308

309

323

324

325

325

326

326

326

327

327

328

329

329

329

337

344

389

390

392

395

396

404

411
53. Muscles on the outside of the Shoulder 420

54. Muscles on the inside of the Shoulder 422

55. The Pasterns . . . . 432

56. The Pasterns . . . . 435

5\%. Section of the Leg . . . 435

58. Lamenesses to which the Fore

Extremities are subject

436

59. A few of the Muscles of the Hinder Extremities

60. Muscles of the Outside of the Thigh 439

61. The Haunch and Hind Legs. . 440

62. The Hock . . . . . 443

63. The Hoof . . . . 451

64. The Base of the Foot . . . 451

65. The Coronary Ring . . . 452

66. Suspensory Apparatus . . . 4 473

67. Horse-shoe . . . . . 487

68. Hoof and Shoe . . . . 4 48s

69. Ditto . $\quad . \quad . \quad .488$

70. Horse Sandal . . . . $49 \mathrm{~J}$

71. Ditto . . . . . 491

7.2. Diagrams showing the priuciple of Traction.

558

73. Progression of Feet in a Horse's Walking . . . .

74-77. Diagrams illustrative of the principle of Traction .

563

78. Figure illustrative of Propulsion . 564

79. Diagram of the Wheel . . 561

80. Figure illustrative of Misapplication of the Traces . . . 565

81, 82. Grecian mode of Harnessing Horses 565

83. Ditto of Outer or Third Horse . 566

84. Sections of the shoulder, to show the proper position of the Trace . 56 i

85-88. Diagrams illustrative of the principle of the Cylinder or Poller . . . 570,571

89-91. Diagrams showing the transportation of a heavy stone - 571, 572

92-94. Figures, showing the approximation of the Cylinder to the Wheel

95. Ancient Pole and Axletree : $\quad 573$

96. Diagram of Wheel and Axle . . 574

97-101. Forms and Positions of Wheels . . . . 576,577

102. Motion of Conical Wheel . . 577

103. Diagram of the Motion of a Cone . 578

104. Figure of Cylindrical Mill-stone . 578

105. Proper Form of Wheel . . 578

106. Fìgure of Chariot . . . 581

$10 \%, 108$. Figures of Curvatures of Roads and Whbeels 


\section{THE OX.}

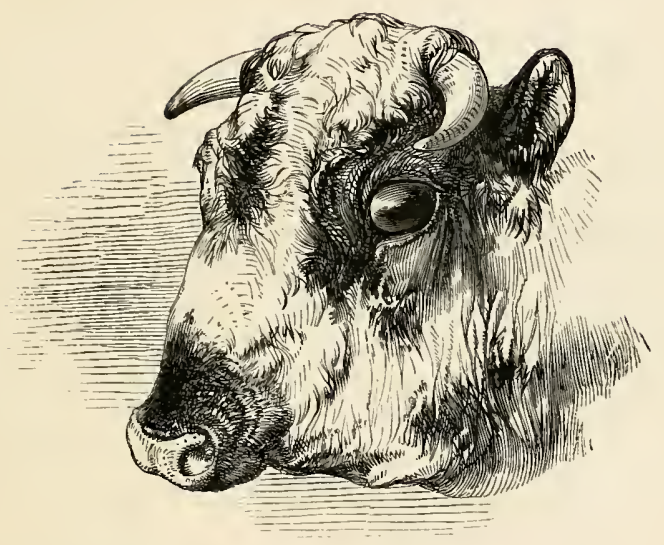

\section{BY W. C. L. MARTIN,}

IATE ONE OF THE SCIENTIFIC OFFICERS OF THE ZOOLOGICAL SOCLETY oF LONDON. 



\section{THE OX.}

\section{CHAPTER I.}

Among the various orders of mammalia, from which man has reclaimed and domesticated certain species-species, the possession of which, in a state of subjection and dependence, contribute essentially to his welfare-that of the Ruminantia, or ruminating animals, affords him the greatest number; and those not of the lowest importance. To this order belong the camel, the llama and its allies, the different species of the ox, the sheep, and the goat. Since the remotest periods of history, the ox and the sheep have been regarded in the light of property; nor is their intrinsic value less appreciated after a lapse of ages. Who does not know how intimately the well-being of a nation is connected with its agrarian produce, whether animal or vegetable; and how closely the interests of commerce and of agriculture are inter-llended together? It has been said by some one, that he who makes two stalks of corn grow where only one grew before, is a benefactor of his country; and by a parity of reasoning, he who improves the breeds of domestic cattle, feeds two on the land which before only supported one; and he who devises superior modes of management witl regard to the extension of their ntility, also serves the interests of the community. On topies like these, however, we need not insist; let us at once to our subject.

The $\ddot{O} x$, then, is one among the ruminating order of quadrupeds. All the animals of this order have certain characteristics in common, which distinctly mark the differences between them and the animals of all other orders. They have cloven hoofs; and they are destitute of incisors, or cutting teeth in the upper jaw. With regard to the hoof we may observe that, as in the horse, the terminal bone of the toe is incased with horn; but the horse has only a single series of phalangal bones, the ruminants two; and hence the expression-cloven. But besides these there are, in some groups, as the deer, an extralateral toe on each side, consisting of three minute phalangal bones, supported by a small stylet. As in the horse, the canon-bone is single, but generally shows, more or less by a longitudinal furrow, that in an early stage it consisted of two portions, first coalescing, and at length becoming ossified into one.

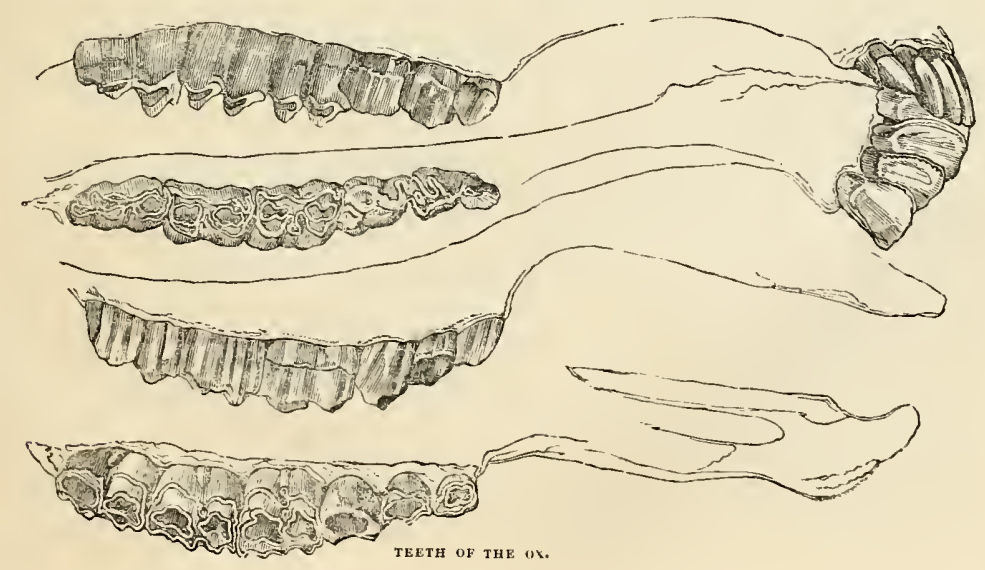


With respect to the teeth, though there are no incisors in the upper jaw, the gum is hardened, forming a fibrous and elastic pad, fitted to sustain the pressure of the lower incisors, eight in number, the position of which is rather oblique than vertical. The molars are six in number on each side, above and below. Of these the first three are preceded by milk, or deciduous teeth: the three posterior are originally permanent. Their surface is marked by two pairs of crescentic ridges. In the lower jaw, their crescents have the convexity outwards; in the upper jaw, the reverse. These crescents, as they wear down by use, show a centre of bone surrounded by a coat of enamel. In general, there are no cauine teeth: these exist, lowever, in the upper jaw of the camel, the llama, the male of the musk-deer, and chevrotains, and the male of many true deer.

The act of rumination, or chewing the cud, supposes a peculiarly complicated structure of the stomach, to be more fully explained hereafter. We may, however, observe, that the four distinct cavities, or receptacles, are so arranged that the coarsely-ground lerbage receired into the first large cavity, or paunch, is thence gradually propelled into the second; riz., the hood, or honey. comb, through a valrular communication. Here it is compacted into small balls, which, while the animal reposes at its ease, and in evident enjoyment, are retumed scriatim to the mouth, by a sort of spasmodic action, and are thoroughly remasticated. The aliment thus finely ground is re-swallowed, but instead of being carried into the paunch, it is tumed aside in its passage down the gullet, or œsopliagus, by a voluntary closure of the muscular edges of the entrance into the panuch, and so carried into the third, or plicated compartment, termed manyplies, or manyplus, whence, after compression between the foliations of that receptacle, it passes through a valvular orifice into the fourth; viz., the rud, or abomasum, which is the true digestive stomach.

Now, the suckling calf does not ruminate; for, while nourished by the mother's milk, the process cannot be accomplished, and is not requisite. The proportion which the different compartments of the stomach, at this early age, bear to each other, is consequently, very different to that which afterwards obtains, when the aliment is changed from milk to herbage. The lunge paunch, for instance, is, at this early period, far less capacions than the fourth stomach, or rud, which is inleed, at this time, the largest of the compartments, and receives at once the milk as it is swallowed: here, by the action of the gastric juice, the milk is curdled previously to digestion. It is the imer membrane of this portion of the stomach which is salted and driel, and, under the name of remet, msed in making cheese: its effect resides in the gastric juice with which it is imbined.

These general details apply to all the Rumi$n$ ntia; but in other respects the various orders, or groups composing this class, differ from each other in many well-marked peculiarities, and in according halits. The camel, tall, gaunt, and augular, wends his way over the deserts of the east, with measured stepss, slowly and silently pursuing his course from Aleppo or Bagdad, to Iecca or El-Basral, laden with bales of merchandise. The llama and vicugna seale the rugged and precipitous cordilleras of Peru and Chili. The light-limbed antelope scours the desert, and the wide karroo. The swift deer rejoices in the glades of the forest. But from these ruminants, and others, the true $\mathrm{Ox}_{\mathrm{x}}$ tribe, or the genus Bos, is at once to be discriminated, though it must be confessed. that some of the buge and heavy (so called) antelopes of Africa-as the koorlo, the hartebeest, and the bekr-el-wash of the Arahs (the bubalus of the ancients) -in some respects approximate towards it. The genus Bos, has been subdivided by naturalists into several subgenera; but with these sub-scetions, which naturalists of the present day carry out to an unwarrantable excess (as if science consisted in pusling analysis to an extreme), we shall have nothing to do; suffice it for us to detail, in brief terms, its leading characters.

In both sexes the head is armed with horns (we of course except the polled domestic breeds of cattle), and these horns consist of an external layer of corneous fibres compacted together, and sheathing a hollow or cancellous bony core, continued laterally from a bold occipito-frontal ridge. Hence are oxen termed hollow-horned ruminants; together with antelopes, goats, \&c., in contradistinction to deer; the progressive increase of the horns is marked by successive ridges, or rings, at their hase; oxen have neither suborbital sinuses nor interdigital pits (as the sheep), nor inguinal pores; their form is heavy and massive; their statue generally large; the limbs are low and strong; the haunches wide; the shoulders thick; the head is large; the forehead or chaffron, expanded; the muzzle, excepting in the subgenus (Ovibos, musk-ox, for example), is broad, naked, and moist; the tongue is rough with hard, horney papillæ, directed backwards, and assists greatly in the act of grazing; the neck is thick, deep, compressed laterally, carried horizontally, and furnished with a pendant dewlap; the spinous processes of the anterior dorsal vertebre at the withers are very long and stout. All the $O x$ tribe are gregarious in their habits; and no quarter of the globe (Australia excepted) is destitute of its indigenous species, existing in a state of freedom. They roam over hills or plains, or tenant the glades of the forest. In all the species the 
teats of the female are four in number. The skin is thick.

When we said that no quarter of the globe, cxcepting Australia, is destitnte of its native species, we did not forget that, throughout the rast extent of South America, no indigenous wild ox has, as far as the researches of the naturalist go, ever existed, at least under the present condition of that portion of the surface of the globe. The immense herds of cattle which now roam the pampas, are the descendants of those domestic oren which were originally introduced by the Spaniards; and, it may be added, that although in North America the bison Americanus and the musk ox are indigenous species, the domestic ox, now of such value, is in like manner an importation; while the indigenous species are disappearing before the advance of colonization. It is said indeed, that some attempts have been, at different times, made to domesticate the Amerisan bison; and that this species has interbred with the ordinary cattle of European origin which have returned, in the prairies, to a state of wildness. But on this point we confess ourselves very sceptical, alliongh Catesby asserts it. Even should instances of this hind have occurrel, the possibility of obtaining a permanent mixed breed, the descendants of hybrids is out of the question, the two species being more remote from each other than are the horse and the ass. When Catesby says "that to mix the breed (of bisons) with tame cattle wonld much improve the breed (of domestic cattle)" is a general opinion, we think that in every sense, he is writing at random. It may be the "general opinion," but that is of little importance ; for where it possible to procure sucls a hybrid stock, we could not expect to find the domestic ox improved by such a cross. We are among those who believe, that species closely allied, have, in times passed, coalesced, and may coalesce now; but we say again, that anatomical differences render these species remote: and eveu were their intermixture possible, nothing is to be gained by a procedure, interdicted by instinct, in such a case as this, excepting, indeed, to nentralize all that the grazier and the dairy farmer regard as points of excellence in their favourite cattle.

This reference to the American bison, asserted not only by Catesby, but by Peunant and others, to interbreed with the common race of cattle, * leads us here to pause, in order that we may take a general survey of the known existing species of the genus Bos, and especially of the species domesticated, in order that the true position of the ordinary ox with respect to them, may he the better appreciated. We shall find it to differ in important particulars. Let us first turn to Asia.

"Curier says, "Il produit arec nos vaches," but upon what authority we know not.
The wild and semi-domesticated cattle of this portion of the globe have yet to be thoroughly known. There is one, however, to which we would first direct onr attention; namely, the gayal, or gyall, an animal which appears to exist both in a wild and domestic state, and respecting which there is, consequently, a degree of confusion.

In the provinces of Aracan, Chittagong, or Chatgaon, Tipura, and Silhet, this species is well known; but it seems to have been regarded by some as identical with the gour, at least there is some misunderstanding in the works of writers on the subject.

The Gayâl (Bos Grvœus, Colebroolre, Asiat, Rev., vol, viii.) is evidently identical with the Gyall (Bos frontalis, Lambert, Linn. Trans.) and the Jungly Gau (Bœuf des Jongles, of M. Duvancel, Bos Silhetanus of F. Cuvier). This animal, also called Gajjal (Garaya, Sanscr., Gavai, or Gayâll, Hind., Gobaygoru, Beng., Mèthaná, Mountaineers east of Silhet: Shiâl, Mountaineer's east of Chatgaon), may be thus described :- Shape and size that of the European bull. Horns short, and distant at their base, rising in a gentle curve directly up and out; ovate at their base, but not decidedly flattened: front broad and tufted, with long curled hair: dewlap deep and pendant: withers elevated, but destitute of anything like a hump: neck maneless: tail moderate: the body covered with dark brown hair, lighter colour on the lielly, and generally white on the legs. A fine specimen of this animal, which we have examined, exists in the gardens of the Zoological Society, London; and in general aspect its appearance approximates more closely to that of the ordinary ox, than does that of any other species with which we are acquainted; nevertheless, the elevation of the withers, and the fall of the croup, would not escape the most ordinary observer. Duvancel, indeed for some time believed that this species mas identical with our domestic oxen. but he had then only seen tame specimens in the menagerie at Barmckpore. Subsequently lie hunted them at the foot of the Silhet mountains, and obserred that they were as common, and as widely spread, as the wild buffaloes; and even more wild, though, at the same time, more easily domesticated: the cows in a state of servitude, yield the richest milk in abundance. Let us now see what Mr. Harris says, in a letter to Mr Lambert. "This animal," he observes, "which I lave kept and reared these last sercn years, and know by the name of grall, is a native of the hills to the north-east and east of the Company's province of Chittagong, in Bengal, inhabitiug the range of hills which separates it from the country of Aracan. The male grall is like our bull in shape and appearance, but, I conceive, not quite so tall; is of a blackish lrown colonr: the homs short, lut thick and strong towards the A 2 
base, round which, and across the frout, the hair is thick and bushy, and of a dirty white colour; the chest and forehead are broal and thick, he is naturally rery bold, and will defend himself against any of the heasts of prey. The female differs little in appearance; ber horms are not quite so large, and her make is somewhat more slender; she is very quiet; used for all purposes of the dairy, as also ( $I$ have been informed by the natives) for tilling the ground, and is more tractable than the buffalo. The milk which these cows give has a peculiar richness in it, arising, I should conceive, from their mode of feeding, which is always on the soung shoots and branches of trees, in preference to grass. I constantly made it a practice to allow them to range abroad amongst the hills and jungles at Chittagong, during the day, to browse, a keeper attending to prevent their straying so far as to endanger losing them. Ther do not thrive in any part of Bengal so well as in the aforesaid mentioned province, and in the adjoining one, Tipperal, where, I believe, the animal is also to be found. I have heard of one instance of a female gyall breeding with a common bull."

The subjoined is the head of the gyall, as given in the Linn. Trans. vol, vii., from a specimen which died in London in 1802, described by A. B. Lambert, Esq., to whom the above letter was transmitted :-

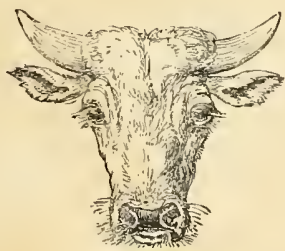

HEAD OF GYALL.

Accorling to Dr. Buchanan the ery of the gayâl is a kind of lowing, sluriller and not so loud as that of the common European ox, with no resemblance to the grunt of the Judian $0 x$.

Mr. Macrae states that the gayal exists in a wild state in the range of mountains that form the eastern houndary of the provinces of Aracan. Chittagong, Tipperal, and Silhet; and he adds that the Cúcis, or Lunetas, inhabiting the hills immediately to the eastward of Chittagong, have herds of them in a domesticated state. The animal is called Gabay in the Hindu Sástra, but seems, however, to be little known beyond the limits of its native mountains, excepting to the inhabitants of the provinces above mentioned. The animal is of a dull heavy appearance, but at the same time possesses great strength and activity. Its dispo- sition is gentle, and even in a wild state, on its native hills, it is not considered dangerous; never standing the approach of man, much less sustain ing his attack. The Cúcis hant the wild ones for the sake of their flesh. The gayâl is a forest animal, and prefers the tender shoots and leaves of shrubs to grass. It is domesticated by the Cńcís, but does not undergo any labour. The cow goes eleven months (puery eleven, perhaps from nine to ten) with young, gives but little milk (Duvancel says abundance), and does not yield it long; but that little is remarkably rich, almost equalling cream, which it resembles in colour. The Cúcis, however, according to Macrae, do not make any use of the milk, but rear the gayals entirely for the sake of the flesh and the skin: from the hide of this animal they form their shields. These domesticated herds roam at large in the forests near their village during the day, but return of their own accord at evening; being early taught to do so by being fed, when young, every night with salt, of which these animals are very fond. The Hindus, in the province of Chittagong, will not kill this gayâl (their gabay) which they hold in equal veneration with the cow ; but they hunt and kill another gayâl (as'l gayal, or seloi), as they do the wild buffalo. The gayâl, as experiments have proved, will breed with the Indian bull, of the zebu race, and the mixed breerl is fertile. Here, then, we have a species, if not identical with our race of cattle, at least so closely allied as to intermingle with it ; indeed, we strongly suspect it to have intermingled with the humped zebu race of the east, which carried to the plains has increased in the development of the fatty-cellular* mass on the withers, and in the expansion of the dewlap. The annexed figure of the domestic gayâl, from Colebrooke (Asiatic Researches, vol. viii.), might pass for that of a cow of the zebu race. The wild breed is more thickset and robust, than the tame, but presents the same

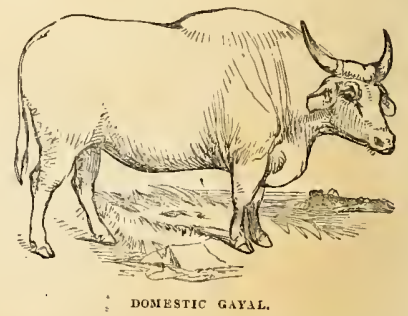

* This local aceumulation of fatty mater by domest.e animai. in warm climates is very remarkable: we have instances of it in the large tailed and fat-rumped sheep of Syria and southern Asia. it takes plaee in the part where there is a natural tendency to its leposition; viz., the croup of the sheep, the withers of the $0 x$. 



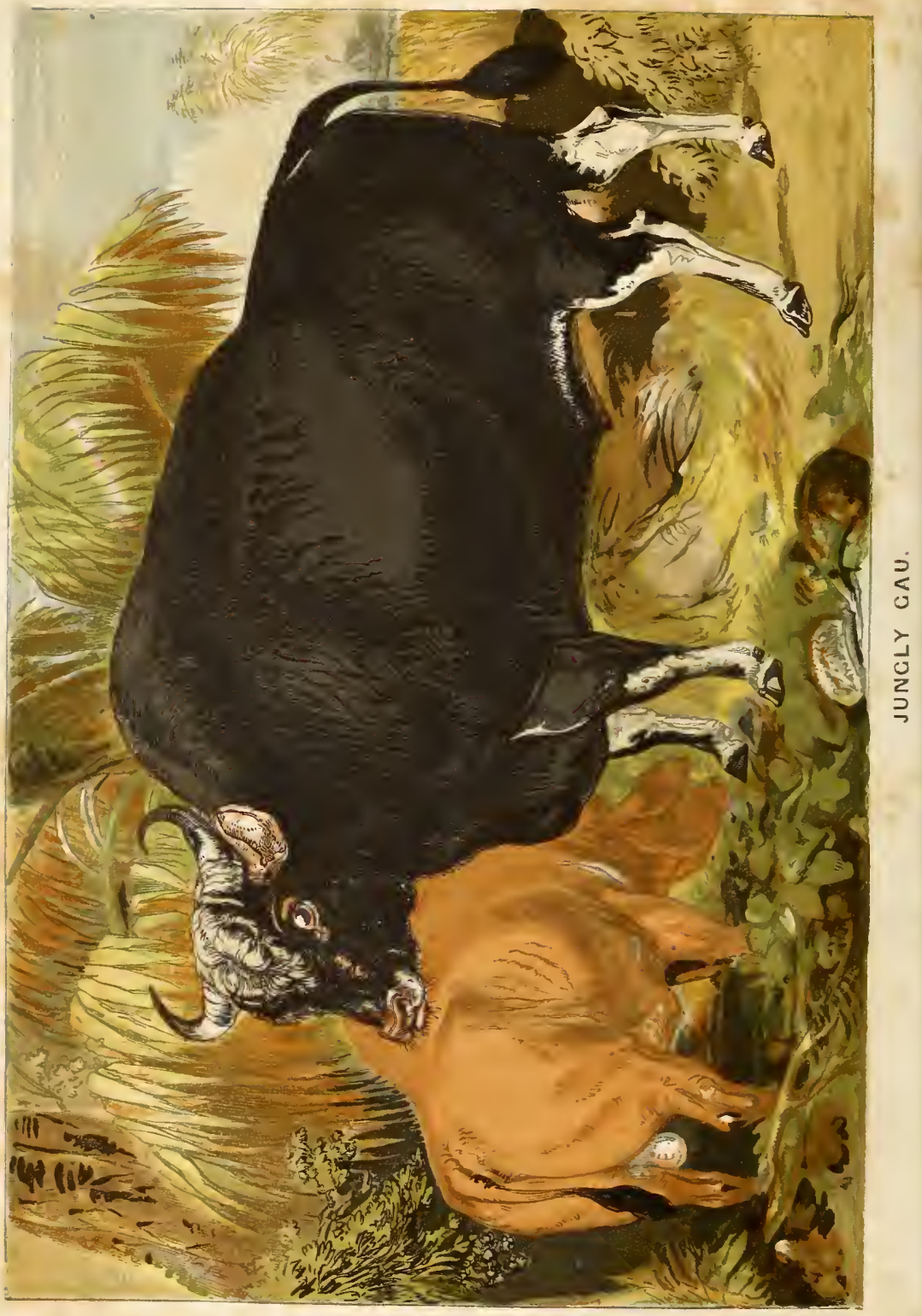


general contour. A noble specinen of the gayâl is preserved in the British Museum.

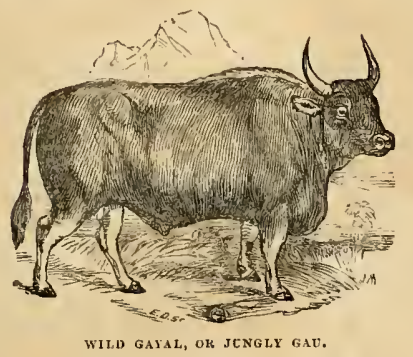

But what is the as'l gayâl, or seloi, (" the other gayâl") which the Brahmins of Chittagong do not refuse to kill; is it the wild gayâl? It has been taken for that animal by some writers, but it is a distinct species. The give the head of a female of the true asseel (as'l) gayâl, fiom Hardwicke, and we cannot help being struck with

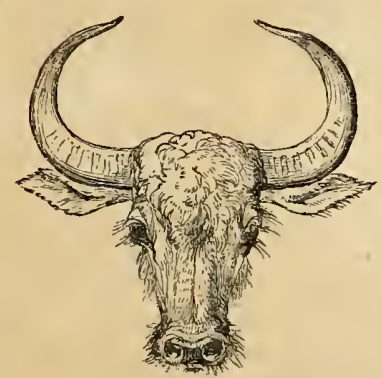

HFAD OP AS'L GAYAL, SELOT, OR GOUR.

the difference between it aud the head of the Hindu gabay, The horns are compressed, and decidedly angular, and there is no frontal tuft of curled hair This as'l gayâl ("the other gayâl," which the Brahmins will hunt) is evidently the gour (Bos Gour, Traill, in Edinburgh Philosoplical Journal, October, 1824), of which specimens of the horns have been long preserved in the musenm of the Zoological Society.

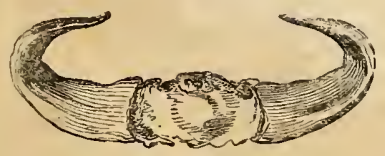

HORNS OF GOVR
Had we not seen the gayal at the gardens of the Zoological Society, we should have lieen (as we were) undecided as to the subject; but the scrutiny of that animal, during a few minutes, proved to us that the head above, regarted as that of a wild gayâl, is, indeed. that of " another gayâl," which the Brahmins will hunt, and which is no other than the gour of Traill, a species destitute of dewlap, and far more remote from the domestic ox than the gayâl or Hindu gabay.

According to Dr. Traill, the gour is nearly six feet high at the withers; the limbs are vigorous, clean made, and more deer-like than bovine (very different from the short, thick legs of the gayâl); the back is strongly arched; and, when the animal stands still, the line from the nose to the base of the tail presents a nearly uniform curve. This appearance is owing to the curved form of the chaffron, and still more to a remarkable ridge, of no great thickness, which rises six or seven inches above the general line of the back, from the last of the cervical to the middle of the dorsal vertebrx, where it gradually declines and becomes lost This elevation is very conspicuous in gours of all ages, although they be loaled with fat, and has no resemblance to the hunch found on the withers of the zebn breed of cattle. There is not a trace of the dewlap, which is well marked in the gayal. The hair of the skin, generally, is short and sleek, having somewhat of the oily appearance of fresh sealskin. The colour is deep brownisl black, almost approaching to a bluish black. Between the horns is a tuft of curling, dirty white hair; and over each hoof is a ling of the same colour.

With respect to the locality and habits of this gour, we may state that it is found in most of the mountain districts of Ceutral India; but, according to Captain Rogers, is rery common on the mountain table-land of $\mathrm{IJn}_{\mathrm{n}} \mathrm{Pât}$, in the province of Sergojah, in South Bahar. "This table-land is about thirty-six miles in length; by twenty-four or twenty-five miles in breadth, and rises abore the neighbouring plains probably two thousand feet. 'The sides of the momntain slope with considerable steepness, and are furrowed by streams that water narrow valleys, the verdant bauks of which are the favourite haunts of gours. On being disturbed they retreat into the thick jungles of saul-trees, which cover the sides of the whole range. The south-east side of the mountain presents an extensive mural precipice, from twenty to forty feet ligh. The rugged slopes at its feet are covered by impenetrable green jungle, and abound with dens formed of fallen blocks of rocks, the suitable retreat of tigers, bears, and hyenas. The western slopes are less rugged, but the soil is parched, and the forests seem withered by excess of heat. The summit of the mountain presents a mixture of open lawns and woods. There were 
once twenty-five villages Mon yn Pât; but these have long been deserted on account of the number and ferocity of the beasts of prey. On this mountain, however, the gour maintains his seat. The Indians assert that even the tiger has no chance in combat with a full-grown gour, though he uaty occasionally succeed in carrying off an unprotecter calf. 'The wild buffialo abounds in the plains below the mountains; but he so much dreads the gour, according to the natives, that he rarely attempts to invade its haunts; aud the huntiug party only met with three or four urnas (arnees, or wild buffaloes) on the mountain. The forests which shield the gour abound, however, with hog-deer, saumers (sambur deer), and porcupines."

The gour is very fierce, and, when wounded, turns upon his enemy. Captain Rogers, who hunted this animal, states that the only cry he ever heard it utter, and that only when struck by the bullet, was a short bellow, imitated by the syllables $u g h-u g h$. The gours herd together in parties of ten, fifteen; or twenty; they browze on the leaves and tender shoots of trees and shrubs, and also graze along the banks of streams. During the cold weather they retire to the covert of the saul forests; but the return of the hot season brings them out to feed in the green lawus and valleys; they do not wallow, like the buffalo, in the mire and swamp. The female generally produces young in August ; the bull-calf is called purorah during the first year, and the cow-calf pareeah; the full grown cow goûrin. It is asserted, by the natives, that the gour will not endure captivity, and that, even if taken young, the mountain-calf droops and dies. (See Edinburgh Phil. Journ., rol, xi.)

With respect to the wild buffalo, called urna, arna, arni, or arnee, (Bos Urni Kerr), anı animal common throughout Bengal, some consider it as a species distinct from the common buffalo of India (Bos Bubalus) used as a beast of burden; while others are of a contrary opinion. To judge, however, from the skull and horns, of which latter a pair of enormous size are preserved in the museum of the Zoological Society, and several in the British Museum, we are inclined to the belief that it is distinct; at least we have never seen any specimen of the buffalo, with horns presenting similar charncters. We do not, however, insist on this; for the buffalo of different countries exhilits great rariation: the Manilla buffalo, for example, of which snecimens exist in the Zoological Gardens, is of very small size, with small horns. In the mawals, or hilly tracts along the ghauts, great numbers of the long-horned variety of the inffich are bred; and Dillon states that the buftulo of Malabar is larger than the ox, with white eys and flat horns, often two feet long: the limbs are thick and short. "It is an ugly animal, almost destitute of hair, goes slowly, and carries very heavy burdens. Herds may be seen, as of common cows; and they afford milk, which serves to make butter and cheese : the flesh is good, though less delicate than that of the ox. The animal swims perfectly well, and traverses the broadest rivers. Besides the tame buffaloes, there are wild ones, which are extremely dangerous, tearing men to pieces, or erushing them with a single blow of the head. They are less to be dreaded in the woods than elsewhere, because thcir horns often eatch in the brauches, and give time for the persons pursued to escape by flight. Probably this wild buffalo is the arnee, which is described as a large and formidable beast, conspicuous for strength and ferocity. Its horns are remarkable

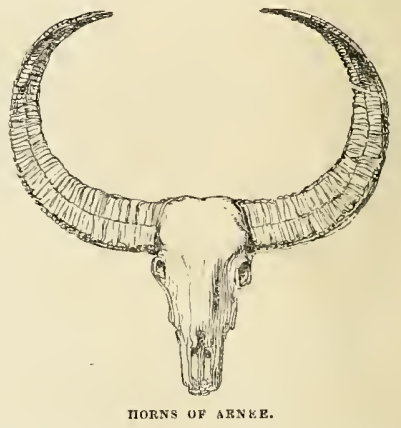

for their enormous size, often measuring from furr to six feet in length; they rise upwards, first inclining outwards and backwards, and then arching gradually towards each other, they form a bold crescent. They are compressed on their anterior and posterior surfaces, and rough with numerous transverse furrows and ridges. The cliaffion is narrow and convex.

With respect to the semi-domesticated buffilo, it is spread from India throughout Siam, Coclin China, China, Malacea, Borneo, Java, and Sumatra. Westward, it has been carried into Persia, the Crimea, Turkey, Greece, Spain, and Italy. In Stimatra the buffalo exists in a wild as well as in a reclaimed state; and wild buffaloes are common in the forests of Abyssinia, where the are lunted, the thick hide being valuable for the manufacture of shields. Accordiug to Mr. Mars. den, there are two sorts of tame buffaloes, or carbows, in Sumatra; one black, the other white. The animals of this latter colour are rarely eaten by the uatives, who assert that the flesh is unwholesome, and that those who partake of it are covered with blutches. Mr. Marsden, indeed, re. gards the whiteness as the result of disease in the 
animal itself, or as a species af albiuism. In Italy the buffalo is black, with fierce glowing eyes. Its introduction took place in the sixteenth century; and it now roams, in a state of wildness, over the swampy plains of Calahria, the Poutine Marshes, and various other localities suitable to its habits of wallowing in the mud or water.

The history of the buffulo need not here de. tain us. There is a species of ox, little known to European naturalists, existing both in a tame and wild state, in Thibet. This species is called the yak (Bos grumiens). No living specimen, as far as we are aware, has ever been seen in Europe; but we have had an opportuuity of examiuing slins, more or less imperfect, of one of which the following is a description :-Nostrils narrow, converging below, with a small naked space between them, and a narrow, uaked border round them; so that there is no true, broad, naked muzzle, as in the common ox, but a hairy muzzle, as in the musk ox (Ovibos moschatus). The ears are small and pointed; the forellead is covered with black curling locks. The hair of the back is smooth; the colour a deep chocolate brown, a white stripe occupying the ridge of the withers, and another the centre of the croup. From the shoulders, sides, and muder part of the body, and also from the inner side of the thighs, a pendant mane of long hair hangs down, falling in huge masses, so as to cover the limbs and almost touch the ground. This mane is grizzled black, excepting a central lime of pure white along the belly. The tail is tufted with a huge mass of glossy white and rather coarse hairs, eighteen or twenty inches in length. In size the animal could not have exceeded the small Scotch breed of cattle. The homs, and part of the legs. were deficient; hut, according to Gmeliu and Tumer, and to judge froun specimens in the British Museum, the horns are small, round, hent forward, and pointed. The withers are elevated, aud the col ur is sulject to variation: we have seen a shin the tail of which was tufted with black hair's

From long antiquity the Tartars lave used the flowing tail of this animal as a staudard in battle, and as one of the distinguishing insignia of officers of high rank. In Turkey the tail of the horse is used in like manner. In India the tail of the yak is frequently mounted on ivory or silver handles, elegantly ornamented: these instruments are called chowries, and elephants of state are taught to carry them in their proboseis, and wave them gracefully to aud fro, for the purpose of keeping away the flies.

Of the halits of the wild yak little is known. It is a native of the mountains of Thibet and Bootan, and is said to be sullen and ferocious. Respecting the tame lreed, Turner, in his "Account of an Embassy to China," says, "These cattle, though not large-boned, seem, from the profuse quantity of hair with which they are pro. vided, to be of great bulk. They have a down. cast, heavy look, and appear, what indeed they are, sullen and suspicious; discovering much impatience at the near approach of strangers. They do not low loud, like the cattle of England; but make a low grunting noise, scarcely audible, and that but seldom, and when under some uneasiness. These cattle are pastured, in the coldest parts of Thibet, upon the short herbage pecnliar to the mountains and bleak plains. The chain of mountains situated between the latitudes of $27^{\circ}$ and $28^{\circ}$, which divides Thibet from Bootan, and whose summits are mostly clothed with snow, is their favourite haunt. Iu this vicinity the southern gleus afford them food and shelter during the severity of winter; in milder seasons the worthern aspect is more congenial to their uature, and admits a wider range. They are a very valuable property to the tribe of itiuerant Tartars called Duckba, who live in tents, and teud them from place to place; they, at the same time, afford their herdsmen an easy mode of conveyauce, a good covering, and wholesome subsistence. They are nerer employed in agriculture, but they are extremely useful as beasts of burden; for they are strong, sure-footed, and carry a great weight. Tents and ropes are maunfactured of their hair; and amolgst the humbler ranks of herdsmen I have seen caps and jackets made of their skins. The hest requital with which the care of their keepers is at length rewarded, for selecting them good pastures, is in the abmdant quantity of rich milk which they give, and in the butter produced from it, which is most excellent. It is their custom to preserve this in skins, or hladders, and the air being thus excluded from it, it will keep, in this cold climate throughout the year; so that, after some time tending their herds, when a sufficient store is accumulated, it remains only to load their cattie, and drive them to a proper market, with their own produce, which constitutes, to the utmost verge of Tartary, a most material article of commerce."

Bell, in his travels in Tartary, notices this animal as the bubul of the natives (T'zulimm Tartars). He met with it only in its tame state, and sars that its body and limbs are very handsome; that it has a high shoulder and flowing tail : several skulls, and an imperfect skin stuffed are in the British Museum.

In former times a hnge wild ox, calied the momassus, or bonassus, the bison, and as some think, also the urus, spread over the cental portion of Europe, and was common in Pconia (the modern Bulgaria), Hungary, Poland, and also further westward. The uames of this animal in the present day are as follow:-bison, risen, uisont, \&c., of barbarous 
origin ; our, auer, ur, auerachs, aurochs (from a primitave syllable, the root of Taurus, and the word tor, a mountain signifying grandeur, elevation, antiquity); in Polish tur, Russian tor, Danish $z y r$, in Moldavian $z i m b r$, and Lithuanian $z u b r$. This noble animal may be regarded as on the eve of extinction, unless, indeed, it be specifically the same with a species found in the Caucasian range, and observed by the traveller Bell, in the country of the Tzulimm Tartars, and respecting which he says, "On the hills and in the woods near this place, are many sorts of wild beasts, particularly the urus, or uhr-ox, one of the fiercest animals the world produces; their force is such that neither the wolf, the bear, nor the tiger, dare to engage with them,"**

Be this, however, as it may, the aurochs or zubr (Bos Urus), the European lison, once so widely spread, is now confined to the forests of Bialowicza (pronounced Bealawezha), in Lithuania, where it is protected by stringent laws: he who kills a zubr without permission of the Russian government, has to pay as a fine 2000 rubles; or, if unable to meet the penalty, mnst suffer transportation to Siberia. Formerly the penalty was death.

This species is wonderfully massive and robust in its proportions; its withers are thick, and elevated, and covered, as are the neck, sides of the

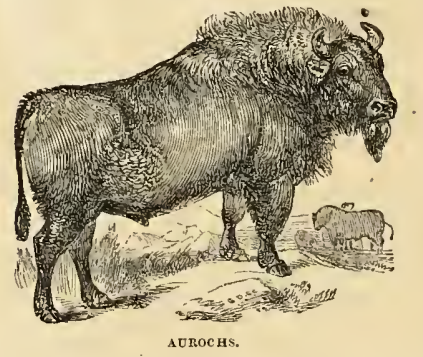

head, and lower jaw, and throat, with long rough hair, forming a sort of mane beneath the throat, like a beard. This mane is often a foot in length, and is thickest during the winter, especially in old bulls; the hair covering the trunk and limbs is soft and woolly; the tail which is short, is furnished with a tuft of stiff hairs at its extremity; the eyes are small, but their expression is extremely wild and sarage, and when the animal

* Cuvier contends that the uras of the Hercynian forest, described by Cesar and others, was distinet from the bison; ba Ji. Weissenborn maintains the contrary. The urus is said to have been renarkuble for the enormou's magnitude of its horns; the bison for its mane:

- Villosi terga bisontes

Latisnue ficri cornibis uri."-HippoL. is irritated they glare with fury; the tongue, lips, and palate, are blue. An odour, described as between musk and violets, is exhaled from the skin, and especially that portion which covers the convexity of the forehead. This odour is much stronger in the male than the female, and may be perceived at a considerable distance from the herd. The horns are large, round, and lateral, with the points sweeping upwards and forwards; the head is large and heavy, and carried low. The male aurochs is upwards of six feet in height at the shoulders, and is a most formidable animal; so great is its strength that, according to Dr. Weissenborn, trees of five or six inches in diameter are levelled by the thrusts of a bull. He fears neither the wolf nor the bear, but assails them with horns and hoofs; an old bull is a match for four wolves; and although a pack of wolves may sometimes hunt down a strayed aurochs, the collected herd has nothing to fear from any animal.

Dense thickets, near the swampy banks of rivers, are the favourite retreats of this species; but in summer, according to Dr. Weissenborn, the herds select sandy spots; in winter they shroud themselves in the thickest parts of the rast pine woods, keeping quiet by day, and browsing by night, finding sustenance in the joung shoots and bark of sapling trees. At this season the foresters put supplies of food for them, in the viciuity of their haunts. In spring they visit spots where the herbaceous plants are beginning to vegetate; they are fond of tree lichens.

The voice of the aurochs is a short, deep, grunt, which may be heard at a considerable distance; it betokens irritation, and it would be then madness to venture near the animal; indeed, at no time is this safe, for though the zubr is very shy, and avoids the approach of man, yet if fallen in with accidentally, the animal's fury is aroused, and it immediately prepares to assail the intruder. When excited by passion, the animal thrusts out its tongue repeatedly, and lashes its sides with its tail; the eyes glow like fire, roll furiously, and seem starting in their sockets, and the liead is lowered for the onset. When taken young, they become, it is true, accustomed to their keepers; but the approach of other persons renders them furious; and event the keepers are not safe, and must always wear the same sort of dress when going near them. It is remarkable that the aurochs displays the greatest antipathy towards the ordinary domestic cattle; it avoids the neighbourhood of sports where they feed; or if the contact is unavoidable, is roused to fury, and attacks them, goriug them to death. All experiments to obtain a mixed breed have utterly failed.

'The aurochs, notwithstarding its bulk, is very swift for a short course; it rushes on with its head low, its hoofs being raised at every step 


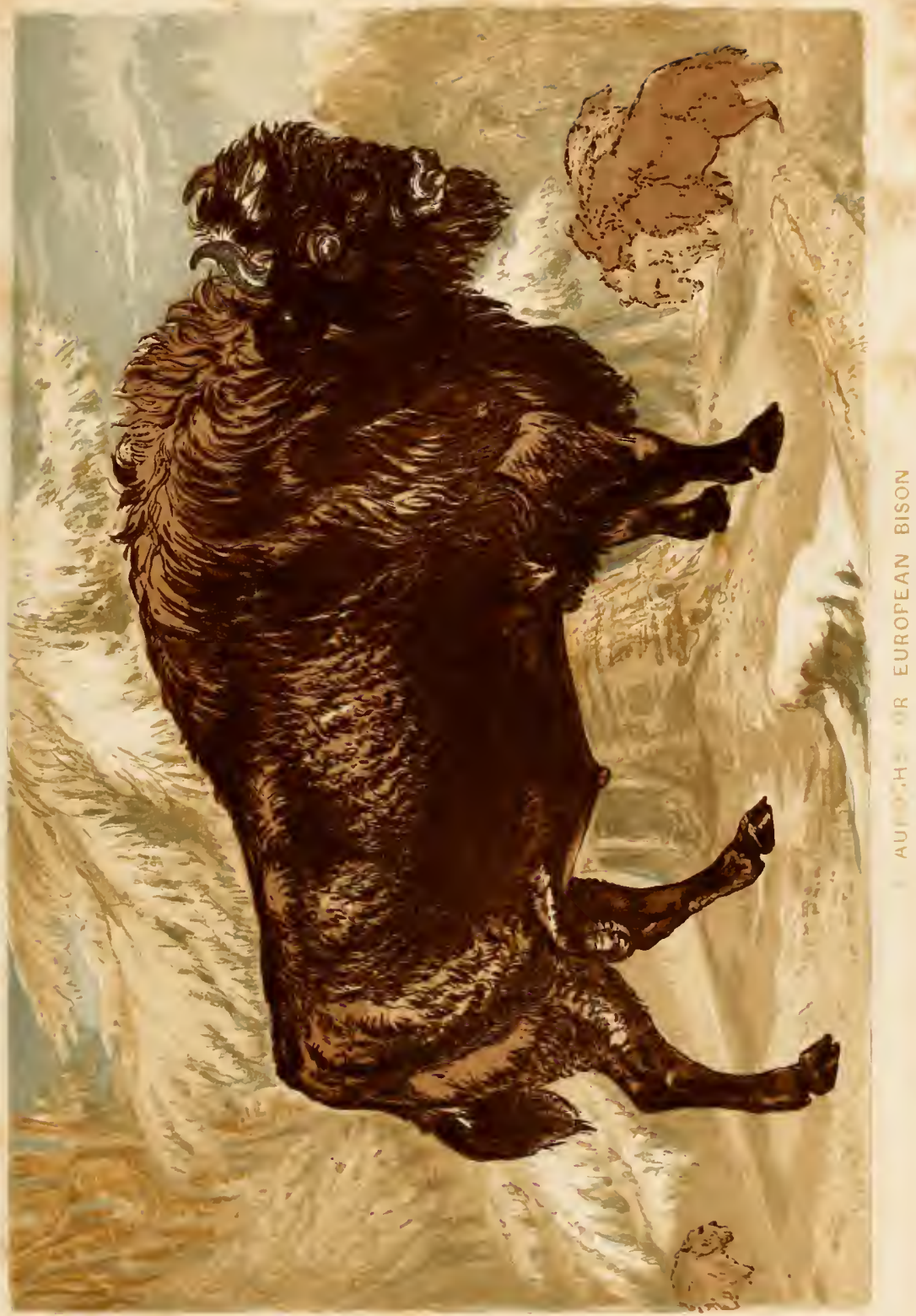



above the forehead; it is fond of the bath, and swims with great ease and vigour.

Of all the senses of this animal, that of smell appears to be in the highest perfection; and the herd can only be approached from the leeward; its Hesh is in high esteem, and is said to have a bluish tinge, when roasted.

The colour of this animal during the summer, is a deep brownish-black, or nearly black; but the fur acquires a greyer, or more rusty tint, previous to its renewal in the spring. A magnificent specimen of this animal, almirably stuffed, adorns the British Museum; it was sent ly the emperor of Finssia.

All agree that the Poonian bonassos of Aristotle, is the aurochs, or zubr; but a doubt has been started relative to the urus of Cresar, found in the vast forests of France and Germany in his day. "These uri (he says) are little less than elephants; their aspect, colour, and form, are like those of a bull; they are extremely strong and swift, and spare neither man nor beast they get sight of. These, when trapped in pitfalls, the hunters immediately kill. The youths, exercising themselves by this sort of bunting, are hardened by toil ; and those among them who lave killed most, bringing with them the horns as testimonials, acquire great praise. But these uri camnot be habituated to man, or made tractable, not even when young. The great size of the horns, as well as their form and quality, render them very different to those of our oxen; these horns, when carefully selected, they rim with silver, and use them as drinking cups at their ample feasts."*

* The fashion of using horns as drinking cups at festivals was common among our $\$$ axon ancesturs, and even after the Norman conquest; and inheritances of land were transferred with the transfer of a horn, and established in fee by a horn. Several of these horns are

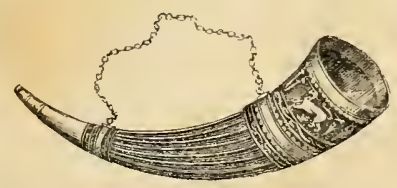

HORN OF ULPHUS.

still estant. The horn of Ulphus, says the anthor of Old England, " is a remarkable curiosity, still preserved in the sacristy of the cuthedra] at York. Ulphus was a Dumish nobleman af the time of Caoute, who, as Camden in forms ns, 'by reason of the difference which was like to rise betweeen his sons about the sharing of his land and lordship after death, resolved to make them all alike; and thereupon coming to Fork with that horn, wherewith he was used to drink filled it with wine, and kneeling devoutedly before the altar of God, and St. Peter, prince of apostles, drank the wine, and by that ceremony enfeoffed this church with all his lands and revenues.' During the civil wars the horn of Ulphus came into the possession of Lord Fairfax, after being sold ta a goldsmith; and it was subsequently restored to the church by the Fairfux family, in 1675.

Of about the same antiquity is the Pusey horn. (Árcheol. vol. iii.) It is "a real vx-burn two feet one-half inch long, the circumference in the largest part one fout, in the midale nine winches one-fourth, at
Pielying on the rords of Cresar, and guided in his opinion by the huge horned fossil relics of some species of ox, found in the British Isles and Continental Europe, Cuvier regardəd the urus as a distinct species from the bison or bonassus, and as being at once characterized ly the immensity of its horns: and further he is stipported in his opiniou by the application of the terms, urus and bison, by other Latin writers, to two apparently distinct animals: thus Pliny says, "There are two remarliable species of wild oxen, the maned bison and the urus, whose strength and swiftness are extraordinary, and which common people in their ignorance call bubali." Martial says, "Illi cessit atrox bubalus atque bison."

Dr. Weissenborn contends that the Latin writers had no opportunities of comparing the bison and urus, and that they used the terms loosely, or, perhaps, gave the term bison to the Poenian animal, and urus to the Hercynian one; the former of which, being often captured, they were accustomed to see most frequently in the circus; while the latter was never taken alive by the Gauls or Germans, excepting in pits, and then killed on the spot. The bubalus, mentioned by Martial, he regards as the buffalo from North Africa. He farther observes, that Solinus (third century) expressly states that bisons ("setosi colla, jubas horridi") swarmed in the Hercyuian forest, where Cæsar places the urus; and he asserts that formerly, befare the present breed of anrochs had degenerated, and when the bulls weighed two thou sand pounds, their horns were of prodigions magni tude, and that homs, even of the present race in

the small end two inches one-fourth " On a ring of silver gilt that girt it was the following inscription:

"Kyng Knowde (Canute) geve Wyllyam Pewse

This horne to holde by thy lond."

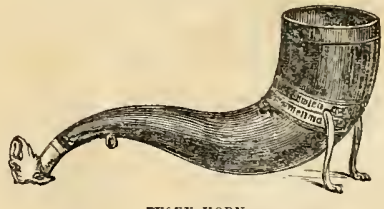

PUSEY HORN.

The following account of the Borstal horn is given in the third volume of the Aichæologia:-

Edward the Confessor had a royal palace at Brill, or Brchul, in Bucks, to which he often retired for the pleasure of hunting in his forest of Bernwuod. This forcst, it is said, was much infested by a wild boar, which was at last slain by one Nigel, a huntsman, who presented the boar's head to the king; and for the reward the king gave to him one hyde of lande, called Derehyde, and a wood called Hulewode, with the custody of the forest of Bernwood, to bold to him and his heirs per unum cornu, quod est charta predictse forestre.

The original horn has been preserved by the lords of Borstal under the name of Nigel's horn, and is now $(1773)$ in the possession of John Aubrey, Esq., son and heir of Sir Thomas Aubrey, Burt., to whom this cstate lias descended withan alicnation or forfeiture, from before the Conquest to the present time, by several heirs femile from the family of Nigel to that of Aubrey. (Archerologia, iii. 15.) 
Lithuania, of ten measure, from tip to tip, round their curves and over their forehead, four French feet. Herodotus, speaking of the Pconian wild oxen, notices their enormous horns ( $\dot{\omega} \nu \tau \alpha \kappa \epsilon p \in \alpha \quad \dot{v} \pi \in \rho \mu \epsilon \gamma \alpha \theta \epsilon \alpha)$. However, we shall not dwell on this disputed point, as it is little to our present purpose. Whether the bison of the Caucasian mountains is identical with the Litluanian lison, we have yet to learn; M. de Baer, of the St. Petersburg academy, is of opinion that it is. Formerly, some naturalists regarded the aurochs as the origin of our domestic cattle, but this theory is now utterly rejected. The common ox has thirteen pairs of ribs, the aurochs fourteen pairs; the lumber vertebræ of the common ox are six in number, those of the aurochs are five; the front of the common ox is flattened, that of the aurochs is protuberant, and broader in the proportion of three to one; the occipital space between the horns forms an arch, instead of reing flat. We subjoin the skulls of the young and adult aurochs in profile.

Judging from these skulls, we see no appearance of horns of such magnitude as were so conspicuous in Crsar's urus ; but fossil skiulls, in recent deposits, present us with horns of huge size, and if these are to be attributed to Cæsar's urus, we must

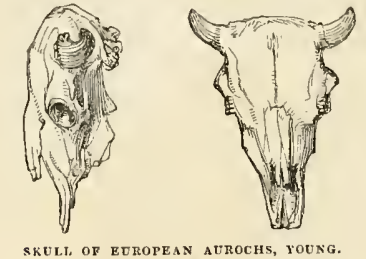

(Profile view.)

(Front view.)

regard that animal as extinet, and different from the aurochs of Lithuania. To the fossil bones of the ox we shall hereafter revert; but we may here

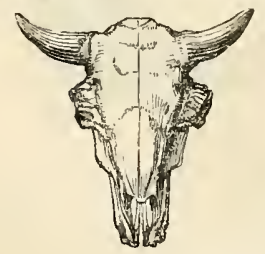

(Front view.)

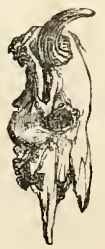

(Profile view.) observe, that the skulls of the fossil aurochs and the Cæsarian urus are very distinct, but tliey are found in the same districts and deposits.

Closely allied to the aurochs or zubr, is a distinct species of bison peculiar to North America: it is the bos Americanus of Gmelin, the peecheek of the Algonquin Indians, moostoosh of the Crees, adgiddah of the Chippewayans. This huge and formidable animal roves in vast herds over the prairies that are watered by the Arkansa. Platte, and Missouri, and the upper branches of the Sas. katchewan and Peace rivers. At no very remote period the American bison existed in the westem parts of Pennsylvania: but they have gridually retired before the march of colonization, and are now rarely to be seen south of the Ohio, or to the enst of the Mississippi. In new Mexico and California the bison is numerous. Northwards, its territory extends to the parallel of the great Slave Lake.

The American bison is migratory in habits, wandering from district to district in search of food. It spreads in troops over the umdulating prairies, where the grass is abundant; it visits the marshes overgrown with bullrushes and various water plants, and during the heat of the summer resorts to shady rivulets, streams, and pools, where it delights to bathe. Herds of twenty thousand have been seen crossing rivers a mile in breadth, on their passage to some distant feeding ground. They visit the salt-licks, and are there to be found at all seasons of the year; some leaving the saline morass, others travelling torards it.

These herds are incessantly persecuted by the hunter, who often sadly thins their numbers with his rille; and the Indians get up great hunting matches, using both gun and arrow with admirable address. The flesh is in great request, and prepared in various ways. The tongue is accolnted a delicacy, and the hump, or rather the flesh on the long spinous processes of the anterior dorsal vertebræ, forming the withers, is excellent. Much of the bison meat is made into pemmican for keeping; and a good bison cow furnishes dried flesh and fat sufficient to make a bag weighing ninety pounds: a fat bull bas yielded a hundred and fifty pounds weight of tallow. The Indians dress the skins, often with the hair on; they serve as blankets, and warm wrappers, and are sold for a considerable sum. The theece is also useful, and spun and woven iuto various articles; and Dr. Richardson informs us that some of the bison wool has been manufactured in Fugland iuto a remarkably fine and berutiful cloth. In the colony of Osmalioya, on the Red River, a warm and durable coarse cloth is formed of it. The horns are converted into powder flasks.

The bison, like the aurochs, has a lugge head, and high massive withers, covered with a full mane of long coarse hair, which assists in giving an air of preponderance to the anterior portion of the animal, compared with its hinder quarters; its head is carried low, the horus are short and black, the eye is small and ferocious, and the sense of smell is extremely acute. The bull stands upwards of six feet high at the withers, but the cow 
is much less. At certain times the bulls are very furious, and fight desperately with each other;

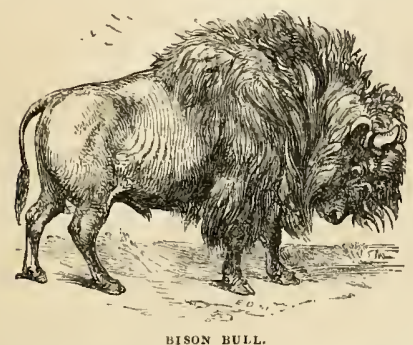

nor is the chase unattended by danger, for a wounded bison often turns on his assailant, whose life is placed in imminent jeopardy. These animals strike both with the horus and loofs, and endeavour to trample upon their enemy. old bulls, which are sometimes to be met with singly, are very dangerous; for the greater part of the jear the bulls and cows live in separate herds, excepting that one or two old bulls generally accompany a herd of cows, and conduct its movements.

In some anatomical points the American bison is more remote from the common ox than the anrochs, or zulur. The ribs consist of fourteen pairs, and, according to Cuvier, the lumbar vertebre are only four in number. The skull much resembles
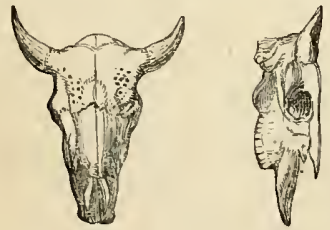

SKULL DF YOUNG FEMALE EI SOX.

$$
\text { (Front view.) (Profile view.) }
$$

that of the aurochs, but is remarkable for its comparative smallness in the female.
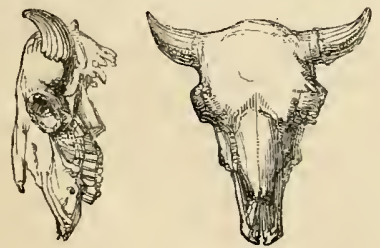

SKULL OF OLD AMERICAN BISOX. (Profile view.) (Front vi(w.)
In the high latitudes of North America, the lands of the Esquimaux, from the 61 st to the 75 th degree of latitude, a species called the musk ox exists; it is the Ovilos Moschatus of Blainville, and constitutes the type of a new genus.

The horns are expanded at their base, forming a helmet-like mass, covering the forehead, whcre their roots are in contact with each other; from this mass they emerge round and tapering, bending down between the eye and ear, and then sweeping suddenly upwards. The ears and tail are short, the eyes moderate, the nostrils oblong, and inclined to each other from above downwards; there is no true naked muzzle, but a very narrow bare line surrounds each nostril, the rest being covered with hair; there is no furrow in the upper lip. In size this species scarcely equals the suallest of the Scottish or Highland breed of cattle, but apnears to be larger than it really is, from the profusion of long matted woolly hair with which it is covered, and which hangs on each side almost to the ground, concealing the limls to the pasterns; the tail is entirely hidden; beneath the lower jaw throat, and chest, the hair flows full, long, and mane-like; the general colour is dull, grizzled, umber brown, darker on the sides and under-surface; on the centre of the back is a brownishwhite mark, or saddle.

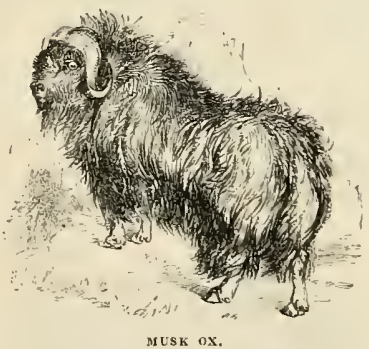

The musk ox frequents wild, bleak, and rocky situations, and is extremely vigorous and active; during the winter it feeds chiefly on lichens, and in summer on grass. Its flesh is strongly imbued with musk, especially at certain seasons; but at other times it is tolerable, and eaten both by the Esquimaux and fur-hunters.

In the month of september these animals collect in large herds, which are followed by the hunters, not, however, without risk, for the bulls are very daring and irascible, and when bard pressed or wounded will rush with impetuous fury on their enemy. The general mode, howerer. adopted by the hunter, is that of concealing himself in some convenient spot whence to scatter destruction; the animals, seeing no foe, remain 
bewillered without attempting to escape, while their companions drop on every side. On the least appearance of their destroyer they instantly take to flight, and scale the steep declivities of the rocks with the ease of a chamois.

The rool of this animal might be turned to good account; it is very fine, and stockings equal to those of silk are said to have been manufactured from it in France.

In adverting to the buffalo, both wild and domesticated, we purposely forbore to notice a ferocious animal, the Cape buffalo (Bos Caffer), a native of the wilds of Southern Africa, where, associated in herds, it frequents the borders of woods and thickets, and the watered ravines and glens among the hilly grounds. This savage beast is fond of wallowing in pools and swamps, and in the muddy ooze, covering its almost naked but dense hide, with defensive clothing against the attacks of iusects. The horns of this species form at their base a solid rugged mass, corering the forehead, from which they bend downwards, and somewhat outwards, gradually dimishing to the points, which suddenly curve mpward. The distance between the points of the horns is frequently five feet, but the rugose massive base of each is in contact forming an impenetrable helmet: their colour is black. With these formidable weapons the Cape buffalo has been known to transfix a horse instantaneously, lift him up, and hurl him with crushing violence to the ground. The eye if this animal is savage and lowering, and betokens great ferocity; the ears are large, and generally observed to be torn, either from combats among the animals themselves, or from the laceration of spines and thorns, as they force their way through the dense thickets.

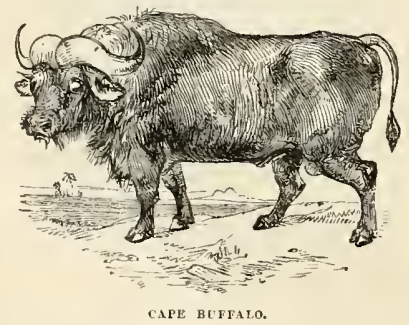

The Cape buffalo does not exceed the ordinary ox iu height, but is much more massively and heavily built, and is a far more ponderous animal, with short thick limbs, and a dense hide nearly destitute of hair; on the lips and throat, homever. the hairs are long, rather thickly set, and very coarse.
When the Cape buffilo is wounded, he plouglis up the ground with his horns, scattering the turf and stones on all sides around, and rushes through the thickets and up the rugged sides of the steep ascent with wonderful energy. Often, instead of escaping, nrged by revenge, he returns as suddenly to the attack, and appears in the midst of his assailants, one or more of whom often fall victims to his rage; he gores them, tramples upon them, and presses his whole meight upon them, as if to glut his revenge, and bellows with mingled pain and fury, till some well-aimed bullet lays him prostrate on the earth. At all times old solitary bulls are dingerous, and will make an attack on any intruder, even if unassailed.

Among the natural enemies of the larger quadrupeds the lion is the only adversary which this beast las to fear; but even the monarch of the desert does not almilys prove rictorious, and in stances occur in which several buffaloes have unite in the rescue of an attacked companion, and gored the foe to death.

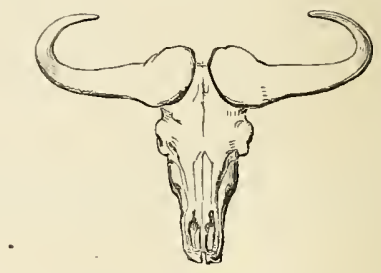

SKULL OF CAPE BUFFALO.

An allied, but distinct species is described by Col. H. Smith, under the title of Bos Pegasus; it is a native of Western Africa. Another species, from Central Africa, with short and comparatively feeble horns, and having the large ears covered with shaggy hair, is termed by $\mathrm{Mr}$. Gray, Bos Brachyceros. Several heads of this species are in the British Museum.

Captain Lyon, in his travels in Northern Africa, describes eertain bovine animals, with which naturalists do not appear to be well acquainted. They are very numerons in the mountains of Wadan. One, which gives this name to the mountains in question, viz., the waden, is stated to be of about the size of an ass, with very large head and horns, a short, reddish hide, and large bunches of hair hanging from each shoulder to the length of eighteen inches or two feet; it is of a very fierce disposition. The second, bogra el weish (bekr-elwash), is evidently the Antilope bubalus, or wild $o x$ of the Arabs, and generally referred by naturalists to the antelope group; it is heary and sluggish. A third animal is noticed as the white buffalo; of light contour, vigorous and active in its 
motions, and, at the same time, so shy and swift, that it is not easily procured. These buffaloes calve in April or May.

From this rapid survey of the animals of the bovine group, we fund that though three species, the gaval, the yak, and the common buffilo are known both in a state of domestication, and also in a wild condition, yet that no wild species exists, perhaps excepting the gayal, which can be regarded as specifcally identical with the domestic cattle of Europe, or with the zebu breeds of Asia. It may be objected, that we here overlook the wild white ox of Chillingham Park, and of Craven and Chatelherault Parks, \&c. (the Bos Scoticus of some authors): but we cannot regard this as a wild species; it exists nowhere as a free denizen of the forest; it is not found in the wilds of Central or Eastern Europe, and in England it is kept, like the deer, within the bounds of a park. That it is specifically identical with our domestic race cannot be doubted; and if tradition is to be credited, this lireed is descended from a wild stock which once roamed the wooded wastes of our island, and of which the lingering relics owe their existence to the care of man. We learn from Fitz-Stephen, who wrote in the time of Henry the Second, that the mighty forest, north of London, was the lair of stags, deer, boars, and wild bulls; and later writers notice the existence of wild cattle in the more uncultivated districts of Scotland and the North of Fingland. The waste district of Craven was formerly the ahode of herds of wild white cattle; but there are grounds for believing that the white cattle of Craven Park (Yorkshire', were brought from Whalley Abbey (Lancashire), upon its dissolution in the thirtythird year of Henry the Eighth; perhaps, however, only to replenish the original but diminished stock of the park. The white wild cattle of Chillingham have the muzzle black, and the whole of the inside of the ear, and the tip externally red; the horns are moderate in size, of an elegant contour, sweeping upwards, and of a white colour passing into black at the tips. Some of the bulls have a thin, upright mane, an inch and a half, or two inches long. The weight of the oxen (not bulls), says Mr. Culley, "Observations on Live Stock," p. $\mathbf{7 4}$, is from thirty-five to forty-five stone, and of the cows, from twenty-five to thirty-five stone, the four quarters (fourteen lbs. to the stone). The beef, he adds, is finely marbled, and of excellent quality. These cattle are extremely shy and savage, and at certain times the bulls are very ferocious. The cows conceal their young in the dense fern and underwood; and it is daugerous to approach the lair; for should the mother perceive the approach of an intruder, or the herd be alarmed by the bellow of the calf, an impetuous attack from the former, or even the whole troop, is the immediate consequence. Formerly these cattle were hunted with the pomp and circumstance of the chase in the olden time, but accidents oceurred from time to time, and at last the parkkeeper, selecting his individual, has resorted to the plan of strikiug it down with a well-directed rifle ball.

Now comes the question, - are these cattle originally wild cattle in our island and continental Europe, and, we may add, Western Asia ; or have they ever been limited to our island; and are they to be regarded as truly wild, or as feral only, that is, emancipated like the cattle of South America? Cuvier, be it remembered, regards the urus of the Hercynian Forest, or, at least, oxen whose skulls have enormous horns, the fossil remains of which are found in the superficial beds of our tertiary strata, to have been the root of our ordinary breed. We believe these skulls to be referable to the ancient urus of Crsar, a distinct species from the aurochs, or zubr, notwithstanding Dr. Weissenborn's opiniou to the contrary. But, then, what has the urus, of which these fossil bones are the relics, to do with the wild white cattle of our parks, a race evidently identical with our domestic cattle, and very like the Devonshire and some of the Welsh and Highland cattle in form and aspect? We need not repeat Cæsar's account of the urus, which animal he most expressly distinguishes from any breed of domestic cattle he knew in Italy or Westeru Europe. Its gigantic statue, its enormous horns, its untameable ferocity, are sufficient to demonstrate its specific distinctuess. We are ready to admit, and, indeed, the fact is evident, that in remote ages, antecedent to Cresar's invasion, this mighty urus tenanted our island, if, indeed, then an island; this fact is proved by the oceurrence of its remains in caves, arid in the deposits alluded to; but we have no proof that, therefore, the Crsarian urus is the parent of our European breed of domestic cattle; and as little, that the wild oxen of our parks are of the urus stock. Crsar tells us, that the aucient Britons were in possession of large herds of cattle, on the milk and flesh of which they principally subsisted, neglecting the cultivation of grain. That these eattle were not uri we may be assured, any more than were the domestic eattle of Gaul, Germany, or Italy, otherwise Cæsar would have noticed the fact and corrected his assertion, that the uri were untameable. Besides this, a huge-horned ox, or urus, an aurochs, or bison, perhaps of the same stock as the Lithuanian breed, also inhabited Western Europe and England (if then an island) is unquestionable, from the skulls and bones in a semi-fossil state which are found in abundance. In addition to these there are fossil skulls of species decidedly different, but which we cannot positively say were identical with the present tame breed. They accompany the remains of 
elephants, stags, horses, and carnivorous animals. On an examination of the fossil skulls of the bovine race in the British Museum, we distinguished the following:-

First. A huge horned species, with an arched occipito-frontal ridge, from Athol, Perthshire. The forehead is flat, or rather concave, with a slight central longitudinal ridge; the horns, or rather born-cores, are first directed laterally, then forwards, and at the tips, upwards, with a graceful flexure; their extent between the tips is three feet six inches. The skull is three feet in length, and the breadth between the roots of the horns is about ten inches and a half. The distance from the transverse ridge to the origin of the nasal bones is fourteen inches, and across the centre of the forehead the measurement is nine inches and three quarters.

This species is certainly the Bos Primigenius of Bojanus, and others; and many examples, far exceeding it in the dimensions of the horns, have been found in our island and on the continent, in alluvial deposits and lacustriue marls. In the Mag. of Nat. Hist., N.S., for 1838 (Mareh), Mr. Brown, of Stanway, gives an account of a pair of horn-cores, with portions of bone and with the foreheid adhering to them, discovered at Clackton, on the Essex coast, about ten miles south of Walton, which measured along the outer curve, from the base to the tips, three feet in length. The circumference of each at the lase was eighteen inches. They were embedded with the remains of the elephant in a mass of drift sand overlaying the London clay. "As no doubt," says the narrator, "the horus themselves were of a proportionate thickness and length to these gigantic remains, what a formidable creature must be the ox, or wild bull. which ranged through the ancient forests!"

Dr. Fleming describes a skull in his possession, twenty-seven inches and a half in length, and nine inches between the horns. MIr. Woods describes the horns of a skull, found in an ancient tumulus on Wiltshire dowus, as measuring thirty-three inches in span, and having a circumference of fifteen inches at the base. With these relies were associated the bones of deer, and boars, and fragments of ancient British pottery; a proof of the coeval existence of man with the huge-homed ox; though, as he observes, the latter was most probably destroyed by the aboriginal inhabitants before the invasion of Britain by Cesar.

Professer Owen notices a skull, found in the drift overlaying the London elay at Herne Bay, of which each horn-core along the curve measures three feet three inches, with a basal circumference of nearly nineteen inches.

That these skulls, found as we have said over Europe, are the relics of Casar's urus, seems very probable. Such is the opinion of Professor Owen ; and it is evident, that while the remains are specifically and widely distinet from those of the fossil aurochs, or bison, the two animals tenanted at the same time the same regions. Professor Owen says, "it is remarkable that the two kinds of great wild oxen, recorded in the "Niebelungen Lied," of the 12th century, as having been slain with other beasts of chase, in the great hunt of the forest of Worms, are mentioned under the same names which they received from the Romans:"

\footnotetext{
"Dar nach schlnch er sihiere einen wisent und einen elth, Starcher ure vier, und einen grimmen sthelch."

"After this be straightway slew a bison and un elk Of the strong uri foor, and a single fierce schelch."
}

These verses are also quoted by Dr. Weissenborn, in Mag. Nat. Hist., N.C., 1838, p. 248, with the observation: that, "if we consider how many tautologies occur in that fantastic poem, and that Sifrit slew a lion on the same occasion, we may suppose that the author cared less for realities than for words conveying proper associations, and that he was glad to find two names for the same fierce animal." But if Dr. Weissenborn had compared the huge-horned fossil skulls in question with the fossil skulls of the aurochs, or bison, he would have seen the striking contrast between them.

Secondly. In the British Mnseum is a skull, in some respects like that of the fossil urns, but differing in the following particulars: It is flatter on the forehead, and broader in proportion, measuring from the occipito-frontal ridge to the begimning of the nasal bones, eleven and a half inches; between the horns, eight inches and a half; between the orbits (which are less prominent), ten inches; the ridge is quite straight; the horn core, following the curve along the outside, measures two feet two inches; the horns sweep outwards, and turn forwards at the tips. It has much resemblance to the skults of the long horved breeds of our domestic cattle; and thongh we do not positively assert it, we think it to he different from the huge homed species, or urus (Bos Primigenius). The locality whence it was obtained is not known, but it belongs to Sloane's collection.

Thirdly. Several skulls of a short horned, but very long fronted ox, described by Professor Owen as the Bos Longifrons. It could not have exceeded, even if it equalled, the ordinary domestic ox in stature. An imperfect skull, which we mensured gave the following: Width of the orbits, nine inches; from the froutal ridge, which is moderately arched, to a line level with the upper rim of the orbits, seven inches; distance between the basis of the horns seren inches; horn-core, following the curve, from eight to nine inches. The fossil relics, probably, of this species, are found in the same deposits as those of the Bos Primigenius. 
viz., in fresh-water drifts, in logs beneath the pent, und in caverns. Many specimens liave leen obtriued from Ireland; from the fresh-water pliocene deposits on the Essex coast; the freshwater drift at Kiensington; and from the cares of Kirktale and Oreston. The relies in question consist of the bones of the extremities; which are ratber shorter, but thicker in proportion to their length than those of an ordinary domestic ox : and Professor Owen, who attributes them to the Bos Longifrons, says with reference to them, that "at all events (whether attributable to this species or not), they testify the existence of an ordinary sized bos with the extinct caruivora of that remote period, and one, therefore, more likely to become their prey than the comparatively gigantic bison and urus." This small short-horned species Professor $O$ wen is inclined to regard as the origin of several of our mountain varieties of domestic cattle: those, for example, of Wales, and the runts and kyloes of the Scottish Highlands; and with great propriety he observes, that the domestic descendauts of a primitive ritce of wild cattle are more likely to be met with on the mountains than in the lowlands of Britriu, because the aborigines retaining their gromnd longest in the mountain fastmesses may be supposed to have driven thither such domestic cattle as they possessed before the foreign invasion, and which we may presume, therefore, to have been derived from the suljugation of a native species of bos.

With all deference to so great an authority, we are not convinced, by any means, that this Bos Longifrons was the origin of any of our mountain breeds. This species had a loug visage, and narrow in proportion to its lengtb. In our mountain breeds, the front is broad and flat, the length short in proportiou; the horns fine (or wanting); the limbs fine boned; but the limbs in the Bos Longifrons were short and thick boned, and the horns, though short, very thick in proportion. But granting the views of Professer Owen to be correct, what is the inference? namely this: that originally distinct species have commiugled together; for our long-horned old breeds, it must be admitted, rere not of the stock of the Bos Longifrons; and the theory of the non-intermixture of allied species, falls to the ground.

Fourthly. The fossil skull of a bison, from Derschaw, a town near Dantzig. Tlis sliull is described in a letter to Sir Hans Sloane from Mr. Jacob Klein, in the "Philosophical Trausactions" for 173l-2 (Vol. XXXVI., p. 427), acconpanied by a grand figure. It is remarkable for the convexity and bold swellings of the forehead; and the horns, which are larger than those of the modern aurochs (at least in general), spread late. rally, with even a backward inclination; the distance between the roots of the horns is thirteen inches; and the length of the horn, following the outer eurve, is twenty-two inches. Besides this skull there are a pair of massive hortes, evidently belongiug to the same species, from Walton in Essex; they formed part of Dr. Mantell's collection. Of these horus, the one we measured is twenty-one inches in length, its circumference at the base being fifteen inches. This species is the Bos (bison) Priscus of Bojantus; and Professor Owen, in his "History of British Fossil Mammalia," figures the frontlet and horn-cores of the same species, from the pliocene clay, Woolwich. This animal existed contemporaneously throughout Europe with the urus of Cæsar, and its remains occur in the same deposits. The anatomical points of difference between this skull and those of the Bos Primigenius, or any of the true taurine section, are very striling. In the ox, the forehead is flat and square; in the bison or aurochs, convex, and bioader than long; in the ox, the occiput declines from the ridge at an acute and sudden angle; in the bison, the occiput forms an obtuse angle; and its plane, which is quadrangular in the $o x$, is seni-circular. There are other distinctive characters of no less importance; but we shall not euter into minutix.

Here, then, we have an aurochs conjointly with a urus or long-horned ox, on the same grounds together; and one, too, with massive horns, such as Dr. Weisseuboru contends for, on historical testimony were possessed anciently by the Lithuanian animal; an aurochs, moreover, which might have lived, as Solinus (third century) asserts, in the Hercynian forest, where Cresa. places the urus; and probably also in Poonia, conjointly with the huge-horned $\mathrm{ex}$ of Herodotus. Have we not here a solution of the difficulties in which Dr. Weissenborn, looking to listorical notices, and not to the fossil relics of species, was enveloped. We have in the same regions the "villosi terga lisontes," and the "latis feri cornibus uri," " excellenti vi et velocitate;" and both these animals were known in ancient Pome, and exhibited iu the amphitheatres. The urus of Cæsar, the descendaut of a long line of ancestry, which survived many changes during the pliocene period of the tertiary system of geology, has perished; man has effected its ultimate extirpation: but the relies of the bison or aurochs, which flourished in a coeval age, has had a somewhat better fate ; it still exists, under protection, in the forests of Lithuania; aud, if the species be the same, in the chain of the Caucasian mountains. And here we may observe, that we are wartanted in our belief that the Lithuauian aurochs is the desceudant of the race whose fossil bones are aloundant, from a comparison of the sliull and skeleton of the individual sent by the Emperor of Russia to the British Museum, with the fossil 
skulls and bones in our various cabinets. These relies we have not personally compared with the bones of the skeleton in question, as the latter were not accessible when we visited the Museum. Perhaps it will still be in our power to make the comparison; but that will be of little consequence, as it has been made by Professor Owen, whose opinion is of the highest weight. The following is his summary : "The metacarpal and metatarsal bones present the same slender proportions, compared with those of the $\mathrm{ox}$, which distinguish the fossils. There are fourteen pairs of ribs; the skull shows the same expanse, conrexity, and shortness of the portal region, as does the fossil skull of the Bison Priscus; the horn-cores have the same advanced origin, and the same direction. These, however, are relatively shorter than in most of the fossil skulls, and the general size of the existing aurochs is less than that of the ancient or fossil specimens. Admitting, with Cuvier, that such characters are neither constant nor proper for distinction of species, we may recognise in the confined sphere of existence to which the aurochs has been progressively reduced, precisely the conditions calculated to produce a general loss of size and strength, and a special diminution of the werpons of offence and defence. I cannot perceive, therefore, any adequate ground for abandoning the conclusion to which $I$ had arrived from less perfect materials, available to that end, before the arrival of the entire skeleton of the Lithuanian aurochs; viz. : that the species were contemporary with the mammoth, the tichorhine rhinoceros, and other extinct mammals of the pliocene period."

The subjoined are figures of the fossit slicll of the aurochs, from Cuvier; the original is in the Museum of Paris :-

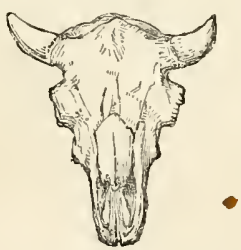

ROSSIL ADROCHS.

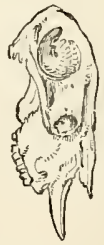

(Profile view.)
Fiftbly. Thefossil skull of a bison (bison Americanus?) from the cliffs near Eschscholtz Bay, arctic circle, brought to England by Captain Beechey. This skull is smaller, less convex on the forehead, and with all its prominences less boldly marked than the fossil auroch's skull previously noticed.

Sixthly. The fossil skull of a musk ox, from the cliffs at Eschscholtz Bay, brought to England by Captain Beechey. It appears to be identical with that of the present living species, Ovibos Moschatus. Different writers describe the fossil skulls of oxen and bisons, found in Europe and North America, under various names: Bos Trochocerus, Hermann; Buffle Fossile de Siberie, Cuvier; Bos Latifrons, Harlan ; Bos (bison?) Bombifrons, Harlan; Bos Vanaliculatus, Fischer; Bos Velaunus, Robert. But as we have had no opportunity of comparing these relies with others, we cannot say how far they are really distinct.

Abundant remains of a species of ox were found by Captain Cantley, in the Sewalik mountains, at the southern part of the Himalayas, between the Sutlej and the Ganges, partly lying on the slopes, among the ruins of falling cliffs, and partly in situ in the sandstone, in company with the bones of the mastodon, elephant, rhinoceros, hippopotamus, hog, horse, various species of deer, several carnivora, crocodiles and gavials, fresh-water tortoises, and fishes. From this sketch of the taurine and bison sections of the bovine group, we advert to our question, the descent of the wild oxen (so called) of some of our parks from an indigenous race; that they are the descendants of any of the species, the skulls of which we have examined, except, perhaps, the second (p. 14), we cannot admit; yet these are skulls of the wild oxen of England, if then insular. Now, let us remember, that there was a time in which Western Europe received its first tide of colonization, and that at that time man possessed flocks and herds. When Cæsar landed on our shores, he found the Celtic tribe in the possession of the dog, the horse, the ox, and even the domestic fowl. Had they not carried these animals along with them in their early migrations, sedulously preserving them, while they hunted down the wild and the ferocious? We think so; the urus is extirpated; it was so in Britain in Cæsar's time; and the aurochs is reducerl to a few individuals protected by Imperial mandate. But the ancient Britons had tame cattle in abundance, and among these a white breed peculiarly valued; this breed was long maintained, and, as may be expected, principally in the mountain fastnesses, neverentirely subjected to the dominion of the Romans nor yet to that of the Saxon invaders. "Howel dha," says an able writer, "describes some of the cattle in the tenth century as being white, with red ears, resembling the wild cattle at Chillingham castle. An early record speaks of a bundred cows with red ears being demanded as a compensation for certain offences against the princes both of North and South Wales. If the cattle were of a dark or black colour, a hundred and fifty were to be presented. When the Cambrian princes did homage to the king of England, the same number of cattle, and of the same description, were rendered in acknowledgment of sovereignty. Speed tells us 
that Maud de Breos, in order to appease King John, whom her husband had offended, sent to his queen a present from Brecknockshire, of four hundred cows and a bull, all white with red ears; and the same records that describe the white cattle with red ears, speak also of the dark, or blackcoloured breed, which now exists, and is general throughout the principality." We may liere observe, the Celtic tribes of antiquity regarded the ox as one of the earliest productions of creation, and as claiming something like reverence.

We have here, then, notices of a valued breed of white cattle. The descendants of these might, at various times, have become feral; that is, have roamed in the wild forests, and returned to a natural state of independence (as has, in recent times, occurred in South America); and of these feral herds the Chillingham wild cattle may be the lineal descendants, jf, indeed, not of the tame race once so much esteemed.

We are strengthened in this view of the subject by the fact, that similar breeds exist in other parts of Europe. In Italy there is a noble breed of white cattle, the bulls being models of beauty ; such, indeed, as the sculptured figures of antiquity portray with spirit and fidelity. Herds of this breed graze in the wild solitudes of the Campagna of Pome, tended by raccari, or herdsmen. The

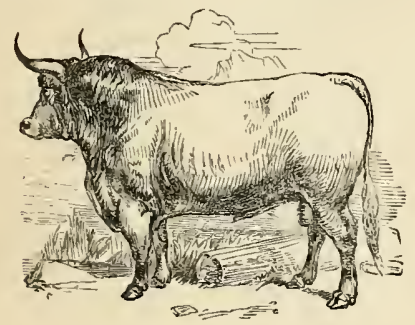

BULL OP THE CAMPAGNA OP BOMK.

bulls are very fierce; and the amphitheatre of Rome, built upon the site and with the materials of the Mausoleum of the Emperor Augustus, in the Campus Martius, exhibits a regular succession of combats, the relies of those of the olden time; among which bull-fights are most relished by the successors of the excited crowds, who once thronged the Colosseum and the Flavian amphitheatre. These noble white bulls are liept in the vaults which once held the ashes of the imperial Cæsars (now dens for wild bulls and buffaloes); they bound from their prison upon the arena, and are encountered by giostratori (of whom the most celebrated are from Viterbo), who exhibit the most consummate courage and address.
In Hungary there is a breed of white cattle, of large size, of which a magniticent specimen adorns the uurivalled zoological collection in the British MInseum. This breed is not maned, if we may judge from the specimen, lilie the Chillingham race (though in the latter the mane is really very trifling), and has rather longer horns, but still fine, white, and with black and sharp points. In the "Pictorial Museum of Animated Nature," ( $\mathrm{rol}$ i. p. 161, fig. 709 ), is represented a scene in Moldavia, where the people still maintain, to a certain degree, the nomadic habits of antiquity. It is a caravan of oxen, traversing the country, transporting, in tall wicker vehicles, of singular construction, various articles of produce, provisions, and other things to the towns, scattered at wide distances about the vast plains of that region. We allude to this merely for the purpose of noticing the fact that the oxen are all white.

In Poland a race of white oxen is still preserved. A fine specimen is placed, in the British Museum, between the Chillingham Bull and the Hungarian : it is smaller than the latter, but larger than the former, and it is nameless. Nevertheless, those who look with the eye of a zoologist upon the three specimens, cannot but feel convinced of their close relationship.

But why, it may be asked, should white cattle have been preserved and valued before others? for from such a preference does our argument go to account for the maintenance of these white races, and the preservation of our white Chillingham wild breed, the descendants of a tame or feral race of antiquity. We know not why, but certain it is that white animals have ever leen much esteemed by man. In ancient Persia the chariot of Jupiter was drawn by eight white horses, of Nisean breed, accounted sacred.* Virgil describes the Thracian steeds of Turnus as surpassing the snow in whiteness; the priests and judges of Israel rode on white asses; the consecrated luull, offered as a sacrifice to Apis by the ancient Egyptians, was white, without one black hair, otherwise its slanghter was unlawful; the sacred bulls of the Hindoos are white. We might enlarge upon this point, but it is useless. Ноwever, this predilection may serve to account for the maintenance, in its purity, of a white breed of cattle in different countries and through a long period of time, and for the preservation of the white feral race, in our island, after the destruction of the rest.

Thus, then, have we rentured our opinion, that the Chillingham breed of oxen is not descended from the huge long-horned urus, little in-

* The chariots of the ancient Persian kings were drawn by white horses. The horses consecrated to the sun were white; ial the white horse was the ancient Saxon standard.

"Ter centum nivei tondent dumeta juvenci."-VIrsit. 
ferior in size to the elephant * but from a feral race, spruug from the stock introduced by the earliest colonizers of this portion of the globe, and of which the aboriginal wild stock, probably extinct. was different from that untameable race of uri. But, at the same time, we admit that the aboriginal stock of the domestic ox may once bave roamed over the whole of Europe, and the adjacent parts of Asia. In Spain and Portugal, where extensive wilds and vast forests afford ample range and pasturage, vast herds of a feral, or semi-feral, race of cattle roam at liberty. The great forest of Alemtejo is celebrated for these cattle, which are very fierce, and, at certain times, the dangerous chase of these animals is conducted on an extensive scale. The finest and boldest are selected for the revolting contests of the arena; and others are tamed and broken in for the ordinary purposes of husbandry. During the chase serious and even fatal accidents often happen both to man aud horse. The men are armed with long and sharp goads; and their object is to separate the bulls from the herd, and force them into an enclosure, a work requiring the greatest daring and arldress. Were the Alemtejo to become disforested and cultivated, we may easily conceive how the lingering relics of its feral herds might come to grace a park, and be looked upon as the survivors of an original and a truly wild race. So, in our island, when the extensive woods yielded to the axe; when the marshes were drained, and cultivation, the effect of civilization and an in. crease of population, began to make progress, the tauri syliestres of Fitzstephen would rapidly di. minish in numbers, their last relics finding refuge and protection in the parks of kings or nobles.

Lord Tankerville, in a letter to Mr. Hind. marsh, who read a paper on these cattle before the Bristol Association, in 1838, says of them, "They have pre-emineutly all the characteristics of wild animals, with some peculiarities that are sometimes very curious and amusing. They hide their young : feed in the night, hasking or sleeping during the day; they are very fierce when pressed, but, generally speaking, very timorous, moving off on the appearance of any one, even at a great distance. Yet this varies very much at different seasons of the year, according to the mamner in which they are approached. In summer I have been for several weeks at a time without getting sight of them, they, on the slightest appearance of any one, retiring into a wood, which serves them as a sanctuary. On the other hand, in winter, when comirig down for food into the imer park, and heing in contact with the people, they will let you almost come among them, particularly if on horseback. But then

* Domestication generally promotes an increase in size ruthe than diminishes $\mathrm{it}$. they have also a thousand peculiarities ; they will be feeding sometimes quietly, when, if any ono appear suddenly near them, particularly coming down the wind, they will le struck with a sudden panic, and gallop off, rumning one after another, and never stopping till they get into their sanctuary. It is observalle of them as of red deer, that they have a peculiar fuculty of taking advantage of the irregularities of the ground; so that on being disturbed, they traverse the whole park, and yet you hardly get a sight of them: their usual mode of retreat is to get up slowly, set off in a walk, then a trot, and seldom begin a gallop till they have pat the ground between you and them, in the mamner that I have described. In form they are beautifully shaped, short legs, straight back, horns of a very fine texture, thin skin, so that some of the bulls appear of a cream colour; they have a cry more like that of a wild beast than that of ordinary cattle. With all the marks of high breeling they have also some of its defects; they are bad breeders, and much subject to the $r u s h$, a complaint common to animals lired in and in, which is unquestionably the case with these as long as we have any account of them.

"When they come down into the lower part of the park, which they do at stated hours, they move like a regiment of cavalry in single files, the bulls leading the vall, as in retreat it is the bulls that bring up the rear. Lord Ossulston was witness to a curious way in which they took possession, as it were, of a new pasture recently opened to them. It was in the evening, about sunset ; they began by lining the front of a small wood that seemed quite alive with them; when, all of a sudden, they made a dash forward altogether in a line, and charging close by him across the plain, they then spread out, and after a little time began feeding.

"Of their tenacity of life the following is an instance. An old bull being to be killed, one of the keepers had proceeded to separate him from the rest of the herd, which were feeding in the outer park. This the bull resenting, and having been frustrated in several attempts to join them, by the keeper's interposing (the latter doing it incautionsly), the bull made a rush at him, and got him down; he then tossed him three several times, and afterwards knelt down upon him, and broke several of his ribs. There being no other person present but a boy, the only assistance that could be given him was by letting loose a deer-hound belonging to Lord Ossulston, who immediately attacked the bull, and by biting his hcels, drew lim off the man, and eventually saved his life. The bull, however, never left the keeper, but kept continually watching and retmruing to him, giving him a toss from time to time. In this state of things, and while the dog with singular sagacity and courage was holding the bull at bay, a mes- 
senger came up to the castle, when all the gentlemen came out with their rifles, and commenced a fire upon the bull, principally by a steady goorl marksman, from behind a fence, at the distance of twenty-five yards; but it mas not till six or seven balls had actually entered the head of the animal, one of them passing in at the eye, that he fell at last. During the whole time he never Hinched, nor changed his ground, merely shaking his head as he received the several shots. Many more stories might be told of hair-breadth escapes, accidents of sundry kinds, and an enlless rariety of peculiar hatits observable in these animals, as more or less in all animals existing in a wild state; but I think I have recapitulated all that my me. mory suggests to me as deserving of notice."

\section{CHAP'TER II.}

IT is agreed by all naturalists, that the domestic ox of Europe, divided as it may be by the effects of treatment, soil, food, and climate, into peculiar breeds, is every where specifically identical. But the humped, or zebu race of the east presents such marked differences from those breeds in form and roice, that mauy eminent writers hesitate not to regard it as of distinct origin.

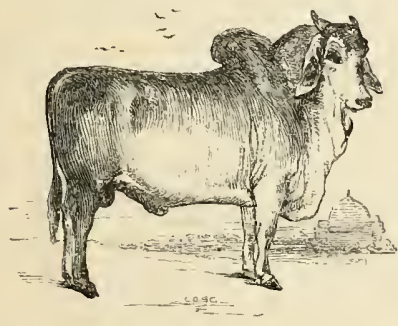

LARGE ZEBU, OR, BRAHMIN BULL.

Narrow high withers, summounted by a large, fatty hump; an arched back rising at the croup, and then descending suddenly to the tail; slender limbs; a large, pendulous dewlap falling in folds; long, peudant ears, and a peculiarly mild expression of the eye, characterize the zebu race of India; a race varying in size from that of our largest cattle, to a dwarf and ofteu hornless breed, not exceeding a young calf in stature. Of both the large and dwarf races specimens exist in the gardens of the Zoological Society. Between these breeds there are many of intermediate stature, and one, of Surat, has the hump double.

The zebu race is not confined to India, China, and the Indian islands, but is found on the eastern coast of Africa, and in the island of Madagascar, wbere, as in India, it is used for the purposes of draught and burden. In ancient times, this race, as well as a race destitute of the zebu peculiarities, existed in Egypt; the figures of both are plainly delineated on ancient mouuments and temples. An Egyptian paintiug, in the British Museum, represents two herds of oxen, of which the foremost in the upper compartment is distinguished by its hump and shorter horns from the long-horned, straight-backed cattle in the lower compartment. Perhaps, however, it was rather in Upper than in Lower Egypt that the zebu breed prevailed; such, at least, is the case in the present day. In Lower Egypt, as

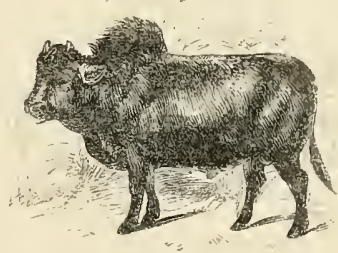

DW.ARF ZERU.

Burckhardt states, it is almost unknowu; but it begins in Dongola, whence all along the Nile, as far as Senaar, no others are seen. In the Galla country there is a race of large zebu cattle, generally of a white colour, high on the limbs, with a small hump, but, on the contrary, with horns of great bulk and length, and sweeping upwards. In Bomou there is a very large white race, with immense horms, which first bend downtrards, and then turu upwards with a half spiral revolution. According to Clapperton, the corneous external coat of these horns is very soft, distinctly fibrous, and at the base not much thicker than a human nail. The bony core is very cellular, and so light that the pair together scarcely weigh more than four pounds. The dimensions of one of these homs were as follows:-Length measured on the curve, three feet seven inches; circumference at the base two feet; length in a straight line from base to tip, one foot five inches and a half. This species, he adds, has a small neck, and is the conmon domestic breed of Bormou, where the 
buffalo is said to have small borns. It is, perhaps, a similar breed that Bruce speaks of, as occurring in Abysinia; only he describes the horns as very heavy, and as acquiring theix extraordinary size from discase. His words are, "the extraorlinary size of these horns proceeds from a disease that the cattle have in these comtries, of which they die, and is derived, probably, from their pasture and climate. When the animal shows symptoms of this disorder he is set apart in the very best and quietest grazing place, and never driven or molested from that moment. His value lies then in his horns, for his body becomes emaciated and lank in proportion as the horus grow lirge. At the last period of his life, the weinht of his heat is so great that he is unable to lift it up, or, at least, for any space of time; the joints of his neck become callous at last, so that it is not any longer in his power to lift up his head. In this situation he dies, with scarcely flesh to cover his bones, and it is then his horns are of the greatest ralue. I have seen horns that wonld contain as much as a common-sized water pail, such as they make use of in the houses in England." (Travels, vol. vi.)

How far we may credit Brace's account, we have no means of ascertaining. We may, however, remark, en passant, that there appears to be in many parts of Africa a tendercy in cattle to the development of the horns. The Duteh, when they took possession of the Cape, found the Hottentots, then a pastoral people, to be the owners of herds of cattle remarkable for the length of their borns, and the breed still prevaijs. Nor are somewhat parallel instances of a tendency to the increase of external parts of the frame wanting in the sheep. The sheep with a long tail, loaded with fat, and occasionally trailing on the ground, extends from Egypt through a considerable portion of Africa. Most of the sheep in Guinea are gaunt and loug-limbed animals, with large, pendulous ears, and two tassels of skin hanging from the throat; and there is a Fezzon variety like the Guinea sheep, but with a pendulous deriap instead of tassels.

To return to the zebu cattle of India. If any circumstance could incline us to adopt the idea that the zebu has sprung from an original type, distinet from that of the ox of Europe (regarded by Cuvier, but we think on insufficient grounds, as the descendants of the ancient urus), it would be its extreme antiquity. From the earliest period this zebu race has been an object of veneration in India; as may be expected, therefore, carved delineations of it are common in the oldest temples; among which we may particularize the celebrated ave temples of Ellora, where it is very spiritedly chiselled; and, also, the Seven Pagodas, as they are commonly termed, at Mahámailaipur, on the
Coromandel coast, the carvings of which faithfully represent it. Nor are otlrer sculptured remains of remote antiquity destitute of figures of this race, which, as far back as two thousand years before the Christian era, presented the same characters precisely as it does at the present time. We fond it, as well as the western race of cattle, on the sculptured monuments of Egspt, where A pis was worshipped in the form of a bull, of a black colour, and where snow-white bulls were offered in sacrifice. Rosellini (plate xx. M.C.) figures a brahmin or zebu bull, copied from one of the tombs at Thebes, with short horns, and a hump on the shoulders; it is represented with a rope round its neck, from which a flower is sus. pended; probably the decoration of a devoted victim. Cuvier, it is true, regards the zebu as identical with our race; but he, also, is inclined to regard the gayal as resulting from a mixture of this breed with the buffalo: an idea undeserving of the slightest entertainment.

To these observations we may add, that the voice of the zebu approaches more to a grunt than to the lowing of our kine, or the low deep roar of our bulls; and, again, its style of colouring is altogether different: true, some are white, and we, also, have white cattle; but our white cattle have, invariably, red or black ears, an indication that one of these colours has given place to the white, with which, indeed, most of our coloured animals are more or less rariegated, and which in the snowy examples is only spread to its maximum, * the ears being left. In the zebu race, the prevaiking colour is ashy grey, not disposed in abrupt patches, but merging by gradations into the white of the under parts; such, at least, is its standard style of colouring. But we confess that this ground is less tenable than the persistency of the characteristics of the race from remote ages.

Whether the zebu race be originally distinct from the European, or the contrary, we are certain that they will interbreed, and a mixture of the races seems to prevail more or less in Persia; the former becoming more numerous as we approach the frontiers of India. It is not unlikely, that the Greeks possessed a mixed breed, in which, though the liump was wanting, the amplitude of the dewlap remained. The oxen represented by the Greek statuaries are high in the fore-quarters, with an arched neck, and a deep dewlap, displaying marked perpendicular folds; the crupper, too, is rounded, and the general contour seems intermediate between the western and zebu breeds.

If the theory, that the western and Indian cattle are from one aloriginal stock, be conceded, which, it may be asked, approaches the nearest to

* Let us lnok at the Chillingham white eattle, and we shall see in this fact, a proof of their descent from a race molified in colour by the domestieution of their progenitors. 
the primitive type? Deciledly the European. The hump, the large pendulous ears, the loose large dewlap, the loose slin, and the very contour of the zebu, show that it is farther removed from a state of nature tlian the bulls of the Campagna of Rome or of Bulgaria. These characters are parallel to others of a similar nature in the sheep, and seem to be greatly connected with climate. We do not think the species from which the ordinury domestic os spruug, to have been a native of Eastern Asia or India. TWe believe, therefore, that the domestic zelu breed (if really of the same specific identity) has been introduced into the far east, at some remote epoch, where, receiver as a gift from the gods, it would soon become connected with religious rites, cerenınies, and superstitions, till it became itself an idol, the incaruation of some mystic deity. Arrian, in his "Indian History," says, "The whole country of India is divided into one hundred and twenty-two nations, according to Megasthenes. Like the Seythians, the Indians were anciently a wandering race; and until Bacchus or Triptolemus made a conquest of them, tilled no lands, and had neither houses, towns, nor temples; clothed themselves in the skins of wild beasts; ate of the fruit of the tala, a palm-tree, and of the flesh of animals of the chase. Bacehus built them cities; gave them laws; taught them agriculture, aud the use of wine, as he had taught the Greeks; and how to yoke their oxen to the plough. He also instructed them in military discipline; the worship of the gods, to be performed with drums and symbols: he introduced the satyric dance, and the custom of suffering the hair to grow." Here we have the picture of a migratory people, probably from the Tartarian wilds, wandering with their herds, and spreading over the plains of India; and this is the more probable, as Professor Pask finds the grammatical structure of the Telega, Tamil, Carnatica, and Malayalina tongues, which he regards as those of the most ancient tribes, to agree with the Finnish and Tartar; whence he supposes that one great race of men, which may be styled the Seythian, in the most ancient times, extended from the Frozen Sea to the Indian Ocean, until the chain was broken by a great inundation of people of our own race, which he calls the Japetic. Who were these ancient invaders? Tribes speaking a perfectly distinct language from the Tartar,namely, the Sanscrit, the parent of so many of the moderu Indian dialects? According to Sir IV. Jones, and other scholars, it was from Iran* that the stream issued which drove the Scythian tribes southwards, and spread, like a torrent, over the northern part of India and the adjacent region, as the Gothic or Scandinavian flood of population

\footnotetext{
- By Iran is cvidenty meant Western Asia, including Persid.
}

has spread over Europe in later periods. Hence. then, it is that the early legions of ludia are interwoven with or parallelized with those of Greces (and, perhaps, still more of Egrpt); insomuch that, when Alexander invaded India, he found abundant sources of analogy in the theogonies of the Indians and of his own country, to amuse his veterams. (Fur some interesting historical details on the sulject, see Lieut.-Col. Todd's " Comparison of the Hindu and Theban Hercules;" Trans. Royal Asiat. Sec., vol. iii. p. 139.) For an account of the connexion between the Greck and Egyptian mythologies, and the adoption of religious festivals and ceremonies by the Greeks from the latter, we have but to consult Herodotus (Futerpe, ii.); and knowing. as we do, from the same author, and from sculptures and mummies, the adoration paid by the Egrptians to the ox, we shall be at no less to conceive how loth these people, and the Sanscritic tribes from Iran, derived from one and the same source their rites and ceremonies. The traditions of the Celtic tribes lead us to understand that the ox was lucld by them also in a sort of reverence. The original seat of the Celtic brauches of the human race is to be traced to Western Asia; and nations, alike ignorant of Homer and his Iliad, refer to Troja (a city or territory of mystery) as the primitive cladle of their race. The claim of the Cumri of Britain to a Trojan origin was maintained in the earliest ages, loug before the fabrication of Geoffroy of Monmouth; and to this origin the Umbri, the Ligurians, the Teneti, the Sabines, and the Latins, also laid claim.

If Arrian, then, be right, it was Triptolemus, or Bacchus, that taught the worship of the ox, which the Scythian nomades already possessed, and had carried with them in their wanderiugs; and hence (setting other reasons aside) me may conclude that the Indian ox, modified by climate, is not an aboriginal of the regions sontb of the Indus.* But while we say this, and while we acknowledge that no wild type exists in a region where the wild stocks of wher domesticated spe. cies exist, and where we might expect it to be found were that country is cradle, still we cannot help suspecting that, in some parts of India, this breed is crossed with the gayal. Colonel Smith alludes to a variety of large size, having a hump on the back which sometimes weighs fifty pounds; the horns are short and bent backwards, and the colour is usually red or brown. Mr. Bird ("Asiatic Res.,"vol. viii.) has proved, by direct experiments not only that the zebu and gayal will breed toge ther, but that the offspring is fertile. We have

* Wandering tribes are mlikely to have comesticated any of the wild animals of the countries they roamped in ; they carry tiune anjmals witb them, but the domesticution of animals snploses a setuled dumicile, and a rertain degree of civilization. 
already said that the Brahmins hoh the wild gayal sacred, and refuse to hunt it.

The large zehu, or brahmin bull, is certainly a noble animal, and much more active than any of our breeds. These animals are used in India as beasts of dranght and burden, and also for the saddle. We learn that Lient.-Col. Skinmer, of Danah, on the borders of the Bichaneer desert, one hundred miles west of Delhi, maiutains a large stock of them: and sir or seven beasts are always kept saddled to carry the military despatches. They remain saddled three or four hours, when, if not wanted, they are relieved by fresh ones. They will travel, with a soldier on their back, fifteen or sixteen hours in the day, at the rate of six miles an hour. Their action is fine, and they bring their lind legs under them in as straight a line as the horse. Such is their activity that they can clear a five-barred gate with ease. Thevenot says ("Telation," vol. iii., p. 151), "As the oxen in India are by no means ungovernable, there are many persons who employ them in travelling, and who mount them as they do horses. Their ordinary gait is easy. Insteal of a bit a small cord is passed double through the gristle of the nose, and to this is attached a stout cord in the fashion of a bridle, which is kept up by the hump the animal has on the forepart of his back, and which is wanting in our oxen. The animal is saddled like a horse, and when a little excited into action it goes very quickly; some, indeed, gallop as well as a good horse. These cattle are in veneral use throughout the whole of India; and they use no other in ploughs, coaches, and chariots, which are drawn by oxen, their number being in proportion to the weight of the load."

It would seem that white oxen are highly esteemed in India, as they have been in other larts of the world. Otearius (rol. i., p. 458) notices the procession of an Indian prince, who was drawn in a carriage harnessed to two white oxen, which were as lively and active as horses. Bishop Heber observes that the Thakoors, the nobility of the Fajpoots, generally travel in covered wagous drawn by white oxen, whose horns they gild.

"The two oxen," says Tayernier, "wlich were harnessed to my carriage, cost me nearly six hundred rupees. The reader need not be astonished at this price; for these are oxen of great strength, and which travel journeys of twelve to fifteen leagues a day, for sixty days, and always on the trot. When they have done lialf their day's work, they liave two or three balls (the size of a penny loaf) of wheaten flour, kneaded with butter and coarse sugar; and, in the evening, their ordinary fare cousists of chick-peas, lruised and steened half-an hour in water."

By some tribes these cattle are bred on a most extensive scale. Te are informed by Lient. Col.
Sykes ("Proceedings Zool. Soc.," 1830-1, p. 13), that the Brinjarees, a singular erratic people, breed vast numbers of brahmin cattle; and that " an army rarely moves in the field without 15,000 or 20,000 bullocks to carry its grain. Dwarf cattle are not met with in Dukhun,"

The buffalo, however, divides the palm of nsefulness with the zebu, in the agricultural labours of India; and, in some places, supersedes it, being of a more hardy and robust constitution. In Dulhun, for example, the buffalo, which is one of the long-homed variety, "is mostly bred in the mawals, or hilly tracts along the Ghauts. In those tracts much rice is planted; and the male buffalo, from his superior hardihood, is much better suited to resist the effects of the heavy rains, and the splashy cultivation of the rice, than the bullock. The female is also infinitely more valuable than the cow, from the very much greater quantity of milk she yields."

The bull is regarded as sacred by the Hindoos; and privileged individuals, devoted to BalSiva, are turned loose by the worthy Bralimins to wander at their pleasure. They become quite tame and fearless, and coolly help themselves to fruit, grain, or vegetables, exposed for sale in the shopwindows, and obstruct the streets and highways, and take up their quarters where it suits them. Devout persons think it a merit to pamper thew; and they become fat and indolent. No one dare presume to injure them; but when they put their muzzle into baskets of grain, or other produce, the owner contents himself with driving them array with his handkerchief, or, at most, only slaps their head or neck, respectfully addressing the animal by the title of Mahraj-your worship!* "In Hindu mythology," says Colonel Todd ("Trans. Poyal Asiat. Soc.," vol. ii., p. 560), "the bull Nauda is at once the guardian of one of the two gates of heaven, of Iswara, or Bal-Siva, and lis steed. The astronomic allusion thus blended with mythology is evident,-viz., the entrance of the sun into the sign of Tanrus, the equinoctial festival of remote antiquity, and regarded as a jubilee by the Indo-Scythic nations hemming the shores of the Mediterranean to the Indian Ocean.'

In ancient Eggpt, Osiris and Isis were respectively renerated under the forms of the bull and cow. The great visible deity of Memphis was the bull Apis; of Heliopolis, the bull Mnevis; and a third bull is mentioned by some writers, Hernuphis, of Hermonthis, in the Thebaid.

The bull Apis, says Herodotus, is the calf of a cow that is incapable of bearing another. The marks that distinguish him from all others are

* Col. Briggs states, that he has seen the sacred ox hrought into an Indian eourt of justice, and Brithins swore by placing their hands on the animal, and calling it to bear witness of their veracily.-Leters on India, p. 72. 
these :-his lorly is black, except one square of white on the forehead; he has the figure of an eagle on his back, a double list of liair on the tail, and a scarabmus under his tongne. To this deity, kept in state, bulls were sacrificed of unblemislied form and of a snow-white colour, without one llack hair. When the vietim is slain, they cut off the head, which they carry, with imprecations, to the public place, uttering over it this imprecation: "May all the evils impending over those that now sacrifice, or over the Egyptians in general, be averted on this head." They then sell it to the Greeks, if any are present; or, if not, throw it into the river. In India, "Siva, as the principle of fertility, has lis sacred bullocks, which are to be chosen according to certain marks. In front of most of his temples there is a colossal stone figure of a bull; and, at certain times, a bullock, with a chaplet on his head, accompanied by a number of men, is led in a lind of procession, intended to represent the course of the sul. It is considered a fortunate omen, when he will eat grass from the hand of a person who approaches him; which is exactly the same thing that Pliny relates of the Apis."

The goddess 1sis, of the Egrptians, was represented as a female figure, with the horns of a cow, such as the Greeks, says Herodotus, represent Io. The sacrificial offering was a bullock, the cow being sacred to the deity, and therefore never sacrificed. It was accounted, by the women of Crrene, a crime even to strike a cow.

This widely-spread worship of the ox to which the Indo-Scythic nations were so strongly addicted, influenced the Israelites, who, as is well known, soon after leaving Egypt, set up a golden calf as a god, And again, Jeroboam, reverting to the worslip in Egypt, set up calves at Bethel, as oljects of superstition. In this bovine adoration we have undoubtedly one of the most ancient of superstitions which have prevailed among mankind.

In whatever part of the world the original domestication of the ox was effected, this most valuable animal spread with the sprearling of nations; it is universal over Europe and Asia, except within those icy regions where the reindeer supplies its place; its range extends over the whole of Africa and the great island of Madagas. car ; and, within modern days, it has been introduced from Europe into the vast continent of America, and the islands of the southern acean. In these new regions it has multiplied excessively, and herds roam the plains in a state of semi-wiluness. South America owes the ox to the Spaniards; the earliest imported, according to Azara, were Audalusian. Captain John de Salazar, born in the city of Pomar, in Arragon, carried over seren cows and a bull to the coast of Brazil, whence they were trunsported by the rivers Parana aud Par gua, to the city of Assumption, in 1546 , sever: months being occupied in their transport. Frot this stock sprung the feral cattle of the extensivi Pampas, of which so many travellers have given most interesting descriptions. Besides thousandof unowred cattle, living in a state of freedom. there are extensive herds, which, though they roam at large, have their owners, and are the property of those on whose estancias, or pastur age estates they feed; they are under the charge of stock-keepers, who prevent their passing beyonil certain limits, or recover them when they lave wandered. The estancia of General San Rosas is said to comprise serenty-four square leagues of land, and to contain 300,000 head of cattle, lesides wild horses. The great value of these cattle consists in their hides and tallow; and for these alone thonsands are annually slaughtered. About 800,000 ox ludes are annually exported from Buenos Ayres and Monte Viedo to Europe. Mr. Damin states that from Monte Viedo alone the exportation is 300,000 , and the home cousumption from waste very considerable. "In order to obtain these hides (he adds) some horsemen join together, and arrange themselves in two ranks, which form an angle; they then press on the sides a small uumber of cattle, and one of the horsemen, who goes last in the angle, hamstrings the animals with " knife in the shape of a crescent, or half-moon, fastened to the end of a staff. While this goes on the horsemen continue to ride forwards, and when they have thus secured a sufficient number of animals, they retrace their steps, and the person, who hamstrung them, gives each beast thus maimed a finishing stroke with a sharp spear, and the horsemen dismount to strip the carcass, sometimes of the fat and suet, lut always of the skin; this they do with such dexterity, that some men, without assistance, will strip trenty-six cattle at a day's work. When a single head of cattle is to be killed for tlie sake of its Hesll, a horseman throws a lasso over its horns or neck, and another does the same orer one of its fect, then straining in opposite directions they prevent it from struggling free, and so strangle it. Admirable is the dexterity with which, when the animals pass as they rush forwards, the lasso is thrown, so that directed backwards under its feet, the animal, at the pleasure of the horseman, is entangled either by one foot or by two together." The carcasses of the oxen left on the plain are soon devoured ly carnivorous birds, vultures, and caracaras, whicl

* The lasso was an instriment linown to and used liy the an cient Egyptians. It does not appear, however, that they limnched when in full gallop on horseback, as do the Gauchos of Sumil America. They are always represented with it on tiot, and ano probably the plan was to lie in ambush, and throw it as the atrit. lope, or the bekr-el wash, or wild os of the urals (anteloge bul witus passed by. 
crowd in flocks to the feast. In many places corrals or enclosures are established for the slaughter of cattle and horses, and in which they are kept till wanted, Mr. Darwin particularly notices the great corral at Buenos Ayres, where numbers of cattle are kept for slanghter to supply food for the people, whom he justly terms a "beefeating" population. The cattle are dragged by means of the lasso to the spot; and he observes that, "the strength of the horse, as compared to that of the bullock, is quite astonishing; a mau on horseback having thrown his lasso (or lazo) round the horns of a beast, can drag it anywhere he chooses. The animal having ploughed up the ground with outstretched legs in vain efforts to resist the force, generally dashes at full speed to one side; but the horse, immediately turning to receive the shock, stands so firmly that the bullock is almost thrown down, and one would think would certainly have its neck dislocated. The struggle however, is uot one of fair strength, the horse's girth being matched against the bullock's extended neck, In a similar manner a man can hold the wildest horse, if caught with the lazo just behind the ears, When the bullock has been dragged to the spot where it is to be slaughtered, the matarlor, with great caution, cuts the ham-strings; then is given the death-blow - a noise more expressive of fierce agony than any I know. I have often distinguished it from a long distance, and have always known that the struggle was drawing to a close. The whole sight is horrible; the ground is almost made of bones, and the horses and riders are drenched with gore."

In the Falkland Islands cattle and horses were introduced by the French iu 1764. The cattle are magnificent, but the horses are small. From the injudicious slaughter of the cows the bulls in these istands greatly preponderate in number. These bulls wander about singly, or in groups of two or three. "I never (says Mr. Darwin) saw such magnificent beasts; they truly resemble the ancient sculptures in which the size of the head and neck is lut rarely equalled among tame animals. The young lulls run away for a short distance, but the old ones did not stir a step except to rush at man and horse, and many of the latter have been thus killed."

In Paraguay, according to Azara, an estancia of two square maritime leagnes can feed 4000 head of cattle, under the direction of a superintendant and four men. The ordinary duty of these five individuals, a duty requiriug a hundred horses, is to collect the herd once a week, driving them from all quarters to a rodéo, or circuit, where an account is taken of their numbers, and those selected for slaughter which are deemed most fat. Where there is much forest land, he adds, the herds of horued.cattle take refuge in the woods during the wintcr. In order that the plains may yield a supply of fresh teuder grass in the spring, they are fired in the autumn, and should it happen that a lierd of cattle are encircled by the conflagration, they dare the flames, and dash through. On the contrary, the horses remain in the circle, violently kicking until they are burned to death. "The cattle suffice here for almost evcry necessary of life; the greater part of the population neither taste bread nor any thing else but flesh-meat. With the homs are made gollets, combs, and spoons; a horn, with a cork at the large end, the small end being opened, serves as a pitcher, The inhalitants form out of the hide all sorts of cordage and string, as well as the greater part of their ntensils; on their hides they sleep, and with them they cover their cabins. The fat supplies the place of oil, of the suet they make soap and caniles; the bones are a substitute for firewood in. many places where the latter is wanting; the skulls are used as chairs in the estancias. From the milk they make various dishes of curds, which though in general not very excellent (becanse the cream and every unctious particle are removed), might be as good as in Holland; and the same may lie saici of the butter."

Von Spix, in his "Journey from the city of St. Paulo to the Iron Foundry of Ypannema," gives very similar accounts; but he adds that, besides the herds which roam wild, every farmer kecps as many tame oxen and cows as he requires for the purposes of agriculture, and for milk, which is partly made of cheese These tame cattle are kept in the vicinity of the fazenda, and run free in the meadows during the day, and are only shut up in an enclosure at night. The flesh of the tame cattle is preferred to that of the wild, as from the quiet life they lead it is fatter, and more tender. Their milk, also, is excellent; but a cow will yield only a third of the quantity that a good milch cow gives in Europe. The hide of the cattle, which is decidedly the most valuable part, when stripped off, is stretched upon the ground by means of short pegs, a little salted. and dried in the sum. "The flesh, cut into thin strips, a little salted, and dried in the air, is an important article of exportation from the harbours of St. Panlo and Rio Grande do Sul to the cities in the north, particnlarly to lio de Janeiro, Bahia, Pernambuco, and Maranhâo; where, under the names of Carne Seca do Sertâo, Passoca, or Came Marqueda, it constitutes all essential part of the subsistence of all the Brazillians, but especially of the negro slaves."

'Thongh the cows in Brazil yield rich milk, the Brazillians have not succeeded in making butter, or establishing a dairy, in the European manner; and, as Von Spix states, even the emperor, who pussesses in his very neighbourhood one of the finest herds of cows, must content himself with 
Irish salt butter, which has performed a voyage of some months. The cow, in Brazil, yields but little milk, though that little is excellent; and it is oh. served, that cows importer immediately from Europe to that country, lose their milk; a fact which, as Spix suggests, is -probably to be explained by the increased action of the cutaneous system, and the flow of perspiration, from the effects of the climate.

Australia, New Zealand, and the islands of the southern seas, and of the North Pacific, have received cattle from Europe; and, indeed, in many of these jslands, the cattle have become feral. Such is the case in the Sandwich Islands (North Pacific), of which Hawaii is the chief. "With the appearance of Vancouver,"says Otho Von Kotzebue, "arose the fortunate star of these islands. Among the innumerable benefits he conferred upon them, they are indebted to him for the possession of sheep and cattie. Tameamea (the native king), declared these animals under a tabu for ten years, which allowed time for so large an increase that they now run wild in the forests." It was at Hawaii that the enterprising botanical and zooloical traveller, Mr. David Douglas, lost his life. He left Califoruia for that island, whence, "after surmounting innumerable dangers, with almost unexampled courage and success, be fell a victim to one of those accidents, improperly so called, which a mysterious Providence, for wise purposes, sometimes permits to befall his creatures." $\mathrm{He}$ lost his way, while on the road to Hido, and fell into a pit excavated for the purpose of entrapping wild eattle, and into which a bull had previously fallen. The result may be anticipated.

In some parts of Australia, and partieularly in the forests adjaceut to Port Essington, there abound wild oxen, wild buffaloes, ponies, and pigs. It has been suggested, that these animals, with the exception of the buffaloes, are the desceudants of the stock left at Port Raffles, when the settlement was broken up; but the buffaloes brought, perliaps, originally from some of the islands of the Indiau Archipelago, are supposed to be of longer standing in the country. The oxen are said to be very fine; numbers, we believe, were met with by the late expedition from Port Essington into the interior. At some future day, perhaps, they may prove of immense advantage. The settlement at Port Raffles was abandoned in 1828 , because it was only resorted to by Malay traders.

We have represented the ox as used for the saddle in many parts of India ; such is its use, also, in many districts of Africa. In the Mandara valleys, the " bullock" (says Major Denham) "is the bearer of the grain and other articles to and from the markets. A smail saddle of plaited rushes is laid on him, when sacks, made of goat. skins and filled with corn, are lashed on his broad and able back. A leathern thong is passed throngh the cartilage of his nose, and serves as a britle; while on the top of the load is mounted the owner, his wife, or his slave. Sometimes the daughter of a rich Shouaa will be mounted on her particular bullock, and precede the loaded ranimals, extruvagantly adomed with amber, silver rings, coral, and all sorts of finery; her hair streaming with fat; a black rim of kohal, at least an inch wide, ronnd each of her eyes, and, I may say, arrayed for conquest at the crowded market." Carpets and robes are spread on her clumsy palfrey, to form a saddle, she sits astride, guides her animal by the nose bridle, and, notwithstanding his sluggish nature, "her vanity still enables her to torture him into sometling like caperings and eurvetings."

A nearly similar picture of the saddle-ox is given by Mr. Burchell, in his "Travels in South Africa :"-

"These oxen are generally broken-in for riding when they are not more than a year old. The first ceremony is that of piercing the nose, to receive the bridle; for which purpose they are thrown on their back, and a slit is made in the septum, or cartilage, between the nostrils, large enough to admit a finger; in this hole is thrust a strong stick, stripped of its bark, and having at one end a forked branch, to prevent it passing through. To each end of it is fastened a thong of hide, of a length sufficient to reach round the neck, and form the reins; and a sheepskin, with the wool on, placed across the back, together with another, folded up and bound on with a rein long enough to pass several times round the body, constitutes the saddle. To this is sometimes added a pair of stirrups, consisting only of a thong, with a loop at each eud slung across the saddle. Frequently the loops are distended by a piece of wood, to form an easier rest for the foot. While the animal's nose is still sore, it is mounted, and put into training, and in a week or two is generally rendered sufficiently obedient to its rider. The facility with which the Hottentots manage the ox, and their adroitness, have often excited my admiration : it is made to walk, trot, or gallop, at the will of its master; and being rather longer legged, and rather more lightly made than the ox iu England, trasels with greater ease and expedition; walking three or four miles an hour, trotting five. and galloping, on an emergency, seven or eight."

Pack-oxen are also much employed in South Africa, in the same manuer as the pack-horses were formerly in England, and the mules are still in Spain. So rapidly does a string of pack-oxen travel along that it is not easy to keep. up with them and their nimble-footed drivers, even by mounted horsemen; for they trot or gallop over the roughest gronnd, where huge rough stones 
scattereil about render it dangerous to give the spur to the horse, or proceed at a quicker paee than a cautious walk.

One of the great benefits rendered by the ox in Sonth Africa, is by its labour in the shafts of the wagon, especially as far as the interests of the Enropean settlers are concerned The usual mode of travelling over the plains and vast karroos of this region, is in large, heavy, tilt-covered wagons, drawn by ten or twelve oxen in pairs. It is astonishiug what toil these often ill-treated and cruelly-used animals will endure, and how patiently they undergo privation. The driver, generally a Hottentot, uses a whip, with a liandle of strong bamboo, twelve or fourteen feet in length, having a thong still longer; this he cracks from time to time, calling the cattle by their respective names, and directing them by the exclamations of "hott" and "haar," to the right or left; occasionally he applies the lash to quicken their speed. But the severities of the Hottentot's lash are nothing to the revolting tortures, which Barrow relates the Dutch-African boors of his time to have inflicted, not only with indifference, but even in wantomess, upon their exhausted cattle. These barbarities, however, we shall not shock common liumanity by detailing. During serene and pleasant weather, no kind of travelling is more pleasant. The roads across the desert, it is true, are merely rude tracks of wheels, which have previously jassed, and sometimes the way leads over rugged and broken, or rocky ground; but still the scenery is often interesting: the flowers, the birds, the antelopes, arrest the admiration of the new settler; and as a number of wagons generally travel together, forming a sort of caravan, the hours of day pass pleasantly; and at night, the fires are lighted, the wagons ranged in proper order, and the party bivonac till morning.

In a similar manner the bullock caravans traverse the wide plains of Moldavia, Wallachia, and Tartary.

There are different breeds of oxen at the Cape, and on Southern Africa; formerly, if Leguat (see his "Yoyages," \&c., 1720,) is to be creditel, the zebu breed extended thither: but it does not exist there now. According to Percival, the large dranght oxen form a peculiar breed, distinguished by a large head, loug horns and legs, with very broad hoofs; they are lank before, but brond behind. Besides this, there is a race of smaller stature, and beautifnl figure, something like the Alderney breed of Europe. The cows of this breed afforl a great quantity of milk, and the oxen are fattened for the table. The beef, however, of the Cape is, on the whole, coarse and indifferent; this is partly owing to the feeding of the cattle upon sour acrid grass and shrubs, instead of in rich pastures, and partly to the exh.ustion of the animals, which are often driven from long distances, and kiled in this unfit state, without proper rest, or any attempt to get them into a good condition.

The universal dispersion of the domestic ox is at once a proof of its intrinsic value to man; but it is in Europe that its value is the most highly appreciated, and perhaps ever has been, and not without cause. Though it must be confessed, that its importance in ancient times, at least amongst the Greeks and Romans, was based upon somewhat different grounds to what it is in modern Europe; and the poets sang more of sheep and shepherds than of herds and herdsmen. The milk of the goat and the sheep was as much, or more used than that of the cow; and it was rather for the sake of its flesh and labour, that the ox was esteemed, than for those qualities which our grazier or our dairy-farmer expects.

Virgil's description of a choice lheifer for breeding would astonish an English farmer:-

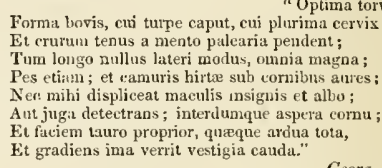

Georg. iii.

LITERAL TBANSLATION.

Of the stem looking heifer, whose head is ugly, whose neck is brawny,

And whose folds of dewlap hang from the chin down the legs :

Again, no moderation be there in the length of her sile; all her parts large;

Even her foot; and her rough ears under her cravkled horns; Nor would she displease me if marked with large spots of white Or if refusing the yoke, and sometimes dangerous with her horn And approaching a bull in aspect, and slogether stately,

And who as she goes along sweeps her foutsteps with the extrenity of her tail."

Aecording to Varro, the ox should have ample horns of a blackish colour; a broad forehead and chest; wide nostrils, and a thick pendant dewlap; the ears hairy, the shoulders thick, but not humped; the hips round, the tail hanging to the heels, and rough with hair ; the legs rather short. the knee-joints straight, a little protuberant, and at a proper distance from each other; the feet should neither be broad, nor clank as the beast walks; the hoof must not be too deeply divided, and each part should be equal and smooth; the hide should neither be rough nor hard to the touch. The strongest have the hide of a black colour; those which come next, have it red; the third, dun; the fourth, white. The cattle of the last being the tenderest; those of the first colour, the hildiest; the others, intermediate between them.

'The labouring ox, as described by Columella, should be young, square, with latge limbs, and 
lofty horns, black and stout; the forehead should he broad and rough, the ears lıairy, the eyes and lips hlack, the muzzle upturned, the nostrils wide, the neck long and brawny, the dewlap large, and reacling almost to the knees, the chest broad, the shoullers massive, the belly large and protulierant, the sides well stretched out, the Hauks broad, the back straight, or a little declining, the legs compact and straight but rather short, the knee-joints well set, the hoofs large, the tail long and hairy; the whole body should be soft to the touch, and the skin corered with short, thick hair, of a red colour, or dark bromn. With respect to the lull, he should resemble the ox, only with a greater development of limb and bulk; his aspect should be stern, his horns shorter, his neck more brawny, so as even to preponderate orer the volume of the trunk; the belly should be more confined.

The cow should be tall and long made, with a very large belly, and very broad forehead; the eyes should be black and open, the horns graceful and smooth, the ears black and hairs, the jaws straight, the demlap large, the legs and hoofs moderate. Our ancient writers give the same description. All insist upon a muscular frame, a brawny neck, a wide chest, large hoofs, stout limbs, and long tail; and such are the animals of Greek and Roman sculpture,

It is evident, that the breed of oxen which the Romans aimed at, was a strong-limled, heary, massice sort, fit for labour, from which the cow even was not excluded:-

"Ex sequore eerne

Plura "domum tardis decedere plaustra juveacis."

"You will see the numerous wagons, with the slow, heavy loaded beifers,

Move homewards from the plain."

The wagon and the plough were for the ox: in Italy, in Greece, and in the East, agricultural labour was its lot; nor is the practice of working the $o x$, in Europe, yet abolished, althongh the horse now takes his share, which was not anciently the case.

Allusious to oxen engaged in the labour of the plough are abundant, both in the Scriptures and classic writings. The plough of antiquity was of simple construction, and in the East still continues to be a rude iustrument, and adapted only for a light soil, or for making superficial furrows. Among the Romans, as is evident from Virgil (Georg. I., 169, et seq.), the tiller of the ground made his own plough, which was fitted for a pair of oxen, aud over which, while at work, the ploughman was obliged to bend, loading it with his own weight, in order to keep the share steadily and uniformly on the ground.

Another use to which the ox was anciently applied, was that of treadiug out the corn. To this practice the Mosaic injunction alludes:"Thou shalt not muzzle the ox when he treadeth out the corn ;" aud Homer also refers to it :-

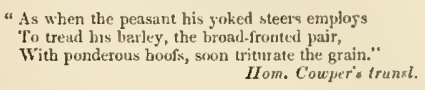

Virgil describes the manner in which the threshing-floor must be laid down, showing that nothing like the modern style of thresling could have been used. He directs, that "the threshingfloor be well levelled with a huge cyliudric roller, and consolidated with binding clialk, that weeds may not spring up, and that it may not become dusty, or full of chinks." Among the Remans, however, horses were also employed in this work, * and Isaiah (xxiiii. 27), also, alludes to horses or horsemen.

The custom of threshing by the treading of animals is still common in northern Africa, where the neddars, or nedders, the "Libyce areæ," of Horace, receive the sheares, which are opened and spreacl out, and oxen, or mules and horses, three or four abreast, are driven round and round, till all the grain is trampled out. These nedders are merely rouud, level plats of ground, in the open air, "daubed over with cow-duug, to present as much as possille, the earth, sand, or grasel from rising; a great quantity of them all, notwithstanding this precaution, must unavoidably be taken up with the grain; at the same time, the straw, which is their only fodder, is hereby shattered to pieces; a circumstance very pertiuently alluded to in 2 Kings xiii. 7 , where the king of Syria is said to have "made the Israelites like the dust by threshiug." ("Shaw's Travels.")

In other parts, as in Syria and Asia Minor, a dray, on which a driver sits, or which he loads with a weight, is drawn over the sheares by oxen. The flat under-surface is stuck full of tints or pieces of iron, arranged in regular rows. This is the trilunlum of Varro and Virgil; and is mentioned by Isaial. "Behold, I will make thee a new sharp threshing instrument having teeth: thou shalt thresh the mountains, and beat them small, and shalt make the hills a chaff" (ch. xli. 15). We do not kuow in what the traha, or trahea, differed.

Another method is by a sledge, moving on three or four wooden rollers, with iron bands, having acute serrated edges to cut the straw: on

- The Romans used the flail in their barns; and Columella says, that "when the ears only are reaped they una be carried to the barn, and afterwards, duriug the winter, beaten nut with flails, or trodien out by cattle. But if it be fonnd conrenjent to beat out the cora in the threshiag-floor (area), there is no doubt this work is better doue by hurses than hy oxen; and if there are few of these a triluila, or traba (sorts of sledges or planks, sometimes oa rollers), may be added, either of which rery easily bruises the straw. When ears only are threshed, it is done the best with flails." The bruised straw was important as fodder, jis reduction by crushing readering it fit for food of cattle. 
this sledge the driver is seated, and the oxen go round and round the threshing-fioor. This was anciently used by the Carthaginians, and Varro calls it "plostellum Pasuicum," or the Carthaginian wain. This is the cart-uheel (as our translation renders it) which Istial says is not turned about on the cummin (see ch. xxiii. $2 \%$ ), and is doubtless of great antiquity. According to Niebuhr, this machine, which lie saw used in Arabia, is there called nouridsj.

By all these moles the straw was ground or cut up to chaff, in order to be given as food to cattle ; but our object is to preserve the straw, instead of beating it to pieces.

We have said that the ox (generally in pains) was used for drawing wagons; this has been the practice in the East from the days of old, and still continues: it was so, also, in Greece and Italy, but the buffalo has to a great extent superseded it. The allusions in the Scriptures to wagons drawn by oxen are so numerous, and so familiar to all, that reference to them is needless. The modern Syriun wagons, of rude construction, are probably not more remote from those which Joseph sent out of Egypt to bring back Jacol and his family, than are the threshing machines of the same country, and are, moreover, very sinilar to those of ancient Greece and Italy.

Virgil notices the full udders of the cow; but the milk of the cow was not in the general use and estimation that it is in the present day. The milk of sheep and goats was, and, indeed, still is, in many districts of Italy, in Greece, and Syria, in greater requisitiou. Syeaking of goats, the poet says,

" Hinc largi copia laxtis

Quam magis exhąustn, spumaverit ubera muletra

Lati magis pressis manabunt flumina mammis."

$$
\text { Georg. iij. }
$$

"Hence a plenteous ahundance of milk,

The more the pail froths with their exhansted udder,

The more will the joyous streams flow from thcir pressed dugs."

Referring to the sheep, he gives directions re specting their feeding, and a supply of salt, to increase the quality of their milk, and give it a slightly saline flavour. (See the same book, line 394 , et seq.)

It was from the milk of the goat and sheep that cheese was made; the pinguis caseus, the pressi copia lactis. Thus in the Odyssey of Homer,

"He next betakes him to his evening cares,

And, sitting down, to milk bis ewes prepares :

Ot half their udders eases first the dams,

Then to the mothers' teats submits the lambs.

Half the white stream to hardening cheese he press'd,

And bigh in wicker-baskets heap'd: the re t,

Reserved in bowls, supplied the mighty fcast."

Pope's transl.

Lactea demittunt.-Georg. is. 521 .

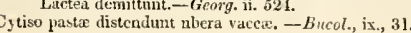

So, likewise writes Virgil :

"Quod surgente die, mulsere, horisque diumis

Nocte premunt; quod jam teneluris, et sole cadente,

Sub lucem exportans caliathis, adit oppida pastor;

Aut parco sale contingunt, hiemique reponunt."

Georg. iii.

"What they have milked at the dawn of day, and at full day,

They press at night; what they milk in the evening, and at sunset, The shepherd, at daybreak, carries to town in pans;

Or they infuence it witl a little salt, and lay it up for winter."

Ewe cheese was formeriy made in England, and is still made in some part of Wales and Scotland ; it is common on the continent.

With respect to butter, the Greeks and Romans knew little or nothing about it. Aristotle, who gives directions about cheese, says nothing respecting butter; cheese is mentioned by the poets both of Greece and Rome, but not butter. Pliny, however, does describe a preparation under the term butyrum (from $\beta$ oùs an ox, and zupòs cheese), an im perfect sort of butter, mixed with curd, which he enumerates anong the materials of the Pharma copoia, though lie states it to be accounted a delicacy among barbarians. The following is his direction for making it:-

"From milk, also, butyrum is made: a choice article of food among barbarian nations, the use of which distinguishes the rich from the common people. The most is obtained from the cow, and hence its name; the fattest from sheep: it is also made from goats' milk. In winter the milk requires to be made warn, in summer merely churned, by rapid shaking in long vessels, of which the moutl is closed. except a narrow orifice for admitting the air. A little water is added, for the production of acidity. The part that clots swims at the top; this, being remored and salt added, is

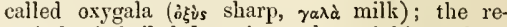
mainder is boiled down in earthen pipkins; there the superuatant matter is butyrum, of an oleaginous nature. The stronger the flavour of this the more valuale (in medicine) is it accounted. It is an old ingredieut in many mixtures. Its nature (internally taken?) an astringent; it is an emollient, a filler up, and purifier of wounds (applied externally?)." Such was Pliny's butrrum, at which a Dorset dairyman would be horvified. Butter, little as it was known in Greece and Italy of old, was in early ages made and used, as an article of diet, and of culinary processes, in the East. "And be took butter and milk, and the calf which he had dressed, and set it before them." (Genesis xviii. 8.) In the present day, throughout Syria and Arabia, butter still continues to be regarded as an epicurean delicacy, "lautissimus cibus"; and the mode in which it is separated from the milk coufirms the accuracy of Pliny. Burckhardt, in his notes on the Bedouins, says, "By the present Arabs, the camel's milk is used to drink, either alone or mixed with rice and flour, and either sweet or 
sour; the butter is made of goat or sheep's milk. It is put into a goat-slin, tied to one of the tent poles, and for one or two hours constantly moved backwards and forwards. The buttery substance then coagulates, the water is poured out, and the butter is put into another skin. If, after two days, they have collected a certain quantity of butter, they place it over the fire, throw in a handful of bourgoul (whent boiled with some leaven, and then dried in the sun), and leave it to boil, skimming it carefully. After having boiled for some time the bourgoul precipitates all the foreign substances, and the butter remains quite clear at the top." We learn from the same learned traveller that, by the Syrian Arabs, "the sheep and goats are milked, during the three spring months, morning and evening. They are sent out to pasture before sunrise, while the lambs or kids remain near the camp. About ten the herd retuins, and the lambs are allowed to satiate themselves; after which the ewes belonging to each are tied to a long cord, and milked one after another. When a ewe is feeble in health, her milk is left wholly for the lamb. The same process occurs at sunset. From a hundred ewes or goats, the milk of which is alwars mixed together, the Arabs expect, in common years, about eight pounds of butter per day, or about seveu hundred weight in the three spring months. What the Arab's family does not use, is sold to the peasants or townspeople."

In Barbary, according to Shaw, the milk of the ewe is put into a goat-skin turned inside out, then suspended from one side of the tent to the other, and on passing it to and fro in one unifor'm direction, a separation of the buttery and wheyey parts is quickly occasioned. In the Levant they tread the skin bags, partially filled with milk, with their feet, till the butter separates. Between the skiu bag of the Arabs and the long ressel of Pliny's description, there is no essential difference.

The fondness of the Arabs for butter is excessive; they eat it in large quantities; the richer who can afford it, not only swallowing it by cupfuls, but even saturating their food with it. And if Pliny alluded to these people, his expression, "Butyrum, barbararum gentium lautissimus cibus, et qui divites a plebe discernat," is most descriptive. In fact, they not only eat it in quantities before breakfast, but as Burckhardt assures us, snuff the concrete oil up their nostrils. "Some tribes," lie adds, "welcome a guest by pouring a cup of melted butter on his head. Our way of spreading butter thinly on bread seems the height of absurdity to them, and indeed to other Asiatics. When they do eat it with bread at all, it is in the way which was taught us by a Bedouin, who, observing us sitting on the ground refreshing ourselves with buttered breal and dates, looked compassionately on our ignorance of the true use of butter, and to give us a valualile lesson on the sulject, commenced breaking ofl' a thin bit of bread about the size of a crown-piece, and heaping thereon as large a lump of butter as it would support, threw it into his mouth with great satisfaction. He pursued his instruction, until his rapid progress towards the bottom of our butter-skin obliged us to declare ourselves sufficiently instructed." Inured to constant and severe exercise in the open air, the Arabs know nothing of the malady termed drspepsia; they can endure hunger for days, and then eat to repletion, and swallow butter by wholesale witlout the least injury. D'Arvieux states that the Arabs regale themselves with butter and honey at breakfast; adding, that althongh these do not seem to suit very well, experience teaches that it is no bad mixture, nor disagreeable to the taste of one if ever so little accustomed to it. This mixture of butter and honey recalls to our mind an expression in Isaiah, "for butter and honey shall every one eat that is left on the land." (Ch. vii. 22.)

Again, in second of Samuel (xvii. 29), we read that Shobi, and Machir, aud Barzillai brouglit "honey and butter, and sheep, and checse of line for David, and for the people that were with him, to eat." In Deuteronomy (xxxii. 13, 14), we read of "honey out of the rock, and oil out of the flinty rock ; butter of kine (not sheep), and milk of sheep, with the fat of lambs." The language is figurative, it is true, but the association of delicate viands is ad naturam. In Job (xs. 17), we read of " brooks of honey and butter;" and in the book of Proverbs the expression, "Surely the churning of milk bringing forth butter," alludes to the mode of procuring this delicacy, which was not effected as in our island in the present day. by allowing the separation of the cream from the milk, aud subjecting the former to the action of the churn, but by churning the milk itself.

In India, a liquid butter, termed ghee, is in general use, and the mode of its preparation forcibly reminds us of Pliny's description. The milk, when first drawn from the animal, is boiled in earthen vessels for two, or even three hours; it is then allowed to cool, and a little curdled milk, called tyre, is added to promote its coagulation. By the next morning the whole mass has been converted into tyre, or coagulated acid milk : about five or six inches in depth are then taken from the top of each vessel, and put iuto an earthen jar, where it is churned by means of a split bamboo, rapidly turned round and round: after half an hour's churning a little hot water is added, and the chuming is continued till, in about half an hour afterwards, the butter begins to separate. When this butter has been kept for two or three days, and has becoune rancid, as it will in a hot climate, it is melted in an earthen vessel, and boiled until 
all the water that may be mixed with it is evaporated; a little tyre and salt, or betel-leaf, is then added, and it is put into pots to be kept for use, and is sometimes preserved for many months. It is a very important article of iuternal traffic through a great part of India, and is in general consumption among all the natives who can afford to buy it; but from its strong smell and flavour it is distasteful to Europeans.

Of the demand for the ox as a sacrifice before the altar, in ancient times, we need not speak, nor of the use of its flesh as food, though that of the "fatted calf" was in far higher esteem. At the present day throughout Southern and Eastern Europe, beef is not regarded in the same light as it is in England, and is considered to be inferior to mutton. Thus Cervantes, in allusion to the comparative cheapness of the former, says of Don Quixote, that "three-fourths of his income were scarce sufficient to afford a dish of hodgepodge, in which the mutton bore no proportion to the beef."

\section{CHAPTER III.}

IT is not within our province to enter minutely $\mid$ cow of the middle-horned breed, in order that its into the osteology of the ox, nevertheless we anuex general characteristics, which mere description a view of the skeleton of this animal, viz. of a could not convey, may be seized upon by the eye.

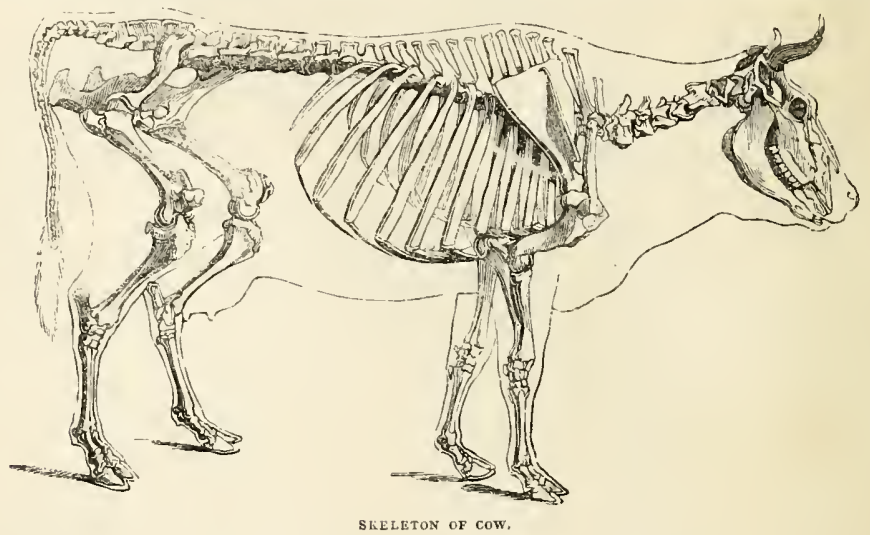

On comparing the skeleton of the ox with that of the horse, we perceive that the height is less, in proportion to the length, than in the latter. In the horse, if we remove the neck and tail, the body and limbs describe the limits of a square; not so in the ox, which is shorter on the limbs than the horse, and has the trunk comparatively more elongated. The head of the ox is in a line carried from the shoulders, and is hraced up to the spinous processes of the dorsal vertebræ by a powerful ligumentum nuchre. The frontal aud occipital bones are cancellous, the $t w 0$ tables of bone being separated; and these cells are continued up the osseous core of the horns, so that the cranial cavity is really less than from an external view' of the skull might be anticipated; the sca- pula, or blade bone, has its upper edge straight, the angles being acute; the ribs are thirteen on each side, eiglit true and five false; they are hroader in proportion than those of the horse, and the last pair are more remote from the pelvis, or haunch. The number of the vertebra is as follows; neck, or cervical, 7 ; dorsal. 13 ; lumbar, 6 ; sacral, 4 ; caudal, $\mathrm{J} 6$. The pelvis differs greatly from that of the horse; the ischial portion is produced, with the tuberosity truncated, so as to present three angles, and the haunch, or iliac portion, is more spread; hence an angularity of the haunch compared to what we see in the contour of the horse. The spinal column of the trunk does not fall geutly in, as we see in the horse, but is rather arched, and then carried straight to the set-on of 
the tail without any downward curve. The humerus, or shoulder bone, forms a considerable angle with the scapula, and is succeeded by the radius and ulna, or bones of the fore arm; of which the latter enters into the structure of the elbow joint, and becoming soldered to the radius is, continued to the knee, composed of carpal or wrist bones, consisting of six bones in two layers, of which two only form the lower range. To these succeed the metacarpal or shank bone, analagous to the canon bone of the horse, but furrowed exteriorly: it lias a small splint bone posteriorly, with sesemoid bones at its lower end, where two articulating processes receive the two first bones of the digits, or toes. The linder limbs are on the same plan; the small bones of the hock (really the tarsus) consist of fire bones, of which the elevated calcaneum, or heel bone, receives the tendons of the back of the thigh. The thigh bone is larger and longer than the humerus, and the metatarsal bone, or shank, longer and slenderer than the metacarpal, or shank bone of the fore limbs. The bones of the toes are also smaller. The annexed cut represents the forefoot of the ox (A), and the hind foot of the same (B).
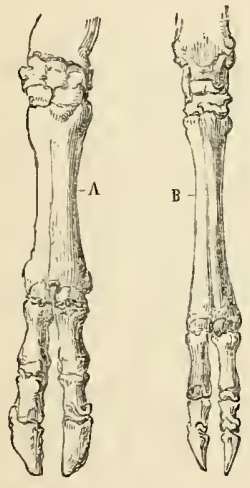

BIND AXD FORE FEET OP OX.

We have already detailed the characteristic peculiarities in the dentition of the ox, peculiarities which distinguish between the ruminants and all other herbivirous quadrupeds; but, as in the case of the horse, there are certain points connected with the dentition of the ox, which onght to be understood by every practical farmer, for it is by the characters and changes of the incisor teeth of the lower jaw, that the age of the ox may be the most correctly estimated. The regular number of these incisors, as we have stated, is eight in number; but the first set are decidnous. being gradually shed, and replaced by a new series. The new born calf has generally two central incisors

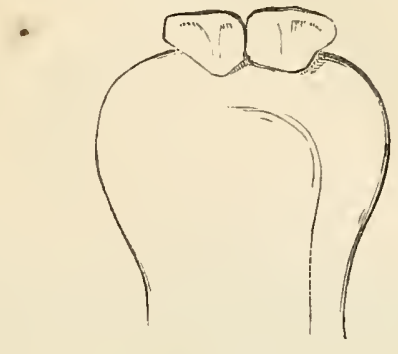

BIRTH.

protruding through the gum, and more or less developed; these, like the others about to follow, are covered with white enamel, and have sharp edges and slender roots. About the close of the second rreek, a tooth on each side of this central

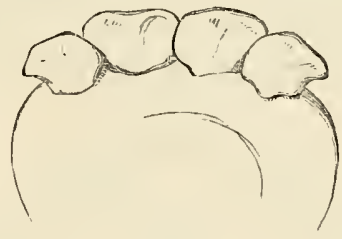

SF.COND WEEK.

pair cuts the gum, making the number four ; at the end of the third week, the number will be in

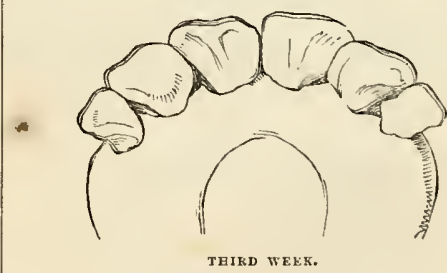

creased to six; and at the termination of the fourth reek the full number of the deciduous, or milk-incisors, will be complete. At this time the upper line of the sharp edges of the two central incisors has begun to wear, the osseous portion of the tooth appearing where the enamel is abraded ; this increases, and, in the course of two months 
the next teeth will begin to show signs of wearing, and in about three months the next in succession;

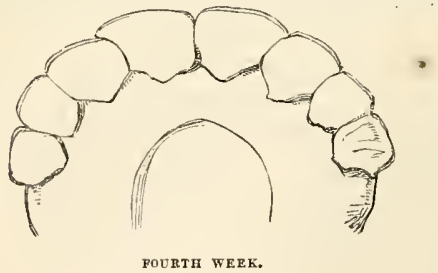

till in the course of four months or a little more, the whole set show the effects of use, but the four central teeth by far the most decidedly. At this time, independently of their wearing down by attrition, the two central teeth begin to diminish in size; at first this is not very perceptible, but, in the course of a few months, the change will be very palpable. This diminution is the result of a process of absorption, which goes on with increased rapidity as the new teeth, in their nutrient cells beneath, become more and more developed; the worn surface of the teeth, in question assumes a triangular form, with an oblique inclination inwards, the osseous portion appearing as a distinct central mark. At the age of about eight mouths

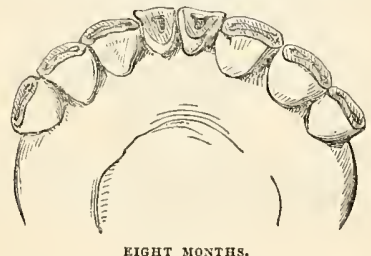

the diminution and wearing down of the two central incisors is very decided; and before the close of the twelvemonth, the next incisor on each side

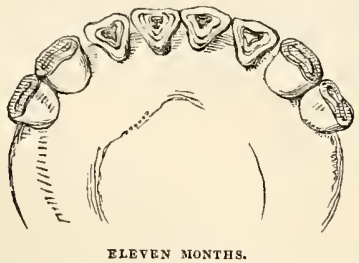

will show the same appearance, and the four, instead of being close together, will be separated from each other, especially at their base: at the close of fifteen months, the number of teeth thus

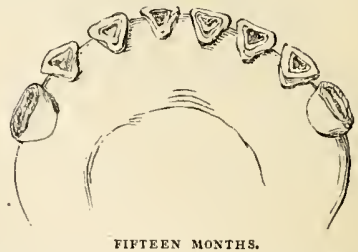

diminished by absorption, worn by use, and separated from each other, will extend to sis; and at the close of eighteen montlis the whole eight will

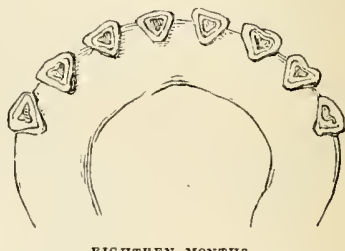

appear as little worn rudiments. During these changes the $o x$ experiences more and more diffculty in cropping his herbage, and from this cause and the action going on connected with the formative process of the permanent teeth, in their capsules, or cells; the animal is subject to many disorders, and is liable to become out of condition, especially in pasture grounds where the herbage is not abundant and succulent.

Still these rudiments of teeth remain for some months, their decrease continuing, first, more especially in the two central teeth; till, at the com-

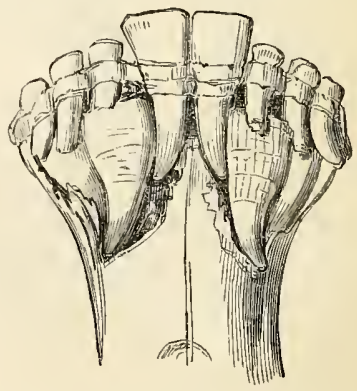

TWO YEARS.

mencement of the second year, the two central permanent teeth shoot up, and put out the mere 
relics of their predecessors. During this pracess, / will have extended to the whole set. The teeth the extremity, or alveolar margin of the jaw itself, become flattened at the top, with a dark central is growing and wilening, so as to afford room for the development of the rest of the teeth yet in their capsules; and the increase of both teetl and jaw goes on in according harmony. It is not until towards the close of the second year that the next incisor on each side takes the place of its temporary predecessor; nor until the close of the third that

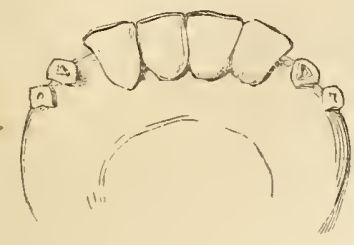

THIRD TEAR.

the next in rotation succeed. The corner milk teeth, however, are now mere rudiments, and they

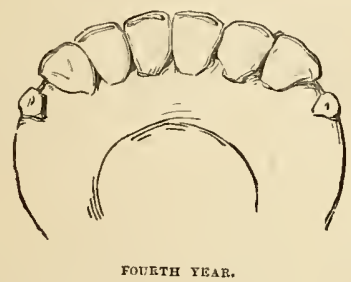

give place at the close of the fourth, or beginning of the fifth year, to their sucressors: in all these changes some allowance must be made for the vigour or the weakness of the animal; but such is the average routine.

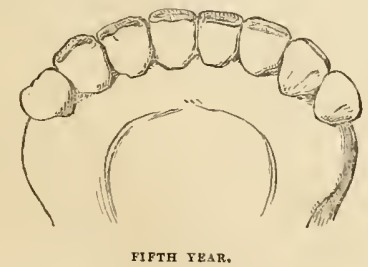

The last teeth obtained are smaller than the rest, and can scarcely be said to he fully grown until a few months have elapsed. The whole set is complete, but while the outer teeth have been growing, the two central permanent teeth first and then the next, have been wearing, and show the marks of attrition; which, at the age of six years,

voL. 1.

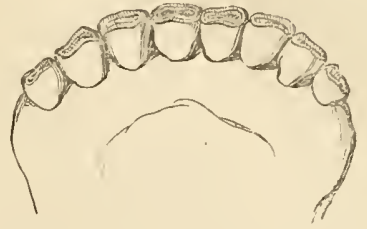

SIXTH YEAR.

mark, bounded by a line of bone, and this by the layer of enamel. As yet the four middle teeth are the largest; but, again, ly slow degrees $n$ change takes place, and the process of absorption and wearing down goes on. First, the two central teeth show this, then the next on each side, till, at the age of ten, the four middle teeth are smaller

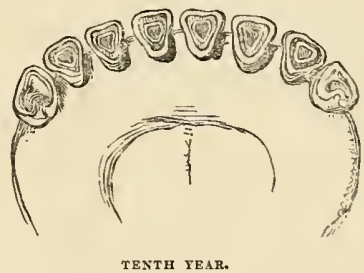

than the outermost tro on each side, which, nevertheless, are greatly worn. The amimal has turned the grand climacteric, and the teeth continue more and more to show the ravages of age: but, as among other domestic animals, and the human species, not invariably to the same extent, the process being slower or quicker, according to circumstances. At sixteen the ox is old, but there are many instances in which the cow will give milk to the age of eighteen or twenty; and rare cases are on record in which the cow has given milk, and suckled a calf, at a later date, even in her thirtyfirst or thirty-second year.

With respect to the grinders, or molar teeth, they cannot be courenieutly examined in the living animal; nor even, were they accessible, could a very certain conclusion be deluced from them.

'The calf is born with one or two milk grinders on each side above and below; but by the fifteenth or twentieth day, the number is increased to three.

A fourth unolar, permament, appears in the sixth or eighth month after binth; a fifth molar, permanent, in the twentieth or tweuty-second month after birth; and a sixth molar, in ahout the fiftieth or fifty-second month. The first milk molar is shed about the time when the fifth molar 
appears, and the second and third, at intervals of ten or trielre months.

It has been usual to judge of the age of cattle by their horns, but we shall show that this is a fallacious method, and of course inapplicable to the polled breed.

The calf at its birth has the horns in the form of small osseous tubercles covered with a corneous layer; the osseous tubercle sprouts from the frontooccipital ridge, and continues to increase by the deposition of osseous particles, secreted by the arteries from the blood. 'The core of the horns is, in fact, extremely vascular, and the channels of the blood-vessels may be seen along its extent, as if cut by a gauge; it is also multitudinously perforated for the passage of ressels, and, consequently, a fracture of this part is followed by profuse bleeding. The core is hollow, or cavernous, communicating with the frontal sinuses, and is lined, as well as the latter, with a continuation of the delicate membrane, spread over the nasal cavity and exteusive turbinated bones. The horny case, like the nails of the fingers, or the scales of the manis, is formed in the same way, growing by successive additions to its base as the core developes. Horn may be regarded as composed of hairs, agglutinated into a mass; and in some animals, as the prongluck, of the rocky momtains, the fibrous nature of its structure may be readily perceived.* From its mode of growth from the cutis, horn consists of layers, or lanine, placed upon one another, the addition taking place on the inner, or under surface, so that layer after layer is carried onwards by the successive deposits of others in rotation. At some periods, a greater secretion and deposition of homy matter occasionally takes place than at other times, and this often produces a thickening, in consequence of the addition of the extra quantity of matter. To such a cause are the rings at the base of the horns of cattle owing. The cow generally exhibits one ring at the base of the horn when three years old; a second is added when at the age of four years; and so on for several successive years: hence, adding two to the number of rings exhibited, her age is supposed to be pretty accurately calculated. But this is fallacious; for, if a heifer become impreguated at the age of two years, her horn immediately shows a ring, as it would have done when three years old, consequently she may be a year older than the calculation. Again, in some cows the rings are very imperfect, or not distinctly marked, and rin into each other, so that it is almost impossible to count them. Indeed, after the age of six or seven, the successive additions are generally very irregular and undefined, the surface appearing rugose, withont definite annular elevations; hence the test

- It is so in the Burmese oxen with huge horns, described by Capt. Clapperton. cannot be applied. Moreover, an aged cow may be made to appear much younger than she really is, by having one or two of the upper rings neatly rasped and scraped down, so as to become continuous and uniform with the smooth surface beyond.

In the bull, which has thicker and shorter horns than the cow, the first ring does not make its appearance until the animal is five years old; and the successive rings are often irregular and confused. Sometimes, indeed, they can scarcely be made out at all; and all attempts to judge of age by this test are nugatory. The same observations apply to the bullock.

And here we may advert to the peculiarities in the horns of the bullock, which exceed, in size and length, those either of the bull or cow. When the stag, or the buck of the fallow deer, is emasculated, the antlers are either not reproduced, or are small and malformed; whereas, in the bullock, on the contrary, the homs, instead of being arrested in their growth, shoot out in length, and very frequently assume a graceful tournure.

At the base of the horns in cattle, the corneous investment is rery thin, especially where it unites with the cutis: here it covers a vast plexus of vessels and nerves, rendering a blow upon the part extremely painful. To one aware of this circum stance, it is revolting to witness the ruthless manner in which the drovers use their ashen sticks, striking at the junction of the horn with the skull, and either almost paralyzing, or, on the other hand, infuriating the animal with the agony produced. Heartily do we wish such a weapon changed for a slight goad, which, used properly is a far more humane instrument; and that blows upon the head (and the foot also) were punishable. The cruelties of Suithfield are notorions: there is not room to tie half the beasts sent there to the rails. The packing of the beasts into circles within that once extensive and suburban, but now miserably limited space, is managed during the night; and the barbarities practiced to effect this object are unfit to be written. Nor are they much dininished when an animal has been sold, and is to be driven through, and extricated from a mass of fifteen hundred cattle; often a bullock half blinded with the hammering of bludgeons, and maddened by pain and fright, escapes from its tormentors, and rushing along the streets, occasions the destruction of life, and spreads terror as it goes. Perhaps a time may come, hastened by the railway mode of conveyance for carcasses slaughtered at a distance, in which the suisance of Smithfield will be abolished, and also the slaughter-houses in the most crowded portions of our metropolis. The danger in driving cattle to these dens of blood, the cruelties inflicted in forcing them to enter (for the scent of gore produces instinctive horror), the 
effluvia of prutrescent matter exlaled from them, and the disgusting oljects exposed to view, combine to render them the disgrace of London. In these points, at least, Paris is far superior.

With regard to the senses of the ox, namely, sight, hearing, smell, and taste, they are respectively enjoyed in that degree of perfection which is in accordance with the habits and necessities of the animal.

Sight.-From the earliest times the eje of the $0 x$ has been celebrated for beanty, and the calm tranquility of its expression. Homer has applied the epithet, "ox-eyed," to the queen of the deities of classic mythology.* The eye of the ox is full and prominent; it is defended by long-lashed lids, and a membrana nictitans. The pupil is oblong, and the tapetum lucidum may be seen through it. The sight is diurnal and acute: like the borse, however, the ox can discern objects very tolerably during the dusk of eveuing, and even at night; but the latter is a season of repose, during which it chews the cud at leisure.

We know not from what cause, but the bull, as is generally admitted, is apt to become furious and excited at a display of red or scarlet colours; a cloak, or mantle, will often rouse his anger. A red flag is used by the giostratori of the Roman amphitheatre; and the matadores of the Spanish arena,

"Shake the red eloak, and poise the ready brand."

When the ox labours under inflammation of the brain and its membranes (phrenitis), the sensibility of the retina is morbidly increased; and the sight of a red garment rouses the animal to perfect madness. Many accidents have happened to persons, with red about their dress, while crossing fields in which a bull was grazing at biberty.

Hearing.-This ense is acute in the ox; the external ears are more ample than those of the horse, and freely moveable. In the polled breeds, the external ears are generally larger than in the horned races; but we do not kuow that the sense is more refined. It does not appear that musical sounds exert any decided influence on cattle. The sound of the trumpet, the huntsman's balloo, and the cry of the pack, excite the horse; the jingling bells of the wagoner's team are be lieved to be agreeable to the animals; and those also of the caravans of mules which traverse the rugged mountains of Spain. It is, indeed, the enstom in Sivitzerland to hang bells around the necks of the cattle, not, however, with the object of pleasing their ears, but as a means of tracing them when they have strajed among the hills; the slightest tinkle being heard, in those still and elevated regions, at a great distance.

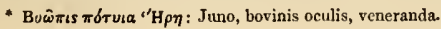

Smell.-The ox enjoys this sense in great perfection. The nasal eavity is ample; and there is a free communication between the internal nares, which is not the case in the horse, the septum making a complete division. The brain of the ox is not more than half the size of that of the horse; but get the olfactory nerves are nearly as large; and, indeed, comparing the volume of the two brains, nearly larger.

The sense of smell aids that of taste in the selection of suitable food; the instinct, guided thereby, impelling the animal to reject what is noxious or improper.

Taste.-The sense of taste, if not at a high ratio, is, nevertheless, sufficiently developed for the requirements of the animal, and enables it to distinguish and enjoy the flavour of sach plants as are suited to its nutriment. We may, however, observe, that both this sense and that of smell are liable, in the domestic ox, to be deceived; especially under particular circumstances, as when, after being kept on winter-fodder, they are turned out to graze in the spring, when the scent of the young herbage is scarcely developed. It is very doubtful whether wild herbivorous animals are ever so deceived; they are constantly iu the exercise of their instinctive faculties, which thereby become more acute and discriminating; while, on the contrary, the tendency of domestication is to curb instinct, which, for want of constant exercise, becomes enfeebled, or less imperious in its governance. Hence it happens that domestic cattle, introduced into strange pastures, often perish from eating poisonous plants, which the cattle accustomed to those pastures have learned, by experience, to refuse. The more an ox is stall-fed, the more likely is it, if allowed to graze, to crop deleterious herbage.

We are told in the "Swedish Pan" (Amœnit. Academ., rol. ii.) that oxen eat two hundred and seventy-six plants, and refuse two hundred and eighteen. Among the noxious plants most accessible to grazing cattle are meadow sweet (spiræa ulmaria); hemlock (conium maculatum); water hemlock (phillandrium aquaticum); water cowbane (cicuta virosa); meadow saffron (colchicum autumnale); hellebore (belleborus fotidus); monkshood (aconitum napella); foxglove (digitalis purpurea); and yew (taxus baccata). Happily, however, in our island, such is the excellence of pasturage, that fatal accidents, from poisonous plants, are not of very common occurrence.

It is remarkable, that while the meadow sweet and the long-leaved water bemlock, or cowbane, are deleterious to the ox, the goat feeds upon them, not only with relish but with impunity.

When Linnæus visited Tornea, he found a terrible malady sweeping away the cattle of the district, and which he at once traced to the long- 
leaved water hemlock. Scarcely, in fact, had he crossed the river, and landed from his boat on the meadow, before he felt convinced of the origin of the mischief. This deadly plant grew there in abundance; and it appeared that, as soon as the cattle left off their winter-fodder, and returned to pasturage, they died swollen and convulsed: as the summer came on the mortality decreased, and still more so with the advance of autumu, "The least attention," says Limneus, "will convince us that hrutes reject whatever is hurtful to them, and distinguish poisonous plants from salutary by natural instinct : so that this plant is not eaten by them in the summer and autumn, which is the reason that, in those seasons, so few cattle die; namely, such only as either by accident, or pressed by extreme hunger, eat of it. But when they are let into the pastures, in spring, partly from their greediness after fresh herls, and partly from the emptiness and hunger they have undergone during a long winter, they devour every green thing which comes in their way. It happens, moreover, that herls, at this time, are small, and scarcely supply food in sufficient quantity. They are, besides, more juicy, and covered with water, and smell less strong, so that what is noxious is not easily discerned from what is wholesome. I observe, likewise, that the radical leaves were always bitter, the other's not, which confirms what I have just said. I saw this plant, in an adjoining meadow, mowed along with grass for winter-fodder; and therefore it is not wonderful that some cattle, though but few, should die of it in winter. After I left Tornea, I saw no more of this plant till I came to the rast meadors near Limmingen, where it appeared along the road; and when I got into the town, I beard the same complaints as at Tornea of the anmual loss of cattle, with the same circumstances."

Hunger will, indeed, often drive cattle to feed upon herbs more or less unfitted ly nature for them; and it has been remarked, that when they have suffered the ill effects of their want of caution, they become more wary for the future, having learned a lesson from experience. In the "Swedish Pun" we are told, for exanjle, that the rattle which feed in the neighbourhood of Fahluma, where monkshood grows abundantly, generully leare this deadly plant untouched; but that cattle brought from a distant quarter, and introduced into the same grounds, often venture to eat it, and, if too large a quantity be taken, perish. In like manner, the cattle reared on the plains of Schonen and Frestragothia, have been found to fall into dysentery when they come to the woodland parts, from feeding upon plants which the cattle accustomed to those places have learned to refuse.

In our country, it is from feeding on the shoots of the yew that cattle most frequently sulfer; it appears to be a temptation to horses kept almost entirely on dry fodder, and to oxen put upon short allowance. Actions-at-law have, in this country, not mufrequently been bronght against parties, who from neglect in nut enclosing their yew trees, by a İedge, paling, or other defence, have permitted the stray cattle of the plaintiff to gain access to the trees, and there feed until fatal results ensucd. Notwithstanling the poisonons qualities of the yew, it is given, according to $M$. Husard, in Hanover and Hesse, to cattle, in winter and when foctder is scarce. Small quantities are at first mixed with the other food, and the proportion of the yew-cuttings is gradually increased until the latter form the principal portion of the sustenance. This is a curious instance of inuring the system, by degrees, to a vegetalle poison; and MI. Husard, who was evidently astonished by it, undertook some experiments on the sulject. He gave to an emaciated and feeble horse, a pound and a half of oats, and a half pound of yew, withont producing any apparently bad effects. He tried the same experiment on a healthy mare, in good condition, with the same results. He then took seven ounces of yew, bruised it, and mixed it with twelve ounces of water, and gave it to a horse which had fasted four hours, and in an hour afterwards the animal died. In this case the yew was taken unmixed with other food, on an empty stomach.

To the plants already noticed as deleterious to cattle, we may had the henbane (hyoscyamus niger), the wild or hedge parsley (cancalis infesta), the wild poppy (papaver sonmiferum), and various species of ramunculus, or crowfoot.

Subsequently to the investigation by M. Hesselgreen ("Swedish Pan"), on the plants of Sweden injurious to cattle, M. Yvart, in France, investigated the properties of nearly seven hundred common plants, with a view to their effects upon our domestic herbivorous animals. Many plants, he observes, are ntterly refused by them all: among the principal of these, growing in marshy places, are the following:-The common butterwort (pinguicula vulgaris), common hooded milfoil (reticularia vulgaris), forget-me-not (myosotis palustris), perfoliate pondweed (potomageton perfoliatum), long-leaved cowbane (cicuta virosa), longleaved sundew (drossera longifolia), water pepper (polygonum hydropiper), sweet-flag (acorus calanus), water crowfoot (ranumculus aquatilis), great spear-wort (ranunculus lingua), and water milfoil (myriophyllum spicatum).

There are other plants which either grow in shady spots, or muist pastures, which all cattle reject. Such are the common thornapple (datura stramonium), common henbane (hyoscyamus niger), black-berried nightshade (solanum nigrum), dwarfelder (sambucus ebulus), mountain dryas (dryas octopetala), black horehound (ballota nigra), common 
white horehouml (marrubium rulgare), impatient lady's smock (cardamine impatiens), common celandine (chelidonium majus), and the blue erigeron (erigeron acre). It must here, however, he noticed, that many of these plants, when very young, are sometimes cropped by the cattle, without any ill effects: and that, on the contrary, some uutritious plants are, when in seed, refused from their perfume being too strougly diffused. But, after the animals have endured a long continued fast, their eagemess interferes with their discrimination.

Some plauts are of ten eaten by cattle, while green and fresh; yet, singular to say, they are refused if offered in a faded or dry state. Among these are cock's comb (rhiuanthus crista galli), the horsetails (equisetum), the bedstraws (galium), which spoil the lias, and the common buckbean (menrauthes trifoliata). Again, there are others, such as the cranfoots (ramuculus), and the swallow-worts (asclepias), which loose their noxious properties when dried, and may be eaten ly the cattle without injury.

Some plants are stimulants, or cordials; such are the garlies (allium), and the docks (rumex).

The gout not only feeds with impunity upon several plants refused by other cattle, but eveu eigerly seeks for them. Of these we may mention the common mare's-tail (hippuris vulgaris), common prickly seed (echinospermum lappula), the greater water plantain (alisma plantago), highly injurious to other domestic animals; the wood anemone (auemone memoralis), the meadow anemone (a. pratensis), the spring anemone (a. vernalis), celery-leaved crowfoot (ranunculus sceleratus), the knotty-rooted figmort (scrophularia nodosa), and tame-poison (asclepias vincetoxicum), of which it is extremely foud. To these may he added, the small water-wort (elatine hydropiper), box-leaved andromeda (a.calcyculata), biting stonecrop (sedum acre), snapdragon (autirrhinum liuaria), stinking chamomile (authemis cotula), black-berried bryony (bryonia alba), marsh lousewort (pedicularis palustris), wood lousewort (p. sylvatica), hemp agrimony (eupatorium cynnabiuum), anuual mercury (mereurialis anmua), deleterious to all domestic animals; corn horsetail (equisetum arveuse), marsh horsetail (e. palustre), and the male polypody (polypodyum filix mas).

Some plants are eaten solely by the hog; but it is only their roots, in general, that are sought after. Among these are the common cyclamen (cyclamen Europæum), common asarabacca (asarum Europaeum), the white and the sellow waterlily (nsmphrea alba, and lutea), towards which the horse exlibits a marked aversiou; the water soldier (stratiotes aloides), sea-wrack-grass (fostera mariua), and maiden-hair (aspleninm trichomaues). The hog also greedily searches the ground for earth or pig-uuts, the roots of two species of um- belliferous plants, bunium bullocastanum, and h. flexuosum.

A few plants are relished by all domestic herbiverous animals, and are much sought after; among these are the comnon millet-grass (millium eflusum) meadow soft-grass (bolcus lanatus), annual meadow-grass (poa annua), oats, barley and wheat, the carrot and parsilip, the great round-leaved willow (salix caprea), the Norwegian cinquefoil (potentilla Norvegica), the creeping trefoil or Dutch clover, and other species of cluver, lucern, sainfoin, \&c. But many of these plants must he in different states in order to be equally liked by every domestic species. It is observed of the cotton grasses (eriopharum) that they are lurtful to cattle from their hairs, which are apt to serve as a nucleus, to those concretions of extraneors matters sometimes found in the stourach. The utility of rootiug up as much as possible all noxious plants from pasture grounds, and the ditches around them, is palpable, and it rould be well if the farmer attended to this point more than is usually the case. We ourselves have seen in Cheshire the long-leaved water hemlock, or cowbane, in the greatest abundance in the ditches of the meadows, from which, with a little trouble, it might have been extirpated.

It is not very easy, unless the fact be ascertained from circumstances, to deteruine positively that a suffering beast is labouring under the effects of poisonous plauts taken into the stomach. The general symptoms are stupor, and great swelling; a refusal of food, a grinding of the teeth, and a rolling about as if from extreme agony or colic. The first thing to be done is to clear the stomachbag, and freely washing out the contents by meaus of the stomach-pump, pleuty of warm water being used, and the operation being persevered in till no particle remaius behind; brisk aperients should then be given, followed by carminatives.

It is a remarkable fact that, although the ox is decidedly herbiverous, yet in some countries it is fed, during a part of the year at lenst on a proportion of animal diet. In Norway, for example, the herils and flocks are driven to the mountains, aud are there depastured; but during the loug wiuter they are housed and fed partially on the hay growu within the immediate preciucts of the farm, and hrought from the hills, and more plentifully on a kind of food which, to our English farmer, must appear very strange and disgustiug, but which the cattle are said to relish very much. This food consists of a thick gelatiuous soup, made by boiling the lueads of tish, and mixing horse dung with the broth. The boat of the fitrmer in Norway supplies not only himself and his family with the stiple portion of his winter sulsistence, but his cows also. A writer in the "Edinburgh Journal, of Natural History," says: " We are assured liy M. 
Yvart, that in Auvergne, fat soups are given to cattle, especially when sick or enfeebled, for the purpose of invigorating them. The same practice is observed in some parts of North America, where the country people mix, in winter, fat broth with the vegetables given to their cattle, in order to render them more capable of resisting the severity of the weather. These broths have been long considered efficacious by veterinary practicioners of our own comtry, in restoring horses which have been enfeebled through long illness. It is said by Peall to be a common practice in some parts of India to mix animal substances with the grain given to feeble horses, and to boil the mixture into a sort of paste, which soon brings them into good condition, and restores their vigour. Pallas tells us, that the Fussian boors make use of the dried flesh of the hamster reduced to powder, and mixed with oats, and that this occasions their horses to acquire a sudden and extraordinary degree of embonpoint. Anderson relates in his history of Ireland, that the inhabitants feed their horses with dried fish when the cold is very intense, and that these animals are extremely vigorous, though small. We also know that in the Feroe Islands, the Orkneys, the Western Islands, and in Norway, where the climate is still very cold, this practice is also adopted; and it is not uncommon in some very warm countries, as in the kingdom of Muskat in Arabia Felix, near the straits of Ormuz, one of the most fertile parts of Arabia, fish and other animal substances are there given to the horses in the cold season, as well as in times of scarcity."

We may here add, that other herbivorous animals, also, occasionally partake of animal food, to which they are doubtless led by instinct as to a stimulus required by the system, for the maintenance of a due degree of euergy. In Lapland, for example, the reindeer devours the lemming, a little rodent animal, allied to the vole or fieldmouse, and which often swarms in myriads in that country. The American reindeer, according to the assurance of Franklin, are accustomed to c.evour mice, and also to gnaw their fallen antlers.

Though not very delicate as an organ of taste, the tongue of the ox is of great assistance in the prehension and collection of food. It is shorter than that of the horse, and rough on the upper surface with retroverted horny papilla; by its action it combs the grass together into a roll, in order to bring it between the incisor teeth, and the pad of the upper jaw. During the mastication it disposes the food between the grinders, and by the assistance of the bars or ridges on the palate, forms it into balls for swallowing: in the act of drinking it constitutes a trough, through which the fluid passes; it is used to clear the naked muzzle from various impurities, and also as a rasp to rub its own coat, or that of its companion, in token of friendship. It is from this babit of rasping each other's coats, that compacted balls of hair are so often formed in the stomach, where they lodge, to the interference more or less decided, with its digestive functions. These matted balls of hair are found in the rumen or paunch, and also in the abomasum, or true digesting stomach; they vary in size, and are often formed at a very early age. In some cases, bits of straw, wood, and other extraneous matters are mixed with the hair; and occasionally they consist of distinct layers, with a central nuclens consisting of a nail, a bit of stone, or some other substance.

While speaking of the tongue, we may remark the os hyoides, or its bony support, and the larynx connected with it, differ much from the same parts in the horse; but these parts will be better understood by comparing the annexed figures.

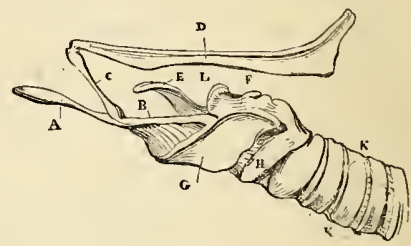

LARYNX OF HORSE.

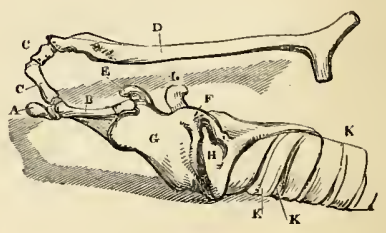

LARYNX OF OX,

In both cuts the letters refer to the same parts: A. The spur of the os hyoides. B. The base or greater cornu. c. The inferior lateral cornu: $\mathrm{c}^{\mathrm{l}}$. The middle cornu (wanting in the horse). D. The superior lateral cornu. ז. The epiglottis. F. The arytenoid cartilage. G. The thyroid cartilage. н. The cricoid cartilage. к. The cartilaginous rings of the trachea, with their ligamentons interspaces. L. The rima glottidis, or entrance into the windpipe, defended by $\mathbf{E}$, the epiglottis; long, narrow, and pointed in the horse; thick, ronnded, and curled in the ox. In the horse the elongated spur (A) binds the tongue more tightly down, and interferes with its freedom; while in the ox, the short tuberculous spur permits far greater liberty of motion. The difference in the form of 
the thyroid, cricoid, and arytenoid cartilages, is too palpable to be overlooked.

Intelligence,-Intelligence appears to be more limited in the ox than in the horse. The brain is comparatively smaller in the former than in the latter; and the ratio of intelligence is probably in about the same proportion. But we must not regard the ox as remarkable for stupidity. The working ox knows its driver, and readily obeys his word of command, displaying, at the same time, considerable docility and willingness. The cow not only knows, but often evinces decided affection towards the person by whom she is regularly milked and fed, and not unfrequently refuses the attentions of another. Cows, pastured in the fields, draw towards the accustomed spot, at the usual milking time, and, by their lowing, seem to give notice of their readiness. In Switzerland, the herds feeding on the mountains are called home to their chalet by the sound of the Alp-horn. The Alp-hom is merely a wooden tube, of simple construction; and its deep, mellow, and prolonged note, heard at a distance tloating over the upland pastures, and frequently echoed in succession by crags and rocks, makes a pleasing impression on the traveller. On many of the ligher Alps this hom is sounded regularly at sunise and at sunset. At whatever part of the day it is blown, to collect the cattle, the cows are seen, as soon as its note can reach their ears, scampering away for the chalet, often at a gallop. In one of the volumes of the "Menageries," the writer says, "A correspondent informs us that he once witnessed the evident dismay of a cow in not being able to obey the summons. She was a very pretty young creature, and was lying ruminating, in a little dell, by herself. Presently the Alp-horn was heard; and the peasant who sounded it, was seen in front of a chalet that stood on a green hill, at no great distance. The poor creature instantly rose, but could not proceed; for she was lamed and sorely wounded, most probably from some fill she had met with. After dragging herself along for the distance of some yards, she stood still and lowed: the horn sounded again, and again, making a great effort, she went on a few yards. She then laid herself down and lowed most piteonsly, fixing her eyes, all the time, on her companions, who were running, from every direction, to the chalet. The poor creature seemed to be suffering, not merely from her hurts, but also from that pain a punetual person feels on breaking an engagement, or failing in the performance of a duty. The traveller hurried to the chalet, to tell the peasants what had happened, and returned with them to see them assist the grieving alsentee. By the time they reached the dell she had made a little more progress, but was again prostrate on the ground, and lowing in a melaucholy manner. When the pea- sants came near to her she rose up, and ceased her complaints at once: and, though, with all the aid they could give her, she was obliged several times to lie down again, she did not repeat them; and at last she reached the dairy, where she lowed in a very different tone."

In Norway a wooden trumpet, about five feet long, made of two hollow pieces of birch-wood, bound together with slips of willow throughont its whole length, is used to call the cattle feeding on extensive hilly pasture grounds. Its notes may be heard at a great distance; lut, instead of being mellow, they are extremely harsh and discordant.

In Terceira, one of the Azores, where cattle are abundant, the oxen are remarkable for docility and intelligence. They are very fine and large, with horns of a prodigions size, and " are so gentle and familiar, that when, among a thousand collected together, the owner shall call one by its name (for, like our dogs, they have each their own name), the ox will not fail to come to him."" Voyage de la Compagnie des Indes de Hollande," vol. i., p. 490.

In South Africa the oxen know their names, and obey the voice of the driver.

But all instances of the intelligence of the ox, that we have ever heard of, fall short of those related by Kolben and others, relative to the backeley, or war oxen, of the Hottentots, while that people were in a state of pastoral independence. The $o x$ was the sharer of its master's toils and wars, bis assistant on the plain, and the guardian of his flock; it seemed, indeed, to lose its ordinary character in his service, and rise into a higher state of being. "The Hottentots," says Kolben (vol, i., p. 160), "have oxen, which they use with success in battle: they call them backeleys; the word backeley, in their language, signifying war. Every army is always provided with a large troop of these oxen, which permit themselves to be governed without tronble, and which their leader lets loose at the appoiuted moment. The instant they are set free they throw themselves with impetuosity on the opposing army: they strike with their horns, they kick with their heels, they overthrow, they rip up and trample beneath their feet, with frightful rapidity, all that opposes; so that, if they be not promptly driven back, they phunge with fury into the midst of the ranks, throw them into disorder and confusion, and thus prepare for their masters an easy victory. The manner in which these animals are trained does great honour to the talent of these people." In another place the same writer says, "These backeleys are, moreover, of great use to their owners as guardians of their flocks. When out, in the pasture-lands, at the least sign of their conductors, they will hasten to bring back the cattle, which are straying at a distance, and keep them herled together They 
lush on strangers with fury; whence they are of great service against the boschnen, or robbers, who may attempt the plunder of the flock. Each kraal has at least half a dozen of these backeleys, which are chosen from amongst the most spiritid oxen. On the death of one, or when, in consequence of old age, it becomes unserviceable (in Which case its owner kills it), another ox is selected from the herd to succeed it. The choice is referred to one of the old men of the kraal, who is thought to be the most capable of discerning that which will most easily receive iustruction. They associate this noviciate ox with one of long experience: and they tench him to follow this companion, either by beating, or some other method. During the night they are tied together by the horus, and they are thus also kept during a greater part of the day, until the learner has become a good guardian of the flock. These guardians know all the inhabitants of the kraal,-men, women, and children; and testify towards them the same respect that a dng displays to all those who live in the house of his master. There is, therefore, no inbabitant of the kraal who may not, with all safety, approach the flocks: the backeleys never do them least injury. But if a stranger, and particularly an European, should offer to take the same liberty, without being accompanied by some Hottentot, he would be in great danger: these guardians of the flock, which usually feed around it, would come upon him full gallop; and then, unless he be within hearing of the shepherds, or have fire-arms, or good legs, or unless a tree be near in which to climb, he is sure to be lilled. It would be useless for him to have recourse to sticks or stones; a backeley has no fear for such feeble weapons."

Le Vaillant, who first met with these backeley oxen, among the Nimiqua tribe ("New Travels in the Interior of Africa," vol. ii.), confirms Kolben's details, though he denies that they are used by all the Hottentot nations. He adds, that they are not only capable of repelling wild lieasts, but even venture to attack them; and that a hyreua, however hungry, will never come near a flock guarded by two or three of these formidable animals, a number of which will eren make head against a lion. It does not appear, as far as we can learn, that any of the tribes of Southern Africa rear buckeley oxen in the present day. They have milch cows, and use milk in clifferent forms, fresh or curdled; they have oxen for draught, burdens, and the saddle, but not war-oxen.

Reproduction.- - The heifer ought wot to be allowed to breed until turned two years old; the reason is obvious, her own system, before this period, is not sufficiently matured for the tax upon it - a tax which will be paid, not only by the dam, but also by her progeny, for both will suffer from a deficiency in nutriment, the whole of which is necessary for the growth of the former, which, duriug the second year, is rapid. If the bull be kept separate from the herd of cows, the farmer may regulate the succession of calves ahnost at pleasure, so as to suit his pasture, or his arrangements. The best time, as it respects the mother, the calf, and the free supply of milk, is when the spring grass is leginning to shoot luxuriantly, affording a good and sufficient store of nutriment. It is true that veal and botter yield a better profit at an earlier period, but the breeder must judge in points of this nature from circumstances.

The period of gestation in the cow is generally stated as nine calendar months, or two hundred and seventy days; but there is often considerable variation of time. M. Tessier observes (in a memoir read to the Foyal Academy of Sciences, in Paris), that the shortest period, as far as his opportunities of observation enabled him to ascertain, was two hundred and forty days, the longest three hundred and trenty-one; the difference being eighty-one days.* This range of time is very extraordinary, and appears to depend on the care paid to the animal, and on its state of health; by which the development of the calf is influenced throush the sanguiferous system of the mother.

With respect to the bull, he does not attain to a due rlegree of strength till two years old, and is in higher vigour at three; but how long the breeder mas keep him after that age must depend upon his own jutgment, and a variety of circumstances.

The cow seldom produces more than a single calf, sometimes, however, twins, and very rarely three. In the case of twins, if they be respectively male and female, the female is generally, but not always, umproductive. Females, thus conditioned, are terned free-martins: they are evidently the taura of Golumella. (Libr. vi.) Varro also uses the word taura, as applied to a cow of this description. Bewick states, that the freemartin resembles the bullock more than the cow in form; an olservation also made ly Hunter, who adds, that its flesh is generally considered finer in fibre than that either of the bull or cow, and to surpass that of the ox or heifer, in delicacy of flavour; but there are not wanting exceptions where the flesh has turned out nearly as bad as bull-beef, and certainly worse than that of a cow. For an account of the anatomical peculiarities of the freemartin, by John Hunter, see "Philosophical Transactious," rol. lxix. p. 289 ; and also Professor Owen's edition of Hunter's " Observations," 1837.

Every twin female, however, is not necessarily barren, even when the other calf is a male. This has been satisfactorily proved: it was, indeed,

* In the "Bulletin des Sciences," by the Soc. Philomatique, Pais, 1797, M. Tessier says, that out of 160 cows, sme calved in 241 days, and tive in 308; giving a latitule of 67 rays.-See Sir E. Home's Paper on Phil. Trans., Part I. for 1822. 
known to Hunter; and, in the "Observations" above alluded to, Professor Owen adds a confirmatory note, from "Loudon's Magazine of Natural History," stating that a cow in the possession of J. Holroyd, Esiq., of Witliers, near Leeds, produced twius, a bull calf, and a cow calf. As popular opinion was strong on the necessary barremuess of the female, Mr. Holroyd determiued to put it to the test, and reared both calves up to maturity. In due tiuse this heifer brought forth a bull calf, and had, regularly, calves for six or seven years afterwards. In the “Farner's Magazine," for November 1806, there is an account of a twin heifer, belonging to Mr. Buchan, of Killingtringham, which produced a calf : she was vely handsome, with a well-formed udder, and was a good milker. In the same Magazine, November 180\%, another instance of a similar nature is recorded, and others might be adduced. When the twins are both bull calves, or both cow calves, they are generally equally productive,

There is an instance on record in the "British Farmer's Magazine," May 18:8, of a cow which produced three calves at a birth, precisely resembling each other.

In the "Nouveau Bulletin des Sciences," a most extraordinary account is given of a cow which produced nine calves at three successive birtlıs. First, in 1817, four cow calves; secondly, in 1818, three calves, two of them females; aud thirdly, in 1819 , two calves, both females. With the exception of two, belonging to the first birth, all were suckled by the mother.

And here we may offer a few remarks on the principles by which the breeder ought to be grided in the successful management or improvement of his stock, in whatever points he wishes it to excel; whether in those required by the grazier or the dairy-farmer. Every man, whether grazier or dairy-farmer, is desirous of turuing his cattle to the most advantage; nor can this be done, unless the size of the farm, the soil, chimate, the produce and the nature and extent of the pasturage, be well considered; for the cattle that the farm is best adapted for maintaining will be the most profitalle. It is, howerer, essential, whaterer the cattle be, whether for the purpose of the diciry, or for the immediate supply of the marliets with their flesh, that they be well bred, and excellent of their kind. To the dairy-farmer, the most important points are, the quantity of milk yielded, its quality, its value for the production of butter, or of cheese, a freedom in the cows from vicious habits and ill temper, their character as good and healthy breeders, the ease with which, when useless as nilkers, they become fattened for the market, and the nature and quautity of food requisite for this purpose. To the grazier, the quickness of becoming fat, and at as little expeuse as possible, the fineness of the grain of the meat, or of the muscular filores, the mode of laying on the fut, the smallness of bone, soundness of constitution, and congeniality with the soil and the climate, are the chief points which he takes into consideration. If he is wise he will never stint keep, nor transfer his stock from a good to an indifferent soil, and this is true also with respect to the dairs-farmer.

Contour, or beauty of form, is desirable; indeed it is more or less connected with what may he termed utility of form, that is, a preponderance of those parts in the beast which are most delicate for the table, and bear the highest price, over the parts of inferior quality, or offal. This is connected with smalluess of bone, but not a preternatural smallness, and with a tendency to depositions of fat, whicl, however, should not be carried to an extreme, otherwise the quantity of flesh is disproportionate, and its fibre is dry and insipid; nor is the weight of the beast proportionate to its admeasurement. Previously to the time of $\mathrm{Mr}$. Bakewell,* the cattle in general were large, longbodied, big-boned, flat-sided, slow to fatten, great consumers of food, and often black, or foul-fleshed, or as it is called in Yorkshire, "lyery." This truly patriotic breeder, acting upon true principles, energetically set to work on the improcement of cattle, and, in defiance of opposition and a thousand difficulties, lived to see the success of liis longcontimed efforts. Experience and a close and acute observation had taught him that " like produces like;" in other words, that the qualities of the parents, such as beauty, or utility of form, disposition to fatness, goodness of flesh, abundance of milk, and eveu temper, were inherited by their offspring; and that by careful selections on the side both of the sire and dam, a breed might be ultimately established, to which the title blood could be distinctly applied. This, of course supposes a primary selection, but a selection of such of the offspring as exhilited the properties which constituted their perfection, in the highest degree ; and again of the offspring of these, and so on progressively. At first, Mr. Bakewell was necessitated to breed in and in, but as his stock increased he was enabled to interpose more or less remote removes between the meubers of the same family; and ultimately he established the Dishley, or New Leicester long-horus, a breed remarkable for smalluess of bone, roundness of form, aptitude to fatten upon a moderate allowance, aud fineness of flesh. But while be accomplished this, rendering the animals admirably suited for the grazier, it was found that their qualities as milkers were much deteriorated; the dairy-farmers, consequently retained their old breed, uoted for the richuess, though perhaps not

* Born at Dishley, in Leicestershire, 1725. His father and grandfather resided on the estate before him. 
the great abundance, of the milk. We are not here speaking about the differences or the distinguishing excellences of the various breeds of cattle, but of the principles upon which excellences, it matters not of what sort, may be obtained. "Like produces like," and both parents must present the same excellences, the same characteristics. It was by following out these rules that $\mathrm{Mr}$. Bakewell arrived at perfection in his breed; indeed by some he is thought to have pushed his priuciples too far, and the following remarks bave perhaps some justice in them:- "It was his grand maxim that the bones of an animal intended for food, could not be too small; and that the fat being the most valuable part of the carcass, it could not, consequently, be too abundant. In pursuance of this leading theory, by inducing a preternatural smallness of bone, and rotundity of carcass, he sought to cover the hones of all his animals exterually with masses of fat. Thus the entirely New Leicester breed, from their excessive teudency to fatten, produce too small a quantity of eatable meat, and that, too, necessarily of inferior flavour and quality. They are, in general, found defective in weight, proportioually to their bulk; and if not thoroughly fattened their flesh is crude and without flavour; while, if they be so, their carcasses produce little else but fat, a very considerable part of which must be sold at an inferior price to make candles instead of food: not to forget the very great waste that must ever attend the consumption of over fattened meat.

"This great and sagacious improver $(\mathrm{Mr}$. Bakewell) very justly disgusted at the sight of those huge, gaunt, leggy, and misshapen animals with which his vicinity abounded, and which scarcely any length of time, or quantity of food, would thoroughly fatten, patriotically determined upon raising a more sightly and profitable breed; yet, rather unfortunately, his zeal impelled him to the opposite extreme. Having painfully, and at much cost, raised a variety of cattle, the chief merit of which is to make fat, he has apparently laid his disciples and successors under the necessity of substituting auother that will make lean."-Illustrations of Natural History, p. 5.

Granting the truth of these structures, which we scarcely can, to the full extent, what is the inference as it respects the system of breeding? Namely this: that by pursuing the proper mode, by proper selections, and by joining like excellences and properties in the sire and dam, and not by rashly crossing distinct breeds, but by making one breed the great foundation, and working upon it, rememberiug that "like produces like," not only will the point aimed at be attained, but that it may even be overshot, thus demonstrating the power which the judicious breeder possesses.

Since Mr. Bakewell's time, the New Leicester breed has become degenerated; by sume the stock has been bred in and in tooclosely, and by others very injudiciously crossed. In the mean time the shorthorned breeds of catrle have been gaining an ascendency, so that few really excellent long horns are now to be seen. This, however, has nothing to do with the great principles we have endeavoured to illustrate ; they apply alike to all breeds of cattle. Every breeder, then should well consider the properties of the stock from which he breeds, investigate their good qualities and their bad qualities, and while he endeavours to keep up or improve the former, he should study to remove the latter. His selection must be strict; the heifer or cow should have as few of the bad points as possible, every excellence in perfection, and be in good health; the bull should be of the same kind, and if related, only in a remote degree; nor should he have been brought up on a pasturage differing from that of the cow, or under the influences of a different local climate; he should not ouly possess the good points desired, in all their perfection, hut he should also have the points which the farmer cousiders to be the excellences of his own stock, as admirably developed. Thus acting with judgment, he may expect improvement, aud if he fail, there is some concealed fault which has been overlooked, either on the one side or the other, or some defect in their parents, and which, (in accordance with the tendency there is in families to exhibit, from time to time, certain peculiarities, latent perhaps for a generation), has again made itself manifest; consequently, on both sides there ought to be what is termed "good blood." But this is to suppose a stock already improved to a great extent; and here we may repeat the injunctions laid down by the Rev. $H$. Berry, which more particularly apply to the farmer commencing de novo. "A person selecting a stock from which to breed, notwithstanding he has set up for limself a standard of perfection, will obtain them with qualifications of different descriptions and in different degrees. In breeding from such he will exercise his judgment, and decide what are indispensable or desirable qualities, and will cross with animals with a view to estahlish them. His proceeding will be of the 'give and take hind.' $\mathrm{He}$ will submit to the introduction of a tritling defect in order that he may profit by a great excellence; and between excellences perhaps somewhat incompatible, he will decide on which is the greatest and give it the preference.*

* "A person wuuld often be puzzled; he would find different individuals possessing different perfections in different degrees:one, good flesh, and a tendency to fatten, with a bad form; another, with fine form, but bal tlesh, and little disposition to acquire fat. What rule should he lay down, by the observanee of which good might be generally produced, and as little evil as possible effected? Uritiry. The truly good form is that which secures constitution, health, and vigour; a dispositiou to lay on flesh with the greatest possible reductiun of offal. Having obtained this, other thiogs are 
"To a person commencing improvement, the best advice is to get as good a bull as he can, and if he be a good one of his kind, to use him indiscriminately with all his cows; and when by this proceeding, which ought to be persisted in, his stock has, with an occasional change of bull, become sufficiently stamped with desirable excellences, his selection of males shonld then be made to eradicate defects which he thinks desirable to be got rid of.

" $\mathrm{He}$ will not fail to keep in view the necessity of good blood in the bulls resorted to, for that will give the only assurance that they will transmit their own valuable properties to their offspring; but he must not trust to this alone, or he will soon run the risk of degeneracy. In animals evincing an extraordinary degree of perfection, where the coustitution is decidedly good, and there is no prominent defect, a little close breeding may be allowed: but this must not be injudiciously adopted, or carried too far: for, although it may increase and confirm valuable properties, it will also increase and confirm defects; and no breeder need be long in discorering that, in an improved state, anjmals have a greater tendency to defect than to perfection. Close breeding from affinities impairs the constitution and effects the procreative powers and therefore a strong cross is occasionally necessary."

The dairy-farmer, however, is less concerned in this high breeding than the grazier: yet he is not by any means indifferent in the matter; for his aim ought to be, to obtain a breed no less valuable as milkers than for their disposition to fatten when the milk is dried. These two qualifications are not to be attained very easily; jet they may be, and, indeed, have been attained, and especially among the improved short-horn breeds, as those of Durham and Yorkshire, or the crossbreeds between the old Shropshire and the Holderness. The breeds most valued in the great dairies around the metropolis are mixed between the Yorishire, Holderness. and Durham. For quality and quantity of milk they are eminent; they yield, on the average, each cow, a gallon of milk per day, and often nine quarts; and when dry, they are in general readily fattened for the bntcher.

With respect to the poiuts of symmetry in cattle, of which the various breeds exhibits several degrees of modification, there are certain rules which are generally ackuowledged as applicable to good cattle of all kinds.

THE BulL.-The forehead of the bull should be broad and short, the lower part, that is, the nasal part and jaws, tapering; and the muzzle fine; the ears moderate; the neck gently arched from the head to the shoulders, small and fine where

of minor, though perhaps of considerable importance."-Prize Essay, by the Rev. H. Berry. it joins the head, but boldly thickening as it sweeps down to the chest, which should be deep, almost to a level with the knees, with the briskets well developed. The shoulders should be well set, the shoulder-blades oblique with the bumeral joint advancing forwards to the neck. The barrel of the chest should be round, withont hollowness between it and the shoulders. The sides should be ribbed home, with little space between them and the hips; the whole body being barrel-shaped, and not flat-sided. The belly should not hang down, being well supported by the oblique abdominal muscles, and the flanks should be round and deep. The hips should be wide and round, the loins broad, and the back straight and flat. The tail should be broad and well haired, and set on high, and fall abruptly. The breast should be broad; the forearms short and muscular, tapering to the knee; the legs straight, and clean, and fineboned. The thighs should be full and long, and close together when viewed from behind. The hide should be moderately thin, with a mellow feel, and moveable, but not lax; and it should be well covered with fine soft hair. The nostrils should be large and open; the eyes animated and prominent; the horns clean and white.

THe Ox.-In the ox, the masculine characters, so prominent in the bull, are softened; the neck is carried nearly straight from the top of the shoulders, without an arch; and the general frame is lighter, but the points of excellence are the same.

The Cow.-Cows of a coarse, angular, gaunt figure may give good milk, and that in abundance, as, indeed, was the case with some of the old unimproved breeds; but it is desirable, and moreover it is possible, to unite qualities as a milker with such an aptitude to fatten, as will render her valuable when dry, and profitable to the butcher. In a cow thus constituted, the head must be long, rather small and fine; the neck thin and delicate at its junction with the head, but thickening as it approaches the shoulder and descends to the chest; the breast should be at least moderately broad and prominent, with a small dewlap; the chine should be full and fleshy; the ribs well arched, and the chest barrelled; the back straight, the shoulders fine, the loins wide, the hips well formed and rounded, the rump long; the udder should be moderate with a fine skin, and of equal size both before and behind; the teats should not be too large or lax, and they should be equidistant from each other. If the vascular system be well developed, the milk-vein, as it is termed, is generally large; and thongh this vein is not connected with the ndder, but carries the blood from the foreparts to the inguinal vein, still it has been taken, and with some justice, as the criterion of a good milker. The eyes should be clear, calm, and tranquil, indicative of a gentle temper; 
the skin thin, but mellow; and the hair soft. Most farmers are acquinted with the following lines, which give a risumé of the points of such a cow as that we bave described:-

"Slec's long in her firce, and fine in ber hom;

She'll quichly get lut without cadie or corm;

She's clean in ler jawx, and lull in her chine;

She's heavy in llank, and tine in her loin.

"She's bront in her rilss, and long in her nump

A struight and the bark without ever a bump;

Slec's wide in her hips, and ealm in her eye's;

She's fine in her shunlers, and thin in her thighs.

"She's light in her neck, and small in her tail ;

She's wide at her loreast, and goot at the pail;

She's fine in her bure, and silky ot stin;

She's a grazier's without, und a butcher's within."

Cows thus admirnbly formed will often yield from twenty to twenty-four quarts of milk daily, anc some, in the spring time, in good pasturnge, even thirty, or more. 'The milk may, perhaps, yie]d less butter in proportion than thit of some otler breeds of cattle; lut it rould appear that as the cow advauees in age to her sixth and seventh year, the milk becomes riclerer; and it is well linown that the extensive dairymen of London prefer a cow which lus had a thircl or fourth calf, aud is five or six years old, to a younger animal.

We are perfectly aware that Mr. Culley ("Observations on Live Stock,") considers it as an impossiblity to unite good milker's with good feeders; for, ho says, whenever we attempt loth, we are sure to get neither in perfection:- "In proportion as we gain the one, in the same projortion we lose the other: the more milk, the less beef; and the more we pursue beef, the less milk we get. In truth, they seem to be two diffesent varieties of the sane kind, for very different uses; and, if so, they oucht most certainly to he diflerently pursued by those who employ them. If the dairyman wauts milk, let him pursue the milking tribe; let him liave both bull and cons of the best and greatest milking family he can find; on the contrary, lie that wants feeding or grazing cuttle, let him procure a bull and cows of that sort which feed the quickest, wherever they are to be found. By pursuing too many objects at once. we are apt to lose sight of the principal; and by aiming at too much, we often lose all. Let us ouly keep to distinct sorts, and we shall obtain the prize in due time. I apprehend it has been much owing to the mixing of breeds and improper erossings that has kept us so long from distinguishing the most valnable kinds." $\mathrm{Mr}$. Culley wroto in 1807, and since his day many improvements have taken place in the breeds of cattle; and experience has proved that the improved Yorkshire cow, in which the characters of the Durham and Holderness are mingled, unites the two qualities in high perfection. Not that she displays them at the same time: while giving milk she may, and perhaps will he, in tolerable store condition, showing her aptitude to futten; but when, in process of timo, or by desigu, she hecomos dry, she then fittens rapidly, and costs litthe in prepartion for the butcher.

Formerly, the lahouring ox, or steer, was greatly employed for the purposes of draught, in the cart or at the plough; and on some largo furms teams of oxeu are still maintained. In North and Soutl Devon, the greater part of the agricultural labeur is performed ly oxen: and ox teams are common in Sussex and Herefordshire. Four good steers will do as much work, either at the plough or in the cart, as three moderate horses. They are worked in yokes, and require to be shod, in order that the loof may be de. fended, otherwise inflammation would soon ensue, and the heast would be ultimately erippled. The hoof being bifid, the shoes are accordingly adapted; and they should be thin and light. In Devonshire, oxen are generally put to furm labour when they are about two years old, and they are kept to work for three or four yeurs; they are then grazed $o r$ fel on hay for eight or ten months, and in that time are realy for the market. Mr. Youtut, speaking of these oxen, sars, respecting their feeding, that, "if the grnss land is good, no corn, or" cake, or turnips are required for the first winter; but, of course, for a second winter, these must be added. The grazier likes this breed best at five years old; and they will usually, when talien from the plongh, fetch as nuch money as at six: at eight or nine years, or older, thoy are rapidly declining in value." It is ly no means, lowever, in all parts of Devonshire, that the ox is used for the plough; and the reason is, that the demand for oxen among graziers is so great that the breeders obtain good remunerating price for them before they are old enough to be put to lubour or about the time in which they are fit for breaking in; and this circumstance leuts to a consideration of the expedieney or inexpediency of the general employment of oxen in laborions service. On the continent the ox is most extensively used for the cart and the plough, as it was in ancient times; but in Englind the great demand of the ox for food (and that of the best yuality, rendering attention to breeling and feeding of paramount importance), the slowness of the ox, and its inferiority as a beast of draught, compared with the horse-the improvement in our working class of horses-and the greater ease with which the latter are trained and managed, all appear to combine in rendering the services of the ox fur less necessury than they would otherwise be, and have been, and still are, on the contiment. A farmer who ean sell four or five oxen for a good profit, at two years old, will not keep them for the plougb, especially when two horses 
will do the work of three or four oxen, and that for many years; yet, in large farms, it may be advantageous to keep a few oxen at least for the lighter work, so as to sare the time of the horses, which might be deroted to more important labour; and this the ratlier as the keep of the working $0 x$ is less expensive than that of the working carthorse. Mr. Culley, no ordinary judge in agricultural matters, is a decided advocate for the partial employment of the ox under proper circumstances. He admits that oxen are not in all things equal to horses, lut urges that the advantage of employing them, "in every kind of work wherein they suit, is very considerable." They may be entployed in "several kinds of home-work, such as ploughing, loading dung, corn, \&c., equally as well as horses." And he adds, "I advance this opivion on several Fears' experience, and believe that most farmers might use some oxen along with their horses; but would recommend that oxen and horses be in separate draughts, because the difference of the step is so unequal." In a note, he further observes, "The author and his brother, in partuership, at this time employ about 150 oxen in the dranght, which is mentioned here as a proof that they approve of drawing oxen in many cases, after more than thirty years' experience. They use them in carts singly, and two in a plough with cords, without a driver, where they go equally as well as two horses, though not quite so swift; and I am happy to add, that the working of oxen is becoming more general every day, as many of our neightours are following this example."

Mr. Youat, who commends the activity and excellences of the North Devon cattle, as workers, is evidently in favour of teams of oxen for agricultural labours. In Devonshire, he says, four osen, or six growing steers, are the usual team employed in the plough; and certainly, he adds, "the oxen move along with an agility that would scarcely be expected from cattle: the team may be watched a long while without one harsh word being heard, or the goad or whip applied. The opponents of $o x$ husbandry should visit the valleys of North and South Deron, to see what the animal is capable of performing, and how he performs it. The profit arising from the use of oxen in this ristrict is owing to the activity to which they are trained, and which is unknown in any other part of the lingdom. During harvest time, and in catching weather, they are sometimes trotted along, with the empty wagons, at the rate of six miles an hour; a degeee of speed which no other ox lut the Devon bas leen able to stand." Of course the saddle oxen of India and Africa are bere excepted.

Notwithstanding the recommendations of $\mathrm{Mr}$. Culler, and the riews of Mr. Youat, it does not appear to us that any advance has been recently made in the employment of oxen in husbandry; neither do we think it probable. There is a general penchant for the horse: the small or middling farmer finds a few horses sufficient for his purpose, and is naturally unwilling to burden himself with inferior workers, which, after all, must be well fed; and the large farmer, aware of the superior efficacy of the horse, thinks it scarcely worth while to have an effective team of neat cattle, when his horses are so often idle, and when, in busy times, a few more hired for the occasion, or purchased, if even to sell again, will enable him to get through the work with expedition. Besides all this, as we have already said, the $0 x$, in our densely-populated islant, is required, as early as possible, by the butcher : the demand being pressing, such, in fact, as to render the importation of foreign stock, if not positively necessary, at least (as is deemed by parliament) not to be debarred.

The oxen of Devon may work quickly and spiritedly, but such as we have seen have been slow in their movements, especially in hot weather, by which they always appeared to us to be greatly distressel, far more so than the horse; besides which, they seemed more exhausted by severe muscular exertion, and less capable of rallying. Nor need we wonder at this, when we consider the complicated process of rumination which must take place in the ox before digestion and assimilation can invigorate the exhausted system; remembering, at the same time, that, during muscular exertion the whole process is suspended. Consequently an hour or two devoted to rest is of far less service to the os than to the horse. If the ox labours at the plough during a whole day, with two hours' intermission, and in that intermission takes food, it is of no use; nay, it has only distended the pauuch, rendering him less capable of work; and in the evening, he may then, perhaps, if not orerheated, begin the process of rumination; this completed, he takes more food, and, with perhaps a filled paunch, is again required to labour the next morning, to the arrest of rumination. Thus, either the ox must be punished, or allowed to do only part of a day's work; and then only after the rumination of the last meal has been completed, and before the paunch is reloaded; or, on the other hand, the work must be light, and the pace not over-urged. We may admit the $0 \mathrm{x}$ as an assistant in husbandry, but not as a principal. On the contiment, the ox works slowly; and Buffon well observes that "the ancients limited to one hundred and twenty paces, at most, the extent of the furrow which the ox ought to trace by an uninterrupted continuance of efforts and morements ; after which, they say, one ought to cease urging him on, but permit lim to take breath some moments before carrying out the some furrow, or beginning another," In our climate the farmer is anxious to get his 
seed into the ground, and to see man and beast do a good day's labour.

Still, however, on large farms, a team or two of oxen may be found very serviceable for work suited to their powers and requirements: they may be available, but the horse is essential ; not, indeed, abstractedly so, but according to the views and habits of the English farmer.

\section{CHAPTER IV.}

WE may now proceed to investigate the various breeds iuto which the ox has ramified by the care and agency of those interested in the improvement of our domestic cattle. But, by way of a preliminary step, let us glance at the principal races of Continental Europe, from some of which certain of our breeds have, it is said, but recently descended; we allude to our (now improved) shorthorned cattle, originally, it is believed, from Holland, or some adjaceut parts of the continent, and according to a vague tradition imported into Yorkshire (or that division of the East Riding called Holderness), in the seventeenth century. We may also mention the Alderney and Jersey breeds, originally from Normandy, and still often directly received from that province. In France the breeders and cattle-dealers divide their oxen into two principal sections; " Bœufs de haut crû." and " Bœufs de nature." The "bœufs de haut crû" are of small or middle size, with a wild aspect, a thick skin, rough hair, and ample dewlap: the horns are more or less black or greenish; the suet is particularly abundant. These cattle are more peculiar to the hilly and mountain districts than to the plairs. To this section belong the breeds of Limosin, Saintonge, Angoumois, La Marche, Gascogue, Auvergne, Bourbon, Charolais, Burgogne, Morvan.

The "boufs de nature" are of moderate or large stature; the body and head are small; the nose and ears fine, the horus white, the skin fine and supple, the hair soft, the aspect tranquil. These cattle readily fatten; and are chiefly cunfined to districts of little elevation, and to lands abounding in pasturage. To this section belong the breeds of Cholet, Nantes, Angers, Le Narais, Bretagne (Brittany), Maine, Pays d'Auge, Cutentin, Franche-Comté, Camargue, \&c.

Beginning with the breeds of the first section, we may observe, that the cattle of $\mathbf{~ L i}$ mosin are of moderate stature, somewhat elongated in form, and robustly made: the head is large; the horns are massive, long, and pointed, sometimes sweeping upwards, sometimes downwards. The shoulders are thick, the withers low, the region of the loins somewhat hollow, the dewlap lax, the general colour white or straw-yellow. Weight, from 600 to 850 lbs.

The breeds of Angoumois and Saintonge present very similar cliaracters, but are of inferior size.
These cattle are used for work in their respective provinces, and also in Perigord and HiutPoitou; afterwards they are fattened, some in Normandy, and others in Limosin ; and numbers are sent to the slaughter-houses around Paris.

The cattle of La Marche, and Berri, and Touraine, closely approximate to those of Limosin; but are lower in stature, with long, heavy horns, turned up at the tips, and of a greenish colour. Numbers are fed in the pasture-grounds of Normandy.

The Gascon breed are of considerable size, from 700 to $800 \mathrm{lbs}$. in weight: they are long low beasts, with a huge head and horns; the skin is very thick; the colour generally of a dull white, sometimes with a tinge of sooty-brown, which appears mostly on the head. Oxen of this breed are consumed at Bordeaux, and are slanghtered for the provision of shipping; some few are fattened in Limosin, and sent to Paris.

The Auvergne cattle are of small size, weighing from 750 to $850 \mathrm{lbs}$; they are short in stature, but broad and thick, with large bones, and a heavy contour; the head is short and broad, the muzzle thick, the horns short, turned up, and somewhat twisted and crumpled; the belly hangs low ; the usual colour is red, with marks of white, more or less large, on the sides and back.

The cattle of this breed are reared in the mountains of Aurergne, whence they are brought down, at the age of three years, to work in the. plains of Haut-Poitou; they are afterwards sent to fatten in the pastures of Normandy. Some, however, are retained at Poitou, and are fattened on hay, in the neighbourhood of Heraie-SaintMaixeut, and of La Motte-Sainte-Heraïe, and turu out good beasts: they are known by the name of "Mottois."

There is a breed of small cattle in Bourbon, with a slender head and neck, and long pointed horns; their colour is red, mottled with white. These small native Bourbon cattle are in little esteem; and a breed, brought from some other province, is far more valued, and is fattened in Bourbon on hay.

The Charolais cattle are of moderate stature, weighing from 600 to $850 \mathrm{lbs}$; t their contour is short, robust, and massive; the head is well proportioned and plump; the horns are short and 
fue, with a slightly green tinge; the back and loins are almost straight; the belly is voluminons; the colour is milk-white, sometiuses with red spots.

The oxen of this excellent breed, which is doubtless capable of great improvement, are fattened, after having worked for three years, in the pastures of Charolais, and supply the markets both of Paris and Lyons.

A smaller breed of very similar cattle is sprcad throughout the province of Nivernois; these cattle are very gentle, the skin is thin, and the contour less massive than that of the preceding breed. The oxen are used for farm-labour, and afterwards fatted. The best are sent to Morvan for the markets.

The Burgogne, or Burgundy, breed of cattle are small, and much like the breed of Berri or La Marche: their colour is white. This breed is in little estimation, and is altogether nncultivated; its hide is inferior in quality; it yields but little suet, and the quality of the flesh is indiflerent.

We now come to the breeds of the second section, "les boufs de nature."

An excellent breed of cattle is found in the district around Cholet (Anjou), the oxen often attaining to the reight of $900 \mathrm{lbs}$. The proportions are very tolerable: the head is brood and short; the horns are long and white, with black tips; the shoulders, loins, and rump art on the same level; the breast is deep; the dewlap small; the most common colours are grey, black, or brown. The Cholet cattle are not bred in that district, but in Bas-Poiton, and are afterwards sent to Cholet, where they are fattened on hay, cabbages, \&c., and killed at the age of six or seven years. These cattle find good markets in the various provinces; and numbers are sent to Paris, more particularly between the months of April and July. It is in Bas-Poitou also that a breed called Nantes cattle are reared, and which are afterwards distributed in the environs of the latter place. The oxen are used for farm-labour in the Pays de Retz, and over a great part of Bretagne and Ärjou, and especially along the borders of the Loire, from Angers to Normandy. There is, about Nantes, a smaller breed also, with a finer head; the oxen are much employed in the neighbourhood of Remues and Fougères, and are nltimately sent to the pastures of Normandy.

In the marais. or low district, along the coast between Machecoul and Fochefort, several breeds of cattle appear to be reared and fed, the oxen heing used for labour. Of these the largest breed often weighs 900 or 1000 lbs. : the contonr is not first-rate: the head is long, the horns large, the skin thick, the tallow abundant and oily. 'I'his is the ox of the marais, to the north of Lugon.

The $\mathrm{x}$ of Fontenay is smaller and more com. mon; it is reared in the large marais between Lucon and Rochefort.

At Amnis, Poitou, and in the marais of La Charente, a Flanders breed of $\mathrm{x}$ prevails, originally from the Netherlands, or Holland. It is of tall stature, long in the body, and high in the limbs, with the volume of the trunk diminished: the head is long, the horns very large, the skin dense. The cows are always meagre, but give a great quantity of milk.

Besides these, there is a mixed breed, resulting from crossing the Flanders stock with the others.

In Basse-Bretagne, there is a very diminntive breed of cattle, with a fine liead and slender limbs; the horus are very long, and black at the tip. The colour is red and white, or black and white. It is fed in Basse-Bretagne chiefly for ship provisions, though a few, fattened in the pastures of Normandy, find their way to the Paris markets.

An excellent breed of middle-sized cattle prevails in Maine. The oxen weigh about seven hundred pounds. The head and neck are fine, the horus short and white, the dewlap is almost wauting, the haunch is flat, the tail high set, the colour white and red. This breed is noted for gentleness of disposition, and is both widely spread and very much esteemed. The ox is worked to the age of six or seven years, and then sent to the pastures of Normandy. This breed has been crossed by one from Holland; and the mixed stock, of superior size, were first bred by M. Boreau de la Besnardière, of Angers, who introdnced some bulls from that country.

In the Pass d'Ange, a breed of cattle, originally from Holland prevails. The oxen of this breed are of large size, usually weighing one thousand or twelve hundred pounds. Their contour is very good: the head is short, and broad, the horns white, thick, short, and round, the tail high-set, the hair thick; the skin is thick, the colour is black or brown, mixed with white, the head being often entirely of the latter colour, These oxen readily accumnlate an abundance of fat, which is, in general, of a slight yellow tinge.

Coming from a good stock, and more care being taken in the breeding of this race than is usual in France, the ox of the Pays d'Auge is superior to most others. The breed was originally introduced about fifty years since, by M. de la Roque, a stock feeder, who oltained it in Holland; and, from the selections made in the choice of individuals destined for breeding, it maintains all its original excellences, which are in full perfection at the serenth or eighth year. Many oxen, howerer, are sold for slanghter at the age of three or four years; lut some are liept for three or four years to labour, and are then fattened.

In the district of Cotentin, in Normandy, there is a breed of considerable size, with a long head 
and long slender horns, and having the back ridged, the thighs lank, the limbs slender, the body volu minous, and the skin thin. The colour is blackish browu.

Betreen this old, coarse breed, and the Holland of the Pays d'Auge, has resulted a mixed race, which often attains to a very a large size, with the limbs stouter, and in better proportion, and with a general increase in bone as well as flesh. This breed is usually nottled, red and white, and it is almost the only one bred in the Normandy pastures, and there also fed. The original cattle of Franche Comté are very small, and of little value; the horns are often crumpled, and the general colour is blond, or brown. There is, however, an improved breed in Franche Comté, which supplies the cattle feetlers in the arrondissement of Avesnes.

In the Pays de Camargue, at the embouchure of the Rhoue, a wild, savage breed exists, less remarkable for stature than for strength and solidity of contour. The boly is stout and robust, the belly extremely voluminous: the horns short, and so arched as to form a perfect crescent; the skin is thick, and covered with black hair.

These cattle, which inhabit the island of Camargue, in the mouth of the Phone, a little below Arles, are in a seni-domesticated condition, and are noted for their strength and ferocity. They are said to have been brought, originally, from Auvergne. Their heavy contour, their black colour, their savage habits, and their great strength, give them a certain degree of similarity to the massive buffalo. It is this fierce breed which furnishes the bulls for the combats of the amphitheatre, which still from time to time, are exhibited at Nimes and at Tarascon.

Such are the priuciple breeds of France, as detailed by M. Desmarest; but as he observes, there are innumerable shades of variation; and, we may add, that clianges and improvements are perpetually taking place, insomuch that old breeds are gradually giving place to new, or, by admixture, are losing their original characters. In Normandy, celebrated for its pasture lands, we have seen excellent cattle, not at all resembling the dlierney breed, but large, straight-backed, deep, and broadbreasted, well barrelled, short-horned, and mottled red and white. In other parts of France, we have seen small and meagre cattle, without the slightest pretensions to blood, but, at the same time, tolerable milkers. A writer in the "Penuy Magazine" says, "The Norman breed gives the character to all the cattle usually met with in the north of France, except near the lihine. They are mostly of a light red colour, spotted with white; their horns are short, and stand well out from the forehead, turning up with a black tip; the legs fine and slender, the hips high, and the thighs thin. The cows are good milkers, and the milk is rich. They are in general extremely lean, which is owing, in a great measure, to the scanty food they gather by the sides of roads and along the grass ballis which divide the fields. In Normandy itself they have good pastures, and the cattle are larger and look better. The Alderney and Jersey breeds, which, from the extreme richuess of their milk, are much prized in gentlemen's dairies in England, are smaller varieties of the Norman, with shorter horns, more turned in, and a more deer-like form."

In Switzerland there are two or three breeds of active, handsome cattle, well adapted for riuning the mountain pastures; of these the most celebrated is the Freyburg stock, much cultivated in the rich grounds between the mountains in the neighbourhood of Gruyères or Greyerz so celebrated for its cheese; the cows are of good size, wide in the flanks, strong in the horn, and short in the bone; the set-on of the tail is prominent, and detracts from their appearance; as milkers they are excellent, either when ranging in their pastures, or when stalled and fed with clover, hay, and lucern. The oxen are slow and heavy, but at the same time powerful, and work well; they also fatten readily; but in Switzerland, as throughout the continent generally, the stall-fed fatted steer is in far less estimation than in the British islands. It is of little consequence whether the meat be lean or fat, coarse or fine grained, when the mode of cookery is such as to break down the texture of the Hesl, or to disguise it in such a manner that it would be difficult to say of what auimal it is a part. In the Jura mountains, a breed of cattle similar to the Swiss, but of small stature, greatly prevails. These cattle are very harly and active, and clamber about the mountains, or among the rocks and woods with the activity of goats; the cows are good milkers, and are of great importance to the mountain peasants; the oxen are very strong for their size, and are used for labour; they invariably draw by the horns. The cattle of this breed are mostly red; they thrive on scanty fare, and are well fitted for the locality they occupy.

In Switzerland, Savoy, and the adjacent mountain-districts, considerable attention is paid to the cows, which have generally bells round their necks, and are attended by cowherds, who use the Alphorn to colleet them at stated times. These bells are not intended merely as ornaments, or to give pleasure to the ear, they are of great utility; for when a cow happens to stray on the mountains, the vacher or his dog has always a guide in the bell, the slightest tinkle of which is heard at a grent distance in those lofty and still regions.

With respect to the nastoral economy of these mountain districts, it is in keeping with the character of the country. The richer proprietors or breeders in the Alps, possess tracts of pastur- 
age, and sometimes houses at different heights. During the winter they live at the foot of the mountains in some sheltered valley, and house their cattle; but on the return of spring they quit their winter abode, and ascend gradually as the heat brings out vegetation on the higher lands, ou which, during the summer, the cattle feed at large. In autumn they descend by the same gradations to the valley.

The farmers or proprietors, who are less weal thy, have a resource in certain common pastures, to which they send their cows, the number possessed by each person being determined by his means of keeping them during the winter. Eight days after the cows have been driven up to these common pastures, all their owners assemble, and the quantity of milkeach cow produces is accurately weighed. This operation of weighing is repeated one day in the middle of summer, and again at the end of the scason. The milk of all the cows has, in the mean time, been put together, and marle into butter and cheese; and this common product is divided into shares, according to the quautity of milk each owner's cow sielded on the days of trial.

The chalets or public dairies on these common pastures have always some persons residing in them during the summer months, when the churn and the cheese press are never idle: some of them are in such lofty situations, that to go to them and return to the valley below, take up the time of a whole day. The cheese is made in copper cauldrons of an enormous size, and is itself formed into masses incouveniently heary ; a cheese weigling two hundred pounds is by no means a rarity in the mountains of Savoy and Switzerland; and in some of the chalets such a cheese is put into the press every day during the summer season. The cows are milked morning and evening. At the approach of sunset they may be seen slowly traversing the mountain pastures, from every quarter (either going of their own accord, or in obedience to the sound of the Alp-horn), to the chalet, in order to be milked. 'These cattle are said to know so well the proper season for shifting their quarters and seeking the milder climate of the valleys, that they would set off themselves and returu direct, each to its winter station, even if not conducted.

In the Jura ion the frontiers of France towards Switzerland) excellent butter is made, and great quantities of cheese.

In the North of Italy, where the colebrated Parmesan cheese is made, the cattle resemble those of Swit\%eriand. Parmesan cheese is made from skimmed milk, and saffron is added to give flavour and colour; Gruyères cheese is made entirely from new milk.

In other parts of Italy is found an improved breed of cattle, remarkable for the great size of the horns; but in the Campagua of Rome a very vol $\mathrm{r}$. fine race, to which $5 \theta$ have previously alluded, exists in a semi-wild state, under the care of keepers, or vaccari. Some of the bulls are extremely noble animals, often white, others are grey, more or less tinged with brown; the horus are large, well tumed and pointed. Many of these animals have a name and genealogy, and are bred on the celebrated tenuta, or cattle farm, of some nobleman or great landed proprietor ; and these particulars are specified in the printed bills distributed at the door of the amphitheatre when a great bull-fight is about to take place.

Of the cattle of Hungary, Wallachia, \&c., me have ahready spoken; they are white, or whitish, with long horns; and a similar breed prevails in Russia. From this latter country, tallow and hides are imported into England; and cattle are reared in vast numbers, but principally in the more southern provinces. In the district adjacent to St. Petersburgh, and even Mloscow, few cattle are reared, and the markets are supplied by cattle driven from distant parts. The herdsmen live in a state of barbaric simplicity, and are, iu fact, nomadic in their habits. 'They travel with their herds to St. Petersburg, Moscow, and other large towns which depend more on them for a due supply than on the farmers of the adjacent districts. The following notice of these cattle from Johnson's "Russia, "gives a good picture of the mode in which they perform their long journeys :- "Aloug the road we passed one or two large droves of horned cattle proceeding to St. Petersburg; we learned that they were brought from the provinces south of Moscow. These cattle are all of a white colour, well made, and of about seven hundred weight. Their journey to St. Petershurg generally occupies three months; they travel from eight to sixteen miles during the night, and are allowed to pasture and rest during the day, on the sides of the road; the herds are attender by one or two men, who conver their cooking utensils, baggage, dc., in a wagon drawn. by two oxeu, and while their numerous cattle repose undisturled under the shade of the delicate binch, they stretch themselves on the ground, arid fass their time in a true Scythian state. Here are also seen a few sheep, but of an inferior bvoed, and covered with hair somewhat like that of a goat. This country is not favourable for tire pas. ture of sheep, owing to the coarseness of the grass and the quantity of wood. Little or no atiention seems to be used in the rearing of any other domestic animal except the horse; to hini glone the Russian devotes his whole attention, and from him he derives his livelihood."

The Calmucks on the Koomanian steppe (estimated at 20,000 families), on the western' side of the Lower Volga, feed vast numbers of hlack cattle, as well as camels, horses, sheep, and gonts. In winter, wheu the grass of the plains is entirely 
destroyed, the lierds find abundant pasturage in the swamjy trasts along the river Sarpa, on the low shores of the Caspian, and on the level ground bordering the river Kooma above Kislar. In the north of Russia a few small cattle exist, but here the ox gives place to the reindeer.

In Norway cattle are abundant, but of small size; and the same observation applies to Ice. land, which originally derived its cattle from the former country. The Iceland cattle have much resemblance to those of the Orkney Islands, but are, perhaps, larger: To the natives of Iceland their cattle are of the utmost importance; and, though the management of the stock is conducted on no principles, the breed is not destitute of pretensions to a tolerable form and contour, and might, by judicious management, be greatly improved. Mackenzie, in his "Account of Iceland," observes, that "The cattle, in point of size and a) pearance, are very like the largest of our Highland sorts, except in one respect,-those of Iceland are seldom seen with horns. As in other countries, we meet with finer cattle on some farms than on others; but (he adds), from every observation I could make, and information I could obtain, the Iceland farmers know nothing of the art of breeding stock. The bulls are in general ugly, and no use is made of them till after they are five years old. In rearing a bull-calf no more attention is paid to him than others. Taking all circumstances of management together, 1 had some reason to be surprised to find the cattle, upon the whole, to be so handsome. The cows, in general, yield a considerable quantity of nilk; many of them ten or twelve quarts a day, and some a good deal more."

In another place, the same writer observes, "The cow, horse, and sheep afford the principal sonrce of wealth, comfort, and subsistence to the Icelander. A cow on the farm of the Amtmand Stephenson, we were assured, gave regularly every day twenty-one quarts of milk. Their value is wal snown and appreciated by the Icelanders, who take the greatest care of them in the winter, and séeni to shake off their habitual listlessness while employed in gathering the hay that is to support tham through the inclemencies of that season."

$\mathrm{H}_{\mathrm{u} y}$ is, in fact, the great harvest of Iceland; forkiply some corn was cultivated, but the inhaliitants find it more to their advantage to attend to the rearing of cattle. In 1804 there were on thę island 4,751 farms, with 20,325 head of borned cattle, 218,818 sheep, and 26,254 horses. The common food of the people is lutter, milk, and fish: fresh meat and rye bread are holiday fare.

In Sweden the cattle are small, and the pas. turfo mounds generally indifferent: and, from the nature of the alinate, all domestic animals must "ve kejt in stables. or under cover, from four to seven months in the year, and fed on dried fodder. In the north of Sweden the reindeer takes the place both of the horse and the ox.

In Denmark, a superior race of cattle exists ; to the rearing of these, as well as of horses, sheep, and swine, great attention is paid. The horned cattle are, indeed, reared on an extensive scale, chiefly with a view to the prodnce of butter and cheese, and for salted meat. The stock of horned cattle, of all ages, has been estimated at 1,607,000, and the number exported averages yearly about 20,800 oxen, 6,800 cows, and 5,760 calves. Of butter alone upwards of eleven millions of pounds weiglit are the annual average export; and of cheese about 9,200 cwt. Lard, salt-meat, and hides are also exported in great quantities. Desmarest says, that some of the cows from Denmark, which are fed in the rich pastures of Holland, give from eigliteen to twenty pints (Frencls measure) of milk daily.

In the Austrian states, the Hungarian lreed of cattle is common, great numbers being driven from the vast plains on which tley are bred, and sold to the farmers and graziers.

In Lower Saxony, Westplalia, and other districts in Germany, a fine breed of cattle, with short horns prevails. This breed is nearly allied to the Friesland stock and our own Holderness short-horned cattle. They are of various colours: but mouse-colour, or fawn intermingled with white, are the most common. Fied cows of this breed are less frequently to be met with. "They are good milkers in moderate pastures, and the oxen fatten readily when grazed or stall-fed at a proper age. They are fine in the horn and bone, and wide in the loins; but they are not considered so hardy and strong for labour as the Hungarian oxen. If prejudice did not make the breeders select the calves with large bone and coarse fentures, to rear as bulls, in preference to those which resemble the cows, this breed would in every respect equal our best short-horns. The cows are frequently fattened while still in milk, and are fit for the butcher by the time they are dry. The same system is followed by some of the great milkmen in the neighbourhood of London, with their large Holderness cows. This breed is much esteemed in all the northern parts of Europe." It extends into Denmark, and is reared on the plains of Jutland; it is also spread in Prussia and Hanover.

In Groningen, Friesland, Guelderland, Utrecht, and Holland, a fine short-horned race of cattle, differing little from the preceding race, has long existed: indeed, Bewick calls this the Holstein or Dutch breed; and $\mathrm{Mr}$. Cully attributes to this race the origin of our Holderness or Yorkshire short-liorns. This ancient short-homed race may, in fact, be tracel from Jutland and IIolstein, 
along the western portions of Europe, through the Netlerlands, to the horlers of France. At all times the cows have been noted for the quantity of milk vielded, and also for an aptitude to fatten, thus exhibiting qualities upon which the breeder, aiming at improvement, might work with a certainty of success. In reference to our shorthorned breed, Mr. Culley sars, "There are many reasons for thinking this breed has been imported from the continent:-First, because they are in many places called the Dutch breed. Secondly, because we find very few of these cattle any where in this island excepting along the eastern coast, facing those parts of the continent where the same kind of cattle are still bred, and reaching from the southern extremity of Lincolnshire to the borders of Scotland. The long-horus and these bave met upon the mountains which separate Yorkshire from Lancashire, and by crossing have produced a mixed breed, called 'half-long-horus,' a very heavy and strong but not unuseful kind of cattle; but we do not find that the one kind have spread further west nor the others further east. Thirdly, I remember a gentleman (Mr. M. Dobinson) of the county of Durham. who went, in the early part of his life, into Holland, in order to buy bulls; those he lirought over were of much service in improving the breed: and this $\mathrm{Mr}$. Dobinson and his neighbours, even in my dav, were noted for having the best breed of short-horned cattle, and sold their bulls and heifers for very great prices. But afterwards, persons of less knowledge going over, brought home some bulls that, in all probability, introduced along that coast the disagreeable kind of eattle, well-known to the breeders adjoining the river Tees by the appellation of 'lyery,' or 'double-lyered;' that is, black-fleshed; for, notwithstanding one of these creatures will feed to a vast weight (and though fed ever so long), it will not have one pound of fat about it, neither within nor without; and the flesh, for it does not deserve to be called beef, is as black and coarsegrained as horse-flesh." Such cattle, however, are not now to be seen. Here, then, we must look for the origin of our Durham and Holderness race, one of the most important within the limits of the British islands.

With respect to Spain and Portugal, as we have already said, vast herds of cattle, in a semi-wild state, feed in the extensive forests and mountain regions. They are found in the great forests of Alemtejo (Portugal), and in the mountain region of the Sierra Nevada (extending over the southern part of Spain south of the Guadalquiver), including the Sierra de Aguaderas, the Sierra de Estancias, the Montes de Granada, \&c., covering nearly 12,000 square miles. Besides these fierce, wild, or rather feral, cattle. there are tame breerls of large size, and numerous in the ligher mountain districts; but in the plains and tahle-lands they are of small stature. We cannot learn that much attention is paid to the improvement of horned cattle either in Spain or Portugal. Oxen are used for lahour in the cart or wagon, and also for carrying luggage, but the flesh is not in esteem; there are, indeed, graziers and cowherds in the lills, but more attention is paid to the goat, of which both the flesh and the milk are used extensively. In no part of Europe are goats so numerous as in Spain.

It is from the herds of cattle which wandt. uncontrolled by man, that the bulls destined for the amphitheatre are talien. An eye witness thus describes the mode of capturing the bulls in the forest of Alemtejo. In this forest, he sars, "some hundreds of square miles are occupied by growing timber; but within its bounds large open spaces exist, which serve for pasturages; and occasionally a farm, a vineyard, or an olive grove may be seen struggling, as it were, for existence, amidst the vast solitudes. But though occasional glimpses of culture appear, they are far too few and fal between to offer any serious check to the increase and independence of the herds which roam arouml them undisturbed. It was in this forest that I witnessed, for the first time, the method of capturing the wild bulls. I received intimation that the village of Alcoxetc, on the Tagus, was to be the scene of a bull-fight, and that the villagers for many miles round were invited to join in the hunt; which was to take place on the following day. I accordingly crossed the river in company with many persons, mostly military, each being provided with a long pole, having a small spike fixed in one end, and mounted as inclination ur ability suited. When we arrived at the opposite bank, a little before daybreak, we found two hundred and fifty or three hundred persons assembled; some mounted on different sorts of quadrupeds, from the noble Andalucian horse to the humble back donkey, and many on foot. They were all armed in a similar manner to ourselves. As som as darlight hegan to appear, we all murched uth toward the forest. The morning was peculiarly fine, and the interest of the beantiful scenery wis heightened by the varied costumes of the persons by whom we were surrounded. As soou as we had advanced some distance into the wood, we halterl for the purpose of refreshment, before the arduons and somewhat perilous duties of the day began. After a hasty meal, we divided into two parties; one stretehing in a long line to the right, and the other to the left. We had not adranced far in this manner before we fell in with a herd of cattle, having twelve bulls with it; which no sonere deseried us, than they bounded off with the speeil of lighining. The sport now begrn; we put our 
horses to the utmost speed, threading our way among the tall pine-trees as well as we could, and endeavouring, by wild cries, to drive the bulls to the other party. At length, after about an hour's chase, some balf-dozen of us, who were better mounted than the rest, came up with them, and conmenced the attack with our long poles. The manner was this:-one person riding at full speed, gave the bull nearest to him a sharp prick with the goad; which it no sooner felt than it turned upon its assailant and gave chase: another horseman then coming up, attacked it on the other side; when, leaving its first assailant, it turned upon the second ; he. in like manner, was rescued by a third; and so on. The attention of the infuriated animal thus distracted prevented its escape, and gave time for the other hunters to come up. The bulls were, at length, thus separated from the herd. A sufficient number of men having arrived to form a circle round them, we commence operations for the purpose of driving them towards the town. All the skill of the riders was now necessary, and all the activity possessed by both man and horse, to keep clear from the pointed horns, which, on every side, were directed against them, as well as to prevent the herd from breaking through the living net with which it was surrounded. This was, perhaps, the most difficult part, and was attained by keeping each bull separately engaged, and thus preventing united action. For what line was sufficient, armed as we were, to resist the simultaneous rush of these powerful animals? The continued activity and exertion requisite had knocked up many of the poor jades who had started in tle morning, and the circle became smaller and smaller as the day advanced; several, too, had been carried off severely gored and rounded by the horns and feet of the bulls. I, however, and the party with whom I started, were resulved to see the conclusion; and, redoubling our efforts, we, at length, about four o'clock in the afternoon, succeeded in driving them into an enclosure, where a number of oxen (all at one time wild), with bells, were quietly grazing. Here they were kept till required for the next day's sport.

"The square of Alcoxete had been fitted up in the form of an arena, with seats, or rather standing places all round; the centre was carefully cleaued, all stones removed, and fresh sand strewed; at one side a cart was stationed, for a purpose to be presently described; at the other, a pen was fitted up for the reception of each bull, as it was to make its appearance, communicating by a door with a place where the herd was enclosed. The difficulty of bringing the bulls from their temporary resting place to the scene of their humiliation was not less than that of their original capture. Tlurough the forest they had only the trees and shrubs before them, to which they were accustomed; and if the line of huntsmen alone was sufficient to awaken their rage and terror, amidst scenes familiar to them, how much more must those feelings have been excited when passing through the streets of a town, crowded with people, the houses gaily decorated with red, blue, white, and green hangings, and greeted with a thousand tongues in the jovfulness of expectation! Twice the terrified and furious herd turned and dashed through the assembled crowd, tossing and goring all who ventured to oppose them; and twice the circling horsemen brought them back. One fine black bull took to the river, and swam out about two miles before a boat could be put off to re-capture it. Several of the English soldiers, who were quartered near the town, swam after it; and one of them, an excellent swimmer, had nearly reached it, when a fishing-boat came up, and, fixing a cord round the bull's horns, towed it in. The soldier, however, was resolved not to have his trouble for nothing; and, mounting on its back, was landed safely, amidst the shouts of the spectators. The sport of baiting the bulls, for the purpose of taming them, began at three in the afternoon, when the heat of the sun bad somewhat abated. Six of the wild animals were ushered into the circus, surrounded by a band of mounted picadores, and accompanied by sereral tame cattle with bells; when, one by one, they were secured with cords to the cart, and a leathern cap placed on the points of the homs; after which they were all driven into the pen. The circus was then cleared, and the Spaniards entered gaily attired in the Andalucian costume, the grace and elegance of which must be seen to be properly understood. The hair, which is worn long, is confined in a black silk bag, which is fastened with bows of black ribbon; the light-coloured velvet jacket, covered with gold lace and silver-gilt buttous; the velvet vest, richly embroidered, the lace shirt, red silk sash, relvet breeches, and silk stockings, all harmonizing in colour and form, set off the figure to the best advantage, and add to the grace and elegance for which the Andalucian is so justly celebrated. These men, of whom there were five or six, are accustomed, from their infancy, to the dangerous employment of bull-fighting; and the agility and dexterity displayed in evading the furious attacks of the bull are astonishing. After carefully examining the arena, they each armed themselves with four short barbed darts, and waited for the coming of the bull. They had not to wait long; the door was thrown open, and the animal rushed into the centre, greeted by the shouts and vivas of the spectators. One of the Spaniards, advancing, invited the attack; when the bull, who at first, bewildered and amazed, had stood tearing up the eartl with its feet, till 
almost hid from view by the cloud of dust, lashing itself into fury with its tail, rushed upon its opponent. All who were not accustomed to such spectacles thought the man must inevitably have perished; but just as the long and powerful horns seemed to touch his body, he stepped nimbly aside, and turning smartly round, planted all four darts in the animal's neck, just behind the horus. Loud shouts of applause rewarded his dexterity ; and the bull, more enraged than ever, ran round the area, tearing up the earth, and bellowing with rage, until encountered by a second picadore, with the like success. After the Spaniards had exhausted themselves in exciting the rage of the buil, they quitted the area; the populace were admitted to throw the bull. This was generally done by one man leaping between the horus, upon which he supported limself in an upright posture, till relieved by his companions, who threw the bull to the ground. The cry of largo, largo, was the signal for its liberation; when, some tame cattle being admitted, it was led by them to the pen. Six bulls were thus baited the first day, the other six on the day following. Three weeks afterwards I had these very animals under my charge, as baggage oxen, as tame and gentle oxen as could be desired."

In this instance the object was not the destruction but the subjugation of the beasts. But it is far otherwise in the regular amphitheatres of Spain and Portugal, where a bull is only occasionally saved by acclamation, after having killed several horses, or wounded several men, to the delight of the spectators, and especially the female portion, who wave their handkerchiefs in token of their approbation of the animal's courage.

Sir J. C. Hobhouse saw three horses killed by one bull; he was saved by acclamations, which were redoubled when it was known he belonged to a priest. This occurred iu 1809 , in the great amphitheatre of Santa Maria, opposite to Cadiz.

The Spanislı bull-fight, disgraceful to any civilized community, and revolting to every wellregulated mind, is powerfully described by Lord Byron, in his poem of Childe Harold. He painted from nature :-

" The lists are op'd, the spacious area clear'd, Thousands on thousands pil'd are seated round;

Long ere the first loud trumpet's nute is heard

No vacant space for lated wight is fousd.

Here dons, grandees, but chietly dames abound.

"Hushed is the din of tongues; un gallant steeds, With milk-white crest, gold spur, and light-pois'd lance,

Four cavaliers prepare for venturous deeds,

And, lowly bending, to the hists advance.

Rich are their scarfs, - their chargers featly prance.

If in the dangerous game they shine to day,

The crowd's loud shout, and ladies' lovely glance,

Best prize of betler acts, they bear away.

And all that kings or chiefs ere gain their toils repay.
"In costly sheen, and gaudy cloak array'd,

But all on fuot, the light-limbed matadore

Stauds in the centre, eager to invade

The lord of lowing herds, - but not before

The ground with cantions tread is travers'd o'er,

Lest anght unseen should lurk to thwart his speed His arms a dart, - he fights aloof,-nu nore

Can man achicve without the friendly steed-

Alas ! too oft cusdemn'd for him to bear aod bleed!

"Thrice sounds the clarion,-lo! the signal falls:

The des expands, - and expectation mute

Gapes ruund the silent circle's peopled wills.

Bnuads with one lashing spring the mighty brute, And wildly staring, spurns with sotading foot

The sand,-nor blindly rushes on his fue.

Here, there, be poiots his threatening front, to suit

$H$ is first attack, wirle waving to and fro

His angry tuil; -red rolls his eye's dilated glow.

"Sudden be stops; bis eye is fixed-away,

Away! thou heedless boy! Prepare the spear !

Now is thy time to perish, or display

The skill that yet may check his mad career.

With wcll-timed croupe the nimble coursers veer,-

On founs the bull,-but not unscathed he goes. Streams from his flank the crimson turrent clear.

He flies-be wheels-distracted with his throes;

Dart folluws dart, lance lance,-loud bellowings speak his woes.

"Again be comes! nor dart nor lance avail ;

Nor the wild plunging of the cortur'd horse

Though man and man's avenging arms assail,

$V$ ain are his weapons, vainer is his force

One gallant steed is stretch'd a mangled corse;

Anuther-hidewus sight! unseam'd appears :

His gary chest reveals life's panting source:

Though death-struck, still his feeble frame he rears,

Staggeriog, but stemming all, his lord unharmed be hears.

"Foil'd, bleeding, breathless, furious to the last, Full in the centre stands the bull at bay,

'Mid wounds and clinging darts, and lances brast, And foes disabled in the brutal fray :

And now the matadores around him plar,

Shake the red cloak, and poise the ready lrand.

Once more through all he bursts his thundering way,-

Vain rage! the mantle quits the cunting hand,

Wraps his fierce eye,- $t$ is past, - he sinks upon the sund.

"Where bis vast neck just mingles with the spioe, Sheath'd in his form the deadly weapon lies;

He stops-be starts-disdribing to decline: Slowly be fulls, amidst triumphant cres, -

Withnut a groan, without a struggle dies!

The decorated car appears; - on high

The corse is pil'd.-sweet sight for vulgar eyes ?

Four steeds that spurn the rein, as swift as shy,

Hurl the dark bulk along, scarce seen it dashing by."

In noticing the horned cattle of Spain, we may be pardoned this digressive allusion to one of the principal objects to which the finest and noblest bulls are destined. Selections are made, not for the purpose of founding breeds of high strain, but for the combats of the amphitheatre; and all ideas of a fine bull are ceutered in those qualities which render it promising as a combatant in "the brutal fray." The points of gladiatorial excellence are of paramount importance. Its ralue is according to the sport it is likely to afford in the arena; for this purpose it was reared, and not for the advantage of the dairyman or the grazier.

From this glimpse of the various races of cattle, or rather the principal races of cattle on the con- 
tinent, as far as any thing very definite is known respecting them (and this, we confess, is very little), let as turn our attention to the races which prevail within the British Islands,

In no part of the world has so much capital and so much skill been expended in the improvement of hormed cattle, as in Great Britain. We speak of recent times; for formerly it was not so: our agricnlture was bad, our farming operations condncted on no principles, and our management of cattle was in accordance with the rest. Setting aside the now commou culinary herbs of the garden, we knew nothing of the various plants, lucern, sainfoin, clover, and others, termed artificial grasses, Nor was the cultivation of turnips, or mangel wurzel, and similar vegetables, in extensive operation. In fact, we bad not wherewith to feed cattle in winter, and the art of stalling was not imaginerl.

"The roast beef of old England," partial as we have ever been, as a nation, to this sort of animal diet, was a very different thing to the roast beef of the present day; and then it was not the diet of the middle or lower classes, the wenthy alone could frocure it; and that only during the summer, while the cattle fed in the pastures, and throve on the natural herbage ; but, in October and Novemlier, cattle were slaughtered for winter consumption ; the carcass was cut up, and put into brine, and during that season nothing but salt meat could be ohtained; we mean by those who could afford to furchase it. Salt fish was the ordinary, or staple animal food of the lower classes; and from this, and the want of finits, roots, greens, legumes, \&c., dreadful diseases were engendered, and (as cleanliness was out of the question) became perpetuated ; now smouldering, and now, the season of the year concurring, breaking out, and depopulating towns, villages, and hamlets, We are not speaking of remote times, but of comparatively recent periods. "Three or four centuries ago," say's Gilbert White, "before there were any enclosures, sown grasses, field turnips, or hay, all the cattle that had grown fat in summer, and were not killed for wiuter use, were turned out soon after Michaelmas, to shift as they could through the dead months, so that no fresh meat could be had in winter or spring. Hence the marvellous account of the stores of salted flesh found in the larder of the eldest Spencer, in the days of Elward the Second, even so late in the spring as the third of May (viz. six hundred boars, eighty carcasses of beef, and six lundred of sheep). It was from magazines like these that the turlunlent barons supported in idleness their riotous swarm of retainers, ready for any disorder or mischief. But agriculture is now arrived at such a pitch of perfection that our best and fattest meats are killed in winter; and no man needs eat salted flesh, unless he prefer it, that has money to buy fiesh.". But thcre were thousands, the serfs of the soil, who had no money to bny either salted or fresh meat, and a little reflection will serve to show what their condition must have been in the olden time of merry England, had not the religious establishments, the abbeys and priories, on which it is now the fashion to pour obloquy, expended their reveunes for the good of the district-for the benefit of the poor aud the starving. 'Take, for example, Chartreux House (Charter House), founded by that "perfect gentle knight," Sir Walter Mauny. On this monastery the tyrannical barbarian, Henry the Eiglnth (to whom the cause of Protestantism owes nothing) laid his despoiling clntch. Let us pass over the fires at Tylum, in which the prior, with other monks, perished; lut mark what a foustain of clarity (one out of hundreds) the ruthless mowarch stopped. The time serving commissioner, or govemor, Ffyloll, states, that the proctor of this monastery used to account for an espenditure, chiefly for hospitality, charity, and buildings, of $\& 1051$ a year; the regular receipts being $\{6424 \mathrm{~s}$; ; the eity of London benevolently making up the deficiency. Not regarding the dearth of the season, neither the increase of their number, nor yet their approaching ruin, the monks (and Ffyloll pleads it as a reason for crushing them) "would have, and hath, that same fare continued that was then used, and monld have plenty of bread, and ale, and fish, given to strangers in the buttery, and at the buttery door; and as large distributions of bread and ale to all their servants, and to vagabonds (travellers) at the gate, as was then used." The poor, in reality, depended on the charity (never grudging) of the religious houses; but, of course, "the roast beef of old England" was a thing unknown. Barley bread, bean bread, and stock fish, formed the ordinary, or rather better sort of fare, washed down with bad ale, in which that "poisonous weed," hops, had neither part nor parcel.

"The roast beef of old England!" alas, alas! how few who use these words dream of the real condition of feudal England, from the time of the Normail couquest to that of the bishop-unfrocking Elizabeth, and even still later. The expression is accepted as an intimation that roast sirloius were as "plentiful as blackberries;" and to this belief history adds something, by throwing a mantle of oblivion over the frequent famines, which, bringing plagues in their train, so often, in the "olden time," desolated the towns and villages-" haply villages" -of "merry Emyland." How vast is the distance in fare, clothing, and all the luxuries, nay, common needs of life, between a nobleman and a humble peasant, or serf! Let us, en passant, revert to a nobleman's household book (Earl of Northumberland) in the days of Henry the Eighth, from the statements of which we may easily judge as to the consumption of roast beef liy the communalty :-

"One humlred and nine fat beeves are to be 
bought at Allhallow tide, at thirtcen shillings and fourpence a-piece; and twenty-four lean beeves are to be bought, at St. Helen's, at eight shillings a-piece ; these latter are to be put into the pastures to feed, and to serve from Midsummer to Mlichnelmas; which is, consequently, the only time the family (consisting of 223 persons) eats fresh beef. During all the rest of the year they live on salted meat. One hundred and sixty gallons of mustard are allowed in a year, which imdeed seems requisite for the salt heef. Six hundred and twenty sheep are allowed, at twenty pence a-piece, and these seem, also, to be all eat salted, except between Lammas and Michaelmas. Only twenty-five hogs are allowed, at two shillings a-piece; twenty-eight reals (calves), at twenty-pence, and forty lambs, at tenpence or a shilling. These seem to be reserved for my lord's table, or that of the upper servants, called the knight's table. The other servants, as they eat salted meat almost through the whole year, and with few or no vegetables, had a very bad and unhealthy diet, so that there camnot be any thing more erroneous than the magnificent ideas formed of the Proast Beef of Old Englend. My Lord and lady have set on their table for breakfast, at seven o'clock in the morning, a quart of beer, as much wine, two pieces of salt fish, six red herrings, four white ones, or a dish of sprats ; in flesh days, half a chyne of mutton, or a chyne of beef, boiled. If we consider the maguificent and elegant manner in which the Venetian and other Italian noblemen then lived, with the progress made by the Jtalians in literature and the fine arts, we shall not wonder that they considered the ultra-montane nations as barbarous. The Flemish appear to have much excelled the English, and even the French." (Hume.)

Agriculture, at this period, was in a rude state; whole tracts, now under the plough, were then undrained hogs or morasses, or rough woodlands, concealing a thin and barbarous population. Take, as an example, the Weald of lient, formerly a wild, uncultivated forest; roads were few, and none good, and pack-horses were the ordinary means of carrying on internal commerce. The implements of husbandry were rude; no provision, or but little, was made for cattle during the winter months; nor were systematic attempts at elevating the breeds undertaken by the farmer. We are not, however, to suppose that no good breeds of cattle existed; England is essentially a corn-growing and a grazing country ; and her green pasture lands, her verdant meadows, and fertile vales, watered by streams or rivers, have ever nourished herds of kine; our humid climate and eloudy skies are favourable to the production of grasses, clothing the fields with verdure. As the woods disappeared, and the marshes were drained, the extent of pasturage increased ; the operations of farming legan to be conducted on a better
Jlan; the eattle began also to improve; from differences of situation and pasture, or from accidental or intentional intermixture, the old stocks soon assumed new characteristics, and ramified into breeds varying in ininor details, though still preserving their outstanding characters. Of these some were of great value from the abundance of milk, others from their tendency to fatten and keep in condition, even on inferior pasture grounds; and others from their strength and hardiness its working steers. Mixtures of these breeds produced others, and thus varieties were ever springing up, and coalescing, or running into each other by imperceptible gradations, till at length, somewhat after the middle of the last century, science and experience were called in to the lreeder's aid; and persevering patience ami great pecuniary outlay were ultimately productive of the most beneficial results.

From the earliest times, as far as we can learn, two or three distinct stocks of cattle appear to have existed in Great Britain. Of these one prevailed in Lancashire, and the adjacent counties, and particularly in the district of Craven, in Yorkshire. It was also spread over a great part of Ireland, as Tipperary, Limerick, Munster, \&c. This breed, now greatly moditied, was remarkable for the enormous length and bulk of the horns, for thickness of hide, and deep, curling hair. The general form was rather coarse, and the limbs big-boned; but the cows yielded milk remarkable for its riclness.

Another stock, which we may term original, is represented by the cattle of Deronshire, Herefordshire, Wales, and the Scottish Highlands. In this stock, varying in stature according to climate and pasturage, the horns are of moderate size, fine, well-turned and sharp-pointed; the limbs are clean, the figure compact, and the expression aniniated; the oxen fatten readily, and the cows rield rich milk, To this stock the wild cattle of Chillingham evidently belong, and perhaps represent it in its pristine purity.

Of the antiquity of these two very distinct races there is no doubt, and it is not improbable that the latter was from the earliest times more exclusively confined to the hilly and mountain districts, while the long-horned breed occupied the low flat lands, and the midland counties. Besides these two races we have an ancient stock of polled cattle (if indeed it is distinct from the middlehorned stock) represented by the Galloway and Angus ox, generally black, of which vast numbers are depasturated in Norfolk and Suffolk, where a polled breed, more or less directlr sprung from the Galloway, now prevails. To this stock the semi-wild cattle of Chatelherault Park, Lanarkshire, belonging to the Duke of Hamilton, appear to approximate. These feral cattle are larger 
and more robust than the Chillingham, the hody is dinn white, the inside of the ears, the muzzle and hoofs black instead of red, and the forepart of the leg from the knee downwards, is mottled more or less with black; the roof of the mouth and the tongue are black, or largely spotted with black. The cows, and also the bulls, are generally polled or horuless. As we have observed, the polled cattle of Galloway are black, and in these don eattle of Chatelherault Park, the black shows itself, as if to proclaim what was the original colour; the inside of the ears of the Chillingham wild cattle are red. With respect to the short-horned breed, or the Durham and Holderness stock, often called the Dutch or Holstein, we have already expressed an opinion that it is not of ancient British origin, but that it is from a race spread over the north western portion of the continent, and prevalent in Guelderland, Utrecht, Holland, \&c. There is, in fact, a tradition that the short-horned breed was introduced into Holderness about the middle or close of the seventeenth century.

The Alderuey race of cattle is confessedly of French origin, and numbers are still imported from Normandy. Though often kept in parks and pleasure grounds, few professed farmers, except in Hampshire, esteem these cattle; for though the milk is extremely rich, the cow yields but little, and consequently does not repay its keep.

The cattle of Great Britain, as the breeds are at present established, may be divided according to the foregoing remarks, into the following primary sections:-First, Long Horns; secondly, Middle Horss ; thirdly, Polled Cattle; and fourthly, Short Horns, exclusive of the Alderney. Of these the three first are of nntraceable antiquity in our islands, so that we may call them original, withont entering into the question relative to their primeval source; as we call the Red Men of America, or the natives of the South Sea Islands, aborigines, though it is evident that at some remote period their invading ancestors colonized the lands, and perhaps extirpated prior possessors.

The above sections do not, we are ready to admit, derive their nomenclature from points of zoological importance; indeed the horns alone, taken as a standard, would be iuadmissible; but it so happens, that in conjunction with certain forms of horn other characters are associated, and varions important qualities, of no ordinary interest to the farmer or breeder; consequently, in the terms "long-horu," or "short-horn," other points are included, these appellations being used for envenience, the farmer knoring well the whole that they imply.

Each of these sections is subdivided into various families or breeds, distinguished by minor but not unimportant peculiarities; and these breeds are not only numerous, but are continually inter- bleuding, improving, or deteriorating, according to the skill of the breeder, and the object at which he aims. Some breeds, by no means destitute of value, especially in dairy counties, are of such mingled origin, that like mongrels among dogs, it is difficult to assign them very definitely to any section: but these are undergoing perpetual modification.

Looking at the cattle of Great Britain as a whole, we may justly regard them as unequalled by any country in the world, whether we take into consideration quantity or quality of milk, quality of flesh, its fineness of grain, a tendency to the acquisition of fat, or points of symmetry, all, in fact, that the dairy farmer, be his produce butter or cheese, all that the grazier for the market, can wish for ; the cattle of our islands are pre-eminent. Nor is this to be wondered at-climate, production, enterprise, skill, and money combine their agencies. There is, besides, a spirit of emulation, and agricultural societies, under the patronage of the nobles, themselves competitors for the prize, tend to the advancement of the great object-the improvement of domestic cattle. Nor must we here overlook the aumual exhibition of prize-cattle in London, by the Smithfield Cattle Club, an exhibition interestiug not only to those immediately engaged in agricultural pursuits, but to those who appreciate the national importance of improvements in every branch of the Res nustica. Here are to be seen the result of exertions, carried on principally during the last eighty or ninety years, with a view to unite and bring to perfection the most desirable points in the various breeds of our domestic cattle. Nor are agricultural implements and machinery of the latest and most improved construction overlooked. Specimens of artificial manures, soils of various districts differing from each other in geological formation, and the results of analytic chemistry both as respects soil and artificial manures, are there to be examined. Rare, or new roots, plants, or seeds, adapted for our climate, and promising to benefit by their introduction, together with vegetables grown to peculiar perfection by some new mode of culture, are also exhibited. The atility of such an exhibition, independent of the emulation it produces, is very evident. "In spite of the advances which agriculture has made during the present century, how slowly do improvements extend beyond the intelligent circle, in which they were first adopted! And it is one of the great advantages of institutions, such as the Smithfield Club, to spread them more rapidly and widely, by drawing the agriculturist from the secluded scenes in which he carries on his occupations, and bringing them before him in the manner best calculated to demonstrate their practical value."

With respect to the prize oxen aud sheep, it must be acknowledged that they are fattened often 
to a distressing degree; and many have asserted that the stimulus of prizes for bringing an animal into a state of unnecessary fatuess is a work of supererogation; and if this were all, so it would be; but breed, contour, age, the nature of the diet, its quantity, and the time of fattening, are all points to be taken into consideration; lience this over.accumulation of fat is regarded simply in the light of a test by which the properties of such and such breeds are tried. A piece of artillery is tried by a charge of powder far greater than is ever required for actual service; in like manner an $o x$ is fattened for exhibition beyond a useful marketalle condition, simply by way of showing the capacity of the breed for acquiring, at the least expense of food, and at the earliest age, such a condition as the public demand really renders necessary.

Having so far sketched a rapid outline of the ox of our islands in former times, when agriculture was practised rudely, and little winter fodder, or none, stored up, - of the old stocks, time-immemorial occupants of their peculiar districts, and of the recent improvements which have tended to raise our horned cattle generally to so high a degree of excellence, it will be necessary before entering more circumstantially into the characters of our primcipal breeds, and their points of distinction, to give a list of the technical names applied by the farmer to neat cattle of different ages, and of different sex.
The general name of the male of neat cattle* is Bull: during the time be sucks lie is called a bull-calf, until turued a year old; he is then called a stirk, or yearling bull; and then, in order, a two, three, or four year old bull, until six, he is then said to be aged. When emasculated he is called an ox-calf, or stot-calf, until one year old, when he takes the name of stirk, stot, or yearling; on the completion of his second year he is called a two years old steer, and in some comnties a twinter, then a three years old steer, and at four, an ox, or a bullock, which latter names are continned. We may here remark that the term ox is often used as a general or common appellation for neat cattle, in a specific sense; as the British $o x$, the Indian ox, and that irrespective of sex. The female is termed Cow ; but while sncking the mother, a cow-calf; at the age of a year she is called a yearling quey, in another year a heifer or twinter, then a three years old quey or heifer, and at four years old a cow. These appear to be the terms in general use, but others, to be regarded perbaps as provincialisms, may prevail in some districts.

Let us now proceed with the breeds of British cattle, the subject demauds a separate chapter.

- "Neat," from neaz Saxon, (not French " net" clean, neat,) all kind of beeves as ox, cow, heifer, \&c. Nearhynd, neathered, a keeper of beeves.

\section{CHAPTER V.}

$W_{E}$ have said that one of the stocks of British cattle, to which we may apply the term original, was a long-horned variety, the stronghold of which was Craven, in the West Riding of Yorkshire and Lancashire, whence it direrged over the midland counties. This breed prevailed also in rarious parts of Ireland; while a light, active, middlehorned breed, also claiming to be called original, but now much crossed with the Deroushire and Hereford breeds, occupied the more hilly and mountain districts. Long-borned cattle are not so often to be seen pure as formerly. Within our own remembrance, however, they were the ordinary cattle of the midland counties; the huge horns generally swept in a curre downwards, and often met before the muzzle in such a manner, that the points were obliged to be sawed off in order that the animal might be at liberty to feed. In other instances the horns took a literal direction, first sweeping horizontally outwards, and then curving gently forwards; accasionally the horns seemed somewhat distorted, and the tournure of each did not precisely correspond.
These long-horned Craren, or Lancashire, cattle were large, loug-bodied, and coarse in the bone; but they had good points: the hide was thick and mellow; and thongh the milk was not abundant it ras extremely rich.

The great improver of this breed was Mr. Balsewell, who founded what was termed the new Leicester breed of long-horns; but, before his time, other spirited individuals had made successful attempts; and among them may be mentioned Sir Thomas Gresley, whose seat, Drakelow House, was on the borders of the Trent, near Burton. Sir Thomas Gresley's stock was celebrated in its day; and, in or abont the year 1720, a small farmer at Linton, in Derbyshire, but close to the borders of Leicestershire, commencing upon this stock, pushed its improvement still further; till unfortunately, some disease broke out, which, baffling all remedies, carried off the greater part of his cattle and put a stop to his enterprise.

The Gresley stock was the origin also of the Cauley breed of Mr. Webster, who crossed it with 
a pure Lancashire strain; and a bull termed/reasonably short space of time. It was on the Bloxedge, of this intermixture, was of noted ce- Canley stock, viz., two heifers and a long-horn lebrity.

The Canley lreed spread, and maintained its reputation, and became incorporated with the stocks possessed by other breeders, who saw the importance of improvement in those poiuts which concern the grazier, viz.,-utility of form, and a propeusity to fattening at an early age, and in a

bull, of superior qualities, that Mr. Bakewell, of Dishley, began lis important experiments; and from them arose the new Leicester, or Dishley loug-horns. His aim was not so much improvement for the dairy, or the small farmer, to whom milk was the primary object, as for the grazier; cousequently, smallness of bone, rotundity of cou-

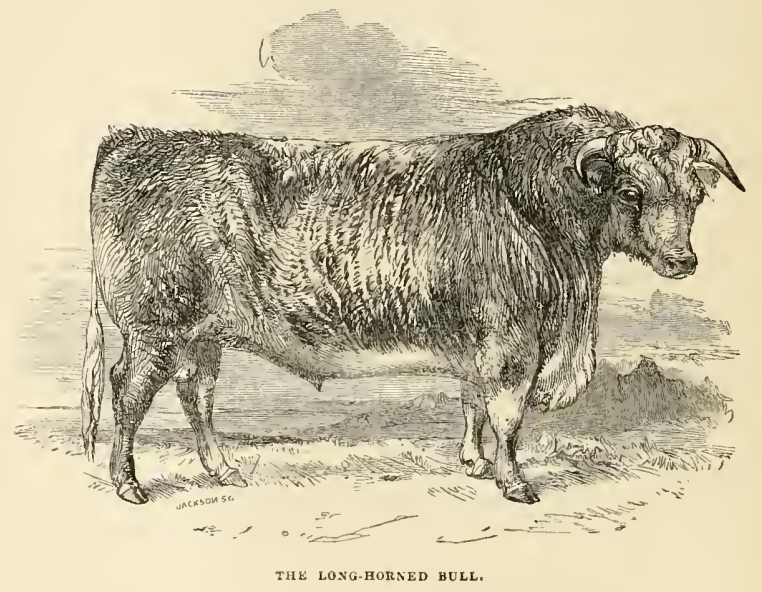

tour, and a disposition to the laying on of fat, where its accumulation was most advantageous, mere his great aim; and he fully succeeded. It is remarkable, that one of the results of this high breeding manifested itself in the contour and size of the horns, which, first sweeping outwards and downwards, shot forward at the points. In the bulls, their length seldom exceeded two feet; but in oxen and cows, they measured from two and a half to three and a haif feet in length.

With respect to the general principles of breeding pursued by $\mathrm{Mr}$. Bakewell, aud applicable to every description of cattle, we shall not here repeat what we have already stated. Certain it is that the practice of this theory is found to be ever successful when judiciously carried out; for "like produces like." A bull, the produce of the Canley heifer, Comely and the Westmoreland bull, was called Twopenny, and was in high repute; but a bull termed $D$, still more valuable, was the grandson of Twopenny, and horn of an immediate relative. And here, if we may venture to judge, Mr. Bakewell was in fault; he bred two mnch in and in, aud thereby prepared the first steps of a future degeneracy, which, we have every reason to believe, soon manifested itself. For, although much may be attributed to the subseqnent triumpls of the improved short-horns, and its intermixture with offsets from the Dishley stock; yet certain it is that the Leicester, or improved Dishley, breed have left little more than a name behind them.

We must not suppose, however, that $\mathrm{Mr}$. Bakewell was the only man of his day (about 1750.60) who bent his mind to the improvement of the long-horns. There were other labourers in the field; but all appear to have taken the Canley breeds as the foundation upon which to work: for example, the bull Shakspere, the property of Mr. Fowler, of Rollwright, Oxfordshire, was the son of D, by a daughter of Twopenny, and was perhaps the most valuable bull, of the breed, that ever existed. He approached perfection as nearly as possible; and from him, aud heifers of the same stock, Mr. Fowler raised a breed of long-horns of extraordinary value. For example, in 1791, at a sale, which it was his custom to hold at certain intervals, five bulls and six cows returned the sum of $£ 2,204$. One bull, Garrick, sold for $£ 250$, aged five years; another, Sultan, two years old, 2230 ; another, Washington, $£ 215$; and not a bull for 
less than $£ 15 \%$. Of cows, the first, Brindled Beauty, by Shakspere, sold for $\{: 273$; and the lowest for $\$ 120$, In 1789, MIr. Fowler refused 500 guineas for ten bull calves.

Direct from the Canley stock, and MIr. Fowler's bull Shakspere, was raised a splendid breed of long-horns, by Mr. Princep, of Croxall, in Derbyshire, which was highly esteemed, as were those of Mr. Paget, of Ibstock, in Leicestershire, Mr.
Mundy, of Derby, and several other successful breeders, whose labours we need not here follow out.

While the successful cultivation of the longhorns was thus carried on in England, we inust not silppose that the cognate breed of Ireland was neglected. But there was, referable to this lreed, a singular variety, prevailing more especially in the north of Ireland, of rude figure, with large benes and hcavy dewlip, which, either, fros some inhe-

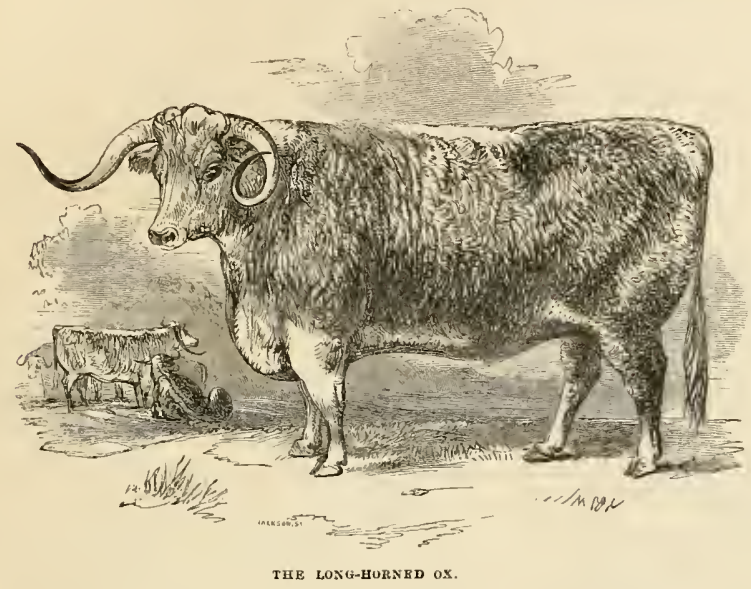

rent idiosyncracy, or, more probably, from the obstinate prejudices or indolence of the snall farmers, never received improvement; while on the contrary, in other districts, first by the introduction of the old Lancashire stock, and subsequently by the accession of bulls of the new Leicester breed, and others of the improved Canley strain, the long-horned cattle began to rise in quality, and lost their heavy slouching aspect, and their disproportion of bone to flesh. Yet it was found that, in proportion as these long-horns improved for the purposes of the grazier, and acquired, with better contour, a tendency to fatten even on ordinary diet, the quantity of milk yielded by the cows became diminished, to the detriment of the cottier or small farmer, who could not pretend to rear beasts for the slaughter market, and who depended upon his milk and its products. It is true that, in the grazing grounds, or parks, of the gentry and nobles, who aimed at a raluable stock, in the sense of the feeder, the improvement of the breed was worth every effort; nor were efforts spared. We need not enumerate the spirited and enterprising individuals who were foremost in this work, nor detail the success which cromned their exertions. As a proof, however, of this success we may state that, in 1802 , ten bullocks, aged six years, were sold, at the fair of Ballymahoe, for 400 guineas, and ten four years old heifers or cows for 300 guineas. These cattle were bred by Lord Oxmantown (afterwards Earl of Rosse), and rere, in all respects, models of their kind. The effects. of these improvements seem to linger still in Ire land, whence the English grazing-grounds and markets derive most of the long-horned cattle which are now to be seen; but all do not carry the marks of this improvement, many being coarse, bons beasts, which will do little credit to the best pasturage.

Within the last twenty years, the short-homs have been introduced into Ireland, and a half-bred stock has been the result; this stock is lards, though less so than the old breed of long-horns, which, especially among the small farmers, still maintains its ground.

Besides the long-horned, and half long-horned breeds, there is, in lreland, a very distinct race of middled-horned cattle, which, though very generally spread, seems to be more prevalent in the mountain districts. This breed, which is active, wild and very lardy, and when removed from the lills 
to good pasture-land rapidly fattens, is evidently allied to the Welsh or Highland cattle, and will claim further notice when we come to the middlehorned races of our islands.

It was in the course of a few rears, comparatively speaking, that the long-horned breed attained to its perfection, and in as short a time it experienced a decline. The Dishley loug-horns have run through their allotted date; perhaps they were bred too much in and in, a circumstance always tending to ultimate deterioration; perhaps after the days of those who brought the long-horns to perfection, others came into the field with less skill, and, in attempting to improve, reversed the good that had been done: but more probably it is that the breed gave way before the rising dynasty of the improved short-horns, which now began to acquire the ascendancy. Be this as it may, certain it is that the Dishley breed is extinct. Parely, indeed, in Lancashire, Leicestershire, or Westmoreland, are pure long-horned cattle to be seen; and it is the same in other counties where they once prevailed. Not that the traces of the improved longhorns are altogether effaced; iu their palmy days they elevated the races of the midland counties, and though these, generally speaking, are now so mixed as to be of no definite breed, yet they were originally long-horns, and more or less influenced by the Dishley; they lost, to a greater or less degree, their original coarseness, and became permanently ameliorated.

In the midland counties, at the present time, either the short-horned breed prevails, or a crossed breed between this and the long-horns, the degrees of affinity to either side varying almost infinitely. We say nothing here of the cattle introduced from Scotland, Wales, Irelaud, \&c., for the express purpose of fattening in parks and grazing grounds, for the markets, we allude to the native cattle of the district, the cattle of the farmer or dairyman.

In Lancashire and Westmoreland, as we have said, few pure long-horned cattle are to be met with; in some parts half-long-horned beasts may be seen, but mostly short-horns. In the former county, indeed, many Irish cattle are fed, and among these a fair proportion of long-horus occur; and some farmers, both in the northern and southem portion still prefer the long-horns for the dairy ; but erosses are the most prevalent

The cattle of Derbyshire were originally longhorns, of a coarse breed, indifferent for the feeder, but excellent for the dairy-farmer. Within the last few years this breed has become greatly modified, and few of the old unimproved stock remain. During a recent visit to this county me occasionally saw cattle retaining a proportion of the original characters,- - viz., a thick, heavy head, with spreading and irregularly-turned horns, an angular figure, and a thick hide covered with long hair; but these were by no means general; a crossed breed, in which the strain of the short horns was decided, was what we mostly observed; and not unfrequently pure cattle of this race, identical with those of Yorkshire.

For a long series of years Cheshire has been renowned as a dairy county, cheese being its noted product, and the cattle have been celebrated as milkers. They were originally long-horns of various crosses, and of little beauty, being angular and ill-formed, with thin thighs, a wide loin, and a light fore-quarter; but the udder was large, and its veins very apparent, the belly deep, with prominent milk-reins. Some of these lean angular cows have been known to yield twenty-four quarts of milk per day, but only for a short time; the average is eight or ten quarts, of which four quarts returu a pound of cheese, while it takes twelve or fourteen quarts for the production of a pound of butter. It is estimated that there are 100,000 cows in Cheshire, each of which gives two-and-a-half hundred weight of cheese in the course of the year, making an annual total of 1,250 tons.

Recently improvements on this breed have been attempted, and many short-horns introduced; but, after all, a pure race is not much sought after, quantity and quality of milk being the great desideratum. Indeed it is not clear that a total alteration of the old breed, inured, as it is, to the climate and pasturage, and modified, by a combination of circumstances, in such a manner as to meet the riews of the dairy-farmer, would lead to any benefit; nor that the quantity and quality of the cheese, yielded by the short-horned breed, would equal that obtained from the old stock. Nay, there are comllaints, as it is, that the cheese of Cheshire is not quite what it used to be. Artificial grasses, cabbages, and Swedish turnips, are greatly cultivated in Cheshire, as winter-fodder, for the cattle, which, during the colder months, are housed in sheds, or kept in sheltered yards, and supplied with straw and hay as their ordinary food. If, however, the weather is not very severe, they are generally turned out daily into the adjacent fields; from which, having picked up but little, they gladly return to their stall, and feed lieartily. Previously to calving, in February or March, the cows are dried, and fed with straw and hay, and, after calving, with crushed oats, brewers' grains (where accessible), and green fodder. When the grass is ready, they are turned out into the meadows; and, if the winter management has been judicious, and not too much dry food, as straw, given, they soon yield milk in abundance. The calves are generally suffered to subsist exclusively on the mother's milk for three weeks; then they are weaned, and fed upon warm whey, buttermilk, skimmed milk, oatmeal gruel, and gradually introduced to vegetable aliment. During the first winter they are fed largely on hay. 
While speaking of the cattle of Cheshire, we must not forget to observe, that a small herd of wild white cattle, like those at Chillingham, is preserved in the Park at Lyme Hall. These cattle are very shy, frequenting the higher grounds in summer, and the woods in winter: during the latter season they are supplied by the keepers with hay.

The original cattle of Staffordshire were of the long-horned stock, afterwards greatly improved by the Dishley breed; but these have given place to the Yorkshire short-horns, and are seldom to be seen, except perhaps towards the borders of Derbyshire, and even there they are considerably modified. The prevailing breed is the result of crossings of the short-horned stock and the old long-horns. Middle-horned Devon cattle have been introduced upon the farms of some agriculturalists of note, and polled Galloways have also attracted attention. In many large parks and grazing grounds, as those of Trentham, numbers of black Scotch cattle are fattened; and the narkets of the principal towns are well supplied with beef of first-rate quality. In those parts of Staffordshire adjacent to Derbyshire and to Cheshire, excellent cheese is prepared; but little, we believe, comes to the London market. It is the practice, in these districts, to kill the calves (those excepted which are intended to be reared) at a very early age; consequently the veal is usually small and inferior. This observation applies also to Cheshire and Derbyshire; on the other hand, the veal in the London markets is often too old. The differeuce between the veal in London, and that in the towns of Staffordshire, and the counties immediately adjacent, is very striking. The London markets are chiefly supplied from Essex, where the calves bought by the farmers, at ten or fourteen days old, are fed for twelve or fourteen weeks before being sent to the London butchers.

The same changes, with respect to the cattle, have taken place in Shropshire as in Staffordshire. The old long-horn, which formerly prevailed there, was a coarse but hardy beast, generally streaked with a broad line of white along the back; and, though not disposed to fatten, was well fitted for the dairy. Few of these old cattle are now to be seen: the Holderness and the Hereford breeds have not only modified the stock, but, to a certain extent, usurped its place; while various brecds from Wales, small but good and hardy cattle, are cultivated by the smaller farmers.

Our remarks respecting the decline, or admixture of the long-horned stock, and the ascendancy of the Durham or Holderness breed, are applicable to Nottinghamshire, Northamptonshire, Cambridgeshire, Bedfordshire, \&c. In the latter county Holderness cattle, and other short-horns, prevail; but not to the exclusion of Devons and Herefords, with Highland cattle, for fattening. In Buckinghamshire the short-horns have superseded the long-horns; and the same may be said of Berkshire and Wiltshire. In Hampshire the long-horns have disappeared; and, in some favourable tracts, short-horns are to be seen; but, in its southern portion, the Alderney and Suffolk breeds prevail; while, more inland, a mixed breed, between the Alderney and Suffolk, Hereford, or Devon, is cultivated. In the Isle of Wight, a small mixed breed, good for the pail, but worthless for the feeder, is mostly to be found.

In Oxfordshire the improved long-horns have ceased to retain their ground; a few of a mixed race still remain, but the introduction of the shorthorns, by Sir C. Willoughby and other spirited improvers of neat stock, has ended in the prevalence of the latter. Against their introduction oljections were raised at the time by breeders, who feared the pasturage not adapted to their constitution; their fears, however, proved utterly groundless.

It would appear, then, from this survey, that in a short time (if such is not the case at present) the long-horned stock of cattle, formerly the characteristic breed of our Midland counties, and brought during the last century to perfection by Mr. Webster, Mr. Bakewell, and other zealous cultivators of the ox, will disappear; it will merge into other breeds; it will become, so to speak, absorbed and lost, and the old Craven or Lanca shire ox, as well as the improved Leicesters of Mr. Bakewell's cultivation, will be known only by description. They have succumbed before the superiority of the short-horns, cattle of larger bulk, of earlier maturity, and even superior aptitude to fatten, compared with the best improved longhorns, and also hardier than the latter.

The fact is, that the great improvers of the long-horns, while they aimed at, and succeeted in producing a grazier's-stock, rendered the cattle as a dairy-stock, inferior to the old coarse breed, and entailed upon it a delicacy of constitution which disqualified it for the ordinary farm. Mr. Culley says, speaking of the comparative merits of the long-horns and short-horus, in his day (1807), "When I say the long-horns excel the short-liorns in the quality of the beef, I mean that preference is only due to the particular variety of long-horns selected, improved, and recommended by that attentive breeder, Mr. Bakewell; for as to the long. horned breed in common, I am inclined to think their beef rather inferior than superior to that of the generality of short-horns; and there is little doubt but a breed of short-horned cattle might be selected, equal, if not superior, to eren that very kindly-fleshed sort of Mr. Bakewell's provided any able breeder, or body of breeders, wonld pay as much attention to these as Mr. Bakewell and his neighbours have done to the long-horns. 
But it has hitherto been the misfortune of the / breeder. We find this race in Sussex, in Hereshort-horned treeders to pursue the largest and fordshire, in Cornwall, Devonshire, Wales, and biggest boned ones for the best, without considering that those are the best that jay the most money for a given quantity of food." It would almost appear as if Mr. Culley had ventured to prophecy. His anticipations have been more than realized; and whether we regard milk or Hesh, the short-horns have risen pre-eminent. Breeders have stepped forward, and the result of their efforts is notorious.

But before we inrestigate the pretensions of the short-horus, an old, an aboriginal breed has a claim upon our notice; we mean that which is usually denominated the middle-horned, that of which the Chillingham wild ox may be taken as a type.

The Middle-Horned Stock. - This stock, once, perhaps, more extensively spread in our island than at present, still prevails in many districts, ramified into varieties according to the nature of the locality, and the improvements of the

\section{Scotland.*}

These cattle are distinguished by an air of vivacity, almost of wildness; the head is small, with a broad forebead, and graceful horns; the eye is large and animated, the body well built, the limbs vigorous, the setting of the tail high, the skin mellow and elastic, aud the hair curly; the colour is red, or black, often unbroken by white. With respect to milk, the cows yield rather a moderate quantity on an average, but it is of superior quality. There is a remarkable tendency to the acquirement of fat, which marbles the grain of the Hesh, rendering it of first-rate excellence. Every breed of this stock, however, is not of the same value, and different breeds have different points of superiority. In Cornwall, for example, a small black race of cattle formerly prevailed, and may still be found in the western moorlands. This breed is similar to some of those found in the Scottish Highlands; and from its hardiness

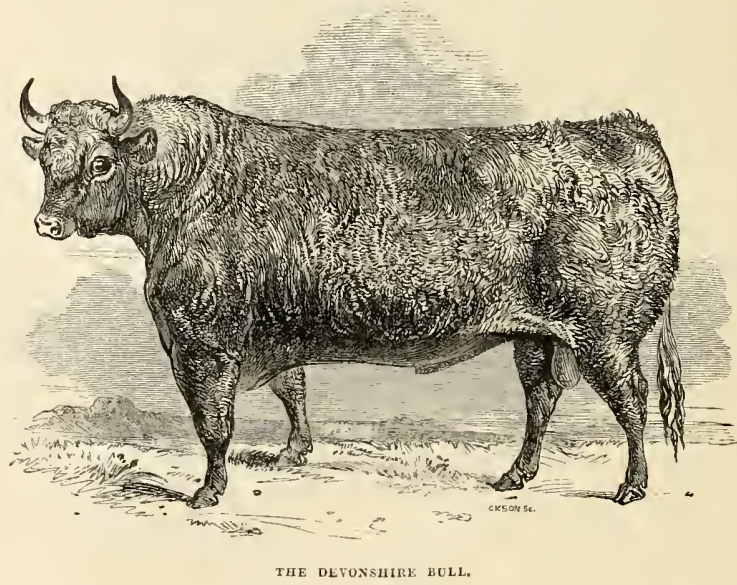

is well fitted for the locality it occupies: its hair is deep, close, aud curly, and the skin thick, two points of advantage in a climate of alteruate storms and calms, cold and heat. During the summer the commons and wild moorlands, supply a sulticiency of food ; and when in their winter sheds, chopped straw, furze, heath, and other coarse herbage, are sufficient. Hence these cattle are maintained at very little cost, and as they yield a fair quantity of milk, and when put upon moderately good fure, rapidly fatten, they will suit the small farmer, perhaps half-farmer, half-fisherman, in a bleak mountain-district, over which the ocean tempest is driven so frequently.

In more favourable districts the North Devon

* It wnuld seem as if those eattle had heen driven westwardly and nurthwardly from the other parts of our island, and found a permancnt asylum in the mountainous districts, though, us we have airealy said, we suspect them to have been aborigines of these districts, an old long-borned race oceupying the more lcvel and markhy parts. 
breed, one of high excellence, or a cross between the Deron and the old Cornish is cultivated, and sometimes a cross between the latter and the Alderney. The pure North Devon cattle, how. ever, are decidedly preferred; and though the short-horned Durham breed has been introduced, and crosses hetween it and the Devon occurred in the fertile parts, yet the pure Devous are better adapted for the country generally, and are also more easily obtained. Excellent butter and clouted cream are made in Cornwall, but no cheese, or lut little, and that very inferior.

There is perbaps, no county in which oxen are (or till very lately were) more useful for the plough, and the wain or cart, than in Cornwall. The plongh is very simple, with a straight mouldloard, and is drawn by four or six oxen; there is a peculiar wain of light construction, well adapted for the rough roads of this country, and nsually drawn by oxen; these are generally put into harness at three years old, and worked until the age of seven or eight; the strong roads render their shoeing necessary; but with thcir fect thus defended, they exhibit consideralle activity, and get through more work daily than night be expected. It must be acknowledged, that for lightness of step, spirit, and energy at the plough, the North Devon cattle are unequalled; and these are the most valued in Cornwall. No heavy breed is suited for a rugged, hilly country, nor indeed is any, unaccustomed to such a district, and, as it were, not duly acclimated. We are informed that far fewer oxen are now employed for labour in Cornwall than within even the last ten or fifteen years. This may be owing to the increasert demand for oxen in the grazing counties where they are fattened, viz., Somersetshire, \&.c., or to an improved system of husbandry, and better roads.

Many of the finest Devonshire uxen are fattened for the market in Somersetshire and Dorsetshire. The cattle of Devonshire are admirable; of these the purest are to be found in the northern portion of that county bordering the Bristol Channel; such at least is the opiniou of some, who regard

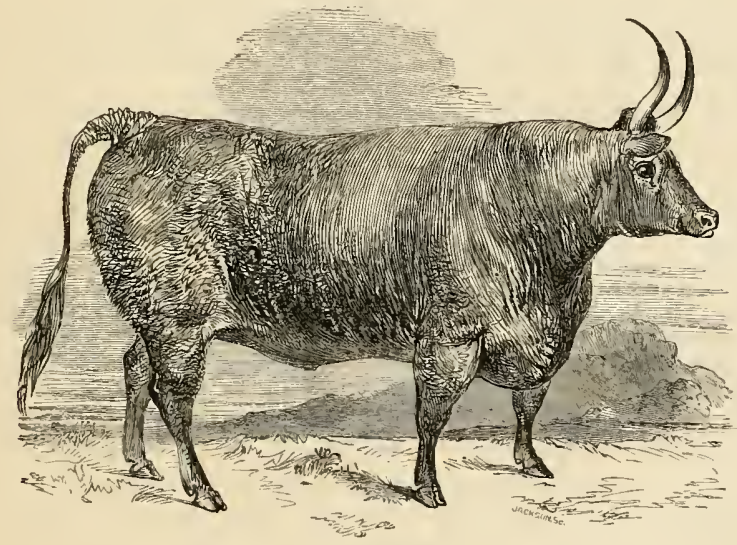

THE DEVONSHIRE OX.

the larger variety found in the South, as mixed with other breeds of inferior strain; but there is, perhaps, something of ultra-refinement in this view of the matter.

The Devonshire bull has the head small; the muzzle fine; the nostrils ample; the horns tapering, and of a waxy vellow; the eye large and clear; the neck thick, and arched above, with little dewlap; the chest is broad and deep: the breast prominent: the limbs fine-boned; the fore- arm muscular; the hips are high, and the hind quarters well filled up; the thighs are voluminous: the tail long, slender, set on high, and tufted at the extremity. The ox is taller, and more lightly made, with fine withers, and a slanting shoulder; the breast is prominent; the limbs are fine-boned, muscular, and straigbt, but rather long; the neck, too, is thin, and rather long. the head small, the muzzle fiue; the horns longer than in the bull, slender, and tapering. The whole form, indeed, 
indicates activity and freedom of action. The skin is moderate, and covered with mossy or curling hair; but occasionally it is smooth and glossy. The colour is nniversally red, chestnut, or bay, seldom varied with white: a paler space surrounds the eye, aud the muzzle is yellow.

The cow is far inferior to the bull in bulk and stature; and the latter is inferior to the ox. The cow is active, with a full eye, and animated expression; the muzzle is very fine, and the general contour light; the ribs, however, are well-arehed, giving greater internal room than might at first be supposed, a point essential to a good breeder. With respect to the qualities of the Devonshire cattle, they are, by many, esteemed of the highest order, while others underrate them. The oxen, as workers at the plough, on a light soil, are, from their docility and easy action, of first-rate order; but, on heavy soils, although they are willing to exert their strength, at a dead pull, to the utmost, their want of weight and muscular power is a disadvantage. In light farm-work their alertness is conspicuous; and two oxen will perform the labour of one horse. Oxen, however, are not used for labour universally throughont Devonshire, nor, where the practice still continues, is it so much in vogue as formerly; for the breeders obtain a remunerating price from the graziers for their oxen, at an earlier age than that at which it is nsual to break them in.

It is the general plan to take oxen into work at two years old : they are put to light labour, for the first year or two, and then to harder work, till the age of five or sis, when they are grazed or fed on hay, corn, oil-calie, or turnips, for the market; for which they are ready in about twelve months, or even earlier. Few oxen equal the Devons in the promptitude with which they fatten; they do not, indeed, attain to the weight of the larger breeds, but they lay on flesh rapidly, and with a small proportionate consumption of food; and the meat is of first-rate quality, being fine-grained and beautifully marbled.

As it regards the dairy, the North Deronsinire cow holds a moderate rank: some cows yield much more than others; and the milk is extremely rich, producing a more than ordinary proportion of cheese or butter. A good cow will give about three gallons of milk per day, for the first twenty weeks after calving; after this the milk decreases, and stops at the end of about nine months; so that the total annual amount will not be more than abont a gallon and a half per day: but then, the proportionate quantity of butter is considerable. A cow of mixed breed, between a North Devon and a Yorkshire bull, has been found to give twenty-four quarts of milk per day, for five months after calving; but the milk was less rich than that of the pure Devon breed, twelve quarts pro- ducing only one pound of butter; while eight quarts of the milk of the pure Devon cow returned the same quantity. This, and other mixed breeds, prevail about Exeter, and along the whole vale of the Exe. Many are excellent, being fine in the coat, horn, and bone, and short in the legs.

Pure North Devon cows are kept chiefly for breeding, and are superior as nurses, the calves thriving rapidly on their rich milk: a good cow will often fatteu two calves a year. When dried, at the proper age, the Devon cows rapidly acquire Hesh, and make fair grass-fed beef, in three or four months. The cows weigh from 30 to 40 st.; the oxen from 50 to 60 st., and upwards. Numbers of the latter are sent, from the northern parts of the country to the London market, and the markets of the principal towns in the west of England.

Devonshire is celebrated for a delicacy prepared from the milk, well-known as clouted cream. In order to obtain this, the milk is suffered to stand in a vessel for twenty-four hours; it is then placed over a stove or slow fire, and very gradnally heated to an almost simmering state, below the boiling point. When this is accomplished (the first bubble having appeared), the milk is removed from the fire, and allowed to stand for twenty-four hours more. At the end of this time the cream will have arisen to the surface, in a thick or clouted state, and is removed: in this state it is eaten as a luxury; but is often converted into butter, which is done by stirring it briskly with the hand, or a stick. The butter thus made, though more in quantity is not equal in quality to that procured from the cream which has risen slowly and spontaneously; and, in the largest and best dairies in the vale of Honiton, the cream is never clouted-except when intended for the table in that state.

With respect to the South Devon breed, it appears to be superior, for the dairy, to the pure North Devon; ; some cows being almost equal to the best short-horns in the quantity of milk : these cattle are profitable also to the grazier and the butcher; but their flesh is not equal, in fineness of grain or delicacy, to that of the North Devon breed. They closely resemble the Hereiords, and inleed, often have white faces.

To the east of Devonshire lie the counties of Dorsetshire and Somersetshire, noted for their agricultnral produce. Dorsetshire sends vasts quantities of butter to London; and cheese is made from the skimmed milk. This cheese is most esteemed when streaked with blue mould; but it is consumed almost exclusively in the county itself. The vale of Blackmoor is very rich, and affords pasturage to numbers of cattle: these are mostly of a mixed breed, in which the strain of the Devonshire prevails; but there are also numbers of South Devons. Crosses with the Durham 
race, and also with the Hereford, are not uncommon in Dorsetshire; the object being to obtain good dairy cows, irrespective of other qualities. In the more hilly districts; where the pasturage is scanty, a hardy race of half long-horned cattle prevails; these are generally brindled on the sides, with a white stripe down the back, and white on the under parts. This race, originally long-horued, is now crossed with the Devon, and is much improved: the cattle are hardy; they fatten quickly, and the cows are good milkers.

Except in some parts, oxen are not much used in husbandry; and where they are so the pure North Devons are preferred. After working for three or four years, the oxen are fatted for the markets; and many find their way to London.

Somersetshire is celebrated both for corn and the products of the dairy. In that part which borders upon Devonshire, and along the coast, the cattle are of the North Devon breed; and, having good pasturage, are nsually superior in size to the original stock. Those of the vale of Taunton are very fine, and well suited both for the grazier and the dairy-farmer. Less light than those of North Deron, the oxen have nearly as much activity, are equally docile, and considerably stronger: hence they are cfficient workers. In other parts of the county, while this breed is preferred for husbandry labour, and for aptitude to fatten, another is reared for the purposes of the dairy, principally of the Durham or short-horned stock, or a cross between this and others. The dairy-farmers seldom graze, except a few dried cows for the adjacent market; but in the centre of the county, from the Mendip Hills to Bridgewater on the west, and Chard on the south, grazing for the market is extensively carried on. The cattle are either of the Devon or Hereford strain; they are mostly bought in $\mathrm{Fe}$ bruary, and kept on hay till spring, when they are turned ont to graze, an acre or an acre and a half, according to the pasturage, being allowed to each ox. They are in condition by Michaelmas : many are kept till Christmas, hay being gradually given, in proportion as the grass fails, till it is required entirely. Great numbers of these cattle are sent to London. In the south-east portion dairy-farms prevail, and the business of cheese-making begins soon after Lady-day. Of the cheeses of Somersetshire the Bridgewater and the Cheddar are particularly celebrated. Of the latter little is made at the village so named; it is chiefly in the grazing lands round Glastonbury, and at other places, as Huntspill, South Brent, East Brent, \&c.

The dairy-farmers in Somersetshire usually sell off their cows for fattening at the age of about twelve years, as the milk then begins to deteriorate in quality, and it would be unprofitable to continue them for the pail. Vast numbers of calves are bred, and of these a great proportion voL. I. are fattened by hand from the pail, the calves being separated from their dams at the age of three or four days; those that are intended for rearing are fed principally on whey, and turned to grass in spring; but to the others, milk, whey, and occasionally linseed-meal are given.

Herefordshire possesses a peculiar breed of middle-horned cattle, allied to the Devons, but heavier and coarser, of a red colour, with white faces, and with white along the back and under parts. The true Herefords are shorter in the leg, heavier in the chine, and wider and rounder in the hips than the Devons; the head is also larger in proportion, and less fine, and the hide thicker, but mellow and supple. As milkers they are inferior to the Devons, but acquire an earlier maturity, and fatten both more rapidly and to a greater weight; consequently, the oxen are commonly sold off at the age of two or three years, in a state fit for the feeder. The graziers of Buckinghamshire, and other counties, purchase, for fattening, great numbers of these oxen at the rarious fairs, especially the Michaelmas fair at $\mathrm{He}$ reford; they are brought to the London markets, when ready, and meet an excellent sale. Few oxen are, in fact, fattened in Herefordshire; but only heifers and cows for lome consumption. Herefordshire is essentially a breeding county (not a dairy nor yet a feeding comty); and the great object is to supply the graziers with a valuable stock. The cows preferred are worthless as milkers; but such as experience has taught the breeder will produce the best offspring: they are rather small and light, but roomy; insomnch that they often bear bull-calves which soon attain to thrice their own weight. These cows, however, when dried, fatten rapidly, and become full-fleshed and rounded.

Formerly it was the custom to work the oxen for two or three years before sending them to market; but it is now found far more profitable to take advantage of their early maturity, and sell them without nnnecessary delay, thereby saving fodder, and also obviating the slow return of capital which the long-keeping of oxen necessarily entails.

As dairy-farming is not practised (at least as a general rule) in Herefordshire, the milk of the breeding cows is given almost all to the calres; nor is this plan to be condemned: the breeder's great aim is to ripen his beasts for the grazier, or at least for early fattening. A mingled system of breeding and dairy-farming would defeat its object and leal to loss, for neither department would be properly conducted.

Gloucestershire, elosely as it approximates to Herefordshire, is a dairy county, celebrated for its bitter and cheese, but especially the latter, of which large quantities are sent to the London market. 


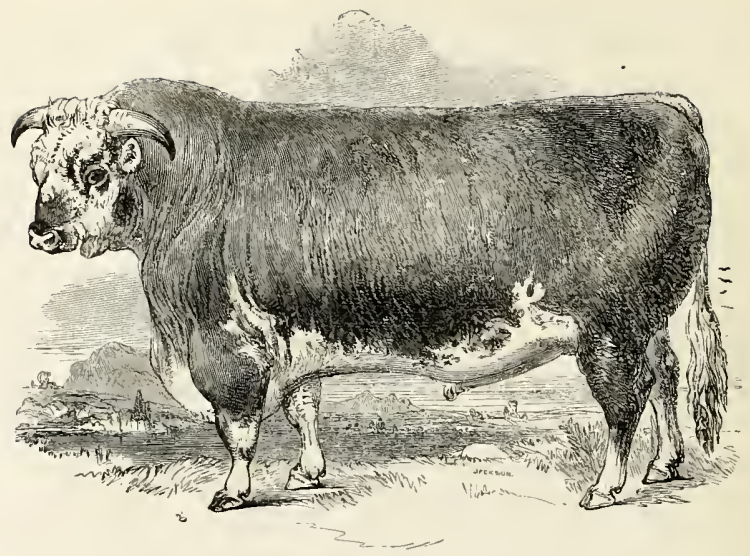

HERH FOND HULL,

The ofd Gluucester breed of cattle was rather small, of a reddish brown colour, with a streak of white ruming up the back from the base of the tail ; indifferent in figure, but well adapted for the dairy. This old middle-homed race is now seldom to be met with, at least pure; it has been crossed by the long-horns of Wiltshire; and this mixed breed, while it exhilited superiority of size, and a tendency to fatten, was little, if at all, deteriorated as to milking qualities. In the hilly or Cotswold districts, a mixed breed, of variable goodness, prevails. The Cotswold hills extend across the county from Chipping Campden to Batls, and are dirided into an upper and a lower range: the soil of the upper range is chiefly a calcareous sand, a few inches deep, resting on oolite, or, as it is commonly called, stonebrash. Cattle, but principally sheep, are kept on these hills, and even the poorest tracts are admirably adapted as pasturage for the latter; where these have well manured the land, it bears tolerable crops of oats and balley. In the lower hills, aud in the valleys between them, the soil is deeper, and affords fair pasturage to cattle, of which numbers are kept for the jurpose of the dairy, and good cheeses are made. Winter and spring vetches are sown in consideralle quantity, and supply both the cattle and sheep when green fodder is scarce. In general, however, the cattle are badly fed during the winter.

It is in the more fertile and lower portions of this county, such as the rale of Berkeley and the banks of the Severn and Ledden, that the richest land for the cultivation of crops and the pasturage of cattle is found. Here the old pastures are left untouched for the cows, that the cheese may retain its celebrity; and here, consequently, dairy-farming is most advantageously and extensively carried on. In the vale of Gloncestershire there are many raluable crosses of cattle; some between the old breed and the long-horns, others between this cross breed and Durham and Yorkshire short-horns. Milk, remarkable both for richness and the quantity yielded, is the dairy. man's olject; and for this he sacrifices all other properties of the cattle. Hereford and Devon cattle are also kept, but only for work and for fattening: of these many are fed in the neighbourhood of Gloucester.

In the management of the milch cattle of this fertile district, old rich pastures are greatly preferred for them; for it has beeu ascertained by experience that lands, however luxuriant, which have been much or recently mamured, produce an alteration in the quality of the milk, so as to render the cheese made from it very inferior. It is also found to be an excellent plau to remove the cattle frequently from one pasture to another; and, when the hay is off, to tun them upon the new after-grass of the meadows, the succuleut young herbage being conducive to ahundance of good milk.

The produce of a good cow should average from three and a half to four and a half hundred weight of cheese per annum, or from twelve to eighteen quarts of milk per day. Some first-rate cows, on rich pasturage, have been known to yield twenty-four quarts every day, at two milkings, for 


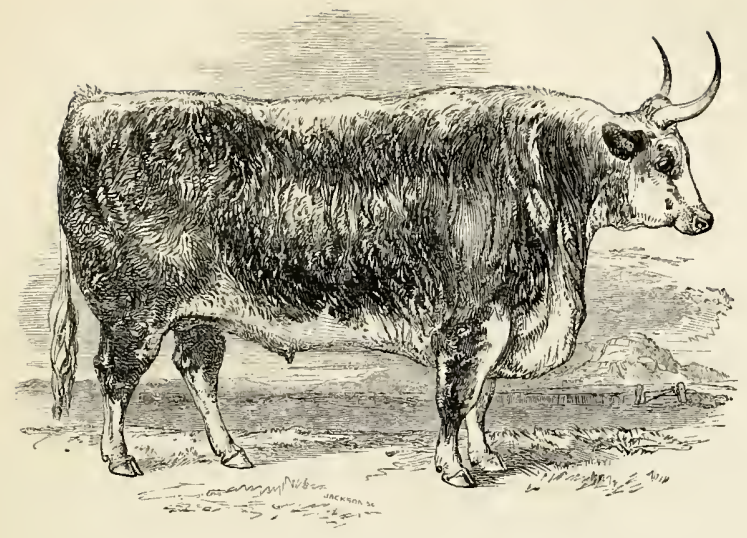

HEREFURD OX.

the space of seven months after calving; but this is an uncommon circumstance. After the seventh month the quantity of milk rapidly diminishes, till within six weeks previously to calving agnin, when the cow is no longer milked. Mr. Rudge, in his "Agricultural View of Gloncestershire," considers that the profit, on a dairy of twenty good cows, costing $£ 20$ each (in all $£ 400$ ), fed upon forty acres of land, will amount to about $£ 136$ per annum. He calculates the cost of the dairy utensils as under $\& 24$.

Two sorts of cheese are made, single and double Gloucester; the former is prepared from skimmed milk, and a superior sort from a mixture of skimmed and pure milk ; the double Gloucester from pure unskimmed milk only. Great quantities are made in the vale of Berkeley.

During winter the milch cows are kept in dry and sheltered situations, and supplied with hay, as are also the young store beasts; in the hilly districts, however, less attention is paid to them at this season, and they often suffer greatly. This is bad management anil false economy: the cows ought to be kept in fair condition, so as to benefit immediately by the spring pasturage. Sufficient shelter is often too much neglected: good sheds are essential as a protection against severe cold; nor are they less serviceable in the extreme heats of summer. Deficiency of food, moreover, deteriorates and stunts the growth of the roung stock, foiling the best endeavours for the improvement of the breed. This mismanagement is, however, chiefly confined to the hilly district, where the soil is umproductive, rendering winter fodder scarce; or where, from old custom, no efficient attempts are made to meet the exigency. More liberality would be far more profitable.

The prevalent breed of cattle in Sussex closely resembles that of North Devon; there are, however, certain points of difference: and, on the whole, the Sussex ox is a heavier and coarser animal than the Devon, but equally valuable for farmlabour, and for the fineness of the grain and the marbling of the flesh.

Sussex is not a great dairy county ; but it contains rich marsh-lands, well adapted for the pasturage of sheep and oxen, and docn-lands, where a thin soil overlays the chalk, and produces grasses arlmirably fitted for the peculiar breed of sheep, "the South Downs," which are so celebrated for the excellence of their flesh. In some parts of the downs, along the slopes of the hills and in the hollows, there is excellent arable land, on which oxen as well as horses are worked, the former being preferrell by many.

The centre of the county constitutes the wealden district, composed of various elays and sands, with suberdinate beds of limestone, grit, and shale. Here the land is poor; but, in some parts, tolerable crops of wheat, uats, and clover are obtained : there are extensive wools of fir and birch, and moorlands overgromu with heath and the bilberry plant

The centre of this county, as is evident from its present state, was once almost imponetrable from its dense forests, heaths, and morasses. Here, from remote times, the peculiar breed of ox still 
prevalent has existed. Its colow is of a uniform blood bay, or chestnut red; the horns are well-set and tapering; the head is small, the eye large, the throat clean, the neck thin; but the shoulders are thick and heavy, and the forelimbs rather coarse, - that is, less fine in the bone than in the Devon. The barrel is well formed and capacious; the back straight; the hips wide and well covered; the tail is thin and tufted at the extremity, and is set on nearly as high as in the Devon; the hide is mellow and fine; the coat is mostly sleek, but sometimes wavy.

The Sussex cow is kept principally for the sake of breeding: her milk, though excellent in quality, being small in quantity; hence her place in the dairy is supplied by various crossed breeds, which are found to answer best for the pail.

The cow is lighter in the shoulders than the $o x$, and her neck is thin; but altogether her contour is not so good: there is, moreover, a wildness in her aspect, and a restlessness in her temper, which render her not very manageable; yet, when dried, she fattens with extraordinary rapidity, and becomes well covered with flesh.

It is usual to rear all, or almost all, the calves in this comty ; the males for labouring oxen, the females for breeding, or for fatteriug at an early age. They are selilom kejt with the mother for more than ten or twelve weeks, when they are weaned, and fed on grass and hay. After losing her own calf, a good cow will suckle another, and sometimes even two, for the butcher.

Besides this pure Sussex breed, a larger and heavier breed is also to be seen, the result prola- bly of a cross with the Hereford, though no white face betrays the admixture. The oxen of this larger variety are slow, and less adapted for work than those of the lighter but still vigorous and powerful variety, which almost equal the horse as good and obedient workers. These oxen are generally broken in at three jears old, kept at labour until six, and then fattened for the butcher by seven. Some, however, work them longer; and oxen have been brought into excellent condition in their eleventh or twelfth rear, and sold to great advantage. This plan saves the necessity of so frequently breaking in joung oxen; but it is doubtful whether, as a general rule, aged beasts will fatten so kindly, or produce meat of a quality so good, as others in their prime.

Not only oxen but heifers are used for the cart and the plough; these are not in a condition to breed, and are treated like oxen, being, after three or four years' labour, fattened for the market.

The Sussex oxen find a ready sale in the London markets; their average weight is one hundred and twenty stone, but some have been known to exceed two hundred stone. In this county winter stall-feeling is greatly practised, and is attended with many advantages. Some farmers, however, prefer feeding the oxen loose in the yard, as they find the animals fatten more quickly-no doubt the geutle exercise increasing their appetite and digestive powers; but then, besides what they consume, they waste and trample down much provender, which, were the oxen tied in their stalls, would be saved: they are then more easily fed, and more manure can be preserved. Previously

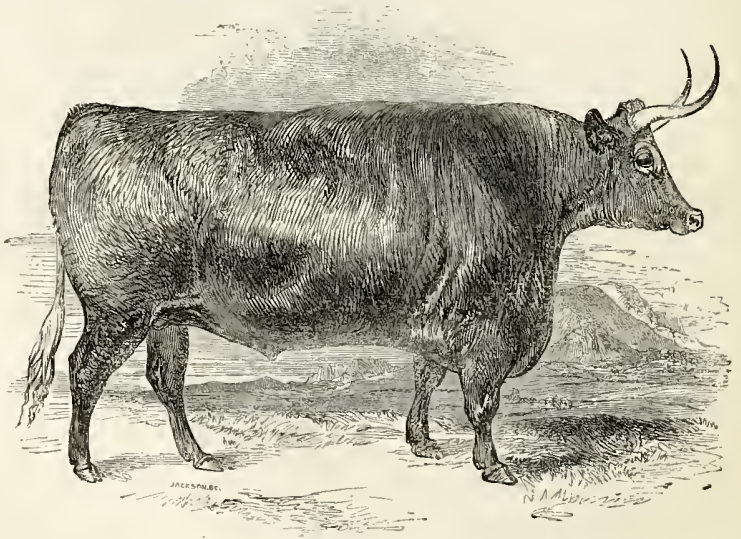


to the stall (or yard) feeding, the oxen intenterl for fattening are sent, after their spring labour at the plough is over, to feod during the summer in the marsh-lands, and on the atter-grass of the hay-meadows. On the approach of winter they are stalled every night; and when winter sets in, having been accustomed to it, are kept constantly tied up.

The Sussex cattle prevail in the adjacont parts of Surrey ; but short-horms, Devons, and various crosses are also to be met with. In the weald of Kent, also, Sussex cattle are used for the cart and plough, and grazed in the Romney marshes, where, however, sheep are more profitable. In the eastern parts of Kent few cattle, except for the produce of butter for home consumption, are kept, and these are of various and mingled breeds. Scotch and Welsh cattle are fed by some farmers in the strawyard during the winter, and fattened ly grazing in the marshes during the spring and summer. In some parts stall-feeding is also practised; but Fent cannot be called a cattle or a dairy county.

Following the middle-horned cattle from England to Wales, we may observe that severul breeds of this aboriginal race have exister from the earliest times, and still maintain their ground in the mountain-land of Cambria.

In form they much resemble the Devons, Herefords, and Sussex breed; but from the nature of their pasturage they are smaller, wilder, more hardy, and thrive on poorer fare: they are usually fine in the head and limbs, actire, and vigorous. The colour is black, dark brown, or red, sometimes contrasted with white. In the vales the cattle are larger, and often crossed with other lrecds, as those of Herefurdshire and Gloucestershire. In Ionmoutlishire Durhams, Irish, and Sortch eattle have been introduced, especially the Ayrshire breed, which is excellent for the dairy; lut the old breed, closcly allied to that of Gilamorganshire, maintains its ground, especially in the more northern parts and on the hills.

In Carmarthenshiro, Breckuockshire, Cardiganshire, and Pembrokeshire, an old and useful breed of black cattle still prevails. The Pembroke $0 \mathrm{x}$ is short in the limb, with moderately small bone; deep and round in the carcass, with rough short hair ; and a hide of moderate thickness, and pleasant to the touch. The head is moderately small, the aspect animated, and the horns are white. Some inlividuals have white about the face and under parts, and some are of a dark bromn. These cattle are small but hardy, and the oxen fatten well on indifferent land. The character of the meat is first-rate; the grain is fine and beautifully marbled, and its flavour excellent. The cows are fair milkers, and, from their hardiness, are very profitable to the small farmer or cottager. The oxen are as profitable to the grazier; they are good workers, strong and active, aul are ready at the age of four or tive years for the market, arriving early at maturity. Great numbers of these cattle are sent to the Iondon market. A similar but superior breed of cattle occupied Glamorganshire, generally of a red or a brown-red colour, often with white faces, and otherwise varied with white. The head was small, the aspect lively, the neck inclined to be arched,

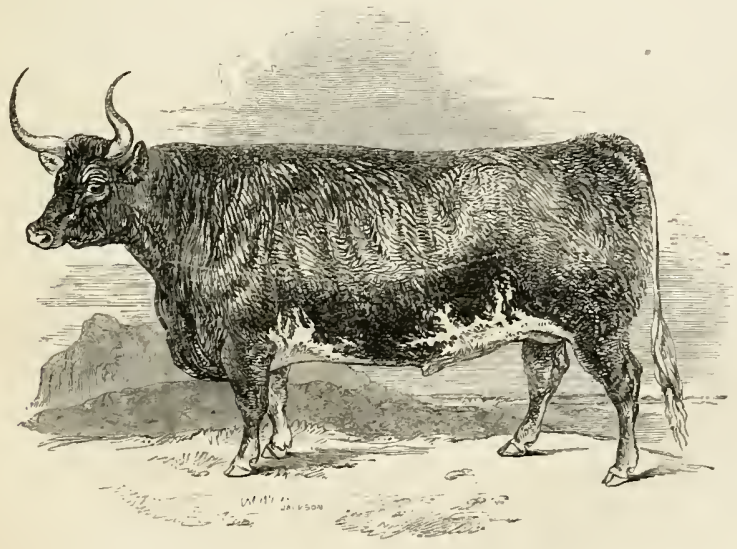




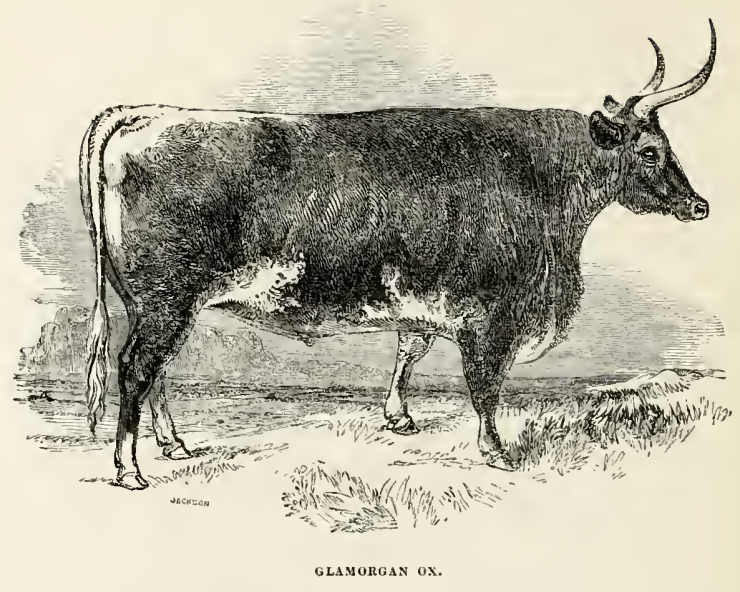

the carcass round and well tnrned, the back rising to the root of the tail, which was peculiarly elevated. The aptitude to fatten, the early maturity and docility of the oxen, and the fineness of the beef, rendered the Glamorgan lreed highly valnable; and no beasts sold at a higher proportionate rate in the London market. Fifty years ago they were purchased by the great feeders in Leicestershire, Warwickshire, Wiltshire, and other connties; and George the Third had a valuable and wellselected stock on his farm at Windsor, which was often recruited by fresh accessions from the native district. Glamorganshire was then a noted cattle district; but, during the war, the farmers neglected their cattle for the plough : they commenced raising corn, alternating the crops with tumips, and increasing the stock of the sheep. The result was that the cattle speedily degenerated, and were no longer sought after. Nor is it until recently that serious exertions have been made to restore the breed to its pristine excellence by intelligent and spirited individuals. Crosses with the Hereford were tried, and, at first, with some show of success; but soon, after one or two generations, the defects of the Glamorganshire strain reappeared. Crosses still more unlikely to succeed were tried; till at length one with the Ayrshire bull was attempted, and the result has been successful. This mixed breed is equal in hardiness to the old; the oxen are good workers and fatten readily; the beef is admirable; and the cows yield more milk than did those of the old stock. This improved breed is becoming extended, though it meets a rival in the pure Herefords, which are, ly some breeders, preferred, and by some still used to cross the Glamorgan. In the more billy districts the old Glamorgan breed suffered less deterioration than in the vales; lut it is there subject to poor and scanty food. In summer the pasturage is bare and meagre, and in winter the only resource is wretched hay from the peat lands; consequently the cattle are small and stunted; yet they prodnce excellent beef, and, on better land, become quickly fattened. Numbers are sent to the London market.

In Monmouthshire, now an English connty, the Glamorgan cattle prevailed, and still occupy the bills; in the vales Herefords are prevalent, and cows from the rich tracts of Gloncester, these being esteemed for their milk. In some parts Durham short-horns have been introduced, and also the Ayrshire breed: but, of late years, many Irish cattle, and those not excellent, have been imported; their low price tempting purchasers to the injury of the mative breeders.

Many cattle are bred in Radnorshire: the principal breed is a cross between the Pembroke and Hereford. The colour is red or brindled, with a white face. The characteristies of this cross are, a good figure, a moderate size, and a readiness to fatten when removed from the coarse mountain-pastures to the feeding districts of England. Droves of these cattle are sent to the pasture-lands of the comities of Oxford, Leicester, Northampton, \&c., whence they find their way to the London market. For the dairy the old unimproved breed is preferred, the strain of the Herefords tending 


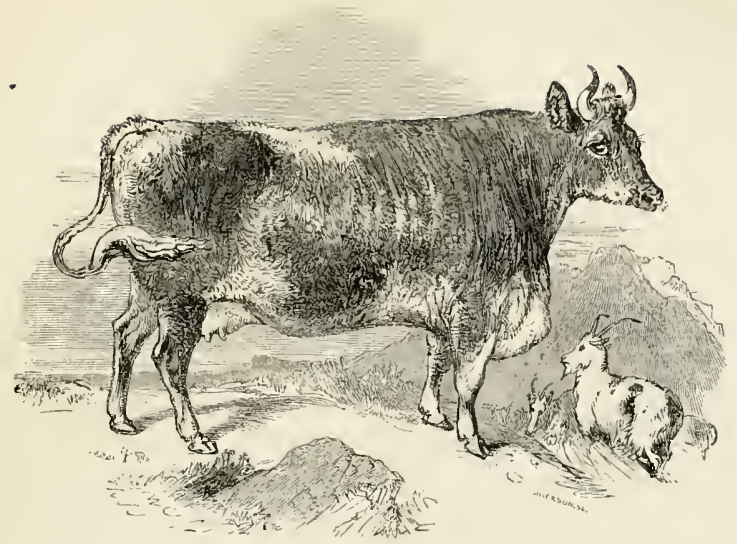

KERHY cow.

to the diminution of the quantity of the milk, while it improves size and aptitude to fatten.

In Montgomeryshire there are two varieties of cattle: those in the mountains are small, shortlegged, of a red colour, with dusky faces, indifferent in figure, but hardy, and tolerable milkers-yet not without an aptitude to fatten. Those in the rich vale of the Severn and its tribntaries are not unlike the Devons; of a brown colour, excepting a white line down the abdomen, with slender welltumed homs. The cows are tolerable milkers, aud the oxen fatten readily. In this part of the county excellent cheese is made. Many Herefords are grazed in the pasture-lands.

In Denbighshire and Flintshire the dairy is much attended to, and both butter and excellent cheese are produced. In the former county black cattle occupy the hills; but in the vales a mixed breed, in which the strain of the long-hom is evident, chiefly prevails. In Flintshire, indeed, the cattle, though generally excellent both for the dairy-farmer and the grazier, are of no definite breed: they are the results of varions crossings, many resembling the ordinary cattle of Cheshire.

In Merionethshire, Carnarvonshire, and the Isle of Anglesey, a race of black cattle, with rather longer horns than are usually seen in the true middle-horned races, is prevalent. This breed is decidedly in the highest perfection in Anglesey, and is doubtless of great antiquity. It is of small size, but astonishingly hardy and vigorous: the chest is deep and ample, with a large clewlap; the barrel is round, the haunches elevated and well spread, the shoulders rather heavy, the hide mellow, the hair black and curling; the forehead is flat, and the horns sweep boldly npwards. Vast numbers of these black cattle are bred in the island, and droves are sent into the pasture-lands of England for fattening. Formerly it was the custom to swim the droves across the straits of Menai, not without danger from the rapidity and foree of the current; but now the celebrated chain-bridge prevents the necessity of this practice. The number of black cattle annually exported from this island has been estimated at ten thousand; but, of course, this is liable to fluctuation, nor is it easy to obtain an accurate estimate.

Anglesey is a breeding district exclusively; it is adapted neither for the dairy nor for feeding. Spenking of the Isle of Anglesey, we are naturally led to the Isle of Man; for to both these Islands the ancients applied the title of Mona-a word of uncertain origin, but supposed to be derived from the ancient British word Mon, which means isolated. The cattle of the Isle of Man are generally small, and of Welsh or Scotch breeds, - riz., Angleseys, Kyloes, and Galloways, especially in the rude and hilly parts; but larger hreeds of mixed strains have been introduced upon better pasture-lauds.

A native middle-horned race of cattle exists every where in Ireland, and particularly in the hilly and mountain districts, where, from its hardiness, it thrives on indifferent pasturage, and contrives unshielded, during the winter months, to find support. There are several varieties of this stock, varying in minor details of size and contour; 
but all are of small size, active, and vigorons. Some are of a black colour, like the Anglesey cattle, or those of Argyleshire, with rouglt curly hair; others are brindled; others are mottled red and white; some, again, are black or brown, with white faces. All fatten rapidly when removed from a moorland pasturage to good feeding lands; and the cows often prove excellent milkers. Among these the Kerry breed is much esteemed; it is mottled, but in many points is not unlike the North Devons: the neck, however, is thicker, and the shoulder heavier; the stature also is inferior, and the limbs shorter. The Kerry cow is a serviceable beast; it yields, in proportion to its size, a fair quantity of excellent milk; and, when driecl, it quickly fattens, even unon inferior fare. In Connaught a larger and inproved lreed is found, still, however, presenting the same characters.

It must here be observed, that in many places, and especially where agricultural improvements have been carried on, the cattle have been crossed with various breeds from England and Scotland, insomuch that the original characters are either altogether lost, or considerably modified. This observation applies equally to the middle-horned races and to the old heavy long-horns. Durham short-horns, Herefords, North Devons, and Ayrshire cattle have been introduced by zealous cultivators, giving rise to valuable mixed breeds. These improvements are, of course, umdertaken exclusively by landed proprietors, or large farmers: the small farmer, who keeps a few cows only, or the peasant, who keeps one, are content with the old breeds. Yet however slowly, and however checked ly circumstances, the march of improvement, once legun, will, it is to be trusted, continue to adrance, and spread its benefits uuversally.

Little cheese is made in Ireland; but vast quantities of butter are exported, not only to Enggland but to other parts of Europe. In the dairy counties,-viz., Carlow, Cork, Kerry, Leitrim, Sligo, Waterford, and others, the principal object is the acquisition of good milch cattle; and, as milkers, some of the old breeds are excellent. Irrespective of butter, however. Ireland has a most important trade in cattle; besides supplying an immense quantity of beef to the navy and merchants' ressels, vast numbers, both of live cattle and slaughtered carcasses, are imported into England. We have no means now of correctly ascertaining the extent of this traftic; but formerly, while the law placed the traffic on the footing of a coasting trade, the official data were astonishing. In $1812,79,285$ head of oxen and cows, of the estimated value of $£ 439,128$ were imported into England, constituting the eighth part of the beef consumed. In 1824 the number of cattle amounted only to 62,393 , and, in 1825 , to 63,524 .

Within the last twenty years the facilities of transporting both cattle, carcasses, and salted meat, by means of steam-vessels, have been rapidly increased; consequently, cateris paribus, a proportionate increase of traffic, it may be concluded, has taken place; bnt we have no returns upon which to form a correct estimate. Certain it is that cattle may be shipped at an Irish seaport one day, and landed in England on the next; whereas, formerly, they were often detained, by

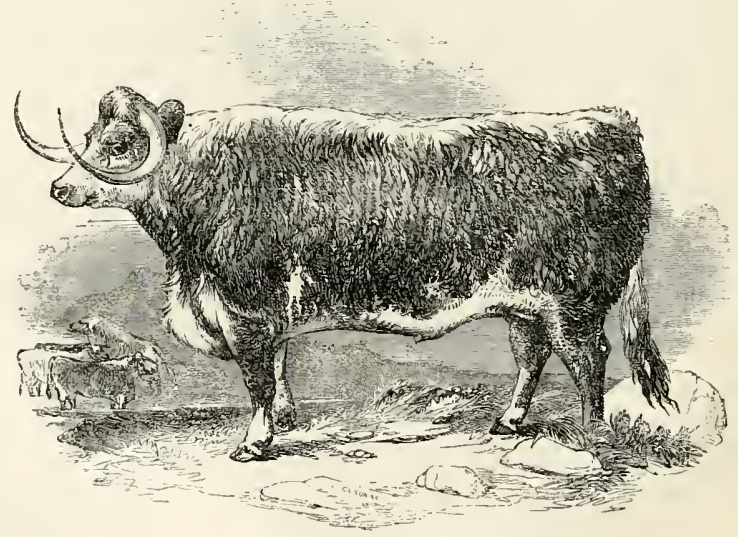

IRISH O 
stress of weather, for days at sea, the vessel being driven far out of her course, and the cattle all the time suffering for want of food and water.

Turning to Scotland, it may be observed that, from the most remote times, this land of heath and mountain bas been the nursery of an original breed or race of black cattle, of wild aspect, of beautiful symmetry, and though small, yet vigorous and hardy; patient of hunger and cold, and rapidly fattening on tolerable land. These cattle are middle-horned; the head is short, broad, and flat across the forehead, and adorned with elegantly-turned horns; the muzzle is fine, the eye bright and large, the body compact, and the limbs short, clean, and muscular. Several varieties may be noticed; and of these the restern race, occupying the Hebrides, or Westem Islands, and the adjacent parts of the mainland, is the most pure. Change the colour from black to white, and there is little difference between a beautiful kyloe from Arran, Islay, or the Isle of Skye, and one of the wild cattle of Chillingham: if we may venture an opinion, they display more nearly than any other breed the characters of the mountain cattle of our island when invaded by Casar. We say the mountain cattle, because we suspect that a larger and heavier long-horned race even then tenanted the swampy plains and low grounds of many portions of the country.

The kyloes, or black cattle of the western isles and highlands of Scotland, constitute the chief wealth of that portion of Caledonia. The Helurides alone, including Long Island (composed of of Lewis, Uist, and others), are calculated to con- tain a hundred and fifty or sixty thousand head of these cattle, of which perhaps thirty thousand annually cross the ferries for the mainland; whence great numbers find their way into the parks and pasture-lands of England, even to the southern coast.

It must not be supposed that the droves speedily reach their southern destination; on the contrary, their joumey is very protracted, and broken by long intervals. During the first winter they are allowed to graze in the pastures of the north; and then, as the spring advances, are driven farther sontl. As tbey proceed in this manner from stage to stage, their numbers diminish by sales, or by the respective lots reaching the parties to whom they were consigned: but those destined directly for the midland or southern counties, where the pasture-lands of some large landed proprietor await their reception, are months upon the road, unless indeed, as is often the case, they are sent by sea to some convenient port, and there landed.

In a well-bred kylve, the following characters are conspicuous: The head is small and short, with a fine and somewhat up-turned muzzle; the forehead is broad; the homs wide apart at their base, tapering, and of a waxen yellow; the neck is fine at its junction with the head, arched above, and abruptly descending to the breast, which is broad, full, and very prominent; the shoulders are deep and broad, and the chine is well filled, so as to leave no depression behind them; the limbs are short and muscular, with moderate bone ; the back is straight and broad; the ribs boldly arched, and

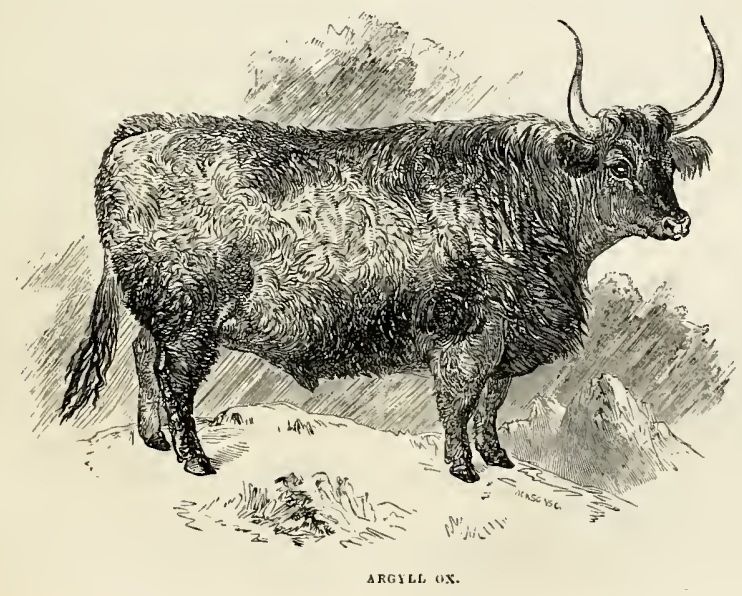


brought well up to the lips; the chest deep and voluminous; the tail high set, and largely tufted at the tip; the coat of hair thick and black: such is the bull. The ox differs in proportion. The cow is far more slightly built, and her general contour is more elongated. Although, as we have said, black is the ordinary or standard colour of the kyloe, many are of a dark reddish brown, and some of a pale or whitish dum.

Some little difference in size, as might be expected, exists among the kyloes of different localities. Those of the Isle of Skye, and of Lewis and Uist, are rather smaller than those of Islay, Jura, Argrleshire, Lochaber, or Inverness.

Multitudinous as are the cattle bred and reared in the Hebrides, few are fattened there; nor is much attention paid to the dairy; few farmers keeping more milch cows than will serve the wants of the family in milk, butter, and cheese.

The kyloe cow does not yield much milk, but that is of extraordinary richness. In North Uist and Tiree, however, where the herbage is generally good, both cheese and butter are made for the markets, each cow being estimated to yield twentytwo or twenty-four pounds of the latter, or from eighty to ninety pounds of the former during the summer.

Great attention is paid to the rearing of calves; and far more than under the old regime, to the treatment of the cattle, which formerly had little or no provision made for them during the winter, and were ill-fed even during the summer; the consequence of which was, that a large per centage died of starvation, and diseases attendant upon innutritious fare. The cows, it is true, were housed during the winter; often, indeed, they shared the rude shealing of the peasant; but this bettered their condition very little, for suffering and privation were the lot of the family.

In well-managed estallisliments at the present time, the cattle are treated upon principle. The calves, all of which are reared, are generally produced in February, March, and April; three times a day they are allowed to draw milk from the udders of their dams, which are afterwards emptied by the dairy-maid; when at the age of three or four months, the calves are sent only twice a day to their dams in the meadows, and are weaned in September, or early in October. During the winter they are housed, and fed on hay and turnips, as are also the breeding cows; the rest are kept in the pastures, and when these become bare, are supplied with coarse hay, and sometimes with turnips or potatoes.

In Argyleshire the kyloes are larger than in the Hebrides, and many of them are models of beauty-jictures of a noble semi-wild race; descendants of the old mountain-breed, which once roamed the wilds of Caledonia, and came "crush- ing the forest" to meet the fierce hunter: Well has the poet described the ancient wild bull :-

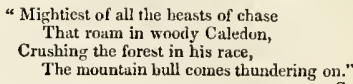

Scoтt.

Besides these kyloes, there are other breeds in Argyleshire; the Ayrshire cow is principally used for the dairy.

In the eastern counties of the Highlands, as A berdeenshire, Forfarshire, Bauffshire, Kincardineshire, \&c., various breeds of kyloes, more or less improved, prevail. Aberdeenshire is a great grazing land, and in this and the adjacent counties there are many spirited aud successful breeders. Great numbers of cattle from this part of Scotland are purchased by the English graziers for the London market. In the Shetland Islands, the Orkneys, and the northern counties of Scotland, a small, shaggy breed of cattle, evidently of the same stock as the kyloes of the western isles, is commonly to be seen. Stunted in growth by hard fare on the bleak moorlands, still these dwarfish cattle have much to recommend them. 'T'hey are fitted for their high nortliern locality ; their deep, rough curly coat defends them against the severities of the minter; they live where most other cattle would starve; in some favoured spots they even fatten; and if transported to some tolerable pasturage, become ripe for the butcher with incredible rapidity. But they do not thrive if taken too far south; they become enervated; they pine in the midst of plenty; and disappoint the hopes of the grazier. Within late years this breed of stots has been improved, by erossings with the kyloes of the western isles and the Argyleshire strain; and excellent cattle are sent to the south, to be fattened in congenial pastures.

In Ayrshire, Carrick, and the adjacent portion of the Lowlands, there is an admirable breed of milch cattle, independently of those that are grazed there for the butcher, which, from whatever source they originated, owe much to the care and selection of judicious breeders. At some period or other there has evidently been a cross of the Durham or Holderness, and perhaps also of the Alderney. This breed, which became established from the middle to the close of the eighteenth century, has found its way not only into England, but also into Ireland and Wales; recommended by the excellency of the cows as milkers, although they are under the middle size. It has been estimated that a good Ayrshire cow will yield, for two or three months after calving, five gallons of milk daily; for the next three months, three galloins daily; and a gallon and a half for the following three months. This milk is calculated to return about two humdred and fifty pounds of 


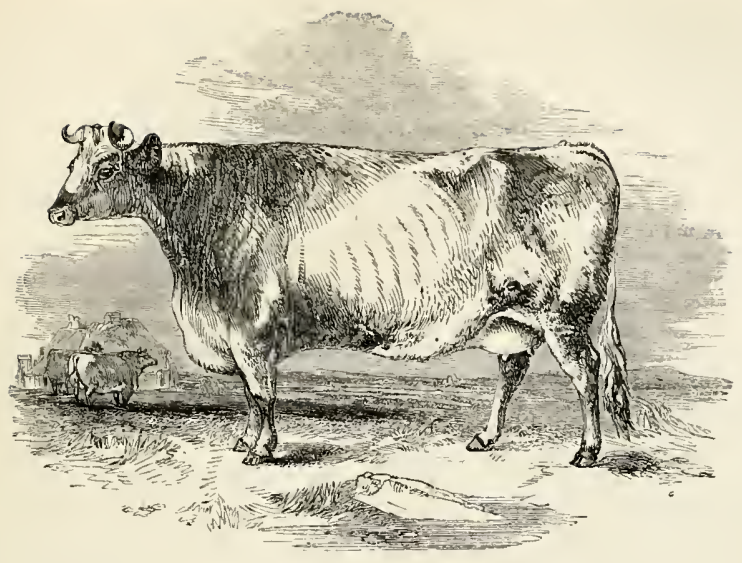

AYISHIRE COW

butter annually, or five hundred pounds of cheese. The foregoing estimate is, however, somewhat exaggerated; and, perhaps, during the best of the season, four or four and a half gallous of milk is the average product daily of a good cow, kept in fair condition. Every thirty-two gallous of mnskimmed milk will yield about twenty-four pounds of cheese, and ninety gallons, twenty-four pounds of butter. We are supposing a good farm, and a first-rate stock of Ayrshire cows; and, considering the size of the cattle, this return from each cow is very considerable. The mode in which the cows are treated by an enterprising and successful farmer, of Kirkum, is thus detailed :- He " keeps his cows constantly in the byre (or shed), till the grass has risen so as to afford them a full bite. Many put them out every good day through the winter and spring, but they poach the ground with their feet, and nip up the young grass as it begins to spring; which, as they have not a full meal, injures the cattle. Whenever the weather becomes dry and hot, he feeds his cows on cut grass in the byre, from six o'clock in the morning to six at night, and turns them out to pasture the other twelve hours. When rain comes, the house-feeding is discontinued. Whenever the pasture grass begins to fail in harrest, the cows receive a supply of the second growth of clover, and afterwards of turnips strewed over the pasture-ground. When the weather becomes stormy, in the months of $\mathrm{Oc}$ tober and November, the cows are kept in the byre during the night, and in a short time afterwarls during both night and day: they are then, fed on oat-straw and turnips, and continue to yield a considerable quantity of milk for some time. Part of the turnip crop is eaten at the end of harvest and beginning of winter, to protract the milk, and part is stored up for green food during the winter. After this store is exhausted, the Swedish turnip and potatoes are used along with dry fodder, till the grass can support the cows. Chaff, oats, and potatoes are hoiled for the cows after calving, and they are generally fed on rye-grass during the latter part of the spring."

In this part of Scotland, a peculiarly rich cheese, termed Dunlop cheese (from the district of that name, in Cumningham, where it was first made), is prepared. It is the product of the unskimmed nilk; but common or inferior cheese is also made from the milk after it is skimmed.

With regard to the Ayrshire breed of eattle, as fitted for the grazier, it is less so than for the dairy-farmer; nevertheless, in rich lands, the oxen fatten with considerable facility, and even the cows accumulate flesh; but, then, they cease to vield much milk, and, as there are decidedly better breeds for the purpose of the grazier, few are purchased by the great cattle-dealers for depasturing on the luxuriant feeding-grounds of England. Undoubtedly their great value is as milkers, and that principally in their own territory, to the feed and climate of which they seem to be constitutionally adapted.

The improved Ayrshire cow, of the present day, has the head small, but rather long, and narrow at the nuzzle, though the space between 
the roots of the horns is considerable; the horns are small and crooked, the eye is clear and lively, the neck long and slender, and almost destitute of a dewlap; the shoulders are thin, and the forequarters generally light; the back is straight, and broad behind, especially across the hips, which are roomy; the tail is Iong and thin. The carcass is deep, the udder capacious and square, the milkvein large and prominent; the limbs are small and short, but well knit; the thighs are thin; the skiu is rather thiu, but loose and soft, and covered with soft hair. The general figure, though small, is well proportioned. The colour is varied with mingled white and sandy-red.

The bulls mostly preferred by the dairy farmers are comparatively light in the head and neck, broad in the hips, and full in the flanks; the neck is arched above, the horns are short and wide apart, and the limbs short, but muscular.

It has been calculated that there are in Ayrshire upwards of 60,000 head of cattle, of which, more than half are dairy-cors.

In Lanarkshire, celelrated for the rearing of calves, the Ayrshire cattle, which are chiefiy in request, acquire more weight and size, and are heavier in the fore-quarters than those reared in the latter county: they are superior in grazing qualities, and not much deteriorated as milkers. Much butter and cheese are manufactured along the banks of the Clyde, ehiefly for the supply of Glasgow, Edinburgh, and other large towns, which receive, also, great quantities of the delicate veal which is reared and fed in the district of Strathhaven, along the borders of Ayrshire. The fattening of calves for the market is an important business in Lanarkshire, or Clydesdale; and numbers of newly-dropped calves are regularly bought up from the farmers of the adjacent districts, in order to be prepared for the butcher. The mode of feeding them is very simple: milk is the chief article of their diet; and of this the calves require a sufficient supply from first to last; added to this, they must be kept in a well-aired place, neither too hot nor too cold, and freely supplied with dry litter. It is usual to exclude the light, at all events to a great degree, and to put a lump of chalk within their reach, which they are foud of licking. Thus fed, calves, in the course of eight or nime weeks, often attain to a very large size,-viz., eighteen to twenty-six stones, exclusive of the offal; far heavier weights have occurred, and that withont any deterioration in the delicacy and richness of the flesh. This mode of feeding upou milk alone, at first, appears to be expensive; but it is not so, when all things are taken into consideration; for, at the age of nine or ten weeks, a calf, originally purchased for eight shillings, will realize seven or eight pounds. For four, or even six weeks, the milk of one cow is sufficicut,-indeed, half the quantity for the first fortniglit; but afterwards it will consume the greater portion of the milk of two moderate cows; but, then, it requires neither oilcake nor linseed, nor any other food. Usually, however, the calves are not kept beyond the age of six weeks, and will theu sell for five or six pounds each: the milk of the cow is theu ready for a successor. In this manner, a relay of calves may be prepared for the markets from early spring to the end of summer,- a plan more advantageous than that of over-feeding one to a useless degree of corpulence.

In Lanarkshire, mauy black cattle are fed in the upland grazing tracts of the eastern portion; they are usually turned into the pastures in the antumn, after the coarse grass is made into hay, which is to supply them during the depth of winter. In the spring they arc sold off, and taken by the drovers iuto the pastures of England, \&c., a fresh relay being purchased for the next autumn and winter grazing.

In the Lothians, and south-eastern parts of Scotlani, many cattle are kept, both for the purposes of the dairy-farmer and the grazier. The breeds are various; for the dairy, the Ayrshire and the Foxburgh cow are in great request, the latter being a cross between the Durluam or Holderness short-horned bull and a kyloe cow. In some parts the pasturage will support the larre and heary short-horns, in their purity. In the neighbourhood of Jedburgh, Kelso, \&c., a great quantity of veal is fattened for the market. Black cattle, short-horned bullocks, in fact, cattle of several breeds and mixtures, are fed in the pasture-lands, or stalled during the winter on hay, straw, and turnips.

The influence of the pastoral or agricultural societies generally tends to the extension of the improved short-horns, from Durham, \&c., the value of which is fully appreciated, and by means of which decided modifications of the older races are in progress.

This portion of Scotland contains much fine land, deroted both to tillage and pasture; and every branch of agriculture is carried on with intelligence and activity. In the neighbourhood of Edinburgh, large dairies are kept for the supply of the city with milk: many of these establishments are excellently managed. The cows are fed upon fresh grains from an ale-hrewery, half a bushel being given to each cow twice a day, and also two feeds of grass or turnips; or, when they can be procured, tares, and similar articles of green forlder. A little salt is supplied with each meal, as it promotes digestion and preserves the animal's health. A warm infusion of the sproutings of malt, in which a due quantity of salt is dissolved, is by many given twice a day. One bushel of malt will make sufficient of this infusion (boiling water being used) for forty cows at one time, 
Some give an alternate meal of steamed potatoes and fresh turnips; but others prefer giving the potatoes raw, as they tend to the production of milk. Potatoes boiled till they dissolve in the water, and given with salt, are found to eurich the milk. At the commencement of the turnip season, it is the plan of some to give less of the infusion of malt-sproutings as drink, and to substitute distillers' grouts, or "draff," in order to ensure the quality of the milk.

Some dairymen change their stock, or the greater part of it, every year, fattening off, or selling the cows, as soon as they become dry; and purchasing others which have recently calved, to take their place, thereby ensuring an uninterrupted supply of milk throughout the year. It is not from these establishments that the buttermilk used in Edinburgh (as it is thronghout Scotland generally) is sent out, but from the dairy-farms of the country around.

We may now turn to the polled or hornless races of cattle, of which Galloway furmishes us with a breed remarkable for many excellences.

We hare already said that we do not regard the polled cattle as distinct from the horned breeds, with which in general form, contour, and qualities, they closely agree. We see little essential difference between the polled cattle of Galloway and those of Argyleshire, or Arran,-in every respect they are black cattle, or kyloes, ouly destitute of horns. If, then, we arrange the polled breeds under a separate head, it is more for the sake of convenience than of absolute propriety.
The Polled Stock of Catrle.-The semiwild cattle of Chatelherault Park, in Lanarkshire, the descendants of an ancient race, are mostly, if not always polled, - and probably the present polled black cattle of Galloway may be derived from the same ancestry.

Formerly, few polled cattle were to be seen in this district of Scotland; but within the last century the breed has greatly prevailed, and it is highly valued. Occasionally, cattle make their appearance with very minute or rudimentary horns, attached, however, to the skin merely, and not sheathing a bony core, indications of a tendency to the acquisition of these natural weapons; and were the point to be followed up by the breeder, these might be soon restored. The breeder, however, is interested in keeping his polled Galloways pure; they are in great request by the grazier, they are of considerable size, fatten readily, accumulating flesh on the best parts; they are less wild than the horned black cattle, and less quarrelsome, and uuder certain circumstances, as on ship-board, may be packed somewhat closer than the others.

A well-bred Galloway ox is of admirable form: all is close and compact; the barrel is rounded and ribbed home to the hip-bones; the chest is deep, the shoulders thick and broad; the neck short and thick; the head clean; the back straight and broad; the limbs short, but ex. tremely muscular; the skin moderate, but mellow, and well covered with long soft hair, - that on the ears, which are large, is peculiarly rough and long.

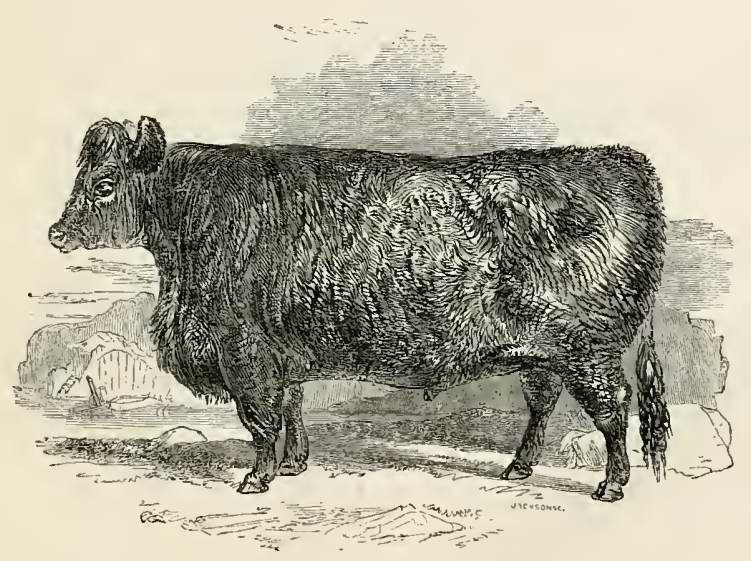

GaLLOWAY OX 
In the bull, the head is heary, the neck thick, and boldly erected above; the frontal crest or ridge is elevated and covered with long hair; and the general form is rolust, with great depth of chest and roundness of barrel.

The cow is much lighter, but yet presents those points whieh attract the regard of the grazier. As a milker she is inferior; for though her nilk is rich, it is deficient in quantity, and on the average will not amount to more than six or eight quarts per day, during the summer months, after which it rapidly diminishes. This inferiority as it respects milk is of little importance to the Galloway farmer, his chief pursuit being the rearing of grazing stock; consequently, as a rule, he never kills his calves, but looks to profit from them at a future day. These are generally dropped at the latter part of wiuter, or very early in spring, and are permitted access to the mother, at certain times daily, as long as she continues in milk. For the first five months the dairy-maid and the calf, morning and evening, divide the contents of the udder pretty equally between them; after this period, when the calf begins to graze, its allowance is diminished, till, the cow drying, this supply is of course stopped altogether. During the winter the young animal is housed at night, and fed upon hay, turnips, and potatoes, with a liberal hand.

of the calves bred, a few of the most promising females only are reserved as breeders,--the other females are rendered sterile; heifers in this condition fatten with great rapidity, arrive very early at maturity, and as their meat is deemed peculiarly delicate, sell for good prices. Some of these heifers have attained to singular weights for their stature,--one of great beauty, called the Queen of the Scots, fetl in Norfolk, and exhibited at the Smithfield cattle show, a few years since, weighed one hundrerl and ninety stones, of eight pounds to the stone. She stood five feet two inches at the shoulder, and was a model.

Many thousands of polled eattle are sent from Galloway every year to the south, and rapidly fatten in pastures but little more luxuriant than those on which they were reared, although it must be confessed, that there are in Galloway, fine tracts both of grass and white clover. It is chiefly in Norfolk and Suffolk that the polled Galloways are fed for the London markets, they are purchased by thedrovers, or joblers, at the various cattle fairs in the district, often in large numbers, and are then sent onwards in droves of two or three hundred, preceded by a man called the topsuan, who makes arrangements for their rest at different stations, and takes care that sufficient grass, hay, or turnips are provided for them. In about three weeks they arrive in Norfolk, the travelling expenses amounting to about twenty-four shillings a head in summer, and thirty-four or thirty-five shillings in winter.
The average cost of a stirk in his second year, is from three to four pounds; in the third year, six or seven pounds; and of oxen in the fourth year, ten, eleven, or twelve pounds, taken by the lot. Hence it is apparent that a jobber who purchases, six or eight humblred head of cattle, (whether he pay in bills, or cash) involves himself in a serions undertaking; if he clears from three to five shillings a heail, he is amply remunerated, but should the markets in Norfolk or Suffolk be low, he must sell at a loss, and may thus be ruined; moreover, he must expect some casualties on the road, and these must be taken into the account.

Besides these large speculators, there are others who travel from fair to fair, and purchase cattle, varying according to the extent of their means, from twenty to a hundred head; these they resell, or drive over the borders to Carlisle, in hopes of disposing of them to advantage at the cattle fairs. If successful, they return home to make fresh purchases, and soon set off again for the English borklers. Thus the stock of the Galloway breeders is continually changing hands, twenty-five, or perhaps thirty thousand head of cattle being thus annually transferred to the English pasture-lands.

In Dumfries, the largest cattle market in the south of Scotland is held, and lere vast numbers of polled black cattle are bought and sold.

A very fine polled breed of cattle has long existed in Angus (Forfarshire) and the adjacent parts of Kincardineshire. This breed is closely allied to, or perhaps is really identical with that of Galloway, and is equally celelurated for its quietness of disposition, its tendency to fatten, and its fitness for stall-feeding. These cattle are, however, more apt to be somewhat marked with white than the Galloway, they generally rum larger, are longer in the leg, thimner on the shoulder, and flatter in the side; on the whole, perhaps, they are not equal to the Galloways in the fineness of the meat; never. theless, some beasts of extraordinary quality have been exhibited and gained prizes, both at the shows of the Highland Society of Perth, and those of Smithfield.

There is considerable difference both in the climate and in the treatment to which the Galloway and Angus doddies are respectively subject. In Galloway, the climate is generally moist, and after the first winter the cattle are liept in the pastures, and supplied with hay only during the severities of the season. In Forfarshire, on the contrary, which is a great turnip county, the cattle are wintered in straw-yards, and supplied with turnips as well as ilry foldler, and grazed on dry pastures during the summer. Hence, perhaps, the superiority of size in the Angus cattle to the Galloways, their sleeker coat, and their generally better condition, when sold off to the drover; 
nevertheless, when driven to the south, they do lerlges, that "the Angus polled cattle generally are not quite so well answer the expectations of the not of that superior quality and value which an acgrazier or the butcher;-probably they thrive best count of the fieillor breed would seem to indicate, in their own district, to the soil and climate of or, what is the case with many other breeds, they which they are peculiarly adapted, and to which are exceedingly valuable in their own climate, and they owe their characteristics. Still, however, they on their own soil, but they do not answer the remunerate the grazier, aud at the fairs of Brechin somewhat unrensonable expectations of their purand Forfir grent numbers are purchased by the English dealers,

In this district many calves are fattened for the butcher, and great care is taken in rearing them; a cow often gives suck to two calves-her own and a stranger; aud in this case they are allowed to drain her udder (one on each side) three times a day: when these are weaned, two other calves supply their jlace. The first set are weaned and ready for grass early in May, the second set early in August. After this, a single calf, destined for the butcher, is put to the cow; and thus, five calves are suckled; the four first being usually inteuded for stock. Such, at least, is the plan followed by some of the large breeders, who have extensive cow-houses, and every convenience for attending to cattle, and who carry ou the business with spirit. Among these, Mr. Youatt particularizes Mr. Watson, of Keillor, as a gentleman whose judicious efforts in the rearing and improvemeut of this breed were crowned with marked success. We are informed that this gentleman obtained more than one hundred prizes, besides several valuable pieces of plate; and that he raised the Keillor breed to the highest possible grade of excellence At the same time Mr. Youatt acknow-

Leaving Scotland for Fingland, we shall find that the counties of Norfolk and Suffolk present us with polled breeds of cattle, not originals of the two counties respectively, but the result of the introduction of the polled cattle of Scotland.

Formerly, it appears that the Norfolk cattle were of the niddle-homed hreed, somewhat resembling the Devons; but this breed gradually gave way before the Gallowass, of which Norfolk was one of the chief feeding di-tricts for the London markets. It was rational that the farmers, seeing the superior value of the latter, should endeavour to naturalize them; and this they not only accomplished, but, in process of time, their old stock became almost entirely superseded. Yet the Norfolk polled cattle have departed from the pure Galloway type ; and this is what might have been anticipated. Change of soil and climate, perhaps, with other causes, have produced their effects ; and though the characteristics of the Galloway breed are not lost, they are greatly modified. The cows are, perhajs, somewhat improved as milkers, lut the cattle generally stand higher on the limbs than do the Galloways, and are Hatter in the ribs and thimner in the chine; they are taller, but not so

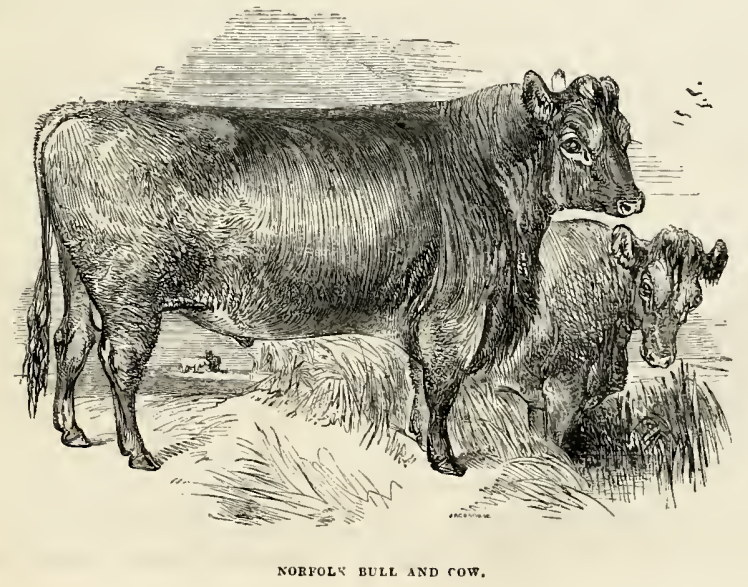




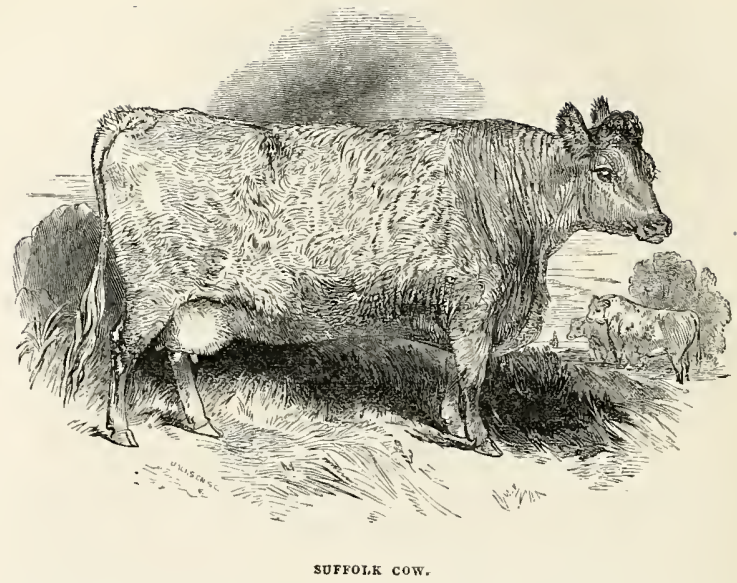

heavy for their stature; they do not feed so rapidly, nor is the meat so fine in grain. Some are black, but most are of a red tint, often more or less varied with white. It must be confessed, however, that with regard to the excellence of these cattle there is great difference; perhaps the regular accession of pure Galloways militates generally against any very extensive efforts by way of their improvement: yet it is certain that where their cultivation has been properly attended to, great success has been the result. Another point which tells against them, is the introduction and spread of the Durham and Yorkshire short-horns; nor must we overlook the Devon breed, which by many landed proprietors in Norfolk is highly esteemed. It is by Devon oxen that the farmlabour in Norfolk is performed, as far, at least, as these animals are employed; and Devon cows are much used for the purpose of the dairy.

In Suffolk a breed of polled cattle, known by the name of Suffolk duns, has been long celebrated; though the dun colour is now by no means a common character; indeed it is not preferred; for with late improvements other colours, as red, red and white, brindled, and yellowish or creamy white, have almost abolished the dum. There can be little doubt but that the polled Suffolk cattle owe their origin to the Galloways; not that they are of the pure strain of the Galloways: on the contrary, they are the result of interbreedings with them; and their chief qualifications are as milkers, rather than feeders; although, in this latter respect, even the lean cows when dried show

no little of the properties of their Galloway progenitors. A good Suffolk milking cow is lean and spare, with a light thin head, a clean neck, and little dewlap; slender, but short limbs; a heavy and well-ribbed carcass, a large udder, and swollen milk-veins. Generally the hip-bones are high and prominent, the loins narrow, and the chine hollow. There is in all this nothing of the true Galloway contour, and where the points characteristic of this breed prevail, though but in an inferior degree, the animal is fitter for the feeder than the dairyman.

Few cattle excel the Suffolk as milkers; a good cow, in the plenitude of her milk, will often yield six gallons a day; some have even yielded eight: nor is the milk destitute of richness, especially when the animals have good pasturage. Mr. Culley, who says that the best butter and worst cheese are maile in Suffolk, gives the following summary as the yearly produce of one of these cows, which, "like all other deep milkers, are very lean, very plain, and very big-bellied." He quotes Mr. Young as his authority :

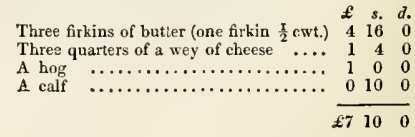

He adds, that the weight of this breed of cattle is, on an average, about fifty stones.

Mr. Parkinson has a different calculation : he 
considers the quantity of butter as amounting to one hundred and eighty four lbs.; which, at one shilhing per $1 \mathrm{~b}$., will return $9 l$. $4 s$. : a hog, $2 l$.; the calf, 15s.; and the skim-milk cheese from $2 l .5 s$. to $2 l$. $15 s$. Total about $15 l .13 s$.

Perhaps the medium between these two statements approximates to the truth. Mr. Youat says that fifty thousand firkins of butter are sent to London each year from Suffolk; but we do not know on what grounds he makes his estimate.

With respect to Suffolk cheese, it is, as Bloomfield says, " the well-known butt of many a flinty joke."

\section{"If dronght o'ertake it faster than the lenife, Most fair it bids for stubborn length of life; And, like the onken shelf whereon ' $t$ is lairi, Mocks the weak efforts of the bending blade; $\mathrm{Or}$ in the hog troogh rests, in perfect spite, Too big to swallow, and too hard to bite."}

The Suffolk dairy-farmers in gencral pay but little attention to their breed of cattle; or, rather, are actuated by no sound principles. They usually kill the bulls in their fourth year, irrespective of their intrinsic excelleuce; and the valuable and the worthless share the same fate: consequently, should the progeny of any particular bull exhibit more than ordinarily good qualities, the chance is, that no advantage can be taken of the discovery, the sire having been. slaughtered before it was made. Besides, the bull is in perfection from his fourth to his seventh year; and this is an im. portant consideration. The heifers also are bred from at too early an age, before the system is fairly matured; in consequence of which their growth is stopped, or their constitution enfeebled. Indeed, unless the cows display more than ordinary qualities as milkers, it is not unusual to fatten them for the butcher, even at four years of age; a plan which surely cannot be commended.

When dried, the Suffolk polled cow acquires a good condition with considerable rapidity, and fattens to forty or forty-five stones; the meat is of good quality - that, indeed, of the ox very superior.

Besides the polled cattle we have here noticed, varieties destitute of horns oceur, which confessedly belong to a horned race, and must not be considered as distinct. For instance, there are polled Devonshire cattle, or riats, as they are termed, which, in all points, the horns excepted, exhibit the characters of that breed. There are polled cattle of the short-horned or Yorkshire breed : the fact is, as we have before intimated, there are polled cattle of most breeds; the absence of horns is a mere accidental defect, rendered hereditary by the interbreeding of the cattle thus deficient; but these cattle, nevertheless, often exhibit a tendency to the development of their natural horns, or, indeed, show more than rudiments of them; so that it would be easy to extract a homed from a polled stock. Hence, then, we regard the distinetion between poller cattle and others as arbitrary, or to be made only for convenience, unless there are other grounds of separation.

Vast numbers of pure Galloways, and many Welsh and Irish cattle, are fed in Suffolk: shorthoms have been also introduced, and some Devons are also to be seen. Norfolk and Suffolk are both great turnip counties.

We may now turn to the breed of cattle known under the title of short-horns, a breed which, irrespective of the form or length of the horns, has good claims to be regarded as constituting a distinct variety, and which, by the judicious exertions of various cultivators, has been elevated to a state of high perfection.

The Short-rorned Breed.-This breed, called by many the Dutch breed, and believed to be originally from Holland, has been long known in the counties of Durham and lork, where the cows are held in high reputation as milkers: but the oxen were indifferent feeders, their skin red, coarse in the offal, ill-formed, and produced meat of an inferior quality. How great is the change which the breeder's pains and care have effected!' In no strain of eattle is this more palpable; for now, while their milking properties are preserved, the tendency to fatten is brought to a very high ratio; and these qualities are combined with size, a magnificent figure, the production of beef most beautifully grained, and of the highest excellence. Qualities, indeed, hitherto considered as incompatible with each other, meet together in the improved short-horns of Holderness or Teeswater celebrity. In Mr. Culley's time ("Obs. on Lire Stock," 4th edit., 1807) we find, from his orm statement, the great improvement which had taken place in this breed. He observes, that these cattle differ from others "in the shortness of their horns, and being wider and thicker in their form and mould, feeding, consequently, to the most weight; in affording by much the greatest quantity of tallow when fattened; in having very thin hides, with much less hair upon them than any other breeds, Alderneys excepted. But the most essential difference consists in the quantity of milk which they give beyond any other breed. The great quantity of milk, thinness of their hides, and little hair, is probably the reason why they are tenderer than the other kinds, Alderneys excepted. It is said of this kind, and, I suppose. very justly, that they eat more food than any of the other breeds; nor shall we wonder at this when we consider that they excel in these three valuable particulars,- - viz., in affording the greatest quantity of beef, tallow, and milk. Their colours are much varied; but the generality are red and 


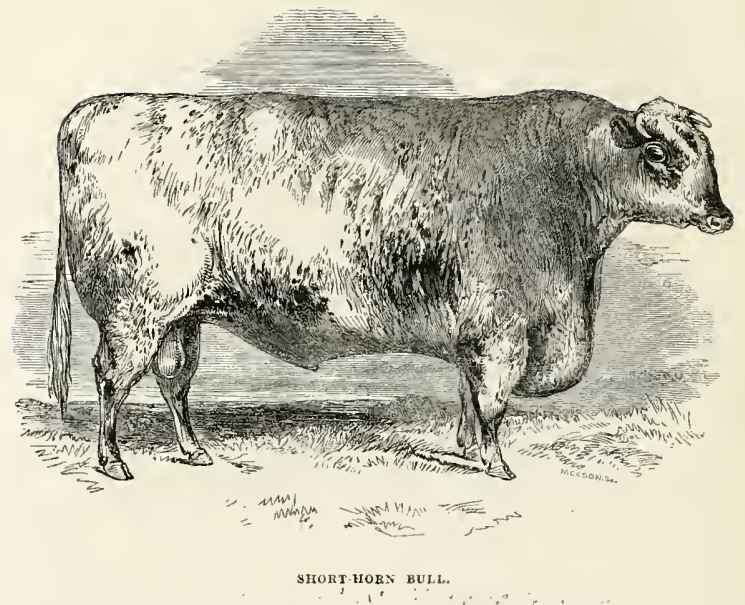

white mixed, or what the breeders call flecked: when properly mixed the colour is very pleasing and agreeable." Much in Mr. Culley's time remained to be done; but he says, "In a jonrney through Lincolnshire, I was happy to fiud that many sensible breeders had improved their breed of short-horned cattle (since my visiting that fiue country ten years before) by good bulls and heifers, brought from the counties of Durham and York, on both sides of the Tees, where the best are confessedly bred. In another excursion, in 1789 , I met with a Mr. Tindale, of — near Sleaford, who had the best breed of cattle which I ever saw in that comnty, and perhaps inferior to few in any part of the kingdom. I was shown an ox, near Lincoln, of this breed, that for true form and nice handling exceeded any bullock I ever remember to have seen."

With respect to the milking properties of these cattle, the same writer states that there are instances of cows giving thirty-six quarts of milk per day, and of forty-eight firkins of butter being made from a dairy of twelve cows during the season; but the general quantity is twenty-four quarts of milk per day, and three firkins of butter, from a cow.

The improvement in the short-horns, which commenced on the banks of the 'Tees, under' the superintendence of spirited individuals, not only continued progressive, but extended its influence around. By what crosses the Teeswater strain became established it is scarcely possible to say; there is, we believe, some reason for thinking that one was with the semi-wild white breed, and

another with choice cattle imported directly from Holland. Be this as it may, the Teeswater stock became celebrated, though still not perfect, the oxen heing often extravagantly large, and, sometimes, not true in their proportions. We hear of an ox bred by Mr. Milbank, which, when slaughtered, at five years old, weighed (the four quarters) 150 stones, of fourteen pounds to the stone, producing sixteen stones of tallow, - and of a cow, killed at the age of twelve years, which weighed up wards of 110 stones. It was reserved for Mr. C. Collings to accomplish the perfection of the Teeswater breed, already so excellent. It was by accident that this experienced breeder became possessed of a young bull (a calf when Mr. Collings purchased him), in which he discovered qualities adapted, as he thought, and as it proved, to elevate the strain. This bull he named Hubback; he was smaller than the generality of the Teeswater cattle, of excellent contour, and with an extraordinary propensity to fatten, insomuch that his utility as a bull was limited to a short period. From this bull descended a renowned stock; he was the sire of the dam of the celebrated bull Foljambe, and Foljambe was the sire both of the sire and dam of Favourite, the sire of the "Durham Ox," which, in February 1801, was sold for public exhibition. In improving bis breed Mr. C. Collings had reconrse to a single cross with the polled Galloway; he then bred back to the short-horns, and the result was a stock called the Alloy, at first in contempt, but afterwards by way of distinction. His cross was between a short-horned bull, called Boling- 
broke, and a beautiful red Galloway cow, which produced a bull-calf; this, in due time, was the sire of a bull-calf by a pure short-horned cow called Johanna; this latter bull-calf again became the sire of the cow Lady, by a pure short-horn cow, which was the dam also of the noted bull Favourite.

Thus was the Alloy stock founded. Of the estimation in which this stock was held some idea may be formed when we state, that, by public auction, the cow Lady, at the age of fourteen, sold for two hundred and six guineas; a daughter of the same cow, called Countess, at nine years old, for four hundred guineas; another daughter, Laura, at four years old, for two hundred and ten guineas: a son, Major, three years old, for two hundred guineas; another, George, still a calf, for one hundred and thirty guineas.

Mr. Bailey, in his "Survey of Durham," gives a returu of the sale of part of Mr. C. Collings's stock, in October 1810 , with the names of the purchasers. Omitting the latter, we may be permitted to give a transcript of the catalogue, which is far from being destitute of interest:

cows.

\begin{tabular}{|c|c|c|c|c|c|}
\hline Name. & 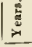 & Dam. & Sire. & In Calf by & $\begin{array}{l}\text { Price. } \\
\text { Guineas. }\end{array}$ \\
\hline Cherry ..... & 11 & Old Cherry .. & Favourite.... & Comet ... & 83 \\
\hline$\cdots$ & 4 & " $\quad$ ". & Com & Mayduke & 35 \\
\hline ress .. & 5 & Cherry ....... & Favourite.... & Comet .. & 170 \\
\hline Countess .. & 9 & Lady ....... & Cupid ...... & 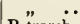 & 400 \\
\hline Celia a .... & 5 & Countess .... & Favourite.... & Petrarch & 200 \\
\hline Johanna .. & 5 & Johaona .... & $\quad, \quad \cdots$ & $n$ & 130 \\
\hline Lady $\quad .$. & 14 & Old Phcenix.. & $\begin{array}{l}\text { Grandson of } \\
\text { Bolingbroke }\end{array}$ & Comet... & 206 \\
\hline Cathleoe .. & 8 & $\begin{array}{l}\text { Daughter of d. } \\
\text { of Phcenix }\end{array}$ & Washington.. & $"$ & 150 \\
\hline a... & 4 & Lady ...... & rite.... & & 210 \\
\hline$\cdots \cdots$ & 3 & Duisy $\ldots \ldots$ & $t \ldots \ldots$ & Mayduke & 410 \\
\hline Daisy .... & 6 & Oid Dassy $\cdots$ & $\begin{array}{l}\text { Grandson of } \\
\text { Favourite }\end{array}$ & Comet ... & 340 \\
\hline$\ldots$ & 4 & Countess.... & Favourite.... & Petrarch & 70 \\
\hline & 4 & $\begin{array}{l}\text { Hiss Wash- } \\
\text { ington }\end{array}$ & Marsh ...... & Comet.. & 120 \\
\hline ose.. & 4 & Eliza $\ldots \ldots$ & Comet...$\cdots$ & Mayduke & 45 \\
\hline $\begin{array}{l}\text { Flor } \\
\text { Miss }\end{array}$ & 3 & $\cdots$ & & & 70 \\
\hline Magdaleae & 3 & Heifer by & $\begin{array}{l}\text { S. of } \mathrm{Fa} \\
\text { Comet }\end{array}$ & & 170 \\
\hline & & & & & \\
\hline
\end{tabular}

BULLS.

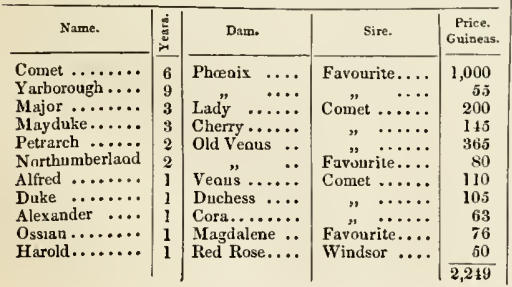

BULL CALYES UNDER ONE YEAR OLD.

\begin{tabular}{|c|c|c|c|c|}
\hline Name. & Dam. & & Size. & $\begin{array}{l}\text { Price. } \\
\text { Cuneas }\end{array}$ \\
\hline 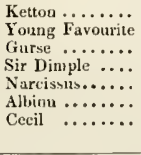 & 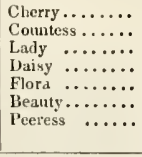 & $\begin{array}{c}\text { Comet } \\
\text { " } \\
\text { " } \\
" \\
" \\
\text { " }\end{array}$ & $\begin{array}{l}\ldots \ldots \ldots \\
\ldots \ldots \ldots \\
\ldots \ldots \ldots \\
\ldots \ldots \ldots \\
\ldots \ldots \ldots \\
\cdots \cdots \cdots \\
\cdots \ldots \ldots\end{array}$ & $\begin{array}{r}59 \\
149 \\
137 \\
90 \\
15 \\
60 \\
170 \\
65.5\end{array}$ \\
\hline
\end{tabular}

HEIFEIS.

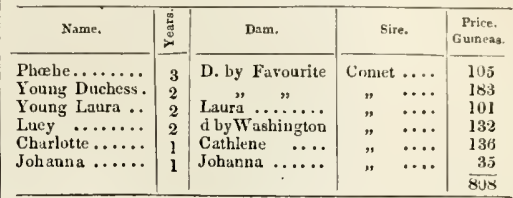

HEIFER CALVES UNDER ONE YEAR OLD

\begin{tabular}{|c|c|c|c|}
\hline Name. & Dam, & Sire. & $\begin{array}{l}\text { Price. } \\
\text { Guıneas. }\end{array}$ \\
\hline $\begin{array}{l}\text { Lucilla........ } \\
\text { Calista ....... } \\
\text { White Rose... } \\
\text { Ruby ...... } \\
\text { Cowslip ...... }\end{array}$ & 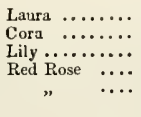 & 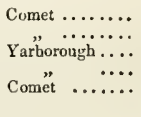 & $\begin{array}{r}106 \\
50 \\
75 \\
50 \\
25 \\
306\end{array}$ \\
\hline
\end{tabular}

In September, 1818, Mr. Robert Collings's stock was sold off, and realized prices equal to those obtained by Mr. Charles Collings (his brother).
Oae 2 year old Cow sold for 331 guineas.
Oae 4 year old Cow sold for $\mathbf{3 0 0}$ guineas.
One 5 year old Cow sold for 370 guineas.
Oae 4 year old Bull-calf sold for 270 guioeas.
One 4 year old Bull sold for 621 guineas.

Besides these successful breeders, others of scarcely less note appeared in the field, and to the result of their labours the general elevation of the present race of short-horus is owing; nor have they degenerated in the hands of their successors. There are at the present time, gentlemen who engage with great spirit in this patriotic work, and whose respective stocks have gained great and deserved celebrity.

There is in the present improved short-horns, a nnion of many qualities, once deemed incom. patible: early maturity, quick feeding, and that to a great weight, an abundance of inside fat, and meat of a fiue grain, while the cows are plentiful and steady milkers, and fatten rapidly when dried; these are the characteristics of the breed. Many improvers, it is true, look rather to the grazing properties of these cattle, and forget their value for the dairy; they esteem them in proportion to their early arriving at maturity. and 


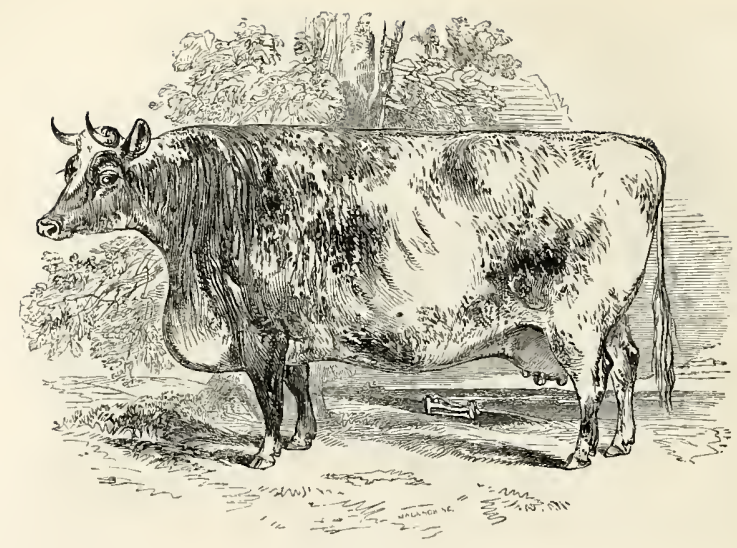

SHORT-HORN COW.

their aptitude to fatten; and selecting their breeding stock with such views, the milking properties of the cows become in reality dimimished. But this is to develop one excellency at the expense of another, and that without necessity ; for in this breed, as has been abundantly proved, both qualities can exist, not of course at the same time, for the milking cow does not fatten until dried, but in subjection one to the other. If indeed the milk yielded by the improved short-horns be somewhat less in quantity than that given by the old unimproved strain, it is of far richer quality, and returns more butter in proportion. Nearly four gallons of milk have been yielded, morning and evening, even by the highest bred short-homs, and some have even given more; and these very cattle have proved, after having been dried and fattened, admirable in the carcass. To the dairy-farmer, therefore, the short-horns are as valuable as to the grazier; and indeed it is with cows of an improved short-horn breed, from Yorkshire or Durhan, that the great dairies for the supply of London with milk are stocked. The Yorkshire cow indeed has always been a favourite with the London dairymen but formerly, when dry, she fattened slowly, cousumed much food, and therefore sold to a disad. vantage : but the improved breed fattens with surprising rapidity, and whether the dairyman keep his cows one year or three, and then sells them, or feeds them, for the lutcher, they return a profit.

The short-horns of Holderness; and, indeed, of Yorkshiro generally, owe their modern im- provement to judicious crossings, and especially to the influence of the Teeswater and Alloy strains. It must not, however, be supposed that the old breed is universally improved; on the contrary, many of the dairy-farmers give the rough breed the preference, partly from prejudice, and partly because the milking properties of the improved breed have been more or less sacrificed to the development of a constitutional tendency to the accumulation of fat. Mr. Youatt, referring to this subject, well olserves, " Experience has gradually established the fact, that it is prudent to sacrifice a small portion of the milk to assist in feeding, when the cow is too old to continue in the dairy, or when, as in the neighbourhood of large towns, her services as a dairy cow are dispensed with at an early age. This cross being judiciously managed, the diminution of milk is so small, and the tendency to fatten so great, that the opinion of Mr. Sale is correct,-- " I have always found in my stock, that the best milkers, when dried for feeding, make the most fat in the least time.' This is a doctrine which will be better understood and universally acknowledged by and by, for many of the improvers of the short-horns have but half done justice to their excellent stock. $\mathrm{He}$ wonld deserve well of his country who, with skill and means sufficient, would devote himself to the illustration of this point."

It is a remarkable fact, that the short-horned cow improres both in the quantity and quality of her milk as she grows older; that is, a cow of six years of age is superior, as a milker, to one of two 


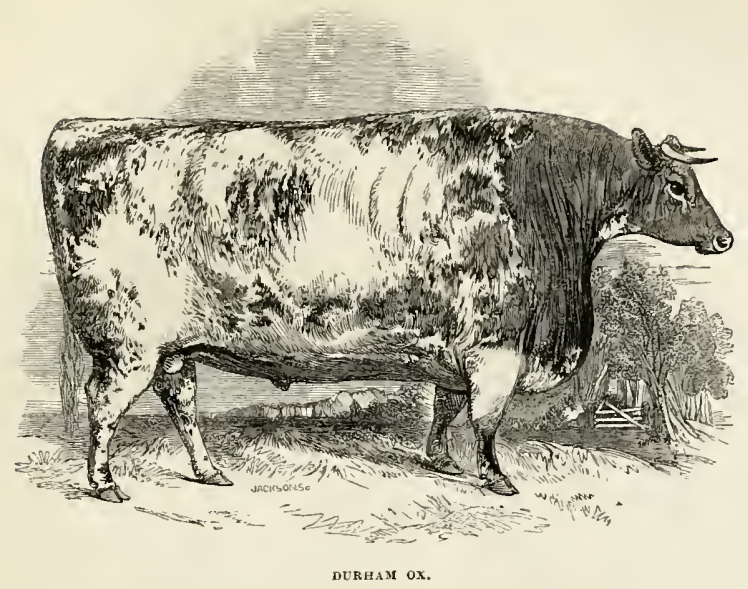

or three years of age; and her milk will yield more butter in proportion. The milk of a single cow, on which the experiment was made, returned $373 \mathrm{lbs}$. of butter, in the space of thirty-two weeks; the lowest weekly amount being seven lbs., the highest, sixteen. Her milk, during the time, averaged nearly twenty quarts per day; her food was grass and cut clover until the turnip season; but the pasture was not of first-rate quality. With abundant proofs of the value of the short-horns as milkers, it is the breeder's interest not to neglect this point, which is compatible with every property he can desire.

The weight to which some of the improved short-horns have been fed is astonishing. The "Durham Ox," when slaughtered,was 165 imp. st. 12lbs. the four quarters, besides yielding $11 \mathrm{st}$. $2 \mathrm{lbs}$, of tallow; the hide weighed 10 st. 2 lbs. His age was eleven years. Many high-fed oxen, at three or four years of age, weigh from one hundred to one hundred and twenty stone the four quarters, and some much more.

One of the most extraordinary oxen of the pure short-horn breed, was an animal fed in Lincolnshire by Lord Yarborough, and exhibited under the erroneous appellation of the "Lincolnshire $\mathrm{Ox}$ "; he measured five feet six inches in height at the shoulders, eleven feet ten inches to the root of the tail, eleven feet one inch in girth, and three feet three inches across the hips, shoulders, and middle of the back. His breast was only fourteeu inches from the ground. The depth of the fore quarters, and the comparatively shortness of the hmbs, are characteristics of this high-bred strain.

The short-horns are in the present day every where spreading, and their value is generally appreciated; it may reasonably be expected that in a few years they will either supersede or greatly modify the old breeds of most of the English grazing and breeding districts. Crosses between the Durham bull and Devonshire cows have proved in all respects admirable; their quality of flesh, aptitude to fatten, and milking properties being first-rate, while, at the same time, they exceed the pure Devons in size.

There is in Lincolushire a breed of shorthorns, well known in the London markets as "Dutch cattle," or "Lincolns," which present us with uone, or but few, of the characteristics of the high-bred Durham or Holderuess breeds; they are large-boned, coarse, and heary in the head; with the limbs high, and the loins and hips wide: the meat is coarse-grained, and the fat not well laid on. The cows, as milkers, are moderate; they are mostly white and red; but a dun rariety is also to be seen, which was introduced by $\mathrm{Sir}$ C. Buck, of Hanby Grange, about the middle of the last century. This dun stock appears to be of mixed origin.

We nust not suppose that no improvements have been effected in the coarse Lincolnshire breed; ou the contrary, several successful attempts have been made, and particularly by crosses with the Durham, by means of which the size of the bone, aud the ungainly form, were materially 
altered for the better; while a disposition to fatten more rapidly also resulted. These crossed Lincolns are, therefore, far more valnable than those of the old strain, but still are deficient in the fineness of the grain of the meat.

Besides these, there is an improved breed called the "Turmills," from the name of its founder, Captain Turnill, of Reesby-on the-Wold. Whether he effected his object by crossing with some other breed, or simply by a judicions selection of the native stock, is not rell known; bnt, certainly, he was very successful, and produced an animal, lighter in the head, finer in the form, far less bony, less high on the limbs, fuller in the breast, and round in the barrel. Their general contour is good, and they evince a propensity to fatten rapidly. Some of the Lincolnshire farm. ers still prize and cultivate this breed, which has excellent grazing qualities, the oxen soon becoming ripe for the market, especially when put up for stall-feeding, a plan which seems to suit them admirably. They are generally bought at the age of three years, in a lean state, by the jobbers or the graziers, and are ready for the butcher in the course of the ensuing summer or autumn.

Lincolnshire, besides its own breed, presents us with various others; many Irish cattle are fed there, as well as cattle from the north, and also from Yorkshire and Durham; destined mostly for London. The farmers, who look to dairy qualities, have mixed breeds of almost every description; which answer their purpose very well, being, in general, good milkers.

Under the head of short-horns, will range the Normandy, Guernsey, or Alderney cattle, which, though originally from the French continent, are now naturalized in our island. These cattle prevail in Hampshire, especially near the coast; but inland are crossed with other breeds, and, nerhaps, most successfully with the Devons, both as respects milking and feeding qualities.

The Alderney cattle are angular, and awkwardly shaped,- of small size, thin-necked, small boned, with high shoulders, hollow behind, short in the rump, with pendent bellies, and a voracious appetite. The cows yield only a small portion of milk, but it is of the most extraordinary richness; and, on this account, they are often lept in the parks and pleasure-grounds of the opulent, where, we must confess, they are both useful and even ornamental. Their gentleness, their diminutive size, end even their singular contour, together with the excellence of their milk, render them favourites, where no remunerating return for their keep is expected or desired. We own that we admire them; hnt, perhaps, some old associations influence our feelings. In proportion to the quantity of milk, the butter it yields is astonishing; a single cow has been known to give nineteen ponnds of butter weekly for several successive weeks. This, of course, is a very rare and remarkable occurrence; the average is from six to eight or nine pounds weekly, during the season, supposing the cow to be first-rate of her kind.

Meagre as the Alderney cow is when in milk, and unlikely as she may appear in the eyes of the grazier, it is nevertheless a fact, that, when dried, slie fattens with great rapidity. This property in the ox is very valnable, and though fat Alderney cattle are not often seen in the London market, some have been occasionally exhibited at the Smithfield Cattle Show; one exhibited in 1802 by the Duke of Bedford weighed (the four quarters) 95 st. 3 lbs, exclusive of inside fat, which was 17 st. 3 lhs., Smithfield weight (8lbs. to the stone).

The Alderney cattle are generally of a mingled white and sandy-red, or fawn colour; the latter being mostly disposed in large, abrupt patches.

Here we close our account of the main breeds and varieties of the British $0 \mathrm{x}$, - as far, at least, as they are definite. The fact is, that most of onr breeds are progressively changing; the decline of the improved long-horns, and the sudden elevation of the Durham and Yorkshire short-horns, are noints of singular importance and interest; nor is the intrusion of the short-horns into every county destitute of palpable results; changes are going on, breeds are hecoming modified, new varieties arising, and fresh intercrossings taking place every day, In many, perhaps in most, instances, judgment and experience preside; and the multiplication of agricultural societies and similar institutions, for the adjudication of prizes for cattle, prove the interest taken by the great landowners in the improvement of our breeds of cattle; or, rather, of the res mistica generally. We fancy, however (and it is perhaps but a fancy), that more attention is paid to the grazier's than to the dairy-farmer's cattle, and that cattle combining the almost opposite properties of milkers and feeders are taken less into consideration than their great importance merits, at least as far as the former quality is concerned. Taking the Smithfield Cattle Show as an example, it appears to us that, there, the feeder's art only is regarded; fineness of bone, symmetry, excessive fat acquired npon a stated diet, and early ripeness, seem to be considered as the main objects. Other institutions of a similar character follow in the wake; but may not, and are not, the genuine milking cattlethe cottager's most serviceable animals, the small farmer's or the cheese or butter dairyman's stockregarded with less interest? Does not the park or stall-fed steer of the great landowner take a higher rank than the cow-however well-bred and beautiful, and however fitted for the grazier when dry-of the dairyman? Is not too exclusive an 


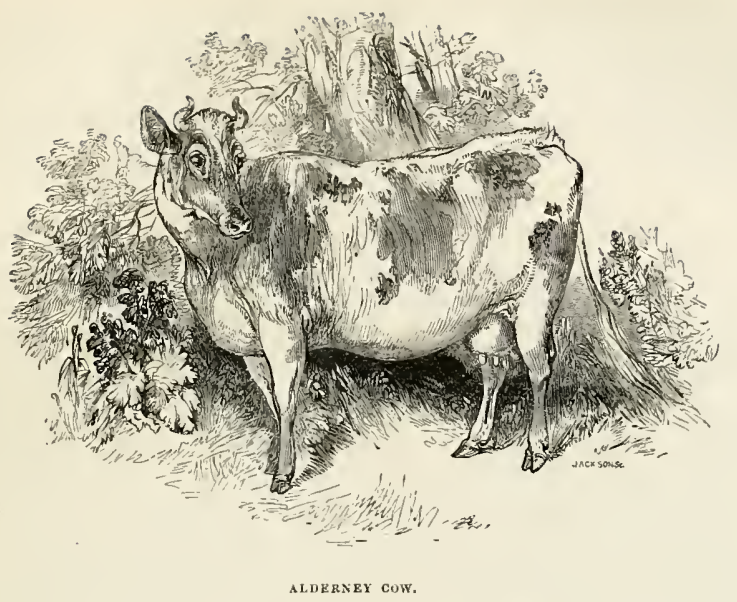

attention given to the beasts of the feeder? We think it is; and, if so, may we not expect a degeneracy in our milking cattle, and live to hear complaints that all our-celebrated cheeses are not equal to what they were formerly? Has a prize ret been given for the cow which during the season has returned the greatest weight of prime cheese or lutter, and when dry made well-fatted and fine-grained beef for the bntcher, in a fair space of time? Few such prizes, as far as we can learn, have been declared. Happily, each party understands its own interests, and acts accordingly; soil, climate, and old habits and customs, are ever inflnential. Yet, as we have said, modifications go on, almost insensibly; and the raunted breeds of to-day may be superseded before the close of another century. Of the cattle least liable to such a change are the middle-horns of Nortl Devon, Wales, and Scotland; though other breeds may intrude upon their pasture-grounds, it will be long before they lose their characteristics. Of ancient lineage, they are likely to keep up the strain uncontaminated; and though interbred with in other districts, they will still maintain their footing in their native strongholds. The causes which have tended to their preservation will, to a certain degree, continue their influence; and it may even be their destiny to modify the shorthoms. "Omnium versatur urna, serius, ocrìs."

We may here say a few words respecting the mode of judging of the reight of the cattle while standing in the stall or market. Some men, by practice and experience, are so expert in this cal- culation, that they are seldom more than a few pounds out in their speculation; they know the breed and its qualities; and taking into consideration the stature and fatness of a given animal, will arrive at a very accurate conclusion. Hundreds of beasts are thus purchased by the test of the eye and hand alone. In the "Penny Cyclopædia" we have the following directions:-

"When an ox is fat, his weight may be very nearly guessed by measuring his girth immediately behind the fore legs, and the length from the tip of the shoulder to the perpendicular line which touches the hinder parts, or to a wall against which the animal is backed. The square of the girth in inches and decimals is multiplied by the length, and the product multiplied by the decimal $\cdot 238$. This gives the weight of the four quarters in stones of fourteen lbs. This rule is founded on the supposition that there is a certair proportion between the net weight of the quarters and that of a cylinder, the circumference of which is the girth and the axis the length taken as above. The proportion has been ascertained by observation and repeated comparison. The measurement will, at all events, indicate the proportional increase during the period of fattening."

Few farmers, we suspect, will hase recourse to this method. When the live weight ran be ascertained, the rest is easy; for experience has shown the proportion between the saleable quarters and the offal, in different states of fatuess; and tables have been constructed, by which the net weight is fuind by mere inspection. Nultiplying the live 
weight by 0,605 gives a near approximation to the neat dead weight in an ox moderately fat, and of good breed.

The average dead weight of bullocks, taking numbers together, ranges from 80 to 85 stones, Smithfield weight (that is $8 \mathrm{lbs}$. to the stone); and of calves, $144 \mathrm{lbs}$. So that if London be yearly supplied with 200,000 carcasses of beef, each car- cass weighing about 82 stones, or $656 \mathrm{lbs}$., the number of pounds consumed, including bone, will amount to $131,200,000$; and supposing the number of calves at 30,000 , averaging $144 \mathrm{lbs}$. each, the total weight will amount to $4,320,000$ lbs. : so that in veal and beef alone, setting aside mntton, lamb, pigs, poultry, game, cured provisions, fish, \&c., the total amounts to $135,520,000 \mathrm{lbs}$.

\section{CHAPTER VI.}

Having thus detailed the principal breeds or va- $\mid$ require a small portion of permanent grass, rieties of the British $O x$, we may now proceed to fenced off, to allow the cow to take exercise, which some observations relative to the management or is necessary for her health. Her food must be treatment of horned cattle; a subject of great im- raised in regular succession, and cut for her. The portance, inasmuch as their health, the quantity and quality of milk yielded, and their quick ripening for the butcher are involved in it. The simplest and perhaps the most economical mode of feeding cattle is by grazing them in fields or on commons, or uncultivated pastures; additional food and shelter being supplied during the winter. But there must be a fitness of the cattle for the land. It onght to be borne in mind, that a cow of large size, and high breed, would starve, or become a miserable object on poor, or peaty land, where one of the small native kind, bardy and active, would manage to keep herself in tolerable condition. Hence, the cottager, or small dairy-farmer, in rude uncnltivated districts, will do wrong to exchange his hardy cows for others accustomed to a rich pas. turage: he would find the hope of deriving from them the quantity of milk they yielded in their own gromids delusive; for though his range of pasturage might lo very extensive, yet it would afford such cattle nothing like sufficient nutriment, and the very act of rambling about to pick up what they could, would only increase their bad condition. Cottagers often keep two or three cows, which they nsually turn out to feed on the grass, in lanes and by-roads, attended during the day by a boy, and driven home at night; they eke out the sustenance of these animals by cutting and carrying the grass of banks, or by collecting the grass of garden lawns, mowed by the gardener; and by purchasing, for a trifle, the grains of persons who brew their own malt-liquor. Occeasionally, within a few miles of London, we have seen such cows in tolerable condition; but in general their quantum of diet is irregular, and their angular points, and tight-bound bide, destitute of a dne layer of subcutaneons cellular tissue, bespeaks an impoverished system. Is it profitable for a cottager-that is, a labourerto keep cows? A writer in the "Penny Cyclopædia" says, "A cottager, with two or three acres (query, from half an acre to an acre) of moderate land, may keep a cow, and thus add much to his earnings as a labourer. For this purpose, he will

earliest green food is rye, then tares, then clover; which may be made to succeed each other so as to give an ample supply. Cabbages, beet-root, parsnips, potatoes, and turnips will continue the supply during winter; and the dung and urine of the cow, earefully collected, will be sufficient to keep the land in condition. This system, lately introduced into some parts of Ireland, has already greatly improved the condition of the industrious poor." In fact, according to this plan, the cottager must pursue a modified system of stallfeeding; and if he can devote a few hours daily to his land, and possesses the requisite knowledge, he will doubtless gain considerably. In the neighbourhood of large towns he will find a ready sale for his milk at the rate of foupence per quart; he will also have a calf yearly for disposal ; and may also keep a few hogs. We think, howerer, that on this system of green crops and roots, if the land be good, three or four cows may be well kept on three acres, with the addition of a little hay, grains, brewers' wash, \&e A cottager, with the whole of his time, or nearly so, at his own disposal, will, if industrious, thus comfortably maintain himself and his family. "A cow is old and unprofitable when she reaches the age of twelve or fourteen years: she should then be sold, and a young one purchased. If the cottager have the means of rearing a cow calf to succeed the old mother, he will do well; if not, he must lay by a portion of the cow's prodnce every year, to raise the difference between the value of a young cow and an old one. The savings-banks are admirable institutions for this purpose; a few shillings laid by when the produce of the cow is greatest, will soon amount to the sum required to exchange an old one for a younger."

The cow, as we have said, should be suited to the pasturage; but on the plan of stall-feeding, or feeding on cut green food in a small enclosure, the cottager may keep a superior animal ; which, properly fed on succulent diet, will yield a considerable quantity of milk, and, when aged, sell for a good price. Generally speaking, a cow may 
be milked to within a month of her calving, which should occur in April or May. She should then be suffered to become dry; otherwise, when she calves, her new milk will be deficient both in quantity and quality. The calf should have the first milk, which nature has intended to clear the intestines of a glutinous substance, which is always present in the new-born animal.

Besides plenty of succulent green food, the milch cow requires good water, and that which has been for some time exposed to the air is the best; cleanliness also is indispensable; a little rock salt to lick may be occasionally allowed, or a little salt given, as conducive to health. At the time of calving, or rather after calving, a little warm water, with some barley or bean-meal mixed with it, will be gladly received; but drenches and medicines should be avoided. Indeed, when a cow is allowed to take proper exercise in the open air, and has a snug shelter or house to resort to in case of stormy weather, heavy rain, or cold, she will generally keep in good health, and recover easily after calving. We suppose the food to be given regularly, and in moderate quantities at a time. Occasionally, cows are apt to show symptoms of jaundice, the result of some disturbance in the function of the liver; the eyes and even the skin assume a yellowish tint, and the animal is languid, and ceases to feed with an appetite. An aperient drauglit, composed of half-a-pound of Glauber salts, an ounce of ginger, and two ounces of treacle, with two quarts of boiling water poured over them, may be given slowly and gently when milk-warm, and repeated every other day. The cow should be kept frum chilly winds, and, if it be winter, have the loins covered with a cloth, and be confined in her shed. This plan will generally prove successful in a short time. We would, however, recommend the cottager to get rid of a sickly cow as soon as possible; for should she have some chronic disease, her milk will not only diminish in quantity, but be bad in quality; and she may die suddenly, and thus prove a great loss; whereas, though he may lose by selling her, he will find his first loss the least in the end. A staring coat, a tight skin, loss of appetite, difficulty of breathing, a husky cough, and general leanness, are indications of disease in the lungs or liver, or both; and the souner she is parted with the better.

It is a common custom to breed from heifers at too early an age; this is to spoil the cow. The heifer should not be under two years old when taken to the bull; and even then it is as well to let her go dry sooner than older cows; indeed, if she be younger, this is imperative; for the tax upon the immature animal by the calf she las borne, and the drainage of the milk from the system subsequently, tend to arrest her growth and due development. A young heifer, moreover, cannot be expected to produce a fine calf.
The above observations apply more particularly to the poor industrious cottager, who, with small means at command, wishes to keep a cow on the best plan: he has no extent of grazing land; commons generally afford but scanty food, and are for the most part overstocked; besides, he may not have the opportunity of availing himself of a common; and the plan of road-side and by-lane grazing cannot be commended, even on the ground of the habits of idleness entailed upon the boy who spends his day in watching the animal, and driving her from one spot to another, or from ditch to ditch, where the bank bolds out a prospect of a tolerable supply. But if the cottager ean rent a small piece of ground, and has time to cultivate it himself, so as to make it produce greater crops of rye, tares, clover, lucern, cabbages, beet-root, potatoes, and turnips, to be raised in succession and cut for his cow, confined in a cow-house, except while taking exercise in her little padduck, or perhans a small orchard, he may certainly make it answer his purpose. If near a large town, he will have a certain sale for all his milk. His own family will need a supply; but from this the cream may be taken, and sold to advantage. He may find it advantageous to make butter; which, as fresh butter sells, ought to bring in a return of ten or twelve pounds per annum, leaving the buttermilk for the use of the family, the rearing of the calf, and the fattening of a hog. After all, however, the affirmative to the question, whether it is profitable for the cottager to keep a cow, will depend on the contingencies of locality; the spare time he has on his hands; the assistance his family can render him; the facilities of disposing the produce to advantage; and the amount of primary outlay he must necessarily encounter; together with the rent of the ground. Where a cottager depends solely on a small piece of land for the support of himself and his family, and for the payment of rent, then indeed his cow is of the utmost importance, if managed with any thing like regularity on a judicious system. It must always be recollected, that cows on poor, but extensive, pasturage give but little milk; that no considerable produce can be expected, be the cow what she may, unless she is supplied with a sufficiency of good succulent food; and that when a man owns only a small plot of ground, this can only be produced by a well-ordered system of crops in rotation. "If (says a writer) a labourer, who has an allotment of half an acre of good light land would entirely devote it to raise food for a cow, his wife and children cutting the food, and tending the cow in a small yard with a shed, or in any cowstall, he would find that he had much greater clear profit than if he had sown bis land every year with wheat, and had always a good crop-which last supposition is impossible; there would be no better stimulus to industry than to let a piece of 
land for this purpose to every man who could purchase a cow, and feed it by soiling."

We may here add, that the green food should be cut twelve or twenty hours before it is given to the cattle, and not wet with dew or rain: it should be supplied at intervals, and in moderation ; as horued cattle are apt to eat voraciously; and the fresh green food is liable to ferment in the paunch, endangering the animal's life from the gases erolved, which distend the abdomen prodigiously. It is but lately that we saw a fine cow which died from this cause: she was left safein her paddock in the evening, but during the night she contrived to get at some clover, or lucern, in an adjacent enclosure, of which she ate voracionsly; in the morning she was found dead, and swollen.

In the neighbourhood of London, where a prodigious supply of milk is demanded, vast numbers of cows, all (or almost all) short-horns, are kept upon the principle of soiling, or stall-feeding, for the sake of their valuable produce. We allude to those large establishments in which four or five hundred cows are kept, and where most of the retail dealers in milk obtain the measure they require. There are, indeed, numerous smaller establishments around London, in which the proprietor, who retails the milk on his own account, keeps from six to twenty, or five and twenty cows; and as he has to compete with the retailer's who purchase their stock at the great establishments, he seldom resorts to the modes of adulteration, which are commonly practised by the ordinary retailers : not that a little water may not be added, but if this be all, the purchaser in London may be well contented. It is calculated that upwards of twelve thousand cows are kept for the supply of London and its increasing environs; and as the amount of milk returned by these cattle is mostly retailed by pennyworths, or two-pennywortlis, morning and evening, we shall readily conclude that the retailers' occupation is one of no little labour. That it is profitable we may conclurle from the fact that "milk-walks" are not unfrequently advertised for sale; but whether the profit be truly fair or just may admit of question. Certain it is that the milk leaves the great dairy in its purity; but what admixtures it may afterwards undergo may require the analysis of the chymist to determine.

Mr. Youatt (whose name we have often mentioned, and to whom we pay a tribute of respect for his extensive acquirements and his private worth) says, in his agreeable style, "the name of new milk has something very pleasant about it, but it is an article which rarely makes its appearance at the breakfast or tea-table of the citizen. That which is got from the cow at night is put by until the morning; the cream is skimmed off, and then, a little water being added, it is sold to the public as the morning's milk. This is the practice of most, or all of the little dairymen who keep their half-dozen cows; and if this were all, and with these people it is nearly all, the public must not complain. The milk may be lowered by the warm water, but the lowering system is not carried to any great extent; for there is a pride among them that their milk shall le better than that of the merchants on a yet smaller scale, who purchase the article from the great dairies; and so it generally is. The milk goes from the yard of the great dairy into the possession of the itinerant dealers perfectly pure; what is done with it afterwards; and to what degree it is lowered and sophisticated, is known only to these retail merchants."

Before we enter upon the treatment of the stalled cows, in these great dairies: those, for example, of Mr. Flight, formerly Mr. Laycock, Mr. Rhodes, and others, we may be permitted to sketch a picture of the interior of one of these exteusive establishments, of which many who live in London have, perhaps, never heard.

We mnst, then, suppose ourselves at Islington, "tellus vaccarum ferax," between two and three in the moming, whence, proceeding towards Highbury, we arrive at a gateway signalised by an inscription, as "Laycoclis Dairy and Cattle Layers." Entering this gateway we soon find ourselves surrouncied by builkings spread over a vast extent of ground, and consisting not only of barns, sheds, and granaries, but comprising also many others devoted to various purposes. We cannot, however, fail to notice a large range of cow-sheds, or, rather, a large -building, within which are comprised six ranges of sheds, parallel with each other; and ruming nearly north and south. Along both sides of every shed, are stalls, each stall being adapted for the reception of two cows; and the whole is so arranged as to afford proper accommodation for sixty-four cows in each shed. The length of each shed is about one hundred and forty feet, and its breadth twenty-four feet. Down the centre runs a drain, to carry off the water and refuse, and thus to keep the stalls clean. At the tlper end of each stall is a trough, supplied with water from large elevated tanks, and having also a receptacle for food. An upright post is placed at each of the upper corners of the stall, to which the cow is fastened by a ring connected with a chain passing round her neck. Adjacent to this building is a plot of ground called the "dungshoot," on which the refuse and clearing of the cow-sheds are emptied at stated times in the day; a store of valuable manure being thus collecter, for the removal of which a direct cart-way from the open road affords every conveuience.

Learing these sheds, we pass through the other buildings of the establishment, which extend over an area of sixteen acres; and here we shall quote an admirable description, drann up from 
notes taken on the spot, which we slould in vain attempt to improve:-

"Much of the ajpearance of a farm-yard now presents itself, fowls roaming about in one part, and pigs housed in another, all being reared and fattened at a trifling expense. Of the four or five hundred cows kept in the lairy, many vary greatly in the supply of milk which they afford, accoriling to their age, the state of their health, the season of the year, \&c.; and the demand for milk, on the part of customers, is also slightly variable. From these circumstances it often results that the daily supply of milk may be more than equal to the demand; and the overplus, as well as the buttermilk resulting from the butter made at the dairy, is then profitably used as food for swine.

"The pigs, which are very numerous, are kept in well-constructed piggeries, presenting none of that dirty appearance which disfigures pigsties in common farm-yards. Adjacent to the piggeries is a mixing room, in which the wilk destined for the pigs is mixed with such solid food as may be given to them. The mixture is effected in large wooden vessels, from which the food is convesed to the piggeries.

"Not far from the piggeries are several workshops for operations commected with the establishment. One is a wheelwright's slop, for repairing the numerous carts and vehicles employed; a second is a smith's shop, for the repair and adjustment of iron-work; a third is a shoeing-shop, for shoeing oxen employed in the team.

"For the better understanding the use of many parts of this establishment, it may be desirable to observe, that the proprietor, Mr. Flight (Mr. Laycock has been dead several years), is a cow-farmer as well as a cow-keeper; that is, he not only keeps the cows for the sake of their milk, but grows the food on which they are, in a great measure, fed. He possesses two or three very extensive farms, at some distance from London, where the hay, turnips, mangel-wurzel, and other articles of cattlefood, are grown in sufficient abundance for the wants of the dairy. This extensive plan of operations is productive of much advantage ; for while, on the one hand, the farms supply food to the dairy, the dairy supplies manure to the farms. The farm implements, too, can be repaired at the workshops connected with the dairy; and the oxen employed in teams, at the farms, are shod by the proprietor's own men. For these, and various other reasons, a constant intercourse is maintained between the dairy and the farms, one of which is at Enfield.

"Near the buildings just spoken of there is a tank for kyanizing wood intended for palings, stakes, posts, gates, \&c.; and adjacent to this is a kitchen-garden. From this point, extending to the boundary of the premises on the west, are the buildings called cattle-layers, unconnected with the dairy or milk-department of the establishment, but devoted to the reception of cattle for a few hours previous to their arrival at Smithfield market. The layers are very extensive sheds, bounded by walls at the back and ends, roofed with tiles, supported by pillars, some iron and some wood, aud open in front. A rack runs along the back of each shed, in which the food for the cattle is placed. Tanks of water, supplied by pipes and cocks from three or four pumps, placed in different parts of the premises, are conveniently placed for affording drink for the cattle. The ground is covered with clean straw; and the cattle, during the short time they are kept here, have considerable space of open ground in which to roam abont, gates being placed at the different openings to prevent the cattle in one layer from mingling with those in another. The number of cattle which could be contained in these layers would amount to several thousands; but nearly two thousand can be properly and conveniently received at one time.

"When we turn from Upper Street, Islington, into what is called the Liverpool Road, and proceed onwards for a considerable distance, we come to the western boundary of Laycock's establishment; and within this boundary is the principal part of the cattle-layers. In order to keep this part of the establishment distinct from the dairy, the cattle enter and leave the layers by a gate, in the Liverpool Road, far distant from the dairyentrance in the Islington Road. Northward of the cattle-layers is a tract of gromnd occupied by sheeppens, in which five thousand sheep, on their way to Smithfield, may be received.

"Returning thence to the dainy-entrance we pass a plot of ground in which are four very large grain-pits. One of the most important articles of food for the cows, in the large London dairies, is the grains or spirit-malt resulting from the process of brewing. The proprietor of this establishment contracts with one of the great porter-breweries for the purchase of the refuse grains; and these grains brought from the brewery, in wagons belonging to the cowkeeper, are deposited in large brick-built pits; or, rather, a portion of the supply is thus deposited to equalize the stock on hand, because they are procurable iu greater quantities from the brewers in spring and autumn, than in the other seasons. The grains are firmly trodden down in the pits, and corered with a thick lajer of moist earth, to keep out the rain and frost in winter, and the heat in summer. Mr. Youat, speaking of the general custom of the London dairies, with respect to this article of food, says, - A cow consumes about a bushel of these grains daily, the cost of which is from fourpence to fivepence, exclusive of carriage and preservation. The 
grains are, if possible, thrown into the pit while warm, and in a state of fermentation, and they soon tum sour; but they are not liked by cattle the worse on that account; and the air, being perfectly excluded, the fermentation cannot run on to putrefaction. The dairymen say that the slow and slight degree of fermentation, which goes on, tends to the greater development of the saccharine and nutritive principle; and they will have on hand as large a stock as they can afford, and not open the pits till they are compelled. It is not uncommon for two years to pass before a pit of grains is touched; and it is said that some have lain nine years, and been perfectly good at the expiration of that period.

"Between the grain-beds and the milkingsheds are various buildings devoted to different purposes. One is a mill-room, for grinding and crushing the dry food occasionally given to the cows, such as beans, de. The mills and crushingmachines are worked by a horse, who tramps his nerer-ending circular path in a room beneath. Other buildings are employed as granaries, and as receptacles for the food eaten by the cows. When turnips or mangel-wurzel are at the proper season to be used as food, each cow will eat half a hundred weight per day, besides a bushel of grains and a small quantity of other food; so that the quantity required, by the whole dairy, amounts to several tons weight per day.

" Another cluster of buildings is appropriated as an hospital. Among several hundred cows it cannot but happen that some will be occasionally on the sick list; and for their accommodation about a dozen meatly-constructed stalls or boxes we certainly must not call them sheds-are set apart. Each stall is fitted up as comfortably as possible for the invalid; and the necessary tackle is at hand for securing the animal when any operation is to be performed. A veterinary surgeon is attached to the establishment, under whom is placed, not only the management of the cows in the hospital, but the general care and health of all those lelonging to the dairy. The average value of a cow is, we believe, abont twenty pounds; so that the whole constitute a property well worthy of careful supervision.

"Besides the six milking-sheds before alluded to, there are two or three others, situated not far distant, and under different roofs. These are, to a greater or less extent occupied, according to the number of the cows in the dairy, which varies at different seasons. One shed, more lofty than the rest, is devoted to the reception of those cows who are no longer being milked, but are under process of fattening for the London market. This is a very remarkable feature in these establishments; instead of keeping a cow as long as milk may be drawn from her, there is a minimum of supply, below which the cow is not deemed to yield what is required of her. The cows are thus very frequently changed; they are bought for the dairy when they are in good milking condition, milked for a certain length of time, taken to the fattening-shed while comparatively young, and sold in Smithfield at a price which renders this plan more profitable than the retention of a milch cow till she is old. Considerable diversity of system prevails in this respect; for it is not until experiments on a large scale can be made, that the mast profitable management of a cow can be determined. The expense of purchasing the cow, of feeding her during her continuance in the dairy, and of fattening her for market, as well as the produce of the dairy and of the fattened cow, all vary with the circumstances under which the cowkeeper conducts his establishment, and with the locality in which he is situated; and these diversities give rise to the different systems observed in different dairies. When it is determined to fatten a cow for market, she is fed on grains, clover, chaff, oilcake, and, in some instances, boiled linseed. Oilcake is the residue obtained after expressing the oil from rape and linseed; it is, in fact, the seed after the greater portion of the oil has been removed from it, and has been found to possess a remarkable fattening quality, when given to cows."

We may here add, that each cow is allowed a portion of salt, given either with the grains, or mingled with the hay when it is made up into ricks, a plan which not only secures it from becoming mouldy, but renders it more grateful and nutritious to the cattle. It should never he forgotten, that salt is essential to the health of cattle. Wild cattle regularly visit the salt-licks in North America; aud in South America the herds absolutely require to have the barrero,--for so is called a saline or nitrous earth, which the herds of horned and other cattle seek with avility, and without which they fail, and die in the course of four months. From the twenty-seventh degree of south latitude to the Malovine Islands, the horned cattle, as well as other animals, have no need of the barrero, because the waters and the pasture grounds are sufficiently salt; but northward beyond this latitude the barrero is necessary; and the plains which do not contain it do not feed either the horse, the ass, the mule, the ox, the goat, or the sheep. Such is Azara's statement, and we believe it to be generally correct.

To return to Laycock's dairy:-_." It will be seen from the above description, that the establishment embraces several different departments, but the most prominent of these is that by which families are supplied with milk. Milk is one of the few articles of consumption which is almost invariably taken to the customer, and not sent for by the customer to the sellers; 
and the retail sellers, with their brightly polished cans, decked round the edge with a whole regiment of little cans and measures, are welcome contributors to the breakfast-table. It has been recently observed, "the cry of 'Milk!' or the rattle of the milk-pail, will never cease to be heard in our streets. There can be no reservoirs of milk, no pipes through which it Hows into the houses. The more extensive the great capital becomes, the more active must be the individual to carry about this article of food. The old cry was, 'Any milk here?' and it was sometimes mingled with the somd of 'Fresh cheese and cream!' It then passed into, 'Milk! maids below!' which was finally shortened into 'Mio!' which some wag interpreted into, 'Mi-eau' (demi-eau), half water. But it must still he cried, whatever be the cry. The supply of milk to the metropolis is, perhaps, one of the most beautiful combinations of industry we have. The days are long since past when Finsbury had its pleasant groves, and Clerkenwell was a village, and there were green pastures in Holborn, and St. Pancras boasted only a little church standing in meadows, and St. Martin's was literally 'in the fields.' Slowly, but surely, does the baked clay stride over the clover and the buttercup; and yet every family in London may be supplied with milk by eight o'clock every morning at their own doors." ("London,"No. VIII, "Street Noises," p. 137.) These itinerant milk dealers, as already stated, are of two classes, viz., those who keep cows and retail the produce, and those who purchase milk from the large dairies, such as Laycock's. In this latter mode of dealing, the purchaser agrees to give so much per gallon, and to milk the cows necessary to produce the required quantity. The milkers, therefore, whom we see at the dairy are not, generally speaking, attached to the establishment, but are either the purchasers of the milk, or are sent by the purchasers. As the cows do not always yield an equal quantity of milk, the milliers may sometimes take more, at other times less, than the stipulated quantity; and, in order to adjust the quantity, each milker takes the milk which she lias drawn to the "measuring room," where it is measured. If the quantity be more than agreed on, a portion is emptied into a store vessel in the measuring room; whereas, if it be less, the requisite quantity is added from the store vessel. A clerk and dairy-woman are in attendance to superintend these arrangements. The morning's milking commences at three o'clock, and in an hour, or an hour and a half, the whole process is finished, the number of milkmaids (mostly Welsh) bearing some convenient proportion to that of the cows. The scene is interesting, and even picturesque. The second milking commences at about twelve o'clock, and is carried on in the same orderly way. Of the large quantity of milk thus obtained, the greater portion leaves the dairy within an hour, and is soon afterwards cried in the streets, or at the doors of the retailer's customers.

After the milking is concluded, the sheds are cleaner with great eare, and the cows supplied with food, and otherwise treated according to the season.

" It has been estimated that about twelve thousand cows are necessary for the supply of London and its environs with milk, and that, taking the average quantity yielded by each cow throughout the year at nine quarts per day, the total quantity is about forty million quarts per annum. Considering that this milk is usually sold by the retail dealers at four pence per quart, after much of the cream is removed from it, that this cream is sold at three slillings per quart, and that a good deal of water is mixed with the milk by some retailers, it has been calculated that at least sixpence per quart is paid by the consumer for the real pure milk. This gives, for the value of the milk cousumed in the metropolis, an annual sum very little short of one million sterling. Since, from various causes, the daily stupply of milk at the great dairies is liable to Huctuation, while, at the same time, it is necessary that the supply should not be lower than the demand, it follows, that there is often a superfluous quantity of milk after all the dealers are supplied. To turn this milk to a profitable account, a dairy, or butter room, is attached to the establishment. At Laycock's, this room is near to the measuring room; it is fitted up with the various vessels and implements for making butter; all, as may be supposed, scrupulously clean. The higher families in London use a great deal of cream, instead of milk; and large shallow vessels are also kept in this room for forming cream from the milk. The quantity of butter made here within a given time varies with the fluctuation in the supply of milk; but a ready market is found for all of it. The butter-milk and skim-milk are profitably employed as food for swine in the piggeries; so that the whole produce is brought into requisition.

"The greater part of the observations made respecting Laycock's dairy, may, with a little modification, be applied to another large and wellknown establishment, at Islington; viz., that of the Messi's. Rhodes. Here, as at the other, several hundred cows are kept, principally for the supply of retail dealers. The superfluous milk is skimmed for cream, or is made into butter; and the cows, when dry, are fattened for the market. There are slight differences in the dairy management, according to the view which each proprietor may take of his own interest,- - such as the arrangement and fitting up of the cow-sheds, the mode of supplying water, the degree of lilierty of movement given to the cows between the hours of milk- 
ing, and the general system of feeding; but the main features of the establishments bear a good deal of resemblance."

In Messrs. Phodes's establishment, for example, the coms are never untied while they are retained as milkers; some have stood in the stall for more than two years; they have water standing in cisterns before them, and these cisterns have each a wooden cover, which is put on while the cows are eating their grains, in order to prevent their drinking at that time, and tainting the water by dropping any of the grains into it. On the contrary, at Laycock's dairy, the cows are turned out once every day to drink from troughs in the yard; and they remain out from half an hour to three hours, depending on the weather and the season of the year. Moreover, from the end of Jume until Michaelmas, they are turned into fields or enclosures, from six in the moming until twelve or one; and again from two o'clock in the afternoon to about three o'clock the following morning, when they are stalled for milking. On these two systems, Mr. Youatt observes, "We can readily conceive that, from the want of exercise and consequent cutaneous perspiration, Rhodes' cows may give a somewhat greater quantity of milk than Laycock's; but, on the other hand, when we think of an animal tied in the cormer of a stall for twelve, or eighteen, or twenty-four months together, we cannot help associating the idea of disease, or a tendency to disease at least, with such an umnatural state of things; the feet and the digestive system would particularly suffer, and we should suspect a little vitiation of all the secretions, and some deterioration in the quality of the milk. We should like to know the comparative state of the health of the animals in the two establishments. The inchination of our opinion would be strongly in favour of Laycock's plan."

During the "joint-stock" mania, which promised to supply the public with every thing through the medium of "companies," the article of milk was not overlooked. A large "Metropolitan Dairy" was established; but it utterly failed as a speculation, and passed into private hands. The same may be said of the "Caledomian Joint-Stock Dairy," at Edinburgh. This was a noble bmilding : from an entrance saloon, the visitor passed into the great byre, or cow-house, divided by cast-iron pillars and partitions into stalls for two hundred cows. The byre was thirty feet high, and from its centre rose a large dome, for the purpose of light and ventilation. The drinking-troughs were of stone, and supplied with water by pipes. Beneath the byre was a range of arched vaults for the reception of the litter and refuse. This establishment came ultimately into private hands. The fact is, that, to conduct a large dairy establishment, knowledge and experience are required; and one uncontrolled proprietor can work out plans, the importance of which he understands, in which, were he acting under a committee, he might be thwarted; besides, acting for himself, and responsible to no one, he acts decidedly and interestedly.

In all dairy establishments, ventilation and cleanliness are indispensable; and if butter is made, the dairy proper, or butter-room, should be as near the cow-house as possible, as the milk suffers more or less considerably from being agitated, or too much cooled, before it is set for the cream to rise. The milk should be brought from the cows, without being exposed to the outer air, before it is set to cream; which should be in vessels arranged on a stone slab, below the level of the ground; the apartment being sunk to the depth of three or four feet, and kept perfectly dry. The air may be admitted through perforated zinc plates, or woven-wire windows, placed opposite to each other, having shutters which may be opened or closed according to the temperatme and state of the weather. Glazed windows may be added, and should be open, excepting in very hot or very cold weather. The situation should be dry, and well shielded from the north, east, and south.

Dairies in natural or artificial caves, which occur in some countries, with springs of water at hand, are aduirable for coolness and uniformity of temperature; but in England we must not look for such advantages; nor are they needed. A verandah round a dairy is very useful ; it shades the sun in summer, and is a protection against the cold and damp in winter. There should be a washhouse, with every convenience for hot water, for scalding the dairy utensils, and for warming milk; and if cheese be made as well as butter, a churning-room, with presses, and a cheese-room are also needed.

"In Switzerland and in Holland the cowhouse and dairy often have a very neat appearance, within a short distance from the principal residence. The plan in both comtries is very similar; the style of the roof is the chief difference. In the common dairy-farms of Holland the farmer and his family live under the same roof with the cows. In the Netherlands, especially in North Holland, or Friesland, a cow-house is as clean as any dwelling-house, and the family often assemble and take their meals in it. The following description of a cow-house and dairy, under one roof, combines all that is useful, with considerable neatness internally and externally :- " It is a building about sixty feet long, by thirty wide, with a verandah running round three sides of it. The dwelling is not here attached as it usually is in common (Dutch) dairies, and the building is not surrounded by a farm-yard. These are the only circumstances in which it differs from that of a common peasant's. The dairy-room is sunk below the level of the 
soil, and is paved with bricks; the sides are covered with Dutch tiles, and the arched roof with hard cement. The cow-house, like all in Holland, has a broad passage in the middle, and the cows stand with their heads towards this passage, which is paved with clinkers, or bricks, set on edge. Their tails are towards the-wall, along which runs a broad gutter, sunk six or eight inches below the level of the place on which the cows stand. This gutter slopes towards a sink covered with an iron grate, which communicates, by a broad arched drain, with a vaulted tank, into which all the liquid flows. The gutter is washed twice a day before the cows are milked. The cows staind or lie on a sloping brick floor, and have but a small quantity of litter allowed them, which is removed every day, and carried to the dung-heap, or the pigsties, to be more fully converted into manure. When the litter is remored, the bricks are swept clean, and in summer they are washed with water. In Holland the cows' tails are kept up by a cord tied to the end of them, which passes over a pully with a weight at the other end, as we see (used to see) practised with horses that have been nicked; thus they cannot hit themselves or the person who milks them. (We do not see any thing in this practice very commendable.) The manner in which the cows are fastened is worthy of notice:-Two slight pillars of strong wood are placed perpendicularly, about two feet distant from each other, so that the cow can readily pass her head between them; on each of these is an iron ring, that rums freely up and down, and has a hook in its cireumference; two small chains pass from these hooks to a leathern strap which buckles round the neck of the cow. Thus the cow can rise and lie down, and move forward to take her food, which is placed in a low manger between the two pillars; but she cannot strike her neighbour with her horns. The mangers, or troughs, are of wood, or of bricks cemented together, and are kept as clean as all the rest of the cow-house." The food is brought in carts, which are driven at once between the cows, whose mangers are thus conveniently supplied; what is not wanted is stored above, and when wanted is readily thrown down before the cows. By this plan mnch trouble is saved, and one man can attend to many animals. From November till May the cows never leave the cow-house. In summer, when they are out, if they are in adjacent pastures, they are driven home to be milked; but if the pastures are far off, which is sometimes the case, they are milked there, and the milk is brought home in boats : but this is not thought so good for the butter, which is then always chimed from the whole milk, without taking the cream rise. The finest and best-flaroured butter is always made from the cream as fresh as possible: and to make it rise well the milk should be set as soon as it is drawn, and agitated as little as possible. The greatest quantity is seldom obtained when the quality is the finest. When great attention is paid to the quality, the milk is skimmed about six hours after it is set, and the cream then taken off is churned by itself. The next skim. ming makes inferior butter. It is, in fact, essential that the dairy should be as near the cow-house as possible. In Holland the milk is carried in brass vessels, exquisitely clean.

The subjoined plans"will conrey a clear idea of the Dutch cow-house and dairy, above described.
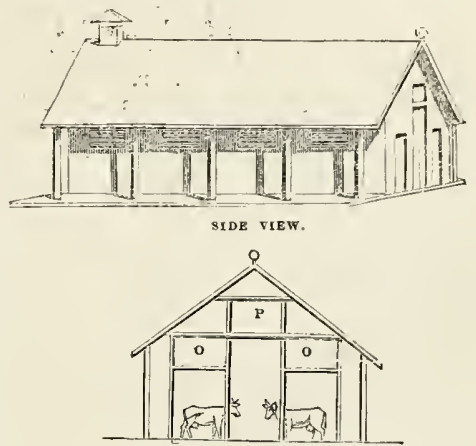

SECTION OF COW-HOUSE.

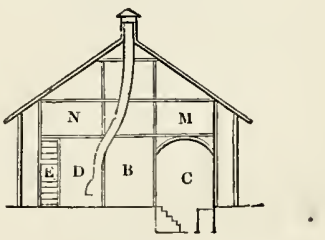

SECTION OF DAIKY.

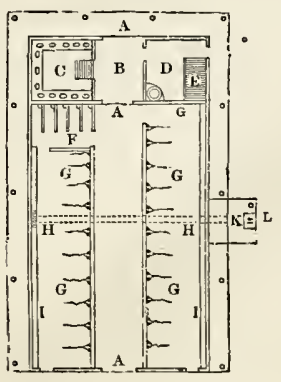

GROUND PLAN. 
A A A, passage through the cow-house and dairy, ten feet wide, paved with bricks, set on edge, or Dutch clinkers. The food is hrought along this passage in a small cart, and distributed to the cows. B, part of the passage above mentioned, closed in with doors, and forming a vestibule to the dairy. $c$, the dairy-room, in which only milk, cream, and butter are kept; it is sunk three feet under the level of the cow-house, and covered with a brick arch; it has one latticed window, and several ventilators, on a level with the place on which the milk vessels are set. $D$, the room where the utensils are scalded, and where cheese is made; in one corner is a freplace, with a large kettle or a copper set. E, stairs to go up to the cheese-room $M$, and the loft $N$. F, calf-pens, in which the calves are tied up to fatten, so that they cannot turn to lick themselves; there is a small trough with pounded chalk and salt in each pen. $G$, the place for the cows, without partitions, each cow being tied to two posts by two small chains and two iron rings which run on the posts; the chains are fastened to abroad leathern strap, which is buckled round the neck of each cow. H $\mathrm{H}$, two sinks, or drains, with iron gratings over them, to catch the fluid refuse from the gutters I I, which run along each side of the cow-house. $\mathrm{K}$, the tank for the refuse, vaulted over, with a door, $\mathbf{r}$, to clean it out, and a pump to pump up the liquid manure. 00 , in this section are places where the green food or roots are deposited for the day's consumption.

With respect to the fluid manure, of which the Dutch and Flemish are socareful, it is generally wasted by the dairy-farmers of England. Yet, as a manure for gardens, \&c., it is very valuable; and in Belgium would return, by contract, an average of $£ 2$ per cow by the year; four hundred cows would thus produce $£ 800$ per annum in this manure alone; good interest for the outlay of constructing the vaulted tanks for its reception.

Such is the general outline of the plan of stallfeeding milch cows. The system may be carried on by the cottager with a small plot of ground and one cow; and it is so, more or less thoroughly, by the large dairymen, who supply London and other populous towns or cities with milk; as well as by the farmers of Holland and Belgium where farms are small, where great attention is paid to agriculture, and where manure is extremely valuable. In England, however, within the last few years, comparatively speaking, the system of stall-feeding has been adapted to the process of fattening cattle, which goes on without interruption throughont the winter as well as the summer, so that fat beasts, even the most highly fatted, grace the markets at Christmas, and attract a crowd around the butcher's decorated shop. Generally speaking, the practice of stalling milch cattle is little practised in our island, or only partially, and at certain seasons of the year; but the practice of stall-feeding oxen for the butcher is extensively carried on, and the stall fed $o x$ is now an expression familiar to our ears, and well understood; whereas, in former times, vaunted as " the roast beef of England" may be, all the beasts killed in the dear winter months were miserably thin; and salt beef was the ordinary fare, even of the most opulent, from November to May.

We have explained the management of the milch cattle in Laycock's and Rhodes's dairies, and, as a parallel to the picture, we may deseribe the general plan followed by some of the great distil. lers and brewers about London, with respect to stall-feeding oxen for the markets. We may take, as an example, Booth's extensive distillery at Brentford, where many huudred oxen are annually fattened, while the utmost order, cleanliness, and regularity prevail.

The building for this purpose, attached to the distillery, is 210 feet long, and 180 feet wide; the side walls are about 10 feet in height; there are twenty windows on each side, and eight at each end; these are not glazed, but can be closed up or set open at pleasure; in the roof, however, there are glazed skyhghts, so that were every window closed the place would be amply lighted. Beneath the roof, which forms one ridge, is an ample hayloft, supported by nnmerous castiron and wooden pillars; while around the whole building a passage six feet in width is carried, aud a similar passage rums between every two rows of oxen. The whole building will contain three hundred and twenty-three oxen; but it must not be suprosed that the stalls are always filled; the stalls are double, about seven feet and a half wide, and ten feet in depth, from the manger to the drain or gutter behind the cattle. The gutters are all inclined, so as readily to throw the contents into the larger drains into which they merge. The mangers extend along the whole length of each row of cattle; these are for the wash, or fluid food; but each ox has, besides, a distinct manger, into which the grains, and other solid food, are put, when these are not mixed with the wash, or the refuse of fermented liquor.

This wash is kept in a large elevated tank, in a different part of the premises: from this tank pipes convey the contents to the long mangers; that which supplies each having its own tap, so that any single range may be filled irrespective of the others. The wash thus stored up is very nutritious, as it contains the finer particles of the ground malt, and the greater portion of the barleymeal, used in the mashing-process. 'The grains are preserved in pits, lined with brick set in cement: they are trodden down, and covered with earth or road-stuff, in order to exclude the air and 
keep them of a uniform temperature. Each pit is about twelve feet square and twelve in depth.

With respect to the treatment of these oxen in their stalls, their food is given in definite quantities, as ascertained hy experience; no green, succulent food, so essential to milch cows, is given, nor any hay uncut; but little oilcake is used, for it is found that rough clover chaff, mixed with the wash, will fatten with considerable expedition, and that, to any exteut. Litter is very sparingly used, but great attention is paid to cleanliness.

Mr. Youatt calculates, that 6,000 or 7,000 head of cattle are thus fattened in and about London, within the precincts of various brewers' and distiller's' establishments.

That the practice of stall-feeding, under the circumstances above detailed, is very judicious and economical, cannot be doubted; but whether under very different circumstances it is so, admits of inquiry.

When cattle feed in enclosed and rich pastures, though they may thrive well, yet there is a thorongh waste of their mauure, and more grass land must be preserved untouched by the plough, than otherwise need be. An advocate for stalling says, "their dung falling in heaps on the grass, does more harm than good. The urine, indeed, fertilizes the soil, in wet weather, when it is dilnted; but in dry weather, it only burns up tle grass. 'If we calculate what would be the amount of manure collected, if the cattle were kept in yards or stables, and fed with food cut for them, and brought there, and also the loss of grass by treading in the pastures, we shall have no doubt, whether the additional labour of cutting the grass and bringing it home daily, is not amply repaid by the saving. But if we also take into the account the variety of artificial grasses, pulse, and roots, which may be grown with advantage on land unfit for permanent grass, and the quantity of arable land which may thus, be kept in the highest state of cultivation, we shall be convinced that the practice of these countries where the cattle are kept constautly at home, is well worthy of imitation. It may be of use to the health of the animals to be allowed to take a few hours' air and exercise, in a pasture near the stable; but there is no advantage in having any grass-crop there; on the contrary, the harer of grass the crop is, the better. They will relish their food better when they are taken in, after a few hour's' fasting. A bite of fresh short grass might, on the contrary, give them a dislike to their staler food. When cut grass is given to the cattle in their stalls, it is best to let it lie in a heap for twelve hours at least, before it is given them It heats slightly, and the peculiar odour of some plants which oxen and cows are not fond of, being mixed with that of the more fragrant, the whole is eaten without waste. Experience has shown that many plants which cattle refuse in the field, where they have a choice, possess nutritions qualities when eaten mixed with others in the form of hay, There are few deleterious plants in good grass land or water meadows, and these are readily distinguished and weeded out. 'I'he quantity and the quality of the dung of cattle stalled and well fed is so remarkable, that its value makes a considerable deduction from that of the fool given; especially of green food, such as clover, lucern, tares, and every kind of leguminous plant: we shall not be far wrong if we set it at one-fourth. This supposes a sufficient quantity of straw for litter, aud a collection of the liquid parts, in proper reservoirs or tanks. In order to make the feeding of cattle advantageous, the buildings must be conveniently placed, with respect to the fields from which the food can be brought. Moveable sheds with temporary yards, which can be erecterl in different parts of a large farm, according as different fields are in grass or roots, are a great saving of carriage, both in the bringing food to the cattle and carrying the dung on the land. A clay bottom should be selected, in a dry and rather high spot if possible. But if permanent buildings for cattle, constructed of rough materials and thatched with straw, were erected in the centre of about forty acres of arable land, in different parts of a large farm, it would probably be a great saving in the end," A due supply of water, and of rock salt to lick, are very essential, and a free use of the currycomb or rough straw-whisp, is adrantageous both in point of cleauliness and health.

On the other hand it must be confessed that on large farms the system of soiling or stalling cattle is very expensive, and the more so in proportion to the extent of the farm; the labour of bringing in the cut food is greatly increased, and the time of the men is we may say almost wasted, in consequence of the distance of the fields in which the green fodder is grown. In fact, there is an expenditure of the time both of men and horses, day after day, to which most farmers would decidedly object. It is true that many straw-yarls and cattle-sheds might be conveniently scattered over a large farm: but to this plan there are several objections; they cannot be all equally under the eye of the farmer; they involve in their construction, considerable outlar, and even then, unless at great expense, must be destitute of tanks for the fluid manure; the plan involves the necessity of keeping more men and horses or labouring steers, than would otherwise be necessary, and consequently of more carts, barrows, and similar implements, items which tell when a farmer balances his accomts. Balancing these expenses against the manure returned, and the greater extent of crops (be they what they may, as wheat, beans, or any of the artificial grasses) which he 
can raise for profit in the market, an agriculturalist may soon decide as to whether on his farm, the plan is advisable or the contrary. We should say that if he has the facility of purchasing manure in large towns, at a moderate price, and at times when men, horses, and carts can be most conveniently spared, he will not find the system of soiling the most profitable. We are not now alluding to the plan of keeping cattle during the winter in straw-yards and sheds, or cow-houses, when they require both shelter and a supply of food, which the grazing land cannot yield; nor to the stalling of oxen for high feeding, and consequently, for sale at high prices; nor to the cottager's plan of soiluig his cow on the produce of less than a single acre; but to the plan of soiling throughout the year a great number of cattle on a farm of great extent. The advantages of this system must then be determined by the nature of the soil and its products, the views and designs of the cultivator, and the facilities he bas of purchasing manure. Some manure he will have on his own farm; he must stable his working horses or oxen, and a great proportion of their food will be lucern, tares, clover, \&c. Here, then, in manure, he will have some return; but the experiment, on a large scale, may not bear a proportionate degree of advantage. In Holland, Flanders, and other countries, from the size and produce of the farms, soiling becomes more or less a matter of necessity. In Eugland it has not yet heen adopted as a general farming system; but who can prophecy what it may be? In 110 country are the climate and soil more fitted for producing a succession of green crops and nutritious roots than in England and Ireland; and the small dairy-farmer would, in most cases, find soiling his most economical plan, both as regards his land and lis cattle. Let him sow rye and winter barley earty in autumn, so as to come in for cutting when spring is tolerably advanced : some sown later, with winter tares and the young clover which has not been cropped in autumn, will succeed. Then come the artificial grasses, sown at proper intervals, clover and spring tares, lucern, and sainfoin. Mangel-nurzel, or beet, turnips, swedes, potatoes, straw-chaff, hay, \&c., serve for winter provender. On this plan he may keep more cows than be otherwise could do ; and also two or four oxen (saleable at an improsed price in a few years) to perform the ordinary labours of the farm.

But, as we have said, stall-feeding is now practised with a view more particularly to the rapid and heary fattening of beasts for the market. We hase alluded to the system pursued by the great brewers and distillers about London; here, however, it is to the opulent feeders and breeders, the owners of large estates, or extensive graziers, that we now refer,-to those who send their prize-cattle to the different exhibitions in which the testimonial of merit is awarded to each candidate, in degree, by the most competent judges. We must not suppose that it is at Christmas only the results of their skill are to be seen. We are, at that time (in and about the metropolis) gratified witl proofs of what can be done, and of the high pitch to which they have brought the feeding qualities of their oxen, and of the excellence of their plan of fattening; but other cattle, finely fed, jet not prize cattle, leave their stalls, during the course of the autumn and winter, for the London market, a market in which cattle of all grades and hreeds, from the stalled Durbam ox to the lean Irish cow, meet as oll common ground.

In stall-feeding for the market, without judgment, experience, and attention, there will be a loss, not a profit, oul the part of the feeder; and this mainly depends upon the proportion of the food to the healthy digestion of the animal, and its according increase in weight. Too much as well as too little food may be given; and, moreover, the property of that food has to be taken into consideration ; for a truss of well-made clover, or sainfoin hay, will contain far more nutriment than the same weight of hay of inferior quality, and which, in the end, will be found the most expensive.

If an animal be underfed, though it may contiuue in health, and even keep up its flesh, it will not fatten; on the contrary, if more than what the digestive organs can fairly manage be given (and an animal may be induced to take it), derangement of health may he anticipated. Yet the food should be ample; that is, its quantity should be such as shall he proved by experiment to produce the greatest progressive increase of flesh: this point being ascertained, the food should be carefully weighed, and no more given daily than what is needful.

A well-regulated mixture, or alternation of diet, is also essential. An ox will not fatten kindly on one article of food, however excellent it may be in quality, or well adjusted as to quantity : the food should he given, moreover, at definite intervals, with strict punctuality. A little gentle exercise daily, in a yard or bare paddock, is very useful: it improves the appetite and tone of the digestive organs; it renders sleep more refreshing; and the invigorating untainted air, acting through the medium of the lungs, gives a renewed impetus to the circulation. It is useless to say that exposure to cold winds and driving sleets should be guarded against; for every one must be aware that a stallfed beast is not fitted for sudden exposure to incle. ment weather.

Green succulent fodder, excepting occasionally and in limited quantities, is seldom given: saccharine roots are more largely used, but they are not given alone, heing too watery, although they 
are excellent when mixed with dry food, such as cut straw, cut hay, and clover, lucern, or sainfoin hay ; to these are usually added vilcake, and even corn ground or bruised, such as barley, of which the uutritive qualities are very great.

In this mode of fattening cattle, double stalls are the best; for experience proves that all our domestic animals are more quiet and happy when they have a companion of their own species than wheu solitary. Of all our domestic animals the cat only is not gregarious by nature; the $\operatorname{dog}$, the horse, the ass, the sheep, the goat, and the ox are emiuently gregarious; nor can we interfere with this innate disposition to associate with their fellows without producing restlessness. The dog, though he makes his master his friend, pays his compliments to his fellow-dogs as he rambles abroad; the solitary horse in his paddock stretches his neck over the hedge or palings to greet his fellows on the road, and hails with joy the arrival of a companion; in the stable, if he have no other friend, he will form an association with the dog or the cat, or any living thing which has a fellowfeeling with him. It is from the inpulse of this deeply-rooted instinct that sheep follow their leader, and leap the wall after him in succession. So with regard to the ox: essentially gregarious by uature, the impulse, like that of a migratory bird for departing at the appointed season, is dominant, and ought not, under good management, to be checked. The indulgence is to the benefit of the feeder; for the beast, contented with its companion, is neither fretful nor melancholy, and therefore feeds cheerfully and heartily, ignorant of its destiny.

There is a point at which a beast, already fat, ceases to pay, by his increase, for food and attendauce; the animal ought then to be sold, and another should be put into his place. But what indicates this point? This,-viz., the trifling increase of weight made weekly in comparison with the amount of food consumed, on which food a lean beast would thrive very rapidly. This point attained, there is a loss in keeping the animal; with this loss, and that not of small amount, the feeder must be coutent who fattens an animal to au extraordinary degree of ripeness for competition at one of the exhibitions. He must, in fact, pay for his triumph; nor is he to be condemned for showing to what a pitch of perfection he has brought his cattle and his system of feeding. It is at Christmas that the display of the carcasses of these overfatted beasts, in the large butchers' shops of the metropolis, takes place, attracting often a crowd of wondering observers.

With respect to the order in which the Smithfield market is supplied with cattle, which are sent thither from every part of the kingdom, but in larger numbers from some districts than others,
Mr. Youatt says, a little before Christmas the fat beasts, to supply beef of unusual quality, come in. "They are sent from every part; from Norfolk and Lincoln, Leicestershire and Northampton, Sussex, the western and midland counties, and from the stall-yards more in the neighbourhood of the metropolis. Christmas having passed, the Norfolk cattle, comprising all sorts, but among them home-breds and Galloways, throng to the market; and their numbers, compared with those of other districts, increase as the spring advances."

From calculation of the respective numbers from the different districts, at different seasons of the year, the same writer has ascertained, that, "on the average, in February, March, and April, there is an arrival of 16,000 Norfolks, nearly all stall fed cattle; while, from the north, including chiefly Leicester and Northampton, there come but 600 . In May, June, and July, he found the Norfolk cattle to increase to 17,800 , and those from the north to rise from 600 to 3,675 . In July, August, and September, the grass-fed cattle begin to pour in. The earliest are from the marshes of Essex; and therefore the beasts from the centre and midland districts rise to 5,350 , while those from Norfolk strangely decrease to 580. Some Leicesters, however, soon become ripe, and quickly follow; long droves from Northamptonshire and Lincoln are not far belind; and the northern cattle, in the preceding quarter 4,675 , rise to 16,340 . Iu October, November, and the early part of December. the grass-fed beasts still continue to occupy the market, and no less than 33,000 have been found to arrive from Leicester, Northamptoushire, \&c.; while the supplies from the marshes and the midland counties still partially keep up, and may be estimated at 6,400 , besides 2,380 Norfolks. The grass-season is now past, and dependence begins to be placed on stall-feeding; and therefore, as observed, the northern cattle suddenly fall to 600 , and the Norfolks rise to $16,000 . "$

This statement does not take into account the carcasses sent by railway to. wholesale carcassbutchers; nor does'it allow for the results of rapid and incessant commiunication, by means of steamvessels, with different parts of our coast. Besides, our market now receives considerable numbers of cattle from Holland and Belgium, \&c.; and also eured provisions, of which a great proportion consists of beef.

Of the extent of the importations of cattle from abroad, and of the great number of carcasses sent by railroad to London, the following modified extracts from the pubhic journals will convey some idea:-

April 13, 1816: Smithfield. - Simce Monday last the arrivals of foreign stock in the port of London have been considerably on the increase, and of improved quality. They' have amounted to 
21 oxen from Hamburg, 150 oxen and cows, together with 350 sheep from Rotterdam; 76 oxen and cows, 151 sheep, and 1 calf, from Harlingen. To-day we had an offer of 250 oxen and cows, and 210 sheep from Holland and Germany. At Hull about 140 head of stock have come to hand from Rotterdam, a few of which have found their way to London by railway.

From Norfolk, Suffolk, Essex, and Cambridgeshire, we received $1,600^{\circ}$ Scots, home-brets, and short-horns; from the midland and westem counties, 230 Herefords, runts, Devons, \&e.; and from Scotland, 300 Scots, chiefly polled.

The arrivals at Newgate and Leadenhall of country-killed meat, exclusive of 40 carcasses of foreign heasts, and 90 of sheep, are given as follow:-

\begin{tabular}{|c|c|c|c|c|c|}
\hline & Beasts. & Sheqp. & Calves & & Pigs. \\
\hline Scotland.... & 60 & ... 700 & 0 & & 620 \\
\hline Yorkshire ... & . 90 & $\ldots 650$. & $\ldots \ldots$ & & 700 \\
\hline Lineolnshire . & .100 & $\ldots \ldots 220$. & $\ldots$ & $\ldots$ & . 190 \\
\hline folk ..... & .120 & ... 160. & $\cdots$ & $\ldots$ & 200 \\
\hline Suffolk $\ldots$. & . 80 & $\ldots 230$. & $\cdots$ & $\ldots$ & - 150 \\
\hline Cambridgeshir & re 80 & ... 200 . & $\ldots$ & $\ldots$. & - 200 \\
\hline Essex....... & . 30 & $\ldots \ldots 100$. & $\ldots \ldots 160$ & $\ldots$ & - 220 \\
\hline Surrey ..... & .50 & 300 & 300 & & 300 \\
\hline Devonshire . & 0 & $\ldots \ldots 40$. & $\ldots$ & & 100 \\
\hline Wiltshire ... & .90 & ... 160 . & ....180 & $\therefore \alpha$. & - 200 \\
\hline Other parts.. & 200 & $\ldots 300$ & ... 300 & & 200 \\
\hline Total & 900 & $\ldots 3,060$ & $\ldots 940$ & .. & 3,080 \\
\hline
\end{tabular}

Let us turn to another date, Nay 15, 1816 : Smithfield.-The past week's imports of live stock, into London, have consisted of 18 oxen from Prussia; 20 oxen from Hamburg; 120 oxen and cows, 240 sheep, 59 lambs, and 11 calves, from Holland. To-day we have had 18 beasts from Prussia, with about 100 oxen and cows, and 150 sheep, from Holland. The following statement shows the total importations during the four months in 1844,1845 , and 1846 , ending May 5 th.

\begin{tabular}{|c|c|c|c|c|c|}
\hline & 1841 & & 1815. & & \\
\hline & $\begin{array}{l}\ldots 202 \\
\ldots 84\end{array}$ & $\ldots$ & & & \\
\hline & . 5 & $\ldots$ & 13 & $\cdots$ & 103 \\
\hline & . 57 & $\ldots$ & 865 & $\ldots$ & 8,947 \\
\hline & .. 1 & $\ldots$ & 1 & & 27 \\
\hline & $\ldots 67$ & & 161 & & 21 \\
\hline
\end{tabular}

The week's arrivals of conntry-killed carcasses (the weather being warm) at Nerrgate and Leadenhall, amounted, in all, to 250 beasts, 500 sheep, 120 calves, and 300 pigs; the previous week brought up 197 beasts, 850 sheep, 320 calves, and 690 pigs. Of live stock, Smithfield received from Norfolk, Suffolk, Essex, and Cambridgeshire, 1,600 Scots, home-breds, and short-horns; from the westem and midland counties, 400 Herefords, Devons, runts, \&c.; from the other parts of England, 380 of various breeds; and from Scotland 320 horned and polled Scots.

June $29,1846 .-T h e$ arrivals from abroad within the previous week were as follow:-12 oxen from Prussia; 20 oxen from Hamburg; 120 cows, 50 oxen, 150 lamus, and 8 calves from Holland, in tolerable condition. At Hull, nearly 400 head of beasts and sheep arrived from Rotterdam; at Plymonth, 40 oxen from Sprain. To-day (June 29), 250 foreigu beasts, 300 sheep, 80 lambs, and 6 calves.

The arrivals at Newgate and Leadenhall of country-killed carcasses amounted, during the week, to 17.2 beasts, 5.13 sheep, 110 calves, and 530 pigs. During the previous week, the numbers stood at 188 beasts, 435 sheep, 130 calves, and 460 pigs.

Octolier 12, 1846.-(Monday.)-The imports of foreign cattle during the previons week are as follow:-

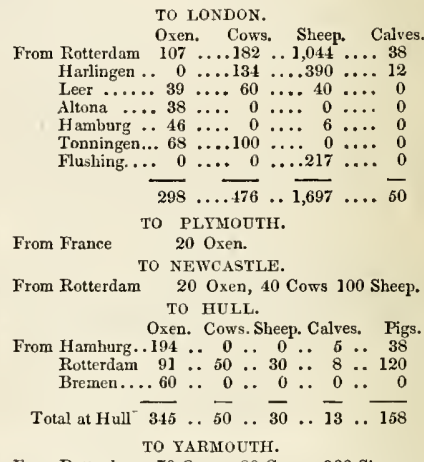

From Rotterdam 70 Oxen, 80 Cows, 200 Sheep.

The arrivals of country-killed meat at Newgate and Leadenhall (the markets having been heavily supplied with meat slaughtered in the metropolis) amounted only to 70 carcasses of beef, 200 of mutton, 90 of veal, and 120 of pork.

Smithfield received of home-fed beasts, 1,800 short-horns from the northern counties; 700 Herefords, runts, and Devons from the western and midland districts; and 300 of various breeds from other parts of England.

With respect to the importation of salted or cured provisions, of various kinds, from foreign comntries into the United Kingdom, the returns laid before Parlianent, reckoning from the 5 th day of January to the 5th day of Jnly, 1846, give the following:-93,322 cwt. of salted beef; 27,105 cwt. of salted pork; 1,326 ewt. of bacon; and 5,447 cwt. of hams of all sorts. During the same nzonths there were re-exported from the United Kingdom, as merchandise, 705 cwt. of salted beef; $1,726 \mathrm{cwt}$. of salted pork ; and $611 \mathrm{cwt}$. o f bams of all kinds. 
Recently, London has received considerable quantities of preserved meat from Russia. One vessel, the "Marquis of Chandos," from Taganrog, brought into St. Catherine's Dock 24,822 packages; each package was enclosed in a tin case, and its contents weighed from 8 to 10 pounds; the total, therefore (which was consigned to a house in London), must, at the lowest calculation, have amounted to 198,576 pounds. Formerly it was the practice in Russia, as it is in South America, to destroy the cattle merely for the profit that could be realized in England from the tallow, hides, and bones; but the abolition of the duty on salted provisious has materially changed affairs, and we may expect that the London market will receive" large snpplies of cured beef from Russia, and that of good quality.

The statistics into which we have thus entered will serve to show the increase in the importation of live stock from the continent into England; the average amount of country-killed meat sent to Nergate and Leadenhall; and the number of horned cattle weekly driven into Smithfield; as well as the quantities of salt provisions imported. In all these particulars, relative to the great introduction of country-killed meat, foreign cattle, and foreign cured provisions into Loudon (and other large towns and seaports), we cannot but feel that a great change has taken place within the last few years; and it is easier to see the causes than to tell to what extent it may be carried. Railroads, steam-vessels, and the opening of our ports have, indeed, brought about many alterations, and will bring others. Nor is it only from foreign ports that the rapid transport of cattle (their introduction being duty free) takes place; by the same means great numbers are imported from Ireland and Scotland, and in good condition, instead of being worn and wasted by a tedious and boisterous royage as was too often the case formerly. WVe learn that from the port of Aberdeen, during the last twelve years, there have been shipped 99,891 head of fat cattle, weighing, in the aggregate, nearly fifty thousand tons. When to this we add shipments from the ports of Peterhead, Fraserburg, Banff, and Inverness, we shall have an aggregate of nearly a quarter of a million of prime animals exported from the north of Scotland to London in twelve years. It is worthy of remark, too, that although the opening of our ports for the admission of foreign cattle had, perhaps, at first, the effect of slightly diminishing the exports from Aberdeen, the returns for the last three years show an extraordinary increase; and we believe that the cattle dealers, generally, admit that the prices during that period have been of the most remunerating kind. When, indeed, we consider the increasing population of Great Britain generally, and the rapidly progressive extension of the capital in all directions, we cannot for a moment entertain the idea that any arrivals of foreign cattle, though the numbers should be far greater than what they are at present, will interfere with the interests of the breeder or dealer within the limits of our own shores.

To revert to the sales of cattle at Smithfield, we may observe, that all the cattle sent there are consigned to salesmen, who, whatever they may do covertly, are prohibited we believe by law from huying or selling on their own account. The grazier has, in fact, little or nothing to do personally in the business. He trusts to his salesman, who is acquainted exactly with the state of the market, and knows all the butchers, dealers, or contractors who frequent the sales. $\mathrm{He}$ is well enabled to anticipate fluctuations in price; he can see at a glance the characters of the cattle intrusted to him; and he can tell at once what lots will find the readiest market, and return the highest price. It is his interest to do the best for his employer, and to take every fair advantage of the state of the market in his behalf. The grazier could not act so well for himself were he to try on the spot; nat, he might even lose his money, which he is sure of by employing an accredited salesman.

How many a weary mile hare the drores of cattle from distant districts (those excepted which are sent hy steam-vessels or railroads) to trarel, before they reach the salesman in London! Long is the way from the Highlands of Scotland to the Great City on the Thames;-yet this distance have the droves of kyloes to travel, nnder the guidance of a set of men well known as drovers, shrewd, hardy, weatherbeaten men, who make this their busmess, and in whom implicit confidence is placed. Not that one set of drovers go through the whole jonrney. The Highland drovers usually sell their cattle in the Lowlands, or within the English borders, and return home; and the English drovers, who now take charge of them, continue the route till near London, when, surrendering their charge to others, they retrace their steps, to repeat in due time their labours.

"If," says a writer on this subject,* "we could exhibit, as in a picture gallery, some of the rarious characters who are gathered together, with their flocks and herds, at the fairs of merry England and trysts of Scotland, the reader would acknowledge that scarcely any occupation could produce so many specimens of the human form of striking aut picturesque aspect. The drovers are dirided into several classes, but each offers rich subjects for the painter; and if we were to include not only those whose business it is to drive the live stock to the markets and fairs, but also those who breed and rear it, what raried and animated

* Penny Magazine, No. 736. 
forms of life might be summoned around us. There is the shepherd of the South Downs and Salisbury Plains; his congeners of the Lowlands and Highlands of Scotland; and the lassie that herds her parents' small flock in some romantic mountain-spot, that kindly puts forth a few blades of grass on which her hardy black-faced charge live, till the time arrives for their journey southward; the Highlander, wrapped in his tartan, following his kyloes in the same direction; and the drover, who is familiar only with Smithfield, and the great roads in the suburbs of London. Nor must we forget the old topsman, who has truly the air of a dweller out of doors; but its savage wildness is a stranger to his features, which are noble and manly, with a free and piercing glance, and when the stock is selling well, lighted by a smirk, which seems to express some contempt for the southrous, though he has no objection to their siller.

"According to Sir Walter Scott, the Highlanders excel all others as herdsmen; but their peculiar characteristics are lost, or of little value, when the herd is exchanged for the flock. 'The Highlanders, he remarks, 'are masters of this difficult trade of driving, which seems to suit them as well as the trade of war. It affords exercise for all their habits of patient endurance, and active exertion. They are required to know perfectly the drove roads which lie over the wildest tracks of the country, and to avoid, as much as possible, the highways, which distress the feet of the bullocks and the turmpikes, which annoy the spirit of the drover: whereas, on the broad green or grey track which leads across the pathless moor, the herd not only move at ease and without taxation, but, if they mind their business, may pick up a monthful of food by the way. At night the drovers usually sleep along with their cattle, let the weather be what it will ; and many of these hardy men do not once rest under a roof from Lochaber to Lincolnslire. They are paid very highly, for the trust reposed is of the last importance; as it depends upon their prudence, vigilance, and honesty, whether the cattle reach the final market in good order, and afford a profit to the grazier. But as they maintain themselves at their own expense, they are especially economical in that particular. At the period we speak of, a Highland drover was victualled for his long and tiresome journey with a few handfuls of oatmeal and two or three onions, renewed from time to time, and a ram's horn filled with whiskey, which he used regularly, but sparingly, every night and morning. His dirk, or skene dhu (black knife), so worn as to be concealed by the arm, or under the plaid, was his only weapon, excepting the cudgel with which he directed the movements of the cattle A Highlander was never so happy as on these occasions. There was a variety in the whole journey which exercised the Kelt's natural curiosity and love of motion: there were the constant change of place and scene, the petty adventures incidental to the traffic, and the intercourse with the various farmers, traders, and graziers, intermingled with occasional merrymakings, not the less acceptable to Donald that they were void of expense : and there was the consciousness of superior skill ; for the Highlander, a child among flocks, is a prince amongst herds ; and his natural habits induce him to "disdain the shepherd's slothful life," so that he feels himself nowhere more at home than when following a gallant drove of his country cattle in the character of their guardian."

“'In No. 90 of the 'Quarterly Review,' there is an interesting notice of a drover poet, commonly called Rob Donn (i. e., Brown Robert). He wrote in Gaelic, and the reviewer treats him as one of the true sons of song.

"Allan Cunningham has given us a picture of the collected riches of a mountain country,-viz., its cattle, being assembled for their journey to the south. 'The hills and valleys of the interior Highlands, which, in rougher times, sent out, under a Graham or a Cameron, bands of armed men, now in the season pour forth the herds of cattle which they rear for the eager markets of England, where a savoury mouthful is ever welcome. The cattle which form the drove are gathered together on a set day, and at an appointed place, the foot of a mountain, the side of a lake, or near a castle in the neighhourhood of a village, or, more likely still, a battle-field; herdsmen are selected to conduct the different portions into which the herd is divided, while over all a confidential person, a sort of chief, topsman as he is called in the Lowlands, presides, who directs all the movements, makes all the bargains, and is responsible to the owners for the profits. This person, the topsman, gives the order, a signal generally, when to move or halt; he is always busy, now in the front and then in the rear, and is consulted by his subordinates in all difficulties. He knows the safest roads over the wildest tracks; Shapfell is as well known to him as Schehallion; he prefers the greensward way, which is pleasant to the hoof of his charge and affords them a mouthful, to the hard and dusty public road, which distresses the feet of his cattle and affords little in the way of food. English parties on their way to the north, to look at the wild deer and wild hills, and trace the scenes of Scott or of Ossian, are often startled by a drove emerging from a glen, or rounding the base of a mountain, coming lowing along, urged or direeted by their drivers, who, wallet on back and staff in hand, are conducting them to the south. These topsmen are now generally paid for their labour and trust, but in days not yet distant the Highland proprietor 
accompanied his drove to the south, and with his profit in his sporran, returned to the mountains.'

"The English country drover who meets the drovers from Scotland, is to this day much the same sort of man as he was fifty years ago, and his calling is one of the few which the sweeping influences of modern improvements have hitherto but little affected ; railroads do not materially affect his trade, at least he professes he caunot perceive any difference. The cattle he drives have improved to a degree almost beyoud belief, and as he surveys the different members of his drove in advance of himself, he cannot see one representative of his old friends the Craven, and other such coarse ungainly animals as it fell to his lot to drive some four or five and fifty years ago. The roads he travels have partaken of the general and leneficial improvements of the present century; but to his mind these are a disadvantage rather than a gain. Formerly he often crossed wide tracts of uucultivated waste-land, aud heaths of some miles extent, where the timid rabbit, the fleeter hare, and their joint enemy the fox, occasionally afforded him and his almost human companion, his dog, some sport. The cattle or sheep under his cliarge formed picturesque groups on these wide tracts, and nature displayed her beauties around him: the golden blossoms of the prickly furze, the delicate blue-bell, the deep green of some and the silvery appearance of other members of that beautiful class of plants, the fern tribe; never seen to so much advantage, or with such feelings of pleasure and delight, as when planted on a barren heath by the hand of nature, and contrasting with the yellow sand-banks or parched and stunted grass that feebly strives to show itself amidst the carpet of purple heather that nearly covers the whole expanse, backed by the hills over which he toiled in the summer-heat some four or five days before. Amid such scenes as these, perbaps lighted up by a bright morniug sun, and the heavy dewdrops looking like crystals showered over the surrounding objects, he left the secluded hamlet, by eventide had sup. plied his beasts with fodder, and taken his place on the village green, discussing local news with the old, or watching the merry-making of the young, retiring early to his rest, and closing his eyes while the village youths, untired by the labours of the day, rang a peal from the bells of the village church. In scenes like these, so peculiarly English, and capable of supplying the painter or poet with subjects or themes, did the drover pass his life. It might be that, like Peter Bell, nature never found the way into his heart, and that

'At noon when by the forest's edge He lay, beneath the branches high, The soft blue sky did never melt Into his heart; he never felt The witehery of the soft blue sky.
A primrose by a river's brim, A Jellow prmrose was to him, And it was nothing more.' WORDSWORTH,

Perhaps so: - and we will therefore follow him in the actual business of the day. 'The drover, then, calls on the graziers who have cattle or sheep to send to market or fair; and when be has collected a sufficient number he proceeds on his journey, which, however interesting, is, we will suppose, from long familiarity passed unregarded, except an occasional remark on passing some well cultivated piece of ground which he knew forty years back a harren waste, where nohody thought of growing mangel-wurzel or cow-cabbage. His journey varies from one hundred miles a week, more or less as the case may be, and within six or eight miles of London he surrenders his charge to the care of another man, and returns home to perform the same services over again, accompanied by his faithful dog, whose family he not unfre. quently carries on either side of him, in the ample pockets of lis smock-frock.

"The drover who takes from the country drover the charge of the herd or flock, resides in the suburbs of London, at a convenient distance to afford food or pasture to the numerous droves that arrive weekly for the supply of the metropolis. $\mathrm{He}$ is paid for sheep at so much per score, and cattle per head; and his business is to drive the cattle into the market, and to wait uutil they are sold and paid for. The average rate for cattle is ninepence per head, aud reckoning that in Smith field one hundred and sixty thousand are annually sold, a sum of $£ 5,000$ a year is paid to this class of drovers; allowing for about five hundred head per week, which are brought by steam,-droves occasionally taken to market by country drovers themselves, - and a certain number which are foddered and driven to market, either from their own fields, or the layers at Islington. There are also above a million and a half of sheep driven into Smithfield yearly, for which the drovers are paid a considerable sum.

"The drover is liable for any damage or accident that may happen to the stock, until sold and delivered to a drover that may be called a butcher's drover, for he ouly drives from the market to the shop or slaughter-house of the purchaser. The cattle generally arrive in the suburbs on the Sunday morning, where the master-drover and his men are ready to receive them. These men he pays about ten shillings per day, and they have besides the chance on their return of driving purchases for butchers who live along the road, of which they generally avail themselves. After resting the remainder of the day and night, the drover is up and stirring at a very early hour on Monday, as his drove must be at market by five, where the 
salesman is ready to receive them, and they are tied up according to his direction. If there is not room for this, they are formed into off-droves, consisting of circles of cattle with their heads toward the centre of the ring. This is not effected withont severe blows, and other cruel punishments; indeed the scene is one of great brutality, and need not be detailed. During the dark nights of winter the drovers are furnished with torches; and the flashing of these, the shouts of the men, the lowing of the beasts, the tremulous cries of the sheep, and the rattling of sticks on the heads and bodies of the animals, combine to produce a scene of wild confusion. By the dawn of day, however, the poor animals, tired and sore, are terrified into maiutaining the requixed position for the convenience of the purchasers to examine them. The butcher now arrives, chooses such as suit his purpose, and, after chaffering with the salesman for some time, the bargain is struck. The sales. man then takes ont a pair of scissors, cuts a small portion of hair off the rump as a mark, and the purchaser repairs with him to the bankers to make the payment. 'The suburban drover is now told the beasts are paid for; on which he takes a knife from his pocket, and cuts off all the loose hair from the tail, placing his distinguishing mark on the animals with a piece of red ochre. The towndrover seldom drives for any but butchers and other drovers. Some of them do not leave the market at all, but merely drive sheep in and out of the pens. Like the last class of drovers, they are licensed by the clerk of the market, pursuant to rules and regulations made by the city authorities. The licence must be renewed annually to entitle the holder to wear his badge, without which he could not stand in the market or drive cattle or sheep in the cities of London or West. minster and the suburbs. The charge for a renewal of the licence is five shillings, and in it the person of the drover is minutely described, with particulars respecting his age, trade, height, complexion, residence, colour of hair and eyes. When a drover is fined for ill-using cattle or sheep it is endorsed on his licence; which in that case is not renewed without some trouble, and producing securities for future good behaviour." It must be confessed, lowever, that the difficulty of extricating the terrified beasts, when sold, from the dense throng of others which fill the allotted space, too often leads to acts of ruthless barbarity: the men lose thcir temper, and shower blows on the most sensitive parts of the poor animal, as the lroofs, roots of the horns, and nose, till, maddened with agony and rage, it rushes forward, not unfrequently committing serious mischief. As may be easily conceived, a visit to Smithfield on a crowded market-day is not unattended by danger.

The greatest number of the cattle sent to
Smithfield are purchased by the great carcassbutchers, from whom the smaller retail butchers buy their needfal supplies.

The convenience of resting-grounds or cattlelayers for the droves, about the outskirts of London, need not be insisted on. We have already alluded to Laycocls"s estabhishment at Islington. In this, the cattle are supplied with fodder at a stipulated price, one shilling the night per head; besides which the manure is the property of the owner of the layer, and also the milk given by the cows (for numbers of milch cattle are bronght up from the country) during their sojourn, the office of milking being performed by his own people. This latter is a great advantage to a person who keeps an extensive dairy as well as a cattle-layer, inasmuch as he has an opportunity of testing the milking qualities of the animals before they go to market, and of regulating his purchases accordingly: he has, in fact, the best of the herd at his command.

When we consider the comparatively small space occupied by Smithfield market (once a field extending outside of the city walls, but now a spot imbedded in the heart of London), and the consequent confusion and danger arising every Monday and Friday from the number of cattle forced into its area, terrified by blows and the novelty of their situation, we may wonder that no better and more aptly arranged market has been established, constituting one of the many improvements of London, during the present day. The fact is, that, in the year 1833, a spirited and opulent individual, Mr. Perkins, at an outlay of $£ 100,000$ erected and opened a noble cattle-market in tlie Lower Road at Islington. It occupied an area of twentytwo acres, and no expense was spared to make it convenient for the purpose. Sheds, pens, troughs, drainage, general arrangement, comfort for the cattle, facilities for the purchasers, were all combined. The arrangements rendered disorder and confusion impossible; every possible want was foreseen : a market-tavem, stables, sheds, and even shops, were planned, as were also abattoirs or slanghtering-houses closely adjacent. But the well-designed experiment (which ought to have been successful) failed: and why? Old habits, inveterate custom, and perhaps interested opposition, rendered the scheme abortire; and Smithfield, with its confusion, its dangers, and its almost inevitable barbarities, maintains its ground. A writer on this sulject says, "Remonstrate with the grazier and the butcher; tell them of the impropriety of driving sheep and bullocks throngl crowded streets, exposing passengers to danger as well as the cattle to injury, and causing detriment to shops; they will answer,- that is all very true, but that Smithfield has a venerable name, and that cattle of every kind are brought to it from all 
quarters of the kingdom: that the man with a few pounds in his pocket has a chance of suiting himself, as well as he who comes to lay out hundreds: that the market-place occupies a kind of centre near the General Post-office and old established places of business, and is, therefore, very favourably sitnated for the prompt transaction of business; and that to remove it would run the risk of splitting the one nuiversally supplied market into many. There is some reason in these statements; mere attachment to old habits, or the mere power of monopoly on the part of the corporation of the city of London, cauld not of themselves have prevented the removal of Smithfield market." "What effect the railroads are destined to have on Smithfield yet remains to be seen. May we not expect that the amount of country-killed meat brought to London, especially during the colder months of the year, will tend at least to abate its more glaring nuisançes; and those, moreover, of the slaughter-houses in some of the most crowded parts of the metropolis:

We have, in the foregoing pages, alluded to the trysts or cattle fairs of Scotland; and we may add that these are not markets appointed by public authority, but by concert among the dealers, on a notice from the drovers or purchasers from the south or interior of Scotland (sometimes we believe made at the churches), that they are ready to purchase on a certain day at some appointed place. At the trysts thus concerted (many in May and during the summer), the sellers and buyers meet and bargain for the cattle. It would appear, however, that there are trysts held at customary terms, on the same plan as our English cattle-markets; and of these several are held annually about four miles from Falkirk, Stirlingshire. The following sketch of the Octoher Falkirk tryst, 1846, from the "Glasgow Chronicle," will give a picture of their importance, and serve as a specimen of the extent of business then transacted :- "The third and last of our great markets commenced on Monday. It was easy to predict from the state of prices at the September tryst, and the rise that has subsequently taken place in the price of sheep in all the principal districts throughout the country, that this our concluding and influential market would exhibit a rise. Last week a great many dealers passed to the north, eager to avail themselves at once of top lots, and the encouraging prospect afforded by the late results of sales in England. We understand that a great many sheep thus changed hands, and of course never appeared at Falkirk. Perhaps more than the usual number of buyers from the south arrived on Saturday and Sunday; and everything wore the aspect of a keen competition. On Monday forenoon, the Stenhouse moor was early filled with a splendid array of flocks, and despite the heary rain they appeared in tolerable condition. The day cleared up towards ten o'clock, when sales became a rapid business. From eleven oclock till four P.M. the road from the tryst to Falkirk (about four miles) contiuned one dense mass of droves; and we do not recollect that such quickness of sale has characterized any tryst for the last twenty years. On Tuesday the usual cattle supply was on the ground, and these in general may be said to have been in fine order, though but few fat cattle were offered for sale An advance, in the same proportion as that which took place on sheep, may be noted on this species of stock; and we may state that some of the best lots were purchased by dealers from the south before reaching the pnarket. On the whole, the sale may be said to have been a brisk one; and when we left the grounds the stock was nearly all sold off. Of horses the supply was not so numerous as, we liave seen, and very high prices were asked for all kinds of serviceable animals. This had the effect of retarding sales in the early part of the day. A. fair amount of business was, however, ultimately:transacted, though at prices not considered favourable to the buyer. Indeed many experienced dealers consider that horseflesh has reached its maximum. Two-year-old colts were selling at from $£ 25$ to $£ 40$." Of the cattle purchased at these trysts great numbers are driven to Norfolk and Suffolk for fattening, and other counties take their share. It is thus then that we receive black cattle from the north of Scotland;-but we must not forget that cattle from all parts and of all breeds, from Wales, Hereford, Devonshire, Yorkshire, Durlıam, Sussex, Lincolushire, and other counties, find their way to London. The system already described upon which the drover acts, is everywhere pretty much the same: he must be a man of trust and probity. The great thoroughfares through which cattle take their way to London, are by the great northern road over Highgate Hill, and through Islington; by the eastern outlet of the city,-viz., the Whitechapel road; and the western road, through Uxbridge, from Wiltshire, Herefordshire, Gloncestershire, \&c. From Devonshire and the southwestern counties the road approaches London through Woking, Weybridge, and Kingston. The majority of the droves, however, excepting those from the east, strike off towards Islington, for the rest which the cattle-layers there afford them, before the Monday market at Smithfield.

With respect to the principal cattle fairs of England, little need be said. At these markets for the sale of live stock, at which the cattle of the surrounding district destined by their owners for sale are congregated, beasts of all sorts and qualities are to be seen : bulls and cows, heifers, oxen, and even calves. But it is universally the 
case, unless from some cause the market is depressed, good cattle readily find purchasers. They are driven by the farm servants to the market, and their owners are on the spot: the eager contention between the buyer and the seller; the chaffering about a single sorereign; the indifference assumed of each party ; and at last the hearty elosure, has often amused us. A year since, at Reading cattlefair, we patieutly waited to witness the sale of a young bull of the short-horned breed, splendid in figure, a perfect beauty (which sold for a large sum); bought, after long harangues and a copious display of verbiage intermingled with affected sang-froid on both sides, by a man who from his appearance did not seem worth five pounds. We were moreover somewhat surprised that, while large six or seven year old bulls attracted attention, this young and admirable creature attracted but little notice, except from the lynx-ejed buyer, who for three good hours, while we stood by, never lost sight of his object and took it off in triumph, agreeing to the demand with a true English slap on the hand of the seller, and an agreement on the part of the latter to stand treat for a glass to the success of the purchaser.

We have now before us an account of the Hereford October Fair, in which some very fine oxen were exposed for sale, and among them ten beautiful steers, which sold on the average for more than $£ 33$ each.

But on these provincial fairs we need not dwell, as there is no one ignorant of their nature.

\section{CHAPTER VII.}

As the fattening of cattle depends not only on the quantity, but on the quality of the food taken, some observations on this point, may not be out of place.

All materials to which the term aliment may be applied, that is, all such as are fitted to supply and maintain the solid and fluid constitnents of the frame, must be capable of solution by the digestive agency of the stomach. They must be converted into a fluid called chyle; and this is again reconverted into solids and fluids of different natures, by the power of assimilation, which renders them part and parcel of the living body; the chyle is in fact received into the blood, becomes incorporated with it, and thus tends to the refreshment, the invigoration, the growth, and the nutriment of the body. Those substances alone which have been endowed with life (animal or vegetable), can be considered as affording nutriment-at least to the higher orders of living beings; so that the maintenance of life involves the destruction of life. The fuuction of digestion supposes the revolution of the materials of the food into their organic molecules; but it is only when the stomach becomes diseased, or when diet induces a morbid action, that the resolution of the proximate principles into their primary elements takes place, various gases being then resolved.

The proximate principles of alimentary substances,-namely, fibrin, gelatin, gluten, albumen, sugar, starch, oil, \&c., consist, sometimes of three, sometimes of four, elementary constituents. In the regetable lingdom these elements are generally three,-viz., oxygen, bydrogen, and carbon. In animal substances, they are generally four,- - viz., oxygen, hydrogen, carbon, and nitrogen or azote. In vegetable matter the predominance of carbon is characteristic; in animal matter the predomi- nance of nitrogen or azote; and when in any animal matter, as, for example, fat, azote is absent, it approximates to regetable matter, as oil. To animals which are decidedly carnivorous, azote is necessary, and they do not prosper if kept on food destitute of this prineiple; dogs, for example, when fed exclusively ou crystallized sugar (loaf sugar) and distilled water, being thus deprived of azote die in a few weeks. The same observations apply to gum, which contains no azote. Nevertheless, gum is far from being destitute of nutriment; and in the hotter countries, where azotized food can be better dispensed with than in northern latitudes, man will subsist for a considerable period on this substance alone. During the gum-harvest at Senegal the Africans live entirely upon it, about eight ounces being the daily allowance of a man, and in general they continue in good health, and even im. prove in plumpness.

With respect to sugar, when not purified, but combined with gluten, gum, and other vegetable matters, in its natural state as expressed from the cane, it is pre-eminently nutritious, and the negroes during the cane-harrest thrive upon it notwithstanding the increased toils of the season. By the removal of the substances which contain azote, as gluten and vegetable fecula, its nutritive powers are sensibly diminished. Hence coarse brown sugar is more nutritious than loaf, or refined, and crystallized sugar. Raspail observes, that "sugar will not ferment by itself; why then expect that it should ferment without albumen in the stomach? Neither sugar nor gluten taken singly are nutritive, but they become alimentary when united."

According to Majendie animals derive the azote which enters into their composition entirely from their food; and, consequently, he argues that none of the higher orders of animals can live, for a consider 
able period on food entirely destitute of azote; it is true that even carnivorous animals can live for a certain time upon food entirely destitute of azote, but in that case the excretions become altered; and it may be further observed that several vegetable and animal substances destitute of azote are highly nutritious, provided at the same time azote can be supplied from some other element containing it, though in small proportion. It would seem, however, that vegetable aliments acquire an accession of azote in the digestive organs, though probably at the expense of some part of the system. The nutritive properties of animal and vegetable oils or fats are well known, but still they do not contain azote as one of their primary or elementary principles.

The proximate principles in which azote, with oxygen, hydrogen, and carbon, occur, are, first, fibrin, which constitutes the chief part of the substance of muscles, especially those of adult animals, together with a principle called osmazome, to which meat owes its sapid flavour when dressed. Osmazome, however, is not a simple substance, but contains several salts or alkalies in combination with hydrochloric and lactic acid. In the muscles of young and white-fleshed animals, as real, little osmazome but a great proportion of gelatine is present; the gravy of veal, unlike that of beef, easily gelatinizes. In the muscles of dark-fleshed game, whether furred or feathered, osmazome (and therefore flavour) is prevalent.

Secondly, albumen (the white of an egg being an example). This principle forms the constituent part of oysters, mussels, and similar shellfish. It occurs in the green feculæ of plants in general; and abounds in the fruit of Hibiscus esculentus, used in Sicily to thicken soups, and in the bark of elm (ulmus campestris).

Thirdly, gelatin.-Gelatin exists in the skin, tendons, ligaments, the swimming bladder of the sturgeon and other fishes. Isinglass, for example, is gelatin. It differs in its qualities from albumen; it does not coagulate, is slowly soluble in water, and produces a tremulous jelly. Its nutritious qualities are very considerable: but we question whether it is quite so digestible as it is usually considered to be. This observation applies to the albuminous oyster or shellfish. Albumen, be it observed, coagulates at a temperature of $165^{\circ}$ Fabr., and becomes curdled or solidified by acids and the gastric juice. Milk is curdled by rennet, though not by boiling.

Fourthly, mucus.- This is an animal secretion (especially on certain membranes termed mucous membranes), which differs both from albumen and gelatin. Unlike the former it is not coagulable by heat, and unlike the latter it is not precipitated by vegetable astringents.

With regard to the vegetable principles which come under this list, we may first notice gluten, which contains from fourteen to twenty per cent of azote. Gluten is met with associated with starch in the seeds of the cereal plants known as grain, in many other seeds and fruits, and in the green and sappy parts of plants which yield feculæ. Separated from the other principles with which it is generally combined, gluten is moist, white, soft, and glutinous; but when dry, hecomes hard, grey, with a somewhat glossy conchoidal fracture. Birdlime is impure gluten. In the seeds of leguminous plants, as peas, beans, \&c., a substance closely allied to gluten exists, it is termed legumen, and also regeto-animal substance.

Gluten exists in the leaves of most edible plants, as the cabbage, lucern, sainfoin, \&c. When in combination with saccharine matter, and in a fluid condition, the fluid thus impregnated is capable of undergoing a vinous fermentation; indeed in the conversion of wheat-flour to bread, a sort of fermentation takes place evolving alcohol.

Gluten in its natural states of combination with starch, fat, sugar, oil, is extremely nutritious; take wheat, barley, peas, and other edible pulse, as examples. Besides gluten there is a principle in oily seeds, in many dry plants and their elaborated juices, which, whent triurated with water, produces an emulsion, termed emulsin, vegetable albumen, vegetable casein, or amygdaliu. How far this substance differs from gluten, does not appear to be definitely ascertained. Some chemists regard it as identical with the casein of milk, and others are of opinion that it cannot be distinguished from animal albumen. The nutritious qualities of the seeds containing it, such as rape, \&c., are well known.

The proximate principles which consist of oxygen, hydrogen, and carbon are as follow:-

Gum.-This exists in all vegetables, more or less, and in some abundantly; it oozes spontaneously from the bark of many trees, as tbe cherry, the plum, and the acacia. It abounds in many roots, as the carrot, the parsnip, \&c., and in many fruits, as the gooseberry, the currant, \&c.; united with agreeable vegetable acids. Pure gum is entirely soluble in water, forming mucilage ; but it is insoluble in alcohol. In its fluid state it is the nutriment of plants, and circulates largely through the leaves of many, as the lime. We have alluded to the nutritive qualities of gum in its pure state, but when in its natural state, combined with other principles, it adds greatly to the value of regeta. bles as aliment.

Sugar, or the saccharine principle.-This is very abundant in many vegetables, as the sugarcane, the beet, the carrot; in various fruits, as the grape, the melon, the fig; in some gumresinous extracts, as manna. It gives sweetness to the nectar of flowers, and is contained in honer, which is nectar that has undergone some process 
in the stomach of the bee. It is found in the milk of animals; and it is produced, by a depraved action of the digestive and assimilating organs, in that almost incurable disease termed diabetes mellitus.

Starch and sugar are mutually convertible into each other. Sugar is the principle by which seeds are enabled to germinate rapidly, thus forming from the starch their omn nutriment. This is familiarly exemplified in the process of malting,which is, first, the forced germination of barley; and then, at a certain point, drying it in a kiln, whereby its vitality is destroyed. Many seeds containing starch, and therefore insipid, may be made agreeable and wholesome by steeping them in water till they begin to germinate, when the starch is converted into sugar. The Burmese, by this process, transform the seed of the cotton-plant into a grateful article of diet. In the ripening of many, as those of the banana, a remarkable transformation of starch into sugar takes place. The sago-palms, when about to Hower, have the starch in their lofty stems all converted into sugar; they must be, therefore, cut down when the flower first begins to show itself, otherwise the sago they contain would be altogether lost. A sweet liquid from flowering palms (once in a state of starch) is drawn, and fermented into toddy, or palm-wine.

On the contrary, many seeds, as the common pea, which contain saccharine matter before they are ripe, have, as they ripen, this saccharine matter converted into starch; and, when they germinate, this starch is reconrerted into sugar.

Among the grasses of our meadows, many, at an early stage of their growth, have the stems very saccharine; but this sweetuess is lost at a later period, and the stems are insipid. This loss of saccharine matter diminishes their nutriment: hence it is an error to cut grass for hay when too ripe; for though, after it is stacked, it may be restored to a proper condition by the fermentation that then occurs, yet this is not unattended with risk, nor is the hay so savoury and acceptable.

In many trees, as the birch, the sugar-maple, and others, the starch in spring is converted by the ascending sap into a saccharine fluid; and from that of the maple concentrated sugar is obtained in America; while in England the sap of the birch is often fermented into a sort of wine.

Sugars may be divided into several kinds, according to the plant from which they are obtained. Some are eapable of crystallization, and others are not. Sugar of both these kinds exists in the sugar-cane; the latter constituting what is known under the terms treacle or molasses. Some sugars are susceptible of fermentation; others, however, are not so. The sugar of manna is neither crystallizable nor capable of fermentation. Honey is capable of fermentation, and yields the old Celtic beverage called mead or metheglin.
With respect to the sugar of milk, though it does not naturally erystallize, it may be converted into granular sugar by the action of dilute sulphnric acid, and is then, though not previously, susceptible of fermentation.

Starch.-Starch; chemically considered, differs from sugar and from gum only in the greater proportion of carbon which it contains; and, by removal of this superabundance of carbon, it is converted into one or other of the above principles. This change occurs in plants during their flowering, and in grains during their germination, as well as in the stomach during the process of digestion. In combination with gluten, or wheaten flour for example, starch is capable of undergoing fermentation; and this takes place during the process of converting the flour to bread, while it is in the state of dough. The precise nature of the action which goes on is not well understood; but the digesti bility of the flour is thereby increased, and its fituess as an article of food consequently improved.

Starch abounds in all the cereal grains, but in the greatest purity in rice, millet, barley, maize, \&c.; in wheat it is combined with gluten; with saccharine matter in oats and some leguminons seeds; with mucilage in potatoes, rye, and Windsor beans. In other vegetables it is differently combined, producing aliments various in degree of nutriment and digestibility. All seeds or roots yielding starch in abundance are termed farinaceous.

Starch is digestible and uutritious, but requires other princjples to be taken in conjumction with it; with milk, sugar, eggs, \&c., it constitutes one of the most wholesome and acceptable of aliments, and fattens rapidly.

Oily or Fatty Matters.-These principles are met with both in animal and in vegetable bodies; and they occur in a variety of forms, from fluid to soft, and to lard or concrete; but they caunot be mistaken. Unlike as these matters are to gum, sugar, and starch, yet their constituent elements are the same, excepting that they contain a larger proportion of hydrogen; and during digestion in the stomach the most dissimilar are brought into more intimate relationship than might have been anticipated. Sugar and starch are both susceptible of fermentation, during which they part with a portion of their carbon, which, uniting with oxygen, is evolved in the form of carbonic acid gas. From starch in fermentation, when a certain quantity of carbon is dissipated, sugar is the result:- a portion of carbon and oxygen being taken, the hydrogen remaining undiminished, alcohol is the product. This, in the words of Dr. Prout, is an oleaginous body of a weak* kind,-composed,

* "When we speak of a strong compound, we mean that its constituent supermolecules are like those of strong cane-sugar; less complicated than the supermolecules of a weak principle, like those of the sugar of honey..... The sugar of honey is more easily decomposed than the sugar of the cane."-Proct. 
like oils, of olefiant gas and water; and thus the analogy is complete, for all farinaceous and saccharine aliments undergo changes in the digestive organs similar to what occurs in fermentation, before they can be assimilated in the system,namely, conversion into oil.

"Though," says Dr. Prout, " the proportions of the different ingredients of the chyle, as ultimately formed, are liable to be varied according to the nature of the food, yet, whatever the nature of the food may be, the general composition and character of the chyle al ways remain the same. The stomach must, therefore, be endowed with a power or faculty, the agency of which is to secure this uniform composition of the chyle by appropriate action upon such materials as circumstances may bring within its reach. Two, indeed, of the clief materials from which the chyle is formed, the albuminous and the oleaginous principles, may be considered to be already fitted for the purposes of the animal economy, without undergoing any essential change in their composition. But the saccharine class of elements, which form a rery large part of the food of all animals (except of those subsisting entirely on flesh), are by no means adapted for such speedy assimilation. Indeed, one or morc essential changes must take place in saccharine alinents previously to their conversion either into the albummous or into the oleaginous principles. Most probably, under ordinary circumstances, these essential changes are altogether chemical; that is to say, these changes are such as do take place, or, rather, as would take place, if the elements of the substances thus changed in the stomach could, out of the body, be so collocated as to bring into action the affinities necessary for the changes produced in the stomach. Thus, as we know, the saccharine principle spontaneously becomes alcohol, which, as has been stated, is an oleaginous body of a veak kind. When, therefore, in the stomach, it is requisite that sugar be converted into oil, it is probable that the sugar passes through precisely the same series of changes it undergoes out of the body during its conversion into alcohol. We cannot trace the conversion of sugar into albumen, because we are ignorant of the relative composition and of the laws which regulate the changes of these two substances. The origin of the azote in the albumen is likewise unlinown to us at present; though, in all ordinary cases, it seems to be appropriated from some external source. That the oleaginous principle may be converted into most if not into all the matters nevessary for the existence of animal bodies, seems to be proved by the well-known fact, that the life of an animal may be prolonged by the absorption of the oleaginous matter contained within its own body."

'Thus, then, do animals fed on farinaceous and saccharine vegetables acquire, at least, a large proportion of their fat; but oleaginous matters are in themselves highly nutritious, " being already fitter for the purposes of the animal economy, without uudergoing any essential change in their composition;" yet, as oils are insoluble in water, they are not available for the support of the body till this immiscibility be overcome. Hence they are apt to oppress the stomach during the early stages of digestion, if taken alone, withont bẹing mingled with substances wlich facilitate their uuion with water. When this is accomplished, they are easily assimilated. Thus oil or fat, blended with farinaceous matters, or, as it is naturally, with milk (butter), =becomes very nutritive; and thus the butter, which might disorder the stomach if swallowed, alone, is grateful when spread upon bread or mingled with potato-meal.

We may here observe that the too copious use of saccharine matters, or of sacchanine vegetables, may in certain cases prove:burtful ; for "the derangement, or prartial suspension, of the conversion of the saccharine principle (in man) into the albuminous or oleaginous, not only constitutes a formidable species of dyspepsia, but the massimilated saccharine smatter passing through the kidners, gives occasion to the disease termed diabetes." In certain forms of disease, oxalic acid (poisonous acid of sugar) is produced and detected in the blood; and the production of lactic acid from the same source, forms, when in excess, one of the most troublesome kinds of acidity of the stomach.

Without alluding to water as an alimentary principle, which consists of oxygen and hydrogen aIone, we may here conclude our observations on the proximate elements of alimentary substances and their elementary constituents. Of the various condiments and stimulants, acids, \&c., we need here say nothing; there is, however, one article,namely, common salt, which, from its existence in the blood, and its importance in the animal economy, requires some notice; and it is necessary, in order to show this, to enter to a certain extent into the process of digestion, that is, into a short explanation of the solvent or reducing powers of the stomach, and the means by which the solution of aliments, and their combination into a fluid mass termed chyme, in the stomach, is effected. This operation is by the agency of a fluid termed the gastric juice, poured out of glands chiefly in the pyloric portion of the stomach, - the fourth stomach, or ahomasum, in ruminant animals. The alimeut then, having been duly masticated to a proper consistence and mingled with saliva, is convered into the stomach, and brought under the action of the fluid there secreted. By the agency of this secretion, and perhaps some other energy exerted by the stomach, the food is converted into a more or less fluid 
state, or, in other words, becomes diluted with an aqueous product. One important ingredient of this influential secretion-indeed, a necessary ingredient-is chlorine, in some state or other of combination. This secretion, in its bealthy state, always contains more or less of chlorine; and the powerful influence of this elementary principle appears most materially to contribute towards effecting the union of the food with the aqueous fluid or water. "The chlorine," says Dr. Prout, "thus so indispensable to the reducing process, is, perhaps, more frequently the subject of derangement than any thing concerned with the assimilation of the food. It often happens that, instead of chlorine, or a little free muriatic acid, a large quantity of free muriatic acid is elicited; which free muriatic acid not only gives rise to much secondary uneasiness, but more or less retards the process of reduction itself."

"The source of this chlorine, or muriatic acid, must," he adds, "be the common salt (chloride of sodium, formerly called muriate of soda), which exists in the blood; to suppose that it is generated is quite unnecessary. The chlorine is, therefore, secreted from the blood; and it may be demanded, what is the nature of the agency capable of separating chlorine from a fluid so heterogeneous as the blood? We are acquainted with one agent that exerts such a power,-namely, electricity; and this agent seems to be employed by the animal economy for its operations, in the same manner, and on the same principles, as the materials themselves are employed from which the animal body is constructed. Perbaps, therefore, the decomposition of the salt of the blood may be fairly referred to the immediate principle of this agency, electricity. But bere the question arises, what becomes of the soda from which the muriatic acid has been disunited? The soda remains of course behind, in the blood, and a portion of it is no doubt requisite to preserve the weak alkaline condition essential to the fluidity of the blood; but the larger portion of this soda is probably directed to the liver, and is elicited with the bile in the duodenum, where it is thus again brought in union with the acid which had been separated from the blood by the stomach. These observations, illustrating the importance of common salt in the animal economy, seem to explain in a satisfactory manner that instinctive craving after this substance which is shown by all animals." Thus then in the stomach, through the great nerves which supply it, a sort of galvanic operation goes on; indeed, Dr. Phillip and others have demonstrated, that when, on dividing the eighth pair of nerves, the secretion of the stomach is suspended, it may be restored by establishing a galranic current through the divided part of the nerves next the stomach. But besides the necessity of salt, as above detailed, its use as a condi- ment, a stimulant to the appetite, is not to be overlooked, and the expression in Job, "Can that which is unsavoury be eaten without salt?" is applicable in a great degree to varions animals besides man.

Keeping in view the above observations relative to the proximate principles of alimentary substances, and the ultimate elements of these, we shall be enabled to judge better respecting the nutritive qualities of the different sorts of food on which cattle may be most advantageously fattened. The $o x$ is herbivorous; we shall have, therefore, principally to look at the quality of its vegetable aliment, although, as already stated, soups in some parts of France are given to the cattle when enfeebled, and boiled fish serves in Norway as part of their winter fare. In our country, celebrated for the richness of its pasturage, and abounding in the cerealia and saccharine roots, \&c., the land is neither parched during the snmmer, nor, (unless under some calamity), unproductive during the winter. there is, therefore, a choice of food both dried and in a green or a succulent state.

An inquiry as to the comparative advantages of malt and of barley as food for cattle has been lately instituted by the commissioners of excise, on the ground that steeped or semi-malted barley is liable to be turned to other purposes than those for which it is demanded by the cattle feeder. Indeed, without being kiln-dried, steeped and germinating barley is available for the purposes of the brewer or distiller, and thus the excise might be defranded. Professor Thomas Thompson, of the University of Glasgow, states, that, in 1805 , among many experiments made, "a quantity of barley was ground, and mixed with a good quantity of oat-seed, to prevent it colering into a pulp; the mixture was infused in water of about the temperature of 190 degrees, and the infusion drawn off, after standing several hours. It speedily became sweet, and the wort drawu off was as sweet as wort from malt. Being fermented, it made excellent beer. The brewers who assisted were much struck with this experiment; they imitated it snccessfully, and in a few years all the beer in Edinburgh was made from raw grain. The brewers were prosecuted by the excise, they were prohibited from using raw grain, but no penalty was exacted. From this experiment, which was often repeated, it is evident that the starch in barley, when infused in hot water, is converted into sugar in a few hours. I believe that the same change goes on in the stomach, and that starch is speedily converted into sugar of malt, or dextrine, which is soluble starch, composed exactly as sugar is." We think, therefore, that the utility of previously converting the starch into sugar is questionable, as the due quantity necessary for conversion into fat will alone be formed in the digestive system, and the rest be taken up as nutriment in other combi- 
nations or forms. This seems to be the view of Professor Lyon Playfair, who thus states his opinion: "First, I am clearly of opinion, that in the present state of our knowledge no applicable process is known by which malt can be rendered unfit for the purpose of distilling. and yet useful for feeding cattle; but, at the same time, I conceive that such a process could be discovered by investigation.

"Second, a careful consideration of the sulject has led me to the conclusion that the boon (of semimalting barley) would not be so great as farmers at present believe. Barley, in the act of germinating, loses a certain amount both of the constituents which form the flesh, and those which form the fat, of the auimal. These are partly converted into carbonic acid and ammonia, which pass into the air in the form of gas, and are, therefore, lost to the farmer. The former is the principal loss; for the ammonia arising from the destruction of the Hesh-forming principle is developed at the latter end of the process. A given weight of barley is, therefore, of greater nutritious ralue, both as regards the production of muscle and fat, than the same weight converted into malt. The starch in the barley, during the act of germination, has passed partly into a kind of sugar, which, being soluble, and more easily digested, will pass more rapidly into fat. The advantage of malt as food is, I apprehend, founded on its easy digestibility ; in fact, in a practical point of view, you might conceive it to be barley half digested. But there are other plans of rendering food easily digestible without destroying part of its nutritious qualities, as is done in the act of malting, and such o erations are familiar to farmers. I conceive, then, that barley loses part of its nutritious qualities in passing into malt; and that, as there are other modes of aiding the digestibility of an aliment, the boon of allowing its use for the purposes of feeding cattle is not so great as to warrant government endangering part of the revenue by granting such a boon."

Professor Thompson, from his semi-malting or infusing experiments, comes to the same conclusion, and says, "I do not thimk that malt is a better food for cattle than barley."

Let us now see what another great chemist and physiologist says ppon the same subject. Professor Graham, of the Unirersity College, London, thus expresses his views: "I can find no evidence that cattle have ever been fed exclusively on malt, for fattening or any other purpose, or that malt lias ever formed a large proportion of the food of cattle. The high price of malt might preclude its being used for such a purpose in this country; but in Germany, where the manufacture and use of malt are subject to no restriction, it is not employed for fattening cattle, as I have been assured by Professor Liebig. In the process of malting barley a loss of nutritive substance takes place, which is estimated by the same chemist at from fire to seven per cent. The starch of the grain is saccharized, and rendered soluble, which is also the first step in the digestion of unmalted grain. Although less nutritive, unalt may, therefore, be more digestible by cattle than the original unmalted grain, even when the latter is softened by grinding and mashing in hot water. It is well known that the infu. sion of malt, or sweet wort, acts as an aperient on man and cattle, and camot be used largely as nutriment. Malt acts in the same way upon cattle, and this has been found practically to keep within narrow limits the proportion which it may be al lowed to form of their food. But in a small proportion it lias been pretty generally observed to be beneficial both to horses and black cattle in certain conditions of health; still, it is to be observed, rather as a condiment than as the staple of their food.

"Coarse sugar, or molasses, might, I beliere, be substituted for malt with the same beneficial effects.

"It is a common opinion that fixed oils prevent the fermentation of worts; and that, consequently, malt might be made unsuitable for brewing by mixing hinseed oil with it, an addition which would not injure the malt as food for cattle. Comparative experiments which $I$ have made on the fermentation of malt alone, and of malt-meal which was previously mixed with a fourth of its weight of linseed oil, showed that fermentation takes place in the latter case, al though it proceeded more slowly than in the former; and that the presence of oil reduced the product of alcohol to a small extent; the malt alone yielding seven per cent. more alcohol than the same weight of malt mixed with oil.

"Ground linseed, or linseed meal, is, I find, more effective than oil in checking fermentation. The addition of one-fomth of that substance to malt occasioning a loss of alcohol amounting to fourteen per cent. Linseed meal, also, when mixed with ground malt, renders it wholly unsuitable for mashing, as that operation must be conducted, in ordinary brewing, by making the liquid thick, so that the sweet wort drains amay from the grains only partially and very slowly. If malt should be issued to the farmers for the purpose of fattening cattle duty free, I would, therefore, snggest that it be groumd and mixed with linseed meal rather than linseed oil.

" It would, perhaps, be a greater advantage to the agricultural interest to allow molasses to be introduced duty free, on condition that it should be mixed, when landed, with a considerable proportion of linseed meal, which would prevent its being used for fermentation, or for any other purpose except as food for cattle."

We have here nothing to do with the financial question involved: the point to be decided is, whether barley or malt present the greatest staple of nutriment for cattle? WVe say, mhesi- 
tatingly, simple barley, ground to accommodate it to the active powers of the stomach. It contains in itself both the flesh-making principle (gluten) and the fat-making principle (starch or sugar) in great abundance; and to convert the starch into sugar by mashing, and abstract the saccharine result, is to deprive it of a portion of its intrinsic value. It is true that linseed meal, mixed with mashed barley (we speak not now of excise questions), will give it all that it has lost in the mashing; but this is really to pay extra for what might have been better, or as well, dispensed with ; we, therefore, place barley before malt; but, query; can the feeder afford barley? that is, will the price of his fattened oxen remunerate him for outlay in this species of grain? This must alto. gether depend on circumstances, and is somewhat out of our province.

With respect to pulse, such as beans, peaș, \&c., abounding in gluten or legumen; and other nutritive principles, we need not enter into any details; we must not, however, omit to observe, that the pods of the carob-tree (ceratonia siliqua') have been much recommended as food for cattle, and will no doubt; prove advartageous; especially as they may be now introduced, daty free, from the south of Europe and the shores of the Mediterranean generally, especially the Levant. This leguminous plant (an evergreen) is almost the only tree that grows at Malta, relieving the barren aspect of the white stone enclosures by its dark foliage. The pods contain, besides the beans, a sweet nutritious pulp, which is a common article of food in the countries where the tree grows naturally. The pulp is not unlike manna, both in taste and consistence, and is sometimes used as sugar to preserve other substances. This plant is called kharoob by the Arabs, and algaroba by the Spaniards, who use the pods in feeding horses after the pulp is expressed. They contain impure sugar, gluten, gum, lignin, and other principles which render them very nutritious; they have been in request from a very ancient period, and are, probably, "the husks that the swine did eat:" in fact, they are eagerly devoured by cattle at the present day in Palestine and Egypt. To what extent these pods have been employed as food for cattle in England we camnot tell; but there is every reason to believe that their introduction would be beneficial both to the merchant and the farmer. They would counterbalance the failure of the turmipcrop, and moderate the price of oileake; two very important objects, independent of their intrinsic value.

Oilcake is composed of the crushed seeds (linseed) of the flax plant (linum usitatissimum), and contains condensed mucilage, some oil, starch, \&c.; it is the residuum of linseed from which the oil las been expressed. Great quantities of this seed are imported from Russia; but it comes likewise from Prussia, Holland, Italy, Turkey, America, and also from India. The Indian linseed yields a larger quantity of oil than the Russian, but the plant itself is dwarfish. The importation of linseed into the United Kingdom, for the purpose both of sowing (especially in Ireland) and of crushing, amounts annually to about four millions of bushels; in 1837 the amount was $3,321,089$ bushcls; but, besides this, there is a very extensive importation of oilcake, which, notwithstanding the quantity that is home-made, meets with a good market.

Oil is also expressed from the seed of the rape (brassica napus), and of the cole or colza (brassica campestris), and the residue, in the form of a lard cake, containing starch and mucilage, known as rape-cake, is used on the continent for the feeding of cattle, as linseed cake is in England. Rape-cake is valuable as a manure, and for that purpose is imported in large quantities. When ground into powder, and drilled with the seed on light poor lands, it supplies nourishment to the young plants, and greatly accelerates their growth. In Flanders it is much used, mixed with the fluid refuse of the cattle-stalls, as a manure for flaxland.

The cultivation of rape and cole, on heavy clay soils, as spring food, is greatly recommended; both plants are hardy, and resist the winter's frost. The same observations apply to other varieties of the cabbage, some of which yield an enormous weight of food; and though they impoverish the ground, yet their substance, in all well-regulated farming establishments, is restored to the ground in the shape of manure; indeed, it is asserted by many experienced agriculturists, that in this respect the cabbage is superior to the turnip. When given to cattle, cabbages should be sliced in the same mamer as turnips or beet-root. When milch cows are fed with them all the decayed leaves should be carefully removed, as they communicate an unpleasant flavour both to the milk and the butter. Oxen fatten well on cabbages and oilcake, increasing rapidly in flesh.

In England, where the cultivation of the cabbage on a large scale, as food for cattle, is by no meaus so general, even on the soils best adapted for the purpose, as might be expected, those sorts which have a large close head are preferred; but in France, where labour is abundant and forage scarce, the large branching sorts are thought more profitable, because they yield a succession of leaves, fresh ones springing when the old ones are removed. Of these cabbages, the thousand-headed sort, the large cabbage of Poitou, and the tall cabbage called chou caralier, the stem of which is often six feet high, giving off large broad leaves, 
without any close head, are most in request. On good and rather stiff loam, well manured, the cabbage thrives best, and its leaves then acquire a great proportion of mutritive matter, insomnch that no vegetable produces so great a miss of vitluable food for cattle on the same spase of ground; and when it is considered that the different sorts cau be cultivated in rotation, so as to succeed eich other, their importance becomes augmented.

We need scarcely say that the turnips (brassica rilpa) hold a prominent rank among the articles used as food for eattle. The roots of this consist of a large mass of cellular tissue in which stareh and sugar are deposited; but they also contain a large quantity of water, the proportions of the ingredients in 100 parts of turnips being, according to Dr. Lyon Playfair, as follow:-

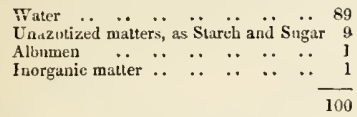

The regular cultivation of turnips, on a large scale, was origiually iutroduced from Flanders into Norfolk little more than two centuries ago; in the course of a century afterwards, it extended over the north of England and the south of Scotland, though for a long time the cultivation was carried on only by a few disceming individuals; in process of time, however, the value of the turuip erop hecame universally appreciated, and its cultivation general. Sevenal varieties of turnips are now known to agriculturalists, produced from the Brassica rapa by cultivation; but the Swedish tırnip, or Ruta-baga, is a variety of the Brassica campestris.

As a culinary root for the table the turnip has been long prized, and many varieties have been raised; but it is those of a larger kind than the kitclien-garden sorts, which now form so important a part of the improved systems of agriculture on all light soils. They are to a great extent the foundation of good systems of cropping ; they supply the manure required for the subsequent crop. while, at the same time, the ploughings, hoeings, and stirrings which they require, subserve the good of the land by the clearance of weeds.

Whether tumips be sown broadcast, or in the row plan (and the latter is the preferable way, at least we think so), the land requires preparation and minure. For this purpose, especially on light lands, bone-dust has been found very efficacious, and the more so if the farmer can add to it (as he ought) a fiir quantum of cowhouse minure. But within the last few years, another manure has been introducerl-we allinde to guano (that is, the longcollected rejectamenta of penguins, and other birds, which tenant varions rocks or promontories in the Southeru Orean). This is no novelty. It was known to the aneient Peruviaus. During the reign of the lncas, the destruction or annoyne of the birls during their breeding senson, fuil, indeed, at all times, the wanton disturbance of the hirds, weres lisitesl with severe punishments; nas, according to Garcilasso de la Vega, with death. "Ihis witer. alludes more particularly to a tract of coatst exceeding two leagues in length, between Areguipa and Tarapaca, divided into islands respectively under the care of superinteudents. In the old worli. however, the value of this mantme wis appreciated from the earliest ages; not indeed that the lirits were fish devourers, for they were pigeons; and in Persia from the days of olden time hate thene birds been kept for the salie of their duugr, so essential to the growth of the melon; indced, the Scriptural expression, relative to the value of a certain measure of "doves duug," during the fumine in Sanaria (2 Kings vi. 2.5), eviclently refers to the use of this article in raising crops of vegetables essential to the health of the natives of Western Asia. (See Pict. Bible.)

Since the discovery of guano in the islands of the Pacific Ocean, vast stores of this manure bave bcen found on islands situated on the west cortst. of Southern Africa, that from Ichaboe being of the richest quality : this island we believe is now quite exhausted, but it oceurs on rocky hendlinds, and unmolested islands, where sea fowl breed in congregated thousands, so that supplies continue still to arrive in our ports. Guano differs considerably in its constituents according to age, purity, and various other circumstances. Its analysis, therefore, as published by different chemists, offers an according range of variation, but the following are the component parts of the most valuable specimens, - riz. urate of ammonia, oxalate of ammonia, oxalate of lime, phosphate of ammonia aul mignesia, of lime and of soda, sulphate of potass an.l of soda, muriate of ammonia and of soda, alumina, and a waxy or fatty matter in small quantities.

From its richness in ammoniacal salts, it claims the furst position among animal manures. These salts, according to Von IIartius, " act very favourably on vegetation. They abstract from the air its earbonic acid, and it is through its means that those various proximate principles are formed, as starch, mucus, resin, lignin, \&e., which constitute the body of the plant. With the exception of the oxalite and phospluate of lime, nearly all the salts are solulile in water. The urate of ammonia is not so, but then in the atmosphere it undergoes a decomposition, by which carbonate of ammonia is formed, which is equally soluble with the rest of the saltis, and is taken up by plants, and contributes rery much to their mutrition.

"The ease with which these salt3are decomposerl by the air and rendered partly vo'atile, will pieltly account for the fact, that plituss, manured with 
guano, generally present early in the morning accumulations of dew on the points of their leaves. The guano absorbs the surrounding air, aud also the vapour that may be in it, which is especially serviceable to plants, and this is why guano is so valuable a manure in dry and barren regions."

Compared with dove-cote manure, its fertilizing power has been estimatedat from three to four times greater; and it is reckoned to be five times stronger than might soil. In the cultivation of turnips, guano has been found by repeated experiments to be superior either to bone dust or farm manure; it is used at the rate of from three to five hundred weight per acre, distributed on the drills, with the best effect both as regards amount of produce and early and vigorous growth. We are not, however, about to enter into auy details respecting the culture of turnips ; we refer to them only as formiug an important part of the food of cattle, insomuch that a failure in the crops, generally, camot but be regarded as a serious calamity.

"It may be considered (says an anthority on this subject) that the most advantageons mode of consuming turnips is to draw them and cut them in slices in the field, there to be consumed in troughs by sheep, to whom corn or oil-cake, as well as hay, is regularly given.

"When the crop of turnips is abundant, part of them may be stored for the cattle in the yard or fatting stalls, and for the milch cows and heifers. They will require nothing but good straw if they have plenty of turnips, and no hay need be used unless it be for the horses; and even they will thrive well on Swedish turnips and straw, with a small quantity of oats. Turnips are often left in the field all winter, which greatly deteriorates them. If they cannot be fed off before Christmas they should be taken up with the tops on, and set close together, covered with the tops, on a piece of grass in some dry spot. They will thus be quite sufficiently protected from the frost: or the tops may be cut off, within an inch of the crowru of the root, and the turnips be then stored in long clamps five feet wile and four foet high, sloped like the roof of a house, and covered with striw and earth, in which state they will keep till they are wanted. It is advantageous to have different varieties of turnips which will come to perfection in succession ; and it is useful to sow some at different times for this purpose."

Among other vegetables useful as food for cattle, the beet tribe claim notice. The root of the field-beet, mangold wurzel, or mangel worzel (Beta altissima), which was long known in Germany, was introduced at the close of the list century it is said by Dr. Lettsom, a physician of great eminence, and is now very extensively cultivated. The common red beet (Beta vulgaris) is cultivated in gardens for the sake of its delicate root; but there is another species, the chard beet (Beta cycla), inferior in the size of its root, but remarkable for the thickness and size of its leaves, which are yellow, white, green, or crimson, in different varieties. On the continent these leaves are used in soups, and the ribs are stewed; in Fngland the leaves are sometimes substituted for spinach, but they are held in little estimation; yet cattle are extremely fond of them, and the plant. which is very loxuriant, might be cultivated with advantage, as field produce, in rows; the more so, as it is an excellent substitute for fallow on light good loams.

If sown in May in drills two feet wide, and thinned out to the distance of a foot from plant to plant, in rows, they will produce an abundance of leaves, which may be gathered in August and September; these, a central bunch being left on each plant, are rapidly renewed, affording a succession of food. These plants do not seusibly exhaust the soil, and, what is more, the leaves add much to the milk of cows, without imparting to it that disagreeable flavour which it is apt to acquire when the cattle are fed npon cabbages or turnips, and which is owing in some measure to the rapidity with which these latter run into the putrefactive fermentation. The leaves of the chard-beet when steamed with bran, chaff, or refuse grain, form a very good food for pigs, and also for bullocks put up to fatten.

With respect to field-beet or mangold wurzel, its root is too well known to need any description, nor need we comment on its culture, which is most successfully carried on in deep sandy loams made rich by repeated manuring. The sowing time is May, and the roots should be taken up and stored for winter use towards the close of autumn; the top as well as the tap root being removed, and the earth scraped carefully away. They may be packed in the barn or root-louse, in layers altemating with layers of straw; the whole mass being then well covered and defented from the frost. Or they may be put into trenches, having a good layer of straw at the bottom and on the sides, till they rise in a ridged pile three feet above the level of the ground, the whole being then covered with straw, and a thick outerlayer of the earth dug out of the trench; aronnd the mound a drainage gutter with free out lets must be dug, in order that no water may soak into the interior of the mound. When the roots are required for use, the mound must be opened at one end, and after the requisite quantity is extracted, the opening carefully covered up as before. In either of these two modes they may be kept till spring.

There are few crops more valuable as winter food for cattle than the beet or mangold wurzel. Swedish turnips (or Ruta baga) exceed them in the quantity of nourishment, weight for weight; 
but on light and well mauured soils the produce of the beet per acre is much greater. According to Einhof and Thaer, eighteen tons of mangold wurzel are equal to fifteen tons of ruta baga, or seven and half tons of potatoes, or three and half tons of good meadow hay, each quantity containing the same nourishment; but the roots may be grown upon less than an acre, whereas it will take two or three acres of good meatow land to produce the equivalent quautity of hay. Of all these root-crops, it appears that the least exhausting to the land is that of the beet. The mangold wurzel is admirable for bullocks given with dry food, but cows fed too largely on it are said to become too fat and to lose their milk; under some eircumstances, however, this very circumstance would prove an advan. tage, especially when it is desirable to dry and fatten off cows, and prepare them as soon as possible for the butcher. A white variety of the beet is cultivated in France for the extraction of sugar from its juice.

The carrot (Daucus carota), of which there are many varieties, affords a valuable root for the food of cattle. In England the large orange carrots are most frequently raised in the fields for winter cousumption, but on the continent large white and yellow sorts are more esteemed. In Belgium it is common to sow the white carrots in spring amongst barley which is reaped early; as soon as the barley is eut, the land is cleared of weeds and stubble, and liquid manure is poured over its surface. The carrots which were scarcely visible, and the tops of which were eut off in reaping, now shoot up, and where they require are thinned by hoeing. At the end of autumn the erop is carefully forked up, and the ground prepared for some other crop. Where hay is scarce, carrots form a very economical substitute ; they must be kept in dry root-houses or in trenches. From twenty to forty pounds of carrots with a small quantity of oats is a sufficient allowance for a working horse for twenty-four hours; these roots, however, when cut and steamed are rendered more uutritious. Parsnips are also treated in the same way, and also potatoes.

From these roots we may turn to the artificial grasses (as they are commonly but erroneously called), of which several are of the highest importance to the cattle-keeper. Among these lucern (Medicago sativa) is pre-eminent. This plant, one of the leguminous family, was in high repute in ancient times, and is spoken of with great com meudations by the writers on agricultural topies; nor has it lost its celebrity in the present day, and wherever husbandry las made progress it is largely cultivated, granting the soil and the elimate to be suitable. Where these are favourable lucern grows with astonishing rapidity and luxuriance; but as it will not bear extreme frost, nor Hourish on a poor cold wet soil, nor jet on sterile stony ground, the farmer must exercise discretion. Deep rich loam which has beeu previously trenched and well manured, is rather light, and thoroughly drained, is the best; and the produce of every such acre will be astonishing. Its growth is singularly rapid; that of clover is not to be compared to it: a tuft of lucern will rise to a foot above the surface, after being mown, in the time that clover will rise only a few inches. It lasts from eight to twelve years, striking its roots deep into the soil, where they are out of the reach of drought; and in the most parched and sultry weather, when the herbage arouud languishes or withers for want of moisture, the lucern rises fresh, green, and vigorous. Its great bane is a wet subsoil ; this must be dry and rich, and the surface must be clear of weeds. Land, on which two successive crops of turnips have been raised, and which have been fed off witl sheep, when well prepared gives a good return of lucern. In the month of March the sowing should take place. A small quantity of barley, perhaps a bushel to the acre, should be drilled into the g:ound, and at the same time from thirty to forty pounds of the lucern seed sown broad-cast; the ground must be now harrowed and lightly rolled, so as to lay it flat and even, without water furrows.

When the crop appears it must be well weeded, otherwise there is a great probability that it will fail. When the barley is reaped, the stubb]e should be eradicated either by the hoe or the harrow: at least this is a good practice, especially if the plants of lucern be strong. In a short tine it may be cut as fodder, but sheep should not be depastured on it, as they bite too close to the root. It should always be cut as soon as the flower is formed, and also cleared of weeds.

The second year will generally bring in an early crop, and it may be cut four or five times during the season; the ground being each time weeded or cleared by means of a sort of harrow.

The cottager, with a small plot of ground, wil] do well to sow lucern in rows, and eut at regular intervals a portion for his cow, using the hoe for the purpose of keeping the ground elear from weeds.

Of all green fodder, both for horned eattle and horses, lucern is perliaps the best. Horses fed upon it, with the addition of a little corn, will keep up their strength and condition under hard lahous. Cows thrive upon it, and return a full supply of milk; but lucern must not be given to cows or oxen in too large quantities at a time,-it must not be given when wet with rain or dew: and the best plan is to keep it for twenty-four lours after it is eut, in order that the juices mas be evapo. rated to some extent under a partial fermentation; a process which, while it adds to the nutritire qualities of the lerb, renders it less liable to inHate the stomach of the cattle, or, as the farmer 
would say, produce "hoove," that is distention of the stomach from gas.

Lucern is not easily made into hay: it is too succulent to dry rapidly, and a shower of rain, in its half dry state is almnost sure to spoil it, as the stem is quickly soaked with moisture, which does not readily evaporate; yet, in favouralle seasons, a heavy crop of good hay may be obtained, the produce of an acre being nearly donble that of clover.

Sainfoin (Hedysarum onobrichis) is another leguminous plant of great value; unlike lucern, however, it prefers a calcareous or clalky soil to a deep, rich loam, and flourishes where the latter would perish. Its root is strong and fibrous, and strikes deep into the stony soil, finding moisture even in the driest seasons : but a wet, coll, heavy subsoil is very detrimental to the health of this plant, and causes the roots to perish; and, as in the case of the lucern, it decays when choked up by dank weeds or grass. A crop of sainfoin on a fit soil, and properly; trigneged with occasional topdressings of ashes and manure, will last for eight

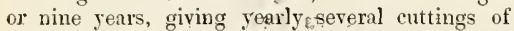
green fodder or two of hay. "Sainfoin is usually sown in the spring, in a thin erop of barley or oats, the same general plan being pursued with respect to its cultivation as with lucern; and the farmer must not expect to see it in full luxuriavce till the second year.

Sitinfoin hay should be made, if possible, in dy hot weather, so that all the juices of the plant may be evaporated before the stack be made. This is important, for if any moisture be left the whole is apt to become mouldy; indeed it is recommended that in precarions weather it be carried green (if not wet with showers or dew) under cover, and stacked in alternate. lasers, with good, dry straw. By this means it will impart some of its fragrance to the straw, and lose none of its nutritive qualities. The same observation applies both to lucern or elover. Sainfoin hay is extremely relished by eattle, and if well made is very mutritious; nor is it less acceptable in its green state, and this, perhaps, is the most advantageous way in which it ean be used.

Clover (Trifolium) is mother important plant, of which several species are cultivated, some being peremial, as the Dutrh clover (Trifolium repens), the cow.grass clover ('Trifolium medium), the lesser yellow trefoil (Trifolium minns): some biennial, as the common red or brown clorer (Trifolium prittense): and some annual, as the French clover (Trifolium incamitum).

It is the red or brown clover which is generally cultivated, both as green fodder and as hay for cattle; this is usually sown with barley or oats. but sometimes among wheat or rye, in the spring. In Norfolk it is the practice to sow it with barley; in Scotland it is often sown with wheat; and in Belgium with rye. But this depends on the system of rotations adopted in different countries.

The first crop of clover is generally mown and made into hay. During this process care must be taken lest the tender leaves of the plant he broken off in drying; consequently, the swarth should not we tossed up and shaken about, as is done with common meadow hay, but merely turned orer and exposed to the sun and air; and then, when all moisture is evaporated, carefully stacked up. Should the clover, unfortunately, become soaked with rain, nay, even if the rain should continue, the farmer must wait nntil fine dry weather returns, and completes the process of drying; if this is not effected the hay will certainly become musty. But however spoiled in appearance, if it be at last fiirly stacked in a dry state, with salt scattered in, it will be acceptable to the cattle in winter, and even nutritious. A writer says, that "A very good method in those seasons when a continuance of dry weather camnot be reckoned upon, particularly when the secoud crop is cut in September, is to take advantage of two or three dry dars to cut the clover, and turn it as soon as the dew is completely dried off the upper side; the next day do the same, and in the evening, carry the green dry clover, and lay it in alternate layers with sweet straw, so as to form a moderately sized stack. A fermentation will soon arise, but the dry straw will prevent all danger from too much heating, and, acquiring the flavour of the clover, will be eaten with aridity by the cattle. To those, who make elover hay for the use of their own stock in winter, we recommend this as far preferable to the common method, even when there is less danger from the weather. In northern climates it would probably save the crop two years out of three."

Many firmers are in the habit of sowing ryegrass (Lolium perenne) in a small proportion with clover. especially on lands which have been repeatedly cropped with the latter, and therefore somewlat exhausted. The plan is very excellent, for when the mixed crop is cut and made into hay, the young rye-grass wili prove a good corrective to the heating qualities of the clover. It is true that pure elover-hay is preferred in and about London, where it is extensively used cut into chaff, and mixed with oats, beans, \&e, and given to hardworking horses. With respect to horned cattle, green clover with tares and other artificial grasses is largely giren; and if the succession of crops is well mannged, a supply of green fodder may be obtaint d from Nay to the end of November.

The French clover (Trifolium incarnatum) has been introducerl from the south of France only within the last fers years. This plant is a valuable adlition to our list of artificial grasses, and when sown 
in the spring it rapidly arrices at perfection. One of its principal uses is as early food for ewes and lambs; for this purpose it is sown in autumn, after barvest, the stubble land heing barrowed so as to raise the mondl. On this the clover-sed is sown at the rate of 18 or 20 llis. an acre, the rolled in well. It springs up and stands the winter well ; and on the return of spring appears in luxuriance. It makes excellent hay, and may be clenred off the ground in good tinie to plough the land and clean it for turnips. ' It may be mixed with rye-grass; but from its rapid and vigorous growth is not well adipted for sowing with a crop of corn; indeed it is doultful whether this should be done with any clover.

Tares or vetches (Vicia sativa), of which there are several varieties, constitute a very important green crop, thriving lest on heary soils, and yielling a profitable return. One sort is much more hardy than the other, and will stand the s?erest winter: this may be sown in the autumn for early spring fodder, the more tender sort in March, and it will come in three or four weeks after the former. A good farmer will aim at a succession of green crops, and tares may be sown from spring till August, for winter use. If the farmer has more tares than he absolutely needs, he may make them into excellent hay should the weather permit; or depasture sheep upon them, cutting the forder and securing it in proper racks, that it may not be trodden underfoot and wasted. A succession of tares and brown clover may be kept up from May to November. Tares require the land to be well manured; but they besone ar excellent substitule for a summer fallow on heary soils, and thus amply repay the outlay in labour and manure expended upon them.

Such are the roots and artificial grasses on which cattle are fed ; we here sar nothing of the ordinary grasses of the meadow, nor of common hay, straw, chaff, or grains, for with these all are familiar. In supplying cattle with artificial fresh-cut grasses, luceru, sainfoin, clover, \&c., care must be taken, and we repeat our-injunction that they be cut in as dry a state as possible, and left for twenty-four hours to undergo partial fermentation before being given to the cattle; and eren then they should be -allowed only in moderate quantities at a time, other. wise the animals are apt to become hooven or hoven, owing to the evolution of carburetted hydrogen in the panuch; indeed, we have known cows, which had been previously feeding on a rather scanty grass pasturage, thus affected after heing turned upon a rich aftermath. Of all the artificial grasses, none is more apt to render cattle hoven than lucern rashly given; they are apt to gorge themselves: whereas, if a small portion o:ly be allowed from time to time, they masticate it mole thorough$l_{y}$, rendering it much more readily digestible, and consequently letter adiapted for yielding to the assimilating organs the principles of nutrition. The cow will thus retain her health, and yield more and richer milk. Many practical farmers consider lucern, at all times, too stimulating for milch cows; they aver that, if largely used, it deteriorates the milk, and is apt to produce eruptions about the thighs and abdomen, from which exudes an acrid humour, producing foul incrustations, loss of hair, and irritation of the skin, together with great debility and loss of appetite and milk. This disease, termed by the Freuch rafle, or jet de la lucesne, may be removed by a change of diet, cleanliness, and exercise; the water should be soft and pure, with a little flour mixed with it; and the food, if green, sprinkled with a little salt.

Some have oljected to mangold wurzel for milch cattle, but we doubt whether on sufficieut grounds; for it is often the sudden change from one diet to another, without rariation, and not the article of diet itseli, that is injurions. When mangold wurzel is given with a proper proportion of hav, it has been proved by experiment to be very salutary; but if the statement in the "Farmers' Journal "for $\mathbf{1 8 1 4}$, is to be relied upon, it has, when given alone, produced a partial paral ysis and a loss of milk; but in the instances narrated it appears that the cows were suddenly tritusferred to this diet without any admixture. Half a bushel of sliced mangold wurzel, morning and eveniug, with a good allowance of sweet hay in the intermediate portion of the day, has been tried, and found to keep cows not only in health, but in the finest milking condition. That there is nothing deleterious in this root appears from its analysis:- - a thousand parts contain about 50 of sugar, 22 of mucilage, 2 of starch, 6 of extract, 35 of woods filre or lignin, and $\$ 85$ of water. Yext to mangold wurzel, many farmers regard parsnips as the most valualle root; indeed, in some districts, and particularly in Jersey, this root is largely used, both for milch cows and for fattening oxen. They are best when steamed. as are also potatoes; indeed, cut straw or chaff (not the husk of grain, which is most dangerous, and scarcely if at all digestible) forms a much more nutritous food when steamed and giren warm than in its crude condition. On steamed roots, steamed chaff, and a little has, many large farmers keep not only milch cows, but oxen and working horses, at least during the winter. We are talking of stall-fed cattle, and not of such as are depastured in the fields, though, where the fields are eaten hare, a regular allorrance of food on the same principles is necessary. A discreet allowance of green fodder, cut grass, mangold wurzel sliced, turnips sliced, steamed roots and hay, or cut straw and brewer's grains, clover, chaff, and oilcake, or linseed boiled or unboiled, form the sta]le articles of the diet of cattle; and the proportion in 
which any of these is to be given, depends on the condition of the animals, and whether they are milch cattle or cattle for fattening. When oats are given they should be always lruised, as they are very difficult of digestion, and often produce serious mischief, remaining unchanged in the alimentary canal.

Previously to stall-feeding cattle, it is advisable to keep them for a short time on a bare pasture. By this plan the stomach acquires tone and vigour, the appetite is healthily increased, and the animals feed with a greater relish, and fatten more rapidly. During their feeding the healthy tone of the stonsach should be maintained, and the diet in proportion to the ease of good digestion, which should always " wait on appetite."

In the treatment of cattle, whether in the field or in the stall, good clean water is essential. Where no good water is otherwise accessible, it is better to sink wells, and pump the water into stone troughs, than to allow the animals to drink from a muddy, filthy pond, full of putrescent animal and vegetable matters which generate many diseases. Such water injures the quality of the milk, and disorders the digestive organs. These evil effects are often attributed to the grass, whereas the cause is in the water and not in the pasturage. It is notorious that cows pastured in districts where marshes and stagnant pools abound, into which the drainage of the land is carried, are sulject to that scourge of cattle known as "Red Water," and also to severe diarrhœa.
Cattle in their pastures drink at will, and usually take from 12 to 18 or 20 gallons in the course of twenty-four hours; but, when stall-fed, it is necessary to supply them twice or three times a day, according to the nature of their food. If fed on dry provender, they require water more frequently than when eating succulent herbage or juicy roots; and neglect in this point is one of the causes of various inflammatory diseases which often make their appearance to the loss of the feeder. With a due supply of pure water, cleanliness, the free application of the currycomb, ventilation, and a little gentle exercise daily in a bare enclosure, are very important concomitants. A hot, close, undrained cow house, into which pigs, fowls, ducks, \&c., have free access, is a disgraceful spectacle.

The management of milch cows is a simple affair. It is on good old natural pastures that they maintain the best health, return the most milk, and select the herbage best suited to their appetite ; but when houser or stalled, the great rule is not to overtax their digestive powers, while a sufficiency of food is supplied, and that wholesome and of more than one sort. If overfed, the cow will have some difficulty in bringing forth her calf; her udder will sympathize with the derangement of the stomach, and the vital fuuctions will be all in disorder. Good sense and a little experience must be brought into operation. The same remarks apply to cattle fattened in the stall for the butcher.

\section{CHAPTER VIII.}

IN entering upon the subject of the diseases of cattle, our plan will be to render it acceptable to the farmer or grazier who pretends to no anatomical knowledge, but yet is glad of some advice by which to be guided in the treatment of the more ordinary cases of malady which demand his attention. He cannot always have instant recourse to a veterinary surgeon, and in slight disorders may not deem it needful, though we must say we doubt the soundness of his policy. It is by the veterinary surgeon only that all operations must be performed: and in cases of severe accidents his skill must be called into requisition. Nothing is more to be reprobated than the practice, unhappily still too geveral, of applying to a farrier, ignorant alike of anatomy, physiology, and the syraptoms of disease ; or to a druggist, who is in the habit of compounding drenches of various nostrums (many worse than useless), when the lives of cattle are at stake. This practice is the more inexcusable, when professed and well-educated veterinary practitioners are within call of the farmer, - and of such few towns or rural districts are now destitute. It is not, however, for the veterinary surgeon that we now write; it is, as we have said, for the farmer, and that by way of guide and advice.

The ox, like the human subject, is liable to numerous maladies, arising from different causes; - to fever, to inflammatory affections of the brain, lungs, liver, intestines, and other organs ; to paralysis, and other diseases connected immediately with the nervous system; to various chronic diseases, and to sudden derangement of the complicated digestive apparatus from improper food. To these classes of diseases others might be added, setting aside injuries from external causes which are constantly happening.

Before entering into these more fully, a few preliminaries relative to the constitutional temperament of the domestic ox may not be out of place; it is indeed a point that demands our notice.

Comparing the ox with the horse, neither the nervous nor the arterial system of the former exhi bits the same energy as that of the latter. The brain 
of the ox is small; the nervous energics are soon exhausted, nor are they so easily recruited by rest, as in the horse: the ox will not endure severe labour, especially if huried, and will frequently sink down with exllutustion; iu illness it is sooner prostrated than the horse, and more subject to paralytic weakness. The chest, moreover, has less volume, and the free play of the lungs is more frequently oppressed by the distension of the stomach, which, with the abdominal viscera, occupy more room in proportion, as being of comparatively predominant importance. The ox, indeed, is expressly formed for giring milk and flesh as the food of man; and though this animal has been emplosed in labour from the earliest times, it was for slow labour, with frequent intervals of rest.

The pulse of the ox is quicker than that of the horse, ranging from fifty to sixty in a state of health; in the horse it is under forty. In cattle, near the time of calving, the pulse often rises to eighty or eighty-five, and in milch cows is always quicker than in oxeu. The arteries generally, those arising from the heart immechately, being excepted, are comparatively much smaller than in the horse; while, on the contrary, the veins are far larger, and indeed the whole venous system is more developed, and especially so in good milch cows, in which the subcutaneous abtomiual vein for milk veirı), is taken as a criterion of their qualities

It is not always an easy thing to feel the arterial pulse in cattle; this may, however, be generally effected at one of the following arteries:The submaxillary, a branch of the carotid which dips nuder the augle of the lower jaw ; the temporal artery rumning np between the eye and ear; or the anterior auricular artery, which supplies the anterior muscles of the ear. The pulsation of the heart itself may be tried by placing the hand on the left side of the chest, a little within and behind the ellow. The warmth or unnatural coldness of the ears, and the heat of the blood at the roots of the horns, are points to be attended to in conjunction with the pulse.

When blood is abstracted from cattle, the external jugular vein is that commonly selected for the lancet; it is rery apparent, rumning along the side of the throat from the angle of the lower jaw. A skilful operator will use a stroug broad-shouldered lancet, but the farmer contents himself with the fleam, which in his hands is more certain and safe; but, whether the lancet or the fleain be employed, the neck should not be strapped or corded round, as the pressure being alike on both sides of the reck impede the return of the blood from the head; firm pressure of the fingers a little below the spot where the puncture of the vein is to be mule, will suffice to render it prominent. Ocuasionally, in affections of the mouth or nasal or ans, a flow of blood is obtaiued from the ressels of the palate by free incisions on the latter : and sometimes certain reins of the limbs (the cephalic of the fore limb, the siphliena of the hind himb) are selected. In inflammatory diseases, prompt and cfficient bleeling is indispensable; and this should be carried so far at once as to affect the circulation, and thereby, if possible, arrest the course of the disense. 'Timid bleerling, rendering its repetition needful, is to be escliewed; but at the same time atteution should be paid to the age, constitution, and vigour of the animal In an aged cow which has hatd numerous calves less loss of blood will suffice than in a young one whose coustitution is unimpaired, or an ox in full vigour, From the latter, two gallons of blood may be extracted, while fiom the first half the quantity will probably suffice. To bleeding, aperi. ent medicine should be added; and in this we can scarcely ever do wrong, for cattle bear aperients, especially with a little carminative to excite the action of the stomachs, better than the horse, in whom they sometimes produce dangerous irritation of the alimentary canil

It is to the inflammatory diseases of cattle, which demand prompt measures carried out with bolduess yet discretion, that we shall first direct our attention.

SIMPLE FEVEY.

Cattle, especially in swampy lands, are subject to attacks of fever; this is sometimes pure or idiopathic, and occasionally assumes an intermittent form; but if suffered to ptoceed, some vital organ, predisposed to take inflammation, becomes as it were the centre of irritation, and the case may terminate fitally.

In simple fever the animal is languid and dull, it refuses food, the hide loses its mellowness, the flanks heave, the horn is hot at its base, and the pulse is hard and quick. In a day or two the animal seems better, but after a brief interval the symptoms return with increased riolence, the breathing becomes more laborions, rumination censes though the animal often lies down, but this is from weakuess, and the mouth is dry aud hot. Mischief is now coming on, and, most probably, in the form of inflammation of the hungs.

This disease is, perhaps, the most prevalent in autumn, when cattle are exposed in damp lands, and heavy cold fogs set in at night, or partial frosts which crisp the griss, yet luxuriant though harsh. It may arise from miasmatous exhalations, or from water putrescent with decomposed leares or other regetable matters. At the beginning of the disease, the judicious farmer will remore the animal, and take away some blood, giving afterwards a cuthartic dose, composed of from eight to twelre ounces of Epsom salts (sujphate of magnesia), two or three ounces of sulphur, two drachms of powdered ginger, the whole mixed in a quart of warm water; half a pint of linseed oil may be added. 
The diet must be reluced and mashes given, with repetitions of the cordial purgative, till the animal recains is wonted cheerfulness, and every symptom has disappeared.

It not unfrequently happens that fever, appearing at first in a slight and simple form, suddenly puts on a decidedly inflammatory character; or, on the contrary, assumes a low typhoid form, in which, as in the human subject, the vital energies give way under the process of what is not unaptly termed a secretly consuming fire.

\section{IYFLAYMITORY FEVER.}

This disease, called black quarter, quarter-ill, evil-joint, blood-sticking, and other meaningless names, is often prevalent in certain districts and during certain years, occasions extensive nortality. Young cattle are the inost commonly seized, their habit being more disposed to plethora than aged suljects. Sometimes the disease appears to be epidemic, or at least attacks whole herds turned imprudently from spare diet upon luxuriant pastures, sulijected to wet cold nights, while the blood vessels are receiving an inordinate addition of the vital fluid from the assimilating system.

So rapidly does this fever come on, that the slight precursor febrile symptoms are often unnoticed; and so quick is its course that there is little time, or none, to have recourse to remedies. Generally, however, the ordinary symptoms of simple fever may be noticed, but these all at once assume a most aggravated form; the animal labours nnder a general venous congestion, and dies a mass of putridity.

The first stage of this disease is highly inflammatory. 'The pulse is quick, hard, and strong; the eyes are inflamed and protruding; the tongue is dry and parched ; the breathing labonred and quick, with deeper inspirations at intervals; the lhead is stretched forth, the neek at full extent, and an agitated expression marks the countenance; the appetite is gone, and of course rumination suspended. This is the first, or perlaps, in reality, the second stage; at all events it is the first noticed, and these symptoms are apparent, though in particular cases some may be more marked than others. What is now to be done-and promptitude must attend every effort? Let these things be done: Bleed, aiming at once for all, and bleed freely, even to fainting: then give active aperients; and if necessary bleed again, but now with caution, and not within six or eiglnt hours after the first operation; for the strength of the animal, and the state of its extaustion, are points to be liept in mind; but recourse must be had to a second and copious bleeding unless a decided impruvement has already mauifested itself. Sedatives should succeed the brisk aperients : half a drachm or a drachm of digitalis (foxglove leaves properly dried and powdered), one drachm of tartarized antimony, and four drachms of nitre, mixed in any demulcent liquid, may be given twice a day. A seton of black hellebore should be inserted into the dewlap. Should the disease continue, the animal utters low distressing moans, and is generally unconscions of surrounding oljects; it will stand gasping, but without change of posture, for a considerable time; and when it attempts to move it staggers and reels, and the hind quarter's seem affected with a partial paralysis; the loins are so tender that the slightest pressure produces pain; and swellings arise on the shoulders, back, and limbs, which, when pressed, make a crackling noise. These swellings arise from an effusion of some gas into the cellular tissue, the consequence of a putrescent state of the blood. Debility now rapidly increases, and the animal drops; perbaps it rises again, but it again falls prostrate, and after making vain attempts to recover its limbs, sinks into a comatose state, and dies. Sloughing ulcers, in this stage, often spread over the abilonen, the limbs, and other parts; the mouth, muzzle, and tongue are ulcerated; a sanious offensive fluid drops from the mouth and nose; and the alvine excretions are extremely fetid, and mixed or streaked with blood. In this state the poor beast may continue two or even three days, till relieved by deatl.. Farmers call these ulceratious and their concomitants, black quarter; and the paralytic state of the limbs, quarter evil, or joint-murrain.

If the decease be not checked in its inflammatory stage, the chance of saving the animal when congestion of every organ, brain, lungs, heart, liver, intestines, \&c., from the violent excess of arterial action has commenced, is very precarious. The first olject will be to relieve the congestion under which the vital powers of the system succumb; if previous bleeding has been neglected there is no room for liesitation, for weak as the animal may appear the system must be relieved; but if the animal has been freely bled and purged, the question will arise how far will it be prudent to abstract more blood. As a general rule, blood should he taker, and the state of the pulse should be watched: if it become softer there is still hope; but if it fail, and become more and more indistinct, the flow of blood should be stopped. Active aperients should be administered, beginning with a pound dose of Epsom salts, succeeded by half-pound doses at intervals, until the bowels are acted upon. Nor slould injections be neglected in aid of the medicine. These may consist of half-a-pound of common salt, and a little oil, in four quarts of water or thin gruel. The swellings of the limbs and loins should be fomented with hot water, and the fetid sloughing ulcers washed repeatedly during the day with a solution of chloride of lime (half-an-ounce of the chloride 
in a gallon of water); the muzzle aud tongie sliould be similarly treated. Some practitioners recommend that a pint of this solution be gently homed down into the stomach, perhaps more than once; for if there be hoove, or distension of that organ by gas, this solution will combine with it, prevent its farther formation, and correct the fotor, which is often almost umbearable.

After these remedies, and supposing the bowels to have been well cleared, mashes of thick gruel should be offered, or even gently poured down the gullet.

If the ulcers cleause, the swellings disappear, and the animal begins to eat,-indications of incipient recovery, tonics may be giren, but not previously. One or two drachms of gentian (pulv. gentianæ), and half-a-drachm of ginger, mixed with gruel and balf-a-pint of good ale, may be given twice or thrice a day. The curative process of the ulcers will be promoted by dressiugs of tincture of aloes. The seton, however, should be contimued for two or three weeks.

It is easier to present the attack of this formidalile disease than to cure it. Cattle, and young cattle especially, should not he suddenly put into rich pastures; they should be previously purged, and introduced by degrees, heing occasionally removed into a bare pasture, where, without gorging to repletion, they may digest at leisure what they have taken. Too much water is dangerous, especially if taken when the animal is from any cause overheated. Putrescent ponds, turf-pits, and the like, are to be avoided, as the water is noxions even if taken in moderation. Young growing cattle should not he too highly fed. There is no occasion to starve them; hut there is a medinm which good seuse will dictate. The stock, moreorer, should be daily inspected; and should any suspicious symptoms appear,-any shivering, any heaving of the flanks, any difficulty of respiration, any dulness or redness of the eyes, - a purgative, and the loss of a little blood, may stop the approaching mischief.

\section{TYPHUS FEVER.}

Inflammatory fever in cattle of all ages, hut more particularly in adult beasts, sometimes assumes a low, lingering, typhoid form. The gait is staggering, the appetite is gone; diarrhoea succeeds moderate doses of medicine, or comes on spontaneously. Tumours appear on the limbs, back, udder, \&c., and ulcerate, and the breath is fetid. This disease is most prevalent in the spring and autumn; especially on marshy lands, subject to miasmatous exhalations. It is sometimes epidemic, and fatal to a great extent, sweeping away numbers of valuable cattle. Occasionally it is accompanied by a catarrb, but mostly by diarrhoea or dysentery, the indication of inflammation or congestion of the mucous membrane of the intestines. The same decided treatment which we have describerl in inflammatory fever, nust be adopted: the lancet must be used holdly. The purgative of salts, \&e., slould be given, and its action kept up by six or eight ounce loses of sulphur. If the dysentery be violent, calomel and opiurn will be found useful, in doses of thirty or forty grains of the former, and a drachm of the latter, mixed in thick gruel: emollient injections should be administered, and castor oil given in doses of a pint. The irritation of the jutestines must be allayed, and their healthy and vigorous action induced. A seton of hellebore should be inserted in the dewlap; and the general treatment be conducted as we have detailed in inflammatory fever.

CATARRH, OR HOOSE ; EPIDEMC CATARRI, OR INFLU EXZA; AND MALIGXNAXT CATARRH, OR MURRAI.

Catarrh, or Hoose, consists in inflammation of the lining memlrane of the great nasal carities, spreading to the fauces, the glands of the throat, and the laryus and wind-pipe. It is mostly, perhaps, in the spring and autumn that catarrh prevails; it is caused by sulden changes of temperature, as, for example, a change from a close, over-heated, and crowded cowhouse to a bleak unsheltered pasture, dming cold rain or stormy easterly wind. Cattle heated by being overdriven, and exposed to a cold current of air, are apt to be affected by it.

This disease commences by fehrile symptoms : the pulse is quick and hard; the roots of the horns are lot; the ears and head are droop. ing; the animal is dull, repeatedly conghs, and neglects to feed. In a short time a discharge from the nostrils takes place; the animal swallows with difficulty, and exhibits great debility. If neglected, the disease insidionsly pursues its course, atrophy ensues, the lnngs become affected, and consumption supervenes. However slight catarrh may appear at first, it should not be, as it too often is, regarded with indifference. The cow has a discharge from the nose, her milk decreases, she conghs, her flanks heare, she loses flesh; and perhaps, when it is too late, the farmer takes the alarm, and sends for the veterinarian.

The treatment of this disease, if taken in tine, is simple. Blood must be alstracted (the animal having been placed under shelter and apart), and this must be followed by saline aperients, salts and ginger, in wher or gruel; after which doses of nitre (uitrate of potass) may be given two or three times a day in gruel. The dose may be from two to four drachms. Nitre will allay inflammation, and act upon the kidneys. Griel, warm lran mashes, with a little grass or good har, constitute the best diet. If the difficulty in swallowing is 
considerable, a seton in the dewlap should not be omitted; or the throat may be blistered (thongh not readily) by rubbing the skin with the common blister ointment, or a liniment consisting of an ounce of the powdered blisterfly, two onnces of oil of turpentine, and six ounces of common oil.

Catarh is sometimes epidemic, spreading over whole districts, and assuming a very virulent and dangerous form. At the commencement the fever is very severe, the respiratory passages are greatly inflamed, there is a distressing loose, and the aspect is agitated. Sometimes the bowels are confined; but sometimes diarrhoea comes on, and is very troublesome. If not checked, a stage of debility supervenes, the fever assumes a typhoid form, crackling air-filled tumours in the cellular tissue show themselves about the head, loins, and limbs ; the breath becomes fetid, the ammal stag. gers, its coat is staring, its flesh wastes away, the discharge from the nostrils is sanious, and death ends the scene.

During the febrile stage, bleeding freely and promptly, with a repetition of the bleeding if necessary, together with active aperients and sedatives (digitalis, tartarized antimony, and nitre), as recommended in inhammatory fever, warm mashes and injections, must be resorted to. But in the stage of debility little can be lone. Doses of nitrons ether (two or three drarhms) and laudanum (half an ounce), mixed in gruel, may perhaps be serviceable. Should the fever pass off, and simple weakness only remain, tonics, such as gentian and ginger, may le given.

Catarrh sometimes appears in the form of a malignant epidemic, sweeping away the cattle of whole districts, and, in fact, spreading over whole countries. Such was the dreadful murrain, about the mildle of the eighteenth centur, which depopulated the fields of England, and baffled all attempts at cure. The disease began with a violent febrile attack, which rapidly assumed a typhoid form. and ran on to gangrene. This murrain is said to have been traced from Italy, through France, Germany, and Holland, into England. In 1745 , more than 200,000 cattle perished in Holland. In 1747, more than 40,000 eattle died in Nottinghamshire and Leicestershire, and 30,000 died in Cheshire in half a year. From the earliest ages, indeed, the murrain has been known. It was by murrain that the cattle of Egypt died, as narrated in Exodus. Homer describes a similar pestilenee, during the siege of Troy, which extended its inthence to man. It is noticed by various Greek and Roman writers, and described at length, by Virgil, in his Georgics, Book nI. From time to time it has appeared during what are called the middle ages, and has continued to lreak out at intervals, in different kingdoms of Europe, almost to our tlay.

The precursory symptoms of this murrain were thase of catarrh in an aggravated form, and increasing in violence till the typhoid state came on, with ulcerations in the mouth, swelling of the glands of the throat, a thin fetid discharge from the nostrils, air-filled or emphysematous-tumours on different parts of the limbs and body, or even an almost universal emphysema of the whole cellular tissue, which, on pressing the skin, was manifest by the crackling sound. Sometimes the beasts dropped and died instantly; sometimes, from inflammation of the brain, they lecame delirious and mad with fury, and died exhausted if not at once destroyed.

Fer, comparatively, recovered ; some, lrowerer, when every hope seemed lost, began rapidly to improve, and were ultimately restored to health.

On dissection after death the fourth stomach anil intestines were generally fonnd highly inflamed, often gangrenous or ulcerated. The lungs were gorged with blood, and the bronchial tubes and windpine filled with purulent matter; the urain often exbibited traces of inflammation, and the cellular tissue was emphysematous; the body ran rapidly into a homille state of decomposition.

Of the remedies tried, some most ahsurd, childish, and superstitious, we need say nothing, as none were found to avait; and the legislature appointed inspectors to visit the farms throughout the country, and see that the infectel beasts were destroyed and instantly buried; half the value of the animals being allowed in compensation on duly authorized certificates. This was a wise and energetic measure, for thougl the disease was unquestionably epictemic, it appeared to be also contagious; and it was on this supposition that the wholesale destruction of the infected was ordered. In many instances, indeed, where the diseased were promptly killed and huried, the rest of the stock on the farm escaped. It is true that many farmers availed themselves of this law, and the ignorance of the overseers or judges, to get rid of worn out old beasts, or of such as lingered under other ailments, claiming the remuneration for their destruction: this, was however, after all, a minor evil and of little import.

\section{INFLAMMATION OF THE LARYNX AND WINDPIPE.}

Besides the catarhal affections described, cat ${ }^{-}$ tle are subject to intlammation of the lining menbrane of the larynx and windpipe, often extending through the bronchial tubes. This is a formidable disease, sometimes apparently epidemic, but more frequently the result of sulden atmospheric changes in cold damp situations. The disease commences with the usual symptoms of fever, shivering, loss of appetite, a quickened pulse, and a laboured, husky, wheezing respiration, to which succeeds great debility. The least pressure along the throat evidently gives great pain, the animal 
moves its head stiffly and with difficulty, and cannot swallow without a marked effor the drinks administered.

On examination after death, the lining membrane of the laryux and bronchiæe show the results of violent inflammation in ulcerated patches and gangreue, the gullet being also more or less involved in the disease. The windpipe is generally filled with purulent matter; and if the disease has extended to the bronchial tubes, the same appearances are there also presented; but these tubes are often choked up with parasitic worms of the genus filaria, and they appear also in the windpipe. In bronchitis of the lrorse, a species of the worm strongylus equinus in like manner is fomd to throng the bronchial tubes. It is not easy to ac. count for the presence of these worms, unless we suppose their minute eggs to be taken in with the air or food, and pass through the lacteals into the blood, which carries them through the circulation, till at length they find a nidus appropriate for their development; but there is still this ditticulty, - whence came the eggs into the air or among the food? The worms, as it would appear, are exclusively the inmates of living creatures: how do they spread? how do they extend their colonies? This is not the place for speculation. In laryngitis, that is, inflammation of the larynx not extending down the windpipe, recourse must be had very promptly to bleeding, smart aperients, blisters, and a seton of hellebore. If the disease runs on, suffocation ensues; but, should this catastrophe threaten, tracheotomy must be performed; that is, the trachea must be opened, and respiration carried on through a tube or canula. No one but an experienced veterinary surgeon can perform the operation, or should attempt it. If the disease extend to the trachea or windpipe, the sume treatment is necessary.

In bronchitis, or inflammation of the branches of the windpipe which ramify through the lungs, the symptoms are a cough, which becomes more and more husky and wheezing; a rapid and laborious breathing; the flanks heaving; the belly tucked up; the hide staring; the skin hidebound; an anxious restless expression; a disinclination to move; an increase of the painful cough, and a hurriedness of respiration, on taking a few steps. The animal wastes away, and dies a skeleton, often by suffocation; the air-tubes being blocked np by the thickening of the lining menbrane, by mucus, and by worms.

To this disease young cattle are peculiarly subject; and we need not say that it is one of a most destructive nature. The great object at the commencement of the attack is to subdue the inflammation by bleeding, active aperients, and sedatives; if these means prove unsuccessful there is little hope. When the tubes are thickened, clogged with mucus, and worms, what can be done? Could the irritating parasites be removed there would be a chance of recovery. Spirit of turpentine promises at least occusional success. In calves labourno under hoose and the initation of bronchial worms, spirit of turpentine has been found efficacious, and might be in older cattle. Mr. Dickens recommends, in cases of hoose or cough in calves, the bronchial tubes of which are filled with minute worms, the following draught, repeated at intervals of a meek or ten days:-

$$
\begin{gathered}
\text { Linseed oil, } 1 \mathrm{oz} . \\
\text { Oll of turpentine, } 4 \mathrm{oz} \text {. } \\
\text { Oil of carraways, } 20 \mathrm{drops} \text {. } \\
\text { Mix. }
\end{gathered}
$$

A contributor to the "Veterinarian" has found the following mixture very successful, viz.:-

$$
\begin{aligned}
& \text { Spirit of turpentine, } 6 \mathrm{oz} . \\
& \text { 'Tincture of opium, } 1 \mathrm{oz} . \\
& \text { Balsum of sulphur, } 1 \mathrm{oz} . \\
& \text { Gentian, } \\
& \text { Ginger, }
\end{aligned}
$$

The dose of spirit of turpentine for grown-up cattle may extend from two to four ounces, with as much linseed oil, a few drops of caraway, and a little gruel.

The rationale is as follows: the turpentine, so peculiarly destructive to worms, is taken up into the system, enters into every part of the circulation, and is recognizable both in the urine and breath. It is thus brought into contact with the worms, whom it immediately destroys; their hold being loosened, they are then easily expelled from the larynx by the cough, and the lad symptoms will gradually abate. The dose may be repeated every other day, or twice in the week.

\section{INFLAMMATTON OF 'PHE LUNGS, OR PNEUMOXIA.}

With the bronchial disease, previously described, there is generally an attendaut inflammation or congestion of the lungs (that is of their cellular substance) to a greater or less extent; but sometimes pneumonia manifests itself independently and in an acute form. It is generally the result of over-driving cattle when in an unfit state from fat to travel hard or work long. The disease commonly makes its appearance within a day or two from the exciting cause of it, and is characterized by dulness, a frequent congh, a dro ping of the head, and a heaving of the flanks, to which the animal often tuns its head; the horus, ears, and legs are cold, the pulse is small and quick, but sometimes not quicker than usual. Respiration is evidently painful ; this, the frequent act of turning the head to the sides expressively indicates; but the cough is not so frequent as in bronchitis. Frequently the animal grinds the teeth, and utters sloort groans. The cattle generally stand, sometimes lie dom, and this is 
alwars the case with calres. The smallness of the pulse, arising from congestion of the cellular tissue of the lungs, should not deter us from bleeding, nor from cautiously repeating the abstraction of lloor if necessary. In the horse, when labouring unler inflammation of the lungs, aperient medicines are dangerous; but in horned cattle this is not the case, and brisk medicines may be administered with advantage, assisted by injections. The sides should be blistered or firerl hy the cantery, and setons of hellebore inserted into the dewlap. Bran mashes and gruel may he given, and the animal on recovering must be kept low, and only allowed hy degrees to retum to its ordinary diet. Acute pneumonia sometimes appears as an epidemic, and rapidly passes through its stages, mostly ending fatally. In this disease the symptoms of ordinary pienimonia are all aggravated. The muzzle is dry, the mouth is lrot, the flanks heare, there is excessive thirst, the coat is rough, the hind limbs are feehle, and the alrine excretions are either hard and black, or liquid, dark, and fetid; soon the spine exhibits signs of tenderness, especially over the lumbar region, there is harsh grinding of the teeth. moaning, riolsnt heiring of the flanks, and a convulsive cough; the eyes aie wild, the expression is agitated, the nostrils open and close as if with a spasmodic effort, sometimes tumours appear on the skin, and occasional shivering is succeeded by violent sneating; alternately the back becomes arched, the belly contracted, the pupils of the eres dilate, stupor comes on, and the beast falls and dies. After death the lungs are found on examination to be gorged with black blood, often offensive and putrescent ; in some parts they appear hepatized or solidified like liver; sometimes tubercles filled with purulent matter are present; the pleura, or investing membrane of the lungs, is thickened; and the heart and diaphragm exhihit the ravages of inflammatory action. Generally the fourth stomach is intlamed, and the moniplus filled with hardened material. From the horribly putrescent state of the gorged blood in the lungs, this disease has been called gangrenous inflammation of those organs, but the term is incorrect. This disease, at various times, has appeared in different parts of the continent, in Germany, France, Denmark, de.; in England it is also known, and is often the cause of great mortality. It is only at the commeneemente of this fearful malady that there is much chance of doing good. A free use of the lancet is imperative; bleeding must be pushed to its utmost estent, and smart aperients with injections must succeed; these having acted, sedatives, as nitre, digitalis and emetic,tartar combined. may be given at regular intervals. Some veterinary surgeons recommend as a purgative two scruples of the powder of croton seeds, to be followed up lis salts and the injection pump. (No farmers should be without the enemalump of Read's invention, or at least a simple apparatus, always at hand.) Setons in the derrlap, and firing the sides, or blisters should not be omitted. Should the inflammatory symptoms rield, care and a cantions diet will be all that is ordinarily needed, unless the debility be such as to reuder tonic draughts advisable.

The following observations by Mr. Lord, in the "Veterinarian" for July, 1811 , are very interesting: "In the latter end of last April," he writes, "the Farl of Kingston sent for me, and told me that his cows were dying very fast from some disease that had been in his farms for the last year, and which his steward believed to be incuralle. After a minnte examination I found the symptoms as follows :-pulse in almost all that were affected from 93 to 120 , but very small; horns, ears, and legs cold; the animals heaving violently at the 1lank, and grunting as if in great pain, also grinding the teeth. With the stethoscope I could discern the bronchial respiration in some, and the mucous rile in others.

- Treatincht. - In tlie enrly stage I blerl largely, notwithstanding that the pulse was small, as 1 consider this arises from pumonary congestion, which bleeding removes. I next fired and blistered the sides, and gave uhite helldbore half a drachn, morning and night, as long as they conld bear it, and-changing it then for tartarized antimony and nitre, keeping the bowels open by occesional laxatmes. With this treatment I cured four out of five of the beasts which the steward and attendants considered as sure to die, and I have more recovering.

"A gentleman who lives near me, and who hat lost seventeen cows with it, had tried a great many remedies, and not sared a patient. $\mathrm{He}$ asked me to look at the last two of his stock, and which were ill with a similar disease, telling me, at the sanse time, I might try any experiment I wished on them, as he knew they would not recover. To his astonishment, with the above treatment, I had them well in ten days."

The success which attended the mode of treatment in these cases is rery encouraging, and ought to le bome in mind. With respect to the use of the stethoscope in detecting the condition of the heart, lungs, and other internal organs, ve must explicitly state that it is of the highest importance to the veterinary surgeon, as well as to the physician; but it requires an experieuced ear and habitual practice with it, to derire positive information from its application; we therefore doult whether in the lands of the famer or grazier it would be of much practical service. muless he deroted himself to the siudy of the healthy actim of the heart, lun s, $d c$., and made 
a series of comparative observations on the sounds they commmicate to the ear, and the sounds which the same organs convey in different conditions of disease. This is part of the study of the modern veterinaty surgeon.

PLEURITIS, OR INFLAMMATION OF THE INVESTING MEMBR.ANE OF THE LUNGS AND THE LINING MEMERANE OF THE CAVTTY OF THE CHEST.

Although in acute pneumonia the pleura covering the cellnlar mass of the lungs is generally involved in the inflammation, yet inflammation confiued to the pleura itself is not of uneommon occurrence. Many causes conduce to this affection; exposure to keen draughts of wind, a wet couch, over-exertion, blows on the sifle, lying all night on the frozen ground unsheltered from the weather, these and the like may induce the diserse.

In pleuritis the shivering fits come on with great frequency and violence, during which the shoulder's quiver; and this latter symptom occuis even when there is no general shivering. The breathing is quick, short, and abrupt, like rapic panting; there is a short but painful cough, there are twithings and a wary motion of the skin of the sides, and the animal shrinks as if from pain when the latter are pressed. The flanks are tucked up, and the expression of the countenance is distressed; if the disease go on, it usually terminates in the effusion of serum, not unmixed with coagulated lymph in the chest (in fact a dropsy of the chest), which oppresses the lungs, prevents their action, and destroys life. In pneumonia we observed that the lungs were gorged with black putrescent blood; in this disease they are smothered in water, which fills the cavity enclosing them. The treatment of pleuritis is however the same as preumouia. The lancet is the anchor-sheet of hope, assisted by aperients, blisters, setons, and low diet.

Oecasionally pleuritis changes its acute for a chronic form, and the animal lingers on, becoming emaciated and weak, with a dry cough, tendemess of the sides and loins, and difficulty of respiration, as in asthma, accompanied by a short groan and a drawing down of the angles of the lips, with a heaving of the sides. The animal at length dies, wasted away to a mere skeleton. On examination. the lungs are found more or less extensively adherent to the sides of the chest, bound by firm binds, the result of inflammation; there is generally fluid, also, in the chest, and in the pericardium. Where the pleura of the chest and lungs do not adtere, the membrane is thickened and has its textrure chituged. In these cases there is no lope of cure. An animal, indeed, may live and enjoy life, when, after acute pleuritis, adhesions exist between the lungs and chest; but then all inflammatory action is sublued. On the contrary, in these cases it goes on like a smouldering fire, sometines apparently extinguished, but again returning; new adhesions succeeding to tlose previously formed, till the lungs can no longer per. form their functions.

In animals which have died from pleuritis, we have often observed the pleura of the chest appear as if very minutely granulated. We remember once, in the human subject, seeing the pleura studiled with calcareous patches of some thickness; and a similar deposit sometimes occurs in cattle.

\section{CONSCMPTION, OR PHTHISIS.}

Neglected catarrh, or inflanmation of the lungs, often produces tubercles in the lungs, which, increasing in size and rumning together, at length stippurate, forming abscesses in the substance of those organs. The progress of consumption is insidious: in the human being life continues even when a great portion of some of the lobes of the lungs is wasted away by ulceration. The hollow, distressing cough, the hectic flush, the overbright eye, the expectoration of purulent matter, often mised with blood, foretel the result; lut if a sufficient quantity of the lungs is left for respiration, mless some larger blood-vessel or tubercle burst and produce sulden snflocation, the patient lingers on.

In the ox the same thing occurs. We have seen extensive tubercles in the lungs of oxen, killed in good condition for the market: and the fact has often smrprised us: but on considering that the progress of the tubercles is at first slow, that they do not for a long time interfere with the functional duties of the lungs, that the animal reposes at ease in a stall or yard, fattening, notwithstanding the tuberculous affection of the lungs; so that, most probably, the rapid increase of the disense resulted from the long journey to London, during which respiration was necessarily hurried, and a larger quantity of blood sent through the lungs, while time was not allowed before the butcher's stroke for the wasting of the bods:-on considering these points our surprise diminished.

We have said that neglected catarh, or inflammation of the lungs, often produces phthisis; and such is the fact: but we suspect that there must be in such cases a predisposition to this scrofnlous affection. Often, indeed, phthisis manifests itself withont ans previous definite symptoms. Minute tubercles liave ex. isted dormant in the lungs, perhaps, for years, nay, perlaps, even from birth; but some excitiug caise not to be clearly appreciated or detected,tritling cold, a hurried walk, a sudden chill after perspiration, damp garments, or some trifling neglect, is followed by dull pain in the chest, a hollow peculiar cough, measiness in lying on one 
sile or the other, and other symptoms, which go on for months, or years, till some additional cause accelerates the progress of the disorganization, when copious purtlent expectoration, hectic night sweats, dehility, severe diarhoea, and emaciation, end in death. If these observations apply directly to our fellow-creatures, so they do to the dumb brute. During the pregress of consumption in the human subject, the appetite is often undiminished, though digestion is slow and difficult; and the mind is not only clear, but roused to intense activity. In the ox, the appetite seldom fails much, - the animal is lively; nay, in cows, the sexual desires seem not only unabated but increased; but the animal is subject to abortion. During pregnancy the syuptoms of consumption are generally much mitigated; the great current of blood is directed elsewhere for an especial object; but, after delivery, the disease goes on with accelerated rapidity, In cattle, besides the hollow cough, there are purulent and sometimes bloody discharges from the mouth and nostrils, and irrepressible dharhoea; the skin is evidently very painful when pressed; the cellular tissue beneath is either inflamed or becoming disorganized; the surface of the slim is dry and scaly, and some writers afirm that it will even creak as the animal mores feelly along. In the human subject we have more than once seen the cellular tissue, to a large extent, not only benenth the skin, but hetween the muscles of the chest and limbs, dissolved into purulent matter.

We have adverted to the fact that in some constitutions there is a predisposition to phthisis ; this predisposition is hereditary; the offspring of consumptive parents are liable to censumption. This fact should be deeply considered by the breeder of cattle. The calf of a consumptive cow may grow up to be a beautiful heifer; she may even breed; but soon after she generally manifests symptoms of the disease, which runs a rapid course. Mr. Youatt says, that he has knewn two dairies almost destroyed by this hereditary taint. No breeder or dairy-farmer would wish for a feeble stock liable to be carried off. To breed from such a stock, and thereby extend, as it were, the empire of the disease, is not only for the farmer to do a personal iujustice himself, but the community at large. The best plan to be taken with cattle which show the primary symptoms of phthisis (indicated by an inward hollow cough, low and gurgling) is, to feed them as quickly as possible for the butcher, - in a short time this will be too late. It often happens, at the commencement of the disease, that the animal rallies; there is an evident improvement; from some cause the progress of the disease is temporarily suspended: let not the farmer hope for ultimate recovery; the beast will now fatten, perhaps, as well, with care, as if no mischief had begun in the lungs; Jet him fatten the animal without delay, and thus secure himself from loss.

When phthisis is fairly confirmed, medical treatment is of no avail; but, in the incipient stage, blisters, sedatives, and cautious bleeding, with a seten on the side, or in the dewlap, may arrest for some time its further progress. The animal, moreover, should be housed in a comfortable and well-ventilated stable, apart from other cattle, and not exposed to the north or easterly winds; it should never be hurried or alarmed; the litter should be always kept dry, and the skin often currycombed, in order to excite the action of the cutaneous vessels.

With respect to the use of iodine in incipient phthisis, some practitioners speak very highly. Ir. Youatt says, that though he will not affirm that he has discovered a speeific for consumption in eattle, yet he has saved some that would otherwise have perished. He would urge on practitioners the study of the symptoms of phthisis, and attention to the inward, feeble, painful, hoarse, gurgling cough, of consumption; and as soon as they are assured that this termination of catarrh, or pneumonia, or pleurisy, begins-that tubercles have formed, and have, perhaps, begun to suppurate-let them have recourse to the iodine in the form of the iodide of potass, given in a small mash in deses of three grains, morning and evening, at the commencement of the disorder, and gradually increased to six or eight grains. To this should be added proper attention to comfort, yet not too much nursing, and free access to sneculent not stimulating food. The medicine should be continued not only until the general condition of the beast begins to improve, but until the character of the cough has been essentially changed.

\section{INFLAMHATION OF THE HEAFT AND PERICARDIUM.}

In the horse, an animal called to violent and continued muscular exertion, to the toils of the chase and the course, inflammation of the heart is by no means of uncommon occurrence; but in the ox it rarely occurs as a disease per se; the synuptoms cannot be mistaken, the pulse is full and very strong, and the heart may be seen and felt violently pulsating against the left side of the chest; and each stroke may be heard, even at a distance.

Copious bleeding through a large orifice, even to fainting, and repeated if the symptoms are not decidedly suppressed, with smart aperients, are the ouly means on which any dependence is to be placed.

Inflammation of the pericardium, or sac enveloping the heart, occurs occasionally from extraneous causes. Cattle have sometimes a strange 
propensity to swallow sharp-pointed substances, as pieces of wire, large needles, nails, \&c.; aud these articles, which, when accidentally taken into the stomach of other animals, work out their way externally, generally withont much injury, take in cattle a more dangerous cousse. A few years since we saw a child, on the upper part of whose ahdomen a singular conical tumour appeared, and which revealed to the touch the presence, immediately below the skin, of a hard and apparently sharp sulstance, the nature of which we could not conjecture. A very slight incision with a lancet served to expose the point of a needle; we applied a pair of small forceps, and drew out a needle upwards of an inch and a half in length. This needle; which was black, must have been swallowed, and have worked its way through the coats of the stomach and the muscular parietes of the abdomen; ret it did not appear that the chilk had ever manifested any srmptoms of illness or fever; nor was it till the needle came to the skin, and there caused a pricking pain, that any thing was liscovered.

In cattle such sulstances often, perhaps mostly, work their way into the pericardium, producing inflammation, and either extensive nlceration or dropsy of the chest. Several cases of this kind are ou record in which pieces of wire, large pins, and needles, have been discovered after death sticking in the pericardium. The symptoms in these cases are obscure, till effusion in the chest is detected by the ear or the use of the stethoscope. We need not say that no directions for medical treatment in such cases can be given.

\section{INFLAMMATION OF THE LIVER, OR HEPATITIS.}

Acute inflammation of the liver does not appear to be a rery common disease in cattle, and occurs mostly in such as are stall-fed on high diet, and debarred from due exercise. The symptoms of this disease are not always very determinate. There is generally a yellowness of the eyes and slin, indicative of a cessation of action in the liver, which no longer separates the bile from the blood. Considerable fever exists, inlicated by dryness of the muzzle, heat of the mouth, and a quickened pulse; the ablomen, especially on the right side, is tumid, and pressure gives decided pain; the animal often turns its head round, and endeavours to lean the muzzle against it. The bowels are generally constipated; but this condition often alternates with violent purging. Mr. Bromu, in the "Veterinarian," remarks, that a diminution in the milk of the milch cow is one of the first symptoms, and that the cream drawn from it presents a ropy appearance, and has a saltish taste. As the disease progresses the aspect of the animal hecomes dull and depressed, and the appetite impaire.l; the animal loses its orlinary activity, its gait is stiffened or staggering, with a halt on one or more of the limbs. The eyes are dull, and the transparent comea sometimes becomes opaque; the nose is alternately dry and moist: the mucous membranes, the nasal secretions, and the skin, are ycllorv.

In protracted cases, when the animal begins to recover, "a yellow scurf rises from the skin, which gives the hair the appearance of being dusted with turmeric." Rumination is either wholly or partially suspended, the secretion of milk is limited, and inflammation usually appears in one or more quarters of the udiler. Tumours not unfrequently appear in different parts of the body, and, on bursting, discharge a fetid matter.

In some cases the respiration is at first frequent, and accompanied with a short painful cough; but in most instances it is not much disturbed. The bowels are generally obstinately constipated, with occasional intermissions of diarrhoea: but some cases occur in which the amimal is attacked by violent purging, the alvine excretions being copious, dark, and fetid. During the progress of the disease the pulse varies considerably in its character, but is usually feeble.

The treatment recommended is moderate bleeding in the early stages of the disease, which it may be often necessary to repeat : after this one drachm of calomel, suspended in thick gruel, with half a drachm of opium, and two drachms of ginger, may be given. In the course of six or eight hours after this, an aperient, composed of eight ounces of Epsom salts, four ounces of sulphm; and half a pint of linseed oil, with gruel, may be administered, and repeated in twelve or eighteen hours if the prior dose has taken no effect. "In serere cases a blister may be applied to the right side, and a drachm of calomel, half a drachm of opium, two drachms of gentian, owe of ginger, and two of nitre, administered in gruel trice a day."

In cases where diarhoea occurs from the commencement, the aperient dose should be either entirely omitted or given in only half the quantity; but the calomel and opium, \&c, repeated morning and evening. In all cases the diet should he restricted and simple, and as little stimulating as possible

Active inflammation of the lirer may yield to a certain extent, and ultimately merge into a chronic form; the liver now becomes preternaturally enlarged and indurated, sometimes soft and spongy ; it is often studded with tubercles of large size filled with pumlent matter. It is the nidus of numerous hrdatils; and fluke-worms (distoma hepaticum) inhabit cysts in its substance and even the biliary ducts.

Chronic inflammation, howerer, is not necessarily the result of active inflammation; it occurs 
when no such inflammation has previously existed, and it may continue for a considerable period without any decided symptoms being manifest. We have frequently seen decided indications of chronic disease of the liver in animals slaughtered for sale, and which were in good condition. This disease may run on to a horrible extent before it destroys life, though the animal may be meagre, weak, dull, and hide-bound. Mr. Youatt narrates a case in point: "A cow came up from the west to Smithfield market, in the year 1832 ; she was in tolerable condition, yet not in such a state as to afford a chance of her being bought by any respectable butcher; she was, therefore, set apart for the sausage-makers, and to them she was sold. She walked jretty well with the other cattle; and had no indication of disease, except enlargement of the belly, yellowness of the skin, and her not carrying so much flesh as the rest. On examination after death, the liver weighed no less than 137 lbs., and measured, from one lobe to another, more than a yard and a quarter. There was little of the common appearance of inflammation; but it was evident that there were numerous hydatids; in fact, they occupied the larger portion of the organ, and had hollowed it into carities of greater or smaller size. One cavity, nearly thirty inches in circumference, presented, when opened, the appearance of a honey-comb, all the cells of which and the wlole excavation were filled with hydatids, from the size of a sparrow's egg to that of a swan; there were nearly three hundred of them. Some cysts were filled with blood, and others with matter of a fibrous character, and others had large filrous cords extending from side to side. A few portions presented nearly the character of healthy liver; but in general, where there were no hydatids, the substance resembled a deposit of matter that had gradually hardened into cartilaginous cells; and the centre of the liver was perfectly fibro-cartilaginous, without any trace of its original structure. This disease had probably existed during a long period, and hal only interfered with health by preventing her attaining the usual condition of fatted cattle." It is evident that the small portion of sound liver secreted bile sufficient for the purposes of an imperfect state of digestion and assimilation only, and not of that healthy state necessary for an animal's thriving properly.

The same olservation is applicalle to many such instances, of which the fullowing is an example. It is related by $\mathrm{Mr}$. Goodworth (" Veterinarian," June 1831), of a cow, the property of a neighbour, that she hai calved, and done well: "She was milked twice a day, and appeared in good health, for six weeks: when the maid going to milk her in the morning found her very nneasy, and evidently ill. The cow was bled, and the messeuger sent to a druggist for medicine; but although he was absent only a ferw minutes, the cow was dead on his return. On opening the body, all the abdominal viscera were found in perfect health except the right lobe of the liver, which was much en: larged; and an incision being made in it, a quart of matter, of the colour aud consistency of cream, escaped."

We learn from these facts how difficult it is to predict with certainty respecting the existence of chronic disease of these organs, the symptoms of which are obscure. Yet it is one which annually carries off numbers of cattle; some of which, at least, might, by treatment in the early stage of the malady, have been saved.

Mr. Brown details the symptoms as follows :"In ehronic inflammation of the liver the lieast is commonly low in flesh, hide-bound, the skin slightly tinged with yellow from a seurf that gives the hair a staring, dirty appearance; the eyes are chull, and considerably sunk in the orbits, the ears drooping, the countenance altogether dejected; the animal feeds sparingly, is disinclined to walk, and when made to move the operation is listlessly performed. Although the animal is feeding in a succulent pasture the bowels are often confined, and the exerement is voided stiff, and glazed, probably, with dark-coloured bile; but in other catses diarrhcea commences. In either states of the bowels neat cattle will often linger on a life of misery for many months, until they are rendered useless by a disease which, probably, might have been relieved if active treatment had been adopted early enough to have arrested the morbid action."

With respect to the treatment, serviceable only in the early stage of the disease, it must consist of alterative doses of calomel combined with a small proportion of opium, and carried off ly an oily mixture. We are aware that an authority of weight, viz. Mr. Yountt, oljects to the use of calomel in chronic inflammation of the liver, as often producing "injurious effects," and recommends only gentle purgatives combined with aromatics; but where the liver has assumed a morbid action, and alteration of its substance is going on, we cannot expect to see very decidel effects result from such a plan.

It sometimes happens that when the liver hecomes softened and spongy, a sudden and violent hemorthage from it takes place, eausing death ahmost instantly.

JAUNDICE, OR TELI.OWS.

Jaundice, to a greater or less extent, is the accompraniment of ehronic intlammation of the liver; it arises from the obstruction to the passage of the bile through the ducts, either from alteration of the intimate structure of the liver, or from the pressure of tubercles or tumonis.

There is, however, another and very common 
cause of jaundice, which in noticing the morbid affections of the liver we cannot here omit to describe; we allude to the obstruction of the biliary ducts by gall-stones. It is astonishing how often gall-stones are found in the gall-bladders of cattle: they vary in size from a pin's head to a walnut, and as long as they cause no olstruction, they neither inconvenience the auimals nor interfere with health. But sometimes, nay very often, they enter the duct which conveys the bile to the intestiues (the crstic dnct) from the gall-bladder, which unites with a larger common duct from the liver itself, before entering the duodenum. When a gall-stone enters the cystic duct, it soou becomes impacted; it stops the current of the bile; spasmodic action of the mus. cular fibres of the duct, occasioned by the irritation, and accompanied by violent agonr, succeeds; the skin and eyes become suffused with bile; generally in due time (longer or shorter according to the size of the stone or calculus) the duct is dilated, and the obstructing olject passes into the larger commou duct, along which, not, however, without causing some obstruction, it proceeds till it comes to its entrance iuto the intestiue (duodenum). Here again it meets with a fresh difficulty; this entrance is surrounded by muscular fibres, which act as a sort of valre, or rather as a constriction, yielding freely to the pure bile, but contracting on the irritation of a preternatural object. Before this barrier is forced, spasmodic agony again takes place; at length the muscular fibres yield, and the gall-stone passes into the intestine; the pain ceases, but it is some time before the jaundice of the skin disappears. Uufortunately, when this occurrence bas once taken place it opens the way for repetitions of the whole affair, and calculi sometimes lodge in the ducts for a consider. able time, producing confirmed jaundice. This state of thiugs cannot exist without producing general derangement of the system; the alimentary canal is immediately affected; loss of appetite, constipation, thirst, a hard quick pulse, a heaving of the flanks from increased and febrile respiration, duluess, and loss of strength and flesh, with yellowness of the skin, of the eyes, and of every secretion, milk, urine, ic., are prominent symptoms. The skin becomes diy, and throws off yellow mangy scurf, and the hair becomes ragged, and falls off in unsightly patehes; then, perhaps, an uncontrollable diarrhœea comes on, under which the poor beast may sink. It can scarcely be possible, with this state of affairs, that the liver will not become more or less inflamed; and thus may gall-stones produce a disease in that organ which did not previously exist. Hence, then, while a jaundiced state of the skin may result from ehronic inflammation of the liver, the obstruction of gallstones in the biliary ducts may not only produce the same yellow suffusion, but even excite inflam- mation, which perpetuates the jaundice. It is the opinion of some writers, that the presence of flukeworms (distoma hepaticum) in the biliary ducts will produce jaundice. We will not say that these parasites may not occasionally produce it, but we can say that of numbers, not a few, of ruminants of every speries, which it has been our lot to exanine after death, not one was jaundiced when Aluke-worms alone were found in the liver or biliary ducts; the same observation applies to liydatids in the sulstance of the liver. Indeed we lave found fluke-worms in the liver of some of the best fed and most healthy-looking sheep that were ever slaughtered by the butcher. It is a fact that the liver of the finest codfish is infested by hundreds of colelmin thous worms, coiled up in cells or crypts, aud which move and crawl for a long time after being extricated from their nidus.

With respect to the treatment of jaundice: Could we, as in the ease of the human patient, be informed as to the character and seat of the agony the animal is undergoing during the passage of gallstones, we should have recourse to opium, sedatives, hot fomentations, and subsequent aperients; but, as a general rule, the poor animal eudures its pain unnoticed, and the jaundiced appearance and evident illuess of the beast alone afford us indications of what it may have suffered.

In cases of jaundice, let the region of the liver be well and carefully examined ; it is important to deteruine bow far this organ is affected, if possible; under all circuustances (unless the animal be in a state of weakness aud emaciation), the abstraction of a small quantity of blood is advisable; and if the animal suffers spasmodic pain, let an opiate (an ounce of laudanum or a drachm of pulv. opii, in gruel) be given; follow this up, after a few hours, by purgatives of Epsom salts, in sixounce doses with ginger, aided by copious injections. If there be no spasmodic pain, and the usual symptoms of jaundice only appear, aperients, mashes, and low diet may be suecessful. Some practitioners recommend aloes, Barbadoes soap, and Venice turpentine; but simple aperieuts are more safe, and quite as efficacious. Should the liver be swollen and tender, blisters, setons, and perhaps even calomel (though it should never be rashly administered), may be requisite. After all, jaundice is not one of the most tractable of diseases. and wheu once confirmed will often bid defiance to the efforts of the most skilful veterinarian. All nostrums in this disease (and many there are in vogue among the ignorant), as saffron, \&c., are either absolutely inert or injurious. Of the same character are some of the remedies for jaundice in the human patient. One which came under our personal cognizance in a certain part of Staffordshire, not many years since, was as follows: A number of dew-worms stewed down in good stale ale, 
the liquor to be strained, and a teacupful taken, three or four times a day. Our patient preferred this nostrum to our "stuff," as he called it, and the animal lingered long till it died.

\section{INFLAMMATION OF THE SPLEEN OR MELT,}

The symptoms of this disease are obscure; seldom perhaps is the spleen affected, independently of other organs, as the heart, lungs, and liver. Yet pure inflammation and disorganization of the spleen occasioually occurs; but all our knowledge of this affection is derived from the anthority of others. Professor Volpi, clinical lecturer at the Veterinary College, Milan, in a work published in $\mathbf{1 8 1 3}$, says, that "cattle are subject to a very acute lind of iuflammation of the spleen, which generally destroys them in three or four days; it is not, lowever, of a contagions nature, for it does not attack any other species of animals, nor can it be attributed to marsh miasmata (the surgeon will remember the affection of the spleen connected with ague in the human patient). because it some. times happens in very dry situations. We generally subdue this formidalle disease by free and repeated bleedings, by giving nitre in a quantity of from two to four ounces a day, to which we may add two ounces of aloes, and six ounces of Glauber salts." Mr. White ("Compendinm, \&c."), who refers to this account, states, that "this disease has often occnrred in some rich meadows in Somersetshire, situated near a river by which they are often inmolated (shall we not liere call ague to mind?). The disease was first noticed about six rears ago, druing a continuance of very dry and hot weather (jutrescent exhalations then no doubt prevailing). It was then attributed to contagion, arising from the putrid carcass of a cow that had been thrown into the river, and suffered to remain in a shallow place mutil it hecame very offensive. A great number of cows died that year, particularly on that farm, near the place where the pntrid body had remained, and the disease has been occurring from time to time ever since. In every cow that lias died they have fomd the spleen very much enlarged, appearing as if it were bursting with vers dark coloured fluid blood. This is the only morbid appearance they had noticed, until I was desired to examine three cows that were then lying dead of the disorder. I found the spleen as they had described it; also that two or three pints of the dark fluid with which the spleen was distended had oozed throngh its investing membrane into the stomach. The veins of the brain were loaded, and there was a small quantity of extravasated blood in one of the ventricles (of the brain). One of them, a store cow, was slaughtered; and in her, the heart and lungs were not much altered, but the brain and spleen were in the state before de. scribed. In the others, the heart and lungs as well as the spleen and brain were much inflamed. It is remarkable that every animal which has been attacked by this disease has died, except one, and that one was bled until it became faint. Others have been bled, but never, as far as I know, to that extent."

Te profess ourselves unable to lay down any specific details respecting the diagnosis of this disease; but if with certain symptoms a beast on a farm dies, and dissection demonstrates disorganization of the spleen, we may be pretty sure that others similarly affected labour under the same complaint. TVe suspect the disease to be local as to district, and comected with poisonous exhalations or miasmata ; for we know that in obstinate cases of ague (in the human sulject) the spleen becomes enlarged and inclurated to a great extent, and though the ox may not show decided symptoms of ague, (or though these symptoms may be overlookel,) the cause which produces ague may operate with its morbific energy upon the spleen. On this disease we have no olservations to make, and no directions to give, excepting that where it is positively ascertained to prevail, bleeding, blisters, setons, aperients, and afterwards tonics, bat especially a change of pasture, appear to be the most probable means of effecting good results. It is greatly to be desired that all farmers, breeders, or cattle-feeders would make it a rule that no beast which died, except from aceident, should be buried uutil carefully examined by a professed veterinary surgeon.

INFLAMMATION OF THE BRAIN, PHPENSY, MAD STAGGERS OR SOCGH (PHRENITIS), AND APOPLEXY.

Inflammation of the brain is a common disease in cattle, resulting from plethora, high feeding, over-driving, ill-usage; it occurs most generally in sultry weather, and in animals which have fed upon a stimulating diet. The beast at the commencement of the disease is dull, it hangs down its heal and seems oppressed with stupor, the action of the heart is gently increased, and the pulse is hard and rapid, the pupils are dilated, and the muzzle hot and dry; gradually wild delirinm comes on, the eyes are intlamed, protruded, and fierce, the animal is roused to fury, staggers about, bellowing hideously, and as if actuated by a sudden impulse, rushes at every living thing which may catch its eye. After madly plunging, and rushing with furious energy, it suddenly falls and lies awhile senseless, or perhaps struggling convulsively; in a slort time it regains its feet, and again exlibits every symptom of fury ; again it falls, and agnin rises, till at length it sinks comatose and dies.

It is only at the commencement of the disease, even if it were possible without risk of human life 
afterwards to attempt any thing, that medical treatment will generally avail.

Bleed from a free orifice, even to fainting; and give a quick purgative consisting of aloes, half an ounce or one ounce, with half a pound of salts, and water; some recommend a scruple or half a diachm of the powder of croton-nut, in water or gruel; setons of hellebore in the dewlap, are also advisable. Occasionally cattle have been restored, even when the attack of phrensy has come on; bnt it is then very difficult to secure a beast; if however this be effected, the lancet and active purgatives are the only remedies to be trusted.

Apoplexy is a disease to which cattle are subject, and from the same causes as produce phrenitis; it is however far more sudlen in its attack. It consists in a violent rush of blood to the brain, which gorges the vessels to the utmost, when the animal falls, struggles perhaps for a short time with great force, and then sinks into a kind of stupor, and dies. Sometimes a vessel ruptures, and effusion of blood on the surface of the brain takes place. In some districts apoplexy is called bloodstriking, and the word is not unhappily applied. In these cases, while life continues, the only chance is in bleeding freely from a large orifice; should this in a measure restore the animal to itself, the same measures as in inflammation of the brain must be adopted.

Inflammation of the brain, when the animal becomes furious, is often mistaken for rabies, especially if any suspicion exist that a rabid dog has been in the neighbourhood, or if a strange dog lus been seen about the farm or cow-house. It is not easy to distinguish always between rabies and phrensy. Mr. Youatt says, that a rabid ox will plot mischief, and endearour to lure his victims within bis reach: while the phrensied ox rushes blindly at every thing. In the former the saliva and foam are discharged from the mouth in greater quantity than the latter.

The following is an admirable description of rabies in the ox, from Mr. Youatt's work on cattle, which we transeribe, the rather, that though we have seen this disease often in the dog, and dissected the animal after death, we have never seen it in the ox. We need scarcely say that rabies is produced by the bite of some rabid animal, but mostly a dog; the disease generally appears about the expiration of the fifth week, though the animal must not be considered free from danger antil after double this num. ber of months. At the commencement, "the beast will appear dull, languid, feverish, scarcely grazing, and idly ruminating. These may be the precursory symptors of many a different illness, and the previous circumstances alone could excite suspicion of what is about to follow. The eyes become anxions, protruded, red; there is considerable discharge of saliva, and to this succeeds a thirst that can scarcely be quenched. There is no hydrophobia, no dread of water, at any time. This is a circumstance which cannot be too strongly impressed on the mind, and which may preserve him from danger, anxiety, and fear, who has to do with domesticated auimals of any kind, that all the constant and characteristic dread of uater is confined to the human being. The horse, and the ox, and the sheep, occasionally exhibit a momentary dislike to fluids, but generally they will drink to the last, and their desire of water is increased rather than diminished by the disease. The dog has never a dread of water. As in the dog, so also in the ox, the disease, from some cause unknown, takes two essentially different characters. The dog, labouring under what some sportsmen call dumb madness, is frequently harmless through every stage of the complaint; so in the ox the symptoms that we have mentioned are sncceeded by frequent and pitiful lowings, a continual and painful attempt to evacuate the fæces. Staggering and weakness of the loins appear on the second or third day, and these affections are soon succeeded by palsy of the hinder extremities. The animal sits on its hannches making ineffectual attempts to rise, looking wofully around it, eagerly plunging its muzzle into the water, when placed within its reach, but it makes no attempt to do mischief.

"At other times the early symptoms are succeeded by a dreadful state of excitation. The animal is eager to do every kind of mischief; he stands across the path, bellowing incessantly, and tearing $u p$ the ground with his horns. In a few cases the quiet and melancholy madness suddenly changes into that of a ferocious character. There is no cure now, no nostrums will avail here, and the animal should be destroyed as soon as possible. One circumstance should be carefully remembered, the poison in all rabid animals seems to reside in the saliva, and the saliva of an $\mathrm{ox}$ is as dangerous as that of a dog. We inoculated a dog with the saliva of a rabid bull, and it also became rabid and died. Dr. Ashburner inoculated a fowl from the saliva of a rabid cow, and two months afterwards the fowl had a wild strange appearance, and its eyes were bloodshot, it ran at the other fowls, and became gradually paralytic and died."

Neither the milk of a cow labouring (unsuspectedly) under the precursory symptoms of rabies (and perhaps used by the family), nor the flesh of a rabid animal, if eaten, can communicate this disease. No person, we presume, would knowingly drink the one, or eat the other. It may however be satisfactory to persons who may partake of milk, drawn from a cow which in a few days dies rabid, to be assured that they have nothing to apprehend. A miscreant only would send the flesh to market; yet this, we are informed, has been done. If a beast is known to be bitten by a rabid dog, the 
wound must be carefully searched ont, the hair cut away, and lunar caustic introduced and brought into contact with every part, and made to act thoroughly upon it. For this purpose, if requisite, the wound must be enlarged, so that every crevice and corner be probed and burnt by the caustic. On the efficient application of the caustic the animal's life depends; but unfortunately it often happens that in an animal like the ox, thickly covered with hair, some laceration or puncture escapes notice; a circumstance that must keep the farmer on the alert for months.

That inflammation of the lrain, occurring after suspicious circumstances, should be mistaken for rabies, is not surprising; and the following case communicated by Mr. Hayes to the "Veterinarian," vol. $\mathrm{x}$., may not be uninteresting :

"On the 2nd of Mar, 182\%, I was returning from visiting a patient, when on coming to a place called Huf Green, in the tommship of Ashley, Cheshire, I was surprised at seeing about twelve men chasing a cow, with long poles, ropes, \&c. endeavouring to entangle her and throw her down that they might kill her. She had calved about two months before. She roared and tore about most lideously. I inquired the cause of all this, and was told that she began to be in this way in the morning, but had shown symptoms of being inwell a day or two before: that she had completely torn all the timber down in the inside of the shippen (cow-house) that moruing, and roared and slavered most frightfully, rumning her head against every thing that came in her way; also, that there had been in the neighboulhood seven other cows in the same way, within the previous six weeks, all of which had been shot; that there had been a strange dog killed close by, which they thonght was rabid, and which they supposed hal bitten these cows. When the first cow began to be ill they sent for a practitioner of Linutsford ; this gentleman was of opinion that the cow was rabid, and ordered her to be destroyed, and which order was issued against the present cow. I waited till she was got into the barn, tied down, and secured. I then asked the owner if he wonld allow me to examine her, to which he consented. The pulse was so fluttering and quick that I could not count it; the pupils were exceedingly dilated; the mouth foaming; the tongue protruling out of the inouth; and very quick and short respirations. The action of the heart could be felt in every part of the body, with such convulsive jerks as to shake the whole frame so violently, that it might be seen and heard at a cousilerable distance. I signified to the owner a desire to try what I sould do by the effects of two or three days' treatment, and he readily agreed I should do what I thonght proper with her. I immediately opened the jugular vein, and let the blood flow till the strong action of the heart ceased, and the people about me thought she was dying. I then inserted a seton on each side of her neck, from the poll to the parotid glands, dressed the setons with blister ointment, and rubbed all the top of the head and neck with the same. I gave her nitre, four drachms; supertartrate of potass (cream of tartar), four drachms; castor oil, six ounces; tartarized antimony (tartar emetic), a drachm and a half; carbonate of soda, four drachms; Glauber salts, eight ounces; with three drops of prussic acid : this to be given three times a day in gruel; also, six quarts of gruel to be horned ilown, three or four times a day. After taking five doses she began to purge much black and very offensive matter; on the third day she began to eat a little hay and mashes, and from this time she recovered. Her owner kept her three years, during which time she continued healthy: she was at last sold to the butcher, after being fattened. I attended four other cows, directly after this, in the same neighbourhood, they had the same symptoms as those I have just described; all of them recovered."

A beast which has heen dragged through an attack of phrenitis, or of apoplexy, is liable to a recurrence of the disease. We recommend as a general rule, that after due preparation by purgatives, mashes, scanty fare, $\&$ c., it be fattened for slaughter, or, if this he inconvenient, that as soon as recovered it be disposed of for that purpose.

ENTERITIS, OR INFLANMATION OF THE PERITONEUM OR LINING MEMBRANE OF THE ABDOMEN AND INVESTIRG MEMBRANE OF THE INTESTINES.

Enteritis, or inflammation of the bowels, as it is commonly called, generally attacks cattle of middle age and robust health, and may result from sudilen exposure to cold, or to drinking cold water when overheated, to impure water, to mildewed food, or to a diet generally too stimulating. Occasionally it prevails in certain districts, as if epiclemic, occasioned probably by some acrid or unwholesome plants, abundant in the localities on which cattle feed; the disease appears to be the most prevalent in hot summers.

Enteritis comes on suddenly; the first symptoms are shivering, dulness, loss of appetite, dryness of the muzzle, a rapid but small pulse, the hair is rough, the loins tender, the abdomen swelled on the left side, and incaprable of enduring pressure. The bowels are confined, the animal moans, and often turns its head to the side; if the disease be not now checked, the hind limbs tremble and show signs of deplorable weakness, the animal staggers if it attempt to move, its flanks heave, the head is stretched out, the eves are red and betray great anxiety, the moans indicative of intense suffering increase in frequency, and the rapidity of the small pulse is further accelerated. The bowels con- 
tinue obstinately confined, the fæces are hard and glazed with slime; but occasionally liquid fæces are forced with dreadful agony through the iudurated mass obstructing the lower bowels; the mouth foams; the animal grinds its teeth; the alodomen is tucked up, though the swelling of the left side is still prominent. The urine is thick, turbid, ancl exhales au offensive penetrating odour. The animal now sinks, consciousness hegius to fail, it rises up again with a convulsire effort, but again sinks down, the hearl is rolled abont or raised only to come heavily to the ground, till the scene terminates either in convulsions or in a state of torpor.

Dissection after death shows, very often, an extent and violence of inflammation which are truly astomishing. Not only are the subcutaneous muscles of the abdomen in a state of congestion but even putrescent, and the subcutaneous iessels of the cellular tissue are gorged with black bloorl. The abdomen is filled with a bloody effusion; the peritoneum is more or less universally inflamed, and llack gangrenous patehes appear in rarious parts of the intestines; the liming or mucous membrane of the intestines is also inflamed and ulcerated; the liver is enlarged and softened; the lungs are in a state of congestion, and there is effusion both in the chest and pericardium. The fourth stomach is highly inflamed, and dry hard layers of food are found in the manyplus, while the paunch is generally found distended with dry regetable matters. We do not say that all these morbid appearances present themselves together ; but ulceration, abdominal effusion, and congestion of the lungs, are almost always present.

When enteritis, or inflammation of the bowels, and especially the small intestines, is accompanied by severe inflammation of the mucous lining of the fourth stomach or abomasum, the French distinguish the disease by the name of gastro-enteritis. But in gastro-enteritis it is chiefly the nucous membrane of the portion of the intestine succeeding the stomach, viz. the duodenum, which is inflamed.

With respect to the treatment in pure enteritis, that is, inflammation of the peritoneum, it is very clear that prompt and energetic measures alone can be serviceable. Let not the smallness of the pulse deter from bleeding. blood should be taken even till symptoms of fainting appear; to this should succeed purgatives, the first a full dose, followed at intervals by smaller doses, till the bowels act freely; these should be assisted by injections. The abdomen should be fomented with hot water, and blistered, and gruel and mashes alone given. Anodyues, that is preparations of opium, are very useful. Immediately after bleeding an anodyue may be given, half an hour before the aperient medicine; it may simply consist of half an ounce or an ounce of laudanum (tinct. opii), or half a drachm of powdered opium (pulv. opii), in gruel. The aperient may consist of nitre (four drachms), cream of tartar (four drachus), castor oil (six ounces), carbonate of soda (four drachms), and Glauber or Epsom salts (eight ounces), in gruel. The following is another form of aperient, which may be useful:--Barbadoes aloes (six drachuns), common salt (six ounces), ginger (two drachms), water (one quart), tincture of opium (two or three fluid drachms). If this aperient be used the anodyne draught need not be given; but in severe cases we should prefer relieving the pain as soon as possible. For this purpose we must trust to bleeding and opium, followed up by aperients and injections.

Enteritis must be carefully distinguished from Colic, whether flatulent or spasmodic; for though the latter may end in inflammation, the pain in the first instance results from another cause. Though colic can scarcely be classed among inflammatory diseases, yet it will be useful to notice it in the present flace, in order that its symptoms may he compared immediately with those of enteritis.

\section{COLIC, OR FRET.}

We will frst notice that variety to which the name of Flatulent Colic is given.

Flatulent colic arises from the distention of the alimentary canal with gas, owing to the fermentation of the food. The abdomen swells; the animal moans with pain; it is extremely restless, continually getting up and lying down, and ever and anon striking at the belly with the hind feet, or with the horns. Gas is expelled at intervals both from the mouth and bowels; perhaps the animal appears for a while relieved, but the pain again commences; of ten there is a rumbling noise, caused by the passing of the gas from one part of the bowels to another, or by the peristaltic action altering the position of inflated portions. There is no violent shivering succeeded by symptoms of burning fever, though the pain may quicken the pulse; there is no prostration of strength; and during the remission of pain the animal mores freely. The most effectual remedy for this disease consists in the chloride of lime, of which two drachms may be mixed with a quart of warm water, two drachms of powdered ginger, and twenty drojs of essence of peppermint. While the aromatics are grateful stimulants to the bowels, the chloride of lime unites with the extricated hydrogen gas, and causes the greater portion of it to disappear. The beast should be walked about, but not violently driven, lest rupture or entanglement of the intestines take place, and the animal be thus lost from want of common prudence.

It will be advisable now to give an aloetic purgatire, assisted by injections. This may con- 
sist of Barbadoes aloes (six drachms), common salt (six ounces), ginger (three drachms), and tincture of opium (two or three fluid drachms), with a quart of water. Accumulations of unbruised oats will of en bring on violent colic, not unlikely to end in inflammation.

Spasmodic colic is distinguished from the former by the absence of any great tumefaction and tension of the abdomen; it does not so much arise from the presence of a large quantity of gas in the bowels, as from acrid food and other irritating substances. The agony is accompanied by evident spasms, which have their intermissions and again return; but little gas is expelled from the alimentary canal; the animal moans, paws the ground, strikes at its side with hoof and horn, and, in its excruciating pain, sometimes even lunges at its attendant. This kind of colic, if it continues, is apt to run into inflammation; and it is a point which must be borne in mind. The first thing to relieve the pain and spasm will be a dose of laudanum (one fluid ounce) with sulphuric ether (half an ounce), in thin warm gruel ; should it appear, from the continuance of the pain, that any inflammation has taken place, blood must be immediately abstracted, and, whether or not this be done, aloetic purgatives must be administered, assisted by injectives.

Great attention must be paid on the recosery of t'le animal to its diet, as the least irritating cause is apt to bring back all the bad symptoms.

Spasmodic colic, if it continue, is known occasionally to produce an entanglement of the bowels; their wreathing peristaltic action is irregular: they infold each other in their spasmorlic disturbance, and sometimes become knotted into loops and intricate folds, among which a portion of the intestine becomes tightly embraced, strangulation of the bowel being thus effected. Inflammation now comes on and death soon superrenes: there is no remedy. This kind of strangulation or lnot is mostly caused, when it occurs, by brutal and improper treatment: the animal in its agony is relentlessly driven about, perhaps by a dog, the owner ignorantly supposing that such violent exercise is serviceable ; the hurried irregularity of the peristaltic action is thereby increased, the spasmodic constriction of the muscular fibres of the bowels is more vehement, they intertwine each other, the fatal noose is tightened, perhaps the mesentery is ruptured, and death ensues; and all this might have been prevented.

Another resnlt of continued spasmodic colic is what is termed introsusceptio; - that is, one portion of the bowels being perhaps spasmodically contracted, is forced forward by the strong peristaltic action of the intestines, and so runs into the succeeding dilated portion, perhaps to a rery considerable extent; often the peristaltic action of the intestines is inveried, and in that case a lower portion of the bowel is forced into the portion preceding it. The latter, as far as we have observed in animals, appears to occur the most commonly. The agony resulting from this introsusception, or infolding and sliding of one portion of intestine into another, must be horrible; the mesentery is generally lacerated; inflammation comes on and the animal dies. The symptoms indicative of this occurrence are indefinite, and the same observation applies to strangulation. But we may suspect the mischief from the increase of pain and the inutility of medicines. If any thing is likely to prove beneficial it must be bleeding, conjoined with opium.

In our dissection of animals numerous examples of introsusception have come under our notice, but none in which the appearances of inflammation have not been strongly marked; in most cases, indeed, rapidly as the disease must have been hurried to its close, adhesion was found to have commenced between the enclosed and the enclosing portions; the peritoneal covering of both being in contact.* It always, or almost always, appeared to us connected with an inversion of the natural direction of the peristaltic action; that action by which the aliments are carried through the windings of the intestinal canal. In cattle introsusception is of rare occurrence, though perhaps less so than is supposed. In carnivorous animals, as we can personally testify, it is by no means uncommon.

It is astonishing what strange remedies are sometimes given in colic, under the idea of extricating the supposed knot, or forcing the passage of the bowels obstructed, which the ignorant cow-leech knows not how, but which he confidently asserts he can set to rights. Some pour down the animal's throat a quantity of quicksilver, some use shot, while some prefer a living trout. A pupil of Mr. Dick, says Mr. Youat, who takes the account from the "Quarterly Journal of Agriculture," was consulted respecting an ox labouring under constipation of the bowels. The disease proved obstinate; it resisted every remedy; and the case was abandoned as utterly hopeless. At this stage of the business the old-established leech of the district stepped in and confidently engaged to set matters right. $\mathrm{He}$ commcnced with no less artive a remedy than a lively trout, transferred from the river to the stomach of the patient, with the conviction that his agent would thread his way through all the mazes of the intestines, and he ascribed the failure of so notable a dose to the previous mismanagement of the Edinburgh student. All such remedies may serve to create a smile in the well informed, but the ignorant look at things in a different light; they know nothing, and therefore are easily imposed

* We may illustrate this by pushing up (not inverting) one portion of the finger of a glove into the other, so that the black surfaces of the received and receiving portion are in contavt. This is done, aot by inverting, but by rucking up one part iato another, froas a certain spol where the infolding begios. 
upon by the most egregious quackery. In their own ignorance they too often consider the most ignorant cow-leech the best, and they listen with implicit faith to the dark sayings of their oracle.

In some rare cases both strangulation and introsusception have been found on the same subject. In no instance, however, have we met with such an vccurrence in any animal whatever.

INFLAMMATION OF TIIE MUCOUS MEMBRANE OF THE FOURTH STOMACH OR ABOMASUM AND OF THE SMALL INTESTINES (GASTRITIS AND GASTROENTER1TIS).

Inflammation of the abomasum (gastritis), or rather of its mucous membrane, is a most serions disease, nor is it of very unfrequent occurrence; generally the inflammation is not limited to the abomasum, but extends through the duorlenum. This is the gastro-enteritis of anthors. It appears to be brought on in most instances by improper food, by acrid plants, by bad water, by musty hay, and other causes which are not easily ascertained.

The symptoms of this disease (for we need not minutely distinguish between gastritis and gastroenteritis), are heaviness, loss of appetite, disturbed breathing, fever, a hot dry muzzle and tongue; sometimes diarrhœa, occasionally vomiting; and in milch cows either a cessation of the milk or an alteration in its quality; it irritates or eren inflames the udder, and the milk when drann off is thin, yellowish, and stringy with threads of coagulum. Its smell is often offensive, and sometimes it has a reddish tinge, as if slightly coloured by blood.

According to M.Gellé, "among the most constant symptoms of inflammation of the gastro-intestinal mucous membrane is loss of appetite, with the arrest of rummation. If the inflammation be intense the tongue seems to be contracted, and is evidently straighter and more rounded than is natural; the papilla which cover it become elevated and injected: the tongue moreover is red towards its point, and also along its edges. In certain intense cases of gastritis, and in some serious affections of the paunch or of the abomasum, the duodenum and liver participate in the inflammation, and the tongue is yellow or green. This colouring sometimes extends to all the visible mucous membranes. Vomiting, when there has been primitive or secondary affection of the stomachs, denotes almost always a most intense inflammation, either, as is most commonly the case, continued from the abomasum or pylorus, or also from the gullet itself. Hence it is common in chronic gastro-enteritis and rare in acute. Nevertheless, if one part of the food is vomited and the other passes from the abomasum into the duodenum, it may be presnmed that the seat of the inflammation exists principally in the abomasum.
"The diminution and eren the cessation of the secretion of milk, constant in cows labouring under gastritis, is only the result of the displacement of the vital action of the secretory organ in consequence of the violent action which attacks the mu cous membrane of the digestive organs." In other words, there is an immediate sympathy between the udder and true digesting stomach or abomasum; and the inflammatory condition of the mucous memlrane of the latter produces an inmediate effect on the former, both as to the quantity aud quality of its secretion.

This disease, like all others of an inflammatory type, varies in intensity. In mild cases a moderate abstraction of blood, with purgatives of Epsom salts and sulphur, with a little olive or castor oil, will prove beneficial, the diet being confined to gruel and mashes. In severer cases the bleeding must be carried to its full extent, and even repeated, followed by purgatives and doses of opium or laudauum; injections should also be resorted to, and a seton in the dewlap may be useful.

IVe cannot but remark that this disease is one which the professed veterinary surgeon alone can understand, and which he alone can treat. When the farmer, then, sees his cow feverish, nneasy, without appetite, perhaps sick, and fiuds the milk changed from what it ought to be to a disgusting secretion, which, if an honest man, he will not mix with that of healthy corrs, let him send for the veterinary surgeon (not the cow-leech), and trust the case into his hands. And here we may state that one object we have in view is to make the farmer and cattle-keeper cautious, and distrustful both of his own opinion and that of the village oracle, half blacksmith half doctor, who is quite as fit to attend the good man on his sick-bed, as he is one of the animals in the rard or cow-house.

Let us now attend to another disease intimately connected with inflammation of the mucous membrane of the alimentary canal: we allude to dysentery, which we cannot well notice without taking diarrhœa also into consideration.

\section{DYSENTERY AND DIARRHEA.}

These two diseases are both characterized by excessivealvine evacuations; and the latter disease,viz. diarrhoa, which is simple purging, may run on into the former. Dysentery we conceive to be always connected with congestion or inflammation of the mucous lining of the intestines, involving disturbance of the functions of the liver and the true digesting stomach. In true dysentery we have fever, tenderness of the loins and abdomen, frequent and perhaps bloody purging accompanied by tenesmus and spasms, as in colic. Dysentery is often the concomitant of other disorders; but here we speak of dysentery as an acute disease per se, occasionally 
merging into a chrouic form, and too often resulting in death.

True drsentery begins with slivering, succeeded by deciled febrile symptoms and pain in the bowels, with mucous alvine evacuations, loss of appetite, and nausea; tenesmus and muco-sanguinolent purging succeed, not without pain; the pulse is hard, small, and frequent ; the tongue dry ; the urive scanty; prostration of the strength rapidly comes on, and the pulse becomes feeble; the tongue is covered with a brown fur; offensive and dark-coloured alvine evacuations now occur, the body is emaciated; the limbs totter, they become spasmodically contracted, torpor and death ensue. Sometimes, after a degree of apparent convalescence, the disease returus and assumes a chronic form; the food, mixed with mucus and blood, passes through the bowels only half digested; the pulse is feeble; there is great emaciation of the frame, dropsy ensues, and the animal dies worn out. On examination after death the mucous membrane of the liowels, but especially of the large iutestines, is found to be inflamed, ulcerated, or gangrenous ; in chronic cases the peritoneum participates in the inflammation, and adhesions and effusion of serum are the result. In the first inflammatory attack of dysentery the abstraction of blood is required, and this must be followed by opium and calomel (a drachm of each) in thick gruel, repeated in a day or two if necessary, with mashes in the interval. No green or succulent food must be allowed; and the animal should be well housed and littered. There may be occasion to repeat the opium and calomel three or four times, or even oftener, till the bowels begin to act naturally, when oleaginous aperients may be givel1.

Diarrhœe or purging may arise from various causes, and may mostly be regarded as an effort of nature to get rid of some irritating matter in the alimentary canal. This cannot be called a disease. But diarrhea often assumes a very severe and obstinate character and runs at last into dysentery. It commences with a frequent and abundant evacuation of fotid matter, owing perhaps to a sudden change from dry to green food, to impure water, or to some particular state of the atmosphere; in a short time the purging becomes more severe, and the evacuations become mucous; the animal suffers severe griping pain, rapidly loses flesh, and at length wastes away to a skeleton. Milch cows and calves are more subject to the disease than oxen. The cow ceases to yield her usual supply of milk; she appears cheerful, eats and drinks; but the diarrhoa or scouring is incessant, and at last she dies. On examination after death the liming membrane of the fourth stomach or abomasum will generally be found much thickened and pallid, with effusion of serum between it and the muscular coat; and these appearances extend to a greater or less degree through the alimentary canal. There is not umfrequently effusion also in the cavity of the abdomen, and that to a considerable extent.

It is evident that in these cases the disease begins in a low inflammation, or state of irritability of the mucous membranes; and all attempts to check its progress by astringents and aromatics will be useless, unless the healthy condition of the mucous membranes be first restored. In the commencement of the disease, as soon as its obstinate character is revealed, the abstraction of a small quantity of blood may be serviceable, and a dose of chalk, mercury, and opium may be given daily in the following proportions:- Chalk, one ounce; opium, one drachm ; calomel, half a drachm; ginger, two drachms. These may be mixed in thick gruel. Some recommend the addition of three or four drachms of catechu; but we fear that powerful astringents may rather produce nischief than benefit. Indeed, if the above prescription acts in restoring the healthy condition of the mucous mem. brane, it may be necessary to give castor oil occasionally, in doses of a pint, with ten grains of powdered opium. The diet should consist of good sound hay, given in small quantities, and a handful or two of wheat-flour may be stirred up in the water. After all, this lind of diarrhoea is not easily subdued, and too often wears down the animal, which dies emaciated and dropsical.

In some diseases, as pneumonia, the occurrence of diarrhoea may be regarded as favourable; but in other diseases, as consumption, it is one of the symptoms of approaching dissolution: it may be moderated perhaps by astringents, as chalk, one ounce; powdered catechu, two drachms; powdered allspice, two drachms; powdered caraway-seeds, half an ounce. Let all these ingredients, except the chalk, be simmered in balf a pint of water; then add the finely-powdered chalk, mixed in half a pint of ale. To this a small quantity of opium may be added if the purging be accompanied by griping pains.

In simple but acute diarrhœa, before it assumes a dysenteric form, an oleaginous purgative, in order to remove the cause of the irritation of the bowels, may precede the mixture of chalk, opium, calomel, and ginger; this latter medicine may then be repeated twice a day, or only once if the purging be not violent. If given trice a day half a drachn of the opium will suffice with each dose. Should febrile symptoms make their appearance, indicative of mischief in the mucous lining of the alimentary canal, bleeding may be followed by the chalk, calomel, and opium, as above directed. Injections of starch with laudanum, or gruel, or linseed tea (infusion of linseed) with laudanum (half an ounce) will be serviceable in acting as emollients and sedatives, and should not be neglected. 


\section{INFLAMMATION OF THE KIDNEYS.}

The kidneys in the ox are of large size, and, unlike those of the sheep, lobulated in structure; that is, they cousist of numerous distinct lobules united together. These organs are subject to several affections, as red water, gravel, calculus, and also pure inflammation. Acute inflammation of the kidneys may be produced by blows on the loins, by violent muscular exertion, by exposure to cold, and by bad or musty food.

The first symptoms are, a frequent desire to void urine, accompanied by a straining effort, which causes the ejection of small quantities only (strangury), a tenderness and heat on the loins, dulness, loss of appetite, and fever. In a few days these symptoms increase, and the urine, instead of being limpid, is tinged with blood; streaks of pure coagulated blood also appear in it. The horns and ears are cold, the muzzle dry, the pulse hard and quick, the breathing accelerated. Severe dysentery or diarrhøa now comes on, with violent straining; the alvine excretions are scanty and foetid: at length they cease, though the straining continues as serere as before. The animal moans heavily from intense pain; its hack becomes bowed as it stands crouching; the difficulty of passing the urine increases, and at length total suppression ensues. The animal trembles, breaks out into sweats, and utters distressing groans; the hind limbs become paralysed, the pulse sinks, and the poor beast falls to rise no more.

After death the inflammation of the kidneys is found to extend to the large intestines, and in cows often to the uterus, and the blood is strongly tainted with urine. The treatment in such cases must be prompt and decided. The first thing to be done is the abstraction of blood, and that in no stinted quantity; the loins must be fomented with hot water for a cousiderable time, and afterwards covered with a large mustard-poultice, or rubbed with an irritating ointment composed of one drachm of tartarized antimony and five or six of lard. This will produce pustules, and great irritation of the skin: blister-ointment, from the wellknown effects of the cantharis on the urinary organs, is inadmissible. Purgatives must be administered, and emollient injections of gruel, or linseed infusion, and laudanum. The food should consist of bran-mashes and gruel. The purgatires to be selected are oleaginous, as castor or linseed oil : they must be persevered in until the bowels are fairly unloaded and their action is natural.

During the inflammatory symptoms no diuretic medicines certainly should be given; they will only stimulate fruitlessly or injuriously the inflamed kiducys, which will soon begin to act naturally when the inflammation is subdued. In the "Veteriuarian" for 1810, however, Mr. Rush recom- mends the following draught, at first twice and afterwards once a day:- "Oil of juniper, half an eunce; oil of turpentine, one ounce; tincture of opium, one ounce; linseed-tea, a pint." This mixture, he states, proved beneficial in some cases which he treated for several days without any amendment. The draughts appeared to cause an increase of the discharge of blood at first; but afterwards it began to abate, and diminished daily. This medicine may be useful when the discharge of blood continues after the pain and strangury have been subdued; but we should prefer trying laudanum and linseed-tea alone. Some practitioners, under these circumstances, recommend astringents; as two drachms of powdered catechu three drachms of alum, half a drachm of opium and two drachms of ginger, which are to be sinmered, in half a pint of water, for a few minutes: to this decoction must be added a pint of ale to form a drench, which may be repeated in a day or two. That this mixture will act as an astringent cannot be doubted; but we question its effects on the kidneys.

BLAIN OR GLOSS-ANTHRAX, INFLAMMATION OF THE TONGUE AND PARTS ADJACENT.

The causes of this disease are very obscure Some attribute it to the eating of certain acrid plants, as various species of ranunculus, \&c.; but on doubtful grounds. It sometimes appears as an epidemic; and in its latter stage it lias been proved to be contagious. Its attack is generally sudden, and variable as to severity; but the affection not unfrequently runs on to gangrene of the tongue and parts adjacent, accompanied with malignant typhus, and the auimal dies a miserable olject.

At the commencement of blain the animal exhibits the ordinary febrile symptoms, with dulness and the refusal of food. A discharge of saliva from the mouth now appears and rapidly increases: it is at first limpid, but, as the disease gains ground, it becomes purulent, bloody, and extremely fotid. The inflammation now extends itself; the head and throat swell, often to an alarming degree; the pharynx, or back of the cavity of the mouth, partakes of this congestion and intumescence, to the obstruction of breathing; and sometimes this is carried to such an extent that suffocation is the result. In cases where this event does not take place large ulcers break ont around the tongue and beneath it, and gangrene spreads its destructive ravages; a state of low typhus accompanies this disorganization, and the animal perishes.

If the mouth of a beast lahouring under this disease be examined, the tongue will appear to be singularly elevated and swollen; inderneath it and around its sides appear numerous large vesi- 
cles or bladders, varying in colour from red to a dark livid hue. Sometimes these vesicles appear even on the upper part of the tongue: they burst and form deep ulcerations; and as they burst others appear in their tmn, till, at last, the tongue and parts adjacent are covered with virulent ulcers. The sides of the tongue become gangrenous; incisions into it neither produce yain nor bring blood: the disease has now rum its fatal course

The appearances on dissection, after death, are ulceration and mortification of the tongue, inflammation of the muscular and glandular mass between the branches of the lower jaw, inflammation and ulceration of the pharynx, esophagus, the paunch, and abomasum, sometimes even accompanied by patches of gangrene. The vegetable matter in the paunch exhales an overwhelming fotid odour; that in the manyplus is dry and hard; the small intestines exhibit very often traces of high inflammation, and the large intestiues as frequently manifest palpable iudications of the same morbid action. It often happens that ulcers form about the heels of the foot and between the clefts of the hoofed toes, discharging a foetid matter.

At different times this disease appears as an epidemic, both in our island and on the continent, carrying off vast numbers of cattle; thongh the extent of the mortality has been most probably increased by the inefficacy of the modes of treatment adopted. Mr. Youatt assures us that this disease is contagious: it is not communicated by the breath, but, like glanders in the horse, by actual contact. The beasts must graze in the same field, eat at the same manger, or drink at the same trough ; and the saliva of the diseased beast must be received on some abraded, or, at least, a mucous surface. Hence it is requisite that the most stringent precautions be adopted and fully carried out. Instances are on record in which liuman beings have been inoculated with this malady and died. Mr. Youatt, who observes that many instances related have perhaps little foundation in truth, gives the following as well authenticated:-" A man held down the tongue of an ox, with a silver spoon. in order to examine the mouth, which had many of the characteristic vesicles. He afterwards, and without any great care about cleaning it, ate some broth with the same spoon. Not many days had elapsed when his mouth felt sore, pustules appeared on the side of the tongue, malignant fever ensued, and he died. When this disease raged at Nismes, in 1731, it was communicated, not only to the humau being, but to various species of domesticated animals.

It is requisite therefore in attending cattle labouring under the blain, to be careful that the saliva of the animal, discharged from the mouth, touch no sore or abraded part, nor lodge upon the lips. Should such an accident occur, a slight ap- plication of the lunar caustic to the spot will prove a sufficient security.

In the early stage this disease may be generally treated successfully; the mouth must be secured, the tongue and parts connected with it examined, and every vesicle freely opened with a lancet, so as to give free vent to the glairy fluid they contain: the mouth and tongue should then be well washed with salt and water, and cleansed as much as possible. If, however, the fluid of the vesicles is at all offensive, as is likely to be the case, if they appear dark or livid, a solution of chloride of lime (two drachms to a quart of water) should be applied very freely and frequently. After this, smart purgatives should be given, and, if the fever be high, blood abstracted. If there be ulcers about the feet they must be washed with a solution of chloride of lime also, and dressed with tincture of aloes and myrrh, or compouml tiucture of benzoin (friar's balsam), lioth to be obtained at the druggist's. In unhealthy sluggish ulcers, a little of the chloride (butyr) of antimony may be cau tiously applied.

Should the disease be in a more advanced stage, the free lancing of the vesicles in the mouth is to be thoroughly effected, and the lotion of chloride of lime applied copiously several times a day. Physic must be given; but whether blood should be abstracted or not will now depend on the pulse and the claracter which the fever assumes. If slonghing of the tongue has taken place, the same plan must he followed out, the solution of the chloride of lime heing gradnally strengthened; and should the ulcerations or sloughing parts show a healthy surface, they may be washed with tincture of myrrh. The animal should be supported upon good gruel, poured gently and slowly down the gullet, if the beast refuse to take it: the horn, however, is not often needed. It may be necessary to give tonics also, as gentian and ginger, in doses of two drachms each, mixed with gruel and half a pint of good ale, twice a day.

In this disease many absurd and even disgusting nostrums have been administered, and some unsafe plans put into practice, to the disgrace of those whose common sense ought to have taught them better. That the village blacksmith, or cowleech, should boast his quack remedies and his pretended skill, is not to be wondered at; but that he should impose upon persons who in all other affairs show discernment, is indeed surprising. Perhaps, however, we do not make sufficient allowance for human credulity, and forget that there is as much pleasure "in being cheated as to cheat."

From experiments which have been made it would appear that the blain is one of those diseases which seldom occur a second time in the same individual. How far, when the epidemic is 
spreading abroad, would it be advisable to inoculate for it, and then, watching the result, commence the treatment of the disease, upon its first appearance, when it is easily manageable? We are not aware that any experiment, with this object in view, has ever been made.

THRUSH, OR APHTHE OF THE MOUTH.

In many respects this disease bears a close resemblance to blaiu: it commences with inflammation of the mouth, attendant perhaps upon some disease; and in a short time the sides of the tongue, and inside of the mouth generally, are covered with small pustules which break and ulcerate. There is seldom much fever or loss of appetite; and a few aperient doses, with a lotion of tincture of myrrh, alum, and water for the mouth, will generally prove successful in the course of a week or ten days. Sometimes, however, the ulceration spreads alarmingly, and the symptoms begin to be formidable. If the pulse permit (for great debility then comes on quickly) some blood must be taken away, and the mouth well washed with a solution of chloride of lime, and afterwards with tincture of myrrh. Thrush is generally connected with derangement of the digestive organs produced by damaged food, foul water, and similar things; but sometimes it appears as an epidemic, especially on the continent, where the disease assumes a more dangerous form than in our island, the inflammation extending to the throat.

In catarrhal affections vesicles called barbs or paps, of a red colour, sometimes appear in the moutl, but oftener when its membranes are iuflamed; these the cow-leech will sometimes ignorantly remove by the scissors or hot iron, producing unpleasant nlcers. In such slight cases a few doses of physic are all that is required; or, should some degree of ulceration take place, an alum mash is sufficient to heal them. These little bladders often appear over the sublingual glands, the orifices of which are enlarged and distended with saliva.

We may here also observe that the submaxillary and parotid glands are, from various canses, subject to acute inflammation and swelling called strangullion; and sometimes abscesses are formed, which become malignaut, and are difficult to cure. This is more especially the case with the parotid gland (under the ear). In catarrh, and in epidemic diseases of a severe character, the parotid glauds are generally hot, swollen, and painful, rendering the action of the lower jaw very difficult. The swelled gland, moreover, presses upon the adjacent blood-vessels, impeding the current of blood.

Hot fomentations, frequently applied, are useful; and, when suppuration has commenced, it should be encouraged by hot poultices, and the abscess freely opened as soon as the fluctuation of the purulent matter is clearly distinguishable; the abscess will then generally fill up; but if allowed to burst of itself, ulcers, often of a phagedenic character, or apt to hecome gangrenous, will be the result. For these ulcers washes of chloride of lime nust be used, and afterwards dressings of tincture of aloes.

During the inflammatory stage there will be considerable fever, rendering the abstraction of a little blood advisable, with aperients and sedatives; but when ulceration has commenced tonics should be administered. The food should consist of gruel and mashes requiring but little mastication. Contusions, and the llows of cattle-drivers, nerciless in the use of their sticks about the heads of the poor beasts subjected to their harbarity, are not unfrequently the cause of inflammation and suppuration of the parotid gland; bnt the disease very often commences spontaneously, or is sympathetic with general derangement of the system.

\section{ACUTE RHEUMATISM.}

Rheumatism is a disease to which horned cattle are peculiarly subject, from exposure to wet and cold, and the vicissitudes of the weather, more especially in the early part of spring. Cows after calving, and beasts in general in a weak state from recent illness, if not shielded from piercing cold, are extremely liable to this affection. It consists of inflammation of the fascia of the nuscles, the ligaments of the joints, and the synovial membranes. Sometimes the inflammation extends to the chest, and inrolres the pericardium. Acute rheumatism commences with fever and loss of appetite; the animal moves stiffly, erery action being painful; the spine seems to have lost its elasticity; the loims are tender when pressed; and the animal is unwilling to stir. In this stage it is called by farmers chine-felon, an expression which has no definite meaning. In a short time the joints swell, and cannot be bent nithont intense agony; they are very hot, and often the veins around them assume a varicose appearance: the disease is now called joint-felon. Ulceration of the cartilages of the joints frequently supervenes; the hind quarters become weak and contracted, or even palsied; the animal is no longer able to stand; and, after lingering for some weeks almost incapable of motion, is relieved from misery by death.

Rheumatism appears in a chronic as well as in an acute form, especially in old cattle which have been worked hard, and exposed to frequent alterations of temperature, or in aged cows subjected to damp or wet. In fine warm weather little appears to indicate the existence of rheumatism, except perhaps that some of the joints of the limbs are swelled; but in bitter weather, when keen east or north-east winds prevail, or when sleet and 
snow are falling, then the animals droop, and move about stiffly and in pain.

Acute rheumatism is not easily cured; when it appears to be so it is apt to return; or it may assume a chronic form, and, though subdued for the present, show itself on the first exposure of the beasts to cold or wet.

In the early stages a free abstraction of blood is indicated; active aperients also are required, in which sulphur should constitute an ingredient. After the bowels have been well purged, a dose consisting of nitre, two drachms ; tartarized antimony, one drachm; and spirit of nitrous ether, one fluid ounce, may be given in warm gruel twice a day. To this mixture opium (from half a drachm to one drachm) may be occasionally added. The affected joints must be fomented with hot water or decoction of poppy-heads; and the following embrocation may be used:-Camphorated oil, four ounces; oil of turpentine, two ounces; landanum, one ounce.

The animal must be comfortably housed, and supplied with gruel. If the swelling of the joints, indicating the excess of synorial fluid, continues, after the acute inflammation is subdued, they should be well rubled, once or twice a day, with an ointment of iodide of potass (one part of the latter, by weight, to seven of lard). This ointment will be found effective in dispersing tumours, enlargements of the glands, and indurations of the udder. Besides being applied externally, three or four grains of iodide of potass (the dose being increased to six or eight grains by degrees) may be given in a small mash, morning and erening.

With respect to the treatment of chronic rheumatism, few explicit directions can be given, excepting that such cattle ought never to be exposed to cold winds or driving sleets. If turned out during the middle of the day, in winter, they should be comfortably housed in the evening.

Tumours of the knees often occur in cattle out at pasture in damp grounds. The swelling oceupies the fore part of the knee, and its elasticity indicates the presence of fluid in the tissue immediately beneath the skin. At first there is but little pain; in course of time, however, the tumours increase-inflammation begins; it extends to the joint, which is painful, and soon becomes deprived of the power of motion. These tumours contain a glairy lluid; on being punctured the fluid escapes, and the swelling subsides. Stimulating liniments, blisters, and the hot iron, have been used with variable success.

Sometimes hard tumours make their appearance: it is generally to one knee only that this sort of tumour is confined, it does not yield to pressure. is painful, and the animal is lame. Occasionally deep firing has succeeded in removing it, when blisters, and even a seton through it, have had no beneficial effect. In both the kinds of tumours. above noticed, which are often connected with neglected rheumatism, though in some cases, perhaps, they are independent of this affection, the iodide of potass, both as an external application, and as an internal medicine, has been. found very efficacious. We have already described the proportions to be used in making the ointment, and the doses to be administered.

We may now pass to the consideration of certain diseases immediately comnected with the nervous system, irrespective of acnte inflammation of the brain, or of any of the viscera of the chest or the abdomen. We mean those diseases in which the nerves of some part, or the nervous system generally, are immediately disturbed, irritated, or paralysed, and to the affections of which the leading symptoms have direct and express reference. Hence are these diseases called "nervous," not that there is no disturbance of any other part of the frame, quite the contrary, but hecause the nerves bear the brunt, as it were, of the attack.

\section{PALSY, OR PARALYSIS.}

This disease, which bears among farmers and cow-leeches the ridiculous names of joint-yellows, tail-rot, tail-ill, or tail-slip, is by no means an unfrequent disease, especially in low marshy situations, and during a cold and changeable spring. Scanty food, lod water, damp, ill-ventilated, and filthy cow-houses, also conduce to it. Overworked cattle turned out into humid pastures, during a cold sleety night, perhaps while sweating profusely, and with no shed to protect them, are very liable to palsy.

$\mathrm{Palsy}$ in cattle, is generally confined to the binder quarters, and both sides are alike affected.

Sometimes the attack is sudden, but in most cases it comes on gradually. It begins with debility, and a trembling or failing of the hind limbs; the appetite is now impaired or suspended, and the animal staggers as it walks: soon, the hind limbs drag along feebly, and with difficulty perform their office; the pastem joint is bent to the ground, and the animal is supported upon it ; the other joints of the limbs give way in turn, and the animal sinks down upon the ground.

It occasionally happens that cows left well, or apparently so, in the pastures, at the close of day, will be found chilled and palsied in the morning: the attack has been sudden, hut it may be weeks before the animals are restored, and some perhaps will never recover.

It is astonishing to learn the excess of ignorance which in many districts prevails relative to the cause of this disease. It is believed that the source of all the evil is in the end of the cow's tail, and that it runs up this appendage to the loins and limbs. The cow-leech feels towards the 
tip of the tail, where the caudal bones terminate, i little soft space, succeeded by a firm cartilaginous and somewhat swollen portion, in which are inserted the long hairs forming the tuft of the tail. Now this little soft intermediate portion, between the last caudal bone and the cartilaginous base on which the long hairs grow, this part, which acts as a flexible attachment of the whip-like brush to the more solid portion abore, is supposed to be preternatural, a disease, a softening or wasting of the bones, and is the "tail-slip," the cause of all the mischief. Acting ou this idea, some cut the end of the cow's tail off, others make incisions along its under surface, and to add to the poor creature's agony, rub salt, tar, and other detestable things into the wound. Others add witcheraft to aid these operations, and suppose that a twig of mountain-ash or rowan bound on the end of the tail, has a potent charm, and is as efficacious in its way as the "so potent art" of Prospero. Some again seek out a cat, not a "brindled cat," but a black eat, and, having secured it, pass it three times round the cow's body; the cat being thus nnceremoniously treated, mews, and scratches, and struggles violently, until at length she escapes from the clutches of the mighty magicians, possessed, as they believe, by some one of the malevolent emissaries of the prince of darkness, to whose agency the cow owed her "tail-slip" and its attendant consequences. Mr. Dick, of Edinburgh, in the "Quarterly Journal of Agriculture," exposes these absurdities with some effect, and he labours to prove that this soft space is natural, and explains the general structure and use of the tail in these animals with great ingenuity ; but we much doubt whether those whose ignorance and eredulity are so great as to lead them to such follies would believe Mr. Dick's assertions, or understand his arguments, even were they (which is not likely) to read his paper. It is only with the general diffusion of kmowledge, which begiming like a small stream spreads wider and wider as it pursues its course, and will spread till its waters cover the earth, that these lingering relies of superstition, by no means banished from the rural and secluded parts of our island, will be utterly exploded. Let fays and fairies, Puck, Oberon, and Titania, and him, the daiuty Aricl, bodied forth from "airy notling," by the poet's imagination, gracefully act their parts in his pages, and let us devoutly believe in them while re read; but these creations of fancy never entered the mind of the village farrier-leech. He doctors his cattle by knife, nostrums, and witchcraft, learned alike in surgery, physic, and magic; and thus fortified, "boldily undertakes the job." Who unless on good authority would believe the following details, they refer to a poor cow which laboured under affection of the feet and swelling of the joints, and which cane under the notice of a friend of Mr. Tait, of Portsay, who repeats the narrator's words: "Soon after commencing practice in this district, I was particularly struck with the appearance of a cow belonging to a cottar. On inquiring the cause of the animal's apparent helplessness, my informant stated to me that she had the crocliles (tumours of the joints, in consequence of neglected rheumatism, often accompanied by alceration of the cartilages), but was now in a way of getting better, a man having pared out the uorm that uas the cause of the awful complaint; that the man knew the very spot where the urorm lodged, and that he appeared to have great experience, having tracelled much as a beggar. In fact he had sawn off two inches from each claw of her feet. The cow was in a woful plight, her joints enlarged, her muscles shrunk, and her skin clinging to her bones." After remonstrating with the cottar on his folly, Mr. Tait's friend persuaded the man to remove the beast to a suitable spot, so as to give her a chance of recovery. In a short time she began to be convalescent, and to move about a little, and would have been restored in time, had not the beggar removed a part of the bones of her feet, along with his pretended worm.-Veterinarian, August, 1834.

No comments are here needed.

With respect to the treatment of this species of palsy, bleeding will be serviceable in the first instance, followed by warm cordial purgatives, in each dose of which there may be an ounce of ginger, and half a pint of good ale. The bowels must be kept freely relaxed; this is most essential: the animal should be comfortably housed, and well littered: and a rug or coarse blanket should be thrown over the loins, which latter may be well rubbed occasionally with a stimulating embrocation, as turpentine, olive oil, and hartshom (or liq. aumonix); or blisters may be produced by thoronghly rubbing in the blister ointment.* The food should consist of gruel, with a little hay, and green fodder. In three or four weeks, if all goes on well, recovery will talie place.

Nux romica, or its principle strychnine, have been recommendel in these cases; and in France, the former has been given with success, in ounce doses. It is not a medicine to be used rashly, or by any but a reterinary surgeon, in the treatment of cattle.

\section{EPILEPSY.}

In many animals, particularly in such as are kept in confinement and fed high, epilepsy is a frequent disease; but it is not of common occurrence among horned cattle, and indeed then it is

- One drachm of tartar emetic, with sis of lard, make a powerful irritant, causing a pustular eruption of the skin, when properly rubbed, and is useful in cases where blister ointment is inadmissible. 
chiefly in young cattle that it takes place. Young beasts in high condition, excited by overdriving, or a sultry state of the atmosphere, are the most liable to be seized with it. It arises from a sud. den determination of blood to the head, the ammal suddenly staggers, reels aud falls, the limbs are convulsed, often violently, the flanks heave with astonishing force, the jaws are clenched, the teeth grind, the mouth foams with froth, and the fxees and urine are discharged involuntarily. Sometimes the animal hellows loudly, but this is not always the case. The fit varies greatly in duration, sometimes it is over in half a minute, at other times it may last for many minutes, the convulsions gradually cease, the animal rises staggering and bewildered, it gazes around, and gradually recovering its faculties, commences its repast as before. It is seldom that an amimal which has fallen in a fit of epilepsy has not a return of the complaint, perhaps even during the same day, and that more than once. The disease is in fact liable to become habitual, the fits following each other at shorter intervals, till in one of more than usual severity the animal dies. Bleeding, active aperients, and a restricted diet, are the only remedies, with a seton in the dewlap, or on the sides of the neck. If by these measures, actively pushed, no retum of the convulsive fits occurs for several weeks, the beast may be cantiously prepared for the butcher.

CHOREA, OR ST. TITUS'S DAXCE.

Chorea is a frequent disease in young dogs, and occurs either with the distemper, or after it. That singular affection of the limbs of the horse, called string-halt, appears to be a species of chorea. In horned cattle the disease is not known to occur.

\section{TETANUS, OR LOCKED JAW.}

This terrible malady is less common in the ox than in the horse, but when it comes on it is eqnally unmanageable. It is generally the effect of serere punctured roumls; in working oxen it may be prodnced by incautious shoeing, one or more nails being rudely driren to the quick. Long and severe travel will produce it, and it often makes considerable ravages among the droves of cattle, during their toilsome and exhausting journey from the north to the sonthern markets. Mr. Youatt assures us, that tetanus stands at the head of the list of those diseases which sweep away the greatest number of victims from the herds travelling southwards. Unfortunately tetanus is generally confirmed before its approach even is suspected; nay, it is not then always immediately discovered. The animal stands in the field motionless, with its head stretched out, and the neck rigid. At first perhaps no notice is taken of this, but the animal still continnes, having scarcely stirred a yard from the spot, but in the same fixed attitude; its appearance excites alarm, the muscles of the jaws are found to be spasmodically contracted, and the jaw firmly set or locked. What is to be done, must be done promptly, for in a short time it will be too late to attempt any thing. Blood must be taken in a full stream, till symptoms of fainting manifest themselves, and the animal staggers. This may relax the muscles, and the opportunity must be instantly taken to give a powerful aperient, as half a drachm of the farina of croton-nut in a little gruel; this medicine may be then followed up, if practicable, by full doses of salts, a pound in solution with ginger, and afterwards at due intervals (every six hours) by small doses. These medicines may be assisted by copious and repeated injections, consisting of salts dissolved in five or six quarts of water. Let the medicines be given slowly and gradually, or they will pass into the paunch, and produce no effect, but by giving them gently and gradually they pass into the fourth stomach. When the bowels begin to act freely, then recourse must be had to that powerful antispasmodic, opium. A drachm or a drachm and a half of the powdered opium, suspended in gum-water, or linseed-tea, may be given twice or three times a day. Still the action of the bowels must be kept up by doses of salts, sulphur, and ginger, and a seton may be introduced into the dewlap. During this time the back, loins, neck, and head, should be covered with sheepskins, or thick rugs to induce perspiration; and the jaws and neck often rubbed with a stimulating embrocation, as spirit of turpentine, camphorated oil, ammoria, and laudanum. Some persons have recommended the pouring of cold water over the body by means of buckets, the stream being continued for a considerable time; but we doubt the benefit of such treatment.

We bave drawn up a favourable case, we have supposed the bleeding to have relaxed the muscles of the jaws, and the purgatives to have operated effectually.

But suppose the most profuse bleeding has not caused the relaxation of the jaws; it has been repeated, but the spasmodic condition of the muscles remains. The case is hopeless.

Suppose the medicines take no effect. In this case we may conjecture very safely that the draughts have passed into the paunch, and remain there inert. The most direct method is to have recourse to the stomach-pump, if it can be applied. The tube must be passed down the gullet, into the paunch, or rumen, and warm water be injected into that compartment till it oxerflows; the contents will then either le discharged by the action of vomiting, or they will pass through the third and fourth stomach into the intestines, and the desired purgative effect will ensue. If the contents of the stomach be rejected, the aperient medicines must be again resorted to. 
We are quite aware that all these plans are more easily directed than put into practice. The stomach-pump for cattle is not in the possession of every farmer, the fleam is mislaid or lost, there are no medicines to be obtained immediately, none perhaps are kept on the farm, and the nearest veterinary surgeon is alsent: under these circumstances what is to be done? Bleed, and bleed freely, a sharp penknife adroitly used will open the jugular vein; let injections and fermentations be in the mean time prepared, and let some one be sent off for the proper medicines, or for the veterinary practitioner, who, understanding the case, will (or ought to) bring them with him. Let us suppose that the beast recovers, the disease and the remedies have given a shock to the system not easily surmounted; nay, a relapse may take place, against which it is loopeless to contend. What is the plan most advisable under all these eircumstances? Cautious and gradnal preparation for the butcher. The food should be at first suited to the animal's enfeebled frame; gruel and mashes, with a little ale occasionally added, a small quantity of succulent green fodder may be also giren from time to time, but nothing requiring laboured mastication; for the very action of the muscles of the jaws is apt to bring on sudden cramps and spasms, indicative of the irritability of the nerves which supply them. By slow degrees the diet may be amended, and the animal at length restored to good condition. After all it is an expensive and un satisfactory affair, and at whatever price the farmer may sell the beast, he will not be remunerated.

$$
\text { RABIES, OR CANINE MADNESS. }
$$

We have stated enough respecting this horrible disease in our description of the symptoms and treatment of phrenitis. (See page 131.)

\section{HOOVE, CHOKING, ETC.}

We may now pass on to a consideration of certain casualties (for the term diseases is scarcely applicable), as hoove, choking, and obstructions, connected with the digestive organs, which render a description of them a requisite preliminary. At the same time we shall not recapitulate the process of rumination, which we have giren as one of the characteristies of an extensive and very natural order of the mammalia.

To commence, then, with a plain description of the digestive organs of the ox, it may be observed, that the pharynx or posterior part of the mouth merges into the œsophagus or gullet, a tnbe remarkable in this animal for the thickness and strength of its component tissues, and which runs down the neck on the left side of the windpipe, and, entering the chest, passes close to the spine, by the base of the heart, leaving the venæ caræ to the right, and the aorta to the left; retiring from the spine by degrees, it pursues its course to the diaphragm, and passes through the opening between the crura of that muscle in its course to the stomach. After passing the diapliragm it increases in size until it assumes almost the form of a funnel, and terminates in a canal which opens ints all the stomachs. The parietes of the gullet or œsaphagus consist of an external coat of loose cellular tissue, a simple expansible membrane; to this succeed two layers of muscles, the fibres of which in the ox are spiral, but the fibres of one muscular coat wind their way round the tube in a contrary direction to those of the other. By this arrangement the gullet is not only readily contracted or elongated, in the act of grazing, swallowing, \&e., but it is more freely dilatable than it would be if (as in the horse) one set of muscular fibres were longitudinal and the other circular.

The inner or lining membrane of the gullet, though extending from the pharynx, loses its mucous character, and becomes smooth and cuticular. It lies in very numerous longitudinal plaits, so as to allow of room for dilation as the masticated food passes along.

'The œesphagus, as we have said, terminates in a sort of canal, shoot, or gutter, common to the four compartments of the stomach; this canal is not a simple tube, it is a singular reduplication not easily deseribel; it is part and pareel of the several stomachs; its roof is formed of a continuation of the csophagus, and its base of two muscular pillars. "This canal varies in length from two to twice as many inches, and conducts to the entrance into the manyplus or third stomach. These muscular pillars are duplicates of the roof of the first and second stomachs (the rumen and the reticulum), which lie immediately beneath. When they are distended by the action of the muscles at their two extremities, the edges hecome so elosely fitted to each other that fluids, descending from the cesophagus with little force, pass over them and enter the abomasum (fourth stomach) through the manyplus. When they are relaxed the food descends into the rumen or ascends from the reticnlum" (in rumination).

Mr. Spooner, of the Royal Veterinary College, thus describes this canal, which to be clearly mnderstood must be examined:- "There extends from the base of the osophagus a smooth passage or canal over the reticulum and through the manyplus into the fourth stomach. The base of this passage is formed of two projecting muscular pillars, the contractability of which, he beliered, was under the influence of the will; so that when their edges are brought together they form a distinct chamnel, by means of which fluids pass on to the abomasum without entering either of the other stomachs. Yet he could conceive that the act of deglutition might be mnch altered by long deprivation of water and considerable thirst, and, the 
animal swallowing with more than usual effort, that the stream may fall with so much force on these pillars that they will be forced asunder, and the fluid will fall into the rumen." It would appear, in fact, that in the natural process of digestion fluids pass at once into the abomasum; and here we see the reason why it is that fluid medi. cines, given to cattle, should be allowed to trickle down, and not gulped at once, so as to force by the effort the muscular pillars of the canal, and so descend into the rumen or paunch. Let this be borne in mind on giving drenches to these animals ; and let the operation be gently and quietly conducted. Professor Dick recommeuds that the operator, standing on the right hand of the cow, should pass his left arm under the cow's jaw, and take hold of her left cheek with two of his fingers, and then, with a horn or bottle, pour the liquid into the right side of the mouth -with his right hand, giving both the tongue and jaws as much liberty as possible. An assistant should steady the head, and assist in keeping it moderately high by taking hold of the horns. If our reader does not fully comprehend the structure of the canal in question,- - and unless he examine it carefully we will forgive him for not understanding a mere description,- let him at least trust to our assurance that a hurried mode of giving medicine to cattle will defeat the object in riew. The violent gulp to get the volume of fluid down will send it into the rumen, where it will be useless. Hence it is, too, that balls, bolnses, or medicines in a solid form are unsuitable; they are sure to pass into the rumen (all solids do), and they are there lost. From this survey of the esophagus and the œsophagean canal, we may now proceed to describe the different stomachs. Of these the first is the rumen or paunch. This is a large muscular reserroir, occupying, when naturally distended, threefourths of the cavity of the abdomen. It is an oblong sac, lying obliquely, and is divided internally by redupliratures or septa, of thick and muscular structure, into two large compartments, which are again subdivided by transversal lands. Of the two primary divisions, one superior the other inferior, the former oocupies the left portion of the abdomen, extending over the flank; the other sac occupies the anterior portion of the abdomen, the mass of intestines being interposed between it and the right flank. The rumen has three distinct coats. The external coat is a continuation of the general peritoneum. Beneath the peritoneum is a muscular layer of considerable thickness, especially where its reduplicatures form the septa of its compartments. (Double tripe, as it is called, when the rumen is prepared for the table, is merely a portion of these strong septa.) The lining membrane of the rumen is cuticular, and not endowed with much sensibility. It is generally covered, except along the ridges of the muscular septa, with multitudinons papillæ, giving a mossy roughness to the surface.

The second stomach is the reticulum or honeycomb; it is the smallest of all the stomachs, and possesses great muscular power, being well adapted for grasping and pressing the food. The coats are of the same character as those of the rumen, with this exception-that the muscular consists of two layers, the fibres of one running longitudinally, those of the other transversely. The lining cuticular coat, moreover, assumes the form of a vast number of pentagonal cells, like those of the honey. comb, but much more shallow; in these cells the mouths of numerous minute glands open, pouring out a mucous fluid.

The third stomach is termed manyplus, manyplies, manifold, and other names, in allusion to its internal foliations. This stomach is a strong muscular sac, with duplicates of the cuticular coat, each cluplicature containing within its cellular tissue blood-vessels, and a thin but powerful layer of muscular fibres.

This singular foliated lining is studded by nu. merous follicular glands and little prominences of a conical form, like minute spires, some of which are almost as firm and hard as horn. This stomach is evidently constructed for the retention of the food, for the resolntion of the finest filres into pulp between the rasp-like foliations, and its ultimate preparation for the fourth or true digesting stomach.

The fourth chamber is termed the abomasum; it is somewhat conical in form, and lined by a soft villons membrane, from which a mucous fluid and also the gastric juice are secreted. The extent of this membrane is increased by its being thrown into a number of longitudinal folds or puckers; one of these folds acts as a sort of valve at the orifice between this stomach and the manyplus; it yields to the entrance of food, but oploses an effectual obstruetion to its return. Hence it is that vomiting the contents of this stomach is a rare occurrence in cattle, and can only be produced by such violent spasmodic efforts as terminate in death. The pyloric or lower orifice of this stomach, which leads into the first portion of the intestinal canal (the duodenum) is embraced by circular fibres, forming a sphincter muscle, which permits the gradual transit of the digested aliments.

The ammexed figure shows the stomachs laid open, so as to display their internal strueture.

The length of the intestinal canal in the ox is very considerable, averaging from fifty to sixty yards; whereas in the horse its length is only from thinty to thirty-five yards ; but in the latter animal it is much more capacious, and the crecum and colon are cellated, which is not the case in the ox. The intestinal canal bas three 


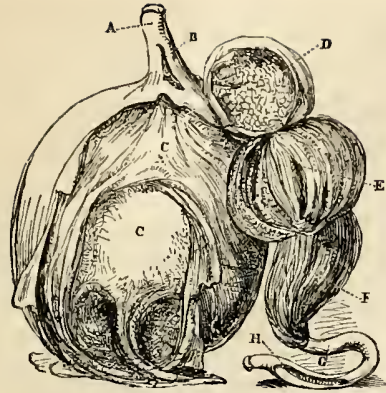

(A) The oesophagus enlarging as it approaches the stomach: it is laid open at (B) the commencemeot of the canal or gutter, which commuoicates with the several stomachs.

(c) The rumea or paunch, showing the muscular septa or cartains which divide it iato compartments.

(o) The reticulum, with its hooeycomb lining.

(E) The manyplus, cxhibiting its rough internal foliations.

(P) The abomasum, with its plicated villous liaing.

(G) The duodenum, laid opeo at $(\mathbf{s})$.

coats-an external peritoneal investment; a muscular coat, for the purpose of effecting that peristaltic action which is maintained along the canal during the process of healthy digestion; and an interual mucous lining, thickly studded with minute glands, which pour out a lubricating secretion. Under the action of purgatives this secretion becomes increased in quantity and more aqueous in its character. The intestines are all attached to a thin membranous reduplication termed the mesentery, which binds them to the spine. The mesentery is studded with glands, through which the lacteals or nutrient vessels run, conveying the chyle into the thoracic duct, which carries it almost directly to the right cavities of the heart. Besides these there are important arteries, veins, and uerves.

The duodenum, or first portion of the intestinal canal, receives, at the distance of ten or twelve inches from the stomach, the secretion of two remarkable viscera-the liver and the pancreas; that of the liver is termed bile, that of the pancreas the pancreatic juice. These two secretions are evidently essential to the formation of healthy chrle.

The duodenum merges at a somewhat indefinite point into the jejunum, and this again into a portion called the ileum; but between the two last there is no marked distinction. The jejunum and ileum constitute the border of the mesenteric expansion, and are disposed in the form of numerous spiral convolutions; their length is very great, in order that the food as it passes may be drained of all the chyle, for the principal absorption of chyle takes place in this portion of the intestinal canal. This remarkable coil occupies the right side of the abdomen and the right flank; and it is on this side that the ox lies while ruminating, in order to give full liberty to the stomach.

The ileum, or concluding portion of the small intestiues enters the large intestines between the crecum and the colon. The cxcum is simple in its structure, of an arched form, and about a yard in length. It is not as in the horse puckered by longitudinal bands into deep and numerous cells, consequently it can contain only a comparatively small proportion of semidigested aliment.

The colon is of great length, measuring thirtythree or thirty-four feet. It is simple, and not puckered by bands as in the horse, but is convoluted in returning flexures, beautifully disposed. From its simple structure there is no obstruction to the passage of the food ; but this is compensated for, by its length, and it is here that the last or yet unabsorbed portions of chyle are taken into the lacteals, the feculent matter alone remaining.

The colon merges into the last portion of the intestines, called, from its straight course, the rectum; it is of simple structure, and is guarded at its termination by the usual sphincter muscle.

The subjoined cut will give an idea of the arrangement of the intestinal canal in the $o x$.

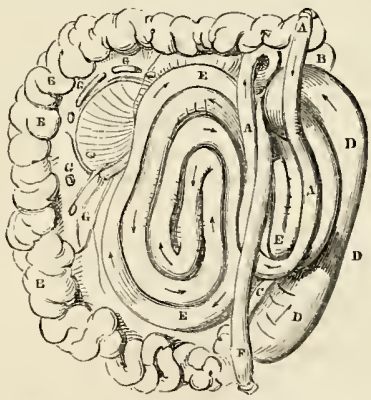

$\begin{array}{llll}\text { (A) Duodenum. } & \text { (B) Jejunum. } & \text { (c) Ileum, } & \text { (D) Cecum. }\end{array}$ $\begin{array}{llll}\text { (B) Colon. } & \text { (F) Rectum. } & \text { (G) Mescatery, with glaads, lacteals, }\end{array}$ nerves, and blood-vessels.

We might here enter much more profonndly into the structure and functions of the alimentary canal, were it consistent with our plan, which will not permit minute structural disquisitions.

From this outline we may proceed to a consideration of those casualties connected more especially with the gullet and stomachs, which place life in jeopardy, and too often produce fatal results.

\section{OBSTRUCTION OF THE GULLET, OR CHOKING.}

All roots given to cattle should be first cut into small pieces; carelessness in this point is inexcusable. It is not because roots have been 
given several times, without being chopped up, and no evil consequences have ensued, that the farmer or his servant may plume themselves on their security. If they neglect this precaution they will most surely rue it some day. One of the cows or oxen, carelessly masticating, will swallow a large portion of turnip or parsnip, or perhaps a whole potato, and it will remain fixed in the gullet; firmly impacted sometimes at its commencement, oscasionally lower down, and often within a few inches of the dilatation of the cesophagus, where it joins the rumen. It may be felt externally, and there can be little mistake about the matter. What ensues?-difficulty of respiration; violent husking spasmodic action of the unscles of deglutition; repeated and violent contractions of the abdominal muscles-all laboured efforts to expel the impacted root; the neck is strangely arched, the nose poked forwarl; mucus drips from the mouth; and the alvine evacuations are frequent, perhaps involuntary. But this is not all; if the animal be not relieved it becomes hooven, that is, the stomach becomes distended wiih gas, the diaphragm, and consequently the hungs, are oppressed, and the animal is in imminent danger. Something muit be done, and done promptly. The farmer knows it: he secures the head of the beast; puts a balling-iron or some rude gag in the mouth, and then forces down the handle of a cart-rhip, a stiff piece of cord, or a long stave, in order to drive the olstructing olject into the rumen. This ruds treatment, it is true. sometimes succeeds; hat it often happens that the gullet is frightfully lacerated, and the animal dies in cousequence.

Now, in these cases, if the obstructing substance be at the commencement of the gullet, it may of en be withdrawn ly the lund, the arm lieing defended by the ordinary balling-iron. But if this is impossible, the obstruction being too low down, a probang nust be used. Several very ingenions instruments of this kind have been invented, some with screws in the end to fix into the substance, some with spring forceps to grasp it: a wooden gag being placed in the mouth and there secured, having a perforation of sufficient extent to allow the probang to pass thruugh. These are, no doubt, admirable instruments in the hand s of the practised veteriniry surgeon, but we are not so sure that they would prove successful in the hands of the farmer, even if he possessed them. They require nicety and practice in their management. The improvements in the cattle probang are due to Dr. Monro, Mr. Read, Mr. Simonds, and others; and we shall perhaps be accused of an oversight if we neglect to describe one or two of the most useful, not that descriptions in these cases are of much utility. Let us suppose a tube or catheter made of spiral wire, covered with leather or India-rubber cloth, baving a perforated bulb at the extremity : length four feet and a half. To give this tube the requisite firmmess, it is furnished with a stylet of good whalebone, which fits the tulue as a sword does its sheath; to this there is in convenient handle. A necessary appendage to this instrument is a gag, like the letter $O$, with bandles, from which straps go to the root of the horns so as to secure it in its place. Through the orifice of the gag the probang is introduced with gentle pressure against the palate, it descends the æesophagus, and forces the obstruction into the rumen. Let the stylet be withdrawn, and the gas which inflates the rumen escapes through the tube, the bulk of which, as we have said, is perforated with numerous orifices like a cullender. This is a most useful instrument; for in cases of hoove, that is, distention of the rumen with gas, it gives immediate vent to the confined air, and instantly relieres the animal. It is a simple œsophagus-tube and probang combined. Mr. Read, taking this as his foundation, adiled a sort of corkscrew to it for working into the obstructing substance, which is thus secured and retracted. The tube is somewhat larger and stronger than that of the previously described probang, and the bulb of superior size, though still fitted for passing down the gullet. At the end of the strlet is a delicate corkscrew, which, while the instrument is passed down the esophagus, is concealed within the bulb, and there safely guarded, the stylet being duly retracted and firmly secured by a contrivance for that purpose. When the bulb arrives at the obstructing hody, the stylet is unfastened and pushed forwards; the corkscrew now passes throngh an orifice, and of course presses with its point against the impacted root. The stylet is now turned round and round, so as to work the corkscrew into the sulstance, and thus a fair purchase upon it is obtained, or it is broken up into small pieces, which readily pass into the rumen. Mr. Simonds has inventert a problang armed with a kind of forceps for grasping the obstructing substance, of which the following is a description :- The instrument consists of an elastic hollow tuhe, through which passes a flexible stylet, furnished at the top end with a screw and handle, and at the other with a pair of spring forceps. When used, the forceps are to be withdrawn within the goblet-like bulb of the catheter, and secured by the screw at the other end. The instrument is introduced into the œsophagus, and passed onwards until the bulb (opened at the end) is brought into contact with the root. The stylet has now to be pushed forward, the spring forceps pass out from the bull, and by a little address and working in different ways, soon grasp the olject: when this is effected it is easily ascertained, for when the stylet is withdrawn, if the olject is not grasped, the spring forceps are closed and again retracted within the bulb. If the root be grasped it may be readily extricated. The 
difficulty in the use of this instrument consists in fixing the obstructing body in the forceps, and it is often necessary to turn them in different directions before this can be accomplisherl. The forceps are serrated in their inner surface, and made somewhat tapering, for the purpose of passing readily between the root and the sides of the œsophagus.

When a skilful veterinary surgeon is not on the top with these or similar instruments, a good common probang which will not lacerate the gullet may be readily made. A piece of stout cane between four and five feet long must be procured, or a long elastic peeled willow wand; this must be armed at the extremity with a piece of sponge, or cork, well secured, aud covered tightly with soft leather, so as to form an egg-shaped bulb, with the broad end lowest. Lest this bulb, however well secured, should by any chanre slip, let both ends of a piece of strong twine passed throngh it be wound round the cane, and reach beyond the handle portion. Whalebone may be used instead of cane, but long strips of this are not always to be obtained at the moment. The farmer, or cattle-feeder, however, should always have a probang and an œsophagus-tnbe in readiness.

In some cases the obstructing substance has been found to be so rigidly impacted, that its removal by any other means than by opening the œsophagus is impossible. This operation can only be attempted by a good anatomist. Sometimes it is even necessary to puncture the distended rumen in the left flank for the purpose of letting out the gas which threatens suffocation.

\section{HOOVE, OR DISTENTION OF THE STOMACH FRON GAS.}

When eattle, and expecially such as have been kept on scanty fare, are turned into rich pastures, or stray by accident into fields of clover, lncern, or the like, they are apt to eat ravenously and take in a larger quantity of food than the powers of digestiou are capable of managing. The rumen is overloaled; its contents, from the effects of warmth and moisture begin to ferment, and large volumes of gas are rapidly evolred; the rumen soon becomes awfully distended, even to bursting, for the pillars of the nesophagean canal are closed tightly, and prevent the escape of the gas tlurough the nesophagus, and the more the rumen is distended, the more firmly is this canal closed. The rumen now presses on the diaphragm; respiration and the action of the heart are greatly impeded; the whole body of the animal, especially the left site, is blown up till the rery skin seems about to give way: the tongue hangs from the mouth dripping with spume: the eves are bloodshot and glazy; deep moans attest the torture of the poor beast; it crouches with its back bent np; insensibility comes on; it staggers, it falls, it struggles conrulsively, and dies. We have known cows, well at night, found dead in the morning from howre, having strayed into an enclosure of lucern or clover.

The first object in these cases is to procure the liberation of the gas (at first carburetted hydrogen, but as the disease continues sulplinretted hydrogen), and this must be done promptly. The œsophagus-tube with its perforated bulb and strlet must be introduced through the æsophagus into the rumen, and the stylet withdrawn; a quantity of gas then escapes, the flanks sink, the breathing is more easy, and the animal is relieved. But this tube cannot be kept in the gullet for any great length of time; it must be withdrawn, and in the meantime gas again acenmulates. The tube may again be introduced; and afterwards measures must be taken to relieve the stomach effectually. The stomach-pump must be resorted to, and throngh its tube a quantity of warm water thrown into the rumen, and pumped out agaiu, until the acid fermenting fluid is washed away, and perhaps a considerable portion also of the coarsely masticated contents besides; after which the process of rumination may go on, especially if the stomach be ronsed by a pint of warm ale with a few teaspoonfuls of ginger.

Mr. Youatt recommends in these cases, after the first relief is obtained, that chloride of lime, in the proportion of two drachms to two quarts of water, should be thrown into the rumen by means of the stomach-pump (the horn will not auswer, for from the closure of the pillars to the csoplyagean canal, the fluid thus administered will pass into the $3 \mathrm{~d}$ and 4 th stomach). The modus operandi of this medicine is as follows:-Chlorine has a stronger affinity for hydrogen than for lime, potass, or soda, consequently it separates from the lime, and uniting with the hydrogen forms muriatic gas. This gas having a strong affinity for water, is immediately absorbed by the fluid contents of the stomach, and quitting its gaseous for a fluid state is reduced to a very small volume, in the form of a wenk muriatic acid, while the lime is disengaged; yet no mischief will arise either from the corrosire acid or the caustic lime, for there is an affinity between these again, so that they combine and form an inert muriate of lime.

This, sars Mr. Youatt, is "not mere theorr, but when brought to the test of practice is found to be verified in every particular, hence has resultel one of the most important improvements on cattle medicine that modern times have produced." Chloride of lime is, or ought to be, in the posses. sion of every farmer, and nlwars at hand. It may be requisite to repeat this injection into the paunch in the course of a couple of hours, should a fresh evolution of gas take place.

It often happens that urgent cases of hoore 
occur at a distance from the farmhouse, or under circumstances in which neither an cesophagustube nor a stomach-pump are accessible, and sourething must be done immediately. Let the farmer mark the prominence of the left flauk, and pluuge a sharp-pointed knife into the distended rumen which there presents itself so conspicuously. This will be followed by a rush of gas, steam, fluid, and even portions of food. It is, however, necessary to introduce a tube, for the wound will otherwise close; or if this be not attainable, the orifice must be kept open by means of a smooth piece of stick, or any other mode that suggests itself at the time, until all the gas is liberated. In this operation the danger does not arise from the wound of the paunch, which is comparatively insensible, but from other causes-viz. from a pumcture of the spleen or kidney, or from the escape of the contents of the stomach into the abdomen, and from peritoneal iuflammation. The spleen and kidney nay be avoided if the following rule be adhered to: Let a line be drawn close along the spinal column from the haunch bone to the last rib; from the ends of this line let two others of the same length be drawn obliquely down the flank, the whole forming an equilateral triangle; the lower apex of this triangle is the most suitable spot for the incision.

Though sometimes successful, this is a rude operation; as the stomach on the escape of the gas sinks, it too often happens that both fluid and solid matiers are discharged through the incision into the cavity of the abiomen, so that although the animal is relieved for the time, it ultimately sickens and dies. It is in fact only strong necessity that can justify the use of the knife; the proper instrument for performing this operation is a trochar, similar to that used by surgeous for tapping the human subject in cases of dropsy. It consists of a steel stylet, terminating in three sharp-edged facets converging to a fine point. It has a stout handle, and is sheathed in a silver canula or closely fitting tube, from the lower end of which the point of the instrument emerges, while a rim or guard around its base prevents its slipping into the abdomen. When the instrument is plunged in, the steel stylet is withdrawn, and the cauula (four inches long) is left in the wound and secured there as long as may be necessary ; it forms a continuous tube from the stomach to the outer surface of the llank, and is long enough to allow of the sinking of the rumen without danger of the escape of its contents into the abdominal cavity. When all danger is over, the canula may be removed and the wound closed by firm adhesive plaister. Carnipative aperients, as salts, ginger, and caraway powler, may be given in order to clear the bowels, and diminish the chance of inflammation. Mashes may then be allowed, but the animal must be restricted for some time in its food.
In some districts it is the practice, we believe, in cases of hoove, to throw pailfuls of cold water over the animal; the object is to produce sudden shocks, during which the pillars of the osophagean canal sometimes yield and allow the gas to escape; occasionally, however, tlie stomach gives way instead of these muscular pillars, and the beast is lost. Sucking calves occasionally become hooven from some accidental cause; they are apt to suck various objects, even each others' ears, drawing in and swallowing a great quantity of air; they may be readily relieved by the introduction of a tulse or probang.

A most singular case of hoove is quoted by Mr. Youatt from one of the French periodicals (Recueil de Méd. Vet. 1826), which, as it may put persous on their guard and lead them to examine the mouth and cesophagus, even when the animal is relieved by the trochar, we shall here repeat. A cow which had been tmned into her pasture in perfect health, was found in the course of the morning labouring under great excitement, and making frequent and violent efforts to romit, and then galloping over the field with her mouth half open, and the saliva running from it as if she was mad. Her eyes were haggard and fixed and starting from their orbits, and the nostrils were unusually dilated. When she stood still her back was bowed, but presently she would stretch herself out and bound over the field. Her paunch began speedily to swell, she moaned dreadfully, and could not be still for a moment. The practitioner not having a trochar with him, punctured the rumen with a listoury; a vast quantity of gas rushed violently out; the enlargement of the abdomen subsided, and she appeared to be perfectly at ease. But presently the efforts to vomit recommenced, and the aperture into the paunch being accidentally closed, she began rapidly to swell àgain.

The practitioner now suspected that the cause of all this mischief lay somewhere in the gullet or the entrance into the first stomach. He carefully examined along the whole extent of gullet in the neck, but could not detect any obstruction. He then opened the mouth and raised the head in order to introduce a flexible osier rod iuto the gullet, when the animal again making a sudden and more violent effort to vomit, he saw the tail of a suake in the posterior part of her mouth; he seized it immediately with his right hand, and steadying himself by laying firm hold of the horn with his left hand, he drew it out. It was dead, and measured three feet and eleven inches in length; there was no appearance of bite or wound in it, but it was covered with a greenish spume. The efforts to vomit immediately ceased, the hoove disappeared, the cow began to ruminate, and quickly regained her appetite aud spirits. 
How the snake came into such a situation it is scarcely possible to say, though it was donbtless taken in alive.

\section{DISTENTION OF THE RUMEN WITH FOOD.}

It is not always easy to discriminate between distention of the rumen with food and hoove. In both cases the abdomen and flarks are distended, but in the former, the left flank feels hard and firm, and is less protuberant than in hoove, and these particulars being taken into consideration with the character of the food recently swallowed, will generally lead the farmer or practitioner to form a correct opinion. Nevertheless the probang and tube should be always used, lest there be gas in the stomach, and even if there be none, the instrument will serve to indicate the extent to which the rumen is filled.

This disease geuerally occurs in stalled cattle fed upon unboiled potatoes, uncrushed oats, and other indigestible materials. It is termed by farmers graiu-sick, or maw-bound.

If the stomach be not relieved, inflammation comes on and the animal dies, and in severe cases prompt measures are necessary, for the pressure on the diaphragm, and the consequent oppression of the heart and lungs, are soon followed by insensibility and death.

At all times it is desirable to know the exact nature of the food swallowed, for this may require some modification of the plan of relief to be pursued; indeed, if the rumen be distended with hard heavy materials as potatoes, au operation may be imperatively demanded.

Should the case be not severe, the animal may be made to move about; and a drench be given composed of carminatives and aperients, followed by other doses at intervals till the medicine operates: injections should be also administered, and it may be adrisable to take away some blood. 'After the action of the aperients the process of rumination may be excited by cordials. In sererer cases the animal will not be able to move, and must not be disturbed; indeed the difficulty of respiration forlids any measures but those tending to immediate relief. Supposing that the stomach be distended by light materials, as wheat-chaff, chopped straw, and the like, the contents may be extricated by means of the stomach-pump, a quantity of water being first thrown in and then immediately pumped out, when some of the matter will be returned with it: this process may be repeated. It may happen, however, that the tube of the stomach-pump becomes stopped up by the chaff, and the action of the machine impeded. Under such circumstances suceess has followed the injection of water into the rumen, until it begins to react upon its contents and discharge them by p̧omiting. When this ceases, carminative aperients must be given, and repeated till the bowels, work freely. The drenches must be aided by clysters. The recovery of an animal in eases of this nature is generally slow; it is long before the stomach regains its tone, and a healthy appetite retums; this should be remembered with reference to the diet, which ought to be restrieted, and consist in a great meusure of gruel.

In cases when the stomach is gorged to the full with solid heary food, as undigested potatoes, unaltered grain, and similar materials, which no stomach-pump can remove or efforts in romiting throw off, while approaching dissolution threatens, one plan is yet left, viz. a bold operation. A free incision of about five inches long must be made through the left flank into the rumen; a rush of the more fluid contents will immediately take place, and after the stream has subsided the operator must introduce his hand and carefully remove all the solid masses of food, and empty the paunch completely. Great care, however, must be taken that no food escapes from the paunch into the abdomen, and the wound must be sewed ap. This is a dangerous operation, less perhaps from the incision into the rumen, which will bear severe treatment with comparative impunity, than from the escape of food into the abdomen, and the inflammation it will necessarily engender, which will certainly prove fatal. In the "Veterinarian" for 1834 , an interesting case in point is related by Mr. Steel, of Biggar, N.B. He was sent for to see a cow apparently hooven, and in the ntmost extremity. A surgeon had already punctured the rumen with a trochar, lut no gas escaped, and it became at once evident that the stomach was distended with undigested food ; she had overfed herself in clover pasture. Both Mr. Steel and the surgeon who was present concurred in the necessity of an immediate operation, for it was evident that no time was to be lost. "I made," says Mr. Steel, "an opening into the stomach about five inches in length, when the contents came rushing out in a large stream, and continued doing so for some time; when it had stopped coming of itself, I introduced my hand and removed a great deal more of it. The quantity of this undigested mass which was removed is almost incredible. After being satisfied with what I lad removed, I stitched up the wound and had the cow raised upon her feet: and being afraid of inflammation taking place as the weather was very hot, I drew a quantity of blood from her, gave a pint of olive oil and eight ounces of Epsom salts, which acted rery slightly next day. The second day the cow required bleeding and a purgative. On the third das, there being hard food in the rumen, the point of a syringe was introduced, and the mass divided, and some tepid water injected throngh the wound; a dose of physic was again given." Thongh this corr laboured at the time 
under a severe catarrh, she ultimately recovered. It is most advisable in these cases to relieve the rumen at once of all matter therein collected; the wound should not be disturbed if possible, and there is danger in injecting water, lest a portion mixed with broken-down vegetable matters find its way into the abdominal cavity.

After an operation of this kind, and indeed after a simple puncture of the rumen by a trochar for the escape of gas, an adhesion (from circumscribed inflammation) usually takes place between the portion of the rumen which had been wounded and the lining of the flank in contact with it. In common language, the stomach at that part sticks to the side. If this adhesion be extensive, it will more or less interfere with the act of rumination; it may even suspend rumination, producing what is called "loss of cul." This, indeed, may result from the debility and over-stretching of the fibres of the rumen during hoove, or the distention from food. Cordial aperients and tonic medicines will, in the latter case, be of service. This affection, however, results from other causes, which we may here notice.

\section{I.OSS OF CUD.}

Loss of cud not only proceeds from the causes to which we have just alluded, but is often a marked symptom in other complaints, and may be taken as a sure evidence of disorder of the digestive organs. In severe inflammatory diseases rumination is generally suspended, as well as in states of constitutional debility and prostration of strength. In the former case the stomach will recover its powers as the animal improves; in the latter case the restoration of the strength by tonies, as gentian, is required, and cordials, with gentle aperients, may be also given; as four ounces of salts, one ounce of powdered gentian, and half an ounce of ginger, with a little ale and gruel, every other morning.

Loss of cud is often produced by an accumnlation of dry or noxious vegetable matter between the foliations of the third stomach or manyplus, and to this affection we shall at once proceed.

RETENTION OF FOOD IN THE MANYPLUS, CALLED CLUE, OR FARDEL-BOUND.

We have described the manyplus as a sac provided internally, with numerous foliations or duplications of its articular lining, covered with nultitudes of rough or hardened papillie. In this stomach the food undergoes its last preparation for the abomasum, or true digesting stomach: it is situated between the liver and the right sac of the rumen, so that, when over-distended, it will press upon the former. Not unfrequently it may prove an obstruction to the return of the blood to the heart.
As dissection after death proves, there are few severe diseases, especially of an inflammatory nature, as catarrh, enteritis, pleuritis, fever, \&c., in which the manyplus is not affected; generally it contains between its duplicatures layers of comminuted vegetable matters tightly pressed, and as dry as hardened oatcake. At other times it is full of a soft pultaceous mass, emitting a putrescent and most disgusting odour. In both these cases no nutrient matter passes into the abomasum, the door of communication being blocked up. Sometimes the duplicatures of the manyplus are found to be gangrenous, and the abomasum in a state of high inflammation.

But it is not only from sympathetic inflammation, and consequent loss of function, that the manyplus is liable to suffer; it is often the seat of original disease, sometimes slow or chronic in its course, sometiues rapilly terminating in death.

The causes of this disease are obscure. It has been attributed to acrid plants; to a sudden change of diet, as from green fodder to hay, especially if bad; to coarse and fibrous food, whether green or dry. Sometimes it rages in certain districts, and produces great mortality.

As the causes are obscure so are the symptoms. Cases have occurred in which the dried food must have been lying in the manyplus for several weeks (as was proved by the nature of the food) without materially affecting the animal's health. At other times an animal, previously in perfect vigour, is suddenly taken ill, and, in spite of all that can be done, falls and dies. The following examples are in point :-

An epidemic disease broke out among the cat tle at Bourbourg. A farmer had a valuable cow, and was desirous of saving her; he therefore sent her to a distant and uninfected district, where she could not by any possibility obtain vetches, which had constituted her previons food. Here she remained for six weeks, to all appearance well; at the end of the six weeks she was seized with the prevalent malady, and died. On examination of the stomachs, the third was found to be filled with dry hard compacted vetches. How far this condition of the manyplus was connected with the fatal disease which carried the animal off, we are not able to say. The long continuance of dried vegetable matter in the manyplus, taken weeks previously, is remarkable; and we can only account for it by supposing that the derangement was, for a long time at least, confined to a portion of the manyplus only, the other portion continuing the performance of its duties.

$\mathrm{Mr}$ Cartwright, in the "Veterinarian," records the following: "A drove of cattle, on their journey from Anglesea to London, crossed Bangor Ferry, all apparently in excellent health. They stopped one night in a field near Bangor, and proceeded; 
but had not gone far when one of them was taken ill. and being unable to continue the journey was slaughtered. A little farther on two other beasts began to fail; and when the herd arrived on the borders of Shropshire, the malady was spreading rapidly among them. They were dull and moaning: they remained obstinately standing, refusing to move along. Measures were instantly resorted to; they were bled, and purgative drenches were administered; but four of them presently died. In two of these the manyplus was full, and clogged with soft food; in the third the greater part of the food was soft, but what was in the larger curvature was hard and friable. In the fourth beast the manyplus was filled with hardened lavers: each layer was so dried that it would suap short, and was moreover covered witn a thin pellicle of secretion, of a bluish colour, that could be separated. The leaves of the stomach were of a pinkish hue, and the blood-vessels injected. Among the contents of the stomach of each were found a number of small seeds of some unknown plant, to which the disease was attributed. Four other beasts were taken ill, and with difficulty recovered; for although medicine in great quantities was administered, it was eight or nine days before any action of the bowels was effected."

Generally speaking this disease comes on with dulness, dryness of the muzzle, and protrusion of the tongue; the pulse is quick and hard; the membranes of the eyes and nostrils are bloodshot; the eyes are starting, the head is extended, the limbs are tottering, and the animal is nuwilling to move. The bowels are constipated; the urine scanty, and either red or dark-coloured. In cows the secretion of milk is either stopped, or the milk is offensive both to taste and smell. As the disease gains ground the determination of blood to the head becomes more manifest, the animal loses consciousuess, the abdomen swells, the frame trembles, the eyes are glairy, the limbs become cold, and the animal sinks torpid. Many or most of these symptoms occur in other inflammatory diseases, consequently the diagnosis is ly no means easy, nor are there any which enable the practitioner to say whether the food in the manyplus is divested of its juices, or is in a pultaceous state; yet these differences must result from separate causes. In the first instance we must suppose a violent contraction of the manyplus from some irritation, producing a firm pressure of the comminuted vegatable matter between the leaves of the stomach, which latter, acting like a screw-press, forces out the juice and superalded moisture of the mass, converting it into hard, dry, friable layers, which may be crushed to powder. In the second instance the inflammatory action of the stomach must produce a sort of paralysis, or loss of power, so that no action is exerted on the accu- mulating pultaceous matter, which gradually becomes jutrid. But it would appear that in some part of the stomach the leaves may exert pressure, while in another part there is loss of power.

With respect to the treatment of this disease, when it occurs as a primary affection, much de. pends on its severity: the abstraction of blood will relieve the system; and this must be followed by copious aperient draughts, poured gently down the gullet, or slowly injected by the stomachpump, the tube of which must be introduced for some distance into the csophagus. The olject is to throw the medicine into the manyplus, and thence into the abomasum, without its being forced through the pillars of the nesophagean canal into the piunch. A free operation of the medicine is a favourable symptom. Some writers recommend that a gentle stream of warm water, with a little Epsom salts dissolved in it, be transmitted into the manyplus, through the tube of the stomachpump, with the object either of diluting and carrying forward the pultaceous mass, or, on the other hand, of softening and breakiug down the dry friable layers, and washing them into the abomasum. We doubt not that a perseverance in this plan might be productive of benefit; and certainly it could produce no evil consequences. Should the animal recover, the greatest cantion relative to its diet is requisite. This should consist only of bland mashes and thin gruel, till the stomach is enabled to take by degrees the most simple green food.

It appears to us that two diseases, termed wood-evil and red-water, are mere modifications of this affection of the stomach, or are symptomatic of its existence; and it is under this impression that we bere notice them. They certainly are intimately connected with debility and functional derangement of the digestive organs; and an accumulation of matter is always found in the manyplus.

WOOD-EVIL, MOOR-ILL, OR PANTAS.

This disease is brought on in cattle by their devoming the acrid buds of trees, by bad winter provision, by impure water, and similar causes. It comes on with febrile symptorns, heat of the mouth, and quickness and hardness of the pulse; the coat is staring, the skiu hide-bound; the eyes and nostrils are bloodshot, the thirst is great, and there is obstinate constipation of the bowels. The beast loses flesh, and exhibits a ca. pricious appetite; it will pick up bones, sticks, pieces of linen, \&c., and grind them for a long time in the mouth; the filthiest puddle is prefer'red to clear water; the urine is geuerally scant $y$; it is tinged red, and has a penetrating odour; the milk is affected and disgusting; there is an indisposition to move, and the animal utters moans indicative of internal pain; the shoulders and 
chest are stiff, the flanks heave, the limbs are unsteady, and the brain shows signs of congestion. Such are the symptoms in violent cases, in which, if the disease be not arrested, the animal dies. The appcarances observed on dissection after death are inflammation of the bowels, of the fourth stomach, sometimes of the lungs, and a repletion of the manyplus, with undigested and generilly compressed vegetable matter. In these cases bleeding and aperients are the principal remedies; but in milder cases, where there is little or no febrile action, aperients alone may be trusted; or, if the abstraction of blood be deemed advisable, a small quantity only need be taken. A good aperient medicine may consist of six drachms of Barbadoes aloes, six ounces of Epsom salts, two drachms of ginger, and a quart of thin gruel. Another, perhaps generally speaking to be preferred, may be made with eight ounces of Epsom salts, eight ounces of olive-oil or linseed-oil, and a quart of thin gruel.

\section{RED WATER AND BLACK WATER.}

This disease must not be confounded with acute inflammation of the kidneys, attended by hemorrhage, which tinges the water with blood. Red water is indeed so called from the colour of the urine, and we have stated that such is its colour, in cases of retention of food in the manyplus and in wood-evil; but it is very doubtful whether the colour, in these diseases, is at all owing to the presence of blood. Mr. R. Thompson attributes it to the absorption of vitiated bile, which passing into the blood stains all the secretions; and this opinion is corroborated by the fact that, in red water at least, the liver is enlarged, inflamed, sometimes rotten, and the gall-bladder distended with thick dark bile. This is the view taken by most veterinary surgeons of the present day; and, as Mr. Spooner observes, it is "supported both by an analysis of the urine, and an examination of the viscera, in fatal cases."

As to the connexion of red water with disorder of the manyplus, we have the express testimony of many experienced practitioners. Mr. Youatt says, "The manyplus is perfectly dry; baking could hardly add to the hardness; were it not for its weight it might be kicked about as a football. The leaves of the manyplus cling to the food contained between them; the papillae leave their evident indentations on the hardened mass; and that mass camnot be detatched without considerable portions of the cuticle clinging to it. The fourth stomach is empty, and the lining membrane covered with brown mucus, exhibiting patches of inflammation underneath...... The kidney is of a yellowish-brown colou;, and sometimes a little enlarged; but there is rarely any inflammation or disease about it." He adds, that the lungs have a yellow tinge, and the fluid in the pericardium is yellow, the chyle in the lacteals yellow, the skin dark yellow, and also the conjunctiva of the eye. These are symptoms of jaundice.

Mr. White (late veterinary surgeon of the First Dragoons) states that, after a careful examination, he is of opinion that red water originates in weakness of the stomach from feeding on bad hay during the winter. "In cows that have died of this disorder we almost always find an accumulation of the fibrons parts of liay, in the third or foliated stomach, compressed into thin cakes, and matted together. The cuticular coat of the leaves of the stomach generally separates with those cakes of matted fibres, and the muscular coat is found weakened and distended."

There is considerable variety in the symptoms of this malady. Sometimes the urine is but slightly altered, sometimes it is of a deep yellowish red; at other times brown and turbid, and even of a blackish tint. When the latter is the case it is termed black water. We can easily conceive that, from the continued bilious irritation of the kidneys, their minute vessels may at length begin to pour out blood; but granting this to be the case, we are not to attribute the seat of the disease to these great excretory organs-they are passive sufferers only; we might as well regard the yellowness of the conjunctiva as indicative of disease of the eye. We need not wonder that from the same cause there is often distressing stranguary, nor that $d y$ sentery should precede obstinate constipation of the bowels.

Practitioners, though they mostly agree as to the chief organs affected during the progress of the disease called red water, differ in their opinion as to its exciting cause : each judges from his own experience. Some, for example, attribute it to the noxious herbage of low undrained swampy lands; and there is no doubt that in such situations it is often prevalent. Others consider that it is of most. frequent occurrence in dry and hilly districts, where little grass and less water is to be obtained during a lot summer, and instance localities of this description where it rages like an epidemic: we believe that they also are correct. Peat and moss lands have been kuown to prodnce this disease. It will result from feeding on the budding leaves of copses in spring, and the decaying leaves in autumn; and at these two seasons of the year it is most especially prevalent. A diet of bad hay duriug the winter will cause it; so will a sudden change of pasturage. The disease often occurs in cows after calving, perhajs from a change of diet, or some mismanagement: change of pasturage, from a stony or flinty soil to a heavy clay soil, has been known to cause it. It sometimes ravages a farm; while in the next, divided from the other only by hedgerows, it is unknown. Of two adjoin- 
ing fields one may be dangerous, the other safe; nay, a field safe during certain parts of the year, may be dangerous during another. Atmospheric influences may also have their effect; for it sometimes appears as an epidemic of a malignant character. Whatever, in fact, affects the digestive organs, including the liver, may give rise to attacks of this often fatal malady.

As we have already said, red water must be distinguished from inflammation of the kilneys, which is often combined with enteritis. True red water commences with dulness, languor, and loss of appetite; rumination ceases; the urine is at first brownish, and then of browing yellow, and ultimately appears like dark porter: sometimes there is great stranguary, but this is not an invariable symptom. The skin is of a dirty yellow; the eyes and notrils are suffused with yellow, as is also the little milk that the cow may yield: its taste and odour are unpleasant. If blood be drawn the serum which separates from the coagulum is of a brownish yellow. The pulse is quick; the animal can scarcely be forced to move; the loins are tender, and show signs of weakness; the ears and limus become cold. At first diarrhœa makes its appearance, but only at first; lut this suddenly stops, and is succeeded by obstinate constipation. The nrine now becomes even still darker; the disease may be termed black water; the animal now rapidly sinks and dies.

The duration of this disease, from its commencement to its fatal termination, varies according to circumstauces: it may continue for weeks.

It is rarely, excepting in the early stage of the disease, that the red water is curalle. If the animal be robust, and the slightest febrile action present, moderate bleeding will be beneficial, but the flow of blood should be stopped as soon as the pulse is the least degree faltering. Some practitioners dislike the abstraction of blood in this malady, but we can see no danger if caution be nsed; and botli Mr. Simonds of Twickenham, and Mr. Harrison of Ormskirk, who have had extensive experience in its treatment, resort, unless there be good reason for the contrary, to this mode of treatment. The next step is the administration of purgatives and injections. The purgative draughts should be gently poured down the gullet, or slowly thrown down by means of the patent stomach-pump; a good aperient drench may consist of twelve or fourteen ounces of Epsom salts, four ounces of sulphur, half an ounce of carbonate of ammonia, and half an ounce of ginger, in thin gruel or warm water.

After the first drench smaller doses should succeed at intervals of six or eight hours, with a repetition of the mijections, until the bowels act freely. Mr. Harrison states that he has seen a scruple of calomel given in a pint of yeast produce purging when other remedies have failed, the life of the animal being thus saved when there was little hope.

After the bowels have been well purged, tonics and diuretics may be given: as a drachm of ginger, a drachm of gentian (in powder), and an ounce of spirit of nitrous ether in a little gruel twice a day

As the animal improves the skin will become clear, the breathing easy, and appetite will return; still the urine from previous irritation of the kidneys may continue dark coloured or black. Under these circumstances a few doses of oil of turpentine and laudanum (of each one ounce) in linseed tea may be given with advantage. Great attention must be paid to the diet, which should consist of mashes, gruel, linseed tea, and fresh vetches or meadow-grass, but never in large quantities at a time.

Snch then is the mode of treatment for this disease, for which in various parts of the country some of the most absurd remedies are in vogue. Sonse place their faith on a handful of oatmeal and salt fried until dark brown, and given in a quart of cold buttermilk; others give salt and milk, coal-ashes mingled with water, salt mixed with some of the animal's own blood, water thickened with the clay of the beast's pasturage, and some have a great opinion of brandy ; some trust to bole armeniac, salt, and a decoction of nettles; others to alum and the juice of nettles, or writingpaper boiled to pieces in skimmed milk. Mr. Parkinson. (whose ideas of medicine and anatomy are certainly very extraordinary, to say the least) recommends in his "Treatise on Live Stock," two or three handfuls of nettles stewed in three quarts of water until reduced to one quart; this when cool is to be given and followed up by another draught, consisting of a pint of common salt dissolred in a quart of chamber-lye. This he says is infallible; but he has known the disease cured by doses of buttermilk and pig's dung, and also by a frog in a quautity of cold water. Captain J. Henderson, in his "Surrey of Caithness," recommends a frog or a trout put alive down the animal's throat.

It would be scarcely perhaps worth while to notice these puerile absurdities which only merit contempt, were it not for two reasons : first, becanse we desire to see them abolished, which will only result from their uselessness and eren mischierous consequences being pointed out; secondly, because it is not to this disease alone that the administration of similar remedies is restricted. The cowleech's "good old" pharmacopœia contains little else but such nostrums. Take the following as a cure for catarih:-Balsam of sulphur, two ounces, Barbadoes tar, one ounce, the yolks of two eggs. These are to be incorporated by beating in a basin, then add ginger, aniseeds, cummin-seeds, elecampane-root, grains of paradise, and liquorice-root, of 
each one ounce, in powder; salt of tartar, one and a half ounce; honey, four ounces; mix together and add by little at a time, continually stirring, one quart of warm ale or gruel, if of gruel add a wineglass of gin or lrandy. This is to be given lukewarm. Some of the ingredients are inert, others are highly stimulating; the disease is of a most inflammatory character. But what knows or cares the cow-leech about that? His nostrum is a specific; should the beast die, reasons "plenty as blackberries" are ready on the "doctor's" lips to prove that neglect on somebody's part (any one's but his own) was the real cause of ill-success. The common cordial drink of the cow-leech, given indiscriminately, consists of two ounces of mixed spice, one ounce of ginger, one ounce of amiseed, one ounce of long pepper, one ounce of diapente, one ounce of grains of paradise, one ounce of fenugreek, one ounce of turmeric, one ounce of mithridate, one ounce of galengal. and one ounce of caraway seeds, in beer, ale, or gruel. If the luge rumen of the cow were less sensitive and irritable than it is, or did the cow-leech know how to give a draught so as to throw his execrable compositions into the abomasum instead of the rumeu, what mischief would not ensue! Well may this mixture be called a felon drink;* would that those who give it had to take some of it themselves! However we shall here quit the subject, hoping that those who keep cattle will at least consult common sense before they trust to snch nostrums, and desist from giving poisons in inflammatory diseases.

In taking a review of the three last diseases to which we have adverted, viz. retention of vegetable matter in the manyplus, wood evil or pantas; and red water, we cannot but perceive that they belong to the same generic group, and that they are distinguished from each other more perhaps by name than by auy radical difference (except we call that of degree so) or distiuction of type. In each state the treatment is the same as to principle, varied in minor points according to circumstances, and the judgment of the practitioner.

CONCRETIONS IN THE STOMACH AND MECHANICAL OBSTEUCTIONS OF THE ALIMENTARY CANAL.

Cattle are very apt, urged by some morbid condition of the stomach, to swallow rarious strange articles, as linen, leather, pieces of iron, \&c., and such for example as liandkerchiefs and other parts of dress, shoes, gloves, scissors, pieces of wood, bits of coal, and the like. Numerons instances of this nature are on record, and many farmers, no doubt, could supply others from their own persoual experience.

Occasionally no mischief appears to result from this unnatural act, but generally the presence of

- The farmer and cow-leech call numerous diseases, as rheumatism, fever, palsy, \&c., by the name of felon. these matters in the rumen produces irritation: the due performance of rnmination is interrupterl, the animal is dull, aperients have no beneficial effeci, it becomes worse, and at last dies, when, the stomach being opened, the cause of the mischief is discovered. Scissors and other sharp instruments will sometimes work their way through the coats of the rumen, and protrude hetween two of the ribs; frequently they pierce the pericardium and canse death. Large substauces interfering with the action of the rumen, while the animal still continues to feed, conduce to the distention of that viscus, and occasionally, on the performance of the operation of opening that sac, the source of the evil is detected and removed.

It very often happens that bits of stick, iron, or stone, taken into the stomach form the nucleus of a large globular calculus consisting of the various compounds of lime or silex, beautifully arranged in concentric layers. These concretions are extremely firm aud hard, and when sawn into two pieces the flat surface of each takes as glossy a polish as marble. They vary in size; we have seen specimens of extraordinary magnitude. It is in the rumen principally, if not exclusively, that these calculi of the stomach are found, and their presence is often unsuspected until after death. Yet we camnot suppose that they produce no derangement of the digestive organs, and we believe that they are most commonly to be met with in beasts that do not thrive well, and that manifest irregularity of appetite. Whether they cause this, or are themselves the results of some morbid action continuing to exert an unfavourable influence, may he a matter of opinion, but of one thing we may be sure, they will not tend to the abatement of the morbid condition of the stomach which conduced to their formation: the rule of action and reaction may be reasonably suspected.

Cattle are prone to lick their own hides and the hides of each other. The hair swallowed passes into the stomach and becomes natted, by means of the saliva and mucus, into balls; a nail, a bit of stick or a portion of fibrous vegetable matter, sometimes, but not always, constituting their nucleus. These bird's-nest-Jike balls are found both in the rumeu and the abomasum. In the former they are often mingled with vegetable matters, with threads of cotton, linen or woollen, with particles of earth, straw, and other substances. In the abomasum they consist exclusively of iutertwined matted hair. How long these balls may remain in the abomasum, and what functional derangements they may occasion, it is not easy to say. Sometimes, however, these balls either pass into the iutestinal canal, or are formed there, producing a fatal obstruction. The farmer dreuches the poor beast, but to no purpose, not perhaps that the merlicine fails in its office, but a mecha. 
nical olistruction prevents its lue operation; this only adds to the animal's agony, and it dies worm out by pain and perhaps inflammation. Could the nature of the obstruction be ascertained some measures perhaps might be resorted to, and even when circumstances lead to a suspicion of the real state of the case, though it be suspicion only, no harm can be done by acting as if it were confirmed. Injections to a large extent of soap-water aud oil should be administered, and that repeatedly, and a pint of linseed oil, with twenty grains of the farina of croton-seed, or twenty drops of good croton oil may be poured slowly down the gullet; this purgative with a little gruel may be repeated every eight or ten hours, till the obstruction be forced. Should pain and fever render it desirable blood must be taken away, and it may be necessary to repeat the bleeding.

Balls of hair, however, are not the only mechanical obstructions of the ahmentary canal. Balls of hard undigested fibrous vegetable matters, sometimes mingled with hair, threads, and extraneous articles, but by no means always so, are often impacted in the lower bowels; medicines give no relief, and the auimal sinks after enduring indescribable agony. The same treatment must be he repursued as that already described, and not unfrequently the hand, if the substauce be in the rectum, will better remove the obstacle than any medicine. This observation applies both to hairballs and to hardened fœcal matter. Horses are very subject to this obstruction, and it occurs frequently in cattle fed too much upon dry food. Some recommend in these cases, hesides purgative medicines, injections of tobacco-water (an ounce of totracco infused in a gallon of boiling water), but in the use of this injection great caution is requisite. We have known it prostrate the nervous system even to dissolution. It may be tried as an ultimate resource. We are inclined to recommend injections of oil, gruel, and laudanum (of the last two ounces), in cases where the straining produces agony; the opium may not only ease the pain, but cause the muscular fibres of the lower bowels to relax from their constriction, while it will not interfere with the operation of the purgative medicines.

\section{ENLARGEMENT OF THE MESENTERIC GLANDS.}

We have said that, in the mesentery, to which the bowels are attached, there are numerous glandular bodies through which the lacteals or nutrient ducts pass in their course to the thoracic duct, or great receptacle of the chyle. In the ox, as in the human subject and other animals, these glands are liable to enlargement; they are affected with a scrofulous disease, and in this condition arrest the currents of nutrition, the abdomen swells greatly, the limbs and frame become emaciated, the eyes sunk, the membranes of the nose and mouth pallid, the respiration huried, the pulse quick, and the prostration of strength extreme; there is often an unpleasant cough and other symptoms of consumption which increase till the animal dies, almost a skeleton. Sometimes tumours can be felt liy passing the hand over the surface of the abdo. men, but this is not always the case.

In such a discase little or nothing can be done. Doses of mercury and opium, as two scruples of calomel and half a drachm of powdered opium given every evening, with tonic draughts (gentian, or infusion of cascarilla) during the day, may perhaps mitigate the symptoms. To these remedies occasional aperients may be added. Fight or ten grains of iodide of potass, chivided into two doses, may be given daily iu gruel, the quantity of the iodide being gradually increased to ten grains for each dose. If this be used, the mercury and opium must be omitted. Warm stabling and good food are of course essential. After all, little, we repeat it, can be done; the disease has generally made great progress before it is suspected, and it runs its course. Frequently it is associated with a tuberculous state of the lungs, and also with enlargements of the glands gewerally.

Though mature cattle are not exempt from this malady, it occurs most commonly in joung weakly beasts, poorly fed and reared in low damp situations. Let it be remembered that, as in consumption, the tendency to it is hereditary. It is, in fact, a form of consumption, the index of a scrofulous diathesis.

\section{POISONS.}

Cattle sometimes partake of poisonons plants, as the water-hemlock, the yew, and others, and perish in consequence; nor is it easy to determine from the symptoms alone that they are suffering from such a cause. The animal is torpid, and swells ; its thirst is excessive, but it refuses food; it grinds its teeth evidently from agony ; stamps, paws the gromd, strikes at its flanks, and sometimes rolls on the ground as if labouring under the spasmodic pains of colic.

Occasionally the animal becomes infuriated, as if agitated by frenzy; this state of madness contiuues for a longer or shorter period, ending in general palsy, torpor, and death.

Examination of the body, in these cases, rereals inflammation of the paunch and reticulated stomach; and often also of the abomasum and small intestines; while the mauyplus is filled with hardened vegetable matter. The cuticular coat peels readily from off the muscular coat of the rumen and reticulum or honescomb-the sign of commencing disorganization; and the abomasum is not unfrequently ulcerated. 
If it be ascertained that an animal has fed on noxious plants, instant recourse must be bad to the stomach pump; the stomach must be deluged with water until the rumen overflows, and the contents are rejected by vomiting. Nor will one operation of the kind be sufficient, it must be repeated ; and afterwards smart aperieuts, consisting of salts, oil, and gruel, must be slowly poured or injected down the cesophagus, and repeated every six or eight hours until the bowels are well purged.

Supposing that there be a mere suspicion that poison of this kind (known to be accessible) has been taken, but that in reality the symptoms arise from some distention of the rumen only, attended by severe colic, still no harm will be done. The rumen will be relieved, and the bowels emptied of irritating matter; and a cordial with a little opium will complete the cure.

With respect to mineral poisons, it is not often that they are accidentally swallowed by cattle. Arsenic may indeed be given wilfully, and perhaps a piece of bread-and-butter, sprinkled with arsenic for the destruction of rats, may be left carelessly in the way of cows and devoured; but these are rare cases. No one can tell the eause of the horrille suffering endured by the poor animals; they die, and perhaps after death the presence of poison is detected in the stomach. Let us, however, suppose it to be known that arsenic has been swallowed-what is to be done? A quantity of limewater or of chalk and water must be injected into the stomach, and, after remaining a few minutes, pumped out, a fresh quantity being injected. This may be repeated two or three times, and at last a fresh quantity injected and left, in order to neutralize the arsenic, if any remain in the stomach. Aperients of salts and oil must then be given, and their operation assisted by clysters of oil, salt, and gruel.

Corrosive sublimate (bichloride of mereury, or oxymuriate of mercury), though never given iuternally to cattle, is often rashly used by ignorant persous as an external application to ulcers, maugy spots, and other cutaneous affections. It is a most dangerous remedy; for it will pass into the system by absorption, and produce serious illness or even death. The animals become dull, they cease to ruminate; frothy saliva drops copiously from the mouth; they moan, and more restlessly; strike at their flanks, and are tormented with violent and often bloody purging. After death traces of active inflammation appear in the intestines, and in the rumen, honeycomb, and abomasum. In this case the remedy will consist of the white of a number of eggs beaten up, and mixed with a little gruel; this mixture must be gently poured down the gullet, and repeated every hour till the symptoms abate ; aperients may afterwards be adminis- tered, and copious injections of gruel. Too often however all remedies prove useless, frequently there is no time to have recourse to them. Mr. Youatt relates an instance in which several cows thus perished: their skin was mangy, a man freely washed the disordered parts with a strong solution of corrosive sublimate, and before he had finished dressing the last cow the first had expired, and the rest followed in rotation, all being dead within two hours from the application of the lotion. On examination the intestines were found to be ulcerated, and the differeut stomachs were highly inflamed. "The gas which proceeded from the abdomen was of so poisonous a character, that the butcher who opened the animals, although warned of the danger, yet exposing himself to the blast of the gas as it escaped, had erysipelatous swelling of the face and head, which threatened his life."

'The various preparations of lead are poisonous, and Mr. White records a very singular fact, relative to the fatal effects resulting from these preparations, to cattle grazed in the neighbourhood of lead-mines. "A very serious disease," he observes, "has at times occurred in the vicinity of Mendip, and in those parts where the lead mines are worked, which has proved very destructive not only to cattle, but also to horses, to dogs, and even to poultry. 'This disorder is termed mindering by the inhalitants, and the animals so affected are said to be mindered. I have been informed by a respectable farmer at Wookey, who appears to be well acquainted with the disorder, that he has never kuown sheep affected by it. After heavy rains the brook which flows through the meadows of Wookey overflows its banks, and covers some of the adjacent lands; and these, after the water has retired, have their grass so impregnated with lead as to be rendered poisonous; and it has been observed that those animals which feed close to the stream or pick up the long grass on the margin of the water are most quickly affected; it is said that the water also is poisonous. It seems probable that the poison consists of the carbonate of lead, which is sublimed in immense quantities on smelting the ore, aud is carried through the atmosphere to a considerable distance and deposited very extensively on the surface of the hill. During a heavy rain, this carbonate of lead is washed down in great quantities into the meadows and the brooks, and gradually subsiding, imparts that poisonous quality to the grass that has done so much injury. A dog has been known to be mindered after picking a hone in a meadow that has been thus poisoned. So far do the imjurions effects of the lead-mines extend, that the meadows near Wookey-hole have been thus poisoned, though the nearest mine from which the metal could have been derived, was situated near Priddy, a distance of several miles. The disorder sometimes occurs 
on different parts of the hill, and especially near the smelting places, from which it has been thought that the deleterious matter consists of the lead-ore itself, in a state of powder. But it is known to impart a sweet taste to the grass, which the lead-ore, however finely powdered, has not the power of doing. It must therefore, I think, be a carbonate of lead, or some saline compoind, but how the latter can be formed, it may be difficult to explain. If the lead-ore contains sulphur, then a sulphate of lead may be sublimed, and diffused to some distance, but I think it more probable that it consists of a light powdery oxide of lead, or a carbonate or super-carbonate. Sometimes the disorder has occmred close to the smelting places. One farmer, the propictetor of a mine, lost fifteen cattle by it, that broke down a fence near the smelting place one night, and ate freely of the grass romd the banks. A respectable and intelligent farmer of Wookey hole also lost eight head of cattle at one time, in consequence of his meadows being overflowed."

The progress of the effects of this poison is variable, according to the quantity taken, sometimes the cattle perish in a few days, sometimes they limger for weeks, sometimes eren for months; but few ultimately recover.

The symptoms, when urgent, are great difficulty of breathing, with a loud wheezing, to be heard at a considerable distance, and threatening suffocation, which sometimes takes place. Occasionally, when the attack is not extremely violent, the beast lingers for a week or two and dies from inflammation of the lungs. Sometimes these symptoms come on gradually, and terminate in epilepsy ; the animal loses its appetite, the bowels are confined, the kidneys gradually cease their secretion, the fits return more frequently and endure for a longer time, till at length the animal dies wasted to a skeleton.

With respect to the treatment of the animals, drenches of common salt and water, repeated frequently till the bowels are unloaded, assisted by free injections of the same, are said to have been occasionally successful; a solution of Epsom salts, combined with linseed-oil, is also recommended, opium being given afterwards to allay the irritation. We would suggest scruple or half drachm, or even drachm doses of calomel, with two scruples or a drachm of opium twice a day, aperient medicines being given in the interval.

There is a well-known disease, resulting from the absorption of lead into the system, in the human subject, called colica Pictounm. It terminates in paralysis. We are not aware that similar cases have ever occurred in cattle.

I. Barthé describes a disease in the joints and synovial bursæ of cattle and horses in the neighbourhood of copper-mines, which is attributed to the exhalations from the metal during smelting. In some cases the joints bave anchylosed at least to a great extent, and the synovial membranes been more or less destroyed. In the neighbourhood of smelting establishments for zinc, as at Liege, similar effects are sail to have been produced. We cannot say to what extent such cases occur in England, it is reasonable, however, to suppose that the same causes will produce the same results.

We may now pass on to a consideration of some of the more local and external diseases, or injuries to which cattle are subject, the treatment of which, by the ignorant cow-leech, of ten produces irreparable mischief.

There are two diseases to which the horse is subject, but, as there is reason to believe, not the cow : we mean glanders and farcy : at least no well anthenticated cases are on record. One of the sfmptoms of farcy in the horse, is inflammation and thickening of the absorbents, especially at the valves; the absorbents have a corded feel, and at greater or less distances along their course, where the valves are situated, small tumours or buttons arise, arresting the current of the fluid contained. Farcy is a highly contagions disease, and often accompanies glanders; but though true contagious farcy either does not occur or very rarely occurs in the $o x$, inflammation of the absorbents is not uncommon.

\section{INFLAMMATION OF THE ABSORBENT VESSELS OF THE SKIN.}

As in farcy the absorbents are corded and show buttons at the valves along their course, these buttons become hard and schirrous, and some suppurate, and degenerate into ulcers. This disease may be more or less extensive, and may result from various causes, as from wounds rendered foul and irritable by improper dressings, from diseased hoofs, or ulcers of some of the joints of the limbs. The absorbents running from these wounds or ulcers become irritated and inflamed, and the whole system sympathizes. As soon as the ulcers heal, the active inflammation of the absorbents subsides, though a thickening or cording of their tissue may remain for a considerable period. During the stage of inflammation the buttons often burst, and ulcerate, producing considerable mischief. They are extremely difficnlt to heal, but still there is no danger of contagion.

Mr. Youatt describes the cases of four oxen, which at different times, respectirely, during the course of three years, were seized with what the farmer to whom they belonged considered as farcy:- cording of the absorbents, with farcy-buds or buttons extended up the limbs from the fetlock to the forearm; some of the buds were schirrous, others in a state of ulceration. In each 
instance the animal lavoured at the time under a severe cough. Simple treatment, and the application of the hot iron to the buttons, effected restoration to health; the wounds healed, and the thickening of the absorbents subsided, the cough at the same time disappearing.

In two montls afterwards, the cough and thickening of the absorbents returned, and the same means were again resorted to, with the same success.

Although these were believed to be cases of farcy, and they certainly bore a close resemblance to that disease, yet Mr. Youatt is decidedly of opinion that it was in resemblance only that the agreement consisted, and that when such cases occur the farmer need not entertain serious apprehension of the baleful disease known as farcy breaking out in his herd.

\section{DISEASES OF THE EYE AND EYEIJDS.}

The eye of the $o x$ is very subject to injury from blows, from thrusts with the prong of the stable-fork, and from the horns of other cattle; sometimes the eye itself is destroyed, sometimes bony tumours or excrescences are formed on the ring of the orbit, and sometimes the superciliary ridge of the orbit is fractured. In these cases little can be done, but they ought never to have occurred. When the superciliary ridge is fractured, the fractured portion must be readjustel as well as possible, and secured by a bandage, and blecding and purgatives resorted to in order to allay fever and inflammation. Bony excrescences may be sometimes removed by means of a fiue saw, the root being afterwards slightly touched by the cautery. In other cases their growth may be checked and exfoliation produced by the application of the cautery, at a low temperature, but a fine saw or clisel is alwars preferable. These excrescences not unfrequeutly degenerate into a state of caries. 'The animal should be destroyed, and the sooner the better.

Ophthalmia oftenarises in cattle from injury to thc eye, or from the presence of irritatiug substances lodged beneath the eyelids. Sometimes it proceeds from constitutional causes alone, and returns periodically ; indeed this form of ophthalmia is hereditary, like consumption, and a radical cure is almost hopeless. Ophthatmia arising from irritating substances, or from blows, generally yields to bleeding, to purgatives and fomentations, or the goulard lotion (composed of the liq. plumbi superacetatis and water), with a little laudanum; when the actire inflammation is subdued, a lotion of the sulphate of zinc (white vitriol) may be used with advantage. Periodical ophthalmia, though relieved for a time, usually terminates in blinduess; it might perhaps be treated with good effect by small doses of calomel and opium, repeated daily for a short time, and by mercurial lotions; but when the character of the disease is ascertained, the farmer prefers preparing the beast for the slaughter-house; and probably this is his best course.

Severe inflammation of the eyes, with eruptions about the mouth, and swellings of the tongue and throat, often occur in young cattle fed on wet pasture-lands, especially if much wooded. Sometimes superficial ulcerations of the cornea make their appearancc, and if the case be rashly treated blindness will ensue. It may be as well under these circumstauces to take away a little blood; gentle purgatives must be administered, and the eyes fomented with warm water or a decoction of poppy-heads ; some prefer cold evaporating lotions, as cold water with a little spirit, the goulard lotion, aud afterwards a weak wash of sulphate of zinc. Change of locality is essential, and while the disease continues, the animal should be housed.

Cataract and amaurosis or gutta serena are not unknown among cattle; the latter, however, is very rare. In the aqueous cliamber of the eye of the horse a small hair-like parasitic worm, nearly an inch in length, has been occasionally discorered; and we believe that in the eyes of horned cattle a similar parasite has been known to occur, accompanied by the ordinary symptoms of ophthalmia.

The eyelids of cattle are frequently affected with diseases, independent of the inflammation which extends to them in cases of ophthalmia; the edges, along which the sebaceous glands opeu, are souretimes sulject to a pustular eruption and ulceration: in these cases the slin is often mangy, and the animals are in wretched condition. Aperients of sulplus, and alteratives, consisting of one drachm of æthiops mineral (sulphate of mercury), two drachms of nitre, and fuur of sulphur, given every nighıt, will be found useful ; the eyelids must be smeared with the oiutment of nitrite of mercury (ungt. bydrargri nitratis, P.L.), more or less diluted with pure spermaceti ointment, or pure olive oil, every night and usorning, by means of a camel-hair pencil (no jron must come in contact with the preparation). The ointment of the nitric-oxide of mercury (ung. hydr. nitric-oxyd. P.L.) diluted in a similar way is also valuable. This is essentially the golden ointment, so much in vogue.

Warts occasionally form on the eyelids and prove troublesome; these may be removed by means of a sharp pair of scissors, the places being afterwards touched with luuar caustic. In weakly or aged cattle, ill-fed and out of condition, an cedematous or dropsical swelling of the eyelids not unfrequently occurs, the cellular tissue being puffed up with serum, infiltrated into it ; the tumefiction pits upon pressure like dough. A restoration to good health and strength is the only remedy.

In high fed and fattening oxell, on the contrary, the eyelids are found to be puffed up by some gas, which distends the cellular tissue: a slight scratch 
with the point of a lancet will allow of the escape of the gas, up.n pressure; lut it is better to let the eyelids alone, and give a dose of physic.

The haw, or membrana nictitans, of the eyes, is sometimes found to be swelled, inflamed, and even ulceratei from irritation; and is not unfrequently enlarged and protruded in consequence. Cooling masbes, as goulard lotion, with a little laudanum, will diminish the inflammation, and afterwards the astringent solution of sulphate of zinc (from two to four grains to an ounce of pure water) must be applied two or three times a day, to the part itself, a camel-hair pencil being used for the purpose. This treatment, if persevered in, will often effect a cure. Where fungous excrescences sprout, they may be delicately touched by the caustic. The haw should never be removed if possible; this moveable curtain cleanses and defends the surface of the eye, and its loss is a serious inconvenience. In some cases however the veterinary surgeon may advise its excision. and to him alone must the operation be intrusted.

FOUL IN THE FOOT, LOO, OR LOW.

The foot of the ox is extremely vascular; the bones of the toes are perforated by numerous veins and arteries; the veins are larger and more tor tuous than in the horse, and are very conspictious on the pastern. It is from this vasealarity that sprains of the foot, to which from its bifid character it is peculiarly liable, are so often followed in the ox liy serious consequences, or that accidental wounds produce so mueh inflammation. Scarcely a drove of cattle passes along the road among which several of the oxen are not lame; and it is on the feet that the brutal drover ever and anon strikes them to hurry them along, haply to their slaughter. Often have we traced the course of a herd of oxen by the blood-stains on the ruad; the feet are not only strained, the joints swelled and inflamed, but the hoof is worn to the quick or wounded by sharp flints, or thorns, or pieces of fractured glass. Piest, fumentations, and dressings of tar ointment for the hoof, will generally effect a restnration : lut if the lameness be severe, bleeding from the veins of the coronet, and that to a considerable extent, is alsolutely requisite; for in the joints of the toes inflammation cometimes in duces anchylosis. The veins may be opened by a sharp scalpel or drawing-kuife, by a lancet, or a small fleam. Severe wounds of the toes, after being well washed, may be dressed with Friar's balsam on a pledget of lint, rag, or soft tow, bound on by stout rollers or bandages.

Thorns, nails, pieces of glass, dc., remaining unnoticed in the foot, between the toes, or on the the sole, often produce uupleasant abscesses; and iuflammation of the parts within the hoof from overdriving on hard roads will occasionally end in the same result, especially if the horn be worn to the quick. When oxen are pricked by a nail in bad shoeing (we allude to working oxen), as is so fiequently the case in horses, abscesses and sinuses will form; these are termed quittors, in the horse, and are not easily managed.

When a travelled beast continues lame after rest sufficient for the restoration of footsore cattle, or when a beast begins to limp, the lameness rapidly increasing, let it be secured and the foot carefully examined. Suppose a nail or similar substance be found driven into the sole, or auy part of the hoof, common sense will direct its extraction, and its extraction will be probably followed by a flow of purulent matter. Suppose there be a punctured wound only, with inflammation and an abscess more or less deeply seated: in both cases the hoof around the spot must be neatly and cautiously pared down, and, as far as it has separated from the parts beneath, remored; let the alscess be opened, and the purulent matter have a free exit. A poultice of linseed meal may be then applied and changed twice a day, and in a few days, if all goes on well, and healthy healing take place, a little butyr of antimony spriukled over the denuded part every day will induce a new secretion of horn, while a simple bandage or a pledget of suft tow bound over the whole will be a sufficient dressing. If fungous granulations appear they may be levelled with a sharp pair of scissors or a knife, and touched with caustic.

If on examination of the foot of a lame animal no wound appears, it will be necessary to try the hoof in every part by a pair of pincers, and when the pressure gives pain, indicated by the flinching or shrinking of the animal, let the horn be there shaved away and the abscess laid open.

Perhaps, however, suppuration has not commenced, but the inflammation is strong and active; under such circumstances the foot must be well fomented aud afterwards enveloped in a large linseed-meal poultice; this will soften the horny hoof, and promote the suppnration, while at the same time it relieves the pain and inflammation. In lue time the abscess shows itself on the coronet, and must be opened by a lancet; the direction of the sinus should be ascertained by a probe, and the horn shaved away along its course so as to lay it open; should there be several sinuses the same plan must be resorted to with each. Poultices must now be renewed until healthy granulations appear, and every particle of loose or unsound horn must be removed; butyr of antimony may now be lightly applied, or the wound may be dressed with Friar's balsam on lint; this must he renewed every day, and a bandage wrapped firmly and evenly round the hoof.

Cattle, especially such as are fattening upon stimulating food, are subject to iutlammation, 
cracks, soreness, fungous excrescences, and a foetid discharge between the toes. If the disease be neglected the inflammation extends; in a few days abscesses form and burst, and others succeed until the foot becomes completely disorganized; the animal in the mean time wears away, and becomes a miserable object; the toes are now thrown far apart, the bones become carious, simuses extend in all directions, and purulent matter is profusely discharged. In this state the animal may linger for several months until it dies worn out by pain and exhaustion.

A common but brutal remedy in these cases is to rub a tarred rope or horsehair line to and fro between the hoofs, in order to remove the excrescence and stimulate the surface to secrete healthy horn; dressings of stimulant applications are afterwards applied.

If the inflammation be high, bleeding from the veins of the coromet and aperients are necessary. A linseed-meal poultice may then be used, and renewed twice a day until suppuration has taken place, and the sloughing ulcers assume a bealthy appearance. A little turpentine may be added to the poultices. Fungous granulations must be touched with the caustic, or sprinkled over with verdigris or sugar of lead. In cases where there is a foul foetid discharge, a lotion of a solution of chloride of lime will prove serviceable. When the ulcers are healthy they may be dressed with tincture of myrrh, or Friar's balsam. Stall-fed cattle should be turned to grass.

Some practitioners recommend the applicatiou of the following ointment as soon as the ulcers are cleared by the poultice: viz. hogs-lard and turpentine, of each four ounces; melt together over the fire, and as soon as removed from the fire stir in one ounce of blue vitriol very finely powdered, and continue stirring till the ointment is cold.

Mr. Pottie, in the "Veterinarian" (vol. viii.), after describing this disease, which he aptly terms foot-rot in the ox, and the dreadful state of disorganization which often ensues, baffling every plan of treatment, adds, - "All this, if the patient be put under proper treatment from the beginning, may be easily and certainly avoided. All the practitioner has to do is to produce a slough of considerable thichness and extent from between the toes. There are several escharotics that will do this, but some are too strong, and some too weak; the former excite an intolerable degree of pain (which the ox will not bear with the same fortitude as the horse), the latter operate too slowly, requiring several applications, and often not producing mortification until an abscess has formed, when the use of any caustic is of little scrvice: I find the powdered sulphate of copper answers the purpose better than any agent with which I am acquainted. The foot in the first place is well cleaned by washing with lot water and soap : it is dried; a pledget of tow is covered on one side with common tar, and over this spread a thick layer of sulphate of copper. The pledget is then introduced between the toes placed in close contact with the digital commissure, and retained by attaching its ends to a ligature round the pastern. From the moment the escharotic begins to operate the internal process appears to be arrested, but unless that portion of skin upon which the application is laid sloughs away the disease will be re-established. In many cases one dressing is sufficient to produce the sloughing, in others two or three may be requisite. When the commissure is soft, yielding, and moist, one application is in general enough; others are necessary when this part is hard and hormy, for then the caustic operates upon it with difficulty. The escharotic loses its power in about forty-eight hours, and it need not be removed sooner. At the end of this time it will be seen whether or not another application is necessary. More than three dressings I have never had occasion to apply; the slough comes away with the first, the second, or third; subsequently the sore is kept clean and washed once or twice a day with the acetate of zinc or any other astringent lotion. Nothing more is required. The slough once separated, the lameness disappears, and the animal returns to her food and yields her usual quantity of milk." That this mode of proceeding will prove successful if put into operation before abscesses have formed is un. questionable, the escharotic destroys the diseased part, it sloughs away, and new and healthy skin is reproduced. It too often happens, however, that abscesses have formed before the disease is attended to ; their free opening for the exit of pentup matter, the removal of every unsound and detached portion of horn, poultices, with or without turpentine till the ulcers are cleared, all sloughs removed, and healthy flesh is forming, constitute the great plan of treatment. Tincture of myrrh or Friar's balsam, with a little butyr of antimony, as already stated, will complete the cure.

Whether the last described variety of " foul in the foot" (or rather perliaps this real foul in the foot) is contagious, is not ascertained; it will at all events be prudent to separate the diseased beast from the rest of the herd.

One cause of this disease in cattle feeding on low marshy grounds, appears to result from "the combined operation of moisture and friction, by means of the mud and dirt between the toes."

Mr. Parkinson in his work on "Live Stock" gives the following mode of treatment, as eminently successful in these cases: the farmer who has faith in it, may try it. He says, "My father's method of curing (foul in the foot) was to cut up a sod where the diseased foot had trodden, and 
either turn it over, sward side downwards, or hang it on a ledge, in that position. I am unable to account for this cure, to me it is incomprehensible; but in all the experiments I have tried, this remedy, so simple and cheap, has proved the best. The first year I was at Slane we had many cattle troubled with this complaint. I applied nothing else but what may be called a charm, and they all more readily recovered than when I used severer applications; therefore in future I mean never to have recourse to any remedy but the sod, though probably rest is the greatest restorative."

DISEASES OF THE SKIN.

Cattle kept in wretched horels or cow-houses, or badly fed on unwholesome food during the winter, are liable to mange. It is said that too luxurions a diet will produce it, but we have never known it result from such a cause: often, however, from neglect of eleanliness, and a scanty pittance of immutritious food. It commences with a violent itching, the tormented animal rubs itself against posts, palings, gates, or the boles of trees ; the hair about the neck, slroulders, and sides, is soon worn off, and the skin is red, thickened, and rises in long ridges or creased folds. The cow becomes dull, feeds little, loses flesh, and fails in her milk. In some places a thick scurf appears, in others sores or scabs, from frequent and violent rubbings. Occasionally the surface of the skin becomes covered with scabs, which peel off, and are succeeded by foul ulcers. In the mean time the animal is infested with lice; they abound in myriads, tormenting the miserable creature, and combine with the disease of the skin to render it an ohject of disgust and apprehension. Not only are these parasites communicated to healthy cattle in the same field, but the disease of the skin also; the slightest contact, or the circumstance of lying on the same spot, are sufficient to cause the communication either of the mange, or of the lice, or of both.

Cattle infected with the mange should be kept strictly apart from all others; the first thing to be done is to render the skin as free from scurf, loose hairs, and dirt, as possible ; this may be done by means of a wisp of straw, or the curry-comb, then let a strong sulphur ointment be well rubbed in with a hard brush.

The fullowing ointment generally succeeds :-

Flowers of sulphur, one pound ; turpentine, four ounces; strong mercurial ointment, two ounces; and linseed oil, a pint. Warm the oil, and mix the turpeutine and sulphur with it, incorporating the whole well together; afterwards add the mercurial ointment, by rubbing the whole together in a large mortar, or by means of a stout spatula on a slab.

This ointment must be carefully applied to vol, s. every part, and will soon bogin to take effect. In the mean time it will be well to give interually six or eight ounces of sulphur, with a drachm or even two of ethiops mineral, every third day.

Some persons employ tobaceo-water as a lotion in this disease, but this is a dangerous remedy ; itcauses trembling, sweating, utter prostration of strength, and sometimes even death. Others use a strong solution of corrosive sublimate, a still more dangerous application, and one which has caused the ileath of eattle in numerous instances. We have alluded to its effects when noticing poison. If this deadly poison is deemed requisite in very inveterate cases (and it is better in these cases to effect a gradual than a rapid cure), the following prescription is recommended:-

\section{$\mathbf{R}$}

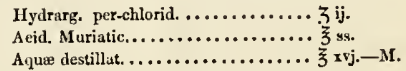

We purposely write the above prescription in this mamner, in order that it may be made up by no one (the veterinary surgeon excepted) but a respectable chemist. Before using it the animal must be well washed with soap and water, by means of a hard brush; the lotion may then be applied in small quantities, and not at once, over an extensive surface, lest mischief occur. We cannot, however, conclude, without strongly advising the farmer to have nothing to do with it himself, nor to allow it to be applied by the cow-leech. The veterinary surgeon will avail himself of it, only when all other means lave failed, and knowing the danger will act with due caution.

When cattle are infested with lice alone, these may be destroyed by an ointment consisting of four or five ounces of sulphur, four ounces of turpentine, and twelve ounces of linseed oil. It is said that the powder of stavesacre, mixed with lard and train oil, will kill these parasites. It is generally believed that the mange in cattle, like the scab in sheep, and the itch in the human subject, is immediately caused by the presence of numbers of a peculiar species of mite (acarus), which produce minute pustules in the skin, within which they live and multiply, and thus extend the disease from one part to another: they are tiny skin-burrowers, tormenting the animal, and feeding on the serum or water within the pustules, caused by their irritating presence. Though this is true with respect to the human subject and the sheep, we do not know whether these minute parasites have been demonstrated in the slin of horned cattle.

\section{TARBLES.}

Tarbles are tumours on the skin of cattle, produced by the presence of the larvæ or maggots of a species of gad-fly, or breeze (Wstrus Bovis, 
Clark ; Hypoderma Bovis Latr.) a dipterous iusect, notorious iu ancient as well as in moderm days, and which the Romans, as Virgil states, termed asilus; the Greeks ostrus.

The following account of this insect is given in the "Pictorial Museum of Animated Nature" :-

"The gadfly of the ox has the chest of a dark brown colour, with a yellow patch on the back, and the abdomen has alteruate rings of black and yel. low. The appearance of this fly drives the cattle mad with terror; they utter loud bellowings, gallop over the fields,

$$
\begin{aligned}
& \text { 'and scour the plain } \\
& \text { In all the bright severity of noon:' }
\end{aligned}
$$

exhausting themselves with efforts to escape.

"The female of this insect is geverally believed to deposit her eggs, in the fatty aud cellular part of the slin of cattle, by means of a singular ovipositor, consisting of a horny tube shutting up in four pieces sliding within each other like a telescope; the terminal portion ends in five points, which together constitute a borer. Of the five points, three appear to be curved, the other two are straight and shorter. By some the puncture with this instrument is said to cause temporary but intense pain, an acrid secretion being, it is supposed, instilled into the wound; aud it is from an instinctive dread of the suffering it produces, as they insist, that the herd are scattered by the fly when it makes its appearance. The costrus tarandi, however, is an equal terror to the reindeer; and, according to Linnzeus, this fly lays its eggs merely on, not in, the skin of that aumal, the grubs afterwards burrowing their way and causing large tumours.

"Some naturalists consider that the puncture of this fly does not occasion any pain, and that numbers of eggs are deposited in places on the hide, from which the ox could have lashed off the insect with its tail; and Réaumur says that he has seen an ox flap away the ordinary ties collected upon a part full of these tumours.

"On the contrary, Mr. Brary Clark contends that the gadfly does not pierce the skin with its oripositor at all, but merely glues it to the bairs, and that afterwards the grub eats its way under the skin, causing swelling and suppuration. It is indeed difficult to decide between such conflicting opiuions; for it is almost impossible to bring the matter to the test of personal observation. Rétumur, who supposes a puncture, though without pain, to be made, says, "Whenever I have succeeded in seeing these insects at work, they lave usually shown that they proceeded quite differently from what I had imagined; but unfortmuately I have never been alile to see one of them pierce the hide of a cow under my eyes.' If then the gadtly does not pierce the skin, or pierces it without giving pain, to what are we to attribute the teror of the herd? The same query equally applies to the terror displayed by the remdeer, of which Linnxus says, that " though amongst a herd of five hundred there were not above ter of these flies, every one of the herd trembled, and kept pushing its reighbour about;' aud that, 'when the fly touched any part of their bodies, they instantly made efforts to shake it off.' It luas been suggested that the buzzing noise of the gadtly strikes the cattle with instinctive terror, as the whiring noise made by the rattlesnake does those auimals liable to the reptile's attack.

"Again, we are assured that the gadfly of the lorse (œstrus equi) is belseld with every sign of agitation by the latter; aud assuredly that species deposits its eggs ou the lairs.

"Learing then the question open as to whether the gadlly of the ox makes a puncture or not, certain it is that at a very early periud the grubs are foumd beneath the skin of the beast; where they lie, tumours, called warbles, form, and suppuration takes place in the cellula tissue. It is on the purulent matter that the grubs feel; and as they grow the tumours become more extensive. Each grub is thus as it were a tenant of a cell, which at once protects it and supplies it with nutrimeut. These tumours have each an extermal orifice, and this is necessary for the due respiration of the grub: its spiracles are placed at the hinder part of the body, and the position the grub occupies brings the tail to the orifice, through which it emerges, rising to a level with the external surface. Another object, besides the freedom of respiration, is answered by this orifice remaining open; it gires to the purulent matter a free exit, and prevents the suppuration from $c x$ tending to a dangerous degree. In due time the grub has attained its full growth, and is reacly to assume the pupa state; it now pushes its way through the orifice, and, filling to the ground, burrows in the earth, passes through a brief season of torpor, and appears in August a winged gadily, to contiure its progeny. Many of the grubs, however, perish; various lirds watch their egress from the tumours, and seize them as they are endeavouring to escape. The jackdaw and magpie are exper't at this service to cattle; and the bird called Pique Boenf of Soutlem Africa is of the same benefit to the large anelopes, \&c."

It is said that the larva always escapes from its cell in the morning, between six aud eight o'clock, as if guicled by some inysterious instinct to choose a time in which it will be exposed neither to the scorching heat of the sun of midlay nor the cold of night.

In general warbles do not affect the liealth of the beast, nor interfere with its condition, though instances of the contrary are on record. In the years 1823 and 1824 , these insects were so wu- 
merous, throughout the department of Loiret, in France, and the tumours aceumulated to such an extent on the cattle, that many beasts perished from fever and inflammation; a disposition to inflammatory fever prevailed among domestic auimals at the time, and the slight irritation of the tumours most probably sufficed to induee the inflammatory disease.

Farmers are mostly eareless about warbles; but these suppurating tumonrs render the hide of the beast less raluable to the tanner; so that, if for no other reason, the larwe should be destroyed: the best way is by crushing them, and pressing them out with the finger. It is some time after the destruction and expulsion of the larva that the cell is filled up, even then a weakness and a disposition to erack remain for a long period.

WOUNDS, BRUISES, STRAINS, ETC.

Cattle are suljeet to wounds from various sources. They often stab each other with their horms; they sometimes run against sharp hedgestakes, or the points of sharp agricultmal implements, and similar articles. These wounds are sometimes very deep, and the cow-leech aggravates the mischief ly irritatiug applications; he applies the same to trilling wounds, and converts an accident of little consequence into an afficir of some maguitude.

When an animal has received a deep and formidable wound, as in the chest, the shoulder, the neck, or side, but yet no vital organ is injured, the first thing to be done is to prevent high fever and iuflammation. Blood must be abstracted, aud saline aperients administered; then let the wounded part be well fomented with a decoetion of poppy heads, next covered with soft lint, and a large linseed-meal poultice placed over it. These must be repeated till the inflammation be subdued, and the wound begins to discharge healthy purulent matter-the sign of the commencement of granulations. It is requisite that the wound should heal up from the bottom, and that the matter should liave a free rent; it will be now therefore necessary to introduce a tent or plug of soft tow, of sufficient size, smeared with a digestive ointment, which may consist of lard and turpentine, of each four ounces. Melt these together, and add an ounce of verdigris (acetate of copper). This will lieep down the granulations at the sides and upper part of the wound, while they are filling up the bottom. It is sometimes necessary to enlarge the external orifice of the wound to allow of the escape of inatter; for if this be confined it will lead to extensive suppurating sinuses, and otler misclief.

It often happens that wounds bleed freely, some large vessel being injured. This generally is not attended witl danger; but if the How of blood continue longer than is deemed prodent (for it will relieve the animal), it may be stopped by firm pressure alapted to the situation of the wound. In managing this some judgment is requisite; for it is not always easy to secure the compress. The bleeding laving ceased, the treatment already de. scribed must be pursued.

If the sides of the chest of $a$ beast be punctured, lut as far as can be told the lungs have escaped uninjured (for should they be lacerated there will be little or no hope), the wounil must be closed, and kept elosed by stont adhesive plas. ter, and the treatment recommended in pleuritis adopted. Bleeding, aperients, and doses of nitre combined with digitalis and tartarised antimony, are the chief medicines. 'The wound must be looked at in a day or two, and healed by tents, as described, from its deepest part; if it discharges matter, this must have vent extemally. We need not say that the case is preguant with danger.

It not unfrequently happens that the abdomen is wounded, and that some of the lowels protrude. These should be first cleaned from dirt with warm water, and then be gently and cautiously returned, even if it he necessary to enlarge the wound for the purpose, and to throw and secure the beast with cords. The elges of the wound must then be brought together, and secured with stitches of thread, in the skin only, or with metallic sutures, which are better and not liable to give way. A bandage sliould be neatly and closely applied, its folds being lrought round the body and prevented from slipping. The medicinal treatment will consist of bleeding, aperients, \&e., according to the symptoms which supervene.

In all these cases the aid of a reteriuary surgeon is quite indispensable. His anatomical lnowledge will be called in requisition, and the farmer must rely on his judgment. Nerves, tendous, and ligaments are often lacerated by wonnds; and injuries or fractures of bones may occur. The peculiar liue of treatment to be pursued in each case (and no two cases will be precisely alike) must be directed by the experienced practitioner.

When eattle meet with severe strains or bruises, it will be often necessary to take away blood and administer aperients. The injured parts must be well fomented, and afterwards covered with a poultice, if the situation of the part will admit of it. When the inllanmation has subsiced, but swelling and stiffuess remain, a stimulating embrocation of oil, hartshorn, and turpentine will be very useful.

It often happens that severe strains produce inflanmation of the fetlock or the paster -joints, accompanied lyy swelling, heat, and great teuderness. Bleeding from the reins of the coronet, poultices, rest, and afterwards embrocations, conlstitute the plau of treatment: blisters, should the stiffiness not sulusile, will he needful. Too frequently these strains of the feet are neglected, and 
result in permanent lameness; callus, or a bony deposit, is formed around the joints, producing a ring-like exostosis, and the beast is crippled, and hobbles along suffering great pain at every step. In these cases neurotomy, that is dividing, or rather cutting away, a small portion of the sentient nerve which supplies these parts, is recommended by Mr: Youatt; indeed he was the first to propose it, and his plan has been found successful. "There is not," he says, " a farmer who has not had cows in his dairy that have lost for a time full lalf of their milk on account of the pain which tender or dis. eased feet have occasioned. There is not a grazier who has not occasionally lost the advautage of three and four months' feeding from the same cause. In the London dairies tender feet is ofteu a most serious ailment, and compels the milkman to part with some of his best cows, and in very indifferent condition too. Why should not the operation of neurotomy be resorted to here? There is nothing difficult in it to any one who is acquainted with the anatomy of the part, and its beneficial effect caunot alunit of dispute." Mr. Youatt thus describes this operation:- "The ox is cast and secured, the hair having been previouly cut from the limb or limbs (to the necessary extent) on which the operation is to be performed. The leg is then to be removed from the hobbles and distenled, and a tight ligature passed round it beneath the knee to prevent bleeding. Then, on the centre of the back of the leg, but a little inclining towards the inside, and about two and a half inches above the fetlock, the artery will be felt for and recognised by its pulsation. Lying immediately inside the artery, towards the other leg, is the rein, and close to that the nerve, so that the nerve will be found about one-sixth part of an inch within the artery. The artery, we repeat it, is recoguised by its pulsation, the vein by its yielding to the pressure of the finger, and the nerve by its being a bard myielding body. The operator then makes a cautious incision, an inch and a half in length, upon the nerve, taking care merely to cut through the integument. The cellular substance is dissected through, and the nerve exposed; a crooked needle, armed with silk, is next passed under it to raise it a little; it is dissected from the cellnlar substance beneath, aud about three-quarters of an inch cut out, the first incision being made at the upper part, in which case the socond cut will not be felt. There is only one nerve to be excised here, because the operation is to be perfurmed a little above the lifurcation of the nerve. The edges of the wound are now brought together; a small bit of tow or lint is placed orer them, and npon that a banlage is drawn tolerably tiglit. The wound sliould not be examined for the first three days, after which it may be dressed with the healing ointment (cala- mine cerate, or the tincture of aloes). In about three weeks it will be quite healed, but the relief will be inmediate; the milk of the cow will return, and the grazing beast will begin to fatten iu a day or two."

A case in point is related by Mr. Gutteridge, in the "Veterinarian" for 1841. The operation was conducted exactly as detailed by Mr. Youatt, and the wound bandaged; a purgative was given, and the cow pat upon a diet of mashes. On the third day the bandage was removed, and the wound dressed with tincture of aloes. "The part," he adds, "healed in less than three weelss; but the cow got up immediately after the operation, free from lameness, to the great joy not only of the owwer but every person preseut. The milk which had stopped altogether returned in a few days, and the cow is now in fine condition."

We enter into these details somewhat explicitly, not because we aim at instructing the firmer or grazier how to perform the operation in question, luat because we wish to impress upon him the inportant fact, that there is a simple, a safe, and an efficacious remedy in these cases of severe lameness, which, as he knows to his cost, are but too frequent. The means of relief are in his power, and be need not, in despair, give up the case as hopeless.

It is now time that we pay some attention exclusively to the cow, with reference to gestation, parturition, and these diseases or accidents to which she is exclusively halle.

\section{GESTATION AND PARTURITION.}

The matural period of gestation is generally stated as two hundred and seventy diys, or nine calendar months, but there is consilerable variation in this respect; according to the experience of some breeders, the avernge is two hundred and eighty-four or two hundred and eighty-five diys: sometimes the period is still longer, and miler these circumstances the offspring mostly prove to be bull-calves. The pregnancy of a cow may be determined by a practised ear, or ly means of the stethoscope, in as early a stage of it as six or eight weeks. If the ear or instrument be applied to the right flank, begimning on the superior part of it and shifted backwards and downwards, the pulsation of the heal of the fietal calf will soon be heard, twice as frequent at least as that of the parent; each pulsation will betray the double beating of the foetal heart, and the rushing of llood through the ressels of the placenta will at the same time be audible.

The cow has now to nourish the fuetus; still for some montlss, if in good condition and not halfstarved, little difference will be perceived in the quantity of milk yielded. At leugth the decline of milk is palpable, and for a month or three weels at least before the anticipated time of calving, she 
should be allowed to dry. Cows in poor condition should be dried at least two montls before calving, otherwise from deficiency of mutriment the calf will be stunted, weakly, and even if it live, of little worth. Too high and luxurious feeding must on the other hand be avoiled, for fever and inflammation are then apt to follow parturition.

Besides the reasons for drying the cow before calving to which we have alluded, another is, that if the animal be milked too long, so that on calving the new milk clescends into the udder, while the flow of the old milk continues, there is immiuent danger either of prerperal fever, or of inflammation of the udder. Experience has abundantly proved that ou these grounds alone, the cow (though yielding a tolerable supply) should be dried before the secretion of new milk for the expected young one commences.

Other precantions must be taken with regard to cows in the latter montlus of gestation, and especially as the time approaches. The bowels must be kept in a relaxed condition, and the food should be linited in quantity; at all times the rumen when loaded presses upon the uterus, but more especially so during gestation, and should the rumen become distended with food or gas, or the manyplus become filled with hardeued and matted regetable fibres, arresting the dise and healthy process of digestion, the pressure of the enormous rumen may conduce to the destruction of both parent and offspring. It sometimes occasions an alteration in the position of the foetus, it always renders parturition difficult, and fatal cases oftener, perhaps, arise from this than from any other cause. Farmers in general seem to be little aware of the nccessity of regulating and moderuting the diet of cows on the eve of parturition, ret there are few who have not lost cows from this neglect. The food allowed, moreover, must not be stimulating; the system takes on at this time a febrile excitement; hence in cows which have been ligh fed in rich pastures, or on much dry food, it will be well to have recourse both to a mild dose of aperient medicine and the lancet, blood being taken in moderation according to the strength of the subject.

It is the absurd and cruel prictice of some, when they observe the precursor signs of parturition, or even when the latter has commenced, to rouse the cow and drive it about, hoping, we supposc, thereby to hasten the process which nature lerself has undertaken to regulate, implanting in the bensts instincts obedient to her law. The consequence of this ignorant, brutal practice is inflammation and all its train of evils, and not unfrequently death. What does instinct teach the animal? to leare the rest of her companions, to retire to some quiet spot, to the shelter of the herlge, or the side of a coppice, in order that she may escape disturbance till she has brought forth her young. The wild cattle, when they calve, select some seques- tered situation, amidst the dense thickets of the wood, there they hide their progeny, and go several times every day to suckle it, remaining near it at night. The domestic cow lias lost her original shyness, but still she seels an undisturbed spot and quits the herd.

If her pasture afford no shelter, the cow should be put into some quiet retreat, and be housed in severe or stormy weather.

The precursor signs of parturition are too well known to be minutely detailed; restlessness, moaning, a visible and rapid eulargement of the ndder, accelerated respiration, and a dropping of the abdomen first attract notice. Soon, the restlessness increases, the animal keeps getting "1] and lying down, at last she remains lying on the ground, and if all go on well is soon delivered of her offspring.

During this time she may be cantiously looked at, but not unnecessarily disturbed; if the presentation of the calf is natural, the farmer must not be impatient; if the lahour is protracted longer than is usual, while the throes continue, and the animal's strength keeps up, it is better not to interfere ; but then, it will be requisite to ascertain that the position of the calf is natural. In a natural position the forelegs of the calf project, and the heal lies upon them and a little betreen them, the muzzle reaching down as far as the knees, the back of the caif corresponds with that of the mother, and its under surface with the mother's abdomen. This being ascertained, the farmer may hope that nature will accomplish her work.

Supposing, however, that the pains abate or cease, and that an hour or so elapses mithout any sign of their return, then some assistance is required. Under these circumstances, the best plan is to excite the uterus to action; let two drachms of finely powdered ergot of rye be mixed with a bason of gruel and a pint of good ale, and gently poured down the gullet, and if necessary let this be res peated at intervals of an hour or rather less, but without the ale, till the pains begin to return. Some practitioners have found ergot of rye inert, even when given in doses of two or three ounces, others have administered it in small doses with the best effects. Of the peculiar powers of this medicine no one can doubt, and in cases where it fails, is inefficiency may lie attributed to one of two cruses : first, its being impure, not genuine, or having lost its original strength ; secondly, to its having passed into the rumen, where, mixed with a quautity of coarsely ground vegetable matters, it may remain perfectly inert, dose after dose being given to no purpose. (We need here scarcely say, that no rumination takes place during parturition.) If, however, the medicine be genuine and escipe falling into the rumen, it seldom if ever fails. Supposing, however, that after waiting three or 
four hours, the erot of rye should not revive the action of the uterus, mechanical means must then be resorted to. If the calf be dead, there must be no delay ; if alive, it may still be saved; but the cow must be disturbed as little as possible; by dexterous manipulation, the slip-knot of a cord may be fastened round each leg, immediately above the fetlock, and another cord secured around the lower jaw, cantiously but firmly, yet avoiding all unnecessary violence, the calf may be drawn forward by degrees, and at length extricated. If, however, it he firmly impacted, we may be sure it is dead, and the removal of one shoulder will be requisite, in order to effect its extrication and save the mother. This may very readily be done, by guarding a small hooked knife with the fingers, and making an incision round the fore-arm of the calf, so as to cut the slin in a circular manner, while care is taken that no injury is done to the mother. This being accomplished, the skin should be turned as far back as possible by the fingers, and slight force will then suffice to detach the shoulder. T'his removal will give the room required.

Let us put another case; suppose that the pains do not subside, or are recalled by ergot of rye, and that the calf, although in its natural position, makes no advance; under these circumstances, let the slip-cords be applied to the fore-legs, and held by an assistant, or rather if possible, let him take hold of the fore-legs, and let the operator grasp the head, or place his hand in such a position as to bear upon it and urge it forwards, then let each simultaneously and with cautious firmness assist the uterus in its action, pulling only while each throe continues, and waiting for their successive return. By this mode of procedure, the object bcing to assist nature in her efforts, the young animal may be delirered. Let the operator only have patience, and the uterus continue to act, and in ninety-nine cases out of the luundred, mother and offspring will be saved.

But cases occur in which the presentation is unnatural, and in wbich without prompt assistance the calf will never be brought forth. Some of these cases are easily managed, others put the skill of the practitioner to the test. Sometimes the fore-legs instead of projecting are doubled back at the knees. They must be carefully brought forward, the calf being pressed back for the purpose, if necessary, and lest they should return to their wrong position, it may be advisable to put a slipknot of strong tape around them, which latter being kept on the gentle stretch, will prevent the re-occurrence of the accident. In other cases the head of the calf is bent under the chest, or tumed back over the shoulders, or to one side of the shoulders. It may be necessary to put a slip noose on each fore limb, which being done, the operator must force back the fotus till he can secure the head. which must be brought into its matural position; a slip noose must then be applied to the under jaw ; the position of the head being righted, the assistant must gently draw the three cords or pieces of tape forwards, and the throes of labour if necessary be assisted ; sometimes, with this umnatural position of the liead, the fore limbs may be also bent back; the great olject will be to push the fotus back, so as to bring head and limbs forward, and secure them in their proper position. This is not very easy, and the operator must expect his arm to be benumbed in the attempt.

Other cases occur in which all the feet present, the foetus being doubled up. The aim in this instance will be to alter the position of the fotus, and bring the fore limbs and head forward, slip nooses being vecessary as in the previous case, but this camnot always be effected; the next attempt, therefore, will be to bring the hind limbs forward, and so deliver the cow.

Sometimes the fotus is found altogether in a reversed position, its limls uppermost, that is directed to the back of the mother, and the tail or crupper presenting. To turn the calf into its natural position, under these circumstances, is very difficult, or rather impracticalle. It is seldom indeed attempted; for as a rule it will be found best to push the calf back, so as to bring forwarl the hind legs, and secure them with slip-knots, and then draw the foetus gradually forward. In such cases as these all chance of saving the calf is lost, the mother only must be considcred, indeed the calf will he generally found dead.

In other cases the calf lies with its feet uppermost, and the limbs doubled up, and the head foremost, but depressed. The elevation of the head and the drawing forward of the fore linus, securing them mith cords or tapes, are to be accomplished as promptly as possible, and assistance given during the pains.

Various other cases of unnatural positions occur, into the details of which we need not enter; what we have briefly said on this subject is to put the farmer on his guard, to warn bim against unnecessary interference, and to show him the necessity of having recourse when any difficulty occurs to a skilful practitioner, whose knowlerge of anatomy will enable him to act with promptuess and sound judgment. We say nothing here of the Cresarian operation, which some practitioners have recommended in extreme cases, where from malformation or other canses, extrication of the calf othermise is deemed impossible. We doubt whether this operation is ever needed; the calf, already dead, may be cut to pieces, and thus extracted, even if things come to the worst, and the mother be saved, but this operation will destroy the mother to a uural certainty. It is a horrible operation, involving the puncture of the rumen, and the 
opening of the abdominal cavity. If it be impossible, utterly impossible, to deliver the cow otherwise, it will be most merciful and equally profitable to shoot her dead upon the spot, and thus terminate her life and her sufferings.

Cows not unfrequently produce twins; in these cases there is seldom much trouble, for the calres are nsually small; in instances of wrong position, therefore, they are more easily manngeable. Inversion of the uterus sometimes results from the violent spasmodic efforts of severe parturition. The immediate return of this organ to its natural site is impcrutive, but it can only be effected by a professional practitioner. The treatment of the case, and the application of proper compresses and bandages, so as to prevent the recurrence of the inversion, must be exclusively uuder his direction.

Rupture of the uterus during parturition in consequence of too powerful an action of that organ may occur; the pains cease, the ears, muzzle, and limbs become cold, the abdomen swells, and the animal dies. In such a case nothing can be done. Happily it is very rare. When a cow has brought forth her calf without any untoward event, she ought to be left with it undisturbed for two or three hours; a warm mash, or some warm gruel (but not an unlimited quantity of cold water as Mr. Parkiuson recommends) may be put before lier. Her time will be chiefly occupied by those attentions to her little one which nature dictates, and which the youngling requires. In the course of four hours it will be pruclent to give an aperient drench, which will tend to prevent puerperal fever or inflammation of the udder. Should the udder be swollen and the teats tender, it will be necessary to draw off the milk three or four times a day, hut this will seldom be needer if the calf have free access to its parent. The presence of her young one keeps the cow quiet, contented, and happy; its absence renders her restless, impatient, miserable, and feverish; it should play at her side in the field, or, if in the cow-house, should be allowed to suck at least three times a day. It is seldom that the laws of nature can he broken with impunity, and the early removal of the calf from its parent is not unattended with danger. In whatever way the calf is intended to lie reared, it should remain witl the mother for the first few days at least, till the milk is fit for the dairy. The first flow of milk after parturition, commouly called beastings, is of an aperient quality, and is expressly intended for the young animal, from whose bowels it carries off the black glutinous matter, accumulated during the latter montlis of fotal existence. If the first milk be denied, constipation of the bowels, not always easily removed, is a common result. The prejudice which exists in the minds of some farmers that the first milk is injurious to the calf is a great error; it is a gentle medicine prepared by nature for the young ruminant. With respect to the placenta or afterbirth in the cow, it is generally expelled within fifteen hours, often sooner, after the birth of the calf; but instances are on record of its having remained for the space of ten days withont producing any lad effects. In these cases the cow-leech has recourse to various means, and to stimulating drenches, more likely to bring on inflammation than act as intended. In some instances it is advisable to assist the expulsive efforts by drawing forward the umbilical cord during each accession. But when the natural efforts with this assistance are insufficient, and the amimal appears ill and distressed, it may be necessary to separate the placenta from its attachments by the hand, an operation requiring great caution and care, and to be attempted only by a veterinary surgeon. Some farmers after the birth of the calf attach a small weight to the umbilical cord, in order to facilitate the separation and expulsion of the placenta; there is no great harm in this, and if a cow be weakly and the expulsive pains slight, it may be of service. The placenta of the cow consists (besides the membranes) of numerous cotyledons, or tufts of vessels which form the union between the chorion and the uterus. It would be meedless here to enter into anatomical miutiæ.

\section{ABORTION, MISCARRTAGE, OR SLINEING.}

No domestic animals are so subject to abortion as the cow. It is produced by various causes. It often occurs in cattle which are too highly fed, and in a constant state of excitement; it results from rank and acrid plants irritating or disturbiug the due action of the stomachs, and frequently occurs in low marshy districts. It has been known to follow the drinking of hard mineral or ferruginous water. It frequently happens in cows that have suffered from catarrh; and hoove or dis. tention of the rumen will produce it. Fright from any cause will bring it on, thunder-storms have been known to do so; putrid odours and the foul air of ill-conditioned cow-houses are among the causes producing it It sometimes appears as an epidemic, both in very wet seasons or in seasons of great heat. Blows, over exertion, whatever hurries or agitates; sudden change of food and peculiar conditions of the atmosphere may be also enumerated. There is another cause also to which we must advert, viz. sympathy. For example, one cow among a number of others casts her calf, in a few days several of her pregnant companions are taken ill in the same way; nor is the mischief easily arrested, it spreads, and perhaps contiguous herds become influenced as if by a contagion. A cow, moreover, which has once cast her calf is almost sure to do so the succeeding gear, influencing perhaps a new set of companions, and thus 
is the destructive habit perpetuated. But how is this to be accounted for upon sympathy? During her period of pregnancy the cow is extremely irritable, and easily affected; in every disturbance of the mind or body the uterus strongly sympatlises, it is influeuced by whatever influences any other part of the symptom, or makes an impression upon the nerves. A cow, we will suppose, prematurely casts her calf, it is dead, often putrid, the placenta is expelled at intervals in putrid fragments; the noisome odour directly affects the other cattle, they become agitated, they run about, and by bellowing express their uneasiness; in a few days their turn comes round, and several perhaps lose their lives. It is thus that peculiar odours, especially when the stomach is irritable, produce vomiting, and sometimes, as we ourselves lave seen, eveu epileptic convulsions. In the pregnant cow it is the irritable uterus, and not the stomach which becomes affected; it is excited to unnatural action, abortion takes place, and if the cow recover, the habit has commenced, and abortion will again and again occur.

The signs of approaching abortion are dulness, loss of appetite, diminution of milk, the abdomen loses its rotundity and sinks; the breathing is quick and laborious, the gait is slightly staggering, the animal moans frequeutly, the pulse becomes small, and sometimes intermittent; and a yellow glairy fluid discharge announces the approaching evil. Labour soon comes on; the animal is in jeopardy and often perishes; still greater is the danger if abortion be the result of injury or violence; the symptoms are more distressing; hemorrhage from the uterus often takes place, or the mouth of the uterus is spasmodically contracted, and the throes continue increasing in strength, but without relasation of the mouth of the uterus, until the latter is ruptured. We do not say that hemorrhage, or spasmodic constriction of the mouth of the uterus always occur, nevertheless the labour in most instances is protracted and dangerous.

In these cases the treatment must be regulated by circumstances. Is the foetus dead? if so (and it will be known by the fœtid discharge), the sooner it can be got rid of the better; the cow must be secluded from all the others, and the animal treated as if natural parturition had come on. If she be plethoric the loss of a little blood may tend to prevent subsequent fever; if not, warm mashes may be given, and if the action of the uterus be sluggish, ergot of rye may be administered. It is desirable that the placenta be removed as soon as possible, and this and the foetus must be immediately buried deep in some remote spot, with quick lime, and covered up with earth closely trodden dowu. A dose of physic may be given; and in the mean time the cow-house should be well washed out with a solution of chlo- ride of lime, and the cow herself very thoroughly cleaned and purified by a similar solution; she should not be allowed to visit the herd on her recovery, but be fattened for sale to the butcher; for other purposes she is useless, and it will be unsafe for her to mix with the rest of the cattle. In this way the spread of the mischief may be prevented, but the other cows should be narrowly watched. Various superstitious ceremonies have been resorted to for the purpose of averting this evil, which has occasionally made lavoc among the cows of farms; but the only means are those recommended : if, however, several cases of abortion succeed each other year after year, the farmer, if he can do so without serious loss, had better sell all his stock for fattening, and procure an entirely new herd, otherwise he will have to submit to yearly disasters.

If the symptoms of abortion are incipient, and there is rcason to believe that the foetus is not dead (its motion being felt), there is hope that the disaster may be prevented. It will be necessary to lessen the arterial action by bleeding according to the size and strength of the beast, and aperient medicine should be given directly afterwards. As soon as the medicine begins to operate a sedative may be administered, as half a drachm of opium in a little gruel, but stimulant and cordial comforting drinks, those favourite multifarious compounds of the cow-leech, should be avoided; if the cow be weak, a pint of good ale in gruel is the best comforter. We need not say that the cow should be kept quiet and alone.

It is not often, however, that the signs of approaching abortion are perceived in so early a stage as to give the farmer much chance, and this is too often destrojed by the death of the foetus, in which latter case the aim must be rather to expedite labour, than to attempt any preventive measures.

We believe that if the food and condition of breeding cattle were cautiously attended to, and a little blood taken from such as are plethoric, about the end of third month, and a mild aperient draught administered, abortion would very rarely occur. If one case has occurred on a farm, let the condition of the rest of the cows be immediately looked to; should they have even been in the way at the time (the accident happening before any persou became aware of it) still by prompt measures much may be done; bleeding, medicines, restriction of food, and of necessary sedatives, may avert the calamity ; if proper precautions with regard to the cow which has suffered abortion have been taken, there is almost a certainty of success. IVe should not despair of preventing future abortion in a cow, which had only once experieuced this affliction; the measures must be decided, yet followed out with eaution. 
MLK FEVER, PUERPERAL FEVER, OR DROP.

This is a formidable disease which comes on sometimes in a few hours, at other times in a few days after calving, but seldom in a cow at lier first parturition; it generally attacks plethoric cows of mature age, which bave been fed luxuriously; yet it not unfiequeutly appears in lean spare cattle, especially when they have been removed a few weeks liefore calving, from a scanty to a rich pasture, or to stall-feeding upon abundance.

Mr. Yourtt cousiders this disease to be primarily inflammation of the uterus or of the peritoneum, but that afterwards it assumes an intensity of cliaracter truly specific. "The affection is origrinally that of some particular viscus, but it soon is lost in a general inflammatory state, as rapid in its progress as it is violent in its nature, and is speedily followed by a prostration of vital power that often bids defiance to every stimulus."

This is not quite the view of the case taken by other veteriuary surgeons. Mr. Spooner says, - It used to be supposed that the nterus or womb was the principal seat of the disease, but it has now been ascertained that this organ is not affected in one case out of ten. To Mr. Friend, of Walsall, we are principally inclebted for directing our attention to the brain and nervous system, and it his since been placel beyond doubt by the researches of other practitioners, that these organs are the principal seats of the disease. There are, however, two varieties, one exceedingly dangerous, the other comparatively attended with little danger, and this accounts for the different opinions given as to the fatality of the disease. Iu the severer description, the brain as well as the spine is inrolved; in the milder form the fesions appear confined to the region of the loins. Cows rarely become affected with this disease until they have had several calves, and the short-hom breed is more liable to it than others."

We are inclined to agree with $\mathrm{Mr}$. Spooner and $\mathrm{Mr}$. Friend in their views respecting the nature of true puerperal fever in cattle; yet doubtless it is sometimes accompanied by peritoneal inflammation which often follows parturition, and though a distinction between the two diseases must be marle, it is not improbable that peritoneal inflammation may induce lesion of the spinal cord, and cerebral congestion; we know indeed that it does. Mr. Spooner observes that the name of this disease, puerperal fever, " is calculated to mislead, and to induce the supposition that it is the same as the puerperal fever of women after child-birth, **

* Puerperal fever must be considered either as a disorder of the whule system, producing local inflammation as one of $j$ ts consequences, wbich is the opinion of Buras and many others, or as a symptomatic or sccondary fever, the result of an active and extensive inflammation of the pelvic aod abdominal viscera in the fe- whereas in point of fact it is a peculiar discase af. fecting cows alone." The symptoms of this disease in eattle are thus detailed by Mr. Simonds :- "In the severer affection, the first symptom is a stargering gait; the respiration soon becomes disturbed, the eyes appear promineut and glassy, and the pupils greatly dilater. After reeliug about for a while, the animal falls, often to rise no more; the head is turned to the side, and the animal be. comes unconscious. Liquids if given with the horn (the tube of the stomach-pump slould be used) frequently enter the larynx without producing coughing or iritation; the nerves of sensation aplear to lave lost their power; the animal afterwards loses the power of motion in the fore extremities as well as the hind, and sensation, too, is sometimes lost with or without the power of motion." Sometimes, observes Mr. Spooner, "the auimal lies in a comatose state, at others exhibits great pain and distress. The disease sometimes destroys life in a few hours, and if the animal dies, it is senerally within forty-eight hours of the attack. The pulse is in most cases much quickiened, being from seventy to eighty in a minute, but soon becomes very weak. The appetite is of course totally lost, rmmination suspended, and there is generally fatal constipation. It must be eonfessed that the majority of cases of this severe affection prove fatal. On examining the body after deatl, the principal disease is found to exist in the brain and spinal chord, the latter in the greatest degree at the region of the loins. The chord itself is often discoloured, and the vessels of the membrane immediately covering it injected with blood; sometimes these vessels are ruptured. The brain often presents a similar appearance though in a less marked degree. The third stomach is always found full of hard undigestible food, and sometimes the other viscera present intlammation. The uterus is generally found in the same state as it usually is a few days after parturition, but occasionally it is discorered in a state of the most intense inflammation. In these cases inflammation of the uterus aul parts comnected with it, appears added to the other disease. When sucls is the case there is usually greater pain exhibited, and external appearances demonstrate its presence." In these cases of in-

male, more particularly of their peritnocal surfaces ; the opinion of Gordon, and most practitioners in this country. Some consequently bleed freely, others, if they bleed at all, hleed spraringly and with caution. Buras says, "I have slated that in peritoneal infammation blood-letting and laxatives are the prineupal remedies, but in this disease blool-letting must be emplayed with greater caution. It must be resorted to very early, and ought not to be pushed very far. My experience would lead me to say that the distinction between this and simple peritonitis in point of practice is, that in the latter we can searcely bleed wo much, whereas in the former the lancet can ouly be used early with any prosucet of atvuntage." Consecutently, as he elsewhere observes, " it is important to distinguish this disease from simple peritonitis." Others advise a contrary mode of praetice, and bleed according to the strength of the patient, regarding the disease as peritooeal inflammation. 
tense inflammation of the uterus and parts adjacent, we should be inclined to regard the lesion of the spinal chord as secondary, did not the latter so often occur independently. Moreover in the milder variety of this disease the spinal chord is the principal seat of the affection. "The symptoms of the milder form of this disease are much less severe; the animal drops and is unable to rise, but continues feeding, and possesses consciousness and sensibility. The disease is a local affection, affecting the spinal chord, but confined to the loins. The bowels are costive, and the bladder often loses the power of discharging its contents. If the case goes on favourably, the animal rises of her own accord in three days or a week. In both affections the digestive organs are greatly deranged, and as Mr. Simonds well expresses it, the food, no longer obeying the laws of vitality, is acted upon by those of chemistry, fermentation often takes place, and the animal is frequently hooven."

The treatment of the disease, thus described, must be modified according to the urgency of the symptoms and the state of the pulse. If the pulse be hard or full as well as quick, blood must be taken away in sufficient quantity to reduce its force and render it softer ; but if it be weak, fluttering, and quick, bleeding is inadmissible. Should the strength of the pulse rise after the first bleeding, and its bounding character return, it may be necessary to repeat the abstraction. The bowels must be efficiently purged, this is imperative, but not always easily affected. The medicine may be composed of one pound of Epsons salts, two ounces of flower of sulphur, half an ounce of ginger, and ten or sixteen grains of the farina of croton seed, or fifteen drops of croton oil, in warm water. This mixture, leaving out the croton, may be repeated in half doses every six hours, assisted by the copious injection of thin gruel and salts, until the bowels operate. The medicine should be given by means of Read's stomach-pump, the tube being passed halfway down the œesophagus, and the fluid thrown in as gently as possible, so as to escape the rumen. The course of the spine should be blistered, or well rubbed with blister ointment, turpentine, hartshorn and oil. In very severe cases, at the commencement of the disease, the animal is sometimes cold, and the vital powers seem at their lowest ebb: under these circumstances a diffusable stimulant may be desirable, such as an ounce of nitrous ather in thin gruel; should the pulse rally and beat strongly, the lancet must be used, but with caution.

A continuance of the secretion of milk is a favourable prognostic in the disease in question; if the flow of milk does not stop, recovery mostly takes place, but if the contrary the animal generally dies.

An attentive consideration of the symptoms above detailed, and of the morbid appearances observable after death, all alike indicative of lesion of the spinal chord and of the brain, cannot but lead us to believe, that though inflammation of the uterus and peritoneal membranes may attend this deranged condition of the centre of the nerrous system, it is not its necessary accompaniment. On the other hand, however, is there not reason to believe that this spinal and cerebral mischief, so far from being always primary, is often secondary, and the result of peritonitis? A cow after calving is taken ill, she is evidently feverish, she is restless and neasy, shifts her feet, paws the ground, breathes with difficulty, and heaves at the flanks; the udder is enlarged, hot, and tender, and there is a total or partial suspension of the flow of milk; the muzzle is hot and dry, the mouth open, and the tongue protruded; the eyes are staring, the look is wild, the animal utters moans or half-suppressed lowings, she now becomes irritable, sometimes frantic, dashing her head about, and butting at persons near her; she grates her teeth, she foams at the mouth, she is evidently delirious. Here we have the symptoms of a highly inflammatory disease, which if not checked, will be followed by a stage of utter prostration of the vital powers. As to the seat of this inflammation, there can be no doubt; it involves the uterus and the peritoneal membrane.

In a short time the second stage supervenes, the cow begins to stagger, she reels about, the pupils become dilated, the loins and limbs lose their nervous power, she falls: she rises perhaps with difficulty, but the paralysis becomes more decided, her limbs are useless; she sinks, she turns her head round to her side, she appears in agony ; life begins to ebb, and torpor mercifully closes the scene.

Here we have, as consequent upon inflammation, symptoms denoting congestion of the brain and affection of the spine. On examination after leath intense inflammation of the uterus and peritoneum, with derangement of the thirr stomach, will be foumd accompanied by a morbid appearance of the spinal chord and its sheath. Suppose the case not to have heen traced from the beginning, would not those who made the post mortem examination differ as to which was the primary, and which the secondary affection; or as to whether the peritoneal inflammation and the affection of the spinal cord had any mutual relationship? "Occasionally," says Mr. Spooner, "it is found in a state of the most intense inflammation ;" and we cannot quite agree with him when he adds-" In these cases inflammation of the uterus, \&c. apjears added to the other (the spinal) disease."

But we are going into the discussion of points somewhat out of place in connexion with our present plan. Let us rather point out what is to be 
done under the circumstances last described. First, then, we have a stage of high fever and great inflammation, often escaping careless observation, till the stage of collapse supersenes. In this stage the quick, hard, but perhaps small pulse will indicate bleeding. The intense inflammation must be subdued if possible; the disease runs a most rapil course and must be arrested. Let then the blood flow in a full stream to the amount of six, eight, or ten quarts, according to the size and strength of the animal. Small bleedings are inefficient, they tend rather to bring on the stage of debility than to cut short the inflammation. Let purgatires be then given, as salts, sulphur, and cruton, as recommended previously, assisted by injections, and persevered in till the bowels act well. This is most important; once get the bowels to act, and the battle is half won. Sedatives may perhaps be then needed. Perhaps the stomach is distended with gas, this must be allowed exit through the flexible tube introduced into the rumen, and a solution of chloride of lime must be given (see "Hoove"), and this may be necessary to be done before either bleeding or purgatives can be resorted to with any hope of advantage.

Suppose the second stage described has supervened, something, perhaps, may yet be done with a prospect of success; if the beast is in the field, her removal is impossible: she must be supported in an easy position, with the fore-parts a little elevated by means of trusses of straw ; if the weather is changeable or cold, a rough tent of sacks or matting may be reared up over her; and if she can eat, a warm mash given. Now, as to bleeding, all will depend upon the state of the pulse; if it be weak, trembling, or intermittent, no blood must be abstracted; the powers of the system will give way under the least depletion. But if the pulse be quick, small, hard, and wiry, the lancet may be used, but the pulse must be cousulted as the flood flows, and the vein stopped at its first tremulous wavering. Here judgment will be required, in order to decide the point at which to stop. The next thing to be done is to urge the bowels to action by purgatives and injections. This is often a difficult affair to be accomplished; and if all measures fail there is little hope. Blisters or stimulating embrocations should be applied to the spine along the lumber region, and the limbs kept from being chilled. Gradually, perhaps, the cow will recover, the milk may in a measure return, and eren some little degree of appetite; she will, perhaps, after a few days, endeavour to regain her feet, and may be assisted by a sling. For a long time, however, she will remain weak, and (the fever having absolutely subsided) tonies (as four drachms of gentian, two drachms of ginger, and a little good ale, in gruel) may be giren tirice a day; but neither spirits nor those villanous compounds called cordial drenches. We need scarcely say that the favourable termination we have pictured is not in every case realized. Puerperal fever is sometimes epidemical, and a dreadful epidemic it is; and moreover a cow, who has once suffered under this malady, is exceedingly liable to its recurrence at her next parturition. It is for the farmer to judge whether he will prepare the animal for the butcher, or keep her and endeavour by proper measures to secure her as far as possible from the recurrence of the disease when she calves the next year. Bleed ing, gentle aperients, and a rather spare diet, during the last few weeks, may do great service.

GARGET, OR IXFLAMMATION OF TIJE SUESTANCE OF THE UDDER.

The udder of the cow is divided into four compartments; and it often bappens that one or more of these compartments becomes swelled, hot, inflamed, and knotty. This inflammation is accompanied by fever, more or less severe according to the violence of the inflammation ; and this ferer is often preceded by a shivering fit of three or four hours' duration. Garget is apt to occur in highlyconditioned heifers after their first calving ; it may be produced in cows by cold and wet during parturition, when the active secretion of fresh milk takes place. Bruises will cause it, as will also a careless mode of milking, the compartments of the udder not being thoroughly drained; in which case the milk that is left becomes a source of initation. From whatever cause it may arise, garget often proves a troublesome disease, and not unfrequently terminates in suppuration, extensive abscesses, and gangrene.

In the begimning of this affection, before the inflammation has proceeded to a great degree, it will be advisable to let the calf go with its parent on the field or close; the young animal will suck freely, relieving the udder of the milk, and as it takes plenty of exercise will not be apt to suffer from overloading the stomach. But besides this, the quarter of the udder affected should be fairly drained three times a day, lest any milk remaining there coagulate and add to the mischief. We need not say that the milk should be drawn gently, so as to gire as little pain as possible. An active aperient should be administered, and the diet restricted. These measures, if resorted to in time, will generally prove effectual. But the early stage is sometimes orerlooked, and the inflammation and pain have arrived at a serious lieight; the cow will not permit the calf to suck; there is considerable fever; the animal loses her appetite and ceases to ruminate; and the danger of suppuration is imminent. Bleeding must now be resorted to and afterwards aperients. The udder must be well fomented for some hours with hot water, or the decoction of poppy-heads, and then with a firm 
but gentle hand drained of its milk. Sometimés blood tinges the milk of the affected quarter, and sometimes eren purulent matter is mixed with it. After the udder is drained, the affected quarter or quarters should be well rubbed with a weak camjhorated mercurial ointment (oamphor one ounce, reduced to powder by means of a few drops of spirit of wime, one ounce of mercurial ointment, and half a pound of lard or elder ointment, intimately mixed together). In the evening the fomentation and milking should be repeated, the ndeler cleaned, and fresh ointment applied. In the course of a few days the glimlular enlargements and the pain will most probably materially diminish, especially if the purgatives act well; but if not it may be advisable to have recourse to jodine both externally and intemally. The ointwent may consist of one part of iodide of potass added to seven parts of lard, and must be used instead of the mercurial preparation; and six or eight grains of iodide of potass may le given in gruel every day. From time to time the udder must be carefully examined, for matter soon forms in the centre of the indurations, and if not at once evacuated, will produce sinuses extending in various directions; these will at length burst extermally, and terminate in foul irregular ulcers, spreading rapilly to the destruction of one or more of the quarters. Nothing will prevent this but a free opening of the abscess as soon as it is formed; there must be no besitation, for if allowed to burst of itself, even should no sinuses be formed, it will cause a vast destruction of the glandular mass before the external slsin gives way; and the consequence will be a deep ragged ulcer and gangrene; the spreading of which will not be arrested, perhaps, unless by the use of the knife. Under these circumstances, the first thing to lie done is to cleanse the ulcer, which should first be washed with warm water, and then freely laved with a solution of the chloride of lime; repeated applications of this solution will not only remove the disgusting efilurium, but arrest the spread of destruction, and induce a healthy condition of the part. The process of healing by granulation will now commence, and the part may be dressed with Friar's balsam, and occasionally washed with the solution, till the cure is complete.

It not unfrequently happens that, after active inflammation of the udder is subdued, a chronic induration will remain, and that for a considerable time; not only lesseuing the flow of milk from the affected quarter, but rendering that milk unfit for use. From time to time the induration becomes very tender, indicative of increased vascular action, and the milk is sometimes tinged with blood. These cases yield readily to repeated applications of the iodide of potass, in the form of an ointment, as before directed, and to the administration of the same medicine internally.
Loss of milk, or milk of a disgusting taste and odour, and cousequently unfit for use, results from derangement of the digestive organs, and especially from morbid affections of the fourth stomach, and the animal is said to labour under " ndder-ill." When the priunary disease is neglected, and the impure milk not drawn off completely, inflammation and all its consequences, as already described, often ensue. If the cow be feverish bleeding will be requisite, and aperients must be giveu; the animal should also be put into a field of short but wholesome grass, where she will te obligerl to trise considerable exercise in procuring a sufficiency of food. By these means the digestive organs will gain tone and energy, and the secondary or sympathetic affection of the udder will subside, the milk will be sweet and in proper quantity, and the general health become contirmed.

\section{SONE TEATS.}

Cows after calving, and especially young cows, are very subject to tenderness and soreness of the teats. They become inflamed, often excoriated or covered with cracks, from which a sanious discharge oozes. Those who milk the cattle are often very careless both as to the dipping of this discharge into the milk, and to the pain which they inflict on the cow. In both proints there is nothing to excuse them, nor can language too severe be applied to them. Many a good cow is spoiled by the milker. Under the pain inflicted the animal often licks violently, and this will at last become habitual; she will retain her milk, and contract a habit of retaining it, by which its quantity will speedily become diminished. The cow requires soothing and gentle treatment; the teats before milking should be well cleaned, and fomented for some time with warm water, in order to ease and mollify them. No unnecessary violence in milking should be used, but at the same time the ndder must be thoroughly drained, for it is seldom that the teats suffer without the udder in some degree participating in their tenderness ; and a slight cause may aggravate this into positive inflammation. After milling, the teats may be dressed with a cooling and somewhat astringent ointment, composed of two drachms of sugar of lear, and a draclim of alum finely powdered, added to four ounces of spermaceti ointment.

$$
\text { VOW-POX, OR VARIOLA. }
$$

It is to Dr. Jenner, of Berkley, Gloucestershire (who died February 21, 1823, aged seventyfour), that we owe the practice of vaccination, as a preservative from the attack of that destructive scourge of the luman race the small-pox. The experiments of this philosophic man were begun in 1797 and published in 1798. He had observed that cows were subject to a certain infections erup- 
tion of the teats, and that those persons who became affected by it, while milking the cattle, escaped the small-pox raging around them. 'This fact, known to farmers from time immemorial, led him to a course of experiments, the result of which all are acquainted with. Yet in one opinion, an opinion in which many medical men of the highest eminence have coincided, Dr. Jenner appears to lave been wroug. He regarded the cow.pox not as an original disease of the cow itself, but as one communicated to that animal from the horse. He conceived that the sanious fluid of the disease of the heels, called grease, so common in horses, was the source of the pustular eruption in question. Cows, feeding in the same pastmre with horses thus affected, might lie down on the spots where the sanious discharge from the grease had dripped, and in this mamer the teats might become inoculated; or persons who had dressed or rubbed the heels of horses night with unwashed hands eugage in milking the cows, and thus inoeulite them. But query. Will the matter of grease produce the cowpos in man or animals? Will inoculation from the diseased lieels of the horse produce in the luman sulject the true cow-pox pustule, and exenption from small-pox? Inoculation with this nutter may indeed produce a pustular disease, but not cow-pox. It may produce unpleasant sores, and convert simple cuts into festering wounds; these, however, in no respect bear any analogy to the vaccine disease. Yarious experiments have been made on the subject by Woodville, Simmons, Professor Coleman of the Teterinary College, Bartholini, Dr. Pearson, and others, which demonstrate the error of the theory; and though there mat be some few medical men who yet retain the opinion, it has been abandoned by those who liave closely investigated the sulject. The two diseases, as the veterinary surgeon well knows, have nothing in common between them.

The cow is sulject to two kinds of pustular eruption on the teats, both infectious, and usually comprehended under the same name; but of these one only must be regarded as the genuine cowpox. In the spurious disease the pustules are small and of irregular shape; in the genuine disease they are large and round, with a central depression, and accompanied by more or less of fever and general derangement. In both, however, they are filled with a limpid fluid which by degrees liecomes opaque and purulent. A scab is then formed, which in a sluort time peels off, leaving the skin sound beneath. If, however, the pustules are broken, thes degenerate into ulcers larger, deeper, and more difficult to heal in the genuine than in the spurious cowpox. To distinguish between these two species of pustular eruption is importint: the true disease may be known by the large size of the pustules, their depression, the decided ring of iuflammation around them, and the constitutional disturbance of the animal. In both cases the treatment is simple; an aperient draught and a cooling lotion are all that is needel. If ulcers are produced they may be occasionally washer with a weak solution of chloride of lime, and powdered with a little calamine, or dressed with the calamine cerate of the London Pharmacopoia.

It is a remarkable circumstance connected with the history of the cowpox, that althougl its powers as a prophylactic against the smallpox had long been kuowu among farmers in many parts, not only of onr own country but of the continent, medical men regarded it as a popular error, and consequeutly paid no attention to the subject; nay, the farmers themselves never dreamed of practising the inoculation of it, and Dr. Jenner's ideas of propagating it by inoculation were at first treated by the medical world as visionary-as a wild speculation unworthy of serious consideration. For twenty year's the subject occupied his thoughts before he ventured, against the ridicule of his medical brethren, to commence his series of experiments. But he did commence-he multiplied his experiments - his most sanguine expectations were realized; and the name of Jenner now ranks, not indeed amongst those of heroes and warriors, but amongst those of the benefactors of the human race.

\section{DISEASES AND TREATMENT OF CALVES.}

From those diseases which more inmediately concem the cow, we may now turn to those which peculiarly affect the calf, and which, setting accilents aside, are nearly all more or less connected with a deranged state of the digestive organs. In the calf, as we have said, while feeding exclusively on its mother's milk, the first three stomachs are undeveloped, the abomasum or true digesting stomach alone being required; but as it begins to partake of vegetable food the first three stomachs gradually increase, and begin to labour in the performance of the duties now imposed upon them. In both states the powers of digestion are often overtaxed : for the calf is apt to take more than it can properly digest, especially if not allowed free exercise, or if the bowels have not been cleared of the black excrementitious matter (meconium) with which they were loaded after birth. Some farmers refuse the first milk or beastings to the calf, ignorant that it is a purgative expressly intendel by nature for this purpose; the consequeuce of which is that, early as it is to begin with medicine, some aperient is rentered absolutely necessary, recourse to which night have been prevented had nature not been interfered with. The mischief, however, is done; and the only question to be settled is, what purgative must be chosen? Two or three ounces of castor oil, mixed up with the yolk of an egg into 
an emulsion, and a scruple of ginger, may be added to a little thick gruel to form a drench. This is a safe and generally an efficacious medicine; but no necessity for it ought to have existed.

Some farmers, again, anxious to render their calves fat for the butcher as expeditiously as they can, and forgetting both the natural weakness of the digestive powers and the small volume of the stomach (the first three being nndereloped), allow the calves either to suck ad libitum, or give them, if brought up at the pail-that is, by haud-a greater quantity of milk than can be digested. The idea of oppressing or overloading the stomach never enters into tbeir minds. They imagine that the more food the young creature takes the more it will fatten; and they allow it no exercise lest it should "wear the flesh off its bones." The sto. mach soon becomes deranged; its functions are suspended; the milk, acted upon by the acid, coagulates, and forms a hardened mass of curd, which fills the abomasum even to distention. The muscles are now affected with spasms; they are violently cramped, and feel hard and lnotted: this the farmer calls being affected with the cords. Flatulent colic next ensues, which often rums into inflammation and terminates fatally. Generally the bowels are obstinately confined; but this condition is sometimes preceded by diarrhora. The quantity of hardened curd which is taken from the stomach after death is often enormous; and it is lot unfrequently compressed into a mass resembling new cheese in appearance and solidity. We may easily form an idea of the agony which the poor little animal must have suffered; and we are sorry to say that numerous calves are subjected to it till released by death.

Prevention in these cases is easier than the cure: indeed, uuless remedies be early applied all attempts are futile. What can break up and dissolve a mass of indurated eurd, filling the stomach and oppressing all its powers? As we have said, early treatment alone can be expected to succeed. Some practitioners recommend the frequent administration of warm water, in which two ounces of Epsom salts are dissolved; this they direct to be given by the stomach-pump, or if by a horn to be poured gently down the gullet. Others recommend drenches of lime-water, potass, salts, and gruel, with the design both of acting upon the bowels, and at the same time correctiug the acidity of the stomach. The farmer should always keep a bottle of "solution of potass in lime-water" in readiness. Its preparation is directed as follows: Take a lump of quick-lime of the size of an egg, and pour on it in a convenient vessel as much water as will slake it. This being done, then pour upon it one pint of boiling water, stir the whole up, and eover close. While this is allowed to stand for some time, take an eight-ounce bottle, and put into it two onnces of subcarbonate of potass (salt of tartar), and fill up the bottle with the limewater already made, pouring it off rather turbid than in a state of purity. Cork this up and label it: it is now realy for use. Take of this solution two teaspoonfuls, and add it to a little gruel or warm water in which an ounce of Epsom salts bas been dissolved in order to make the draught, which may be repeated every six hours. If the calf suffers violent colic pains, a teaspoonful of tincture of opium, with a scruple or half a drachm of ginger, may be given; and injections of gruel, with a teaspoonful of tincture of opium (laudanum), administered. It is not always that this solution is in readiness, or that it can be quickly prepared; we recommend under such circumstances a drench, eomposed of a scruple or half a drachm of carbonate of ammonia, or two drachms of carbonate of soda, with two ounces of Epsom salts (sulphate of magnesia), and a little ginger, in gruel.

If the calf by these means be relieved, the next olject is to prevent a recurrence of the mischief. A lump of chalk may be put into a trough near the young auimal, and to which it has free access. The calf will lick the chalk, and the particles of this taken into the stomach will correct the acidity which is so apt to be generated in that viseus. It is a common plan to give chalk to calves under the idea that it makes their flesh white; this is a mistake, excepting so far as good health in the calf produces whiter and better veal. Three times a day only should the calf be allowed to suek, and then not to repletion; a bundle of sweet grass or good hay tied up with a string may be hung before it; it will be allured to pick a little, and the flow of saliva being excited, the digestion will be thereby assisted. If convenient, it may be allowed the range of a paddock or small field with advantage, the air, the exercise, and the smell of the fresh lierbage, even its attempts to nibble will prove beneficial. Weakly calves, and especially such as are fed by hand, often require, on recovering from this distention of the stomach, a total change of food; a raw egg beat up in gruel, made of grits or arrow-root, with a little milk only, and some sugar, may be given for a few days, the proportion of the mills being gradually increased; should the bowels be confined, two ounces of olive oil will act sufficiently.

When the calf begins to change its milk diet for oue of vegetable substances, it is liable to distention of the yet feeble rumen with crude materials, or to obstruction of the manyplus, which las not yet acquired sufficient power to act upon hard fibres. This is often the case, when the calf is allowed to feed too plentifully on lay. Dulness, fever, constipation of the bowels, and swelling of the aldomen, indicate the nature of the disorder, 
and unless prompt measures be resorted to the animal will die. Aperients and the use of the stomach-pump will be required, the rumen must be unloaded, and the manyplus stimulated to action.

Calves are subject to diarrhcea or scouring from various causes; the milk may disagree with the stomach and disorder it, change of dict may produce it, or whatever has been taken which irritates the alimentary canal. If not severe, diarrhœa need not be regirded with appreheusion; it is an effort of nature to get rid of the irvitating matters, and only requires to be cliecked when it continues too long, or the animal begins to droop. Occasioually diarrhoa merges into dysentery, with mucous and bloody purging. In the treatment of diarrhoea, a mild purgative, as two ounces of castor oil, may first be given, or three ounces of Epsom salts, two drachurs of sola, and half a drachm of ginger, in half a pint of thin gruel. This will remove the cause of disturbance. Afterwards, four tablespoonfuls of the following mixture may be given morning and uight:-Powdered chalk one ounce, pordered catechu four drachms, powdered ginger two drachms, powdered opium half a drachm, mucilage of gum arabic two ounces, peppermint-water six ounces. This mixture requires to be shaken up well each time it is given. Gruel male of fine wheat-1lour, arrow-root, or bean mushes with a little pea-flour will be useful; no green or ascescent foud should be allowed.

We have described the hoove in cattle, and that affection of the bronchial tubes (see "Bronchitis") in which they are crowded by innumerable parasitic worms. To this disease calves are extremely subject, and it often produces death. There is a hard husky cough, a staring coat, a heaving of the flanks, great debility and einaciation. After death the bronchial tubes are found to be filled with worms, often in incredible numbers. In this disease turpentine has peculiar claims npon our notice, as its use has been in many instances attended with the best results. It acts evidently through the medium of the circulation, being directly absorbed into the system; as it impregnates even the breath, we may easily conceive its effect upon the parasites.

In the 1 itl volume of the "Veterinarian," Mr. Dicliens illustrates the advantages of this medicine by several examples. 'To each calf, he says, I gave the fullowing draught: Linseed oil four ounces, turpentine one ounce, oil of caraways twenty drops, "In a day or two afterwards the beneficial effects of this were quite disceruible. The animals appeared to husk much less, the oil seemed to have acted beneficially upon the intestinal canal, and their appetite had improsed. The dose was repeated to each in about ten days, and again after the lapse of another ten days; after which my patients were all well and required no more medical assistance. I have siuce been called to many eases, and have pursued the same treatment, adhering to my three doses at the interval of ten days; but of course I have proportioned the dose to the age and size of my patient, the dose stated being for animals from six to ten moths old."

In the same work (18.11) the following cases are recorded:- " I was called," sajs a practitioner in the country, "to see seven calves (September 3rd, 1810) that were affected with this disease; the owner had already lost five, though, as be said, he had tried every thing. The symptoms mere hurried respiration, staring coat, a dry husk, heaving of the flanks, with difficulty of moving or unwillingness to move. They were reduced to perfect skeletons; two of them were then fast sinking. The treatment consisted of inserting setons in the dewlap, and blistering the lower part of the throat. Each had from half an ounce to an ounce and a half (according to their age) once a day of a mixture composed of spirits of turpentine six parts, tincture of opium and balsam of sulphur, of ench one part, with gentian and ginger, of each one drachrn. Five soon recovered, the other two died on the second das, having taken two doses of the mixture. On examining the lungs they appeared quite filled with these parasites, some of which when washed and examined were brown, and appeared dead, the others were quite alive. I had a great many calves nnder treatment the last antumn, and was rery successful after I began to administer the turpentine, but I never gave the tonic except in the cases above mentioned, and when the patients were in an exceedingly debilitated condition. I have found the disease to follow the keeping of animals upon a bare pasture, from the latter end of May to the beginning of Angust, and with a bad supply of water. Cows are sometimes affected."

Calves are subject to inflammation of the lungs; the treatment, modified according to the age and strength of the calf, will be the same as that already described in adult beasts. Calves of six months old require only a fourth of the dose of mediciue ordinarily given to cattle, and one-half is sufficient for calves of twelve months old.

A disease termed navel-ill is apt to appear in roung calves between the third and tenth day after birth. Perhaps a little oozing of blood from the umbilical cord at first took place, which was stopped by the application of caustic, or by a ligature too near the abdomen, and the result is inflammation. Sometimes, however, this inflammation comes on without any known cause; the part swells, and perhaps suppurates; in the latter case, as soon as the abscess points it must bo opened by a lancet. Fomentations, poultices, and medicine, cousisting of a few two-ounce doses of 
castor oil made into an emulsion with the yolk of an egg, constitute the course of treatment. If, however, great debility, as is often the case, should succeed, stimulants may be given, as a little ale in gruel, or a little port wine with powdered gentian (half a drachm).

When about a year old calves are very subject to inflammatory complaints. These may be prevented by a litfle medicine, and keeping them on a scanty pasture. Quick forcing at this period ly luxurious diet is one of the great sources of destruction among young cattle; it is by degrees only that they should be brought to a rich grazing ground, or to dry and stimulating food.

With regard to the weaning of calves, different practices prevail in different counties; it may however be laid down as a rule, that when calves, male or female, are designed for rearing, they should not be weaned before six weeks or two months old; milk is their natural food, and it is incontestable that the longer a calf sucks, the stronger the animal grows up, the better its form and contour, and the more healthy and sound its constitution. If the mother does not yield a sufficiency of milk, let the calf be also fed from the pail, due care being taken that its stemach be not overloaded. No calf should be weaned suddenly, the clrange of diet must be effected by degrees, a little good sweet hay or grass being allowed. To this at last the calf will take almost exchusively: a little skimmed milk, buttermilk, or a mash may be now occasionally given; some feed the calf when weaned three times a dity, but it is better to give the food oftener, though in less quantity at a time. It should however be sufficient, and of good quality, otherwise the animal will be stunted in growth. It is an excellent plan to allow it to feed in the field or paddock with its mother a few hours every day; the fresh air and the exercise strengtben its limbs and give tone to the digestive organs, and its contour becomes better developed. Hence it is that calves liept constantly in a stable or cow-house, seldom thrive so well in the long rum as those which are allowed exercise. In choosing calves for rearing, those born in the spring are to be preferred; before the severities of winter come on they will have acquired strength to bear the cold, which is trying to younger and feebler animals, and against which they should be carefully guarded. No calves should be reared but those which are perfect in form, with broad hips in the female, a capacious chest, and sound lungs. Some recommend that calves intended for rearing should be allowed to suck the mother for three or four days, but no more, and then brought up by hand at the pail. "When the calf is a week old, skimmel milk, which has becn boiled and allowed to cool again so as to be milk-warm, may be given. After a time this may be cliluted with water and a little meal stirred into it, or some thin gruel may be made to which skimmed milk is added. Carrots or turnips make an excellent food for calves, especially if they are boiled with cut hay and given warm. In this way calves may be reared with very little milk, till they can live on grass alone. A bull calf, if not intended to be kept as a bull, may be castrated when three months old."

Calves may be, and constantly are, reared in this manner, but, as we have said, the longer a calf sucks, the finer animal in all respects does it grow up, and the more it will ultimately sell for, so that the profit will pay for the milk consumed.

'To a snall farmer who depends on his milk and its produce we doubt the advantage of rearing calves, excepting on the meagre plan above described.

Calves intended for the buteher may be weaned earlier than others; in dairy districts they are generally sold as soon as possible, for it is chiefly in the neiglibourhood of large towns that the practice of fattening calves for the market is profitable. The calf dealer, therefore, buys up the calves in the dairy districts, and sells them again to those who rear them. The poor animals are often carried to a great listance in carts, packel together on their sides, with their four feet tied firmly together, and their heads banging over the lack and sides of the cart. This is a most cruel and barbarous practice, and ought to be abolished by the Legislature. It is distressing to behold the poor animals, lound in this uneasy position, in which they often remain whole days without food or drink, so that when they arrive at the place of sale they are so weak and atteruated, that many of them die; and all of them require the greatest care and attention before they recover sufficient strength to bear their natural food. If allowed to satisfy their appetite at first, excessive diarthoa supervenes, and they frequently die. In these cases active astringents are utterly useless, they only accelerate the fatal termination. The exhausted calves mist be fed upon boiled milk, given by little and little at a time. To the milk thus prepared arrow-root or fine flour may be added, and occasionally an egg well beaten up previously. Gradually the tome of the stomach will be restored, and the animals begin to thrive.

A writer on the treatment of calves for the butcher, makes the following observations :-

"When the calf begins to thrive on the milk which he sucks, or which is given bim warm from the cow, nothing more is necessary than to keep him extremely clean and dry, to give him plenty of air, but not much light, and never to disturb him between his meals, which are generally twice in the day, at the usual time of milking the cors. Where it can be conveniently done, it is better to 
let them suck three times a day. If one cow does not give sufficient milk to satisfy the calf when he begins to get large, another cow must be at hand. Where a number of calves are fattened at once, and no butter or cheese is made, the number and age of the calves must be regulated by the number of cows and the quantity of milk which they give, so that there sliall be milli enough for all.

"The calf pens should be made like narrow stalls, each for the accommodation of only one calf, just wide enough to allow him to lie down, but not to tum abont and lick himself, which, if it become a habit, will much retard his progress in fattening. The bottom of the pen should be paved with brick, and washed clean morning and evening $\rightarrow$ or it should be boarded; the boards should be six inches from the ground, and have holes bored in them to let the urine drain through. A piece of chalk or powdered limestone is frequently put in a small trough, which the calf licks, and thus corrects the acidity which is apt to be generated in the stomach. The common notion that it makes the flesh whiter is a mistake, except so far as good health in the calf produces whiter flesh. When the calres are taken out of their stalls to suck the cows, they must not be allowed to play instead of sucking. If they appear not to have much appetite a little salt may be rubbed into their mouth, and they may occasionally have a raw egg put down their throat. At five or six weeks old, if a little sweet hay is tied in a small bundle with a string and hung before them, they will pick a little of it; and by thus exciting the saliva the digestion will be assisted. It is only by minute attention that the suckling of calres can be made more profitable than the making of butter or cheese. When it is well managed, and the price of real is about one-half the price of butter by the pound, there is an adrantage in snckling, but otherwise making butter is more profitable.

"Calves should be fat by eight or nime weeks old, and it is seldom advisable to keep them above twelve weeks. When they get large they take a much greater quantity of milk, in comparison with what they do at seven or eight weeks old, to produce the same increase of flesh. A calf of sixteen or eighteen stones (eight pounds to the stone) the four quarters, and well fatted, will always sell better than one that is larger.

"When milk is scarce, and the calves.have not enough to satisfy them, it may be necessary to give them some substitute, such as meal mixed with warm milk, or balls of meal and water with a little gin in them, which makes them drowsy. Linseed made into a jelly with boiling water and mixed with warm milk is given by some, or powdered oil-cake. All these substitutes can only be recommended when the milk fails - they deteriorate the flesh more or less. The best plan, in voL. I. such a case, is to sell the largest calves, and reduce the number so that they may all have their fill of milk. To know the weight of the four quarters of a calf when killed, take the live weight and multiply it by $0 \cdot 6$. Thus if a live calf weighs 200 pounds, his four quarters when he is killed will weigh $200 \times 0.6=120$ pounds."

It is a general practise on the continent to kill calves at a very early age, often indeed when only four or five days old; the flesh is soft, flabby, and tasteless; indeed, to most persons unaccustomed to such veal, if veal it can be termed, it is disgnsting. It may not perhaps be positively unwholesome, but upon this ground it is that no calf under ten days old is permitted in France and Switzerland to be slaughtered for the market; a considerable penalty is attached to the infraction of this law. In England veal is highly esteemed, and is confined chietly to the tables of the more opulent and middle classes; but in France, as far as our own personal observation goes, it is either less esteemed, or is more accessible to the humbler classes. In small country villages, for example, we have often had a dish of veal placed before us at the rude inn, or cabaret, when no other " butcher's meat" graced the table. We cannot say much in its praise; we do not of course allude to Paris, or the large cities or towns. but to the far-between hamlets visited occasionally by the pedestrian traveller, who wishes to see France, not as she displays herself in the great eity, but in the rural districts.

Essex has been long celebrated for the real sent up by the feeders in that county to the London market: They are purchased when a week or fortnight old, at the various markets held from time to time in Romford, Chelmsford, Colchester, Braintree, Maldon, \&c. Some of these calves are sent from the dairies about London, and in Middlesex generally, others from Suffulk and the adjacent counties. They are generally fed for about twelve or thirteen weeks, and then sent to the Romford and Smithfield markets, where they are purchased by the London butchers, or are killed by the Essex butchers and sent to Nergate and Leadenhall markets. Since the establishment of railroads, numbers of country-killed calves, as well as live calves, are sent to the metropolis from various counties, and Essex is not the almost exclusive district, which it formerly was, for the supply of London.

\section{MEDICINES ENPLOYED IN THE TREATMENT OF CATTLE.}

It may be useful to conclude our obserrations on the diseases of cattle with a brief account of the principal medicines employed in their medical and surgical treatment, many of which the farmer ought to keep in his possession for instant use 
when required. With respect to the doses proper for different ages, we may observe, as a general rule, that a calf of twelve months old requires only half the quantity of medicive constituting the full dose for an adult beast; a calf of six months only a quarter; and younger cattle still less. For example, twelve ounces of Epsom salts form the average dose for an adult ox; six ounces for a calf in the tivelfth month; three ounces for a calf three months old; and two ounces for younger calves. The strength and size of individual animals and the nature of the disease must also be taken into consideration. The doses given in the following observations are those for adult cattle.

Medicines for cattle may be conveniently, if not very rigidly, divided into several heads,-viz. aperients, alteratives, and specific medicines; diuretics; sedatives and febrifuge medicines; antispasmodies; tonies; stimulants and cordials; astringents; and extemal applications.

\section{APERIENTS (INCLUDING INJECTIONS).}

Aperients are of great importance, but much of their efficacy depends upon the manner in which they are given. The cow-leech throws his drench rapidly down the gullet, the mass of fluid forces the pillars of the osophagean canal, the medicine enters into the insensible rumen or paunch, and remains there inert; if he had allowed it to trickle gently down, or given it slowly by means of the stomach pump, it would have passed on through the reticulated or third stomach into the fourth or abomasum, and prodnced the desired effects. Injections or clysters are very useful aids to the operation of purgatives; they clear the lower bowels of hardened matter, and excite the peristaltic action generally. In inflammation of the mueous coat of the intestines, as for example, in dysentery, emollient or sedative injections are very valuable; they allay irritation, and tend to tranquillize the system generally, co-operating with other medicines. Injections have been too much neglected in the treatment of horned cattle. The veterinary surgeon, indeed, has appreciated their vtility, bnt the farmer has thought less respecting them than might have been supposed, considering the ease and yeadiness with which they may be administered.

Aperient injections may be composed of a few ounces of common salt, or E Esom salts, linseed oil, and four or five quarts of water (warm) or thin gruel. Soap and water forms an excellent aperient injection.

Sedative injections may consist of gruel or starch, with two scruples of powdered opium, or balf an ounce of tincture of opium (laudanum).

Injections may be given by means of a large bladder and pipe; but liead's stomach and enema pump is far preferable, and should be in the pos- session of every large cattle keeper. There are many occasions of emergency requiring its use, and the veterinary surgeon does not always carry one abont with him.

With respect to purgative or aperient medicines, the neutral salts take the first place.

COMLION SALT (CHLORIDE OF SODIUM OR MURIATE OF SODA).

This is an excellent purgative and vermifuge in doses of four, six, or eight ounces, combined with Barbadoes aloes, linseed oil, and ginger. In small doses common salt acts as a powerful stomachic; it invigorates the stomach; and produces an appetite when other medicines fail; when mixed with their food it is exceedingly relished by cattle, and is indeed essential to their health: We have already alluded to it in our observations on diet.

Common salt as au aperient often acts well after Epsom salts have failed, perhaps from the stimulus it gives to the stomach; and if several doses of the latter have been administered without effect, common salt should be substituted.

EPSOM SALt (SUlphate of Madesta).

This salt is, of all others, the most commonly employed as a purgative for cattle; its action may be inereased by croton oil, or the farisla of the croton nut; and, lyy the addition of sulphur to small doses of Epsom salts, given every six hours, the effect of the first full dose may be kept up. A full dose averages twelve, fourteen, or sixteen ounces,- a small dose six or eight ounces.

\section{GLADBER's SALT (SUlPHATE OF SODA).}

As this salt requires more water for its solntion than Epsom salt, and as it effloresces when exposed to the atmosphere, it is less used than the latter. It is, however, an excellent purgative, and may be given in the same doses as Epsom salt.

Among other purgatives we may notice the following:-

\section{ALOES.}

This drug is almost the only purgative on which, in the treatment of the horse, dependence can be placed, but it is seldom used in the treatment of horned cattle. Its action is very variable and unsatisfactory, though it may be alministered in combination with salts, castor oil, and other medicines. The dose is from one to two or three ounces, in powder, mixed with gruel, \&c.

\section{SUI.PHUR.}

In union with small doses of salts, sulphur is of great service in keeping up the action of the bowels after the first operation of a full dose of 
the medicine. It may be given in doses of six, eight, or ten ounces.

\section{CROTON (OIL OF, AND FARINA OF THE SEEDS).}

As croton oil is mostly adulterated, and as the powder or farina loses its strength by keeping, it is the best plan to have recourse to the seeds themselves, which may be preserved in a wellstopped bottle. When required they should be deprived of their shells and pounded.

Croton is but rarely used, and then generally in combination with other medicines. It is a powerful purgative. Dose:- of the seed, from ten to forty grains; of the essential oil, from ten to forty drops.

\section{CASTOR OIL.}

This is an excellent but expensive purgative, and is often a useful adjunct to lipsom salts. It may be given in doses of six, eight, or twelve ounces.

\section{IINSEED OIL.}

This is little inferior to castor oil, and is very much cheaper. Its dose is the same as that of the preceding oil. The same observations apply to Olive OrL.

Such are the principal purgatives employed in the treatment of cattle. Whatever the medicine may be which is selected to form a drench, it will be generally necessary to add some cordial or stimulant to it, in order to excite the insensible lining of the pannch. Of these cordials the cow-leech has a great variety, such as cardamon seeds, cummin seeds, pepper, coriander, \&c., \&c., all of which are superseded by ginger and caraway seeds powdered (in doses of one, two, or three drachms, and more as may le required), and essence of peppermint.

We subjoin a few forms of purgatives, which may be readily made $u p$ by the farmer:-

$$
\text { AN ACTIVE PURGATIE: }
$$

Sulphatc of magaesia ....... twelve ounces

Sulphur ................. four ounces

Dissolve in a quart of gruel or warm water ; if a still more active dose be required, from ten to twenty grains of the farina of croton seed may be added.

$$
\text { AN OLEAGINOTS PURGATIVE. }
$$

Sulphate of magnesia........ six ounces

Sulphur ................ two ounces

Puwdered ginger............ two drachms

Dissolve in thiu gruel or warm water, and add

Linseed oil ............... twelve ounces.-Mix,

ALOETtC PURGative, USEFUl in colic.

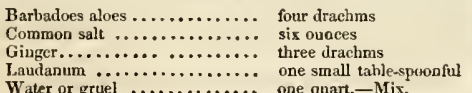

For young calves, castor oil, in doses of two or three ounces, with a little ginger, forms the safest aperient. When older, the following drench may be given :-

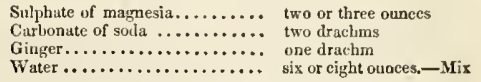

\section{ALTERATIVES AND SPECIFIC MEDICINES.}

These are medicines that exert a peculiar influence on certain organs, altering their diseased action or stimulating their respective secretion; some of these medicines, as iodine, affect the glandular systom through the absorbents; others, as æthiops mineral, act on the cutaneous secretions; others, as calomel, excite the action of the liver; others, as ergot of rye, exert a peculiar effect on the uterus. We know little or nothing of their modus operandi, experience only has made us acquainted with their effects.

\section{CALOMEl (SUBMURIATE OR PROTOCHLORIDE OF MERCCRT).}

Calomel is not often administered to cattle, it is most nseful in dysentery and in diseases of the liver. It is given in doses of from half a drachm, to two drachms, in combiuation with half a drachm of powdered opium in thick gruel; but the professed veterinary surgeon only should be entrusted with it.

\section{SULPHATE OF MERCURY OR ETHIOPS MTNERAL.}

This is very useful in cutaneous diseases, and is generally given, combined with sulpliur and nitre. It is administered in doses of half a drachm, to two drachms. An excellent alterative for bidebound cattle is composed of a drachm of xthiops mineral, two drachms of nitre, and four drachms of sulphim. To be given once a day.

\section{IODINE.}

Both as an external application, and a medicine taken internally, iodine is extremely valuable in cases of glandular affections, and induratel swellings of the udder ; a useful ointment may be romposed of one drachm of iodine and seven drachms of lard. The iodide of potassium is however a more convenient preparation. It may be made into an ointment in the same proportions as the pure ioline, and in the dispersion of hardened tumours and enlarged glands, acts with decided advantage. The iodide of potass given internally materially assists in the absorption of tumours, and is strougly recommended in phthisis or consumption, when tubercles have formed on the lungs, indicated by an inward, hollow, feeble, 
and gurgling cough, succeeding catarrh, or inflammation of the lungs. The dose is from three grains, morning and evening, to eight or ten grains (the increase being gradual), in a small mash.

\section{ERGOT OF RYE.}

Spurred rye exerts a peculiar action on the uterus, exciting its contractile efforts, and is given occasionally, when, in lingering parturition, the powers of that organ are exhansted. The average dose of ergot of rye in powder is from two to three drachms, and this may be repeated at intervals of half an hour, or an hour, till the porrers of the uterus are roused.

\section{DIURETIC MEDICINES.}

Diuretics are medicines which excite the action of the kidneys; they are not much employed in the treatment of cattle, but may be sometimes used with advantage.

\section{TURPENTINE}

Turpentine is not only a diuretic, it is also an antispasmodic, and a vermifuge; that is, a certain destrover of intestinal worms. Externally applied it is stimulating and irritant. The dose of turpentine is from one ounce to four, with linseed oil. The following diuretic has been found to be serviceable :-

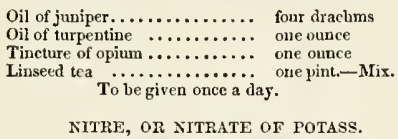

Nitre is a diuretic, and also a useful, cooling, or febrifuge medicine, in inflammatory diseases. Its dose is from two to eight drachms.

\section{SEDATIVES \& FEBRIFUGE MEDICINES.}

These are medicines calculated to allay fever, and moderate the action of the arterial system. In some respects opium and laudanum come under the denomination of sedatives; nothing allars irritation so promptly as opium, and it is often requisite even to combine it with purgatives. But we shall again recur more particularly to this estimable drug.

\section{NITRATE OF POTASS.}

We have already stated this salt to be a very useful febrifuge, in doses of two or four drachms. A solution of nitrate of potass in water, forms a good cooling lotion to local bruises.

TARTAR EMETIC, OR TARTRATE OF ANTIMONY.

Tartar emetic possesses great efficacy in lowering the strength of the pulse, and in inflammation of the lungs, pleurisy, catarrb, \&c., is a most valuable medicine. Its dose is from a scruple to a drachm.
Tartar emetic made into an ointment, with lard, forms a powerful irritant to the skin, often very beneficial.

\section{DIGITALIS.}

The powder of the dried leaves of the foxglove acts with great efficacy in reducing the action of the heart, and the general irritability of the system. Its operation must be narrowly watched, as it is apt to accumulate, as it were, in the system, and to produce a sudden degree of exhaustion, a sinking of the vital powers to an alarming degree. It will almost always render the pulse intermittent, but this need not cause any alarm, it is indeed a desideratum indicative of the subjugation of the fever. Digitalis powder must be kept in a closely stopped bottle, with dark coloured paper pasted around it so as to exclude it, from the action of the light, which destroys its active principle. The dose of this medicine, for cattle, is from a scruple to a drachm, once or twice a day.

The following prescription constitutes a good fever-mixture for cattle, in pleurisy, and other inflammatory diseases:-

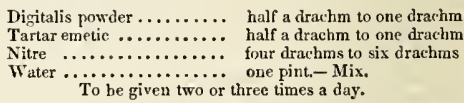

The powder of white hellebore is sometimes given in inflammation of the lungs, as a sedative Dose, one scruple.

\section{SPIRIT OF NITROUS ETHER}

This medicine is often employed in fevers, and inflammatory diseases, at their advanced stage, when great debility is present. It has been found beneficial in advanced stages of epilemic catarrh ; it rouses, to a certain degree, the powers of the system, while it acts as a febrifuge and sudorific. Dose, from two drachms to an ounce. Half an ounce is the average dose.

\section{ANTISPASMODICS.}

In some respects we may place the spirit of nitrous ether, last noticed, among antispasmodics, and also spirits of turpentine, both of which are nseful in cases of colic. The great antispasmodic, however, is opium.

\section{- OPIUN.}

This drug is both an antispasmodic and a sedative In diarrloea, drsenterr, inflammation of the bowels, in colic, in locked jaw, and spasmodic affections generally, it is of the highest importance. Opium is most conveniently administered in the form of a powder, suspender in mucilage or gruel; the dose is from half a drachm to a drachm, or a 
drachm and a half, once or twice a day, in some cases three times a day.

\section{LAUDANUM OR TINCTURE OF OPICM.}

Tincture of opium possesses the same properties as the powder of opium. The dose is from half an ounce to about an ounce.

\section{SCLPHURIC ETHER.}

Sulphuric ether is a powerful antispasmodic and stimulant, and is sometimes employed in colic and other spasmodic affections It may be given in doses of two drachms, four drachms, or one ounce. It has been found useful in cases of hoove, promptly condeusing the gas in the stomach, without causing any dangerous initation.

\section{TONICS.}

In cases of great debility, especially during slow recovery from fever, inflammatiou, or other diseases, tonics are often extremely useful; but they must not be administered injudiciously, or before the ferer has totally subsided. The best tonics are gentian, columbo, \&c.

\section{GENTIAN.}

Powdered gentian is generally given with a drachm or two of ginger, in doses varying from one to four drachms, in water or a little good ale. In cases of debility, after red water, Mr. Harrison recommends a drachm of gentian and ginger and an ounce of spirit of uitrous ether, in gruel, twice a day.

\section{COLUMBO-ROOT.}

Powder of columbo-root is given with ginger in the same doses as gentian. It is useful in debility which follows after dysentery.

\section{SULPHATE OF IRON.}

Sulphate of iron is occasionally given as a tonic to cattle, in doses of from two to four drachms, combined with gentian.

\section{STIMULANTS AND CORDIALS.}

Cordials and stimulating drenches, composed of a mixture of ingredients, are great farourites with the corr-leech, and much mischief is often caused by their imprudent administration. A good cordial draught requires for its composition but few drugs, and may be made agreeable instead of disgusting to the palate. Ginger, caraway-seeds bruised, a few drops of oil of aniseed, or, what is far better, oil of peppermint (commonly called essence of peppermint), and a little carbonate of ammonia, or carbonate of soda (if there be acid on the stomach), with good ale, neither hard nor acid, will malie the best cordial drenches.

\section{GINGER.}

Dose, from half a drachm to four drachms.

\section{CARAWAY-SEEDS.}

Bruised caraway-seeds, thongh inferior to ginger, are useful as a cordial. Dose, from half an ounce to two ounces.

It may be as well while talking of cordial medicines, which relieve and warm the stomach, and excite its digestive powers, to notice the chloride of lime, so well known as a disinfectant. In cases of hoove or distention of the stomach by gas, generated from the food, chloride of lime acts as a cor. dial, though upon chemical principles only. Two drachms of chloride of lime, in two quarts of water, constitutes a dose, it must be given by means of the stomach-pump. When in the stomach, the chloride separates itself from the lime, and combines with the hydrogen gas, for which it has a more powerful affinity than for lime: it thus forms muriatic gas. This gas bas a strong affinity for water, and is quickly alsorbed by the fluid always contained within the stomach; thus quitting its gaseous for a fluid form, it quickly disappears, or is reduced to a thousandth part of its former bulk. Muriatic acid is now formed; but no mischief results from this circumstance, nor from the liberation of the lime, for there being a chemical affinity between the lime and the muriatic acid, a recomposition is formed, and an inert solution of muriate of lime is the result. This is not theory, but has been brought to the test successfully in practice. Mr. Youatt says that chloride of lime, administered internally in blain, in the malignant epidemic, and in diarrhœea, and dysentery, is of essential service: " in the last disease it is particularly beneficial, in changing the nature of the intestinal discharge, and depriving it of its putridity and infection, and disposing the surface of the intestines to take on a more healthy character.'

\section{CHLORIDE OF LIME.}

Its proferties see above. Dose, two drachms. We cannot call this salt a cordial, nor is it easy to say under what head it should be ranged. Its action depends upon the laws of chemistry.

SUBCARBONATE OF AMMONIA.

Subcarhonate of ammonia is a stimulant not often given to cattle, it is sometimes added in doses of half a drachm or a drachm, with ginger, to a purgative drench, and occasionally also to a cordial drench. It has been used in cases of hoove, but not with very marked success.

\section{AMDIONIA LIQUID.}

Liquid ammonia is given by some practitioners in cases of hoove of sudden occurrence, and produced by green food. It is given in doses of an ounce and a half, mixed in a pint of water. Mr Spooner says, "Experience has prosed to me its 
efficacy whenever the meteorization has been recent and produced by green food; because in this case, there has been no inflammation of the digestive organs. The effects of the medicine should be assisted by leading the animal about, and by clysters of warm water, holding in solution a handful of common salt. These will generally prouluce an evacuation of the large intestines. But whenever the state of the pulse, the redness of the tongue, and the heat of the mouth, have caused me to suspect intlammation, I have had recourse to sulphuric ether, because it promptly condenses gases, and does not cause any dangerous irritation." See "Chloride of Lime."

\section{CARBONATE OF SODA.}

Carbonate of soda is sometimes combined with aperient drenches, in doses of half an ounce, or an ounce, and upwards, as a corrector of acidity, and with cordials for the same purpose. It is given to calves, with both these medicines, in doses of one or two drachms.

\section{CARBONATE OF POTASS.}

This salt is seldom used. Its properties are the same as those of carbonate of soda. Dose, from two to four drachms and upwards.

\section{CARBONATE OF LIME, OR CHaLK.}

This is a most useful antacid, and is given in diarrhœa, often with advantage. In diarrhœa of the calf, where an acid sccretion is usually generated in large quantities, it is almost indispensable, and a lump of chalk, to lick, should be always placed within the animal's reach. The dose varies from a drachm to an ounce.

\section{-ASTRINGENTS.}

Astringents are medicincs which act upon the bowels, and check the course of diarrhcea, by their effect upon the mucous membrane. They consist of lime, or prepared chalk, opium, catechu, lino, combined or not with aromatic cordials. Of lime and opium we have already spoken.

\section{CATECHU.}

Catechu is the gum-resin of a tree of the acacia tribe. It is a very useful and effectual astringent, with chalk and opium. Its average dose is two drachms.

\section{KINO.}

A gum-resiu, closely allied to catechu, but much more expensive, and seldom used for cattle.

\section{ALUM.}

Alum is a powerful astringent, and is not unfrequently used, especially in the diarrhoa of calves. It is generally administered in the form of alum whey, as follows:-

Powdered alum ............ two draclums

Hot milk ............... one pint

Pour off the whey from the curdy precipitate, and arld a drachm of ginger, and if the purging be cxcessive, a scruple of opinm.

A good cordial astringent drench may be composed as follows :-

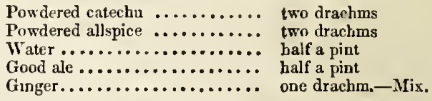

Another may be prepared thus:

Towdered catechn ........... two drachms

Prepared chalk, in powder........ four or eight drachms

Ginger, in powder ........... one drm, or two drms

Opium, in powder ..........., half a drachm

Gruel or water..$\ldots \ldots \ldots \ldots$, half a pint.-Mis.

Simmer the ingredients for a few minutes, and add a pint of good ale.

The doses for calves in the proportions already noticed.

Such are the principal medicines necessary in the treatment of the diseases of cattle requiring internal remedies. We say nothing of alcohol nor of nine, which however are sometimes necessary: the latter in cases of extreme debility or exhaustion, the former, under the forms of gin or brandy, as an addition to cordial draughts for calves when tormented with purging and colic. Mr. White recommends the following cordial for calves:-

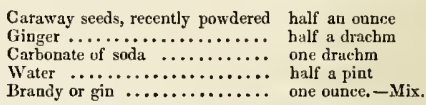

By way of a substitute for ginger, mustard may be used as a necessary component in purgative drenches, which depend greatly for their efficacy on the carminative with which they are accompanied. Flour of mustard may be given in doses of one or two ounces. In indigestion arising from change of pasturage, often termed meadowsickness, the following mild purgative is recommended:-

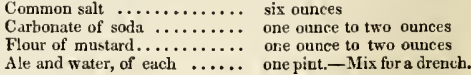

\section{EXTERNAL APPLICATIONS.}

SETONS.

Setons are very useful in many inflamma. tory diseases. They are formed by means of passing a piece of rope or a portion of the root of black Hellebore through the skin, mostly the dewlap, by means of a proper seton ncedle. Setons 
act as counter-irritants; and in inflammation of the lungs or other important organs, should not be neglected. Black hellebore-root is an irritant, and produces a free discharge of matter.

\section{BLISTERS.}

Blisters are efficient counter-irritants; but the thick hide of the ox is not readily affected by them. The common blister-ointment with turpentine will sometimes act, or the following:Powder of blister-fly, one ounce; olive oil, six ounces; oil of turpentine, four ounces.-Mix. To be well rubbed in.

An ointment composed of one drachm of emetic tartar and six of lard will produce great irritation.

Boiling water and the hot iron are powerful counter-irritants, and their use is sometimes, in severe cases, resorted to.

\section{POULTICES.}

Linseed-meal forms the best poultice. If the ulcers to which it is applied be foul, a little of the chloride of lime should be mixed with it. If it be the object to bring the nlcer to a proper state of suppuration, a little turpentine may be added. No other stimulus is needed, still less the torturing causties of the cor-leech.

\section{DISINFECTANTS.}

Of these, none are equal to chloride of lime. Half an ounce of the powder may be dissolved in a gallon of water; with this the cow may be well washed, as is needful after abortion (see "Abortion"), and the floor and walls of the cow-house. As a purifying lotion for foul ulcers, of the feet, udder, \&c., it is of eminent service; it induces a healthy action, and abolishes the often overpowering foetor.

\section{STIMULANTS.}

Turpentine and hartshorn, with camphorated oil, form a good stimulating embrocation, useful in strains, chronic rheumatism, \&c. An ounce of the two first may be added to two ounces of the latter.

\section{OINTMENTS.}

Ointments are prepared for different purposes. A good digestive ointment for wounds is composed of lard and turpentine, of each four ounces, melted together, with one ounce of finely-powdered verdigris or acetate of copper added to it and well mixed.

Calamine ointment is useful in superficial wounds. It is generally termed a "healing ointment;" and when deep wounds have assumed a healthy character, may be applied with advantage. Calamine is an ore of zinc, consisting of the oxide combined with carbonic acid and mixed with earthy matter.
Sulphur and mercurial olntment, with linseed oil and a little turpentine, form an unguent very efficacious in mange and similar cutaneous discases.

White lead, or subcarbonate of lead, is the basis of a cooling and drying ointment, often useful in excoriations or torn wounds of the skin.

In the preparation of ointment, wax, oil, and lard, are useful in different proportions. The wax gives firmness and consistency, the oil fluidity.

\section{CACSTICS.}

Of all caustics, nitrate of silver, or lunar caustic, is the most powerful, and oue over which the operator has great command. In wounds inflicted by the bite of a rabid dog its free application to every recess or sinnosity of the wound is essential, and cannot be too much insisted upon. Lunar caustic is useful in removing warts and other slight cutaneous excrescences.

Caustics of a milder nature are often applied to fungons excrescences, and unhealthy granulations. Verdigris or acetate of copper, mixed with an equal proportion of sugar of lead, finely powdered, is sprinkled on the diseased surface, and acts with good effect.

Powdered sulphate of copper, or blne vitriol, is recommended as a caustic or escharotic, in order to produce sloughing in the disease termed foul in the foot. (See "Foul in the Foot.")

Chloride of antimony, commonly called butyr or butter of antimony, is a very useful and convenient caustic where a superficial action only is required. It does not produce any deep corrosion; and in indolent ulcers, cankered foot, the foot-rot in sheep, and in the removal of warts or excrescences, it is of great value.

\section{DRESSINGS.}

Setting aside ointments, there are other dressings of importance in the wounds and sores of cattle; and of these, tincture of aloes, tincture of myrrh, and compound tincture of benzoin or Friar's balsam, may be noticed.

In recent wounds, tincture of aloes is an excellent dressing; and in foul ulcers discharging fotid purulent matter, equal parts of this timeture and of the solution of chloride of lime form an excellent application.

Tincture of aloes may be thus prepared:

Powdered aloes ............ eight ounces

Powdered myrrh............. one ounce

Rectified spirit $\ldots \ldots \ldots \ldots \ldots \ldots$ two quarts

Water .................. two quarts.-Mix.

Let it stand for fourteen days, being frequently well shaken : it is then fit for use.

Tincture of myrrh is useful for the same purposes as the tincture of aloes, and also as an application to cankered patches about the mouth.

Compound tincture of benzoin or Friar's balsam(London Pharmacopœia) is an excellent dressing 
for sluggish nlcers. Its general use is the same as that of the tincture of aloes.

LOTIONS.

Cooling lotions are often useful in bruises, or sprains with superficial inflammation. A solution of nitrate of potass forms a good cooling lotion in these cases. In inflammation of the eye, the goulard lotion is of great service. It may be made with a teaspoonful of the goulard extract (liquor plumbi superacetatis) to balf a pint of pure water.

A tonic or astringent lotion of great service when active inflammation of the eye has subsided, is composed of sulphate of zine (white vitriol) and water, in the proportion of three or four grains of the former to an ounce of the latter. It should be used weak at first (two grains of sulphate of zinc to an ounce of water), and gradually increased in strength. When debility of the vessels alone remains, it produces very good effects.

\section{FOMENTATIONS.}

The chief benefit derived from fomentations results from the warmth of the water. The warm Hluid opens the pores of the skin, excites the actiou of the cutaneous vessels, produces perspirittion, and is thus useful in relieving pain and abating local inflammation. It has a soothing effect on the nerves. Some use decoctions of various herbs as fomentations; but herbs do not increase the benefit of the warm water. Poppyheads, however, from the opium which they coutain, are perhaps advantageous. A little laudanum would be better.

PLASTERS OR CHARGES.

Plasters or charges are useful in cases of sprain, or chronic local debility, arising from bruises or rheumatism. They are useful when spread on the loius of old cows, weakened by chronic rheumatism. They give a permanent, support to the part, and keep up a constant but gentle stimulus to the skin, from which they are not easily removed.

They consist of pitch, resin, wax, de., thickly spread upon coarse cloth or a piece of leather.

Tar spread upon cloth forms an excellent covering for broken horns; it excludes the entrance of atmospheric air into the sinuses or cells of the skull, and also the ingress of flies or other insects. It forms also a useful plaster for spreading over a wound penetrating into the chest or the abdominal carity, from which it excludes the air. Mixed with lard and spread on cloth it makes a good bandage for the defence of sore feet against the mud or wet, and also saves them from becoming bruised.

Of the medicines and external applications above enumerated, and from which we have designedly excluded corrosive sublimate, as very daugerous excepting in the most cautious hands, there are some which the farmer or eattle-keeper ought to keep by him in store for instant use. Of these we may enumerate salts, linseed-oil, ginger, sulphur, opium, chloride of lime, chalk, nitre, linseedmeal, turpentine, tincture of aloes, or compound tincture of benzoin, tar, plasters, and perhaps ergot of rye.

He should be furnished with a hollow or tubular probang and Read's stomach and enema-pump, a seton needle, and a fleam with different sized lancets for grown-up cattle and younger beasts. These should always be iu order, and ready for instant use. In acute diseases delay is dangerous; an hour lost, and all the mischief may be done.

With regard to the numerous drugs, some of them, as turmeric, \&c. inert, and others dangerous, which disfigure the shelves of the cow-leech, the less the farmer concerns himself with them the better; let him beware of nostrums "good" for such and such diseases, and which thongh sanctioned by custom, ought, like the ridiculous compounds of the Pharmacopœia of the olden time, to be rejected as unworthy of notice. Science in the practice of medicine, whether man or one of the lower animals be concerved, aims at simplicity, at the production of certain results by efficient and well-directed means, and at the assistance of nature in her operations. Let it be rememlered too that it is better to prevent a disease than to cure it; diet, air, cleanliness, due exercise, are all points of consideration, and require attention. Sudden change of pasturage, the sudden substitution of high diet for meagre fare, the exposure of heated cattle to wet or cold, over-driving, careless milking, rasls blows, all these and more, in their turn have caused the destruction of bundreds and hundreds of valuable animals. The means of preserving health should he as sedulously studied and attended to as those of euring disease; nor, witl this aim only (and other motives, those of kind feeling and humanity should operate) ought the comfort of cattle to be neglected. The rules which reason dictates for the preservation of health, are indeed of primary consileration. These rules should be observed by the healthy, and care must be taken, lest, while in good health, the barriers against disease be destroyed. 


\section{THE HORSE.}

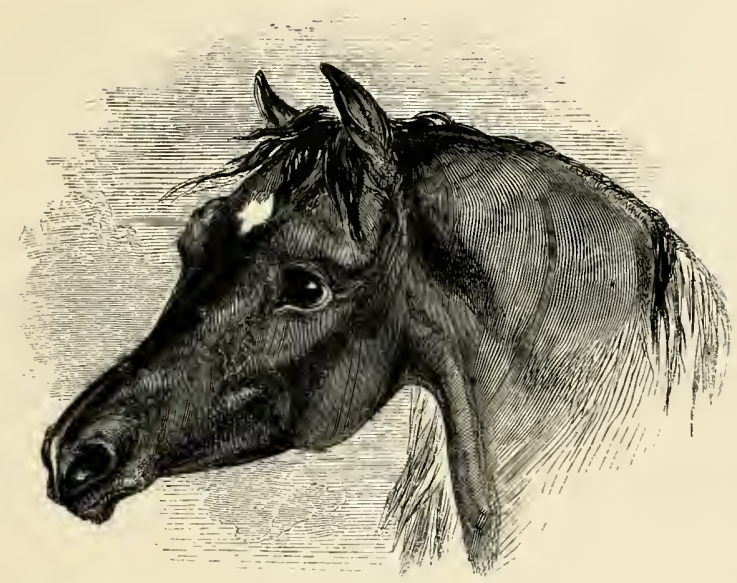

BY WILLIAM YOUATT.

WITH A TREATISE ON DRAUGHT.

vol. 1 



\title{
THE HORSE.
}

\author{
- CHAPTER I.
}

ITS EARLY IIISTORY.

THat this animal existed before the Flood, the researches of geologists afford abundaut proof. There is not a portion of Europe, nor scarcely any part of the globe, from the tropical plains of India to the frozen regions of Siberia-from the northern extremities of the New World to the very southern point of America, in which the fossil remains of the horse have not been found mingled with the bones of the hippopotamus, the elephant, the rhinoceros, the bear, the tiger, the deer, and various other animals, some of which, like the mastodon, have passed away.

There is scarcely a district in Great Britain in which the fossil remains of this animal have not been discovered. In the majority of cases the bones are of nearly the same size with those of the common breed of horse; at the present day; but in South America the bones of horses of a gigantic size have been dug up.

Whether the horse had then become the servant of man, or for what purpose he was used, we know not. Every record of him was swept away by the general inundation, except that the ark of Noah preserved a remuant of the race for the future use of man.*

In the sacred volume, which, besides its higher claims to stand at the head of "The Farmer's Library," contains the oldest authentic history of past transactious, an enumeration is made of certain valuable gifts that were presented to Abraham by Pharaoh, the monarch of Egypt. They consisted of sheep, oxen, asses male and female, camels, men-servants and maid-servants; but the horse is not mentioned.t This can scarcely be accounted for, except on the supposition that this noble animal was not then found in Egypt, or, at least, had not been domesticated there.

The first allusion to the horse, after the period of the Flood, is a perfectly incidental one. It is said of Anah, the son of Zibeon, a contemporary of Isaac, who was born about the year before Christ 1590 , that he found the mules in the wildernessthe progeny of the ass and the horse-as be fed

* An interesting account of the history of the horse, from the earliest period, by Colnnel Hamilton Smith, will be found in the 12th volume of the "Naturalist's Library:" Mr. Karbeck has also some valuable remarks on the same subject, in the 14th volume of the "Veterinarian,"

+ Gen. vii. 16 . the asses of his father.+ The wilderness referrel to was that of Idumea or Seir. Whether these were wild horses that inhabited the deserts of Idumea, or had been subjugated by man, we know not. History is altogether silent as to the period when the connexion commenced or was renewed between the human being and this his most valuable servant.||

Nearly a century after this, when Jacob de. parted from Lahan, a singular account is given of the number of goats and sheep, and camels, and oxen, and asses which lie possessed; but no mention is made of the horse. $\$$ This also would lead to the conclusion that the horse was either not known or was not used in Canaan at that early period.

Another century or more passed on, and wag. gous-conveyances drawn by animals-were seut to Canaan to bring Joseph's father into Egypt. No mention is made of the kind of animals by which these vehicles were drawn; but there are many fragments of the architecture of the early ages, and particularly of the Egyptian architecture, in which the chariots, even on state occasions, were drawn by oxen. We cannot, however, come to any certain conclusion from this; but at no distant period, while Joseph and his father were still living, a famine, preceded by several year's of plenty, occurred in Egypt. Joseph, who had arrived at the chief office in the state under Pharaoh, had aviailed himself of the cheapuess of the corn during the plentiful years, and had accumulated great quantities of it in the royal granaries, which he after. wards sold to the starving people for money, as long as it lasted, and then for their cattle and horses.

This is the first certain mention of the horse in sacred or profane history; but it affords no clue as to the purposes to which this animal was then devoted. In a few year's, however, after the ces. sation of this famine, some elucidation of this

‡ Gen. Ixxvi. 24

i Colonel Hamilton Smith has the following interesting observations on the eariy history of the borse:- "We know su little of the primitive seat of civilis.tion, the original centre, perhaps in Bactria, in the higher valley's of the Oxus, or in Cashmere, whente knowledge radiated to China, India, and Egypt, that it may be surmised that the first domesticution of the post-diluvian horse $w$ as achieved in Central Avia, or commenced nearly simultaneuusly in several regions where the wild animals of the horse form existed. \$ Gen. xxxii, 15. 
interesting point is obtained. When Jacob lay on his deathbed, he called his sons around him, and under the influence of that inspiration which has been withheld in later times, prophesied what would be the character and fate of their descendants. Of Dan he says, "Dan shall be a serpent ly the way, an adder in the path that biteth the horse's heels, so that his rider shall fall backward."* We have nothing here to do with the fulfilment of this prediction. That which principally concerns the reader is the office which is, for the first time, assigned to the horse. He is ridden.

We hear no more of the horse until the time of Job, who lived about twenty years before the Israelites were brought ont of Egypt by Moses. $\mathrm{He}$ was well acquainted with the horse, and admired him on account of his unrivalled beauty and the purposes to which he was devoted. Job's description of the horse is quoted in almost every work on the subject, and Dr. Blair cites it as an instance of the sublimity of the inspired writers. "Hast thou"- the Divine Being is supposed to inquire of Job-" given the horse his strength? Hast thou clothed his neck with his beautiful mane? The glory of his nostrils is terrible. He paweth in the valley, and rejoiceth in his strength. He hurries on to meet the armed men-he mocketh at fear-he turneth not his back from the sword. The quiver rattleth against him-the glittering spear and the shield-he swalloweth the ground with fierceness and rage; neither believeth he that it is the sound of the trumpet (ordering a retreat). He saith among the trumpets, ha! ha!-and he smelleth the battle afar off, and heareth the thunder of the captains and the shouting." +

It appears from this that the horse, nearly fifteen hundred years before the birth of Christ, was nsed for the purposes of war. The noble auimal which $\mathbf{J}_{0}$ b described belonged to the cavalry service of that time.

The sume author assigns to him another task. Job had been previously speaking of the ostrich and of the hunting of that bird, and he says, "What time she lifteth herself on high,"-springs from the ground as she runs, - "she scometh the horse and his rider." $\ddagger$

In less than twenty years after this, we are told that Pharaoh "took six hundred chosen chariots and all the horses and chariots of Egypt, and all the horsemen, and pursned the Isrnelites to the Red Sea."

* Gep. slix. 17.

+ Job xxsix. 10-25. The Hebrew word which is translated "thunder" in the 19th perse, also signifies the mane of a harse. Whoever has obsarved how much the mane of a thorough-bred perfect horse, and under some momentary excitement, contributes to the nobleness of his appearance, will enterinto the sublimity of the question, "Hast thou clothed his neck with his beautiful mane?" "o "clothing the neck with thunder" no meaning cen be attached.

t. Job xxxix. 18 . I) Exod, xiv. 9. classes of horses, the cbosen chariot horse, the more ordinary chariots, and the cavalry. In fact, the power and valne of the horse were now fully appreciated. Buxtorff says that the word "parash," or "horseman," is derived from the Hebrew root to prick or spur, and that the rider derived his name from the use of the spur. It would seem that riding was at this period not only a familiar exercise, but had attained a degree of perfection not generally imagined.ई

In what country the horse was first domesticated there are no records certainly to determine. The most ancient of all histories is silent as to his existence in the time of Abraham; although it can hardly be imagined that this noble animal was not used when Nimrod founded the Babylonish monarchy, full two hundred years before the birth of Abraham-or Semiramis, one hundred and fifty jears afterwards, reigned over the same.country -or the Shepherd Kings, a little while before that period, conquered Egypt. It is natural to imagine that the domestication of the horse was coeval with the establishment of civilization.

The author was disposed, in a former edition of this work, to trace the first domestication of the horse to Egypt; but farther consideration has induced him to adopt the opinion of Colonel Hamilton Smith, that it took place in Central Asia, and perhaps vearly simultaneously in the several regions where the wild animals of the horse form existed. From the higher valleys of the Oxus and from Cashmere the knowledge of his usefulness seems to have rarliated to China, India, and Egypt. of

The original horse of the southern and western countries came from the north eastern part of Asia, the domicile of those who escaped from the ravages of the Flood. Indeed, without the aid of the hor'se, the advancensent of colonisation. would have been exceedirigly slow.

Colonel Smith is perfectly correct when he says that "to ancient Egypt we appear to be indebted for the first systematic attention to reviving and improving the breeds of horses; numerous carved or outlined pictures represent steeds whose symmetry, beauty, and colour, attest that they are designed from high-bred types." Grooms also are represented is " rubbing their joints and sedulously attending to their comfort on every proper occasion." The horses, in all those tasteful works of art, are represented as either being loose or harnessed to chariots: no mounted cavalry are to be seen until a cumparatively late period. It is the same with the bas-reliefs of Persepolis. On the frieze, however, of the temple of Minerva, in the Acropolis of Athens, built many years before the destruction of Persepolis, there were numerous

\$ Berenger's History of IIorsemankhip, i. 11.

4) Nitululist's Librisy, vol, xii. p 76. 
figures of men on horseback, but not one of a horse nation of horsemen than the Greeks, but chariots harnessed to a chariot. The following cut was were occasionally used by them in their solemn fesfaithfully copied from the frieze of that temple. tivals in honour of their divinities, and therefore This is a singular fact, and might lead to a very naturally found on the frieze of their temples. wrong conclusion-namely, that the chariot was in Among the Greeks, however, chariots were never common use in Persia, and not known in Greece; used for the purposes of war, but only in their whereas the Persians were far more decidedly a public games. *

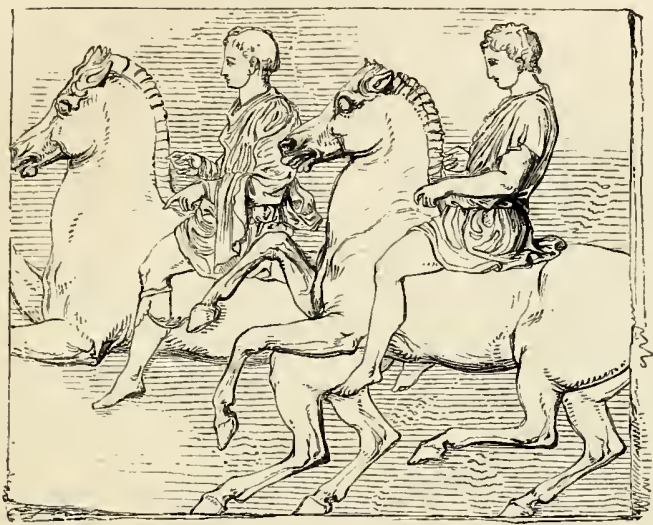

The breeding of the horse, and his employment for pleasure and in war, were forbidden to the Isra. elites. They were commanded to hough or hamstring those that were taken in war. The sheep yielded them their wool, and the cattle their milk, and both of them their flesh. By the latter of these animals the land was tilled, and the corn trodden out; while the rulers and the judges, and even the kings of Israel, are carried by asses. The horse is occasionally mentioned in the early period of the Israelitish commonwealth. No definite duty, however, is assigned to him; and it is

* It may not be useless to pause for a momeat, and study the firm and character of these horses and their riders.

There is considerable difference in the form and action of the two hozses. The right-baud one, and the foremost of the two, is stadly defective in the portions of the fore-arms which we are permitted to see. The near oue is poorly supplied with muscle.

The aff-horse is out of all keeping. The large ears placed so low ; the clumsy swelling of the lower part of the neck; the bad uaion of it with the breast; the leugth and thinness of the barrel, compared with the bulk of the fore parts, notwithstanding the natural and graceful position of the hind legs, show no little want of skill in the statuary.

The more animated head of the left and binder horse, the inflated nostril, the opeoing of the mouth, the form and prominence of the cye, and the laying of the ears, sufficiently confirm the accounts of which we hare of the spirit-sometimes untameable - of the primitive horses. The neck, however, is too short even for nae with these immense forehands; it springs badly out of the chest; the shoufler is very defcctive; hut the fore-arms, their expression and their position, are exceedingly good; the long fore-aims and shor

said of the then monarch that "He shall not multiply horses to himself." $\dagger$. There were two reasons for this: they were destined to be a peculiar people, preserving in the narrow confines of their country the knowledge and worship of the true God : therefore they were forbidden the means of waudering to other lands. The nature of their country likewise forbade the extensive breeding of the horse. It consisted, in a great measure, of mountains, and was bounded on the west by the sea, and on three other sides by deserts. It was not until the time of Solomon, five hundred years

leg are excellent; and so are the off fetlock and foot; hut the barrel is deficient, the carcase is lengthy, and the hind quarters are weak compared with the fore-arms.

The beautiful execution of the riders cannot escape obserration. The perfect Grecian face, the admirable expression of the countenance, the rounding and perfection of every limb, are snfficient proofs that the riders were portraits, as probably the borses were to a very considerable extent.

These animals remind us of some of the heavy nnes of the present day particularly; they have the heauties and the defects of maoy of the modern Holstein horses; they are high, but perhaps heavy-actioned courageons, spirited, possibly fierce. They exhibit the germs of many future improvements, and, taken altogether, may be examined with considerable pleasure, remembering that they arc horses of nearly two thousaod three bundred years ago. Art has done much for the borse since that period, but the consteoance and figure of the human being were at that time perfect. These borsemen have not even the switu to guide the animal; but they are holding by the mane with the left hand, and are evidently directing the horse by pulling the mane, or pressing the aeck with the right hand a little higher up.

+ Deut. xvï. 16 . 
after the Israclites had left Egynt, that the horse was domesticated among them ; and then so rapidly did he increase that Solomon had a thousand and four hundred chariots, and twelve thousand cavalry, and stabling for forty thousand horses.* The greater fart of these horses were imported from Egypt.

The sacred historian gives the price both of the chariots and the horses. It is the oldest document of the kind on record. The horse, including probably the expense of the journey, cost one hundred and fifty shelels of silver, or rather more than serenteen pounds. $\dagger$ The chariot cost six hundred shekels, or a little more than sixty-eight pouuds. Of the comparative value of money at that period it is impossible to speak; lut it was probably many times greater than at present.

It is a question yet disputed, whether the use of chariots or the art of riding was first cultivated. According to Colonel Hamilton Smith, the northern nations were exclusively riders. At Nineveh, in Asia Minor, and India, they were both charioteers and riders. In Greece, Palestine, and Egypt, they were originally charioteers only.t The probalility, however, is, that although one might prevail in particular eras and countries, the other would not long remain unpractised.

Before a sketch of the history of the European horse is attempted, it may be interesting to collect the accounts given by historians of the character and management of the horse in earlier periods.

Upper Egypt and Ethiopia were inhabited by lorsemen, of wild and preducious habits ; plundering those who fell into their power, or hiring themselves to increase the army of any foreign potentate. Many troops of them altended Xerxes in his expedition into Greece.

In Lilyya, Numidia, Mauritania, and the settlements on the northern coast of Africa, comprising Morocco, Barbary, Tunis, and Tripoli of the present day, and the northern part of the Sahara, or Great Desert, the horses were numerous and fleet. Elian describes them as being somewhat slenderly made, and seldom carrying much flesh; requiring little care and attendance from their owners; content with the common pasture which the country afforded, and on which they were turned, without further care or notice, as soon as their work was done. Their present treatment is not a great deal better.

They were at first ridden, as they are represented on the fresco of the Parthenon, without either bridle or saddle; and the rider had nothing but a switch or stick by which to guide them. This is said to have given them an ungracefu] and

\footnotetext{
*I Kings ×. 26.

+1 Kings x, 29.

F Nat. Lib. vol, xii. p. 88 .

II Berenger's Hist. of Horsemanship, vol. i. p. 1].-This is a work of great research and fidelity. We have found it truly invaluable in our investigation of the early history of the horse.
}

awkward appearance; their necks being straight and extended, and their noses pointing somewhat upwards. "It may, in some degree," says Berenger, "be difficult to conceive how a wand on stick could be sufficient to guide or control a spirited or obstinate loorse in the violence of his course, or the tumult of battle; but the attention, docility, and memory of this animal are such, that it is hard to say to what a degree of obedience he may not be reduced. There is no reason why these horses should not be brought to understand the intention and obey the will of his rider with as much certainty and readiness as our cart-horses in our crowded streets attend to the voice of their driver, by which they are almost solely governed." $\$$ The older writers say that the horse was touched on the right of the face, to make him go forward-on the left, to direct him to the right -on the muzzle, when he was required to stop; while the heel was used to urge him forward. The guidance of the horse by the gentle touch of the fingers is well represented in the engraving given at page 189.

Passing the Isthinus of Suez, ancient writers say not a word of the horses of Arabia. These deserts were not then inhabited by this noble animal, or there was nothing about him worthy of record.

Palestine, during the later periods of the Jewish monarchy, contained numerous horses. Mention has been made of the forty thousand stalls for horses built by Solomon; but they were all brought from Egypt, and a very little portion of the Holy Land was ever devoted to the breeding of horses after the settlement of the Israelites in it.

Syria acquired little reputation on this account, nor did Asia Minor generally, with the exception of the country around Colophon, between Smyrna and Ephesus, whose cavalry was so numerous and well trained that they were always in request as mercenaries, and deemed to be invincible.

We must now travel to Armenia, on the rest of Media, before we meet with anything to arrest our steps. A beautiful breed of horses was cultivated in this district. The chariot of Xerxes was drawn by Armenian horses, being the stateliest

$\$$ Silius Italicus thus describes the management of the early horse :-

" Paret in ohscquium lenta mode ramine virge,

Verbera sunt præcepta fuge, sunt verbera fræni."

"All needless here the bit's coercive force

To guide the motions of the pliant horse:

Form'd by the rod alone, its aids they know,

And stop and turn ohedient to the blow."-Berenger, vol. i. pp. 24 and 26.

II In all long and tedious wars the assistance of the Colophonian troops was courted, and the party that obtained supplies from them

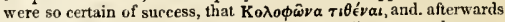
among the Rumans, "Colopbonem imponere," were used proverbially for putting a conclusion to any affair. Strabn, lih. xiv. 
and the noblest which his extensive empiro could produce.*

Some writers, describing the horse at a later period, mention the great care that was taken of the dressing and adoming of the mane. Vegetius gives a long account of this. It was cut into the form of an arch or bow; or it was parted in the middle, that the hair might fall down on either side; or, more generally, it was left long and flowing on the right side-a custom which has been retained to the present day. $\downarrow$

Many old sculptures prove that the horsemen of almost every country mounted on the right side of the animal. There are a few exceptions to this. The mane hanging on that side would assist the rider in getting on the horse. There were not any stirrups in those days. The modern horseman always mounts on the left side, yet the mane is turued to the right. ${ }^{\dagger}$

Media produced numerous horses of the same character as those from Armenia.

Cappadocia stood highest of all the eastern countries for its breed of horses; not perhaps so speedy as those from some other districts, but distinguished for their stately appearance and lofty action. Old Blundeville, from the iuspection of many of the ancient sculptures, says that these were more heavy-headed than the horses of the Parthians.|| Perhaps they were so; but no one can dispute the stateliness of their figure, and their proud and high and equal step. Although often ridden, they were better calculated for the chariot. This kind of horse seems to have pleased the ancients; and their painters and statuaries are fond of exhibiting them in their most striking attitudes. The horses in the cut at the commencement of this chapter are illustrative of the remark. Oppian says of them, what is true at the present day of many horses of this character, "when young, they are delicate and weak; but strength comes with years, and, contrary to other horses, they are better and more powerful when advanced in age." $\$$

The Parthians fought on foot in the army of Xerxes. Either they had not begun to be celelrated as horsemen, or there were reasons which no author states for their being dismounted at that time. No very long period, however, passed before they became some of the most expert riders that the world could produce, and were reckoned, - and justly so, almost invincible. They are described as being exceedingly active and dexterous in the management of their horses. They were as formidable in flight as in attack, and would often

* Berenger, vol. i. p. 20.

+ Denso juba, et dextro jactata recumbit in armo.-Virgil.

\$ Vegetius, lib. iv. c. 7 .

i Blundeville's Fower Chieftst Offices, p. 3.

5 Brrenger, vol. i. p. 22. turn on the back of the animal, and pour on their pursuers a cloud of arrows that at once changed the fortune of the day.

Vegetius gives a singular account of the manner of their breaking in their horses, and rendering them sure-footed when galloping over the most irregular and dangerous grounds; for they were lighter and hardier horses than those of the Cappadocians or Medes, and better for their peculiar pace and manner of fighting. A spot of dry and level ground was selected, on which various troughs or boxes, filled with chalk or clay, were placed at irregular distances, and with much irregularity of surface and of height. Here the horses were taken for exercise; and they had many a stumble and many a fall as they galloped over this strangely uneven course; but they gradually learned to lift their feet higher, and to bend their knees better, and to deal their steps sometimes shorter and sometimes longer, as the ground required, until they could carry their riders with ease and safety over the most irregular and dangerons places. Then it was that the Parthians could fully put into practice their fasourite manouvre, and turn upon and destroy their unsuspecting foes. They could also travel an almost incredible distance without food or rest. I

To the Scythiaus, the Medes, and the Parthians, in after times, and in rapid succession (if, indeed, they were not different names for hordes of one common origin), succeeded the Ostraces, the Urals, the Monguls, the Calmucks, the Nogays, the Visigoths, the Ostrogoths, and the Huns-all people of the vast plains of Central Asia, which lias been well denominated the nursery of nations. These were all horsemen. Some of their leaders could bring from two to three hundred thousand horsemen into the field. The speed of their marches; their attacks and their retreats; the hardihood to which they inured themselves and the animals by which they were carried; the incursion, and often settlement, of horde after horde, each as numerous as that to which it succeeded;these are circumstances that must not be forgotten in our rapid sketch of the horse.

At the end of the eighth century, when the Saracens overran a great part of Europe, they brought with them a force of two hundred thousand cavalry, in a much higher state of discipline than the Goths and Huns of former ages.

Of the horses in the south of Asia and the east of the Indus little mention occurs, except that both chariots and cavalry were summoned from this distant region to swell the army of Xerxes.

Celebrated as the horses of Persia afterwards became, they were few, and of an inferior kind,

I Quot sine aqua Farthus millia currat equus.-Properlius, lib.iv. eleg. 3. 
until the reign of Cyrus. That monarch, whose life was devoted to the amelioration and happiness of his people, saw how admirably Persia was adapted for the breeding of horses, and how necessary was their introduction to the maintenance of the independence of his country. He therefore dcroted himself to the encouragement and improvement of the breed of horses. He granted peculiar privileges to those who possessed a certain number of these animals; so that at length it was deemed ignominious in a Persian to be seen in public, except on horseback. At first the Persians vied with each other in the beauty of their horses, and the splendour of their clothing; and incurred the censure of the historian, that they were more desirous of sitting at their ease than of approving themselves dexterous and bold horsemen;* but under such a monarch as Cyrus they were soon inspired with a nobler ambition, and became the best cavalry of the East. The native Persian horse was so highly prized, that Alexander considered one of them the noblest gift he could bestow; and when the kings of Parthia would propitiate their divinities by the most costly sacrifice, a Persian horse was offered on the altar.

Vegetius has preserved a description of the Persian horse, which proves him to have been a valuable animal, according to the notions of those times; but capable of much improvement, according to the standard of a more modern period. $\mathrm{He}$ says that "they surpassed other horses in the pride and gracefulness of their paces, whicb were so soft and easy as to please ard relieve, rather than fatigue the rider, and that the pace was as safe as it was pleasant; and that, when they were bred on a large scale, they constituted a considerable part of their owner's revenue." He adds, as a commendation, " the graceful arching of their necks, so that their chins leaned upon their breasts, while their pace was something between a gallop and an amble." The horsemen of the present day would decidedly object to both of these things, and that which follows wonld be a still more serious cause of objection:- "They were subject to tire upon a long march or journey, and then were of a temper which, unless awed and subdued by discipline and exercise, inclined them to obstinacy and rebellion; yet, with all their heat and anger, they were not difficult to be pacified."

Both the soldier and the horse were often covered with armour from head to foot. They adopted much of the tactics of the Parthians in their pretended flight. Even when retreating in earnest, they annoyed their pursuers by the continual discharge of their arrows. Arrian gives a curious accoint of their manner of riding. They had no bridles, like the Greeks: but they governed their horses by means of a thong or strap, cut

\footnotetext{
* Athenæus, lib. xii. 4
}

from the raw hide of a bull, and which they bound across their noses. On the inside of this noseband were little pointed pieces of iron, or brass, or ivory, moderately sharp. In the mouth was a small piece of iron, in the form of a small bar, to which the reins were tied, and with which the noseband was commected. When the reins were pulled, the small teeth on the noseband pinched the horse, and compelled him to obey the will of the rider. The modern caveson was probably derived from this invention.t

It is time to proceed to the early history of the horse in Europe. Many colonies of Egyptian semigrated to Greece. They carried with them the love of the horse, and as many of these noble animals as their ships would contain. It would appear that the first colony. about the time of the birth of Moses, landed in Thessaly, in the north of Greece. Their appearance mounted on borseback, according to the old fable, terrified the native inhabitants, and they fled in all directions, imagining that their country was attacked by a set of monsters, half horse and lalf man, and they called them Centaurs. Such was the origin of the figures which are not unfrequent among the remains of ancient sculpture.

Another and a more natural interpretation offers itself to the mind of the horseman. The Thessalians were the pride of the Grecian cavalry. Before the other provinces of Greece were scarcely acquainted witb the name of horse, their suljugation of him was so complete, that, in the language of another poet of far later days, but not inferior to any that Greece ever knew,

$$
\text { "These gallants }
$$

Ifad witcheraft in $t-$ they grew unto their seat,

And to such wondrous dining brought their horse

As they hid been incorpsed, and demi-natured

With the brave beast."

Hence the origin of the fable and of all the expressive sculptures. Bucephalus, the favourite war-horse of Alexander, was probably of this breed. He would permit no one to mount him but his master, and he always knelt down to receive hin on his back. Alexander rode him at the battle of the Hydaspes, in which the noble steed received bis death-wound. For once he was disobedient to the commands of his master: he hastened from the heat of the fight; he brought Alexander to a place where he was secure from danger; he knelt for him to alight, and then dropped down and died.\|

Sixty years afterwards, another colony of Egyptians landed in the southern part of Greece, and they introduced the knowledge of the horse in the neighbourhood of Athens. Their leader was called Erichthonius, or the horse-breaker; and after his death, like the first Centaur, he

+ Arrian. Hist. Ind. lib. 17. Berenger, vol. i. p. 301.

₹ Shakspeare, Hamlet, Aet iv. scene 7 .

Plutarih, in Alex., Arrian. v. e. 3. 
found a place in the Zodiac under the name of "The Archer." Erichthonius likewise occupied a situation among the constellations, and was termed Auriga, or the charioteer.

The Thessalians always maintained their character as the first and the choicest of the Grecian cavalry. In point of fact, it was the only part of the country in which horses conld with decided advantage be bred. It abounded in rich pastures, whereas the rest of Greece was comparatively dry and barren.*

From various of the Greek anthors we can very satisfactorily trace the rapid improvement which about this time took place in the character and management of the horse. It has been stated that the soil and produce of Greece were not favourable for the breeding of horses, and that it could be a matter of profit ouly in Thessaly. They soon, however, became necessary in almost every part of the country, both for offence and defence; therefore, in most of the cities, and particularly in Athens and in Sparta, in order to induce the inhabitants to keep the requisite number, a new order of citizens was instituted, deemed the second in rank in the commonwealth, and distinguished by certain honours and privileges. The equites, or knights, in the Roman reputlic, were formed on the same model.

It is in some of the Grecian sculptures that we first see the bit in the horse's mouth, but it is not always that we do see it; on the contrary, there is frequently neither bridle, saddle, nor stirrup. It however was freqnently necessary to make use of cords or thongs, in order to confine the horse to the place at which it suited the rider for a while to leave him. These cords were fastened round the animal's neck, and may be seen in several of the ancient figures. According to some writers, the occasional struggles of the animal to escape from these trammels, and the strength which he exerted in order to accomplish his purpose, first suggested the idea of harnessing him to certain machines for the purpose of drawing them; and it is evident that soon after this it must have occurred to the horsemen, that if this rope were put over the head, and over the muzzle, or perhaps into the mouth of the aninial, he would

\footnotetext{
- Blundeville, who was an excellent classic as well as horseman, says:- "The horses of Greece have good legges, great bodyes, comely heads, and are of a bigh stature, and very well made forewarde, but not backwarde, because they are pyn-buttocked. Notwithstanding, they are verye swift, and of a bolde courage. But of all the races in Greece, hoth the horses and mares of Thessaly for their bewtie, bignesse, bountie and courage, of al authors are most celebrated. For which cause Xerxes, on his comming into Greece, made a running of horses in chariots to be proclaymed only in Thessalia, because hee woulde bave his owne horses to runne wythe the best horses in Greece. Julius Cæsar, also, beying Dictatour of Rome, knowyng the courage of these horses, was the first that ordeyned them as a spectacle before the people to fyghte wythe wylde bulls, and to kyil them,"-The Fower Chiefest Offices belonging to Horsemanship, p. 4.
}

be more easily fastened or led fiom place to place. and more securely guided and managed, whether the man was off or on his back. Hence arose the bridle. It probably was at first nothing more than the halter or cord by which the horse was usually confined. An improvement on this was a detached cord or rope, with prolongations coming up on both sides of the month, and giving the rider much greater power over the animal; and after that, for the sake of cleanliness, and to prevent the wear and tear of the rope, and also giving yet more command over the animal, an iron bit was fitted to the month, and rested on the tongue, and the bridle was attached to each end of it. It was the common snaffe bridle of the present day, the iron being jointed and flexible, or often composed of a chain. There were, however, no cross pieces to these bits at the month, but simple knobs or bulbs, to the inside of which the bits were attached.

Bits and bridles of this kind occur frequently in the Athenian sculptures of the time of Pericles, about four hundred and thirty years before the Christian era; but the headgear of the bridle had not been long introduced, the bit being supported, in some figures, by the buckling or tying of the bridle about the nose, a little above the muzzle. These, however, soon disappear, and we have the present snaffle with very little alteration, except a straight leather or cord from the head to the noseband, and that not always found. The chain under the chin is occasionally observed, probably for the sake of keeping the bit steady in the mouth.

In no period of Grecian history, so far as the author is aware, was the severe and often cruel curb-bit known. This was an invention of aftertimes. The only instrument of punishment which was then attached to the bit was found in the knobs at the corners of the mouth: they had sharp or rough points on their inner surface, which by a turn or twist of the bridle might easily be brought to bear painfully on the cheeks and angles of the mouth. A bit so constructed was termed a lupatum, from the supposed resemblance of these sharp projections to the teeth of a wolf. It would seem that this was, among the Romans, almost coeval with the introduction of the bit, for the poet attributes it to Neptune, the fabulons parent of the horse.t

No mention is made of saddles, such as are used in modern times; but by way of ornament, and partiy of convenience too, the horses were often covered with beantiful cloths, or with the skins of wild beasts, secured by a girth or surcingle. Thus the horse of Parthenopius was covercu

+ "Neptunus equo, si certa priorum, Fama patet, primus teneris læsisse lupatis Ora, et littoreo domuisse in pulrere fertnur."

"Neptune. if we may credit give to fame, First tiught with bits the generous horse to t, nic." 
with the skin of a lynx, and that of Aneas with a lion's skin. In their religious or triumphal processions the housings of the horses were particularly magnificent, being frequently adorned with gold and silver and diamonds. Fich collars were also hung round their necks, aud bells adorned their crests. The trappings of the young knight in the days of clivalry did not exceed those of the Grecian warrior on days of ceremony.

The stirrup was likewise unknown. The adoption of that convenient assistance in mounting the horse was of singularly late date. The first mention of it occurs in the works of Eustathius, about the 1158th year of the Christian era; but it was used in the time of William the Conqueror, nearly a century before that. Berenger gives the figure of a horse saddled, bridled, and with stirrups, copied from the Bayeux tapestry, which was embroidered in the time of the Conqueror by his wife, and describes the circuustances preceding and attending his descent into England. The heroes of ancient times trusted chiefly to their own agility in leaping on their horses' backs, and that whether standing on the right side or the left.

They who fought on horseback with the spear or lance had a projection on the spear, or sometimes a loop of cord, about two feet from the bottom of it, which served at once for a firmer grasp of the weapon, and a step on which the right or the left foot might be placed, according to the side on which the warrior intended to mount, and from which he could easily vault on his courser's back. The horse was sometimes taught to assist the rider in mounting by bending his neck or kneeling down.* The magnates always had their slaves by their horse's side to assist them in mounting and dismounting. Some made nse of a short ladder; and it was the duty of the local magistracy, both in Rome and Greece, to see that convenient stepping-stones were placed at short distances along all the roads.

The boot for the defence of the leg from the dangers to which it was exposed was very early adopted, and the heel of it was, occasionally at least, armed with a spur.

The horses' feet were unshod, the paved or flinty roads, which are now so destructive to the feet, being in a manner unknown. Occasionally, however, from natural weakness of the foot, or from travelhing too far or too fast over the causeways, lameness then, as now, occurred. In order to prevent this, the Greeks and the Fomans were

\footnotetext{
* Thus the Roman poet:-

"Inde inclinatus collum, submissus et armos

De more, inflexis præbebat seandere terga

Cruribus."

"Downwards the horse his head and shoulders bent,

To give his rider a more free ascent."
}

Silius Italicus. accustomed to fisten a sort of sandal or stocking, made of sedges twisted together like a mat, or else of leather, and where the owner could afford it, strengthened with plates of iron, and sometimes adorned with silver and even with gold, as was the case with the horses of Poppxa and Nero. $\dagger$

There was a peculiarity in the Greek mode of riding, at least with regard to the cavalry horses, and, sometimes, those used for pleasure. Two or three of them were tied together by their bridles, and the horseman, at full speed, leaped from one to another at his pleasure. This might occasionally be useful ; when one horse was tired or wounded, the warrior might leap npon another; but he would be so hampered by the management of all of them, and the attention which he was compelled to pay to them all, that it never became the general way of riding or fighting; nor was it practised in any other country. Homer, in his fifteenth Iliad, alludes to it as a feat of skill attempted in sport. The following is a translation of the passage:- "Just as a skilful horseman riding four chosen horses along a public road to some great city, where his course is to terminate, the whole town assembles to behold him, and gaze upon him with wonder and applause; while he leaps with ease from the back of one horse to another, and flies along with them."

The Greeks must have carried their management of the horse to a very high state of perfection; and the Greciau horse must have been exceedingly docile, when exhibitions of this kind could take place.

It was, however, to the draught of the chariot that this animal was principally devoted in some other countries, and among the Greeks in the early period of their history. No mention is made of a single horseman on either side, during the ten year's' siege of Troy; but the warriors all fought on foot or in chariots.

The chariots rere simple in their structure, open at the back, and partly on the sides; and containing the driver in the front, and the warrior standing on a platform, usually somewhat elevated. These vehicles seem to have been rarely brought into collision with each other; but they were driven rapidly over the field, the warrior hurling his lances on either side, or alighting when he met with a foe worthy of lis attack. These chariots were not only contrived for service, but were often most splendidly and expensively ornamented. They were the prize of the conqueror. Sometimes they were drawn by three horses; but the third was a spare one, in case either of the others should be tired or wounded. Some had four horses yoked abreast: such was the chariot of Hector.

+ Appendix to the Trauslation of Xenophon's Rules, p. 51. 
The charioteer, although at the time inferiol to, or under the command of the warrior, was seldom or never a menial. He was often the intimate friend of the warrior; thus Nestor, and even Hector, are found acting as charioteers. When not the personal friend of the warrior, he was usually a charioteer by profession; and drove where he was directed.

Occasional mention is made of the currus falcati, chariots with armed instruments in the form of scythes, projecting from the axles of the wheels, by means of which whole ranks might be mown down at once. They were confined, however, to the more barbarous nations, and were used neither by the Greeks nor the Romans. They were advantageous only on tolerably open and'level ground; and it not unfrequently happened that, affirghted by the clamour of the battle, or by wounds, the horses became ungovernable, and, turning on the ranks of their friends, threw them into complete disorder. They were on this account laid aside, even by the barbarians themselves.

In process of time, war-chariots of every kind fell into disuse, and the higher classes of warriors were content to fight on horseback, where their personal strength and courage might be as well displayed, and discipline could be better preserved.

Still, almost to the period of the Christian era, and long after that in many countries, the use of the horse was confined to war, to the chase, and to public pageants. The first employment of the Egyptian colonists, when they landed in Thessaly, was to rid the forests of the wild cattle, and other dangerous animals, with which they were then peopled. In the central and southern parts of Greece, the country was more open, and the wilder animals were scarcely known; but in Assyria and Persia, and every country in which the legitimate prey of the hunter was found, the horse was employed in its pursuit.

In process of time, in order to decide the comparative value of different horses, or to gratify the vanity of their owners, and also to give more effect to certain religious rites and public spectacles, horse-races were introduced. The most celebrated of these exhibitions was that at Olympia, in Pelopomnesus, held every fourth year, in honour of Jupiter. The young men flocked thither from every district of Greece, to contend in every manly exercise-hurliug the javelin, leaping, running, wrestling and boxing. The candidates were persons of unblemished reputation-the contest fairly and honourably conducted, and the conqueror, crowned with a laurel, or with gold, was received in his native town with acclamations of joy. A breach was made in the wall of the town for one who had so distinguished himself to pass. $\mathrm{He}$ was, for life, entitled to precedency at every public exhibition; he was exempted from all taxes and inferior civil offices; his name was enrolled in the archives of his country, and statues were erected to his memory. This was the source of the noble spirit of emulation and the ardent love of country by which the Greek was distinguished.

Nearly a century, however, passed before the attraction of the exhibition was increased by the labours of the horse. The first colonists could bring with them only a few of these noble animals. In several of the wars in which they were engaged, their deficiency in cavalry was lamentably apparent. It was not until the 23d Olympiad that the horse mingled in the contest.

During the first two Olympiads after this horsemen alone appeared. Of these races the accounts are exceedingly imperfect. Each horse was ridden by his owner, who was obliged to undergo preparatory trials for the space of thirty days. The horses were divided into full and under-aged; but no explanation is given by any writer of the precise meaning of these terms, nor is any thing said of the weight of the riders. We only know the space to be run over, which somewhat exceeded four miles. There was one race, called Colne, in which mares alone were permitted to run. Towards the end of the course the riders were compelled to leap from their backs, and, keeping the bridle in their hands, to run alongside of them to the winning-post.

In the 25th Olympiad chariot-races were introduced. The chariots were arranged alreast of each other at the starting-post; the places-for it will appear that these gave some important advantages-having been previously decided by lot. An altar was erected on one side, upon which stood a brazen eagle, dedicated to Jupiter, and a dolphin, sacred to Neptune. At a signal from the presiding officer, the eagle, by some mechanism, sprang into the air, the dolphin sank under ground, and away the horses started. The hippodrome, or course, was about one-third of a mile in length; and at the farther end was a pillar, round which the chariots were to be driven, and back again to the starting-place, six times, making rather more than four miles.

The rounding of this pillar was the first test of the skill of the driver and the docility of the horses, and many au accident happened there.

This dangerous spot was no sooner passed, than the competitors came at once upon a strange figure placed to try the courage and nerve of the horses. It was an enormous statue, called Taraxippus, the terrifier of horses-and, according to the old writers, well worthy of the name. None of them describe this strange deity, but all agree that he used sadly to frighten the steeds, and often to endanger their lires, and that of the driver.

A little farther on was a lofty rock, in the very centre of the course, leaving only a very narrow defile, in the passing through which the skill of 
the charioteer was severely tried; while several men, placed on the rock, increased the confusion, and the terror of the horses, by the continual braying of their trumpets.

As may be well supposed, the number of the competitors was much diminished ere the conclasion of the race. Some ran against the pillar, others were frightened out of the course by the horrible statue, and not a few were wrecked on that fearful rock. Some were destroyed on the spot; others, who escaped without serious injury, were derided by the spectators, on account of their want of skill; and the fragments with which the course was covered rendered almost every step perilous. The conqueror in such a race well deserved the crown which be received, and the honours that were bestowed on him.

What were the opinions which prevailed at this early period respecting the proper form - the points of the horse? Let that master horseman, Xenophon, declare. "The first thing that ought to be looked to is the foot; for as a house would be of no use, though all the upper parts of it were beautiful, if the lower parts of it had not a proper foundation, so a horse would not be of any use in war, if he had tender feet, even though he should have all other good qualities; for his good qualities could not be made any valuable use of." This maxim, more than two thousand two hundred years old, bespeaks at once the horseman.

"Thick hoofs make a horse's feet better than thin ones." This must be self-evident, where there was no artificial protection of the foot. The force with which the foot will come in contact with the ground at every step will produce sufficient expansion of the heel; but it is only a strong foot that can long endure the concussion, without being worn away.

"It likewise must not be forgotten to see whether the hoofs are high or low, and near the ground, both before and behind." Few things are of greater importance than this. If the inclination of the foot in front is less than its usual angle (forty-five degrees), it indicates a contracted foot, and a morbidly hollow sole, and inflammation of the laminx, and speedy and incurable lameness. If the inclination is greater, and the angle acuter than it should be, there is flatness of the sole, and liability to serious bruise of it, or, perhaps, pumiced feet.

"The pasterns, or boues immediately above the hoofs and below the fetlocks, ought not to be straight like those of a goat; for this would shake the rider, and such legs are more subject to inflammation; nor ought these bones to be too low, for the fetlock wonld be chafed and ulcerated, if the horsẻ was ridden over ploughed grounds, or among stones." If he had added that the oblique pastern was sadly liable to sprain, and there would often be injury through the whole course of the flexor tendon, nothing could have been added to the force of his observation.

"The bones of the legs ought to be large, since they are supporters of the body; not, however, thick with veins, or cellular matter." $\mathrm{He}$ is speaking of the war-horse and the hunter, and what can be more correct?

"If the colt in walking bends his knees freely, you may judge, when he comes to be ridden, that his legs will be supple; and supple joints are justly commended, as they make a horse less liable to stumble, and not tire so soon as when his joints are stiff."

"The thighs under the shoulders (the fore-arms), when they are large, are both powerful and graceful ; and the chest being large, contributes not only to beauty and strength, but to a horse's being able to continue a long time in one pace."

"The neck should proceed from the chest, rising upwards, and it should be loose about the bend of the head: the head, too, being bony, should have a small cheek. The eve should be standing out, and not sunk in the cheek. The nostrils that are wide are not only better adapted for breathing than those that are compressed, but likewise cause the horse to appear more terrible in battle. The top of the head being large, and the ears small, makes the head appear more elegant. The point of the shoulder likewise, being high, renders that part of the body more compact." The author was evidently aware of the advantage of this form, but he did not know the principles on which it was fouuded.

"The sides, being deep and swelling towards the belly, make a horse in general more commodious to be seated on and better able to digest his food. The broader and shorter his loins are, the more readily will he throw his fore feet out; and the belly that appears small, being large, not only disfigures a horse, but makes him weaker and less able to carry his rider." How beautifully again he seizes the point, although we of the present day smile a little at his illustration!

"The haunches should be large and full of flesh, that they may correspond with the sides and the chest ; and when all these are firm, they make a horse lighter for the course and fuller of animation." *

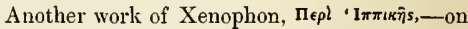
the management of the horse,- exhibits equal proof of a knowledge of the points and proper treatment of this animal, mixed with the same ignorance of the principles on which these things are founded. He was an acute observer, and the facts made their due impression, but no one had yet taught the anatomy and physiology of the horse.

* I I" $\pi \alpha \rho X \imath k \delta s$, or Duties of the Master of the Horse in the Arny, chap. $i$. 
The Romans, from the rery building of their city, paid much attention to the breeding and management of the horse; but this was more than seven hundred years after this animal had been imported into Greece, and his value and importance had begun to be almost universally acknowledged.

Horse and chariot races were early introduced at Rome. The chariot-races fell gradually into disrepute, but the horse-races were continued to the times of the Cæsars, and the young men of the equestrian order were enthusiastically deroted to this exercise. There were not, however, any of the difficulties or dangers that attended the Gre. cian races. They were chiefly trials of speed, or of dexterity in the performance of certain circles, now properly confined to our theatrical exhibitions. The rider would stand upright on his steed, lie along his back, pick up things from the ground at full speed, and leap from horse to horse in the swiftest gallop.

A singular circumstance in the management of this animal by the Romans, was the superior value which they attributed to the mare. Their natural historians, agriculturists, and poets, unite in this opinion. Perhaps this might in part arise from the custom of the Romans to castrate all the horses that were employed in mercantile and agricultural pursuits. The horse, however, was not degraded by the operation or the labour, but rather he was made to occupy the situation for which nature designed bim; and from this time, and gradually over every part of Europe, he has become one of the most useful of the servants of man.

To the Romans may be attributed the invention of the curb-bit. The Emperor Theodosius is represented in one of the ancient sculptures as using a bit with a tremendously long lever, and which could inflict dreadful punishment if the rider were so inclined.

It may readily be supposed that a knowledge of the horse now became more perfect and more diffused. Terentius Varro, who flourished about the year seventy before Christ, and during the existence of the commonwealth, has given a description of the horse, which has scarcely been excelled in modern times. "We may prognosticate great things of a colt," says he, "if when running in the pastures he is ambitious to get before his companions, and if, in coming to a river, he strives to be the first to plunge into it.
His head should be small, his limbs clean and compact, his eyes bright and sparkling, his nos. trils open and large, his ears placed near each other, his mane strong and full, his chest broad, his shoulders flat and sloping backward, his barrel round and compact, his loins broad and strong, his tail full and bushy, his legs strait and even, his knees broad and well knit, his hoofs hard and tough, and his veins large and swelling over all his body."*

Virgil, eighty or ninety years afterwards, gives some intcresting accounts of the horse, and particularly when taken from the pursuits of war and employed in the peaceful service of agriculture.

A few years after him followed Columella, who, in a work deroted exclusirely to agriculture, treats at length of the management of the horse and of many of his diseases.

To him succeeded Palladius on agriculture, the management of the rineyard, and the apiary, \&c.; and he also describes at considerable length the treatment and the diseases of the horse.

About the same time, or somewhat before, the Roman emperors, being continually engaged in foreign wars, and in many of these expeditions the cavalry forming a most effective dirision of the army, veterinary surgeons were appointed to each of the legions. The horse and his management and diseases were then for the first time systematically studied. The works, or extracts from the works of a few of them are preserved. There is, however, little in them that is valuable.

About the middle of the fourth century a volume of a different character on the veterinary art was written by Vegetius, who appears to have been attached to the army, but in what situation is unknown. His work, with all jts errors, is truly valuable as a collection of the best remarks that had been written on veterinary matters, from the earliest age to his day, and including extracts from the works of Chiron and Hippocrates, which would otherwise have been lost. The history of the symptoms of the various diseases is singularly correct, but the mode of treatment reflects little credit on the veterinary acquirements of the author or the age in which he lived.

Almost in his time the irruptions of the Goths commenced, and shortly after every record of science was swept away in both the eastern and the western empires.

- Berenger, p. 82 . 


\section{CHAPTER II}

THE FOREIGN BREEDS OF HORSES.

WE commence again with that country connected with which we have the earliest history of the horse.

\section{THE EGYPTIAN HORSE.}

Notwithstanding the flattering reports of travellers, and the assertion of Dr. Shaw that the Egyptian horses are preferable to the Barbary ones in size, beauty, and goodness, the modern horse of this comntry had little to recommend him. The despotism under which the inhabitants groaned altogether discouraged the rearing of a valuable breed, for their possession was completely at the mercy of their Turkish oppressors, and the choicest of their animals were often taken from them withont the slightest remmeration for the wrong. It was therefore a common practice with the owners of superior or good horses to blemish or to lame them, in order that they might not be robbed of them by order of the Bey.

Of the state to which the native horses were reduced, and even many in the corps of the Mamelukes-the body-guard of the Bey-the following evidence from a competent observer will determine:- "Although the horses there seldom pass out of a foot pace except for a gallop of one hundred yards, most of them are foundered, and none, if quickly trotted ten miles, would be able from want of wind and stamina to go farther." *

The testimony of Burckhardt is to the same effect:- "The Egyptian horse is ngly, of coarse shape, and looking more like a cart-lorse than a racer. Thin legs and knees and short and thick necks are frequent defects among them. The liead is sometimes fine, but I never saw good legs in an Egyptian horse. They are not able to bear any great fatigne, bat, when well fed, their action occasionally is more brilliant than that of the Arabian. Their impetuosity, however, renders them peculiarly desirable for heavy cavalry, and it is upon this quality alone that their celebrity has ever been founded."

Since the accession of Mehemet Ali to the government of Egypt, a beneficial change has been effected in the internal management and prosperity of the country, and the improvement of the breed of horses has especially engaged his attention. He has even gone so far as to establish a veterinary school at Abou-Zabel, and, as shonld be the case with every institution of this kind, he has not only identified it with the cavalry service, but with the agricultural interests of the country. The happy conseqnences of this are neither doubtful nor distant.

There is a long but narrow tract of desert be-

* Wilson's Expedition to Egypt in 1803, p. 250. tween the Nile and the Red Sea, on which some Arabian horses $\uparrow$ of the choicest breed are reared.

\section{THE DONGOLA OR NUBIAN HORSE.}

The kingdom of Dongola, the modern Nubia, lying between Egypt and Ayssinia, contains a breed of horses different from any other that either Arabia or Africa produces. Mr. Bruce speaks of it in the following strong terms of approbation:"What figure the Nubian breed of horses would make in point of swiftness is very doubtful, their form being so entirely different from that of the Arabian; but if beautiful and symmetrical parts, great size and strength, the most agile, nervons, and elastic movements, great endurance of fatigue, docility of temper, and, beyond any other domestic animal, seeming attachment to man, can promise any thing for a stallion, the Nubian is, above all comparison, the most eligible in the world. Few of them are less than sixteen hands high."

Bosman, whose descriptions prove him to be no bad horseman, thus speaks of them:- - "The Dongola borses are the most perfect in the world, being beautiful, symmetrical in their parts, nervous and elastic in their movements, and docile and affectionate in their manners. One of these horses was sold in 1816, at Grand Cairo, for a sum equivalent to one thousand pounds." The Dongola horses are usually of a black colour, but there are some bright bays and sorrels. When their exereise is over, the usual bridle is taken away, and a lighter one put upon them; for the inhabitants tell of many battles that were lost, from their being attacked when their hor'ses were umbridled.

The slender yet finely set on neck, the noble crest, the elevated withers, the beantiful action and bearing of the animal were admirable; but the long and slender legs, the reakness of the fore-arn, the narrowness and want of depth of the chest, and even a deficiency of substance alout the flank and quarters, could not escape olservation. Such an animal might have speed, but his endurance must be doubtful, and it is difficult to suppose that any breed of English horses could be materially improved by it.

Some of these horses have lately reached Eng. land; and one of them was recently in London, and belonged to an officer of the Life Guards.

\section{THE HORSE OF ETHIOPIA OR ABYSSINIA.}

Ludolph, in his history of this country, sars that the horses are strong, nimble, mettlesonie, and mostly black. They are used only for war

$\uparrow$ Comparative View of the Racer, sce, p. I $\$ 8$. 
and in the chase; they travel no long and fatiguing journeys, and all the drudgery of every kind is performed by the mule.

An Abyssinian, who accompanied Ludolph to Europe, expressed a great deal of pity for the horses when he saw them drawing heavy carts, and loudly exclaimed at the cruelty of putting so noble a creature to such base and servile employ. ment. He said that he woudered at the patience of the animals, and was every moment in expectation that they would rebel against such unheardof tyranny.*

The number of horses in Ethiopia must have considerably decreased, for Cyrtacus, a former

- Ludolph's New History of Ethiopia. 1684, p. 53. king of that country, entered Egypt at the head of one hundred thousand cavalry.

The art of shoeing had not in Ludolph's time (the middle of the seventeenth century) reached Abyssinia; and consequently, when the natives had to travel over rough and stony ground, they dismounted and got upon mules, and led their horses in hand, that by having no burden to carry they might tread the lighter.

Bruce says little of the Ethiopian horses; but Mr. Salt, an enterprising traveller, says that the horses are generally strong, well-made, and kept in good condition; that their accoutrements are also good, and the men themselves are excellent horsemen.

THE BARB.

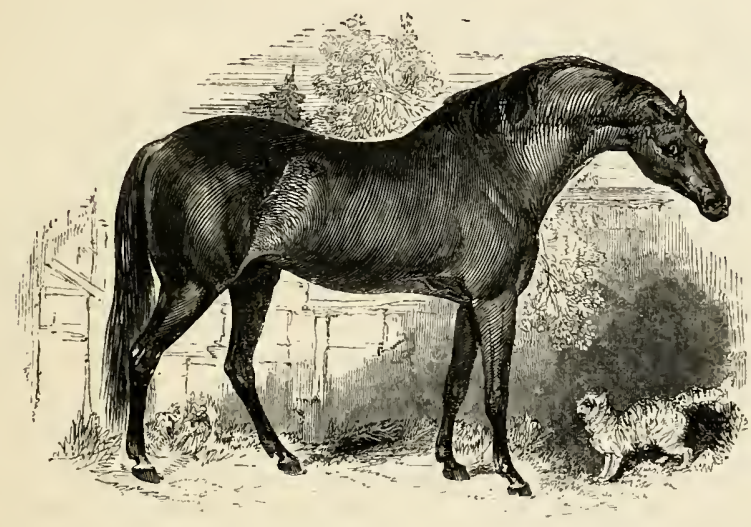

THE GODOLPFIN ARABIAN

By the term Barbary is understood the northern part of Africa, extending along the coast, and as far inland as the Great Desert, from the frontiers of Egypt and the Mediterranean. The Arabs that are found in this extensive district are mostly the descendants of those who emigrated or were driven from eastern Arabia. The horses are likewise all of Arab stock, considerably modified by change of climate, food, and management. Mr. Bruce relates, that " the best African horses are said to be descended from one of the five on which Mahomet and his four immediate successors fled from Mecca to Medina, on the night of the Hegira." This must be received with very considerable allowance. The inhabitants of almost the whole of these conntries are as cruelly oppressed as the Fellahs of Egrpt, and the consequence of that oppression is the same. The Arabs will scarcely be induced to cultivate a breed of horses of much value, when, without scruple or compensation, they may be deprived of every colt by the first man in power that chooses to take a fancy to it. It is. only among the tribes of the Desert, who are beyond the reach of the tyrants of their country; that the barb of superior breed, and form, and power, is to be found.

The common horse of Barbary is a very inferior animal-just such a one as many years of supineness and neglect would produce; but the following are the characteristic points of a true barb, and especially from Moroceo, Fez, and the interior of Tripoli :- The forehand is loug, slender, and ill-furnished with mane, but rising distinctly and boldly out of their withers; the head is small and lean; the ears well-formed, and well-placed; the shoulders liglit, sloping backward, and flat; 
the withers fine and high ; the loins straight and short; the flanks and ribs round and full, and with not too much band; the haunches strong; the croup, perhaps, a little too long; the quarters muscular and well developed; the legs clean, with the tendons boldly detached from the bone; the pastern somewhat too long and oblique; and the foot sound and good.* They are rather lower than the Arabian, seldom exceeding fourteen hands and an inch, and have not his spirit, or speed, or continuance, although in general form they are probably his superior.

The barb has chiefly contributed to the excellence of the Spanish horse; and, when the improvement of the breed of horses began to be systematically pursued in Great Britain, the barb was very early introduced. The Godolphin Arabian, as he is called, and who was the origin of some of our best racing blood, was a barb; and others of our most celebrated turf-horses trace their descent from African mares. They are generally first mounted at two years old. They are never castrated, for "a Mussulman would not mutilate or sell the skin of the beast of the Prophet." The horses alone are used for the saddle, $f$ and the mares are kept for breeding. The cavalry exercise to which their horses are exposed is exceedingly severe. The Moorish method of fighting principally consists in galloping at the very height of their horses' speed, for the distance of a quarter of a mile or more, then suddenly stopping while the rider throws his spear or discharges his musket. By way of exercise, they will sometimes continue to do this without a moment's intermission to change or to breathe their horse. All that is required of the best-tanght and most valuable Barbary horse is thus to gallop and to stop, and to stand still, all the day if it is necessary, when his rider quits him. As for trotting, cautering, or ambling, it would be an unpardonable fault were he ever to be guilty of it. A Barbary horse is generally broken in in a far severer way, and much earlier than he ought to be, and therefore he usually becomes unfit for service long before the Arabian. The usual food of the barb is barley and chopped straw, and grass while it is to be found, but of the provision for winter food in the form of hay they are altogether ignorant.

Captain Brown, in his Biographical Sketches of Horses, gives the following interesting account of a barb and his rider, at the Cape of Good Hope :-In one of the violent storms which often

- Berenger, p. 127.

+ No Arab ever mounts a stallion; on the contrary, in Africa they never ride mares. The reason is plain. The Arabs are constantly at war with their neighbours, and always endeavour to take their enemies by surprise in the grey of the evening, or the dawn of day. A stallion no sooner smells the stale of the mare in the enemy's quarters, than he begins to neigh, and that would give occur there, a vessel in the road diagged her anchors, and was forced on the rocks, and beaten to pieces. The greater part of the crew perished immediately, but some few were seen from the shore clinging to different pieces of the wreck. No boat could venture to their assistance. Meanwhile a planter came from his farm to see the shipwreck, and perceiving no other chance of escape for the survivors, and knowing the spirit of his horse and his excellence as a swimmer, he determined to make one desperate effort for their deliverance, and pushed into the midst of the breakers. At first both disappeared, but they were soon seen on the surface. Nearing the wreck, he induced two of the poor fellows to quit their hold and to cling to his boots, and so he brought them safe ashore. He repeated this perilous expedition seven times, and saved fourteen lives; but on his retum, the eighth time, his horse being much fatigued, and meeting with a formidable wave, the rider lost his balance and was overwhelmed in a moment. The horse swam safely to land, but his gallant rider was seen no more. The Cape was then a colony of the Dutch The Directors christened one of their new vessels after him, and ordered a pillar to be erected to his memory, but the local authorities refused to the son a trifling place which his father filled. †

The barb improves towards the Western coast of Africa, both in his form and graceful action.

Deep in the Sahara Desert is a noble breed of barbs, known by the name of the "Wind-sucker or the Desert-horse." Jackson says of him, that the Desert-horse is to the common Barbary horse what the Desert-camel is to the nsual camel of burden; but that he can only be induced to eat barley or wheat-oats are never given to horses in Africa; but that, supplied with a little camel's milk, he will travel almost incredible distances across the Desert. $\mathrm{He}$ is principally employed in hunting the antelope and the ostrich.

There is some little exaggeration, however, about this, for when he is brought towards the coast, and can no longer get his camel's milk, he will eat the barley and the straw which are given to him, and will thrive and get fat upon them. If he chances to die, it is from being suffered to gorge too much of his new food; or if he loses a portion of his speed and wind, it is because he has been taken out of his exercise, and permitted to accumulate flesh and fat too fast.

More in the centre of Africa, in the kingdom of Bournou, is a breed, which Mr. Tully, in his

the alarm to the party intended to he surprised. No such thing can ever bappen when they ride mares only. On the contrary, the African trusts only to superior force. They are in an open plain country, must be discovered at many miles' distance, and all such surprises and stratagems are useless to them.

; De Page's Travcls Round the World, and Sharman's Voyage to the Cape of Good Hope. 
almost romantic history of Tripoli, reckons superior even to those of Arabia or Barbary ; it possesses, according to him, the best qualities of both those breeds, being as serviceable as that of Arabia, and as beautiful as that of Barbary.

On the south of the Great Sabara Desert we fiud again the Arabian or the Barbary horse in the possession of some of the chief s of the Foulahs and the Jalofs; but the general character of the aniual is in those torrid regions much deteriorated. These horses are small, weak, unsafe, and untractable. The Foulahs, however, can bring into the field no fewer than 16,000 cavalry. Some writers have asserted, that in the kingdom of Benin a much larger number conld be collected.

In the country lying between that of the Fouluhs and the kingdom of Benin, there are few horses immediately on the coast, but they are more numerous iu the inland districts. Bosman, however, says of them that they are very ill-shaped; that they carry their heads and necks more projecting and depressed than even the ass; that they are slow and obstinate, and only to be forced on by dint of blows; and that they are so low, that a tall man sitting on their backs could touch the ground with his feet. He adds that at Fida, on the slave-coast, whence he journeyed inland to Elmina, he bought five or six of them, each of which coșt him somewhat less than four pounds, but they did him no manner of service, and he was compelled to leave them behind. Neither horses, nor any other produce of value, can be looked for in these unhappy countries, so long as they are desolated by the abominable slave-trade, under the sanction of the more civilised but truly unchristian uations of Europe.*

\section{THE CAPE OF GOOD HOPE HORSE.}

Nothing is certainly known of the western coast of Africa, descending towards the south; but arriving at the Cape of Good Hope, we find that the horse, if a native of that country, is only occasionally seen in its wild state. The horses that were introduced by the first colonists, the Dutch, were mostly procured from Batavia, Java, and South America. At the very commencement of the colony, many horses were imported from Persia. These were mingled together, and crossed in every possible way, except that not one notion of scientific improvement seems to have entered the head of the Dutch boor. They were a small hardy race, capable of enduring a great deal of fatigue, but in every way sadly neglected; never dressed, and often ill-fed.

When the Cape was ceded to the English, both the colonists and the government set earnestly to work to improve these undersized animals, and with very considerable success. The vol. $t$.

- Bosman's Coast of Guinea, p. 366.
British light regiments of dragoons, in their passage to the East, can now frequently draw considerable supplies of lor'ses from this colony, and some regiments have been entirely mounted here. This is sufficient proof of the deuree of inprovement which they have reached. It is, however, said that the riding-masters have occasionally much trouble in breaking in the Cape horses, which are naturally vicious, and especially when put beyond the pace to which they had been accustomed. They rarely stand above fourteon hands high; they are hardy, and when thoroughly broken in, are capable of cnduring great privation and fatigue. They are rarely shod while they remain in the colony, or if they are, it is only on the fore feet. Their principal food is carrots, with a small quantity of corn. No hay is grown near Cape Town, nor are there any pastures on which the horses can be turned.+

The wild horses have long disappeared near to the colony, and we have no authentic record that any of them were ever taken and attempted to be domesticated.

The horse is rarely seen in auy part of the eastern coast of Africa. It is not a native of Madagascar, but is again found in Ajan and Adel, on the southern frontiers of Abyssinia.

\section{THE ARABIAN HORSE.}

Although modern Europe owes so much to Arabia for the improvement in her breed of horses, it may be doubted whether these animals were found in that country as a matter of merchandise, or indeed existed there at all in large numbers in very early times. The author of the book of Job, in describing the wealth of that patriarch, who was a native of Arabia, and the richest man of his time, makes no mention of horses, although the writer slows himself rery conversant with that animal. Five lsundred years after that, Solomon imported spices, gold, and silver, from Arabia; | but all the horses for his own cavalry and chariots, and those with which he supplied the Phoenician monarchs, he procured from Egypt.§

There is a curious record of the commerce of different countries at the close of the second century. Among the articles exported from Egypt to Arabia, and particularly as presents to reigning monarchs, were horses.

In the fourtl century, two hundred Cippadocian horses were sent by the Roman emperor as the most acceptable present he could offer a powerful prince of Aribia.

So late as the seventh century the Arabs had few horses, and those of little value; for when Mahomet attacked the Koreish neir Mecca, he

+ Percivall's Cape of Good Hope, p. 161.

* Percivall's Cape of Good Hope, p. 145.

II 2 Chron. ix. It. 
had but two horses in his whole army: and at the close of his murderous campaign, although he drove off twenty-four thousand camels and forty thousand sheep, and carried away twenty-four thousand ounces of silver, not one horse appears in the list of plunder.

These circumstances sufficiently prove that, however superior may be the present breed, it is comparatively lately that the horse was naturalised in Arabia. Indeed the Arabs do not deny this; for until within the last century, when their horses began to be so deservedly valued, they were content to limit their pedigree to one of the five on which Mahomet and his four immediate successors fled from Mecca to Medina on the night of the Hegira.

Although in the seventh century the Arabs had no horses of value, ret those which they had derived from their neighbours began then to he preserved with so much care, and propagated so uniformly and strictly from the finest of the breed, that in the thirteenth century the Arabian horse began to assume a just and umrivalled celebrity.

There are now said to be three breeds or varieties of Arabian horses: the Attechi, or inferior breed, on which the natives set little value, and which are found wild on some parts of the deserts; the Kadischi, literally horses of an unknown race, answering to our half-bred horses-a mixed breed; and the Kochlani, horses whose genealogy, according to the modern exaggerated accounts, has been cultivated during two thousand years. Many written and attested pedigrees extend, with true Eastern exaggeration, to the stud of Solomon. The Kochlani are principally reared by the Bedouin Arals, in the remote deserts. A stallion may be procured without much difficulty, although at a great price. The Arabs imagine that the female is more concerned than the male in the excellence and value of the produce, and the genealogies of their horses are always traced through the dam.

The Arab horse would not be acknowledged by every judge to possess a perfect form. The head, however (like that which is delineated in the titlepage), is inimitable. The broadness and squareness of the forehead; the smallness of the ears; the prominence and brilliancy of the eye; the shortness and fineness of the muzzle; the width of the nostril ; the thinness of the lower jaw, and the beautifully developed course of the veins, - will always characterize the head of the Arabian horse. The cut in the title-page is the portrait of the head of a black Arabian presented to William IV. by the Imaum of Muscat. It is a close and honest likeness. The muzzle, the nostrils, and the eye, are inimitable. In the sale of the Hampton Court stud, in $183 \%$, this animal realized five hundred and eighty guineas; it was bought for the King of Wurtemberg, and is highly prized in Germany.

The body of the Arab mas, perhaps, be considered as too light, and his chest too narrow; but

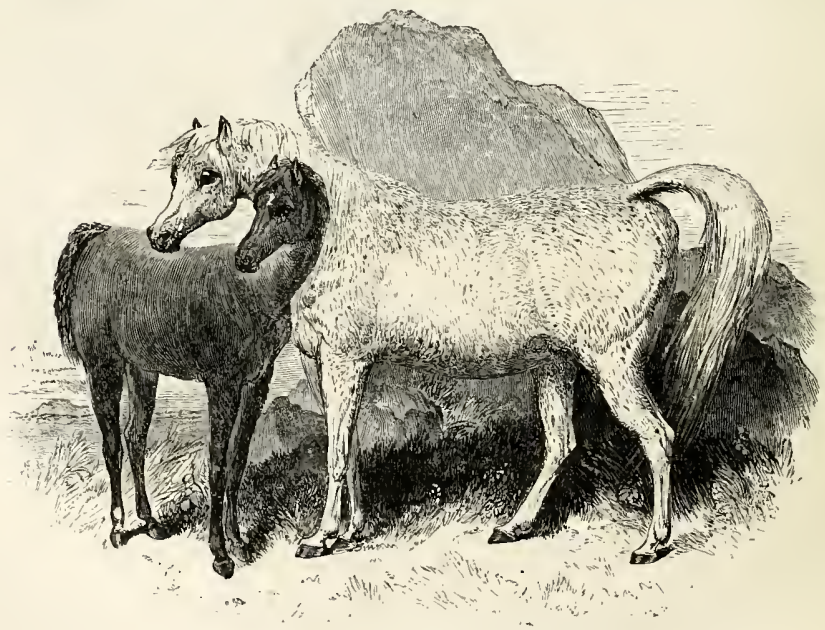


behind the arms the barrel generally swells out, and leaves sufficient room for the play of the lungs. This is well exhibited in the cut of the grey Arabian mare, whose portrait is here given. She is far inferior to the black one in the peculiar development of the head and neck, but in other respects affords a more faithful specimen of the true form of the Arabian horse. She is of the purest caste, and was a present from the same potentate by whom the black Arabian was given. The foal at her foot was by Acteon. She was sold for one bundred guineas only. Perhaps her colour was against her. Her flea-bitten appearance would not please every one. The foal, which had more than the usual clumsiness belonging to the youngster, sold for fifty-eight guineas.

The neck of the Arabian is long and arched, and beautifully joined to the chest. The black horse in the frontispiece afforded a perfect specimen of this. In the formation of the shonlder, next to that of the head, the Arab is superior to any other breed. The withers are high, and the shoulder-blade has its proper inclination backwards. It is also thickly clothed with muscle, but without the slightest appearance of heaviness.

The fineness of his legs and the oblique position of the pasterns might be supposed by the uninitiated to lessen his apparent strength; but the leg, although small, is deep, and composed of bone of the densest character. The tendons are sufficiently distinct from the bone, and the starting muscles of the fore-arm and the thigh indicate that he is fully capuble of acsomplishing mony of the feats that are recorded of him.

As a faithful specimen of the general form of these horses, with, perhaps, a little deficiency in the head and neck, we refer once more to the following portrait of a bay Arabian-an animal of the purest caste, presented also by the Imaum of Museat. It was sold for four hunilred and ten guineas. The higher price that was given for the black Arabian proves that he was the general favourite; but the bay one, although not so striking in his figure, was a stronger, a speedier, and a better horse.

The Barb alone excels the Arabian in noble and spirited action; but if there is a defect about the latter, he is perfect for that for which he was designed. $\mathrm{He}$ presents the true combination of spoed and bottom : strength enough to carry more than a light weight, and courage that would cause him to die rather than yield.

Mr. Burckhardt, in a letter to Professor Sewell, says that "the tribes richest in horses are those who dwell, during the spring of the year at least, in the fertile plains of Mesopotamia; for, notwithstanding all that is said of the desert horse, plenty of nutritious food is absolutely requisite for its reaching its full vigour and growth. The numerous tribes on the Red Sea, between Akaba and Mecca, and especially those to the south of Mecca, and as far as Yemen, have very few horses; but the Curdes and Bedouins in the east. and especially in Mesopotamia, possess more horses, and more valuable ones, than all of the Arabian Be-

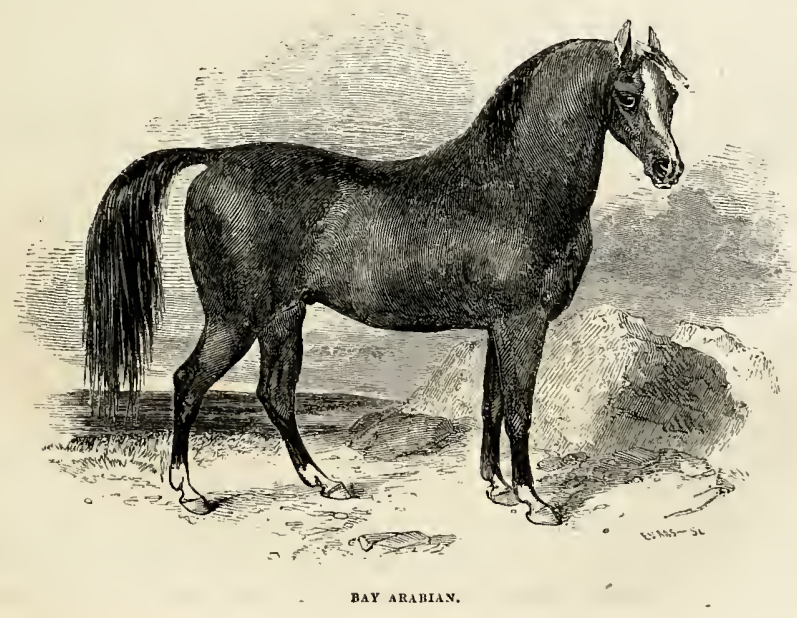


douins; for the richness of their pastures easily nourishes the colts, and fills their studs." These observations are very important, and are evidently founded on truth. He adds, that "the number of horses in Arabia is not more than fifty thousand; a number far inferior to that found in any part of Europe, or Asia, on an equal extent of ground."

"During the Wahabee goverument, horses became scarcer every year among the Arabs. They were sold by their masters to foreigu purchasers, who carried them to Yemen, Syria, and Bassora, which latter place supplies India with Arabian horses, because they were afraid of having them seized upon by their chiefs-it having become the custom, upon every slight pretext of disobedience or crime, to declare the most valuable Bedouin mare forfeit to the public treasury."

Syria is the best place to purchase true Arabian blood-horses; and no district is superior to the Naurau, where the horse may be purchased from the first hand, and chosen in the very encampments of the Arabs themselves, who fill these plaius in the spring. The borses bought at Bassora for the Indian markets are purchased secondhand from Bedouin dealers. These procure them from the Montifell Arabs, who are not careful in maintaining a pure breed. Damaseus would be the best residence for a person constantly employed in this trade.

While the number of horses generally is much smaller than had been supposed, there are comparatively fewer of those of perfect quality and beauty,-perhaps not more than five or six in a whole tribe; probably not two luundred in the whole desert. Each of these, in the desert itself, may be worth from one hundred and fifty to two lundred pounds; but very few, if any, of these have ever found their way to Europe.

There has, however, been much exaggeration with regard to these pedigrees. Burckliardt says, that in the interior of the desert, the Bedouins never make use of any, because, among themselves, they lnow the genealogy of their horse almost as well es that of their own families; but if they carry their lorses to any distance, as to Bas. sora, Bagdat, or Damascus, they take care to have a written pedigree made out, in order to present it to the purchaser. In that case only would a Bedouin be found possessed of his horse's pedigree. He would laugh at it in the desert.

The Fochlani are principally reared by the Bedouin Arabs in the remoter deserts. One of them was sold at Acre for the sum of fifteen thousand piastres.

It is an error into which almost every writer on the history of the horse has fallen, that the Arabian is bred in the arid deserts, and owes the power of endurance which he possesses in his adult state to the bardships which be endured while he was a colt. The real fact is, that the Arabs select for their breeding-places some of those delightful spots, known only in countries like these, where, though all may be dry and barren around, there is pasture unrivalled for its succulence and its nutritious or aromatic properties. The powers of the roung animal are afterwards developed, as they alone could be, by the mingled influence of plentiful and healthy food, and sufficient, but not, except in one day of trial, cruel exercise.

The most extraordinary care is taken to preserve the purity of the breed. Burckhardt states that the favourite mare of Savud the Wahabee, which he constantly rode in all his expeditions, and was known in every part of Arabia, produced a colt of very superior beauty and promise, and it grew to be the finest stallion of his day. Sarud, however, would never permit him to be used for the purposes of breeding, because his mother was not of pure blood; and not knowing what to do with him, as the Bedouins never ride stallions, he sent him as a present to the scheriff.

The parentage and birth of the foal are carefully recorded by competent witnesses, whose certificate includes the marks of the colt, and the names of the sire and dam.

The colt is never allowed to fall on the ground at the period of birth, but is caught in the arms of those who stand by, and washed and caressed as though it were an infant. The mare and her foal inhabit the same tent with the Bedouin and his children." The neck of the mare is often the pillow of the rider, and, nore frequently, of the children, who are rolling about upon her and the foal. No accident ever occurs, and the animal acquires that friendship and love for man which occasional ill-treatment will not cause her for a moment to forget.

At the end of a month the foal is weaned, and is fed on camel's milk for one hundred days. At the expiration of that period, a little wheat is allowed; and by degrees that quantity is increased, the milk continuing to be the principal food. This mode of feeding continues another hnndred days, when the foal is permitted to graze in the neighbourhood of the tent. Barley is also given; and to this some camel's milk is added in the evening, if the Arab can afford it. By these means the Arab lorse becomes as decidedly characterised for his docility and good temper, as for his speed and conrage. The lindness with which he is treated from the time of his being foaled, gives him an affection for his master, a wish to please, a pride in exerting every energy in obedience to his commands, and, consequently, an apparent sagacity which is seldom found in other breeds. In that delightful book, Bishop Heber's "Narrative of a Journey through the Upper Provinces of India," the following interesting cha- 
racter is given of him:- " My morning rides are very pleasant. My horse is a nice, quiet, goodtempered little Arab, who is so fearless, tliat he goes without starting close to an elephant, and so gentle and docile that he eats bread out of my hand, and has almost as much attachment and coaxing ways as a dog. This seems the general character of the Arab horses, to judge from what I have seen in this country. It is not the fiery dashing animal I had supposed, but with more rationality about him, and more apparent confidence in his rider, than the majority of English horses."

When the Arab falls from his mare, and is unable to rise, she will immediately stand still, and neigh until assistance arrives. If he lies down to sleep, as fatigue sometimes compels him, in the midst of the desert, she stands watchful over him, and neighs and rouses him if either man or beast approaches. The Arab lorses are taught to rest occasionally in a standing position; and a great many of them never lie down.

The Arab loves his horse as truly and as much as the horse loves him; and no little portion of his time is often spent in talking to him and caressing him.

An old Arab had a valuable mare that had carried him for fifteen years in many a rapid weary march, aud many a hard-fought battle; at length, eighty years old, and unable longer to ride her, he gare her, and a scimitar that had been his father's, to his eldest son, and told him to appreciate their value, and never lie down to rest until he had rubbed them both as bright as a mirror. In the first skirmish in which the young man was engaged, he was killed, and the mare fell into the hands of the enemy. When the news reached the old man, he exclaimed, that "life was no longer worth preserving, for he had lost both his son and his mare, and he griered for one as much as the other." $\mathrm{He}$ immediately sickened, and soon afterwards died.

A Bedouin bad committed some offence, and was pursued by the governor's guards in the direction towards Jericho. They were so close upon him that his only chance of escape was to gallop down the almost perpendicular declivity of the hills that overlooked the town. His mare precipitated herself down it at full speed, leaving the soldiers lost in admiration and astonishment. She, however, dropped dead on entering Jericho. The Bedouin, who would not quit her, was taken weeping over the body of his faithful companion. "Ali Aga," says M. Chateanbriand, "religiously showed me her footsteps along the face of the mountain." A Macedonian could not have beheld those of Bucephalus with greater veneration.

'The following anecdote of the attachment of an Arab to his mare has often been told :- " The whole stock of an Arab of the desert consisted of a mare. The French consul offered to purchase her, in order to send her to his sovereign, Louis XIV. The Arab would have rejecter the proposal, but he was miserably poor; he had scarcely a rag to cover him, and his wife and his children were starving. The sum offered was great, -it would provide him and his family with food for life. At length, and reluctantly, lie vielded. He brought the mare to the dwelling of the consul, dismounted, and stood leauing upon her; he looked now at the gold, and then at lis favourite. 'To whom is it,' said he, 'I an going to yield thee up? To Europeans, who will tie thee close,-who will beat thee,-who will render thee miserable. Return with me, my beauty, my jewel, and rejoice the hearts of my children.' As he pronounced the last words, he sprung upon her back, and was presently out of sight."

One of our own countrymen, the enterprising traveller, Major Denham, affords us a pleasing instance of the attachment with which the docility and sagacity of this animal may inspire the owner. He thus relates the death of his favourite Arabian, in one of the most desert spots of Central Africa. His feelings needed no apology: we naturally honour the man in whom true sensibility and undaunted courage, exerted for useful purposes, were thus united.

"There are a few situations in a man's life in which losses of this nature are felt most keenly; and this was one of them. It was not grief, but it was something rery nearly approaching to it; and though I felt ashamed of the degree of derangement I suffered from it, yet it was several days before I could get over the loss. Let it, however, be remembered, that the poor animal had been my support and comfort,- nay, I may say, companion, through many a dreary day and night ; - had endured both hunger and thirst in my service; and was so docile, that he would stand still for hours in the desert while I slept between his legs, his body affording me the only shelter that could be obtained from the powerful influence of a noonday sun: he was yet the fleetest of the fleet, and ever foremost in the chase."

Man, however, is an inconsistent being. The Arab who thus lives with and loves his horses, regarding them as his most valuable treasure, sometimes treats them with a cruelty scarcely to be credited. The severest treatment which the English race-horse endures is gentleness compared with the trial of the young Arabian. Probably the filly has never before been mounted. Her owner springs on her back, and goads her over the sands and rocks of the desert for fifty or sixty miles without one moment's respite. She is then forced, steaming and panting, iuto water deep enough for her to swim. If, immediately after this, she will 
eat as if nothing had occurred, her character is established, and she is acknowledged to he a genuine descendant of the Kochlani breed. The Arab does not think of the cruelty which he thus inflicts; he only follows an invariable custom.

We may not perhaps believe all that is told us of the speed and endurance of the Arabian. It has beew remarked, that there are on the deserts which this horse traverses no mile-stones to mark the distance, or watches to calculate the time; and that the Bedouin is naturally given to exaggeration, and, most of all, when relating the prowess of the animal, that he loves as dearly as his children: yet it cannot be denied that, at the introduction of the Arabian into the European stables, there was no horse comparable to him. The mare in her native deserts will travel fifty miles without stopping; she has been urged to the almost incredible distance of one hundred and twenty miles, and, occasionally, neither she nor her rider has tasted food for three whole days.

Our horses would fare badly on the scanty nourishment afforded the Arabian. The mare usually has but two meals in twenty-four hours. During the day she is tied to the door of the tent, ready for the Bedoun to spring, at a moment's warning, into the saddle; or she is turned out before the tent ready saddled, the bridle merely being taken off, and she is so trained that she immediately gallops up at her master's call. At night she receives a little water; and with her scanty provender of five or six pounds of barley or beans, and sometimes a little straw, she lies down content, if she is accustomed to lie down at all, in the midst of her master's family.

Buckliardt relates a story of the speed and endurance of one of them, and shows with what feelings an Arab regards his quadruped friend:-" A troop of Druses, on horselack, attacked, in the summer of 1815, a party of Bedouins, and pursued them to their encampnent: the Bedouins were then assisted by a superior force, and becoming the assailants in their turm, killed all the Druses excepting one who fled. He was pursued by some of the best mounted Bedouins, but his mare, although fatigued, could not be overtaken. Before his pursuers gave "1 the chase they called to him, and legged to be permitted to kiss his excellent mare, promising him safe conduct for her sake. He might have taken them at their word, for the pledge of an Arab, in such circumstances, might have been relied on: he however refused. Tliey immediately left the pursuit, and, blessing the noble beast, eried out to the fugitive, 'Go and wash the feet of your mare and drink off the water.' This expression is often used by the Bedouins to show the regard they have for their mares."*

\footnotetext{
* Comparative Vicw of the Racer, p. 151.
}

A periodical writer, on what authority is not stated, but he is right in most of the particulars if not in all of them, says, that "taking the comparative excellence of the different races, Nejed, between the desert of Syria and Yemen, and now in the possession of the Wahabis, is generally reckoned to produce the grandest, noblest horses; Hejaz (extending along the Red Sea, from Mount Sinai to Yemen, and including in it Medina and Mecca) the bandsomest; Yemen (on the coast of the Red Sea and the Indian Ocean, and the most fertile part of Arabia) the most durable; Syria the richest in colour; Mesopotamia the most quiet; Egypt the swiftest; Barbary the most prolific: and Persia and Koordistan the most warlike." $t$

The introduction of the Arabian into England, and the concern which he has had in the improvement of the English borse, will be treated of in the next chapter.

\section{THE PERSIAN HORSE.}

Next in the route which has been pursued along the south of Asia, towards the east, and yielding only to the Arabian in leauty and value, stands the Persiam horse. He is of larger growth than the Aralian,- - purposely lred so,- and on that account some foreign-still east country, but not pure Arabian blood, being introduced. A larger animal, one more adapted for modern war, is the result, but with some diminution of speed and endurance. The Persian is a nobler-looking animal at the first glance, but he will not bear the accurate examination that only increases our admiration of the other. Berenger thus describes their principal points:- "They are in general swall headed; they have long and somewhat too fine foreheads, and they are rather too narrow chested; their legs are a little small, but their croups are well fashioned, and their hoofs good and firm. They are docile, quick, light, bold, full of spirit, capable of enduring much fatigue, swift, sure-footed, hardy in constitution, and contented with almost any provender." They have, since his time, lost somewhat of the beanty, elasticity, docility, speed, and almost never-failing endurance.

The Persian horses constituted in ancient times the best cavalry of the East. The improved, incomparable Aralian lreed was not then in existence.

An entertaining traveller (Sir R. Kerr Porter) gives the following account of them:- "The Persian horses seldom exceed fourteen or fourteen and a half hands high, set certainly, in the whole, are taller than the Arabs. Those of the desert and country about Hillah run very small, but are full of bone and of good speed. General custom feeds and waters them ouly at sunrise and sunset,

+ The Sportsman, vol. iii. p. 256. 
when they are cleaned. Their nsual provender is barley and chopped straw, which, if the animals are picketed, is put into a nose-bag and liung from their heads; but if stabled, it is thrown into a small lozenge-shaped hole left in the thickness of the mud-wall for that purpose, but much higher up than the line of our mangers, and there the animal eats at his leisure. Hay is a kind of food not known here. The bedding of the horse consists of his dung. After being exposed to the drying influence of the sun during the day, it becomes pulverised, and, in that state, is nightly spread under him.* Little of it touches his body, that being covered by his clothing, a large nummud from the ears to the tail and bound firmly round his body by a very long surcingle. But this apparel is only for cold weather; in the warmer season the night-clothes are of a lighter substance, and during the heat of the day, the animal is kept entirely under shade.

"At night he is tied in the court-yard. The horses' heads are attached to the place of security by donble ropes from their halters, and the heels of their hinder legs are confined by cords of twisted hair, fastened to iron rings, and pegs driven into the earth. The same custom prevailed in the time of Xenophon, and for the same reason: to secure them from being able to attack and maim each other, the whole stud generally consisting of stallions. 'Their keepers, however, always sleep on their rugs amongst them to prevent aceident; and sometimes, notwithstanding all this eare, they manage to break loose, and then the combat ensues. A general neighing, screaming, kicking, and snorting, soon rouses the grooms, and the scene for a while is terrible. Indeed no one can conceive the sudden uproar of such a moment who has not been in Eastern countries to hear it, and then all who have, must bear me witness that the noise is tremendous. They seize, bite, and kick each other with the most determined fury, and frequently cannot be separated before their heads and haunches stream with blood. Even in skirmishes with the natives, the horses take part in the fray, tearing each other with their teeth, while their masters are in similar close quarters on their backs."

His description of a Persian race does not altogether remind ns of Newmarket or Doncaster.

"My curiosity was fully on the spur to see the racers, which I could not doubt must have been chosen from the best in the nation to exlibit the perfection of its breed before the sovereign. The rival horses were divided into three sets, in order

* It is the usual flooring of the stable and the tent. The united influence of the stur and air deprives it of all unpleasant odurr, and when from use it becomes a second tinte utfensive, it is again exposed to the sun, and all unpleasint smell once more titken away. to leugthen the amusement. They had been in training for several weeks, going over the ground very often during that time; and when I did see them, I found so much pains had been taken to sweat and reduce their weight, that their bones were nearly eutting the skin. T'he distance marked for the race was a stretch of four-indtwenty miles, and, that his majesty might not have to wait when lie had reached the field, the horses had set forward long before, by three divisions, from the starting point, (a short interval of time passing between each set,) so that they might begin to come in a few minutes after the king lad taken his seat. The different divisions arrived in regular order at the goal, but all so fatigued and exhausted, that their former boasted fleetness hardly exceeded a moderate canter when they passed before the royal eyes."

The plains of Persepolis, Media, Ardebil, and Derbane, rear annually a great number of valuable horses, but those bred in Kurdistan are accounted the best both in beauty and strength.

\section{THE CIRCASSIAN HORSE.}

The Circassian horse, although inferior to the Persian, does not often find his equal among the predatory hordes with which this part of Asia abounds. Vast numbers of horses and sheep are reared in the plains of Circassia, and they and the slaves which are made in their excursions, form the principal articles of the commerce of the natives. Almost every family of distinction aims at possessing a peculiar breed of horses, excelling, in their estimation, that of any other tribe. Each breed is distinguished by its peculiar mark, to forge or to place which on an inferior breed, would be punished with death. The most valuable breed of all is in the possession of the reigning family, and its distinguishing mark is a full horse-shoe. These horses possess considerable strength and speed.

\section{THE EAST INDIAN HORSE.}

We will now travel farther eastward, and examine the breeds of lorses in our Indian possessions. They are small, and, although some have considerable endurance and courage, they wear the general character of degeneracy from a nobler stock. First in value is the Toorky, originally from a Toorkoman and a Persian, beautiful in his form, graceful in his action, and docile in his temper. When skilfully managed his carriage is stately and grand. His spirit rising as his exerertions are required, he exhibits to his beholders an appearance of fury in the performance of his task, yet preserving to his rider the ntmost playfulness and gentleness. They are usually from fourteen to fifteen hands high, and have the common defect of the East India horse-smallness 
and length of bone below the knees and about the locks.

Next comes the Irance, well limbed, and his joints closely knit, and particularly powerful in the quarters, but with large head, and hanging ears, and deficiency of spirit.

The gentle and docile Cosakee is deep in the girth, powerful in the fore-am, but with large head and rat-hammed; hardy, and calculated for long journeys and severe service.

The Mojinniss have spirit, beauty, speed, and perseverance.

The Tazsec is slight, hollow-backed, and, for that reason Ferhaps, deficient in strength. His hind legs are ill placed, and dragged as it were lehind him, and he is stubborn and irritable; yet this horse is sought after on account of the peculiar easiness of his paces, a matter of no small consideration where the heat is so great and the slightest exertion fatiguing.

A sale of horses near the Company's stud, at $\mathrm{Hissar}$, is thus described by an excellent judge :"Not less than one thousand horses were shown. There were all above fourteen hands and a half in height, high-crested, and showy-looking animals. The great defect seemed a want of bone below the knee. which is general to all the native horses throughout India; and also so great a tendency to fulness in the hocks, that, in England, it would be thought half of them had blood spavins."

There are other studs in different parts of the country, in which some valuable stallions are kept for the purpose of improving the various Indian breeds. Almost all of them have a greater or lesser portion of Arabian blood in them, which gires them the appearance of good cavalry horses, but renters them inferior to the Arabians generally in swiftness and always in endurance. For this reason the native cavalry are principally mounted on Arabian horses, which are brought in great numbers, but of no considerable value, from Arabia and Syria.

It may be readily supposed that it was not long before races were established in the East Indies, and that they were properly patmonized by the goremment. They were, however, confined almost entirely to the Arabian horses, for those of half blood were manifestly inferior to them.

In 1828, Recruit, ly Whalebone, a horse of some celebrity at the tin e, was sent out to Calcutta. This was deemed a proper opportunity to decide the question of superiority between the pure Arab, and the true English racing bleod, and he was matched against Pyramus, the best Arabian in Bengal. The distance was two miles, with give and take weights, fourteen hands to carry nine stone, and the Arabian to be allowed seven pounds; Recruit carried ten stones twelve pounds, and Pyramus only eight stones three pounds. They started well tegether, and ran the first part of the distance neck and neck, but at about half the distance, Recruit took the lead, and the Arabian was beaten easily by several lengths. The distance was run in three minutes and fift $y$. seven seconds. Another trial took place between Champion, a first-rate Arabian, and Constance, a moderately good thorough-bred English horse. The Arabian won in a canter; the question, therefore, is thought by some persons to be yet undecided.

There is an East Indian pony, called the Tattoo, varying from ten to twelve hands in height. This is a serviceable and hardy animal for carrying baggage or any light weight. Tavernier describes one which he saw ridden by a young Mogul prince, of seven or eight years of age, and which was not much larger than a greyhound.

In 765 one, not more than seven hands, or twenty-eight inches in height, was sent from India, as a present to the queen of George III. It was taken from the ship to the palace in a hackneycoach. It was of a dun colour; and its hair resembled that of a young fawn. It was four years old, well proportioned, had fine ears, a quick eye, with a handsome long tail, and was thoroughly gocd-natured and manageable.

The Mahrattas were tro porrerful tribes or nations, inlabiting the central part of Hindoostan, and their territory extending from sea to sea, across the south of the Deccan. Their wars among themselves, or in union with the British against Tippoo Saib, and afterwards against their former protectors and allies, are prominent oljects in the modern history of India. Their troops consisted almost entirely of cavalry, composed of one of the hest varieties of the half-hlood Arabian and native horse. The Mahratta, when not on horseback, may be said to be almost constantly employed in shampooing his horse. It is properly so called, for he rubs him violently with bis wrists and elbows, as well as his hands, and moulds and bends his limbs in every direction. The IIahrattan way of riding is a singular and, according to European notions, a very ungraceful one. His knees are as high as his horse's back; he holds on with his heels, and clings with his hands either to the mane or the peak of the saddle. With such aids, his seat is more secure than at first sight it would appear to be. The peak of the saddle rises in the form of a crane's neck, and is said to have been borrowed from the Moguls. A crupper and a martingale are almost indispensable accompaniments of the Mahratta horse-furniture. It is a singular kind of crupper, howerer, not projecting from the centre of the saddle, lut attached to both sides. The tobsa, or leathern ressel out of which the horse eats his corn, is also attached to the 
crupper; and this part of the trappings is generally ornamented with silver knobs, or witl silk tassels or embroidery.

Their horses, like most of those in the East, are picketed, not only during the day, but very frequently in the night. A rope is carried from the headstall on each side to a peg driven into the ground. A rope, or thong, is also tied round the fetlocks behind, and carried backwards twenty or thirty feet, and fastened to a peg. This pulls the horse lack, and keeps him, when standing, on the stretch, but does not prevent him from lying down. When they are thus tethered, their eyes are covered, that they may not be alarmed by any object that passes. They are also clothed, in order that the beautiful, glossy appearance of their coat may be preserved.

They use the snaffle-bridle, but it is so jagged and pointed that the animal may be punished to the full content of any barbarian that may ride him. 'The headstall is usually ornamented, and from the rein a thong descends by which the horse may be occasionally reminded of his duty. The horseman has neither whip, switch, nor spur, but the horse is controlled, if he is disposed to rebel, by the cruel argument of the bit.

The breast of the Mahratta horse is more splendidly ornamented than any other part. $\mathrm{Nu}$ merous coins, of different size and value-rupees and double rupees-are formed into plates more or less highly ornamented, and which in time of war form a rich booty for the conqueror. The mane, too, is generally plaited with silk-braids, and silver knobs attached to them, with a beautiful top-knot between the ears. If the rider has distinguished himself in war, some curions tails, sail to be taken from the wild cow, dangle on either side.*

\section{THE BIRMAN AND CHINESE HORSE.}

The Birman horses are small, but spirited and strong. There is one at present (1842) in the menagerie belonging to the Zoological Society of London. It does not stand more than twelve hands high; but he is a beantiful little fellow, and a picture of strength.

In Siam the horses are few, and inferior to those of the Birman empire.

In Cochin-China, on the eastern coast of the peninsula, the horses are still small; but they are letter formed, and more active and strong, than they are in Siam. In Sumatra and Java the horses have not increased in size; but in form and usefulness they scarcely yield to any in the south-west of Asia. In Borneo they are few, and scarcely deserving of notice. The horses of China are, generally speaking, small, ill-formed, weak, and without spirit; indeed they have little occasion for the horse in the greater part of that immense empire.

\section{THE AUSTRALIAN HORSE.}

The new colonies of the British in Australia and its dependencies will present something more satisfactory. The greater part of the horses in New South Wales-the eastern coast of Australia, were derived from the Cape of Good Hope and from India. Very little judgment was employed in the selection, and indeed very few horses of good quality could have been procured from either place. The consequence was, that a writer so late as 1824 says of them, that "they are principally of the nag kind, and bred withont much care. They are not very sightly in appearance, being narrow-chested and sharp-backed, and sadly deficient in the quarters. They have an incurable habit of shying, and they are not very sure-footed." The New South Wales horses are seldom stabled; but are supposed to be healthier, and better able to endure fatigue, when kept in the open air. This, however, is probably only an excuse for neglect.

The sheep, however, prospering so well, and the cattle rapidly increasing and improving, the colonist began to be a little ashamed of his horses. Several of a better kind, cart and blood, were consequently imported from the mother-country an Arabian was procured from India-and the Australian horse soon began to be a very different sort of animal. A writer of a few years' later date says:- "We lave few thorough-bred carthorses, almost all of them having a spice of blood about then, which makes them unsteady at draught, restive, and given to jibbing when put to a hard pall." This was a very erroneous cliarge, and the writer seems to be aware of it, for he adds, "This may arise in a great measure from their being badly broken in." It was the faulty management and education of the horse, and not the portion of pure blood which he had acquired, that produced vices like these. The writer proceeds:- "We have many fine gig, carriage, and sadille horses, and even some that have pretensions to rank in the list of racers." In fact races were instituted at Sidney. A turf-chub was formed, and horses of no despicable qualities entered the lists.

An excellent stallion, named Bay Cameron, was imported from England, and the owner netted by him, for the first season or two, more than six hundred pounds per annum. Horses generally rose more than fifteen per cent. in value. Even at Sidney, two hundred pounds and more were given for a horse of extraordinary figure and powers; and no good saddle, gig, or cart horse could be purchased for less than forty pounds. 
These horses were found to be remarkably hardy, and could undergo considerable fatigue. The greatest fault was a heaviness of the head, with a considerable degree of obstinacy and sulkiness-as much, however, the fault of education as of natural disposition.*

A still later writer says, "that the lreed is rapidly improving, and particularly the draught horses, from the importation of some of the Cleveland breed from England." The true drayhorse, however, was yet to be found, and could not be procured from any of the native horses, not eveu with the assistance of the Cleveland. The mixture of English blood had not lessened the endurance of the native breed; for at the hottest time of the year, with the thermometer at times as high as ninety-six degrees in the shade, the writer says that he has ridden the same animal fifty miles a day for three successive days. They will all go through a vast deal of work, but they would have more endurance, if they were not broken in for the saddle and for harness so young. It is no unusual thing to ride them sixty miles in less than seven hours, and immediately turn them out, to pick up what seanty herbage they can find. The number of good horses was so rapidly increased that their price had materially diminished, and scarcely more than thirty-five pounds could be got for the best of them.

The traveller adds, that there are some diseases to which the horse is subject in England, which are as yet unknown in New South Wales. Glanders has never made its appearance there. Greasy heels, the almost peculiar disease of Britain, have not been seen there. Strangles, however, are prevalent, and, the author of the present work learns from another source, unusually severe. ${ }^{+}$

In Van Dieman's Land the breed of horses, originally derived from India, is very good. A valuable breed of cart-horses is beginning to be formed. The riding-horses are small, but they are hardy. Horses of every kind are sixty per cent. dearer in Van Diemen's Land than in New South Wales; because the colony is smaller, and the number of horses that are bred is comparatively small. Their treatment is not so good as in the larger colony. Many of them know not the taste of corn, and, when it is given to them, it is usually in the straw.

Returning again to the continent of Asia, there is nothing in China to detain us; for through the whole of the southeru part of that immense empire the horses are small, weak, without spirit, and altogether undeserving of notice.

* Two Years in New Suuth Wales, by P. Cunningham, vol. i. p. 296 .

+ Breton's Excursions in New South Wales, in 1833, p. 330.

$\$$ Ibid. p. 332 .

1) Widowsun's State of Van Diemen's Land in 1829, p. 184.
THE TARTARIAN HORSE.

Tartary comprehends a vast extent of country, reaching from the Eastern Ocean to the European dominions of Russia, through the central part of Asia and Europe. Eastern Tartary belongs chiefly to China-the Western has been subjected by Russia, but a small portion of it about the Caspian Sea claims to be independent. The tribes which inhabit this immense space are dissimilar in their appearance, and manners, and customs ; but, with a few exceptions, the character of the horse is nearly the same.

The wild horse is found in various parts of Tartary; but nowhere can it be considered as the remnant of an original race that has never beeu domesticated. The horses of the Ukraine, and those of South America, are equally the descendants of those that had escaped from the slavery of man. The origin of the horses of Tartary has been clearly traced to those that were employed in the siege of Azof, in 1657. Being suffered, from want of forage, to penetrate into the desert in order to find subsistence, they strayed to too great a distance to be pursued or recalled, and became wild and created a new breed. They are generally of a red colour, with a black stripe along the back. They are divided into numerous herds, at the head of each of which is an old stallion, who has fought his way to the crown, and whose preeminence is acknowledged by the rest. On the approach of apparent danger, the mares and their foals are driven into a close body, in front of which the males are ranged. There are frequent contests between the different herds. The domesticated horse, if he falls in their way umprotected by his master, is instantly attacked, and speedily destroyed; but at the sight of a human being, and especially mounted, they all take to flight, and gallop into the recesses of the desert. The young stallions as they grow up are driven from the herd, and are seen straggling about at a distance, until they are strong enough to form herds of wild mares for themselves.

The Cossacks are accustomed to hunt the wild horses, partly to keep up their own stock, and partly for food. A species of vulture is sometimes made use of in this affair. The bird pounces upon the poor animal, and fastens itself on his head or neck, fluttering his wings, and perplexing, and half-blinding him, so that he becomes an easy prey to the Tartar. The young horses are generally tamed withont much difficulty; they are, after a little while, coupled with a tame horse, and grow gentle and obedient. The wild horses thus reclaimed are usually found to be stronger and more serviceable than any which can be bred at home.

In the great deserts of Tartary, the herds of wild horses are much larger. Many thousands, as on the Pampas of South Ameriea, are often col- 
lected together. The Kirghise Tartars either capture them for use, or spear them for food.

The flesh of the horse is a frequent article of food among the Tartars; and although they do not, like the Indians of the Pampas, eat it raw, their mode of cookery would not be very inviting to the European epicure. They cut the unscular parts into slices, and place them under their saddles, and after they have galloped thirty or forty miles, the meat becomes teuder and sodden, and fit for their table. At all their feasts, the first and last, and most favourite dish, is a horse's head, unless they have a roasted foal, which is the greatest delicacy that can be procured.

When water was not at hand, the Scythians used to draw blood from their horses, and drink it; and the Dukes of Muscovy, for nearly two hundred and sixty years, presented the Tartar ambassadors with the milk of mares.*

Some of the Tartar and Kalmuck women ride fully as well as the men. When a courtship is taking place between two of the joung ones, the answer of the lady is thus obtained. She is mounted on one of the lest horses, and off she gallops at full speed. Her lover pursues, and if he overtake her, she becomes his wife; but it is seldom or never that a Kalmuck girl once on lorseback is caught, unless she has a partiality for her pursuer. $t$

The domesticated horses belonging to the Tartars that wander over the immeuse plains of Central Asia are little removed from a wild state. They are small and badly made, but capable of supporting the longest and most rapid journeys on the scantiest fare.

One well-known circumstance will go far to account for their general hardiness. The Tartars live much on the flesh of horses; and the animals that are nuable to support the labour of their frequent and rapid emigrations are first destroyed; the most vigorous are alone preserved.

Berenger gives the following account of the Tartar horses:- "Although but of a moderate size, they are strong, nervous, proud, full of spirit, bold, and active. They have good feet, but some-

* Most of the Tartars manufacture a liquor called koumiss, from the milk of the mare. It has a very pleasant taste of mingled sweet and sour, and is considerably outritions. The Tartars say that it is an excellent medicine, and almost a specific in cunsumption, and sume diseases of debility. It is thus made:-To a certain quantity of fresh mare's milk, a sixth part of water, and an eighth part of very sour milk, or of old koumiss, is added. The vessel is covered with a thick cloth, and set in a place of moderate warmth, It is thus left at rest twentr-four hours, when the whole of it will bave become sour, and a thick sulustance will have gathered on the top. The whole is then heaten with a stick, in the form of a chum-staff, until it becomes blended into one homogeneous mass. Tweoty-fuur hours after this the beatiog is repeated, or the liquur is agitated in a churn, until the whole is again mingled together. The process is now cumplete, and the koumiss is formed; but it must be always well shaken before it is used.-Transuctions of the Royal Society of Edinburgh, vol, i. p. 181.

The Tartars have discovcred a method of ohtaining an ardent what narrow ; their heads are well-shaped and lean, but too small; the forehead long and stiff; and the legs over long: yet with all these imperfections they are good aud serviceable horses, being unconquerable by labour, and endowed with consisiderable speed. The Tartars live with them almost in the same manner that the Arabs do with their horses. When they are six or eight months old, they make their children ride them, who exercise them in small excursions, dressing and forming them by degrees, and bringing them into gentle and early discipline, and, after a while, making them undergo hunger and thirst, and many other hardships. The men, however, do not ride them until they are five or six years old, when they exact from them the severest service, and enure them to almost incredible fatigue, travelling two or three days almost withont resting, and passing four or five days with no more or better nourishment than a handful of grass, and with nothing to queuch their thirst." + This discipline as much exceeds that of the Arabs in severity and horrible barbarity, as the Arabs excel the Tartars in civilisation.

The horses of the Nogais Tartars are some of the luest of the roving tribes. They are stronger and taller than the others; and some of them are trained to draw carriages. It is from them that the Khan of Tartary derives the principal part of his supplies. It is said that in case of uecessity they could furnish a hundred thousand men. Each of the Nogais commonly has with him four horses; one is for his own riding; a second to mount if the first shonld be tired; and the other two to carry his provisions, his slaves, and his booty.

\section{THE TOORKOMAN HORSE.}

Turkistan is that part of South Tartary, northeast of the Caspian Sea, and has been celebrated from very early times for producing a pure and valuable breed of horses. They are called Toorkomans. They are said to be preferable eren to the pure Persians, for actual service. They are large, from fifteen to sixteen hands high, swift, and inexhaustible under fatigue. Some of them have

spirit frum this koumiss, which they eall rack, or racky, frum the name given to the spirit manufactured in the East Indies.

Dr. Clarke saw the process of the manufarture:- "The still was compused of mud, or very close clay. For the neck of the retort a cane was used; and the receiver was entirely covered by a coating of wet clay. The brandy had just passed over. The women who had the management of the distillery, wishing to give us a taste of the spirit, thrust a stick with a small tuft of camel's hair into the receiver, dropped a purtion of it on the retort, and waring the instrumcnt ahove her head, scattered the remaining liquor in the air. I asked the meaning of this cerennny, and was answered that it was a religious custom to give always the tint of the brandy which they drew fron the receirer to their god. The stick was then plunged into the liquor a second time, when more brandy adhering to the camel's bair, she squcezed it into the palm of ber dirty haod, and having tasted the liquor, presented it tu our lips."-Clarke's Trarels in Russia, p. 239.

+ Clarke's Travels in Russia, p. 333.

† Berenger ou Horsemanship, vol. i. p 135. 
travelled nine hundred miles in eleven successive days. They are, however, somewhat too small in the barrel,-too long on the legs,-occasionally ewe-necked, and always having a head out of proportion large: yet such are the good qualities of the horse, that one of the pure blood is worth two or three hundred pounds, even in that country.

Captain Fraser, who is evidently a good judge of the horse, thus relates the impression which they made on him, in his "Journey to Khorasan :" - "They are deficient in compactness. Their bodies are long in proportion to their bulk. They are not well-ribbed up. They are long on the legs, - deficient in muscle,-falling off below the knee; narrow-chested,-long-necked,- - head large, uncouth, and seldom well put on. Such was the impression I received from the first sight of them, and it was not for some time that their superior valuable qualities were apparent to me."

The Toorkomans trace their breed of horses to Arabian sires; and, most anxious that a suficient proportion of the pure blood shall be retained, they have frequent recourse to the best Arabians they can procure.

Before a Toorkoman starts on an expedition, he provides limself with a few hard balls of barleymeal, which are to serve both him and his horse for subsisteuce until his return; but sometimes when, crossing the desert, he is unusually faint and weary, he opens the jugular vein of his horse, and drinks a little of the blood, by which he is undoubtedly refreshed, and he thinks his horse is relieved. According to Sir John Malcolm, the Toorkoman will think little of pushing the same horse one hundred miles a day for some successive days; and, he adds, that a horseman mounted on a Toorkoman horse brought a packet of letters from Shiraz to Teheran, a distance of five hundred miles, in six days.

\section{THE TURKISH HORSE.}

The Turkish horses are descended principally from the Arab, crossed by the Persian and other kindred varieties. They possess all the gentleness and tractability of the parent race, but they have lost some of their vigour and speed. They have contributed materially to the improvement of the English breed. The Byerley and the Helmsley Turk are names familiar to every one conversant with horses, aud connected with our best blood.

The learned aud benevolent Busbequins, who was ambassador at Constantimople in the seventeenth century, gives the following account of the Turkish horses. Our grooms, and their masters too, may learn a lesson of wisdom and humanity from his words.

"There is no creature so gentle as a Turkish horse, nor more respectful to his master, or the groom that dresses him. The reason is, because they treat their horses with great lenity. I myself saw, when I was in Pontus, passing through a part of Bithynia called Axilos, towards Cappadocia, how indulgent the countrymen were to young colts, and how kindly they used them soon after they were foaled. They would stroke them, bring them into their houses, and almost to their tables, aud use them even like children. They hung something like a jewel about their necks, and a garter which was full of amulets against poison, which they are most afraid of. The grooms that dress them are as indulgent as their masters; they frequently sleek them down with their hands, and never use a cudgel to bang their sides, but in cases of necessity. This makes their horses great lovers of mankind; and they are so far from kicking, wincing, or growing untractable by this gentle usage, that you will hardly find an ill-tempered horse amongst them.

“But, alas! our Christian grooms' horses go on at another rate. They never think them rightly curried till they tbunder at them with their voices, and let their clubs or horse-whips, as it were, dwell on their sides. This makes some horses even tremble when their keepers come into their stable; so that they hate and fear them too. But the Turks love to have their horses so gentle, that at the word of command they may fall on their knees, and in this position receive their riders.

"They will take up a staff or club upon the road with their teeth, which their rider has let fall, and hold it up to him again; and when they are perfect in this lesson, then, as a reward, they hare rings of silver hung on their nostrils as a badge of honour and good discipline. I saw some horses when their master was fallen from the saddle stand stock still without wagging a foot till he got up again. Another time I saw a groom standing at a distance in the midst of a whole ring of horses, and at the word of command, they would either go round or stand still. Once I saw some horses, when their master was at dinner with me in an upper room, prick up their ears to hear his voice, and when they did so they neighed for joy."

\section{THE AMERICAN HORSES.}

Before we can advance eastward into Europe, it will be convenient to dispose of the horses of the American continents. In South America, although constant warfare is carried on against them, there are innumerable herds of wild horses; and in the back settlements of the south-western states of North America, there is a horse resembling the wild horse of the Pampas; but both are evidently the descendants of those who have escaped from the slavery of man.

THE WILD HORSE OF SOUTH AMERICA.

All travellers who have crossed the plains extending from the shores of La Plata to Patagonia 
have spoken of numerous droves of wild horses. Some affirm that they have seen ten thousand in one troop. They appear to be under the command of a leader, the strongest and boldest of the herd, and whom they implicitly obey. A secret instinct teaches them that their safety consists in their union, and in a principle of subordination. The lion, the tiger, and the leopard* are their principal enemies. At some signal, intelligible to them all, they either close into a dense mass and trample their enemy to death, or, placing the mares and foals in the centre, they form themselves into a circle and welcome him with their heels. In the attack, their leader is the first to face the danger, and when prudence demands a retreat, they follow his rapid flight.

In the thinly-inhabited parts of South America it is dangerous to fall in with any of these troops. The wild horses approach as near as they dare: they call to the loaded horse with the greatest eageruess, and if the rider is not on the alert, and has not considerable strength of arm and sharpness of spur, his beast will divest himself of his burden, take to his heels, and be gone for ever. Byron beautifully describes this in his Mazeppa:-

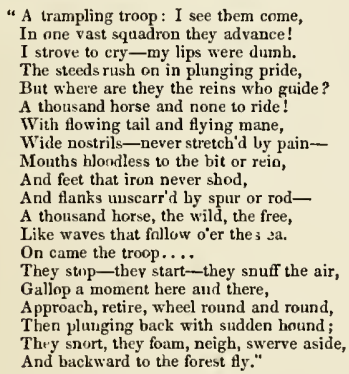

Captain Head gives the following account of a meeting with a troop of wild horses, where the country is more thickly inhabited. Some poor captured animals are supposed to be forced along by their riders at their very utmost speed:- "As they are thus galloping along, urged by the spur, it is interesting to see the groups of wild horses one passes. The mares, which are never ridden in South America, seem not to understand what makes the poor horse carry his head so low and look so weary. $t$ The little imnocent colts come running to meet lim, and then start away fright-

* These animals are of a different race from those which go under the same naines in the Old World, and are very inferior in strength,

+ An Englishman once attempted to ride a mare, hut he was hooted and pelted by the natives, and thought himself fortunate to escape withont scrious injury.-Sir J. Carr, in his Northern Summer, p. 44, states that it is only a shout time since mares began to be ridden in Russia. ened; while the old horses; whose white marks on their flanks and backs betray their acquaintance with the spur and saddle, walk slowly away for some distance, then breaking into a trot as they seek their safety, snort and look behind them, first with one eye and then with the other, turning their noses from right to left, and carrying their long tails high in the air." +

The same pleasing writer describes the system of horse-management among the rude inhabitants of the plains of South America. They have no stables, no fenced pastures. One horse is usually kept tied at the door of the hut, fed scautily at night on maize; or at other times several may be inclosed in the corral, which is a circular space surrounded by rongh posts, driven firmly into the ground. The mares are never ridden, or attempted to be tamed, but wander with their foals wherever they please.

When the Gaucho, the native inhalitant of the plains, wants horses for himself or for the supply of the traveller, he either goes with his lasso to the corral, and selects those possibly who on the preceding day had for the first time been backed, or he scampers across the plain, and presently returns with an unwilling, struggling, or subdued captive. When the services of the animals have been exacted, he either takes them to the corral and feeds them with a small quantity of maize, if he thinks he shall presently need them again, or he once more turns them loose on the plains.

Travellers give some amusing accounts of the manner in which all this is effected. Miers $\|$ thus describes the lasso, simple in its construction, but all-powerful in the hands of the Gaucho:-

"The lasso is a missile weapon nsed by every native of the United Provinces and Chili. It is a very strong plaited thong of equal thickness, half an inch in diameter and forty feet long, made of many strips of green hide plaited like a whipthong, and rendered supple by grease. It has at one end an iron ring, above an inch and a half in diameter, through which the thong is passed, and this forms a rumning-noose. The Gancho, or native of Peon, is generally mounted on horseback when he uses the lasso. One end of the thong is affixed to his saddle-girth: the remainder he coils carefully in his left hand, leaving abont twelve feet belonging to the noose-end in a coil, and a half of which he holds in his right hand. He then swings this long noose horizontally round his head, the weight of the iron ring at the end of the noose assisting in giving to it, by a continued circular motion, a sufficient force to project it the whole length of the line."

When the Ganchos wish to have a grand breaking-in, they drive a whole herd of wild horses

* Hcad's Journey across the Pampas, p. 258.

1 Miers' Travels in Chile, vol. i. p. 88 . 
into the corral :- " The corral was quite full of horses, most of which were young ones abont two or three years old. The capitar (chief Gancho), mounted on a strong steady horse, rode into the corral, and threw his lasso over the neck of a young horse, and dragged him to the gate. For some time he was very unwilling to lose his comrades ; but the moment he was forced out of the corral, his first idea was to gallop away: however a timely jerk of the lasso checked him in the most effectual way. The peons now ran after him on foot, and threw a lasso over his fore-legs just above the fetlock, and twitching it, they pulled his legs from under him so suddenly, that I really thought the fall he got had killed him. In an instant a Gancho was seated on his head, and with his long knife, in a few seconds, cut off the whole of the horse's main, while another cut the hair from the end of his tail : this, they told me, was a mark that the horse had been once mounted. They then put a piece of hide into his mouth to serve for a bit, and a strong hide halter on his head. The Gaucho who was to mount arranged his spurs, which were unusually long and sharp,* and while tro men held the horse by his ears, he put on the saddle, which he girthed extremely tight. He then caught hold of the horse's ear, and in an instant vanlted into the saddle; upon which the man who held the horse by the halter threw the end to the rider, and from that moment no one seemed to take further notice of him.

"The horse instantly hegan to jump in a manner which made it very difficult for the rider to keep his seat, and quite different from the kick or plunge of an English horse: however, the Gaucho's spurs soon set him going, and off he galloped, doing everything in his power to throw his rider.

"Another horse was immediately brought from the corral; and so quick was the operation, that twelve Gauchos were mounted in a space which I think hardly exceeded an hour. It was wonderful to see the different manner in which different horses behaved. Some would actnally scream while the Gauchos were girding the saddle upon their hacks; some would instantly lie down and roll upon it; while some would stand without being held, their legs stiff and in unnatural positions, their necks half bent towards their tails, and looking vicious and obstinate: and I conld

* The manufacture of the Ganeho's boots is somewhat singular :- "The boots of the Gauchos are formed of the ham and part of the leg-skin of a colt taken reeking from the mother, which is said to be sacrificed for the sole purpose, just at the time of bearing, when the hair has not begun to grow. At this stage the skin strips off easily, and is very white and beautiful in texture and appearance. The ham forms the calf of the boot; the hock easily adapts itself to the heel; and the leg above the fetlock constitntes the foot; the whole making a neat and elegant half bnot, with an aperture sufficient for the great toe to project through."Andrew's Journey in South America, vol. i. p. 26. not help thinking that I would not have mounted one of those for any reward that could be offered me, for they were invariably the most difficult to subdue.

"It was now curious to look around and see the Ganchos on the horizon in different directions, trying to bring their horses back to the corral, which is the most difficult part of their work, for the poor creatures had been so scared there that they were unwilling to return to the place. It was amusing to see the antics of the horses; they were jnmping and dancing in different ways, while the right arm of the Ganchos was seen flogging them. At last they bronght the horses back, apparently subdned and broken in. The saddles and bridles were taken off, and the young horses trotted off towards the corral, neighing to one another." +

When the Gancho wishes to take a wild horse, he mounts one that has been used to the sport, and gallops over the plain. As soon as he comes sufficiently near his prey, "the lasso is thrown round the two hind legs, and as the Gancho rides a little on one side, the jerk pulls the entangled horse's feet laterally, so as to throw him on his side, without endangering his knees or his face. Before the horse can recover the shock, the rider dismounts, and snatching his poncho or cloak from his shoulders, wraps it round the prostrate animal's head. He then forces into his month one of the powerful bridles of the country, straps a saddle on his back, and hestriding him, removes the poncho; upon which the astonished horse springs on his legs, and endeavours by a thousand vain efforts to disencumber himself of his new master, who sits quite composedly on his back, and, by a discipline which never fails, reduces the horse to snch complete obedience, that he is soon trained to lend his whole speed and strength to the capture of his companions." +

These animals possess much of the form of the Spanish horse, from which they sprang; they are tamed, as has been seen, with far less difficulty than could be thought possible; and although theirs is the obedience of fear, and enforced at first by the whip and spur, there are no horses who so soon and so perfectly exert their sagacity and their power in the service of man. They are possessed of no extraordinary speed, but they are capable of enduring immense fatigue. They are frequently ridden sixty or seventy miles withont drawing bit, and have been nrged on

+ Head's Journey across the Pampas, p. 258.

* Basil Hall's Journey to Peru and Mexico, vol. i. p. 151. The Jesnit Dobrizhoffer, in his bistory of the Abipones, a nation of Paraguay, and speaking of the tamed horse (vol. ii. p. 113), says, that "Stirrups are not in general use. The men leap on their backs without assistance." 
by the cruel spur of the Gaucho more than a hundred miles, and at the rate of twelve miles in the hour.

Like the Arab horses, they know no intermediate pace between the walk and the gallop. Although at the end of a day so hard, their sides are horribly mangled, and they completely exhausted, there is this consolation for them,they are immediately turned loose on the plains, and it will be their own fault if they are speedily caught again. The mare is occasionally killed for food, and especially on occasions of unusual festivity. General San Martin, during the war for independence, gave a feast to the Indian allies attached to his army iu which mares' flesh, and the blood mixed with gin, formed the whole of the entertainment.

On such diy and sultry flains the supply of water is often scanty, and then a species of madness seizes on the horses, and their generous and docile qualities are no longer recognised. They rush violently into every pond and lake, savagely mangling and trampling upon one another; and the carcasses of many thousands of them, destroved by their fellows, have occasionally been seen in and around a considerable pool. That is one of the means by which the too rapid increase of this quadruped is, by the ordinance of nature, there prevented. Humboldt says that during the periodical swellings of the large rivers, immense numbers of wild horses are drowned, particularly when the river Apure is swollen, and these animals are attempting to reach the rising grounds of the Llanos. The mares may be seen, during the season of high water, swimming about followed by their colts, and feeding on the tall grass, of which the tops alone wave above the waters. In this state they are pursued by crocodiles, and their thighs frequently bear the Irints of the teeth of these carnivorous reptiles. They lead for a time an amphibious life, surrounded by crocodiles, waterserpents, and marsetees. When the rivers return again into their beds, they roam in the sarannah, which is then spread over with a fine odoriferous grass, and seem to enjoy the renewed regetation of spring. *

Numerous herds of wild horses abound in the west of Louisiana, and of all colours. They are, like those on the Pampas, the remains of the Spanish horses, and are luunted, caught, and sometimes destroyed for food, by the savage inhabitants of the back settlements.

Mr. Lnw, in his beautiful delineations of the British quadrupeds, gives the following account of the horses of North America :-

"North America seems as well adapted to the

* Humboldt's Pers, Nar. vol. iv. p. 394.-Lyell's Geology. temperament of the horse as any similar countries in the old continent. The Mexican horses are derived from, but somewhat deteriorated by, a less careful management. Mexican horses have likewise escaped into the woods and savannahs, and although they have not multiplied, as in the plains of the Plata, thence they have descenled northward to the Rocky Mountains, and the sources of the Columbia. The Iudians of the country have learued to pursue and capture them, employing them in liunting, and transporting their families from place to place-the first great change that has taken place for ages in the condition of the Red Man of the North American woods. The highest ambition of the young Indian of these northern tribes, is to possess a good horse for the chase of the buffalo. The Osages form large hunting-parties, for the chase of horses in the coun. try of the Red Canadian River, using relays of fresh horses, until they have run down the wild herds. To steal the horse of an adverse tribe, is considered as an exploit almost as heroic as the killing of an enemy, and the distances that they will travel and the privations they will undergo in these predatory excursions are scarcely to be believed."

The Anglo-Americans, the Canadians, and the colonists of the West India Islands, have all acquired the domesticated horse. The Canadian is found principally in Canada, and the northern States. He is supposed to be of French descent, and many of the celebrated trotters are of this breed. Miention will be made of some of these when the paces of the horse are described.

These horses are much used for winter travel ling in Canada, and in the northern States. One of them has drawn a light cabriolet over the ice ninety miles in twelve hours. Their shoes are roughened by the insertion of two or three steel screws, instead of the common European method. The curry-comb is never used upon them in the winter, for a thick fur has grown over them to protest them from the inclemency of the season. They are animals never refusing the collar, yet they are accustomed to bad usage. Those of the United States are of every variety, bnt crossed by the modern English race, or the Arab. The improvement of the horse, at this time, occupies much of their attention. Horse-races are estahlished in many places, and particularly in the southern States; and they have adopted, to a very considerable degree, the usages of the English turf. They have different varieties of useful horses for riding, and for their public and private carriages. Habit, arising from some cause or whim now not known, has made them partial to the trotting horse; and the fastest trotting horses in the world are to be found in the United States, The breeds of the West India Islands 
are those of the parent states.' "The horses of Cuba are derived from Spain, and retain the distinctive characters of the parent stock; and those of the English colonies have been improved by continued intercourse with the mother country.

A much valued correspondent, Mr. Rotch, of Louisville, in the State of New York, thus addresses the author:- "From my own personal experience, I should say that all our stock in America seems to possess a hardier constitution and are much less liable to disease than in England; aud that animals, but a few generations removed from those actually imported, acquire much stronger constitutions than their ancestors, and it has been a question : with me, and acceded to by the late Rev. H. Berry, whether importations of some of our pure-bred auimals might not sometimes be made into your country with advantage. I am sure that our hacks and roadsters will endure a great deal more fatigue and hardship than the same description of horse in England. I speak with confidence in these matters, because I have been a breeder in both comntries."

That the greater hardship and labour to which the American horse of this description is exposed would produce a greater development of animal power, there can be no doubt, and a cross from the best of such a breed could not fail of being advantageous; but we must adopt and perpetuate the circumstances that produced this superior power, or we should not long retain the advantage of the cross.

Iu the extensive territory and varied climate of the United States several breeds of horses are found.

The Conestoga horse is found in Pennsylvania and the middle states; long in the leg and light in the carcass; sometimes rising seventeen hands; used principally for the carriage; but, when not too high, and with sufficient substance, useful for hunting and the saddle.

The English horse, with a good deal of blood, prevails in Virginia and Kentucky, and is found to a greater or less degree in all the States. The Americans have at different times imported some of the best English blood. It has been most diligently and purely preserved in the southern States. The celebrated Shark, the best horse of his day, and equalled by few at any time, was the sire of the best Virginian horses; and Tallyho, a son of Highflyer, peopled the Jerseys.

\section{THE MODERN EUROPEAN HORSES.}

The limits of our work compel us to be exceedingly" brief in our account of the breeds of the different countries of Europe. We start from the south-west of this quarter of the world.

\section{THE SPANISH HO RSE.}

The Spanish horses, for many a century, ranked next to those of Barbary and Arabia. They descended from the Barbs, or rather theywere the Barbs transplanted to a European soil, and somewhat altered, but not materially injured by the change. Solleysel, the parfait mareschal, gives an eloquent description of them :- "I have seen many Spanish horses; they are extremely beautiful, and the most proper of all to be drawn by a curious pencil, or to be mounted by a king, when he intends to show himself in his majestic glory to the people."

The common breed of Spanish horses have nothing extraordinary about them. The legs and feet are good, but the head is rather large, the forehand heavy, and yet the posterior part of the chest deficient, the crupper also having too much the appearance of a mule. The horses of Estremadura and Granada, and particularly of Andalusia, are most valued. Berenger, whose judgment can be fully depended on, thus enumerates their excellences and defects:-"The neck is long and arched, perhaps somewhat thick, but clothed with a full and Howing mane; the head may be a little too coarse; the ears long, but well placed; the eyes large, bold, and full of fire. Their carriage lofty, proud, and noble. The breast large; the shoulders sometimes thick; the belly frequently too full, and swelling; and the loin a little too low; but the ribs round, and the croup round and full, and the legs well formed and clear of hair, and the siners at a distance from the bone-active and ready in their pacesof quick apprehension; a memory singularly faithful ; obedient to the utmost proof ; docile and affectionate to man, yet full of spirit and courage."* The Parfait Mareschal shall take up the story again :- "There will not be found any kind of horse more noble than they, and of their courage! why I have seen their entrails hanging from them, through the number of wounds that they have received; yet they have carried off their rider safe and sound with the same pride with which they brought him to the field, and after that they have died, having less life than courage." + It is delightful to read accounts like these, and we know not which to admire most, the noble horse or the man who could so well appreciate his excellence.

The modern Spanish horses are fed upon chopped straw and a little barley. When the French and English cavalry were there, during the Peninsular war, and were without preparation put upon this mode of living, so different from that to which they had been accustomed, they

- Berenger's Horsemanship, p. 151.

+ Solleysel's Compleat Horseman, part i. p. 211. 
began to be much debilitated, and a considerable mortality broke out among them; but, after a while, they who were left regained their strength and spirits, aud the mortality entirely ceased.*

\section{THE PORTUGUESE HORSE.}

There was a time when the Lusitanian or Portuguese horses were highly celebrated. The Roman historian Justin compares their swiftness to that of the winds, and adds, that many of them might be said to be born of the rinds; while, on the other hand, Berenger, who lived at a time when the glory of the Spanisl horse had not quite faded away, says, that "the Portugal horses are in no repute, and differ as much from their neigbbours, the Spaniards, as crabs from apples, or sloes from grapes." $\dagger \mathrm{He}$ thus accounts for it. When Portugal was annexed to Spain, the latter country was preferred for the establishment of the studs for breeding, and the few districts in Portugal which were sufficiently supplied with herbage and water to fit them for a breeding country were devoted to the rearing of horned eattle for the shambles and the plough, and mules and asses for draught. Hence, the natives regarded the horse as connected more with pomp and pleasure than with utility, and drew the comparatively few horses that they wanted from Spain. The present government, however, seems disposed to effect a reform in this, and there are still a sufficient number of Andalusian horses in Portugal, and Barbs in Africa, fully to accomplish the purpose.

\section{THE FRENCH HORSE.}

According to the survey of 1829 , France contained 2,400,000 horses, iucluding those of every description. The number of mares was $1,227,78 \mathbf{i}$. The greater part of these were employed in the breeding of mules, and perhaps not more than a fourth part were used for keepiug up the number of horses. Besides these, nearly 27,000 horses are annually imported into France, either on speculation of immediate sale, or for the express purpose of improving the breed.

Two-thirds of the French horses are devoted to purposes of light work, and possess a certain degree, and that gradually increasing, of Eastern blood. There is room, however, for a great deal more than the French horse usually possesses. One-third of the horses are employed in heavy work; 70,000 in post work, and about the same number are registered as fit for military use, a]though not more than half of them are on actual service. The ascertained number of deaths is about one in twelve or thirteen, or leaving the average age of the horse at twelve. This speaks strongly in favour of the humanity of the French,

* Recueil de Mét., Cet., I83\%, p. 80.

+ Berenger, p. 153 . or the hardihood of the horses, for it exceeds the average duration of the life of the horse in England by more than two years. Calculating the average value of the French horse at 400 francs, or $16 l .13 s .4 d$., there results a sum of $960,000,000$ francs, or $40,000,000$ pounds sterling, as the gross value of this species of national property.+

It must be supposed that so extensive a country as France possesses various breeds of horses. Auvergne and Poitou produce good ponies and galloways; but the best French horses are bred in Limousin and Normandy. From the former district come excellent saddle-horses and hunters, and from the latter a stronger species for the road, the cavalry service, and the carriage.

M. Hoilel has recently published an interesting work on the varieties of the horse in France. He states that in the time of the Romans there were but two kinds of horses, - the war-horse, and the sumpter or pack-horse. The carriage, or draught-horse, was comparatively or quite unknown: and even men of the highest station suffered themselves to be indolently drawn by oxen. Great care was taken to preserve or to renew the strength and speed of the war-horse, and African or Arab blood was diligently sought. An animal, the type of the English Cleveland breed, the handsomest and strongest description of the coachhorse, was thus procured. By degrees, this horse was found too valuable for a hackney, and too high-trotting for a long journey, and a more smoothly moving animal was gradually introduced. Still the charger did not grow quite out of fashion, and in Normandy the rearing of this animal be. came an object of much attention to the farmer. At first they were bred too slow and ponderous, but by degrees a horse was obtained of somewhat lighter action and considerable speed, without much sacrifice of strength, and they now constitute a most valuable breed. "I have not elsewhere," says M. Hoüel, "seen such horses at the collar, under the diligence, or the post-carriage, or the farm-cart. They are enduring and energetic beyond description. At the voice of the brutal driver, or at the dreaded sound of his never-ceasing whip, they put forth all their strength; and they keep their condition when other horses would die of neglect and hard treatment" The little Norman cart-liorse is, perhaps, the best for farm-rork. The Norman horsesand the same observation applies to all the northern provinces of France-are very gentle and decile. A kicking or vicious one is almost unknown there; but they are, with few exceptions, treated with tyranny and cruelty from first to last. The reign of telror may to a certain degree be necessary where there are many perfect horses; but the principle of cruelty should not * Jourual des Haras, Marcl, 1837. 
extend, as it too often does, to the treatment of every lind of horse.

Something must be attributed to both causes. There is more humanity among the French than the English pensantry; but, on the other hand, there are horrible scenes of cruelty to the horse hourly taking place in the streets of Paris. that would not be tolerated for a moment in the British metropolis.

The breeding of horses has more decidedly become a branch of agricultural attention and speculation than it used to be; for it has been proved to the farmer that, with the proper kind of pasture, and within a fair distance of a proper market, instead of lieing one of the most uncertuin and unprofitalie modes of using the land, it yields more than an average returu.

The establishment of races in almost every part of France has given a spirit to the breeding and im. provement of the borse which cannut fitil of being exceedingly heneficial throughout the whole of the French empire. In fact, it may be stated, without exaggeration, that the rapid improvement which is taking place is attributable principally to this cause. In order to effect the desired improvement, the French, and with much judgment, have had recourse to the English thorough-bred holse far more than to the native Arabian. A great many of the best English stallions lave been purchased for the French studs, and hase been beneficially employed in improving, and often creating, the hunter, the racer, aud almost all of the better class of horses used for purposes of luxury.

It has been stated that the most valuable native horses are those of Normandy; perhaps they have been improved by the Enghish hunter, and occasionally by the English thorough-bred horse; and on the other hand, the English roadster, and the light dranght horse, has derived considerable advantage from a mixture with the Norman, not only in early times when William the Conqueror was so eager to improve the horses of his new suljects liy means of those of Norman blood, lut at many succeediug periods.

A certain numlier of Normandy horses used to be purchased every year by the Freuch government fur the use of the other departments. This led occasionally to considerable trickery and evil. None of the Norman horses were castrated inti] they were three, or sometimes four years old; and then it frequently happened that horses of superior appearance, but with no pure blood in them, were sold as belonging to the improved breed; and it was only in their offspring that the cheat could be discovered. The govermment now purchases the greater part of the Normandy horses in their first year, and brings them up in the puhlic studs. They cost more money, it is true; but they are better bred, and hecome finer animals. There is no deception with regard to these horses, and the amelioration of the other breeds is secured.

Every country that has occupied itself with the amelioration of its breed of horses, has deemed it necessary to have a public register of the names and progeny of those of an acknowledged race England has had its stud-book nearly half a century, containing a list of all the horses of pure blood that have existed in the country. France, in the year 183\%, had her first stud-book, in which are inscribed the names of 215 stallions, of pure English blood, imported into France or holn there; 266 Arabs, Barbs, Persian, or Turkish horses; 274 English mares of true blood, and 41 Eastern mares. Their progeny is also traced, so far as it was practicable. This work will form an epoch in the equestrian annals of that country.

\section{THE SARDINIAN AND CORSICAN HORSES.}

They are small, well-made, and capable of enduring much fatigue; as for their other qualities (and they are not much changed at the present day from what they formerly were), Blundeville shall speak of them:- "The horses that come out of the Isle of Sardygnia and Corsica have short bodyes and be rerye bolde and conrageous, and unquiet in their pace, for they be of so fierce and hote cholericke complexion, and therewith so much used to running in their coun. trie as they rill stand still on no grounde. And, therefore, this kynde of horse requireth a dis. creete and pacient ryder, who must not he over hastie in correcting him for feare of marring him altogither."*

\section{THE ITALIAN HORSE}

Was once celebrated for the beauty of his form and his paces; but, like everything else in that degraded country, he has sadly degenerated. The Neapolitan horses were particularly remarkable for their size and majestic action; there was, however, a degree of clumsiness about the heads and forehand, and general appearnce, which the seeming grindeur of their action would not always conceal; and they were occasionally untractable and vicious to an alarming degree. They are now much deteriorated, and, in fact, with but few exceptions, scarcely of any value.

Some of the Italian races are a disgraceful burlesque on those of other countries. At Rome they have become a necessary appendage to the annual carnival, and there is no other of the pastimes of that gay season in which the people take an equal delight. Some of the horse-races resemble those in other countries, and are faily contested; but much oftener the Poman course

- Blundeville's Four Chiefest Offices. 
presents nothing but the horse running withont any rider, and not from his own spirit and emulation, but startled by noises and goaded on by ridiculous and hatbarous contrivances.

The horses termed Buberi-because the race was at first contested by Barbs-are brought to the sturting-post, their liests an 1 their nack gaily ornom ante 1 ; while to a girth which gas roun l the bo ly of each ara attachal several luose straps, having at their en:ls small balls of leal thickly set with sharp steel points. At every motion these are bronght int contact with the flanks and bellies of the horses, and the more violent the motion the more dreadful the incessant torture. On their backs are placed sheets of thin tin, or stiff paper, which, wheu agitated, will make a rustling, rattling noiss.

It is difficult to conceive of the rearing, kicking, pawing, aud snorting which occurs at the startiug-place. A rope placed across the street prevents them from geiting away, and a stout peasant is employed with each horse in a struggle of downright strength, and at the hazard of limb and of life, to restrain him. Oscasionally some of them do break away and pass the rope before the street -the race-course-is cleared, and then many serious accidents are sure to happen.

Wheu all is reaty for stalting, a troop of dragoons gallop through the street in order to clear the way. A trumpet sounds - the rope drops-the grooms let go their hold, and the horses start away like arrows from a bow. The harder they run the mure they are pricked; the cause of this they seem scarcely able to comprehend, for they bite and plunge at each other, and a terrible fight is sometimes commenced. Others, from mere fright or sulkiness, stand stock-still, and it is by brute force alone that they can be again induced to move.

A strong canras screen is passed along the bottom of the street. This is the goal. It has the apnearance of a wall; but some of the horses, in the excess of thoir agony and terror, dart full against it, tear through it, or carry it away.

After all, the prize is nothing more than an ornamental flag; but it is presented by the governor of Rome, and it is supposed to be a pledge of the speed and value of the horse which will descend as an heir-loom from generation to generation among the peasantry, to whom many of these horses belong. The decision of such a race, however, can have little to do with the speed or strength or valus of the horses in any respect. The Italians, however, enter into the affair with all their characteristic eagerness of feeling, and are guilty of every kind of extravagancs. During the first six days of the carnival, the horses are fairly classed according to the age, height, degree of breeding, \&c.; but on the two last days - the choice days - they run all together, and some in the manner that I have described, and thus increase the confusion, the riot, and the danger of the exhibition.*

The Corso is very nearly a mile, and it has occasionally been lun in two miuntes and twentyone second; ; a very quick pace for small horses, many of them not more than fourteen hands high.

Before we quit the neighbourhoor of Italy, ws may perhaps notice another curions mode of horseracing, practised in Malta. The horses here are indeed mounted, but they have neither saddle nor bridle. The riders sit on the bare back, and have nothing to guide or to spur on their horses but a small pointed instrument, not unlike a cobbler's awl. These horses are small barbs, well tempered, or they would resist this mode of management, and they certainly are not swift. By pricking the horse on one side or the other of the neck, the rider can guide him a little in the way he should go, and certainly he may urge him to his fullest speer; but still, althoigh it affurds a novel and amusing sight to the stranger, the horse and the spectators are degraded by such an exhibition.+

\section{THE AUSTRIAN HORSE.}

The following account is given by the Duke of Ragusa of the imperial establishment for the breeding of horses at Mesohagrès, near Carlsburg, in Anstria:-"This is the finest establishment in the Austrian monarchy for the breeding and improvement of horses. It stands on forty thouseud acres of land of the best quality, and is surroundel in its whole extent, which is fifteen leagues, by a

* Penny Magazine, 1833, p. 425

+ Races of a similar character take place at Florence, of which Mrs. Piozzi gives the following deseription:- "The street is covered with sawdust, and made fast at both eads. Near the startiagpost are elegant booths, lined with red velvet, for the court and first nobility. At the other end a piece of tapestry is hung. to prevent the creatures from dashing their brains out when they reach the goal. Thousands and tens of thousands of people ou foot fill the course, so that it is a great wonder to me still that numbers are not killed. The prizes are exhibited to view in quite the old clasical style - a piece of erimsin damask for the wutuer ; a small silver basin and ewer for the seconl; a ad so on, leaving no perfurmer unrewarded.

"Al lust come out the horses, withont riders, but with a narrow leathera strap bung aeross their boties, which has a lump of ivory fixed to the end of it, all set full of sharp spikes like a hedgehog, and this goads them along while galloping worse than any spur could do, because the fister they run the more this odl machine keeps jumpiog up and down, aod pricking ther sides rodicnlunsly coough; and it m ikes one laugh to see that some of them are so tickled by it as oot to run at all, but set about plunging in order to rid themelves of the inconvenience, iostearl of driving forward to divert the mub, who leap, and caper, and shout wih delight, and lish the laggers along with greut indignation indted, aad with the mo $t$ comrcal gestures. I never saw horses in so droll a state of degradatiou before; for they were all striped, or spotted, or painted of some colour, to distioguish them Irom each other."

This curious scene is described on account of the strnnglymarked picture it affords, not of the poor horses, but of the inhabitumts of Italy, once the abode of everything that was honourable to human nature; fart perhaps, also, of certain writer, when they sacrifice good and kiadly feeliag to affectation and folly.

$\ddagger$ Penny Mag., 1833, p, 426. 
broad and deep ditch, and by a broad plantation sixty feet wide. It was formerly designed to supply horses to recruit the cavalry; at present its object is to obtain stallions of a good breed, which are sent to certain dépots for the supply of the provinces. To produce these, one thousand lrood mares and forty-eight stallions are kept; two hundred additional mares and six hundred oxen are employed in cultivating the gronnd. The plain is divided into four equal parts, and each of these subdivided into portions resembling so many farms. At the age of four years the young horses are all collected in the centre of the establishment. A selection is first made of the best animals to supply the deficiences in the establishment, in order always to keep it on the same footing. A second selection is then made for the use of the other: none of these, however, are sent away until they are five years old; but the horses that are not of sufficient value to be selected are sold by auction, or sent to the army to remount the cavalry, as circumstances may require.

The whole number of horses at present here, including the stallions, brood-mares, colts, and fillies, is three thousand. The persons employed in the cultivation of the ground, the care of the animals, and the management of the establishment generally, are a major-director, twelve subaltern officers, and eleven hundred and seventy soldiers.

The imperial treasury advances to the establishment every year one hundred and eighteen thousand florins (the half rix-dollar or florin is in value about $2 s .1 d$. English money), and is reimbursed by the sale of one hundred and fifty stallions, which are sent every year to the provinces at the price of one thousand florins each, and by the value of the horses supplied to the cavalry. The other expenses of every description are paid for by the produce of the establishment, which is required to defray, and does defray all. This is, therefore, an immense estate-a farm on a colossal scale-with a stud in proportion managed on account of the sovereign, and which produces a considerable revenue, independently of the principal object which is attained, the propagation and multiplication of the best breeds of horses. He can always supply the wants of his army at a price almost incredibly small. For a horse of the light eavalry he pays only one hundred and ten florins, for the dragoons one hundred and twenty, for the cuirassiers one hundred and forty, for the train one hundred and sixty, and for the artillery one hundred and eighty. It is a great element of power to possess at home such an immense resource against a time of war, at an expense so far below that which the powers of the west and south of Europe are compelled to incur.

So early as 1790, a very superior Arabian, named Turkmainath, was imported into Germany, and his stock became celebrated, not only in Hungary, but throughout most of the German provinces. In 1819, the Archduke Maximilian, brother to the emperor, purchased some valuable racers and hunters in England, and sent them to Austria. Some of them went to the imperial establishment of which mention has just been made, and the others contributed materially to the improvement of the horses wherever they were distributed. Races have been established in various parts of the Austrian dominions, and particularly at Buda and at Pest, in Hungary. Of the good effect which this will have on the breed of horses there can be no dispute, provided the race does not degenerate into a mere contest of superiority of speed, and exhibited in an animal that from his youth must inevitably be injured or ruined in the struggle.

The gipsies ased to be the principal horsedealers in Hungary, but they have been getting into comparative disrepute since the establishment of the noble studs scattered through this district. He who wants a horse, or to speculate in horses, may now go to head-quarters and choose for himself.

\section{THE RUSSIAN HORSE.}

It may be well supposed that this animal will be of a very different character in various parts of this immense empire. The heavy cavalry, and the greater part of the horses for pleasure, are descended originally from Cossack blood, but improved by stallions from Poland, Prussia, Holstein, and England; and the studs, which are now found on an immense scale in various parts of Russia. The lighter cavalry, and the commoner horses, are, as these have ever been, Cossacks, without any attempted improvement, and on that account more hardy and better suited to the duties required from them.

It has been supposed that no horse, except the Arab, could endure privation like the Cossack, or had combined speed and endurance equal to him. The Cossack, however, was beaten, and that not by horses of the first-rate English blood, in a race which fairly put to the test both qualities. It was a cruel affair; yet nothing short of such a contest would have settled the question.

On the 4th of August, 1825, a race of fortyseven miles was run between two Cossack and two English horses. The English horses were Sharper and Mina, well known, yet not ranking with the first of their class. The Cossacks were selected from the best horses of the Don, the Black Sea, and the Ural.

On starting, the Cossacks took the lead at a moderate pace; but, before they had gone half a mile, the stirrup-leather of Sharper broke, and he ran away with his rider, followed by Mina, and they 


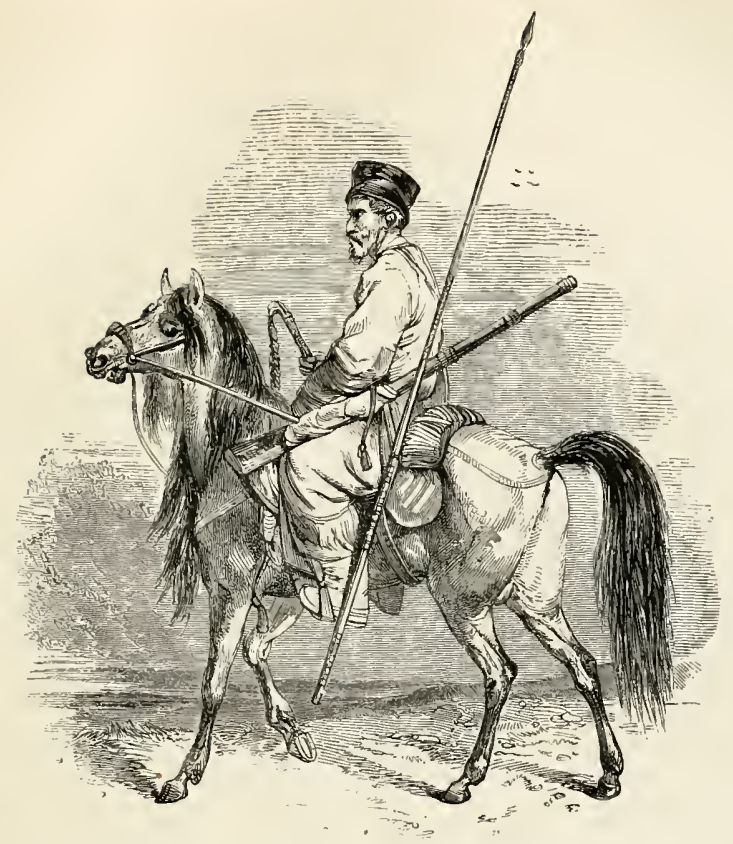

This cut represents a Cossack soldier accoutred for his journey, and having all that is necessary for him or for his horse. It gives a faithful but somewhat flattering representation both of the soldier and his steed.

went more than a mile, and up a steep hill, before they could be held in.

Half the distance was run in an hour and fourteen minutes. Both the English horses were then fresh, and one of the Cossacks. On their return Mina fell lame, and was taken away, and Sharper began to show the effects of the pace at which he had gone when running away, and was much distressed. The Calmuck was completely knocked up, his rider was dismounted, a mere child was put on his back, and a Cossack on horseback on either side dragged him on by ropes attached to his bridle, while others at the side supported him from falling. Ultimately Sharper performed the whole distance in two hours and forty-eight minutes - sixteen miles an hour for three successive hours; and the Cossack horse was brought in eight minutes after him. At starting the English horses carried full three stone more than the Cossacks; and during the latter part of the race a mere child had ridden the Cossack.

The Emperor Nicholas has established races in different parts of his vast empire, for the improvement of the Cossack and other horses. On the 20th of September, 1836, the races at Ouralsk took place. The distance to be run was eighteen wersts, or about four and a half French leaguesrather more than ten miles. Twenty-one horses of the military stud of the Cossacks of Oural started for the first heat, and which was won in twenty-five minutes and nineteen seconds by a horse belonging to the Cossack Bourtche-Tchourunief The second race was disputed by twenty-three horses of the Kergheese Cossacks, and which was won in twenty-five minutes and five seconds by the horse of the Cossack Siboka-Isterlaie. On the following day the winners of the two first heats strove for the point of honour. The course was now twelve wersts-three French leagues or about 
six miles and three quarters. It was won in fifteen minutes by the horse of the Cossack BourtcheTchourunief. The Russian nohlemen who were present, admiring the speed and stoutness of the horse, were anxious to purchase him; but the Cossack replied that "All the gold in the world should not separate him from his friend, his brother."**

In Southern and Western Russia, and also in Poland, the breeding of horses and cattle has lately occupied the attention of the great land proprietors, and has constituted a very considerable part of their aunual income. There is scarcely now a signorial residence to which there is not attached a vast court, in four large divisions, and surrounded by stables. In each of the angles of this court is a passage leading to beautiful and extensive pasture-grounds, divided into equal com. partments, and all of them having convenient sheds, under which the horses may shelter themselves frorn the rain or the sun. From these studs a larger kind of horse than that of the Cossacks is principally supplied, and more fit for the regular cavalry troops, and also for pleasure and parade, than conmon use. The remounts of the principal houses in Germany are derived herice; and from the same source the great fairs in the different states of the German empire are supplied.t

The stud of the Russian Countess Orloff 'Tshesmensky, in the province of Walonese, contains thirteen hundred and twenty horses, Arabs, English, natives, and others. The ground attached to it amounts to nearly eleven hundred acres; and the number of grooms, labourers, and others is more than four thousand. The sum realized by the sale of horses is of considerable annual amount; and they are disposed of not only on the spot itself, but in the regular markets both of St. Petersburgh and Moscow.

* Journal des Haras, Jan. 1837, p. 256.

+ "The bretding of cattle is also zealously and profitably pursued. The cow-houses form the greater portion of the other buildings attached to the mansion. The largest of these is destined for the mileh cows, and abother square building serves for a milking house. These duiries are disposed and fitted up like these in Switzerlund. In the middle is a jet of water. Slabs or tables of marble occupy tvery side, and a slight inclination of the floot permits the observance of the greatest pussible cleanliness. An upper story serves for the maaufacture of different kinds of eheese. which are made in imitation of, and sometimes equal those which are most esteemed in other parts of Europe.

" Jhere is another space or court inclosed with walls, and with little buildings closed with iron bars. This is destined to be a menagerie for bears of the rarest and most beautitul colours, and yielding the cloiest furs. This speculation is a very profitable one. A eub of six monthe old, with black hair poiated with silver white, yields a very light skin and fur, and which will obtain a con-iderable price, expecially if there are others of the same fineoess and variegated colour suffieient to make a pelisse. A garment of this kiod will sometimes be sold fur six hundred or one thousand pounds. The skins of the old bears are employed for carpets, or linings of carriages, and the most supple of them furm the elothing of the coachmen."-Journal des Haras. Althongh this oote refers to caule and bears, it does oot waoder from the design of the Farmer's Series, since it describes the siogular agricultural pursuits of the Russian and Pulish noblemen.
THE ICELAND HORSE.

There are numerous troops of horses in this cold and inhospitable country, descended, according to Mr. Anderson, from the Norwegian horse, but, according to Mr. Horrelow, being of Scottish origin. They are very small, strong, and swift. There are tlousands of them in the mountains which never enter a stable; lut instinct or habit has taught them to scrape away the snow, or break the ice, in search of their scanty food. A few are usually kept in the stable; but when the peasant wants more he catches as many as he needs, and shoes them himself, and that sometimes with a sheep's horn.+

\section{THE LAPLAND HORSE.}

This animal, according to Berenger, is small, but active and willing-somewhat eager and impatient, but free from vice. He is used only in the winter season, when he is employed in drawing sledges over the snow, and transporting wood, forage, and other necessaries, which in the sumner are all conveyed in boats. During the summer these horses are turned into the forests, where they form themselves into distinct troops, and sclect certain districts, from which they rarely wander. They return of their own accord when the season begins to change, and the forests no longer supply them with food.||

\section{THE SWEDISH HORSE}

Is small, but nimble and willing. $\mathrm{He}$ is almost entirely fed on bread, composed of equal parts of rye and oatmeal. To this is added a considerable quantity of salt, and, if he is about to start on a long journey, a little brandy. "While changing horses we were not a little entertained at the curious group formed by the peasants and their steeds breakfasting together; both cordially partaking of a large hard rye cake. The horses sometimes belong to three or even more proprietors: it is then highly amusing to observe the frequent altercations between them: each endeavouring to spare his own horse. Their affection for their horses is so great that I have seen them shed tears when they have been driven beyond their strength. The expedition, however, with which these little animals proceed is surprising when we consider the smallness of their size, which hardly exceeds that of a pony. The roads being universally good throughout Sweden, they frequently do not relax from a gallop, from one pust-house to another."

\section{THE FINLAND HORSES}

Are jet smaller than the Swedes, and not more

\# Kerguelea's Voyage to the North.

$\pi$ Berenger, p. 150.

\$ Sir A. de Capel Brooke's Travels in Sweden. 
than twelve hands high. They are beautifully formed and very fleet. They, like the Swedes, are turned into the forests in the summer, and must be fetched thence when they are wanted by the traveller. Although apparently wild, they are under perfect control; and can trot along with ease at the rate of twelve miles in the hour.

Fish is much used, both in Finland and Lap. land, for the winter food of horses and cattle.

\section{THE NORWEGIAN HORSE}

Is larger than the Swedish or Finland, bnt is equally hardy and manageable, and attached to its owner, and its owner to it. The roads in Norway are the reverse of what they are in Sweden: they are rongh and almost impassable for carriages, but the sure-footed Norwegian seldom stumbles upon them. Pontoppidan speals of their occasional contests with bears and wolves, and chiefly the latter. These occurrences are now more matter of story than of actual fact, but they do sometimes occur at the present day. When the horse perceives any of these animats, and has a mare or foal with him, he puts them behind him, and then furionsly attacks his enemy with his fore legs, which he uses so expertly, as generally to prove the conqueror; bnt if he turns ronnd in order to strike with his hind legs, the bear closes upon him immediately, and he is lost.

Of the horses of the islands of Feroe, still belonging to the Danish crown, Berenger speaks in terms of much praise. He says that "they are small of growth, but strong, swift, and sure of foot, going over the roughest places with such certainty that a man may more surely rely upon them than trust to his own feet. In Suderoe, one of these islands, they have a lighter and swifter breed than in any of the rest. On their backs the inhabitants pin'sue the sheep, which are wild in this island; the pony carries the man over places that would be otherwise inaccessible to him - follows his rider orer others-enters into the full spirit of the chase, and even knocks down and holds the prey under his feet until the rider can take possession of it." "*

\section{THE HOLSTE1N AND MECKLENBURG HORSES.}

Retnrning to the Continent, and having crossed the Baltic, we meet with a horse as different from those which have just been described as it is possible to imagine. The horses of Holstein and Mecklenburg, and some of the neighbouring districts, are on the largest scale. Their usual height is sixteen, or seventeen, or eighteen hands.t They are heavily made; the neck is too thick; the shoulders are heavy; the backs are too long, and

* Berenger's History of Horsemanship, p. 149.

+ There are two in the Queen's stubles in P.mlico, that are nearly twenty hands in height. the croups are narrow compared with their fore parts: but their appearance is so noble and com. manding, their action is so high and brilliant, and their strength and spirit are so evident in every motion, that their faults are pardoned and forgotten, and they are selected for every occasion of peculiar state and ceremony.

Before, however, we arrive at the native country of these magnificent horses, we must glance at the attempt of one nolle individual to improve the general breed of horses. In the island of Alsen, separated from the duchy of Sleswick by a narrow channel, is the noble halitation of the Duke of Augustenbourg. His stud is attached to it, and nnder the immediate management of the noble owner. It contains thirty marts of pure blood, and fifteen or sixteen stallions of the same grade; and all of them selected with care from the best thorongh-bred horses in England. Notwith. standing this selection of pure blood, or rather in its peculiar selection, it has been the olject of the dulie to produce a horse that shall be nseful for the purpose of pleasure, commerce, and agricultnre. Some of the stallions are reserved for his orn stud; lut with regard to the others, such is the spirit with which this noble establishment is condacted, and his desire to improve the race of horses in Sleswick, that he allows more than six hundred mares every year, belonging to the peasants of the isle of Alsen, to be covered gratnitousiy. He keeps a register of them, and in the majority of cases he examines the mares himself, and chooses the horse which will best suit her form, her beauties, her defects, or the purpose for which the progeny is intended. It is not therefore surprising that there should be so many good horses in this part of Denmark, and that the improvement in Sleswick, and in $\mathrm{Hol}$ stein, and also in Mecklenbnrg, should be so rapid, and so universally acknomledged.

There is another circnustance which should not be forgotten - it is that by which alone the preservation of a valuable breed can be secnred-it is that to the neglect of which the deterioration of every breea must be partle, at least, and, in many cases, chiefly traced. The dnke in his stud, and the peasants in the surrounding country, preserve the good breeding mares, and will not part with one that has not some evident or secret fault about her.

How much have the loreeders of Great Britain to answer for in the deterioration of some of our best breeds from this canse alone!

There is, however, nothing perfect under the sun. This determination to breed only from horses of pure biood, although care is taken that these horses shall be the stontest of their kind, has lessened the size and somewhat altered the peculiar character of the horse in the immediate 
districts; and we must go somewhat more southward for the large and stately animal of which frequent mention has been made. The practice of the country is likewise to a certain degree unfriendly to the full development of the Augustenbourg horse. The pasturage is sufficiently good to develop the powers of the colt, and few things contribute more to his subsequent hardihood than his living on these pastures, and becoming accustomed to the vicissitudes of the seasons : yet this may be carried too far. The Sleswick colt is left out of doors all the year round, and, except when the snow renders it impossible for him to graze, he is, day and night, exposed to the cold, and the wind, and the rain. We are no adrocates for a system of nursing laborious to the owner and injurious to the animal, but a full development of form and of power can never be acquired amidst outrageous neglect and privation.

\section{THE PRUSSIAN HORSE.}

Prussia has not been backward in the race of improvement-or rather, with her characteristic policy, she has taken the lead, where her influ- ence and her power were concerned. The government has established some extensive and well-regulated studs in various parts of the kingdom; and many of the Prussian noblemen have establish. ments of their own. In some of the marshy districts, and about the mouth of the Vistula, there is a breed of large and strong horses suited to agricultural purposes. The studs produce others for pleasure or for war. In the royal studs particular attention has been paid to the improvement of the Prussian caralry-horse. He has acquired considerably more fire and spirit, and strength and endurance, without any sacrifice either of form or action.

\section{THE FLEMISH AND DUTCH HORSE.}

The Flemish and Dutch horses are large, and strongly and beautifully formcl. We are indebted to them for some of the best blood of our draughthorses, and we still have frequent recourse to them for keeping $u p$ and improving the breed. They will be more particularly described when the carthorse is spoken of.

\section{CHAPTER III.}

\section{HISTORY OF THE ENGLISH HORSE.}

The earliest record of the horse in Great Britain is contained in the history given by Julius Cæsar of his invasion of our island. The British army was accompanied by numerous war-chariots, drawn by horses. Short scythes were fastened to the ends of the axle-trees, sweeping down every thing before them, and carrying terror and devastation into the ranks of the enemy. The conqueror gives an animated description of the dexterity with which these horses were managed.

What kind of horse the Britains then possessed, it would be useless to inquire; but, from the cumbrous structure of the car, and the fury with which it was driven, and the badness of the roads, and the almost non-existence of those that were passable, it must have been both active and powerful in an extraordinary degree. It is absurd to suppose, as some naturalists have done, that the ponies of Cornwall and of Devon, or of Wales, or of Shetland, are types of what the British horse was in early times. He was then as ever the creature of the country in which he lived. With short fare and exposed to the rigour of the seasous, he was probally the little hardy thing which we yet see him; but in the marshes of the Nen and the Witham, and on the borders of the Tees and the Clyde, there would be as much propor- tionate development of frame and of strength as we find at the present day.

Cæsar deemed these horses so valuable, that he carried many of them to Rome; and they were, for a considerable period afterwards, in great request in various parts of the Roman empire.

Horses must at that time have been exceedingly numerous in Britain, for we are told that when the British king, Cassivellaunus, dismissed the main body of his army, he retained four thousand of his war-chariots for the purpose of harassing the Romans, when they attempted to forage.

The British horse now received its first cross; but whether the breed was thereby improved cannot be ascertained. The Romans having established themselves in Britain, found it necessary to send over a numerous body of cavalry, in order effectually to check the frequent insurrections of the natives. The Romau horses would breed with those of the country, and, to a greater or less extent, change their character; and from this time, the English horse would consist of a compound of the native animal and those from Gaul, Italy, Spain, and every province from which the Roman cavalry was supplied.

Many centuries afterwards passed by without leaving any record of the character or value, im. 
provement or deterioration, of the horse. About the year 630 , however, according to Bede, the English were accustomed to use the saddle. $\mathrm{He}$ says, that "the bishops and others rode on horseback, who until then were wont to go on foot; and that even then it was only on urgent occasions that they thus rode. They used mares only, as a mark of bumility, the mare generally not being so handsome or so much valued as the horse."

About nine hundred and twenty years after the first landing of Cæsar, we find the various British kingdoms united, and Alfred on the throne. Nothing that concerned the welfare of his kingdom was neglected by this patriotic monarch, and some of the chronicles relate the attention which he paid to the breeding and improvement of the horse. An officer was appointed for this especial purpose, who was entitled the Hors-Than, or Horse-Thane, or as the historian renders it, Equorum Magister, Master of the Horse. In every succeeding reign, this officer was always near the royal person, especially on every state oceasion.*

Athelstan, the natural son of Alfred, having subdued the rebellious portions of the Heptarchy, was congratulated on his success by some of the continental princes, and received from Hugh Capet of France, who solicited his sister in marriage, several German running-horses. Hence our breed received another cross, and probably an improvement. We are not, however, certain of the precise breed of these horses, or how far they resembled the beautiful state horses, whether black or cream-coloured, which we obtain from Germany at the present day. Athelstan seems to have placed peculiar value on these horses or their descendants, or the result of their intercourse with the native breed; for he soon afterwards (A.D. 930) decreed, that no horses should be sent abroad for sale, or on any account, except as royal presents. This proves bis anxiety to preserve the breed, and likewise renders it probable that that breed was beginning to be esteemed by our neighbours.

It is not unlikely that, even at this early period, the beautiful effect of the English soil and climate, and care in the improvement of the horse, began to be evident. This will be a subject for pleasing inquiry by and bye : but the experience of every age has proved that there are few countries in which the native breed has been rendered so much more valuable by the importation of a foreign stock, and every good quality of a foreign race so certainly retained, as in England.

In a document bearing date A.D. 1000 , we have an interesting account of the relative value of the horse. If a horse was destroyed, or negligently

* Berenger's History of Horsemanship, vol. i. p. 308. lost, the compensation to be demanded was thirty shillings; for a mare or colt, twenty shillings; a mule or young ass, twelve shillings; an ox, thirty pence; a cow, twenty-four pence; a pig, eight pence; and, it strangely follows, a man, one pound.t

In the laws of Howell Dha, Howell the Good, Prince of Wales, enacted a little before this time, there are some curious particulars respecting the value and sale of horses. The value of a foal not fourteen days old is fixed at four pence; at one year and a day it is estimated at forty-eight pence; and at three years, sixty pence. It was then to be tamed with the bridle, and brought up either as a palfrey or a serving horse, when its value became one hundred and twenty pence. That of a wild or unbroken mare was sixty pence.

Even in those early days, the frauds of dealers were too notorions, and the following singular regulations were established. The buyer was allowed time to ascertain whether the horse was free from three diseases. He had three nights to prove him for the staggers; three months to prove the soundness of his lungs; and one year to ascertain whether he was infected with glanders. For every blemish discovered after the purchase, one-third of the money was to be returned, except it should be a blemish of the ears or tail, which it was supposed to be his own fault if the purchaser did not discover. The seller also warranted that the horse would not tire when on a journey with others, or refuse his food from hard work, and that he would carry a load or draw a carriage up or down hill, and not be resty.

The practice of letting horses for hire theu existed; and then, as now, the services of the poor hack were too brutally exacted. The benevolent Howell disdains not to legislate for the protection of this abused and valuable servant. "Whoever shall borrow a horse, and rub the hair so as to gall the back, shall pay four pence ; if the skin is forced into the flesh, eight pence; if the flesh be forced to the bone, sixteen pence." If a person lamed a horse, he was to forfeit the value of the animal; and if he was supposed to have killed a horse, he was to purge himself by the oaths of twenty-four compurgators.

Then, as now, it would appear that some young men were a little too fond of unwarrantable mischief, or perhaps there were thieves in the country, even so soon after Alfred's days, showing also the estimation in which this portion of the animal was held, and the mauner in which the hair was suffered to grow, for it was decreed that he who cut off the hair from a horse's tail was to maintain him

+ According to the Anglo-Saxon computation, forty-eight shillings made a pound, equal in silver to abuut three pounds of our
present money; fire pence made one shilling. The actual value of these coins, however, strangely varied in different times and circumstances. 
until it was grown again, and in the mean time to furnish the owner with another horse. If the tail was cut off with the hair, the miscreant who inflicted the outrage was muletcd in the value of the animal, and the horse was deemed unfit for future service.

Athelstan seems to have placed considerable value on some of his horses; for he bequeaths, in his will, the borses given him by Thurbrand, aud the white horses presented to him by Lisbrind. These are apparently Saxon names, but the memory of them is now lost.

With William the Conqueror came a marked improvement in the British horse. To his superi. ority in cavalry this prince was chiefly indebted for the victory of Hastings. The farourite charger of William was a Syraniard. His followers, both the barons and the commou soldiers, principally came from a country in which agriculture had made more rapid progress than in England. A very considerable portion of the kingdom was divided among these men ; and it cannot be doubted that, however unjust was the nsurpation of the Norman, Eugland benefited in its husbandry, and particularly in its horses, by the change of masters. Some of the barons, and particularly Roger de Boulogne, earl of Shrewsbury, introduced the Spanish horse on their newly-acquired estates. The historians of these times, however-principally monks, and knowing nothing about horses-give us very little information on the subject.

The Spanish horse was then highly and deserredly valned for his stately figure aud noble action, and was iu much request in the tilts and tournaments that were then in fashion. The Spanish horse was the war-horse of every oue who could afford to purchase and properly accoutre so noble an animal. The courage and the skill of the rider were most perfectly displayed when united with the strength and activity, and spirit and beauty, of the steed.

One circurnstance deserves to be remarked, namely, that iu none of the earliest historical records of the Anglo-Saxons or the Welsh is there any allusion to the use of the horse for the plough. Until a comparatively recent period, oxen alone were employed in Eugland, as in other countries, for this purpose; but abont this period-the latter part of the tenth centnry-some innovation on this point was commencing, and a Welsh law forbade the farmer to plough with horses, mares, or cows, lut with oxen alone. On one of the pieces of the Bayeux tapestry woven in the time of William the Conqueror (A.D. 1066), there is the figure of a man driving a horse attached to a harrow. This is the earliest notice that we have of the use of this animal in field-labour.

In the reign of Henry I. (A.D. 1121), the first Arabian horse, or at least the first on record, was introduced. Alexander I., king of Scotland, pre- sented to the church of St. Andrew's an Arabian horse, with costly furniture, Turkish armour, many valuable trinkets, and a considerable estate.

There have heen some pretensions to the existence of a breed derived from or improved by this horse, but no certain proof of it can be adduced.

In the reign of Henry II. several foreign horses were imported, but of what kint is not mentioned. Maddox speaks of "the increased allowance that was made for the subsistence of the King's horses that were lately brought from beyond sea." "*

Smithfield is also now first spokeu of as a horse-market, a field for tournaments, and a racecourse. Fitzstephen, who lived at that time, gives the following animated account of the scene:"Without one of the gates of the city is a certain field, plain or smooth, both in name and situation. Every Friday, except some festival intervene, there is a fine sight of horses brought to be sold. Many come out of the city to buy or look ou-to wit, earls, barons, knights, and citizens. It is a pleasant thing to behold the horses there, all gay and sleek, moving up and dorn, some on the amble and some on the trot, which latter pace, altlough rougher to the rider, is better suited to men who hear arms. Here also are colts, yet ignorant of the bridle, which prance and bouud, and give early signs of spirit and courage. Here also are managed or war horses, of elegant shape, full of fire, and giving every proof of a generous and uoble temper. Horses also for the cart, dray, and plough, are to be found here;-mares, big with fual, and others with their colts wantonly rumning by their sides.

"Every Suuday in Leut, after dimer, a company of young men ride out into the fields, on lorses that are fit for war, aud excellent for their speed. Erery one among them is taught to run the rounds with his horse. The citizen's sons issne out through the gates by troops, furnished with lances and shields. The younger sort have their pikes not headed with irou; and they make representation of battle, and exercise a skirmish. To this performance many courtier's resort, when the court is near; and young striplings, yet uninitiated in arms, from the families of barons aud great persons, to train and practise.

" They begin by dividing themselves into troops. Some labour to outs:rip their lealers, withont being able to reach them: others unhorse their antagonists, yet are not able to get beyond them. A race is to be run by this sort of horses, and perhaps by others, which also in their lird are strong and Heet; a slout is immediately raised, and the common horses are ordered to withdraw out of the way. Three jockeys, or sometimes only two, as the match is made, prepare themselves for the contest. The horses on their part are not without emulation:

\footnotetext{
* History of the Exchequer, p. 252.
} 
they tremble and are impatient, and are continually in motion. At last, the signal once given, they start, devour the course, and hurry along with unremitting swiftness. The jockeys, inspired with the thought of applanse aud the hope of victory, clap spurs to their willing horses, brandish their whips, and cheer them with their cries." This animated description reminds us of the more lengthened races of the present day, and proves the blood of the English horse, even before the Eastern breed was tried.*

Close on this fullowed the Crusades. The champions of the Cross certainly had it in their power to enrich their native country with some of the choicest specimens of the Eastern horse, but they were completely under the influence of superstition and fanaticism, and common sense and usefulness were forgotten.

An old metrical romance, however, records the excellence of two horses belonging to Richard Cœur de Lion, which he purchased at Cyprus, and were, therefore, probably of Eastern origin :-

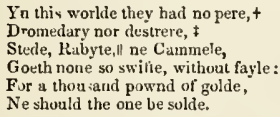

The head of the war-steed was ornamented with a crest, and, together with his chest and flanks, was wholly or partially protected. Sometimes be was clad in complete steel, with the arms of his master engraved or embossed on his bardings. The bridle of the horse was always as splendid as the circumstances of the knight allowed, and thus a horse was often called brigliadore, from briglia doro, a bridle of gold. Bells were a very favourite addition to the equipment of the horse. The old troubadour, Arnold of Marson. sass that "nothing is so proper to inspire confidence in a knight and terror in an enemy."

The price of horses at this period was singularly uncertain. In 1185 , fifteen brecding mares sold for two pounds, twelve shillings, and sixpence. They were purchased by the monarch, and distributed among his tenants; and, in order to get something liy the bargain, he charged them the great sum of tour sliillings each. Twenty years afterwards, ten capital horses brought no less than twenty pounds each ; and, twelve years later, a pair of horses were imported from Lomilardy, for which the extravagant price of thirty-eight pounds, thirteen shillings, and fourpence was given. The usual price of good handsome horses was ten pounds, and the hire of a car or cart, with two horses, tenpence a.day.

To King John, bateful as he was in all other

* Leland's Itinerinary, vol. viii.; and Berenger, vol. i. p. 165. + Peer, equal. † War.horse. respects, we are much indebted for the attention which he paid to agriculture generally, and particularly to the improvement of the breed of horses. He imported one hundred cliosen stallions of the Flanders breer, and thus mainly contribute $f$ to prepare our noble species of draughti-horses, as unrivalled in their way as the hor'ses of the turf.

John accumuldted a very numerous and ralualle stud. He was eager to possess liusself of every horse of more than usual power; and at all times gladly received from the tenants of the crown horses of a superior quality iustead of money for the renewal of grants, or the parment of forfeitures belonging to the crown. It was his pride to render his cavalry, and the horses for the tournament and for pleasure, as perfect as he cuuld. It was not to be expected that so haughty and overbearing a tyrant would concern himself much with the juferior kinds; yet while the superior kinds were rapidly becoming more valuable, the others would, in an indirect manner, partake of the improvement.

One hundred years afterwards, Edward II. purchased thirty Lombardy war-horses, and twelve heavy dranght-horses. Lombardy, Italy, and Spain were the countries whence the greater part of Europe was then supplied with the most valuable cavalry or parade horses. Those for agricultwal purposes were chiefly procured from Flanders.

Edward III. devoted one thousand marks to the purchase of fifty Spanish horses; and of such importance did he consider this addition to the English, or rather, mingled blood then existing, that formal application was made to the kings of France and Spain to grant safe-conduct to the troop. When they had safely arrived at the royal stud, it was compited that they had cost the monarch no less than thirteen pounds, six shillings, and eightpence per horse, equal in value to one liundred and sixty pounds of our present money.

These horses were bought in order to enable him successfully to prosecute a war against Scotland, and to prepare for a splendid tommament which he was about to hold.

Eutire horses were alone used for this mimic contest, and generally so in the duties and dungers of the field. It was rarely the custom to castrate the colts; and the introduction of the female among so many perfect horses might occasionally be productive of confusion. The mare was at this period comparatively despised. It was deemed disgrnceful for any one above the common rank to ride her, and she was empleyed only in the most servile offices. This feeling and practice was then preva. lent in every part of the world. When, however, it begin to be the custom to castrate the young horses, the worth and value of the mare was soon appreciated; and it is now acknowledged that, usually, she is not much, if at all, inferior to the perfect horse in many respects; while she has far 
more strength, proportionate courage, and endurance than the gelding. *

This monarch had many running-horses. The precise meaning of the term is not, however, clear. They might be light and speedy animals in opposition to those destined for the cavalry service, or horses that were literally used for the purpose of racing. The average price of these ruuning-horses was twenty marks, or three pounds, six shillings, and eightpence.

Edward was devoted to the sports of the turf and the field, or he began to see the propriety of crossing our stately and heavy breed with those of a lighter structure and greater speed. There was, however, one impediment to this, which was not for a very long period removed. The soldier was cased in heavy armour, and the knight, with all his accoutrements, often rode more than twentyfive stones. No little bulk and strength were required in the animal destined to carry this back-breaking weight. When the musket was substituted for the cross-bow and battle-axe, and this iron defence, cumbrons to the wearer and destructive to the horse, became useless, and was laid aside, the improvement of the British horse in reality commenced.

While Edward was thus eager to avail himself of foreign blood, he, with the too frequent selfishness of the sportsman, would let no neighbour share in the advautage. The exportation of horses was forbidden under heavy penalties. One case in which he relaxed from his severity is recorded. $\mathrm{He}$ permitted a German merchant to re-export some Flanders horses which be had brought on speculation; but he strictly forbade him to send them to Scotland. Nay, so jealous were these sister-kingdoms of each other's prosperity, that so late as the time of Elizabeth, it was deemed felouy to export horses from England to Scotland.

The English horse was advancing, although slowly, to an equality with, or even superiority over those of neighbouring countries. His value began to be more generally and highly estimated, and his price rapidly increased-so much so, that

* The anthor of this work does not feel disposed to pass over another circumstance connected with the purchase of these horses, althongh not very creditable to his profession at that period. In the accounts of the charges for the education of the horse, there was usually one termed Troynelli. This is monkist Latin, and not to be found in our modern dictionaries. It refersed to certain instruments which the ferrarii or solearii-blacksmiths and shoeing-smiths-used in order that the borses inight be tanght a short namby-pamby pace, designated ambling. They consisted of strong $y$ arn or iron-chains, by which the fore-feet were connccted together, and only a certain degree of liberty allowed them, whilc a shee with a long toe was placed on the hinder feet. Perhaps these artificers were scarcely worthy of hetter employment at that time; and yet it was poor work to teach the noble war-horse to amble, and to spoil him for the field of danger, in order to please the ladies who graced the front seats at the tournament, The warrior ambling!

"She shall make him amble on a gossip"s message,

And take the distaff with a hand as patient

As e'er did Hercules!"-Rouce. the breeders and the dealers, then, as now, skilful in imposing on the inexperienced, obtained from many of the young grandees enormous prices for their cattle. This evil increased to such an extent, that Richard II. (1386) interfered to regulate and determine the price. The proclamation which he issued is interesting, not only as proving the increased value of the horse, but showing what were, four hundred and fifty years ago, the chief breeding districts, as they still continue to be. It was ordered to be published in the counties of Lincoln and Cambridge, and the East and North Ridings of Yorkshire; and the price of the horse was restricted to that which had been determined by former monarchs. A more enlightened policy has at length banished all such absurd interferences with agriculture and commerce.

We can now collect but little of the history of the horse until the reign of Henry VII., at the close of the fifteenth century. He continued to prohibit the exportation of stallions, but allowed that of mares when more than two years old, and under the value of six shillings and eightpence. This regulation was, however, easily evaded; for if a mare could be found worth more than six shillings and eightpence, she might be freely exported on the payment of that sum.

The intention of this was to put an end to the exportation of perfect horses; for it is recited in the preamble "that not only a smaller number of good horses were left within the realm for the defence thereof, but also that great and good plenty of the same were in parts beyond the sea, which in times past were wont to be within this land, whereby the price of horses was greatly enhanced," \&c. The exception of the mare, and the small sum for which she might be exported, shows the unjust contempt in which she was held. Another act of the same monarch, however unwillingly on his part, restored her to her proper rank among her kind.

It had been the custom to keep large herds of horses in the pastures and common fields, and when the harvest was gathered in, the cattle of a great mauy owners fed promiscuously together. The consequence of this was that the progeny presented a strange admixture, and there was often a great deterioration of the favourite and best breed. On this account an act was passed prohibiting stallions from being turned out into any common pasture. This, at no great distance of time, necessarily led to the castrating of all but a very few of the best stallions, and then, on comparing the powers and work of the mare with that of the gelding, she soon began to be accounted more valuable-more service was exacted from her-she was taken more care of, and the general breed of horses was materially improved. 
Polydore Virgil, who flourished in this reign, confirms the statements already made, that "the English horses were seldom accustomed to trot, but excelled in the softer pace of the amble."

Henry VII. was an arbitrary monarch, and seemed to be too fond of prohibitory acts of parliament; but so far as the horse was concerned, they were most of them politic, although tyrannical.

Succeeding monarchs acted on the same principle, and by prohibiting exportation, and encouraging a numerous and good breed of horses, by public rewards and recompences, every necessary incitement was afforded rapidly to improve the breed.

Henry VIII., a tyrannical and eruel prince, but fond of show and splendour, was very anxious to produce a valuable breed of horses; and the means which he adopted were perfectly in unison with his arbitrary disposition, although certainly calculated to effect his object. He affixed a certain standard, below which no horse should be kept. The lowest height for the stallion was fifteen hands, and for the mare thirteen hands. Those whose local interests were injured loudly complained of this arbitrary proceeding. The small breed of Cornish horses was in a manner extinguished. The dwarfish but active and useful inhabitants of the Welsh mountains rapidly diminished, the Exmoors and the Dartmoors were compelled to add an inch to their stature, and a more uniformly stout and useful breed of horses was produced.

The monarch was determined to effect and to secure his ohject. At "Michaelmastide" the neighbouring magistrates were ordered to "drive" all forests and commons, and not only destroy such stallions, but all "unlikely tits," whether mares or geldiugs, or foals, which they might deem not calculated to produce a valuable breed.

By a singular coincidence, the year of his reign, 1540, which found him thus arbitrarily employed in the domestic improvement of his people, or rather in the accomplishment of his favourite objects-the splendour of his tournaments and the magnificence of his pageantrieswas that in which he accomplished another tyrannical, but master-stroke of policy, - the suppression of the monasteries.*

He next had recourse to a sumptuary law in order more fully to accomplish his object, and, appealing to the pride of those who were concerned, he had no difficulty in this matter. Every archbishop and duke was compelled, under certain

* There is a singular entry in the Jomrnals of the House of Lords, which shows how much they had this horse business at heart:-"Hodie (I5th Junii, I540) tandem leclu esl billa educationi equorum procerioris stature, et communi omnium consensu, nemine discrepante, expedita." penalties, to keep seven trotting stallions for the saddle, each of which was to be fourteen hands high at the age of three years.

There were very minute directions with regard to the number of the same kind of horses to be kept by the other ranks of the clergy and nobility, and the statute concludes by enacting, that every person having benefices to the amount of one hundred pounds yearly, and "every layman, whose wife shall wear any French hood or bonnet of velvet," shall keep one such trotting stallion for the saddle.

These enactments, tyrannical as they appear to us, were quietly submitted to in those days, and produced the kind of horse which was then alone comparatively useful, and whose strength and noble bearing and good action were the foundation of something better in after days.

The civil dissensions were at an end, there was no fear of foreign invasions-no numerous cavalry were needed-the labours of agriculture were performed chiefly by oxen, or by the smaller and inferior breeds of horses, - races were not established-the chase had not begun to be pursued with the ardour and speed of modern daysnothing, in fact, was now wanted or sought for, but an animal more for occasional exhibition than for sterling use, or if useful, principally or solely with reference to the heavy carriages and bad roads and tedious travelling through the country. If this is rightly considered, it will be acknowledged that, with all his faults, and with the confession that he was ever more actuated by the determinations of his own ungovernable passions than the advantage of his people or of posterity, we still owe him thanks for the preservation of that breed of horses from which in after times sprung those that were the glory of our country and the envy of every other.

The following extract from a manuscript dated 1512 , in the third year of the reign of Henry VIII., and entitled the Regulations and Establishment of the houseliold of Algernon Percy, the fifth Earl of Northumberland, may give the reader a sufficient knowledge of the different kinds of horses then in use.

"This is the ordre of the chequir roul of the nombre of all the horsys of my lordis and my ladys that are apoynted to be in the charge of the hous yerely, as to say, gentil-hors, $\dagger$ palfreys, $\ddagger$

+ The gentil horse was one of superior breed, in distinction from the ordinary race. The same term is at present applied to Italian horses of the best breeds.

$\ddagger$ Palfreys were smaller horses of an inferior breed. The best of them, distinguished for their gentleness and pleasant paces, were set apart for the females of the family:- "The bard that tells of palfried dames." Others of inferior value were ridden by the domestics or servants of every kind. Thus Dryden says,

"The smiths and armourers on palfreys ride." 
hobys, * naggis, $\uparrow$ cloth-sek hors, $\ddagger$ malehors. $\| \mid$ through the nation. He invited two Italians, puFirst, gentil-hors, to stand in my lordis stable, pils of Pignatelli the riding-master of Naples, and six. Item. Palfreys of my lady's, to wit, one for placed them in his serrice; and he likewise had an my lady, and two for her gentil-women, and oone Italian farrier named Hannibale, who, Berenger, for her chamberer. Four holyss and naggis for quaintly remarks. "did not discorer any great my lirdis oone saddill, riz., oone for my lorde mysteries to his English brethren, but yet tanght to ride, oone to lede for my lorde, and onne to stay at home for my lorde. Item. Chariot hors to stond in my lorde's stable yerely. Seven great trottynge hor's to draw in the chariott, $\S$ and a nagg for the chariott-man to ride; eight. Again, hors for lorde Perey, his lordship's son and heir. A grete doble trottynge horse, 9 for my lorde Percy to travel on in winter. Item. A grete doble trottynge hors, called a curtal,** for his lordship to ride on out of townes. Another trottynge gambaldynge + hors, for his lordship to ride upon when he comes into townes. An ambling hor's for his lordship to journey on dayly. A proper amblyng little nagg for his lordship when he goeth on hunting or hawking. A gret amblynge gelding or trottynge gelding to carry his male."

Sir Thomas Chaloner, who wrote in the early part of the reign of Elizabeth, and whose praise of the departed monarch may be supposed to be sincere, speaks in the highest terms of his labour to introduce into his kingdom every variety of breed, and his selection of the finest animals which Turkey, or Naples, or Spain, or Flanders, could produce. Sir Thomas was now ambassador at the court of Spain, and had an opportunity of seeing the valuable horses which that country could produce; aud he says that " England could furnish more beautiful and useful breeds than any which foreign kingdoms could supply." The fact was, that except for pageantry or war, and the slow travelling of those times, there was no motive to cultivate auy new or valuable breed. The most powerful stimulus had not yet been applied.++

Berenger, who mould be good authority in such a case. provided experienced and skilful persons to preside in his stables, and to spread by these means the rules and elements of horsemanship

* ITobys-Hohbies wele strong and active horses of rather small size, and suicl to huse been originally of Irish extration. Thus Luvies, in his atconnt of Ireland sass:- "For twenty hobblex armed-Irib horse-sultiel's-so called because they served on hublices; they had $6 r$. per diem."

+ The vaggis, or nuga, so culled frnm their supposed propensily to seigh, kugga. They nere sinill, and not much valued, but active horses:- "Thy nars," silys Pliur,

"The lement things alive, So very hard thun liv'st to drive."

\# The cloth-sek was the horse that carried the cloak-bag

if Male, or mail, was equivalent to portmintean. Ihns, in Chancer, "I bive delu's and p urdons in ny mole."

$\$$ The chariot or cor was the velicle in variuus forms, but far inferior to the charion or enach in coumon nse, in which the furniture or nuveables were conveyed, or, perchance, the inferior females of the family. The lord and the lady usnally rode on horseback. They were slow-paeed, heary horses, perbaps not much unlike the them more than they knew before."

There is nothing worthy of remark in the short reign of Edward VI., except the constituting the stealing of horses a felony without benefit of clergy.

In the twenty-second year of Elizabetl, the use of coaches was introduced. It has been already remarked that the heads of noble houses travelled almost from one end of the kingdom to the other on horseback, unless occasionally they took refuge in the cars that were generally appropriated to their household. Even the Queen rode behind her master of the horse when she went in state to St. Paul's. The convenience of this nerw mode of carriage cansed it to be immediately adopted by all who had the means; and the horses were so rapidly bought up for this purpose, and became so exorbitantly dear, that it was agitated in pariiament whether the use of carriages should not be confined to the higher classes.

This fashion would have produced an injurious effect on the character of the English horse. It would have too much encouraged the breed of the heavy and slow horse, to the comparative or almost total neglect of the lighter framed and speedy one; lut, gunpowder having been invented, and heavy armour beginning to be disused, or, at this period, having fallen into almost perfect neglect, a lighter lind of horse was necessary in order to give effect to many of the manœuvres of the cavalry. Hence arose the light cavalry-light compared with the horsemen of former daysheavy compared with those of modern times; and hence, too, arose the lighter horse, which, except for a few particular purposes, gradually superseded the old heavy war and draught horse.

An account has already been given of the occasional races at Smithfield. They were mostly

took the fanily to church nn Sunduy. It must not oe furgntten, as marking the charuter of the rehicle and its contents, that the charint-mus, or coxthman rode by the side of the horses, and so ronducterl them and the carriage.

I" "A grete doble or dusble trottynge hotse," means a large and broid backed horse, the depressinn along whose lack yires almust the appearance of two horsex juined together. Thus the lirench speak of le double bislet; and Virgil, refering to the borse, says, "At diplex ayiur per lunhos spina" (Groorg. I11.)

** A curtal horse is one with a docked tail. Thus, Ben Jonson:-" Huld my stirrup, my one lacquey, and look to my curtal the nther."

++ Gambaldynge.-Gambuld was the nld word for gambol, and it means a horse thit was fond of plyying and prancing alontthe kind of horse on which a nobleman conld best shom himself off when he entered a town.-Berenger on Horsemanship, vol. ii. p. 178, to whom the anthor acknowledges much obligation bere, and on other occasions.

if De Republiea Anglorum instauranda. 
accidental trials of strength and speed, and there were no running-horses, properly speaking-none that were kept for the purpose of displaying their speed, and dedicated to this particular purpose alone. liegular races, however. were now established in various parts of England, fir'st at Garterly in Sorkshire, then at Crupton, at Theobalil's on Enfielil-chase, and at Stanford. the There was no aclinowledged system as now-no breed of racing-horses; but hackneys and hunters mingled together, and no description of horse was excluded.

There was at first no course marked out for the race, but the contest generally consisted in the running of train-scent across the country, and sometimes the most difficult and dangerous part of the country was selected for the exhibition. Occasionally our present steeple-chase was adopted with all its dangers, and more than its present barbarity; for persons were appointed cruelly to flog $n$ long the jaded and exhansted horse. $f$

By degrees, however, certain horses mere deroted to these exhibitions, and were prepared for the race, as far as the mystery of the training stable could then be explored, somewhat in the same way as at present. The weight of the rider, howerer, was not always adjusted to the age or performances of the horse; but no rider could start who meighed less than ten stones.

The races of that period were not disgraced by the system of gambling and fraud which in later times seems to have become almost inseparable from the amusements of the turf. No heary stakes werc run for; and no betting srstem had been established. The prize was usually a wooden bell adorned with flowers. This was afterwards exexchanged for a silver bell, and "giren to him who should rum the best and farthest on horseback, and especially on Shrove Tuesday." Hence the common phrase of "bearing amay the bell."

Horse-racing became gradually more cultivated; but it was not until the last year of the reign of James I. that rules were promnlgated and generally snbscribed to for their regulation. That prince was fond of field-sports. He had encouraged, if he did not establish, horse-racing in Scotland, and he brought with him to England his predilection for it; but his races were often matches against time, or trials of speed and bottnm for absurdly and crutlly long distances. His favourite courses were at Croydon and on Enfieldchase.

* Boncher, in his History of Stamford, says, that the first valutule pulblic prize $\pi$ as run for at that place in the tme of Charles I It was a silscr-gilt chp and cover, of the salue of eight pounds, prurided by the corporation.

+ This pethaps requires a litue explanation. A match was formed culled the "Wild-Gonse Chave, "betworn two horscs, and a tulerably sure trial it was of the speed and hunting propertes of the horse. IThichever horse obtained the lead at welve score yards from the starting post, the other was compelled to follow him nherever he xent, and to keep withs a certain distunce of him, as iwice
Although the Turkish and Barbary horses had been freely used to produce with the English mare the breed that wis best snited to this exercise, little improvement had been effected. James, with great julgment, determined to try the Arab breed. Piobalily he had not forcotten the stors of the Arabian that had been presented to one of his Scottish churches, five centuries hefore. He purchased from a merchant, named Markham, a celebrated Arabian horse, for which lie gave the extravagant snm of five hundred pounds. Kings, however, like their subjects, are often thwarted and governed by their servants, and the Duke of Newcastle took a dislike to this foreign animal. $\mathrm{He}$ wrote a book, and a very good one, on horsemanship; but he described this Arabian as a little bony horse, of ordinary shape; setting him down as almost wortliless, because, after being regularly trained, he seemed to be deficiert in speed. The opinion of the duke, probably altogether erroneous, liad for nearly a century great weight; and the Arabian liorse lost its reputation among the English breeders.

A south-eastern horse was afterwards brought into England, and purchased by James, of Mr. Place, who afterwards became stud-master or groom to Oliver Crommell. This beautiful animal was called the White Turk; and his name and that of his keeper will long be rememiered. Shortly after this appeared the Helmsley Turk, introduced by Villiers, the first duke of Buckingham. He was followed by Fairfax's Morocco barb. These horses speedily effected a considerable change in the character of our breed, so that Lord Harleigh, one of the old school, complained that the great horse was fast disappearing, and that horses were now bred light and fine for the sake of speed only.

Charles I., however, ardently pursued this favourite olject of English gentlemen; and, a little before his rupture with the parliament, established races in $\mathrm{H}_{j}$ de Park and at New: market.

We owe to Charles I. the introduction of the lit into universal nse in the cavalry service, and generally out of it. The invention of the bit has been traced to as early as the time as the Roman emperors, but for some inexplicable reason it had not been adopted by the English. Charles I., lowerer, in the third rear of his reign, issued a proclamation stating that such liorses as are employed in the serrice, being more easily managed

or thrice his leng!b, or else to be "beaten op," whipped np to the mark by the judlyes who rode to see fuir play. If one horse got betore the other twelve score yards, or any ceriain distance, according as the match was made, he $n$ as accounted to lse beaten. If the lorse which at the heginning was lehind, could get befire bim that tarst led, then the other wus bunnd to $(s) l o w$, and so on, nnil one got two lundred and forly sards, the eighth part of a mile. belore the other, or relinsed some break-neck leap which the other had taken.-Berenger, vol. ii. p. 188. 
by means of the bit and the snaffle, he strictly charged and commanded that, except in times of disport-racing and hunting-no person engaged in the cavalry service should, in riding, use any snaffes, lint bits only.

It was feared by some that the love of hunting and racing was making somewhat too rapid progress; for there is on record a memorial presented to Charles, "touching the state of the kingdom, and the deficiency of good and stout horses for its defence, on account of the strong addiction which the nation had to racing and hunting horses, which, for the sake of swiftness, were of a lighter and weaker mould.'

The civil wars somewhat suspended the inquiry into this, and also the improvement of the breed; yet the advantage which was derived by both parties from a light and active caralry sufficiently proved the importance of the change that had been effected. Cromwell, perceiving with his monted sagacity how much these pursuits were commected with the prosperity of the country, had his stud of race-horses.

At the Restoration a new impulse was given to the cultivation of the horse, by the inclination of the court to patronise gaiety and dissipation. The races at Newmarket, which had been for a while suspended, were restored; and, as an additional spur to emulation, royal plates were given at each of the principal conrses. Charles II. sent his master of the horse to the Levant, to purchase brood mares and stallions. These were principally Barbs and Turks.

James II. lived in too unquiet a period to be enabled to bestow much time on the sports of the turf or the field. He has, however, been represented as being exceedingly fond of hunting, and showing so decided a preference for the English horse as, after his abdication, to have several of them in his stables in France. Berenger speaks of this with much feeling:- "He expressed a peculiar satisfaction in having them, and that at a time, and in a situation in which it is natural to think that they were rather likely to have given him uneasiness and mortification than to have afforded him pleasure."

William III., and Anne, principally at the instigation of her consort, George, Prince of Denmark, were zealous patrons of the turf, and the system of improvement was zealonsly pursued; every variety of Eastern blood was occasionally eugrafted on our own, and the superiority of the newly-introduced breed above the best of the original stock began to be evident.

Some persons imagined that this speed and stoutness might possibly be further increased; and Mr. Darley, in the latter part of the reign of Queen Anne, had recourse to the discarded and despised Arabian. He had much prejudice to contend with, and it was some time before the horse which he selected, and which was afterwards known by the name of the Darley Arabian, at tracted much notice. At length the value of his produce began to be recognised, and to him we are mainly indebted for a breed of horses of unequalled beauty, speed, and strength.

The last improvement furnished all that could be desired: nor was this true only of the thoronghbred or turf horse - it was to a very material degree the case with every description of horse. By a judicious admixture and proportion of blood, we have rendered our hunters, our hackneys, our coach-nay, even our cart-horses, stronger, more active, and more enduring, than they were before the introduction of the race-horse.

The history of the horse in England is a very interesting one. The original breed - that of which mention is first made in history - seems to have been a valuable one. The Conqueror carried away many specimens of it, and they were long held in repute in every country subjugated by the Romans. The insular situation of Britain, and its comparatively little need of the war-horse, led, under several monarchs, to a culpable degree of negligence; and although, perhaps, on the whole, the English were not far belind their Continental neighbours, yet at no period, until within the last century and a half, has Great Britain been at all distinguished on this account: but from that time, and especially during the latter part of it, the British horse has been sought after in every part of the world. There is nothing in our climate that can account for this-nothing in our soil, or this superior excellence would have been acknowledged long ago. "The grand first cause," says Mr. William Percivall, in his introductory lecture at University College, in 1834, — " that, by the steady prosecution and scientific management of which this success has been brought about, appears to me to be breeding; by which I do not only mean the procuration of original stock of a good description, but the continual progressive cultivation of that stock in the progeny by the greatest care in rearing and feeding, and by the most careful selection. On these two circumstances, and particularly on the latter, a. great deal more depends than on the original characters or attributes of the parents. By these means we have progressed from good to better, losing sight of no subsidiary help, until we have attained a perfection in horse-flesh unknown in the whole world beside."*

The love of the turf, and the anxious desire to possess horses of unrivalled excellence, have within the last twenty years spread over the European continent. Everywhere stud-houses have been built and periodical races established, and sporting societies formed of persons of the greatest weight

* Veterinarian, vol. vii. p. 3. 
in the community, and, everywhere, zealous at- / lish horse. This is a circumstance with regard to tempts have been made to improve the native which there is no dispute. It is a matter of hisstock. The coursers of the East might have been tory-and it is highly creditable to our sporting easily procured; a new supply of Arabian blood men and breeders. Mr. Percivall has rightly stated might have been obtained from the native country the cause, but there are some circumstances conof the Barb; but French, and Italians, Germans, nected with this pre-eminence that may give occaRussians, and Flemings, have flocked to the Bri- sion for serious reflection, and which will be best tish Isles. The pure blood of the present Barb considered as the respective breeds of horses pass and Arabian has been postponed, and all have in review. deeply drawn from that of the thorough-bred Eng-

\section{CHAPTER IV}

\section{THF, DIFFERENT BREEDS OF ENGLISH HORSES}

THE RACE-HORSE.

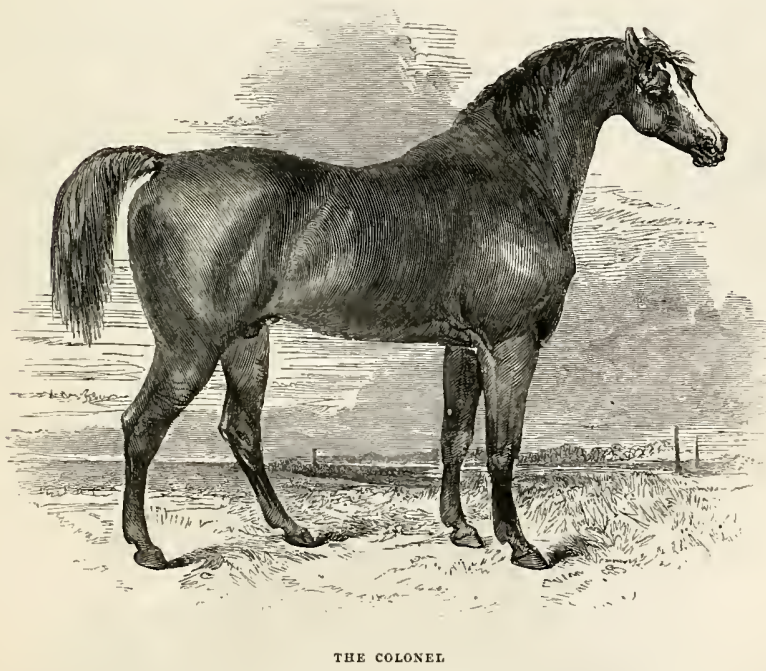

THERE was much dispute with regard to the origin | breeding. If the pedigree of a racer of the present of the thorough-bred horse. By some he was traced through both sire and dam to Eastern parentage; while others believed him to be the native horse, improved and perfected by judicious crossing with the Barb, the Turk, or the Arabian. "The StudBook," which is an authority acknowledged by every English breeder, traces all the old racers to some Eastern origin, or at least until the pedigree is lost in the uncertainty of an earlier period of tions, as in the cases of Sampson and Bay Malton, day is required, it is traced back to a certain extent, and ends with a well-known racer; or if an earlier derivation is required, that ends either with an Eastern horse or in obscurity.

It is now admitted that the present English thorough-bred horse is of foreign extraction, improved and perfected by the influence of climate and diligent cultivation. There are some excep- 
in each of which, although the best horses of their day, there was a cross of vulgar blood; but they are only deviations from a general rule. In our best racing-stables this is an acknowledged principle; and it is not, when properly considered, in the slightest degree derogatory to the credit of our country. The British climate and British skill made the thorough-bred horse what he is.

The beautiful tales of Eastem countries and somewhat remote days may lead us to imagine that the Arabian horse possesses marvellous powers; but it cannot admit of a doubt that the Englishtrained horse is more beautiful and far swifter and stouter than the justly-famed coursers of the desert. In the burming plains of the East and the frozen climate of Russia, he has invariably beaten every antagonist on his native ground. It has been already stated that, a few years ago, Recruit, an English horse of moderate reputation, easily beat Pyramus, the best Arabian on the Bengal side of India.

It must not be objected that the number of Eastern horses imported is far too small to produce so numerous a progeny. It will be recollected that the thonsands of wild horses on the plains of South America descended from only two stallions and four mares, which the early Spanish adventurers left behind them.

Whatever may be the truth as to the origin of the race-horse, the strictest attention has for the last fifty years been paid to his pedigree. In the descent of almost every modern racer not the slightest flaw can be discovered; or when, with the splendid exceptions of Sampson and Bay Mal- ton, one drop of common blood has mingled with the pure stream, it has been immediately detected in the inferiority of form and deficiency of stamina, and it has required two or three generations to wipe away the stain and get rid of its consequences.

The racer is generally distinguished by his beautiful Arabian head; tapering and finely-seton neck; oblique, lengthened shoulders; wellbent hiuder legs; ample muscular quarters; flat legs, rather short from the knee downward, although not always so deep as they should be; and his long and elastic pastern. These will be sepa rately considered when the structure of the horse is treated of.

The Darley Arabian was the parent of our best racing stock. He was purchased by Mr. Darley's brother at Aleppo, and was bred in the neighbouring desert of Palmyra. His figure contained every point, without much show, that could be desired in a turf-horse.

The immediate descendants of this invaluable horse were the Deroushire or Flying Childers; the Bleeding or Bartlett's Childers, who was never trained; Almanzor, and others.

The two Childers were the means through which the blood and fame of their sire were widely circulated; and from them descended another Childer's, Blaze, Snap, Sampson, Eclipse, and a host of excellent horses.

The Devonshire or Flying Childers, so called from the name of his breeder, Mr. Childers, of Carr House, and the sale of him to the Duke of Devonshire, was the fleetest horse of his day. He

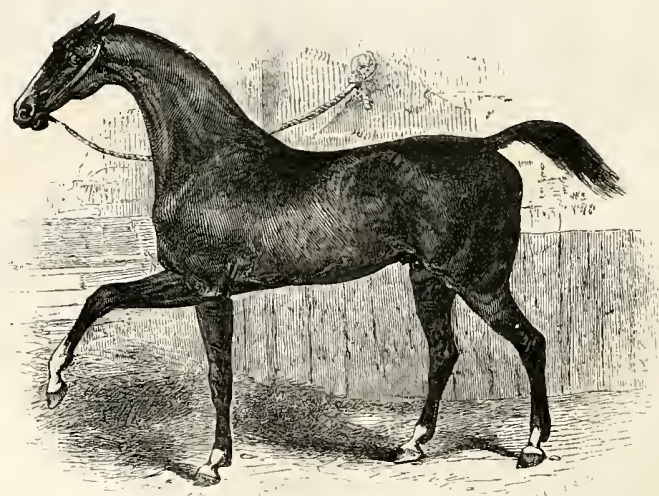


was at first trained as a hunter; but the superior speed and courage which he discovered caused him to be soon transferred to the turf. Common report affirms that he could run a mile in a minute; but there is no authentic record of this. Childers ran over the round course at Newmarket (three miles, six furlongs, and ninety-three yards) in six minutes and forty seconds, and the Beacon course (four miles, one furlong, and one hundred and thirty-eight yards) in seven minutes and thirty secouds. In $177 \%$, a mile was run by Firetail in one minute and four seconds.

In 1755, Bay Malton, the property of the Marquis of Rockingham, ran the four-mile course at York in seven minutes and forty-three seconds, this being seven seconds less time than it had ever been accomplished in before. Some of these old ones could run fast as well as stoutly. Twenty years afterwards there was a beautiful horse, the son of Eclipse, and inheriting a great portion of his speed without his stoutuess. He won almost every mile-race for which he ran, but he never could accomplish a four-mile one. He broke down in 1779 , running over the Beacon course.

One of the most really severe races that ever was run took place at Carlisle in 1761. There were no less than six heats, and two of them dead heats. Each of the six was honestly contested by the winning horse; therefore he ran in gond earnest twenty-four miles: yet there was no breaking dowu, nor any account of the slightest injury received.

The following are some additional instances of the mingled speed and endurance of these horses, and deserve to be placed on record:-
In October 1741, at the Curragh meeting in Ireland, Mr. Wilde engaged to ride one hundred and twenty-seven miles in nine hours. He performed it in six hours and twenty-one minutes. He employed ten horses, and, allowing for mounting and dismounting, and a moment for refreshment, he rode during six hours at the rate of twenty miles an hour.

Mr. Thornhill, in 1745, exceeded this; for he rode from Stiltou to London and back, and again to Loudon, being two hundred and thirteen miles, in eleven hours and thirty-four minutes. This amounts, after allowing the least possible time for changing horses, to twenty miles an hour for eleven hours, and on the turnpike-road and uneven ground.

Mr. Shaftoe, in 1762, with ten horses, and five of them riddeu twice, accomplished fifty miles and a quarter in one hour and forty-nine minutes. In 1763 , he won a still more extraordinary match. He engaged to procure a person to ride one hundred miles a day for twenty-nine days, having any number of horses not exceeding twenty-nine from which to make his selection. He accomplished it on fourteen horses; but on one day he was compelled to ride a hundred and sixty miles, on account of the tiring of his first horse.

Mr. Hull's Quibbler, however, afforded the most extraordinary instance on record of the stoutness as well as speed of the race-horse. In December 1786, he ran twenty-three miles round the flat at Newmarket, in fifty-seven minutes. and ten seconds.

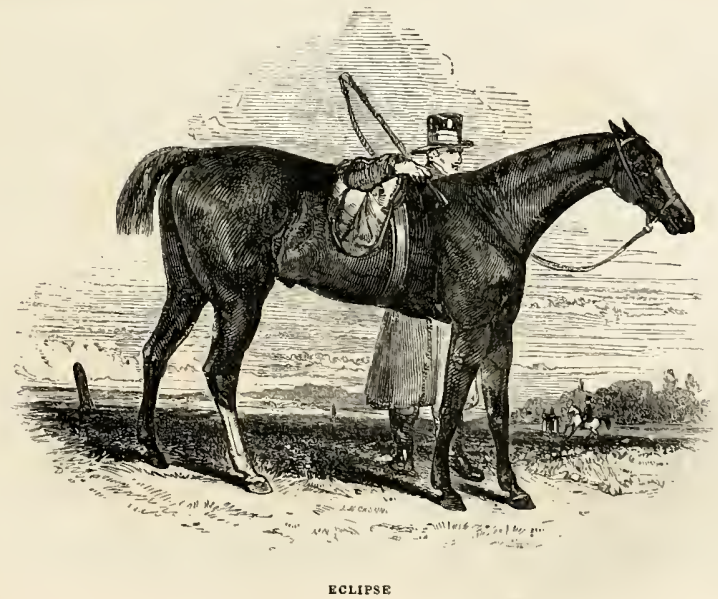


Eclipse was got by Marsk, a grandson of Bartlett's Childers.* He was bred by the Duke of Cumberland, and sold at his death to Mr. Wildman, a sheep salesman, for seventy-five guimeas. Colonel O'Kelly purchased a share of him from Wilduan. In the spring of the following year, when the reputation of this wonderful animal was at its height, O'Kelly wished to become sole orner of him, and bought the remaining share for eleven hundred guineas.

Eclipse was what was termed a thick-wiuded horse, and puffed and roared so as to be heard at a considerable distance. For this or some other cause, he was not brought on the turf until he was five years old.

O'Kelly, aware of his horse's powers, had backed him freely on his first race, in May 1769. This excited curiosity, or perhaps roused suspicion, and some persons attenipted to watch one of his trials. Mr. John Lawrence says, that "they were a little too late; but they found an old woman who gave them all the information they wanted. On inquiring whether she had seen a race, she replied she could not tell whether it was a race or not, but that she had just seen a horse with a white leg running away at a monstrous rate, and another horse a great way behind, trying to run after him; but she was sure he never would eatch the white-legged horse if he ran to the world's end."

The first heat was easily won, when O'Kelly, observing that the rider had been pulling at Eclipse dnring the whole of the race, offered a wager that he placed the horses in the next heat. This seemed a thing so highly improbable, that he immediately had bets to a large amount. Being called on to declare, he replied, "Eclipse first, and the rest nowhere!" The event justified his prediction; for all the others were distanced by Eclipse with the greatest ease, and thus, in the langnage of the turf, they had no place.

In the spring of the following year he beat Mr. Wentworth's Bucephalus, who had never before met with his equal. Tro days afterwards he distanced Mr. Strode's Pensioner, a very good horse; and in the August of the same year he won the great subscription at York. No lorse daring to euter against him, be closed his short career, of seventeen months, by walking over the Newmarket course for the king's plate, on October the 18th, 1770. He was never beaten, nor ever paid forfeit, and won for his owner more than twenty-five thousand pounds.

Eclipse was afterwards employed as a stallion,

- The pedigree of Eclipse affords a singular illustration of the descent of our thorough-bred horses from pure Eastern blood:-

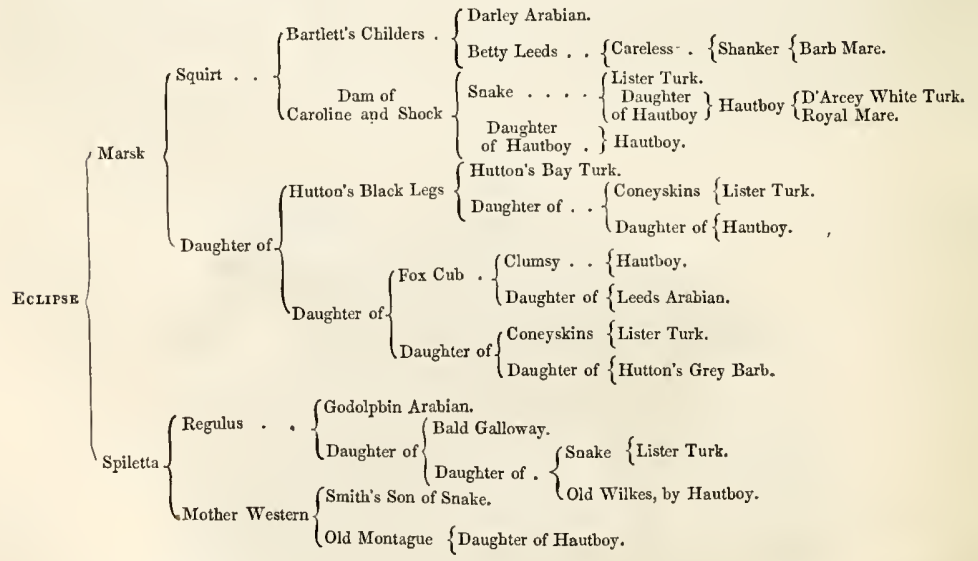

The pedigree of Eclipse will likewise afford another curious and while he was actually leading to the dog-kennel, he was spared illustration of the uncertainty which attends thorough-bred horses. at the intercession of oue of Sir Harry's grooms. Neither BarMarsk was sold at the sale of the Duke of Cumberland's stud for a tlett's Childers, nor Snake, was ever trained. On the side of the mere trife, and was suffered to run almost wild on the New dam, Spiletta never started but once, and was beaten; and the Forest. - He was afterwards purchased for ooe thousand guineas, Godolphin Arabian was purchased from a water.cart in Paris.and before his death covered for oae hundred guineas. Squirt, Smith's Breeding for the Turf, p. $\mathbf{6}$.

when the property of Sir Harry Harpur, was ordered to be shot; 
and produced the extraordinary number of three hundred and thirty-four winners, and these netted to their owners more than one hundred and sixty thousand pounds, exclusive of plates and cups.*

The profit brought to the owner of this extraordinary animal by his services as a stallion must have been immense. It is said that ten years after he was withdrawn from the turf, O'Kelly was asked at what price he would sell him. At first he peremptorily refused to sell him at any price; but after some reflection he said that he would take twenty-five thousand pounds, with an annuity of five hundred pounds a year on his own life, and the annual privilege of seuding six mares to him. The seeming extravagance of this sum excited considerable remark; but O'Kelly declared that he had already cleared more than twenty-five thousand pounds by him, and that he was young enough still to earn double that sum. In fact he did live nearly ten years afterwards, covering at fifty guineas a mare for some part of the time; but his feet having been strangely and cruelly neglected, he became founderel. His feet now rapidly grew worse and worse until he was a very uncertain foal-getter, and the value of his progeny was more than suspected. He died in February 1789 , at the age of twenty-five sears. Of the beauty and yet the peculiarity of his form there has been much dispute. His lowness before was evident enough, and was a matter of objection and reproach among those who could not see how abundantly this was redeemed by the extent and obliquity of the shoulder, the broadness of the loins, the ample and finely-proportioned quarters, and the swelling and the extent-the sloping and the power of the muscles of the fore-arm and of the thighs.

A little before the death of Eclipse, M. St. Bel, the founder of the Veterinary College in St. Pancras, had arrived from France. In teaching the French pupils the general conformation of the horse, and the just proportions of his various parts, it had been necessary that reference should be made to some horse of acknowledged excellence. It occurred to St. Bel that this extraordinary and unbeaten horse would be the proper standard to which the Euglish student might be referred for a similar purpose, and with considerable trouble he formed an accurate scale of the proportions of this noble animal. The reader is presented with it in the subjoined note.t

* The produce of King Herod, a descendant of Flying Childers, was even more uumerous. He got no less than four hundred and ninety-seven winners, who gained for their proprietors upwards nf two hundred thousand pounds. Highflyer was a son of King Herod.

+ PROPORTIONS OF ECLIPSB.

Although it is perfectly true, as stated by Mr. Blaine, in his "Outlines of the Veterinary Act," that "for racing, we require that the greatest possible quantity of bone, and muscle, and sinew,
More than twenty years after the Darley Arabian, and when the value of the Arabian blood was fully established, Lord Godol phin possessed a beautiful but singularly-shaped horse which he called an Arabian, but which was really a Barb. His crest, lofty and arched almost to a fault, will dis. tinguish him from every other horse.

It will likewise be seen from the cut (p. 199), that he lrad a sinking behiud his shoulders, almost as peculiar, and a corresponding elevation of the spine towards the loins. His muzzle was uncom mouly fine, his head beautifully set on, his shoulders capacious, and his quarters well spread out. He was bought in France, where he was actually employed in drawing a cart; and when be was afterwards presented to Lord Godolphin, he was in that nobleman's stud a considerable time before his value was discovered. It was not until the birth of Lath, one of the first borses of that period, that his excellence began to be appreciated. $\mathrm{He}$ was then styled an Arabian, and became, in even a greater degree than the Darley, the founder of the modern thorough-bred horses. He died in 1753 , at the age of twenty-nine.

An intimate friendship subsisted between him and a cat, which either sat on his back when he was in the stable, or nestled as closely to him as she could. At his death, she began to refuse her food, and pined away, and died. Mr. Holcroft gives a similar relation of the attachment between a race-horse and a cat, which the courser would take in his mouth and place in his manger and upon his back without hurting her. Chillaby, called from his great ferocity the Mad Arabiau, whom one only of the grooms dared to approach, and who savagely tore to pieces the image of a man that was purposely placed in his way, had his peculiar attachment to a lamb, who used to employ himself for many an hour in butting away the flies from his friend.

Another foreign horse, was the Wellesley Arabian; the very picture of a beautiful wild horse of the desert. His precise country was never determined. He is evidently neither a perfect Bart, nor a perfect Arabian, but from some neighbonring province, where both the Barb and Arabian would expand to a more perfect fulness of form. This hor'se has been erroneously selected as the pattern of a superior Arabian, and therefore we have introduced him: few, however, of his produce were trained who cas add much to his reputation.

should be gol into the smallest bulk, and that, in addition to great flexibility and some leogth, the limbs must be strongly uuited, the chest deep and eapacious, and the hinder extremities furnished with powerful muscles; for hunting, we must have a similar yet somewhat bulkier horse, with powerful loins, and more powerful quarters; and for the hackney, while we undervalue not the strength of the loins and the quarters, we look more to the elevated withers, and the deep aud muscular shoulders, and the straight and well-formed leg:" yet there is a nearer and a truer proportion between the several paris of these kindred animals than manv persons are disposed to 
At the commencement of the last century, when public races had been established in the neighbourhood of almost every large town, and when many of them were especially patronised by royalty, although there was sufficient oplortunity given for the value of the joung stock to be exhibited, or at least guessed at, the contest principally lay among the adults. The kind of contest which was best calculated to try the real worth of the horse, and to promote the actual improvement of the breed, was one of mingled speed and endurance. They were mostly heats for distances of three or four miles. Occasionally they were for greater lengths, even extending to six or eight miles: and in one case, when the Duke of Queensberry's Dash beat Lord Barrymore's Highlander, twelve miles. This, however, was cruel and absurd, and never established itself among the best supporters of the turf.

Four miles constituted the average distance, not only for king's plates, but for simple matches; and the horses did not sleep on their way. There were occasionally as extraordinary bursts of speed as are now witnessed in our mile-and-a-half races.

Did the horses of those days come to any ex. traordinary harm? Did they ruin themselves by the exertion of one day, and appear no more? The anonymous writer of a most interesting and valuable work-" A Comparative View of the English Racer and Saddle Horse during the Last and Present Centuries"-mentions a horse called Exotic,

allow; and this sketch of them in Eclipse will not only be interesting, hut useful, to the geoeral horseman.

The length of the head of the horse is supposed to be divided into tweaty-two equal parts, which are the commoa measme for every part of the body.

Three heads and thirtee a parts will give the height of the horse fr om the furetop to the grouad.

Three heads from the withers to the ground.

Three heads from the rump to the ground.

Three heads and three parts the whole leagth of the body, frum the most promineat part of the chest to she extremity of the buttocks.

Two heads and twenty parts the heigh of the hody, through the middle of the ceatre of gravity.

Two heads and seven parts, the height of the highest part of the chest from the ground.

Two heads and five parts, the height of the perpendicular line which falls from the articulation of the arm with the shoulder, directly to the hoof.

One head and twenty parts, the beight of the perpendicular line which falls from the top of the fore-leg, dividing equally all its parts to the fetlock.

One head and nineteen parts, the height of the perpeodicular liae from the elhow to the ground.

Ooe head and niueteen parts, the distance from the top of the withers to the stifle. The same measure also gives the dis tance from the top of the rump to the ellow.

One and a half head, the length of the aeck from the withers to the top of the head. The same measure also gives the leagth of the aeck from the top of the bead to its insertion jnto the chest.

One head, the width of the neck at its union with the chest.

Twelve parts of a head, the width of the neek in its aarrowest part.

The same measure gives the breadth of the bedd taken below the eyes.

One head and four parts, the thickness of the hody from the middle of the back to the midale of the belly. that was on the turf eleven years. "We do not know," says our author, "how many times he started during this period, but in the course of it he won eighteen times. In his seventh year on the turf he won a race at Peterborough consisting of four heats of four miles each."

"Four horses were handicapped by Dr. Bellyse at Newcastle-under-Lyne-Sir John Egerton's Astbury, Mr. Milton's Handel, Sir W. Wyune's Tarragon, and Sir Thomas Stanley's Cedric. The following was the result :- Of the first three heats there was no winner, Tarragon and Handel being each time nose and nose; and, although Astbury was stated to have been third in the first heat, yet he was so nearly on a level with the others, that there was a difficulty in placing him as such. After the second heat, the steward requested two other gentlemen to look with him steadily as they came, to try to decide in favour of one of them, but it was impossible to do so. In the third dead heat Tarragon and Handel had struggled with each other until they reeled about as if they were drunk, and could scarcely carry their riders to the scales. Astbury, who had lain by after the first heat, then came out and won. The anuals of the turf cannot produce another such contest, founded on a thorough knowledge of the horses, their ages, and their previous running."

"In 1737, Black Chance, at five years old, won a plate at Durham, carrying ten stone. With the same weight he won the Ladies' Plate at York, in

The same measure gives the breadth of the hody

Also the rump from its summit to the extremity of the huttocks.

Also the distance from the root of the tail to the stifle.

Also the leagth from the stifle to the bock.

Also the height from the extremity of the hoof to the hock.

Tweaty parts of a head, the distance from the extremity of the buttocks to the stifle.

Also the breadth of the rump or croup.

Ten parts of a head, the hreadth of the fore-legs from their anterior vart to the elbow.

Ten parts of a head, the breadth of one of the hind-legs taken heneath the fold of the luattocks.

Eight parts of a bead, the breadib of the ham taken from the bead.

Also the breadth of the bead above the nostrils.

Seven parts of a head, the distance of the eyes from one great angle to the other.

Also the distance between the fore-legs,

Five parts of a head, the thickness of the knees.

Also the breadth of the fure-legs above the knees.

Also the thickness of the hams.

Four parts of a head, the breadth of the pastern, or fetlock joiat.

Also the thickness of the coronet.

Four and a half parts uf the head, the breadth of the coronet.

Three parts of a head, the thickness of the legs at their narrowest part.

Also the breadth of the hinder legs or shanks.

Two and three-quarter parts of a bead, the thickness of the hindpasterns.

Also the breadth of the shanks of the fore-legs.

Two and a quarter parts of a head, the thickness of the forepastems.

Also the breadth of the hiad-pasterns.

One and three-quarter parts of a head, the thickness of the fore and hind sbanks.

* Nimrod on the Chase, the Road, and the Turf, p. 169. 
that year. In 1738, he won the King's Plate at Guildford, beating several horses. He won the Plate also at Salisbury, at Winchester, at Lewes, and at Lincoln-five King's Plates in one seasou, and every race four miles and contested. The same horse was in the field in 1744 , and he walked over for the annual plate at Farnden."**

What are our racers now? They are speedier. That it would be folly to deny.

They are longer, lighter, but still muscular, although shorn of much of their pride in this respect. They are as beautiful creatures as the eye would wish to gaze on, but the greater part of them give in before half the race is run; and out of a field of fifteen, or even twenty, not more than two or three of them live, in the exertion of their best energies, far within the ropes.

And what becomes of them when the struggle is over? After the severe racing, as it is now called, of former times, the horse came again to the starting post with not a single power impaired;

* About the year 1748, Mr. Fenwick's Match'em was in his glory. He was not only celebrated as a racer himself, but he was father of many of the best running horses of that day. It was said that, in all probability, he gained to his owner more money than any horse in the world. He ultimately died at thirty.three years of age.

+ An accoint of the lengths of the principal race-courses may be acceptable to the reader:-

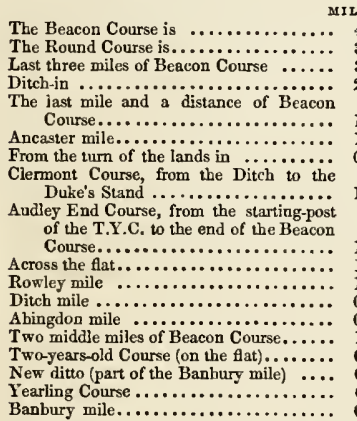

MILES. FUR. YARRS

\begin{tabular}{rrr}
4 & 1 & 138 \\
3 & 4 & 178 \\
3 & 0 & 45 \\
2 & 0 & 97 \\
1 & 1 & 156 \\
1 & 0 & 18 \\
0 & 5 & 181 \\
& & \\
1 & 5 & 217 \\
& & \\
& & \\
1 & 6 & 0 \\
1 & 2 & 24 \\
1 & 0 & 1 \\
0 & 7 & 178 \\
0 & 7 & 211 \\
1 & 7 & 125 \\
0 & 5 & 136 \\
0 & 5 & 136 \\
0 & 2 & 47 \\
0 & 7 & 248 \\
\hline
\end{tabular}

"Previously to 1753 there were only two meetings in the year at Newmarket for the purpose of runniug horses, one in the Spring and another in Octoher. At present there are seven-The Craven, institnted in 1771, in coompliment to the late Earl Craven, and commencing on Easter Monday ; the First Spring, on the Monday fortnight following, and being the original Spring Meeting; the Second Spring, a fortnight after that, and instituted in 1753 ; the $J u l y$, commonly early in that mooth, instituted also in 1753 ; the First October, on the first Monday in that month, being the original October Meeting; the Second October, on the Monday fortnight following, instituted in 1762; and the Third October, or Houghton, a fortnight after that, and instituted 1770. With the last-mentioned meeting, which, weather permitting, generally lasts a week, and at which there is a great deal of racing, the sports of the Turf close for the year, with the exception of Torporley, a very old hunt-meeting in Cheshire, now nearly abandoned; and a Worcester autumn meeting, chiefly for hunters and horses of the gentiemen and farmers within the hunt." - Nimrod-The Turf, 152. and year after year he was ready to meet any and every rival. A single race, however, like that of the Derby, now occasionally disables the winner from ever running again; jet the distance is only a mile and a half. The St. Leger is more destructive to the winner, although the distance is less than two miles.t The race of the day has been run; some heavy stakes have been won by the owner; the animal by whose exertions they were gained is led away, his flanks cut with the whip, his sides streaming with gore, and every sinew strained; and it is sometimes an even chance whether he is ever heard of, or, perhaps, thought of again. He has answered the purpose for which he was bred, and he has passed away.

And by what witchery has all this been accomplished? How came it that skilful and honourable men should have conspired together to deteriorate the character of the racer, and with him that of the English horse generally? Why, there was no conspiracy in the matter. It was

\section{$\triangle 8$ COT HEATH.}

The two-mile course is a circular one, of which the last half is called the old mile. The new mile is straight and up-hill all the way. The T.Y.C. is five furlongs and one hundred and thirty-six yards. EPsom.

The old course, now seldom used except for the cup, is two miles of an irregular circular form, the first mile up-hill. The new Derby course is exactly a mile and a half, and somewhat in the form of a horseshoe: tbe first three-quarters of a mile may be con. sidered as straight running, the bend in the course being very trifling, and the width very great; the next quarter of a mile is in a gradual turn, and the last half-mile straight; the first half-mile is on the ascent, the next third of a mile level, and the remainder is on the descent, till within the distance, where the ground again rises.

The new T.Y.C. is six furiongs; the old T.Y.C., or Woodcot course, is somewhat less than four.

The Craven course is one mile and a quarter. DONCASTER

Is a circular and nearly flat course of about one mile, seren furlongs, and seventy yards.

The shorter courses are portions of this circle. LIVERPOOL.

The new course, now used for both meetings, is flat, a mile and a half round, and with a straight run-in of nearly three-quarters of a mile, and a very gradual rise. MANCHESTER

Is one mile, rather oval, with a hill, and a fine run-in.

A Distance is the length of two hundred and forty yards from the winning post. In the gallery of the winning post, and in a little gallery at the distance post, are placed two men holding crimson flags. As soon as the first horse bas passed the winning post, the man drops his flag; the other at the distance post drops his at the same moment, and the horse which has not then passed that post is said to be distanced, and cannot start again for the same plate or prize.

A Feather-weight is the lightest weight than can be put on the back of a horse.

A Give-and-take Plate is where horses carry weight according to their height. Fourtcen hands are taken as the standard height, and the horse must carry nine stone (the horseman's stone is fourteen pounds). Seven pounds are taken from the weight for every inch below fourteen hands, and seven pounds added for every inch above fourteen hands. A few pounds additional weight is so serious an evil, that it is said, seven pounds in a mile-race are equivalent to a distance.

A Post Match is for horses of a certain age, and the parties possess the privilege of bringing any horse of that age to the post.

A Produce Match is that between the produce of certsin mares in foal at the time of the match, and to be decided when they arrive at a certain age specified 
the natural course of things. The race-horses of the beginning, and even of the middle of the last century were fine powerful animals; they had almost as much fleetness as could be desired, and they had strength that would never tire. He who bred for the turf might in his moments of reflection be pleased by the conviction that, while he was accomplishing his orn purpose, he was breeding an animal valuable to his country. $\mathrm{He}$ might be gratified by this reflection, yet it would not influence the system which he pursued. He would breed to win; and he would naturally try to add a little more speed to the acknowledged power. Thence came the Nambrino and the Sweet Briar, and others who had lost but little of their compactness of form-who had got rid of a portion of that which an enemy might call coarseness, but none of the capacity of the chest, or the substance or the power of the muscular systemwhose speed was certainly increased, and whose vigour was not impaired.

It is not in human nature to be satisfied even with perfection; and it was tried whether a little more fleetness could not be obtained. It was so -and, some thought, with a slight impairment of stontness. There were those, and they were not altogether wrong, who saw in Shark and in Gimcrack an evident increase of speed and little diminution of strength.

It was easy to imagine what would now be the result. The grand principle was speed. It was taken for granted that stoutness would follow -or rather, in the selection of the stock, stoutness was a minor consideration. The result of this was a horse with an elongated frame-as beautiful as his predecessors, or more so, but to the eye of the scientific man displaying diminished muscles and less prominent simews, and sharper and less powerful withers. The fleetness was all that heart could desire, but the endurance was fearfully diminished. Irresistible proof was soon given of this. They conld not run the distances that their predecessors did with ease. Heats became umfashionable-they were esteemed, and with too much truth, severe and cruel. We might refer to the disgraceful exhibitions of Chateau Margaux, and Mortgage, and Lamplighter. The necessary consequence was that the ground run over in the ordinary matches was lessened a full half.

And was not this sufficient to convince the man of the turf-the breeder of horses for his own use-was not this sufficient to convince him of the error which he had committed? Perlaps it was, with regard to those who would give themselves the trouble to think. But the error had been committed. The all-important question was, how could it be repaired? Were they to breed back again to their former stontness? There were indiriduals stout and speedy, but the breed was gone. Beside, the short race had become fashionable. It was determined in two or three minutes. There was not the lengthened suspense of seven or eight rotations of the second-hand of the watch; and who could resist the omnipotence of fashion? Some harsh expressions have been used with regard to the leading sporting characters of that time; but what power had they of resistance? They had bred for speed. They had obtained it. They had obtained that kind of race that would be popular, for it was short. They had no alternative, except with regard to the king's plates. There they should have made a stand. The interests and honour of the country should not have been sacrificed because they had erred. There should have been something left to encourage the continuance of the old and unrivalled blood-something to fall back upon when the fashionable leaders of the sporting world had discovered their error. This battle, however, mnst yet be fought. Additional reasons for it will appear when the present state of the hunter and the road-horse are considered.

There is one circumstance connected with these short races which perhaps has not been sufficiently appreciated. On the old system, the trueness and the stoutness of the horse would generally insure the prize to him that best deserved it; but with the present roung horses and short courses, the actual race being sometimes little more than two or three hundred yards, a great deal depends on the rider. If the cattle are tolerably fairly matched, all depends on him. If he has confidence in the stoutness of his horse, he may distance all his competitors; or he may nurse the fleet but weedy thing to almost the last stride, and dart by the wimning post before his rival has been able to gather hinself up for the last effort.

One thing cannot be demied, that the consciousness in the jockeys of their power, and the account which they will probably be called upon to render of the manner in which they have used it, has led to far more cruelty in the management of these races than ever disgraced the records of former times. Habit had given to the older horses of those days a principle of emulation and of obedience. When the race in reality began, the horse understood the meaning of his rider, and it seldom required any cruel application of the whip or the spur to bring him through if he could win.

Forrester will afford sufficient illustration of this. He had won many hardly-contested races; but on an unfortunate day he was matched against an extraordinary horse, Elephant, belonging to Sir Jennison Shaftoe. It was a four-mile heat over the straight course. They passed the flatthey ascended the hill as far as the distance post - they were nose to nose. Between this and the chair, Elephant got a little ahead. Forrester 
made every possible effort to recover this lost ground, until, finding all his efforts ineffectual, be made one desperate plunge-he seized his antagonist by the jaw to hold him back, and could scarcely be forced to quit his hold. In like manner, a horse belonging to $\mathrm{Mr}$. Quin, in 1753, finding his adversary gradually passing him, seized him by the leg; and both riders were obliged to dismount, in order to separate the-animals.

The youngsters may not have felt all this emulation, nor be disposed painfully to exert their energies to the very utmost; and it may be necessary necessary, in order to accomplish the purpose of the owner by winning the race-that the poor animal should be brutally urged on, until the powers of nature fail, and he retires from the course a cripple for life.

This is a necessary part of the system. It is accounted the duty of the rider-it is a duty on the skilful discharge of which a few of them plume themselves: but it is that which should not be tolerated, and the system of which it is a necessary part should undergo a speedy and an effectual reformation.*

We have been enabled to place at the head of our chapter a portrait of the "Colonel," taken for this work, by Mr. Harvey; and Mr. Goodwin, veterinary surgeon to the Queen, has kindly furnished us with a considerable part of the following account of him and of Fleur-de-Lis :-

He was a chesnut horse, ffteen hands three inches high, with good substance, capital legs and feet, and true action, bred by Mr. Petre in 1825. He was got by Whisker out of a Delphini mare - her dam, Tipple Cider, by King Fergns-the grandam was Sylvia, by young Marsk, out of Ferret, by a brother to Sylvio-Regulus, \&c.

He came out in $182 \%$, when he won the twoyears stakes, beating Kitty, a colt by Trump, and a black colt by Whisker.

* In a former edition of this work, the protest of the author was entered against the barbarous and useless punishment to which some horses were subjected. He bas great pleasure in recording the following confirmation of his opinion:- "There are many jockeys employed by the inferior black-leg species of sportsmen, and even some of a higher class, who will not be convinced that a rider has acted honestly, unless his horse is nearly dissected alive: but, in the strongest prohability, every drop of blood drawn is utterly unnecessary, as it is barbarous and contrary to the very idea of sport, in which even the horse himself ought to share. Such an opinion was given from the heart, as well as from the mature judgment of the late Sir Thomas Charles Bunbury, within a few months of his decease, after five-and-ffty years of experience on the most extensive scale. Although the stout and game horse will run to the whip, the excess of it mnst necessarily sitorten his stride, and, in course, detract from his sueed. Many a race has been lost by a foul cut, or a brutal use of the sptur-either by damping the spirit aud enfeebling the Derve of the horse, or inducing a sulleu disgust and desperation. An esample much talked of at the time, and throngh which a vast sum of money was lost, occurred in the case of a horse of old Duke William, which was pearly home and winning. He received a foul cut with the whip on a tender part, and instantly hung back aud lost the race. With respect to the hot-spirited and washy horses, if they cannot win without the aid of the whip, they will seldom win with it."-Nimrod.
In the same year he carried off tho two-years old stakes at Pontefract, beating Vanish; and the Champagne stakes at Doncaster, beating a filly by Blackleg.

In 1828 he ran a dead heat with Cadland for the Derby, beating Zingaree and twelve others, but he lost the second heat. He won however the St. Leger at Doncaster, beating Belinda, Velocipede, and seventeen others; and walked over for the two hundred sovereigns stakes at the same place. $\dagger$

In 1829 he was beaten at the York Spring Meeting, by Bessy Bedlam, in a match for three hundred sovereigns each-the St. Leger course. He started, but was not placed, for the gold cup at Ascot, being beaten by Zingaree and Mameluke.

In 1830 he won the Craven stakes of ten sovereigns each, beating Harold, Clio, and eight others. He ran second for the gold cup at Ascot, being beaten by Loretta, but beating Greenmantle and Zingaree. In the same year he won a Sweepstake at Stockbridge; and ran third for the gold cup at Goodwood, but was beaten by Fleur-de-Lis and Zingaree.

In 1831 he won the Craven stakes at Epsom; and ran a dead heat with Mouch for the Oatlands at Ascot; but running the second heat with her, he broke down-the suspensory ligaments failing in both legs. He did not continue lame; but the enlargement of the fetlock, and the traces of the iron, plainly indicated that he could no longer be depended upon as a racer.+

We are also gratified in being enabled to present our readers with a portrait of that beautiful and almost unrivalled mare Fleur-de-Lis, by the same artist.

She was bred by Sir M. W. Ridley, in 1822, and was got by Bourbon, the son of Sorcerer, out of Lady Rachel, by Stamford-her dam, Young Tachel, by Volunteer, out of Rachel, sister to Maid of all Work, and by both the sire and the dam was descended from Highflyer. Bourbon started twenty-three times, out of which he was successful seventeen times; and carried off two classes of the Newmarket October Oatland stakes, the Claret, the Craven, and the Trial, besides four

+ At the latter end of 1828 he was sold by Mr. Petre to George IV. for four thousand guineas. He coutinued, however, on the turf, and won many races.

$\ddagger$ He then covered at the Royal Stud, Hampton Court, until that establishmeot was sold at the death of William IV. He was purchased by Mr. Tattersall, at the sale, for one thousand fire Luudred and fifty guineas, who sent him to his present owners, a stud conipany in Russia.

He possessed great speed; but his progeny, like himself, were deficient in that stoutness so essential to a real good horse. D'Egville, Posthaste, Toothill, and The Drummer were some of the most successful of his stock. On the whole, he could not be considered as having always realised the expectations of those who put mares to him. 


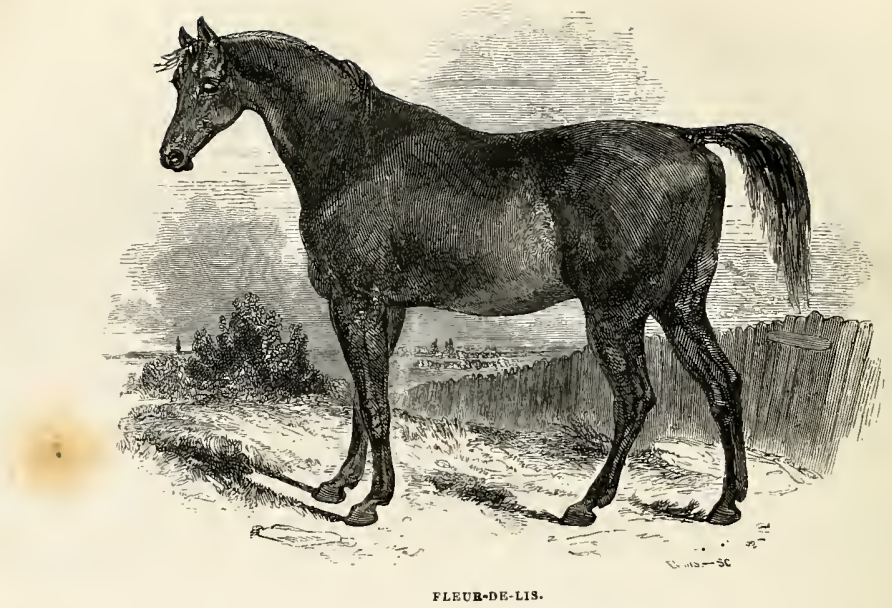

thousand one hundred and thirty guineas in specie.

She was the finest mare in form and size ever produced in England. She stood fully sixteen hands, and had extraordinary good legs, and feet that never failed. Her speed was good, but her forte was distance. Independent of her being so fine a mare in every other respect, her chest was one of extraordinary capacity in an animal of such unusual depth in the girthing place.

She first appeared on the turf at three years old, at Newcastle-upon-Tyne, for the twenty-five guineas sweepstakes-one mile-and beat her four competitors.

On September 8, she won a sweepstake of twenty guineas, and twenty added-six subseribers -at Pontefract.

On the 20th of the same month, she started for the Great St. Leger, and would probably have won it had she not been thrown down in the runniug by Actæon, as she beat Mammon afterwards, and all the best horses of that description. On the $23 \mathrm{~d}$ of September, however, she won a sweepstake of twenty sovereigns each, with twenty added-nineteen subseribers.

On May 20,1826, she was in the sweepstakes of twenty sovereigns each-two miles-seven subscribers, at the York Spring Meeting. Lottery, Actæon, and Catterick was among ber opponents. After the first hundred yards, Lottery got in front, closely followed by the others at strong running. He kept ahead until nearly the distance post, when Fleur-de-Lis shot ahead, Aetæon and Catterick

letting loose at the same time. The filly, however, kept in front, and won in gallant style by half a length.

On the next day she won the gold cup, opposed again by Actæon, and also by the Alderman and six others. The betting was seven to four on the Alderman, and four to one against the winner. The Alderman took the lead, and made all the running up to the distance post. They were in a cluster at the stand, when Actæon and Fleur-deLis came out. A severe struggle took place, the mare winning by a length.

July 6 , she won the gold cup at Newcastleupon-Tyne-ten subscribers. The betting was fifteen to eight in favour of the winner.

On the next day she won the first heat for the town-plate, and walked over the course for the second heat.

On September 19, she won the Doncaster stakes of ten sovereigns each, with twenty added by the corporation - twenty-nine subscribers. She was opposed by Actæon, Lottery, Jerry, and others; but the bets were five to four on Fleurde-Lis.

On the 21st, she wou the gold cup, beating Mulatto, Helenus, and others. The betting was five to four on her.

On the 29th she won the gold cup at Lincoln, walking over the course.

May the 12th, 1827, she won the Constitution stakes at the York Spring Meeting-fifteen subscribers, at twenty guineas each, among which were Jerry, Humphrey Clinker, and Sirius; the betting 
six to five against Fleur-de-Lis. During most of the way, Fleur-de-Lis was in front, Jerry second, Humphrey Clinker third, and Sirius fourth. When between the rails Jerry looked as if he would win; but suddenly swerving, Fleur-de-Lis won easily by two lengths.

On the 27 th, she ran at Manchester, for a tureen, value one hundred guineas, with twentyfour subscribers of ten sovereigns each; betting, five to four on her. On making the last turn she slipped, and nearly came on her side. She, however, recovered; but, after a severely-contested race, lost by half a head.

On July the 13th, she won the gold cup, and sweepstakes of ten guineas each, at Preston; twenty subscribers. The course was three miles and a distance. It was doubted whether any borse could be found to compete with Fleur-de-Lis; but at length Mr. Milton's old grey horse Euphrates and Sir W. Wynn's Signorina entered the lists. The old horse looked as well and appeared as gay as ever, and Signorina was ever a well-known good mare; but the odds were three to one on Fleur-de-Lis. After the usual preparations, the competitors were brought to the post, and away they went. Euphrates made play, dashing off at score, and at about half a mile had got so far ahead, that Fleur-de-Lis, who evidently was waiting on Signorina, found it necessary to creep rather nearer, lest the old gelding should steal the race. Euphrates kept the lead, and seemed determined to do so as long as he could; and he was allowed to do do this until within about a distance from home, when both the mares shot ahead, and the gallant old horse gave it up. The contest now became highly interesting. Signorina ran well in, and was beaten only by a neck.

She likewise won a Goodwood cup, beating the Colonel and Zingaree, both out of the same stables with herself, and nearly distancing a field of others.

This is a continuance of success that is scarcely equalled in the annals of the turf. The loss of the Manchester cup was solely attributable to the accident that occurred while she was running. She likewise failed in the St. Leger; but there she was thrown down by auother horse during the race. She was never beaten in a fair struggle. Her owner, however, was perhaps justified in selling her, as he did, for one thousand five hundred guineas, when be knew that he was consigning her to the royal stud ; for he thus rendered it impossible that the laurels that she had won could ever be torn from her.

She possessed the points and form of a racer to a degree of perfection which has been rarely met with. It is true that she stood nearly sixteen hands; but the depth of her chest, her length, her quarters, her pasterns, marked her as equally framed for motion and for endurance. Her colour was bay, with black legs and feet, and a small stroke on the forehead. The slouched ear has been found fault with by some; others, and perhaps with more truth, have considered it as an indication of pure blood. It has been hereditary in some of our stables, as in the Orville family.

She was bought of Sir M. W. Ridley, for George IV., for one thousand five hundred guineas.

Her produce, after having been put into the stud, was eagerly sought after by foreigners, and sent out of the country. Fleur-de-Lis is now (1812) in the possession of Monsieur Lupin, in France, who bought her at the Hampton Court sale for the inadequate sum of five hundred and fifty guineas. The valuable mare Wings, the dam of Caravan, was sold to the same person for six hundred guineas; and Young MIouse, the dam of Rat Trap, for three hundred and sixty fruineas.

\section{THE HUNTER.}

There are few agriculturists who have not a little liking for the sports of the field, and who do not fancy rich music in the cry of the hounds. To what extent it may be prudent for them to indulge in these sports circumstances must decide, and they deserve the most serious consideration. Few can, or, if they could, ought to keep a hunter. There are temptations to expense in the field, and to expense after the chase, which it may be difficult to withstand. The hunter, however, or the hunting horse, $i$. $e$. the horse on which a farmer, if he is not a professed sportsman, may occasionally with pleasure, and without disgrace, follow the hounds, - is in value and beauty next to the racer.

Fashion and an improved state of the agriculture of the country have materially increased the speed of the chase. The altered character of the fox-hounds, and the additional speed which they have lately acquired, compel the farmer to ride a better horse, or he will not live among his companions after the first burst. Stoutness is still required, but blood has become an essential quality.

In strong, thickly-inclosed countries, the halfbred horse may get tolerably well along; but for general use the hunter should be at least threequarters, or perhaps seven-eighths bred. When he can be obtained with bone enough, a thorough bred horse will form the best of all hunters; especially if he has been taught to carry himself sufficiently high to be aware of and to clear his fences.

He should seldom be under fifteen or more than sixteen hands high; below this standard he cannot always measure the object before him, and above it he is apt to be leggy and awkward at his work.

The first property of a good hunter is, that he should be light in hand. For this purpose his head must be small; his neck thin and especially thin beneath; his crest firm and arched, and his jaws wide. The head will then be well set on. It 


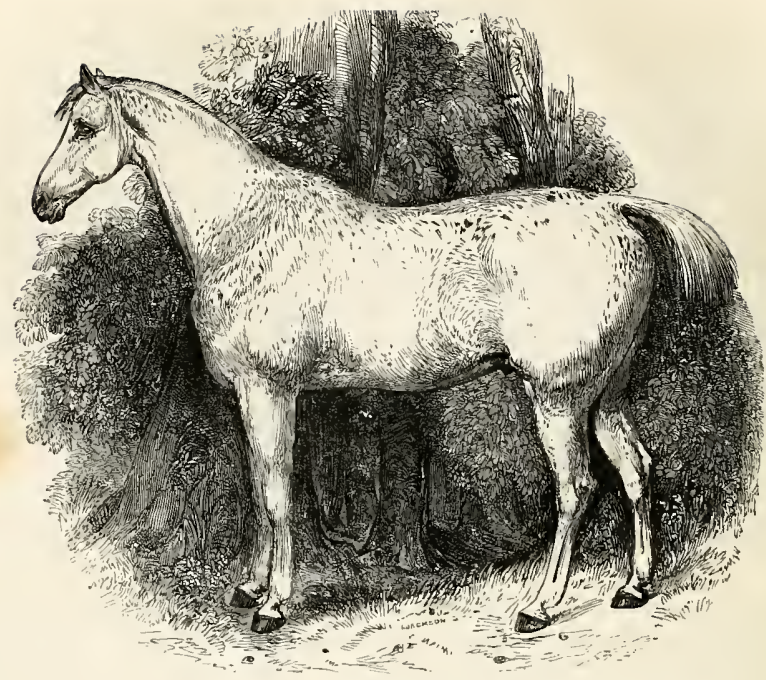

THE HUNTER.

will form that angle with the neck which gives a light and pleasant mouth.

The forehand should be loftier than that of the racer. A tnrf horse may be forgiven if his hind quarters rise an inch or even two above his fore ones. His principal power is wanted from behind, and the very lowness of the forehand may throw more weight in front, and cause the whole machine to be more easily and speedily mored. A lofty forehand, however, is indispensable in the humter; and a shoulder as extensive as in the racer and as oblique, and somewhat thicker. The saddle will then be in its proper place, and will continue so, however long may be the run.

The barrel shonld be romder, in order to give greater room for the heart and lungs to play, and to send more and purer blood to the larger frame of this horse, especially when the run continues unchecked for a time that begins to be distressing. A broad chest is always an excellence in a hunter. In the violent and long-continued exertion of the chase the respiration is exceedingly quickened, and abundantly more blood is hurried through the lnngs in a given time than when the animal is at rest. There must be sufficient room for this, or he will not only be distressed, but possibly destroyed. The majority of the horses that perish in the field are narrow-chested.

The arm should be as muscular as that of the racer, or even more so, for both strength and endurance are wanted.

The leg should be deeper than that of the racehorse-broader as we stand at the side of the horse-and especially beneath the knee. In proportion to the distance of the tendon from the cannon or shank-bone, and more particnlarly a little below the knee, is the mechanical advantage with which it acts.

The leg should be shorter. Higher action is requined than in the racer, in order that the legs may be clearly and safely lifted over many an obstacle, and, particularly, that they may be well doubled up in the leap.

The pastem should be shorter, and less slanting, yet retaining considerable obliqnity. The long pastern is useful, by the yielding resistance which its elasticity affords to break the concussion with which the race-horse from his immense stride and speed must come on the ground: and the oblique direction of the different bones beautifully contributes to effect the same purpose. With this elasticity, however, a considerable degree of weakness is necessarily connected, and the race-horse occasionally breaks down in the middle of his course. The hunter, from bis different action, takes not this length of stride, and therefore wants not all this elastic mechanism. He more needs strength to support his own heavier carcase, and 
the greater weighit of his rider, and to undergo the fatigue of a long day. Some obliquity, however, he requires, otherwise the concussion even of his shorter gallop, and more particularly of his frequently tremendous leaps, would inevitably lame him.

The foot of the hunter is a most material point. The narrow contracted foot is the curse of much of the racing blood. The work of the racer, however, is all performed on the turf; but the foot of the hunter is battered over many a flinty road and stony field, and, if not particularly good, will soon be disabled and ruined.

The position of the feet in the hunter requires some attention. They should if possible stand straight. If they turn a little outward, there is no serious objection; but if they turn inward, his action cannot be safe, particularly when he is fatigued or over-weighted.

The body should be short and compact, compared with that of the race-horse, that he may not in his gallop take too extended a stride. This would be a serious disadvantage in a long day and with a heavy rider, from the stress on the pasterns; and more serious when going over clayey poached ground during the winter months. The compact short-strided horse will almost skim the surface, while the feet of the longer-reached animal will sink deep, and he will wear himself out by efforts to disengage himself.

Every sporting man knows how much more enduring is a short-bodied horse in climbing hills, although perhaps not quite so much in descending them. This is the secret of suiting the race-horse to his course; and unfolds the apparent mystery of a horse decidedly superior on a flat and straight course, being often beaten by a little horse with far shorter stride, on uneren ground and with several turnings.

The loins should be broad; the quarters long; the thighs muscular; the hocks well bent, and well under the horse.

The reader needs not to be told how essential temper and courage are. A hot irritable brute is a perfect nuisance, and the coward that will scarcely face the slightest fence exposes his owner to ridicule.*

* The grey hunter, a portrait of which is given in page 244, possesses a very bigh character in the Croydon buat. He was bred in Warwickshire, and there bis education commeaced. The country being a severe one, the powers of this noble animal were fully dereloped, and be left Warkwickshire in high repute.

He was purchased by Mr. Aolerson, of Piceadilly, for a considerable sum, and by him suld to Mr. Clagget, is 1832 . He became the favourite hunter of that gentleman, and under his guidance performed many gallant feats in vaiuus parts of Surrey. In 1835 he was purchased by Sir Edmund Antrobus at a heavy sum; and for five seasons was the worthy Barooet carried at his ease hy this noble aoimal over hill, ridge, and brook, and maay of those ugly yawos, with which this part of Surrey abounds. The author's friend, Mr. Thomas Tumer, of Croydon, kindly procured him permissien to have a portrait of this noble animal takea by Mr. Harvey; and says in one of bis letters, "I never beard of a hlot an the old horse's escutcheon," vor. $t$.
The principte of preparing both the race-horse and the hunter for their work is the same, and can have no mystery about it. It consists in getting rid of all superfluous flesh and fat by physic and exercise, yet without too much lowering the animal; and particularly in bringing him by dint of exercise juto good wind, and accustoming hin to the full trial of his powers without overstraining or injuring him. Two or three doses of physic as the season approaches, and these not too strong; plenty of good hard meat; and a daily gallop of a couple of miles, at a pace not too quick, will be nearly all that can be required. Physic must not indeed be omitted; but the three words, air, exercise, food, contain the grand secret and art of training.

The old hunter may be fairly ridden twice, or, if not with any very hard dass, three times in the week; but, after a thoroughly trying day, and evident distress, three or four days' rest should be allowed. They who are merciful to their horses, allow about thirty days' work in the course of the season, with gentle exercise on each of the intermediate days, and particularly a sweat on the day before hunting. There is an account, however, of one horse who followed the fox-hounds seventy-five times in one season. This feat has never been exceeded.

We recollect to have seen the last Duke of Richmond but one, although an old man, and when he had the gout in his hands so severely that he was obliged to be lifted on horseback, and, both arms being passed throngh the reins, were crossed on his breast, galloping down the steepest part of Bow Hill, in the neighbourhood of Good. wood, almost as abrupt as the ridge of an ordinary house, and cheering on the hounds with all the ardour of a youth. $\dagger$

+ Sir Joba Malcolm (in his Sketches of Persia) gives an amusing account of the impression which a fox-bunt in the English style made on an Arab.

"I was entertained by listeoing to an Arah peasant, who, with animated gestures, was narrating to a group of his countrymen all he bad seen of this noble hunt. "There came the fox," said he, pointing with a crooked stick to a clump of date-trees, 'there be came at a great rate. I hallooed, but nobody heard me, and I thought he must get away; hut when he got quite out of sight, up came a large spotted $\mathrm{dog}$, and theo another and another. They all had their noses to the ground, and gave tongue-whow, whow whow, so loud, I was frightened. Away went these devils, who seoe found the poor animal. After them galloped the Foriagees (a corruption of Frank, the name given to a European over all Asia), shoutiog and trying to make a noise louder than the dogs. No wonder they killcd the fox among them."

The Treasurer Burleigh, the sage councillor of Queea Elizabeth, could not enter into the pleasures of the chase. Old Andrew Fuller relates a quaint story of him :-

"When some nobleman bad gottea William Cecil, Lord Bur. leigh, to ride with them a huntiag, and the sport began to be cold, "What call you this?' said the treasurer. 'Oh! now the dogs are at fault,' was the reply. 'Yea,' quoth the treasurer, 'take me again a such a fault, and Il give you leave to punish me." "

In former times it was the fashion for women to hunt almost as often and as keealy as the mea. Queen Elizabeth was extremely fond of the chase. Rowland Whyte, in a letter to Sir Robert Sidney, says, "Her Majesty is well, and excellently disposed 
The difference in the pace, and the consequent difference in the breed of the horse, have effected a strange alteration in the nsage of the hunter. It is the almost invariable practice for each sportsman to have two, or sometimes three horses in the field, and after a moderate day's sport the horse has his three or four days' rest, and no ferrer than five or six after a severe run. When a little more speed was introduced into the turf horse, thie half-bred or three-parts-bred horse, which constituted the racer of thirty years ago, soon acquired a portion of the increase of speed, and in consequence of this began to be inconveniently or annoringly close to the hounds. A change then took place in the breed of the hound. This, however, as might be expected, was carried a little too far, and they soon legan to run at a rate to which the far greater proportion of the half-breds were altogether unequal. The thorough-bred horse then began to find his way into the field. The prejudice was strong against him at first. It was said that he conld not take his leaps like the old hunter: but, after a little training, he became equal in this respect to the very best of his predecessors, and superior to the greater part of them. This is well treated of by Nimrod in his work on "The Cbase."

The horse fully shares in the enthnsiasm of his rider. It is beautiful to watch the old hunter who, after many a winter's hard work, is turnerl into the park to enjoy himself for life. His attitude and his countenance when, perchance, he hears the distant cry of the dogs, are a study. If he can, he will break his fence, and, over hedge, and lane, and brook, follow the chase, and come in first at the death.

A horse that had, a short time before, been severely fired on three legs, and was placed in a loose box, with the door, four feet high, closed, and an aperture over it little more than three feet square, and standing himself nearly sixteen hands, and master of fifteen stone, hearing the cheering of the huntsman and the ery of the dogs at no great distance, sprung throngli the aperture without leaving a single mark on the bottom, the top, or the sides.

Then, if the horse is thus ready to exert himself for our pleasure-and pleasure alone is here the object-it is indefensilule and brutal to urge him beyond his own natural ardour so severely as we sometimes do, and even until nature is quite

to hunting ; for every second day she is on horseback, and continnes the sport loug."

This custom soon afterwards began to declinc, and the jokes and scarcasns of the witty cout of Charles II. contributed to dixcomenance $i t$.

It is a curons circumstance, that the first work on hunting that proceeded from the press was from the pen of a female, Juliaua Burnes, or Berners, the sister of Lord Berners, and prioress of the munnery of Sopewell, about the year $\mathbf{1 4 8 1}$. exhausted. We do not often hear of a "hard day," without being likewise informed, that one or more horses either died in the field, or scarcely reached home before they expired. Some riders have been thoughtless and cruel enough to kill two horses in one day. One of the severest chases on record was by the king's stag-hounds. There was an uninterrupted burst of four hours and twenty minutes. One horse dropped dead in the field; another died before he could reach the stable; and seven more, within the week ensuing.

It is very conceivable, and does occasionally happen, that, entering as fully as his master into the sports of the day, the horse disdains to yield to fatigue, and voluntarily presses on, until, nature being exhansted, he falls and dies: but much oftener, the poor animal has, intelligibly enough, hinted his distress; unwilling to give in, yet painfully and falteringly holding on, while the merciless rider, occasionally, rather than give up one hour's enjoyment, tortures him with whip and spur, until he drops and dies.

Although the hunter may not willingly relin quish the chase, he who "is merciful to his beast" will soon recognise the symptoms of excessive and dangerons distress. To the drooping pace and staggering gait, and heaving flank, and heavy bearing on the hand, will be added a very peculiar sound. The inexperienced person will fancy it to be the beating of the heart; but that has almost ceased to pulsate, and the lungs are becoming gorged with blood. It is the convulsive motion of the diaphragm, called into violent action to assist in the now laborious office of breathing. The man who proceeds a single step after tlis, onght to suffer the punishment he is inflicting."

Let the rider instantly dismount. If he has a lancet and skill to use it, let him subtract five or six quarts of blood; or, if he has no lancet, let him deeply cut the bars of the palate with a knife. The lungs will be thus relieved, and the horse may be able to crawl home. Then, or before, if possible, let some porrerful cordial be admin-

* We shondd almost rejuice if the abnsed quailruped, cruelly nrged beyond his powers, were to infliet on his riller the punishment which a Spanish ruffian received when mercilessly torturing, in a similar way, a poor Indian slave, who was earrying him on his back over the mountains. It is thus related by Captain Cochrane (Colombia, ii. 357) - "Shortly after yassing this stream, we arrived at an abrupt precipice which went perpendicularly. down about fifteen hundred feet, to a mountain torrent below. There Lieutenant Ortegas narrated to me the following anendote of the cruelty and punishment of a Spanish officer:-This inhoman wretch having fastened on an immense pair of mule spurs, was incessantly darting the rowels into the bare flesh of the tortured sillero, who in vain remonstrutell with his persecntor, and assured him he could not quicken his pace. The officer only plied his spurs the more in propnrtion to the murmurs of the sillero. At last the man, rouved to the highest pitch of infuriated excitement and resentment. from the relentless attacks of the officer, on reach:ing this place, jerked him from his chair into the immense depth of the torrent below, where he was killed, and his body could uot be recovered. The sitlero dashed off at full spced, escaped into the mountain, and was never after heard of." 
istered. Cordials are, generally speaking, the disgrace and bane of the stable; but here, and almost here alone, they are truly valuable. They may rouse the exhausted powers of nature. They may prevent what the medical man would call the re-action of inflammation, although they are the veriest poison when inflammation has commenced.

A favourite hunter fell after a long burst, and lay stretched out, convulsed, and apparently dying. His master procmed a bottle of good sherry from the house of a neighbouring friend, and poured it down the animal's throat. The patient immediately began to revive: soon afterwards, he got up, walked home, and gradually recovered. The sportsman may not always be able to get this, but he may obtain a cordial-ball from the nearest veterinary surgeon; or, such aid not being at hand, he may beg a little ginger from some good housewife, and mix it with warm ale; or he may give the ale alone, or even strengthened with a little ardent spirit. When he gets home, or if he stops at the first stable he finds, let the borse be put into the coolest place, and then well clothed, and diligently rubbed about the legs and belly. The practice of putting the animal, thus distressed, into "a comfortable warm stable," and excluding every breath of air, las destroyed many valuable horses.

We are now describing the very earliest treatment to be adopted, and before it may be possible to call in an experienced practitioner. This stimulating plan would be fatal twelve hours afterwards. It will, however, be the wisest course to commit the animal, the first moment it is practicable, to the care of the veterinary surgeon, if such a one resides in the neighbourhood and in whom confidence can be placed.

The labours and the pleasures of the hunting season being passed, the farmer makes little or no difference in the management of his untrained horse; but the wealthier sportsman is somewhat at a loss what to do with his. It used to be thonght, that when the animal had so loug contributed, sometimes voluntarily, and sometimes with a little compulsion, to the enjoyment of his owner, he ought, for a few months, to be permitted to seek his own amusement, in his own way; and he was turned out for a summer's run at grass. Fashion, which goverus everything, and now and then most cruelly and absurdly, has exercised her tyranny in the case of the hunter. His field, where he could wander and gambol as be liked, is changed to a loose box; and the liberty in which he so evidently exulted, to an hour's walking exercise daily. $\mathrm{He}$ is allowed vetches, or grass occasionally; but from his box he stirs not, except for his dull morning's round, until he is taken into training for the next winter's business.

In this, however, as in - most other things, there is a medium. There are fow horses who have not materially suffered in their legs and feet, before the close of the lumting season. There is nothing so refreshing to their feet as the damp coolness of the grass into which they are tumed in April or May; and nothing so calculated to remove every eulargement and sprain, as the gentle exercise which the animal voluntarily takes while his legs are exposed to the cooling process of evaporation that is taking place from the herbage on which he treads. The experience of ages has shown, that it is superior to all the embrocations and bandages of the most skilful veterinarian. It is the renovating process of nature, where the art of man fails.

The spring grass is the best physic that can possibly be administered to the horse. To a degree, which no artificial aperient or diuretic can reach, it carries off every humour that may be lurking about the animal. It fines down the rounduess of the legs; and, except there is some bony enlargement, restores them almost to their original form and strength. When, however, the summer has thoroughly set in, the grass ceases to be succulent, aperieut, or medicinal. The ground is no longer cool and moist, at least during the day; and a host of tormentors, in the shape of flies, are, from sunrise to sumset, persecuting the poor auimal. Running and stamping to rid himself of his plagues, his feet are battered by the hard ground, and he newly, and perhaps more severely, injures his legs. Kept in a constant state of irritation and fever, he rapidly loses his condition, and sometimes comes up in August little better than a skeleton.

Let the horse be turned out as soom as possible after the hunting season is over. Let him have the whole of May, and the greater part, or possibly the whole of June; but when the grass fails, and the ground gets hard, and the flies torment, let him be taken up. All the benefits of turning out, and that which a loose box and artificial physic can never give, will have been oltained, whthout the inconvenience and injury that attend an injuliciously protracted run at glass, and which, arguing against the use of a thing from the abuse of it, have been improperly urged against turning out at all.

The Steeple Chase is a relic of ancient foolhardiness and cruelty. It was the form under which the horse-race, at its first establishment, was frequently decided. It is a race across the country, of two, or four, or even a greater number of miles, and it is generally contrived that there shall be some deep lane, or wide brook, and many a stiff and dangerous fence between. It is ridden at the evident hazard of the life of the sportsman; and it likewise puts to hazarl the life or enjoyment of the horse. Many serious accidents have hap. pened both to the borse and his rider, aud tho 
practice must ere long get into disuse; for, while it can have no possible recommendation but its foolhardiness, it has on many occasions been disgraced by barefaced dishonesty.

\section{THE HACKNEY.}

The perfect Hackney is more difficult to find than even the hunter or the courser. There are several faults that may be overlooked in the hunter, but which the road-horse must not have. The former may start; may be awkward in his walk, or even his trot; he may have thrushes or corns; but if he can go a good slapping pace, and has wind and bottom, we can put up with him and prize him: but the hackney, if he is worth having, must have good fore-legs, and good hinder ones too; he must be sound on his feet; even-tempered; no starter; quiet, in whatever situation he may be placed; not heavy in hand; and never disposed to fall on his knees.

If there is one thing more than any other in which the possessor, and, in his own estimation at least, the tolerable judge of the horse, is in error, it is the action of the road-horse: "Let him lift bis legs well," it is said, "and he will never come down."

In proportion, however, as he lifts his legs well, will be the force with which he puts them down again; the jar and concussion to the rider; and the battering and wear and tear of the feet. A horse with too great "knee action" will not always be speedy; he will rarely le pleasant to ride, and he will not, in the long-run, be safer than others. The careless daisy-cutter, however pleasant on the turf, should indeed be avoided; but it is a rule, not often understood, and sometimes disputed, but which experience will fully confirm, that the safety of the horse depends a great deal more on the manner in which he puts his feet down, than on that in which he lifts them up: more on the foot being placed at once flat on the ground, or perhaps the heel coming first in contart with it, than on the highest and most splendid action.

When the toe first touches the ground, it may be readily supposed that the horse will occasionally be in danger. An unexpected obstacle will throw the centre of gravity forrard. If the toe digs into the ground before the foot is firmly placed, a little thing will cause a trip and a fall.

For pleasant riding and for safety also, a hackney should not carry his legs too high. His going a little too near to the ground is not always to be considered as an insuperable objection. The question is, does he dig his toe into the ground?

$\mathrm{He}$ should be mounted and put to the test. Let his feet be taken up and examined. If the shoe, after having been on a week, or a fortnight, is not unnecessarily worn at the toe, and he is felt to put his foot flat on the ground, he may be bought without scruple, although he may not have the lofty action which some have erroneously thought so important.

Every lorse, however, is liable to fall; and hence comes the golden rule of riding, "Never trust to your horse," but almays feel his mouth lightly. He does wrong who constantly pulls might and main; he will soon spoil the animal's mouth. He does worse who carelessly throws the reins on the neck of the horse. Always feel the mouth lightly. The horse may thus have occasional and immediate assistance before he is too much off the centre of gravity, and when a little check will save him. By this constant gentle feeling he will likewise be induced to carry his head well, than which few things are more conducive to the easy, beautiful, and safe going of the horse.

The road-horse may and should, like the hunter, possess different degrees of breeding, according to the nature of the country and the work required of him. When approaching to thorough-bred he may be a splendid animal, but he will be scarcely fitted for his duty. His legs will be too slender, his feet too small, his stride too long, and he will rarely be able to trot. Three parts of blood, or eren half, for the horse of all-work, will make a good and useful animal.

The hackney should be a hunter in miniature, with these exceptions. His height should rarely exceed fifteen hands and an inch. $\mathrm{He}$ will be sufficiently strong, and more pleasant for gencral work, below that standard. Some will imagine, and perhaps with justice, that the portrait which we give of the road-horse represents him as somewhat too tall. He certainly should be of a more compact form than the hunter, and have more bulk according to his height; for he has not merely to stand an occasional and perhaps severe burst in the field, but a great deal of every-day work.

It is of essential consequence that the bones beneath the knee should be deep and flat, and the tendon not tied in.

The pastern should be short, and although oblique or slanting, yet far less so than that of the race-horse or the lunter. There should be obliquity enough to give pleasant action, but not to render the horse incapable of the wear and tear of constant and sometimes hard work.

The foot is a matter of the greatest consequence in a hackney. It should be of a size corresponding with the bulk of the animal, neither too hollow nor too flat, open at the heels, and free from corns and thrushes.

The fore-legs should be perfectly straight. There needs not a moment's consideration to be convinced that a horse with his knees bent will, 
from a slight cause, and especially if he is overweighted, come down.

The back should be straight and short, yet sufficiently long to leave comfortable room for the saddle between the shoulders and the huck without pressing on either. Some persons prefer a hollowbacked horse. He is generally an easy one to go. He will canter well with a lady; but he will not carry a heavy weight, nor stand much hard work.

The road-horse should be high in the forehand, round in the barrel, and deep in the chest; the saddle will not then press too forward, but the in his prime.

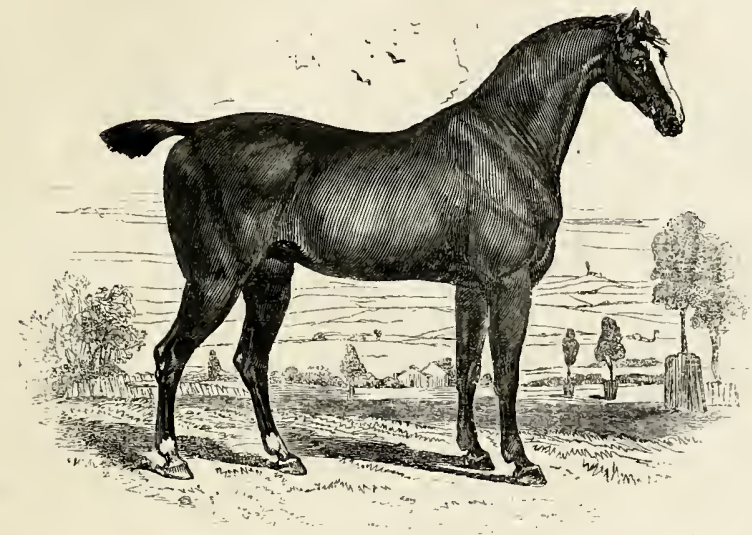

THE HACKNEY.

The above is the portrait of one that belonged to an old friend of the author. He was no beauty, and yet he was tull of good points. He was never out of temper; he never stumbled; he never showed that he was tired; most certainly was never off his feed; but, being a strange fellow to eat, he one day, although the groom had a thousand times been cautioned, gorged himself, and was immediately taken out by his owner, ignorant of this, in order to be ridden somewhat far and fast. At about the middle of the intended journey he almost stopped: he would after this have gone on at his nsual pace, but it was evident that something unusual was the matter with him, and his master stopped at the first convenient place. The stomach was ruptured, and, two days afterwards, he died.

Most of our readers probably are horsemen. Their memories will supply them with many instances of intelligence and fidelity in the horse, and particularly in the hackney-the every-day girths will remain, without crupper, firmly fixed in their proper place.

A hackney is far more valuable for the pleas. antnoss of his paces, and his safety, good temper, and endurance, than for his speed. We rarely want to go more than eight or ten miles in an hour; and, on a journey, not more than six or seren. The fast horses, and especially the fast trotters, are not often easy in their paces, and although they may perform very extraordinary feats, are disabled and worthless when the slower horse is 
gacity and fidelity of the horse. A friend of his, riding home through a wood in a dark night, struck his head against the branch of a tree, and fell from his horse stunned. The steed immediately retmmed to the house that they had lately left, and which was now closed, and the family in bed, and he pawed at the door until some one rose and opened it. He turned about, and the man, wondering at the affair, followed him. The faithful and intelligent animal led him to the place where his master lay senseless.

A few instances are sclected of the speed and endurance of the hackney.

1793, May 13, a hackney, named Sloven, valked twenty-two miles in three hours and fiftytwo minutes. In Norember 1791 she had beaten the then celebrated pedestrian, James Cotterel, by walking twenty miles in three hours and forty-one minutes. It had been previously imagined that no horse could, in fair walking, contend with a man who had accustomed himself to this kind of exercise.

As for the trotting performances of the hackney, they are so numerous, and yet apparently so extraordinary, that some difficulty attends the selection.

In 1822, there was a match of nine miles between Mr. Bernard's mare and Captain Colston's horse, near Gerrard's Cross, for five hundred guineas. It was won easily by the mare, who performed the distance in twenty-seren minutes and forty-six seconds. The horse went the same distance in twenty-seven minutes, forty-nine secondswhich is nearly at the rate of nineteen and a lalf miles an hour.

This, howrever, had been equalled or excelled some years hefore. Sir Edward's Astley's 'Phenomenon mare, when twelve years old, trotted seventeen miles in fifty-six minutes. There heing some difference about the fairness of the trotting, she performed the same distance a month afterwards in less than fifty-three minutes, which was rather more than nineteen miles an homr. Her owner then offered to trot her nineteen and a half miles an hour; but it being proved that in the last match she did one four miles in eleven minutes, or at the rate of more than twenty-one and a half miles an hour, the betting men would have nothing more to do with her.

After this, with shame be it spoken, she lived a life of drudgery and starvation, and occasionally of cruel exertion, until, at twenty-three years old, she became so changed as to be offered for sale at seven pounds. Even in that state she trotted nine miles in twenty-eight minutes and a half, being, as nearly as possible, nineteen miles an hour. Within six months afterwards, it is said that she won four extraordinary matrhes in one day, the particulars of which are not recorded. In her twenty-sixth year she became the property of the late Sir R. C. Daniel, by whom she was well fed, and had no disgraceful tasks imposed npon her; and in a few months she looked as fresh and clean upon her legs as in her best days. So far as speed was concerned, there was nothing in the annals of trotting comparable to her performances.

Of stoutness, whether confined to this pace, or the accomplishment of great distances with little or no rest, there are too many instances; and the greater number of them were accompanied by circumstances of disgraceful harharity.

Mr. Osbaldeston had a celebrated American trotting-horse, called Tom Thumb. He matched him to trot one hundred miles in ten hours and a half. It seemed to be an amazing distance, and impossible to be accomplished: but the horse had done wonders as a trotter; he was in the highest condition; the vehicle did not weigh more than one liundred pounds, nor the driver more than ten stone three pounds. He accomplished his task in ten hours and seven minutes; his stoppages to hait, \&c., occupied thirty-seven minutes; so that, in fact, the hundred miles were done in nine hours and a half. He was not at any time distressed; and was so fresh at the end of the ninetieth mile, that his owner offered to take six to four that he did fourteen miles in the next hour.

An English-bred mare was afterwards matched to accomplish the same task. She was ove of those animals, rare to be met with, that could do almost anything as a hack, a hunter, or in harness. On one occasion, after having, in following the hounds, and travelling to and from cover, gone through at least sixty miles of country, she fairly ran amay with her pider over several ploughed fields. She accomplished the match in ten hours and fourteen minutes, or, deducting thirteen minutes for stoppages, in ten hours and a minute's actual work, and thus gained the victory. She was a little tired; and, being turned into a loose box, lost no time in taking her rest. On the following day she was as full of life and spirit as ever. These are matches which it is pleasant to record, and particularly the latter; for the owner had given positive orders to the driver to stop at once, on her showing decided symptoms of distress, as he valued her more than anything he could gain by her enduring actual suffering.

Others, however, are of a different character, and excite indignation and disgust. Rattler, an American horse, was, in 1829, matched to trot ten miles with a Welsh mare, giving her a minute's start. He completed the distance in thirty minutes and forty seconds, being at the rate of rather more than nineteen miles an hour, and beating the mare by sixty yards. All this is fair; but when the same horse was, some time afterward, matched to 
trot thirty-four miles against another, and is distressed, and dies in the following night-when two hackneys are matched against each other, from Loudon to York, one huudred aud ninety-six miles, and one of them runs one humlred and eighty-two of these miles and dies, and the other accomplishes the dreadful feat in forty hou's and thirty-five minutes, being kept for more than half the distance under the influence of wine-when two brutes in human shape match their horses, the one a tall aud bony animal and the other a mere pony, against each other for a distance of sixtytwo miles, and both are run to a complete standstill, the one at thirty and the other at eighty yards from the winning point, and, both being still urged on, they drop down and die-when we peruse records like these, we envy not the feelings of the owners, if indeed they are not debased below all feeling. We should not have felt satisfied in riding an animal, that had done much and good service, seventy miles when he was thirty-six years old; nor can we sufficiently reprobate the nan, who, in 1827, could ride a small geldiug from 'Dublin to Nenagh, ninety-five miles, in company with the Limerick coach; or that greater delinquent who started with the Exeter mail, on a galloway, under fourteen hauds bigh, and reached that city a quarter of an hour before the mail, being one humdred and seventy-two miles, and performed at the rate of rather more than seven miles an hour. The author saw this pony, a few months afterward, strained, ring-boned, and foundered-a lamentable picture of the ingratitude of some human brutes towards a willing and faithful servant.

\section{THE FARMER'S HORSE.}

The Farmer's Horse is an animal of all work; to be ridden occasionally to market or for pleasure, but to be principally employed for draught. He should be higher than the road-horse. About fifteen hands and two inches may be taken as the best standard. A horse with a shoulder thicker, lower, and less slanting than would be chosen in a hackney, will better suit the collar ; and collar-work will be chiefly required of him. A stout compact animal should be selected, yet not a heary cloddy one. Some blood will be desirable; but the halfbred horse will generally best suit the farmer's purpose. He should have weight enough to throw into the collar, and sufficient activity to get over the ground.

Farmers are now beginning to be aware of the superiority of the moderately-sized, strong, active horse, over the bulkier and slower animal of former days. It is not ouly in harrest, and when a frosty morning must be seized to cart manure, that this is perceived, but in the every-day work of the farm the saving of time, and the saving of provender too, will be very considerable in the course of a year.

It has often been said, that a horse used much for draught is neither pleasant nor safe for the saddle. The little farmer does not want a showy, complete hackney. He should be coutent if he is tolerably well carried; and-if he has taken a little care in the choice of his horse-if he has selected one with sound feet, shoulders not too thick, and legs not too much under bim; and if he keeps him in good condition, and does not scaudalously overweight him, the five days' carting or harrow work will not, to any material degree, unfit him for the saddle; especially if the rider bears in mind, what we have termed the golden rule of horsemanship, always a little to feel the mouth of the animal he is upon.

A farmer, and more particularly a small farmer, will prefer a mare to a gelding, both for riding and driving. She will not cost him so much at first; and he will get a great deal more work out of her. There can be no doubt, that taking bulk for bulk, a mare is stronger and more lasting than a gelding; and, in addition to this, the farmer has ber to breed from. This, and the profit which is attached to it, is well known in the breeding counties; but why the breeding of horses for sale should be almost exclusively confined to a few northern districts, it is not easy to explain. Wherever there are good horses, with convenience for rearing the colts, the farmer may start as a breeder with a fair chance of success.

If he has a few useful cart-mares, and crosses them with a well-knit, half-bred horse, he will certainly have colts useful for every purpose of agriculture, and some of them sufficiently light for the van, post-chaise, or coach. If he has a superior mare, one of the old Cleveland breed, and puts her to a bony, three-fourths-bred horse, or, if he can find one stout and compact enough, a sereneighths or a thorough-bred one, he will have a fair chance to rear a colt that will amply repay him as a hunter or carriage-horse.

The mare needs not to be idle while she is breeding. She may be worked moderately almost to the period of her foaling, and with benefit rather than otherwise; nor is there occasion that much of her time should be lost even while she is suckling. If she is put to horse in Jume, the foalingtime will fall, and the loss of labour occur, in the most leisure time of the year.

There are two rocks on which the farmer often strikes-he pays little attention to the kind of mare, and less to the proper nourishment of the foal. It may be laid down as a maxim in breediug, however general may be the prejudice against it, that the value of the foal depends as much on the dam as on the sire. The Arabs go farther than this, for no price will buy from them a likely mare of the lighest blood; and they trace back the 
pedigree of their horses not through the sire, but the dam. The Greek sporting men held the same opinion, long before the Arab horse was known. "What chance of winning have I?" inquired a youth whose horse was about to start on the Olympic course. "Ask the dam of your horse," was the reply, founded on experieuce.*

The farmer, however, too frequently thinks that any mare will do to breed from. If he can find a great prancing stallion, with a high-sounding name, and loaded with fat, he reckons on having a valuable colt; and should he fail, he attributes the fault to the horse and not to his own want of judgment. Far more depends on the mare than is dreamed of in his philosophy.

If he has an undersized, or a blemished, or unsound mare, let him continue to use her on his farm. She probably did not cost lim much, and she will beat any gelding; but let him not think of loreeding from lier. A sound mare, with some blood in her, and with most of the good points, will alone answer his purpose. Sle may bear about her the marks of honest work (the fewer of these, however, the better), but she must not have any disease. There is scarcely a malady to which the horse is subject that is not hereditary. Contracted feet, curb, spavin, roaring, thick wind, blindness, notoriously descend from the sire or dam to the foal. Mr. Roberts, in "The Veterinarian," says :- "Last summer I was asked my opinion of a horse. I approved of his formation with the exception of the hocks, where there happened to be two curbs. I was then told his sister was in the same stable: she also had two curbs. Kuowing the sire to be free from these defects, I inquired about the dam: she likewise had two confirmed eurbs. She was at this time rumining with a foal of hers, two years old, by another horse, and he also had two curbs."

The foal sliould be well taken care of for the first two years. It is bad policy to stint or halfstarve the growing colt.

The colt, whether intended for a hunter or carriage-horse, may be early handled, but should not be broken-in until three years old; and then, the very best breaking-in for the carriage-horse is to make him earn a little of his living. Let him be put to harrow or light plough. Going over the rough ground will teach him to lift his feet well, and give him that high and showy action, excusable in a earriage-horse, but not in any other. In the

- Bishop Hall, who wrote in the time of James I.. intimated that such was the opinion of horsemen at that period. He asks in one of bis satires (Lib. iv.)

dost thou priz

Thy brute beasts' worth by their dams' qualities?

Say'st thou thrs colt shalt prove a swift pac'd steed Onely because a Jennet did bim breed?

Or say'st thou this same horse shall win the prize,

Because bis dam was swiftest Tranchefice ?" succeeding winter he will be perfectly ready for the town or country market.

\section{THE CAVALRY HORSE}

This is the proper place to speak of the Cavalry Horse. That noble animal whose varieties we are describing, and who is so admirably adapted to contribute to our pleasure and our use, was, in the earliest period of which we have any account of him, devoted to the destructive purposes of rar; and the cavalry is, at the present day, an indispensable and a most effective branch of the service.

The cavalry horses contain a different proportion of blood, according to the nature of the service required or the caprice of the commanding officer. Those of the household troops are from half to threefourths bred. Some of the lighter regiments have more blood in them. Our cavalry horses were formerly large and heary. To their imposing size was added action as imposing. The horse was trained to a peculiar, and grand, yet beautiful method of going; but he was often found deficient in real service, for this very action diminished his speed, and added to his labour and fatigue.

A considerable change has taken place in the character of our troop horses. This necessarily followed from the change that has occurred in the thorough-bred horse. If he has lost much of his muscular form and actual power of enduranee, a similar alteration will take place in the offspring; lightness and activity will succeed to bulk and strength, and for skirmishing and sudden attack the change will be an improvement. It is particularly found to be so in long aud rapid marches, which the lighter troops scarcely regard, while the heavier horses, with their more than comparative additional weight to carry, are knocked up. There is, however, danger of carrying this too far. It was proved that in the engagements previous to and at the battle of Waterloo, our heary household troops alone were able to repulse the formidable charge of the French guard.

There are few things that more imperiously demand the attention of government. If from the habit of running short distances, and with light weights, there is a deterioration in the strength and stoutness of our thorough-bred horses, they will become every year less and less fitted for getting stock sufficiently hardy and powerful to do credit to the courage and discipline of our cavalry.

The following anecdote of the memory and discipline of the troop horse is related on good authority. The Tyrolese, in one of their insurrections in 1809, took fifteeu Bavarian horses, and mounted them with so many of their own men: but in a skirmish with a squadron of the same regiment, no sooner did these horses hear the trumpet and recognise the uniform of their old masters, than they 
set off at full gallop, and carried their riders, in spite of all their efforts, into the Bavarian ranks, where they were made prisoners.

The wounds of a soldier are honourable. The old war-horse can sometimes exhibit his share of scars. One of them, twenty-seven years old, lately died at Stangleton Lodge, near Bedford, that had belonged to one of the regiments of lancers, and was in the battle of Waterloo, and the engagements of the two days that preceded it. No fewer than eight musket-balls were discovered in him after his death, and the scars of several wounds by the sabre and the lance.*

A horse died at Snowhill, near Gainsford, in 1753, that had been in General Carpenter's regiment at the battle of Sherriff-Muir, in 1715, being at that time seven years old. He was wounded by a bullet in his neck in that engagement, and this bullet was extracted after his death. $\dagger$

\section{THE COACH-HORSE,}

This animal in external appearance is as different from what he was fifty years ago as it is possible to conceive. The clumsy-barrelled, cloddyshouldered, round-legged, black family horseneither a coach nor a dray-horse, but something between both-as fat as an ox-but, with all his pride and prancing when he first starts, not equal to more than six miles an hour, and knocking-up with oue hard day's work, is no more seen; and we have, instead of him, an animal as tall, deepchested, rising in the withers, slanting in the shoulders, flat in the legs, with far more strength, and with treble the speed.

There is a great a deal of deception, however, even in the best of these improved coach-horses. They prance it nobly through the streets, and they have more work in them than the old, clumsy, sluggish breed; but they have not the endurance that could be wished, and a pair of poor post-horses would, at the end of the second day, beat them hollow.

The knee-action and ligh lifting of the feet in the carriage-horse is deemed an excellence, because it adds to the grandeur of his appearance; but, as has already been stated, it is necessarily accompanied by much wear and tear of the legs and feet, and this is very soon apparent.

The principal points in the coach-horse are, substance well-placed, a deep and well-proportioned body, bone under the knee, and sound, open, tough feet.

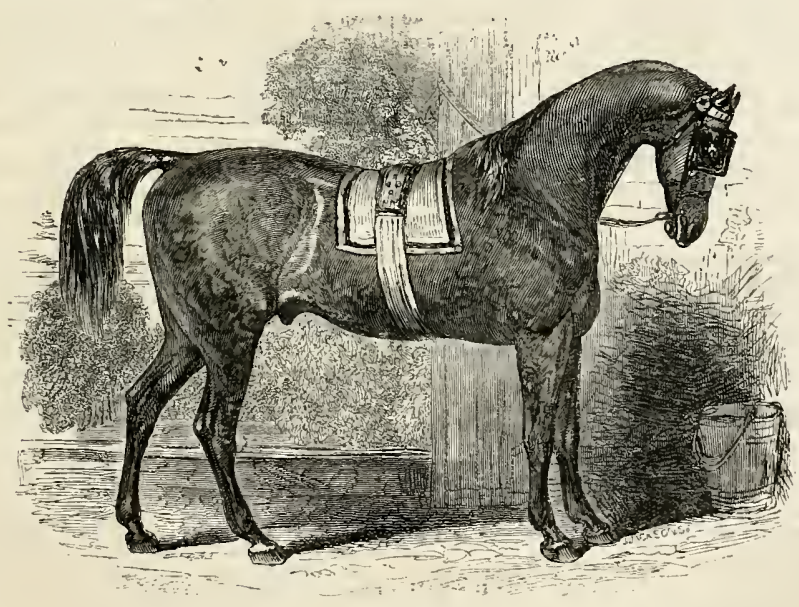

THE COACH-HORSE.

The Cleveland Bay is the origin of the better Yorkshire and Durham, with, perhaps, Lincolnshire kind of coach-horse, and confined principally to on one side, and Northumberland on the other, but

- Journal des Haras, 1836.7, p. 61.

+Gentleman's Magazine, Feb. I753.

\$Wheel carriages, bearing any resemblance to chariots, first came into use in the reign of Richard II. abuut the year 1381; tbey

were called whirlicotes, and were little better than litters or cotes (cols) placed on wheels. We are told by Master John Stowe, that, Richard II. being threatened by the rebels of Kent, rode from the Tower of London to the Miles End, and with him bis mother, 
difficult to find pure in either county. The Cleveland mare is crossed by a three-fourth or thoroughbred horse, of sufficient substance and beight, and the produce is the coach-horse most in repute, with his arched crest and high action. From the thorough-bred of sufficient height, but not of so much substance, we obtain the four-in-hand and superior curricle horse.

Professor Low, in his superb work "Illustrations of the Breeds of the Domestic Animals of the British Islands," which should adorn the library of every sportsman and agriculturist, gives the following account of the Cleveland Bay:-

"It is the progressive mixture of the blood of horses of higher breeding with those of the common race, that has produced the variety of coachhorse usually termed the Cleveland Bay; so called from its colour and the fertile district of that name in the North Riding of Yorkshire, on the banks of the Tees. About the middle of the last century this district became known for the breeding of a superior class or powerful horses, which, with the gradual disuse of the heavy old coach-horse, became in request for coaches, chariots, and similar carriages. The breed, however, is not confined to Cleveland, but is cultivated through all the great breeding district of this part of England. It has been formed by the progressive mixture of the blood of the race-horse with the original breeds of the country. To rear this class of horses, the same principles of lireeding should be applied as to the rearing of the race-horse himself. A class of mares, as well as stallions, should also be used having the properties sought for. The district of Cleveland owes its superiority in the production of this beautiful race of horses to the possession of a definite

because she was sick and weak, in a whirlicote :" and this is described as an ugly vehicle of four boards put together in a clumsy manner.

In the following year he martied Anne of Luxcmhourg, who istroduced the riding upon side-saddles; and so "was the riding in those whirlicotes forsaken, except at coronations and such like spectacles."

Coaches were not used until the time of Elizabeth, when we are told (Stowe's Survey of London and Tiestminster, book i.) "divers great ladies made them coarhes, and rode in them up and down the countries, io the great admiration of all the beholders." The fashion soon spread; and be adds, what is ofteo tno true in the presem day, "the world runs nu wheels with many whose parents were glad to go on foot."

These coaches were heavy and unwieldy, and probably bore some rough resemblance to the state-coaches now used ocrasion. ally in court processions.

The rate of travelling was as slow as the clumsiness of the horses and vehicle would naturally indicate. King George II. died early on Saturday moming. Oct. 21, 1760: the Duke of Devonshire, who was lord chamberlain, arrived in town from Chatsworth in three days; but a fourth and a fifth day passing over, and the lord steward, the Duke of Rutland, not making his appearance, although he had not so fur to travel by more than thirty miles. Mr. Speaker Onslow made this apology for him, that "the Duke of Devonshire travelled at a prodigious rate, not less than firty miles a day "'"

To travel in the stage-coach from London to Epsom, sisteen miles, then took nearly the whole day, and the passengers dined on the road. The coach from Edinburgh to London started once a breed, formed not by accidental mixture but by continued cultivation.

"Althongh the Cleveland Bay appears to unite the blood of the finer with that of the larger horses of the country, to combine action with strength, yet many have sought a farther infusion of blood nearer to the race-horse. They are accordingly crossed by hunters or thorough-bred horses, and thus another variety of coach-horse is produced, of lighter form and higher breeding; and many of the superior Cleveland curricle and four-in-hand horses are now nearly thorough-bred. The bay colour is in the most general estimation, but the grey are not unfrequently used." *

From less height and more substance we have the hunter and better sort of hackney; and, from the half-bred, we derive the machiner, the poster, and the common carriage horse: indeed, Cleveland, and the Vale of Pickering, $\mathrm{m}$ the East Riding of - Yorkshire, may be considered as the most decided breeding conntries in England for coachhorses, hunters, and hackneys. The coach-horse is nothing more than a tall, strong, over-sized hunter. The hackney has many of the qualities of the hunter on a small scale.

Whether we are carrying supposed improvement too far, and sacrificing strength and usefulness to speed, is a question not difficnlt to resolve. The rage for rapid travelling was introduced by the improvement in the speed of the racer, and for a while became the bane of the postmaster, the destruction of the horse, and a disgrace to the English character.

The stages were then twelve, sixteen, or even twenty miles; the horses stout and true, but formed for, and habituated to, a much slower pace; and

month, and occupied sixteen or eighteen days on the journey. A person may uow leave Etlinburgh on Saturday evening, have two spare days in London, and be back again at the Scotch metropolis to breakfast on the next Saturday. Including short stages, one thousand four hundred coaches a little while ago set out from London every day, the espense of earh of which, with four horses, could not be less than two shillings and sixpence per mile.

Hackney-coaches first appeared in London in $I 625$, the first year of the $r$ ign of Charles 1 . Sedan-chairs bad been introduced by the Duke of Buckingham six years before.

Among the numerous kenefits arising from the services of the horse, and the improvemeot of public roads and carriages, is the speedy and regular correspondence by post. The inverition of this usc ful estuhlishment is ascribed to $\mathbf{C y}$ rus the Great. It was adopted by the Greeks and Romans. It was introducerl into France hy Lovis XI. in 1462, and we first read of it in English history about the year 1550, under Eiward VI., when pust-hnuses were established, and horses provided at the rate of one penny per mile. Under Elizabeth a post-master was nominated by goveroment, and ander Charles 1 ., in 1634 , the system assumed its present form. The charge of postage was then fixed at twopence if under eighty miles fourpence between eighty and one hundred and forty; and sixpence if under two himdred and forty miles; but this charge rapidly increased with the increasing price of borses, and the other expenses of conveyance, and afterwards it was further raised by taxation like almost everything else. It is now dininished, with great public advantage, to a general rate of one penny.

The recent introduction of railroads will effect much change in the use of the carriage and road horse.

- Low'a Illustrations, p. 41. 
the increase of two, and cven four, miles an hour, rendered every stage a scene of continuous barbarity, and speedily thinned the stables of the post and stage master. The post-horse has not to the present moment altogether escaped from the systew of barbarity to which he was suljected. He is not expressly bred for his work - that work is irregugular-the pace is irregular-the feeding and the time of rest uncertain-and the horse himself, destined to be the victim of all these means of annoyance and suffering and impairment of natural power, is not always or often either speedy or stout. The coachmaster, on a large scale, has, however, learned, and, generally speaking, follows up a system at once conducing to his own profit, and the health and comfort and prolonged labomr of his horse. He buys a good horse, "one that has," in the language of the highest anthority in these matters, "action, sound feet and legs, power and breeding equal to the nature and length of the ground he will have to work npon, and good wind, without which no other qualification will long avail in fast work."* He feeds him well-lie works him but little more than one hour out of the fourand-twenty-he rests him one day ont of every five-he has everything comfortable about him in his stable-and by these means, that which was once a life of torture is one of comparative, or even positive, eujoyment. This is now the case in large and well-conducted concerns, and where the eye of the master or the confidential manager overlooks and directs all.

In other establishments, and in too many of them, there is yet much animal suffering. The public has to a very considerable extent the power to distinguish betweeu the two, and to uphold the cause of humanity.

Reference has been made to the dreadful operations which the new system of horse management has introduced. The cautery lesions are more numerous and severe than they used to be, in too many of our establislıments. The injuries of the feet and legs are severe in proportion to the increased pace and labour, for where the animal machine is urged beyond its power, and the torture contiuues until the limb or the whole constitution utterly fails, the lesions must be deep, and the torture must be dreadful, by means of which the poor slave is rendered capable of returning to renewed exertion.

There is no truth so easily proved, or so painfully felt by the postmaster, at least in his pocket, as that $i t$ is the pace that kills. A horse at a dead pull, or at the beginning of his exertion, is enabled, by the force of his muscles, to throw a certain weight into the collar. If he walks four miles in the hour, some part of that muscular energy must be expended in the act of walking; and, conse-

\footnotetext{
* Nimror on the Chase, the Road, aud the Turf, p. 98.
}

quently, the power of drawing must be proportionably diminislied. If he trot ten miles in the hour, more animal power is expended in the trot, and less remains for the draught; but the draught continucs the same, and, to enalle him to accomplish his work, he must tax his energies to a serious degree. Skilful breeding, and high health, and stimulating food, and a rery limited time of work, can alone enable him to endure the labour long, on the supposition that the system which has just been described is resorted to. But the coach proprietor is not always sufficiently enlightened, or good-hearted, to see on which side his interest lies; and then the work is accomplished by the overstrained exertion-the injury-the torture-the destruction of the team. That which is true of the coach-horse is equally so of every other. Let the reader apply it to his own animal, and act as humanity and interest dictate.

Many a horse used on the public roads is unable to throw all his natural power or weight into the collar, He is tender-footed-lame; but he is bought at little price, and he is worked on the brutal and abominable principle, that he may be "whipped sound." And so, apparently, he is. At first he sadly halts; but, urged by the torture of the lash, he acquires a peculiar habit of going. The faulty limb appears to keep pace with the others, but no stress or labour is thrown upon it, and he gradually contrives to make the sound limbs perform among them all the duties of the unsound one; and thus he is barbarously " whipped sound," and cruelty is undeservedly rewarded.

After all, however, what has been done? Three legs are made to do that which was almost too hard a task for four. Then they must be most injuriously strained, and soon worn out, and the general power of the animal must be rapidly exhansted, and, at no great distance of time, disease and death release him from his merciless persecutor's.

It is said, that between Glasgow and Edinburgh, a carrier in a single horse cart, weighing about seven hundredweight, will take a load of a ton, and at the rate of twenty-two miles in a day. The Normandy carriers travel with a team of four horses, and from fourteen to treuty-two miles in a day, with a load of ninety hundredweight.

An unparalleled instance of the power of a horse when assisted by art, was shown near Croydon. The Surrey iron railway being completed, a wager was laid between two gentlemen, that a moderate-sized horse could draw thirty-six tons six miles along the road-that he should draw the weight from a dead pull, as well as turn it round the occasional windings of the road. A numerous party of gentlemen assembled near Merstham to see this extraordinary triumph of art. Trelve waggons laden with stones, each waggon weighing 
above three tons, were chained together, and a horse, taken promiscuously from the timber carts of Mr. Harwood, was yoked to the train. He started from the Fox public-house, near Merstham, and drew the immense chain of waggons, with apparent ease, almost to the turnpike at Croydon, a distance of six miles, in one hour and forty one minutes, which is nearly at the rate of four miles an hour. In the course of the journey he was stopped four times, to show that it was not by any advantage of descent that this power was acquired; and after each stoppage he again drew off the chain of waggons with perfect ease. Mr. Banks, who had wagered on the power of the horse, then desired that four other loaded waggons should be added to the cavalcade, with which the same horse again started and with undiminished pace. Still further to show the effect of the railway in facilitating motion, he directed the attending workmen, to the number of fifty, to mount on the waggons, and the horse proceeded without the least distress : and, in truth, there appeared to be scarcely any limitation to the power of his draught: After the trial the waggons were taken to the weighing-machine, and it appeared that the whole weight was as follows :-

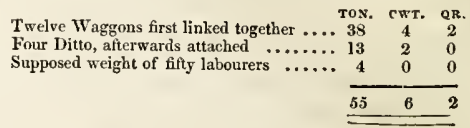

HEAVY DRAUGHT HORSES.

The Cleveland horses have been known to carry more than seven hundred pounds sixty miles in twenty-four hours, and to perform this jouruey four times in a week; and mill-horses have carried nine hundred and ten pounds two or three miles.

Horses for slower draught, and sometimes even for the carriage, are produced from the Suffolk Punch, so called on account of his round punchy form. He is descended from the Norman stallion and the Suffolk cart mare. The true Suffolk, like

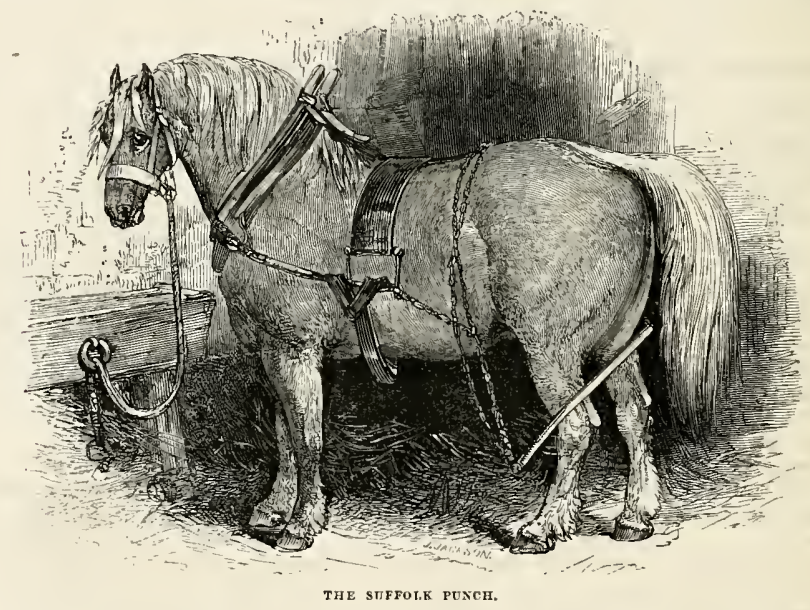

the Cleveland, is now nearly extinct. It stood from fifteen to sixteen hands high, of a sorrel colour; was large headed; low shouldered, and thick on the withers; deep and round chested; long backed ; high in the croup : large and strong in the quarters; full in the flanks : round in the legs; and short in the pasterns. It was the very horse to throw his whole weight into the collar, with sufficient activity to do it effectually and hardihood to stand a long day's work.

The present breed possesses many of the pe culiarities and good qualities of its ancestors It is more or less inclined to a sorrel colour; it is a taller horse; higher and finer in the shoulders; aud is a cross with the Yorkshire half or three fourths bred.

The excellence, and a rare one, of the old Suffolk-the new breed has not quite lost it-consisted in nimbleness of action, and the honesty and continuance with which he would exert him. self at a dead pull. Many a good draught-horse knows well what he can effect; and, after he has 
attempted it and failed, no torture of the whip will induce him to strain his powers beyond their natural extent. The Suffolk, however, would tug at a dead pull until he dropped. It was beautiful to see a team of true Suffolks, at a signal from the driver, and withont the whip, down on their knees in a moment, and drag everything before them. Brutal wagers were frequently laid as to their power in this respect, and many a good team was injured and ruined. The immense power of the Suffolk is accounted for by the low position of the shoulder, which enables him to throw so much of his weight into the collar.

Although the Pumch is not what he was, and the Suffolk and Norfolk farmer can no longer boast of ploughing more land in a day than any one else, this is undoubtedly a valuable treed.

The Duke of Ricbmond obtained many excellent carriage horses, with strength, activity, and figure, by crossing the Suffolk with one of his best hunters.

The Suffolk breed is in great request in the neighbouring counties of Norfolk and Essex. Mr. Wakefield, of Barnham, in Essex, had a stallion for which he was offered four hundred guineas.

The Clydesdale is a good kind of draught horse, and particularly for farming business and in a hilly country. It derives its name from the district on the Clyde, in Scotland, where it is principally bred. The Clydesdale horse owes its origin to one of the Dukes of Hamilton, who crossed some of the best Lanark mares with stallions that he had brought from Flanders. The Clydesdale is larger than the Suffolk, and has a better head, a longer neck, a ligbter carcase, and deeper legs; be is strong, hardy, pulling true, and rarely restive. The southern parts of Scotland are pincipally supplied from this district; and many Clydesdales, not only for agricultnral purposes but for the coach and the saddle, find their way to the central and even southern counties of England. Dealers from almost every part of the United Kingdom attend the markets of Glasgow and Rutherglen.

Mr. Low says, that " the Clydesdale horse, as it is now bred, is nsually sixteen hands high. The prevailing colour is black, but the brown or bay is common, and is continually gaining upon the other, and the grey is not unfrequently produced. They are longer in the body than the English black horse, and less weighty, compact, and muscular; but they step out more freely, and have a more useful action for ordinary labour. They draw steadily, and are usually free from vice. The long stride, characteristic of the breed, is partly the result of conformation, and partly of halit and training; but, however produced, it adds greatly to the usefulness of the horse, both on the road and in the fields. No such loads are known to be drawn, at the same pace, by any horses in the kingdom, as in the single-horse carts of carriers and others in the west of Scotland."*

In the opinion of this gentleman, "the Clydesdale borses, although inferior in weight and physical strength to the black horse, and in figure and showy action to the better class of the draught horses of Northumberland and Durbam, yet possess properties which render them exceedingly valnable for all ordinary uses. On the road they perform tasks that can scarcely be surpassed, and in the fields they are found steady, docile, and safe." $t$

The Heavy Black Horse is the last variety it may be necessary to notice. It is bred chiefly in the midland counties, from Lincolnshire to Staffordshire. Many are bought up by the Surrey and Berkshire farmers at two years old; and, being worked moderately until they are four, earning their keep all the while, they are then sent to the Loudon market, and sold at a profit of ten or twelve per cent.

It would not answer the breeder's purpose to keep them until they are fit for town work. $\mathrm{He}$ has plenty of fillies and mares on his farm for every purpose that he can require; be therefore sells them to a person nearer the metropolis, by whom they are gradually trained and prepared. The traveller bas probably wondered to see four of these enormous animals in a line before a plough,. on no very heavy soil, and where two lighter horses would have been quite sufficient. The farmer is training them for their future destiny; and he does right in not requiring the exertion of all their strength; for their bones are not yet perfectly formed, nor their joints knit, and were he to urge them too severely, he would probably injure and deform them. By the gentle and constant exercise of the plough, he is preparing them for that continued and equable pull at the collar which is afterwards so necessary. These horses are adapted more for parade and show, and to gratify the desire which one brewer has to ontvie his neighbour, than for any peculiar utility. They are certainly noble-looking animals, with their round fat carcases, and their sleek coats, and the evident pride which they take in themselves; but they eat a great deal of bay and corn, and, at hard and long-continued work, they would be completely beaten by a team of active muscular horses an inch and a half lower.

The only plea which can be urged in their farour, beside their noble appearance, is, that as shaft-horses, over the badly-paved streets of the metropolis, and with the immense loads they often have behind them, great bulk and weight are necessary to stand the unavoidable battering and shaking. Weight must be opposed to weight, or the horse would sometimes be quite throm off his

* Low's Illustrations, p. 45.

+ Ib., p. 46 . 
legs. A large lreavy horse must be in the shafts, |constitute strength, and that a compact muscular and then little ones before him would not look well. horse, approaching to sixteen hands high, would

Certainly no one bas walked the streets of acquit himself far better in such a situation. The London without pitying the poor thill-horse, jolted dray-horse, in the mere act of ascending from the from side to side, and exposed to many a bruise, wharf, may display a powerful effort; but he afternuless, with admirable cleverness, he accomodates wards makes little exertion, much of his force himself to every motion; but, at the same time, it being expended in transporting bis own overgrown must be evideut, that bulk and fat do not always $\mid$ carcase.

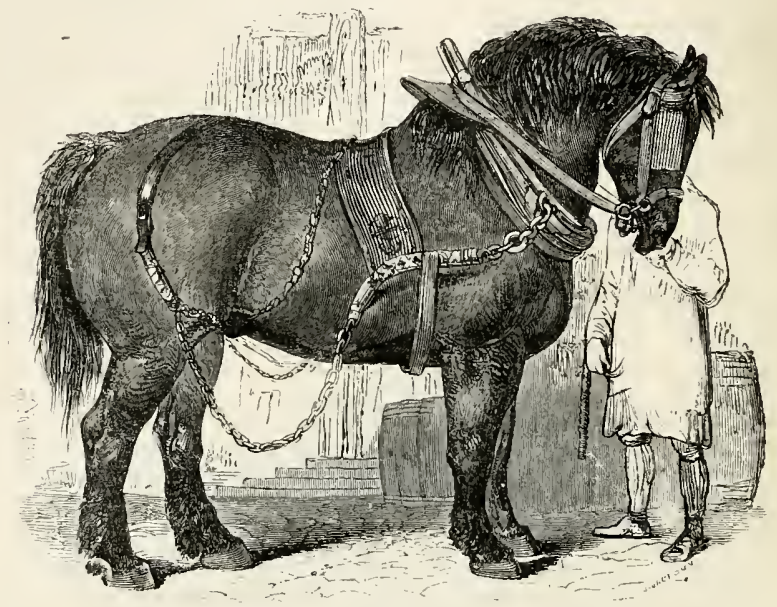

THE HEAVY HLACK HORSE.

This horse was selected from the noble stock of lower part of Lincolnshire is a cold, hungry clay. dray-horses belonging to Messrs. Barclay, Perkins, The true explanatiou of the matter is, that there and Co., London, by the author's friend, Mr. E. are certain situations better suited than others to Braby. While he is a fine specimen of this breed, different kinds of farming, and the breeding of he affords a singular illustration of the mode of breeding often practised with respect to these horses and the education which they undergo. He was bred in Leicestershire; his grandsire was a Flanders-bred horse, and his grand-dam a Wiltshire mare; his sire was a Wiltshire horse, and his dam a Berkshire mare. At two and a half years old he was sold to a farmer and dealer in Berkshire, on whose grounds he was worked until he was four and a half years old. He was then sold at Abing. don fair to the dealer from whom Messrs. Barclay purchased him.

These heavy horses, however, are bred in the highest perfection, as to size, in the fens of Lincolnshire, and few of them are less than seventeen hands high at two and a half years old. Neither the soil, nor the produce of the soil, is better than in other counties; on the contrary, much of the different animals; and that not altogether depending on richness of soil or pasture. The principal art of the farmer is, to find out what will best suit his soil, and make the produce of it most valuable.

The Lincolnsbire colts are also sold to the Wiltshire and Berkshire dealers, as are those that are bred in Warwickshire and Berkshire, at two years, or sometimes only one year old, and worked until the age of four or five years.

A dray-horse should have a broad breast, and thick and upright shoulders (the more upright the collar stands on him the better), a low forehand, deep and round barrel, loins broad and high, ample quarters, thick fore-arms and thighs, short legs. round hoofs broad at the heels, and soles not too flat. The great fault of the large dray-horse is his slomess. This is so much in the breed, that even the discipline of the ploughman, who would, 
be better pleased to get through an additional rood in the day, cannot permanently quicken him. Surely the breeder might obviate this. Let a dray-mare be selected, as perfect as can be obtained. Let her be put to the strongest, largest, most compact, thorough-lired horse. If the produce is a filly, let her be covered by a superior dray-horse, and the result of this cross, if a colt, will be preeisely the animal required to breed from.

The largest of this heavy breed of black horses are used as dray-horses. The next in size are sold as waggon-horses; and a smaller variety, and with more blood, constitutes a considerable part of our cavalry, and is likewise devoted to undertakers work.*

All our heavy draught horses, and some even of the lighter kind, have been lately much erossed by the Flanders breed, and with evident improvement. Little has been lost in deptli and bulk of carcase; lut the forehand has been raised, the legs have been flattened and deepened, and very much has been gained in activity. The slow heavy black, with his two miles and a half an hour, has been changed into a lighter, but yet exceedingly powerful horse, that will step four miles in the same time, with perfect ease, and has considerably more endurance.

This is the very system, as already described, which has been adopted, and with so much success, in the blood-horse, and has made the English racer and hunter, and the English horse generally, what they are. As the racer is principally or purely of Eastem origin, so has the English draught horse sprung chiefly from Flemish blood, and to that blood the agriculturist has recourse for the perfection of the breed. For the dray, the spirit-waggon, and not too heavy loads, and for road work generally, a cross with the Flanders will be advantageous; but if the enormous heavy liorse must be used in the coal-waggon, or the dray, we must leave our midland black, with all his unwieldy bulk untouched.

As an ordinary beast of lighter draught, and particularly in the neighbourhood of London, the worn-out hackney and the refuse of the coach, and eren of the hackney-coach, is used. In the hay-markets of Whitechapel and Camden Town are continually seen wretched teams, that would disgrace the poorest district of the poorest coun-

* Mr. Bell, in his "History of British Quadrupeds," very truly observes, that "the docility of this breed is as complete, although not perhaps so showy, as that of the lighter and nore active kinds; and few persons can have long walked the streets of the netropolis, without witnessing the complete control which the draymeo exercise over their gigantic horses. I have often watched the lacility with which one of them will back a waggon into a narrow street or archway, but a few inches wider than the vehicle itself, and guided only by the voice of the carman, aided perhaps by a few slight movements of his hand." try. The small farmer in the vicinity of the metropolis, hinself strangely inferior to the small farmer elsewhere, has too easy access to that sink of cruelty, Smithtield. They who are unzequainted with this part of the country, would scarcely think it possible, that on the forests and commons within a few miles of Lomdon, as many ragged, wild, mongrel horses are to he found, as in any district of the United Fingdom, and a good horse is scarcely by any chance bred there.

\section{GALLOWAYS AND PONIES.}

A horse between thirteen and fourteen hands in height is called a Galloway, from a beautiful breed of little horses once found in the South of Scotland, on the shore of the Solway Firth, but now sadly degenerated, and almost lost, through the attempts of the farmer to obtain a larger kind; and better adapted for the purposes of agriculture. There is a tradition in that country, that the breed is of Spanish extraction, some horses having escaped from one of the vessels of the Grand Armada, that was wrecked on the neighbouring coast. This district, however, so early as the time of Edward I., supplied that mouarch with a great number of horses.

The pure galloway was said to be nearly fourteen hands high, and sometimes more ; of a bright bay, or browu, with black legs, small head and neck, and peculiarly deep and clean legs. Its qualities were speed, stoutness, and sure-footedness over a very rugged and mountainous country.

Some remains of the old galloways are still to be met with in the Isle of Mull; but they are altogether neglected, and fast degenerating from admixture with inferior breeds.

Dr. Anderson thus describes the galloway :"There was once a breed of small elegant horses iil Scotland, similar to those of Iceland and Sweden, and which were known by the name of galloways; the best of which sometimes reacled the height of fourteen liands and a half. One of this description I possessed, it having been bought for my use when a boy. In point of elegance of shape it was a perfect picture; and in disposition was gentle and compliant. It moved almost with a wish, and never tired. I rode this little creature for twenty-five years, and twice in that time I rode a hundred and fifty miles at a stretch, without stopping, except to bait, and that not for above an hour at a time. It came in at the last stage with as much ease and alacrity as it travelled the first. I could have undertaken to have performed on this beast, when it was in its prime, sixty miles a day for a twelvemonth, running without any extraordinary exertion."

In 1754, Mr. Corker's galloway went one hundred miles a day, for three successive days, 
over the Newmarket course, and withont the slightest distress.

A galloway, belonging to $\mathrm{Mr}$. Sinclair, of Kirby-Lonsdale, performed at Carlisle the extraordinary feat of a thousand miles in a thousand hours.

Many of the galloways now in use are procured either from Wales or the New Forest; but they have materially diminished in number.

old Marsk, before his value was known, contributed to the improvement of the Hampshire breed; and the Welch ponies are said to be indebted to the celebrated Merlin for much of their form and qualities.

The modern New-foresters, notwithstanding their Marsk blood, are generally ill-made, largeheaded, sliort-necked, and ragged-hipped; but hardy, safe, and useful, with much of their ancient spirit and speed, and all their old paces. The catcling of these ponies is as great a trial of skill as the huuting of the wild horse on the Pampas of South America, and a greater one of patience.

The Welsh pony is one of the most beautiful little animals that can be imagined. He has a small head, high withers, deep yet round harrel, short joints, flat legs, and good round feet. He will live on any fare, and will never tire.*

A great many ponies of little value used to be reared on the Wildmoor fens, in the neighbourhood of Boston, in Lincolnshire. They seldom reached thirteen hands; the head was large and the forehand low, the back straight, the leg flat and good; but the foot, even for a Lincolnshire pony, unnaturally large. They were applied to very inferior purposes even on the fens, and were unequal to hard and flinty and billy roads. The

* Pony-hunting used to be one of the favourite amusements of the Welsh farmers and peasantry, a century and a half ago, and it has not, even now, fallen altogether into disuse. The following story of one of these expeditions is founded on fact :-

"A farmer named Hugo Garonwy, lived in the neighhourhood of Llweyn Georie. Although he handled the small tilt plough, and other farmiag tools in their due season, yet the catching of the merlyn, the fox, and the hare, were more congenial pursuits; and the tumbles an 1 thumps which he received, and from which no pony-hunter was exempt, served hut to attach him to the sport. Rugged, however, as the Merioneddshire coast and its eavirons were, and abounding with precipices and morasses, he sometimes esperienced worse mishajs-and so it happened with Garouwy.

"He set out one moraing with his lasse coiled round his wajst, and attended by two hardy dependants and their greyhounds. The lasso was then fumiliar to the Welshman, and as adroitly managed hy him as hy any guaco on the plains of South America. As the hunters elimbed the mountain's brow, the distant herd of ponies took alarm-sometimes galloping onwards, and then suddenly balting and whceling round, snorting as if in defance of the intruders, and furivusly pawing the ground. Garonwy, with the assistance of his servants and the greyhounds, coutrived to c up them up in a corner of the hills, where perpendicular rocks prevented their escape.

"Alieady had he captured three of the most beautiful little fellows in the world, which he expected to sell for $4 l$, or $5 l$. each at the next. Bala fair-to him a considerable sum, and amonnting to a fourth of the annual reat which he paid for his sheep-walk. There remained, however, ooe most untameahle creature, whose crested maue, and flowing tail, and wild eye, and distended nostril, breed became generally neglected, and, at no very distant time, will be almost extinct.

The Exmoor ponies, although generally ugly enough, are hardy and useful. A well-known sportsman says, that he rode one of them half-adozen miles, and never felt such power and action in so small a compass before. To show his accomplishments, he was turned over a gate at least eight inches higher than his back; and his owuer, who rides fourteen stone, travelled on him from Bristol to South Molton, eighty-six miles, beating the coach which runs the same road.

The horses which are still used in Devonshire, and particularly in the western and southern dis. tricts, under the denomination of Pack-horses, are a larger variety of the Exmoor or Dartmoor breed. The saddle-horses of Devonshire are mostly procured from the more eastern counties.

There are still some farms in the seclnded districts in that beantiful part of the kingdom on which there is not a pair of wheels. Hay, corn, straw, fuel, stones, dung, lime, are carried on horseback ; and in harvest, sledges drawn by oxen and horses are employed. This was probably, in early times, the mode of conveyance throughont the kingdom; but it is now rapidly getting into disuse even in Devonshire.

There is on Dartmoor a race of ponies much in request in that vicinity, being sure-footed and hardy, and admirably calculated to scramble over the rough roads and dreary wilds of that mountainous district. The Dartmoor pony is larger than the Exmoor, and, if possible, uglier. $\mathrm{He}$ exists there almost in a state of nature. The late Captain Colgrave, governor of the prison, had a great desire to possess one of them of somewhat superior figure to its fellows; and, having several

showed that he was a perfect Bucephalus of the hills; nor, indeed was it safe to attack him in the ordinary way. Many of the three-year-olds had been known to break the legs of their pursuers, and sume had been dismounted and trampled to death.

"Garonwy was determined to give the noble fellow a chase over the hills, and so overcome him by fatigue before the lasso was flung. The dogs were unslipped, and off they went, swift as the winds, Garonwy following, and the two assistants posted on a neighhouring eminence. Vain was the effort to tire the merlyn. Hugo, naturally impatient, and without waiting to ascertain that the coils were all clear, flung the lasso over the head of the wild horse. The extremity of the cord was twisted round his own hody, and tightening as the animal struggled, the compression became unsupportable, and, at length, in spite of every effort to disengage himself, Garunwy was dragged from his horse.

"The affrighted merlyn finding himself manacled by the rope, flarted off with all the speed of which he was capahle, dragging poor Garonwy over the rocky ground and stunted brushwood. This occurred at some distance from the men. They called in their dogs that the speed of the merlyn might not be increased, hut ere they conld arrive at the spot at which the accident happened, the horse and the man had vanished. Whether the sufferings of the hunter were protracted, or he was dashed agaiast some friendly rock at the commencement of this horrible race, was never known: but the wild animal, frenzied and hlinded by terior, rushed over a beetling eliff, at a considerahle distunce, overhanging the sea-shure, and the humter and the horse were found at the hottom, a mis-shapen semblace 'of what they had been when living."-Cambrian Quarterly Magazine. 
men to assist him, they separated it from the herd. They drove it on some rocks by the side of a tor (an abrupt pointed hill). A man followed on horseback, while the captain stood below watching the chase. The little animal being driven in to a corner, leaped completely over the man and horse, and escaped.

The Highland pony is far inferior to the galloway. The head is large; he is low before, long in the back, short in the legs, npright in the pasterns, rather slow in his paces, and not pleasant to ride, except in the canter. His habits make him hardy; for he is rarely housed in the summer or the winter. The Rev. Mr. Hall, in his "Travels in Seotland," says, "that when these animals come to any boggy piece of gromnd, they first put their nose to it, and then pat on it in a peculiar way with one of their fore-feet; and from the sound and feel of the ground, they know whether it will bear them. They do the same with ice, and determine in a minute whether they will proceed."

The Shetland pony, called in Scotland sheltie, an inhabitant of the extremest northern Scottish Isles, is a very diminutive animal-sometimes not more than seven hands and a half in height, and rarely exceeding nine and a half.

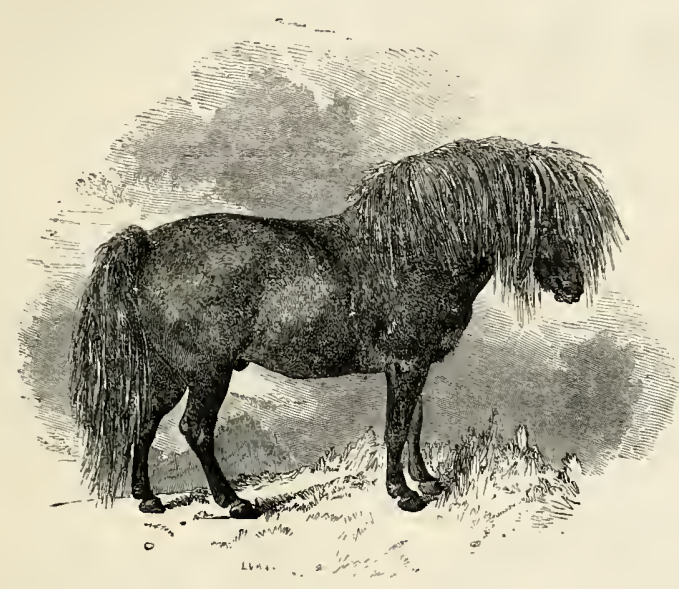

THE SHETLAND PONY,

He is often exceedingly beantiful, with a small head, good-tempered comntenance, a short neck, fine towards the throttle, shoulders low and thick -in so little a creature far from being a blemish -back short, quarter's expanded and powerful, legs flat and fine, and pretty round feet. These ponies possess immense strength for their size; will fatten upon almost anything; and are perfectly docile. One of them, nine hands (or three feet) in height, carried a man of twelve stone forty miles in one day.

A friend of the anthor was, not long ago, presented with one of these elegant little animals. $\mathrm{He}$ was several miles from home, and puzzled how to convey his newly-acquired propcrty. The Shetlander was scarcely mole than seven hands high, and as docile as he was beautiful. "Cau we not carry him in your chaise?" said his friend. The strange experiment was tried. The sheltie was placed in the bottom of the gig, and covered up as well as could be managed with the apron; a few bits of bread liept him quiet; and thus he was safely conveyed away, and exhibited the curious spectacle of a horse riding in a gig.

In the southern parts of the kingdom the Shetlanders have a very pleasing appearance harnessed to a light garden-chair, or carrying an almost babsrider. There are several of them now running in IVindsor Park.

\section{TIE IRISH HORSE。}

In some of the rich grazing counties, as Meath and Roscommon, a large, long blood-horse is reared, of considerable value. $\mathrm{He}$ seldom has the elegance of the English horse; he is largerheaded, more leggy, raggel-hipped, angular, yet 
with great power in the quarters, much depth beneath the knee, stout and hardy, full of fire and courage, and an excellent leaper. It is not, however, the leaping of the English. horse, striding as it were over a low fence, and stretched at his full length over a higher one; it is the proper jump of the deer, beautiful to look at, difficult to sit, and, both in height and extent, unequalled by the English horse.

The common Irish horse is generally smaller than the English. He is stinted in his growth; for the poverty and custom of the country have imposed upon lim much hard work at a time when he is unfit for labour of any kind. He is also deficient in speed.

There are very few horses in the agricultural districts of Ireland exclusively devoted to draught. The minute division of the farms renders it im- possible for them to be kept. The occupier even of a good Irish farm wants a horse that shall carry him to market, and draw his small car, and perform every kind of drudgery-a horse of all-work ; therefore the thorough draught-horse, whether Leicester or Suffolk, is rarely found.

If we look to the commerce of Ireland, there are few stage-waggons, or drays with large cattle belonging to them, but almost everything is done by one-liorse carts. In the north of Ireland some stout lorses are employed in the carriage of linen; but the majority of the garrons used in agriculture or commercial pursuits are miserable and halfstarved animals. In the north it is somewhat better. There is a native breed in Ulster, hardy, and sure-footed, but with little pretension to beauty or speed.*

\section{CHAPTER V.}

THE ZOOLOGICAL CLASSIFICATION OF THE HORSE.

THERE are so many thonsand species of living beings, some so much resembling each otber, and others so strangely and altogether different, that it would have been impossible to have arranged them in any order, or to lave given auy description that could be understood, had not naturalists agreed on certain peculiarities of form which should characterise certain classes, and other lesser peculiarities again subdividing these classes.

The first division of animals is into vertebrated and invertebrated.

Tertebrated animals are those which have a cranium, or bony cavity containing the brain, and a succession of bones called the spine, and the divisions of it named vertebrce, proceeding from the cranium, and containing a prolongation of the brain, denominated the spinal marrow.

Intertebrated animals are those which have no vertebre.

The horse, then, belongs to the dirision vertebrated, because he has a cranium or skull, and a spine or range of vertebræ proceeding from it.

The vertebrated animals are exceedingly nu-

* Pinkerton, in the second valume of his Travels, gives a ellrinus arcount of the state of the lrish horses in the island of Raghery, on the northern coast of Antrim, tarly in the last centary. A puvernment surey of the colast was taken at that time. "Inim must kum," sny" the writer, "that it was but the ouher d:y that the perple of Raghery recollected that a road might be of some rinvitien'e to them, sit that in our excursion we were ohliged to follow the old custom of riding over precipices that wonid not appear contemptible even to a man that enjoyed the use of his legs. It secms that my horse, though fifteen of sisteen years old, had never before felt a bridle in his mouth. He bad, however, merous. They include man, quadrupeds of all kinds, birds, fishes, and many reptiles. We naturally look for some subdivision, and a very simple line of distiuction is soon presented. Certain of these vertelurated animals have mammce or teats, with which the females suckle their young. - The human female has two, the mare has two, the cow four, the bitch ten or twelve, and the sow more than twelve.

This class of vertebrated animals having mammæ or teats is called mammalia; and the horse belongs to the division vertebrata, and the class mammalia.

The class mammalia is still exceedingly large, and we must again subdivide it. $\mathrm{It}$ is stated (Library of Entertaining Knowledge, vol. i. p. 13), that " this class of quadrupeds, or mammiferous quadrupeds, admits of a division into two Tribes.

"I. Those whose extremities are divided into fingers or toes, scientifically called unguiculata, from the Latin word for nail; and II. Those whose extremities are hoofed, scientifically called ungulata, from the Latin word for hoof.

borne it gnod-naturedly and well; but we were now come to a diffienlt part of the road, even the top of a very rugged precipice. $\mathrm{He}$ was evidently frightened; and after many attempts to shake off his fuar, he refusell to proceed anuther step. The reasoning process in hi m:nd was evitlent enongh, and " ten amised me afteru ards :"You may have ynur whim when you cannot do either you or myself mneh harm, hut I do not thocse to ri-k my neck for you or fur any one.' The buille wus taken off, he selected his own path, and the rider was earried over an exceedingly dangerotis heap of rocks, with a degrce of eaution which Mr. Pinkerton con!d not help admiring in the nuidst of his terror." 
"The extremities of the first are armed with claws or nails, which enable them to grasp, to climb, or to burrow. The extremities of the second tribe are employed merely to support and move the body."

The extremities of the horse are covered with a hoof by which the body is supported, and with which he cannot grasp anything, and therefore he belongs to the tribe ungulata or hoofed.

But there is a great variety of hoofed animals. The elephant, the rhinoceros, the hippopotamus, the swine, the horse, the sheep, the deer, and many others, are ungulated or hoofed; they admit, however, of an easy division. Some of them masticate or chew their food, and it is inmediately received into the stomach and digested; but in others the food, previous to digestion, undergoes a very singular process. It is returned to the mouth to be remasticated, or chewed again. These are called ruminantia, or ruminats, from the food being returned from one of the stomachs (for they have four), called the rumen or paunch, for the purpose of remastication.

The ungulata that do not ruminate are, somewhat improperly, called pachydermata, from the thickness of their skins. The horse does not ruminate, and therefore belongs to the order pachydermata.
The pachydermata, who have only one toe, belong to the family solipeda-single-footed. Therefore the horse ranks under the division vertebrata - the class mammalia - the tribe ungulata-the order pachydermata-and the family solipeda.

The solipeda consist of several species, as the horse, the ass, the mnle, and the quagga.

First stands the Eqnus Caballus, or Common Horse.

Animals are likewise distingnished according to the number, description, and situation of their teeth. The horse has six incisors or cutting teeth in the front of each jaw; and one canine tooth or tusk.

On each side, above and below-at some distance from the incisors, and behind the canines, and with some intervening space-are six molar teeth or grinders; and these molar teeth have flat crowns, with ridges of enamel, and that enamel peuetrating into the substance of the tooth.

The whole is thus represented by natural historians :-

$$
\text { Horse.-Incisors } \frac{6}{6} \text {, canines } \frac{1-1}{1-1} \text {, molar } \frac{6-6}{6-6} \text {. }
$$

Total, forty teeth.

To this short chapter we may properly append

THE SKELETON OF THE HORSE.

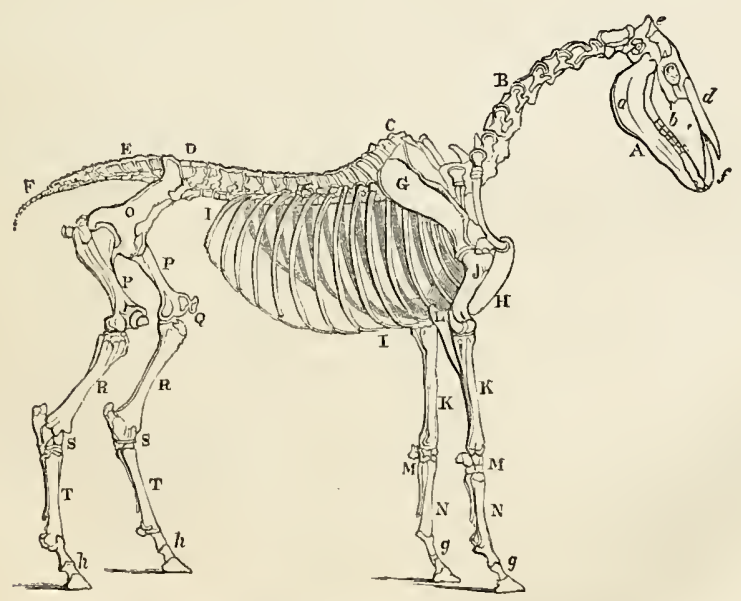


A The Head.

a The posterior maxillary or under jaw.

$b$ The superior maxillary or upper jaw. A little lower down than the letter is a foramen, through which pass the nerves and blood-vessels which chiefly supply the lower part of the face,

c The orbit, or cavity containing the eye.

$d$ The nasal boncs, or bones of the nose.

e The suture dividing the parietul howes below from the occipital bones above.

$f$ The lnterior maxillary bone, containing the upper incisor teeth.

B The Seven Cervical Vertebri, or bones of the neck,

C The Eighteen Dorsal Vertebræ, or bones of the back.

D The Six Lumbar Vertebræ, or bones of the loins.

F The Five Sacral Veitebra, or bones of the hanuch.

F The Cuudal Vertebre, or bones of the tail, generally about fifteen,

G The Scapula, or shoulder-blade.

H The Sttrnum, or fore-part of the chest.

I The Coste or ribs, seven or eight articulatiog with the sternum, and called the true ribs, and ten or eleven united together by cartilage, called the false ribs.

J The Humerus, or upper bone of the arm.

$\mathrm{K}$ The Radjus, or upper bone of the arm.
L The Ulaa, or elbow. The point of the elbow is called the Olecranoo.

M The Carpus or knee, consisting of seven bones,

N The metacarpal bones. The larger metacarpal or cannon or shank in frout, and the smaller matacarpal or splent bone behind.

$g$ The fore pastern and foot, consisting of the Os Suffraginis, or the upper and larger pastern bone, with the sesamoid bones behind, articulating with the canoon and greater pastern; the Os Coronx, or lesser pastern; the Os Pedis or coffin bone; and the Os Navicularc, or navicular, or shuttle-hone, not seen, and articulating with the smaller pastern and coffin bones.

$h$ The eorresponding bones of the hind-feet.

o The Haunch, consisting of three portions, the Ilium, the Ischium, and the Pubis.

$P$ The Femur or thigh.

Q The stitle joint with the Patella.

$\mathrm{R}$ The Tibia or proper leg bone-behind is a small bone called the fibula.

S The Tarsus or hock, composed of six bones. The prominent part is the Os Calcis, or point of the bock.

T The Metatarsals of the hind leg.

\section{CHAPTER VI,}

\section{THE SENSORIAL FUNCTION.}

BeAdtrful as is the horse, and identificd so much with our pleasure and our profit, he has been the object of almost universal regard; and there are few persons who do not pretend to be somewhat competent judges of his form, qualities, and worth. From the nobleman, with his numerous and valuable stud, to the meanest helper in the stable, there is scarcely a man who would not be offended if he were thought altogether ignorant of horse-flesh. There is no sulject on which he is so positive; there is no subject on which, generally speaking, he is so deficient; and there are few horses on some points of which these pretended and self-sufficient judges would not give a totally opposite opinion.

The truth is, that this supposed knowledge is rarely founded on principle, or the result of the slightest acquaintance with the actual structure of the animal - the form and connexion of parts on which strength, or fleetness, or stoutness, must necessarily depend.

In speaking of the structure of this animal, and the points which guide the opinion of real judges of him, we shall, as briefly and as simply as we are able, explain those fundamental principles on which his usefulness and beauty must depend. We require one kind of horse for slow and heavy draught, and another for lighter and quicker work; one as a pleasant and safe roadster -another with more speed and equal continuance, as a hunter-and another still is wanted for the race-course. What is the peculiarity of structurewhat are the particular points that will fit each for his proper business, and, to a certain degree, unfit him for everything else? The farmer will require a horse of all-urork, that can carry him to market and take him round his farm-on which he can occasionally ride for pleasure, and which he must sometimes degrade to the dung-cart or the harrow. What combination of powers will enable the animal to discharge most of these duties well, and all of them to a certain extent profitably?

Much time spent among horses, an acquired love of them, and a little, sometimes possibly too dearly-bought, experience, may give the agriculturist some insight into these matters. We will try whether we cannot assist him in this affairwhether we cannot explain to him the reason why certain points must be good, and why a horse without them must of necessity be good for nothing. Perhaps some useful rules may thus be more deeply impressed upon his memory, or some common but dangerous prejudices may be discarded, and a considerable degree of error, disappointment, and expense avoided.

If we treat of this at considerable length, let it be remembered that the horse is our noblest servant, and that, in describing the structure and economy of his frame, we are in a great measure describing that of other domestic quadrupeds, and shall hereafter have to speak only of points of difference required by the different services and uses for which they were destined. And further, let it be remembered, that it is only by being well acquainted with the structure and anatomy of the horse that we can appreciate his shape and uses, or understand the different diseases to which he is liable. It is from the want of this that much of the mass of ignorance and prejudice which exists as to the tiseases to which he is subject is to be referred. 
The nervous system will first pass in review, for it is the moving power of the whole machine. It consists of the brain, to which all sensation is referred or carried, and from which all voluntary motion is derived-the spinal cord, a prolongation of the brain, and thus connected with sensation and voluntary motion, governing all the involuntary motions of the frame, and by power from which the heart beats, and the lungs heave, and the stomach digests; and one other system of nerves-the ganglionic-presiding over the functions of secretion and of nutrition, and the repair and the welfare of the frame generally.

The following cut represents the head of the horse divided into the numerous bones of which it is composed, and the boundaries of each bone clearly marked by the sutures which connect it with those around.

The upper and broadest part is the cranium or skull in which the brain is contained and by which it is protected. It is composed of nine bones: the two frontals, $a \boldsymbol{a}$; the two parietals, $c c$; the two temporals, $d d$; the occipital, $g$, and the ethmoid and sphenoid, which will be found delineated at figs. $k$ and $l$, and which will be better seen in the cut in the next page.

\section{a a The frontal bones, or bones of} the forehead.

$b \quad$ The supra-orbital foramina or holes above the orhit, through which the nerves and blond-ressels supplying the forehead pass out. The small holes beneath receives the ressels which dip into and supply the bone.

$c$ c The parietal bones, or walls of the skull.

$d d$ The temporal booes, or bones of the temples.

e $e$ The zygomatic, or yoke-shaped arch.

$f f$ The temporal fossa, or pit above the eye.

$g$ The occipital bone, or bone of the binder part of the head.

$h$ The orbits containing and defending the eye.

i i The lachrymal hones belonging to the conveyance of the tears from the eyes.

j $j$ The nasal bones, or bones of the nose.

$k k$ The malar, or cheek-bones.

l $l$ The superior maxillary, or that portion of the upper jaw containing the molar teeth or grioders.

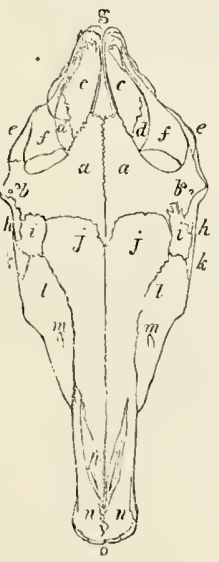

$m m$ The infra-orbital foramea $-\mathrm{a}$ bole below the orbit, through which pass branches of nerves and blnod-vessels to supply the lower part of the face.

$n n$ The inferior maxillary, the lower part of the upper jaw-bonea separate bone in quadrupeds, cuntaining the incisor or cutting teeth, and the upper tishes at the point of union between the superior and iaferior maxillaries.

o The upper incisol or cutting teeth.

$p$ The openiags into the nose, with the bones forming the palate.

There is an evident intention in this division of the head into so many bones. When the fotus-the unborn foal-first begins to have life, that which afterwards becomes bone is a mere jelly-like substance. This is gradually changed into a harder material-cartilage; and, before the birth of the animal, much of the cartilage is taken away by vessels called absorbents, and bone deposited in its stead. In flat bones, like those of the head, this deposit takes place in the centre, and rays or radiations of bone extend thence in every direction. Then, by having so many bones, there are so many centres of radiation; and, consequently, the formation of bone is carried on so much the more rapidly, and perfected at the time when the necessities of the animal require it. At the period of hirth, however, this process is not completed, but the edges of the bones remain somewhat soft and pliant, and therefore, in parturition, they yield a little and overlap each other, and thns, by rendering the birth more easy, they save the mother much pain, and contribute to the safety of the foal.

The first of these bones, or the first pair of them, occupying the broad expanse of the forehead, are called the frontal bones, $a$ a. They are united together by a most curious and intricate dove-tailing, to defend from injury the brain which lies heneath the upper part of them. Lower down, and where the cavity of the nose is to be defended, their union is sufficient, but far less complicated. Thus, at first starting, there is an evident proof of design, an illustration of that adaptation to circumstances which will again and again present itself in the most interesting points of riew. Peculiar strength of union is given where a most important organ is to be defended-the suture is there intricate and laboured. Where less important parts are covered, it is of a far simpler character.

Few things more clearly indicate the breed or blood of the horse than the form of the frontal bones. Who has not remarked the broad angular forehead of the blood horse, giving him a beautiful expression of intelligence and fire, and the face gradually tapering from the forehead to the muzzle, contrasted with the large face of the cart or dray-horse, and the forehead scarcely wider than the face?

At $f$, between the frontal bones, is the pit or carity above the eye, and by the depth of which we form some idea of the age of the horse. There is placed at the back of the eye a considerable quantity of fatty substance, on which it may revolve easily and without friction. In aged horses, and in diseases attended with general loss of condition, much of this disappears; the eye becomes sunken, and the pit above it deepens. It is said that some of the lower class of horse-dealers puncture the skin, and with a tobacco pipe or small 
tube blow into the orifice until the depression is almost filled up. This, with the aid of a bishonned tooth, may give a false appearance of youth, that will remain during some hours, and may deceive the unwary, but the trickery may easily be detected by pressing on the part.
These bones, however, are not solid, but a considerable portion of them is composed of two plates receding from each other, and leaving numerous and large vacuities or cells. These vacuities are called the frontal sinuses. They are shown in the following cut.

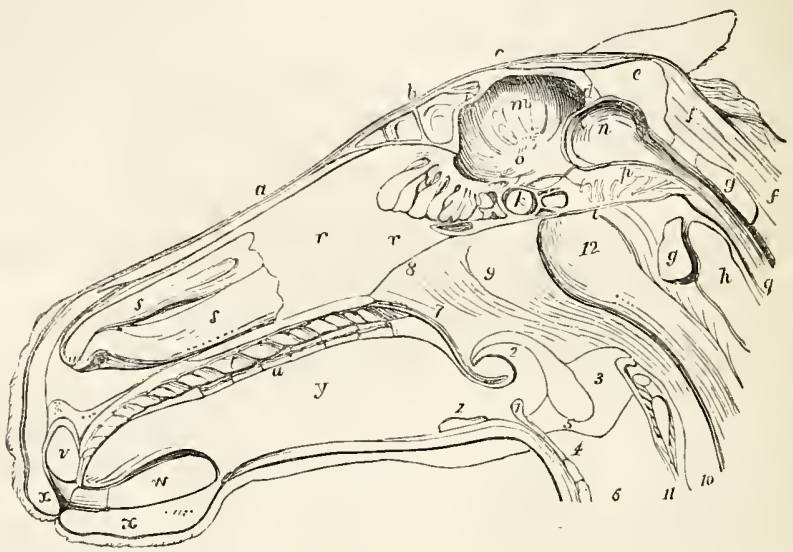

a The nasal bone, or hone of the nose.

$b$ The frontal bone. The cavities or cells beneath are called the frontal sinnses.

c The crest or ridge of the parietal bones.

$d$ The tentorium or hony separation between the cerebrum- and cerebellum.

$e$ The oecipital bone.

$f$ The ligament of the neck, or pack-uax, by which the head is chiefly supported.

$g$ The atlas, sustaining or carrying : the first bone of the neck.

$h$ The dentata, tooth-like, or second bone of the neck.

$i$ The cuneiform, or wedge-shaped process, or base of the occi pital hone. Between it and the other portion of the occipital bone $e$, lies the great foramen or aperture through which the prolongation of the brain-the spinal marrow-issues from the skull.

$k$ The sphenoid, wedge-like, bone, with its cavities.

$l$ The ethmoid, sieve-like, bone, with jts cells.

$m$ The cerebrum, or brain, with the appearance of its cortical and medullary substance.

The cerebellum, or little brain, with its beautiful arborescen appearance.

- A portion of the central medullary, morrow-like, substance of the brain. and the prolongation of it under the name of the crus cerebri, leg of the brain, and from which many of the nerves take their origio.

$p$ The medulla oblongata-the prolongation of the brain after the medullary substance of the cerebrum and cerebellum have united, and fortuing the commencement of the spioal marrow. The columnar appearance of this nortion of the brain is represented, and the origins of the respiratory nerves.

$q$ The spinal marrow extending through a canal in the centre of the bones of the neck, back, and loins, to the extremities of the tail, and from which the nerves of feeling and of motion, that supply erery part of the fiume except the head, arise. $r$ The septum narium, or cartilagixons division between the nostrils.

s. The same cut of at the lower part, to show the spongy iurbioated, turban-shaped, bones filling the cavity of the nustril.

The palate.

$u$ The molar teeth or grinders.

v The inferior maxillary lome, containing the incisur teeth or nippers. The canine tooth or tush, is cuncealed by the tongue.

w The posterior maxillary, or lower jaw with its incisors.

$x$ The lips.

y The tongue.

A portion of the os hyoides, or bone of the tongue, like a Greek u, $v$.

1 The thyroid, helmet-shaped, cartilage, inclosing and shielding the neighbouring parts.

2 The epiglottis, or covering of the glottis, or aperture of the wind-pipe.

3 The arytenoid, funnelshaped, cartilages, having between them the aperture leading into the trachea or windpipe.

One of the chorda vocales, cords or ligaments concerned in the formalion of the voice.

5 The sarculus laryngis, sac or ventricle of the larynx, or throat, to modulate the voice.

6 The irachea or wind-pipe. with its different rings.

7 The soft palate at the back of the mouth, so constructed as almost to prevent the pussibility of romiting.

8 The opening from the hack part of the mouth into the nostril.

The cartilage covering the entrance into the eustachian tube, or communication betreen the mouth and internal part of the ear.

10 The cest phagus, or gullet.

11 The cricoid, ring-like, cartilage, below and behind the thyroid.

12 Muscles of the neck, covered by the membrane of the back part of the month. 
The sinus on the different sides of the forehead do not communicate with each other, but with other sinuses, in the ethmoid, and sphenoid, and upper jaw-bones, and also with the cavities of the nose on their respective sides. These sinuses afford a somewhat increased protection to the brain beneath; and by the continuous and slightly projecting line which they form, they give beauty to the forehead; but their principal use probahly is, like the wiudings of the French horn, to increase the clearness and loudness of the neighing. It will be remarked that they are very irregular in depth, which at one place is an inch or more.

In the sheep, and occasionally in the oxrarely in the horse-the larvæ of maggots produced by certain species of flies, crawl up the nose, lodge themselves in these sinuses, and produce intolerable pain.

Veterinary surgeons have availed themselves of these sinuses, to detect the existence of glanders, that disease so infectious and so fatal. They may suspect that a horse respecting which they are consulted is glandered. It is of great consequence to be sure about this. The safety of the whole team may depend upon it. It may be a puzzling case. There may be no ulceration of the nose within sight. The glands under the jaw may not be close to and seemingly sticking to the bone, which is a common symptom, yet for a considerable time there may have been a discharge from the nostril, and the horse is out of condition. On the other hand, some slight ulceration may be detected in the nostril, but the horse eats well, works well, and is in good plight. It is possible that from the closest examination of the animal, no horseman or veterinary surgeon can give a decide dopinion.

If, however, the horse is glandered, there will probably be considerable ulceration in the upper part of the cavity of the nose, and a collection of matter there. To ascertain this, the veterinary surgeon sometimes makes an opening into these sinuses. He may do it with perfect safety. On that part of the frontal bone, which lies between the eye and the pit above it, and above the inner corner of the eye, there is, on either side, a small depression or hole (see tigure $b$, cut, page 265), which may be easily felt in the living horse. It is what anatomists call a foramen-the supra-orbital foramen. It gives passage to the blood-vessels and nerves of the forehead.

Supposing a line to be drawn across the forehead, from one of these depressions to the other on that line, and about half an inch from the centre of it-it matters uot on which side-the frontal sinuses will be found an inch in depth (compare fig. $b, \mathrm{pp} .265$ and 266). There a perforation may be easily and safely made. A little way above, the brain would be endangered; and, a little be- low this line, the cavity of the nose would be pierced. Some warm water may be injected into this hole, with a common squirt, and it will run out at the nose. If there is matter in the frontal simuses, or any part of the cavity of the nose, below the indirect opening from the sinus into the nose under the superior turbinated tone, it will appear mixed with the water, and the owner may be assured that the horse is glandered; but if the water flows uncoloured, or simply mixed with blood or mucus, the horse may be considered as free from this disease. The thick creamy consistence of pus, its sinking in water, and its capability of being perfectly, although not readily, mixed with water, will distinguish it sufficiently from the natural discharge from the nose, which is ropy, lighter than water, and, when mixed with it, still preserres a kind of stringiness.

It was formerly the practice to inject various liquids into the nostrils, in this way, for the cure of glanders. Some of them were harmless enough ; but others were cruelly acrid. This practice is now, however, abandoned by the scientific practitioner; for it would only be a portion of the cells of the head, and a portion only of the cavity of the nose, and that least likely to be diseased, with which the fluid could be brought into contact.

As the frontal sinuses are lined hy a continuation of the memlurane of the nose, they will sympathise with mauy of the affections of that cavity; but the membrane of the sinuses is suscentible of an inflammation peculiar to itself. The disease is rare, and the cause of it has not been fully ascertained. It is oftenest metastasis of inflammation of the brain,-shifting of inflammation from the brain to the membrane of the sinus, or communication of inflammation from the brain by proximity of situation.

The attack is usually sudden; the horse is dull, lethargic, and almost as cotamose as in stomach-staggers. The first thing that excites suspicion of the actual character of the disease, is heat iu the situation of the frontal sinus when the hand is placed on the forehead. The lethargy soon passes over, and a state of the highest excitation succeeds. The conjunctiva and the membrane of the nose are injected - the pulse is quick and hard - the horse becomes violent and dangerous; he kicks, plunges, and, half conscious and half unconscious, he endeavours to do all the mischief that he can. The disease is now evidently combined with, or is essentially, inflammation of the brain. It is distinguished from madness by this half-consciousness, and also by his being more disposed to bite than he is in pure phrenitis.

The disease is usually fatal. It rarely lasts more than eight-and-forty hours.

The post-mortem appearances are, great inflam. mation of the brain, with frequent effusions of 
blood. The simses are sometimes filled with coagulated blood. The brain seems to be affected just in proportion to the violence which the animal has exhibited.

The treatment should consist of copious bleeding, application of ice to the head, blistering the head, and physic. The trephine is scarcely admissible, from the danger of producing greater irritation.

Sometimes the disease assumes a more chronic form. There is ulceration of the membrane, but not cerebal affection. A purulent discharge then appears from the nose, evidently not of a glanderous character, and none of the submaxillary glands are enlarged. In both the acute and chronic form it is usually confined to one sinus: We are indebted to the late Mr. John Field for the principal knowledge that we have of this disease.* The inner plate of the frontal bone covers a consideralle portion of the anterior part of the brain, and it is studded witl depressions corresponding with irregularities on the surface of the brain.

Immediately above the frontal, and extending from the frontal to the poll, are the parietal bones. They are two, united together by a suture when the animal is young, but that suture soon becoming obliterated. They have the occipital, g, p. 265 , above; the frontals, $a$, below; and the temporals, $d d$, on either side. They are of a closer and harder texture than the frontals, because they are most exposed to injury, and more concemed in defending the braiu.

A very small portion ouly of the parietals is naked, and that is composed of bone even harder than the other part, and with an additional layer of bone rising in the form of a crest or ridge externally. Every other part of these bones is covered by a thick mass of muscle-the temporal muscle, which is principally concerned in chewing the food, but which likewise, by its yielding resistance, speedily and effectually breaks the force of the most violent blow. A woolpack hung over the wall of a fortress, when the enemy is battering to effect a breach, renders the heaviest artillery al most harmless. So the yielding resistance of the temporal muscle affords a sure defence to the brain, however sudden or violent may the blow which falls on the parietal. These benevolent provisions will not be disregarded by the reflecting mind.

On the side of the head, and under the parietals $(d d, p .265)$ are the temporal bones, one on each side, $f f$. These again are divided into two parts, or consist of two distinct bones; the petrous portion, so called from its great or stomy hardness, and containing the wonderful mechanism of the ear, and the squamous portion, from the appear-

* The Veterinarian, vol. iv., p. 198. ance of its union with the parietal, overlapping it like a great scale.

From the latter there projects a portion of bone, $e$, which unites with the frontal, and forms a strong arch-the zygomatic-distinctly to be felt at the side of the head immediately above the eye. This arch is designed to protect the upper part of the lower jaw, the motion of which may very plainly be seen beneath it when the horse is feeding. It is very strong, and it ought to be; for if it were depressed, or forced inward, the horse would starve. There is one species of violence which causes this arch to require no common strength; and that is, the brutal manner in which the collar is often forced over the head.

At the base of the arch is an important cavity not visible in the cut, receiving into it, and forming a joint with, the head of the lower jaw: it will be presently described.

Having reached the base of the temporal bone, it is found united to the parietal, not by a simple suture, as the lower part of the frontals, or the bones of the nose (see fig. $a$ and $j$, p. 265), nor by a dove-tailed suture, as the upper part of the frontals (see the same cut); but it is spread over the parietal in the form of a large scale, and hence, as before observed, called the squamous portion of the temporal bone. In fact, there are two plates of bone instead of one. Was there design in this? Yes, evidently so. In the first place, to increase the strength of the base of the zygomatic arch. This extensive union between the temporal and parietal bones resembles the buttress or mass of masomry attached to the base of every arch, in order to counteract its lateral pressure. The concussion, likewise, which might be communicated by a blow on the top of the arch, is thus spread over a large surface, and consequently weakened and rendered comparatively harmless; and that surface is composed of the union of two bones of dissimilar construction. The hard stony structure of the parietal is very different from the tougher material of the temporal; and thus, as a finger acts on a sounding glass, the vibration communicated to the temporal is at once stopped, and the brain receives no injury.

There is another proof of admirable design. Where is this squamous portion of the central bone situated? On the side of the head. And what is the figure of the cranium or skull, and principally that part of it which contains the cerebrum or brain? It is an elliptical or oval arch (see fig. $m, n, o, p .266$ ). If pressure is made on the crown of that arch-if a blow is received on the suture between the parietals sufficient to cause the elastic materials of which the skull is composed to yield-the seat of danger and injury is at the side. If a man receives a violent blow on the crown or back part of the head, the fracture, 
if there is any, is generally about the temple, and the extravasation of blood is oftenest found there. The following figure will explain this :-

Let the line

A B C represent an elliptical arch, composed of elastic materials. Some force shall be applied at $B$ sufficient to cause it to yield. We cannot compress

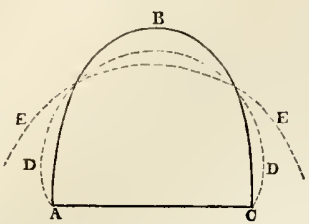
it into smaller compass; but just in proportion as it yields at $B$ will it spur or bulge out at $D$, and give way sometimes as represented at $\mathrm{E}$. In a dome, the weight of the materials constantly acting may be considered as representing the force applied at $B$; and so great is the lateral pressure, or tendency to bulge out (vide $\mathrm{D}$ and $\mathrm{E}$ ), that it is necessary either to dove-tail the materials into one another, or to pass strong iron chains round them. For want of sufficient attention to this, "the dome of St. Sophia, in Constantinople, built in the time of the Emperor Justinian, fell three times during its erection; and the dome of the cathedral of Flerence stood unfinished an hundred and twenty years, for want of an architect."

Nature, in the construction of the horse's head, has taken away the pressure, or removed the probability of injury, by giving an additional layer of bone, or a mass of muscle, where alone there was danger, and has dove-tailed all the materials. Farther than this, in order to make assurance doubly sure, she has placed this effectual girder at the base, in the overlapping of the squamous portion of the temporal bone.

Above the parietals, and separated from them by a suture (fig. $g$, p. 265 , and fig. $e$, p. 266), is the occipital bone. Superiorly it covers and protects the smaller portion of the brain, the cerebellum; and as it there constitutes the summit or crest of the head, and is particularly exposed to danger, and not protected by muscles, it is interesting to see what thickness it assumes. The head of the horse does not, like that of the human being, ride upright on the neck, with all its weight supported by the spinal column, and the only office of the muscles of the neck being to move the head forward, or backward, or horizontally on its pivot; but it hangs in a slanting position from the extremity of the neck, and the neck itself projects a considerable distance from the chest, and thus the whole weight of the head and neck are suspended from the chest, and require very great power in order to support them. In addition to the simple weight of the head and neck, the latter projecting from the chest, and the head hanging from the extremity of the neck, act with enormous mechanical force, and increase more than a hundred-fold the power necessary to support them.

The head and neck of the horse, and particularly of some horses of a coarse breed, are of no little bulk and weight. It will hereafter be shown in what breeds and for what purposes a light or heavy head and weck are advantageous; but it may be safely affirmed that, projecting so far from the chest, and being consequently at so great a distance from the fulcrum or support, the lightest head will act or bear upon the joint between the last bone of the neck and the first rib witl a force equal to many thousand pounds.

How is this weight to be supported? Is muscular power equal to the task? The muscles of the animal frame can act for a certain time with extraordinary force; but as the exertion of this power is attended with the consumption of vital energy, the period soon arrives when their action is remitted or altogether suspended. A provision, however, is made for the purpose, simple and complete.

From the back of the occipital bone (fig. $f$, p. 266), and immediately below the crest, proceeds a round cord of considerable bulk, and composed of a ligamentous substance, which reaches down and is securely attached to the spines of the vertebræe, or bones of the back; and by this ligament - the ligamentum colli, ligament of the neck, commonly called the pack-uax-the head is supported.

There are, however, some admirable contrivances comnected with this bigament. As it proceeds from the head, it is in the form of a round cord. It passes over the atlas, or first bone of the neck, without touching it, and then, attaching itself strougly to the second bone, principally supports the head by its union with this bone. The mechanical disadvantage is increased; but the head is turned more freely on the first and second bones. The principal stress is on the dentata or second bone, so much so, that, in poll-evil, this ligament may be divided without serious inconrenience to the horse. It then suddenly sinks deeper, and communicates with all the other rertebrre. Each of these communications becomes a separate point of support; and as they approach uearer to the base, the mechanical disadvantage, or the force with which the weight of the head aud neck presses and acts, is materially lessened.

The head, then, while the animal is in a state of rest, is supported by this ligament, without any aid from muscular energy.

There is, howerer, something yet wanting. The head must not be always elevated. The animal has his food to seek. In a state of nature this food lies principally on the ground, and the head must be lowered to enable the horse to get at it. How is this effected? This ligament, as it has been called, because it resembles in appearance 
the other ligaments of the body, possesses a property which they have not, and which they must not lave, or they would be useless. No well-knit joint cuuld exist if it had this property. It is elestic. It will yield to a force impressed upon it, and will resume its natural dimensions when that force is removed. It sustains perfectly the weight of the head. That portion of tenacity or strength is given to it which will not give way to the simple weight of the head, but which will yield to a very little additional weight. Its resisting power is so admirably adjusted to that which it has to sustain, that when certain muscles, whose action is to depress or lower the head, begin to act, and add their power to the previous weight it had to bear, the ligament stretches, and when the horse is browsing it is full two inches longer than when the head is erect.

When the animal has satisfied himself, these depressing muscles cease to act, and cther muscles which are designed to assist in raising the head, begin to exert themselves; and by their aid-but more by the inherent elasticity of the ligamentthe head is once more elevated, and remains so without the slightest exertion of muscular power. This is one of the many applicatious of the principle of elasticity which will be discovered and admired in the construction of the animal frame.

The ligament of the neck is inserted into the centre of the back part of the occipital bone, and immediately below the vertex or crest of that bone; and therefore the bone is so thick at this part (see fig. e, p. 266).

Many large and powerful muscles are necessary to turn the head in various directions, as well as to assist in raising it when depressed. The occipital bone, as will be seen in the cut, presents a spine running down the centre, $\mathrm{B}$, and a large roughened surface for the attachment of these muscles $\mathrm{C}, \mathrm{C}$.

Lower down, and still at the back of the occipital bone, are two rounded protuberances $\mathrm{D} D$, by which the head is connected with the atlas, or upper or first vertebra, or bone of the neck; and these are called the condyloid, cup-

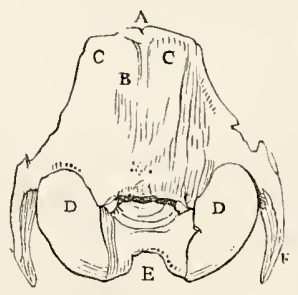
shaped, processes of the occipital bone. All the motions of the head are partly, and many of them wholly, performed by this joint.

Between them is a large hole, the foramen magnum, or great aperture, E, through which the continuation of the brain, termed the spinal cord or marrow, passes ont of the skull.

$A s$ an additional contrivance to support the enormous weight of the head, are two other projections of the occipital bone, peculiar to animals whose heads are set on in a slanting direction, and into which powerful muscles are inserted. They are called the coracoid, beak-like, processes or prolongations, F, F, of the occipital bone.

Running forward, and forming outwardly a part of the base, and inwardly a portion of the floor of the skull, is what, from its wedge-like shape, is called the cuneiform process of the occipital bone (fig. $i$, p. 266). It is thick, strong, and solid, and placed at the bottom of the skull, not only to be a proper foundation for, and to give additional strength to, the arch on either side, but speedily to stop all vibration and concussion.

At the base of the skull, and anterior to or below the occipital, lies thes phenoid, redge-like, bone (fig $k$, p. 266). Its body, likewise called the cuneiform or wedge-shaped process, is a continuation of the same process of the occipital, and, like it, is thick and solid, and for the same important purpose. This bone branches out into four irregular bodies or plates, two of which are called the uings, and two running to the palate, the legs. They could not be represented in the cnt, and there is nothing important belonging to them, so far as this work is concerned. Internally (fig. $k$ ), the sphenoid forms a portion of the cavity of the skull.

of the ethmoid-sieve-like-bone, little can be seen outwardly. A small portion is found in the back part of the orbit and in the cavity of the cranium; but the most important part of it is that which is composed of a great number of thin plates, forming numerous cavities or cells (fig. $l$, p. 266), lined with the membraue of the nose, and entering into its cavity. The upper portion is called the cribriform or sieve-shaped plate, from its being perforated by a multitude of little holes, througl which the nerve connected with smelling passes and spreads over the nose.

Altogether these bones form a cavity of an irregular oval shape, but the tentorium penetrating into it, gives it the appearance of being divided into two $(d, p, 266)$.

The cavity of the skull may be said to be arched all round. The builder knows the strength which is connected with the form of an arch. If properly constructed, it is equal to a solid mass of masonry. The arch of the horse's skull has not much weight to support, but it is exposed to many injuries from the brutality of those by whom he should be protected, and from accidental causes.

The roof of the skull is composed of two plates of bone: the outer one hard and tough, and the different parts dove-tailed together, so as not to be easily fractured; the inmer plate being elastic. By the union of these two substances of different 
construction, the vibration is damped or destroyed, so far as safety requires.

On raising any part of the skull of the horse, the dense and strong membrane which is at once the lining of the cranium and the covering of the brain-the dura mater-presents itself. It is nnited to the membranes below by numerous little cords or prolongations of its substance, conveying blood and communicating strength to the parts beneath. Between this membrane, common to the cranium and the brain, and the proper investing tunic of that organ, is found that delicate gossamers' web, appropriately called the arachnoidthe spider's membrane-and which is seen in other animals, designed either to secrete the fluid which is interposed, for the purpose of obviating injurious concussion, or, perhaps, to prevent the brain from readily sympathising with any inflammatory action prodnced by injury of the skull.

Beneath is the proper investing membrane of the brain-the pia mater-which not only covers the external surface of the brain, but penetrates into every depression, lines every ventricle, and clothes every irregularity and part and portion of the brain.

We now arrive at the brain itself. The brain of the horse corresponds with the cavity in which it is placed (m, p. 266). It is a flattened oval. It is divided into two parts, one much larger than the other-the cerebrum or brain, and the cerebel. lum or little brain ( $n$, p. 266). In the human being the cerebrum is above the cerebellum, in the quadruped it is below; and yet in both they retain the same relative situation. The cerebellum is nearer to the foramen through which the brain passes out of the skull (n, p. 266), and the continuation of the cerebrum passes under the cerebellum ( $p, \mathrm{p} .266)$, in order to arrive at this foramen. In the human head this foramen is at the base of the skull; but in the quadruped, in whom the head is placed slanting, it is necessarily elevated.

He who for the first time cxamines the brain of the horse will be struck with its comparative diminutive size. The human being is not, generally speaking, more than one-half or one-third of the size and weight of the horse; yet the brain of the biped is twice as large and as heavy as that of the quadruped. If it had been the brain of the ox that had been here exposed, instead of that of the herse, it would not have been of half the bulk of that of the horse. If the dog had been the subject, it would have been very considerably larger, comparing the general bulk of each animal. This is singular. The human brain largest in comparative bulk; then the brain of the dog, the horse, the ox. Thus would they be classed in the scale of intęlligence.

If the brain is more closely examined, it will be found that there is none of the roundness and the broadness of that in the human being; it is comparatively tame and flat. There is some irregularity of surface, some small projections and depressions; but they, too, are comparatively diminntive and inexpressive. Were the brain of the beaver, or the hare, or the rabbit, or of almost any bird, substituted for it, there would be no convolutions or irregularities at all.

These irregularities are not so bold and so deep in the ox as in the horse, nor in the horse as in the dog. We do not know enough of the functious of any part of the brain to associate these convolutions with any particular powers of mind, or good or had propensities, although some persons, who are wise above that which is written, have pretended to do so. It would occupy too great a portion of this volume to enter into these questions; but there are some diseases to which the horse is subject, and a very useful operation-the division of some of the nerves for certain pur poses, and which conld not be understood without a previous slight account of this important organ.

When the brain is cut, it is found to be com posed of two substances very unlike in appearance ( $m$, p. 266) ; one, principally on the outside, grey, or asli-coloured, and therefore called the cortical (bark-like) from its situation, and cineritious (ashen) from its colour; and the other, lying deeper in the brain, and from its pulpy nature called the medullary substance. Although placed in apposition with each other, and seemingly mingling, they never run into the same mass, or change by degrees into one another, but are essentially distinct in construction as well as in function.

The medullary portion is connected with the nervous system. The nerres are prolongations of it, and are concerned in the discharge of all the offices of life. They gire motion and energy to the limbs, the heart, the lungs, the stomach, and every part connected with life. They are the medium through which sensation is conreyed; and they supply the mind with materials to think and work upon.

The cineritious part has a different appear. ance, and is differently constituted. Some have supposed, and with much appearance of truth, that it is the residence of the mind-receiving the impressions that are conveyed to the brain by the sensitive nerves, and directing the operation and action of those which give motion to the limbs. In accordance with this, it happens that, where superior intelligence is found, the cineritious portion prevails, and where little beside brute strength and animal appetite exist, the me dullary portion is enlarged. There is, comparing bulk with bulk, less of the medullary substance in the horse than in the ox, and in the dog than in the horse The additional bulk of brain is com- 
posed of cineritious matter; and how different is the character of these animals? - the sluggish, stupid ox, and the intelligent horse; the silly sheep, and the intellectual companionable dog!

In a work like this, it would be somewhat out of place to enter deeply into any metaphysical speculation; but the connexion between the cineritions part of the brain and the intellectual principle, and that between the medullary portion and the mere animal principle, do seem highly probable. The latter is the medium through which the impression is conveyed, or the motion is effected; the former is the substance to which that impression is referred-where it is received, registered, and compared, and by which the operation of the motor nerves is influenced and governed.

The cortical substance is small in the quadruped ; for in their wild state brutes have no concem and no idea beyond their food and reproduction; and in their domesticated state they are destined to be the servants of man. The acuteness of their senses, and the preponderance of animal power, qualify them for this purpose; but were proportionate intellectual capacity added to this - were they made conscious of their strength, they would burst their bonds, and man would, in his turn, he the victim and the slave. The cortical part is found in each in the proportion in which it would seem to be needed for our purposes, in order that intelligence should be added to animal power. Almost every mental faculty, and almost every virtue, too, may be traced in the brute. The difference is in degree, and not in kind. The one being improved by circumstances and the other contaminated, the quadruped is decidedly the superior.

From the medullary substance-as already stated-proceed certain cords or prolongations, termed neries, by which the animal is enabled to receive impressions from surrounding objects, and to connect himself with them; and also to possess many pleasurable or painful sensations. One of them is spread over the membrane of the nose, and gives the sense of smell; another expands on the back of the eye, and the faculty of sight is gained; and a third goes to the internal structure of the ear, and the animal is conscious of sound. Other nerves, proceeding to different parts, give the faculty of motion, while an equally important one bestows the power of feeling.

One division of nerves $(h$, p. 266) springing from a prolongation of the brain, and yet within the skull, wanders to different parts of the frame, for important purposes connected with respiration or breathing. The act of breathing is essential to life, and were it to cease, the animal would die. These are nerves of involuntary motion; so that, whether he is awake or asleep, conscious of it or not, the lungs heave and life is supported. Lastly, from the spinal cord $q$-a farther prolongation of the brain, and running through a cavity in the bones of the neck, back, and loins, and extending to the very tip of the tail-other nerves are given off at certain intervals. This cut delineates a pair of them. The spinal cord $a$, is combined of six distinct columns or rods, rumning through its whole length-three on either side. 'The two upper columns-the portion of spinal marrow represented in our cut, is supposed to be placed

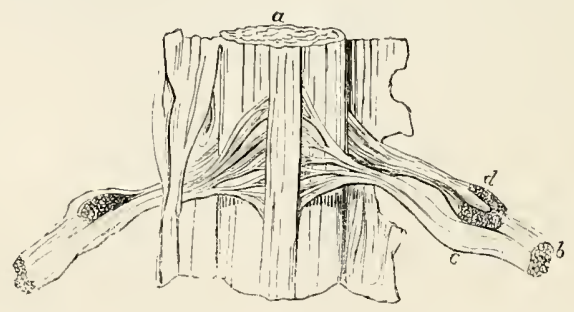

with its inner or lower surface toward us-proceed from those tracks of the brain devoted to sensation. Numerous distinct fibres spring abruptly from the column, and which collect together, and, passing through a little ganglion or enlargement, $d$-an enlargement of a nervous cord is called a gangtion-become a nerve of sensation. From the lower or inner side, a prolongation of the track devoted to motion, proceed other fibres, which also collect gradually together, and form a nervous cord, $c$, giving the power of motion. Beyond the ganglion the two unite, and form a perfect spinal nerve, $b$, possessing the power both of sensation and motion; and the fibres of the two columns proceed to their destination, enveloped in the same sheath, and apparently one nerve. Each portion, however, continues to be wrapped in its own membrane. They are united, yet dis- 
tinct; they constitute one nerre, yet neither their substance nor their office is confounded. Our cut, closely examined, will give at $b$ some idea of the maumer in which these distinct fibres are continued; each covered by its own membrane, but all enveloped in a common envelope.

All these nerves are organs of sensation and motion alone; but there are others whose origin seems to be outside of and below the brain. These are the sympathetic, so called from their union and sympathy with all the others, and identified with life itself. They proceed from a small ganglion or enlargement in the upper part of the neck, or from a collection of little ganglia in the abdomen. They go to the heart, and it beats, and to the stomach, and it digests. They form a net-work round each blood-vessel, and the current flows on. They surround the very minutest vessels, and the frame is nourished and built up. They are destitute of sensatiou, and they are perfectly beyond the control of the will.

The reader, we trust, will now comprehend this wonderful, yet simple machinery, and be able, by and by, to refer to it the explanation of several diseases, and particularly of the operation to which we have referred.

Two of the senses have their residence in the cavity of the craninm-those of hearing and sight.

They who know anything of the horse pay much attention to the size, setting on, and motion of the ear. Ears rather small than large-placed not too far apart-erect and quick in motion, indicate both breeding and spirit; and if a horse is frequently in the habit of carrying one ear forward, and the other backward, and especially if he does so on a journey, he will generally possess both spirit and continuance. 'The stretching of the ears iu contrary directions shows that he is attentive to everything that is taking place around him, and, while he is doing this, he cannot be much fatigued, or likely soon to become so. It has been remarked that few horses sleep without pointing one ear forward and the other backward, in order that they may receive notice of the approach of objects in every direction.**

The ear of the horse is one of the most beautiful parts about him, and by few things is the temper more surely indicated than by its motion. The ear is more intelligible even than the eye, and a persou accustomed to the horse, and an observer of him, can tell by the expressive motion of that organ almost all that he thinks or means. It is a common saying that when a horse lays his ears flat

* " IV'hen horses or mules march in company at night, those in front direct their ears forwaris; those in the rear direct them backward; and those in the centre turn them laterally or across: the whole troop seeming thus to be actnated by one feeliog, which watches the general safety." - Arnolt's Elemexts of Physic, vol. i. p. 478. back upon his neck, and keeps them so, he most assuredly is meditating mischief, and the stander by should beware of his heels or his teeth. In play, the ears will be laid back, but not so deeidedly, or so long. A quick change in their position, and more particularly the expression of the eye at the time, will distinguish between playfulness and vice.

The external ear is formed by a cartilage of an oval or cone-like shape, flexible, yet firm, and terminating in a point. It has, directed towards the side, yet somewhat pointing forward, a large opening extending from the top to the bottom. The intention of this is to collect the sound, and convey it to the interior part of the ear.

The hearing of the horse is remarkally acute. A thousand vibrations of the air, too slight to make any impression on the human ear, are readily perceived by him. It is well-known to every huntingman, that the cry of the hounds will be recognised by the horse, and his ears will be erect, and he will be all spirit and impatience, a consideralle time before the rider is conscious of the least sound. Need anything more be said to expose the absurdity of cropping?

This custom of cntting the ears of the horse originated, to its shame, in Great Britain, and for many years was a practice cruel to the animal, depriving him of much of his beauty; and so obstinately pursued, that at length the deformity became in some hereditary, and a breed of horses born without ears was produced. Fortunately for this too-often abused animal, cropping is not now the fashion. Some thoughtless or unfeeling young men endeavoured, a little while ago, again to introduce it, but the voice of reason and humanity prevailed.t

This cartilage, the conch or shell, is attached to the head by ligaments, and sustained by muscles, on which its action depends. It rests upon another cartilage, round withont, and irregular within, called the annular, ring-like, cartilage, and conducting to the interior of the ear; and it is likewise supported and moved by a third small cartilage, placed at the fore part of the base of the conch, and into which sereral muscles are iuserted.

The ear is covered by skin thinner than in most other parts of the body, and altogether destitate of fat, in order that it may not be too bulky and heary, and may be more easily moved. Under the skin lining the inside of the cartilage are nu-

+ Professor Grognier, in his excellent work, "Précis d'un Cours d'Hygiène Vètérinaire," speaking of this abominable custom, says, "And thus the English completely destroy or disfigure two organs which embellish the head of the most beantiful of all animals, and which, by their various motions, iodicate the thoughts that are passiog throngh his mind-the passioos which agitate bim, and, especially, the desigas which he may be meditatiog, and which it is ofen of great importance to lcarn, in order to guard against the danger which may be at hand." 
merous glands that secrete or throw out a scaly white greasy matter, which may be rubbed off with the finger, and is destined to supple this part of the ear and to keep it soft and smooth. Below this are other glands which pour out a peculiar, sticky, bitter fluid-the wax-probably displeasing to insects, and therefore deterring them from crawling down the ear and amnoying the animal, or by its stickiness arresting their progress.

The internal part of the conch is covered with long hair which stands across the passage in every direction. This likewise is to protect the ear from insects, that can with difficulty penetrate through this thick defence. The cold air is likewise prevented from leaching the interior of the ear, and the sound is moderated, not arrested-penetrating readily but not violently-and not striking injuriously on the membrane covering the drum of the ear. Can these purposes be accomplished, when it is the custom of so many carters and grooms to cut ont the hair of the ear so closely and industrionsly as they do? The groom who singes it to the root with a candle must either be very ignorant or very brutal. It can scarcely be accomplished withont singeing the ear as well as the hair. Many a troublesome sore is occasioned by this; and many a horse, that was perfectly quict before, rendered difficult to handle or to halter, and even disposed to be otherwise vicions, from a recollection of the pain which he suffered during the absurd and barbarous operation.

The sound collected by the outer ear, passes throngh the lower or annular, ring-shaped, cartilage, and through irregularities which, while they break and modify it, convey it on to another canal, partly cartilaginous and partly bony, conducting immediately to the internal mechanism of the ear. This canal, or passage, is called the external auditory passage, and at the base of it is placed, stretching across it, and closing it, a thick and elastic membrane, membrana tympani, called the membrane of the drum. This membrane is supplied with numerous fibres, from the fifth pair, or sensitive nerve of the head, for it is necessary that it should possess extreme sensibility.

Between this membrane and a smaller one almost opposite, leading to the still interior part of the ear, and on which the nerve of hearing is expanded, are four little bones, united to these membranes, and to each other. Their office is to convey, more perfectly than it could be done throngh the mere air of the carity, the vibrations that have reached the membrana tympani.

These bones are highly elastic ; and covered by a cartilaginous substance, elastic also in the greatest degree, by means of which the force of the vibration is much increased.

It is conveyed to a strangely irregular cavity, filled with an aqueous fluid, and the substance or pulp of the portio mollis or soft portion of the seventh pair of nerves, the auditory nerve, expands on the membrane that lines the walls of this cavity.

Sound is propagated far more intensely through water than through air ; and therefore it is that an aqueons fluid occupies those chambers of the ear on the walls of which the auditory nerve is expanded. By this contrivance, and by others, which we have not space now to narrate, the sense of hearing is fully equal to every possible want of the animal.

The Eye is a most important organ, and comes next under consideration, as inclosed in the bones of the skull. The eye of the horse should be large, somewhat but not too prominent, and the eyelid fine and thin. If the eye is sunk in the head, and apparently little-for there is actually a very trifling difference in the size of the eye in animals of the same species and bulk, and that seeming difference arises from the larger or smaller opening between the lids - and the lid is thick, and especially if there is any puckering towards the inner corner of the lids, that eye either is diseased, or has lately been subject to inflammation; and, particularly, if one eye is smaller than the other, it has at no great distance of time been inflamed.

The eye of the horse enables us with tolerable accuracy to guess at his temper. If much of the white is seen, the buyer should pause ere he completes his bargain; becanse, although it may, yet very rarely, happen that the cornea or transparent part is unmaturally small, and therefore an unusual portion of the white of the eye is seen, experience has shown that this display of white is dangerous. The mischierous horse is slily on the look out for opportumities to do mischief, and the frequent backward direction of the eye, when the white is most perceptible, is only to give surer effect to the blow which he is about to aim.

A cursory description of the eye, and the uses of its different parts, must be given.

The eyes are placed at the side of the head, but the direction of the conoid cavity which they occupy, and of the sheath by which they are surrounded within the orbit, gives them a prevailing direction forwards, so that the animal has a very extended field of vision. We must not assert that the eye of the horse commands a whole sphere of vision; but it cannot be denied that his eyes are placed more forward than those of cattle, sheep, or swine. He requires an extensive field of vision to warn him of the approach of his enemies in his wild state. and a direction of the orbits considerably forward, in order to enable him to pursue with safety the headlong course to which we sometimes urge him.

The eye-ball is placed in the anterior and most capacious part of the orbit, nearer to the frontal than the temporal side, with a degree of 
prominence varying with different individuals, and the will of the animal. It is protected by a bony socket beneath and on the inside, but is partially exposed on the roof and on the outside. It is, however, covered and secured by thick and powerful muscles-by a mass of adipose matter which is distributed to various parts of the orbit, upon which the eye may be readily moved without friction, and by a sheath of consilerable density and firmness, and especially where it is most needed, on the external and superior portions.

The adipose matter exists in a considerable quantity in the orbit of the eye of the horse, and enables that organ readily to revolve by the slightest contraction of the muscles. By the absorption of this fatty matter in sickness or old age, the eye is not only to a certain degree sunk in the orbit, but the roof of the orbit posterior to the frontal bone, being deprived of its support, is considerably depressed. Our work shall not be disgraced by any farther reference to the rascally contrivance by which this indication of age is in some degree removed.

In front the eye is supported and covered by the lids, which closing rapidly, protect it from many an injury that threatens-supply it with that moisture which is necessary to preserve its transparency -in the momentary act of closing give a certain and sufficient respite to a delicate organ, which would otherwise be fatigued and worn out by the constant glare of day-defend it when the eye labours under inflammation from the stimulus of light-and, gradùally drooping, permit the animal to enjoy that repose which nature requires.

Extending round both lids, and, it may be almost said, having neither origin nor insertion, is a muscle called the obicularis, or circular muscle. Its office is to close the lids in the act of winking or otherwise, but only while the animal is awake. When he sleeps, this is effected by another and very ingenious mechanism. The natural state of the eyelids is that of being closed; and they are liept open by the energy of the muscles whose office it is to raise the upper lid. As sleep steals upon the animal, these muscles cease to act, and the lids close by the inherent elasticity of the membrane of which they are composed.

The skin of the lid is, like that of the ear, exceedingly fine, in order to prevent unnecessary weight and pressure on such a part, and to give more easy and extensive motion. The lids close accurately when drawn over the eye, and this is effected by a little strip of cartilage at the edge of each of them, which may be easily felt with the finger, and preserves them in a hoop-like form, and adapts them closely to the eye and to each other. The lower cartilage, however, does not present, towards the inner corner of the eye, the whole of its flat surface to the upper, but it evideutly slopes inward, and only the outer edge of the under lid touches the upper. By this means a little gutter is formed, through which the superfluous moisture of the eye flows to the inner corner, where there is a canal to convey it away. By this contrivance it neither accumulates in the eye, nor umpleasantly runs down the cheek.

Along the edges of the lids are placed numerous little hollows, which can be plainly distinguished even in the living horse by slightly turning down the lid. These are the openings into numerous small cells containing a thick and unctuous fluid, by means of which the eves are more accurately closed, and the edges of the lids defended from the acrimony of the tears.

The horse has no eyebrous, and the eyclashes are very peculiarly arrauged. The rows of hair are longest and most numerous on the upper lid, and especially towards the outer or temporal corner, because the light comes from above; and, as the animal stands, particularly when he is grazing, and from the lateral situation of his eyes, the greater portion of the light, and the attacks of insects, and the rolling down of moisture, would chiefly be from the outside or temples. Towards the inner corner of the upper lid there is little or no eyelash, because there is no probable danger or nuisance in that direction. Only a small quantity of light can enter from below, and therefore the lashes are thin and short; but as, in the act of grazing, insects may more readily climb up and be troublesome to the eye, towards the inner angle, there the principal or only hair is found on the lower lid. These apparently trifling circumstances will not be overlooked by the careful observer.

They who are unacquainted with the absurdities of stable manageinent, or who have not carefully examined the abuses that may exist iu their own establishments, can scarcely beliere the foolish and cruel practices of some carters and grooms. When the groom is anxious that his horse should be as trim and neat all over as art can make him, the very eye-lashes are generally sacrificed. What has the poor animal suffered, when, travelling in the noon of day, the full blaze of the sun has fallen upon his eyes; and how many accidents have probably happened from his being dazzled by the light, which have been attributed to other causes ?

If the horse has no eyebrow, there are sereral hairs or bristles scattered on the upper eyelid, and there is a projecting fold of the lid which discharges nearly the same office. It is more conspicuous in old horses than in young ones. Some horsemen do not like to see it, and associate the idea of it with reakness or disease of the eye. This is perfectly erroneous. It is a prorision of nature to accomplish a certain purpose, and has nothing to do either with health or disease. 
On the lower lid is a useful provision to warn the horse of the near approach of any object that might incommode or injure him, in the form of long projecting hairs or bristles, which are plenteously embued with nervous influence, so that the slightest touch should put the animal on his guard. We would request our readers to touch very slightly the extremity of one of these hairs. They will be surprised to observe the sudden convulsive twitching of the lid, rendering the attack of the insect absolutely impossible. The grooms, however, who cut away. the eye-lashes, do not spare these useful feelers.

The eye is exposed to the action of the atmospheric air, and the process of evaporation, destructive of its transparency, is coutinually going on. The eye of the horse, or the visible part of the eye, is, likewise, more prominent and larger than in the human being, and the animal is often subject to extreme annoyance from dust and insects, while he las no hands or other guard to defend himself from the torture which they occasion. What is the provision of nature against this? Under, and a little within, the outer corner of the upper lid, is an irregular body, the lacrymal gland, comparatively larger thau in the human being, secreting an aqueous fluid, which, slowly issuing from the gland, or occasionally pressed out of it in the act of winking, flows over the eye, supplies it with moisture, and eleanses it from all impurities. Human ingenuity could not have selected a situation from which the fluid could be conveyed over the eye with more advantage for this purpose.

When this fluid is secreted in an undue quantity, and Hows over the eye, it is called tears. An increased flow of tears is produced by anything that irritates the eye, and, therefore, a coustant accompaniment and symptom of inflammation. A horse with any degree of weeping should be regarded with much suspicion. In the human being au unusual secretion of tears is often caused by bodily pain, and emotions of the miud; aud so it is accasionally in the horse. We have seen it repeatedly under acute pain or brutal usage. John Lawrence, speaking of the cruelty exercised by some dealers in what they call "firing" a horse before he is led out for sale, in order to rouse every spark of mettle, says, "more than fifty years have passed away, and I have before my eyes a poor mare, stone blind, exquisitely shaped, and showing all the marks of high blood, whom I saw unmercifully cut with the whip a quarter of an hour before the sale, to bring her to the use of her stiffened limbs, while the tears were trickling down her cheeks."

Having passed over the eye, the fluid is conveyed by the little canal to which we have alluded, formed by the sloping of the uuder lid, towards the corner of the eye; and there are two little orifices that conduct it to a small reservoir within, and at the upper part of the lacrymal bone (fig. $i$, p. 265). A little protuberance of a black or pied colour, called the carumcle, placed in the very corner of the eye, and to be seen without opening the lids, is situated between these orifices, and guides the fluid into them. From this reservoir the tears aire conveyed by a long canal, the lacrymal duct, partly bony, and partly membraneous, to the lower part of the nose. A little within the nostril, and on the division between the nostrils, is seen the lower opening of this canal; the situation of which should be carefully observed, and its real use borne in mind, for not only horsemen, but even some care. less veterinary surgeons, have mistaken it for a glanderous ulcer, and have condemned a useful and valuable animal. It is found just before the skin of the muzzle terminates, and the more delicate membrane of the nostril commences. The opening of the canal is placed tlus low because the membrane of the nose is exceedingly delicate, and would be irritated and made sore by the frequent or constant running down of the tears.

There is, however, something yet wanting. We have a provision for supplying the eye with requisite moisture, and for washing from off the transparent part of it insects or dust that may annoy the animal. What becomes of these impurities when thus washed off? Are they carried by the tears to the corner of the eye, and so pass down this duct, and irritate and obstruct it ; or do they accumulate at the imner angle of the eye? There is a beautiful contrivance for disposing of them as fast as they accumulate. Concealed within the inner corner of the eye, or only the margin of it, black or pied, visible, is a triangular-shaped cartilage, the haw, with its broad part forwards. It is concave within, exactly to suit the globe of the eye; it is convex without, accurately to adapt itself to the membrane lining the lid; and the base of it is reduced to a thin or almost sharp edge. At the will of the animal this is suddenly protruded from its hiding-place. It passes rapidly over the eye and shovels up every muisance mixed with the tears, and then, being speedily drawn back, the dust or insect is wiped away as the cartilage again passes under the corner of the eye.

How is this managed? The cartilage has no muscle attached to it; and the limbs and the different parts of the body, when put into motion by the influence of the will, are mored invariably by muscles. The mechanism, however, is simple and effectual. There is a considerable mass of fatty matter at the back of the eye, in order that this organ may be easily moved; and this fat is particularly accumulated about the imner comer of the eye, and beneath, and at the point of this cartilage. The eye of the horse has likewise very strong muscles attached to it, and one, peculiar to quadrupeds, of extraordi- 
nary power, by whose aid, if the animal has not hands to ward off the danger that threatens, he is at least enabled to draw the eye back almost ont of the reach of that danger.

Dust, or gravel, or insects, may have entered the eye, and amnoy the lorse. This muscle suddenly acts: the eye is forcibly drawn back, and presses upon the fatty matter. That may be displaced, but cannot be reduced into less compass. It is forced violently towards the inner corner of the eye, and it drives before it the haw; and the haw, having likewise some fat about its point, and being placed between the eye and an exceedingly smooth and polished bone, and being pressed upon by the eye as it is violently drawn back, shoots out with the rapidity of lightning, and, guided by the eyelids, projects over the eye, and thus carries off the offending matter:

In what way shall we draw the haw back again without muscular action? Another principle is called into play, of which mention has already been made, and of which we shall have much to say, elasticity. It is that principle by which a body yields to a certain force impressed upon it, and returns to its former state as soou as that force is removed. It is that by which the ligament of the neck (p. 266), while it supports-the head, enables the horse to graze-by which the heart expands after closing on and propelling forward the blood in its rentricles, and the artery contracts on the blood that has distended it, and many of the most important functions of life are influenced or governed. This muscle ceases ta act, and the eye resumes its natural situation in the orbit. There is room for the fatty matter to return to its place, and it immediately returns by the elasticity of the membrane by which it is covered, and draws after it this cartilage with which it is connected, and whose return is as rapid as was the projection.

The old farriers strangely misunderstood the nature and design of the haw, and many at the present day do not seem to be much better in. formed. When, from sympathy with other parts of the eye labouring under inflammation, and becoming itself inflamed and increased in bulk, and the neighbouring parts likewise thickened, it is either forced out of its place, or voluntarily protruded to defend the eye from the action of light and cannot return, they mistake it for some injurious excrescence or tumour, and proceed to cut it out. The "haw in the eye" is a disease well known to the majority of grooms, and this sad remedy for it is deemed the only cure. It is a barbarous practice, and if they were compelled to walk half a dozen miles in a thick dust, without being permitted to wipe or to cleanse the eye, they would feel the torture to which they doom this noble animal. A little patience having been exercised, and a few cooling applications made to the eye while the inflammation lasted, and afterwards some mild astringent ones, and other proper means being employed, the tumour would have disappeared, the haw would have returned to its place, and the animal would have discharged the duties required of him without inconvenience to himself, instead of the agony to which an unguarded and unprotected eye must now expose him.

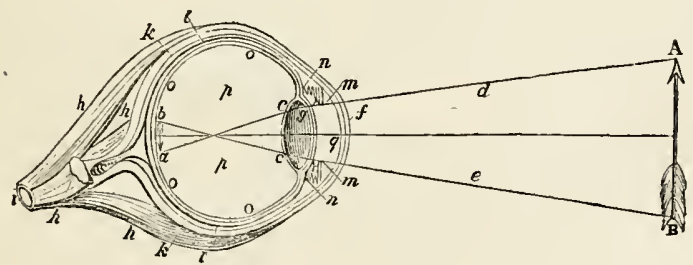

A B a supiosed object viewed by the animal, and an inrertedimage $l$ of which, $a, b$, is thrown on the retina at the hack of the eye.

c $c$ The points where the rays, having passed the cornea andlens, converge by the refractive power of the lens.

$d e$ The rays proceeding from the extremities of the object to the eve.

$f$ The cornea, or horny and traosparent part of the eye, covered by the conjunctiva, noiling different parts together.

$g$ The crystallioe (crystal or glassy) lens, behind the pupil, and in front of the vitreous humour.

$h$ Muscles of the eye.

$i$ The optic nerve, or nerse of sight.

$k$ The sclerotica (hard firm coat) covering the whole of the eye except the portion occupied by the cornea, and being a $q$ seeming prolongation of the covering of the optic nerve.

roL. 1 .
The choroides (receptacle or corering), or chornid coat, corercd with a black secretion or paiat.

$m m$ The iris or rainhow-coloured circular memhrane under the cornea, in front of the eve, and on which the colour of the cye depends. The duplicature behind is the uvea, from being coloured like a grape. The opening in the centre is the pupil.

The ciliary (hair like) processes.

The retina, or net-like expansion of the optic ncre, spread over the whole of the choroides as far as the lens.

The vitrenus (glass-like) humour filling the whole of the carity of the eye behind the lens.

The aqueous (water-like) humour filling the space between the cornea and the lens. 
The loss of blood occasioned by the excision of the haw may frequently relieve the inflammation of the eve; and the evident amendment which follows induces these wise men to believe that they have performed an excellent operation; but the same loss of blood by scarification of the overloaded ressels of the conjunctiva mould be equally beneficial, and the animal would not be deprived of an instrument of admirable use to him.

The ere is of a globular figure, yet not a perfect globe. It is rather composed of parts of two globes; the half of one of them smaller and transparent in front, and of the other larger and the coat of it opaque, behind. We shall most comreniently begin with the coats of the eye.

The conjunctiva, $f$, is that membrane which lines the lids, and covers the fore part of the eye. It spreads over al] that we can see or feel of the eye, and even its transparent part. It is itself transparent, and transmits the colour of the parts beneath. It is very susceptible of inflammation, during which the lining of the lids will become intensely red, and the white of the eye will be first streaked with red ressels, and then covered with a complete mesh of them, and the cornea will become eloudy and opaque. It is the seat of various diseases, and, particularly, in it commences that sad inflammation of the horse's eye which bils defiance to the veterinary surgeon's skill and almost invariably terminates in blindness.

The examination of the conjunctiva, by turning down the lid, will enable us to form an accurate judgment of the degree of inflammation which exists in the eye.

Covering the back part of the eye, aml indeed four-fifths of the globe of it, is the sclerotica, $k$. It is an exceedingly strong membrane, composed of fibres interweaving with each other, and almost defring the possibility of separation. An organ so delicate and so important as the eye requires secure protection.

It is a highly elastic membrane. It is necessary that it should be so, when it is considered that the eye is surrounded by several and very powerful muscles, which must temporarily, and even for the purposes of vision, alter its form. The elasticity of the sclerotica is usefully exhibited by its causing the globe of the eye to resume its former and natural shape, as soon as the action of the muscle ceases.

The sclerotica has rery few blood-vessels - is scarcely sensible-and its diseases, except when it participntes in general disturbance or disorganization, are rarely brought under onr notice.

The cornea is, of we shonld wish it to he, the only visible part of the horse's eye, for the exhibi. tion of much white around it is a sure symptom of wickedness. The cornea fills up the vacuity which is left by the sclerotica in the fore part of the eye, and, although closely united to the sclerotica, may be separated from it, and will drop out like a watch-glass. It is not round, lut wider from side to side than from the top to the bottom ; and the curve rather broader towards the inner than the outer corner of the eye, so that the near eve may be known from the off one after it is taken from the hear.

The convexity or projection of the cornea is a point of consideralle importance. The prominence of the eye certainly adds much to the beauty of the animal, but we shall see presently, when we consider the eye as the organ of sight, that by being too prominent the rays of light may be rendered too convergent, and the vision indistinct ; or, if the cornea is small and flat, the rays may not be convergent enongh, and perfect vision destroyed. In either case the horse may unpleasantly start, or suddenly and dangerously turn roind. An eye neither too prominent nor too flat will be nearest to perfection.

It should be perfectly transparent. Any cloudiness or opacity is the consequence of disease. It is an exceedingly firm and dense membrane, and can scarcely be pierced by the sharpest instrument. The cornea is composed of many different plates, laid over one another ; and hetween each, at least in a state of health, is a fluid that is the cause of its transparency, and the evaporation of which, after death, prodnces the leaden or glazed appearance of the eye. When it appears to be opaque, it is not often, and never at first, that the comea has undergone any change.

There is nothing that deserres attention from the purchaser of a horse more than the perfect transparency of the cornea over the whole of its surface. The eye should be examined for this purpose, both in front, and with the face of the examiner close to the cheek of the horse, under and behind the eye. The latter method of looking through the cornea is the most satisfactory, so far as the transparency of that part of the eye is concerned. During this examination the borse should not be in the open air, but in the stable, standing in the doorway, and a little within the door. If any small, faint, whitish lines appear to cross the cornea, or spread over any part of it, they are assuredly the remains of previous inflammation; or, although the centre and bulk of the cornea should be perfectly clear, yet if around the edge of it, where it unites with the sclerotica, there should be a narrow ring or circle of haziness, the conclusion is equally trne, but the inflammation occurred at a more distant period. Whether huwever the inflammation has lately existed, or several weeks or months have elapsed since it was subdued, it is too likely to recur.

There is one cantion to be added. The cornea in its natural state is not only a beautifully trans 
parent structure, but it reflects, even in proportion to its transparency, many of the rays which fall npon it; and if there is a white object inmediately before the eye, as a light waistcoat, or much display of a white neckcloth, the reflection may puzzle an experienced observer, and has misled many a careless one. The coat should be buttoned up, and the white cravat carefully concealed.

Within the sclerotica, and connected with it by innumerable minute fibres and vessels, is the choroid coat, $l$. It is a very delicate membraue, and extends over the whole of the internal part of the eye, from the optic nerve to the cornea. It secretes a dark-coloured substance or lraint, by which it is covered; the intention of which, like the inside of our telescopes and microscopes, is probably to absorb any wandering rays of light which might dazzle and confuse. The black paint, pigmentum nigrum, seems perfectly to discharge this fuuction in the human eye. It is placed immediately under the retina or expansion of the optic nerve. The rays of light fall on the retina, and penetrating its delicate substance, are immediately absorbed or destroyed by the black covering of the choroides underneath. For the perfection of many of his best pleasures, and particularly of his intellectual powers, man wants the vivid impression which will be caused by the admission of the rays of light into a perfectly dark chamber; and when the light of the sun begins to fail, his superior intelligence has enabled him to discover various methods of substituting an artificial day, after the natural one has closed. Other animals without this power of kindling another, although inferior light, have far more to do with the night than we have. Many of them sleep through the glare of day, and awake and are busy during the period of darkness. The $o x$ occupies some hours of the night in grazing; the sheep does so when not folded in his pen; and the horse, worked during the day for our convenience and profit, has often little more than the period of night allotted to him for nourishment and repose. Then it is necessary that, by some peculiar and adequate contrivance, these hours of comparative or total darkness to ns should be partially yet sufficiently illuminated for them; and therefore in the horse the dark brown or black coat of tlie choroides does not extend over the whole of the internal part of the eye, or rather it is not found on any part on which the rass proceeding from the objects could fall. It does not occupy the smallest portion of what may be called the field of vision; but, in its place a bright variegated green is spread, and more over the upper part than the lower, becanse the animal's food, and the objects which it is of consequence for him to notice, are usually below the level of his head-thus, by suffering the impression to remain longer on the retina, or by some portion of light reflected from this variegated bed on which the retina reposes, or in some other inexplicalle but efficient way, enabling the animal, even in comparative darkness, to possess a power of vision equal to his wants.

The reader may see in the dusk, or even when dnskiness is fist yielding to utter darkness, the beantiful sea-grcen reflection from the eye of the horse. It is that lucid variegated carpet of which we are now spealing.

Who is unaware that in the farling glimmering of the evening, and eveu in the darker shades of night, his horse can see surrounding ohjects much better than his rider; and who, resigning himself to the guidance of that sagacious and faithful animal, has not been carried in safety to his journey's end, when he would otherwise have been utterly bewildered?

If the reader has not examined this beantiful pigment in the eye of the horse, he should take the earliest opportunity of doing so. He will have a beautiful illustration of the care which that Being who gave all things life has taken that each shall be fitted for his situation. The horse has not the intelligence of man, and may not want for any purpose of pleasure or improvement the vivid picture of surrounding oljects which the retina of the human being presents. A thousand minute bnt exquisite beauties would be lost npon him. If, therefore, his sense of vision may not be so strong during the day, it is made up to lim by the increased power of vision in the night.

Perfectly white and cream-coloured horses liave a peculiar appearance of the eyes. The pupil is red instead of black. There is no black paint or brilliant carpet. It is the choroid coat itself which we see in them and not its covering; and the red appearance is caused by the numerous bloodressels which are found on every part of that coat.

When we have to treat of other domestic animals, we shall see how this carpet is varied in colour to suit the situation and necessity of each. In the $o x$ it is of a dark green. He has not many enemies to fear, or much difficulty in searching for nourishment, and the colour of the eye is adapted to his food In the cat and all his varieties it is vellow. We have hearl of the eres of the lion appearing like two flaming torches in the night. There are few of our readers who have not seen the same singular glare from the ejes of the domestic cat. In the wolf, and likewise in the dog, who, in his wild state, prowls chiefly at night, it is grey. In the poor unjustly. persecuted badger, who scarcely dares to crawl forth at night, althongh sheltered by the thickest dirkness, it is white; and the ferret, who is destined to hunt his prey through all its winding retreats, and in what would be to us absolute darkness, his no paint on the choroides. 
Tracing the choroicles towards the fore part of the eye, we perceive that it is reflected from the side to the edge of the lens, $n$, and has the appearance of several plaits or folds. They are actually foldings of the membrane. It is not diminished in size, but it has less space to cover, and there must be duplicatures or plaits. They are usefully employed in the place in which we find them. They prevent the passage of any rays of light on the outsire of the lens, and which, proceeding forward in various directions, and uncondensed by the power of the lens, would render vision confused or imperfect. These folds of the choroides are called the ciliary processes.

Within the comea, and ocenpying the fore part of the ere, is the aqueors humour, $p$, so termed from its resemblance to pure water. It is that by which the cornea is preserved in its protuberant and rounded form. It extends to the crrstalline lens, $q$, and therefore a portion of it, althongh a very small one, is belind the iris $(m, p$. 2it). Floating in this fluid is a membrane, with an oblong aperture, called the Iris. It is that which gives colour to the eye. The human ere is said to be black, or liazel, or blue, according to the colour of this membrane or curtain; and it is denominated the iris, or rainbow, from its beautiful, intermingling hues, The colour varies little in the horse, except that it always bears some analugy to that of the skin. We rarely see it lighter than a hazel, or darker than a brown. Horses perfectly white, or cream-coloured, have the iris white and the pupil red. Then horses of other colours, and that are nsually pied, have a white iris and a lilack pupil, they are said to be wall-eyed. Vulgar opinion has clecided that a wall-eyed horse is never sulject to blindness, but this is altogether erroneous. There is no difference of structure that can produce this exemption; but the mall-eyed horse, from this singular and umpleasant appearance, and his frequent want of breeding, may not be so mnch used and exposed to many of the nsual causes of inflammation.

The aperture in the iris is termed the pupil, and through it light passes to the inner chamber of the eye. The pupil is otlong, and variable in size. It differs with the intensity or degree of light that falls upon the eye. In a dark stable the pupil is expanded to admit a great proportion of the light that falls upon the cornea; but when the horse is hrought towards the door of the stable and more light is thrown upon the eye, the popil contracts in order to keep out that extra quantity which would be painful to the animal, and injurions to vision. When opposed directly to the sun, the aperture will almost close.

This alteration of form in the pupil is effected by the muscular fibres that enter into the composition of the iris. When these fibres are relaxed, the pupil must proportionably diminish. The motions of the iris are not at all under the control of the will, nor is the animal sensible of them. They are produced by sympathy with the state of the retina. When, however, a deficient portion of light reaches the retina, and vision is indistinct, we are conscious of an apparent effort to bring the object more clearly into view, and the fibres then contract, and the aperture enlarges, and more light is admitted.

This dilatation or contraction of the pupil gives a nseful method of ascertaining the existence of blinduess in one eye or in both. . The cornea and crystalline lens remain perfectly transparent, but the retina is palsied, and is not affected by light; and many persons have been deceived when blindness of this description has been confined to one eye. A horse blind in both eyes will nsually have his ears in constant and rapid motion, directing them in quick, succession to every quarter. $\mathrm{He}$ will likewise hang back in his halter in a peculiar way, and will lift his feet high as if he were stepping over some obstacle, when there is actually notling to obstruct his passage, and there will be an evident uucertainty in the putting down of his fect. In blindness of one eye little or nothing of this characteristic gait and manner can be perceived. Although a one-eyed horse may not be absolutely condemined for the common business of the carriage or the road, he is generally deteriorated as a hunter, for he cannot measure his distances, and will run into his leaps.* Many a sportsman, puzzled and angry at the sudden blundering of his horse, or injured by one or more stunning falls, has found a very natural although unexpected explanation of it in the blindness of one eye, and that perhaps produced through his own fiult, by over-riding his willing and excellent servant and causing a determination of blood to the eye, which proved fatal to the delicate texture of the retina. Even for the carriage or the road he is considerably deteriorated, for his field of observation must be materially lessened.

Let the size of both pupils be carefully noticed before the horse is remored from the stable, and, as he is led to the door, observe whether they botl contract, and equally so, with the increase of light. If the horse should be first seen in the open air, let it be observed whether the pupils are precisely of the same size; then let the hand be placed over each eye alternately and held there

* Mi. W. Percivall, however, in his excellent Lectures on the Veterinary Art, vol. iii. p. 201, says, "The loss of one eye does not eofeeble sight, becanse the other acquires greater energy, though it much contracts the field of vision. It is sibid to render the conception erring, and the case of misjudgment of distances is the one commonly bronght forward to show this. All I can say on this point is, that the best hunter $I$ ever possessed, a horse gifted with extraordinary powers for leajing, wus a me-ered horse, and this animul caricd me through a huntiog season, without, to my recullection, makjng one single blunder in leaping." 
for a little while, and let it be observed whether the puyil dilates with the abstraction of light, and equally in each eye.

Hanging from the upper edge of the pupil of the horse, are two or three round black substances, as large as millet seeds. When the horse is suddenly brought into an intense light, and the pupil is closed, they present a singular appearance, as they are pressed out from between the edges of the iris. Au equal number, but much smaller, are attached to the edge of the lower portion of the iris. Their general use is probably to intercept rays of light which would be troublesome or injurions, and their principal function is accomplished during the act of grazing. They are larger on the upper edge of the iris, and are placed on the outer side of the pupil, evidently to discharge the same function which we have attributed to the eyelashes, viz. to obstruct the light in those directions in which it would come with greatest force, both from above and even from below, while, at the same time, the field of view is perfectly open, so far as it regards the pasture on which the horse is grazing.

In our cut $m$ gives a duplicature of the iris, or the back surface of it. This is called the weea, and it is covered with a thick coat of black mucus, to arrest the rays of light, and to prevent them from entering the eye in any other way than through the pupil. The colour of the iris is, in some unknown way, connected with this black paint behind. Wall-eyed horses, whose iris is white, have no uvea.

We now arrive at a body on which all the im. portant uses of the eye mainly depend, the crystalline lens, g, so called from its resemblance to a piece of crystal or transparent glass. It is of a yielding jelly-like consistence, thicker and firmer towards the centre, and convex on each side, but more convex on the inner than the onter side. It is enclosed in a delicate transparent bag or capsule, and is placed between the aqueous and the vitreous humours, and received into a bollow in the vitreous humour, with which it exactly corresponds. It has, from its density, and its double convexity, the chief concern in converging the rays of light which pass into the pupil.

The lens is very apt to be affected from long or violent inflammation of the conjunctiva, and either its capsule becomes cloudy, and imperfectly transmits the light, or the sulsstance of the lens becomes opaque. The examination of the horse, with a view to detect this, must either be in the shade, or at a stable door, where the light shall fall on the animal from above, and in front; and in conducting this examination we would once more caution the intended purchaser against a superfluity of white about his neck. Holding the head of the animal a little up, and the light coming in the direc- tion that has been descrihed, the condition of the lens will at once be evident. The confirmed cataract, or the opaque lens of long standing, will exlibit a pertly appearance, that cannot be mistaken, and will frequently be attended with a change of forma portion of the lens being forced forwards into the pupil. Although the disease may not have proceeded so fir as this, yet if there is the slightest cloudiness of the lens, either generally, or in the form of a minute spot in the centre, and with or without lines radiating from that spot, the horse is to be condemned; for, in ninety-nine cases out of a bundred the disease will proceed, and cataract, or complete opacity of the lens, and absolute blindness, will be the result.

Cataract in the buman being may, to a very considerable extent, be remedied. The opaque lens may be extracted, or it may be forced into the vitreous lumours, and there existing as a foreion body, it will soon be absorbed and disappear. These operations are impossible in the horse, for, in the first place, there is a muscle of which we have already spoken, and to be presently more particularly described, that is peculiar to quadrupeds, and of such power as generally to draw back the eye too far into its socket for the surgeon to be enabled to make his incision; or could the incision be made, the action of this muscle would force out the greater part of the contents of the eye, and this organ would speedily waste away. If, however, the opaque lens coull be withdrawn or depressed, and the mechanism of the eye were not otherwise injured, the operation would be totally useless, for we could not make the lrorse wear those conrex glasses whose converging power might compensate for the loss of the lens.

Bebind the lens, and oceupying four-fifths of the cavity of the eje, is the vitreous humour (glassy, or resembling glass). It seems, when first taken from the eye, to be of the consistence of a jellr, and of beantiful transparency; but if it is punctured a fluid escapes from it as limpid and as thin as water, and when this has been suffered completely to ooze ont, a mass of membrinecus bags or cells remains. The vitreous humour consists of a watery fluid contained in these cells: but the fluid and the cells form a budy of considerably greater density than the aqueous fluid in the front of the eye.

Last of all, between the vitreous humour and the choroid cout, is the retina, o, or net-like membrane. It is an expansion of the substance, $g$, of the optic nerve. When that nerve has reached the back of the eye, and pereirated throus h t'ie sclerotic and choroid coats, it first enlarges into a little white prominence, from $\pi$ hich radiations or expansions of nervous matter Ir reeed, which spread over the whole of the choroid coat, and form the third inrestment of the eye. The mem- 
brane by which this nervous pulp is supported, is so exceedingly thin and delicate, that it will tear with the slightest touch, and break even with its own weight. The membrane and the pulp are perfectly transparent in the living animal. The pupil appears to be black, because in the day-time it imperfectly reflects the colour of the choroid coat beneath. In the dusk it is greenish, be. cause, the glare of day benig removed, the actual green of the paint appears.

On this expansion of nervous pulp, the rays of light from surrounding objects, condensed by the lens and the humours, fall, and, producing a certam image corresponding with these objects, the animal is conscious of their existence and presence.

It may, however, so happen that from the too great or too little convexity of the eye or a portion of it, the place of most distinct vision may not be immediately on the retina, but a little before or behind it. In proportion as this is the case, the sight will be indistinct and imperfect; nor shall we be able to offer any remedy for this defect of sight. There is a shying, often the result of cowardice or playfulness, or want of work, but at other times proving, beyond contradiction, a defect of sight even more daugerous than blindness. A blind horse will resign himself to the guidance of his rider or driver; but against the misconception and starting of a shying horse there is no defence. That horses grow shy as they grow old no one accustomed to them will deny; and no intelligent person will be slow in attributing it to the right canse-a decay in the organ of vision, $-\mathrm{a}$ loss of convexity in the ere, lessening the convergency of the rays, and throwing the perfect image beyond, and not on, the retina. There is a striking difference in the convexity of the cornea in the colt and the old horse; and both of them, probably, may shy from opposite causes - the one from a cornea too prominent, and the other from one too flat. In the usual examination of the horse previously to purchase, sufficient attention is not always paid to the convexity of the coruea.

The remedy for shying will be considered when we speak of the vices of horses.

There is a provision yet wanting. The horse has a very extended field of view, but many persons are not perhaps aware how little of it he can command at a time. There is not one of our readers who can make out a single line of our treatise without changing the direction of the eye. It is curions to follow the motion of the eyes of a rapid reader. Nature has given no less than seven muscles to the horse, in order to turn this little but important organ; and, that they may act with sufficient power and quickness, no fewer than sir nerves are directed to the muscles of the eye generally, or to particnlar ones-while the eye rests on a mass of fat, that it may be tumed witl little exertion of power, and without friction.

\section{MISCLES OF THE EYE.}

There are four straight muscles, three of which, $d, e$, and $f$, are represented, in our cut, rising from the back of the orbit, and inserted

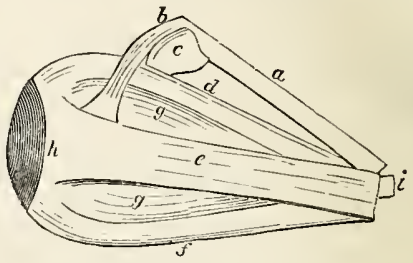

into the ball of the eye, opposite to, and at equal distances from each other. One, $d$, runs to the upper part of the eje, just behind the transparent and risible portion of it, and its office is clearly to raise the eye. When it contracts, the eye must be drawn upward. Another, $f$, is inserted exactly opposite, at the bottom of the eye; and its office is as clearly to depress the eye, or enable the animal to look downwards. A third, $e$, is inserted at the outer cormer, and by means of it the eye is turned outward, and, from the situation of the eye of the horse, considerably backward; and the fourth is inserted at the inner colner, turning the eye inward. They can thus rotate or tnrn the eye in any direction the animal wishes, and by the action of one, or the combined power of any two of them, the eye can be immediately and accurately directed to every point.

These muscles, however, have another duty to discharge. They support the eye in its place. In the usual position of the head of the horse, they must be to a certain degree employed for this purpose ; but when he is grazing or feeding, the principal weight of the eye rests upon them. Another muscle is therefore added, peculiar to quadrupeds, called the retractor (drauer-back), or the suspensorius (suspensory) muscle, $g$. It arises from the edge of the formen through which the optic nerve enters the orbit-surronnds the nerve as it proceeds forward, and then, partially dividing into fonr portions, is attached to the back part of the eye. Its office is evidently to support the eye generally, or, when suddenly called into powerful action, and assisted by the straight muscles, it draws the eye back out of the reach of threatening danger, and in the act of drawing it back causes the haw to protrude, as an additional defeuce.

The power of this muscle is very great. It renders some operations on the eye aimost impos- 
sible. It is an admirable substitute for the want of hands, to defend the eye from many things that would injure it; and, being partially separated into four divisious, it assists the straight muscles in turning the eye.

These muscles discharge another and a most important office. If we examine near and distant objects through a telescope, we must alter the focus; $i$. $e$., we must increase or diminish the length of the tube. We must shorten it a little when we examine distant objects, because the rays, coming to us from them in a less divergent direction, are sooner brought to a point by the power of the lens. Thus the straight and retractor museles drawing back the eye, and forcing it upon the substance behind, and in a slight degree flattening it, bring the lens nearer to the retina, and adapt the eye to the observation of distant objects.

Still, however, being constantly employed in supporting the weight of the eje, these muscles may not be able to turu it so rapilly aud so extensively as the wishes or wants of the animal require ; therefore two others are superadded, which are used solely in turning the eye. They are called oblique muscles, becanse their course is obliquely across the eye. The upper one is most curiously constructed, $a, b$. It comes from the back part of the orbit, and takes a direction up- wards and towards the inner side, and there, just under the ridge of the orbit, it passes through a perfect mechanical pulley, and, turning round, proceeds across the eye, and is inserted rather beyond the middle of the eye, towards the onter side. Thus the globe of the eye is evidently directed inward and upward. Something more, however, is accomplished by this singular mechanism. The eye is naturally deep in the ortit, that it may be more perfectly defended; but it may be necessary occasionally to bring it formard, and eularge the field of vision. The eye is actuilly protruded under the influence of fear. Not only are the lids opened more widely, but the eye is bronght more forward. How is this accomplished? There are no muscles anterior to, or before the eye-there is no place for their insertion. The object is readily effected by this singular pulley, $b, c$. By the power of this muscle-the trochlearis, or pulley-muscle-and the straight muscles at the same time not opposing it, or only regulating the direction of the eye, it is really brought somewhat forward. The lower oblique muscle rises just within the lacrymal bone $(i, \mathrm{p}$. 265 ), and, proceeding across the eye, is fixed into the part of the sclerotica opposite to the other oblique muscle, and it turns the eye in a contrary direction, assisting, however, the upper oblique in bringing the eye forward from its socket.

\section{CHAPTER VII.}

\section{INJURIES AND DISEASES OF THE SKULL-THE BRAIN-THE EARS-AND THE EYES.}

WE have now arrived at a convenient restingplace in our somewhat dry but necessary description of the structure of the horse, and we willingly turu to more practical matter. We will consider the injuries and diseases of the parts we have surveyed. In entering, however, on this division of our work, we would premise, that it is impossible for us to give the farmer such an account of the nature and treatment of the diseases of horses as will enable him with safety to practise for himself, except in the commonest cases. The causes of most diseases are so obscure, their symptoms so variable, and their connexion with other maladies so complicated and mysterions, that a life devoted to professional study will alone qualify a man to become a judicious and successful practitioner on the diseases of the horse and other domestic animals. Our olject will be to communicate suffcient instruction to the farmer to enable him to act with promptness and judgment when he cannot obtain professional assistance, to qualify him to form a satisfactory opinion of the skill of the vete. rinary surgeon whom he may employ, and, more especially, to divest him of those strange aud als: surd prejudices which in a variety of cases not only produce and prolong disease, but bring it to a fatal termination.

\section{FRACTURE.}

We have deseribed the carity of the skull of the liorse as being so defended by the hardness of the parietal bones, and those bones so covered by a mass of muscle, and the occipital bone as so exceedingly thick (see above), that a fracture of the skull is almost impossible. It can only occur from brutal riolence, or when a horse falls in the act of rearing. When, however, fracture of the skull does oceur, it is almost invariably fatal. A blow of sufficient violence to break these bones must likewise irreparably injure the delicate and important organ which they protect. 
The ridge, or outer and upper part of the orbit of the eye, is occasionally fractured. It happens from falliug, or much oftener from violent blows. The slightest examination will detect the loosened pieces; but a professional man alone ean render effectual assistance.

Mr. Pritehard, in the second volume of the "Veterinarian," relates an interesting case of fracture of the orbit of the eye. "A chesnut mare," he says, "received a blow which fractnred the orbit from the superciliary foramen, in a line through the zygomatic processes of the temporal and malar bones to the outer angle of the eye. The detached bone, together with the divided integument, hung over the eye so as to intercept vision. On examining the place where the accident occurred, two portions of bone were found belonging to the orbital arch. After carefully inspecting the wound, and finding no other detached portions, nor any spicule which might irritate or wound, the adjacent portions of the skin were carefully drawn together, and secured by a silver wire, which closed the -wound, and confined the detatched portion of bone in its proper place. A mash diet was ordered.

"On the following day there was considerable inflammation. The eye was bathed with warm water, and a dose of physic administered. On the third day the inflammation and swelling had still more increased. Blood was ubstracted from the vein at the angle of the eye. The swelling and inflammation now speedily abated; and on the 15 th day the wound had quite healed."

If a fracture of titis kind is suspected, its existence or non-existence may be easily determined ly introducing the thumly under, and keeping the fore-finger upon the edge of the orbit.

\section{ixosTosis.}

Bony enlargements of the orbital arch some times arise from natural predisposition or local injury. They should be attacked in the earliest stage, for they are two apt rapidly to increase. Some preparation of iodine, as described in the account of medicines, will be nseful in this case.

\section{CARIES.}

Inflanmation and enlargerrent of the injured bones, followed by alscess and the production of certain bony growths, are of occasional occurrence. A skilful practitioner can alone decide whether a cure should be attempted, or the sufferings of the animal terminated by death.

\section{COMPRESSTON OF THE BRAIY.}

Hydatids are often found within the cranial cavity, and lying upon or imbedded in the brain of oxen and sheep. Their existence is usually fatal to the animal. There is no well-anthenticated account of the existence of an hydatid in the cranial cavity of the horse; but cysts, containing a serous or viscid fluid, are occasionally observed. The following is the history of one:-A horse exhibited symptoms of vertigo, or staggers, which disappeared after copious bleeding and purgatives. About twelve months afterwards the same complaint was evident. He carried his liead low and inclined to the right side, He staggered as he walked, and the motion of his limbs was marked by a peculiar convulsive action, confined to the fore extremities. He moved by a succession of spasmodic boundings. He was completely deaf, and rapidly lost flesh, though he ate and drank voraciously. He remained in this state, to the shame of the owner and the practitioner, several months, and then he had a fresh attack of vertigo, and died suddenly. On examivation of the brain, its membranes were found to be completely reddened; and, between the two lobes of the brain, was a round cyst as large as a pullet's egg. The pressure of this was the manifest cause of the mischief.

\section{PRESSURE ON THE BRAIN.}

This may be produced by some fluid thrown aut between the membranes, or occupying and distending the ventricles of the brain. In the fullgrown horse it rarely occurs; but it is well known to breeders as an occasional disease of the foal, .nnder the name of "water in the head." The head is either much enlarged, or strangely deformed, or both; and the animal dies, either in the birth, or a few days after it.

\section{MEGRIMS.}

There is another kind of pressure on the brain, resnlting from an unusual determination or flow of blood to it. This organ requires a large supply of blood to enable it to discharge its important functions. Nature, in the horse more than in many other animals, has made some admirable provisions to canse this strean to flow into the brain with little velocity, and thereby to lessen the risk of suddenly overloading it or rupturing its vessels. The arteries pursue their conrse to the brain in a strangely winding and circuitous manner; and they enter the skull through bony apertures that will admit of the enlargement of the ressels only to a very limited extent. From various canses, however, of which the most common is violent exercise on a hot day, and the horse being fat and full of blood, more than the asual quantity is sent to the head; or, from some negligence about the harness-as the collar being too small, or the curb-rein too tight-the blood is prevented from returning from the head. The larger vessels of the brain will then be too long and injuriously distended; and, what is of more consequence, the small vessels that permeate the substance of the brain will be enlarged, and the bulk of the brain 
increased, so that it will press upon the origins of the nerves, and produce, almost without warning, loss of power and consciousness.

The mildest affection of this kind is known by the name of Megrims. It comparatively rarely happens when the horse is ridden; but should he be driven, and perhaps rather quickly, he may perform a part of his journey with his usual cheerfulness and ease: he will then suddenly stop, shake his head, and exhibit evideut giddiness, and half-unconsciousness. In $\mathrm{a}$, minute or two this will pass over, and he will go on again as if nothing had happened.

Occasionally, however, the attack will be of a more serious nature. He will fall without the slightest warning, or suddenly run round once or twice, and then fall. He will either liein a state of complete insensibility, or struggle with the utmost violence. In five or ten minutes he will begin gradually to come to himself; he will get. up and proceed on his journey, yet somewhat dull, and evidently affected and exhausted by what had happened, although not seriously or permanently ill.

At the moment of attack, a person who is competent to the task should abstract three or four quarts of blood from the neck-vein; or cut the bars of the palate in the manner to be explained when we describe that part, and whence a considerable and sufficient quantity of blood may be readily obtained. The driver should pat and soothe the animal, loosen the curb-rein, if possible ease the collar, and pursue his journey as slowly as circumstances will permit. When he gets home, a dose of physic sliould be administered if the horse can be spared, the quantity of dry food lessened, and mashes given, or green moat, or he should be turned out to grass for two or three months.

Is all this necessary because a horse has hap. pened to have a fit of the megrims? Yes, and more too in the mind of the prudent man; for it is seldom that a horse has the megrims without the predisposition to a second attack remaining. These over-distended vessels may be relieved for a while, but it is long before they perfectly recover their former tone. It requires but a little increased velocity or force in the vital current once more to distend them, and to produce the same dangerous effects. The testimony of experience is uniform with regard to this; and he would not do justice to himself or his family who trusted himself behind a horse that had a second attack of megrims.

APOPLEXY.

Megrims is apoplexy under its mildest form. In the latter affection, the determination of blood, if not so sudden, is greater, or differently directed, or more lasting. It is seldom, however, that there are not timely warnings of its approach, if the carter or the groom had wit enough to observe them. The horse is a little off his feed-he is more than usually dull-there is a degree of stupidity about him, and, generally, a somewhat staggering gait. This goes off when he has been out a little while, but it soon returns under a more decided character, until, at length, it forces itself on the attention of the most careless.

The actual illness is perliaps first recognised by the horse standing with his head depressed. It bears upon, or is forced against the manger or the wall, and a considerable part of the weight of the animal is evidently supported by this pressure of the head. As he thius stands, he is balancing bimself from one side to the other as if he were ready to fall ; and it is often dangerous to stand near to him, or to mrove him, for he falls without warning. If he can get lis muzzle into a cormer, he will sometimes contimue there motionless for a considerable time, and then drop as if he were shot; but; the next moment, he is up again with his feet almost in the rack. He sleeps or seems to do so as he stands, or at least he is nearly or quite unconscious of surrounding objects. When he is roused, he looks vacautly around him. Perhaps he will take a lock of hay if it is offered to him ; but ere it is half masticated, the eye closes, and he sleeps again with the food in his mouth. Soon afterwards he is, perhaps, roused once more. The eye opens, but it has an unmeaning glare. The hand is moved before him, but the eye closes not; he is spoken to, but he hears not. The last act of voluntary motion which he will attempt is usually to drink; but he has little power over the muscles of deglutition, and the fluid returns through the nostrils.

He now begins to foam at the mouth. His breathing is laborious and loud. It is performed by the influence of the organic nerves, and tlose of animal life no longer lend their aid. The pulse is slow and oppressed-the jugular vein is distended almost to bursting-the muzzle is cold, and the discharge of the fixces involuntary. He grinds his teeth-twitchings steal over his face and attack his limbs-they sometimes proceed to conrulsions, and dreadful ones too, in which the horse beats himself about in a terrible manner; but there is rarely disposition to do mischief. In the greater number of cases these convulsious last not long. All the powers of life are oppressed, and death speedily closes the scene.

On examination after death, the whole venous system is usually found in a state of congestion, and the vessels of the brain are peculiarly turgid with black blood. Occasioually, however, there is no inflammation of the brain or its membranes; but either the stomach coutains a more than usual quantity of food, or the larger intestines are loaded with foul matter. 
This disease is found more frequently in the stable of the postmaster and the farmer than anywhere else. Thirty years ago it was the very pest of these stables, and the loss sustained by some persons was enormous; but, as veterinary science progressed, the nature and the canses of the disease were better understood, and there is not now one case of staggers where twenty used to occur.

Apoplexy is a determination of blood to the head, and the cause is the over-condition of the animal and too great fulness of blood. Notions of proper condition in the horse now prevail very different from those by which our forefathers were guided. It no longer consists in the round sleek carcase, fat enough for the butcher, but in fulness and hardness of the muscular fibre, and a comparative paucity of cellular and adipose matter-in that which will add to the power of nature, and not oppress and weigh her down.

The system of exercise is better understood than it used formerly to be. It is proportioned to the quantity and quality of the food, and more particularly the division of labour is more rational. The stage-horse no longer runs his sixteen or eighteen, or even two-and-twenty miles, and then, exhausted, is turned into the stable for the next twenty hours. The food is no longer eaten voraciously; the comparatively little stomach of the animal is no longer distended, before nature has been able sufficiently to recruit herself to carry on the digestive process; the vessels of the stomach are no longer oppressed, and the flow of blood through them arrested, and, consequently, more blood directed to other parts, and to the brain among the rest.

The farmer used to send his horses out early in the morning, and keep them at plough for six or eight hours, and then they were brought home and suffered to overgorge themselves, and many of them were attacked by staggers and died. If the evil did not proceed quite to this extent, the farmer's horse was notoriously subject to fits of heaviness and sleepiness-he had half-attacks of staggers. From this frequent oppression of the brain-this pressure on the topic nerves as well as other parts, another consequence ensued, unsuspected at the time, but far too prevalent-the horse became blind. The farmer was notorious for having more blind horses in his stable than any other person, except, perhaps, the postmaster.

The system of horse management is now essentially changed. Shorter stages, a division of the labour of the day, and a sufficient interval for rest, and for feeding, have, comparatively speaking, banished sleepy staggers from the stables of the pastmaster. 'The division of the morming and afternoon labour of the farmer's horse, with the introduction of that simple but invaluable contri- vance, the nose-bag, have rendered this disease comparatively rare in the establishment of the agriculturist. To the late Professor Coleman we are indebted for some of these most important improvements.

Old horses are more sulject to staggers than young ones, for the stomach has become weak by the repetition of the abuses just described. It has not power to digest and expel the food, and thus becomes a source of general, and particularly of cerebral, disturbance.

Horses at grass are occasionally attacked by this disease; but they are generally poor, hardworked, half-starved animals, turned on richer pasture than their impaired digestive organs are equal to. Perhaps the weather is hot, and the sympathy of the brain with the undue labour of the stomach is more easily excited, and a determination of blood to the brain more readily effected.

Mr. Percivall gives a very satisfactory illustration of the production of staggers in this way. $\mathrm{He}$ says that "when his father first entered the service of the Ordnance, it was the custom to turn horses which had become low in condition, but were still well upon their legs, into the marshes, in orler to recruit their strength. During the months of July, August, and September, nothing was more common than an attack of staggers among these horses, and which was naturally attributed to the luxuriant pasture they were turned into, combined with the dependent posture of the liead, and the sultry heat to which they were exposed."

Occasionally it will be necessary for the owner or the veterinary attendant to institute very careful inquiry, or he will not detect the real causes of the disease. Does it arise from improper management, to which the horse has been in a manner habituated? Had he been subjected to long labour and fasting, and had then the opportunity of gorging to excess? Did it proceed from accidental repletion - from the animal having got loose in the night, and found out the corn or the chaff bin, and filled himself almost to bursting? There is nothing in the appearance of the animal which will lead to a discovery of the cause-no yellowness or twitchings of the skin, no local swellings, as some have describer; but the practitioner or the owner must get at the truth of the matter as well as he can, and then proceed accordingly.

As to the treatment of staggers, whatever be the cause of the disease, bleeding is the first measure indicated-the overloaded vessels of the brain must be relieved. The jugular vein should be immediately opened. It is easily got at-it is large-the blood may be drawn from it in a full stream, and, being also the ressel through which 
the blood is returned from the head, the greater part of the quantity obtained will be taken immediately from the overloaded organ, and therefore will be most likely to produce the desired effect. No definite quantity of blood should be ordered to be abstracted. The effect produced must be the guide, and the bleeding must be continued until the horse falters, or begins to blow-or, perhaps, with more assured success, until he falls. Some persons select the temporal artery. This is very unscientific practice. It is difficult, or impossible, to obtain from this vessel a stream that promises any decisive success. It is likewise difficult to stop the bleeding from this artery, and, after all, the blood is not drawn from the actual seat of the disease-the brain.

The second step is to ascertain what is the cause of the apoplexy. Has the animal got at the corn or the chaff bin? Had he been orerfed on the evening before, and is his stomach probably distended to the utmost by what he has eaten? In such a case, of what avail can physic be, introduced into a stomach already crammed with indigestive food? Or what effect can twelve or twenty drachms of aloes produce, a small portion only of which can penetrate into the stomach? Recourse must be had to the stomach-pump, one of the most valuable discoveries of modern times, and affording the means of combating several diseases that had previously set all medical skill at defiance. Warm water must be injected. The horse is now incapable of offering much resistance, and the injection may be continued not only until the contents of the stomach are so far diluted that a portion of them can escape through the lower orifice of that viscus, but until the obstruction to vomiting offered by the contracted entrance of the stomach is overcome, and a portion of the food is returned through the nostrils or month.

This being effected, or it having been ascertained that there was no extreme distension of the stomach, recourse should be had to aloes, and from eight to twelve drachms of it may be administered. It will be proper to add some stimulating medicine to the aloes, with a view of restoring the tone of the stomach, and inducing it to contract on its contents. Gentian and ginger are most likely to effect this purpose.

The after-treatment must be regulated by circumstances. For some time the horse should be put on a restricted diet; mashes should be given; green meat in no great quantity; a moderate allowance of hay, and very little corn. When sufficiently recovered, he may be turned out with advantage on rather bare pasture. One circumstance, however, should never be forgotten - that the horse who has once been attacked with staggers is liable to a return of the complaint from causes that otherwise would not affect him. The distended vessels are weakened-the constitution is weakened, and prudence would dictate that such an animal cannot be too soon disposed of.

Let no farmer delude himself with the idea that apoplexy is contagious. If his horses have occasionally slight fits of staggers, or if the disease carries off several of them, he may be assured that there is something wrong in his management. One horse may get at the corn-bin and cram himself to bursting; but if several are attacked, it is time for the owner to look about him. The general cause is too voracious feeding - too much food given at once, and perhaps without water, after hard work and long fasting.

There is one consequence of this improper treatment, of which persons do not appcar to be sufficiently aware, although they suffer severely from it. A horse that has frequent half-attacks of staggers very often goes blind. It is not the common blindness from cataract, but a peculiarly glassy appearance of the eye. If the history of these blind horses could be told, it would be found that they had been subject to fits of drooping and dulness, and these produced by absurd management respecting labour and food.

PHRENITIS,

Primary inflammation of the brain or its mem branes, or both, sometimes occurs, and of the membranes oftenest when both are not involved.

Whatever be the origin of phrenitis, its early symptoms are scarcely different from those of apoplexy. The horse is drowsy, stupid; his eye closes; he sleeps while he is in the act of eating, and doses until he falls. The pulse is slow and creeping, and the breathing oppressed and laborious. This is the description of apoplexy. The symptoms may differ a little in intensity and continuance, but not much in kind.

The phrenitic horse, however, is not so perfectly comatose as another that labours under apoplexy. The eye will respond a little to the action of light, and the animal is somewhat more manageable, or at least more susceptible, for he will shrink when he is struck, while the other frequently cares not for the whip.

In the duration of the early symptoms there is some difference. If the apoplexy proceeds from distension of the stomach, four-and-twenty or sixand-thirty hours will scarcely pass without the cure being completed, or the stomach ruptured, or the horse destroyed. If it proceeds more from oppression of the digestive organs that from abso. lute distension of the stomach, and from that sympathy which subsists between the stomach and the brain, the disease will go on-it will become worse and worse every hour, and this imperfect comatose state will remain during two or three days. The apoplexy of the phrenitic borse will often run its course in a few hours. 
In a case of evident phrenitis, blood-letting and physic must be early carried to their full extent. The horse will often be materially relieved, and, perhaps, cured by this decisive treatment; but, if the golden hour has been suffered to pass, or if remedial measures have become ineffectual, the scene all at once changes, and the most violent reaction succeeds. "The eye brighteus-strangely so; the membrane of the eye becomes suddenly reddened, and forms a frightful contrast with the transparency of the coruea; the pupil is dilated to the utmost; the nostril, before scarcely moving, expands and quirero, and labours; the respiration becomes short and quick; the ears are erect, or bent forward to catch the slightest sound; and the horse, becoming more irritable every instant, trembles at the slightest motion. The irritability of the patient increases - it máy be said to.change to ferocity-but the animal has no aim or object in what he does.. He dashes himself violently about, plunges in every direstion, rears on his hind legs, whirls round and round, and then falls backward with dreadful force." He lies for a while exhausted-there is a remission of the symptoms, but perhaps only for a minute or two, or possibly for a quarter of an hour.

Now is the surgeon's golden time, and his courage and adroituess will be put to the test. He must open, if he can, one or both jugulars: but let him be on his guard, for the paroxysm will return with its former violence and without the slightest warning.

The second attack is more dreadful than the first. Again the animal whirls round and round, and plunges and falls. He seizes his clothing and rends it in pieces; perhaps, destitute of feeling and of consciousness, he bites and tears himself. He darts furiously at everything within his reach; but no mind, no design, seems to mingle with or govern his fury.

Another and another remission and a return of the exacerbation follow, and then, wearied out, he becomes quiet; but it is not the quietness of returning reason-it is mere stupor. This continues for an uncertain period, and then he begins to struggle again; but he is now probably unable to rise. He pants-he foams-at length, completely exhausted, he dies.

There are but two diseases with which phrenitis can be confounded, and they are cholic and rabies. In cholic, the horse rises and falls; he rolls about and kicks at his belly; but his struggles are tame compared with those of the phrenitic horse. There is no involuntary spasm of any of the limbs; the animal is perfectly sensible, and, looking piteously at his flanks, seems designedly to indicate the seat of pain. The beautiful ret fearfully excited countenance of the one, and the piteous, anxious gaze of the.other, are sufficiently distinct; and, if it can be got at, the rapid bounding pulse of the one, and that of the other scarcely losing its natural character in the early stage, camnot be mistaken.

In rabies, when it does assume the ferocious form, there-is even more violence than in phrenitis; but there is method, and trcachery too, in that violence. There is the desire of mischief for its own sake, and there is frequently the artful stratrgem to allure the victim within the reach of destruction. There is not a motion of which the rabid horse is not conscious, nor a person whom he does not recognise; but he labours under one all-absorling feeling-the intense longing to devastate and destroy.

The post-mortem appearances are altogether micertain." There is usually very great injection and inflammation of the membrancs of the brain, and even of portions of the substance of the brain; but in other cases there is scarcely any trace of inflammation, or even of increaserl vascularity.

The treatment of phrenitis lias been very shortly hinted at. The first-the indispensable proceeding-is to bleed; to abstract as much blood as can be obtained; to let the animal bleed on after he is down; and indeed not to pin up the vein of the phrenitic horse at all. The patient will never be lost by this decisive proceeding, but the inflammation may be subdued, and here the first blow is the whole of the battle. The physic should be that which is most readily given and will most speedily act. The farina of the crotou will, perhaps, have the preference. Half a drachm or tro scruples of it may be fearlessly administered. The intense inflammation of the brain gives sufficient assurance that no dangerous inflammation will be easily set up in the intestinal canal. This mediciue can be formed into a very little ball or drink, and in some momentary remission of the symptoms, administered by means of the probang, or a stick, or the horn. Sometimes the phrenitic horse, when he will take nothing else, and is unconscious of everything else, will drink with avidity gruel or water. Repeated doses of purgative medicine may perhaps be thus given, and they must be continned until the bowels respond. The forehead should be blistered, if it can in any way be accomplished; yet but little service is to be expected from this manipulation. The bowels having been well opened, digitalis should be administered. Its first and most powerful action is on the heart, diminishing both the number and strength of its pulsations. To this may be added emetic tartar and nitre, but not a particle of hellebore; for that drug, if it acts at all, produces an increased determination of blood to the brain.

While the disease continues, no attempt must be made to induce the horse to feed; and even 
when appetite returns with the abatement of inflammation, great caution must be exercised both with regard to the quantity and quality of the food.

RABIES, OR MADNESS.

This is another and fearful disense, of the nerrous system. It results from the lite of a rabid animal, and, most commonly, of the companion and friend of the horse-the coach-dog. The account now given of this malady is extracted from lectures which the author of the present svork delivered to his class.

"There is occasional warning of the approach of this discase in the horse, or rather of the existence of somo unusual malady, the real natmre of which is probably mistaken. $\Lambda$ mare, belonging to Mr. Karslake, had during ten days before the recognition of the disease been drooping; refusing her food, heaving at the flanks; and pawiug occasionally. It was plain enough,that she was indis posed, but at length the furious fit came upon her, and she destroyed almost everything in the stable in the course of an hour. "Tlie late Mr. Moneyment had a two-years oll colt brought to his establishment. It was taken ill in the aftemoon of the preceding day, when it first attracted attention by refusing its food, and throwing itself down and getting up again immediately. From such a decription. Mr. Moneymeut concluded that in raşa case of cholic; but, when he went into the rard; and saw the pony, and observed his wild and anxions countenance, and his excessive nerrous sensibility, he was convinced that something uncommon was amiss with him, although he did not at first suspect the real nature of the case.

"The early symptoms of rabies in the horse have not been carefully observed or well recorded; but, in the majority of cases, so far as our records go, there will sot often be premonitory symptoms sufficiently decisive to be noticed by the groom.

"The horse goes out to his usual work, and, for a certain time and distance, performs it as well as he had been accustomed to do: then he stops all at once-trembles, heares, paws, stagrers, and falls. Almost immediately he rises, drags his load a little farther, and again stops, looks abont bim, backs, staggers, aud falls once more. This is not a fit of megrims-it is not a sudden determination of blood to the brain, for the horse is not for a single moment insensib]e. The sooner he is led home the better, for the progress of the disease is as rapid as the first attack is sudden; and, possibly, he will fall twice or thrice before he reaches liis stable.

"In the great majority of cases-or rather, with very few exceptions - a state of excitation ensues, which is not exceeded by that of the dog under the most fearful form of the malady, but there are intervals when, if he had been naturally good tem- pered and had béen attached to his rider or his groom, he will recognise his former friend and seek his caresses, and bend on him one of those piteous, searching looks which, once observed, will never be forgotten: but there is danger about this. Presently succeeds another paroxysm, without warning and without control; and there is no safety for him who had previously the most complete mastery over the animal.

"I was once attending arabid horse. The owner would not have him destroyed, under the vain hope that I had mistaken a case of phrenitis for one of rabies, and that the dioense might yield to the profuse abstraction of blood that I had been prevailed on to effect, and the purgative influence of the furina of the croton-nut with which be had been abundantly supplied in an early stage of the malady. I insisted npon his being slung: so that we were protected from injury from lis dicking or plunging. He would bend hic gaze upon nè ass. if he would seareh me through and through, and would prevail on me, if I could, to relieve him from some dreadful evil by which he was threatened. He would then press his head against mił bosóm, and keep it there a minute or more. All at once, however, the paroxysm would rețirn. He did not attempt to bite me; lut, bad it not been for the sling, he would have plunged furiously about, and I might have found it difficult to escape.

"I had previously attended another horse, which the owner refused to bave destroyed, and to which attendance I only consented on condition of the animal being slung. He had been bitten in the near hind-leg. When I approached him on that side, he did not attempt to bite me, and he could not otherwise injure me; but he was agitated and trembled, and struggled as well as be could; and if I merely touched bim with my finger, the pul. sations rere quickened full ten beats in a minute. When, however, I went round to the off side, he permitted me to pat him, and I had to encounter his imploring gaze, and his head was pressed against me-and then presently would come the paroxysm; but it came on almost before I could touch him, when I approached him on the other side.

"These mild cases, howerer, are exceptions to a general rule. 'They are few and far between. The horse is the servant, and not the friend of man; and if his companion, jet an oppressed one. In proportion to his bulk he has far less of that portion of the brain with which intelligence is connected-less attachment-less gratitude. $\mathrm{He}$ is nevertheless a noble animal, I am not speaking disparagingly of him; but I am comparing him with-next to man-the most intellectual of all quadrupeds. There is neither the motive for, nor the capability of, tbat attachment which the dog feels for his master, and therefore, under the in- 
fluence of this disase, he abandons himself to all its dreadful excitement.

"The mare of Mr. Karslake, when the disease was fully developed, forgot her former drooping, dispirited state: her respiration was acceleratedher mouth was covered with foam-a violent perspiration covered every part of her, and her screams would cow the stoutest heart. She presently demolished all the wood-work of the stable, and then she employed herself in beating to pieces the fragments, no human being daring to expose himself to her fury.

"The symptoms of the malady of Mr. Moneyment's pony rapidly increased; he bit everything within his reach, even different parts of his own body; he breathed laboriously; his tail erect; screaming dreadfully at short intervals, striking the ground with his fore-feet, and perspiring most profusely. At length he broke the top of his manger, and rushed out of the stall with it hanging to his halter. He made immediately towards the medical attendant, and the spectators who were standing by. They fortunately succeeded in getting out of his way, and he turned into the next stall, and dropped and died.

"A young veterinary friend of mine very incau. tiously and fool-hardily attempted to ball a rabid horse. The animal had previously shown himself to be dangerous, and had slightly bitten a person who gave him a ball on the preceding evening: he now seized the young studeut's hand, and lifted him from the ground, and shook him as a terrier would shake a rat. It was with the greatest difficulty, and not until the grooms had attacked the ferocious animal with their pitchforks, that they could compel him to relinquish his hold; and, even then, not before he had bitten his victim to the bone, and nearly torn away the whole of the fiesh from the upper and lower surfaces of the hand.*

"There is also in the horse, whose attachment to his omner is often comparatively small, a degree of treachery which we rarely meet with in the nobler and more intellectual dog, A horse that had shown symptoms of great ferocity was standing in the corner of his box, with a heaving flank, and every muscle quivering from the degree of excitement under which he laboured. A groom, presuming on the former obedience of the animal, ventured in, and endeavoured to put a headstall upon him. Neither the master nor myself could persuade him to forbear. I was sure of mischief, for I had observed the ear lying flat upon the neck, aud I could see the backward glance of the eye; I therefore armed myself with a heavy twitch stick that was at hand, and climbed into the man-

* In the Mruseum of the Veterinary School at Alfort, is the lower $\mathrm{jaw}$ of a rabid horse, which was fractured in the violent efforts of the animal to do mischiet. ger of the next box. The man had not advanced two steps into the box before I could see the shifting position of the fore feet, and the preparation to spring upon his victim; and he would lave sprung upon him, but my weapon fell, with all the force I could urge, upon his head, and he dropped. The man escaped, hut the brute was up again in an instant; and we trembled lest the partition of the box should yield to his violence, and he would realize the graphic description of Mr. Blaine, when he speaks of the rabid horse as 'levelling everything before him, himself sweating, and snorting, and foaming amidst the ruins.'

"I have had occasion, more than once, to witness the evident pain of the bitten part, and the manner in which the horse, in the intervals of his paroxysms, employs himself in licking or gnawing the cicatrix. One animal had been bitten in the chest; and he, not in the intervals between the exacerbation, but when the paroxysm was most violent, would bite and tear himself until his breast was shockingly mangled, and the blood flowed from it in a stream.

"The most interesting and satisfactory symptom is the evident dread of water which exists in the decided majority of cases, and the impossibility of swallowing any considerable quantity. Professor Dupuy gives an account of this cireumstance :'A rabid horse was confined in one of the sick hoxes. His food was given to him through an opening over the door; and a burket was suspended from the door, and supplied with water by means of a copper tube. As soon as he heard the water falling into the pail, he fell into violent convulsions, seized the tube, and crushed it to pieces. When the water in his buckct was agitated, the convulsions mere renewed. He would occasionally approach the bucket as if he wished to drink, and then, after agitating the water for an instant, he would fall on his litter, uttering a hoarse cry; hut he would rise again almost immediately These sympitoms were dreadfully increased if water was thrown upon his head. He would then endeavour to seize it as it fell, and bite with fury at everything within his reach, his whole frame being dreadfully convulsed.

"As the disease progresses, not only is the animal rapidly debilitated, but there is the peculiar staggering gait which is observable in the $\operatorname{dog}$ referable to evident loss of power in the muscles of the lumbar region. I once saw a mare sitting on her haunches and unable to rise, yet using her fore feet with the utmost fury, and suffering no one to come within her reach. She, too, would sometimes plunge her muzzle into the offered pail, and immediately withdraw it in evident terror, while every limb trembled. At other times the lowering of the pail would affright her, and she would fall on her side and struggle furiously. Al- 
though this symptom is not often observed in the $\mathrm{dog}$, it is a satisfactory identification of the disease, when it is so frequently seen in the horse, and so invariably in the buman being.

"The earliest and perhaps the most decisive symptom of the near approach of the rabies in the horse, is a spasmodic movement of the upper lip, particularly of the angles of the lip. Close following on this, or contemporaneous with it, is the depressed and anxious comtenance and inquiring gaze, suddenly howerer lighted up, and becoming fierce and menacing from some unknown cause, or at the approach of a stranger. From time to time different parts of the frame-the eyes-the jars - particular limb-will be convulsed. The eye will occasionally wander after some imaginary object, and the horse will snap again and again at that which has no real existence. Then will come the irrepressible desire to bite the attendants or the animals within its reach. To this will succeed the demolition of the rack, the manger, and the whole furniture of the stable, accompanied by the peculiar dread of water which lias been already described.

"Towards the close of the disease there is generally paralysis, usually confined to the loins and the hinder extremities, or involving those organs which derive their nervous influence from this portion of the spinal cord; lience the distressing tenesmus which is occasionally seen. day.

"The disease rarely extends beyond the third

"After death, there is uniformly found inflammation at the back part of the mouth, and at the top of the windpipe, and likewise in the stomach, and on the membrane covering the lungs, and where the spinal marrow first issues from the brain."

When the disease can be clearly connected with a previous bite, the sooner the animal is destroyed the better, for there is no cure. If the symptoms bear consilerable resemblance to rabies, although no bite is suspected, the horse should at least be slung, and the medicine, if any is administered, given in the form of a drink, and with the hand well protected; for if it should be scratched in balling the horse, or the skin should have been previously broken, the saliva of the animal is capable of communicating the disease. Several farriers have lost their lives from being bitten or scratched in the act of administering medicine to a rabid horse.

It is always dangerons to encourage any dogs about the stable, and especially if they become fond of the horses, aud are in the habit of jumping up and licking them. The cormers of the mouth of the horse are often sore from the pressure of the bit; and when a coach-dog iu a gentleman's stable-aud it is likely to happeu in every stuble and witl every dog-becomes raljid and dies, the horse too frequently follows him at no great distance of time.

If a horse is bitten by a dog under suspicious circumstances, he should the carefully examined, and every wound, and even the slightest scratch, well burned with the lunar caustic (nitrate of silver). The scab should be removed and the operation repeated on the third day. The hot iron does not answer so well, and other caustics are not so manageable. In the spring of 1827 , four horses were bitten, near Hyde Park, by a mad dog. To one of them the lunar caustic was twice severely applied: he lived. The red-hot iron was unspar. ingly used on the others, and they died. The caustic must reach every part of the mound. At the expiration of the fourth month the horse may be considered to be safe.

\section{TETANUS, OR LOCKED JAW.}

Tetauns is one of the most dreadful and fatal diseases to which the horse is subject. It is called LOCKED JAW, because the muscles of the jaw are earliest affected, and the mouth is obstinately and immorably closed. It is a constant spasm of all the voluntary muscles, and particularly of those of the neck, the spine, and the head. It is generally slow and treacherous in its attack. The horse, for a day or two, does not appear to be quite well; he does not feed as usual ; he partly chews his food, and drops it; aud he gulps his water. The owner at length finds that the motion of the jaws is con. siderably limited, and some saliva is drivelling from the mouth. If he tries he can only open the mouth a very little way, or the jaws are perfectly and rigidly closed; and thus the only period at which the disease could have been successfully combated is lost. A cut of a horse labouring under this disease is here given, which the reader will do well to examine carefully.

The first thing that strikes the observer is a protrusion of the muscle, and stiffness of the neck; and, on passing the hand down it, the muscles will be found singularly prominent, distinct, hard, knotty, and unyielding. There is difficulty in bringing the head roumi, and still greater difficulty in bending it. The eye is drawn deep within the socket, and, in consequence of this, the fatty matter behind the eye is pressed forward; the haw is also protruded, and there is an appearance of stra. bismus, or squinting, in an outward direction.

The cars are erect, pointed forward, and im. movable; if the horse is spoken to, or threatencd to be struck, they change not their position. Considering the beautiful play of the ear in the horse when in liealth, and the lind of conversation which he maintains by the motion of it, there is not a more characteristic symptom of tetanus than this immolility of the ear. 'Ihe nostril is expanded 


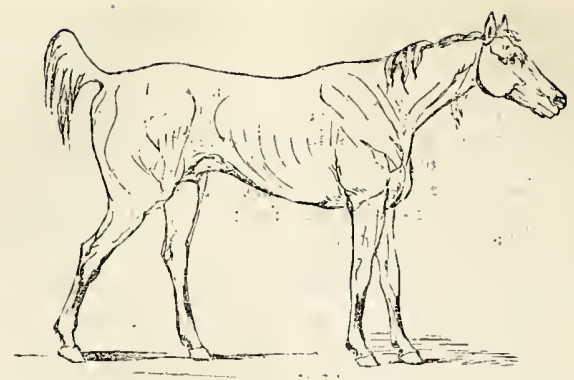

to the utmost, and there is little or no play of it, as in hurried or even natural breathing. The respiration is usually accelerated, yet not always so; but it is uniformly laborious. The pulse gives little indication of the severity of the disease. - It is sometimes scarcely affected. It will be rapidly accelerated when any one approaches the animal and offers to touch him; but it presently quiets down again almost to its natural standard. After a while, however, the heart begins to sympathise with the general excitation of the system, and the pulse increases in frequency and force until the animal becomes debilitated, when it beats yet quicker and quicker, but diminishes in power, and gradually flutters and dies away.

The countenance is eager, anxious, haggard, and tells plainly enough what the animal suffers.

The stiffness gradually extends to the back. If the horse is in a narrow stall, it is impossible to turn him; and, even with room and scope enough, he turus altogether like a deal-board.

The extremities begin to participate in the spasm-the hinder ones generally first, but never to the extent to which it exists in the neck and back. The horse stands with his hind legs straddling apart in a singular way. The whole of the limb moves, or rather is dragged on, together, and anxious care is taken that no joint shall be flexed more than can possibly be helped. The fore limbs have a singular appearance; they are as stiff as they can possibly be, but stretched forward and straddling. They have not unaptly been compared to the legs of a form.

The abdominal muscles gradually become in. volved. 'They seem to contract with all the power they possess; and there is a degree of "hidebound" appearance, and of tucking up of the belly, which is seen under no other complaint. The tail hecomes in constant motion from the alternate and violent action of the muscles that elevate and depress it.

Constipation, and to an almost insurmountable degree, now appears. The abdominal muscles are so powerfully contracted, that no portion of the contents of the abdomen can pass on and be discharged.

By degrees the spasm extends and becomes everywhere more violent. The motion of the whole frame is lost, and the horse stands fixed in the unnatural posture which he has assumed. The countenance becomes wilder and more haggardits-expression can never be effaced from the memory, of him who cares about the feelings of a brute. The violent cramp of a single muscle, or set of muscles, makes the stoutest heart quail, and draws forth the most piteons cries; what, then, must it be for this torture to pervade the whole frame, and to continue, with little respite, from day to day, and from week to week! When his attendant approaches and tonches him, he scarcely moves: but the despairing gaze, and the sudden acceleration of the pulse, indicate what be feels and fears.

Tetanus then is evidently an affection of the nerves. A small fibre of some nerre has been injured, and the effect of that injury has spread to the origin of the nerve; the brain then becomes affected, and universal diseased action follows. Tetanus is spasm of the whole frame-not merely of one set of muscles, but of their antagonists also. The fixidity of the animal is the effect of opposed and violent muscular contraction. It belongs to the lower column of nerves only. The sensibility is unimpaired-perhaps it is heightened. The horse would eat if he could; he tries to suck up some moisture from his mash; and the avidity with which he lends himself to assist in the administering of a little gruel, shows that the feelings of hunger and thirst remain unimpaired.

If the disease terminates fatally, it is usually from the sixth to the eighth day, when, if there has been no remission of the spasms, or only a slight one, the horse dies, exhausted by hard work. The task extorted by the whip aud spur of the most brutal sportsman is not to be compared with it.

About or a little before this time, there are 
occasionally evident remissions. The spasm does not quite subside, but its force is materially les. sened. The jaw is not sufficiently relaxed to enable the animal to eat or to driuk, or for advantage to be taken of an opportumity for the administration of medicine, while the slightest disturbance or fright recalls the spasmodic action with all its violeuce. If, however, the remission returns on the followiug day, and is a little lengthened, and particularly if there is more relaxation of the lower jaw, there yet is hope. If the patient should recover it will be very slowly, and he will be left sadly weak, and a mere walking skeleton.

On post-mortem examination, the muscular fibre will exhibit sufficient proof of the labour which has been exacted from it. The museles will appear as if they had been macerated-their texture will be softened, and they will be torn with the greatest ease. 'The lungs will, in the majority of cases, be highly inflamed, for they have beeu labouring loug and painfully to furnish arterial blood in sufficient quantity to support this great expenditure of animal power. The stomach will contain patches of inflammation, but the intestines, in most cases, will not exhibit much departure from the hue of health. The examination of the brain will be altogether unsatisfactory. There may be shight injection of some of the membranes, but, in the majority of cases, there will not be any morbid change worthy of record.

Tetanus is usually the result of the injury of some nervous fibre, and the effect of that lesion propagated to the brain. The foot is the most frequeut source or focus of tetanic injury. It has been pricked in shoeing, or wounded by something on the road. The horse becomes lame-the injury is carelessly treated, or not treated at all-the lameness, however, disappears, but the wound has not healed. There is an unhealthiness about it, aud at the expiration of eight or ten days, tetanus appears. Some nervous fibre has been irritated or inflamed by the accident, slight as it was.

Docking and nicking, especially when the stump was seared too severely in the former, or the ban. dage had not been loosened sufficiently early in the latter, used to be frequent causes of tetauus. It is frequently comnected with castration, wheu the colt had not been properly prepared for the operation, or the searing iron has been applied too severely, or the animal has been put to work too soon after the operation, or exposed to unusual cold. The records of reterinary proceedings coutain accounts of tetanus following labour, brutally exacted beyond the animal's natural strength, in the draught of heary loads. Horses that have been matched against time have too frequeutly died of tetanus a little while afterwards. Sudden exposure to cold after being beated by exercise has produced this dreadful state of nerrous ac-

vot. $\mathrm{r}$. tion, and especially if the horse has stood in a partial draught, or cold water has been dripping on the loins.

The treatment of tetanus is simple, and would he oftener successful if carried to its full extent. The indication of cure is plain enough-the system must be tranquillized. The grand agent in accomplishing this is the copious abstraction of blood. There is not a more powerful sedative in cases of muscular spasm than venesection. A double purpose is effected. The determiuation of blood to the origius of the nerves, aud by which they were enabled to secrete and to pour out this torrent of nerrous influence, is lessened. The supply of blood to the muscular system is also diminished. The pabulum of the nervous and muscular system - the life of both of them-the capability of acting in the one, and of being acted upon by the other, is taken away. The proper course to be pursued, whether theory or experience are consulted, is, on the first access of tetanus, to bleed, and to bleed until the horse falters or falls. No attention should be paid to any specific quantity of blood to be abstracted, but the animal should bleed on until he drops, or the pulse evidently falters. Twenty pounds have been taken before the object of the practitioner was accomplished, lut he never had occasion to repent of the course which he pursued. Inflammatory action like this must be subdued by the promptest and most efficient meaus; and there is one unerring guide-the pulse. While that remains firm, the bleeding should contiune. The practitioner is attacking the disease, and not in the slightest degree hazarding the permanent strength of the patient.

Next in order, and equal in importance, is physic. The profuse bleeding just recommended will generally relax the muscles of the jaw so far as to enable a dose of physic to be giveu. Eight or ten drachms of aloes should be administered. If the remission of the spasm is slight, there is another purgative-not so certain in its actiou, but more powerful when it does act-the fariua of the Croton nut. There is little or no danger of exciting inflammation of the mucous membrane of the intestines by this prompt and energetic administration of purgative medicine, for there is too much determination of vital power towards the nervous system-too much irritation there-to leave cause for dreading the possibility of metastasis elsewhere. It would be desirable if a certain degree of inflammation could be excited, because to that extent the irritation of the nerrous system might be allayed. There is another reason, and a rery porrerful one-time is rapidly passing. The tetanic action may extend to the intestines, and the co-operation of the abdominal muscles in keeping up the peristaltic motion of the bowels, and expelling their contents, may be lost. 
Clysters will be useful in assisting the action of the purgative. A solution of Epsom salts will constitute the safest and best injection. As to mediche, opium is not only a valuable drug, but it is that on which alone dependence can be placed in this disease. It will be borne in doses, from half a drachm to two drachms.

Blisters are completely out of the question in a disease the very essence of which is nervous irritability.

The application of sheep-skins warm from the animal, and applied along the whole course of the spine, may somewhat unload the congested vessels of the part, and diminish the suflerings of the animal. They should be renewed as soon as they become offensive, and the patient should be covered from the poll to the tail with double or treble clotling.

There is one kind of external application that has not bcen so much used, or so highly valued as it deserves, - gentle friction with the hand over the course of the spine, beginning with the slightest possible pressure and never increasing it much. The horse is a little frightened at first, but he soon gets reconciled to it, and when at the same time an opiate liniment is used, relief has been obtained to a very marked degree.

One thing should not be forgotten, namely, that a horse with locked jaw is as hungry as when in health, and every possible contrivance should be adopted to furnish him with that nutriment which will support him under his torture, and possibly enable him to weather the storm. If a pail of good gruel is placed within his reach, how will he nuzzle in it, and contrive to drink some of it too! If a thoroughly wet mash is placed before him in a pail, he will bury his nose in it, and manage to extract no small portion of nutriment. By means of a small horn, or a bottle with a very narrow neck, it will often be possible to give him a small quantity of gruel; but the flexible pipe that accompanies Read's patent pump will render this of easier accomplishment, for the nutriment may be administered without elevating the head of the horse, or inflicting on him the extreme torture which used to accompany the act of drenching. If the jaw is ever so closely clenched, the pipe may be introduced between the tushes and the grinders, and carried tolerably far back into the mouth, and any quantity of gruel or medicine introduced into the stomach.

It will also be good practice to let a small portion of food be in the manger. The horse will not at first be able to take up the slightest quantity, but he will attempt to do so. Small portions may be placed between his grinders, and they will presently drop from his mouth scarcely or at all masticated : but some good will be done-there is the attempt to put the muscles of the jaw to their proper use. On the following day he will succeed a little better, and make some trifling advance towards breaking the chain of spasmodic action. Experience will teach the careful groom the value of these minutiæ of practice; and the successful termination of many a case may be traced to the careful nursing of the patient.

When the horse is getting decidedly better, and the weather will permit, there can be no better practice than to turn him out for a few hours in the middle of the day. His toddling about will regain to lim the use of his limbs; the attempt to stoop in order to graze will diminish the spasm in his neck; the act of grazing will relax the muscles of the jaws; and he can have no better food than the fresh grass.

\section{CRAMIP.}

This is a sudden, involuntary, and painful spasm of a particular muscle or set of muscles. It differs from tetanus in its shorter duration, and in its occasionally attacking the muscles of organic life. It may be termed a species of transitory tetanus, affecting mostly the hind extremities. It is generally observed when the horse is first brought out of the stable, and especially if he has been hardly worked. One of the legs appears stiff, inflexible, and is, to a slight degrec, dragged after the animal. After he has proceeded a few steps, the stiffness nearly or quite disappears, or only a slight degree of lameness remains during the greater part-of the day.

Cramp proceeds from an accumulation of irritability in the muscles of the extensors, and is a sudden spasmodic action of them in order to balance the power which their antagonists have gained over them during the night.

If a certain degree of lameness remains, the attendant on the horse should endeavour to find out the muscle chiefly affected, which he may easily do by a feeling of hardness, or an expression of pain, when he presses on the extensors of the hock somewhat above that joint. He should then give plenty of good hand-rulbing, or a little more attention to the grooming generally, or a wider or more comfortable stall, as the circumstances of the case may appear to require.

\section{STRINGHALT.}

This is a sudden and spasmodic action of some of the muscles of the thigh when the horse is first led from the stable. One or both legs are caught up at every step with great rapidity and violence, so that the fetlock sometimes touches the belly; but, aftcr the horse has been out a little while, this usually goes off, and the natural action of the animal returns. In a few cases it does not perfectly disappear after exercise, but the horse continues to be slightly lame. 
Stringhalt is not a perfectly involuntary action of a certain muscle, or a certain set of muscles. The limb is flexed at the command of the will, but it acts to a greater extent and with more violence than the will had prompted. There is an accumulation of excitability in the muscle, and the impulso which should have called it into natural and moderate action causes it to take on a spasmodic and, perhaps, a painful one.

Many ingeuious but contradictory theories have been advanced in order to account for this peculiarity of gait. What museles are concerned? Clearly those by which the thigh is brought under the belly, aud the hock is flexed, and the pasterns are first flexed and then extended. But by which of them is the effect principally produced? What muscle, or, more properly, what nerve is coucerned? Instead of entering into any useless controversy on this point, a case shall be related, and one of the most interesting there is on record: the author was personally cognisant of every particular.

Guildford, first called Roundhead, and then Landlord, was foaled in $18: 0$. He was got by Hampden out of a Sir Harry Dimsdale mare. In 1828 , and being two years old, aud the property of the Duke of Richmond, he won a fifty pound plate at Goodwood. In 18:9, and belouging to Lord W. Lennox, he won fifty-five guineas at Hampton. Being then transferred to Mr. Coleman, he won fifty guineas at Guildford; and in the same year, having been purchased by Mr. Pearce, he won sixty guineas at Basingstoke.

In the course of this year stringhalt began to appear in a slight degree, and it evilently, although slowly, iucreased. There soon began to be a little difficulty in getting him off; but when he had once started, neither his speed nor his stoutness appeared to be in the slightest degree impaired. He continued on the turf until 1836 , and won for his different owners seventeen races, the produce of which, exclusive of bets, amounted to 1435 .

The difficulty and loss of advantage in starting had now increased to a degree which rendered it prudent to withdraw him from the turf, and he came into the possession of Dockeray, who used him for the purpose of leading the young horses that he had under training. This is well kwown to be hard work, and his rider was a mau of some weight. In additiou to this, he was generally hunted twice in the week. His first starting into a gallop had something singular about it. It was a horrible kind of convulsive action, and so violeut that he frequently knocked off his shoes on the very day that they were put on: but when he got a little warmed all this disappeared. He galloped beautifully, and was a very sure fencer. The sport, lowever, being over, and he returning to a slow pace, the stringhalt was as bad as ever.
At length the old horse became artful, and it was with great difficulty that he could be made to lead. Sometimes he refused it altogether. In consequence of this he was sent to St. Martin's Lane to be sold. The highest bidding for him was three pounds fourteen shillings, and the hero of the turf and the field was doomed to the ounibus. There he was cruelly used, and this spasmodic convulsion of his hind legs sadly aggravated his torture. The skin was presently rubbed from his shoulders, his hips and haunches were loruised in every part, and his stifles were contiuually and painfully coming in coutact with t'ze pole.

In this situation he was seen by the veterinary surgeon to "The Society for the Prevention of Cruelty to Animals." There is a fund at the disposal of that society for the purchase of worn. out horses, who are immediately released from their misery by the pole-axe of the knacker. 'l'he horse was bought for this purpose, another and laudable motive intluencing the purchase,-the wish to ascertain what light the dissection of an animal that had had stringhalt to such an aggravated extent, and for so long a period, would cast on the nature of this diseuse.

The author of this work saw him a little while before he was slaughtered. He was still a noblelooking animal, aud seemed to possess all his former strength and spirit unimpaired; but he was sadly scarred all over, in consequence of his being put to a kind of work for which his spasmodic complaint so entirely incapacitated him. So aggravated a case of stringhalt had rarely been seen. Both hind legs were affected, and both in an equal degree; and the belly was forcibly struck by the pastern joints every time the hind feet were lifted. The belly and the pastern joint were both denuded of hair, in consequence of this constant battering.

He was destroyed by the injection of prussic acid into the jugular vein, and the dissection of him was conducted by Professor Spooner, of the Royal Veterinary College.

On taking off the skin, all the muscles presented their perfect healthy character. There was not the slightest enlargement or discolouration of the fascire. The muscles of both extremities were dissected from their origins to their tendinous terminations, and their fibrous structure carefully examined. They were all beautifully developed, presenting no inequality or irregularity of structure, nor aught that would warrant the suspicion that any ove of them possessed an undue power or influence beyoud the others. The only abnormal circumstance about them was that they were of, a rather darker yellow in colour than is usually found. This referred to them generally, and not to any particular muscle or sets of muscles.

The lumbar, crural, and sciatic nerres mere examined from the spot at which they emerge from 
the spinal cord to their ultimate distributions. The crural and lumbar nerves were perfectly healthy. The sciatic nerve, at the aperture through which it escapes from the spine, was darker in colour than is usual, being of a yellowish-brown hue. Its texture was softened, and its fibrilla somewhat loosely connected together. The nerve was of its usual size; but on tracing it in its course through the muscles of the haunch, several spots of ecchymosis presented themselves, and were more particularly marked on that part of the nerve which is connected with the sacrosciatic ligament. As the nerve approached the lock. it assumed its natural colour and tone; and the fibres given off from it to the muscles situated inferior to the stifle-joint were of a perfectly healthy character.

On dissecting out a portion of the nerre where it appeared to be in a diseased state, it was found that this ecchymosis was confined to the membraneous investiture of the nerve, and that its substance, when pressed from its sheath, presented a perfectly natural character.

The cavity of the cranium, and the whole extent of the spinal canal, were next laid open. The Lrain and spinal marrow were deprived of their membraneous coverings, and both the thece and their contents diligently examined. There was no lesion in any part of them, not eren at the lumbar region.

The articulations of every joint of the hind extremities then underwent inspection, and no disease could be detected in either of them.

Professor Spooner was of opinion that this peculiar affection was not referrible to any diseased state of the brain or spinal cord, nor to any local affection of the muscles of the limbs, but simply to a morbid affection of the sciatic nerve. He had not dissected a single case of stringhalt in which he had not found disease of this nerre, which mainly contributes to supply the hind extremities with sensation and the power of voluntary motion.

Now comes a very important question. What connexion is there between stringhalt and the supposed ralue or deterioration of the horse? Some experienced practitioners have maintained that it is a pledge of more than usual muscular power. It is a common saying that "there never was a horse with stringhalt that was incapable of doing the work required of him." Most certainly we continually meet with horses having stringhalt that pleasantly discharge all ordinary, and even extraordinary, service; and although stringhalt is excess or irregular distribution of nervous power, it at least shows the existence of that power, and the capability in the muscular system of being acted upon by it. Irregular distributions of vital energy are not, however, things to be desired. They argue disease and derangement of the system, and a predisposition to greater derangement. They materially interfere with the speed of the horse.
This was decidedly the case with regard to the poor fellow whose history has been related.

Stringhalt is decided unsoundness. It is an irregular supply of the nervous influence, or a diseased state of the nervous or muscular system, or both. It prevents us from suddenly and at once calling upon the horse for the full exercise of his speed and power, and therefore it is unsoumdness ; but generally speaking, it so little interferes witl the services of the animal, that although an unsounduess, it would not weigh a great deal against other manifest valuable qualities.

\section{CHOREA.}

This is a convulsive involuntary twitching of some muscle or set of muscles. A few, and very few, cases of it in the horse are recorded. Profes. sor Gohier relates one in which it attacked both fore legs, and especially the left, but the affection was not constant. During fire or six minutes the spasms were most violent, so that the horse was searcely able to stand. The convulsions then became Feaker, the interval between them increased, and at length they disappeared, leaving a slight but temporary lameness. All means of cure were fruitlessly tried, and the disease contiuned until the horse died of some other complaint. In another case it followed sudden suppression of the discharge of glanders and disappearance of the enlarged glands. This also was intermittent duriıg the life of the animal.

\section{FITS, OR EPILEPSY.}

The stream of nervous intluence is sometimes rapid, or the suspensions are considerable. This is the theory of Fits, or Epilepsy. Fortunately the horse is not often afflicted with this disease, although it is not unknown to the breeder. The attack is sudden. The animal stops-trembleslooks racantly around him, and falls. Occasionally the convulsions that follow are slight; at other times they are terrible. The head and fore part of the horse are most affected, and the contortions are rery singular. In a few minutes the convulsions cease; he gets $1 p$; looks around him with a kind of stupid astonishment; shakes his ears; urines; and eats or drinks as if nothing had happened.

The only hope of cure consists in discovering the cause of the fits; and an experienced practitioner must be consulted, if the animal is valuable. Generally spealing, however, the cause is so difficult to discover, and the habit of having fits is so soon formed, and these fits will so frequently return, even at a great distance of time, that he who values his own safety, or the lives of his family, will cease to use an epileptic horse

\section{PALSY.}

The stream of nervous influence is sometimes 
stopped, and dlence results palsy. The power of the muscle is unimpaired, but the nervous energy is deficient. In the human being general palsy sometimes occurs. The whole body-every organ of motion and of sense is paralysed. The records of our practice, however, do not afford us a single instance of this; but of partial paralysis there are several cases, and most untractable ones they were. The cause of them may be altogether unknown. In the human being there is yet another distinction, Hemiplegia, and Paraplegia. In the former the affection is confined to one side of the patient; in the latter the posterior extremity on both sides is affected. Few cases of hemiplegia occur in the horse, and they are more manageable than those of paraplegia; but if the affection is not removed, they usually degenerate into paraplegia before the death of the animal. It would appear singular that this should be the most common form of palsy in the human being, and so rarely seen in the quadruped. There are some considerations, however, that will partly account for this. Palsy in the horse usually proceeds from injury of the spimal cord; and that cord is more developed, and far larger than in the human being. It is more exposed to injury, and to injury that will affect not one side only, but the whole of the cord.

Palsy in the horse generally attacks the hind extremities. The reason of this is plain. The fore limbs are attached to the trunk by a dense mass of highly elastic substance. This was placed between the shoulder-blade and the ribs for the purpose of preventing that concussion, which would be annoying and even dangerous to the horse or his rider. Except in consequence of a fall, there is scarcely the possibility of any serious injury to the anterior portion of the spine. The case is very different with regard to the hind limbs and their attachment to the trunk; they are necessarily liable to many a shock and sprain injurious to the spine and its contents. The loins and the back oftenest exhibit the lesions of palsy, because there are some of the most violent muscular efforts, and there is the greatest movement and the least support. It may, consequently, be taken as an axiom to guide the judgment of the practitioner that palsy in the horse almost invariably proceeds from disease or injury of the spine.

On inquiry it is almost invariably found that the horse had lately fallen, or had been worked exceedingly hard, or that, covered with perspiration, he had been left exposed to cold and wet. It commences generally in one hind leg, or, perbaps, both are equally affected. The animal can scarcely walk; he walks on his fetlocks instead of his soles; he staggers at every motion. At length he falls. $\mathrm{He}$ is raised with difficulty, or he never rises again. The sensibility of the part seems for a while to be dreadfully increased; but, in general, this gradually subsides, it sinks below the usual standard, it ceases altogether.

If he is examined after death, there will usually, about the region of the loins, be inflammation of the membranes of the spinal cord, or of the cord itself. The medullary matter will be found of a yellow colour, or injected with spots of blood, or it will be softened, and have become semifluid.

The treatment is simple enough. It should commence with bleeding, aud, as has been already recommended in iuflammatory cases, until the circulation is evidently affected, until the pulse begins to falter or the horse to reel. T'o this should follow a dose of physic, strong compared with the size of the animal. The loins should be covered with a mustard poultice frequently renewed. The patient should be warmly clothed, supplied plentifully with mashes, but without a grain of corn in them; and frequent injections should be liad recourse to. This will soon render it evident whether the patient will recover or die. If farourable symptoms appear, the horse must not be in the slightest degree ne glected, nor the medical treatment suspended. There is no disease in which the animal is more liable to a relapse, or where a relapse would be so fatal. No misapprehension of the disease, or false humanity, should induce the attendant to give the smallest quantity of corn or of tonic medicine. Palsy in the horse is an inflammatory complaint, or the result of inflammation.

If the heat and tenderness are abating, and the animal regains, to a slight degree, the use of his limbs, or if it is becoming a case of chronic palsy, an extensive and stimulating charge over the loins should be immediately applied. It will accomplish three purposes: there will be the principle of counter-irritation, a defence against the cold, and a useful support of the limbs.

\section{RHETYTISIT.}

It is only of late years that this has been admitted into the list of the diseases of the horse, although it is in truth a very common affection. It is frequent in old horses that have been early abused, and among younger ones whose powers have been severely taxed. The lameness is frequently excessive, and the paiu is evidently excruciating. The animal dares not to rest the slightest portion of its weight on the limb, or even to touch the ground with his toe. He is heaving at the flanks, sweating profusely, his countenance plainly indicutive of the agony he feels; but there is at first no heat, or swelling, or tenderness. With proper treatment, the pain and the lameness gradually disappear; but in other instances the fascize of the muscles become thickened-the ligaments are also thickened and rigid-the capsules of the joint are loaded with a glairy fluid, and the joint is evidently enlarged. This is simply rheuma- 
tism; lut if it is neglected palsy soon associates itself with, or succeeds to, the complaint; and the loss of nerwous power follows the difficulty or pain of moving.

Every horseman will recollect cases in which the animal that seented on the preceding clay to be perfectly sound becomes decidedly lame, and limps as though he had lost the use of lis limbs; yet there is no thickening of the tendons, nor any external inflammatory action to show the seat of the complaint. Mr. Cooper, of Coleshill, relates a case very applicable to the present sulject. A farmer purchased a horse, to all appearance sound, and rode him home, a distance of ten miles. He was worked on the two following days, without showing the least lameness. On the third day it was with great difficulty that he managed to limp ont of the stable. Mr. Cooper was sent for to examine him. The horse had clean legs and excellent feet. The owner would have him blistered all round. It was done. The horse was turned ont to grass for tro months, and came up perfectly sound. The weather soon afterwards became wet and cold, and the horse again was lame; in fact, it presently appeared that the disease was entirely influenced by the changes of the atmosphere. "Thus," adds Mr. C., "in the summer a horse of this description will be mostly sound, while in the winter he will be generally lame."

An account of acute rheumatism, by Mr. Thompson, of Beith, is too valuable to be omitted: "I have had," says he, "fourteen crses of this disease. The muscles of the shoulders and arms were generally the parts affected. The cure was effecter in a few days, and consisted of a good bleeding from the jugular, and a sharp purge.

"One of these cases was uncommonly severe. The disease was in the back and loins. The lorse brought forward his hind legs under his flanks, roached his back, and drew up his flanks with a convulsive twitch accompanied by a piteous groan, almost every five minutes. The sympathetic ferer was alarming, the pulse was 90 , and there was obstinate constipation of the howels. The horse literally roared aloud if any one attempted to shift him in the stall, and groaned excessively when lying. He ras bled almost to fainting; and three moderate doses of aloes were given in the course of two days. Injections mere administered, and warm fomentations were frequently applied to the back and loins. On the third day the phrsic operated briskly, accompanied by considerable nausea and reduction of the pulse. From that time the animal gradually recovered.

"These horses are well fed, and always in good condition; but they are at times worked without mercy, which perhaps makes them so liable to these attacks."

\section{NEUROTOMY.}

To enable the horse to accomplisl many of the tasks we exact from him, we have nailed on his feet an iron defence. Without the protection of the sloe, he would not only be unable to travel over our hard roads, but he would speedily become useless to us. While, however, the iron protects his feet from being battered and bruised, it is necessarily inflexible. It cramps and confines the hoof, and often, without great care, entails on our valuable servant bad disease and excessive torture.

The division of the nerve, as a remedy for intense pain in any part of the frame, was systematically practised by human surgeons more than a century ago. Mr. Moorecroft has the honour of introducing the operation of neurotomy in the veterinary seloool.

He had long devoted his powerful energies to the discovery of the causes and the cure of lameness in the fore-foot of the horse. It was a subject worthy of him, for it involved the interest of the proprietor and the comfort of the slave. He found that, partly from the faulty construction of the shoe, and more from the premature and cruel exaction of labour, the horse was subject to a variety of diseases of the foot: all of them accompanied by a greater or less degree of pain-often of a very intense nature, and ceasing only with the life of the animal.

He frequently met with a strangely formidable disease, in what was called " coffin-joint lameness," but to which Mr. James Turner afterwards gave the very appropriate name of "navicular.joint disease." It was inflammation of the synovial membrane, either of the flexor tendon or navicular bone, or both, where the tendon plays over that bone; and it was accompanied by pain, abrusion, and gradual destruction of these parts.

For a long time he was foiled in every attempt which he made to remove or even to alleviate the disease. At length he turned his thoughts to the probability of subduing the increased sensibility of the part, by diminishing the proportion of nervous influence distributed on the foot. He laid bare one of the metacarpal nerves, and divided it with a pair of scissors. There was always an immediate and decided diminution of the lameness, and, sometimes, the horse rose perfectly sound. This hapny result, however, was not always permanent, for the lameness returued after the lapse of a few weeks, or on much active exertion. He next cut out a small piece of the nerve. The freedom from lameness was of longer duration, but it eventually returned.

He then tried a bolder experiment. He excised a portion of the nerves going both to the inner and outer metacarpals. We transcribe his own acconnt of the result of the first case of complete neurotomy-excision of the nerve on both sides of the leg-that ever was performed. 
“The animal, on rising, trotted boldly and without lameness, but now and then stumbled with the foot operated on. The wounds healed in a few diys, and the patient was put to grass. Some weeks afterwards a favourable account was received of her soundness; but she was soon brought again to us, on account of a large sore on the lottom of the foot operated on, and extending from the point of the frog to the middle and back part of the pastern. The mare, in galloping over some broken glass bottles, had placed her foot npon a fragment of the bottom of one of them, and which had cut its way through the frog and tendon into the joint, and stuck fast in the joint for some seconds, while the animal continued its course apparently regardless of injury. The wound bled profusely, but the mare was not lame. Many days had elapsed before I saw her, and large masses of loose flesh were cut from the edges of the wound, without the animal showing the slightest sign of suffering pain. The processes usually attending sores went on, with the same appearances that took place in sores of parts not deprived of sensilility. Such extensive injury, however, had been done to the joint as rendered the preservation of free motion in it very improbable, even were the opening to close, which was a matter of doubt, and therefore she was destroyed. It appeared clearly from this, that by the destruction of sensibility the repairing powers of the part were not injured; but that the natural guard against injury being taken away by the division of both the nerves, an accident was rendered destructive which, in the nsual condition of the foot, might have been less injurious."*

A The metacarpal nerve on the insile of the off leg at the edge of the shank bone, aad behind the vein and artery.

B The contiaution of the same nerve oa the pastern, aad proceeding downward to supply the back part of the foot with feeling.

C The division of the nerve on the fetlock joint.

D The branch which supplies with feeling the fore part of the foot.

F. The artery between the vein aad nerve.

F The eontinuation of the artery on the pastern, close to, and before the nerve.

G The veia befnre the artery and nerve.

H The same vein spreading over the pastern.

I One of the flexor tendons, the perforalus (perforated).

J The deeper flexor teadon, the perforans Jperforating, contained within the other\}.

K The tendinous band in which the flexors work.

L One of the extensors of the foot.

M The internal or sensible frog.

$\mathrm{N}$ The posterior lateral ligameat.

O The fleshy or sensible lamina covering the coffin bone, the horny crust being removed.

P The horoy erust.

- Veteringrian, vol. ix. p. 363.
The cut in the preceding column gives a view of the nerve inside of the leg, as it approaches the fetlock. It will be seen that branches are given off above the fetlock, which go to the fore part of the foot and supply it with feeling. The continuation of the nerve below the fetlock is given principally to the quarters and hinder part of the foot. The grand consideration, then, with the operator is-does he wish to deprive the whole of the foot of sensation, or is the canse of lameness principally in the hinder part of the foot, so that he can leave some degree of feeling in the fore part, and prevent that alteration in the tread and going of the horse, which the horseman so much dislikes?

The horse must be cast and secured, and the limb to be operated on removed from the hoblles and extended-the hair having been previously shaved from the part. The operator then feels for the throbbing of the artery, or the round firm borly of the nerve itself, on the side of the shank bone or the larger pastern. The vein, artery, and nerve here run close together, the vein nearest to the front of the leg, then the artery, and the nerre behind. He cautionsly euts through the skin for an inch and a half in length. The vessels will then be brought into view, and the nerve will be distinguished from them by its lying behind the others, and by its whiteness. A crooked needle, armed with silk, is then passed under it, in order to raise it a little. It is dissected from the cellular substance beneath, and about three quarters of an inch of it ent out: the first incision being made at the upper part, in which case the second incision will not be felt. The horse must then be turned, and the operation performed on the other side; for there is a nervous trunk on both sides. The wounds are now closed with strips of adhesive plaster, a bandage placed over them, the head tied up for a couple of days, and the animal kept rather low, and as quiet as possible. The incisions will generally rapidly heal; and in three weeks or a month, and sometimes earlier, the horse will be fit for work.

For ring-bone-the side cartilages becoming bony, and there being partial stiffness of the pastern and coffin-joints-the operation of nerving will probably be beneficial. The sense of pain being taken away, the animal will use these parts more, and they will gradually recover their natural action and motion. For the same reason, in old contraction of the feet, it is highly beneficial. The torture occasioned by the pressure of the horny crust on the sensible parts within being no longer felt, and the foot coming fully and firmly in contact with the ground, not only is lameness relieved, but the elasticity and form of the foot partially restored. Where lameness has long existed, unattended with heat of the foot or alteration of shape, and the seat of which could not be ascertained, although probably existing between the varicular I bone and the back tendon that plays over it, net- 
rotomy may be resorted to with decided advantage.

Micchief, however, will result from the operation, if the Iastem or coffin-joints are perfectly stiff, because the concussion occasioned by the forcible contact of the foot with the ground, and unbroken by the play of the joints, must necessarily still more injure the bone. When the sole of the foot is convex or pumiced, the effect of neurotomy will be most destructive. The sole, scarcely able to bear the pressure of the coffin-bone, even when pain induces the animal to put his foot as gently as possible on the ground, being forced below its natural situation, would be speedily worn through and destroyed. So if inflammation existed, although its pain might be removed, yet its progress would be quickened by the bruising to which the parts might be subjected; and more especially would this be the case, if there was any ulceration of the ligaments or cartilages.

The unfettered shoe of Mr. Turner being adopted, at leastso far as we can have it unfetteredattached to the foot on one side alone, and the inner quarter being left free-the foot gradually regains its original healthy form, and when, in process of time, a new portion of nerve is produced, and the sensibility of the foot re-established, the horse continues to be sound. To some extent, immediate good effect is produced as it regards the actual disease. We remore that general constitutional irritability which long-continued pain occasions, and which heightens and perpetuates local disease. We obtain for the patient an interval of repose, and every local ailment soon subsides or disappears, and the whole constitution becomes invigorated.

Mr. Percivall relates two valuable cases of this. A mare with contracted feet was never subject to periodical ostrum, and her owmer lamented in vain that he could not breed from her. She undernent the operation of neurotomy and became an excellent brood mare. A stallion with many a good point about him was useless in the stud: he was suffering from some disease in the feet. A portion of the nerve was excised : his constitution underwent a complete change, and he became sire to a numerous and valuable progeny.

By the operation of neurotomy we destroy pain; and we may safely calculate on the simple effect of that, whether local or constitutional; and, limiting our expectations to this, we shall rarely be disappointed.

The operation of neurotomy having been performed, has the veterinary surgeon nothing else to do? He has got rid of the pain which attended the ossified cartilage - the ring-bone and the anchylosis of the pastern and the coffin-joints ; shall he be satisfied with the benefit he lias obtained, great as it is? He will, or he should now try whether his former means and appliances have not more power. He will see whether, by means of his blister or his firing-iron- the effect of which humanity forbade him to put to the full test before - he cannot rouse the absorbents to increased and more efficient action, and not only arrest the progress of the bony tumour, but remove it. He will not merely suffer the usefulness of his patient to depend on the continued suspension of feeling, but he will assure it by the partial or total removal of the morbid growth.

In contraction of the foot, shall he be satisfied with removing the agony occasioned by the constant pressure of the horn on the sensitive substance interposed between it and the coffin-bone? Shall he leave future improvement to the slow process of nature, or shall he not take advantage of the insensibility which he has produced, and pare the sole thoroughly out, and rasp the quarters to the very quick, and apply the unfettered shoe? When he has produced a disposition to contraction, and some degree of it, should he not actively blister the coronets, and use all other fitting means to hasten the growth of the horn to its pristine dimensions and its origimal quality?

In navicular disease, after he has removed, by the application of neurotomy, that irritation which had so much to do with the perpetuation, if not the origin, of the complaint, should he not, with the assured hope of success, pass his seton needle through the frog, in order to get rid of every remaining lurking tendency to inflammation? The blister and the firing-irow will have as much power in abating inflammation and producing a healthy state of the foot, after that foot had been rendered insensible to pain, as it had before. We should fearlessly say that it would have much more effect, one grand source of irritation having been removed. The veterinary surgeon and the owner of the horse are becoming more and more convinced of this; and the dawuing of a better day has commenced.

The principle of neurotomy is plain and simple-it is the removal of pain. 'Taken on this ground, it is a noble operation. It is that in which every friend of humanity will rejoice. It may be abused. If no auxiliary means are adopted -if in canker or quittor, or inflammation of the laminæ, no means are used to lessen the concussion and the pressure-the destruction of the part and the utter ruin of the horse are the inevitable consequences. The primary result is the removal of pain. It is for the operator to calculate the bearing of this on the actual disease, and the future usefulness of the animal.

On the question of the reproduction of the nerves there is no doubt. A horse is lame, and he undergoes the operation of neurotomy. At the expiration of a certain time the lameness returns, and he is probally destroyed. In the majority of cases it is found that the nerres had united, or rather that a new reritable nervous substance had been interposed. The time at which this is effected 
is unknown. There have not been any definite experiments on the point.

Can the horse that has undergone the operation of neurotomy be afterwards passed as sound? Most certainly not. There is altered, impaired structure; there is impaired action; and there is the possibility of the return of lameness at some indefinite period. He has been diseased. $\mathrm{He}$ possibly is diseased now ; but the pain being removed, there are no means by which the mischief can always be indicated. Beside, by the very act of neurotomy, he is peculiarly exposed to various injuries and affections of the foot from which he would otherwise escape.

\section{INSANITY.}

There is no donbt that the animals which we have subjugated possess many of the same mental faculties as the human being-volition, memory, attachment, gratitude, resentment, fear, and hatred. Who has not witnessed the plain and manifest display of these principles and feelings in our quadruped dependants? The simple possession of these faculties implies that they may be used for purposes good or bad, and that, as in the human being, they may be deranged or destroyed by a multitude of canses which it is not necessary to particularise. In the quadruped as in the biped, the lesion or destruction of a certain part of the brain may draw after it the derangement, or dis. turbance, or perversion of a certain faculty of the mind. It is only because the mental faculties, and good as well as bad properties of the inferior beings, have been so lately observed and acknowledged, that any doubt on this point can for a moment be entertained. The disordered actions, the fury, the caprices, the vices, and more particularly the frenzy and total abandonment of reason, which are occasionally shown by the brute, are in the highest degree analogous to certain acts of insanity in man. It is merely to complete our subject that they are here introduced.

The reader is indebted to Professor Rodet, of Toulouse, for the anecdotes which follow:-A horse, seven years old, was remarkable for an habitual air of stupidity, and a peculiar wandering expression of countenance. When he saw anything that he had not been aceustomed to, or heard any sudden or unusual noise, whether it was near or at a distance, or sometimes when his corn was thrown into the manger without the precaution of speaking to him or patting him, he was frightened to an alnost incredible degree; he recoiled precipitately, every limb trembled, and he struggled violently to escape. After several useless efforts to get away, he would work himself into the highest degree of rage, so that it was dangerous to approach him. This state of excitement was followed by dreadful convulsions, which did not cease until he liad broken his halter, or otherwise detached himself from his trammels. He would then become calm, and suffer himself to be led back to his stall : nor would anything more be scen but an almost continual inquietude, and a wandering and stupid expression of countenance. He had belonged to a brutal soldier who had beaten him shamefully, and before which time he had been perfectly quiet and tractable.

A Piedmontese officer possessed a beautiful and in other respects serviceable mare, but which one peculiarity rendered exceedingly dangerousthat was a decided arersion to paper, which she recognised the moment she saw it, and even in the dark if two leaves were rubbed together. The effect produced by the sight or sound of it was so prompt and violent, that she several times unhorsed her rider. She had not the slightest fear of objects that would terrify most horses! She regarded not the music of the band, the whistling of the balls, the roaring of the cannon, the fire of the bivouacs, or the glittering of arms. The confusion and noise of an engagement made no impression upon her; the sight of no other white object affected her. No other sound was regarded; but the view or the rustling of paper roused her to madness.

A mare was perfectly manageable and betrayed no antipathy to the human being, nor to other animals, nor to horses, except they were of a light-grey colour; but the moment she saw a grey horse she rushed towards it, and attacked it with the greatest fury. It was the same at all times and everywhere. She was all that could be wished on the parade, on the route, in the ranks, in action, and in the stable; but if she once caught a glimpse of a grey or white horse, she rested not until she had thrown her rider or broken her halter; and then she rushed on her imagined foe with the greatest fury. She generally contrived to seize the animal by the head or throat, and held him so fast that she would suffocate him if he were not promptly released from her bite.

Another mare exhibited no terror except of white inanimate objects, as white mantles or coats, and particularly white plumes. She would fly from them if she could; but if she was unable to accomplish this, she would rush furiously upon them, strike at them with her fore feet, and tear them with her teeth.

These instances are selected from various others, because they approach so nearly to what would be termed insanity in the human being. It is confined to one olject-it is a species of monomania, and as decided insanity as ever the biped discovered. One of these horses, the second, was by long and kind attention divested of this insane terror, aud became perfectly quiet and useful; but the other three bid defiance to all means of cure, and to coercion among the rest. If sufficient at- 
tention were paid to the subject, many of the obstinate caprices and inexplicable aversions, which we can neither conquer nor change, would be classed under the term insanity. There cannot be a more remarkable analogy than that which sometimes exists between the insanity of man and these singularly capricious fancies in animals. The sulject is worthy of attention. Has the principle of hereditary predisposition been applied to any of these anomalies?

\section{DISEASES OF THE ETE.}

The diseases of the ere constitute a very important, but a most unsatisfactory division of our work ; for the maladies of this organ, although few in number, are frequent in their appearance: they are sadly obstinate, and often baffle all skill.

We have spoken of Fracture of the orbit, and its treatment. Occasionally a wound is inflicted by a passionate or careless servant. The eye itself is rarely injured. It is placed on a mass of fat, and it turns most readily, and the prong of the fork glances off; but the substance round the eye may be deeply wounded, and rery considerable inflammation may ensue. This should be abated by poultices, and bleeding, and physic; but no probe shonld be used nuder the foolish idea of ascertaining the depth of the wound in the lid, supposing that there should be one; for, from the constant motion of the eye, it is almost impossible to pass the probe into the original wound, and the effort to accomplish it would give a great deal of pain, and increase the inflammation.

The eyelids are sulject to occasional inflammation from blows or other injuries. Fomentation with warm water will be serviceable here.

The horse has occasionally a scaly eruption on the edges of the eyelids, attended with great itching, in the effort to allay which, by rubbing the part, the eye may be blemished. The nitrated ointment of quicksilver, mixed with an equal quantity of lard, may be slightly rubbed on the edges of the lids with considerable good effect.

The eyelids will sometimes become rdematous. Horses that are fed in low and humid pastures are sulject to this. It is also the consequence of inflammation badly treated. The eyelids are composed of a lax structure, and the tissue is somewhat deficient in vitality-hence this disposition to enfiltration. Sometimes the collection of fluid accumulates so rapidly, and so extensively, that the eyes are closed. They should be well bathed with warm water mingled with an aromatic tincture. The cellular substance of the lids will thus be disposed to contract on their contents and cause their absorption.

Old carriage horses are sulject to this œdema; and it frequently accompanies both chronic and common ophthalmia.
Weakness and dropping of the upper lid is caused by diminution or loss of power in its muscles. Dry frictions and aromatic lotions will frequently restore the tone of the parts.

The eyelids are sulject to oceasional injury from their situation and office. In small incised wounds of them great care should be taken that the divided edges uuite by the first intention. This will hasten the cure and prevent deformity. If any of the muscles are divided, it is usually the ciliary or orbicularis palpebrarum. This lesion must be healed, if possible, by the first intention, and eitber by means of adhesive plaster or the suture. The suture is probably the preferable agent.

Suppurating wounds in the eyelids may be the consequeuce of the necessary abstraction of a considerable surface of the skin in the removal of warts or tumours. The principal thing to be attended to is the frequent removal of the pus by means of tow or cottou wool. The rest may generally be left to nature.

Iuversion of the lids is of very rare occurrence in the horse.

Warts are sometimes attached to the edges of the lids, and are a source of great irritation. When rubbed they bleed; and the common opinion is true, that they are propagated by the blood. They should be taken off with a sharp pair of scissors, and their roots touched with the lunar caustic.

The membrane which cover's the haw is subject to inflammation; it is, indeed, a continuation of the conjunctiva, the inflammation of which constitutes oplithalmia. An account of this inflam. mation will be better postponed until the nature and treatment of ophthalmia comes under particulas notice.

The haw, or membrana nictitans, is subject to inflammation peculiar to itself, arising from the introduction of foreign bodies, or from blows or other accidents. The entire substance of the haw becomes inflamed: it swells and protrudes from the inner angle of the eye. The heat and redness gradually disappear; but the membrave often continues to protrude. The inflammation of this organ assumes a chronic character in a very short time, on account of the structure of the parts, which are in general little susceptible of reaction.

The ordinary causes of this disease in the horse are repeated and periodical attacks of ophthalmia, and blows on the part. Young and old horses are most subject to it.

Emollient applications, bleeding, and restricted diet, will be proper at the commencement of the disease; and, the inflammation being abated, slight astringents will be useful in preventing. the engorgement of the part. Rose-water, with subacetate of lead, will form a proper collyrium. If the protruding body does not diminish after proper means have been tried, and for a sufficient period, 
it must be removed with a curved pair of scissors. No danger will attend this operation if it is performed in time; but, if it is neglected, ulceration of the part, and the growth of fungous vegetations, will give a serious character to the affair. A second operation may also be necessary, and even a third, and fungus hrematodes will probably be established.

Ulceration and caries of the cartilage will sometimes be accompanied by ulceration of the conjunctiva. This will frequently prove a very serious affair, demandiner, at least, the removal of the haw.

The caruncula lacrymalis, or tubercle, by means of which the tears are directed into the canal through which they are to escape from the nostril, is sometimes enlarged in consequence of inflammation; and the puncta lacrymalia, or conduits into which the tears pass from the eye, are partially or completely closed. The application of warm and emollient lotions will generally remove the collected mucus or the inflammation of the parts; but if the passage of a stylet, or other more complicated means, are required, the assist. ance of a veterinary surgeon should be immediately obtained. The lacrymal sac into which the tears pass from the puncta has occasionally participated in the inflammation, and been distcnded and ruptured by the tears and mucus. This lesion is termed fistula lacrymalis. It has occasionally existed in colts, and will require immediate and peculiar treatment.

\section{COMMON INFLAMMATION OF THE EYE.}

The conjunctiva is occasionally the seat of great disease, and that which is too often destructive to the eye. Inflammation of the eye may be considered under two forms - the common and manageable, and the specific and fatal. The common inflammation is generally sudden in its attack. The lids will be found swelled, and the eyes partially closed, and some reeping. The inside of the lid will be red, some red streaks visible on the white of the eye, and the cornea slightly dim. This is occasionally connected with some degree of catarrh or cold; but it is as often unaccompanied by this, and depends on external irritation, as a blow, or the presence of a bit of hay-seed or oat-husk within the lid, and towards the outer corner where the haw cannot reach it; therefore the lids should always be carefully examined as to this possible source of the complaint. The health of the animal is generally unaffected; be feeds well, and performs his work with his usual spirit. Cooling applicatious to the eye, as Goulard's extract or tincture of opium, with mashdiet and gentle physic, will usually abate the evil; or the inflammation will subside without medical treatment.

\section{SPECIFIC OPHTHAIMUA, OR MOON-BLINDNESS.}

Should three or four days pass, and the inflammation not be abaterl, we may begin to suspect that it is the ophthalmia, especially if the eye is very impatient of light, and the cornea is considerably clouded. The aqueous humour then often loses its transparency-eren the iris changes its colour, and the pupil is exceedingly contracted. The veterinary surgeon has now an obstinate disease to combat, and one that will generally maintain its ground in spite of all his efforts. For three, or four, or five weeks, the inflammation will remain undiminished; or if it appears to yield on one day, it will return with redoubled violence on the next. At length, and often unconnected with any of the means that have been used, the eye begins to bear the light, the redness of the membrave of the lid disappears, the cornea clears up, and the only vestige of disease which remains is a slight thickening of the lids, and apparent uneasiness when exposed to a very strong light.

If the omner imagines that he has got rid of the disease, he will be sadly disappointed; for, in the course of six weeks or two months, either the same eye undergoes a second and similar attack, or the other one becomes affected. All again seems to pass over, except that the eye is not so perfectly restored, and a slight, deeply-seated cloudiness begins to appear; and after repeated attacks, and alternations of disease from eye to eye, the affair terminates in opacity of the lens or its capsule, attended with perfect blindness either of one eye or both. This affection was formerly known by the name of moon-blindness, from its periodical return, and some supposed influence of the moon. That body, however, has not, and cannot have, anything to do with it.

What is the practitioner doing all this while? $\mathrm{He}$ is an anxious and busy, but almost powerless spectator. He foments the eyes with warm water, or applies cold lotions with the extract of lead or opium, or poultices to which these drugs may be added; he bleeds-not from the temporal arters, for that does not supply the orbit of the eye-but from the angular vein at the inner corner of the eye; or he scarifies the lining of the lid, or subtracts a considerable quantity of blood from the jugular vein. The scarifying of the conjunctiva, which may be easily accomplished without a twitch, by exposing the inside of the lids, and drawing a keen lancet slightly over them, is the most effectual of all ways to abate inflammation; for we are then immediately unloading the distended ressels. $\mathrm{He}$ places his setons in the cheek, or his rowels under the jaw; and he keeps the animal low, and gives physic or fever medicine (digitalis, nitre, and emetic tartar). The disease, however, ebbs and flows, retreats and attacks, until it reaches its 
natural termination, blindness of one or both eyes.

The horse is more subject to this disease from the age of four to six years than at any other period. He has then completed his growth. He is full of blood, and liable to inflammatory complaints; and the eye is the organ attacked from a peculiar predisposition in it to inflammation, the nature or cause of which cannot al ways be explained. Every affection of the eye appearing about this age must be regarded with much suspicion.

It is a common opinion that black horses are more subject to blindness than others. There is considerable doubt about this, or rather it is probable that that colour has no influence either in producing or aggravating the disease.

As this malady so frequently destroys the sight, and there are certain periods when the inflammation has seemingly subsided, and the inexperienced person would be deceived into the belief that all danger is at an end, the eye should be most carefully observed at the time of purchase, and the examiner should be fully aware of all the minnte indications of previous or approaching disease. They are a slight thickening of the lids, or puckering towards the imner comer of the eye; a difference in the apparent size of the eyes; a cloudiness, although perhaps scarcely perceptible, of the surface of the cornea, or more deeply seated, or a hazy circle round its edge; a gloominess of eye generally, and dulness of the iris; or a minute, faint, dusky spot in the centre, with or without minute fibres or lines diverging from it.

The cause of this inflammation is nndonbtedly a strong predisposition to it in the eye of the horse, but assisted by the heated and empoisoned air of many stables. The heated air has much to do with the production of the disease; the empoisoned air a great deal more: for every one must have olserved, on entering a close stable early in the morning, strong fumes of hartshorn which were painful to his eyes and cansed the tears to How. What must be the constant action of this on the eyes of the horse? The dung of the horse, and the litter of the stables, when becoming putrid, emit fumes of rolatile alkali or hartshorn. Often, very soon after they are voided, they begin to yield an immense quantity of this pungent gas. If we are scarcely able to bear this when we stand in the stable for only a few minutes, we need not wonder at the prevalence of inflammation in the eye of the stabled horses, nor at the difficulty of abating inflammation while this organ continues to be exposed to snch painful excitement. Stables are now much better ventilated than they nsed to be, and ophthalmia is far from being so prevalent as it was fifty years ago.

The farmer may not be arrare of another cause of blindness, to which his horse is more particularly exposed, viz., confinement in a dark stable. Many stables in the country have no glazed windors, but there is a flap which is open for a few hours in the day, or while the carter is employed in the stable, and when that is shut down almost total darkuess prevails. Let our reader consider what are his sensations when he suddenly emerges from a lark room into the full glare of light. He is dazzled and bewildered, and some time passes before his vision is distinct. Let this be repeated several times daily, and what will be the consequence? The sight will be disordered, or the eye irreparably injured. Then let him think of his poor horse, who often stumbles and starts throngh no fault of his owm, although he is corrected for his blunlering, but because his eyes are necessarily weakened by these sudden transitions, and disposed to take on sudden inflammation with all its fatal results.

The propagation of various diseases, and this more than any other, from the sire to his progeny, has not been sufficiently considered by breeders. Let a stallion that is blind, or whose sight is defective, possess every other point and quality that can be wished, yet he is worse than useless, for a very considerable proportion of his offspring will most assuredly inherit weak eyes or become totally bhind. There is no fact better established than this.

Mr. Baker of Reigate puts this in a very strong point of view. He was called upon to examine a foal only a few days old, which seems to have some affection of the head, as from its birth it was totally unconscions of any olject, although it appeared to the owner to have good eyes. It ran its head against the wall and the standers by, in such a way as to convince the surgeon that it was quite blind, and on examining the pupil of each eye, he found them greatly dilated and motionless, but beyond this there was no unhealthy appearance.

He inquired about the sire, and found that his vision was very defective, and that of all the stock which he got in that part of the country, not one colt escaped the direful effects of his imperfect sight. He persuaded the owner to have the youngster destroyed, and in tracing the optic nerve in its passage from the base of the brain, he found it in a complete state of atrophy. There was scarcely any nervous substance within the tube that led from the brain to the eye.

The most frequent consequences of this disease are cloudiness in the eye, and cataract. The cloudiness is singular in its nature. It will change in twenty-four hours from the thinnest film to the thickest opacity, and, as suddenly, the eye will nearly regain its perfect transparency, but only to lose it, and as rapidly, a second time. 
The most barbarous methods have been resorted to for the purpose of removing this cloudiness. Chalk, and salt, and sugar, and even pounded glass, have been introduced into the eye mechanically to rub off the film. It was forgotten that the cloudiness was the effect of inflammation-that means so harsh and cruel were very bikely to recall that inflammation-that these rough and sharp substances must of necessity inflict excruciating pain; and that, after all, it generally was not a film on the surface of the comea, but a dimess pervading its substance, and even sinking deep within it, and therefore not capable of being removed. Where the cloudiness can be removed, it will be best effected by first abating inflammation, and then exciting the absorbents to take up the grey deposit, by washing the eye with a very weak solution of corrosive sublimate.

Opacity of the lens is another consequence of inflammation. A white speck appears on the centre of the lens, which gradually spreads over it, and completely covers it. It is generally so white and pearly as not to be mistaken -at other times it is more hazy, deceiving the inexperienced, and occasioning donbt in the mind of the professional man. We have seen many instances in which the sight has been considerably affected or almost lost, and yet the horse has been pronounced sound by very fair judges. The eye must be exposed to the light, and yet under the kind of shelter which has been already described, in order to discover the defect. The pupil of the horse is seldom black, like that of the human being, and its greyish hne conceals the recent or thin film that may be spreading over the lens.

Confirmed cataract in the eye of the horse admits of no remedy, for two obvious reasons: the retractor muscle draws the eye back so powerfully and so deeply into the socket that it would be almost impossible to perform any operation; and, could an operation be performed, and the opaque lens removed, the sight mould he so imperfect, from the rars of light not being sufficiently converged, that the horse would be worse to us than a blind one. The man who has undergone the operation of couching may put a new lens before his eye, in the form of a convex spectacle; but we cannot adapt spectacles to the eye of the horse, or fix them there.

Since the pnblication of the first edition of "The Horse," some controversy has taken place with regard to the occasional appearance and disappearance of cataract without any connexion with the cominon moon-blindness. IIr. Clay deposed in evidence, that cataracts might be formed in a fortuight or three weeks-that he had known many instances in which they had been completed in less time, and without any previous apparent disease of the eyes; and that he had detected them when the owners had not the slightest suspicion of disease in the eye.*

Mr. Cartwright adds, that he has known two similar cases. The first was of a horse that had two cataracts in each eye-two of them of the size of a large pin's head, and the other two treble that size. . There was no vestige of former inflammation; and the person who bred him said that he never had been subject to inflammation of the eye. In December 1831 , these cataracts were plain enough; but in the autumn of 1832 they had completely vanished.

In November 1832, Mr. Cartmight saw a fiveyears old mare, and detected a cataract in the riglt eye, of the size of a coriander seed. $\mathrm{H}_{\theta}$ adrised the orner to get rid of her, thinking that she would go blind; but, being a useful animal, he kept her. In August 1833, Mr. Cartwright saw her again. The cataract had disappeared, and the eyes were perfect.

That excellent veterinarian, Mr. Percivall, had a somewhat similar case. A gentleman brought a horse one morning to the hospital, in consequence of its having fallen in his way to town, and grazed his eyebrow. On examining him carefully, the cornea was partially nebulous, and a cataract was plainly visible. Neither of these defects was sufficient to attract the notice of any unprofessional observer, and both were unconnected with the slight bruise produced by the fall. The owner was told that the corneal opacity might possibly be removed; but as for the cataract, he might regard this as beyond the reach of medicine. He returned with his horse on the fifth day, saying that the physic had operated well, and that he thought the eye was as clear as ever. Mr. Percivall examined the eye, and could discover no relic either of the corneal opacity or of the cataract.

The opinion respecting cataract is therefore essentially modified. It is not necessarily the re sult of previous inflamnation, although in the great majority of cases it is so, nor does it always lead to blindness. Still it is a serious thing at all times, and, although existing in the minutest degree, it is unsoundness, and very materially lessens the value of the horse.

"Were I asked," says Mr. Percirall, "how the practitioner could best distinguish a cataract of the above description from that which is of ordinary occurrence, and known by us all to constitute the common termination of periodical ophthalmia, I should say that the unusually lucid and healthy aspect which every other part of the eye presents is our best diagnostic sign; the slightest indication, lowever, or the slightest suspicion of prior or present inflammation, being a

* Veterinarian, vol. vii. p. 41. + Veterinarian, vol. vii. p. 44. 
reason for coming to a different conclusion. As to the period of time a cataract of this species, supposing it to be membranous, would require for its formation, I should apprehend that its production might be, as its disappearance often would seem to be, the work of a very short interval. perhaps not more than five or six days." As to the cause and treatment of it, we are at present completely in the dark. If it does not soon disappear, the hydriodate of potash administered internally might offer the best prospect of success.

\section{gUtTA SERENA.}

Another species of blindness, and of which mention was made when describing the retina, is Gutta Serena, commonly called glass eye. The pupil is more than usually dilated: it is immovable, and bright, and glassy. This is palsy of the optic nerve, or its expansion, the retina; and is usually produced by determination of blood to the head. We have described it as a consequence of staggers. So much pressure has been occasioned on the base of the brain, that the nerve has been injured, and its function destrored. The treatment of Gutta Serena is quite as difficult as that of cataract. We have heard of successful cases, but we never saw one; nor shonld we be disposed to incur much expense in endeavouring to accomplish impossibilities. Reasoning from the cause of the disease, we shonld bleed and physic, and administer the strychnine in doses, commencing at half a grain, and not exceeding two grains, morning and night-rery carefully watching it. If we succeed, it must be by constitutional treatment. As to local treatment, the seat of disease is out of our reach.

\section{DISEASES OF THE EAR.}

Wounds of the ear are usually the consequence of careless or brutal treatment. The twitch may be applied to it, when absolutely necessity requires this degree of coerciou ; but troublesome nlcers and bruises have been the consequence of the abuse of this species of punishment, and more especially has the farrier done irreparable mischief when he has brutally made use of his plyers.

'These bruises or wounds will generally - fortunately for the animal, and fortunately, perhaps, for the brute that inflicted the injury-speedily heal; but occasionally sinuses and abscesses will resnlt that bid defiance to the most skilful treatment. A simple laceration of the cartilage is easily remedied. The divided edges are brought into apposition, and the head is tied up closely for a few days, and all is well; hut, occasionally, ulceration of the integument and cellular substance, and caries of the cartilage, will take place-deep simuses will be formed, and the wound will bid defiance to the most skilful treatment. The writer of this work had once a case of this kind under his care more than two months, and he was at length compelled to cut off the ear, the other ear following it, for the sake of uniformity of appearance. The lunar canstic, or the muriate of antimony, or the heated iron. mnst be early employed, or the labour of the practitioner will be vain.

It has been the misfortune of the same person to witness two cases in which the auditory passage was closed and the faculty of hearing destroyed, by blows on the ear violently inflicted. No punishment can be two severe for these brutes in human shape. Whenever there is considerable swelling about the root of the ear, and the fluctuation of a fluid within can be detected, it should be immediately opened with a lancet, and the purulent fluid liberated.

The abscess nsually begins to form about the middle of the conch, or rather nearer the base than the point. The incision should be of considerable length, or the opening will close again in four-and-twenty hours. The purulent matter having been evacnated, the incision shonld not be permitted to close until the parietes of the nlcer have adhered to each other, and the abscess is obliterated.

The size and the carrying of the ear do not always please. The ears may be larger and more dependent than fashion requircs them to be, and this is remedied by paring or clipping them to the requisite size. On either side of the projection of the occipital bone, and in a straight line forward and backward, a fold of the skin is pinched up and cut away. The divided edges on either side are then brought together, and confined by two or three stitches-they presently unite, and, the owner has a better-looking horse, and soon forgets or cares not abont the punishment which he has inflicted on him.

The ears of other horses may be supposed to be too close to each other. This fanlt is corrected by another piece of cruelty. Similar slips of skin are cut away on the outside of the base of the ear, and in the same direction. The edges of the wound are then brought together, confined by sutures, and the ears are drawn further apart from each other, and have different directions given to them. A very slight examination of either of the horses will readily detect the imposition.

DEATNESS.

of the occasional existence of this in the horse, there is no donbt. The beautiful play of the ears has ceased, and the horse hears not the voice of his master, or the sound of the whip. Much of the apparent stupidity of a few horses is attributable to their imperfect hearing. It occa- 
sionally appears to follow the decline of various diseases, and especially of those that affect the head and the respiratory passages. It has been the consequence of brutal treatment closing the conduit of the ear, or rupturing the tympannm; and it is certainly, as in other domesticated animals, the accompauiment of old age.
In the present state of veterinary knowledge it is an incurable complaint ; the only thing that can be done is not to punish the poor slave for his apparent stupidity, produced perhaps by overexertion in our service, or, at least, the natural attendant of the close of a life devoted to us.

\section{CHAPTER VIII.}

THE ANATONY AND DISEASES OF THE NOSE AND MOUTH.

WE now proceed to a description of the face, or lower part of the head of the horse. The nasal bones, or bones of the nose $(j j$, p. 265 , and $a$, p. 266), are connected with the frontal bones above, and with the lacrymal, $i$, and the bones of the upper jaw, $l l$, on either side. They are united together by a plain suture, which is a continuation of the frontal, and they terminate in a point at the nostril $(p, \mathrm{p} .265)$. They are rounded and arched above, because they are exposed to occasional violence and injury, which the arch-form will enable them best to resist; and, at the base of the arch, where the main strength should be, they are overlapped by the upper jawbone, as the temporal bone overlaps the base of the parietal. These bones form a principal part of the face; and the length, or shortness, and the character of the face, depend upon them. Sometimes there is an appearance of two little arches, with a depression between them along the sutures. This is often found in the blood-horse, with bis comparatively broad head and face. The single elevated arch is found in the long and narrow face of the heary draught-horse.

The nasal bones pursue their course down the face, in some horses in a straight line; in others, there is a slight prominence towards the upper part; while, in a considerable number, a depression is oliserved a little lower down. Some persons have imagined that this deviation in the line of the face affords an indication of the teuper of the animal, and there may be a little truth in this. The horse with a straight profile may be good or bad tempered, but not often either to any great excess. 'The one with the prominent Roman nose will generally be an easy, good-tempered kind of beast, hardy, ready enough to feed, not always, perhaps, so ready to work, but may be made to do his duty without any cruel urging, and having no extraordinary pretension to speed or blood. On the other hand, a depression across the centre of the nose geverally indicates some breeding, especially if the head is small, but occasionally accompamied by a vicious, uncontrollable disposition.
There is another way, however, in which the nasal bones do more certainly indicate the breed, viz. by their comparative length or shortness. There is no surer criterion of a well-bred horse than a broad angular forehead, prominent features, and a short face; nor of a horse with little breeding than a narrow forehead, small features, and lengthened nose. The comparative development of the head and face indicates, with little error, the preponderance of the animal or intellectual principle.

Fracture of the nasal bones of the horse will sometimes occur from falling, or a kick from the companion, or the brutality of the attendant. It is generally followed by laceration of the lining nembrane of the nostrils, and by hæmorrhage. The hæmorrhage may usually be arrested by the application of cold water externally. In spontaneous hæmorrhage this does not often succeed until a considerable quantity of blood is lost.

In cases of fracture of the nasal bones, the assistance of a veterinary surgeon is indispensable. He alone knows the precise anatomy of the parts, and will have recourse to the elevator or the trephine, as circumstances may require.

The owner must not be too sanguine with regard to cases of this kind; for ozena-ulceration attended by a peculiar and almost insufferable stench-is too often the consequence, or foundation may be laid for the appearance of glanders.

Spontaneous bleeding from the nose must be carefully attended to. It may proceed from overfulness of the capillaries of the membrane of the nose, or determination of blood to the head, or general plethora of the system. Those that are overfed and overfat are most liable to it, as troophorses, brewers' horses, and horses kept for pleasure. It is not common in young horses, or in such as are out of condition, or worked hardly. It is always desirable to know whence the bleeding proceeds; if from the nostril alone, it will usually be confined to one side; if from the lungs, the discharge is from both nostrils, and generally 
mingled with mucus or spume; there is also a quickened respiration, and more or less cough.

If it is apparently connected with some slight cause, a dose of physic and quietness for a day or two will be sufficient; and, if necessary, a slight solution of alum may be injected up the nostril. If the bleeding is apparently from the lungs, a more serious evacuation will be required.

These bones form the roof of an important cavity (see $a, \mathrm{p} .266$ ). The sides are constituted above by the nasal bones, and, lower down, by the upper jawbones (superior maxillaries), while plates from these latter bones project and compose the palate, which is both the floor of the nose and the roof of the mouth ( $t$, p. 266). Above (near fig. 8), not visible in our cut, is a bone called the palatine, although it contributes very little to the formation of the palate. It is the termination of the palate, or the border of the opening where the cavities of the mouth and nose meet (fig. 8). The frontal sinuses, $b$, and large vacuities in the npper jawbone, and in the æethmoid, $l$, and sphenoid bones, $k$, communicate with and enlarge the cavity of the nose.

This cavity is divided into two parts by a cartilage called the septum (see $a$, p. 266). It is of

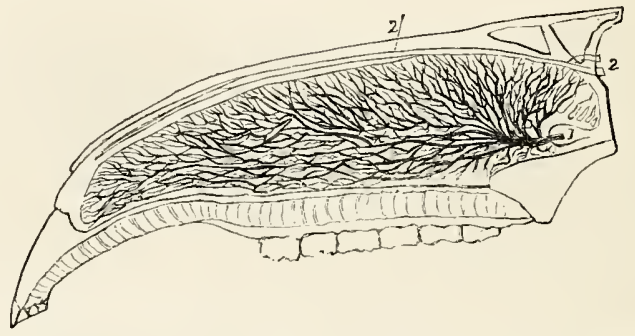

considerable thickness and strength, and divides the eavity of the nose into two equal parts. It is placed in the centre for the purpose of strength, and it is formed of cartilage in order that, by its gradually yielding resistance, it may neutralise almost any force that may be applied to it.

When we open the nostril we see the membrane by which the cartilage, and the whole of the cavity of the nose, is lined, and by the colour of which, much more than by that of the lining of the eyelids, we judge of the degree of fever, and particularly of inflammation of the lungs, or any of the air-passages. The above cut shows the ramifications of the blood-vessels, both arterial and venous, on the membrane of the nose. It beautifully accounts for the accurate convexion which we trace between the colour of the nasal membrane and various diseases or states of the circulation. By the sore places or ulcerations discovered on this membrane we likewise determine respecting the existence of glanders; and the interposition of the septum is a wise and benevoleut provision to hinder the spread of the mischief by cutting off all communication with the neighbouring parts, and also to preserve one nostril pervious when the other is diseased or obstructed. The nasal cavity is, on either side, occupied by two bones, which, from their being rolled up somewhat in the form of a turban, are called the turbinated, or turban-shaped bones, ss, p. 266 ; part of the cartilage is cut away in our cut in order to display them. They are as thin as gauze, and perforated, like gauze, with a thousand holes. Between them are left sufficient passages for the air.

If they were unrolled they would present a very considerable surface; and on every part of them is spread the substance or pulp of the olfactory, or first pair of nerves. These bones, lined with delicate membranes, and covered by the olfactory nerves, are the seat of smell; and they are thus expanded because the sense of smell in the horse must, to a very considerable degree, supply the place of the sense of touch and the lessons of experience in the human being. By this alone he is enabled to select, amongst the nutritive and poisonous herbage of the meadow, that which would support and not destroy him. The troops of wild horses are said to smell the approach of an enemy at a very considerable distance. In his domestic state the horse does not examine the different food which is placed before him with his eye, but with his nose; and if the smell displeases him, no coaxing will induce him to eat. He examines a stranger by the smell, and, by very intelligible signs, expresses the opinion which he forms of him by this inquisition. The horse will evidently recognise his favourite groom when he has nothing else to indicate his approach but the seuse of smell. These cavities are like wise organs of voice. The 
sound reverberates through them, and increases in louduess, as throngh the windings of a French horn.

The extension of the nostril at the lower part of these cavities is an important part of the face, and intimately commected with breeding, courage, and speed. The horse can breathe only through the nose. All the air which goes to and returns from the lungs must pass through the nostrils. In the common act of breathing these are sufficiently large; but when the animal is put on his speed, and the respiration is quickened, these passages must dilate, or he will be much distressed. The expanded nostril is a striking feature in the blood-horse, especially when he has been excited and not overblomn. The sporting man will not forget the sudden effect which is given to the countenance of the hunter, when his ears become ereet and his nostrils dilate as he first listens to the cry of the hounds, and snorts and scents them afar off. The painful and spasmed stretching of this part, in the poor over-driven post-horse, will show how necessary it is that the passage to the lungs should be free and open. The nostrils should not only be large, but the membranous substance which covers the entrance into the nose should be thin and elastic, that it may more readily yield when the necessity of the animal requires a greater supply of air, and afterwards return to its natural dimeusions. Therefore, nature, which arlapts the animal to his situation and use, has given to the cart-horse, that is seldom blown, a confined nostril, and surrounded by much cellular substance, and a thick skin; and to the horse of more breeding, whose use consists in his speed and his continuance, a wider nostril and one much more flexible.

The inhabitants of some comtries were accustomed to slit the nostrils of their horses, that they might be less distressed in the severe and longcontinued exertion of their speed. The lcelanders do so to the present day. There is no necessity for this; for nature has made ample provision for all the ordinary and even extraordinary exertion we can require from the horse.

Some very powerful muscles proceed from different parts of the face to the neighbourhood of the nostrils, in order to draw them back and dilate them. Four of these are given in this cut, which is introduced to complete our present subject, and which will be often referred to in the course of our work; $l, m, o$, and $p$, are muscles employed for this purpose.

\section{THE MUSCLES, NERTES, AND BLOOD-VESSELS OF THB GEAD AND UPPER gABT OF THE NECK.}

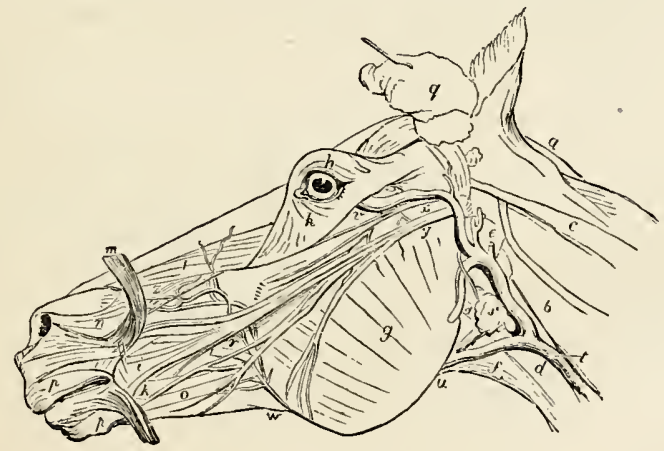

a The npper part of the liument of the neck.

b. The levator humeri (elevator of the shmalder), arising from the tubercle of the occiput, the mastoid (nipple-shaped) process of the temporal bone, and the transverse processes (cross pro'ections) of the four first hones of the neck, and the ligament of the neck, and going to the muscles of the shoulders, and the upper bone of the arm: to draw forward the shoulder and arm; or turn the bead and ueck; and, when the two levators act, to depress the head.

c The tendon common to the complexus major (larger complicated) and splenius (spliot-like):- to the mastoid process of the temporal bone; to hold up the head; or, the museles on one side alone acting, to turn it.

d The sterno maxillaris (belonging to the breast-bone) and upper POL. I. jaw, from the cartilage in front of the chest to the angle of the lower jaw; to bend the head; or, if one only acts, 10 bend it on one side.

$e$ The stylo-maxillaris, from the styloid (pencil-shaped), or coracoid (besk-shaped) process of the occiput, to the angle of the jaw : to poll the jaw backw ard and open it.

$f$ The subscapulo hyoideus, from onder the shoulder-blade, to the body of the os hyoides (the boue at the root of the tongue formed like a Greek $u, v)$ : to draw back that bone.

$g$ The masseter (chewing); a most powerful muscle, constitutiog the cheek of the horse:- from the upper jaw-bone juto the the rough surface round the angle of the lower: in coujunction with the temporal muscle to close the mouth and chewthe food. 
$h$ The orbiculeris (circular) surrounding the eye and closing the lids.

$i$ The zygomaticus, from the zygomatic arch and masseter to the corner of the mouth, to draw back the angle of the nouth.

7. The buccinator (trumpeter), from the inside of the mouth and cheelis, to the angle of the mouth, to draw it back.

$l$ The nosalis lubii superioris (belonging to the nose and upper lip), from a depression at the junction of the superior maxillary aud malar bones, to the angle of the nostril:- to raise the lip, and dilate the nostrils.

$m$ Dilator noris lateralis (side dilator of the nostril), reversed to show the vessels and nerves which it covers, going from the covering of the nasal and frontal bones, to the angle of the month, and side of the nostril :- to retract the npper lip and dilate the nostrils.

$n$ Dilator magnus (great dilator), assisting in the same office.

- Depresser labii inferioris (puller down of the under lip), to the sides of the under lip: to pull it down.

$p$ Orbicularis oris (circular muscle of the month), surrouading the mouth: to cluse the lips, and dilate the nostrils.

$q$ The upper portion of the parotid gland (gland near the ear) reversed, to show the blood-vessels and nurves beceath it.

$r$ The parotid duct piercing the chcek, to discharge the saliva into the mouth.

$s$ The maxillary gland (gland of the Jower jaw) with its duct.

t The jugular (oeck) vein, after the two lranches bave united.

$u$ At this letter, the submaxillary artery, a branch of the jugular, and the parotid dact, pass under and within the angle of the lower jaw; they come out again at $w$, and climb np the cheek to be distributed over the face.

$v$ The vein and artery, passing under the zygomatic arch.

$x$ A branch of the fiftl pair, the sensitive nerve of the face, emerging from nuder the parotid gland.

$y$ The main branch of the portio dura (hard portion) of the seveuth pair, the motor (moving) nerve of the face coming out from bcneath the parotid gland, to spread over the face.

\& Braaches of both nerves, with small blood-vessels.

There are also four distinct cartilages attached to the nostrils, which, by their elasticity, bring back the nostrils to their former dimensions, as soon as the muscles cease to act. The bones of the nose ( $a a, \mathrm{p} .265$, and $p, 266$ ) are also sharpened off to a point, to give wider range for the action of the muscles; while the cartilages are so contrived, as not ouly to discharge the office we have mentioned, but to protect this projection of bone from injury.

There are two circumstances, which, more than any others, will enable the veterinary surgeon, and the owner of a horse, accurately to judge of the character aud degree of many diseases, and to which very few persons pay sufficient attention; these are the pulse, of which we shall presently speak, and the colour of the membrane of the nose. It is the custom of most veterinary surgeons and horsemen to lift the upper eyelid, and to form their opinion by the colour which its lining presents. If it is very red, there is considerable fever; - if it is of a pale pinkish hue, there is little danger. The nose, however, is more easily got at; - the surface presented to the view is more extensive; its sympathy with almost all the important organs is greater; - and the changes produced by disease are more striking and more conclusive. Let the reader first make himself wcll acquainted with the uniform pale pink appearance of that portion of the membrane which covers the lower part of the cartilaginous partition between the nostrils, when the horse is in health and quiet; then the increased blush of red, betokening some excitement of the system-the streaked appearance of inflammation commenced, and threatening to increase-the intense florid red, of acute inflammation-the pale ground with patches of vivid red, showing the half-subdued, Jut still existing fever-the uniform colour, although somewhat redder than natural, predicting a return to healthy circulation-the paleness approaching to white, marking the stage of debility, and sometimes intermingled with radiations of crimson, inducing the suspicion of lurking mischief; and the dark livid colour of approaching stagnation of the vital current. These, with all their shades of difference, will be guides to his opinion and treatment, which every one, who has studicd them, will highly appreciate.

\section{NASAL POLYPUS.}

By a polypus is meant an excrescence or tumour, varying in size, structure, and consistence, and attached by a pedicle to a mucous surface. The true polypus is attached to mucous membranes, and is usually found in the nostrils, the pharynx, the uterus, or the vagina. Tumours have been seen hanging loose in the veins and ventricles of the heart; and in the larger bloodvessels there have been accumulations of the fibrine of the blood, with peduncular attachments.

The nasal polypus usually adheres to some portion of the superior turbinated bone, or it has come from some of the sinuses connected with that carity. It escaped, while small, through the valvular opening under the superior turbinated bone into the cavity of the nose, and there attained its full growth.

No better account, horrever, can be given of the cause of their appearance than that of tumours in other parts of the body. They evidently have a constitutional origin: they are frequently hereditary, and the animal in which they have once appeared is subject to a return of them.

By some neans, probably the increasing weight of the tumour, and being in a dependent situation, the polypus is gradually detached from its base, and forces with it the soft and easily distensible membrane of the nose. As it continues to descend, this portion of membrane is farther elongated, and forms the pedicle or root of the tumour; -if that may be termed a root which is a mere duplicate of its investing membrane.

The polypus, when it hangs free in the nasal cavity, is usually of a pyriform or pear-like shape ; and it varies in weight, from a few drachms to three or four pounds.

How is the surgeon to proceed? Can he lay hold of the polypus by the finger, or the forceps, 
or (for these tumours do not possess much seusibility) the tenaculum? To ascertain this, he will cast the horse, and fix the head in a position to take the greatest advantage of the light. If he cannot fairly get at the tumour by any of these means, he will let it alone. It will continue to grow-the membrane constituting the pedicle will be lengthened-and the polypus will at length descend, and be easily got at. Time and patience will effect wonders in this and many similar cases.

Supposing it to liave grown, and the surgeon is endeavouring to extract it, he must not use any great force. It must not be torn out by the root. The tumour must be gently brought down, and a ligature passed round the pedicle, as high up as it can conveniently be placed. If the polypus can then be returued to the nose, the animal will suffer very little inconvenience; and in a few days it will slough off, and the pedicle will contract, and gradually disappear.

If the polypus is so large that it cannot be well returued after it has been brought down, we must, notwithstanding, use the ligature, passing it round the pedicle sufficiently tightly to cut off the supply of blood to the tumour. We may then immediately excise it. Except the pedicle is exceedingly thick, thrre will be little or no hæmorrhage. Should some bleeding occur, it will probably soon stop, or may be stopped by the cautery, which should however be avoided if possible, for our object is to produce as little irritation as may be in the membrane, and the actual cautery will be applied with considerable difficulty in the carity of the nose.

Iu very bad cases, when the tumour cannot be drawn out of the nose, it may be necessary to slit up the ala or side of the nostril. It will be better, however, not to cut through the false nostril, for that consists of a duplicature of such thin integument, that the stitches can bardly be retained in it, when the horse will be continually snorting at the least inconvenience. It will also be difficult to bring the edges of this thin membrane accurately together again, or, if this be effected, there is scarcely life enough in it for the parts readily to unite. The false nostril should be avoided, and the incision made along the lateral edge of the nasal bone, beginning at its apex or point. The flap will then conveniently turn down, so as to expose the cavity beneath; and there will be sufficieut muscular substance to secure an almost certain union by the first intention. The nostril being opened, the pedicle will probably be displayed, and a ligature may be passed round it, as already recommended; or if it is not actually in sight, it may probably gradually be brought within reach.

NASAL GLEET, OR DISCHARGE FROM THE NOSE.

There is a constant secretion of fluid to lubri- cate and moisten the membrane that lines the cavity of the nose, and which, under catarrh or cold, is increased in quantity, and altered in appearance and consistence. This will properly belong to the account of catarrh or cold; but that which is immediately under consideration is a con. tinued and oftentimes profuse discharge of thickened mucus, when every symptom of catarrh and fever has passed away. If the horse is at grass, the discharge is almost as green as the food on which he lives;-or if he is stabled, it is white, or straw-coloured, or brown, or even bloody, and sometimes purulent. It is either constantly running, or snorted out in masses many times a day; teasing the horse, and becoming a perfect nuisance in the stable, and to the rider. This has been known to continue several months, and eventually to destroy the horse.

If the discharge is not offensive to the smell, nor mixed with purulent matter, it is probably merely an increased and somewhat vitiated secretion from the cavities of the nose; and, all fever having disappeared, will frequently yield to small doses of blue vitriol, given twice in the day. If fever or cough remains, the cough medicine that will hereafter be described must be combined with the tonic. If the discharge is mingled with pus, and very offensive, the vegetable tonies, gentian and ginger, may be added to the copper; but there is now reason to apprehend that the discharge will not be controlled, and will terminate in glauders. Turning into a salt marsh will occasionally effect a cure, when both the mineral and the vegetable touics have failed.

\section{OZENA.}

Ozena is ulceration of the membrane of the nose not always or often visible, but recoguised by the discharge of muco-purulent matter, and the peculiar foetor from which the disease derives its name. It resembles glanders in being confined in most instances to one nostril, and the submaxillary gland on the same side being enlarged; but differs from it, in the gland not being adherent, and the discliarge, from its earliest stage, being purulent and stinking.

There is sometimes a foetid discharge from the nostril in consequence of inflammation of the lungs, or produced by some of the sequelæ of pneumonia; distinguished, however, from ozena by its usually flowing irregularly, being coughed up in great quantities, more decidedly purulent, and the gland or glands seldom affected. The discharge from ozena is constant, muco-purulent, and attended by enlargement of the glands. It is of immense consequence that we should be enabled to distinguish the one from the other; for while ozena may, sometimes at least, be manageable, the other is too frequently the precursor of death. 
The cause of ozena cannot always be discoverel. Chronic inflammation of the membrane may assume another and malignant character. In severe catarrh the membrane may become abraded, and the abrasions may degenerate into foul and fortid ulcers. It is not an unfrequent consequence of epidemic catarrh. It has been produced by caustic applications to the lining membrane of the nose. It has followed hæmorrhage, spontaneous, or the consequence of injury.

In some cases, and those as obstinate as any, it cannot perhaps be traced to any probable cause, and the bealth of the animal has not appeared to be in the slightest degree affected.

The membrane of the nose is highly sensitive and irritable, and an ulcer, in whatever way formed on it, does not readily heal. It often runs on to gangrene and destroys not only the membrane but the bone bezenth and even the cartilaginous septum. This is rarely the case in glanders; and the ravages of the chancrous ulcers are usually confined to the membrane. The ulceration proceeds to a certain point-its progress is then arrested, usually by nature alone-the discharge gradually lessens-it loses its offensive character, and at leng $b$ ceases.

Local applications are seldom available in the treatment of this disease; for we know not the situation of the ulcer, and if we did, we probably could not get at it. Some have recommended setons. Where are they to be applied? If the seat of ulceration is unknown, the seton may only give useless pain. Several post-montem examinations have shown that the frontal sinuses are a frequent seat of the disease. Yct what injection could we nse? An emollient one would be thrown away. A stimulating injection might convert ozena into glanders. Other examinations have shown that the superior portion of the central meatus was diseased. What instrument can be contrived to reach that? Internal medicines are almost thrown away in this complaint: yet something, perhaps, may be done under the form of a local application. The discarded nose-bag (undervalued at least ly too many practitioners) will afford the means of employing an emollient fomentation. The steam from a bran-mash, scalding hot, will probably reach every part of the nasal cavity, and so afford some chance of being beneficially applied to the ulcer. It will, at least, thoroughly cleanse the part. By means of the nose-lag and the warm mash the chloride of lime may be introduced into the cavity, not only combining with the extricated gases, and removing the foetor, but arresting the tendency to decomposition.

Then there is a digestive-a gentle stimulus to abraded and ulcerated surfaces, rousing them to healthy action, and without too much irritating them-turpentine. This may be applied in the form of vapour, and in the best of all ways, by using the fresh jellow deal shavings instead of bran. This digestive may be brought into contact with every part of the Sehneiderian membrane, and has been servicenble.

There is another resource, and one that bids fairer to be successful than any other with which we are acquainted-the spring grass. It is the finest alterative, depurative, and restorative in our whole materia medica; and if it is accessible in the form of a salt marsh, there is no better chance of doing good.

\section{GLANDERS.}

The most formidable of all the diseases to which the horse is sulject is Glanders. It has been recognised from the time of Hippocrates of Cos; and few modern veterinary writers have given a more accurate or complete account of its symptoms than is to be found in the works of the father of medicine. Three-and-twenty huudred years bave rolled on since then, and veterinary practitioners are not yet agreed as to the tissue primarily affected, nor the actual nature of the disease: we only know that it is at the present day, what it was then, a loathsome and an incurable malady.

We shall therefore, in treating of this disease, pursue our course slowly and cautiously.

The earliest symptom of glanders is an increased discharge from the nostril, small in quantity, constantly flowing, of an aqueous character and a little mucus mingling with it.

Connected with this is an error too general, and highly mischievous with regard to the character of this discharge in the earliest stage of the disease, when, if ever, a cure might be effected, and when, too, the mischief from contagion is most frequently produced. The discharge of glanders is not sticky when it may be first recognised. It is an aqueous or mucous, but small and constant discharge, and is thus distinguished from eatarrh, or nasal gleet, or any other defluxion from the nostril. It should be impressed on the mind of every horseman that this small and constant defluxion, overlooked by the groom and by the owner, and too often by the veterinary surgeon, is a most suspicious circumstance.

Mr. James Turner deserves much credit for having first or chiefly directed the attention of horsemen to this important but disregarded symptom. If a horse is in the highest condition, yet has this small aqueous constant discharge, and especially from one nostril, no time should be lost in separating him from his companions. No harm will he done by this, although the defluxion should not ultimately betray lurking mischief of a worse character.

Mr. Turner relates a case very much in point 
A furmer asked his opinion respecting a mare in excellent condition, with a sleek coat, and in full work. He had had her seven or eight months, and during the whole of that time there had been a lischarge from the right nostril, but in so slight a degree as scarcely to be deemed worthy of notice. He now wanted to sell her, but, like an honest man, he wished to know whether he might warrant her. Mr. Tumer very properly gave it as his opinion, that the discharge having existed for so long a time, he wonld not be justified in sending her into the market. A farrier, however, whose ideas of glanders had always been connected with a sticky discharge and an adherent gland, bought her, and led her away.

Three months passed on, when Mr. Tnrner, examining the post-horses of a neighbouring imn, discovered that two of them were glandered, and two more farcied, while, standing next to the first that was attacked, and his partner in work, was his old acquaintance the farmer's mare, with the same discharge from her nostril, and who had, beyond question, been the canse of all the mischief.

The peculiar viscidity and gluiness which is generally supposed to distinguish the discharge of glanders from all other mucous and prevalent secretions belongs to the second stage of the disease, and, for many months before this, glanders may have existed in an insidious and highly contagious form. It must be acknowledged, however, that, in the majority of cases, some degree of stickiness does characterise the discharge of glanders from a very early period.

It is a singular circnmstance, for which no satisfactory account has yet been given, that when one nostril alone is attacked, it is, in a great majority of cases, the near, or left. M. Dupuy, the director of the veterinary school at Toulouse, gives a very singular account of this. He says that, out of eighty cases of glanders that came under his notice, only one was affected in the right nostril. The difference in the affected nostril does not exist to so great an extent in Great Britain ; but, in two horses out of three, or three out of four, the discharge is from the left nostril alone. We might account for the left leg failing oftener than the right, for we mount and dismount on the left side; the horse generally leads with it, and there is more wear and tear of that limb: but we cannot satisfactorily account for this usual affection of the left nostril. It is true that the reins are beld in the left hand, and there may be a little more bearing and pressure on the left side of the mouth; but this applies only to saddle-horses, and even with them does not sufficiently explain the result.

This discharge, in cases of infection, may continue, and in so slight a degree as to be scarcely per. ceptible, for many nionths, or even two or three years, unattended by any other disease, even ulceration of the nostril, and yet the horse being decidedly glandered from the beginning, and capable of propagating the malady. In process of time, however, pus mingles with the discharge, and then another and a characteristic symptom appears. Some of this is absorbed, and the neighbouring glands become affected. If there is discharge from both nostrils, the glands within the under jaw will be on both sides enlarged. If the discharge is from one nostril only, the swelled gland will be found on that side alone. Glanders, however, will frequently exist at an early stage withont these swelled glands, and some other diseases, as catarrh, will produce them. Then we must look out for some peculiarity about these glands, and we shall readily fincl it. The swelling may be at first somewhat large and diffused, but the surrounding enlargement soon goes off, and one or two small distinct glands remain; and they are not in the centre of the climuel, but adhere closely to the jaw on the affected side.

The membrane of the nose should now be examined, and will materially guide our opinion. It will either be of a dark purplish hue, or almost of a leaden colour, or of any shade between the two; or if there is some of the redness of inflimmation, it will have a purple tinge: but there will never be the faint pink blush of health, or the intense and vivid red of usual inflammation. Spots of ulceration will probably appear on the membrane covering the cartilage of the nose-not mere sore places, or streaks of abrasion, and quite superficial, but small ulcers, nsually approaching to a circular form, deep, and with the edges abrupt and prominent. When these appearances are observed, there can be no donbt about the matter. Care should be taken, however, to ascertain that these ulcers do actually exist, for spots of mucus adhering to the membrane have been more than once taken for them. The finger should, if possible, be passed over the supposed ulcer, in order to determine whether it can be wiped awar; and it should be recollected, as was hinted when describing the duct that conveys the tears to the nose, that the orifice of that duct, just within the nostril, and on the inner side of it, has been mistaken for a chancrous ulcer. This orifice is on the continuation of the common skin of the muzzle which runs a little way ap the nostril, while the ulcer of glanders is on the jroper membrane of the nose above. The line of separation between the two is evident on the slightest inspection.

When ulcers begin to appear on the membrane of the nose, the constitution of the horse is soon evidently affected. The patient loses flesh-bis belly is tucked up-his coat unthrifty, and readily coming off - the appetite is impaired - the strength fails-cough, more or less urgent, may be heardthe discharge from the nose will increase in quantity; it will be discoloured, bloody, offensive to the 
smell-the ulcers in the nose will become larger and more numerous, and the air-passages being obstructed, a grating, choking noise will be heard at every act of breathing. There is now a peculiar tenderness about the forehead. The membrane lining the frontal sinuses is inflamed and ulcerated, and the integument of the forehead becomes thickened and somewhat swelled. Farcy is now superadded to glanders, or glanders has degenerated into farcy, and more of the absorbents are involved.

At or before this time little tumours appear about the muscles, and face, and neck, following the course of the veins and the absorbents, for they run side by side; and these the tumours soon ulcerate. Tumours or buds, still pursuing the path of the absorbents, soon appear on the inside of the thighs. They are connected together by a corded substance. This is the inflamed and enlarged lymphatic; and ulceration quickly follows the appearance of these buds. The deeper-seated absorbents are next affected; and one or both of the hind-legs swell to a great size, and become stiff, and hot, and tender. The loss of flesh and strength is more marked every day. The membrane of the nose becomes of a dirty livid colour. The membrane of the mouth is strangely pallid. The eye is infiltrated with a yellow fluid; and the discharge from the nose becomes more profuse, and insufferably offensive. The animal presents one mass of putrefaction, and at last dies exhausted.

The enlargement of the submaxillary glands, as connected with this disease, may, perhaps, require a little farther consideration. A portion of the fluid secreted by the membrane of the nose, and altered in character by the peculiar inflammation there existing, is absorbed; and, as it is conveyed along the lymphatics, in order to arrive at the place of its destination, it inflames them, and causes them to enlarge and suppurate. There is, however, a peculiarity accompanying the inflammation which they take from the absorption of the virus of glanders. They are rarely large, except at first, or hot, or tender; but they are characterised by a singular hardness, a proximity to the jaw-bone, and, frequently, actual adhesion to it. The adhesion is produced by the inflammatory action going forward in the gland, and the effusion of coagulable lymph. This hardness and adhesion accompanying discharge from the nostril, and being on the same side with the nostril whence the discharge proceeds, afford proof not to be controverted that the horse is glandered. Notwithstanding this, however, there are cases in which the glands are neither adherent nor much enlarged, and yet there is constant discharge from one or both nostrils. The veterinary surgeon would have little hesitation in pronouncing them to be cases of glanders. He will trust to the adhesior of the gland, but he will not be misled by its looseness, nor even by its absence altogether.

Glanders have often been confounded with strangles, and by those who ought to have known better. Strangles are peculiar to young horses. The early stage resembles common cold, with some degree of fever and sore throat-generally with distressing cough, or at least frequent wheezing; and when the enlargement appears beneath the jaw, it is not a single small gland, but a swelling of the whole of the substance between the jars, growing harder towards the centre, and, after a while, appearing to contain a fluid, and breaking. In strangles, the membrane of the nose will be intensely red, and the discharge from the nose profuse and purulent, or mixed with matter almost from the first. When the tumour has burst, the fever will abate, and the horse will speedily get well.

Should the discharge from the nose continue, as it sometimes does, for a considerable time after the horse has recovered from strangles, there is no cause for fear. Simple strangles need never degenerate into glanders. Good keep, and small doses of tonic medicine, will gradually perfect the cure.

Glanders have been confounded with catarrh or cold; but the distinction between them is plain enough. Fever, and loss of appetite and sore throat, accompany cold-the quidding of the food and gulping of the water are sufficient indications of the latter of these ; the discharge from the nose is profuse, and perhaps purulent; the glands under the jaw, if swelled, are moveable, there is a thickening around them, and they are tender and hot. With proper treatment the fever abates; the congh disappears; the swellings under the throat subside; and the discharge from the nose gradually ceases, or, if it remains, it is usually very different from that which characterizes glanders. In glanders, there is seldom cough of any consequence, and generally no cough at all.

A running from the nose, small in quantity, and, from the smallness of its quantity, drying about the edges of the nostril, and presenting some appearance of stickiness, will, in a few cases, remain after severe catarrh, and especially after the influenza of spring: and these have gradually assumed the character of glanders, and more particnlarly when they have been acccmpanied by enlarged glands and ulceration in the nose. Here the aid of a judicious veterinary surgeon is indispensable; and he will sometimes experience considerable difficulty in deciding the case. One circumstance will principally guide him. No disease will run on to glanders which has not, to a considerable and palpable degree, impaired and broken down the constitution; and every disease that does this will run on to glanders. He will look then to the 
general state and condition of the horse, as well as to the situation of the glands, the nature of the discharge, and the cliaracter of the ulceration.

If, after all, he is in doubt, an experiment may be resorted to, which wears indeed the appearance of cruelty, and which only the safety of a valualle animal, or of a whole team, can justify. $\mathrm{He}$ will inoculate an ass, or a horse already condemned to the hounds, with the matter discharged from the nose. If the horse is glandered, the symptoms of glanders or farcy will appear in the inoculated animal in the course of a few days.

The post-mortem examination of the horse will remove every doubt as to the character of the disease. The nostril is generally more or less blanched, with spots or lines of inflammation of considerable intensity. Ulceration is almost invariably found, and of a chancrous character, on the septum, and also on the æthmoid and turbinated bones. The ulcers evidently follow the course of the absorbents, sometimes almost confined to the track of the main vessel, or, if scattered over the membrane generally, thickest over the path of the lymphatic. The æthmoid and turbinated bones are often filled with pus, and sometimes eaten through and carious; but, in the majority of cases, the ulceration is confined to the external membrane, although there may be pus within. In aggravated cases the disease extends through all the cells of the face and head.

The path of the disease down the larynx and windpipe is easily traced, and the ulcers follow one line-that of the absorbents. In aggravated cases, this can generally be traced on to the lungs. It produces inflammation in these organs, characterised in some cases by congestion; but in other cases, the congestion having gone on to hepatisation, in which the cellular texture of the lungs is obliterated. Most frequently, when the lungs are affected at all, tubercles are found-miliary tubercles-minute granulated spots on the surface, or in the substance of the lungs, and not accompanied by much inflammation. In a few cases there are larger tubercles, which soften and burst, and terminate in cavities of varying size.

In some cases, and showing that glanders is not essentially or necessarily a disease of the lungs, there is no morbid affection whateverin those organs.

The history thus given of the symptoms of glanders will clearly point ont its nature. It is an affection of the membrane of the nose. Some say, and at their head is Professor Dupuy, that it is the production of tubercles, or minute tumours in the upper cells of the nose, which may long exist undetected, except by a scarcely perceptible running from the nostril, caused by the irritation which they occasion. These tubercles gradually become more numerons; they cluster together, suppurate and break, and small ulcerations are formed. The ulcers discharge a poisonous matter, which is ab. sorbed and taken up by the neighbouring glanis, and this, with greater or less rapidity, vitiates the constitution of the animal, and is capable of coinmunicating the disease to others. Some content themselves with saying that it is an inflammation of the membrane of the nose, which may assume an acute or chronic form, or in a very sliort time, or exceedingly slowly, run on to ulceration.

It is inflammation, whether specific or common, of the lining membrane of the nose-possibly for months, and even for years, confined to that membrane, and even to a portion of it - the health and the usefulness of the animal not being in the slightest degree impaired. Then, from some unknown cause, not a new but an intenser action is set up, the inflammation more speedily runs its course, and the membrane becomes ulcerated. The inflammation spreads on either side down the septum, and the nlceration at length assumes that peculiar chancrous form which characterises inflammation of the absorbents. Even then, when the discharge becomes gluey, and sometimes after chancres have appeared, the horse is apparently well. There are hundreds of glandered horses abont the country with not a sick one among them. For months or years this disease may do no injury to the general health. The inflammation is purely local, and is only recognised by the invariable accompaniment of inflammation and increased secretion. Its neighbours fall around, but the disease affects not the animal whence it came. At length a constitutional inflammation appears ; farcy is established in its most horrible form, and death speedily closes the scene.

What, then, is the cause of this insidious dreadful disease? Although we may be in a manner powerless as to the removal of the malady, yet if we can trace its cause and manner of action, we may at least be able to $d_{\theta}$ something in the way of prevention. Much has been accomplished in this way. Glanders does not commit one-tenth part of the ravages which it did thirty or forty years ago, and, generally speaking, it is now only found as a frequent and prevalent disease where neglect, and filth, and want of ventilation exist.

Glanders may be either bred in the horse, or communicated by contagion. What we have farther to remark on this malady will be arranged under these two heads.

Improper stable management we believe to be a far more frequent cause of glanders than contagion. The air which is necessary to respiration is changed and empoisoned in its passage through the lungs, and a fresh supply is necessary for the support of life. That supply may be sufficient barely to support life, but not to prevent the vitiated air from again and again passing to the lungs, and producing irritation and disease. The 
membrane of the nose, possessed of extreme sensibility for the purposes of smell, is easily irritated by this poison, and close and ill-ventilated stables oftenest witness the ravages of glanders. Professor Coleman relites a case which proves to demonstration the rapid and fatal agency of this cause. "In the expedition to Quiberon, the horses had not been long on board the transports before it became necessary to shut down the hatchwars for a few hours; the consequence of this was, that some of them were suffocated, and that all the rest were disembarked either glandered or farcied."

In a close stable, the air is not only poisoned hy being repeatedly hreathed, but there are other and more powerful sources of mischief. The dung and the urine are suffered to remain fermenting, and giving out injurious gases. In many dark and ill-managed stables, a portion of the dung may be swept away, but the nrine lies for days at the bottom of the bed, the disgusting and putrefying nature of which is ill concealed by a little fresh straw which the lazy horsekeeper scatters over the top.

The stables of the gentleman are generally kept hot enough, and far too hot, although, in many of them, a more rational mode of treatment is beginning to be adopted; but they are lofty and roomy, and the horses are not too mnch crowded together, and a most scrupulous regard is paid to cleanliness. Glanders seldom prevail there. The stables of the farmer are ill-managed and filthy enongh, and the ordure and urine sometimes remain from week to week, until the horse lies on a perfect dunghill. Glanders seldom prevail there; for the same carelessness which permits the filth to accumulate leaves many a cranny for the wind to enter and sweep away the deleterious fumes from this badly-roofed and unceiled place.

The stables of the horse-dealer are hot enough; but a prineiple of strict cleanliness is enforced, for there must be nothing to offend the eye or the nose of the customer, and there glanders are seldom found; but if the stables of many of our post-liorses, and of those employed on our canals, are examined, almost too low for a tall horse to stand npright in them, - too dark for the accumulation of filth to be perceived,- too far from the eye of the master, -ill drained and ill paved,and governed by a false principle of economy, which begrudges the labour of the man, and the cleanliness and comfort of the animal; these will be the very hotbeds of the disease, and in many of these establishments it is an almost constant resident.

Glanders may be produced by anything that iujures, or for a length of time acts upon and weakens, the vital energy of this membrane. They have been known to follow a fracture of the bones of the nose. They have been the consequence of violent catarrh, and particularly the long-contimed discharge from the nostrils, of which we have spoken. They have been produced by the injection of stimulating and acrid substances up the nostril. Everything that weakens the constitution generally will lead to glanders. It is not only from bad stable management, but from the hardships which they endure, and the exhausted state of their constitution, that post and machine horses are so subject to glanders; and there is scarcely an inflammatory disease to which the horse is subject that is not oceasionally wound up and terminated by the appearance of glanders.

Among the causes of glanders is want of regular exercise. The connexion, although not evident at first glance, is too certain. When a horse has been worked with peculiar severity, and is become out of spirits, and falls away in flesh, and refuses to eat, a little rest and a few mashes would make all right again; but the groom plies him with cordials, and adds fuel to fire, and aggravates the state of fever that has commenced. What is the necessary consequence of this? The weakest goes to the wall, and either the lungs or the feet, or this membrane-that of the nosethe weakest of all, exposed day after day to the stimulating, delilitating influences that have been described, becomes the principal seat of iuflammation that terminates in glanders.

It is in this way that glanders have so frequently been known to follow a hard day's chase. The seeds of the disease may have previously existed, but its progress will be hastened by the general and febrile action excited, the absurd measures which are adopted not being calculated to subdue the fever, but to increase the stimulus.

Every exciting cause of disease exerts its chief and its worst influence on this membrane. At the close of a severe campaign, the horses are more than decimated by this pest. At the termination of the Peninsular war the ravages of this disease were dreadful. Every disease will predispose the membrane of the nose to take on the inflammation of glanders, and with many, as strangles, eatarrh, bronchitis, and pueumonia, there is a continuity of membrane, an association of function, and a thousand sympathies.

There is not a disease which may not lay the foundation for glanders. Weeks, and months, and years, may intervene between the predisposing cause and the actual evil; but at length the whole frame may become excited or debilitated in many a way, and then this debilitated portion of it is the first to yield to the attack. Atmospheric influence has somewhat to do with the prevalence of glanders. It is not so frequent in the summer as in the winter, partly attributable, perhans, to the different state of the stable in the summer 
months, neither the air so close or so foul, nor the alternations of temperature so great.

There are some remarkable cases of the connexion of moisture, or moist exhalations, that deserve record. When new stabling was built for the troops at Hytle, and inhabited before the walls were perfectly dry, many of the horses that had been removed from an open, dry, and bealthy situation, became affected with glanders; but, some time having passed over, the horses in these stables were as healthy as the others, and glanders ceased to appear. An inn-keeper at Wakefield built some extensive stabling for his horses, and, inhabiting them too soon, lost a great proportion of his cattle from glanders. There are not now more healthy stables in the place. 'T'he immense range of stables under the Adelphi, in the Strand, where light never enters, and the supply of fresh air is not too abundant, were for a long time notoriously unhealthy, and many valuable horses were destroyed by glanders; but now they are filled with the finest waggon and dray-horses that the metropolis or the country contains, and they are fully as healthy as in the majority of stables above-ground.

There is one more cause to be slightly mentioned-hereditary predisposition. This has not been sufficiently estimated, with regard to the question now under consideration, as well as with respect to everything connected with the breeding of the horse. There is scarcely a disease that does not run in the stock. 'There is that in the structure of various parts, or their disposition to be affected by certain influences, which perpetuates in the offspring the diseases of the sire; and thus coutraction, ophthalmia, roaring, are decidedly hereditary, and so is glanders. M. Dupuy relates some decisive cases. A mare, on dissection, exhibited every appearar 3 of glanders: her filly, who resembled her in form and in her vicious propensities, died glandered at six years old. A second and a third mare and their foals presented the same fatal proof that glanders are hereditary.

Glanders are highly contagions. The farmer cannot be too deeply impressed with the certainty of this. Considering the degree to which this disease, even at the present day, often prevails, the legislature would be justified in interfering by some severe enactments, as it has done in the case of the small-pox in the human subject.

The early and marked symptom of glanders is a discharge from the nostrils of a peculiar character; and if that, even before it becomes purulent, is rubbed on a wound, or on a mucous surface, as the nostrils, it will produce a similar disease. If the division between two horses were sufficiently high to prevent all smelling and snorting at each other and contact of every kind, and they drank not out of the same pail, a sonnd horse might live for years, uninfected, by the side of a glandered one. The matter of glanders has been mixed up into a ball, and given to a healthy horse, witlout effect. Some horses have eaten the hay left by those that were glandered, and no bad consequence has followed: but others have been speedily infected. The glanderous matter must come in contact with a wound, or fall on some membrane, thin and delicate like that of the nose, and through which it may be absorbed. It is easy, then, accustomed as horses are to be crowded together, and to recognise each other by the smell-eating out of the same manger, and drinking from the same pail-to imagine that the disease may be very readily communicated. One horse has passed another when he was in the act of snorting, and has become glandered. Some fillies have received the infection from the matter blown by the wind across a lane, when a glandered horse, in the opposite field, has claimed acquaintance by neighing or snorting. It is almost impossible for an infected horse to remain long in a stable with others without irreparable mischief.

If some persons underrate the danger, it is because the disease may remain unrecognised in the infected horse for some months, or even years, and therefore, when it appears, it is attributed to other causes or to after inoculation. No glandered horse should be employed on any farm, nor should a glandered horse be permitted to work on any road, or even to pasture on any field. Mischief may be so easily and extensirely effected, that the public interest demands that every infected amimal should be summarily destroyed, or given over for experiment to a veterinary surgeon, or recognised veterinary establishment.

There are a few instances of the spontaneous cure of chronic glanders. The discharge has existed for a considerable time. At length it has gralually diminished, and has ceased; and this has occurred under every kind of treatment, and without any medical treatment: but in the majority of these supposed cases, the matter was only pent up for a while, and then, bursting from its confinement, it flowed again in double quantity: or, if glanders have not reappeared, the horse, in eighteen or twenty-four months, has become farcied, or consumptive, and died. These supposed cures are few and far between, and are to be regarded with much suspicion.

As for medicine, there is scarcely a drug to which a fair trial has not been given, and many of them have had a temporary reputation; but they have passed away, one after the other, and are no longer heard of. The blue vitriol and the Spanishfly have held out longest; and in a few cases, either nature or these medirines have done wonders, but in the majority of instances they have palpably failed. The cliniodide of copper has lately acquired some reputation. It has been of 
great service in cases of farcy, but it is not to he depended upon in glanders.

Where the life of a valuable animal is at stake, and the owner adopts every precaution to prevent infection, he may subject the horse to medical treatment; but every humane man will indignantly object to the slitting of the nostril, and the scraping of the cartilage, and searing of the gland, and firing of the frontal and nasal bones, and to those injections of mustard and capsicum, corrosive sublimate and vitriol, by which the horse has been tortured, and the practitioner disgraced. At the veterinary school, and by veterinary surgeons, it will be most desirable that every experiment should be tried to discover a remedy for this pest; but, in ordinary instances, he is not faithful to his own interest or that of his neighhours who does not remove the possibility of danger in the most summary way.

If, however, remedial measures are resorted to, a pure atmosphere is that which should first be tried. Glanders is the peculiar disease of the stabled horse, and the preparation for, or the foundation of, a cure must consist in the perfect removal of every exciting cause of the malady. The horse must breathe a cool and pure atmosphere, and he must be turned out, or placed in a situation equivalent to it.

A salt marsh is, above all others, the situation for this experiment; but there is much cantion required. No sound horse must be in the same pasture, or a neighbouring one. The palings or the gates may receive a portion of the matter, which may harden upon them, and, many a month afterwards, be a source of mischief-nay, the virus may cling about the very herbage and empoison it. Cattle and sheep should not be trusted with a glandered horse, for the experiments are not sufficiently numerous or decided as to the exemption of these animals from the contagion of glanders.

Supposing that glanders have made their appearance in the stables of a farmer, is there any danger after he has removed or destroyed the infected horse?-Certainly there is, but not to the extent that is commonly supposed. There is no necessity for pulling down the racks and mangers, or even the stable itself, as some have done. The poison resides not in the breath of the animal, but in the nasal discharge, and that can only reach certain parts of the stable. If the mangers, and racks, and bales, and partitions, are first well scraped, and scoured with soap and water, and then thoroughly washed with a solution of the chloride of lime (one pint of the chloride to a pailful of water), and the walls are lime-washed, and the head-gear burned, and the clothing baked or washed, and the pails newly painted, and the iron-work exposed to a red heat, all danger will cease.
Little that is satisfactory can be said of the prevention of glanders.

The first and most effectual mode of prevention will be to keep the stables cool and well ventilated, for the hot and poisoned air of low and confined stables is one of the most prevalent causes of glanders.

Next to ventilation stands cleanliness; for the foul air from the fermenting litter, and urine, and dung, must not only be highly injurious to health generally, but irritate and predispose to inflammation that delicate membrane which is the primary seat of the disease. If to this be added regular exercise, and occasional green meat during the summer, and carrots in the winter, we shall have stated all that can be done in the way of prevention.

Glanders in the human being.-It cannot be too often repeated, that a glandered loorse can rarely remain among sound ones without serious mischief ensuing; and, worse than all, the man who attends on that horse is in danger. The cases are now becoming far too numerous in which the groom or the veterinary surgeon attending on glandered horses becomes infected, and in the majority of cases dies. It is, however, somewhat more manageable in the human being thau in the quadruped. Some cases of recovery from farcy and glanders stand on record with regard to the human being, but they are few and far between.

\section{FARCY.}

Farcy is intimately comected with glanders; they will run into each other, or their symptoms will mingle together, and before either arrives at its fatal termination its associate will almost invariably appear. An animal inoculated with the matter of farcy will often be afflicted with glanders, while the matter of glanders will frequently produce farcy. They are different types or stages of the same disease. There is, however, a very material difference in their symptoms and progress, and this most important one of all, that while glanders are generally incurable, farcy, in its early stage and mild form, may be successfully treated.

While the capillary vessels of the arteries are everywhere employed in building up the frame, the absorbents are no less diligently at work in selecting and carrying away every nseless or wornout portion or part of it. There is no surfacethere is no assignable spot on which thousands of these little mouths do not open. In the discharge of their duty they not only remove that which is become useless, and often that which is healthy, but that which is poisonous and destructive. They open upon the surface of every glanderous chancre. They absorb a portion of the virus which is secreted by the ulcer, and as it passes along these little tubes, they suffer from its acrimonious quality; hence 
the corded veins, as they are called by the farrier, or, more properly, the thickened and inflamed absorbents following the course of the veins.

At certain distances in the course of the absorbents are loose duplicatures of the lining membrane, which are pressed against the side of the vessel and permit the fluid to pass in a direction towards the chest, but belly out and impede or arrest its progress from the chest. The virus at these places, and the additional inflammation there excited, is to a greater or less degree evident to the eye and to the feeling. They are usually first observed about the lips, the nose, the neck, and the thighs. They are very hard-eren of a scirrhous hardness, more or less teuder, and with perceptible heat about them.

The poisonous matter being thus confined and pressing on the part, suppuration and ulceration ensue. The ulcers have the same character as the glanderous ones on the membrane of the nose. They are rounded, with an elevated edge and a pale surface. They are true chancres, and they discharge a virus as infectious and as dangerous as the matter of glanders. While they remain in their hard prominent state, they are called buttons or farcy buds; and they are connected together by the inflamed and corded veins.

In some cases the horse will droop for many a day before the appearance of the corded veins or buds-his appetite will be impaired-his coat will stare-he will lose flesh. The poison is evidently at work, but has not gained sufficient power to cause the absorbents to enlarge. In a few cases these buds do not ulcerate, but become hard and diff. cult to disperse. The progress of the disease is then suspended, and possibly for some months the horse will appear to be restored to health; but he bears the seeds of the malady about him, and in due time the farcy assumes its virulent form, and hurries him off. These buds have sometimes been confounded with the little tumours or lumps termed surfeit. They are generally higher than these tumours, and not so broad. They have a more knotty character, and are principally found on the inside of the limbs, instead of the outside.

$\mathrm{Few}$ things are more unlike, or more perplexing, than the different forms which farcy assumes at different times. One of the legs, and particularly one of the hinder legs, will suddenly strell to an enormous size. At night the horse will appear to be perfectly well, and in the morning one leg will be three times the size of the other, with considerable fever, and scarcely the power of moving the limb.

At other times the head will be subject to this enlargement, the muzzle particularly will stell, and an offensive discharge will proceed from the nose. Sometimes the horse will gradually lose flesh and strength; he will be hide-bound; mangy eruptions will appear in different parts; the legs will swell; cracks will be seen at the heels, and an inexperienced person may conceive it to be a mere want of condition, combined with grease.

By degrees the affection becomes general. The virus has reached the termination of the absorbents, and mingles with the general circulating fluid, and is conveyed with the blood to every part of the frame. There are no longer any valves to impede its progress, and consequently no knots or buds, but the myriads of capillary absorbents that penetrate every part become inflamed, and thickened, and enlarged, and cease to discharge their function. Hence arises enlargement of the substance of various parts, swellings of the legs, and chest, and head-sudden, painful, enormons, and distinguished by a heat and tenderness which do not accompany other enlargements.

It is a question somewhat difficult to answer, whether farcy can exist without previous glanders. Probably it cannot. There is the long-continued insidions progress of glanders - the time which may elapse, and often does, before the owner is aware or the veterinary surgeon sure of it-the possibility that minute ulceration may have for a long while existed in some of the recesses of the nose-or that the slight discharge, undreaded and unrecognised, yet vitiated, poisoned, and capable of communicating the disease, may have been long travelling through the frame and affecting the absorbents, and preparing for the sudden display of farcy.

One thing, however, is undeniable, that farcy does not long and extensively prevail without being accompanied by glanders-that even in the mild stages of farcy, glanders may be seen if looked for, and that it never destroys the animal without plainly associating itself with glanders. They are, in fact, stages of the same disease.

Glanders is inflammation of the membrane of the nose, producing an altered and poisonous secretion, and when sufficient of this vitiated secretion has been taken up to produce inflammation and ulceration of the absorbents, farcy is established. Its progress is occasionally very capricious, continuing in a few cases for montlis and years, the vigour of the horse remaining unimpaired; and, at other times, running on to its fatal termination with a rapidity perfectly astonishing.

Farcy has been confounded with other diseases; but he must be careless or ignorant who mistook sprain for it. The inflammation is too circumscribed and too plainly connected with the joint or the tendon.

It may be readily distinguished from grease or swelled legs. In grease there is usually some crack or scurfiness, a peculiar tenseness and redness and glossiness of the skin, some ichorous 
discharge, and a singular spasmodic catching up of the leg.

In farcy the engorgement is even more sudden than that of grease. The horse is well to-day, and to-morrow he is gorged from the fetlock to the haunch, and although there is not the same redness or glossiness, there is great tenderness, a burning heat in the limb, and much general fever. It is simultaneous inflammation of all the absorbents of the limb.

Surfeit can scarcely be confounded with farcy or glanders. It is a pustular eruption-surfeitbumps as they are called, and terminatiug in desquamation, not in ulceration, although numerous, yet irregularly placed, and never following the course of the ausorbents, but scattered over the skin.

Local dropsy of the cellular membrane, and particularly that enlargement beneath the thorax which has the strange appellation of vater-farcy, have none of the characters of real farcy. It is general debility to a greater or less degree, and not inflammation of the alssorbents. If properly treated, it soon disappears, except that, occasionally, at the close of some serious disease, it indicates a breaking up of the constitution.

Farcy, like glanders, springs from infection and from bad stable mauagement. It is produced by all the causes which give rise to glanders, with this difference, that it is more frequently generated, and sometimes strangely prevalent in particular listricts. It will attack, at the same time, several horses in the same ill-conducted stable, and others in the neighbourhood who have been exposed to the same predisposing causes. Some have denied that it is a contagious disease. They must have had little experience. It is true that the matter of farcy must come in contact with a wound or sore, in order to communicate the disease; but accustomed as horses are to nibble and play with each other, and sore as the corners of the mouth are frequently rendered by the bit, it is easy to imagine that this may be easily effected; and experience tells us, that a horse having farcy ulcers cannot be suffered to remain with others without extreme risk.

The treatment of farcy differs with the form that it assumes. As a general rule, and especially wheu the buttons or buds are beginning to appear, a mild dose of physic should first be administered. The buds should then be carefully examined, and if any of them have broken, the budding-iron, at a dull red heat, should be applied. If pus should be felt in them, showing that they are disposed to break, they should be penetrated with the iron. These wounds should be daily inspected, and if, when the slough of the cautery comes off, they look pale, and foul, and spongy, and discharge a thin matter, they slould be frequently washed with a strong lotion of corrosive sublimate, dissolved in rectified spirit. When the wounds begin to look red, and the bottorn of them is even and firm, and they discharge a thick white or yellow matter, the Friar's balsam will usually dispose them to heal.

As, however, the constitution is now tainted, local applications will not he sufficient, and the disease must be attacked by iuterual medicine as soon as the physic has ceased to operate.

Corrosire sublimate used to be a favourite medicine, combined with touics, and repeated moning and night until the ulcers disappeared, unless the mouth became sore or the horse was violently purged, when the snlphate of copper was substituted for the corrosive sublimate. During this treatment the animal was placed, if possible, in a large box, with a free circulation of air ; and green meat or carrots, and particularly the latter, were given, with a full allowance of corn. If he could be turned out in the day, it was deemed highly advantageous. It is related by Mr. Blaine, that a horse, so reduced as not to be able to stand, was drawn into a field of tares, and suffered to take his chance. The consequence was that, when he had eaten all within his reach, he contrived to move about and search for more, and eventually recovered. Nany horses recover under the use of the sullimate, but the great majority of them die.

$\mathrm{Mr}$. Vines introduced a more effective medicine -canthariles, in combination likewise with the vegetable bitters-as a cure for farcy and glanders. It cannot be denied, that many animals labouring under the former, and a few under the latter, were to all appearance radically cured. The medicine was suspended for a while if affection of the lidneys superveued.

A still more effectual medicine has been introduced by Professor Morton, namely, the diniodide of copper, and it has been found of essential service in farcy and in diseases simulating glanders. $\mathrm{He}$ says that its action is that of a stimulant to the absorbent vessels, and a tonic. The gentian root is usually combined with it. Cantharides, in small quantitios, may be advantageously added. An indication of its influence is a soreness of the diseased parts, arising from the absorbent vessels being roused into increased action: the agent should then be for a time withheld.*

* A very interestiog case of the cure of farcy in the human beiog occurred in January, 1840, in the practice of Mr. Curtis, a respectable surgeon of Cainden Town:-

"Mr. G., a student at the Veterioaly College, had, about three weeks before, received a slight wound on the forefiuger of the right hand, while dissecting a glandered horse. The wound bealed; but, about nine days afterwards, a small abscess formed io the part, which he would nut consent to have opened; the pus was therefore absorbed, and the finger got well, and neither the lymphatics our the glands appeared to be affected.

"Ten days afterwards, he was attacked with giddiness while attending the lccure, and obliged to leave the room. He immediately applied to Mr. Curtis. He had three blotches of intammation of the skin of the right leg, varying io extent from two to dou 
Water-farcy, confounded by name with the common farcy, and by which much confusion has been caused, and a great deal of mischief done, is a dropsical affection of the skin, either of the chest or of the limbs, and belongs to another part of our subject.

\section{THE LIPS.}

The lips of the horse are far more importaut organs than many suppose. They are the hands of the animal; and if any one will take the trouble to observe the manner in which he gathers up his corn with them, and collects together the grass before he divides it with his nippers, he will be satisfied that the horse would be no more able to convey the food to his mouth without them, than the human being could without his hands. This has even been put to the test of experiment. The nerves which supply the lips were divided in a poor ass, to illustrate some point of physiology. The sensibility of the lips was lost, and he knew not when he touched his food with them. The motion of the lips was lost, and he could not get the oats between his teeth, although the manger was full of them : at length, driven by hunger, he contrived to lick up a few of them with his tongue; but when they were on his tongue, the greater part of them were rubled off before he could get them into his mouth.

It is on account of this use of the lips, aud that they may be brought into contact with the food without inconvenience or injury to other parts of the face, that the lieads of most quadrupeds are so lengthened. Several muscles go to the lips from different parts of the jaw and face. Some of them are shown in the cut, p. 309 . The orbicularis or circular muscle, $p$, employed in pushing out the lips and closing them, and enabliug the horse to seize and hold his food, is particularly evident; and in the explanation of the cut, the action of other muscles, $i, k, m$, and $o$, was described. The nerves likewise, $y$, taking their course along the cheek, and principally supplying the lips with the jower of motion, and those $z$, proceeding from the foramen or hole in the upper jaw, deserve attention.

The lips are composed of a muscular substance for the sake of strength, and a multitude of small glands, which secrete a fluid that covers the inside of the lips and the gums, in order to prevent fric-

iaches in diameter. The leg was very painful when he walked; and he had also some small blotches on the left leg. He had head-' ache and thirst. His case was sufficiently jlain-farcy was beginning to develop itself. Aperjent medicine was administered.

"On the following day, there were numerous small blutches over both legs and thighs. In many of them the ceotre was of a pale green colour, huving a somew hat gangrenous appearunce. The headache was worse; there was a sensativa of weight over the eyes, and tenderness over the left fromal.

" Mr. Curtis determined to pint ljim under a course of iorline, of the tincture of which ejght minims were ordered every fourth hour, be bowels being kept in a relaxed stinte. tion, and likewise furnish a portion of the moisture so necessary for the proper chewing of the food. The skin covering the lips is exceedingly thin, in order that their peculiar sensibility may be preserved, and for the same purpose they are scantily covered with hair, and that hair is fine and short. Long hairs or feelers, termed the beard, are superadded with the same intention. The horse is guided and governed principally by the mouth, and therefore the lips are endowed with very great sensibility, so that the animal feels the slightest motion of the hand of the rider or driver, and seems to anticipate his very thoughts. The fineness or goodness of the mouth consists in its exquisite feeling, and that depends on the thinness of this membrane.

The lips of the horse should be thin, if the beauty of the head is regarded; yet, although thin, they should evidently possess power, and be strongly and regularly closed. A firm, compressed mouth gives a favourable and no deceptive idea of the muscular power of the animal. Lips apart from each other and hanging down, indicate weakness or old age, or dulness and shuggishness.

The depth of the mouth, or the distance from the fore-part to the angle of the lips, should be considerable. A short protuberant mouth would be a bad finish to the tapering face of the bloodhorse. More room is likewise given for the opening of the nostril, which has been shown to be an important consideration. The bridle will not be carried well, and the horse will hang heavy on hand, if there is not considerable depth of mouth.

The corners or angles of the lips are frequently made sore or wounded by the smallness, or shortness, or peculiar twisting of the snaffle, 'and the unnecessary and cruel tightness of the bearing-rein. This rein was introduced as giving the horse a grander appearance in harness, and placing the bead in that position in which the bit most effectually presses upon the jaw. There is no possibility of safely driving without it, for, deprived of this control, many horses would hang their heads low, and be disposed every momeut to stumble, and would defy all pulling, if they tried to run away. There is, and cau be no necessity, however, for using a bearing-rein so tight as to cramp the muscles of the head, or to injure and excoriate the angles of the lips.

"On the fourth day, the centre of the blotches, which were stil] green, appeared to form cavities, cuntainiag a fluid, from about the size of a shilling to that of a balf-crown. The blotches were surronaded by hard, defioed edges, corered with cuticle, but the thick eniog of which was gradually disappearing.

"Two days after this, the fluid io the cavities was absorbed, but round their edges were lumps, or tubcrcles, ahout the size of peas Several weeks passed before the tubercles quite disappeared.

"Ar. Curtis remarks, that so far as a single case will go, the intractalle nature of this disease scems to arise rather from neglect in its early stage, than from any impossibulity of subduing it." Z'he V'tetinarian, vol. xiij. p. $\mathbf{3 5 3}$. 
The following is the opinion of Nimrod, and to a more competent judge we could not appeal :"As to the universal disuse of the bearing-rein with English horses, it can never take place. The charge against it of cruelty at once falls to the ground, because to make a team work together in fast work, every horse's head must be as much restrained by the coupling-rein as it would be and is by the bearing-rein. Its excellence consists in keeping horses' mouths fresh-in enabling a coachman to indulge a horse with liberty of rein, without letting him be all abroad, which he would be with his head quite loose, and of additional safety to the coach-horse, as proved by the fact of either that or the crupper always giving way when he falls down. There are, however, teams in which it may be dispensed with, and the horses have an advantage in their working against hills. As to the comparison of the road coach-horses on the Continent and our own, let any one examine the knees of the French diligence and post horses, which are allowed perfect liberty of bead, and he will be convinced that the use of the bearing-rein does not keep them on their legs."*

The mouth is injured much oftener than the careless owner suspects by the pressure of a sharp bit. Not only are the bars wounded and deeply ulcerated, but the lower jaw, between the tush and the grinders, is sometimes worn even to the bone, and the bone itself affected, aud portions of it torn away. It may be necessary to have a sharp bit for the headstrong and obstiuate beast; yet if that bit is severely and unjustifiably called into exercise, the animal may rear, and endanger himself and his rider. There can, however, be no occasion for a thousandth part of the torment which the trappings of the mouth often inflict on a willing and docile servant, and which either render the mouth hard, and destroy all the pleasure of riding, or cause the horse to become fretful or vicious.

Small ulcers are sometimes found in various parts of the mouth, said to be produced by rusty bits, but oftener arising from contusions inflicted by the bit, or from inflammation of the mouth. If the curb-bit is in fault, a snaffle or Pelham-lit should be used. If there is inflammation of the mouth, a little cooling medicine may be administered; and to the ulcers themselves, tincture of

* New Sporting Magazine, vol. xiii. p. 99.

The author of the "Essay on Humanity to Brites," takes the same view of the subject. "It is not," says he, "to the extent that has been supposed an instrument of torture. It is absolutely necessary in fast work, and useful on level ground. The objection to it is the tightness with which it is sometimes applied, and then it is a sad confinement to the head, and a source of very great pain. it is also disalvantageous when the horse is going up-hill, because it prevents him from throwing his whole weight into the collar. It cannot, however, be done without, especially in the horse that is onee accustomed to it; but the poor animal needs not to be so tightly reined.-The Obligation and Extent of Humanity to Brutes, by W. Fouatl, p. 149 . myrrh, diluted with water, or alum dissolved in water, may be applied with advantage.

THE BONES OF THE MOUTH.

The bones in, and giving form to the mouth, are the superior maxillary or upper jaw $(b$, p. 263 , and $l, \mathrm{p} .265)$, containing the grinders; the anterior maxillary, or lower part of the upper jaw $(b$, p. $263, n$, p. $265, r$, p. 266 ), containing the uppernippers or cutting-teeth; the palatine bone (below 8 , p. 266), and the posterior maxillary or under jaw ( $a$, p. 263, and $u$, p. 266), containing all the under teeth.

The superior maxillary is, with the exception of the lower jaw, the largest bone in the face. It unites above with the lacrymal hone $(i, \mathrm{p} .265)$; and, more on the side, with the malar or cheek bone, $k$; and a portion of it, continued upward and underneath, enters into the orbit. Above, and on the front of the face, it unites with the bones of the nose, $j$, and below, with the inferior maxillary $n$. That which most deserves notice in it externally is the ridge or spine, seen at $b$, p. 263, but better delineated in the cut of the head, p. 266, continued from the base of the zygomatic arch, and across the malar bone. It and the surface beneath serve to give attachment to the masseter muscle, concerned, almost as much as the temporal one, in the act of cliewing. The dark spot $(m$, p. 265 , and seen likewise at p. 263) marks the foramen or hole, through which a branch of the fifth pair of nerves proceeds to give sensibility to the lower part of the face. As it approaches the teetl this bone separates into two plates, and these are divided by long partitions, which contain and firmly hold the upper grinders. The lower plate then projects inwards, and forms $(t$, p. 266) the principal portion of the roof of the month, and the floor of the cavity of the nose. The corresponding bone, on the other side, meets its fellow in the centre of the palate. The upper jaw-bone contains in it large cavities besides those for the teeth, and these open into and enlarge the cavity of the nose. They are connected with the voice, but not with the smell; for the expansion of the olfactory or smelling nerve has never been traced beyond the bones and membranes of the proper cavity of the nose. The maxillary sinuses are generally filled with matter in bad cases of glanders.

Below these are the anterior maxillary bones ( $f$, p. 263, a, p. 263), containing the upper cutting teeth, with the tushes belonging both to the upper and anterior bones. These are the bones to which (see cut, p. 266) the upper lip is attached. The superior and anterior maxillary bones are separated in animals with long faces, like the horse, that, by overlapping each other, strength might be gained. 
The palatine bone forms but a very small por- arise from inflammation of the gums, propagated tion of the palate. It to the bars, when the horse is shedding his teeth surrounds the edge of -and young horses are more subject to it than the communication be- others-or from some slight febrile tendency in tween the cavity of the the constitution generally, as when a young horse nose and the back parts of the mouth.

THE PALATE.

Adhering to a portion of the three bones just described, and constituting the lining of the roof of the mouth, is the palate $(t$, p. 266), composed of an elastic and dense substance divided into several ridges called Bars. This cut gives a view of them.

It will also point out the bleeding place, if it should occasionally be deemed advisable to abstract blood from the mouth; or if the horse should be attacked with megrims on a journey, and the driver, having no laucet, should be compelled to make use of his knife, the incision should be made betreen the central and second nippers on either side, about an inch within the month, and cutting through the second bar. A stream of blood will be thus obtained, which will usually cease to flow when two or three quarts have escaped, or may generally be arrested by the application of a sponge filled with cold water.

This, however, is a make-shift sort of bleeding that may be allowable on a journey, and possibly in some cases of lampas, but which is decidedly objectionable as the usual mode of abstracting blood. The quantity withdrawn cannot be measured, the degree of inflammation cannot be ascertained by the manner in which it coagulates; and there may be difficulty to the operator, and annoyance and pain to the horse, in stopping the bleeding.

This cut likewise depicts the appearance of the roof of the mouth if the bars were dissected off, and of the numerous vessels, arterial and venous, which ramify over it.

\section{LAMPAS,}

The bars accasionally swell, and rise to a level with, and even beyond the edge of, the teeth. They are very sore, and the horse feeds badly on account of the pain he suffers from the pressure of the food on them. This is called the lampas. It may has lately been taken up from grass, and has been over-fed, or not sufficiently exercised. At times it appears in aged horses; for the process of growth, in the teeth of the horse, is continued during the whole life of the animal.

In the majority of cases the swelling will soon subside without medical treatment; or a few mashes and gentle alteratives will relieve the animal. A few slight incisions across the bars with a lancet or penknife will relieve the inflammation and cause the swelling to subside; indeed, this scarification of the bars in lampas will seldom do harm, although it is far from being so necessary as is supposed. The brutal custom of the farrier, who sears and burns down the bars with a red-hot iron, is most objectionable. It is torturing the horse to no purpose, and rendering that part callous on the delicate sensilility of which all the pleasure and safety of riding and driving depend. It may be prudent in case of lampas to examine the grinders, and more particularly the tushes, in order to ascertain whether either of them is making its way through the gum. If it is so, two incisions across each other should be made on the tooth, and the horse will experience immediate relief.

\section{THE LOWER JAW.}

The posterior or lower jaw may be considered as forming the floor of the mouth $(a$, p. 263 , or $w$, p. 266). The body or lower part of it contains the under cutting teeth and the tushes, and at the sides are two flat pieces of bone containing the grinders. On the inside, and opposite to $a, \mathrm{p} .263$, is a foramen or hole through which blood-vessels and nerves enter to supply the teeth, and some of which escape again at another orifice on the outside, and near the nippers. The branches are broader and thinner, rounded at the angle of the jaw, and terminating in two processes. One, the coracoid, from its sharpness or supposed resem. blance to a beak, passes under the zygomatic arch (see p. 203); and the temporal muscle, arising from the whole surface of the parietal bone (see p. 268), is inserted into it and wrapped round it, and by its action, principally, the jaw is moved and the food is ground. The other, the condyloid, or rounded process, is received into the glenoid (shallow) cavity of the temporal bone, at the base of the zygomatic arch, and forms the joint on which the lower jaw moves. This joint is easily seen in the cut at p. 263; and being placed so near to the insertion of the muscle, or the centre of mation, the temporal muscle must act with very 
considerable mechanical advantage, and, conse. quently, must possess immense power.

This joint is admirably contrived for the purpose which the animal requires. It will admit freely and perfectly of the simple motion of a hinge, and that is the action of the jaw in nipping the herbage and seizing the corn. But the grass, and more particularly the corn, must be crushed and bruised before it is fit for digestion. Simple champing, which is the motion of the human lower jaw, and that of most beasts of prey, would very imperfectly break down the corn. It must be put into a mill; it must be actually ground.

It is put into the mill, and as perfect a one as imagination can conceive.

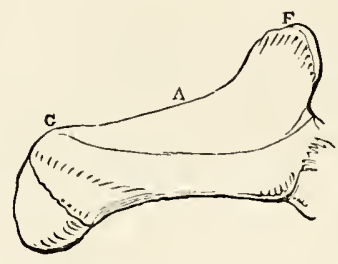

in a different direction. The head of the lotrer jaw is received into this hollow, and presses against these ridges, and is partially surrounded by them, and forms with them a very stroug joint where dislocation is scarcely possible, and the hinge-like or cranching motion is admitted to its fullest extent; permitting the animal violently to seize his prey, to hold it firmly, and to crush it to pieces; but from the extent and curling form of the ridges, forbidding, except to a very slight degree, all lateral and grinding motion, and this, because the animal does not want it.

As before mentioned, the food of the horse must be ground. Simple bruising and champing would not sufficiently comminute it for the purposes of digestion. We then observe the different construction of the parts to effect this. A gives the glenoid cavity of the horse. First, there is the upper ridge assuming a rounded form, $F$, and therefore called the mastoid process; anda peculiarity in the horse-the mastoid process of the squamous portion of the temporal bone: sufficiently strong to support the pressure and action of the lower jaw when cropping the food or seizing an enemy, but not encircling the head of that bone, and reaching only a little way along the side of the cavity, where it terminates, having its edges rounded off so as to admit, and to be evidently destined for, a circular motion about it. At the other and lower edge of the cavity, and on the outside, $G$ is placed-not a curling ridge as in the tiger, but a mere tubercle: and for what rea-
The following cut represents the glenoid cavity, in a carnivorous or flesh-eating, and herbivorous or grass-eating animal, viz. the tiger and the horse : the one requiring a simple hinge-like motion of the lower jaw to tear and crush the food; the other, a lateral or grinding motion to bring it into a pulpy form. We first examine this eavity in the tiger represented at $B$. At the root of the zygomatic process $D$, is a hollow with a ridge along the greater part of the upper and inner side of it, standing to a considerable height, and curling over the cavity. At the lower and opposite edge of the cavity, but on the outside, is a similar ridge, E, likewise rising abruptly and curling over. At $\mathrm{C}$ is another and mole perfect view of this cavity

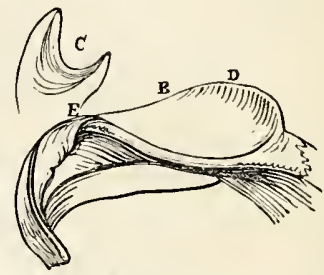

son? evidently to limit this lateral or circular motion-to permit it as far as the necessities of the animal require it, and then to arrest it. How is this done? Not suldenly or abruptly; but the tubercle, of which we have already spoken as strengthening this portion of the zygomatic arch, now discharging another office, has a smooth and gradual ascent to it, up which the lower jaw may climb to a certain extent, and then, by degrees, be stopped. We speak not now of the moveable cartilage which is placed in this cavity, and between the bones, to render the motion easier and freer. It is found in this joint in every quadruped: and it is found wherever motions are rapid and of long continuance.

So great is the conformity between the structure of the animal and his destination, that a tolerable student in comparative anatomy, by a mere inspection of the glenoid cavity, would at once determine whether the animal to which it belonged was earnivorous, and wanted no lateral motion of the jaw ; or omnivorous, living occasionally on all kinds of food, and requiring some degree of grinding motion; or herbivorous, and needing the constant use of this admirably-constructed mill.

At $g . p .309$, is represented the masseter muscle, an exceedingly strong one, constituting the cheek of the horse-arising from the superior maxillary under the ridge continued from the zygomatic arch, and inserted into the lower jaw, and particularly round the rough border at the 
angle of the jar. This acts with the temporal muscle in closing the jaw, and in giving the direct cutting or champing motion of it.

Withiu the lower jaw, on either side, and occupying the whole of the hollowed portion of them. and opposite to the masseters, are the pterygoid muscles, going from the jaws to bones more in the centre of the channel, likewise closing the mouth, and also, by their alternate action, giving that grinding motion which has been described.

The space between the branches of the lower jaw, called the channel, is of considerable consequence. It may be a little too wide, and then the face will have a clumsy appearance: bnt if it is too narrow, the horse will never be able to bend his head freely and gracefully; he will be always pulling or boring upon the hand, nor can he possibly be well reined in.

The jaws contain the teeth, which are the nillstones employed in comminuting the food. The mouth of the horse at five years old contains forty teeth, viz. six nippers or cutting teeth in front, a tush on each side, and six molars, or grinding teeth, above and below. They are contained in cavities in the upper and lower jaws, surrounded by bony partitions, to which they are accurately fitted, and by which they are firmly supported. For a little way above these bony carities, they are surrounded by a hard substance called the gum, so dense, and adhering so closely to the teeth and the jaws as not to be separated without very great difficulty-singularly compact, that it may not be wounded by the hard or sharp particles of the food, and almost devoid of feeling, for the same purpose.

Seven or eight months before the foal is born, the germs or beginnings of the teeth are visible in the cavities of the jaws. The tooth grows, and presses to the surface of the gum, and forces its way through it; and, at the time of birth, the first and second grinders have appeared, large compared with the size of the jaw, and seemingly filling it. In the course of seven or eight days the two central nippers are seen as here represented. They like-

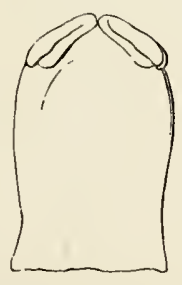

wise appear to be large, and to fill the front of the mouth; although they will afterwards be found to be small, compared with the permanent teeth that follow. In the course of the first month the third grinder appears above and below, and, not long after, and generally before six weeks have expired, another incisor above and below will be seen on each side of the two first, which have now considerably grown, but not attained their perfect height. This cut will represent the appearance of the mouth at that time.

At two months, the central nippers will bave reached their natural level, and between the second and third month the second pair will have overtaken them. They will then begin to wear away a little, and the outer edge, which was at first somewhat raised and sharp, is brought to a level with the inner one,

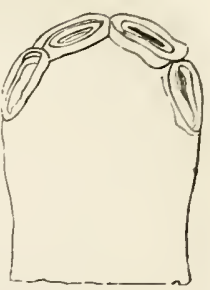
and so the mouth continues until some time between the sixth and ninth month, when another nipper begins to appear on each side of the two first, making six above and below, and completing the colt's mouth ; after which, the only observable difference, until between the second and third year, is in the wear of these teeth.

The term nipper is familiar to the horseman and the farrier, and much better expresses the action of these teeth than the word incisor or cutter, which is adopted by anatomists. Whoever has observed a horse in the act of browsing, and the twitch of the head which accompanies the separation of each portion of grass, will perceive that it is nipped or torn rather than cut off.

These teeth are covered with a polished and exceedingly hard substance, called the enamel. It spreads over that portion of the teeth which appears above the gum, and not only so, but as they are to be si) much employed in nipping the grass, and gathering up the animal's food, and in such employment even this hard substance must be gradually worn away, a portion of it, as it passes over the upper surface of the teeth, is bent inward, and sunk into the body of the teeth, and forms a little pit in them. The inside and bottom of this pit being blackened by the food, constitutes the mark of the teeth, by the gradual disappearance of which, in consequence of the wearing down of the edge, we are enabled, for several years, to judge of the age of the animal.

The colt's nipping teeth are rounded in front, somewhat hollow towards the mouth, and present at first a cutting surface, with the outer edge rising in a slanting direction above the imer edge. This, however, soon begins to wear down until both sulfaces are level, and the mark, which was originally long and narrow, becomes shorter, and wider, and fainter. At six months the four nippers are beginning to wear to a level. The annexed cut will convey some idea of the appearance of the teeth at twelve months. The four middle teeth are almost level, and the corner ones becoming so. The mark in the two middle teeth is wide and faint; in the two next teeth it is darker, and longer, 
and narrower: and in the corner teeth it is darkest, and longest, and narrowest.

The back teeth, or grinders, will not guide us far in ascertaining the age of the animal, for we cannot easily inspect them; but there are some iuteresting particulars connected with them. The foal is born with two grinders in each jaw, above and below; or they appear within three or four

days after the birth. Before the expiration of a month they are succeeded by a third, more backward. The crowns of the grinders are entirely covered with enamel on the top and sides, but attrition soon wears it away from the top, and there remains a compound surface of alternate layers of crusted petraser, enamel, and ivory, which are employed in grinding down the hardest portion of the food. Nature has, therefore, made an additional provision for their strength and eudurance.

This cut represents a grinder sawed across. It seems to be a most irregular and intricate structure; but the explanation of it is not diffi-

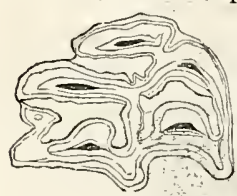
cult. The tooth is formed and prepared in cavities within the jaw-bones. A delicate membranous bag, containing a jelly-like substance, is foumd, in the unborn animal, in a little cell within the jawbone. It assumes, by degrees, the form of the tooth that is to appear, and then the jelly within the membrane thegins to change to bony matter, and a hard and beantiful erystallization is formed on the membrane without, and so we have the cutting tooth covered by its enamel. In the formation, however, of each of the grinders of the horse, there are originally five membranous bags in the upper.jaw, and four in the lower, filled with jelly. This, lyy degrees, gives place to bony matter, which is thrown out by little ressels penetrating into it, and is represented by the darker portions of the cut with central black spots. The crystallization of enamel can be traced around each, and there would be five distinct bones or teeth. A third substruce, however, is now secreted (which is represented by the white spaces), and is a powerful cement, uniting all these distinct bones into one body, and making one tooth of the five. This being done, another coat of enamel spreads over the sides, but not the top, and the tooth is completed. By no other contrivance could we have the grinding tooth capable, without injury and without wearing, to rub down the hay, and oats, and beans, which constitute the stable-food of horses.

The grinders in the lower jaw, having originally but four of these bags or shells, are smaller, and narrower, and more regular, than the upper ones. They are not placed horizontally in either jaw; but in the lower, the higher side is within, and shelving gradually outward; in the upper jaw the higher side is without, and shelving inward, and thus the grinding motion is most advantageously performed. There is also an evident difference in the appearance and structure of each of the grinders, so that a careful observer could tell to which jaw every one belonged, and what situation it oceupied.

At the completion of the first year, a fourth grinder usually comes $\mathrm{np}$, and the yearling has then, or soon afterwards, six nippers, and four grinders above and below in each jaw, which, with the alteration in the appearance of the nippers that we have just described, will enable us to calculate nearly the age of the foal, subject to some variations arising from the period of weaning, and the nature of the food.

At the age of one year and a-half, the mark in the central nippers will be much shorter and fainter; that in the two other pairs will have undergone an evident change, and all the nippers will be flat.

At two years this will be more manifest. The accompanying cut deserves attention, as giving an accurate representation of the nippers in the lower jaw of a two-years-old colt.

About this period a fifth grinder will appear. and now, likewise, will commence another process The first teeth are adapted to the size and wants of the young animal. They are sufficiently large to occupy and fill the colt's jaws; bnt when these bones have expanded with the increasing growth of the animal, the teeth are separated too far from each other to be useful, and another and larger set is required. Evident provision is made for them, even before the colt is foaled. In cavities in the jaw, beneath the first and temporary teeth, are to be seen the rudiments of a second and permanent set. These gradually increase, some with greater rapidity than others, and, pressing upon the roots or fangs of the first teeth, do not, as would be imagined, force out the former ones, but the portion pressed upon gradually disappears. It is absorbed-taken up and carried away, by nnmerous minute vessels, whose office it is to get rid of the worn-out or useless part of the system. 
This absorption continues to proceed as the second teeth grow and press upwards, until the whole of the fang is gone, and the crown of the tooth, or that part of it which was above the gum, having no longer firm hold, drops out, and the second teeth appear, larger and stronger and permanent. In a few instances, however, the second teeth do not rise immediately under the temporary or milk teeth, but somewhat by their side; and then, instead of this gradual process of absorptiou and disappearance from the point of the root upwards, the root being compressed sideways, diminishes throughout its whole bulk. The crown of the tooth diminishes with the root and the whole is pushed out of its place, to the fore part of the first grinder, and remains for a considerable time, under the name of a wolf's tooth, causing swelling and soreness of the gums, and frequently wounding the cheeks. They would be gradually quite absorbed, but the process might be slow and the annoyance would be great, and, therefore, they are extracted.

The change of the teeth commences in those which earliest appeared, and, therefore, the front or first grinder gives way at the age of two years, and is succeeded by a larger and permanent tooth.

During the period between the falling out of the central unilk nippers, and the coming up of the permanent ones, the colt, having a broken mouth, may find some difficulty in grazing. If he should fall away considerably in condition, he should be fed with mashes and corn, or cut meat.

The next cut will represent a three-years-old mouth. The central teeth are larger than the

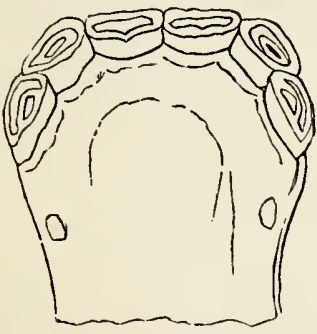

others, with two grooves in the outer convex surface, and the mark is long, narrow, deep and black. Not having yet attained their full growth, they are rather lower than the others. The mark in the two next nippers is nearly worn out, and it is wearing away in the corner nippers. Is it possible to give this mouth to an early two-years-old ? The ages of all horses used to be reckoned from May, but some are foaled even so early as January, and being actually four months over the two years, if they have been well nursed and fed, and are strong and large, they may, with the inexperienced, have an additional year put upon them. The central nippers are punched or drawn out, and the others appear three or four montlis earlier than they otherwise would. In the natural process, they could only rise by long pressing upon, and causing the absorption of, the first set. But opposition from the first set being removed, it is easy to imagine that their progress will be more rapid. Three or four months will be gained in the appearance of the teeth, and these three or four months may enable the breeder to term him a late colt of a preceding year. To him, however, who is accustomed to horses, the general form of the animalthe little development of the fore-hand-the continuance of the mark on the next pair of nippersits more evident existence in the corner ones, some enlargement or irregularity about the gums from the violence used in forcing out the teeth-the small growth of the first and tifth grinders and the non-appearance of the sixth grinder, which if it is not through the gum at three years old, is swelling under it, and preparing to get through-any or all of these circumstances, carefully attended to, will be a sufficient security against deception.

A horse at three years old ought to have the central permanent nippers growing - the other two pairs wasting-six grinders in each jaw, ahove and below - the first and fifth level with the others, and the sixth protruding. The sharp edge of the new incisors, although it could not be well expressed in the cut, will be very evident when compared with the neighbouring teeth.

As the permanent nippers wear, and continue to grow, a narrower portion of the cone-shaped tooth is exposed to the attrition, and they look as if they had been compressed, but it is not so. The mark, of course, gradually disappears as the pit is worn away.

At three years and a half, or between that and four, the next pair of nippers will be changed, and

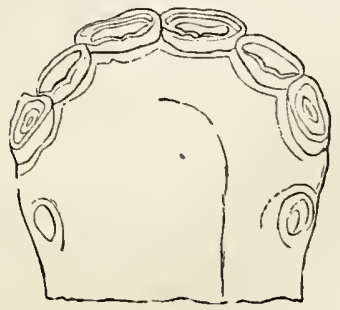

the mouth at that time cannot be mistaken. The ceutral nippers will have attained nearly tbeir full 
growth. A vacuity will be left where the second stood, or they will begin to peep above the gum, and the corner ones will be diminished in breadth, worn down, and the mark becoming small and faint. At this period, likewise, the second pair of grinder's will be shed. Previously to this may be the attempt of the dealer to give to his threeyears-old an additional year, but the frand will be detected by an examination similar to that which has been already described.

At four years, the central nippers will be fully developed; the sharp edge somewhat worn off, and the mark shorter, wider, and fainter. The next pair will be up, but they will be small, with the mark deep, and extending quite across them. The corner nippers will be larger than the inside ones, yet smaller than they were, and flat, and the mark nearly effaced. The sixth grinder will have risen to a level with the others, and the tushes will begin to appear.

Now, more than at any other time, will the dealer be anxious to put an additional year upon the animal, for the difference between a four-yearsold colt, and a five-years-old borse, in strength, utility, and value, is very great; but, the want of wear in the other nippers-the small size of the corner ones-the little growth of the tush-the smallness of the second grinder-the low forehand - the legginess of the colt, and the thickness and little depth of the mouth, will, to the man of common experience among horses, at once detect the cheat.

The tushes (see p. 323) are four in number, two in each jaw, situated hetween the nippers and the grinders-much nearer to the former than the latter, and nearer in the lower jaw than in the upper, but this distance increasing in both jaws with the age of the auimal. In shape it somewhat resembles a cone; it protrudes about an inch from the gum, and has its extremity sharp-pointed and curved. At the age now under consideration, the tushes are almost peculiar to the horse, and castration does not appear to prevent or retard their development. All mares, however, have the germs of them in the chambers of the jaw, and they appear externally in the majority of old mares. Their use is not evident. Perhaps in the wild state of the animal they are weapons of offence, and he is enabled by them more firmly to seize, and more deeply wound his enemy.

The breeder often attempts to hasten the appearance of the tush, and he cuts deeply through the gum to remove the opposition which that would afford. To a little extent he succeeds. He may possibly gain a few weeks, but not more. After all, there is much uncertainty as to the appearance of the tush, and it may vary from the fourth year to four years and six months. It belongs, in the upper jaw, both to the inferior and superior maxillary bones (see $n$, p. 265); for, while its fang is deeply imbedded in the inferior maxillary, the tooth penetrates the process of the superior maxillary at the union of those bones.

At four years and a-balf, or between that and five, the last important change takes place in the mouth of the horse. The corner nippers are shed, and the permanent ones begin to appear. The central nippers are considerably worn, and the next pair are commencing to show marks of usage. The tush has now protruded, and is generally a full half-inch in height; externally it has a rounded prominence, with a groove on either side, and it is evidently hollowed within. The reader needs not to be told that after the rising of the comer nipper the animal changes its name-the colt becomes a horse, and the filly a mare.

At five years the horse's nouth is almost perfect. The corner nippers are quite up, with the long deep mark irregular on the inside; and

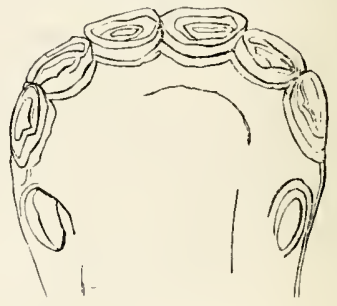

the other nippers bearing evident tokens of increasing wearing. The tush is much grownthe grooves have almost or quite disappeared, and the outer surface is regularly convex. It is still as concave within, and with the edge nearly as sharp, as it was six months before. The sixth molar is quite up, and the third molar is wanting. This last circumstance, if the general appearance of the animal, and particularly his forehand and the wearing of the centre nippers, and the growth and shape of the tushes, are likewise carefully attended to, will prevent deception, if a late four. years-old is attempted to be substituted for a five. The nippers may be brought up a few months before their time, and the tushes a few weeks, but the grinder is with difficulty displaced. The three last grinders and the tushes are never shed.

At six years the mark on the central nippers is worn out. There will still be a difference of colour in the centre of the tooth. The cement filling the hole, made by the dipping in of the enamel, will present a browner hue than the other part of the tooth, and it will be evidently surrounded by an edge of enamel, and there will even remain a little depression in the centre, and also 
a depression round the case of enamel: but the deep hole in the centre of the teeth, with the blackened surface which it presents, and the elevated edge of enamel, will have disappeared.

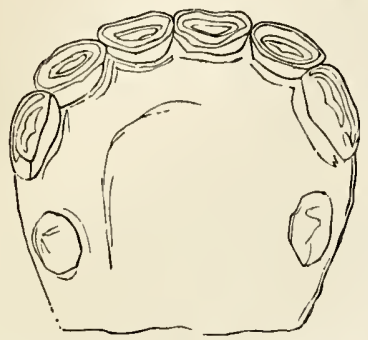

Persons not much accustomed to horses liave been puzzled here. They expected to find a plain surface of a uniform colour, and knew not what conclusion to draw when there was both discolouration and irregularity.

In the next incisors the mark is shorter, broader, and fainter; and in the corner teeth the edges of the enamel are more regular, and the surface is evidently worn. The tush has attained its full growth, being nearly or quite an inch in length; convex outward, concave within; tend. ing to a point, and the extremity somewhat curved. The third grinder is fairly up; and all the grinders are level.

The horse may now be said to have a perfect mouth. All the teeth are produced, fully grown, and have hitherto sustained no material injury. During these important changes of the teeth, the animal has suffered less than could be supposed possible. In children, the period of teething is fraught with danger. Dogs are subject to convulsions, and hundreds of them die, from the irritation caused by the cutting or shedding of their teeth; but the horse appears to feel little inconvenience. The gums and palate are occa-

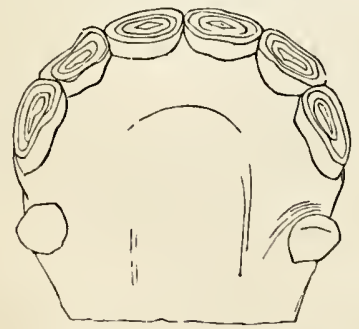

sionally somewhat hot and swollen; but the slightest scarification will remove this. The teeth of the horse are more necessary to him than those of the other animals are to them. The cliild may be fed and the dog will bolt his food; but that of the horse must be well ground down, or the nutriment cannot be extracted from it.

At seven years, the mark, in the way in which we have described it, is worn out in the four central nippers, and fast wearing away in the corner teetli; the tush also is begiming to be altered. It is rounded at the point; rounded at the edges; still round without; and beginning to get round inside.

At eight years old, the tush is rounder in every way; the mark is gone from all the bottom nippers, and it may almost be said to be out of the mouth. There is nothing remaining in the bottom nippers that can afterwards clearly show the age of the horse, or justify the most expe. rienced examiner in giving a positive opinion.

Dishonest dealers have been said to resort to a method of prolonging the mark in the lower nippers. It is called bishoping, from the name of the scoundrel who invented it. The horse of eight or nine years old is thrown, and with an engraver's tool a hole is dug in the now almost plain surface of the corner teeth, and in shape and

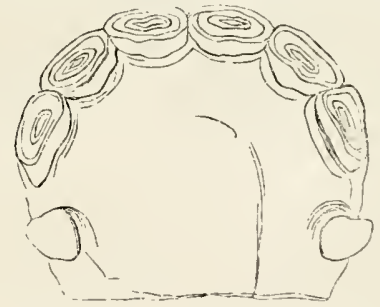

depth resembling the mark in a seven-years-old horse. The hole is then burned with a heated iron, and a permanent black stain is left. The next pair of nippers are sometimes lightly touched. An ignorant man would be very easily imposed on by this trick: but the irregular appearance of the cavity - the diffusion of the black stain around the tushes, the sharpened edges and concave inner surface of which can never be given again-the marks on the upper nippers, together with the general conformation of the horse, can never deceive the careful examiner.

Horsemen, after the animal is eight years old, are accustomed to look to the nippers in the upper jaw, and some conclusion has been drawn from the appearances which they present. It cannot be doubted that the mark remains in them some years after it has been obliterated from the nippers in the lower jaw; because the 
hard substance, or kind of cement, by which the pit or funnel in the centre of the tooth is occupied, does not reach so high, and there is a greater depth of tooth to be worn away in order to come at it. To this it may be added, that the upper nippers are not so much exposed to frictiou and wear as the under. The lower jaw alone is moved, and pressed forcibly upon the food: the upper jaw is without motion, and has only to resist that pressure.

There are various opinions as to the intervals between the disappearance of the marks from the different cutting-teeth in the upper jaw. Some have averaged it at two years and others at one. The author is inclined to adopt the latter opinion, and then the age will be thus determined: at nine years the mark will be worn out from the middle nippers-from the next pair at ten, and from all the upper nippers at eleven. During these periods the tush is likewise undergoing a manifest change -it is blunter, shorter, and rounder. In what degree this takes place in the different periods, long and most favourable opportunities for observation can alone enable the horseman to decide.

The tushes are exposed to but little wear and tear. The friction against them must be slight, proceeding only from the passage of the food over them, and from the motion of the tongue, or from the bit; and their alteration of form, although generally as we have described it, is frequently uucertain. The tush will sometimes be blunt at eight; at other times it will remain pointed at eighteen. The npper tush, although the latest in appearing, is soonest worn away.

Are there any circumstances to guide our judgment after this? There are those which will prepare us to guess at the age of the horse, or to approach within a few years of it, until he becomes very old; but there are none which will enable us accurately to determine the question, and the indications of age must now be taken from the shape of the upper surface of the nippers. At eight, they are all oval, the length of the oval running across from tooth to tooth; but as the horse gets older the teeth diminish in size, and this commencing in their width, and not in their thickness. They become a little apart from each other, and their surfaces are rounded. At nine, the centre nippers are evidently so; at ten, the others begin to have the oval shortened. At eleven, the second pair of nippers are quite rounded; and at thirteen the corner ones bave that appearance. At fourteen, the faces of the central nippers become somewhat triangular. At seventeen, they are all so. At nineteen, the angles begin to wear off, and the central teeth are again oval, but in a reversed direction, viz., from outward; inward ; and at twenty-one they all wear this form. This is the opinion of some Conti- nental veterinary surgeons, and Mr. Percivall first presented them to us in an English dress.

It would be folly to expect perfect accuracy at this advanced age of the horse, when we are bound to confess that the rules which we have laid down for determining this matter at an earlier period, although they are recognised by horsemen generally and referred to in courts of justice, will not guide ns in every case. Stabled horses have the mark sooner worn out than those that are at grass ; and a crib-biter may deceive the best judge by one or two years. The age of the horse, likewise, being formerly calculated from the first of May, it was exceedingly difficult, or almost impossible, to determine whether the animal was a late foal of one year, or an early one of the next. At nine or ten, the bars of the mouth become less prominent, and their regular diminution will designate increasing age. At eleven or twelve, the lower nippers change their original upright direction, and project forward or horizontally, and become of a yellow colour. They are yellow, becanse the teeth must grow in order to answer to their wear and tear; but the enamel which covered their surface when they were first produced cannot be repaired, and that which wears this yellow colour in old age is the part which in youth was in the socket, and therefore destitute of enamel.

The general indications of old age, independent of the teeth, are, deepening of the hollows over the eyes; grey hairs, and particularly over the eyes and about the muzzle; thinness and hanging down of the lips; sharpness of the withers; sinking of the back; lengthening of the quarters; and the disappearance of windgalls, spavins, and tumours of every kind.

Of the natural age of the horse we should form a very erroneous estimate from the early period at which he is now worn out and destroyed. Mr. Blaine speaks of a gentleman who had inree horses that died at the ages of thirty-five, thirtyseven, and thirty-nine. Mr. Cully mentions one that received a ball in his neck, at the battle of Preston, in 1715, and which was extracted at his death, in 1758; and Mr. Percivall gives an account of a barge-horse that died in his sixty second year.

There cannot be a severer satire on the Eng lish nation than this, that, from the absurd prac tice of running our race-horses at two and three years old, and working others, in various ways, long before their limbs are knit or their strength developed, and cruelly exacting from them services far beyond their powers, their age does not average a sixth part of that of the last-mentioned horse. The scientific author of the "Animal Kingdom" declares that " it may be safely asserted, that more horses are consumed in England, in every ten years, than in any other country in the 
world in ten times that period, except those which perish in war."

This affair has, with the English, been too long considered as one of mere profit and loss; and it has been thought to be cheaper to bring the young horse earlier into work, and prematurely to exhaust his strength, than to maintain him for a long period, and at a considerable expense, almost useless. The matter requires much consideration, and much reformation too.

\section{DISEASES OF THE TEETH.}

Of the diseases of the teeth in the horse we know little. Carious or hollow teeth are occasionally but not often seeu; but the edges of the grinders, from the wearing off of the enamel or the irregular growth of the teeth, become rough, and wound the inside of the cheek; it is then necessary to adopt a summary but effectual method of cure, namely, to rasp them smooth. Many bad ulcers have been produced in the mouth by the neglect of this.

The teeth sometimes grow irregularly in length, and this is particularly the case with the grinders, from not being in exact opposition to each other when the mouth is shut. The growth of the teeth still going on, and there being no mechanical opposition to it, one of the back teeth, or a portion of one of them, shoots up considerably above the others. Sometimes it penetrates the bars above, and causes soreness and ulceration: at other times it interferes partially, or altogether, with the grinding motion of the jaws, and the animal pines away without the cause being suspected. Here the saw should be used, and the projecting portion reduced to a level with the other toeth. The horse that has once been subjected to this operation should afterwards be frequently examined, and especially if he loses condition : and, indeed, every horse that gets thin or out of condition, without fever, or other apparent cause, should bare his teeth and mouth carefully examined, and especially if, without any indication of sore throat, lie quids-partly chewing and then dropping-his food, or if he holds his head somewhat on one side, while he eats, in order to get the food between the outer edges of the teeth. A horse that has once had very irregular teeth is materially lessened in value, for, although they may be sawn down as carefully as possible, they will project again at no great distance of time. Such a horse is to all intents and purposes unsound. In order to be fit for service, he should be in possession of his full natural powers, and these powers cannot be sustained without perfect nutrition, and nutrition would be rendered sadly imperfect by any defect in the operation of mastication. Not only do some diseases of the teeth render the act of mastication difficult and troublesome, lut, from the food acquiring a foetid odour during its detention in the mouth, the horse acquires a distaste for aliment altogether.

The continuance of a carious tooth often produces discase of the veighbouring ones, and of the jaw itself. It should therefore be removed, as soou as its real state is evident. Dreadful cases of fungus hæmatodes have arisen from the irritation caused by a carious tooth.

The mode of extracting the teeth requires much reformation. The hammer and the punch should never be had recourse to. The keyed in. strument of the human subject, tut on a larger scale, is the only one that should be permitted.

This is the proper place to speals more at length of the effect of dentition ou the system generally. Horsemen in geueral think too lightly of it, and they scarcely dream of the animal suffering to any considerable degree, or absolute illness being produced; yet he who has to do with joung horses will occasionally discover a considerable degree of febrile affectiou, which he can refer to this cause aloue. Fever, cough, catarrhal affections generally, disease of the eyes, cutaneous affections, diarrhøa, dysentery, loss of appetite, and general derangement, will frequently be traced by the careful observer to irritation from teething.

It is a rule scarcely admitting of the slightest deviation, that, when young horses are labouring under any ferbrile affection, the mouth should be examined, and if the tushes are prominent and pushing against the gums, a crucial incision should be made across them. "In this way," says Mr. Percivall, "I have seen catarrhal and bronchial inflammations abated, coughs relieved, lymphatic and other glandular tumours alout the head reduced, cutaneous eruptions got rid of, deranged bowels restored to order, appetite returned, and lost condition repaired."*

\section{THE TONGUE.}

The tongue is the organ of taste. It is also employed in disposing the food for being ground between the teeth, and afterwards collecting it together, and conveying it to the back part of the mouth, in order to be swallowed. It is likerrise the main instrument in deglutition, and the canal through which the water passes in the act of drinking. The root of it is firmly fixed at the bottom of the mouth by a variety of muscles; the fore part is loose in the mouth. It is corered by a continuation of the membrane that lines the mouth, and which, doubling beneath, and confining the motions of the tongue, is called its fronum, or bridle. On the back of the tongue, this mem brane is thickened and roughened, and is covered

\footnotetext{
- Pereivalrs Hippopathology, rol, ii., p. 173.
} 
with numerous conical papilla, or little eminences, on which the fibres of a branch of the fifth pair of nerves expand, communicating the sense of taste. The various motions of the tongue are accomplished by means of the ninth pair of nerves. The substance of the tongue is composed of muscular fibres, with much fatty matter interposed between them, and which gives to this organ its peculiar softness.

\section{DISEASES OF THE TONGUE.}

The tongue is sometimes exposed to injury from carelessness or violence in the act of drenching or administering a ball, it being pressed agaimst and cut by the edges of the grinders. A little diluted tincture of myrrh, or alum dissolved in water, or even nature unassisted, will speedily heal the wound. The horse will sometimes bite his tongne, most frequently in his sleep. If the injury is trifling, it roquires little care; but, in some instances, a portion of the tongue has been deeply, lacerated or bitten off. The assistance of a veterinary practitioner is here required.

There are some interesting accounts of the results of this lesion. Mr. Dickens of Kimbolton found a portion of the tongue of the mare, extendingas far as the frænulum beneath, lying in the manger in a strangely lacerated condition, and fast approaching to decomposition. He had her cast, and, excising all the unhealthy portions, he dressed the wound with chloride of soda and tincture of myrrh. In less than a week the laceration was nearly healed, aud, soon afterwards, she could eat with very little difficulty, and keep herself in good condition. The injury was proved to have been inflicted by a brutal horsebreaker, in revenge for some slight affront.*

A curions case is recorded in the Memoirs of the Society of Calrados. A horse was difficult to groom. The soldier who had the care of him, in order the better to manage him, fixed in his mouth and ou his tongue a strong chain of iron, deeply serrated, while another man gave to this chain a terrible jerk whenever the horse was disposed to be rebellious. The animal, under such torture, became unmanageable, and the man who held the chain sawing away with all his strength, the tougue was completely cut off at the point which separates its base from the free portion of it. The wound healed favourabiy, and he was soon able to manage a mash. After that some hay was given to him in small quantities. He took it and formed it into a kind of pellet with his lips, and then, pressing it against the bottom of his manger, he gralually forced it sufficiently back into the mouth to be enabled to seize it with his griuders.

* Veterinarian, vol. vi, p. 22.
Another horse came to an untimely end in a singular way. $\mathrm{He}$ had scarcely eaten anything for three weeks. He seemed to be unable to swallow. The channel beneath the lower jaw had much enlargement about it. There was not any known cause for this, nor any account of violence done to the tongue. At length a tumour appeared under the jaw. Mr. Young of Muirhead punctured it, and a considerable quantity of purulent matter escaped. The horse could drink his gruel after this, but not take any solid food. A week afterwards he was found dead. Upon separating the head from the trunk, and cutting transversely upon the tongue, nearly opposite to the se: cond grinder, a needle was found lying longitudinally, and which had penetrated from the side to the inferior portion of the tongue. It was an inch and a quarter in length, and the neighbouring substance was in a state of gangrene.

Vesicles will sometimes appear along the under side of the tongue, which will increase to a considerable size. 'I he tongue itself will be much enlarged, the animal will be unable to swallow, and a great quantity of ropy saliva will drivel from the mouth. This disease often exists without the nature of it being suspected. If the mouth is opened, one large bladder, or a succession of bladders, of a purple hue, will be seen extending along the whole of the under side of the tongue. If they are lanced freely and deeply, from end to end, the swelling will very rapidly abate, and any little fever that remains may be subdued by cooling medicine. The cause of this disease is not clearly known.

\section{THE SALIVARY GLANDS.}

In order that the food may be properly comminuted preparatory to digestion, it is necessary that it should be previously moistened. The food of the stabled horse, however, is dry, and his meal is generally concluded without any fluid being offered to him. Nature has made a provision for this. She has placed in the neighbourhood of the mouth various glands to secrete, and that plentifully, a limpid fluid, somewhat saline to the taste. This fluid is conveyed from the glands into the mouth, by various ducts, in the act of chewing, and, being mixed with the food, renders it more easily ground, more easily passed afterwards into the stomach, and better fitted for digestion.

The principal of these is the parotid gland (see cut, p. 309). It is placed in the hollow which extends from the root of the ear to the angle of the lower jaw. A portion of it, $q$, is represented as turned up, to show the situation of the bloodvessels underneath. In almost every case of cold connected with sore throat an enlargement of the parotid gland is evident to the feeling, and even to the eye. It is composed of numerous small 
glands connected together, and a miuute tube proceeding from each, to carry away the secreted fluid. These tubes unite in one common duct. At the letter $u$, the parotid duct is seen to pass under the angle of the lower jaw, together with the submaxillary artery, and a branch of the jugular vein, and they came out again at $w$. At $r$, the duct is seen separated from the other vessels, climbing up the cheek, and piercing it to discharge its contents into the mouth, opposite to the second grinder. The quantity of fluid thus poured into the mouth from each of the parotid glands amounts to a pint and a half in au hour, during the action of mastication; and, sometimes, when the duct has been accidentally opened, it has spirted out to the distance of several feet.

The parotid gland sympathises with every iuflammatory affection of the upper part of the throat, and therefore it is found swollen, hot, and tender, in almost every catarrh or cold. The catarrh is to be treated in the usual way; while a stimulating application, almost amounting to a blister, well rubbed over the gland, will best subdue the inflammation of that body.

In bad strangles, and, sometimes, in violent cold, this gland will be much enlarged and ulcerated, or an obstruction will take place in some part of the duct, and the accumulating fluid will burst the vessel, and a fistulous ulcer be formed that will be very difficult to heal. A veterinary surgeon alone will be competent to the treatment of either case ; and the principle by which he will be guided, will be to heal the abscess in the gland as speedily as he can, and, probably, by the application of the heated iron: or, if the ulcer is in the duct, either to restore the passage through the duct, or to form a new one, or to cut off the flow of the saliva by the destruction of the gland.

A second source of the saliva is from the $s u b$ maxillary glands, or the glands under the jaw. One of them is represented at $s$, p. 310 . The submaxillary glands occupy the space underneath and between the sides of the lower jaw, and consist of numerous small bodies, each with its proper duct, uniting together, and forming on each side a common duct or vessel that pierces tlirough the muscles at the root of the tongue, and opens in little projections, or heads, upon the franum, or bridle of the tongue, about an inch and a half from the front teeth. When the horse has catarrh or cold, these glands, like the parotid gland, enlarge. This is often to be observed after strangles, and several distinct kernels are to be felt under the jaw. It has already been stated that they may be distinguished from the swellings that accompany or indicate glanders, by their being larger, generally not so distinct, more in the centre of the channel, or space between the jaws, and never adhering to the jaw-bones. The farriers call them vives, and often adopt cruel and absurd methods to disperse them,-as burning them witl a lighted candle, or hot iron, or èven cutting them ont. They will, in the majority of instances, gradually disperse in proportion as the disease which produced them subsides; or they will yield to slightly stimulating embrocations; or, if they are obstinate in their continuance, they are of no further consequence, than as indicating that the horse has laboured under severe cold or strangles.

During catarrh or inflammation of the mouth, the little projections marking the opening of these ducts on either side of the bridle of the tongue are apt to enlarge, and the mouth under the tongue is a little red, and hot and tender. The farriers call these swellings barbs or paps; and as soon as they discover them, mistaking the effect of disease for the cause of it, they set to work to cut them close off. The bleeding that follows this operation somewhat abates the local inflammation, and affords temporary relief; but the wounds will not speedily heal. The saliva continues to fow from the orifice of the duct, and, running into the irregularities of the wound, causes it to spread and deepen. Even when it heals, the mouth of the duct being frequently closed, and the saliva continung to be secreted by the submaxillary gland, it accumulates in the duct, until that vessel bnrsts, and alscesses are formed which eat deeply under the root of the tongue and long torment the poor animal. When, after a great deal of trouble, they are closed, they are apt to break ont again for months and years afterwards.

All that is necessary with regard to these paps or barbs is to abate the inflammation or cold that caused them to appear, and they will very soon and perfectly subside. He who talks of cutting them out is not fit to be trusted with a horse.

A third source of saliva is from glands under the tongue-the sublingual glands, which open by many little orifices under the tongue, resembling little folds of the skin of the mouth, hanging from the lower surface of this organ, or found on the bottom of the mouth. These likewise sometimes enlarge during catarrh or inflammation of the mouth, and are called gigs, and bladders, and flaps in the mouth. They have the appearance of small pimples, and the farrier is too apt to cut them away, or burn them off. The better way is to let them alone-for in a few days they will generally disappear. Should any ulceration remain, a little tincture of myrrh, or a solution of alum, will readily heal them.

Besides these three principal sources of saliva, there are small glands to be found on every part of the mouth, cheeks, and lips, which pour out a considerable quantity of fluid, to assist in moistelling and preparing the food. 
STRATGLES.

This is a disease principally incident to young horses-usually appearing between the fourth and fifth year, and oftener in the spring than in any other part of the year. It is preceded ly cough, and cau at first be scarcely distinguished from common cough, except that there is more discharge from the nostril, of a sellowish colour, mixed with pus, and generally without smell. There is likewise a considerable discharge of ropy fluid from the mouth, and greater swelling than usual under the throat. This swelling increases with uncertain rapidity, accompanied by some fever, and disinclination to eat, partly arising from the fever, but more from the pain which the animal feels in the act of mastication. There is considerable thirst, but after a gulp or two the horse ceases to drink, yet is evidently desirous of continuing his draught. In the attempt to swallow, and sometimes when not drinking, a couvulsive cough comes on, which almost threatens to suffocate the animal-and thence, probably, the name of the disease.*

The tumour is under the jaw, and about the centre of the channel. It soon fills the whole of the space, and is evidently one uniform body, and may thus be distinguished from glanders, or the enlarged glands of catarrh. In a few days it becomes more prominent and soft, and evidently contains a fluid. This rapidly increases; the tumour bursts, and a great quantity of pus is discharged. As soon as the tumour has broken, the cough subsides, and the horse speedily mends, although some degree of weakness may hang about him for a considerable time. Few horses, possibly noue, escape its attack; but, the disease having passed over, the animal is free from it for the remainder of his life. Catarrh may precede, or may predispose to, the attack, and, undoubtedly, the state of the atmosphere has much to do with it, for both its prevalence and its severity are counected with certain seasons of the year and changes of the weather. There is no preventive for the disease, nor is there anything contagious about it. Many strange stories are told with regard to this; but the explanation of the matter is, that when several horses in the same farm, or in the same neighbourhood, have had strangles at the same time, they have been exposed to the same powerful but unknown exciting cause.

Messrs. Percivall and Castley have come the nearest to a satisfactory view of the nature of strangles. Mr. Castley $\dagger$ says, that "the period

* Old Gervase Markham gives the following description of this disease, and of the origin of its name :- "It is," says he, "a great and hard swelling between a horse's nether chaps, upon the rootes of his tongue, and about his throat, which swelling, if it be not prevented, will stop the horse's windpipe, and so strangle or choake him: from which effect, and none other, the name of this disease tooke its derivation."

+ Veterinarian, iii., 406, and vi., 607. of strangles is often a much more trying and critical time for young horses than most people seem to be aware of ; that when colts get well over this conplaint, they generally begin to thrive and improve in a remarkable manner, or there is sometimes as great a change for the worse: in fact, it seems to effect some decided constitutional change in the animal."

Mr. Percivall adds, "the explanation of the case appears to me to be, that the animal is suffering more or less from what I would call stranglefever, - a fever the disposition and tendency of which is to produce local tumour and abscess, and, most commonly in that situation, underneath the jaws, in which it has obtained the name of strangles."

Professor Dick, of Edinburgh, adds that which is conclusive on the subject, that "although the disease commonly terminates by an abscess under the jaw, yet it may, and occasionally does, give rise to collections of matter on other parts of the surface."

To this conclusion then we are warranted in coming, that strangles is a specific affection to which horses are naturally subject at some period of their lives, and the natural cure of which seems to be a suppurative process. From some cause, of the nature of which we are ignorant, this suppurative process usually takes place in the space between the branches of the maxillary uone, and occurring there it appears in the mildest form, and little danger attends. When the disease is ushered in by considerable febrile disturbance, and the suppuration takes place elsewhere, the horse too frequently sinks under the attack.

The treatment of strangles is very simple. As the essence of the disease consists in the formation and suppuration of the specific tumour, the principal, or almost the sole attention of the practitioner, should be dirccted to the hastening of these processes: therefore, as soon as the tumour of strangles is decidedly apparent, the part should be actively blistered. Old practitioners used to recommend poultices, which, from the thickness of the horse's skin, must have very little effect, even if they could be confined on the part; and from the difficulty and almost impossibility of this, and their getting cold and hard, they necessarily weakened the energies of nature, and delayed the ripening of the tumour. Fomentations are a little more effectual. A blister will not only secure the completion of the process, but hasten it by many days, and save the patient much pain and exhaustion. It will produce another good effect-it will, previously to the opening of the tumour, abate the internal inflammation and soreness of the throat, and thus lessen the cough and wheezing.

As soon as the swelling is soft on its summit, and evidently contains matter, it should be freely 
and deeply lanced. It is a bad, although frequent practice, to suffer the tumour to burst naturally, for a ragged ulcer is formed, very slow to heal, and difficult of treatment. If the incision is deep and large enough, no second collection of matter will be formed: and that which is already there may be suffered to run out slowly, all pressure with the fingers being avoided. The part should be kept clean, and a little friar's balsam daily injected into the wound.

The remainder of the treatment will depend on the symptoms. If there is much fever, and evident affection of the chest, and which should carefully be distinguished from the oppression and cholking occasioned by the pressure of the tumour, it will be proper to bleed. In the majority of cases, however, bleeding will not only be unneces. sary, but injurious. It will delay the suppuration of the tumour, and increase the subsequent debility. A few cooling medicines, as nitre, emetic tartar, and perhaps digitalis, may be given, as the case requires. The appetite, or rather the ability to eat, will return with the opening of the abscess. Bran-mashes, or fresh-cut grass or tares, should be liberally supplied, which will not only afford sufficient nourishment to recruit the strength of the animal, but keep the bowels gently open. If the weakness is not great, no farther medicine will be wanted, except a dose of mild physic in order to prevent the swellings or eruptions which sometimes succeed to strangles. In cases of debility, a small quantity of tonic medicine, as chamomile, gentian, or ginger, may be administered.*

\section{THE PHARTNX.}

Proceeding to the back of the mouth, we find the pharynx (carrying or conveying the food to. wards the stomach). It commences at the root of the tongue (see 7,8 , and 9, p. 266); is separated from the mouth by the soft palate (7), which hangs down from the palatine bone at 8 , and extends to

- Mr. Percivall gives the following description of eome untoward cases:- "The submaxillary tumour is often knotted and divided on its first appearance, as if the glands received the primary attack. As it apreads, it becomes diffused in the cellular tissue included in the space between the sides ead branches of the lower jaw, involving all the subcutaneous parts cuntaiged in that interval indiscrimiaately in one uniform mass of tumefaction. Wbile this general turgescence is going on, various parts in the immediate vicinity often take on the same kind of action. In particular, the salivary glands, the parntid, sublingual, the throat, the pharynx and laryns, the nose, the lining membrane, the nostrils, the sianses, the mouth, the tongue, the cheeks, the lips-in fine, in come violent cases, tha whole head appears to be involved in one the epiglottis or covering to the windpipe. When the food has been sufficiently ground by the teeth, and mixed with the saliva, it is gathered together by the tongue, and by the action of the cheeks and tongue, and back part of the mouth, forced against the soft palate, which, giving way, and being raised upwards towards the entrance into the nostrils, prevents the food from proceeding that way. It passes to the pharynx, and the soft palate again falling down, prevents its return to the mouth, and also prevents, except in extreme cases, the act of vomiting in the horse. Whatever is returned from the stomach of the horse, passes through the nose, as the cut will make evident.

The sides of the pharynx are lined with muscles which now begin powerfully to contract, and by that contraction the bolus is forced on until it reaches the gullet (10), which is the termination of the pharynx. Before, however, the food proceeds so far, it has to yass over the entrance into the windpipe (3), and should any portion of it enter that tube, much inconvenience and danger might result; therefore, this opening is not only lined by muscles which close it at the pleasure of the animal, but is likewise covered by a heart-like elastic cartilage, the epiglottis (2), with its back towards the pharynx, and its hollow towards the aperture. The epiglottis yields to the pressure of the bolus passing over it, and lying flat over the opening into the windpipe, and prevents the possibility of anything entering into it. No sooner, however, has the food passed over it, than it rises again by its own elasticity, and leares the upper part of the windpipe once more open for the purpose of breathing. The voice of animals is produced by the passage of air through this aperture, communicating certain vibrations to certain folds of the membrane covering the part, and these vibrations being afterwards modified in their passage through the carities of the nose. In order to understand the diseases of these parts, the anatomy of the neck generally must be considered.

general mass of tumefaction, while every vent is running over with discharge. The patient experiencing this violent form of disease is in a truly pitiable plight. While purtuent matter is issuing in profusion from his swollen nostrils, and slaver foems out from between his tumefied lips, it is distressing to hear the noise that he makes in painful and laboured efiorts to breathe. There is imminent danger of suffocation in such a case as this; and even al. thongh some relief, so far as the breathing is concerned, may be obtaioed from the operation of bronchotomy, yet, from the pain and irritation he is suffering, added to the impossibility of getting aliment into bis stomach, he must speedily sink to rise no more." - Feterinarian, rol. vi. p. 611. 


\section{CHAPTER IX.}

THE ANATOMY AND DISEASES OF THE NECK AND NEIGHBOURING PARTS.

THE neck of the horse, and of every animal belonging to the class mammalia, except one species, is composed of seven bones called vertebra, moveable or turning upon each other (see cut, p. 263). They are connected together by strong ligaments, and form so many distinct joints, in order to give sufficiently extensive motion to this important part of the body. The bone nearest to the skull is called the atlas (see cut, p. 263, and $g$, p. 266), because, in the human being, it supports the head. In the horse the head is suspended from it. It is a mere ring-shaped bone, with broad projections sideways; but without the sharp and irregular processes which are found on all the others. The pack-wax, or ligament, by which the head is principally supported $(f, \mathrm{p} .266)$, and which is strongly connected with all the other bones, passes over this without touching it, by which means the head is much more easily and extensively moved. The junction of the atlas with the head is the seat of a very serious and troublesome ulcer, termed

\section{POLL-EWII.}

From the horse rubbing and sometimes striking his poll against the lower edge of the manger, or hanging back in the stall and bruising the part with the halter-or from the frequent and painful stretching of the ligaments and muscles by unnecessary tight reining, and, occasionally, from a violent blow on the poll, carelessly or wantonly inflicted, inflammation ensues, and a swelling appears, hot, tender, and painful. It used to be a disease of frequent occurrence, but it is now, from better treatment of the animal, of comparatively rare occurrence.

It has just been stated, that the ligament of the neck passes over the atlas, or first bone, without being attached to it, and the seat of inflammation is between the ligament and the bone beneath; and being thus deeply situated, it is serious in its nature and difficult of treatment.

The first thing to be attempted is to abate the inflammation by bleeding, physic, and the application of cold lotions to the part. In a very early period of the case a blister might have considerable effect. Strong purgatives should also be employed. $\mathrm{By}$ these means the tumour will sometimes be dispersed. This system, however, must not be pursued too far. If the swelling increases, and the heat and tenderness likewise increase, matter will form in the tumour; and then our object should be to hasten its formation by warm fomen- tations, poultices, or stimulating embrocations. As soon as the matter is formed, which may be known by the softness of the tumour, and before it has time to spread around and eat into the neighbouring parts, it should be evacuated. Now comes the whole art of treating poll-evil; the opening into the tumour must be so contrived that all the matter shall run out, and continue afterwards to run out as quickly as it is formed, and not collect at the bottom of the ulcer, irritating and corroding it. This can be effected by a seton alone. The needle should enter at the top of the tumour, penetrate through its bottom, and be brought out at the side of the neck, a little below the abscess. Without auything more than this, except frequent fomentation with warm water, in order to keep the part elean, and to obviate inflammation, pollevil in its early stage will frequently be cured.

If the ulcer has deepened and spread, and threatens to eat into the ligaments of the joints of the neck, it may be necessary to stimulate its surface, and perhaps painfully so, in order to bring it to a healthy state, and dispose it to fill up. In extreme cases, some highly stimulating application may be employed, but nothing resembling the scalding mixture of the farriers of the olden time. This is abominable! horrible!! All measures, however, will be ineffectual, unless the pus or matter is, by the use of setons, perfectly evacuated. The application of these setons will require the skill and anatomical knowledge of the veterinary surgeon. In desperate cases, the wound may not be fairly exposed to the action of the caustic without the division of the ligament of the neck. This may be effeeted with perfect safety; for although the ligament is carried on to the occipital bone, and some strength is gained by this prolongation of it, the main stress is on the second bone; and the head will continue to be supported. The divided ligament, also, will soon unite again, and its former usefulness will be restored when the wound is healed.

The second bone of the neck is the dentata, having a process like a tooth, by which it forms a joint with the first bone. In the formation of that joint, a portion of the spinal marrow, which runs through a canal in the centre of all these bones, is exposed or covered only by ligament; and by the division of the marrow at this spot an animal is instantly and humanely destroyed. The operation is called pithing, from the name (the pith) given by butchers to the spinal marrow. The other neck, or rack bones, as they are 
denominated by the farrier, (B, p. 363,) are of a strangely irregular shape, yet bearing considerable resemblance to each other. They consist of a central bone, perforated for the passage of the spinal marrow with a ridge on the top for the attachment of the ligament of the neck, and four irregular plates or processes from the sides, for the attachment of muscles; at the base of one of which, on either side, are holes for the passage of the large arteries and veins. At the upper end of each, is a round head or ball, and at the lower end, a cavity or cup, and the head of the one being received into the cup of the other, they are united together, forming so many joints. They are likewise united by ligaments from these processes, as well as the proper ligaments of the joints, and so securely, that no dislocation can take place between any of them, except the first and second, the consequence of which would be the immediate death of the animal.

The last, or seventh bone, has the elevation on the back or top of it continued into a long and sharp prolongation (a spinous process), and is the beginning of that ridge of bones denominated the withers (see cut, pp. 263 and 344); and as it is the base of the column of neck bones, and there must be a great pressure on it from the weight of the head and neck, it is curiously contrived to rest ujon and unite with the two first ribs.

\section{THE MUSCLES AND PROPER FORM OF THE NECK.}

The bones of the neck serve as the framework to which numerous muscles concerned in the motions of the head and neck are attached. The weight of the head and neck is supported by the ligament without muscular aid, and without fatigue to the animal; but in order to raise the head higher, or to lower it, or to turn it in every direction, a complicated system of muscles is necessary. Those whose office it is to raise the head are most numerous and powerful, and are placed on the upper and side part of the neck. The cut in p. 309 contains a few of them.

$c$ marks a tendon common to two of the most important of them, the splenius or splint-like muscle, and the complexus major, or larger complicated muscle. The splenius constitutes the principal bulk of the neck above, arising from the ligament of the neck all the way down it, and going to the processes of all the bones of the neck, but the first, and tendons running from the upper part of it, to the first bone of the neck, and to a process of the temporal bone of the head. Its action is sufficiently evident, namely, very powerfully to elevate the head and neck. The principal beauty of the neck depends on this mnscle. It was admirably developed in the horse of whose neck the annexed cut gives an accurate delineation.

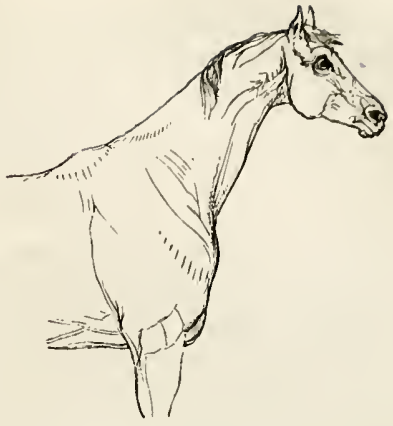

If the curve were quite regular from the poll to the withers, we should call it a perfect neck. It is rather a long neck, and we do not like it the less for that. In the carriage horse, a neck that is not half concealed by the collar is indispensable, so far as appearance goes; and it is only the horse with a neck of tolerable length that will bear to be reined up, so as to give this part the arched and beautiful appearance which fashion demands. It is no detriment to the riding-horse, and there are few horses of extraordinary speed that have not the neck rather long. The race-horse at the top of his speed not only extends it as far as he can, that the air-passages may be as straight as he can make them, and that he may therefore be able to breathe more freely, but the weight of the head and neck, and the effect increasing with their distance from the trunk, add materially to the rapidity of the animal's motion. It has been said, that a horse with a long neck will bear heary on the hand; neither the length of the neck nor even the bulk of the head has any influence in causing this. They are both counterbalanced by the power of the ligament of the neck. The setting on of the head is most of all connected with heavy bearing on the hand, and a short-necked horse will bear heavily, because, from the thickness of the lower part of the neck, consequent on its shortness, the head cannot be rightly placed, nor, generally, the shoulder.

Comnected with the splenius muscle, and partly produced by it, are the thickness and muscularity of the neck, as it springs from the shoulders, in this cut; the height at which it comes out from them forming nearly a line with the withers; and the manner in which it tapers as it approaches the head. The neck of a well-formed horse, howerer fine at the top, should be muscular at the bottom, or the horse will generally be weak and worthless.

Necks devoid of this muscularity are called 
loose necks by horsemen, and are always considered a very serious objection to the animal. If the veck is thin and lean at the upper part, and is otherwise well shaped, the horse will usually carry himself well, and the head will be properly curved for beauty of appearance and ease of riding. When an instance to the contrary occurs, it is to be traced to very improper management, or the space between the jaws being unnaturally small.

The splenius muscle, although a main agent in raising the head and neck, may be too large, or covered with too much cellular substance or fat, thus giving an appearance of heaviness or even clumsiness to the neck. This peculiarity of form constitutes the distinction between the perfect horse and the mare, and also the gelding, unless castrated at a very late period.

This tendon, $c$, belongs also to another muscle, which makes np the principal bulk of the lower part of the neck, and is called the complexus major, or larger complicated muscle. It arises partly as low as the transverse processes of the four or five first bones of the back, and from the five lower bones of the neck; and, the fibres from these various sources uniting together, form a very large and powerful muscle, the largest and strongest in the neck. As it approaches the head, it lessens in bulk, and terminates partly with the splenius, in this tendon, but is principally inserted into the back part of the occipital bone, by the side of the ligament of the neck. In the cut, (p. 309,) almost its whole course can be distinctly traced. Its office is to raise the neck and elevate the head; and being inserted into such a part of the occiput, it will more particularly protrude the nose, while it raises the head. Its action, however, may be too powerful; it may be habitually so, and then it may produce deformity. The back of the head being pulled back, and the muzzle protruded, the horse cannot by possibility carry his head well. He will become what is technically called a star-gazer;heavy in hand, boring upon the bit, and unsafe. To remedy this, recourse is had, and in the majority of cases without avail, to the martingale, against which the horse is continually fighting, and which is often a complete annoyance to the rider. Such a horse is almost useless for harness.

Inseparable from this is another sad defect, so far as the beauty of the horse is concerned;-he becomes eve-necked, i. e., he has a neck like a ewe -not arched above, and straight below, until near to the head, but hollow above and projecting below; and the neck rising low out of the chest, even lower sometimes than the points of the shoulders. There can scarcely be anything more unsightly in a horse. His head can never be got fairly down; and the bearing rein of harness must be to him a source of constant torture. In regard- ing, however, the length and the form of the neck, reference must be had to the purpose for which the borse is intended. In a hackney few things can be more abominable than a neck so disproportionable, so long that the hand of the rider gets tired in managing the head of the horse. In a race-horse this lengthening of the neck is a decided advantage.

Among the muscles employed in raising the head, are the complexus minores (smaller complicated), and the recti (straight), and the oblique muscles of the npper part of the neck, and belonging principally to the two first bones of the neck, and portions of which may be seen under the tendon of the splenius $c$, and between it and the ligament $a$.

Among the muscles employed in lowering the head, some of which are given in the same cut, is the sterno-maxillaris, $d$, belonging to the breastbone, and the upper jaw. It can likewise be traced, although not quite distinctly, in the cut, p. 337. It lies immediately under the skin. It arises from the cartilage projecting from, or constituting the front of the breast-bone $(H$, p. 263), and proceeds up the neck, of no great bulk or strength. At about three-fourths of its length upward, it clanges to a flat tendon, which is seen $(d$, p. 309$)$ to insinnate itself between the parotid and submaxillary glands, in order to be inserted into the angle of the lower jaw. It is used in bending the head towards the chest.

Another muscle, the termination of which is seen, is the levator humeri, raiser of the sboulder, $b$. This is a much larger muscle than the last, because it has more duty to perform. It rises from the back of the head and four first bones of the neck and the ligament of the neck, and is carried down to the shoulder, mixing itself partly with some of the muscles of the shoulder, and finally continued down to and terminating on the humerus $(J$, p. 263). Its office is double. If the horse is in action, and the head and neck are fixed points, the contraction of this muscle will draw forward the shoulder and arm; if the horse is standing, and the shoulder and arm are fixed points, this muscle will depress the head and neck.

The muscles of the neck are all in pairs. One of them is found on each side of the neck, and the office which has been attributed to them can only be accomplished when both act together; but supposing that one alone of the elevating muscles should act, the head would be raised, but it would at the same time be turned towards that side. If one only of the depressor muscles were to act, the head would be bent downwards, but it would likewise be turned towards that side. Then it will be easily seen that by this simple method of having the muscles in pairs, provision is made for every kind 
of motion, upwards, downwards, or on either side, for which the animal can possibly have occasion. Little more of a practical nature could be said of the muscles of the neck, although they are proper and interesting studies for the anatomist.

This is the proper place to speak of the mane, that long hair which covers the crest of the neck, and adds so much to the beauty of the animal. This, however, is not its only praise. In a wild state the horse has mauy battles to fight, and his neck deprived of the mane would be a vulnerable part. The hair of the mane, the tail, and the legs, is not shed in the same manner as that on the body. It does not fall so regularly nor so often; for if all were shed at once, the parts would be left for a long time defenceless.

The mane is generally dressed so as to lie on the right side-some persons divide it equally on both sides. For ponies it used to be cut off near the roots, only a few stumps being left to stand perpendicularly. This was termed the hog-mane. The groom sometimes bestows a great deal of pains in getting the mane of his horse into good and fashionable order. It is retted, and plaited, and loaded with lead; and every hair that is a little too long is pulled out. The mane and tail of the heavy draught-horse are seldom thin, but on the well-bred horse the thin well-arranged mane is very ornamental.*

THE BLOOD-VESSELS OF THE NECK.

Running down the under part of the neck are the principal blood-vessels going to and returning from the head, with the windpipe and gullet. Our cut could not give a view of the arteries that carry the blood from the heart to the head, beause' they are too deeply seated. The external arteries are the carotil, of which there are two. They ascend the neck on either side, close to the windpipe, until they have reached the middle of the neck, where they somewhat diverge, and lie more deeply. They are covered by the sterno-maxillaris muscle, which has been just described, and are separated from the jugulars by a small portion of muscular substance. Having reached the larynx, they divide into two branches, the external and the internal; the first goes to every part of the face, and the second to the brain

The vertebral arteries run through canals in the bones of the neck, supplying the neighbouring parts as they climb, and at length enter the skull at the large hole in the occipital bone, and ramify on and supply the brain.

Few cases can happen in which it would be either necessary o1 justifiable to bleed from an artery. Even in mad-staggers the bleeding is more practicable, safer, aud more effectual, from the jugular vein than from the temporal or any

* Stewart's Stable Ecanomy, p. 110. other artery. If an artery is opened in the direction in which it runs, there is sometimes very great difficulty in stopping the bleeding; it has even been necessary tio tie the vessel in order to accomplish this purpose. If the artery is cut across, its coats are so elastic that the two ends are often immediately drawn apart under the flesh at each side, and are thereby closed; and after the first gush of blood no more can be obtained.

$$
\text { THE VEINS OF THE NECK. }
$$

The external reins which return the blood from the head to the heart are the jugulars. The horse has but one on either side. 'The luman being and the ox have two. The jugular takes its rise from the base of the skull ; it then descends, receiving other branches in its way towards the angle of the jaw and behind the parotid gland; and emerging from that, as seen at $t, \mathrm{p} .309$, and being united to a large branch from the face, it takes its course down the neck. Veterinary surgeons and horsemen have agreed to adopt the jugular, a little way below the union of these two branches, as the usual place for bleeding; and a very convenient one it is, for it is easily got at, and the ressel is large. The manner of bleeding, and the states of constitution and disease in which it is proper, will be hereafter spoken of ; an occasional consequence of bleeding being at present taken under consideration.

It is usual and proper, after bleeding, to bring the edges of the wound carefully together, and to hold them in contact by inserting a pin through the skin, with a little tow twisted round $i t$. In ninety-nine cases ont of a hundred the wound quickly heals, and gives no tronble; but in a few instances, from using a blunt instrument, or a dirty or rusty one; or striking too hard and bruising the vein ; or, in the act of pinning up, pulling the skin too far from the neck and suffering some blood to insinnate itself into the cellular texture; or ne glecting to tie the horse up for a little while, and thus enabling him to rub the bleeding place against the manger and tear out the pin; or from the animal being worked immediately afterward; or the reins of the bridle rubbing against it; or several blows having been clumsily given, and a large and ragged wound made; or from some disposition to inflammation about the horse (for the bieeder is not always in fault) the wound does not heal, or if it closes for a little while, it re-opens. A slight bleeding appears-some tnmefaction commences-the edges of the orifice separate, and become swollen and red-a discharge of sanious bloody fluid proceeds from the wound, followed, perhaps, in a few days by purulent matter. The neck swells, and is hot and tender both above and below the incision. The lips of the round become everted-the swelling increases, particularly abore 
the wound, where the vein is most hard and cordy - the horse begins to loathe his food, and little abscesses form round the orifice. The cordiness of the vein rapidly increases. Not only the vein itself has become obstructed and its coats thickened, but the cellular tissue inflamed and hardened, and is an additional source of irritation and torture.

The thickening of the vein extends to the bifurcation above: it occupies both branches, and extends downwards to the chest-even to the very heart itself, and the patient dies.

The two grand questions here are, the cause and the cure. The first would seem to admit of an easy reply. A long list of circumstances has been just given which would seem to refer the matter entirely to the operator; yet, on the other hand, experience tells us that he has little to do with these morbid effects of bleeding. Mr. Percivall states, that Mr. Cherry tried several times to produce inflammation by the use of rusty lancets, and escharotics of various kinds, and ligatures, and frequent separation and friction of the granulating edges, but in vain. Professor Spooner tried to produce the disease, but could not.

On the other hand, it is well known that while inflammation rarely or never follows the operation of bleeding by some practitioners, others are continually getting into scrapes about it, The writer of this work had three house-pupils, two of whom he used to trust to bleed his patients, and no un. toward circumstance ever occurred : but as surely as he sent the third, he had an inflamed vein to take care of.

There is something yet undivulged in the process of healing the vein, or in the circumstances by which that healing is prevented. The most powerful canses probably are, that the lips of the wound have not been brought into immediate apposition, or that a portion of the hair-a single hair is sufficient-has insinuated itself. The horse has not, perhaps, had his head tied up to the rack after bleeding, which should always be done for at least an hour, during which time the extravasated blood will become firmly coagula. ted, and the flow of blood to the heart will estab. lish its uninterrupted conrse. It is also probable that atmospherie agency may be concerned in the affair, or a diseased conlition of the horse, and particularly a susceptibility of taling on inflammatory action, although the exciting canse may be exceedingly slight.

Of the means of cure it is difficult to speak confidently. The wound should be carefully exanined-the divided edges brought into exact apposition, and any hair interposed between them removed-the pin withdrawn or not, according to circumstances-the part carefully and long fomented, and a dose of physic administered. If two or three days bave passed and the discharge still remains, the application of the budding-ironnot too large or too hot-may produce engorgement of the neighbouring parts, and union of the lips of the wound. This should be daily, or every second day, repeated, according to circumstances. A blister applied over the orifice, or as far as the mischief extends, will often be serviceable. Here, likewise, the parts will be brought into contact with each other, and pressed together, and nnion may be effected. "Sometimes," says Mr. Cartwright, " when the vein is in an ulcerative state, I have laid it open, and applied caustic dressing, and it has healed up. I have lately had a case in which five or six abscesses had formed above the original wound, and the two superior ones burst through the parotid gland, the extent of the ulceration being evident in the quantity of saliva that flowed through each orifice."*

The owner of the horse will find it his interest to apply to a veterinary practitioner as soon as a case of inflamed vein occurs.

Should the vein be destroyed, the horse will not be irreparably injured, and perbaps, at no great distance of time, scarcely injured at all; for nature is ingenious in making provision to carry on the circulation of the blood. All the vessels con. reying the blood from the heart to the different parts of the frame, or bringing it back again to the heart, communicate with each other by so many channels, and in such various ways, that it is impossible by the closure or loss of any one of them long materially to impede the flow of the vital current. If the jugular is destroyed, the blood will circulate through other vessels almost as freely as before; but the horse could not be considered as sound, for he might not be equal to the whole of the work required of him.

\section{THE PALATE-(RESUMED).}

At the back of the palate (see p. 266), and attached to the crescent-shaped border of the palatine bone, is a dense membranous curtain. Its superior and back surface is a continuation of the lining membrane of the nose, and its anterior or inferior one that of the palate. It is called the relum palati, or veil of the palate. It extends as far back as the larynx, and lies upon the dorsum of the epiglottis, and is a perfect veil or curtain interposed between the cavities of the nose and mouth, cutting off all communication between them. Tied by its attachment to the palatine bone, it will open but a little way, and that only in one direction. It will permit a pellet of food to pass into the œsophagus; but it will close when any pressure is made upon it from behind. Two singular facts necessarily follow from this: the horse breathes through the nostrils alone, and these are capacious and easily expansible to a degree seen in no other - Abstract of the Veterinary Medical Asssciation, vol. iv. p. 185. 
animal, an l fully commensurate to the wants of the animal.

It is also evident that, in the act of vomiting, the conteuts of the stomach must be returned through the nostril, and not through the mouth. On this account it is that the loorse can with great difficulty be excited to vomit. There is a structure at the entrance to the stomach which, except under rery peculiar circumstances, prevents its return to the throat, and consequently to the mouth.

The muscles of this singular curtain are very intelligibly and correctly described by Mr. Percivall, in his "Anatomy of the Horse," to which the reader is referred. The same remark is applicable to a very siugular and important bone, and its muscular apparatus, the os hyoides.

\section{THE LARYNX}

Is placed on the top of the windpipe (see 1, p. 266), and is the imner guard of the lungs if any injurious substance should penetrate so far; it is the main protection against the passage of food into the respiratory tubes, and it is at the same time the instrument of voice. In this last character it loses much of its importance in the quadruped, because in the dumb animal it is a beautiful piece of mechanism.

The Epiglottis (see 2, p. 266) is a heart-shaped cartilage, placed at the extremity of the opening into the windpipe, with its back opposed to the pharynx, so that when a pellet of food passes from the pharynx in its way to the csophagus, it presses down the epiglottis, and by this means, as already described, closes the aperture of the larynx, and prevents any portion of the food from entering it. The food having passed over the epiglottis, from its own elasticity and that of the membrane at its base, and more particularly the power of the hyoepiglotideus muscle, rises again and resumes its former situation.

The Thyroid Cartilage (see 1, p. 266j occupies almost the whole of the external part of the larynx, both anteriorly and laterally. It envelopes and protects all the rest; a point of considerable imprrtance, considering the injury to which the larynx is exposed, by our system of curbing and tight reiuing. It also forms a point of attachment for the insertion of the greater part of the delicate muscles by which the other cartilages are moved.

The beautiful mechanism of the larynx is gorerned or worked by a somewhat complicated system of muscles, for a description of which the reader is referred to the 5 th vol. of the Veterinarian, p. $44 \%$. It is plentifully supplied with nerves from the respiratory system, and there are also frequent anastomoses with the motor nerves of the spinal cord. The sole process of respiration is partly under the control of the will, and the muscles of the laryzx concerned in one stage of it are likewise so, lut they al to set inderenlently of the will, for thring sleep and uncons ionsness the machine continues to work.

The origin of the artery which supplies these parts with blood is sometimes derived from the main trunk of the carotid, but oftener it is a branch of the thyroideal artery.

The lining membrane is a continuation of that of the pharynx above and the trachea below. It is covered with innumerable follicular glands, from whose mouths there oozes a mucous fluid that moistens and lubricates its surface. It is possessed of very great sensibility, and its fonction requires it. It is, as has been already stated, the inner guard of the lungs, and the larynx must uudergo a multitude of changes of form in order to adapt itself to certain changes in the act of respiration, and in order to produce the voice. The voice of the horse is, however, extremely limited, compared with that of the human being; the same sensibility, therefore, is not required, and exposed as our quadruped slaves are to absurd and barbarous usage, too great sensibility of any part, and particularly of this, would be a curse to the animal.

\section{THE TRACHEA OR WINDPIPE.}

The course of the inspired air from the larynx to the lungs is now to be traced, and it will be found to be conreyed through a singularly constructed tube $(6$, p. 266$)$, passing along the anterior portion of the neck, and reaching from the lower edge of the cricoid cartilage $(11, p .266)$ to the lungs. In the commencement of its course it is somewhat superficially placed, but as it descends towards the thorax it becomes gradually deeper, and more concealed. In order to discharge its functions as an air-tube, it is essential that it should always be pervious, or, at least, that any obstruction to the process of respiration should be but momentary. Attached to a part endowed with such extensive motion as the neck, it is also necessary that it should be flexible. It is composed of cartilage, an exceedingly elastic substauce, and at the same time possessing a certain degree of flexibility.

The windpipe is composed of cartilage, but not of one entire piece, for that would necessarily be either too thick and firm to be flexible, or if it were suffigiently flexible to accommodate itself to the action of the neck, it would be too weak to resist even common pressure or injury, and the passage through it would often be inconveniently or dangerously obstructed. Besides, it is necessary that this tube should oceasionally admit of elongation to a considerable degree. When the neck is extended in the act of grazing or otherwise, the trachea must be lengthened.

The structure of the cartilage of the windpire is admirably adipted to effect every purpose It 
is divided into rings, fifty or fifty-two in number, each possessing sufficient thichness and strength to resist ordinary pressure, and each constituting a joint with the one above and below, and thus admitting of all the flexibility that conld be required. These rings are connected together by an interposed fibro-ligamentous substance, extensible, elastic, and yet so strong that it is scarcely possible to rupture it; and the fibres of that ligament not running vertically from one to another, and therefore admitting of little more motion than the rotation of the head, but composed of two layers running obliquely, and in contrary directions, so as to adapt themselves to every variety of motion.

These rings are thickest in front, and project circularly, opposing an arch-like form. There, too, the ligament is widest, in order to admit of the greatest motion in the direction in which it is most needed, when the head is elevated or depressed. Laterally these rings are thinner, because they are, to a great degree, protected by the surrouuding parts ; and, posteriorly, they overlap each other, and the overlapping portions are connected together by a strong ligamentous substance. This, while it does not impede the motion of the tube, gives firmness and stability to it.

Within the trachea is another very curious structure. At the points at which, posteriorly, the rings begin to bend inwardly, a muscle is found stretching across the windpipe, dividing the canal into two unequal portions - the anterior one constituting the proper air-passage, and the posterior one occupied by cellular texture. It is to give additional strength to parts. It is the tie which prevents the arch from spurring out. In the natural state of the windpipe this muscle is, probably, quiescent; but when any considerable pressure is made on the crown of the arch at the upper part by tight reining, or at the lower by an ill-made collar, or anywhere by brutal or accidental violence, this muscle contracts, every serious expansion or depression of the arch is prevented, and the part is preserved from serious injury.

It may also be readily imagined that, when in violent exertion, every part of the respiratory canal is on the stretch, this band may preserve the windpipe from injury or laceration. There are many beautiful points in the physiology of the horse which deserve much greater attention than has hitherto been paid to them.

The windpipe should project from the neck. It should almost seem as if it were detached from the deck, for two important reasons: first, that it may easily enter between the channels of the jaw, so that the horse may be reined up without suffering inconrenience; and next, that being more loosely attached to the neck, it may more readily adapt itself to the changes required than if it were enveloped by fat, or muscle to a certain degree unyielding: therefore, in every well-formed neck - and it will be seen in the cut (p. 33i) - it is indispensible that the windpipe should be prominent and loose on the neck. This is not required in the heavy cart-horse, and we do not often find it, because he is not so much exposed to those circumstances which will hurry respiration, and require an enlargement in the size of the principal air-tube.

When the trachea arrives at the thorax, it suddenly alters its form, in order to adapt itself to the narrow triangular aperture through which it has to pass. It preserves the same cartilaginous structure; for if it has not the pressure of the external muscles, or of accidental violence, to resist, it is exposed to the pressure of the lungs when they are inflating, and it shares in the pressure of the diaphragm, and of the intercostal muscles, in the act of expiration. Having entered the chest, it passes a little to the right, leaving the œsophagus, or gullet, on the left; it separates from the dorsal vertebræ; it passes through the duplicature of the mediastinum to the base of the heart, and it divides beneath the posterior aorta. Its divisions are called the bronchial tubes, and have much to do with the well-being of the horse.

Its rings remain as perfect as before, but a new portion of cartilage begins to present itself: it may be traced as high as the tenth ring from the bottom; it spreads over the union between the posterior terminations of the rings; it holds them in closer and firmer connexion with each other; it discharges the duty of the transverse muscle, which begins here to disappear, and the support of the cervical and dorsal vertebre; it prevents the separation of the rings when the trachea is distended; it spreads down upon, and defends the commencement of the bronchial tubes. Some other small plates of cartilage reach a considerable way down the divisions of the bronchi, and the last ring has a central triangular projection, which covers and defends the bifurcation of the trachea.

\section{TRACHEOTOMY}

The respiratory canal is occasionally obstructed, to an annoying and dangerous degree. Polypi have been described as occupying the nostrils; long tumours have formed in them. Tumours of other kinds have pressed into the pharynx. The tumour of strangles has, for a while, occupied the passage. The larynx has been distorted; the membrane of the windpipe, on the larynx, has been thickened, and ulcers have formed in one or both, and have been so painful that the act of breathing was laborious and torturing. In all these cases it has been anxiously inquired whether there might not be established an artificial opening for the passage of the air, when the natural one 
could no longer be used; and it has been ascertained that it is both a simple and safe operation, to excise a portion of the trachea, on or below the point of obstruction.

The operation must be performed while the horse is standing, and secured by a side-line, for he would, propably, be suffocated amidst the struggles with which he would resist the act of throwing. The twitch is then firmly fixed on the muzzle; the operator stands on a stool or pail, by which means he can more perfectly command the part, and an assistant holds a scalpel, a bistoury, scissors, curved needles armed, and a moist spouge.

The operator should once more examine the whole course of the windpipe, and the different sounds which he will be able to detect by the application of the ear, and likewise the different degrees of temperature and of tenderness which the finger will detect, will guide to the seat of the evil.

The hair is to be closely cut off from the part, the skin tightened across the trachea with the thumb and fingers of the left hand, and then a longitudinal incision cautiously made through the skin, three inches in length. This is usually effected when there is no express indication to the contrary on the fifth and sixth rings; a slip from which, and the connecting ligament above and below, about half the width of each ring, should be excised with the intervening ligament. The remaining portion will then be strong enough to retain the perfect arched form of the trachea.

If the orifice is only to be kept open while some foreigu body is extracted, or tumour removed, or ulcer healed, or inflammation subdued, nothing more is necessary than to keep the lips of the wound a little apart, by passing some thread through each, aud slightly everting them, and tying the threads to the mane.

If, however, there is any permanent obstruction, a tube will be necessary. It should be two or three inches long, curved at the top, and the external orifice turning downwards with a little ring on each side, by which, through the means of tubes, it may be retained in its situation.

The purpose of the operation being answered, the flaps of integument must be brought over the wound, the edges, if necessary, diminished, and the parts kept in apposition by a few stitches. The cartilage will be perfectly reproduced, only the rings will be a little thicker and wider.

The following account will illustrate the use and the danger of the tracheotomy tube. A mare at Alfort had great distortion of the rings of the trachea. She breathed with difficulty. She became a roarer almost to suffocation, and was quite useless. Tracheotomy was effected on the distorted rings, and a short canula introduced. She was so much relieved that she trotted and galloped immediately afterwards without the slightest distress. Six months later she again began to roar. It seemed that the rings were now distorted below the former place.

M. Barthélemy introduced another canula, seven inches long, and which reached below the new distortion. She was once more relieved. She speedily improved in condition, and regularly drew a cabriolet at the rate of seven or eight miles in the hour; and this she continued to do for three years, when the canula became accidentally displaced in the night, and she was found dead in the morning.

\section{THE BRONCHIAL TUBES.}

The windpipe has been traced through its course down the neck into the chest. It is there contiuued through the mediastinum to the base of the heart, and then divided into two tubes corresponding with the two divisions of the lungs-the Bronchial Tubes. These trunks enter deeply into the substance of the lungs. They presently subdivide, and the subdivision is continued in every direction, until brauches from the trachea penetrate every assiguable portion and part of the lungs. They are still air-passages, carrying on this fluid to its destination, for the accomplishment of a vital purpose.

They also continue exposed to pressure; but it is pressure of a new kind, a pressure alternately applied and remored. The lungs in which they are embedded alternately contract and expand; and these tubes must contract and expand likewise. Embedded in the lungs, the cartilaginous ring of the bronchi remains, but it is divided iuto five or six segments connected with each other. The lungs being compressed, the segments overlap each other, and fold up and occupy little space; but the principle of elasticity is still at rork; and as the pressure is removed, they start again, and resume their previous form and calibre. It is a beautiful contrivance, and exquisitely adapted to the situation in which these tubes are placed, and the functions they have to discharge.

But we must pause a little and consider the structure and functions of the chest. 


\section{CHAPTER X.}

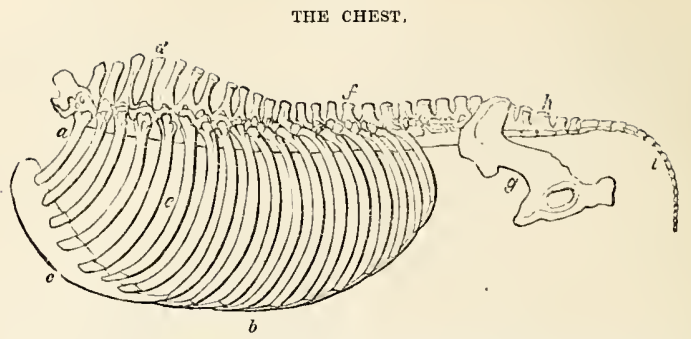

a The first rib.

$b$ The cartilages of the eleven hindermost, or false ribs, connected together, and uniting with tbat of the seventh or last true rib. c The breast-bone.

$d$ The top, or point, of the withers, which are formed by the lengthened spinous, or upright processes of the ten or eleven tirst bones of the back. The bones of the back are eigbteen in number.

e The ribs, usually eighteen on each side; the seven first united to

Tre chest, in the horizontal position in which it is placed in the cut, is of a somewhat oval figure, with its extremities truncated. The spine is its roof; the sternum, or breast, its floor; the ribs, its sides; the trachea, esophagus, and great bloodvessels passing through its anterior extremity and the diaphragm, being its posterior. It is contracted in front, broad and deep towards the central boundary, and again contracted posteriorly. It encloses the heart and the lungs, the origin of the arterial, and the termination of the venous trunks and the collected vessels of the absorbents. The windpipe penetrates into it, and the cesophagus traverses its whole extent.

A cavity whose contents are thus important should be securely defended. The roof is not composed of one unyielding prolongation of bone, which might possibly have been strong enough, yet would have subjected it to a thossand rude and dangerous shocks; but there is a curiously. contrived series of bones, kuit together by strong ligaments and dense cartilaginous substance, forming so many joints, each possessed but of little individual motion, but the whole united and constituting a column of such exquisitely-contrived flexibility and strength, that all concussion is avoided, and no external violence or weight can injure that which it protects. It is supported chiefly by the anterior extremities, and beautiful are the contrivances adopted to prevent injurious connexion. There is no inflexible bony union between the shoukters and the ehest; but while the spine is formed to neutralise much of the concussion that might be received-while the elastic the breast-bone by cartilage; the cartilages of the remaining eleven united to each other, as at $b$.

$f$ That portion of the spine where the loins commence, and composed of five bones.

The bones forming the lip, or hannch, and into the hole at the bottom of whicb the head of the thigh-bone is received.

$h$ The portion of the spine belonging to the haunch, and consisting of five pieces.

$i$ The bones of the tail, usually thirteen in nomber.

comnexions between the vertebræ of the back, alternately affording a yielding resistance to the shock, and regaining their natural situation when the external force is removed, go far, by this playful motion, to render harmless the rudest motion - there is a provision made by the attachment of the shonlder-blade to the chest calculated to prevent the possibility of any rude concussion reaching the thorax.*

At the shoulder is a muscle of immense strength, and tendinous elastic composition, the serratus $m a-$ jor, spreading over the internal surface of the shoulder-blade and a portion of the chest. A spring of easier play could not have been attached to the carriage of any invalid. It is a carriage hung by springs between the scapulæ, and a delightful one it is for easy travelling; while there is combined with it, and the union is not a little difficult, strength enough to resist the jolting of the roughest road and the most rapid pace.

Laterally there is sufficient defence against all common injury by the expansion of the shoulder over the chest from between the first and second to the serenth rib; and behind and below that there is the bony structure of the ribs, of no little

* "Had," says Mr. Percivall, "the entire rib been one solid piece of bone, a violcnt blow might have broken it to pieces. On the other hand, had the ribs been composed from end to end of cartilage only, the form of the arcb could not have been sustained, but, sooner or later, it must have bent inward, and so luave encroached upon the cavity of the chest as to have compressed the organs of respiration and circulation to that degree that could not but have ended in suffocation and death of the animal. It was only the judicions and well-arranged combination of bone and gristle in the construction of the chest that conld answer the ends an all-wise Providence had in view."-Veterinariun, rol.xp. p. 181. 
strength; and their arched form, althongl a flattened arch; and the yielding motion at the base of each rib, resulting from its jointed connexion with the spine above and its cartilacinous union with the sternum below.

A still more important consideration with $\mathrm{re}$ gard to the parietes of the thorax is the manner in which they can adapt themselves to the changing bulk of the contents of the cavity. The capacity of the chest is little affected by the external contraction and dilatation of the heart, for when its ventricles are collapsed its auricles are distended, and when its auricles are compressed its ventricles expand; but with regard to the lungs it is a very different affair. In their state of collapse and expansion they vary in comparative bulk, one-sixth part or more, and, in either state, it is necessary for the proper discharge of the function of respiration that the parietes of the chest should be in contact with them.

The ribs are eighteen in number on either side. Nine of them are perfect, and commonly called the true, or, more properly, sternal ribs, extending from the spine to the sterum. The remaining nine are posterior and shorter, and are only indirectly connected with the sternum.

The ribs are united to the corresponding vertebræ or bones of the spine, so as to form perfect joints-or, rather, each rib forms two joints. The head of the rib is received between the vertebræ and bones of the spine, before and behind, so that it shall always present two articulating surfaces, one opposed to the vertebræ immediately before, and the other to that immediately behind, and both forming one joint, with a perfect capsular ligament, and admitting of a rotatory motion. The head of the rib seems to be receired into the cartilaginous ligamentous substance between the vertebræ. Nothing could be more admirably devised for motion, so far as it is required, and for strength of union, that can scarcely be broken.

Before the ribs reach the stemum, they terminate in a cartilaginous prolongation, or the lower part of the rib may be said to be cartilaginons. There is between the bony part and this. cartilage a joint with a true capsular ligament, and admitting of a certain degree of motion; and where it unites with the sternum there is a fourth joint, with a perfect and complete capsular ligament.

The cartilage of the posterior ribs are united to the bony portion by a kind of joint. They are not, however, prolonged so far as the sternum; but the extremity of one lies upon the body of that which is immediately before it, bound down upon it by a cellular substance approaching to the natme of ligament, yet each having some separate motion, and all of them connected indirectly with the sternum by means of the last sternal rib. It is an admirable contrivance to preserve the requisite motion which must attend every act of breathing every extension and contraction of the chest, with a degree of strength which scarcely any accident can break through.

The sternum, or breast-bone, is more complicated than it at first appears to be. It constitutes the floor of the chest, and is a long flat spongy bone, fixed between the ribs on either side, articulating with these cartilages, and serving as a point of support to them. It is composed of from seven to nine pieces, united together by cartilage; and whatever changes may take place in other parts of the frame, this cartilage is not converted to bone even in extreme old age, although there may, possibly, be some spots of ossific matter found in it.

The point of the breast-bone may be occasionally injured by blows or by the pressure of the collar. It has been, by brutal violence, completely broken off from the sternum; but oftener, and that from some cruel usage, a kind of tumour has been formed on the point of it, which has occasionally ulcerated, and proved very difficult to heal.

The front of the chest is a very important consideration in the structure of the horse. It should be prominent and broad, and full, and the sides of it well occupied. When the breast is narrow, the chest has generally the same appearance: the animal is flat-sided, the proper cavity of the chest is diminished, and the stamina of the horse are materially diminished, although, perhaps, his speed for short distances may not be affected. When the chest is narrow and the fore legs are too close together, in addition to the want of bottom they will interfere with each other, and there will be wounds on the fetlocks, and bruises below the knee.

A chest too broad is not desirable, bnt a fleshy and a prominent one; yet even this, perhaps, may require some explanation: When the fore legs appear to recede and to shelter themselves under the body, there is a faulty position of the fore limbs, a bend or standing over, an uriratural lengthiness about the fore parts of the ôést, sadly disadvantageous in progression.

There is also a poster or appendix to the sternum, which is also cartilaginous. It is called the ensiform cartilage, although it bears little resemblance to a sword. It is flat and flexible, yet strong, and serves as the commencement of the floor or support of the abdomen. It also gives insertion to some of the abdominal muscles, and more conveniently than it could have been obtained from the body of the sternum.

The intercostal musclcs.-The borders of the ribs are anteriorly concare, thin, and sharp-posteriorly rounded, and presenting underneath a longitudinal depression or channel, in which run both blood-ressels and nerves. The space between them 
is occupied by muscular substance firmly attached to the borders of the ribs. These muscles are singularly distributed; their fibres cross each other in the form of an X. There is a manifest advantage in this. If the fibres ran straight across from rib to rib, they might act powerfully, but their action would be exceedingly limited. A short muscle can contract but a little way, and only a slight change of form or dimension can be produced. By running diagonally from rib to rib, these mus. cles are double the length they conld otherwise have been. It is a general rule with regard to muscular action, that the power of the muscle depends on its bulk, and the extent of its action on its length.

The ribs, while they protect the important viscera of the thorax from injury, are powerful agents in extending and contracting the chest in the alternate inspiration and expiration of air. In wlat proportion they discharge the labour of respiration is a disputed question, and into the consideration of which we cannot enter until something is known of the grand respiratory muscle, the diaphragm. Thus far, however, may he said, that they are not inactive in natural respiration, although they certainly act only a secondary part; but in hurried respiration, and when the demand for arterialised blood is increased by violent exertion, they are valuable and porerful auxiliaries.

This leads to a very important consideration, the most advantageous form of the chest for the proper discharge of the natural or extraordinary functions of the thorasic viscera. The contents of the chest are the lungs and the heart:- the first, to render the blood nutrient and stimulating, and to give or restore to it that vitality which will enable it to snpport every part of the frame in the discharge of its function, and devoid of which the complicated and beautiful machine is inert and dead; and the second, to convey this purified arterialised blood to every part of the frame.

In order to produce and to convey to the various parts a sufficient quantity of blood, these organs must be large. If it amounts not to hypertrophy, the larger the heart and the larger the lungs, the more rapid the process of nutrition, and the more perfect the discharge of every animal function.

Then it might be imagined that, as a circle is a figure which contains more than any other of equal girth and admeasurement, a circular form of the chest would be most advantageous. Not exactly so ; for the contents of the ehest are alternately expanding and contracting. The circular chest could not expand, but every change of form would be a diminution of capacity.

That form of chest which approaches nearest to a circle, while it admits of sufficient expausion and contraction, is the best-certainly for some animals, and for all under peculiar circumstances, and with reference to the discharge of certain functions. This was the grand principle on which Mr. Bakewell proceeded, and on which all our improve. ments in the breeding of cattle were founded.

The principle holds good with regard to some breeds of horses. We value the heary draughthorse not only on account of his simple muscular power, but the weight which, by means of that power, he is able to throw into the collar. A light horse may be preferable for light dranght, but we must oppose weight to weight when our loads are heavy. In the dray-horse we prize this circular chest, not only that he may be proportionably heavier before-to him no disadrantage-but that, by means of the increased capacity of his chest, he may obtain the bulk and size which best fit him for our service. But he would not do for speedhe would not do for ordinary quick exertion, and if he were pushed far beyond his pace, he would become broken-winded, or have inflamed lungs.

Some of our saddle-horses and cobs have barrels round enough, and we value them on account of it, for they are always in condition, and they rarely tire. But when we look at them more carefully, there is just that departure from the circular form of which mention has been madethat happy medium between the circle and the ellipse, which retains the capacity of the one and the expansibility of the other. Such a horse is invaluable for common purposes, but he is seldom a horse of speed. If be is permitted to go his own pace, and that not a slow one, he will work on for ever; but if he is too much hurried, he is soon distressed.

The Broad Deep Chest.-Then for the usual purposes of the road, and more particularly for rapid progression, search is made for that form of the chest which shall unite, and to as great a degree as possible, considerable capacity in a quiescent state, and the power of increasing that capacity when the animal requires it. There must be the broad chest for the production of muscles and sinews, and the deep chest. to give the capacity or power of furnishing arterial blood equal to the most rapid exhaustion of vitality.

This form of the chest is consistent with lightness, or at least with all the lightness that can be rationally required. The broad-chested horse, or he that, with moderate depth at the girth, swells and barrels out immediately behind the elbow, may have as light a forehand and as elevated a wither as the horse with the narrowest ehest; but the animal with the barrel approaching too near to rotundity is invariably heavy about the shoulders and low in the withers. It is to the mixture of the Arabian blood that we principally owe this peculiar and advantageous formation of the chest of the horse. The Arab is light; some would say too much so before: but immediately behind the 
arms the barrel almost invariably swells ont, and leaves plenty of room, and where it is most wanted for the play of the lungs, and at the same time where the weight does not press so exclusively on the fore-legs, and expose the feet to concussion and injury.

Many horses with narrow chests, and a great deal of daylight under them, have plenty of spirit and willingness for work. 'They show themselves well off, and exhibit the address and gratify the vanity of their riders on the parade or in the park, but they have not the appetite nor the endurance that will carry them through three successive days hard work.

Five out of six of the animals that perish from inflamed lungs are narrow-chested, and it might be safely affirmed that the far greater part of those who are lost in the field after a hard day's run, have been horses whose training has been neglected, or who have no room for the lungs to expand. The most important of all points in the conformation of the horse is here elucidated. An elevated wither, or ohlique shoulder, or powerful quarters, are great advantages; but that which is most of all connected with the general health of the animal, and with combined fleetness or bottom, is a deep, and broad, and swelling chest, with sufficient lengihening of the sternum, or breast bone, beneath.

If a chest that cannot expand with the increasing expansion and labour of the lungs is so serious a detriment to the horse, everything that interferes with the action of the intercostal muscles is carefully to be avoided. Tight girthing ranks among these, and foremost among them. The closeness with which the roller is buckled on in the stable must be a serious inconvenience to the horse; and the partially depriving these muscles of their power of action, for so many hours in every day, must indispose them for labour when quicker and fuller respiration is required. At all events, a tight girth, though an alnost necessary nuisance, is a very considerable one, when all the exertion of which he is capable is required from the horse. Who has not perceived the address with which, by bellying out the chest, the old horse renders every attempt to girth him tight comparatively useless; and when a horse is blown, what immediate relief has ungirthing him afforded, by permitting the intercostals to act with greater power?

A point of consequence regarding the capacity of the chest, is the length or shortness of the carcase; or the extent of the ribs from the elbow backward. Some horses are what is called ribbed home; there is but little space (see cuts pp. 263 and 344 ) between the last rib and the hip-bone. In others the distance is considerably greater, and is plainly evident by the falling in of the flank. The question then is, what serrice is required from the horse? If he has to carry a heavy weight, aud has much work to do, he should be ribbed home, - the last rib and the hip-bone should not be far from each other. There is more capacity of chest and of belly-there is less distance between the points of support-and greater strength and endurance. A hackney (and we would almost say a hunter) can scarcely be too well ribbed home.

If speed, however, is required, there must be room for the full action of the hinder limbs; and this can only exist where there is sufficient space between the last rib and the hip-bone. The owner of the horse must make up his mind as to what he wants from him, and be satisfied if he obtains that; for, let him be assured that he cannot have everything, for this would require those differences of conformation that cannot possibly exist in the same animal.

The thorax, or chest, is formed by the spine $f$, above (p. 344); the ribs $e$, on either side; and the sternum, or breast-bone, $c$, beneatl.

\section{THE SPINE AND BACK.}

The spine, or back, consists of a chain of bones from the poll to the extremity of the tail. It is made up of twenty-three bones from the neck to the haunch; eighteen, called dorsal vertebra, compos. ing the back; and five lumbar vertebra, occupying the loins. On this part of the animal the weight or burden is laid, and there are two things to be principally considered, easiness of carriage and strength. If the back were composed of unyield. ing materials - if it resembled a bar of wood or iron, much jarring or jolting, in the rapid motion of the animal, could not possibly be endured. In order to avoid this, as well as to assist in turning, the back is divided into numerous bones; and between each pair of bones there is interposed a cartilaginous substance, most highly elastic, that will yield and give way to every jar, not so much as to occasion insecurity between the bones, or to permit considerable motion between any one pair, but forming altogether an aggregate mass of such perfect elasticity, that the rider sits almost undisturbed, however high may be the action, or hoserer rapid the pace.

Strength is as important as ease; therefore these boues are united together with peculiar firmness. The round head of one is exactly fitted to the cup or cavity of that immediately before it ; and between them is placed the elastic ligamentous substance, which has been just described, so strong, that in endeavouring to separate the bones of the back, they will break before this substance will give way. In addition to this there are ligaments running along the broad under surface of these bones-liganents between each of the transwerse processes, or side projections of the bones- 
ligaments between the spinous processes or upright projections, and also a continuation of the strong ligament of the neck running along the whole course of the lack and loius, lengthening and contracting, as in the neck, with the motions of the animal, and forming a powerful bond of union between the bones.

By these means the hunter will carry a heary man without fatigue or strain through a long chase; and those shocks and jars are avoided which would be annoying to the rider, and injurious and speedily fatal to the horse.

These provisions, lowever, although adequate to common or even severe exertion, will not protect the animal from the consequences of brutal usage; and, therefore, if the horse is much overweighted, or violently exercised, or too suddenly pulled upon his haunches, these ligaments are strained. Inflammation follows. The ligaments become changed to bone, and the joints of the back lose their springiness and ease of motion; or rather, in point of fact, they ccase to exist. On account of the too hard service required from them, and especially before they had gained their full strength, there are few old horses who have not some of the bones of the back or loins anchylosed-united together by bony matler and not by ligament. When this exists to any considerable extent the horse is not pleasant to ride-he turns with difficulty in his stall-he is unwilling to lie down, and when down to rise again, and he has a singular straddling action. Such horses are said to be broken-backed or chinked in the chine.

Fracture of the bones of the back rarely occurs, on account of their being so strongly united by ligaments, and defeuded by muscular substance. If a fracture of these bones does happen, it is during the violent struggles after the horse has been cast for an operation.

The length of the back is an important consideration. A long-backed horse will be easy in his paces, because the increased distance between the fore and hind legs, which are the supports of the spine, will afford greater room for the play of the joints of the back. A long spring has much more play than a short one and will better obviate concussion. A long-backed horse is likewise formed for speed, for there is room to bring his hinder legs more under him in the act of galloping, and thus more powerfully propel or drive forward the body : but, on the other liand, a long-backed horse will be comraratively weak in the back, and easily overweighted. A long spring may be easily bent or broken. The weight of the rider, likewise, placed farther from the extremities, will act with mecha. nical disadvantage upon them, aud be more likely to strain them. A short-backed horse may be a good hackney, and able to carry the heaviest reight, and possess great endurance; hut his paces will not be so easy, nor his speed so great, and he may be apt to overreach.

The comparative advantage of a long or short carcase depends entirely on the use for which the horse is intended. For general purposes the horse with a short carcase is very properly preferred. He will possess health and. strength; for horses of this make are proverbially hardy. He will have sufficient easiness of action not to fatigue the rider, and speed for every ordinary purpose. Length of back will always be desirable when there is more than usual substance generally, and particularly when the loins are wide, and the muscles of the loins large and swelling. The two requisites, strength and speed, will theu probably be united.

The back should be depressed a little immediately behind the withers; and then continue in an almost straight line to the loins. This is the form most consistent with beauty and strength. Some horses have a very considerable hollow behind the withers. They are said to be saddle-backed. It seems as if a depression were purposely made for the saddle. Such horses are evidently easy goers, for this curve inward must necessarily increase the play of the joints of the back: but in the same proportion they are weak and liable to sprain. To the general appearance of the horse, this defect is not in any great degree injurious ; for the hollow of the back is uniformly accompanied by a beauti fully arched crest.

A few horses have the curve outward. They are said to be roach-backed, from the supposed resemblance to the arched back of a roach. This is a very serious defect;-altogether incompatible with beauty, and materially diminishing the usefulness of the animal. It is almost impossible to prevent the saddle from being thrown on the shoulders, or the back from being galled;-the elasticity of the spine is destroyed;-the rump is badly set on ; - the hinder legs are too much under the ani$\mathrm{mal}$; - he is continually overreaching, and his head is carried awkwardly low.

\section{THE LOINS.}

The loins are attentively examined by every good horseman. They can scarcely be too broad and musenlar. The strength of the back, and, especially, the strength of the hinder extremities, will depend materially on this. The breadth of the loins is regulated by the length of the transverse or side processes of that part. The bodies of the bones of the loins are likewise larger than those of the back; and a more dore-tailed kind of nnion subsists between these bones than between those of the back. Every provision is made for strength here. The union of the back and loins should be carefully observed, for there is sometimes a depression between them. A kind of line is drawn across, which shows imperfection in the 
construction of the spine, and is regarded as an indication of weakness.

\section{THE WITHERS,}

The spinous or upright processes of the dorsal vertebræ, or bones of the back, above the upper part of the shoulder, are as remarkable for their length as are the transverse or side processes of the bones of the loins. They are flattened and terminated by rough blunted extremities. The elevated ridge which they form is called the withers. It will be seen in the cuts (pp. 263 and 344), that the spine of the first bone of the back has but little elevation, and is sharp and upright. The second is longer and inclined backward; the third and fourth increase in length, and the fifth is the longest;-they then gradually shorten until the twelfth or thirteenth, which becomes level with the bones of the loins.

High withers have been always, in the mind of the judge of the horse, associated with good action, and generally with speed. The reason is plain enough: they afford larger surface for the attachment of the muscles of the back; and in proportion to the elevation of the withers, these muscles act with greater advantage. The rising of the fore parts of the horse, eren in the trot, and more especially in the gallop, depends not merely on the action of the muscles of the legs and shoulders, but on those of the loins, inserted into the spinous processes of these bones of the back, and acting with greater power in proportion as these processes, constitnting the withers, are lengthened. The arm of the lever to which the power is applied will be longer: and in proportion to the length of this arm will be the ease and the height to which a weight is raised. Therefore good and high action will depend much on elevated withers.

It is not difficult to understand how speed will likewise be promoted by the same conformation. The power of the horse is in his hinder quarters. In them lies the main-spring of the frame, and the fore-quarters are chiefly elevated and thrown forward to receive the weight forced on them by the action of the linder quarters. In proportion, however, as the fore-quarters are elevated, will they be thrown farther forward, or, in other words, will the stride of the horse be lengthened. Yet many racers have the forehand low. The unrivalled Eclipse (see p. 235) was a remarkable instance of this; but the ample and finely proportioned quarters, and the muscularity of the thigh and fore-arm, rendered the aid to be derived from the withers perfectly umnecessary. The heary draught-horse does not require elevated withers. His ntility depends on the power of depressing his fore-quarters, and throwing their weight fully into the collar; but for common work in the hackney, in the farmer's horise, and in the hunter, wcil- formed withers will be an essential advantage, as contributing to good and safe action, and likewise to speed.

MUSCLES OF THE BACK.

The most important muscles which belong to this part of the frame are principally those wlich extend from the continuation of the ligament of the neck, along the whole of the back and loins; and likerrise from the last cervical bone;-the superficialis and transicrsalis costanum, or superficial and transverse muscles of the ribs, going from this ligament to the upper part of the ribs to elevate them, and to assist in the expansion of the chest; also the large mass of muscle, the longissimus dorsi, or longest muscle of the back, from the spinous and transverse processes of the vertebræ to the ribs, and by which all the motions of the spine, and back, and loins, to which allusion has been made, are principally produced; by which the fore-quarters are raised upon the hind ones, or the hind upon the fore ones, according as either of them is the fixed point. This is the principal agent in rearing and kicking.

The last muscle to be noticed is the spinalis dorsi, the spinal muscle of the back, from the spinous processes of some of the last bones of the back to those of the fore part; thick and strong about the withers, and broadly attached to them: and more porrerfully attached, anl more strongly acting in proportion to the elevation of the withers; and proceeding on to the three lowest bones of the neck, and therefore mainly concerned, as alrealy described, in elevating the forequarters, and producing high and safe action, and contributiug to speed.

Before the roof of the chest is left, some acci dents or diseases to which it is exposed must be mentioned. The first is of a very serious nature.

FISTULOUS WITHERS.

When the saddle has been suffered to press long upon the withers, a tumour will be formed, hot and exceedingly tender. It may sometines be dispersed by the cooling applications recommended in the treatment of poll-evil; but if, in despite of these, the swelling should remain stationary, and especially if it should become larger and more tender, warm fomentations and poultices, and stimulating embrocations should be diligently applied, in order to hasten the formation of pus. As soon as that can be fairly detected, a seton should be nassed from the ton to the bottom of the tumour, so that the whole of the matter mas bo evacuated, and contmue to be discharged as it is afterwards formed; or the knife may be freely used, in order to get at the bottom of every sinus. The knife lias succeeded many a time when the seton has failed. The after treatment must be 
precisely that which was recommended for a similar disease in the poll.

In neglected fistulons withers the ulcer may be larger and deeper, and more destructive than in poll-evil. It may burrow beneath the shoulderblade, and the pus appear at the point of the shoulder or the elbow; or the bones of the withers may become carious.

Very great improvement has taken place in the construction of saddles for common use and in the cavalry service. Certain rules have now been laid down from which the saddler should never deviate, and attending to which the animal is saved from much suffering, and the mechanic from deserved disgrace.

The first rule in the fitting of the saddle is, that it should bear upon the back, and not on the spine or the withers, for these are parts that will not endure pressure.

Next in universal application is the understanding that the saddle should have everywhere an equal bearing, neither tilting forward upon the points nor backward upon the seat.

When the saddle is on, and the girths fastened, there should remain space sufficient betreen the withers and the pommel for the introduction of the hand underneath the latter.

The points of the tree should clip or embrace the sides without pinching them, or so standing outward that the pressure is all downwards, and upon one place, instead of being in a direction inwards as well as downwards, so as to be distribu. ted uniformly over every part of the point that touches the side. Horses that have low and thick withers are most likely to have them injured, in consequence of the continual riding forward of the saddle, and its consequent pressure upon them. Fleshy and fat shoulders and sides are also subject to become hurt by the points of the trees either pinching them from being too narrow in the arch, or from the bearing being directly downward upon them.

Injury occasionally results from the interruption which a too forward saddle presents to the working or motion of the shoulder, and the consequent friction the soft parts sustain between the shoulder-blade inwardly, and the points of the saddle tree outwardly.*"

WARBLES, SITFASTS, AND SADDLE GALLS.

On other parts of the back tumours and very troublesome ulcers may be produced by the same cause. Those resulting from the pressure of the saddle are called warbles, and, when they ulcerate, they frequently become sitfasts. Warbles are small circular bruises, or extravasations of blood, where there has been an undue pressure of the saddle or harness. If a horse is subject to these

- Percivall's Hippopathology, rol. i., p. 199 tumours, the saddle shonld remain on him two or three hours after he has returned to the stable. It is only for a certain time, however, that this will perfectly succeed, for by the frequent application of the pressure the skin and the cellular substance are bruised or otherwise injured and a permanent sore or tumour, of a very annoying description, takes place. The centre of the sore gradnally loses its vitality. A separation takes place from the surrounding integument, and there is a circular piece of dried and hard skin remaining in the centre. This is curiously called a navel gall, because it is opposite to the navel. No effort must be made to tear or dissect it off, but stimnlating poultices or fomentations, or, if these fail, a mild blister, will cause a speedy separation; and the wound will then readily heal by the use of turpentine dressings, more or less stimulating, according to circumstances.

Saddle galls are tumours, and sometimes galls or sores, arising also from the pressure and chafing of the saddle. They differ little from the warble, except that there is very seldom the separation of the dead part in the centre, and the sore is larger and varying in its form. The application of cold water, or salt and water, will generally remove excoriations of this lind.

With regard, however, to all these tumours and excoriations, the humane man will have the saddle eased and padded as soon as it begins to be of the least inconvenience to the horse.

\section{MUSCLES OF THE BREAST.}

There are some important muscles attached to the breast connected with that expansion of the chest which every horse should possess. In the cut, p. 337, are seen a very important pair of muscles, the pectorales transrersi, or pectoral mus. cles, forming two prominences in the front of the chest, and extending backward between the legs. They come from the fore and upper part of the breast-bone; pass across the invard part of the arm, and reach from the elbow almost down to the knee. They confine the arm to the side in the rapid motion of the horse, and prevent him from being, what horsemen wonld call, and what is seen in a horse pushed beyond his natural power, "all abroad." Other muscles, pectorales magni et parri, the great and little pectorals, rather above but behind these, go from the breastbone to the arm, in order to draw back the point of the shoulder, and bring it upright. Another and smaller muscle goes from the breast-bone to the shoulder, to assist in the same office. A horse, therefore, thin and narrow in the breast, must be deficient in important muscular power.

Between the legs and along the breast-bone is the proper place in which to insert rowels, in cases of inflamed lungs. 
CHEST-FOUNDER.

These muscles are occasionally the seat of a singular and somewhat mysterions disease. The old farriers used to call it anticor and chest-founder. The horse has considerable stiffuess in moving, evidently not referable to the feet. There is tenderness about the muscles of the breast, and, occasionally, swelling. We believe it to be nothing more than rheumatism, produced by suffering the horse to remain too long tied up, and exposed to the cold, or riding him against a very bleak wind. Sometimes a considerable degree of fever accompanies this; but bleeding, physic, a rowel in the chest, warm embrocations over the parts affected, warm stabling, and warm clothing, with occasional doses of antimonial powder, will soon subdue the complaint.

\section{CHAPTER XI}

\section{THE CONTENTS OF THE CHEST.}

THE THYMUS GLAND.

At the entrance of the trachea into the thorax, and ere it has scarcely penetrated between the first ribs in the soung subject, it comes in contact with an irregular glandular body, situated in the doubling of the anterior mediastinum. It is "the thymus gland," or, in vulgar language, the sweetbread. In the early period of utero-gestation, it is of very inconsiderable bulk, and confined mostly to the chest; but, during the latter months, it strangely developes itself,-the superior cornua protrude ont of the thorax and climb up the neck, between the carotids and the trachea. They are evidently connected with the thymus gland, and become parts and portions of the parotid glands.

We are indebted to Sir Astley Cooper for the best account of the anatomical structure, and possible function of the thymus gland. It presents, on being cut into, a great number of small cavities, in which the abundant white fluid of the gland is in part contained. From those cavities the fluid is transmitted into a general reservoir, which forms a common connecting cavity, and is lined by a delicate membrane. Sir Astley, and in this he is supported by Professor Müller, believes that a peculiar albuminous fluid is conveyed by the thymus gland to the veins, through the medium of the lymphaties. It has nothing to do with the formation of the blood, in the fotus or the child.

These two eminent physiologists exert the better part of discretion, by declining to give any hypothesis of its function beyond this, that it supplies the lymphatics with an albuminous fluid.

This gland continues to grow for some time after birth, and remains of considerable size during the first year; it then gradually diminishes, and, about the period of puberty, usually disappears. It has, however, been found in a mare between five and six years old.

\section{THE DIAPHRAGM.}

Bounding the thorax posteriorly,-the base of the cone in the human subject,- the interposed curtain between the thorax and the abdomen in the horse, is the diaphragm. It is an irregular muscular expansion, proceeding from the inferior surface of the lumbar vertebrse posteriorly and superiorly, adhering to the ribs on either side, and extending obliquely forward and downward to the sternum; or rather, it is a flattened muscle arising from all these points, with its fibres all converging towards the centre, and terminating there in an expansion of tendinous substance. It is lined anteriorly by the pleura or investing membrane of the thoracic cavity, and posteriorly by the peritoneum or investing membrane of the abdominal cavity.

Anatomy of the Diaphragm. - In the short account which it is purposed to give of the structure of the diaphragm, the description of Mr. Percivall will be closely followed. "The diaphragm may be divided into the main circular muscle, with its central tendinous expansion forming the lower part, and two appendices, or crura, as they are called, from their peculiar shape, constituting its superior portion. The fleshy origin of the grand muscle may be traced laterally and inferiorly, commencing from the cartilage of the eighth rib anteriorly, and closely following the union of the posterior ribs with their cartilages; excepting, however, the two last. The attachment is peculiarly strong, it is denticulated; it encircles the whole of the lateral and inferior part of the chest, as far as the sternum, where it is connected with the ensiform cartilage. Immediately under the loins are the appendices of the diaphragm, commencing on the right side, from the infelior surfaces of the five first lumbar vertebræ, by strong tendons, which soon become muscular, and form a kind of pillar; and, on the left, proceeding from the two first lumbar vertebræ only, and from the sides rather than the bodies of these vertebræ, and these also unite and form a shorter pillar, or leg. The left crus or appendix is shorter than 
the right, that it may be more out of the way of pressure from the left curvature of the stomach, which, with the spleen, lies undemeath. Opposite to the 17 th dorsal rertebra, these tro pillars unite and form a thick mass of muscles, detached from the vertebræ, and leaving a kind of pouch between them and the vertebræ. They not only unite, but they decussate: their fibres mingle and again separate from each other, and then proceed onward to the central tendinous expansion towards which the fibres from the circular. muscle, and the appendices, all converge."

The diaphragm is the main agent, both in ordinary and extraordinary respiration; it assists also in the expulsion of the urine, and it is a most powerful auxiliary in the act of parturition. In its quiescent state, it presents its convex surface towards the thorax, and its concave one towards the abdomen. The anterior convexity abuts upon the lungs; the posterior concavity is occupied by some of the abdominal viscera. The effect of the action of this muscle, or the contraction of its fibres, is to lessen the convexity towards the chest, and the concavity towards the abdomen: or perhaps, by a powerful contraction, to cause it to present a plane surface either ray. The abdominal viscera that must be displaced in order to effect this, have considerable bulk and weight; and when the stomach is distended with food, and the motion required from the diaphragm in rapid breathing is both quick and extensive, there needs some strong, firm, elastic, substance to bear it. The forcible contact and violent pressure would bruise and otherwise injure a mere muscular expansion; and therefore we have this tendinons expansion, comparatively deroid of sensibility, to stand the pressure and the shock which will always be greatest at the centre.

Yet it is subject to injury and disease of a serious and varied character. Whatever may be the original seat of thoracic or abdominal ailment, the diaphragm soon becomes irritable and inflamert. This accounts for the breathing of the horse being so much affected under every inflammation or excitement of the chest or belly. The irritability of this muscle is often evinced by a singular spasmodic action of a portion, or the whole of it.

Mr. Castley thus describes a case of it:- "A horse had been very much distressed in a run of nearly thirteen wiles, without a check, and his rider stopped on the road towards home, to rest him a little. With diffienlty he was hrought to the stable. Mr. Castley mas sent for, and he says, -'When I first saw the animal, his breathing and attitude indicated the greatest distress. The prominent symptom, however, was a convulsive motion, or jerling of the whole body, audible at several yards" distance, and evidently proceeding from his inside; the beats appeared to be about forty in a minute. On placiung my hand over the heart, the action of that organ could be felt, hut very indistinctly; the beating evidently came from behind the heart, and was most plainly to be felt in the direction of the diaphragm. Again placing my hand on the abdominal muscle, the jerks appeared to come from before backwards; the impression on my mind, therefore, was, that this was a spasmodic affection of the diaphragm, brought on by violeut distress in running." "**

MIr. Castley's account is inserted thus at length, because it was the first of the kind on record, with the exception of an opinion of Mr. Apperley, which came very near to the truth. "When a horse is very much exhausted after a long run with hounds, a noise will sometimes be heard to proceed from his inside, which is often erromeously supposed to be the beating of his heart, whereas it proceeds from the excessive motion of the abdominal muscles." +

Mr. Castley shall pursue his case, (it will be a most useful guide to the treatment of these cases): "Finding that there was little pulsation to be felt at the submaxillary artery, and judging from that circumstance that any attempt to bleed at that time would be worse than useless, I ordered stimulants to be giren. We first administered three ounces of spirit of nitrous ether, in a bottle of warm water; but this producing no good effect, we shortly afterwards gave two drachms of the subcarbonate of ammonia in a ball, allowing the patient, at the same time, plenty of white water to drink. About a quarter of an hour after this, he broke out into a profuse perspiration, which continued two hours, or more. The breathing became more tranquil, but the convulsive motion of the diaphragm still continued withont any abatement. After the sweating had ceased, the pulse became more perceptible, and the action of the heart more distinct, and I considered this to be the proper time to bleed. When about ten pounds bad been extracted, I thonght that the beating and the breathing seemed to increase; the bleeding was stopped, and the patient littered up for the night. In the morning, the affection of the diaphragm was much moderated, and about eleren oclock it ceased, after continuing eighteen or nineteen hours. A little tonic medicine was afterwards administered, and the horse soon recovered his usual appetite and spirits." +

Later surgeons administer, and with good effect, opium in small doses, together with ammonia, or nitric ether, and have recourse to bleeding as soon as any reaction is perceived.

Orer-fatigue, of almost every kind, has pro-

* The Veterinarian, 1831, p. 247.

+ Nimrod on the Condition of Hunters, p. 185.

* The Veterinarian, ]831, p. 218. 
duced spasm of the diaphragm, and so has overdistension of the stomach with grass.

RUPTURE OF THE DIAPHRAGM.

This is an accident, or the consequence of disease, very lately brought nnder the cognizance of the veterinary surgeon. The first communication of its occurrence was from Mr. King, a friend of Mr. Percivall.* It occurred in a mare that had been ridden sharply for half a dozen miles when she was full of grass. She soon afterwards exhilited symptoms of broken-wind, and, at length, died suddenly, while standing in the stable. The diaphragm was lacerated on the left side, throngh its whole extent, throwing the two cavities:into one.

Since that period, from the increasing and rery proper habit of examining every dearl horse, cases of this accident have rapidly muitiplied. It seems that it may follow any act of extraordinary exertion, and efforts of every kind, particularly on a full stomach, or when the bowels are distended with green or other food likely to generate gas. $†$ Considerable caution, however, should be exercised when much gaseons fluid is present, for the bowels may be distended, and forced against the diaphragm to such a degree as to threaten to burst.

An interesting case of rupture of the diaphragm was related by Professor Spooner at one of the meetings of the Veterinary MIedical Association. A horse having been saddled and bridled for riding, was turned in his stall and fastened by the bit-straps. Something frightened him-he reared, broke the bit-strap, and fell backward. $\mathrm{On}$ the following morning he was evideutly in great pain, kicking, heaving, and occasionally lying down. Mr S. mas sent for to examine him, but was not told of the event of the preceding day. $\mathrm{He}$ considered it to be a case of enteritis, and treated it accordingly. He bled him largely, and. in the course of the day, the horse appeared to be decidedly better, every symptom of pain having vanished. The horse was more lively-he ate with appetite, but his bowels remained con. stipated.

On the following day there was a fearful change. The animal was suffering sadly - the breathing was laborions, and the membrane of the nose intensely red, as if it were more a case of iuflammation of the lungs than of the bowels. The horels were still constipated. The patient was bled and physiclsed again, bnt without avail. He died, and there was found rupture of the diaphragm, protrusion of intestine into the thoracic cavity, and extensive pleural and peritoneal inflammation.

In ruptnre of the diaphragm the horse usually

* The Veterinarian, 1828, p. 101

+ Percivall's Hippopathology, vol. ii., No. 1, p. 152. sits on his haunches like a dog, but this is far from being an infallible symptom of the disease. It accompanies introsusception, as well as rupture of the diaphragm. The weight of the intestines may possibly cause any protruded part of them to descend again into the abdomen.

This muscle, so important in its office, is plentifully supplied with blood-vessels. As the posterior aorta passes beneath the crura of the diaphragm, it gives out sometimes a single vessel which soon bifurcates; sometimes two branches, which speedily plunge into the appendices or crura, while nnmerous 'small vessels, escaping from them, spread over the central tendinous expansion. As the larger muscle of the diaphragm springs from the sides and the base of the chest, it receives many ramifications from the internal pectoral, derived from the anterior aorta; but more from the posterior intercostals which spring from the posterior aorta.

The veins of the diaphragm belong exclnsively to the posterior vena cava. There are nsually three on either side; but they may be best referred to two chief trunks which come from the circumference of the diaphragm, converge towards the centre, and run into the posterior cara as it passes throngh the tendinous expansion.

The functional nerve of the diaphragm, or that from which it derives its principal action, and which constitutes it a muscle of respiration, is the phrenic or diaphragmatic. Although it does not proceed from that portion of the medulla oblongata which gives rise to the glosso-pharyngeus and the par vagnm, set there is snfficient to induce us to suspect that it arises from, and should be referred to, the lateral column between the superior and inferior, the sensitive and motor nerres, and which may be evidently traced from the pons varolii to the very termination of the spinal chord.

The diaphragm is the main agent in the work of respiration. The other muscles are mere anxiliaries, little needed in ordinary breathing, but affording the most important assistance, when the breathing is more than usually hurried. The mechanism of respiration may be thns explained: -Let it be supposed that the lnngs are in a quiescent state. The act of expiration has been performed, and all is still. From some cause enveloped in mystery-connected with the will, but independent of it-some stimulus of an unexplained and nnknomu kind-the phrenic nerre acts ou the diaphragm, and that muscle contracts; and, by contracting, its convexity into the chest is diminished, and the carity of the chest is enlarged. At the same time, and by some consentaneons influence, the intercostal muscles actwith no great force, indeed, in undisturbed breathing; but, in proportion as they act, the ribs rotate on their axis, their edges are thrown outward, and 
thus a twofold effect ensues:- the posterior margin of the chest is expanded, the cavity is plainly enlarged, and also, by the partial rotation of every rib, the cavity is still more increased.

By some other consentaneous influence, the spinal accessory nerve likewise exerts its power, and the sterno-maxillaris musele is stimulated by the anterior division of it, and the motion of the head and neck corresponds with and assists that of the chest; while the posterior division of the accessory nerve, by its anastamoses with the motor nerves of the levator humeri and the splenius, and many other of the muscles of the neck and the shoulder, and by its direct influence on the rhomboideus, associates almost every muscle of the neck, the shoulder, and the chest, in the expansion of the thorax. These latter are muscles, which, in undisturbed respiration, the animal scarcely needs; but which are necessary to him when the respiration is much disturbed, and to obtain the aid of which he will, under pneumonia, obstinately stand until he falls exhausted or to die.

The cavity of the chest is now enlarged. But this is a closed cavity, and between its contents and the parietes of the chest a vacuum would be formed; or rather an inequality of atmospheric pressure is produced from the moment the chest begins to dilate. As the diaphragm recedes, there is nothing to counterbalance the pressure of the atmospheric air communicating with the lungs through the medium of the nose and mouth, aud it is forced into the respiratory tubes already deseribed, and the lungs are expanded and still kept in contact with the receding walls of the chest. There is no sucking, no inhalent power in the act of inspiration; it is the simple enlargement of the chest from the entrance and pressure of the air.

From some canse, as inexplicable as that which produced the expansiou of the chest, the respiratory nerves cease to act; aud the diaphragm, by the inherent elasticity of its tendinous expansion and muscular fibres, returns to its natural form, once more projecting its convexity into the thorax. The abdominal muscles, also, which had been put on the stretch by the forcing of the viscera into the posterior part of the abdomen by means of the straightening of the diaphragm, contract, and accelerate the return of that muscle to its quiescent figure; and the ribs, all armed with elastic cartilages, regain their former situation aud figure. The muscles of the sloulder and the chest relax, a portion of the lungs are pressed on every side, and the air with which they were distended is again forced out. There is only one set of muscles actively employed in expiration, namely, the abdominal: the elasticity of the parts displaced in inspiration being almost sufficient to accomplish the purpose.
The lungs, however, are not altogether passive. The bronchial tubes, so far as they can be traced, are lined with cartilage, divided and subdivided for the purpose of folding up when the lungs are compressed, but elastic enough to afford a yielding resistance against both unusual expansion and contraction. In their usual state the air-tubes are distended beyond their natural calibre ; for if the parietes of the thorax are perforated, and the pressure of the atmosphere rendered equal within and without them, the lungs immediately collapse.

\section{THE PLEURA.}

The walls of the chest are lined, and the lungs are covered, by a smooth glistening membrane, the pleura. It is a serous membrane, so called from the nature of its exhalation, in distinction from the mucous secretion yielded by the membrane of the air-passages. The serous membraue generally invests the most important organs, and always those that are essentially connected with life; while the mucous membrane lines the interior of the greater part of them. The pleura is the investing membrane of the lungs, and a mucous membrane the lining one of the bronchial tubes.

Among the circumstances principally to be noticed, with regard to the pleura, is the polish of its external surface. The glistening appearance of the lungs, and of the inside of the chest, is to be attributed to the membrane by which they are covered, and by means of which the motion of the various organs is freer and less dangerous. Although the lungs, and the bony walls which contain them, are in constant approximation with each other, both in expiration and inspiration, yet in the frequently hurried and violent motion of the animal, and, in fact, in every act of expiration and inspiration, of dilatation and contraction, much aud injurious friction would ensue if the surfaces did not glide freely over each other by means of the peculiar polish of this membrane.

Every serous membrane has innumerable exbalent vessels upon its surface, from which a considerable quantity of fluid is poured out. In life and during health it exists in the chest only as a kind of dew, just sufficient to lubricate the surfaces. When the chest is opened soon after death, we recoguise it in the steam that arises, and in the few drops of fluid, which, being condensed, are found at the lowest part of the chest. .

The quantity, however, which is exhaled from all the serous membranes, must be very great. It is perhaps equal or superior to that which is yielded by the vessels on the surface of the body. If very little is found in ordinary cases, it is becanse the absorbents are as numerous and as active as the exhalents, and, during health, that which is poured out by the one is taken up by the other; but in 
circumstances of disease, either when the exbalents are stimulated to undue action, or the power of the alosorbents is diminished, the fluid rapidly and greatly accumulates. Thus we have hydrothorax or dropsy of the chest, as one of the consequences of inflammation of the chest; and the same disturbed balance of action will produce similar effusion in other cavities.

The extensibility of membrane generally is nowhere more strikingly displayed than in the serous membranes, and particularly in that under consideration. How different the bulk of the lungs before the act of inspiration has commenced, and after it has been completed, and especially in the laborious respiration of disease or rapid exertion! In either state of the lungs the pleura is perfectly fitted to that which it envelopes.

The pleura, like other serous membranes, is possessed of very lictle sensibility. Few nerves: from the sensitive column of the spinal chord reach it. Acnte feeling would render these membranes generally, and this membraue in particular, unfit for the function they have to discharge. It has too much motion, even during sleep; and far too forcible friction with the parietes of the thorax in morbid or hurried respiration, to render it convenient or useful for it to possess much sensation. Some of those anatomists, whose experiments on the living animal do no eredit to their humanity, have given most singular proof of the insensibility, not only of these serous membranes, but of the organs which they invest. Bichat frequently examined the spleen of dogs. He detached it from some of its adhesions, and left it protruding from the wound in the abdomen, in order " to study the phenomena;" and he saw "them tearing off that organ, and eating it, and thus feeding upon their own substance." In some experiments, in which part of their intestines were left out, "he observed them, as soon as they had the opportunity, tear to pieces their own viscera without any visible pain.

Although it may be advantageous that these important organs shall be thus devoid of seusibility when in health, in order that we may be unconscious of their action and motion, and that they may be rendered perfectly independent of the will, jet it is equally needful that, by the feeling of pain, we should be warned of the existence of any dangerous disease: and thence it happens that this membrane, and also the organ which it invests, acquire under inflammation the highest degree of sensibility. The countenance of the horse labouring under pleurisy or pneumonia will sufficiently indicate a state of suffering; and the spasmed bend of his neck, and his long and anxious and intense gaze upon his side, tell us that that suffering is extreme.

Nature, however, is wise and benevolent even here. It is not of every morbid affection, or mor- bid change, that the animal is conscious. If a mucous membrane is diseased, he is rendered painfully aware of that, for neither respiration nor digestion could be perfectly carried on while there was any considerable lesion of it; but, on the other hand, we find tubercles in the parenchyma of the lungs, or induration or hepatization of their substance, or extensive adhesions, of which there were few or no indications during life.

The pleura adheres intimately to the ribs and to the substance of the lungs; yet it is a very singular connexion. It is not a continuance of the same organisation; it is not an interchange of vessels. The organ and its membrane, although so closely connected for a particular purpose, yet in very many cases, and where it would least of all be suspected, have little or no sympathy with each other. Inflammation of the lungs will sometimes exist, and will run on to ulceration, while the pleura will be very little affected: and, much oftener, the pleura will be the seat of inflammation and will be attended by increased exhalation to such an extent as to suffocate the animal, and yet the lungs will exhibit little other morbid appearance than that of mere compression. The disease of a mucous membrane spreads to other partsthat of a serous one is generally isolated. It was to limit the progress of disease that this difference of structure between the organ and its membrane was contrived.

The investing membrane of the lungs and that of the heart are in continual contact with each other, but they are as distinct and unconnected, as if they were placed in different parts of the frame. Is their no meaning in this?

It is to preserve the perfect independence of organs equally important, yet altogether different in structure and function-- to oppose an insuperable barrier to hurtful sympathy hetween them, and especially to cut off the communication of disease.

Perhaps a little light begins to be thrown on a circumstance of which we have occasional painful experience. While we may administer physic, or mild aperients at least, in pleurisy, not only with little danger, but with manifest advantage, we may just as well give a dose of poison as a physic-ball to a horse labouring under pneumonia. The pleura is comnected with the lungs, and with the lungs alone, and the organisation is so different, that there is very little sympathy between them. A physic-ball may, therefore, act as a counter-irritant, or as giving a new determination to the vital current, without the propagation of sympathetic irritation; but the lungs or the bronchial tubes that ramify through them are continuous with the mucous membranes of the digestive as well as all the respiratory passages; and on account of the continuity and similarity of organisation, there is 
much sympatly between them. If there is irritation excited at the same time in two different portions of the same membrane, it is probable that, instead of being shared betreen them, the one will be transferred to the other-will increase or double the other, and act with fearful and fatal violence.

\section{THE LUNGS,}

The lungs are the seat of a peculiar circulation They convey through their comparatively little bulk the blood, and other fluids scarcely transformed into blood, or soon separated from it, which traverse the whole of the frame. They consist of countless ramifications of air-tubes and blood-vessels connected together by intervening cellular substance.

They form two distinet bodies, the right somewhat larger than the left, and are divided from each other by the duplicature of the pleura, which has been already described-the mediastimum. Each lung has the same structure, and properties, and uses. Fach of them is subdivided, the right lobe consisting of three lobes, and the left of two. The intention of these divisions is probably to adlapt the substance of the lungs to the form of the earity in which they are placed, and to enable them more perfectly to occupy and fill the chest.

If one of these lobes is cut into, it is found to consist of imumerable irregularly formed compartments, to which anatomists have given the name of lobules, or little lobes. They are distinct from each other, and impervious. On close examination, they can be subdivided almost without end. There is no communication between them, or if perchance such communication exists, it constitutes the disease known by the name of broken xind.

On the delicate membrane of which these cells are composed, innumerable minute blood-vessels ramify. They proceed from the heart, through the medium of the pulmonary artery-they follow all the subdirisions of the bronchial tubes-they ramify upou the membrane of these multitudinous lobules, and at length return to the heart, through the medium of the pulmonary veins, the character of the blood which they contain being essentially changed. The mechanism of this, and the effect produced, must be briefly considered.

\section{THE HEART.}

The Heart is placed between a doubling of the pleura-the mediastinum; by means of which it is supported in its natural situation, and all dangerous friction between these important organs is avoided. It is also surrounded by a membrane or bag of its own, called the pericardium, whose office is of a similar nature. By neans of the heart, the blood is circulated through the frame.
It is composed of four cavities-tro above, called auricles, from their supposed resemblance to the ear of a $\operatorname{dog}$; and two below, termed ventricles, occupying the substance of the heart. In point of fact, there are two hearts- the one on the left side impelling the blood through the frame, the other on the right side conveying it through the pulmorary system; but, united in the manner in which they are, their junction contributes to their mutual strength, and both circulations are carried on at the same time.

The first is the arterial circulation. No function can be discharged-life cannot exist, without the presence of arterial blood. The left ventricle that contains it contracts, and by the power of that contraction, aided by other means, which the limits of our work will not permit us to describe, the blood is driven through the whole arterial circulation--the capillary vessels and the veins-and returns again to the heart, but to the right ventricle. The other division of this viscus is likewise employed in circulating the blood thus conveyed to it, but is not the same flmid which was contained in the left ventricle. It has gradually lost its vital power. As it has passed along, it has changed from red to black, and from a vital to a poisonous fluid. Ere it can again convey the principle of nutrition, or give to each organ that impulse or stimulus which enables it to discharge its function, it must be materially changed.

When the right ventricle contracts, and the blood is driven into the lungs, it passes over the gossamer membrane of which the lobules of the lungs have been described as consisting; these lobules being filled with the air which has descended through the bronchial tubes in the act of inspiration. This delicate membrane permits some of the principles of the air to permeate it. The oxygen of the atmosphere attracts and combines with a portion of the superabundant carbon of this blood, and the expired air is poisoned with carbonic acid gas. Some of the constituents of the blood attract a portion of the oxygen of the air, and obtain their distinguishing character and properties as arterial blood, and being thus revivified, it passes on over the membrane of the lobes, unites into small and then larger vessels, and at length pours its full stream of arterial blood into the left auricle, thence to ascend into the ventricle, and to be diffused over the frame.

\section{DISEASES OF THE HEART.}

It may be readily supposed that an organ so complicated is sulject to disease. It is so to a fearful extent; and it sympathises with the maladies of every other part. Until lately, however, this subject has been shamefully neglected, and the writers on the veterinary art have seemed to be unaware of the importance of the organ, and the 
maladies to which it is exposed. The owner of the horse and the veterinary profession generally, are deeply indebted to Messis. Percivall and Pritchard* for much valuable information on this subject. The writer of this work acknowledges his obligation to both of these gentlemen. To Dr. Hope also, and particularly to Laennec, we owe much. Mr. Percivall well says, "This class of diseases may be regarded as the least advanced of any in veterinary medicine-a circumstance not to be ascribed so much to their comparative rarity, as to their existing undiscovered, or rather being confounded during life with other disorders, and particularly with pulmonary affections."

The best place to examine the beating of the heart is immediately behind the elbow, on the left side. The hand applied flat against the ribs will give the nnmber of pulsations. The ear thus applied will enable the practitioner better to ascertain the character of the pulsation. The stethoscope affords an nncertain guide, for it cannot be flatly and evenly applied.

Pericarditis. - The bag, or outer investing memhrane of the heart, is liable to inflammation, in which the effused fluid hecomes organized, and deposited in layers, increasing the thickness of the pericardium, and the difficulty of the expansion and contraction of the heart. The only symptoms on which dependence can be placed, are a quickened and irregular respiration; a bounding action of the heart in an early stage of the disease; but that, as the fluid increases and becomes concrete, assuming a feeble and fluttering character.

Hydrops Pericardii is the term used to designate the presence of the flnid secreted in consequence of this inflammation, and varying from a pint to a gallon or more. In addition to the symptoms already described, there is an expression of alarm and anxiety in the countenance of the auimal which no other malady produces. The horse generally sinks from other disease, or from constitutional irritation, before the cavity of the pericardium is filled; or if he lingers on, most dreadful palpitations and throbbings accompany the advanced stage of the disease. It is seldom or nerer that this disease exists alone, but is combined with dropsy of the chest or abdomen.

Carditis is the name given to inflammation of the muscular substance of the heart. A well authenticated instance of inflammation of the substance of the heart does not stand on record. Some other organ proves to be the chief seat of mischief, even when the disturbance of the heart has been most apparent.

Inflammation of the Lining of the Heart.Mr. Simpson relates, in the Veterinarian for 1834 , a case in which there were symptoms of

* See Pritchard's papers in the Veterinarian, vol, vi., and Percirall's Hippopathology, vol. ii., part i.

vor. $\mathbf{I}$. severe abdominal pain: the respiration was much disturbed, and the action of the heart took on an extraordinary character. Three or four heats succeeded to each other, so violently às to shake the whole frame, and to he visible at the distance of several yards, with intervals of quietude of five minutes or more. At length this violent beating became constant.

On dissection both lungs were found to be inflamed, the serum in the pericardium increased in quantity, and the internal membrane of the heart violently inflamed, with spots of ecchymosis.

This wonld seem to be a case of inflammation of the heart; but in a considerable proportion of the cases of rabies, these spots of ecchymosis, and this general inflammation of the heart, are seen.

Hypertrophy is an augmentation or thickening of the substance of the heart; and al though not dreamed of a few years ago, seems now to be a disease of no rire occurrence among horses. The heart has been known to acquire double its natural volume, or the auricle and ventricle on one side have been thus enlarged. Mr. Thomson of Bath relates, in the Veterinarian, a very singular case. A horse was brought with every appearance of acute rheumatism, and was bled and physicked. On the following day he was standing with his fore legs widely extended, the nostrils dilated, the breathing quick and laborious, the eyes sunk in their orbits, the pupils dilated, his nose turned round almost to his elbow, sighing, and his countenance showing approaching dissolution.

The pulse had a most irregular motion, and the undulation of the jugular veins was extending to the very roots of the ears. He died a few hours afterwards.

The lungs and pleura were much inflamed; the pericardium was inflamed and distended by fluid; the heart was of an enormous size and greatly inflamed; both the auricles and ventricles were filled with coagulated blood; the greater part of the chordæ tendineæ had given way; the ralves did not approximate to perform their fnnction, and the heart altogether presented a large disorganized mass, weighing thirty-four pounds. The animal worked constantly on the farm, and had never been put to quick or very laborions work.

Dilatation is increased capacity of the cavities of the heart, and the parietes being generally thinned. It is probable that this is a more frequent disease than is generally supposed ; and from the circulating power being lessened, or almost suspended, on account of the inability of the cavities to propel their contents, it is accompanied by much and rapid emaciation. In the Gardens of the Zoological Society of London this is a disease considerably frequent, and almost uniformly fatal. 
It attacks the smaller animals, and particularly the quadrumana, and has been found in the deer and the zebra. It is characterised by slow emaciation, and a piteous expression of the countenance; but the mischief is done when these symptoms appear.

Ossification of the Heart.-There are too many instances of this both in the right and the left auricles of the heart, the aortic valves, the abdominal aorta, and also the bronchial and other glands. Mr. Percivall observes of one of these cases, that " the cavity could have been but a passive receptacle for the blood, and the current must have been continued without any or with hardly any fresh impulse."

Of Air in the Heart destroying the horse, there are some interesting accounts; and also of rupture of the heart, and aneurism, or dilatation of the aorta, both thoracic and abdominal, and even farther removed from the heart and in the iliac artery. The symptoms that would certainly indi. cate the existence of aueurism are yet unknown, except tenderness about the loins and gradual inability to work, are considered as such : but it is interesting to know of the existence of these lesions. Ere long the veterinary surgeon may possibly be able to guess at them, although he will rarely have more power in averting the consequences of aneurism than the human surgeon possesses with regard to his patient.

This will be the proper place to describe a little more fully the circulation of the blood, and various circumstances connected with that most important process.

\section{THE ARTERIES.}

The vessels which carry the blood from the heart are called arteries (keeping air, - the ancients thought that they contained air). They are com. posed of three coats; the outer or elastic is that by which they are enabled to yield to the gush of blood, and enlarge their dimensions as it is forced along them, and by which also they contract again as soon as the stream has passed; the middle coat is a muscular one, by which this contraction is more powerfully performed, and the blood urged on in its course; the inner or membranous coat is the mere lining of the tube.

This yielding of the artery to the gush of blood, forced into it by the contraction of the heart, constitutes

\section{THE PULSE.}

The pulse is a very useful assistant to the practitioner of human medicine, and much more so to the veterinary surgeon, whose patients cannot describe either the seat or degree of ailment or pain. The number of pulsations in any artery will give the number of the beatings of the heart, and so express the irritation of that organ, and of the frame generally. In a state of health, the heart beats in a farmer's horse about thirty-six times in a minute. In the smaller, and in the thorough-bred horse, the pulsations are forty or forty-two. This is said to be the standard pulsethe pulse of health. It varies singularly little in horses of the same size and breed, and where it beats naturally there can be little materially wrong. The most convenient place to feel the pulse, is at the lower jaw (p. 263), a little behind the spot where the submaxillary artery and vein, and the parotid duct, come from under the jaw. There the number of pulsations will be easily counted, and the character of the pulse, a matter of fully equal importance, will be clearly ascertained. Many horsemen put the hand to the side. They can certainly count the pulse there, but they can do nothing more. We must be able to press the artery against some hard body, as the jawbone, in order to ascertain the manner in which the blood flows through it, and the quantity that fiows.

When the pulse reaches fifty or fifty-five, some degree of fever may be apprehended, and proper precaution should be taken. Serenty or seventyfive will indicate a dangerous state, and put the owner and the surgeon not a little on the alert. Few horses loug survive a pulse of one hundred, for, by this excessive action, the energies of nature are speedily worn out.

Some things, however, should be taken into account in forming our conclusion from the frequency of the pulse. Exercise, a warm stable, and fear, will wonderfully increase the number of pulsations.

When a careless, brutal fellow goes up to a horse, and speaks hastily to him, and handles him roughly, he adds ten beats per minute to the pulse, aud will often be misled in the opinion he may form of the state of the animal. A judicious person will approach the patieut gently, and pat and soothe him, and even then the circulation, probably, will be a little disturbed. He should take the additional precautiou of noting the number and quality of the pulse, a second time, before he leaves the animal.

If a quick pulse indicate irritation and fever, a slow pulse will likewise characterise diseases of an opposite description. It accompanies the sleepy stage of staggers, and every malady connected with deficiency of nervous energy.

The heart may not ouly be excited to more frequent, but also to more violent action. It may contract more powerfully upon the blood, which will be driven with greater force through the arteries, and the expansion of the vessels will be greater and more sudden. Then we have the hard pulse,- the sure indicator of considerable fever, and calling for the immediate and free use of the lancet. 
Sometimes the pulse may be hard and jerking, and yet small. 'The stream though forcible is not great. The beart is so irritable that it contracts before the ventricle is properly filled. The practitioner knows that this indicates a dangerous state of disease. It is an almost invariable accompaniment of inflammation of the bowels.

A weak pulse, when the arterial stream flows slowly, is caused by the feeble action of the beart. It is the reverse of fever, and expressive of debility.

The oppressed pulse is when the arteries seem to be fully distended with blood. There is obstruction somewhere, and the action of the heart eau hardly force the stream along, or communicate pulsation to the current. It is the case in sudden inflammation of the lungs. They are overloaded and gorged with blood which cannot find its way through their minute vessels. This accounts for the well-known fact of a copious bleeding increasing a pulse previously oppressed. A portion being removed from the distended and choked vessels, the remainder is able to flow on.

There are many other varieties of the pulse, which it would be tedious here to particularise; it must, however, be observed, that during the act of bleeding, its state should be carefully observed. Many veterinary surgeons, and gentlemen too, are apt to order a certain quantity of blood to be taken away, but do not condescend to superintend the operation. This is unpardonable in the surgeon and censuralle in the owner of the horse. The animal is bled for some particular purpose. There is some state of disease, indicated by a peculiar quality of the pulse, which we are endeavouring to alter. The most experienced practitioner cannot tell what quantity of blood must be abstracted in order to produce the desired effect. The change of the pulse can alone indicate when the olject is accomplished; therefore, the operator should have his finger on the artery during the act of bleeding, and, comparatively regardless of the quantity, continue to take blood, until, in inflammation of the lungs the oppressed pulse becomes fuller and more distinct, or the strong pulse of considerable fever is evidently softer, or the animal exhibits symptoms of faintness.

The arteries divide as they proceed through the frame, and branch out into innumerable minute tubes, termed capillaries (hair-like tubes), and they even become so small as to elude the sight. The slightest puncture cannot be inflicted without wounding some of them.

In these little tubes, the nourishment of the body, and the separation of all the various secretions is performed, and, in consequence of this, the blood is changed. When these capillaries unite together, and begin to enlarge, it is found to be no longer arterial, or of a florid red colour, but venous, or of a blacker bue. Therefore the prin- cipal termination of the arteries is in veins. The point where the one ends, and the other commences, canuot le ascertained. It is when the red arterial blood, having discharged its function by depositing the nutritious parts, is changed to venous or black blood.

Branches from the ganglial or sympathetic nerves wind round these vessels, and endue them with energy to discharge their functions. When the nerves communicate too much energy, and these vessels consequently act with too much power, inflammation is produced. If this disturbed action is confined to a small space or a single organ, it is said to be local, as inflammation of the eye, or of the lungs ; but when this inordinate action spreads from its original seat, and embraces the whole of the arterial system, fever is said to be present, and this usually increases in proportion as the local disturbance is observable, and subsides with it.

\section{INFLAMMATION.}

Local inflammation is characterised by redness, swelling, heat, and pain. The reduess proceeds from the greater quantity of blood flowing through the part, occasioned by the increased action of the vessels. The swelling arises from the same cause, and from the deposit of fluid in the neighbouring substance. The natural heat of the body is produced by the gradual change which takes place in the blood, in passing from an arterial to a venous state. If more lood is driven through the capllaries of an inflamed part, and in which this change is effected, more heat will necessarily be produced there; and the pain is easily accounted for by the distension and pressure which must be produced, and the participation of the nerves in the disturbance of the surrounding parts.

If inflammation consists of an increased flow of blood to and through the part, the ready way to abate it is to lessen the quantity of blood. If we take away the fuel, the fire will go out. All other means are comparatively unimportant, contrasted with bleeding. Blood is generally abstracted from the jugular vein, and so the general quantity may be lessened; but if it can can be taken from the neighbourhood of the diseased part, it will be productive of tenfold benefit. One quart of blood abstracted from the foot in acute founder, by unloading the vessels of the inflamed part, and enabling them to contract, and, in that contraction, to acquire tone and power to resist future distension, will do more good than five quarts taken from the general circulation. An ounce of blood obtained by scarifying the swelled vessels of the inflamed eye, will give as much relief to that organ as a copious bleeding from the jugular. It is a principle in the animal frame which should never be lost sight of by the reterinary surgeon, or the horseman, that if by bleeding the process 
of inflammation can once be checked,-if it can be suspended but for a little while,- -although it may return, it is never with the same degree of violence, and in many cases it is got rid of entirely. Hence the necessity of bleeding early, and bleeding largely, in inflammation of the lungs, or of the bowels, or of the brain, or of any important organ. Many horses are lost for want or insufficiency of bleeding, but we never knew one materially injured hy the most copious extraction of blood in the early stage of acute inflammation. The horse will bear, and with advantage, the loss of an almost incredible quantity of blood,-four quarts taken from him, will be comparatively little more than one pound taken from the human being. We can scarcely conceive of a considerable inflammation of any part of the horse, whether proceeding from sprains, contusions, or any other cause in which bleeding, local (if possible), or general, or both, will not be of essential service.

Next in importance to bleeding, is purging. Something may be removed from the bowels, the retention of which would increase the general irritation and fever. The quantity of blood will be materially lessened, for the serous or watery fluid which is separated from it by a brisk purge, the action of which in the horse continues probably more than twenty-four hours, is enormous. While the blood is thus determined to the bowels, less even of that which remains will flow through the inflamed part. When the circulation is directed to one set of vessels, it is proportionately dimi. nished in other parts. It was first directed to the inflamed portions, and they were overloaded and injured,-it is now directed to the bowels, and the inflamed parts are relieved. While the purging continues, some degree of languor and sickness are felt, and the force of the circulation is thereby diminished, aud the general excitement lessened. The importance of physic in every case of consider. ahle external inflammation, is sufficiently evident. If the horse is laid by for a few days from injury of the foot, or sprain, or poll-evil,.or wound, or almost any cause of inflammation, $a$ physic ball should be given.

In cases of internal inflammation, much judgment is required to determine when a purgative may be beneficial or injurious. In inflammation of the lungs or bowels, it shonld never be given. There is so strong a sympathy between the various contents of the cavity of the chest, that no one of them can be inflamed to any great extent, without all the others being disposed to become so; and, therefore, a dose of physic in inflamed lungs, would perhaps be as fatal as a dose of poison. The excitement produced on the howels by the purgative may min on to inflammation, which no medical skill can stop.

The means of abating external inflammation are various, and seemingly contradictory. The heat of the part very naturally and properly led to the application of cold embrocations and lotions. Heat has a strong tendency to equalize itself, or to leave that substance which has a too great quantity of it, or little capacity to retain it, for another which has less of it, or more eapacity. Hence the advantage of cold applications, by which a great deal of the unnatural heat is speedily abstracted from the inflamed part. The foot labouring under inflammation is put into cold water, or the horse is made to stand in water or wet clay. Various cold applications are also used to sprains. The part is wetted with diluted vinegar, or goulard, or salt and water. When benefit is derived from these applications, it is to be attributed to their coldness alone. Water, especially when cooled below the natural temperature, is as good an application as any that can be used. Nitre dissolved in water, will lower the temperature of the Aluid many degrees; but the lotion must be applied immediately after the salt has been dissolved. ${ }^{\circ}$ A bandage may be afterwards applied to strengthen the limb, but during the continuance of active inflammation, it would only confine the beat of the part, or prevent it from benefiting by the salutary influence of the cold produced by the evaporation of the water.

Sometimes, however, we resort to warm fomentations, and if benefit is derived from their use, it is to be traced to the warmth of the fluid, more than to any medicinal property in it. Warm water will do as much good to the horse, who has so thick a skin, as any decoction of chamomile, or marsh mallow, or poppy heads, or any nostrum that the farrier, may recommend. Fomentations increase the warmth of the skin, and open the pores of it, and promote perspiration, and thus lessen the tension and swelling of the part, assuage pain, and relieve inflammation. Fomentations, to be beneficial, should be long and frequently applied, and at as great a degree of heat as can be used without giving the animal pain. Poultices are more permanent, or longer-continued fomentations. The part is exposed to the influence of warmth and moisture for many hours or days without intermission, and perspiration being so long kept up, the distended vessels will be very materially relieved. The advantage derived from a poultice is attributable to the heat and moisture, which, by means of it, can be long applied to the skin, and it should be composed of materials which will best retain this moisture and heat. The bran poultice of the farrier is, consequently, objectionable. It is never perfectly in contact with the surface of the skin, and it becomes nearly dry in a few hours, after which it is injurious rather than beneficial. Linseed-meal is a much better material for a poulticr, for, if 
properly made, it will remain moist during many hours.

It is occasionally very difficult to decide when a cold or a hot application is to be nsed, and no general rule can be laid down, except that in cases of superficial inflammation, and in the early stage, cold lotions will be preferable; but, when the inflammation is deeper seated, or fully established, warm fomentations will be most serviceable.

Stimulating applications are frequently used in local inflammation. When the disease is deeply seated, a stimulating application to the skin will cause some irritation and inflammation there, and lessen or sometimes remove the original malady ; hence the use of rowels and blisters in inflammation of the chest. Inflammation to a bigh degree, caunot exist in parts that are near each other. If we excite it in one, we shall abate it in the other, and also, by the discharge which we establisb from the one, we shall lessen the determination of blood to the other.

Stimulating and blistering applications should never be applied to a part already intlamed. A fire is not put out by heaping more fnel upon it. Hence the mischief which the farrier often does by rubbing his abominable oils on a recent sprain, hot and tender. Many a horse has been ruined by this absurd treatment. When the heat and tenderness have disappeared by the use of cold lotions or fomentations, and the leg or sprained part remains enlarged, or bony matter tlireatens to be deposited, it may be right to excite inflammation of the skin by a blister, in order to ronse the deeper-seated absorlents to action, and enable them to take up this deposit; but, except to hasten the natural process and effects of inflammation, a blister, or stimulating application, should never be applied to a part already inflamed.

\section{FEVER.}

Fever is general increased arterial action, either without any local affection, or in consequence of the sympathy of the system with inflam. mation in some particular part.

The first is pure fever. Some have denied that that exists in the horse, but they must bave been strangely careless observers of the diseases of that animal. The truth of the matter is, that the usual stable management and general treatment of the horse are so absurd, and various parts of hien are rendered so liable to take on inflammation, that pure fever will exist a very little time without degenerating into inflammation. The lungs are so weakened by the heated and foul air of the ill-ventilated stable, and by sudden changes from almost insufferable heat to intense cold, and the feet are so injured by hard usage and injudicious shoeing, that, sharing from the beginning in the general vascular excitement which charac- terises fever, they soon beeme excited fir beyond other portions of the frame; and that which commenced as fever becomes inflammation of the lungs or feet. Pure fever, however, is sometimes seen, and runs its course regularly.

It frequently begins with a cold or shivering fit, although this is not essential to fever. The horse is dull, unwilling to move, has a staring coat, and cold legs and feet. This is succeeded by warmth of the body; unequal distribution of warmth to the legs; one hot, and the other three cold, or one or more nnnaturally warm, and the others unusually cold, but not the deathlike coldness of inflammation of the lungs; the pulse quick, soft, and often indistinct; the breatling somewhat laborious; but no cough, or pawing, or looking at the flanks. The animal will scarcely eat, and is very costive. While the state of pure fever lasts, the shivering fit returns at nearly the sarne hour every day, and is succeeded by the warm one, and that often by a slight degree of perspiration; and these alternate during several days until local inflammation appears, or the fever gradually subsides. No horse ever died of pure fever. If he is not destroyed by inflammation of the lungs, or feet, or bowels succeeding to the fever, be gradually recovers.

What has been said of the treatment of local inflammation will sufficiently indicate that which should be resorted to in fever. Fever is general increased action of the heart and arteries, and therefore evidently appears the necessity for bleeding, regulating the quantity of blood by the degree of fever, and nsually keeping the finger on the artery until some evident and considerable impression is made upon the system. The bowels should he gently opened; but the danger of inflammation of the lungs, and the uniformly injurions consequence of purgation in that disease, will prevent the administration of an active purgative. A small quantity of aloes may be given morning and night with the proper fever medicine, until the bowels are slightly relaxed, after which nothing more of an aperient quality shonld be administered. Digitalis, emetic tartar, and nitre should be given morning and night, in proportions regulated by the circumstances of the case. The horse should be warmly clothed, but be placed in a cool and well-ventilated stable.

Symptomatic fever is increased arterial action, proceeding from some local cause. No organ of consequence can be much disordered or inflamed without the neighbouring parts being disturbed, and the whole system gradually participating in the disturbance Inflammation of the feet or of the lungs never existed long or to any material extent, without being accompanied by some degree of fever.

The treatment of symptomatic ferer should 
resemble that of simple ferer, except that particular attention must be paid to the state of the part originally diseased. If the inflammation which existed there can be subdued, the general disturbance will usually cease.

The arteries terminate occasionally in openings on different surfaces of the body. On the skin they pour out the perspiration, and on the different cavities of the frame they yield the moisture which prevents friction. In other parts they terminate in glands, in which a fluid essentially different from the blood is secreted or separated: such are the parotid and salivary glands, the kidneys, the spleen, and the various organs or laboratories which provide so many and such different secretions, for the multifarious purposes of life; but the usual termination of arteries is in veins.

THE VEINS.

These vessels carry back to the heart the blood which had been conveyed to the different parts by the arteries. They have two coats, a muscular and a membranous one. Both of them are thin and comparatively weak. They are more numerous and much larger than the arteries, and consequently the blood, lessened in quantity by the various secretions separated from it, flows more slowly through them. It is forced on partly by the first impulse communicated to it by the heart; also, in the extremities and external portions of the frame, by the pressure of the muscles; and in the cavity of the chest, its motion is assisted or principally caused by the sudden expansion of the ventricles of the heart, after they have closed upon and driven out their contents, and thereby causing a vacuum which the blood rushes on to fill. There are curious valves in various parts of the veins which prevent the blood from flowing backward to its source.

\section{BOG AND BLOOD SPAVIN.}

The veins of the horse, although their coats are thin compared with those of the arteries, are not subject to the enlargements (varicose veins) which are so frequent, and often so painful, in the legs of the human being. The legs of the horse may exhibit many of the injurious consequences of hard work, but the veins will, with one exception, be unaltered in structure. Attached to the extremities of most of the tendons, and between the tendons and other parts, are little bags containing a mucous substance to enable the tendons to slide over each other without friction, and to move easily on the neighbouring parts. From violent exercise these vessels are liable to enlarge. Windgalls and thorough-pins are instances of this. There is one of them on the inside of the hock at its bending. This sometimes becomes considerably increased in size, and the enlargement is called a bog-sparin. A vein passes over this bag, which is pressed between the enlargement and the skin, and the passage of the blood through it is impeded; the vein is consequently distended by the accumulated blood, and the distension reaches from this bag as low down as the next valve. This is called a blood-spavin. Blood-spavin then is the consequence of bog-spavin. It very rarely occurs, and is, in the majority of instances, confounded with bog-spavin.

Blood-spavin does not always cause lameness, except the horse is very hard-worked, and then it is doubtful whether the lameness should not be attributed to the enlarged mucous bag rather than to the distended vein. Both of these diseases, however, render a horse unsound, and materially lessen his value.

old farriers used to tie the vein, and so cut off altogether the flow of the blood. Some of them, a little more rational, dissected out the bag which caused the distension of the vein: but the modern and more prudent way is to endeavour to promoto the absorption of the contents of the bag. This may be attempted by pressure long applied. A bandage may be contrived to take in the whole of the hock, except its point; and a compress made of folded linen being placed on the bog-spavin, may confine the principal pressure to that part. It is, however, very difficult to adapt a bandage to a joint which admits of such extensive motion; therefore most practitioners apply two or three successive blisters over the enlargement, when it usually disappears. Unfortunately, however, it returns if any extraordinary exertion is required from the horse.

\section{BLEEDING.}

This operation is performed with a fleam or a lancet. The first is the common instrument, and the safest, except in skilful hands. The lancet, however, has a more surgical appearance, and will be adopted by the veterinary practitioner. A blood-stick-a piece of hard wood loaded at one end with lead-is used to strike the fleam into the rein. This is sometimes done with too great violence, and the opposite side of the coat of the vein is wounded. Bad cases of inflammation have resulted from this. If the fist is doubled, and the fleam is sharp and is struck with sufficient force with the lower part of the hand, the bloodstick may be dispensed with.

For general bleeding the jugular rein is selected. The horse is blindfolded on the side on which he is to be bled, or his head turned well away. The hair is smoothed along the course of the rein with the moistened finger; then, with the third and little fingers of the left hand, which holds the fleam, pressure is made on the vein sufficient to bring it fairly into view, bit not to swell it too much, for then, presenting a rounded surface, it would be apt to roll or slip under the blow. 
The point to be selected is about two inches below the union of the two portions of the jugular at the angle of the jaw. The fleam is to be placed in a direct line with the course of the vein, and over the precise centre of the vein, as close to it as possible, but its point not absolutely touching the vein. A sharp rap with the bloodstick or the hand on that part of the back of the fleam immediately over the blade, will cut through the vein, and the blood will flow. A fleam with a large blade should always be preferred, for the operation will be materially shortened, and this will be a matter of some consequence with a fidgety or restive horse. A quantity of blood drawn speedily will also have far more effect on the system than double the weight slowly taken, while the wound will heal just as readily as if made by a smaller instrument. There is no occasion to press so hard against the neck with the pail, or can, as some do; a slight pressure, if the incision has been large enough and straight, and in the middle of the vein, will cause the blood to flow sufficiently fast; or, the finger being introduced into the mouth between the tushes and the grinders, and gently moved about, will keep the mouth in motion, and hasten the rapidity of the stream by the action and pressure of the neighbouring muscles.

When sufficient blood has been taken, the edges of the wound should be trought closely and exactly together, and kept together hy a small sharp pin being passed through them. Round this a little tow, or a few hairs from the mane of the horse, should be wrapped, so as to cover the whole of the incision; and the head of the horse should be tied up for several hours to prevent his rubbing the part against the manger. In bringing the edges of the wound together, and introducing the pin, care should be taken not to draw the skin too much from the neck, otherwise blood will insinuate itself between it and the muscles beneath, and cause an unsightly and sometimes troublesome swelling.

The blood should be received into a vessel the dimensions of which are exactly known, so that the operator may be able to calculate at every period of the bleeding the quantity that is substracted. Care likewise should be taken that the blood flows in a regular stream into the centre of the vessel, for if it is suffered to trickle down the sides, it will not afterwards undergo those changes by which we partially judge of the extent of inflammation. The pulse, however, and the symptoms of the case collectively, will form a better criterion than any clange in the blood. Twenty-four hours after the operation, the edges of the wound will have united, and the pin should he withdrawn. When the bleeding is to be repeated, if more than three or four hours have elapsed, it will be better to make a fresh incision rather than to open the old wound.

Few directions are necessary for the use of the lancet. They who are competent to operate with it, will scarcely require any. If the point is sufficiently sharp the lancet can scarcely be too broadshouldered; and an abscess lancet will generally make a freer incision than that in common use. Whatever instrument is adopted, too much care cannot be taken to have it perfectly clean, and very sharp. It should be carefully wiped and dried immediately after the operation, otherwise, in a very short time, the edges will begin to be corroded.

For general bleeding the jugular vein is selected as the largest superficial one, and most easily got at. In every affection of the head, and in cases of fever or extended inflammatory action, it is decidedly the best place for bleeding. In local inflammation, blood may be taken from any of the superficial veins. In supposed affections of the shoulder, or of the fore-leg or foot, the plate vein, which comes from the inside of the arm, and runs upwards directly in front of it towards the jugular, may be opened. In affections of the hind extremity, blood is sometimes extracted from the saphana, or thigh-vein, which runs across the inside of the thigh. In foot cases it may be taken from the coronet, or, much more safely, from the toe; not by cutting out, as the farrier does, a piece of the sole at the toe of the frog, which sometimes causes a wound difficult to heal, and followed by festering, and even by canker, but cutting down with a fine drawing-knife, called a searcher, at the union between the crust and the sole at the very toe until the blood flows, and, if necessary, encouraging its discharge by dipping the foot in warm water. The mesh-work of both arteries and veins will be here divided, and blood is generally obtained in any quantity that may be needed. The bleeding may be stopped with the greatest ease, by placing a bit of tow in the little groove that has been cut, and tacking the shoe over it.*

* A great improvement has lately been introduced in the method of arresting arterial hæmorrhage. The operation is very simple and, with common care, successful. The instrument is a pair of artery forceps, with rather sharper teeth than the common forceps and the hlades held close by a slide. The vessel is laid bare, detached from the cellular substance around it, and the artery then grasped by the forceps, the instrument deviating a very little from the line of the artery. The vessel is now divided close to the forceps, and behind them, and the forceps are twisted four or five times rouad. The forceps are then loosened, and, geserally speaking, not more than a drop or two of blood will have been lost. This method of arresting bleeding has been applied by seteral scientific aod benevolent men with almost constaat success. It has been readily and effectually practised in docking, and our patients have escaped much forture, and tetanus lost many a victim. The forceps have been introduced, and with much success, in castration, and thus the principal danger of that operation, as well as the most painful part of it, is removed. The colt will be a fair subject for this experiment. On the sheep and the calf it may be readily performed, and the operator will have the pleasing conscinusness of rescuing many a poor animal from the unnecessary infliction of torture. 


\section{CHAPTER XII}

WE now proceed to the consideration of the diseases of the respiratory system.

THE MEMBRANE OF THE NosE.

The mucous membrane of the nose is distinguished from other mucous surfaces, not only by its thickness, but its vascularity. The blood vessels are likewise superficial; they are not covered even by integument, but merely by an unsubstantial mucous coat. They are deeper seated, indeed, than in the human being, and they are more protected from injury; and therefore there is far less hæmorrhage from the nostril of the horse than from that of the human being, whether spontaneous or accidental. Lying immediately under the mucous coat, these vessels give a peculiar, and, to the horseman, a most important tinge to the membrane, and particularly observable on the septum. They present him with a faithful indication of the state of the circulation, and especially in the membranes of the other respiratory passages with which this is continuous.

The horseman and the veterinary surgeon do not possess many of the auxiliaries of the human practitioner. Their patients are dumb; they can neitlier tell the seat nor the degree of pain; and the blunders of the practitioner are seldom buried with the patient. Well, he must use greater diligence in availing himself of the advantages that he does possess; and he has some, and very important ones too. The varying hue of the Schneiderian membrane is the most important of all ; and, with regard to the most frequent and fatal diseases of the horse-those of the respiratory passages-it gives almost all the information with regard to the state of the circulation in those parts that can possibly be required. Veterinarians too generally overlook this. It has not yet been sufficiently taught in our schools, or inculcated in our best works on the pathology of the horse.

It is the custom with almost every horseman who takes any pains to ascertain the state of his patient, to turn down the lower eyelid, and to form his opinion of the degree of general inflammation by the colour which the lining membrane of the lid presents. If it is very red, he concludes that there is considerable fever; if it is of a pale pinkish hue, there is comparatively little danger. This is a very important examination, and the conclusion which he draws from it is generally true: but on the septum of the nose he has a membrane more inmediately continuous with those of the respiratory organs-more easily got at - presenting a larger surface-the ramifications of the blood-vessels better seen, and, what is truly important, indicating not only the general affection of the membranes, but of those with which he is most of all concerned.

We would then say to every horseman and practitioner, study the character of that portion of the membrane which covers the lower part of the membrane of the nose-that which you can most readily bring into view. Day after day, and under all the varying circumstances of health and disease, study it until you are enabled to recognise, and you soon will, and that with a degree of exactitude you would have scarcely thought possible, the pale pink hue when the horse is in health-the increasing blush of red, and the general and uniform painting of the membrane, betokening some excitement of the system-the streaked appearance when inflammation is threatening or commencing-the intensely florid red of inflammation becoming acute-the starting of the vessels from their gossamer coat, and their seeming to run bare over the membrane, when the inflammation is at the highest-the pale ground with patches of vivid red, showing the halfsubdued but still existing fever-the uniform colour, but somewhat redder than natural, indicating a return to a healthy state of the circulation-the paleness approaching to white, accompanying a state of debility, and yet some radiations of crim. son, showing that there is still considerable irritability, and that mischief may be in the wind-the pale livid colour warning you that the disease is assuming a typhoid character-the darker livid announcing that the typhus is established, and that the vital current is stagnating-and the browner, dirty painting, intermingling with and subduing the lividness, and indicating that the game is up. These appearances will be guides to our opinion and treatment, which we can never too bighly appreciate.

\section{CATARRH, OR COTD}

Catarrh, or Cold, is attended by a slight defluxion from the nose-now and then, a slighter weeping from the eyes, and some increased labour of breathing, on account of the uneasiness which the animal experiences from the passage of the air over the naturally sensitive and now more than usually irritable surface, and from the air-passage being diminished by a thickening of the membrane. When this is a simply local inflammation, attended by no loss of appetite or increased animal temperature, it may speedily pass over.

In many cases, however, the inflammation of a membrane naturally so sensitive, and rendered so morbidly irritable by our absurd treatment, rapidly spreads, and involves the fauces, the lymphatic and some of the salivary glands, the throat, the parotid 
gland, and the membrane of the larynx. We hare then increased discharge from the nose, greater reduess of the membrane of the nose, more defluxion from the eyes, and loss of appetite from a degree of fever associating itself with the local affection, and there also being a greater or less degree of pain in the act of swallowing, and which if the animal feels this he will never eat. Cough now appears more or less frequent or painful; but with no great acceleration of the pulse, or heaving of the flanks.

Catarrh may arise from a thousand causes. Membranes subjected to so many sources of irritation soou become irritable. Exposure to cold or rain, change of stable, change of weather, change of the slightest portion of clothing, neglect of grooming, and a variety of circumstances apparently trifing, and which they who are unaccustomed to horses would think could not possibly produce any injurious effect, are the causes of catarrh. In the spring of the year, and while moulting, a great many young horses have cough; and in the dealers' stables, where the process of making up the horse for sale is carrying on, there is scarcely one of them that escapes this disease.

In the majority of cases, a few warm mashes, warm clothing, and a uarm stable-a fever-ball or two, with a drachm of aloes in each, and a little antimony in the evening, will set all right. Indeed, all would soon be right without any medicine; and much more speedily and perfectly than if the cordials, of which grooms and farriers are so fond, had beeu given. Nineteen horses out of twenty with common catarrh will do well; but in the twentieth case, a neglected cough may be the precusor of bronchitis, and pneumonia. These chest affections often insidiously creep on, and inflammation is frequently established before any one belonging to the horse is aware of its existence. If there is the least fever, the horse should be bled. A common cold, attended by heat of the mouth or indisposition to feed, should never pass without the abstraction of blood. A physic-ball, however, should not be given in catarrh without much consideration. It can scarcely be known what sympathy may exist between the portion of membrane already affected, and the mucous membranes generally. In severe thoracic affection, or in that which may soon become so, a dose of physic would be little better than a dose of poison. If, however, careful investigation renders it evident that there is no affection of the lungs, and that the disease has not proceeded beyond the fauces, small doses of aloes may with advantage be united with other medicines in order to evacuate the intestinal canal, and reduce the freal discharge to a pultaceous form.

If catarrh is accompanied by sore throat; if the parotids should enlarge and become tender- there are no tonsils, amygdala, in the horse-or if the submaxillary glands should be inflamed, and the animal should quid his food and gulp his water, this will be an additional reason for bleeding, and also for warm clothing and a comfortable stable. A hot stable is not meant by the term comfortable, in which the foul air is breathed over and over again, but a temperature some degrees above that of the external air, and where that determination to the skin and increased action of the exhalent vessels, which in these cases are so desirable, may take place. Every stable, both for horses in sickness and in health, should have in it a thermometer.

Some stimulating liniment may be applied over the inflamed gland, consisting of turpentine or tincture of cantharides diluted with spermaceti or neat's-foot oil-strong enough to produce considerable irritation on the skin, but not to blister, or to destroy the hair. An embrocation sufficiently powerful, and yet that never destroys the hair, consists of equal parts of hartshorn, oil of turpentine, and camphorated spirit, with a small quantity of laudanum.

INFLAMMATION OF THE LARTNX.

Strictly speaking, this refers to inflammation confined to the larynx, but either catarrh or bronchitis, or both, frequently accompany the complaint.

Its approach if often insidious, scarcely to be distinguished from catarrh except by being attended with more soreness of throat, and less enlargement of the parotid glands. There are also more decided and violent paroxysms of coughing than in common catarrh, attended by a gurgling noise, which may be heard at a little distance from the horse, and which, by auscultation, is decidedly referrible to the larynx. The breathing is shorter and quicker, and evidently more painful than in catarrh; the membrane of the nose is redder: it is of a deep modena colour; and the horse shrinks and exhibits great pain when the larrnx is pressed upon. The paroxysms of coughing become more frequent and violent, and the animal appears at times almost suffocated.

As the soreness of the throat proceeds, the head of the animal is projected, and the neck has a peculiar stiffness. There is also much difficulty of swallowing. Considerable swelling of the larynx and the pharynx ensue, and also of the parotid, sublingual and submaxillary glands. As the inflammation increases the cough becomes hoarse and feeble, and in some cases altogether suspended. At the commencement there is usually little or no nasal defluxion, but the secretion soon appears, either pure or mixed witl an unusual quantity of saliva.

Auscultation is a very important aid in the 
discovery of the nature and serious or trifling character of this disease. It cannot be too often repeated that it is one of the most valuable means which we possess of detecting the seat, intensity, and results, of the maladies of the respiratory passages. No instrument is required; the naked ear can be applied evenly and flatly, and with a very slight pressure, on any part that it is of importance to examine. The healthy sound, when the ear is applied to the windpipe, is that of a body of air passing uninterruptedly through a smooth tube of somewhat considerable calibre: it very much resembles the sound of a pair of forge bellows, when not too violently worked.

$\mathrm{He}$ who is desirous of ascertaining whether there is any disease in the larynx of a horse, should apply his ear to the lower part of the windpipe. If he finds that the air passes in and out without interruption, there is no disease of any consequence either in the windpipe or the chest; for it would immediately be detected by the loudness or the interruption of the murmur. Then let him gradually proceed up the neck with his ear still upon the windpipe. Perhaps he soon begins to recognise a little gurgling, grating sound. As he continues to ascend, that sound is more decisive, mingled with an occasional wheezing, whistling noise. He can have no surer proof that here is the impediment to the passage of the air, proceeding from the thickening of the membrane and diminution of the passage, or increased secretion of mucus, which bubbles and rattles as the breath passes. By the degree of the rattling or whistling, the owner will judge which cause of obstruction preponderates-in fact, he will have discovered the seat and the state of the disease, and the sooner he has recourse to professional advice the better.

Chronic laryngitis is of more frequent occurrence than acute. Many of the coughs that are most troublesome are to be traced to this source.

In violent cases laryngitis terminates in suffocation; in others, in thick wind or in roaring. Occasionally it is necessary to have recourse to the operation of tracheotomy.

In acute laryngitis the treatment to be pursued is sufficiently plain. Blood must be ab. stracted, and that from the jugular vein, for there will then be the combined advantage of general and local bleeding. The blood must be somewhat copiously withdrawn, depending on the degree of inflammation-the practitioner never for a moment forgetting that he has to do with inflammation of a mucous membrane, and that what he does he must do quickly. $\mathrm{He}$ will have lost the opportunity of struggling successfully with the disease when it has altered its character and debility has succeeded. The cases must be few and far between when the surgeon makes up his mind to any determinate quantity of blood, and leaves his assistant or his groom to abstract it; he must himself bleed, and until the pulse flutters or the constitution is evidently affected.

Next must be given the fever medicine already recommended: the digitalis, nitre, and emetic tartar, with aloes. Aloes may here be safely given, because the chest is not yet implicated. To this must be added, and immediately, a blister, and a sharp one. The surgeon is sure of the part, and he can bring his counter-irritant almost into contact with it.

Inflammation of the larynx, if not speedily subdued, produces sad disorganization in this curiously formed and important machine. Lymph is effused, morbidly adhesive, and speedily orga nised-the membraue becomes thickened, considerably, permanently so-the submucous cellular tissue becomes œdematous; the inflammation spreads from the membrane of the larynx to the cartilages, and difficulty of breathing, and at length confirmed roaring, ensue.

\section{INFLAMNATION OF THE TRACHEA.}

Inflammation of the membrane of the larynx, and especially when it has run on to ulceration, may rapidly spread, and involve the greater part or the whole of the lining membrane of the trachea. Auscultation will discover when this is taking place. If the disease is extending down the trachea, it must be followed. A blister must reach as low as the rattling sound can be de. tected, and somewhat beyond this. The fever medicines must be administered in somewhat in creased doses; and the bleeding must be repeated, if the state of the pulse does not indicate the contrary.

Generally speaking, however, although the inflammation is now approaching the chest, its extension into the trachea is not an unfavourable symptom. It is spread over a more extended surface, and is not so intense or untractable. It is involving a part of the frame less complicated, and where less mischief can be effected. True, if the case is neglected, it must terminate fatally; but it is coming more within reach, and more under command, and, the proper means being adopted, the change is rather a favourable one.

The disorganizations produced in the trachea are similar to some which have been described in the larynx. The same formation of organised bands of coagulated lymph, the same thickening of membrane, diminution of calibre, and foundation for roaring.

\section{ROARING.}

The present will be the proper place to speak of that singular impairment of the respiratory function recognised by this name. It is an unna- 
tural, loud grunting sound made by the animal in the act of breathing when in quick action or on any sudden exertion. On carefully listening to the sound, it will appear that the roaring is produced in the act of inspiration and not in that of expiration. If the horse is briskly trotted on a level surface, and more particularly if he is hurried up hill, or if he is suddenly threatened with a stick, this peculiar sound will be heard and cannot be mistakeu. When dishonest dealers are showing a horse that roars, but not to any great degree, they trot away gently, and as soon as they are too far for the sound to be heard, show off the best paces of the animal: on returning, they gradually slacken their speed when they come within a suspicious distance. This is sometimes technically called "the dealers' long trot."

Roaring is exceedingly unpleasant to the rider, and it is manifest unsoundness. It is the sudden and violent rushing of the air through a tube of diminished calibre; and if the impediment, whatever it is, renders it so difficult for the air to pass in somewhat increased action, sufficient cannot be admitted to give an adequate supply of arterialized blood in extraordinrary or long continued exertion. Therefore, as impairing the function of respiration, although, sometimes, only on extraordinary occasions, it is unsoundness. In as many cases as otherwise, it is a very serious cause of unsoundness. The roarer, when hardly pressed, is often blown even to the hazard of suffocation, and there are cases on record of his suddenly dropping and dying when urged to the top of his speed.

It must not, however, be taken for granted that the roarer is always worthless. There are few hunts in which there is not one of these horses, who acquits himself very fairly in the field; and it has occasionally so happened that the roarer has been the very crack horse of the hunt; yet he must be ridden with judgment, and spared a little when going up hill. There is a village in the West Riding of Yorkshire, through which a band of smugglers used frequently to pass in the dead of night; the horse of the leader, and the best horse of the troop, and on which his owner would bid defiance to all pursuit, was so rank a roarer, that he could be heard at a considerable distance. The clattering of all the rest scarcely made so much noise as the roaring of the captain's horse. When this became a little too bad, and he did not fear immediate pursuit, the smuggler used to halt the troop at some convenient hayrick on the roadside, and, having suffered the animal to distend his stomach with this dry food, as he was always ready enough to do, he would remount and gallop on, and, for a while, the roaring was scarcely heard. It is somewhat difficult to account for this. Perhaps the loaded stomach now pressing against the diaphragm, that muscle had harder work to displace this viscus in the act of enlarging the chest and producing an act of inspiration, and accom. plished it more slowly, and therefore, the air passing more slowly by, the roaring was dimiminished. We do not dare to calculate what must have been the increased labour of the diaphragm in moving the loaded stomach, nor how much sooner the horse must have been exhausted. This did not enter into the owner's reckoning, and probably the application of whip and spur would deprive him of the means of forming a proper calculation of it.

Eclipse was a "high-blower." He drew his breath hard, and with apparent difficulty. The upper air-passages, perhaps those of the head, did not correspond with his unusually capacious chest; yet he was never beaten. It is said that he never met with an antagonist fairly to put him to the top of his speed, and that the actual effect of this disproportion in the two extremities of the respiratory apparatus was not thoroughly tested. Mares comparatively seldom become roarers. It appears to be difficult, if not impossible, to assign any satisfactory reason for this: but the fact is too notorious among horsemen, to admit of doubt.

Roaring proceeds from obstruction in some portion of the respiratory caual, and oftenest in the larynx, for there is least room to spare-that cartilaginous box being occupied by the mechanism of the voice: next in frequency it is in the trachea, but, in fact, obstruction any where will produce it. Mr. Blaine, quoting from a French journalist, says, that a piece of riband lodged within one of the nasal fossæ produced roaring, and that even the displacement of a molar tooth has been the supposed cause of it. Polypi in the nostrils have been accompanied by it. IIr. Sewell found, as an evident cause of roariug, an exostosis between the two first ribs, and pressing upon the trachea; and Mr. Percivall goes farther, and says that his father repeatedly blistered and fired a horse for bad roaring, and even performed the operation of tracheotomy, and at length the roaring being so loud when the horse was led out of the stable, that it was painful to hear it-the poor animal was destroyed. No thickening of the membrane was found, no disease of the larrnx or trachea; but the lungs were hepatized throughout the greater part of their substance, and many of the smaller divisions of the bronchi were so compressed, that they were hardly pervious.

Bands of Coagulated Lymph. - A frequent cause of roaring is bands of coagulated lymph, morbidly viscid and tenacious, adhering firmly on one side, and by some act of coughing brought into contact with and adhering to the other side, and becoming gradually organized. At other times there have been rings of coagulated lymph 
adhering to the lining of the trachea, but not organized. In either case they form a mechanical obstruction, and will account for the roaring noise produced by the air rushing violently through the diminished calibre, in hurried respiration. Thickening of the membrane is a more frequent cause of roaring than the transverse bands of coagulated lymph. In many morbid specimens it is double or treble its natural thickness, and covered with manifold ulcerations. This is particularly annoying in the upper part of the windpipe, where the passages, in their natural state, are narrow. Thus it is that roaring is the occasional consequence of strangles and catarrh, and other affections of the superior passages.

There is scarcely a horse of five or six years old who has not a portion of the thyroid cartilage ossified. In some cases the greater part of the cartilages are becoming bony, or sufficiently so to weaken or destroy their elastic power, and consequently to render it impossible for them to be freely and fully acted upon by the delicate muscles of the larynx.

Chronic cough occasionally terminates in roaring. Some have imagined that the dealers' habit of coughing the horse, i. e. pressing upon the larynx to make him cough, in order that they may judge of the state of his wind by the sound that is emitted, has produced inflammation about the larynx, which has terminated in roaring, or assisted in producing it. That pain is given to the animal by the rough and violent way in which the object is sometimes attempted to be accomplished, is evident enough, and this must, in process of time, lead to mischief; but suficient inflammation and subsequent ossification of the cartilages would scarcely be produced, to be a cause of roaring.

The Disease of Draught-Horses generally.There can be no doubt of the fact, that the majority of roarers are draught-horses, and horses of quick draught. They are not only subject to the usual predisposing causes of this obstruction, but there is something superadded,-resulting from their habits or mode of work, - not indeed necessarily resulting, but that $x$ hich the folly as well as cruelty of man has introduced-the system of tight-reining. To a certain extent, the curb-rein is necessary. Without it there would be scarcely any command over a wilful horse, and it would need a strong arm occasionally to guide even the most willing. Without the curb-rein the horse would carry himself low; he would go carelessly along; he would become a stumbler; and if he were disposed at any time to run away, the strongest arm would have little power to stop him : but there is no necessity for the tight rein, and for the long and previous discipline to which the carriage horse is subjected. There is no necessity that the lower jaw, whether the channel is wide or narrow, should be so forced on the neck, or that the larynx and the portion of the windpipe immediately beneath it should be flattened, and bent, and twisted, and the respiratory passage not only obstructed, but in a manner closed. The mischief is usually done when the horse is young. It is effected in some measure by the impatience of the animal, unused to control, and suffering pain. In the violent tossing of his head he bruises the larynx, and produces inflammation. The head of the riding-horse is gradually brought to its proper place by the hands of the breaker, who skilfully increases or relaxes the pressure, and humours and plays with the mouth ; but the poor carriage-horse is confined by a rein that never slackens, and his nose is bent in at the expense of the larynx and windpipe. The injury is materially increased if the head is not naturally well set on, or the neck is thick, or the jaws narrow.

Connected with this is the common notion that crib-biting is a cause of roaring. That is altogether erroneous. There is no possible connexion between the complaints: but one of the methods that used to be resorted to in order to cure crib-biting might be a cause of roaring, namely, the strap so tightly buckled round the upper part of the neck as to compress, and distort, and paralyse the larynx.

Facts have established the hereditary predisposition to roaring veyond the possibility of doubt.

In France it is notorious that three-fourths of the horses from Cottentin are roarers, and some of them are roarers at six months old; but about La Hague and Le Bocase, not a roarer is known. There is certainly a considerable difference in the soil of the two districts; the first is low and marshy, the latter elevated and dry: but tradition traces it to the introduction of some foreign horses into Cottentin, who bequeathed this infirmity to their progeny.

In our own country, there is as decisive a proof. There was a valuable stallion in Norfolk, belonging to Major Wilson, of Didlington. He was a great favourite, and seemed to be getting some excellent stock; but he was a roarer, and some of the breeders took alarm at this. They had occasionally too painful experience of the communication of the defects of the parent to his progeny ; and they feared that roaring might possibly be among these hereditary evils. Sir Charles Bunbury was requested to obtain Mr. Cline's opinion on the subject. Mr. Cline was a deservedly eminent human surgeon: he had exerted himself in thee stablishment of the Veterinary College: he was an examiner of veterinary pupils, and therefore it was supposed that he must be competent to give an opinion. He gave one, and at considerable length: 
- "The disorder in the horse," said he, "which constitutes a roarer, is caused by a membranous projection in a part of the windpipe, and is the consequence of that part having been inflamed from a cold, and injudiciously treated. A roarer, therefore, is not a diseased horse, for his lungs and every other part may be:perfectly sound.: The existence of roaring in a stallion cannot be of any consequence. It cannot be propagated any more than a broken bone, or any other accident."-A fair specimen of the horse-knowledge of one of the best of the medical examiners of veteriuary pupils.

Sir Charles returned full of glee; the good people of Norfolk and Suffolk were satisfied; Major Wilșon's horse was in high request: but in a few years a great part of the two eounties was overrun, with roarers, and many a breeder half ruined. Roaring is not, however, necessarily hereditary. Mr. Goodwin, whose name is great anthority, states that Taurus, a celebrated racer that had become a roarer, had eovered several mares, and their produce all turned ont well, and had won several races. In no instance did his progeny exhibit this defect, notwithstanding that his own family were notolious for being roarers. Eclipse also is said to have been a roarer.

What then is to be done with these animals? Abandon them to their fate? No, not so; but there is no necessity rashly to undertake a hopeless affair. All possible knowledge must be obtained of the origin of the disease. Did it follow strangles, catarrh, bronchitis, or any affection of the respiratory passages? Is it of long standing? Is it now accompanied by cough or any symptoms of general or local irritation? Can any disorganisation of these parts be detected? Any distortion of the larynx? Did it follow breaking-in to harness? The answer to these questions will materially guide any future proceedings. If there is plain distortion of the larynx or trachea, or the disease can be associated, in point of time, with breaking-in to harness, or the coachman or proprietor has been accustomed to rein the animal in too tightly or too ernelly, or the sire was a roarer, it is almost useless to have anything to do with the case. But if it is of rather recent date, and following closely on some disoase with which it can be clearly connected, careful examination of the patient may be commenced. Is there cough? Can any heat or tenderness be detected about the larynx or trachea? Is there in every part the same uniform rushing noise; or, on some particular spot, can a more violent breathing, a wheezing or whistling, or a rattling and gurgling, be detected? Is that wheezing or rattling either confined to one spot, or less sonorous as the ear recedes from that spot above or below; or is it diffused over a considerable portion of the trachea?

In these cases it would be fair to bleed, purge, and most certainly to blister. The ear will guide to the part to which the blister should be applied. The physic having set, a course of fever medicine should be commenced. It should be considered as a case of chronic inflammation, and to be subdued by a continuance of moderate depletory measures. Probably blood should again be abstracted in less quantity; a second dose of physic should be given, and, most certainly; the blister should be repeated, or kept discharging by means of some stimulating unguent. The degree of success which attends these measures would determine the farther pursiat of them. If no relief is obtained after a fortnight or three weeks, perhaps the experimenter would ponder on another mode. of treatment. $\mathrm{He}$ would again carefully explore the whole extent of the trachea and if he could yet refer the rattle or wheezing to the same point -at which he had before observed it, he would boldly propose tracheotomy, for he could certainly cut upon the seat of disease.

If he found one of these organised bands, the removal of it would afford immediate relief; or if he found merely a thickened membrane, no harm would be done; or the loss of blood might abate the local inflammation. No one would eagerly undertake a case of roaring: but, having undertaken it, he should give the measures that he adopts a fair trial, remembering that, in every chronic case like this, the only hope of success depends on perseverance.

\section{BHONCHOCELE.}

Mr. Percivall is almost the only author who takes notice of enlargement of the thyroid glands - two oval bodies below the larynx, and attached to the trachea. The use of them has never been satisfactorily explained. They sometimes grow to the size of an egg, or larger, but are unattended by cough or fever, and are nothing more than an eyesore. The iodine ointment has occasionally been applied with success. The blister or the seton may also be useful.

\section{EPIDEMIC CATARRH.}

Various names are given to this diseaseinfluenza, distemper, catarrhal fever, and epidemic eatarrh. Its usual history is as follows :-

In the spring of the year-a cold wet spring and that succeeding to a mild winter, and especially among young horses, and those in high condition, or made up for sale, or that have been kept in hot stables, or exposed to the usual causes of inflammation, this disease principally and sometimes almost exclusively prevails. Those that are in moderate work, and that are correspondingly fed, generally escape; or even when it appears in most of the stables in a narrower or wider district, horses in barracks, regularly worked and moderately fed, 
although not entirely exempt, are comparatively seldom diseased.

If it has been observed from the beginning, it will be found that the attack is usually sudden, ushered in by shivering, and that quickly succeeded by acceleration of pulse, heat of month, staring coat, tucked-up belly, diminution of appetite, painful but not loud cough, heaving at the flanks, redness of the membrane of the nose, swelled and weeping eye, dejected countenance-these are the symptoms of catarrh, but nnder a somewhat aggravated form.

It clearly is not inflammation of the lungs ; for there is no coldness of the extremities, no looking at the flanks, no stiff immovable position, no obstinate standing up. It is not simple catarrh; for as early as the second day there is evident debility. The horse staggers as he walks.

It is inflammation of the respiratory passages generally. It commences in the membrane of the nose, but it gradually inrolves the whole of the respiratory apparatus. Before the disease has been established four-and-twenty hours, there is frequently sore throat. The horse quids his hay, and gulps his water. There is no great enlargement of the glands; the parotids are a little tumefied, the submaxillary somewhat more so, but not at all equivalent to the degree of soreness. That soreness is excessive, and day after day the horse will obstinately refuse to eat. Discharge from the nose soon follows in considerable quantity: thick, very early purulent, and sometimes foetid. The breathing is accelerated and laborious at the beginning, but does not always increase with the progress of the disease-nay, sometimes, a deceitful calm succeeds, and the pulse, quickened and full at first, soon loses its firmmess, and although it nsually maintains its unnatural quickness, yet it occasionally deviates from this, and subsides to little more than its natural standard. The extremities continue to be comfortably warm, or at least the temperature is variable, and there is not in the manner of the animal, or in any one symptom, a decided reference to any particular part or spot as the chief seat of disease.

Thus the malady proceeds for an uncertain period: occasionally for several days-in not a few iustances through the whole of its course, and the animal dies exhausted by extensive or general irritation: but in other cases the inflammation assumes a local determination, and we have bronchitis or pneumonia, but of no very acnte character, yet difficult to treat, from the general debility with which it is connected. Sometimes there are con. siderable swellings in various parts, as the chest, the belly, the extremities, and particularly the head. The brain is occasionally affected; the horse grows stupid; the conjunetira is alarmingly red; the animal becomes gradually unconscious, and delirium follows. A curiuus thickening, that may be mistaken for severe sprain, is sometimes observed abont the tendons. It is seen under the knee or about the fetlock. It is hot and tender, and the lameness is considerable. The feet occasionally suffer severely. There is a determination of fever to them far more violent than the original disease, and separation of the laminæ and descent of the sole ensue. It may be easily imagined how roaring may be connected with epidemic catarrh; but it is rarely or never followed by glanders. These changes of situation are not fatal, but the practitioner is rather glad to see them, except indeed when the feet are attacked; for the disease seems inclined to shift its situation or character, and is more easily subdned.

The most decided character in this disease is debility. Not the stiff, unwilling motion of the horse with pneumonia, and which has been mistaken for debility - every muscle being needed for the purposes of respiration, and therefore imperfectly used in locomotion-but actual loss of power in the muscular system generally. The horse staggers from the second day. He threatens to fall if he is moved. He is sometimes down, permanently down, on the third or fourth day. The emaciation is also occasionally rapid and extreme.

At length the medical treatment which has been employed succeeds, or nature begins to rally. The cough somewhat subsides; the pulse assumes its natural standard; the countenance acquires a little more animation; the horse will eat a small quantity of some choice thing; and health and strength slowly, very slowly indeed, return: but at other times, when there had been no decided change during the progress of the disease, no manageable metastasis of inflammation while there was sufficient power left in the constitution to struggle with it, a strange exacerbation of symptoms accompanies the closing scene. The extremities become deathy cold; the flanks heave; the countenance betrays greater distress; the membrane of the nose is of an intense red; and inflammation of the substance of the lungs and congestion and death speedily follow.

At other times the redness of the nostril suddenly disappears; it becomes purple, livid, dirty brown, and the discharge is bloody and fetid, the breath and all the excretions becoming fotid too. The mild character of the disease gives way to malignant typhus : swellings, and purulent ulcers, spread over different parts of the frame, and the animal is soon destroyed.

Post-mortem Examination.-Examination after death sufficiently displays the real character of the disease, inflammation first of the respiratory passages, and, in fatal or aggravated cases, of the mucous membranes generally. From the pharynx, to the 
termination of the sinall intestines, and often including even the larger ones, there will not be a part free from inflammation; the upper part of the trachea will be filled with adhesive spume, and the lining membrane thickened, injected, or ulcerated; the lining tumic of the bronchi will exhibit unequivocal marks of inflammation; the substance of the lungs will be engorged, and often inflamed; the heart will partake of the same affection; its external coat will be red, or purple, or black, and its internal one will exhibit spots of ecchymosis; the pericardium will be thickened, and the pericardiac and pleuritic bags will contain an undue quantity of serous, or bloody serous, or purulent fiuid.

The œsophagus will be inflamed, sometimes ulcerated-the stomach always so; the small in testines will uniformly present patches of inflam. mation or ulceration. The liver will be inflamed - the spleen enlarged-no part, indeed, will have escaped; and if the malady has assumed a typhoid form in its latter stages, the universality and maliguaucy of the ulceration will be excessive.

This disease is clearly attributable to atmospheric influence, but of the precise nature of this iufluence we are altogether ignorant. It is some foreigu injurious principle which mingles with and contaminates the air, but whence this poison is derived, or how it is diffused, we know not. It is engendered, or it is most prevalent, in cold ungenial weather; or this weather may dispose the patient for catarrh, or prepare the tissues to be affected by causes which would otherwise be harmless, or which may at all times exist.

It is most frequent in the spring of the year, but it uccasionally rages in autumn and in winter. It is epidemic; it spreads over large districts. It sometimes pervades the whole country. Scarcely a stable escapes. Its appearance is sudden, its progress rapid. Mr. Willinson had thirty-six new cases in one day. It is said that a celelrated practitioner in London had nearly double that number in less than twenty-four hours.

At other times it is endemic. It pervades one town; one little tract of country. It is confined to spots exceedingly circumscribed. It is dependent on atmospheric agency, but this requires some injurious adjuvant and the principle of contagion must probably be called into play. It has been vife enough in the lower parts of the metropolis, while in the upper and north-western districts scarcely a case has occurred. It has occasionally been confined to a locality not extending half-a-mile in any direction. In one of the cavalry barracks the majority of the horses on one side of the yard were attacked by epidemic catarrh, while there was not a sick horse on the other side. These prevalences of disease, and these exceptions, are altogether unaccountable. The stables, and the system of stable management, have been most carefully inquired into in the infected and the healthy districts, and no satisfactory difference can be ascertained. One fact, however, has been established, and a very important one it is to the horse proprietor as well as the practitioner. The probability of the disease seems to be in proportion to the number of horses inhatiting the stable. Two or three horses shut up in a comparatively close stable may escape. Out of thirty horses, distributed through ten or fifteen little stables, not one may be affected; but in a stable containing ten or twelve horses the disease will assuredly appear, although it may be proportionally larger and well ventilated. It is on this account that postmasters and horse-dealers dread its appearance. In a sickly season their stables are never free from it; and if, perchance, it does enter one of their largest stables, almost every horse will be affected. Therefore also it is that grooms have so much dread of a distempered stable, and that the odds are so seriously affected if distemper has broken out in a racing establishment.

Does this lead to the conclusion that epidemic catarrh is contagious? Not necessarily, but it excites strong suspicion of its being so; and there are so many facts of the disease following the introduction of a distempered horse into an establishment, that this malady must rank among those that are both contagious and epidemic. There are few well-informed grooms, or extensive owners of horses, and living much among them, or veterinary surgeous of considerable practice, who entertain the least doubt about the matter. Then every necessary caution should be adopted. The horse that exhibits symptoms of epidemic catarrh should be removed as soon as possible. The affected horses should be remored, and not the sound ones, for they, although apparently sound, may have the malady lurking about them, and may more widely propagate the disease.

With regard to the treatment of epidemic catarrh there may be, and is at times, considerable difficulty. It is a disease of the mucous membrane, and thus connected with much debility; but it is also a disease of a febrile character, and the inflammation is occasionally intense. The veterinary surgeon, therefore, must judge for bimself. Is the disease in its earliest stage marked by evident inflammatory action? Is there much redness in the membrane of the nose-much acceleration of the pulse-much heaving of the flanks? If so, blood must be abstracted. The orifice should be large that the blood may flow quickly, and the circulation be sooner affected; and the medical attendant should be present at this first venesection that he may close the orifice as soon as the pulse begins to falter. This attention to the first bleeding is indispensable. It is the carelessness 
with which it is performed-the ignorance of the olject to be accomplished, and the effect actually produced, that destroys half the horses that are lost from this malady. The first falter of the pulse is the signal to suspend the bleeding. Every drop lost afterwards may be wanted.

If there is no appearance of febrile action, or only a very slight one, small doses of aloes may be given, combined with the fever medicines recommended for catarrb. As soon as the fæces are pultaceous, or even before that, the aloes should be omitted and the fever medicine continued. It will rarely be prudent to continue the aloes beyond the third drachm.

A stricter attention must be paid to, diet than the reterinarian usually enforces, or the groom dreams of. No corn must be allowed, but mashes and thin gruel. The water should be entirely taken away, and a bucket of gruel suspended in the box. This is an excellent plan with, regard to every sick horse that we do not wish to:reduce too much; and when he finds that the morning and evening pass over, and his water is not offered to him, he will readily take to the gruel, and drink as much of it as is good for him. Green meat should be early offered; such as grass, tares (the latter especially), lucerne, and, above all, carrots. If these caunot be procured, a little hay may be wetted, and offered morsel after morsel by the hand. Should this be refused, the hay may be damped with water slightly salted, and then the patient will generally seize it with avidity.

Should the horse refuse to eat during the two or three first days, there is no occasion to be in a hufry to drench with gruel; it will make the mouth sore, and the throat sore, and tease and disgust: but if he should long continue obstinately to refuse his food, nutriment must be forced upon him. Good thick gruel must be horned down, or, what is better, given by means of Read's pump.

The practitioner will often and anxiously have recourse to auscultation. He will listen for the mucous rattle, creeping down the windpipe, and entering the bronchial passages. If he cannot detect it below the larynx, he will apply a strong blister, reaching from ear to ear, and extending to the second or third ring of the trachea. If he can trace the rattle in the windpipe, he must follow it,- he must blister as far as the disease has spread. This will often have an excellent effect, not only as a counter-irritant, but as rousing the languid powers of the constitution. A rowel of tolerable size between the fore legs cannot do harm. It may act as a derivative, or it may take away a disposition to inflammation in the contiguous portion of the chest.

The inflammation which characterizes the . early stage of this disease is at first confined to the memibrane of the mouth and the fauces. Can fomentations be applied? Yes, and to the very part, by means of a hot mash, not thrown into the manger over which the head of the horse cannot be confined, but placed in that too-much-undervalued and discarded article of stable-furniture, the nose-bag. The vapour of the water will, at every inspiration, pass over the inflamed surface. In the majority of cases relief will speedily be obtained, and that suppuration from the part so necessary to the permanent removal of the inflammation-a copious discharge of mucous or purulent matter from the nostrils-will be hastened. If the discharge does not appear so speedily as could be wished, a stimulant should be applied to the part. The vapour impregnated with turpentine arising from fresh yellow deal sawdust, used instead of bran, will have very considerable effect in quickening and increasing the suppuration. It may even be resorted to almost from the beginning, if there is not evidently much irritability of membrane.

A hood is a useful article of clothing in these cases. It increases the perspiration from the surface covering the inflamed part-a circumstance always of considerable moment.

An equable warmth should be preserved, if possible, over the whole body. The hand-brush şhould be gently used every day, and harder and more effectual rubbing applied to the legs. The patient should, if possible, be placed in a loose box, in which he may toddle about, and take a little exercise, and out of which he should rarely, if at all, be taken. The exercise of which the groom is so fond in these cases, and which must in the most peremptory terms be forbidden, has destroyed thousands of horses. The air should be fresh and uncontaminated, but never chilly; for the object is to increase and not to repress cutaneous perspiration; to produce, if possible, a determination of blood to the skin, and not to drive it to the part already too much overloaded. In order to accomplish this, the clothing should be rather warmer than usual.

The case may proceed somewhat slowly, and not quite satisfactorily to the practitioner or his employer. There is not much fever-there is little or no local inflammation: but there is great emaciation and debility, and total loss of appetite. The quantity of the sedative may theu be lessened but not omitted altogether; for the fire may not be extinguished, although for a little while concealed. There are no diseases so insidious and treacherous as these. Mild and vegetable tonics, such as gentian and ginger, may be given. Two days after this the sedative may be altogether omitted, and the tonic gradually increased.

The feeding should now be sedulously attended to. Almost every kind of green meat that 
ean be obtained should be given, particularly carrots nicely scraped and sliced. The food should be changed as often as the capricious appetite prompts; and occasionally, if neressary, the patient should be forced with givel as thick as it will run from the horn, but the gradual return of health should be well assured, before one morsel of corn is given.*

A very few weeks ago, the author received from his friend, Mr. Percivall, the following account of a new and destruetive epidemic among horses :-

"From the close of the past year and the beginning of the present, up to the time I am writing, the influenza among horses has continued to prevail in the metropolis and different parts of the country with more or less fatality. In London it has assumed the form of laryngitis, associated in some instances with bronehitis; in others - in all I believe where it has proved fatal -with pleurisy. The parenchymatous structure of the lungs bas not partaken of the disease, or but consecutively and slightly. The earliest and most characteristic symptom has been sore throat; causing troullesome dry short cough, but rarely occasioning any difficulty of deglutition, and, in no instance that $I$ have seen, serere or extensive enough to produce anything like disgorgement or return of the masticated matters through the nose, and yet the slightest pressure on the larynx has excited an act of coughing. But seldom has any glandular enlargement appeared. The symptom secondarily remarkable after the sore throat and congh has been a dispiritedness or dulness, for which most epidemies of the kind are remarkable. The animal, at the time of sickening, has hung his head under the manger, with his eyes half shut, and his lower lip pendent, without , erincing any alarm or even much notice, though a person entered his abode or approached him; and if in a box, lis heal is often found during his illness turned towards the door or window, Fever, without any disturbance of the respiration, has always been present; the pulse has been accelerated, though rather small and weak in its beat than indicative of strength; the mouth has been hot, sometimes burning hot, afterwards moist, and perhaps saponaccous; the skin and extremities in general have been warm. Now and then the prostration and appearance of debility have been such, and so rapid in their manifestation, that, shortly after being attacked, a horse has staggeringly walked twenty yards only-the distance from his stable into an infirmary-box. The appetite, though

* An interesting account of ppidemic among horses will be found in the Associalion Part of "The Veterinarian," vols. xii. and $x \mathbf{s}$. A work, by the author of this treatise, is in preparation, on the epidemics that buve prevailed umong all oar donesticated animals.

TOL. I. impaired much, has selım been altogether lost. Generally, if a little fresh hay has been offered, it has been taken and eaten; but to mashes there has been commonly great aversion. During the long continuance of the wind in the east, the sore throat and cough have been unattended by any flux from the nose; but since the wind has shifted within this last fortnight or three weeks, discharges from the nostrils have appeared, profuse even in quantity, and purulent in their nature; in fact, the disease has assumed a more catarihal character--ergo, I might add, a more favourable one.

"The disorder has exhibited cvery phase and degree of intensity, from the slightest perceivalle dulness, which has passed off with simply a change in the diet, to an insidious, unyielding, unsubduable pleurisy, ending in hydrothorax, in spite of everything that could be done, and most timely done. So long as the disease has confined itself to the throat, and that there has been along with that only dejection, prostration, and ferer, there has existed no cause for alarm; but when snch symptoms have, after some days' continuance, not abated, and have, on the contrary, rather increased, and others have arisen which but too well have authorised suspicions that 'mischief was brewing in the chest,' then there became the strongest reasons for alarm for the safety of the patient. What is now to be done? The practitioner durst not bleed a second time, at least not generally, for the patient's strength would not endure it, although he is certain a pleurisy is consuming his patient. He possesses no effectial means for topical blood-letting. Neither blisters nor rowels, nor plugs nor setons, will take any effect. Cathartic medicine he must not administer; nauseants are uncertain and doubtful in their efficacy; sedatives, tonics, and stimulants, and narcotics, appear counter-indicated, inflammation existing, and, when tried under such circumstances, have, I believe, never fitiled to do barm.

"Dissatisfied with one and all of these remedies in the late influenza-mough the losses I have experienced have, after all, not been so very comparatively great, being no more, since the be. ginuing of the year, than three out of nearly forty cases-I repeat, having, as I thought, reason to be dissatisfied for losing even these three cases, consilering that they came under my care at the earliest period of indisposition, I determined, in any similar cases that night occur, to bave recourse to that medicine which, in all membranous inflammations in particular, is the physician's sheet-anchor, and which I had exhilvited, ant still continue to do, myself, in other disorders, though I had never given it a fair trial in epidemics hav. ing that tendency which I have described the 
present one miformly to have indicated, viz., the destruction of life by an inflamuation attacking membranous parts, of a nature over which, being forbidden to bleed, we appeared to possess little or no power. Could we have drawn blood from the sides or breast, by cupping or by leeches, in any tolerable quantity, we might have had some control over the internal disease; but barred from this, and without any remedy save a counter-irritant, which we could not make act, or an interual medicine, whose action became extremely dubious, if not positively hurtful, what was to be done? I repeat, I made up my mind to experiment with the surgeon's remedy in the same disease, namely, mereury ; aud that I have had reason to feel gratified at the result will, I think, appear from the following cases :-

"Cise I.-April 8. Every synuptom of the prevailing epidemic: and considerably aggravated on the $10 \mathrm{th}$, when the horse laboured under much prostration of strength, and staggered considerably in his gait. The following ball was then ordered to be given him twice a day: $\mathrm{P}$ Hydrarg. chlorid. $3 \mathbf{i}$, farin. avenre 3 ss. terebinth. vulg. q. s. ut fiat bol. One to be given moming and night. He soon began to improve; and was returned to the stable on the 26th, convalescent. A second patient of the same character was cured in eighteen days, and a third in nineteen days." The author of this work had the pleasure of witnessing these cases.

Mr. Percivall adds, "Lest it should be said, after the perusal of these three cases, that they do not appear to have been of a dangerons character, or to have acquired auythinis out of the ordinary line of treatment, I beg to observe, that at the periods at which I submitted them to the action of mercury, they so much resembled three other's that had preceded them, and the disease had proved fatal, that, under a continuance of treatment of any ordinary kiud, I certainly should have entertained fears for their safety.

"It must be remembered that they were cases in which blood-letting, except at the commencement, was altogether forbidien; and that at the critical period when mercury was introduced they had taken an unfavourable turn, and that nothing in the shape of remedy appeared available save internal medicine and cuunter-irritation, and that the latter had not and did not show results betokening the welfare of the patients. Under these circumstances the mercury was exhibited. That it enterect the system, and must have had more or less influence on the disease, appears evident from its effect on the gums. That it proved the means of cure, I cannot, from so few cases, take upon myself to assert; but I would recommend it in similar cases to the notice of practitioners."

\section{THE MALIGNANT EPIDEMIIC.}

Continental veterinarians deseribe a malignant variety or termination of this disease, and the imperfect history of veterinary medicine in Britain is not without its records of it. So lately as the year 1815, an epidemic of a malignant character reigned among horses. Three out of five who were attacked died. It reappeared in 1823, but was not so fatal. It was said that the horses that died were ultimately farcied: the truth was, that swellings and ulcerations, with fotid discharge, appeared in various parts, or almost all over them-the natural swellings of the complaint which has just been considered, but aggravated and malignant. Our recollection of the classic lore of our early years will furnish us with instances of the same pest in distant times and countries. We have not forgotten the vivid description of Apollo darting his fiery arrows among the Greeks, and involving in one common destruction the human being, the mule, the horse, the $o x$, and the dog. Lucretius, when describing the plague at Athens, speaks of a malignant epidemic affecting almost every animal-

Nor longer birds al noon, nor beasts at night Their native woods deserted; with the pest Remote they languished, and full frequent died : Bul chief the dog his generous strength resigned.

In 1714, a malignant epidemic was imported from the Continent, and in the course of a few months destroyed 70,000 horses and cattle. It continued to visit other countries, with but short intervals, for fifty years afterwards. Out of evil, however, came good. The continental agriculturists were alarmed by this destruction of their property. The different governments participated in the terror, and veterinary schools were estab. lished, in which the anatomy and diseases of these animals might be studied, and the cause and treatment of these periodical pests discovered. From the time that this branch of medical science began to receive the attention it deserved, these epidemics, if they have not quite ceased, have changed their character, and have become comparatively mild and manageable. As, however, they yet occur, aud are far tou fatal, we must endeavour to collect the symptoms, and point out the treatment of them.

The maliguant epidemic was almost uniformly ashered in by inflammation of the mucous membrane of the respiratory passages, but soon involving other portions, and theu ensned. a diarncea, which no art could arrest. The fever, acute at first, rapidly passed over, and was succeeded by a great prostration of strength. The iuflammation then spread to the cellular texture, and there was a peculiar disposition to the formation of phlegmonous tumours: sometimes there were pustular eruptions, but, oftener, deep-seated tumours rapidly 
proceeding to suppuration. Connected with this was a strong tendency to decomposition, and unless the animal was relieved by some critical flux or evacuation, malignant typhus was established, and the horse speedily simk.

The most satisfactory account of one of these epidemics is given us by Professor Brugnone, of Turin. It commenced with loss of appetite, staring coat, a wild and waudering look, ani a staggering from the very commencement. The horse would continually lie down and get up again, as if tormented by colic, and he gazed alternately at both flanks. In the moments of comparative ease, there were universal twitchings of the skin, and spasms of the limbs. The temperature of the ears and feet was variable. If there happened to be about the animal any old wound or scar from setoning or firing, it opened afresh and discharged a quantity of thick and black blood. Tery shortly afterwards the flanks, which were quiet bcfore, began to heave, the nostrils were dilated, the head extended for breath. The horse had by this time become so weak that, if he lay or fell down he could rise no more; or if he was up, he would stand trembling, staggering, and threatening to fall every moment. The mouth was dry, the tongue white, and the breath fœid; a discharge of yellow or bloody fotid matter proceeded from the nose, and foetid blood from the anus. The duration of the disease did not usually exceed twelve or twenty-four hours; or if the animal liugered on, swellings of the head and throat, and sheath, and scrotum, followed, and he died exhausted or in convulsions.

Black spots of extravasation were found in the cellular membrane, in the tissue of all the membranes, and on the stomach. The mesenteric and lymphatic glands were engorged, black and gangreuous. The membrane of the nose and the pharynx was lighly injected, the lungs were filled with black and frothy blood, or with black and livid spots. The brain and its meninges were unaltered.

It commenced in March, 1783. The barracks then contiued one hundred and sixteen horses; all but thirteen were attacked, and seventy-eight of them died. The horses of both the officers and men were subject to the attack of it; and three horses from the town died, two of which had drawn the carts that conveyed the carcasses away, and the other stood under a window, from which the duug of an infected stable had been thrown out. The disease would probably have spread, but the most summary measures for arresting its progress were adopted; gvery horse in the town wias killed that had had the slightest cominunication with those in the barracks. One horse was iuoculated with the pus discharged from the ulcer of an infected horse, and be died. A portion of his thymus gland was introduced under the skin of another horse, and lie also died.

Cause.-The disease was supposed to be connected with the food of the horses. All the oats had been consumed, and the lolium temulentum, or awned darnel, had bcen given instead. It is said that the darnel is occasioually used by brewers to give an intoxicating quality to their malt liquor. For fifteen days no alteration of liealth was perceived, and then, in less than cighteen hours, nearly forty nerished. The stables were not crowded, and there was no improper treatment. A man disinterred some of the horses to get at the fat ; swellings rapidly appeared in his throat, and he died in two days. A portion of their Hesh was given to two pigs and some dogs, and they died.

M. Brugnone found that bleeding only accelerated the death of the patient. He afterwards tried, and ineffectually, acids, cordials, purgatives, resicatories, and the actual cautery ; and he frankly attributes to the power of nature the recovery of the few who survived.

Gilbert's Account of the Epidemic of 1795.M. Gilbert describes a malignant epidemic which appeared in Paris in 1795 , characterised by dulness, loss of appetite, weakness, pulse at first rapid and full, and afterwards continuing rapid, but gradually becoming swall, weak, and intermittent. The bowels at first constipated, and then violent purging succeeding. The weakness rapidly increasing, accompanied by foetid breath, and foetid evacuations. Tumours soon appeared about the limbs, under the chest, and in the head, the neck and loins. If they suppurated and burst, the animal usually did well; but otherwise he inevitably perished. The formation of these tumours was critical. If they rapidly advaneed, it was cousidered as a favourable symptom; but if they coutinued obseure, a fatal termination was proguosticated.

Bleeding, even in an early stage, seemed here also to be injurious, and increased the debility. Physic was given, and mild and nutritious food, gruel, and cordials. Deep iucisions were made into the tumours, and the cautery applied. Stimulating frictions were also used, but all were of little avail.

These cases have been narrated at considerable length, iu order to give some idea of the nature of this discase, and because, with the exception of a short but rery excellent account of the malignant epidemic in the last edition of Mr. Blaines Veterinary Outlines, there will not be found any satisfactory history of it in the writings of our English veterinarians. It is evidently a disease of the mucous membranes, both the respiratory and digestive. It is accompanied by eally and great debility, loss of all vital power, vitiation of every secretion, effusions and tumours every- 
where, and it runs its course with fearful rapidity. If it was seen at its outset, the practitioner would probably bleed; but if a few hours only had elapsed, he would find, with Messrs. Brugnone and Gilbert, that venesection would only hasten the catastrophe. Stimulants should be administerel ningled with opium, and the spirit of nitrous ether in doses of three or four ounces, with an ounce or more of laudanum. The quantity of opium should be regulated by the spasms and the diarrhoea. These medicines should be repeated in a few lours, comlined, perbaps, with ginger and gentian. If these failed, there is little else to be done. Deep incisions into the tumours, or blisters over them, might be proper measures; but the principal attention should be directed to the arresting of the contagion. The infected shonld be immediately removed from the healthy; all offensive matter should be carefully cleared away, and no small portion of chloride of lime used in washing the animal, and particularly his ulcers. It might with great propriety be administered internally, while the stable and everything that belonged to the patient, should undergo a careful ablution with the same powerful disinfectant.

\section{BRONCHITIS.}

This is not generally a primary disease. That inflammation of the superior respiratory passages, constituting catarrh, gradually creeps downwards and involves the larynx and the trachea, and at length, possibly the farthest and the minutest ramifications of the air-tubes. When it is found to be thus advancing, its progress should be carefully watched by the assistance of auscultation. The distant num'nur of the healthy lung cannot be mistaken, nor the crepitating sonnd of pneumonia; and in bronchitis the blood may be heard filtering or breaking through the divisions of the lobuli, and accountiug for that congestion or filling of the cells with mucus and blood, which is found after iutense inflammation. Inflammation precedes this increased discharge of mucus. Even that may be rletected. The inflamed membrane is thickened and tense. It assumes an almost cartilaginous structure, and the murmur is not only louder, but has a kind of snoring sound. Some have imagined that a sound like a inetallic ring is mingled with it; but this is never very distinet.

The interrupted whizzing sound has often and clearly iudicated a case of bronchitis, and there are many corroborative symptoms which should be regardei. The variable temperature of the extremities will be an important guile-not deathy cold a in jmcumonia, nor of increased temperature as often in catiaryh, but with a tendency to coldness, yet this varying much. The pulse will assist the diagnosis - more rapid than in catarrh, much more su than in the early stage of pneumonia: not so bard as in pleurisy, more so than in catarrh, and much more so than in pneumonia. The respiration should next be examined, abundantly more rapid than in catarrh, pneumovia, or pleurisy; generally as rapid and often more so than the pulse, and accompanied by a wheezing sound, heard at some distance. Mr. Percivall relates a case in which the respiration was more than one hundred in a minute. Mr. C. Percivall describes an interesting case in which the respiration was quick in the extreme; and he remarks that he does "not remember to have seen a horse with his repiration so disturbed."

In addition to these clearly characteristic symptoms, will be observed a haggard countenance, to which the anxious look of the horse labouring under inflammation of the lungs cannot for a moment be compared; also an evident dread of suffocation, expressed, not by inability to move, as in pueumonia, but frequently an obstinate refusal to do so; congh painful in the extreme: breath hot, yet no marked pain in the part, and no looking at the side or flanks.

As the disease proceeds, there will be considerable discharge from the nostrils, mnch more than in catarrh, because greater extent of membrane is affected. It will be muco-purulent at first, but will soon become amber-coloured or green, or greyish green; and that not from any portion of the food being returned, lut from the peculiar hue of the secretion from ulcers in the bronchial passages. Small organized pieces will mingle with the discharge,-portions of mucus condensed and hardened, and forced from the inside of the tube. If the disease proceeds, the discharge becomes bloody, and then, and sometimes earlier, it is fotid.

The natural termination of this disease, if unchecked, is in pneumonia. Although we cannot trace the air-tubes to their termination, the inflammation will penetrate into the loluli, and affect the membranes of the air-cells or divisions which they contain. There is metastasis of inflammation oftener here than in pure pneumonia, and tbe disease is most frequently transferred to the feet. If, however, there is neither pneunonia nor metastasis of inflammation, and the disease pursues its course, the animal dies from suffocation. If the air-passages are clogged, there can be no supply of arterialized blood.

Like every other inflammation of the respiratory passages, bronchitis is clearly epidemic. There is a disposition to inflammation in the respiratory apparatus generally, but it depends on some unknown atmospheric influence whether this shall take on the form of catarrh, bronchitis, or pneumonia. It has not, however, been yet proved to be contagious.

Here again the first step will be to bleed; and 
liere too will be the paramount necessity of the personal attendance of some well-informed person while the animal is bled. This is a lisease of a mucous, $\rightarrow$ and an exteuded mucous surface ; and while our neasures must be prompt, there is a tendency to debility which we should never forget. Although the horse may be distressed quite to the extent which $\mathrm{Mr}$. Charles Percivall describes, yet he would not bear the loss of four pounds of blood withont fainting. No determinate quantity of blood will therefore be taken, but the vein will not be closed until the pulse falters, and the animal staggers, and in a minute or two would fall. This may probably effect the desired object; if it does not, it is possible that the practitioner may not have a second opportumity.

The medical attendant should be cautious in the administration of purgatives, for the reasons that have again and again been stated; but if the bowels are evideutly constipated, small doses of aloes must be given with the febrifuge medicine, and their speedy action promoted ly injections, so that a small quantity may suffice.

A blister is always indicated in bronchitis. It can never do harm, and it not unfrequently affords decided relief. It should extend over the brisket and sides, and up the trachea to the larynx. The food, if the horse is disposed to eat, should be mashes. No corn should be offered, nor should the horse be coaxed to eat.

\section{PNEUMONIA-INFLAMMATION OF THE LUNGS.}

The intimate structure of the lungs has never been satisfactorily demonstrated. They appear, however, to be composed of minute cells or pouches, into which the air is at length conducted, and over the delicate membrane constituting the divisions of which myriads of minute blood-vessels are ramifying. The blood is not merely permeating them, but it is undergoing a vital change in them; there is a constant decomposition of the air, or of the blood, or of both; and, during the excitement of exercise, that decomposition proceeds with fearful rapidity. Then it can readily be conceived that a membrane so delicate as this must be, in order that its interposition shall be no hindrance to the arterialisation of the blood: so fragile also, and so loaded with blood-ressels, will be exceedingly subject to inflammation, and that of a most dangerous character.

Inflammation of the substance of the lungs is the not unfrequent consequence of all the diseases of the respiratory passages that have been treated on. Catarrh, influenza, bronchitis, if neglected or badly managed, or, sometimes in spite of the most skilful treatment, will spread along the mucous membrane, and at length involve the termination of the air-passages. At other times, there is pure pneumonia. This cellular texture is the primary seat of inflammation. It is often so in the over. worked horse. After a long and hai'd day's hunt, it is very common for lorses to be attacked by pure preumonia. A prodigiously increased quantity of blood is hurried through these small ressels, for the vast expenditure of arterial blood in rapid progression must be provided for. These minutest of the capillaries are distended and irritated, their contractile power is destruyed, inflammation is produced, mechanical injury is effected, the ves. sels are ruptured, blood is poured into the interstitial texture, and intense inflamuations and con. gestion, with all their train of fatal consequences, ensue.

The following are the most frequent causes of pneumonia. A sudden transition from lieat to cold ; a change from a warm stable to a colder one; a neglect of the usual clothing; a neglect even of some little comforts; riding far and fast against a cold wiud, especially in snowy weather ; loitering about when nusual perspiration has been excited; loitering tediously by the side of a covert on a chilly blowing morniug.

It has not unfrequently happened that when horses have been turned out too early to grass, or without gradual preparation, pneumonia has supervened. Few are, under auy management, so subject to pneumonia as those who, in poor condition and without preparation, are tumed into a salt-marsh.

On the other hand, a sudden and considerable change from cold to lieat may be followed by inflammation of the lungs. Many horses perish in the dealers' stables from this cause. The circulation is consilerably quickened; more blood, and that with more than natural rapidity, is driven through the lungs, previously disposed to take on iuflammatory action. The sudden removal from a heated stable to the cold air, for the purpose of examination, has also much to do with the production of disease.

Whether it is the consequence of previous disease of the respiratory passages, or that inflammation first appears in the cellular texture of the lungs, pneumonia is usually ushered in by a shivering fit. The horse is cold all orer; this, however, soon passes off, and we have geveral warmth, or heat of the skin above the usual temperature, but accompanied by coldness of the extremities-intense deathy colduess. This is a perfectly diagnostic symptom. It will nerer deceive. It is an early symptom. It is found when there is little or no constitutioual disturbance; when the pulse is scarcely affected, and the flauks lieave not at all, but the horse is merely supposed to be dull and off his feed. It is that by which the progress of the disease may be unhesitatingly nuarked, when m:uny scarcely suspect its existeuce.

The pulse is not always at first much increased 
in rapidity, and but rarely or never hard ; but it is obscure, oppressed. The heart is labouring to accomplish its olject; the circulation through the lıngs is imperled; the vessels are engorged-they are often ruptured; blood is extrarasated into the air-cells; it accumulates in the right side of the heart and in the larger vessels; and in the venous circulation generally there is a mechanical obstruction which the heart has not power to overcome. Hence the obscure, oppressed pulse; the ineffectual attempt to urge on the blood; and hence, too, the remarkable result of bleeding in inflammation of the lungs, for the pulse becomes rounder, fuller, quicker. When blood is abstracted, a portion of the opposiug force is removed, and the heart being enabled to accomplish its object, the pulse is dereloped.

It is only, however, in the early insidions stage that the flanks are occasionally quiet. If the compressibility of the lungs is diminished by the thickening of the membrane, or the engorgement of the vessels, or the filling of the cells, it will be lharder work to force the air out ; there must be a stronger effurt, and that pressure which cannot be accomplished by one effort is attempted over and over again. The respiration is qnickened-laborious; the inspiration is lengthened; the expiration is rapid; and when, after all, the lungs cannot be compressed by the usual means, every mnscle that can be brought to bear upon the part is called into action. Hence the horse will not lie down, for he can use the muscles of the spine and the shoulder with most advantage as he stands; hence, too, the very peculiar stiffness of position-the disinclination to move. The horse with decided pneumonia can scarcely be induced to move at all ; he eanuot spare for a moment the assistance which he derives from certain muscles, and he will continue obstinately to stand until he falls exhansted or dying. How eagerly does the reterinarian ask, when he goes into the stable- "Was he down last night?" And he concludes, that much progress has not been made towards amendment in the case when the answer is in the negative. When the patient, mearied out, lies down, it is only for a moment; for if the inflammation is not subdued, he cannot dispeuse with the auxiliary muscles. He fiequently, and with doleful expression, looks at his sides-at one side or at both, aceordingly as one or both are involved. There is not, howerer, the decidedly haggard countenance of bronchitis; and in bronchitis the horse rarely or never gazes at his flanks. His is a dread of suffocation more than a feeling of pain. The head is protruded, and the nostrils distender, and the month and the lreath intensely hot. The nose is injected from the earliest period; and soon afterwards there is not merely injection, but the membrane is uniformly and intensely red. The variation in this intensity is anxiously marked by the observant practitioner; and he regards with fear and with despair the livid or dirty brownish bue that gradually ereeps on.

The unfavourable symptoms are, increased coldness of the ears and feet, if that be possible; partial sweats, grinding of the teeth, evident weakness, staggering, the animal not lying down. The pulse becomes quicker, and weak and flnttering; the membrane of the nose paler, but of a dirty hue; the animal growing stupid, comatose. At length he falls, but he gets up immediately. For awhile he is up and down almost every minute. until he is no longer able to rise; he struggles sererely; he piteously groans; the pulse becomes more rapid, fainter, and he dies of suffocation. The disease sometimes runs its course with strange rapidity. A horse has been destroyed by pure pneumonia in twelve hours. The vessels ramifying over the cells have yielded to the fearful impulse of the blood, and the lungs liave presented one mass of congestion.

The favourable symptoms are, the return of a little warmth to the extremities-the circulation beginning again to assume its natural character, and, next to this, the lying down quietly and without uneasiness; showing us that he is beginning to do without the auxiliary muscles. These are good symptoms, and they will rarely deceive.

Congestion is a frequent termination of pneumonia. Not only are the vessels gorged-the congestion which accompanies common inflammation-but their parietes are necessarily so thin, in order that the change in the blood may take place although they are interposed, that they are easily ruptured, and the cells are filled with blood. This effused blood soon coagulates, and the lung, when cut into, presents a black, softened, pulpy kind of appearance, termed, by the farrier and the groom, rottenness, and being supposed by them to indicate an old disease. It proves only the violence of the disease, the rnpture of many a vessel surcharged with blood; and it also proves that the disease is of recent date, for in no great length of time, the serous portion of the blood becomes absorbed, the more solid one becomes organized, the cells are obhterated, and the lung is liepatized, or bears considerable resemblance to liver.

In every case of pmeumonia, early and anxious recourse should be had to auscultation. Here, again, is the advantage of being perfectly acqnainted with the deep distinct murmur presented hy the healthy lung. This sound is most distinet in the young horse, and especially if he is a little out of condition. On such a horse the tyro should commence bis study of the exploration of the cliest. There lie will make himself best acquainted with the respiratory murmur in its full state of development. He should next take an older and somewhat fatter horse; he will there recognise the 
same sound, but fainter, more distant. In still timues for a while-the conseruence aud the older auimals, there will sometimes be a little source of inflammation. It occupies a space that difficulty in detecting it at all. Repeated ex- should be employed in the function of respiration, periments of this kind will gradually teach the and by its pressure it irritates the neighbouring examiner what kind of healthy murmur he should parts, and exposes them to intlanmation.

expect from every horse that is presented to him, and thus he will be better enabled to appreciate the different sounds exbibited uniler disease.

If pneumonia exists to any considerable degree, this murmur is soon changed for, or mingled with, a curious crepitating sound, which, having been once heard, caunot afterwards be mistaken. It is caused by the infiltration of blood in to the air-cells. Its loudness and perfect eharacter will characterize the intensity of the disease, and the portion of the chest at which it can be distinguished will indicate its extent.

The whole lung, howerer, is not always affected, or there are only portions or patches of it in which the inflammation is so intense as to produce congestion and hepatization. Enough remains either unaffected, or yet pervious for the function of respiration to be pcrformed, and the animal lingers on, or perhaps recovers. By careful examination with the ear, this also may be ascertained. Where the lung is impervious - where no air passes-no sound will be lieard, not even the natural murmur. Around it the murmur will be heard, and loudly. It will be a kind of rushing sound; for the same quantity of blood must be arterialized, and the air must pass more rapidly and forcibly through the remaining tubes. If there is considerable inflammation or tendency to congestion, the crepitating, crackling sound will be recognised, and in proportion to the intensity of the inflammation. The advantages to be derived from the study of auscultation are not overrated. It was strong language lately applied by an able critic to the use of auscultation, that "it converts the organ of hearing into an organ of vision, enabling the listener to observe, with the clearness of ocular demonstration, the ravages which disease occasionally commits in the very centre of the rib-cased cavity of the body."

A horse with any portion of the lungs hepatized cannot be sound. He cannot be capable of continued extra exertion. His imperfect and mutilated lung cannot supply the arterialized blood which long continued and rapid progression requires, and that portion which is compelled to do the work of the whole lung must be exposed to injury and inflammation from many a cause that would otherwise be harmless.

Anotlier consequence of inflammation of the substance of the lungs is the formation of tubercles. A greater or smaller number of distinct cysts are formed-cells into which some fluid is poured in the progress of inflanmation: these vary in size from a pin's point to a large egg. By degrees the fluid becomes concrete; and so it con-

By and by, lowever, another process, never sufficiently explainer, commences. The tuljercle begins to soften at its centre,-a process of suppuration is set up, and proceeds until the coutents of the cyst become again fluid, lut of a different character, for they now consist of pus. The pus increases; the cyst becomes more and more distended; it encroaches on the substance of the lungs; it comes into contact with other tubercles, and the walls opposed to each other are atsorbed by their mutual pressure; they run together, and form one cyst, or regular excavation, and this sometimes proceeds until a considerable portion of the lung is, as it were, hollowed out. By and hy. however, the vomica presses upon some hronchial passage; the cyst gives way, and the puruleut contents are poured into the bronchiæe, and got rid of by the act of coughing. At other times the quantity is too great to be thus disposed of, and the animal is suffocated. Occasionally it will break through the pleuritic covering of the lung, and pour its contents into the thorax.

Abscesses may exist in the lungs undiseovered.-It is scarcely conceivable to what extent they sometimes exist in animals of slow work, without being detected by the usual means of examination. Mr. Hales says that he gave a physicball to a cart-mare with a bad foot, and she soon afterwards died suddenly. When inquiring as to the cause of death, he was told, and not very goodhumouredly, that his physic had killed her. He asked, if it had purged her violently" "No! " it was replied, "it had not operated at all." She was opened, and the mystery was all unravelled. The thorax was deluged with pus, and there were then in the lungs several large abscesses. one of which cantained at least a quart of pus. The mare had not shown a symptom of chest affection, and the gentleman to whom she belonged deelared that he had believed her to be as sound as any horse he had in his possession.

The resolution or gradual abatement of inflammation is the termination most to be desired in this state of disease, for then the engorgement of the vessels will gradually cease, and the thickening of the membrane and the interstitial deposit be taken up, and the effusion into the cells likewise absorbed, and the lungs will gradually resume their former cellular texture, yet not perfectly : for there will be some induration, slight but general; or some more perfect induration of certain parts: or the rupture of some of the air-cells : or an irritability of membrane predisposing to renewed inflammation. The horse will not always be as useful as 
before; there will be chronic cough, thick-wind, broken-wind; but these merit distinct consideration; and, for the present, we proceed to the treatment of pueumonia.

There is inflammation of that organ through which all the blood in the frame passes-that organ most of all sulject to congestion. Then nothing can be so important as to lessen the quantity of blood which the heart is endeavouring to force through the minute vessels of the lungs, distended, irritated, breaking. Immediate recourse must be had to the lancet, and the stream of blood must be suffered to flow on until the pulse falters, and the animal bears heavy upon the pail. This blood must be extracted as quickly as possible, and the lancet should be broad-shouldered, and the orifice large. This is the secret of treating inflammation of a vital organ. The disease is weakened or destroyed without permanently impairing the strength of the patient; whereas by small bleedings, and with a small stream, the strength of the patient is sapped, while the disease remaius untouched.

Next comes purging, if we dared; for by having recourse to it some cause of excitement would be got rid of, the circulating fluid would be lessened, and a new determination of the vital current produced; but experience teaches, that in pneumonia there is so much sympathy with the abdominal viscera,-there is such a fatal tendency in the inflammation to spread over every mueous membrane, that purging is almost to a certainty followed by inflammation, and that inflammation bids defiance to every attempt to arrest it. It may be said with perfect confidence that, in the majority of cases, a physic-ball would be a dose of poison to a horse labouring under pneumonia.

Nay we not relax the bowels? Yes, if we can stop there. We may, after the inflammation has evideutly a little subsided, venture upon, yet very cautiously, small doses of aloes in our fever medicine, and we may quicken their operation by frequent injections of warm and soap water; omitting the purgative, however, the moment the fæces are becoming pultaceous. We must, however, be assured that the inflammation is subsiding, and there must be considerable constipation, or the purgative had better be let alone.

If we must not give physic, we must endeavour to find some other auxiliary to the bleeding, and we have it in the compound of diyitalis, nitre, and emetic tartar, wlich has been so often recommended.

The greatest care should be taken of the patient labouring under this complaint. His legs should be well hand-rubbed, in order to restore, if possible, the circulation to the extremities. Comfortable flannel rollers should encase the legs from the foot to the knee. He should be covered up warm. There cannot be a doubt about this. As for air, in warm weather he cannot have too much.
In cold weather his box must be airy, but not chilly. We want to determine the blood to the extremities and the skin, but not all the clothing in the world will keep our patient rarm, if he is placed in a cold and uncomfortable situation.

As for food, we think not of it. In nine cases out of ten he will not touch anything; or if he is inclined to eat, we give lim nothing but a branmash, or a little green-meat, or a few carrots.

We now look about us for some counter-irritant. We wish to excite some powerful action in another part of the frame, and which shall divert the current of blood from that which was first affected. We recognise it as a law of nature, and of which we here eagerly avail ourselves, that if we have a morbid action in some vital organ-an unusual determination of blood to it-we can abate, perhaps we can at once arrest, that morbid action by exciting a similar or a greater disturbance in some contiguous and not dangerous part. Therefore we blister the sides and the brisket, and produce all the irritation we can on the integument; and in proportion as we do so, we abate, or stand a chance of abating, the inflammation within.

We have recourse to a blister in preference to a seton; and decidedly so, for our stimulus can be spread over a larger surface,- there is more chance of its being applied to the immediate neighbourhood of the original inflammation-and, most assuredly, from the extent of surface on which we can act, we can employ a quantity of stimulus beyond comparison greater than a seton would permit us to do. Roxels are frequently excellent adjuvants to the blister, but should not be depended upon alone.

In the latter stage of disease the blister will not act, because the powers of nature are exhausted. We must repeat it,- -we must ronse the sinking energies of the frame, if we can, althongh the effort will generally be fruitless. The not rising of a blister, in the latter stage of the disease, may, too often, be regarded as the precursor of death, especially if it is accompanied by a livid or brown colour of the membrane of the nose.

Pneumonia, like brochitis, requires anxious watching. The first olject is to subdue the inflammation, and our measures must be prompt and decisive. If the mouth continues hot, and the extremities cold, and the nose red, we must bleed again and again, and that in rapid succession. The good which we can do must be done at first, or not at all.

When we have obtained a little returning warmth to the extremities, we must continue to administer our sedative medicmes without one grain of a carminative or a tonic: and the return of the deathy-cold foot will be a signal for farther depletion.

The commencement of the state of convalescence requires the same guarded practice, as in 
bronchitis. As many lorses are lost by impatience now, as by want of decision at first. If we have subdued the disease, we should let well alone. We should guard against the return of the foe by the continued administration of our sedatives in smaller quantities; but give no tonies unless debility is rapilly succeeding. When we have apparently weathered the storm, we must still be cautious; we must consider the nature and the seat of the disease, and the predisposition to returning inflimmation. If the season will permit, two or three montls' run at grass should succeed to our medical treatment; but if this is impracticable, we must put off the period of active work as long as it can be delayed; and even after that, permit the horse to return as gradually as may be to his usual emplorment and food.

Most frequent in occurrence among the consequences of inflammation of the lungs, is

\section{CHRONIC COUGH.}

It would occupy more space than can be devoted to this part of our subject, to treat of all the canses of obstinate cough. The irritability of so great a portion of the air-passages, occasioned by previous and riolent inflammation of them, is the most frequent. It is sometimes comnected with worms. There is much sympathy between the lungs and the intestines, and the one readily participates in the irritation produced in the other. That it is caused by glanders can be easily imagined, because that disease is, in its early stage, seated in or near the principal air-passages, and little time passes before the lungs become affected. It is the necessary attendant of thick-wind and broken-wind, for these proceed from alterations of the structure of the lungs.

Notwithstanding the clearness of the cause, the cure is not so evident. If a harsh hollow cough is accompanied by a staring coat, and the appearance of worms, - a few worm-balls may expel these parasites, and remove the irritation of the intestinal canal. If it proceeds from irritability of the airpassages, which will be discovered by the horse coughing after drinking, or when he first goes out of the stable in the morning, or by his occasionally snorting out thick mucus from the nose, medicines may be given, and sometimes with advantage, to diminish irritation generally. Small doses of digitalis, emetic tartar, and nitre, administered every night, frequently have a beneficial effect, especially when mixed with tar, which seems to have a powerful influence in allaying the irritation. These balls should, if necessary, be regularly given for a considerable time. They are sufficiently powerful to quiet slight excitement of this kind, but not to nanseate the horse, or interfere with his food or his work. A blister, extending from the root of one ear to that of the other, taking in the whole of the channel, and reaching six or eight inclies down the windpipe, has been tried, and often with good effect, on the supposition that the irritation may exist in the fauces or the larynx. The blister has sometimes been extended through the whole course of the windpipe, until it enters the chest.

Feeding has much influence on this complaint. Too much dry meat, and especially chaff, increase it. It is aggravated when the horse is suffered to eat his litter; and it is often relieved when spring tares are given. Carrots afford decided relief.

The seat of the disease, however, is so uncertain, and all our means and appliances so inefficacious, and the congh itself so little interfering, and sometimes interfering not at all with the health of the animal, that it is scarcely worth while to persevere in any mode of treatment that is not evidently attended with benefit. The priucipal consideration to induce us to meddle at all with chronic cough is the knowledge that horses afflicterl with it are more liable than others to be affected by changes of temperature, and that inflammation of the lungs, or of the respiratory passages, often assumes in them a very alarming character; to which, perlaps, may he added, that a horse with chronic cough camuot be warranted sound.

When chronic cough chielly occurs after eating, the seat of the disease is evidently in the sulstance of the lungs. The stomach distended with food presses upon the diaphragm, and the diaphragm upon the lungs; and the lungs, already labouring under some congestion, are less capable of transmitting the air. In the violent effort to discharge their fuuction, irritation is produced; and the act of coughing is the consequence of that irritation.

The veterinary surgeon labours under great disadvantage in the treatment of his patients. $\mathrm{He}$ must not only subdue the malady, but he must remove all its consequences. He must leare his patient perfectly sound, or he has done comparatively nothing. This is a task alwars difficult, aud sometimes impossible to be accomplished. The two most frequent consequences of severe chest affections in the horse are recoguised under the termis thick-uind and broken-wind. The breathing is hurried in both, and the horse is generally much distressed when put upon his speed; but it is simply quick breathing in the first, with a peculiar sound like half roaring-the inspirations and expirations being rapid, forcible, but equal. In the second, the breatling is also hurried, but the inspiration does not differ materially from the natural one, while the expiration is difficult, or doubly laborious. The changes of structure which accompany these states of morbid respiration are as opposite as can be imagined. Indmation of the substance of the lungs, diminution of the number or the calilier of the air-passages, are the causes of thick-uind. If the portion of lung employed 
is lessened, or the bronchial tubes will not admit so much air, the quick succession of efforts must make up for the diminished effect produced ly each. In broken-rind there is rupture of the aircells, and an unnatural inter-communication between them in the same lobule, or between those of the neighbouring lobuli. The structure of the lung, and the discharge of function, and the treatment, too, being so different, these diseases require separate consideration.

\section{THICK-WIND.}

When treating of pneumonia, it was observed, that not only are the vessels which ramify over the delicate membrane of the air-cells gorged with blood, but they are sometimes ruptured, and the cells are filled with blood. The black, softened, pulpy appearance of the lungs thus produced, is the rottenness of the groom and farrier, proving equally the intensity of the inflammation, and that it is of recent date. If the horse is not speedily destroyed by this lesion of the substance of the lungs, the serous portion of the effused blood is absorbed, and the solid becomes organised. The cells are obliterated, and the lung is hepatized,-its structure bears considerable resemblance to that of the liver. This may occur in patches, or it may involve a considerable portion of the limg.

If a portion of the lung is thus rendered impervious, the remaiuder will have additional work to perform. The same quantity of blood must be supplied with air; and if the working part of the machine is diminished, it nust move with greater velocity as well as force-the respiration must be quicker and more laborious. 'This quick and laboured breathing can be detected even when the animal is at rest, and it is indicated plainly enough by his sad distress when he is urged to uuusual or continued speed. The inspirations and the expirations are shorter, as well as more violent; the air must be more rapidly admitted aud more thoroughly pressed out: and this is accompanied by a peculiar sound that can rarely be mistaken.

We may guess at the commencement of the evil, by the laborious heaving of the flanks; but by auscultation alone cau we ascertain its progress. The increase of the crepitus will tell us that the mischief is beginning, and the cessation of the murmur will clearly mark out the extent of the congestion.

The inflammatory stage of the disease having passed, and comparative health being restored, and some return to usefulness having been established,-the horse being now thick-winded, auscultation will be far more valuable than is generally imagined. It will faithfully indicate the quantity of hepatization, and so give a clue to the degree of usefulness, or the extent to which we may tax the respiratory system; and it will also serve to dis- tinguish, and that very clearly, between this cause of thick-rind, and the morbid changes that may have resulted from bronchitis, or thickening of the parietes of the air-passages, and not the obliteration of the air-cells.

Of the Treatment little can be sail. We know not by what means we can excite the absorbents to talie up the solid organised mass of hepatization, or restore the membrane of the cells and the minute ressels ramifying over them, now confounded and lost. We have a somewhat better chance, and yet not much, in removing the thickening of the membrane, for counter-irritants, extensively and perseveringly applied to the exterual parietes of the chest, may do something. If thick-wind immediately followed bronchitis, it would certainly be justifiable practice to blister the brisket and sides, and that repeatedly; and to administer purgatives if we dared, or diuretics, more effectual than the purgatives and always safe.

Our attention must be principally confined to diet and management. A thick-winded horse should have his full proportion, or rather more than his proportion, of corn, and a diminished quantity of less nutritious food, in order that the stomach may never be overloaded, and press upon the diaphragm, and so upou the lungs, and increase the labour of these already over-worked organs. Particular care should be taken that the horse is not worked immediately after a full meal. The overcoming of the pressure and weight of the stomach will be a serious addition to the extra work which the lungs already have to perform from their altered structure.

Something may be done in the palliation of thick-wind, and more than has been generally supposed, by means of exercise. If the thickwinded horse is put, as it were, into a regular system of training; if he is daily exercised to the fair extent of his power, and without seriously distressing him, his breathing will become freer and deeper, and his wind will materially improve. IVe shall call to our aid one of the most powerful excitauts of the absorbent system-pressure, that of the air upon the tube-the working part of the lung upon the disorganised-and, adjusting this so as not to excite irritation or inflammation, we may sometimes do wonders. This is the very secret of training, and the power and the durability of the hunter and the racer depend entirely upon this.

Thick-wind, however, is not always the consequence of disease. There are certain cloddy, round-chested horses, that are naturally thickwinded, at least to a certain extent. They are capable of that slow exertion for which nature designed them, but they are immediately distressed if put a little out of their usual pace. A circular chest, whether the horse is large or small, 
indicates thick-wind. The circular chest is a capacious one, and the lungs which fill it are large, and they suprly suficient arterialised blood to produce plenty of flesh and fat, and these horses are always fat. 'J his is the point of proof to which we look, when all that we want from the animal is flesh and fat; but the expanding form of the chest is that which we require in the animal of speedthe deep as well as the broad chest-always capacious for the purpose of muscular strength, and becoming considerably more so when arterialised blood is rapidly expended in quick progression. We ctnnot enlarge the capacity of a circle ; and if more blood is to be furnished, that which cannot be done by increase of surface must be accomplished by frequency of action. Therefore it is that all our heavy draught-horses are thick-winded. It is of little detriment to them, for their work is slow; or rather it is an advantage to them, for the circular chest, always at its greatest capacity, enables them to acquire that weight which it is so adrantageous for them to throw into the collar.

\section{BROKEN-WIND.}

This is immediately recoguisable by the manner of breathing. The inspiration is performed in somewhat less than the natural time, and with an increased degree of labour: but the expiration has a peculiar difficulty accompanying it. It is accomplished by a double effort, in the first of which, as Mr. Blaine has well explained it, "the nsual muscles operate; and in the other the auxiliary muscles, particularly the abdominal, are put on the stretch to complete the expulsion more perfectly; and, that being done, the flank falls, or the abdominal muscles relax with a kind of jerk or spasm."

The majority of veterinary surgeons attribute broken-wind to an emplysematous state of the lungs. In almost every broken-winded horse which he has examined after death, the author of this work has found dilatation of some of the air-cells, and particularly towards the edges of the lobes. There has been rupture through the parietes of some of the cells, and they have evidently communicated with one another, and the air could be easily forced from one portion of the cells to another. There was also a crepitating noise while this pressure was made, as if the attemuated membrane of some of the cells had given way. These were the true broken cells, and hence the derivation of the name of the disease.

Broken-wind is preceded or accompanied by cough-a cough perfectly characteristic, and by which the horseman would, in the dark, detect the existence of the disease. It is short-seemingly cut short-gruuting, and followed by wheezing. When the animal is suddenly struck or threatened, there is a low grunt of the same nature as that of roaring, but not so loud. Broken-wind is usually preceded by cough; the cough bccomes chronic, leads on to thick-wind, and then there is but a step to broken-wind. It is the consequence of the cough which accompanies catarrh and bronchitis oftener than that attending or following pneumonia; and of inflammation, and, prohally, thickening of the membrane of the brouchix, ratler than of congestion of the air-cells.

Laennec, whose illnstrations of the diseases of the chest are invaluable to the human surgeon, comes to our assistance, and, while describing emplysema of the lungs of the human being, gives us an explication of broken-wind, more satisfactory than is to be found in any of our veterinary writers. He attributes what he calls dry catarrh " to the partial obstrurtion of the smaller bronchial tubes, by the swelling of their inner membrane. The muscles of inspiration are numerous and powerful, while expiration is chiefly left to the elasticity of the parts: then it may happen that the air which, during inspiration, had orercome the resistance opposed to its entrance by the tumid state of the membrane, is unable to force its may through the same obstacle during expiration, and remains imprisoned in the cells, as it were, by a valve. The succeeding inspirations introduce a fresh supply of air, and grarlurlly dilate the cells to a greater or less extent; and if the obstruction is of some continuance, the dilated condition of the cells becomes permanent."

Some circumstances attending this disease may now, probably, he accountel for. A troublesome cough, and sometimes of long continuance, is the foundation of the disease, or indicates that irritable state of the bronchial membrane with which broken wind is almost necessarily associated. Horses that are greedy feeders, or devour large quantities of slightly nutritious food, or are worked with a stomach distended by this food, are very subject to broken-rind. More depends upon the management of the food and exercise than is generally supposed. The post-horse, the coach-horse, and the racer, are comparatively seldom broken-winded. They are fed, at stated periods, on nutritious food that lies in little compass, and their hours of feeding and of exertion are so arranged that they seldom work on a full stomach. The agricultural horse is too often fed on the very refuse of the farm, and his hours of feeding, and his hours of work, are frequently irregular; and the carriagehorse, although fed on more nutritious food, is often summoned to work, by his eapricious master, the moment his meal is devoured.

A rapid gallop on a full stomach has often produced hroken-wind. When the exertion has been considerable and long continued. we can easily conceive a rupture of the air-cells of the soundest lungs; but we are inclined to believe, 
that, were the history of these cases known, there would be found to have been a gradual preparation for this result. There would have been chronic cough, or more than usually disturbed respiration after exereise, and then it required little more to perfect the mischief. Galloping after drinking has been censured as a cause of broken-wind, yet we camnot think that it is lialf so dangerous as galloping with a stomach distended by solid food. It is said that broken-winded lorses are foul feeders, because they devour almost everything that comes in their way, and thus impede the play of the lungs; but there is so much sympathy between the respiratory and digestive systems, that one cannot be much deranged without the other evidently suffering. Flatulence, and a depraved appetite, may be the consequence as well as the cause of broken-wind; and there is no pathological fact of more frequent occurrence than the co-existence of indigestion and flatulence with broken-wind. Flatulence seems so invariable a concomitant of broken-wind, that the old farriers used to think the air found its way from the lungs to the abdomen in some inexplicable manner; and hence their " holes to let out broken-wind." They used literally to make a hole near to or above the fundament in order to give vent to the imprisoned wind. The sphincter muscle was generally divided; and althougl the trumping ceased, there was a constant, although silent, emission of foetid gas, that made the remedy worse than the disease.

The narrow-chested horse is more sulject to broken-wind than the lroader and deeper chested one, for there is not so much room for the lungs to expand when rapid progression requires the full discharge of their function.

Is broken-wind hereditary? We believe so, It may lie referred to hereditary conformation-to a narrower chest, and more fragile membraneand predisposition to take on those inflammatory diseases which end in broken-wind; and the circular chest, which cannot enlarge its capacity when exertion requires it, must render both thick and broken wind of more proballe occurrence.

Is there any cure for broken-wind? None! No medical skill can repair the broken-down structure of the lungs.

If, however, we cannot eure, we may in some degree palliate broken-wind; and, first of all, we must attend carefully to the feeding. The food should lie in little compass, - plenty of oats and little hay, but no chaff. Chaff is particularly objectionable, from the rapidity with which it is devoured, and the stomach distended. Water should be given in moderate quantities, but the liorse should not be suffered to drink as much as he likes until the day's work is over. Green meat will always be serviceable. Carrots are particularly useful. They are readily digested, and appear to have a peculiarly beneficial effect on the respiratory system.

It is from the want of proper attention to the feeding that many horses become broken-winded, even in the straw-yard. There is little nutriment in the provender which they find there; and in order to obtain enough for the support of life, they are compelled to keep the stomach constantly full, and pressing upon the lungs. It has been the same when they have been turned out in coarse and innutritive pasturage. The stomach was perpetually gorged, and the habitual pressure on the lungs cramped and confined their action, and inevitalily ruptured the cells when the horse gambolled with his companions, or was wantonly driven about.

Next in importance stands exercise. The pursive or broken-winded horse should not stand idle in the stable a single day. It is almost incredible how much may be done by attention to food and exercise. The broken-winded horse may thus be rendered comfortable to himself, and no great nuisance to his owner;--but inattention to feeding, or one hard journey-the animal unprepared, and the stomach full,-may bring on inflammation, congestion, and deatl. Occasional physic, or alterative medicine, will often give considerable relief.

Thick-wind and broken-wind exist in rarious degrees, and many shades of difference. Dealers and horsemen generally have characterised them by names that can boast no elegance, but are consideribly expressive of the state of the animal. Our readers should not be ignorant of them. Some horses make a shrill noise when in quick action-they are said to be Pipers. This is a species of Roaring. There is usually a ring of coagulated matter romd the inside of the windpipe, by which the cavity is materially diminished, and the sound produced in quick breathing must evidently be shriller. Sometimes the piping is produced by a contraction of the small passages of the lungs.

The Wheezer utters a sound not unlike that of an asthmatic person when a little lurried. This is a kind of thick-wind, and is caused by the lodgment of some mucous fluid in the small passages of the lungs. It frequently accompanies bronchitis. Wheezing can be heard at all times, even when the horse is at rest in the stalle; roaring is confined to the increased breathing of considerable exertion.

The Whistler utters a shriller sonnd than the wheezer, but only when in exercise, and that of some continuance. A sudden motion will not always produce it. It seems to be referable to some contraction in the windpipe or the larynx. The sound is a great nuisance to the rider, and the whistler very speedily becomes distressed. A 
sharp gallop up-hill will speedily detect the ailment.

When the obstruction seems to be principally in the uose, the horse loudly puffs and blows, and the nostrils are dilated to the utmost, while the flanks are comparatively quiet. This animal is said to be a High-blower. With all his apparent distress, he often possesses great speed and endurance. The sound is unpleasant, but the lungs may be perfeetly sound.

Every horse violently exercised on a full stomach, or when overloaded with fat, will grunt almost like a hog. The pressure of the stomach on the lungs, or that of the fat accumulated around the heart, will so much impede the breathing, that the aet of forcille expiration will be accompanied by this hind of sound: but there are some horses who will at all times emit it, if suddenly touched with the whip or spur. They are called Grunters, and should be avoided. There is some altered structure of the lungs, which prevents them from suddenly accommodating themselves to an umexpected demand for exertion. It is the consequence of previous disease, and is frequently followed by thick or broken wind, or roaring.

PHTHISIS PULMONALIS, on CONSUMPTION.

When describing the accompaniments and consequences of inflammation of the lungs in the horse, mention was made of this fatal complaint. It is usually connected with or the consequence of pneumouia or pleurisy, and especially in horses of a peculiar formation or temperament.

If a narrow-chested, flat-sided horse is attacked ly iuflammation of the lungs, or severe catarihal fever, experience tells us that we shall have more difficulty in subduing the disease in him, than in one deeper in the girtl or rounder in the chest. The lungs, deficient in bulk according to the diminished contents of the chest, have been overworked in supplying the quantity of arterial blood ex. peuded in the varions purposes of life, and particularly that which has been required under unusual and violent exertion. Inflammation of the lungs has consequently ensued, and that inflammatory action has acquired an intense character, under circumstances by which another horse would be scarcely affected.

When this disease has been properly treated, and apparently subdued, this horse cannot be quickly and summarily dismissed to his work. $\mathrm{He}$ is sadly emaciated-he long continues so-his coat stares-lis skin clings to his ribs--his belly is tucked up, notwithstanding that he may have plenty of mashes, and carrots, and green meat, and mediciue-his former gaiety and spirit do not return, or if he is willing to mork lie is easily tired, sweating on the least exertion, and the sweat most profuse about the chest and sides-his appetite is not restored, or, perhaps, never has been goor, and the slightest exertion puts him completely off his feed.

We observe him more attentively, and, even as he stands quiet in his stall, the flanks heare a little more laborionsly than they should do, and that heaving is painfully quickened when sudden exertion is required. He coughs sorely, and discharges from the nose a mucus tinged with blood, or a fluid decidedly purulent-the breath becomes offensive-the pulse is always above 40 , and strangely increased by the slightest exertion.

When many of these symptoms are developed, the animal will exhibit considerable pain on being gently struck on some part of the chest; the cough then becomes more frequent and painful; the discharge from the nose more abundant and foetid, and the emaciation and consequent debility more rapid, until death closes the scene.

The lesious that are presented after death are very uncertain. Generally there are tubereles; sometimes very minute, at other times large in size. They are in diflerent states of softening, and some of them have burst into the bronchial passages, and exhibit abscesses of enormous bulk Other portions of the lungs are shrunk, flaceid, indurated or hepatized, and of a pale or red brown colour; and there are occasional adhesions between the lungs and the sides of the chest.

Is this an hereditary disease? There is some difficulty in deciding the point. It has been scarcely mooted among horsemen. One thimg only is known, that the side has been flat, and the belly tucked up, and the animal has had much more ardour and willinguess than physical strength. These conformations, and this disposition, we know to be hereditary, and thus far phthisis may be said to be so too. Low and damp situations, or a variable and ungenial climate, may reuder liorses peculiarly susceptible of ehest affections. All the absurd, or eruel, or accidental causes of pneumonia lay the foundation for phthisis; and, particularly, those causes which tend to debilitate the frame generally, render the horse more liable to chest affections, and less able to ward off their fatal eansequences. The most numerous instances of phthisis occur in those poor persecuted animals that are worn out before their time, and they are frequent enough among cavalry horses after the deprivations and fatigues of a long campaign.

What is the medical treatment of confirmed phthisis? The practitioner must be guided by cireumstances. If the horse is not rery bad, and it is the spring of the year, a run at grass may be tried. It will generally seem to renovate the animal, but the apparent amelioration is too often treacherous. It should always be tried, for it is the best foundation for other treatment. The 
summer, however, having set in, the medicinal effect of the grass ceases, and the flies tease and irritate the animal.

The medical treatment, if any is tried, will depend on two simple and unerring guides, the pulse and the membrame of the nose. If the first is quick and hard, and the second streaked with red, venesection should be resorted to. Small bleedings of one or two quarts, omitted when the pulse is quieted and the nostril is pale, may be effected. Counter-iritants will rarely do harm. They should be applied in the form of blisters, exteuding over the sides, and thus brought as near as possible to the affected part. Sedatice medicines should be perseveringly administered; and here, as in acute inflammation, the chief dependence will be placed on digitalis. It should be given in small doses uutil a slightly intermittent pulse is produced, and that state of the constitution should be maintained by a continued exhibition of the medicine. Nitre may be added as a diuretic, and pulvis antimonialis as a diaphoretic.

Any tonics here? Yes, the tonic effect of mild and nutritious food-green meat of almost every kind, carrots particularly, mashes, and now and then a malt mash. Nothing further than this? We may try, but very eautiously, those tonics which stimulate the digestive system, yet comparatively little affect the circulatory one. Small doses of camomile and gentian may be given, but earefully watched and omitted if the flanks should heave more, or the cough be aggravated.

The treatment of phthisis is a most uusatisfactory subject of consideration as it regards the practice of the veterinarian. If, after the human being has been subjected to medical treatment for a long course of time and at very considerable expense, he so fir recovers that life is rendered tolerably comfortable to lim, he and his connexions are thankful and satisfied, and he will submit to many a privation in order to ward off the return of a disease, to which he is conscious there will ever be a strong predisposition: but the case is different with the horse; and this, the scope and bound of the human practitioner's hope, is worthless to the veterinarian. His patient must not ouly live, but must be sound again. Every energy, every capability must be restored. Can we cause the tubercles of the lungs to be absorbed? Can we disperse or dispel the hepatization? Can we remoctel the disorganised structure of the lungs? Our consideration, then, will be chiefly directed to the detection of the disense in its earliest state, and the allaying of the irritation which. causes or accompanies the growth of the tubercles. This must be the scope and bound of the veterinariau's practice-always remembering that the owner should be forewarued of the gene- ral hopelessness of the case, and that the continuance of his efforts should be regulated by the wish of the proprietor and the value of the patient.

\section{PLEURISY}

The investing membrane of the lungs, and of the thoracic cavity, namely, the pleura, now demands cousideration. We are indebted to Mr. Joln Field, one of the noblest ornaments of the veterinary profession-but cut off in the prime of his days-for the greater part of our knowledge of this disease, and for the power of distinguishing between it and pneumonia, as readily and as surely as we do between pneumonia and bronchitis and epidemic catarrh.

The prevailing canses of pleurisy are the same as those which produce pueumonia-exposure to wet and cold, sudden alternations of temperature, partial exposure to cold, riding agairst a keen wind, immersion as high as the chest in cold water, drinking cold water, and extra rork of the respiratory machine. 'To these may be added, wounds penetrating into the thorax and lacerating the pleura, fracture of the ribs, or violent contusious on the side, the inflammation produced by which is propagated through the parietes of the chest.

It is sometimes confinel to one side, or to one of the pleuræ ou either side, or even to patches on that pleura, whether pulmonary or costal. The inflammation of the lungs which occasionally accompanies rabies is characterised by a singular patchy appearance. That produced on the costa pleura, arising from violence or other causes, rarely reaches the pulmonary covering; and that which is communicated to the tunic of the lungs, by means of the intensity of the action within, does uot often involve the costal pleura. In some cases, however, it affects both pleuræe and both sides, and spreads rapilly from one to the other.

The first srmptom is rigor, followed by increased heat and partial sweats, to these succeed loss of appetite and spirits, and a low and painful cough. The inspiration is a short, suddeu effort, and broken off before it is fully accomplished, indicating the pain felt from the distension of the irritable, because inflamed, membrane. This symptom is exceedingly characteristic. In the human being it is well expressed by the term stitch, and an exceedingly painful feeling it is. The expiration is retarded, as much as possible, by the use of all the auxiliary muscles which the animal can press into the service; but it at length finishes abruptly in a kind of spasm. This peculiarity of breatling, once carefully observed, cannot be forgotten. The next character is found in the tenderness of the sides when the costal pleura is affected. This tenderness often exists to a degree scarcely credible. If the side is pressed upon, the horse will recede with a low painful grunt; he 
will tremble, and try to get out of the way before the hand tonches him again. Then comes another indication, both of pain and the region of that pain - the intercostal muscles, affected by contiguous pleura, and in their turn affecting the panniculus carnosus, or subcutaneous muscular expansion without-there are twitchings of the skin on the side-corrugations - waves creeping over the integument. This is never seen in pueumonia. There is, however, as we may expect, the same disinclination to move, for every motion must give intense pain.

The pulse should be anxiously studied. It presents a decided difference of character from that of pneumonia. It is increased in rapidity, but instead of being oppressed and sometimes almost unappreciable, as in pneumonia, it is round, full, and strong. Even at the last, when the strength of the constitution begins to yield, the pulse is wiry, although small.

The extremities are never deathy cold; they may be cool, they are oftener variable, and they sometimes present increased heat. The body is far more liable to variations of temperature; and the cold and the hot fit more frequently sncceed each other. The mouth is not so hot as in pneumonia, and the lieath is rarely above its usual temperature.

A difference of character in the two diseases is here particularly evident on the membrane of the nose. Neither the crimson nor the purple injection of pneumonia is seen on the lining of the nose, but a somewhat darker, dingier hue.

Both the pneumonic and pleuritic horse will look at his flanks, thus pointing out the seat of disease and pain; but the horse with pneumonia will turn himself more slowly round, and long and steadfastly gaze at his side, while the action of the horse with pleurisy is more sudden, agitated, spasmodic. The countenance of the one is that of settled distress; the other brightens up occasionally. The pang is severe, but it is transient, and there are intervals of relief. While neither will lie down or willingly move, and the pneumonic horse stands fixed as a statue, the pleuritic one shrinks, and crouches almost to falling. If he lies down, it is on the affected side, when the disease is confined to one side only. The head of the horse, with inflammation of the substance of the lungs, hangs heavily; that of the other is protruded.

We here derive most important assistance from Auscultation. In a case of pleurisy we have no crepitating, crackling sound, referable to the infiltration of the blood through the gossamer membrane of the air-cells; we have not even a louder and distincter murmur. Perhaps there is no variation from the sound of health, or, if there is any difference, the murmur is fainter; for the plenral membrane is thickened, and its elasticity is impaired, and the sound is not so readily transmitted. There is sometimes a slight rubbing sound, and especially towards the superior region of the chest, as if there was friction between the thickened and indurated membranes.

To this may be added the different character of the cough, sore and painful enough in both, but in preumonia generally hard, and full, and frequent. In pleurisy it is not so frequent, but faint, suppressed, cut short, and rarely attended by discharge from the nose.

These are sutficient guides in the early stage of the disease, when it is most of all of importance to distinguish the one from the other.

If after a few days the breathing becomes a little more natural, the inspiration lengthened and regular, and the expiration, although still prolonged, is suffered to be completed-if the twitchings are less evident and less frequent-if the cough can be fully expressed-if the pulse softens, although it may not diminish in frequency, and if the animal begins to lie down, or walks about of his own accord, there is hope of recovery. But if the pulse quickens, and although smaller, yet possesses the wiry character of inflammation-if the gaze at the flanks, previously by starts, becomes fixed as well as anxious, and the difficulty of breatling contiunes (the difficulty of accomplishing it, althongh the efforts are oftener repeated)if patches of sweat break ont, and the auimal gets restless-paws-shifts his posture every minute -is unable longer to stand yet hesitates whether he sluall lie down-determines on it again and again, but fears, and at length drops, rather than lies gently down, a fatal termination is at hand. For some time before his death, the effusion and its extent will be evident enough. He not only walks unwillingly, but on the slightest exercise his pulse is strangely accelerated; the feeling of suffocation comes over him, and he stops all of a sudden, and looks wildly about and trembles; but he quickly recovers himself and proceeds. There is also, when the effusion is confirmed, œdema of some exterual part, and that occusionally to a very great extent. This is oftenest observed in the abdomen, the chest, and the point of the breast.

The immediate cause of death is effusion in the chest, compressing the lungs on erery side, rendering expiration difficult, and at length impossible, and destroying the animal by suffocation. The very commencement of effusion may be detected by auscultation. There will be the cessation of the respiratory murmur at the sternum, and the increased grating - not the crepitating, crackling woise as when congestion is going on-not the feebler murmr as congestion advances; hut the absence of it, beginning from the bottom of the chest.

It is painfully interesting to watch the progress 
of the effusion-how the stillness creeps up, and the murmur gets louder above, and the grating sound louder too, until at length there is no longer room for the lungs to play, and suffocation ensues.

The fluid contained in the chest varies in quantity as well as appearance and consisteuce. Many gallons have been found in the two sacs, pale, or yellow, or bloody, or often differing in the two sides of the thorax; occasionally a thick adventitious coat coveriug the costal or the pulmonary pleura-rarely much adhesion, but the lungs purple-coloured, flaccid, compressed, not one-fourth of their usual size, immersed in the fluid, and rendered incapable of expanding by its pressure.

Here, as in pneumonia, the bleeding should be prompt and copious. Next, and of great importance, aperient medicine should be administered -that, the effect of which is so desirable, but which we do not dare to give when the mucous membrane of the respiratory passages is the seat of disease. Here we have to do with a serous membrane, and there is less sympathy with the mucous membranes of either cavity. Small doses of aloes should be given with the usual ferer medicine, and repeated morning and night until the dung becomes pultaceous, when it will always he prudent to stop. The sedative medicine is that which has been recommended in pneumonia, and in the same doses. Next should follow a blister on the chests and sides. It is far preferable to setons, for it can be brought almost into contact with the inflamed surface, and extended over the whole of that surface. An airy, but a comfortable box, is likewise even more necessary than in pneumonia, and the practive of exposure, uncovered, to the cold even more absurd than destructive. The blood, repelled from the skin by the contractile, depressing influence of the cold, would rush with fatal impetus to the neighbouring membrane, to which it was before dangerously determined. Warm and comfortable clothing caunot be dispensed with in pleurisy.

The sedative medicines, however, should be omitted much sooner than in pneumonia, and succeeded by diuretics. The common turpentine is as good as any, made into a ball with liuseed meal, and given in doses of two or three drachms twice in the day. If the constitution is much impaired, tonics may be cantiously given, as soon as the violence of the disease is abated. The spirit of nitrous ether is a mild stimulant and a diuretic. Small quantities of gentian and ginger may be added, but the turpentine must not be omitted.

By auscultation and other modes of examination, the existence of effusion in the chest is perhaps ascertained, and, possibly, it is increasing. Is there any mechauical way of getting rid of it? There is one to which recourse should be had as soon as it is evident that there is considerable fluid in the chest. The operation of Paracentesis, or tapping, should be performed ; it is a very simple one. The side-line may be had reconrse to, or the twitch alone may be used. One of the horse's legs being held up, and, counting back from the sternum to between the seventh and eighth ribs, the surgeon should pass a moderate sized trochar into the chest immediately above the cartilages. He will not have selected the most dependent situation, but as near it as he could with safety select; for there would not have been room between the cartilages if the puncture had beeu lower; and these would have been injured in the forcing of the instrument between them, or, what is worse, there would have been great bazard of wounding the pericardium, for the apex of the heart rests on the sternum. Through this aperture, close to the cartilages, the far greater part of the fluid may be evacuated. The operator will now withdraw the stilette, and let the fluid run through the canula. $\mathrm{He}$ will not trouble himself afterwards about the wound; it will heal readily enongh; perhaps too quickly, for could it be kept open a few days, it might act as a very useful drain. It should be attempted early. Recourse should be had to the operation as soon as it is acertained that there is considerable fluid in the chest, for the animal will at least be relieved for a while, and some time will have been given for repose to the overlaboured lungs, and for the system genernlly to be recruited. The fluid will lie evacuated before the lungs are too much debilitated by laborious action against the pressure of the water, and a state of collapse brought on, from which they will be incapable of recovering. They only who have seen the collapsed and condensed state of the lung that had beeu long compressed by the fluid, can conceive of the extent to which this is carried. It should be added-a fact important and alarming-that the records of veterinary surgery contain very few cases of permavently successful perfurmance of the operation. This should not discourage the practitioner from attempting it, but should induce him to consider whether he may not perform it under happier auspices, before the lungs aud the serous membrane which lines the cavity have been too much disorganised, and the constitution itself sadly debilitated. There could not be any well-founded objection to an earlier resort to paracentesis, and he must be a bungler incleed who wouuded any important part.

It should be ascertained by auscultation whether there is fluid in loth cavities. If there should be, and in considerable quantity, it will not be prudent to operate on both sides at once. If much fluid is discharged there will be acceleration and difficulty of respiration to a very great degree. The practitioner must not be alarmed at this; it will pass orer, and on the next day he may 
attack the other side; or open both at once, if there is but little fluid in either.

Having resorted to this operation, a course of diuretics with tonics should be immediately commenced, and the absorbents roused to action before the cavity fills again.

There is in pleurisy a far greater tendency to relapse than in pneumonia. The lungs do not perfectly recover from their state of collapse, nor the serous membrane from its long maceration in the effused fluid: œdema, cough, disinclination to work, incapability of rapid progression, colicky pains - as the unobservant practitioner would call them-but in truth pleuritic stitches; these are the frequent sequelæ of pleurisy. This will afford another reason why the important operation of paracentesis should not be deferred too long.

There is much greater disposition to metastasis than in pneumonia: indeed it is easy to imagine that the inflammation of a mere membrane may more readily and oftener shift than that of the substance of so large a viscus as the lungs. The inflammation shifting its first ground, attacks almost every part indiscriminately, and appears under a strangely puzzling variety of forms. Dropsy is the most frequent ehange. Effusion in the abdomen is substituted for that of the chest, or rather the exhalent or absorbent vessels of the abdomen, or both of them, soon sympathise in the debility of those of the thorax.

\section{CHAPTER XIII.}

THE ABDOMEN AND ITS CONTENTS.

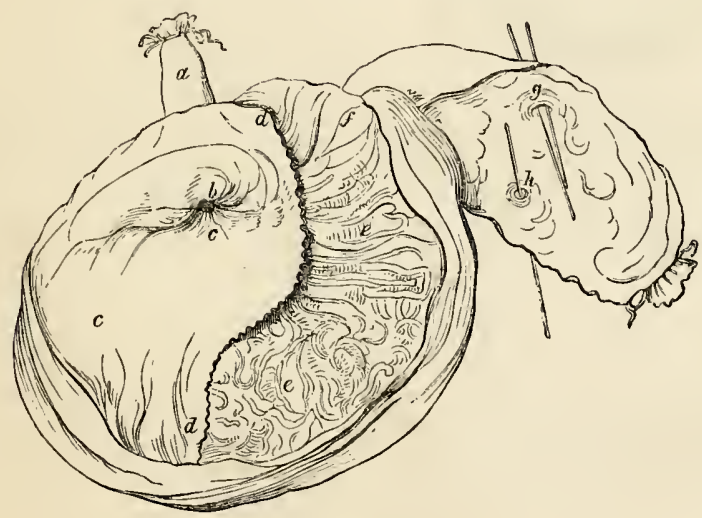

THE УTOMACH.

a The cesophagus or gullet, extending to the stomach.

$b$ The entrance of the gullet into the stomach. The circular layers of the muscles are very thick and strong, and which, by their contractions, help to render it difficult for the food to be returned or vomited.

c The portion of the stomacl which is covered by cuticle, or insensible skin.

$d d$ The margin, which separates the cnticular from the villous portion.

The œsophagus, as has already been stated, consists of a muscular membranous tube, extending from the posterior part of the mouth down the left side of the neck, pursuing its course through the chest, penetrating through the crura of the diaphragm, and reaching to and terminating in e e The mucous, or villous (relrct) portion of the stomach, in which the food is principally digested.

$f$ The communication between the stomach und the first intes tine.

$g$ The common orifice through which the hile and the secretion from the pancrens pass into the first intestine. The two pins mark the two tubes here united.

$h$ A smaller orifice, through which a portion of the secretion of the pancreas cnters the intestines.

the stomach. It does not, however, enter straight into the stomach, and with a large open orifice; but there is an admirable provision made to prevent the regurgitation of the food when the stomach is filled and the horse suddenly called upon to perform unusually hard work. The vol. $\mathrm{r}$. 
œsophagus enters the stomach in a somewhat curved direction-it runs obliquely through the muscular and cuticular coats for some distance, and then its fibres arrange thernselves around the opening into the stomach. Close observation has shown, that they form themselves into segments of circles, interlacing each other, and by their contraction plainly and forcibly closing the opening, so that the regurgitation of the food is almost impossible.

The following is a simple but accurate delineation of the structure of the termination of the œso-

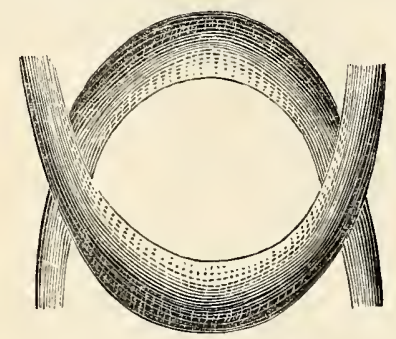

phagus, and the manner in which it encircles the orifice of the stomach. We are indebted to Mr. Ferguson, of Dublin, for this interesting discovery.

A microscope of very feeble power will beautifully show this singular construction. It is not precisely either a sphincter muscle or a valve, but $i$ is a strong and almost insuperable obstacle to the regurgitation of the food. The left side of the stomech is in contact with the diaphragm. It is pressed upon by every motion of the diaphragm, and hence the reason why the stomach is so small compared with the size of the animal. It is indeed strangely small, in order that it might not press too hardly upon the diaphragm, or painfully interfere with the process of respiration, when the ntmost energies of the horse are occasionally taxed immediately after he has been fed.

At the lower or pyloric orifice, the mnscles are also increased in number and in size. These are arranged in the same manner, with sufficient power to resist the pressure of the diaphragm, and retain the contents of the stomach until they have undergone the digestive process.

The situation of the stomach will at once explain the reason why a horse is so much distressed, and sometimes irreparably injured, if worked hard immediately after a full meal. The stomach must be displaced and driven back by every contraction of the diaphragm or act of inspiration; and in proportion to the fulness of the stomach will be the weight to be overcome, and the labour of the diaphragm, and the exhaustion of the animal. If the stomach is much distended, it may be too weighty to be forced sufficiently far back to make room for the quantity of air which the animal in a state of exertion requires. Hence the frequency and labour of the breathing, and the quickness with which such a horse is blown, or possibly destroyed. Hence also the folly of giving too full a meal, or too much water, before the horse starts on a journey or for the chase ; and, in like manner, the absurdity and danger of that unpardonable custom of some grooms to gallop the horse after his drink, in order to warm it in his belly, and prevent gripes.

The horse was destined to be the servant of man, and to be always at his call whether fasting or full: it would seem, therefore, that to lessen much inconvenience or danger, a smaller stomach, in proportion to his size, is given to the horse than to almost any other animal. The bulk of the horse, and the services required of him, demand much nutriment, and that of such a nature as to occupy a very considerable space; yet his stomach, compared with his bulk, is not half so large as that of the human being: therefore, although he, like every other animal, feels inconvenience from great exertion immediately after a full meal, he suffers not so much as other quadrupeds, for his stomach is small, and his food passes rapidly through it, and descends to a part of the intestines distant from the diaphragm, and where the existence and pressure of the food cannot cause him any annoyance.

The stomach has four coats. The outermost is the lining of the cavity of the belly, and the common covering of all the intestines-that by which they are confined in their respective situations, and from which the fluid is secreted that prevents all friction between them. This is called the peritoneum-that which stretches round the inside of the stomach.

The second is the muscular coat, consisting of two layers of fibres, one running lengthways, and the other circularly, and by means of which a con. stant gentle motion is communicated to the stomach, mingling the food more intimately together, and preparing it for digestion, and by the pressure of which the food when properly prepared is urged on into the intestines.

The third, or cuticular (skin-like) coat, $c$, covers but a portion of the inside of the stomach. It is a continuation of the lining of the gullet. There are numerous glands on it, which secrete a mucous fluid; and it is probably intended to be a reservoir in which a portion of the food is retained for a while, and softened and better prepared for the action of the other or true digestive portion of the stomach. The cuticular coat occupies nearly onehalf of the inside of the stomach.

The fourth coat is the mucous or villous (relvet) coat, $e$, where the work of digestion properly commences. The mouths of numerous little vessels 
open upon it, pouring out a peculiar fluid, the gastric (stomach) juice, which mixes with the food already softened, aud converts it into a fluid called chyme. As this is formed, it passes out of the other orifice of the stomach, the pylorus (doorkeepers), $f$, and enters the first small intestine; the harder and undissolved parts being turned back to undergo farther action.

Every portion of the muscnlar coat has the power of successively contracting and relaxing, and thus, in the language of Dr. Bostock, "the successive contraction of each part of the stomach. by producing a series of folds and wrinkles, serves to agitate the alimeutary mass, and, by bringing every part of it in its turn to the surface, to expose it to the influence of the gastric juice, while at the same time the whole of the contents are gradually propelled forwards, from the oritice which is connected with the æesophagus to that by which they are discharged."

The cerebro-visceral nerve is the agent in producing these altcrnate contractions and relaxations. It is the motor nerve belonging to these parts. It has to keep the parietes of the stomach in contact with the food, and the food in contact with the gastric juice. It has to bring the different parts of the food in successive contact with the stomach, and to propel them through this portion of the alimentary canal in order that they may be discharged into the duodenum.

A riscus thus situated and thus employed must occasionally be subject to inflammation, and various other lesions. The symptoms, however, are obscure and frequently mistaken. 'They resemble those of colic more than anything else, and should be met by bleeding, oleaginous purges, mashes, tepid gruel, and the application of the stomach-pump: but, when, in addition to the colicky pains, there appear indistinctness of the pulse-and a very characteristic symptom that is-pallidness of the membranes, coldness of the mouth, frequent lying down and in such position that the weight of the horse may rest on the chest, frequently pointing with his muzzle at the seat of pain, and especially, if these symptoms are accompanied or followed by vomiting, rupture of the stomach is plainly indicated. Considering the situation of the stomach, and the concussions and violence to which it is exposed from the diaphragm and from the riscera around it, this accident will not appear extraordinary. The horse does not necessarily die as soon as this accident occurs. In a case related by Mr. Rogers, the animal died in about four hours after the accident;* but in one that occurred in the practice of the author, three days elapsed between the probable rupture of the stomach, from a sudden

\footnotetext{
* The Farrier and Naturalist, vol. ii., p. 9.
}

and violent full, and the deatlı of the animal, and in which interval he sereral times ate a little food. The rupture was at the right extremity of the stomach, and there were several distinct layers of impacted food between it and the liver. The liver seemed to have acted as a kind of valve. The stomach was found still distended, the edges of the rupture having the dull and sodden appearance of an old wound. There was comparatively little fluid in the abdominal cavity, and no disposition to vomit occurred during any period. $\dagger$

A case showing the iusensibility of the stomach, wisely and kiudly given, considering the shocks and dangers to which this viscus is exposed, is recorded by Mr. Hayes. + A drench was ordered for a horse. For want of a horn, the stable-keeper made use of a wine-bottle, without examining whether it was clean or foul. Shortly afterwards it was discovered that the bottle had contained three or four ounces of liquid blister. This was kept a profound secret until the death of the animal, and that did not happen until twelve days afterwards. The horse had eaten his provender in the same manner as usual, and had performed his usual work until about two hours before his death, when he lay down, rolled about, bruised himself sadly, and died. The food, consisting of hay, oats, and beaus, was lodged and impacted between the folds of the intestines, and the whole abdominal viscera appeared as if they had been thus surrounded a considerable time before death. The stomach was ruptured in many directions, and almost decomposed. Its coats were nearly destroyed, and hung like rags about the orifice through which the food was received, and that through which it naturally was expelled. This account proves how little we are to depend upon any apparent symptoms as indicating the real state of the stomach in the horse.

Mr. Brown relates a case of polypus found in the stomach, and which had remained there unsuspected until it weighed nearly half a pound, it then became entangled in the pyloric orifice, and prevented the passage of the food, and destroyed the horse.\|

BoTs.

In the spring and early part of the summer, horses are much troubled by a grub or caterpillar, which crawls ont of the anus, fastens itself under the tail, and seems to cause a great deal of itching or uneasiness. Grooms are sometimes alarmed at the appearance of these insects. Their history is curious, and will dispel every fear with regard to them. We are indebted to Mr. Bracy Clark for almost all we know of the hot.

+ The Veterinary Medical Associalion, 1836-7, p. 100.
The Veterinarian, sol. x., p. 616.

II llid, vol. vii., p. 76 . 


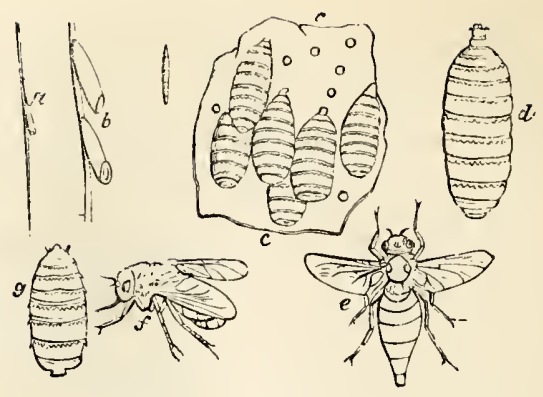

CUT OP THE BOT.

$a$ and $b$ The eggs of the gad-fly, adhering to the hair of the hor'se.

c The appearance of the bots on the stomach, firmly adhering by their hooked mouths. The marks or depressions are seen which are left on the coat of the stomach when the bots are detauhed from their bold.

A species of gad-fly, $e$, the cestrus equi, is in the latter part of the summer exceedingly busy about the horse. It is observed to be darting with great rapidity towards the knees and sides of the the animal. The females are depositing their eggs on the hair, and which adhere to it by means of a glutinous fluid with which they are surrounded ( $a$ and $b$ ). In a few days the eggs are ready to be hatched, and the slightest application of warmth and moisture will liberate the little animals which they contain. The horse in licking himself touches the egg; it bursts, and a small worm escapes, which adheres to the tongue, and is conveyed with the food into the stomach. There it clings to the cuticular portion of the stomach, $c$, by means of a hook on either side of its mouth; and its hold is so firm and so obstinate, that it must be broken before it can be detached. It remains there feeding on the mucus of the stomach during the whole of the winter, and until the end of the ensuing spring; when, having attained a considerable size, $d$, and being destined to undergo a certain transformation, it disengages itself from the euticular coat, is carried into the villous portion of the stomach with the food, passes out of it with the chyme, and is evacuated with the dung.

The larra or maggot seeks shelter in the ground, and buries itself there; it contracts in size, and becomes a chrysalis or grub, in which state it lies inactive for a few weeks, and then, bursting from its confinement, assumes the form of a tly. The female, becoming iupregnated, quickly deposits her eggs on those parts of the horse which he is most accustomed to lick, and thus the species is perpetuated.

There are several plain conclusions to be drawn $d$ The hot detached.

$e$ The female of the gad-fly, of the horse, prepared to deposit her eggs.

$f$ The gad-fly by which the red bots are produced.

$g$ The smaller, or red bot.

from this history. The bots cannot, while they inhabit the stomach of the horse, give the animal any pain, for they have fastened on the cuticular and insensible coat. They cannot stimulate the stomach, and increase its digestive power, for they are not on the digestive portion of the stomach. They cannot, by their roughness, assist the trituration or rubbing down of the food, for no such office is performed in that part of the stomach-the food is softened, not rubbed down. They cannot be injurious to the horse, for he enjoys the most perfect health when the cuticular part of his stoniach is filled with them, and their presence is not even suspected until they appear at the anus. They cannot be removed by medicine, because they are not in that part of the stomach to which medicine is usually conveyed; and if they were, their mouths are too deeply buried in the mucus for any medicine, that can safely be administered, to affect them; and, last of all, in due course of time they detach themselves, and come away. Therefore, the wise man will leave them to themselves, or content himself with picking them off when they collect under the tail and annoy the animal. found.

The smaller bot, $f$ and $g$, is not so frequently

Of inflammation of the stomach of the horse, except from poisonous herbs or drugs, we know little. It rarely occurs. It can with difficulty be distinguished from inflammation of the bowels; and, in either case, the assistance of the veterinary surgeon is required.

Few horses are destroyed by poisonous plants in our meadows. Natural instinct teaches the animal to avoid the greater part of those that would be injurious 
We cannot do better than abbreviate the list of poisonous agents, and the means of averting their fatal influence, given by Mr. Morton, the Professor of Chemistry and Materia Medica at the Royal Veterinary College.* Jt will occasionally be exceedingly useful to the proprietor of horses.

$\mathrm{He}$ begins with the Animal Poisons. The bite of the viper has been occasionally fatal to dogs and sheep. A horse was brought to the Veterinary College that had been bitten in the hind leg while hunting. There was considerable swelling, and the place of the bite was evident enough. Mr. Armstrong mentions a case in which a horse, bitten by a viper, sunk into a kind of coma, from which he could not be roused. The antidote, which seldom or never fails, is an alkaline solution of almost any kind, taken internally and applied externally. There is no chemical effect on the circulation, but the alkali acts as a powerful counterirritant. In very had cases opium may be added to the alkaline solution.

Hornets, Wasps, \&c.-These are spoken of, because there are records of horses being attacked by a swarm of them, and destroyed. The spirit of turpentine is the best external application, and, if given in not undue quantities and guarded by an admixture with oil, may be useful.

Cantharides constitute a useful drug in some few cases. It is one of the applications used in order to excite the process of blistering. It was occasionally employed as a mediciue in small quantities, and, combined with vegetable tonics, it has been given in small doses, for the cure of glanders, farcy, and nasal gleet. It is valuable in cases of general and extreme debility. It is a useful general stimulant when judiciously applied : but it must be given in small doses, and never except under the direction of a skilful practitioner. A drachm of the powdered fly would destroy almost any horse. In the breeding season it is too often shamefully given as an excitant to the horse and the mare, and many a valuable animal has been destroyed by this abominable practice. It is usually given in the form of ball, in which case it may be detected by the appearance of small glittering portions of the fly, which are separated on the inner side of the dung-ball in bot water. If the accidental or too powerful administration of it is suspected, recourse should be had to bleeding, purging, and plentiful drenching with oily and demulcent fluids.

The leaves of the Yew are said to be dangerous to the horse, as well as to many other animals. "Two horses that had been employed in carrying fodder, were thoughtlessly placed under a large yew-tree, which they cropped with eagerness. In three hours they began to stagger-both of them

- Veterinary Medical Association, 1836.7, p. 41. dropped, and, before the larness could be taken off, they were dead. A great quantity of yew leaves were found in the stomachs, which were contracted and inflamed." + Mr. IV. C. Spooner mentions a case of violent suspicion of the poisoning of an ass and a mare in the same way. $\downarrow$ On the other hand, Professor Sewell says that on the farm on which he resided in his early years, the horses and cattle had every opportunity of eating yew. They pastured and slept under the shelter of yew-trees, and were often observed to browse on the branches. $\|$ He thinks that these supposed cases of poisoning have taken place only when enormous quantities of the yew have been eaten, and that it was more acute indigestion than poisoning. There are, however, too mauy cases of horses dying after feeding on the yew to render it safe to cultivate it in the neighbourhood of a farm, either in the form of tree or hedge.

The Hydrocyanic or Prussic Acid belongs to the class of vegetable poisons, but it is scarcely possible for the horse to be accidentally injured or destroyed by it. Ten grains of the farina of the croton nut should be given as soon as the poison is suspected, and the patient should be drenched largely with equal parts of vinegar and thin gruel, and the croton repeated after the lapse of six hours, if it has not previously operated.

The JVater Dropiort (Enanthe fistulosa), common in ditches and marshy places, is generally refused by horses; but brood mares, with appetite somewhat vitiated by their being in foal, have been destroyed by it. The antidote would be vinegar and gruel, and bleeding if there is inflammation.

The Water Parsley (Ethusa Cynapium) deserves not all the bad reputation it has acquired; although, when eaten in too great quantities, it has produced palsy iu the horse, which has licen strangely attributed to a harmless beetle that inhabits the stem.

Of the Common Hemlock (Conium maculatum), and the Water Hemlock (CEnanthe crocata), the anthor knows no barm, as far as the horse is concerned. He has repeatedly seen him eat the latter without any bad effect; but cows have been poisoned by it.

The Euphorbium, or Spurge, so common and infamons an ingredient in the Farrier's Blister, has destroyed many a horse from the irritation which it has set up, and the torture it has occasioned, and shonld never find a place in the Veterinary Pharmacopœia.

Colocynth and Elaterium fairly rank among the substances that are poisonous to the horse

\footnotetext{
+ Loudon's Magazine of Nat. Hist., vol, viii, p. 81 .

† Veterinarian, vol. x. p. 685 .

it Abstract of the Vet. Med. Association, vol. i p. 62 .
} 
and so loes the Bryony Root (Bryonia dioica), notwithstanding that it is frequently given to horses, in many parts of the country, as a great promoter of condition. Many a roung horse has heen brought into a state of artificial condition and excitement by the use of the Bryony. It is one of the abominable secrets of the horse-breaker. This state of excitation, however, soon passes away, and is succeeded by temporary or permanent diminution of vital power. We have occasionally traced much mischief to this infamous practice.

Not lessinjurious is the Savin (Juniperus Sabina). It is well known as a vermifuge in the human subject, and it is occasionally given to the horse for the same purpose; but it is a favourite with the carter and the groom as a promoter of condition. A very great proportion of farmers' servants regard it as a drug effecting some good purpose, although they can scarcely define what that purpose is; and there is scarcely a country stable in which it is not occasionally found, and in which the horse is not endangered or perhaps destroyed by its use. It is high time that the horse-master looked more carefully to this, and suffered no drug to be administered to his horses and cattle, except by his direction or that of the medical attendant. The farmer and the gentleman can scarcely conceive to what an abominable extent this rile practice prevails. The presence of savine will be best detected in the stomach of a horse that has died under suspicious circumstances, by the black-currant-leaf smell of the contents when boiled in a little water, or beaten in a mortar.

The Common Brake (Pteris aquilina) and the Stone Fern (Pteris crispa) are violent and dangerous diuretics, and, on account of their possessing this property, are probably favourites with the horse-keeper and the groom. The diuretic influence is usually evident enough, but not the injurious effect which it has on the lining membrane of the bladder, and the predisposition to inflammation which it excites in the urinary organs. This has been too much underrated, even by those who have inquired into the subject. If the cuticular coat of the stomach is found not merely in a state of great inflammation, but will readily peel or wash off, it must necessarily he a dangerous medicament, and should be banished entirely from the stable.*

Of the mineral poisons it will be necessary to mention only two. Arsenic was once in great repute as a tonic and vermifuge. Doses sufficient to kill three or four men were daily administered, and generally with impunity. In some cases, however, the dose was too powerful, and the animal was destroyed. Two of the pupils of the author

* Ste an account of some experiments on these substances, by Mr. Cupiss, in the eariy numbers of "The Sportsman." were attending the patients of a veterinary surgeon who was confined in consequence of a serious accident. Among them was a valuable horse labouring under inflammation of the lungs. The disease was subdued, and the patient was convalescent. At this period our friend began to regain sufficient strength to travel a short distance. The first patient that he visited was this horse, whose ailments had all passed away. He could not, however, let well alone, but sent some arsenic balls. In less than a week this noble animal was taken to the knacker's. There are far better vermifuges and tonics than this dangerous drug, which will probably soon be discarded from veterinary practice.

Corrosive Sublimate is given internally, and occasionally with advantage, in farcy, and, as an external application, it is nsed to destroy vermin, to cure mange, and to dispose deep and fistulous ulcers to heal.

It may, however, be given in too large a dose, the symptoms of which are loss of appetite, discharge of saliva from the mouth, pawing, looking eagerly at the flanks, rolling, profuse perspiration, thready pulse, rapid weakness, violent purging and straining, convulsions, and death.

The stomach will be found intensely inflamed, with patches of yet greater inflammation. The whole course of the intestines will be inflamed, with particular parts black and gangrenous.

The antidote, if it is not too late to administer it, would be-for arsenic, lime-water, or chalk and water, or soap and water, given in great quantities by means of the stomach-pump ; and for corrosive sublimate, the white of eggs mixed with water, or thick starch, or arrow-root.

Is there really occasion for the owner of horses to be acquainted with these things? Long experience has taught the author that poisoning with these drugs is not so rare a circumstance as some imagine. In the farmer's stable he has occasionally been compelled unwillingly to decide that the death of one or more horses has been attributable to arsenic or corrosive sublimate, and not to any peculiar disease, or to anything wrong in the manner of feeding. A scoundrel was executed in 1812 for administering arsenic and corrosive sublimate to several horses. He had been engaged in these enormities during four long years. The discarded or offended carter has wreaked his revenge in a similar way; but, oftener, in his eagerness to get a more glossy coat on his horses than a rival servaut could exhibit, he has tampered with these dangerous drigs.

The owner may easily detect this. "Arsenic, if mixed with charcoal and heated, emits a very perceptible smell of garlic. Sulphuretted hydrogen, added to a watery solution of arsenic, throws down a yellow precipitate-lime-water a white 
one-and the ammoniaco-sulphate of copper a green one."*

The following are the tests of corrosive sublimate:- "It is sublimed by heat, leaving no residuum, and is soluble in water, alcohol, and sulphuric ether. Lime-water gives either a lemonyellow precipitate, or a brick-dust red one. The iodide of potash occasions a scarlet precipitate. The most curious test is, however, by means of galvanism. A drop of the suspected solution is placed on a sovereign, and a small key being brought into contact simultaneously with both the gold and the solution, an electric current is produced which decomposes the bichloride of mercury, for such it is. The chlorine unites with the iron, and the mercury with the gold." $\neq$

\section{THE INTESTINES.}

The food having been partially digested in the stomach, and converted into chyme, passes through the pyloric orifice into the intestiues.

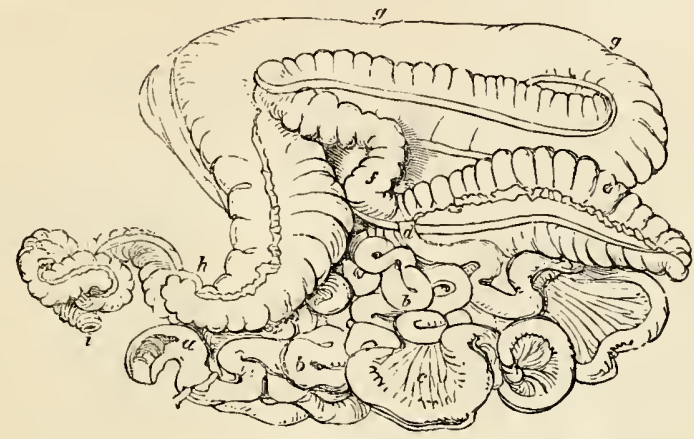

CUT OF THE INTESTINEB.

a The commencement of the small intestines. The ducts which convey the bile and the secretion from the pancreas are seen enteriag a little below.

$b$ b The convolutions or winding of the small intestines.

c A portion of the mesentery.

$d$ The small intestines, terminating in the cæcum.

The intestines of a full-grown horse are not less than ninety feet in length. The length of the bowels in different animals depends on the nature of the food. The nutritive matter is with much more difficulty extracted from vegetable than animal substances; therefore the alimentary canal is large, long, and complicated in those which, like the horse, are priucipally or entirely fed on corn or herbs. They are divided into the small and large intestines; the former of which occupy about sixty-six feet, and the latter twentyfour.

The intestines, like the stomach, are composed of three coats.

The outer one consists of the peritoneum-that membrane which has been already described as investing the contents of the abdomen. By means of this coat, the intestines are confined in their

* Manual of Pharmacy, by Professor Morton, Lecturer on Veterinary Medicine at the St. Pancras Veterinary College, p. 42. e The cæcum, or blind gut, with the bands running along it, puckering and dividing it into numerous cells.

$f$ The beginaing of the colon.

$g$ The continuation and expansion of the colon, divided, like the cæcum, into cells.

$h$ The termination of the colon in the rectum.

$i$ The termination of the rectum at the anus.

proper situations; and, this membrane being smooth and moist, all friction and concussion are prevented. Did the bowels float loosely in the abdomen, they would be subject to constant en. tanglement and injury amid the rapid and violent motions of the horse.

The middle coat, like that of the stomach, is muscular, and composed of two layers of fibres, one running longitudinally and the other circularly ; and by means of these muscles, which are continually contracting and relaxing in a direction from the upper part of the intestines to the lower, the food is propelled along the borrels.

The inner coat is the mucous or villous one. It abounds with innumerable small glands, which secrete a mucous fluid to lubricate the passage and defend it from irritating or acrimonious substauces; and it is said to be villous from its soft velvet-like feeling. This coat is crowded with in 
numerable minute orifices that are the commencement of ressels by which the uutritive part of the food is taken up; and these vessels, uniting and passing over the mesentery, carry this nutritive matter to a proper receptacle for it, whence it is conveyed into the circulation, and distributed to every part.

The intestines are chiefly retained in their relative positions by the mesentery, $c$ (middle of the intestines), which is a doubling of the peritoneum, including each intestine in its folds, and also inclosing in its duplicatures the arteries, the reins, the nerves, and the vessels which convey the nutriment from the intestines to the circulation.

The first of the small intestines, and commeucing from the right extremity of the stomach, is the duodenum, a, a very improper name for it in the horse, for in that animal it is nearly two feet in length. It is the largest and shortest of all the small intestines. It receives the food partially converted into chyme by the digestive potwer of the stomach,* and in which it undergoes another and very important change ; a portion of it being converted into chyle. It is here mixed with the bile and the secretion from the pancreas, which enter this intestine about five inches from its commencement. The bile seems to be the principal agent in this change, for no sooner does it mingle with the chyme than that fluid begins to be separated into two distinet ingredients - a white thick liquid termed chyle and containing the nutritive part of the food, and a yellow pulpy substance, the innutritive portion, which, when the chyle is all pressed from it, is evacuated through the rectum.

The next portion of the small intestines is the jejunum, so called because it is generally found to be empty. It is smaller in bulk and paler in colour than the duodenum. It is more loosely confined in the abdomen-floating comparatively unattached in the cavity of the abdomen, and the passage of the food being comparatively rapid through it.

There is no separation or distinction between it and the next intestine-the ileum. There is no point at which the jejurium can he said to terminate and the ileum commence. Together they form that portion of the intestinal tube which floats in the umbilical region : the latter, however, is said to occupy three-fifths, and the former two-fifths, of this portion of the intestines, and the five would contain about eleven gallons of fluid. The ileum is evidently less vascular than the jejunum, and

* The conversion of food into ehyme is very imperfcctly performed in the stomach of the horse, on account of the smalluess of that viscus, and the portion of it which is occupied by cuticle: therefore, he needs in the upper, part of the duodenum a kind of second stomach, to mix up and dissolve the food. 'That apparatus is evident enough until we arrive at the pancreatic and biliary orifices. gradually diminishes in size as it approaches the larger intestines.

These two intestines are attached to the spine by a loose doubling of the peritoneum, and float freely in the abdominal cavity, their movements and their relative positions being regulated only by the size or fulness of the stomach, and the stage of the digestive process.t

The small intestines derive their blood from the anterior mesenteric artery, which divides into innumerable minute branches that ramify between their muscular and villous coats. Their veius, which are destitute of valves, return the blood into the vena cava. The prime agent in producing all these effects is the cerebro visceral nerve. +

The large intestines are three in number:the cocum, the colon, and the rectum. The first

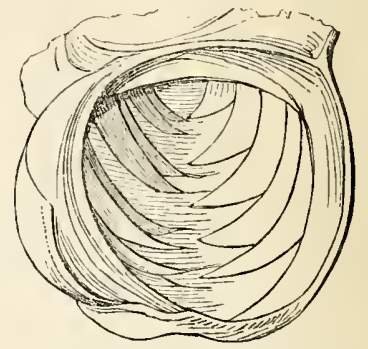

of them is the cacum (blind gut), $c, p$-it has but one opening into it, and consequently everything that passes into it, having reached the blind or closed end, must return, in order to escape. It is not a continuation of the ileum, but the ileum pierces the head of it, as it were, at right angles $(d, p)$, and projects some way into it, and has a valve-the valrula coli-at its extremity, so that what has traversed the ileum, and entered the head of the colon, cannot return into the ileum. Along the outside of the cæcum run three strong bands, each of them shorter than that intestine, and thus puckering it up, and forming it into three sets of cells, as shown in the above cut.

That portion of the food which has not been taken up by the lacteals or absorbent vessels of the small intestines, passes through this valvular opening of the ileum, and a part of it enters the colon, while the remainder flows into the cæcum. Then, from this being a blind pouch, and from the cellular structure of this pouch, the food must be detained in it a very long time; and in order that, during this detention, all the nutriment may be extracted, the cæcum and its cells are largely sup-

+ Percivall's Anatomy of the Horse, p. 256.

$\$$ Youatt s Lectures on the Nervous System, Veterinarian, vol. vii, p. 351. 
plied with blood vessels and absorbcnts. It is principally the fluid part of the food that seems to enter the cæcum. A horse will drink at one time a great deal more than his stomach will contain; or eren if he drinks a less quantity, it remains not in the stomach or small intestines, but passes on to the creum, and there is retained, as in a reservoir, to supply the wants of the system. In his state of servitude the horse does not often drimk more than twice or thrice in a day, and the food of the stabled horse being chiefly dry, this water stomach is most useful to him. The cacum will hold four gallons.

The colon is an intestine of exceedingly large dimensions, and is capable of containing no less than twelve gallons of liquid or pulpy food. At its union with the crecum and the ileum, although larger than the latter intestine $(f)$, it is of comparatively small bulk; but it soon swells out to an enormous extent. It has likewise, in the greater part of its course, three bands like the cxcum, which also divide it, internally, into the same description of cells. The intention of this is evident, - to retard the progress of the food, and to give a more extensive surface on which the vessels of the lacteals may open; and therefore, in the colon, all the chyle is finally separated and taken up. When this is nearly accomplished, the construction of the colon is somewhat changed: we find but two bands towards the rectum, and these not puckering the intestime so much, or forming such numerous or deep cells. The food does not require to be much longer detained, and the mechanism for detaining it is gradually disappearing. The blood-ressels and absorbents are likewise rapidly diminishing. The colon, also, once more contracts in size, and the chyle having been all absorbed, the remaining mass, being of a harder consistence, is moulded into pellets or balls in its passage through these shallower cells.

At the termination of the colon, the rectum (straight gut) commences. It is smaller in circumference and capacity than the colon, although it will contain at least three gallons of water. It serves as a reservoir for the dung until it is evacuated. It has none of these bands, because, all the nutriment being extracted, the passage of the excrement that remains should be hastened and not retarded. The fæces descend to the rectum, which somewhat enlarges to receive them; and when they have accumulated to a certain extent, the animal, by the aid of the diaphragm and the muscles of the belly, presses upon them, and they are evacuated. A curious circular muscle, and always in action, called the sphincter (constrictor muscle), is placed at the anus, to prevent the constant and unpleasant dropping of the freces, and to retain them until the horse is disposed roluntarily to expel them. This is effected by the efforts of the animal, assisted by the muscular coat of the recum, which is stronger than that of any of the other intestines, and aided by the compression of the interual oblique and transverse muscles.

The larger intestines derive their blood from the posterior mesenteric artery. Their veins terminate in the rena portæ.

\section{THE LIVFR.}

Between the stomach and the diaphragm-its right lobe or division in contact with the diaphragm, the duodenum and the right kidney, and the middle and left divisions with the stomach-is the liver. It is an irregularly-shaped, reddish-brown substance, of considerable bulk, and performs a very singular and important office.

It has been already stated (p. 341) that the blood, which has been conveyed to the different parts of the body by the arteries, is brought back to the heart by the veins; but that which is returned from the stomach and intestines and spleen and pancreas and mesentery, instead of flowing directly to the heart, passes first through the liver. It enters ly two large vessels that spread by means of innumerable minute branches through every part of the liver. As the blood traverses this organ, a fluid is separated from it, called the bile. It is probably a kind of excrement, the continuance of which in the blood would be injurious; but, while it is thrown off, another important purpose is answered-the process of digestion is promoted, by the bile changing the nutritive portion of the food from chyme into chyle, and separating it from that which, containing little or no nutriment, is roided as excrement.

Almost every part of it is closely invested by the peritoneum, which seems to discharge the office of a capsule to this viscus. Its arteries are very small, considering the bulk of the liver; but their place is curiously supplied by a vein-the rena porta-a ressel formed by the nnion of the splenic and mesenteric veins, and which seems, if it does not quite usurp the office and discharge the duty of the artery, to be far more concerned than it in the secretion of the bile. There is a free intercourse between the ressels of the two.

There are, scattered through the substance of the liver, numerous little granules, called acini, from their resemblance to the small stones of certain berries. They are united together by a fine cellular web, whose intimate structure has never yet been satisfactorily explained. From the blood which enters the liver there is a constant secretion of a yellow bitter fluid, called bile. The separation of the bile from the blood probably takes place within the acini; the secreting ressels are the penicelli, or those which compose this fine cellular web, and the fluid-the bile-is taken up by the pori biliarii, small vessels, from which a yellowish 
fluid is seen exuding into whatever part of the liver we cut, and is carried by them into the main vessel, the hepatic duct.

The bile, thus formed, is in most animals received into a reservoir, the gall-bladder, whence it is conveyed into the duodenum $(g, p .389)$ at the times, and in the quantities, which the purposes of digestion require; but the horse has no gallbladder, and, consequently, the bile flows into the intestine as rapidly as it is separated from the blood. The reason of this is plain. A small stomach was given to the horse in order that the food might quickly pass out of it, and the diaphragm and the lungs might not be injuriously pressed upon, when we require his utmost speed; and also that we might use him with little danger compared with that which would attach to other animals, even when his stomach is distended with food. Then the stomaoh, so small, and so speedily emptied, must be oftener replenished; the horse must be oftener eating, and food oftener or almost continuously passing out of his stomach. How admirably does this comport with the uninterrupted supply of bile!

\section{THE PANCREAS.}

In the domestic animals which are used for food, this organ is called the sueet-bread. It lies between the stomach and left kidney. It much resembles in structure the salivary glands in the neighbourhood of the mouth, and the fluid which it secretes has been erroneously supposed to resemble the saliva in its properties. The pancreatic fluid is carried into the intestines by a duct which enters at the same aperture with that from the liver. It contains a large proportion of albumen, caseous matter, and a little free acid. Its use, whether to dilute the bile or the chyme, or to assist in the separation of the chyme from the feculent matter, has never been ascertained : it is, however, clearly employed in aiding the process of digestion.

\section{THE SPLEEN.}

This organ, often called the melt, is a long, bluish-brown substance, broad and thick at one end, and taperiug at the other; lying along the left side of the stomach, and between it and the short ribs. It is of a spongy nature, divided into numerous little cells not unlike a honeycomb, and over which thousands of minute vessels thickly spread. The particular use of this organ has never been clearly ascertained, for in some cruel experiments it has been removed, without apparent injury to digestion or any other function. It is, however, useful, at least occasionally, or it would not have been given to the animal. It is perhaps a reservoir or receptacle for any fluid that may be conveyed into the stomach beyond that which is sufficient for the purposes of digestion.

\section{THE OMENTUN,}

Or cawl, is a doubling of the peritoneum, or rather consists of four layers of it. It has been supposed to have been placed between the intestines and the walls of the belly, in order to prevent concussion and injury during the rapid movement of the animal. That, however, cannot be its principal use in the horse, from whom the most rapid movements are required ; for in him it is unusually short, extending only to the pancreas and a small portion of the colon. Being, however, thus short, the horse is exempt from a very troublesome and, occasionally, fatal species of rupture, when a portion of the omentum penetrates through some accidental opening in the covering of the belly.

The structure of the urinary organs and the diseases to which they are exposed will be hereafter considered.

\section{CHAPTER XIV.}

\section{THE DISEASES OF THE INTESTINES.}

THese form a very important and mysterious class of ailments. They will be considered in the order in which the various contents of the abdomen have been described.

\section{THE DUODENCM.}

This intestine is subject to many more diseases than are included in the present imperfect veterinary nosology. The passage of the food through it has been impeded by stricture. A singular case is related by Mr. Tombs:- "An aged horse was taken suddenly ill. He lay down, rolled upon his back, and perspired profusely, with a pulse quick and hard; presently he became sick, and the contents of the stomach were voided through the mouth and nostrils. Blood-letting, purgatives, fomentations, dc. were resorted to, but in sixteen hours after the first attack the horse died. The stomach was distended with food, and there was a complete stricture of the dnodenum, three inches posterior to the entrance of the hepatic duct. The portion of the intestine anterior to the stricture was distended and in a gangrenous state."*

$$
\text { - Veturinarian, vol. viii. p. } 329 .
$$


Mr. Dickens records a somewhat similar case. "A horse was attacked by apparent colic. Proper treatment was adopted, and he got seemingly well. Nine days afterwards the apparent colic returned. He threw himself down, rolled upon his back, beating his chest with his fore feet, or sitting upon his haunches like a dog. All possible remedial measures were adopted, but he died thirty-six hours after the second attack. At the distance of ten inches from the stomach was a stricture which would scarcely admit of the passage of a tobaccopipe, and about which were marks of mechanical injury, as if from a nail or other hard substance. The anterior portion of the intestines was strangely distended." "*

It has been perforated by bots. Mr. Brewer describes a case, the symptoms of which were similar to those already related. "On examining the patient after death, the intestines were found to be altogether free from disease, except a portion of the duodenum, which was perforated by bots, several of which had escaped into the abdomen. Around the aperture the duodenum was in a gangrenous state." $†$

The diseases of the jejunum and the ileum consist either of spasmodic affection or inflammation.

\section{SPASMODIC COLIC.}

The passage of the food through the intestinal canal is effected by the alternate contraction and relaxation of the muscular coat of the intestines. When that action is simply increased through the whole of the canal, the food passes more rapidly, and purging is produced; but the muscles of every part of the frame are liable to irregular and spasmodic action, and the muscular coat of some portion of the intestines may be thus affected. The spasm may be confined to a very small part of the canal. The gut has been found, after death, strangely contracted in varions places, but the contraction not exceeding five or six inches in any of them. In the horse, the ileum is the usual seat of this disease. It is of much importance to distinguish between spasmodic colic and inflammation of the bowels, for the symptoms have considerable resemblance, although the mode of treatment should be very different.

The attack of colic is usually very sudden. There is often not the slightest warning. The horse begins to shift his posture, look round at his flanks, paw riolently, strike his belly with his feet, and crouch in a peculiar manner, advancing his hind limbs under him; he will then suddenly lie, or rather fall down, and balance himself upon his back, with his feet resting on his belly. The pain now seems to cease for a little while, and he gets

- Veterinarian, vol. x. p. 553.

+ Ibid, vol. v. p. 493. up, and shakes himself, and begins to feed; the respite, however, is but short-the spasm returns more violently-every indication of pain is increased-he heaves at the flanks, breaks out into a profuse perspiration, and throws himself more recklessly about. In the space of an hour or two, either the spasms begin to relax, and the remissions are of longer duration, or the torture is augmented at every paroxysm; the intervals of ease are fewer and less marked, and inflammation and death supervene. The pulse is but little affected at the commencement, but it soon becomes frequent and contracted, and at length is scarcely tangible.

It will presently be seen that many of the symptoms very closely resemble those of inflam. mation of the mucous membrane of the bowels : it may therefore be useful to point out the leading distinctions between them.

Strdden in its attack. colic.

Pulse rarely much quickened in the early perind of the disease and during the intervals of ease; hut evidently fuller.

Legs and ears of the natural temperature.

Relief obtained frum rubbing the belly.

Relief obtained from motion.

Intervals of rest.

Strength scarcely affected. INFLAMMATION OF THE BOWELS.

Gradual in its approach, with previnus indications of fever. elt.

Pulse very mileh quickened, but sms!l, and often scarcely to be

Legs and ears cold.

Belly cxceedingly tender and painful to the touch.

Motion evidently increasing the pain

Constant pain

Rapid and great reakness.

Among the causes of colic are, the drinking of cold water when the horse is heated. There is not a surer origin of violent spasm than this. Hard water is very apt to produce this effect. Colic will sometimes follow the exposure of a horse to the cold air, or a cold wind after strong exercise. Green meat, although, generally speaking, most beneficial to the horse, yet, given in too large a quantity, or wheu he is hot, will frequently produce gripes. Doses of aloes, both large and small, are not unfrequent causes of colic. In some horses there seems to be a constitutional predisposition to colic. They cannot be hardly worked, or exposed to unusual cold, without a fit of it. In many cases, when these horses have died, calculi have been found in some part of the alimentary canal. Habitual costiveness and the presence of calculi are frequent canses of spasmodic colic. The seat of colic is occasionally the duodenum, but oftener the ileum or the jejunum; sometimes, however, both the cxcum and colon are affected.

Fortunately, we are acquainted with several medicines that allay these spasms; and the disease often ceases almost as suddenly as it appeared. Turpentine is one of the most powerful remedies, especially in union with opium, and in good warm ale. The account that has just been given of the 
cæcum will not be forgotten here. A solution of aloes will be advantageously added to the turpentine and opium.

If relief is not obtained in half an hour, it will be prudent to bleed, for the continnance of riolent spasm may produce inflammation. Some practitioners bleed at first, and it is far from bad practice; for although the majority of cases will yield to turpentine, opium, and alves, an early bleeding may occasionally prevent the recurrence of inflammation, or at least mitigate it. If it is clearly a case of colic, half of the first close may be repeated, with aloes dissolved in warm water. The stimulus produced on the inner surface of the bowels by the purgative, may counteract the irritation that caused the spasm. The belly should be well rubbed with a brush or warm cloth, but not bruised and injnred by the broom-handle rubbed over it, with all their strength, by two great fellows. The horse should be walked about, or trotted moderately. The motion thus produced in the bowels, and the friction of one intestine over the other, may relax the spasm, but the hasty gallop might speedily cause inflammation to succeed to colic. Clysters of warm water, or containing a solution of aloes, should be injected. The patent syringe will here be exceedingly useful. A clyster of tobacco-smoke may be thrown np as a last resort.

When relief has been obtained, the clothing of the horse, saturated with perspiration, should be removed, and fresh and dry clothes substituted. He should be well littered down in a warm stable or box, and have bran mashes and luke-warm water for the two or three next days.

Some persons give gin, or gin and pepper, or even spirit of pimento, in cases of gripes. This course of procceeding is, however, exceedingly objectionable. It may be useful, or even sufficient, in ordinary cases of colic; but if there should be any inflammation, or tendency to inflammation, it cannot fail to be bighly injurious.

\section{FLATULENT COLIC.}

This is altogether a different disease from the former. It is not spasm of the bowels, but inflation of them from the presence of gas emitted by undigested food. Whether collected in the stomach, or small or large intestines, all kinds of vegetable matter are liable to ferment. In consequence of this fermentation, gas is evolved to a greater or less extent-perhaps to twenty or thirty times the bulk of the food. This may take place in the stomach; and if so, the life of the horse is in immediate danger, for, as will plainly appear from the account that has been given of the oesophagus and upper orifice of the stomach, the animal has no power to expel this dangerous flatus by eructation.

This extrication of gas usually takes place in the colon and cxecum, and the distention may be so great as to rupture either the one or the other, or sometimes to produce death, without either rupture or strangulation, and that in the course of from four to trenty-four hours.

In some ill-conducted establislements, and far oftener on the north than the south of the Tweed, it is a highly dangerous disease, and is especially fatal to horses of heavy draught. An overloaded stomach is one cause of it, and particularly so when water is given either immediately before or after a plentiful meal, or food to which the horse has not been accustomed is given.

The symptoms, according to Professor Stewart, are, "the horse suddenly slackening his pacepreparing to lie down, or falling down as if he were shot. In the stable lie paws the ground with his fore feet, lies down, rolls, starts up all at once, and throws himself down again with great violence, looking wistfully at his flanks, and making many fruitless attempts to void his urine."

Hitherto the symptoms are not much unlike spasmodic colic, but the real character of the disease soon begins to develope itself. It is in one of the large intestines, and the belly swells all round, but mostly on the right flank. As the disease proceeds, tho pain becomes more intense, the borse more violent, and at length death closes the scene.

The treatment is considerably different from that of spasmodic colic. The spirit of pimento would be here allowed, or the turpentine and opium drink; but if the pain, and especially the swelling, do not abate, the gas, which is the cause of it, must be got rid of, or the animal is inevitably lost.

This is usually or almost invariably a combination of hydrogen with some other gas. It has a strong affinity for chlorine. Then if some compound of chlorine-the chloride of lime-dissolved in water, is administered in the form of a drink, the chlorine separates from the lime as soon as it comes into contact with the lydrogen, and muriatic gas is formed. This gas having a strong affinity for water, is absorbed by any fluid that may be present, and, quitting its gaseons form, either disappears, or does not retain a thousandth part of its former bulk. All this may be very rapidly accomplished, for the fluid is quickly conveyed from the mouth to every part of the intestinal canal.

Where these two medicines are not at hand, and the danger is imminent, the trochar may be used, in order to open a way for the escape of the gas. The trochar should be small but longer than that which is used for the cow, and the puncture should be made in the middle of the right flank, for there the large intestines are most easily reached. In such a disease it cannot be expected that the intestines shall always be found precisely in their 
natural situations, but usually the origin of the ascending portion of the colon, or the base of the eæcum, will be pierced. The author of this work, however, deems it his duty to add, that it is only when the practitioner despairs of otherwise saving the life of the animal, that this operation should be attempted. Much of the danger would be avoided by using a very small trochar, and by withdrawing it as soon as the gas has escaped. The wound in the intestines will then probably close, from the innate elasticity of the parts.

\section{INFLAMTITION OF THE BOWELS.}

There are two varieties of this malady. The first is inflammation of the external coats of the intestines, accompanied by considerable fever, and usually costiveness. The second is that of the internal or mucous coat, and almost invariably connected with purging.

\section{ENTERITIS.}

The mnscular coat is that which is oftenest affected. Inflammation of the external coats of the stomach, whether the peritoneal or muscular, or both, is a very frequent and fatal disease. It speedily runs its course, and it is of great consequence that its early symptoms should be known. If the horse has been carefully observed, restlessness and fever will have been seen to precede the attack. In many cases a direct shivering fit will occur: the mouth will be hot, and the nose red. The animal will soon express the most dreadful pain, by pawing, striking at his belly, looking wildly at his flanks, groaning, and rolling. The pulse will be quickened and small; the ears and legs cold; the belly tender, and sometimes hot; the breathing quickened; the bowels costive; and the animal becoming rapidly and fearfully weak.

The reader will probably here recur to the sketch given in page 399 of the distinction between spasmodic colic and inflammation of the bowels, or enteritis.

The causes of this disease are, first of all and most freqnently, sudden exposure to cold. If a horse that has been highly fed, carefully groomed, and kept in a warm stable, is heated with exercise, and has been during some hours without food, and in this state of exhaustion is suffered to drink freely of cold water, or is drenched with rain, or have his legs and belly washed with cold water, an attack of inflammation of the bowels will often follow. An over-fed horse, subjected to severe and long-continued exertion, if his lungs were previonsly weak, will probably be attacked by inflammation of them; but if the lungs were sound, the bowels will on the following day be the seat of disease. Stones in the intestines are an occasional cause of inflammation, and colic neglected or wrongly treated will terminate in it.
The horse pans and stamps as in colic, but without the intervals of ease that occur in that disease. The pulse also is far quicker than in colic. The breathing is more hurried, and the indication of suffering more evident. "The next stage," in the graphic language of Mr. Percivall, " borders on delirium. The eje acquires a wild, haggard, unnatural stare-the pupil dilates-his heedless and dreadful throes render approach to him quite perilous. He is an object not only of compassion but of apprehension, and seems fast hurrying to his end; when, all at once, in the midst of agonising torments, he stands quiet, as though every pain had left him, and he were going to recover. His breathing becomes tranquillised -his pulse sunk beyond all perception-his hody bedewed with a cold clammy sweat-he is in a tremour from head to foot, and about the legs and ears has even a death-like feel. The mouth feels deadly chill; the lips drop pendulous; and the ere seems unconscious of objects. In fine, death, not recovery, is at hand. Mortification has seized the inflamed bowel-pain can no longer be felt in that which a few minutes ago was the seat of exquisite suffering. He again becomes convulsed, and in a few more struggles, less violent than the former, he expires."*

The treatment of inflammation of the bowels, like that of the lungs, should be prompt and energetic The first and most powerful means of cure will be bleeding. From six to eight or teu quarts of blood, in fact, as much as the horse can bear, should be abstracted as soon as possible; and the bleeding repeated to the extent of four or fire quarts more, if the pain is not relieved and the pnlse has not become rounder and fuller. The speedy weakness that accompanies this disease should not deter from bleeding largely. That weakness is the consequence of violent inflammation of these parts; and if that inflammation is subdned by the loss of blood, the weakness will disappear. The bleeding should be effected on the first appearance of the disease, for there is no malady that more quickly runs its course.

A strong solution of aloes should immediately follow the bleeding, but, considering the irritable state of the intestines at this period, guarded by opium. This should be quickly followed by backraking, and injections consisting of warm water, or very thin gruel, in which Epsom salts or aloes have been dissolved; and too much fluid can scarcely be thrown up. If the common ox-bladder and pipe is used, it should be frequently replenished; but with Read's patent pump, already referred to, sufficient may be injected to penetrate bejond the rectum, and reach to the colon and cxcum, and dispose them to evacuate their contents. The horse should likewise be encouraged to drink plen-

- Percivali, s Hippopathology, rol, ii. p. 246. 
tifully of warm water or thin gruel; and draughts, each containing a couple of drachms of dissolved aloes, with a little opium, should be given every six hours, until the bowels are freely opened.

It will now be prudent to endeavour to excite considerable external inflammation as near as possible to the seat of internal disease, and therefore the whole of the belly should be blistered. In a well-marked case of this disease, no time should be lost in applying fomentations, but the blister at once resorted to. The tincture of Spanish flies, whether made with spirit of wine or turpentine, should be thoroughly rubbed in. The legs should be well bandaged in order to restore the circulation in them and thus lessen the flow of blood to the inflamed part; and, for the same reason, the horse should be warmly clothed; but the air of the stable or box should be cool.

No corn or hay should be allowed during the disease, but bran mashes, and green meat if it can be procured. The latter will be the best of all food, and may be given without the slightest apprehension of danger. When the horse begins to recover, a handful of corn may be given two or three times in the day; and, if the weather is warm, he may be turued into a paddock for a few hours in the middle of the day. Clysters of gruel should be continued for three or four days after the inflammation is beginning to subside, and good hand-rubbing applied to the legs.

The second variety of inflammation of the bowels affects the intemal or mucous coat, and is generally the consequence of physic in too great quantity, or of an improper kind. The purging is more violent and continues longer than was intended; the auinual shors that he is suffering great pain; he frequently looks ruand at his Hanks; his breathing is laborious, and the pulse is quick and small-not so small, however, as in inflammation of the peritoneal coat, and, contrary to some of the most frequent and characteristic symptoms of that disease, the mouth is hot and the legs and ears are warm. Unless the purging is excessive, and the pain and distress great, the surgeon should hesitate at giving any astringent medicine at first; but he should plentifully administer gruel or thin starch, or arrow-root, by the mouth and by elyster, removing all hay and corn, and particularly green meat. He should thus endeavour to soothe the irritated surface of the bowels, while he permits all remains of the purgative to be carried off. If, however, twelve hours have passed, and the purging and the pain remain undiminished, he should continue the gruel, adding to it chalk, catecluu, and opium, repeated every six hours. As soon as the purging begins to subside, the astringent medicine should be lessened in quantity, and gradually discontinued. Bleeding will rarely be necessary, unless the inflammation is very great, and attended by symptoms of general fever. The horse should be warmly clothed, and placed in a comfortable stable, and his legs should be hand-rubbed and bandaged.

Violent purging, and attended with much inflammation and fever, will occur from other causes. Green meat will frequently purge. A horse worked hard upon green meat will sometimes scour. The remedy is change of diet, or less labour. Young horses will often be strongly purged, without any apparent cause. Astringents should be used with much caution here. It is probably an effort of nature to get rid of something that offends. A few doses of gruel will assist in effecting this purpose, and the purging will cease without astringent medicine.

Many horses that are not uell-ribbed homehaving too great space between the last rib and the hip-bone-are subject to purging if more than usual exertion is required from them. They are recognised by the term of washy horses. They are often free aud fleet, but destitute of continuance. They should have rather more than the usual allowance of corn, with beans, when at work. A cordial ball, with catechu and opium, will often be serviceable either before or after a journey.

\section{PHYSICKING.}

This would seem to be the proper place to speak of physicking horses-a mode of treatment necessary under various diseases often useful for the augmentation of health, and yet which has often injured the constitution and absolutely destroyed thousands of animals. When a horse comes from grass to hard meat, or from the cool open air to a heated stable, a dose or even tro doses of physic may be nseful to prevent the tendency to inflammation which is the necessary consequence of so sudden and great a change. To a horse that is becoming tou fat, or has surfeit, or grease, or mange, or that is out of condition from inactivity of the digestive organs, a dose of physic is often most serviceable; but the reflecting man will enter his protest against the periodical physicking of all horses in the spring and the autumn, and more particularly against that severe system which is thought to be necessary in order to train them for work, and also the absurd method of treating the animal when under the operation of physic.

A horse should be carefully prepared for the action of pluysic. Two or three bran mashes given on that or the preceding day are far from sufficient when a horse is about to be physicked, whether to promote his coudition or in obedieuce to custom. Mashes should be given until the dung becomes softened. A less quantity of physic will then suffice, and it will more quickly pass throngh the 
intestines, and be more readily diffused over them. Five drachms of aloes, given when the dung bas thus been softened, will act much more effectually and mucl more safely than seven drachms, when the lower intestines are obstructed by hardened fæces.

On the day on which the physic is given, the horse should have walling exercise, or may be gently trotted for a quarter of an hour twice in the day; but after the physic begins to work, he should not be moved from his stall. Exercise would then produce gripes, irritation, and, possibly, dangerous inflammation. The common and alsurd practice is to give the horse most exercise after the physic has begun to operate.

A little hay may be put into the rack. As much mash should be giren as the horse will eat, and as much water, with the coldness of it taken off, as he will drink. If, however, he obstinately refuses to drink warm water, it is better that he should have it cold, than to continue without taking any fluid; but in such case he should not be suffered to take inore than a quart at a time, with an interval of at least an hour between each draught.

When the purging has ceased, or the physic is set, a mash should be given once or twice every day until the next dose is taken, between which and the setting of the first there should be an interval of a week. The horse should recover from the languor and delility occasioned by the first dose, before he is harassed by a second.

Eight or ten tglerably copious motions will be perfectly sufficient to answer every good purpose, although the groom or the carter may not be satisfied unless double the quantity are procured. The consequence of too strong purgation will be, that weakness will hang about the animal for several days or weeks, and inflammation will often ensue from the over-irritation of the intestinal caual.

Long-continued custom has made Aloes the almost invariable purgative of the horse, and very properly so; for there is no other at once so sure and so safe. The Barbadoes aloes, although sometimes very dear, should alone be used. The dose, with a horse properly prepared, will vary from four to seven drachms. The preposterous doses of nine, ten, or even twelve drachms, are now, happily for the horse, generally abandoned. Custom has assigned the form of a ball to physic, but good sense will in due time introduce the solution of aloes, as acting more speedily, effectu. ally, and safely.

The only other purgative on which dependence can be placed is the Croton. The farina or meal of the nut is generally used; but from its acrimony it should be given in the form of ball, with linseed meal. The dose varies from a scruple to half a drachm. It acts more speedily than the aloes, and without the nausea which they produce; but it causes more watery stools, and, consequently, more debility.

Linseed-oil is an uncertain but safe purgative, in doses from a pound to a pound and a half. Olive-oil is more uncertain, but safe; but Castoroil, that mild aperient in the human being, is both uncertain and unsafe. Epsom-salts are inefficacious, except in the immense dose of a pound and a half, and then they are not always safe.

CALCULI, OR STONES IN THE INTESTINES.

These are a cause of inflammation in the bowels of the horse, and more frequently of colic. They are generally found in the cœcum or colon, varying considerably in shape according to the nucleus round which the sabulous or other earthy matter collects, or the form of the cell in which they have been lodged. They differ in size and weight, from a few grains to several pounds. From the horizontal position of the carcase of the horse, the calculus, when it begins to form, does not gravitate so much as in the human being, and therefore calculous concretions remain aud accumulate until their very size prevents their expulsion, and a fatal irritation is too frequently produced ly their motion and weight. They are oftenest found in heavy draught and in millers' horses. In some of these horses they have the appearance of grit-stone or crystallized gneiss. It is probable that they partly consist of these very ininerals, combined with the bran which is continually floating about. An analysis of the Calculi favours this supposition. They are a source of continual irritation wherever they are placed, and are a fruitful cause of colic. Spasnis of the most fearful lind have been clearly traced to them.*

Professor Morton, of the Royal Veterinary College, in his Essay on Calculous Concretions,a work that is far too valuable to be withdrawn from the public view,-gives an interesting account of these substances in the intestinal canal of the horse. Little advance has been or can be made to procure their expulsion, or even to determine their existence; and even when they have passed into the rectum, although some have been expelled, others have been so firmly impacted as to resist all medicinal means of withdrawal, and a few have broken their way through the parietes of the rectum, and lodged in the aludominal cavity. Mr. Percivall, in his "Elementary Lectures on the Veterinary Art," has recorded several fearful cases of this. $\dagger$

Other concretions are described nnder the title of oat-hair calculi. Their surface is tuber. culated and their forms irregular. They are

* Viterinarian, IX., 161.

+ Vol. II., p. 449. 
usually without any distinct nuclei, and are principally composed of the hairy fibrous matter which enters into the composition of the oat. The professor very properly adds, and it is a circumstance which deserves much consideration, that such oats as are husky, with a deficiency of farinaceous matter, are likely to give rise to these accumulations, whenever impaired digestion exists. It is also an undoubted fact, that a great proportion of horses affected with calculi are the property of millers, or brewers. A third species of concretion too frequently existing is the dung-ball, or mixed calculus. It is made up of coarse, indigestible, excrementitious matter, mixed with portions of the "oat-air calculus," and many foreign substances, such as pieces of coal, gravel, \&c., and the whole agglutinated together. They are commonly met with in horses that are voracious feeders, and mingled with particles of coal and stone.

\section{INTROSUSCEPTION OF THE INTESTINES.}

The spasmodic action of the ileum being long continued, may be succeeded by an inverted one from the cœecum towards the stomach, more powerful thau in the natural direction; and the contracted portion of the intestine will be thus forced into another above it that retains its natural oalibre. The irritation caused by this increases the inverted action, and an obstruction is formed which no power can overcome. Even the natural motion of the bowels will be sufficient to produce iutrosusception, when the contraction of a portion of the ileum is very great. There are no symptoms to indicate the presence of this, except contimned and increasing pain; or, if there were, all our means of relief would here fail.

Introsusception is not confined to any particular situation. A portion of the jejunum has been found invaginated within the duodenum,and also within the ileum, and the ileum within the coecum-and one portion of the colon within another, and within the rectum. The ileum and jejunum are occasionally invaginated in various places. More than a dozen distinct cases of introsusception have occurred in one animal, and sometimes unconnected with any appearance of inflammation, but in other cases, or in other parts of the intestinal canal of the same animal, there will be inflammation of the most intense claracter. In the majority of cases, perhaps it is an accidental consequence of pre-existing disease, and occasioned by some irregular action of the muscular tunic, or some irritation of the mucous surface.

A more formidable, but not so frequent disease is

ENTANGLEMENT OF THE BOWELS.

This is another and singular consequence of

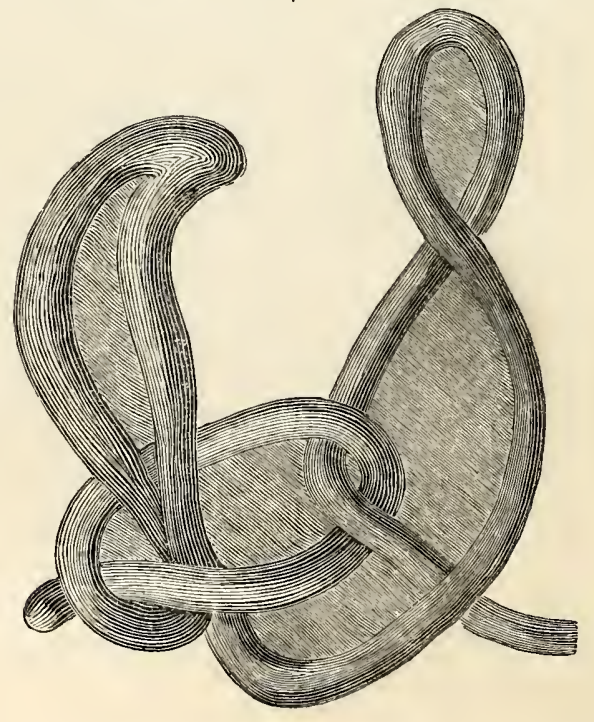


colic. Althongh the ileum is enreloped in the mesentery, anil its motion to a considerable degree confined, yet under the spasm of colic, and during the violence with which the animal rolls and throws himself about, portions of the intestine become so entangled as to be twisted into nooses and knots, drawn together with a degree of tightness scarcely credible. Nothing but the extreme and continued torture of the animal can lear us to suspect that this has taken place, aud, could we ascertain its existence, there would be no cure.

An interesting case occurred in the practice of Mr. Spooner of Southampton. A mare at grass was suddenly taken ill. She discovered symptoms of violent colic, for which anti-spasmodic and aperient medicines were promptly administered, and she was copiously bled. The most active treatment was had recourse to, but without avail, and she died in less than four-and-twenty hours without a momentary relief from pain.

The small iutestines were completely black from inflammation, and portions of them were knotted together in the singular way delineated in the preceding cut. The parts are a little loosened in order better to show the entanglement of the intestines, but in the animal they were drawn into a tight knot, and completely intercepted all passage.

The cause of this was probably some acrid principle in the grass, and many a horse is thus destroyed by the abominable aud poisonous drinks of the farrier.*

\section{woris.}

Worms of different kinds inhabit the intestines ; but, except when they exist in very great numbers, they are not so hurtful as is generally supposed, although the groom or carter may trace to them lidebound, and cough, and loss of appetite, and gripes, and megrims, and a variety of other ailments. Of the origin or mode of propagation of these parasitical animals we can say little; neither writers on medicine, nor even on natural history, have given us any satisfactory accomnt of the matter.

The long white worm (lumbricus teres), much resembling the commou earth-worm, and being from six to ten inches in lengtl, inhabits the small intestiues. It is a formidable looking animal, and if there are many of them they may consume more than can be spared of the nutritive part of the food or the mucus of the bowels. A tight skin, and rough coat, and tucked up belly, are sometimes connected with their presence. They are then, however, roided in large quantities. A dose of physic will sometimes bring away almost incredible qnantities of them. Calomel is frequently given as a vermifuge. The seldomer this drug is atministered to the horse the better. It is the principal ingredient in some quack medicines for the

$$
\text { *Veterinarian, VI. } 12 .
$$

expulsion of worms in the human sulject, and thence, perliaps, it came to be used for the horse, but in him we helieve it to be inert as a vermifuge, or only useful as quickening the operation of the aloes. When the loorse can be spared, a strong dose of physic is an excellent vermifuge, so far as the long round worm is concerned; but a better medicine, and not interfering with either the feed. ing or work of the horse, is emetic tartar, with ginger, made into a ball with linseed meal and treacle, and given every morning half an hour before the horse is fed,

A smaller, darker-coloured worm, called the needle-worm, or ascaris, inhabits the large intestines. Hundreds of them sometimes descend into the rectum, and immense quantities have been found in the cæcum. These are a more serious nuisance than the former, for they cause a very tronblesome irritation about the fundament, which sometimes sadly ammoys the horse. Their existence can generally be discoverell by a small portion of mncus, which, hardening, is found adhering to the anus. Physic will sometimes bring away great numbers of these worms, but when there is much irritation about the tail, and much of this mucus, indicating that they hare descended into the rectum, an injection of linseed oil, or of aloes dissolved in warm water, will he a more effectual remedy.

The tape-worm is seldom found in the horse.

\section{HERNLA, OR RUPTURE.}

A portion of the intestine protrudes out of the cavity of the belly, either through some natural or artificial opening. In some cases it may be returnet, but from the impossibility of applying a truss or bindage, it soon escapes again. At other times the opening is so narrow that the gut, gradually distended by fieces, or thickened by inflammation, cinnot be returned, and strangulated hernia is then said to exist. The seat of hernia is either in the scrotum of the perfect horse, or the groin of the gehling. The causes are violent struggling when under operations, over-exertion, kicks, or accidents. The assistance of a veterinary surgeon is here indispensable.t

+ The following ease of operation for hernia will he accptable to the owner of horses as well as to the veterinary surgeon. I oceurred in the practice of Professor Simond; of the Royal Veterinary College. We borrow his aceount of it from t The Veterinaman."

"The patient was an aged black eart-mare, that hud been Ient by the owner to a neighbour for a day or two. I cannot speak poiturcly as to the carse of the injury which she reseived, but I helieve that it resulteil from her falling in the shafts of a cart laden with mantre. She was brought to my infiruary on the next day, October 18, 1837.

"The most extensive rus ture I had cver scen presented itself on the left sidc. The sac forned by the skin, which was not broken, nor even the hair rubbed off, extended as far forwards at the cartilages of the false ribs, and backwirds to the uduler. A perpendicular line, drawn from the superior to the inferior part of the tumour, measured more than twelve inches It appeared, from its immense size and weight, as if by far the larger part of the colou biul protrided. 
DISEASES OF THE LIVER.

As veterinary practice has improved, much light has lieen thrown on the discases of the liver-not perhaps on the more advanced and fatal stages; but giving us the promise that, in process of time, they may be detected at an earlier period, and in a more manageable state.

"To my surprisc, there was comparatively little constitutional disturbance. The pulse was 45 , and full, with no other indication of fever, and no expression of pain on pressing the tumour.

"She was bled umil the pulse was considerably lowered. A cathartic was given, and the sac ordered to be kept constantly wet with cold water, and to be supported with a wide bandage. She was placed on a restricted and mash diet.

"On the next day, being honoured with a viait by Messrs. Morton, Spooner, and Youatt, I had the pleasure and advantage of submitting the case to their examination, and obtaining ther opinion. Tbcy urged me to attempt to return the protruding viscera, and secure them by a surgical operation; and MIr. Spooner kindly offered to be present, and to give me his valuable assistance

"On the 24 th, our patient was considered to have had sufficient preparatory treatment, and she was operated upon. We arailed ourselves of the opportunity of putting to the test that which some among us had doubted, and others had positively denied, but which had always becn maintained by our talented chemical lecturerthe power of opium to lull the sensation of pain in the horse. We therefore gave her two ounces and a balf of the tincture of opium shortly before she was led from the box to the operating house, and the power of the drug was evident through the whole of the operation.

"After a car ful examioation, externally, as well as per rcctum, in orler to ascertuin the situation and prohable size of the lacerstion of the muscles, an incision was carefully made through the interument into the sac, in a line with the inferior border of the cartilages of the false ribs, which incision was about seven incher in leogth. This, as we had hoped, proved to be directly upon the aperture in the muscular parietes of the abdomen. The intestines were exposed; and, after haviag sufficicntly dilated the opening to permit the introduction of the hand, they were quickly returncd, portion after portion, into their proper cavity, together with a part of the omentum, which we found somewbat annoyiag, it being frequcntly forced back again through the laceration.

"At times it required the cxertion of our united strength to prevent the escape of the intestines, and which was only effected by placing our bands side by side, eoveriog and pressing upon the opering. By these means we succeeded in keeping in the viscera, until we were satisfied that we had placed them all within their proper cavity. At atout the central part of the apcrture, we dccidedly tound the greatest pressure of the intestines to effect an escape.

"A strong metallic suture of flexible wire was then passed throngh the edges of the laceration, taking in the peritunenm and portiuns of the transversalis, rectus, and internal abdominal muscles and other sutures, embracing the same parts, were placed at convenient distances, so as nearly to close the aperture. Two sutures of smaller metallic wire, and three of stont silk cord, were then passed through the external abdominal muscles, and their aponeuroses, which effectually shut up the opening into the abdomen. The integument was then bronght together by the interrupted suture, taking care to hring out the ends of the other sutures, and which had been purposely left long, so that in ease of supervening inflammation, or swelling, they might be readily examined. The whole opesation occupied rather less than an bonr, our poor patient being occasionally refreshed with some warm gruel.

"The hobbles were now quit tly removtd, and, after lying a few minutes, she got up, and was placed in a large elose box. A compress and a suspensory bandage, that could be tightencd at pleasure, were applied to the wound. The pulse was now 84. She was ordered to be watuhed, and to have snme tepid water placed within her reach, but un no account to be disturhed.

"At L0, P.M., the pulse bad sunk to 66 . The respiration, which bad been much acceleraterl, was yuioter. She was resting the leg on the side operated upon, but lid not appear to be suffering any great pain. Some foces had passcd, and she had taken a small quantity of lrun mash. The parts were well fomented with tepid water, an olcaginons draught was administerel, and likewise an cnewa.
If horses, destroyed on account of other complaints, are examined when they are not more than tive years old, the liver is usually found in the most healthy state; but when they arrive at eight or nine or ten years, this viscus is frequently increased in size-it is less elastic under pressureit has assumed more of a granulated or broken down appearance-the blood does not so readily

" 25 th-The pulse is a little quickened; the sac which had contained the protruded intestine was filled with a serous eflusion. I made a dependent orifice in it, and from three to four pints of fluid escaped. This much relieved her, and she continued to go on favourably throughout the day.

" $261 \mathrm{~h}-$ Supunration now began to be established, and the parts were dressed with the componnd tincture of myrrb.

" 30 th-She was enabled to take a little walking excreise; and on this day some of the integumental sutures came away.

"Nov. 4th-The slunghing process being now set up, three of the smaller metallic sutures, that had been used to bring the edges of the luceration together in the external abdoninal museles, came away. The parts were minutely examined, and we detected a sinns running towards the manmex, and filled with pus. With some little diliculty it was opened, and a tape passed tbrough it, so as to allow the pus to escape as quit:kly as it was formed. The appetite was tolerably good, and the pulse ranged from 52 to 56 .

" 6 th-The patient $\mathrm{w}$ as so far recovered that I ventured to turn her into one of the paddocks for a few hours' exercise, taking care to avoid any exposure to cold, if the wealher was stormy.

"1] th-An incident occurred which nearly brought our hitherto successiul case to a fatal termination. I saw her safe about I P.M. ; but at two o clock a messenger came in haste to apprise me that she was in a pond at the bottom of the paddock, and fixed in the mnd. There, indeed, I fonnd ber, at a considerable distance from the bank, and making the most violent efforts to rolease berself. With considerable difficulty, and after many unsuceessful attempts, we succecded in dragging her ashore, so nuch exhausted as to be utterly incapable of rising. A gate was procurcd, and being well covered with straw, she was drawn homeward by two horses; I following, regretting wbat had occurred, and not a little blaming myself for having exposed her to this misfortune.

"Haviag placed her in her box, our first object was her restoration and comfort. Men were set to work to rub her perlectly dry and sone warm gruel, with a little cordial medicine, was given. The state of the wound was next examined, and it was well cleancd with tepid water. It was very dark-coloured. Tlue vitality of the young granulations was appuatently destroyed, and it emitted, in some degree, perhaps, from the mud which had been so long in contact with it, an ofleasive efluvium. It was well dressid with the spirit of nitrous ether, and properly bandaged-in order to prevent its receiving auy futher injury in her ineffectual sttempts to rise.

"We soon, however, began to fear some ill consequence from the continuance of these efforts, and we determined to raise her with the slings, those useful appeadiges to every veteriuary establishment. This was soon effected. We allowed very little bearing on the abdomen, cxecpt when sbe was compelled, in order to ease her hind extremities, which were yet unable to support their share of the weight of the body. Frictions, stimulants, and bandages, were applied to the extremities. An cnema was given, the wound again attended to, and some guel placed within her reach.

"At midnight she was standing at ease in what may not inappropriately be called her cradle. The legs were tolerably warm; the pulse 60 , and full; the encina had done its duty, and she was in a much more comfortable state than I had any right to expect. I ordered her a warm mash and some gruel, for hope began once more to cheer me.

"On the following and succeeding days she continued gradually to regain her strength, but she required great care and attention and it was not until the expiration of the fourth day that I dared to remove her from the sliogs, and then only lor a few hours during the day, carefully replacing her in them at night. Some sligh sloughing took place from the wound; but the principal effect of her immersion was a severe catarrh. She required occasional attendance to the wound: and it was not potil the 12th of Januiry - more than twelve weeks after the op eration-that the last of the metallic sutures came away. She soon a fterwards returned to her usnal work." 
permeate its vessels, and, at length, in a greater or less quantity, it legins to exule, and is either confined under the peritoneal covering, or oozes into the cavity of the belly. There is nothing for awhile to indicate the existence of this. The horse feeds well, is in apprent health, in good condition, and capable of constant work, notwithstandiug so fatal a change is taling place in this important viscus; but, at length, the peritoneal covering of the liver suddenly gives way, and the contents of the abdomen are deluged with blook, or a sufficient quantity of this fluid has gradually oozed out to interfere with the functions of the riscera.

The symptoms of this sudden change are pawing, shifting the posture, distension of the belly, curling of the upper lip, sighing frequently and deeply, the mouth and nostrils pale and blanched, the breathing quickened, restlessness, debility, fainting, and death.

On opening the abdomen, the intestines are found to be deluged with dark venous blood. The liver is either of a fawn, or light yellow, or brown colour-ensily toru by the finger, and, in some cases, completely hroken down.

If the hrermorrhage has been slight at the commencement, and fortunately arrested, yet a singular consequence will frequently result. The sight will gradually fail; the pupil of one or both eyes will gradually dilate, the animal will have gutta serena, and become perfectly blind. This will almost assuredly take place on a return of the affection of the liver. Little can be done in a medical point of view. Astringent and styptic medicines may, however, be triel. Turpentine, alum, or sulphuric acid, will afford the only chance. The veteriniry world is indelited to the late Mr. John Field, for almost all that is known of this sad disease.

\section{JAUNDICE,}

Commonly called THE rELI. but more tractable disease. It is the introduction of bile into the general circulation. This is usually cansed by some obstruction in the ducts or tubes that convey the bile from the liver to the intestimes. The horse, however, has but one duct, throngh which the bile usually flows as quickly as it is formed, and there is no gall-bladeler in which it can become thickened, or hardened into masses so firm as to be appropriately called gall-stoncs. Jaundice does, however, occasionally appear either from an increased flow or altered quality of the bile, or obstruction even in this simple tube. The yellowness of the eyes and mouth, and of the skin where it is not covered with hair, mark it sufficiently plainly. The dung is small and hard; the urine highly coloured; the horse languid, and the appetite impaired. If he is not soon relieved, he some- times begins to express consideral,le uneasiness; at other times he is dull, heavy, and stujid. A charncteristic symptom is lameness of the right fore leg, resembling the pain in the riglit shoulder of the human being in hepatic affections. The principal cuuses are over-feeding or over-exertion in sultry weather, or too little work generally speaking, or inflammation or other disease of the liver itself.

It is first necessary to inquire whether this affection of the liver is not the consequence of the sympathy of that organ with some other part, for, to a very considerable degree, it frequently accompanies inflammation of the bowels and the lungs. These diseases being subdued, janndice will disappear. If there is no other apparent disease to any great extent, an endeavour to restore the natural passage of the bile by purgatives may be tried, not consisting of large doses, lest there should be some undetected inflammation of the lungs or bowels, in either of which a strong purgative would be dangerous; bnt, given in small quantities, repeated at short intervals, and until the bowels are freely opened. Bleeding should always be resorted to, regulated according to the apparent degree of inflammation, and the occasional stupor of the animal. Plenty of water, slightly warmed, or thin gruel, should be given. The horse should be warmly clothed, and the stable well ventilated, but not cold. Carrots or green meat will be very beneficial. Should the purging, when once excited, prove violent, we need not be in any haste to stop it, unless inflammation is beginning to be connected with it, or the horse is very weak. The medicine recommended under diarrhœe may then be exhibited. A few slight tonics should be given when the horse is recovering from an attack of jaundice.

The Spleen is sometimes very extraordinarily enlarged, and has been ruptured. We are not aware of any means by which this may be discovered, except manual examination bs means or the aid of the rectum. The state of the animal would clearly enough point out the treatment to be adopted.

The Pancrcas. We know not of any disease to which it is liable.

The blood contains a great quantity of watery fluid unnecessary for the nutriment or repair of the frame. There likewise mingle with it matters that would be noxions if suffered to accumulate too much.

\section{THE KIDNEYS}

Are actively emplosed in separating this fluid, and likewise carrying off a substance which constitutes the peculiar ingredient in urine, called the urea, and consisting principally of that which would he poisonous to the animal. The kidneys are two D $\mathrm{D} 2$ 
large glandular borlies, placed under the loins, of the shape of a kidney-bean, of immense size. The right kidney is most forward, lying under the liver; the left is pushed more backward by the stomach and spleen. A large artery runs to each, carrying not less than a sixth part of the whole of the blood that circulates through the frame. This artery is divided into innumerable little branches, most curiously complicated and coiled upon each other; and the blood, traversing these convolutions, has its watery parts, and others the retaining of which would be injurious, separated from it.

The fluid thus separated varies materially both in quantity and composition, even during health. There is no animal in which it varies so much as in the borse,-there is no organ in that animal so much under our command as the kidney; and no merlicines are so useful, or may be so iujurious, as dimetics-such as nitre, and digitalis-not only on account of their febrifuge or sedative effects, but because of the power which they exert. They stimulate the lidneys to separate more aqueous fluil than they otherwise would do, and thus lessen the quantity of blood which the heart is labouring to vineulate through the frame, and also that which is determined or driven to parts already overloaded. The main olijects to be accomplished in these disenses is to reluce the force of the circulation, and to calm the violence of excitement. Diuretics, by lessening 1 he quantity of blood, are nseful assistants in accomplishing these purposes.

The horse is subject to effusions of fluid in particular jarts. Swelled legs are a disease almost peculiar to him. The ox, the sheep, the dog, the ass, and even the mule, seldom have it, but it is for the removal of this deposit of fluid in the cellular substance of the legs of the horse that we have recourse to diuretics. The legs of many horses camot he rendered fine, or kept so, with. out the use of diuretics; nor can grease-often comected with these swellings, producing them or cansed by them-be otherwise subdued. It is on this account that diuretics are ranked among the most useful of veterinary medicines.

In injurdicious hands, however, these medicines are sadly abused. Among the absurdities of stable-management there" is nothing so injurious as the frequent use of diuretics. Not only are the kilneys often over-expited, reakened, and disposed to disease, but the whole frame becomes delilitated; for the absorbents have carried away a great part of that which was necessary to the health and condition of the horse, in order to supfly the deficiency of blood occasioned by the inordinate discliarge of urine. There is likewise one important fact of which the groom or the horseman seldom thinks, viz. :- That, when he is removing these humours by the inprudent use of diuretics, he is on!ly attacking a sympton or a consequence of disease, and not the disease itself. The legs will fill again, and the grease will return. While the cause remains, the effect will be produced.

In the administration of diuretics, one thing should be attended to, and the good effect of which the testimony of every intelligent man will confirm: the horse should have plenty to drink. Not only will inflammation be prevented, but the operation of the medicine will be much promoted.

\section{INFLAMMATION OF THE KIDNEYS.}

This is no uncommon disease in the horse, and is more unskilfully and fatally treated than almost any other. The early symptoms are those of fever generally, but the seat of the disease soon becomes evident. The horse looks anxionsly round at his flanks; stands with his hinder legs wile apart; is unwilling to lie down; straddles as he walks; expresses pain in turning; shrinks when the loins are pressed, and some degree of beat is felt there. The urine is voided in small quantities; frequently it is high-coloured, and sometimes bloody. The attempt to nrinate becomes more frequent, and the quantity voided smaller, until the animal strains painfully and violently, but the discharge is nearly or quite suppressed. The pulse is quick and hard; full in the early stage of the disease, hut rapidly becoming small, yet not losing its character of harlness. These symptoms clearly indicate an affection of the urinary organs; but they do not distinguish inflammation of the kidhey from that of the bladder. In order to effect this, the hand must be introduced into the rectum. If the bladder is felt full and hard under the rectum, there is inflammation of the neck of it; if it is empty, set on the portion of the intestines immediately over it there is more than natural heat and tenderness, there is inflammation of the body of the bladder; and if the bladder is empty, and there is no increased heat or tenderness, there is inflammation of the kidney.

Among the causes of diabetes are improper food, and particularly hay that has been mowburnt, or oats that are musty. The farmer should look well to this. Oats that have been dried on a kiln acquire a diuretic property, and if horses are long fed on them, the continual excitement of this organ which they produce will degenerate into inflammation. Too powerful or too often repeated diuretics induce inflammation of the kidney, or a degree of irritation and weakness of that organ that disposes to inflammation from causes that would otherwise have no injurious effect. If a horse is sprained in the loins by being nrged on, far or fast, by a heavy rider, or compelled to take too wide a leap, or by being suddenly pulled up on his haunches, the inflammation of the muscles of the loins is often speedily transferred to the kidness, with which they lie in contact. Expo- 
sure to cold is another frequent origin of this inalady, especially if the horse is drenched with rain, or the wet drips upon his loins; and, more particularly, if lie was previously disposed to inflammation, or these organs had been previously weakened. For this reason, haskney-coach horses and others, exposed to the vicissitudes of the weather, and often fed ou unwholesome provender, have, or should have, their loins protected by leather or somo other clothing. The grand cause, however, of nephritis is the unnecessary quantity or undue strength of the diuretic medicines that are forced on the horse by the ignorant groom. This is an evil carried to an infamous extent, and against which every horseman should sternly oppose himself.

The treatment will only vary from that of inflammation of other parts by a consideration of the peculiarity of the organ affected. Bleeding must be promptly resorted to, and carried to its full extent. An active purge should next be administered; and a counter-inflammation excited as nearly as possible to the seat of disease. For this purpose the loins should be fomented with hot water, or covered with a mustard poultice-the lorse should be warmly clothed; but no cantharides or turpentine slould be used, and, most of all, no diuretic be given intemally. When the groom finds this difficulty or suppression of staling, he immediately has recourse to a dinretic ball to force on the urine; and by thus needlessly irritating a part already too much excited, he adds fuel to fire, and frequently destroys the horse. The action of the pnigative having begun a little to cease, white hellebore may be administered in small doses, with or without emetic tartar. 'The patient should be warmly clothed; his legs well handaged; and plenty of water offered to him. The food should be carefully examined, and anything that could have excited or that may prolong the irritation carefully removed.

DIABETES, OR PROFUSE STALIXg,

Is a comparatively rare disease. It is generally the cousequence of nudne irritation of the kidney by load fool or strong diuretics, and sometimes follows inflanimation of that organ. It can seldom be traced in the horse to any disease of the digestive organs. The treatment is obscure, and the result often uncertain. It is evidently increased action of the kidneys, and therefore the most rational plan of treatment is to endeavour to abate that action. In order to effect this, the same course should be pursued in the early stage of diabetes as in actual inflammation; but the lowering system must not be carried to so great an extent. To bleeding, purging, and counter-irritation, medicines of an astringent quality shonld succeed, as catechu, the powdered leaf of the whortle-berry (uva ursi), and opium. Very careful attention should be paid to the food. The hay and oats should be of the best quality. Green meat, and especially carrots, will be very serviceable.

BLOODY URINE-HEMATURIA.

The discharge of urine of this character is of occasional occurrence. Pure blood is sometimes discharged which immediately coagulates - at other times it is more or less mixed with the urine. and does not coagulite. The cause of its appearance and the soure whence it proceeds cannot always be deternined, lut it is probably the result of some strain or blow. It may or suay not be accompanied by inflammation.

Should it be the result of strain or violence, or be evidently attended by iuflimmation, soothing and depleting measures should be adopted. Perhaps counter-irritation on the luins might be useful. If there is no apparent inflammation, sume gentle stimulus may be administered intermally.

\section{ALBUMINOUS CRINE.}

A peculiar mucous state of the urine of some horses has lately attracted attention. It has been associated with stretching out of the legs, stiffness, disinclination to move, a degree of fever, and costiveuess. Slight bleeding, mild physic, the application of gentle stimulants to the loins, quietness, and gentle opiates, have been of serrice. We are indebted to Mr. Percivall for what we do know of the disease. It is a sulject worthy of the atteution of the veterinary surgeon.

\section{THE BLADDER.}

The urine separated from the blood is dis" charged by the minute vessels, of which we have spoken, into some larger cauals, which terminate in a cavity or reservoir in the body of each kidney, designated its pelvis. Thence it is conveyed by a duct called the ureter, to a large reservoir, the bladder. It is coustantiy flowing from the kidney througl the ureter; and were there not this provision for its detention, it would be incessautly and annoyingly dribbling from the auinal. The lladder lies in, and when distended by urine nearly fills, the cavity of the great bones of the haunch, termed the pelvis. It has three conts, the onter one covering the greater part of it, and being a portion of the peritoneum : the muscular, consisting of two layers of fibres, as in the stomach; the external, running longitudinally, and the inuer circularly, so that it may sield to the pressure of the urine as it enters, and contract again into an exceedingly small space as it runs out, and by tlat contraction assist in the expulsion of the urine. The inner cont contains nu. merons little glands, which secrete a murous fluid to defend the bladder from the acrimony of the urine. The bladder terminates in a small 
neck, round which is a strong muscle, keeping the passage closed, and retaining the urine until, at the will of the animal, or when the bladder contains a certain quantity of fluicl, the muscnlar coat begins to contract, the diaphragm is rendered convex towards the intestines, and presses them on the bladder, and by these united powers the fluicl is forced through the sphincter muscle at the neck of the bladder, and escipes.

\section{INFLAMMATION OF THE BLADDER.}

There are two varieties of this disease, inflammation of the body of the bladder, and of its neck. The symptoms are nearly the same with those of inflammation of the kidney, except that there is rarely a total suppression of urine, and there is heat felt in the rectum over the situation of the bladder. The causes are the presence of some acrid or irritant matter in the urine, or of calculus or stone in the bladder. With reference to inflammation of the body of the bladder, mischief has occasionally been done by the introduction of cantharides or some other irritating matter, in order to hasten the period of horsing in the mare. The treatment in this case will be the same as in inflammation of the kidneys, except that it is of more consequence that the animal should drink freely of water or thin gruel.

In inflammation of the neck of the bladder there is the same frequent voiding of urine in small quantities, generally appearing in an advanced stage of the disease, and often ending in ahmost total suppression. There is also this circumstance, which can never be mistaken by him who will pay sufficient attention to the case, that the bladder is listeuded with urine, and can be distinctly felt under the rectum. It is spasm of the part, closing the neck of the bladder so powerfully that the contraction of the bladder and the pressure of the muscles are unable to force out the urine.

Here the object to be attempted is sufficiently plain. This spasm must be relaxed, and the most likely means to effect it is to bleed largely, and even to fainting. This will sometimes succeed, and there will be at once an end to the disease. To the exhaustion and loss of muscular power occasioned by copious bleeding, should be added the nausea consequent on physic. Should not this speedily have effect, another mode of abating spasm must be tried-powdered opium made into a ball or drink, should be given every two or three hours; while an active blister is applied externally. The evacuation of the bladder, both in the mare and the horse, should be effected through the medium of a veterinary surgeon.

\section{STONE IN THE BLADDER.}

The urine is a very compound fluid. In a state of health it contains several acids and alkalies variously combined, which, under disease, are increased both in number and quantity. It is very easy to conceive that some 'of these may be occasionally separated from the rest, and assume it solid form both in the pelvis of the kilney and in the bladder. This is known to be the case both in the human being and the brute. These calculi or stones are in the horse oftener found in the kidney than in the bladder, contrary to the experience of the human surgeon. The explatuation of this, however, is not difficult. In the human being the kidney is situated above the bladder, and these concretions descend from it to the bladder by their weight. 'The belly of the loorse is horizontal, and the force of gravity can in no way affect the passage of the calculus; therefore it occasionally remains in the pelyis of the kidney, until it has increased so mueh in size as to fill it. We know not of any symptoms that would satisfactorily indicate the presence of a stone in the kidney ; and if the disease could be ascertained, we are unalile to say what remedial measures could be adopted.

The symptoms of stone in the bladder much resemble those of spasmodic colic, except that, on careful inquiry, it will be found that there has been much irregularity in the discharge of urine and occasional suppression of it. When fits of apparent colic frequently return, and are accompanied by any peculiarity in the appearance or the discharge of the urine, the horse should be carefully examined. For this purpose he must be thrown. If there is stone in the blalder, it will, while the horse lies on its back, press on the rectum, and may be distinctly felt if the hand is introduced into the rectum. Several cases have lately occurred of successful extraction of the culculus; but to effect this it will always be necessary to have recourse to the aid of a veterintry practitioner.

Both the practitioner and the amateur will he gratified by the description of a catheter, invented by Mr. Taylor, a veterinary surgeon of Nottingham, which may be introduced into the bladder without difficulty or pain, and the existence and situation of the calculus readily ascertained.

It is made of polished round iron, three feet long, one and a half inch in circumference, and with eight joints at its farther extremity. The solid part between each joint is one and a quarter inch in length, and one and a half in circumference, the moveable part being ten inches, and the solid part two feet two inches. The latter has a slight curve commencing one foot from the handle, and continuing to the first joint of the moveable part, in order to give it facility in passing the urethra, where it is attached to the pareties of the abdomen. 'The joints are on the principle of a half joint, so that the movealle part would only act in a straight line, or curve in one dircetion. The joints are 
perfectly ronuded and smooth when acting either both in its straight and curved state in the followin a straight line or a curve. It is represcuted ing cuts.
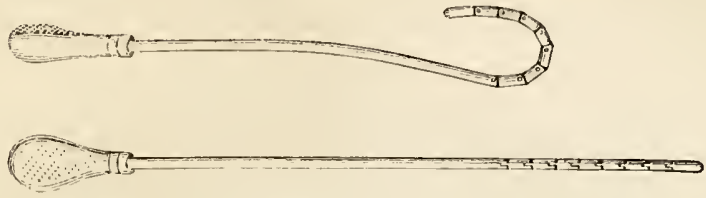

Many horses occasionally void a considerable quantity of gravel, sometimes without inconvenience, and at others with evident spasm or pain. A diuretic might be useful in such case, as increasing the flow of uriue, and possibly washing out the concretions before they become too numerous or bulky.

The urine having passed the neck of the bladder, flows along the urethra, and is discharged. The sheath of the penis is sometimes considerably enlirged. When at the close of acute disease, there are swellings and effusions of fluid, uncler the chest and belly, this part seldom escapes. Diuretics, with a small portion of cordial medicme, will be beneficial, but in extreme cases slight scarifications may be necessary. The inside of the sheath is often the seat of disease. The mocons matter, naturally secreted there to defend the part from the acrimony of the urine, accunulates and becomes exceedingly offensive, and produces swelling, tenderness, and even excoriation, with considerable discharge. Fomentation with warm water, and the cleansing of the part with soip and water, aided perhaps by the administration of a dinretic Lall, will speedily remove every inconvenience. Carters are too apt to neglect cleanliness in this respect.

\section{CHAPTER XV.}

\section{bReEding, castration, \&c.}

This may be a proper period to recur to the subject of breeding, and peculiarly important when there cannot be a doubt that our breeed of horses has, within the last twenty years, undergone a material change. Our ruming horses still maintain their speed, althongh their endurance is, generally speaking, considerably diminished; our draught and carriage horses are perhaps improved in value; but our hunters and hackneys are not what they used to be.

Our observations on this will be of a general nature, and very simple. The first axiom we would lay down is, that "like will produce like," and that the progeny will inherit the general or mingled qualities of the parents. There is scarcely a disease by which either of the parents is affected that the foal does not often inherit, or at least oceasionally show a predisposition to it. Even the consequences of ill usage or hard work will descend to the progeny. There has been proof upon proof, that blindness, roaring, thick wind, broken wind, spavins, curbs, ringbones, and founder, have been bequeathed to their offspring, both by the sire and the dam. It should likewise be recollected that although these blemishes may not appear in the immediate pregeny, they frequently do in the next, or even more distant generation. Hence the necessity of some knowledge of the parentage both of the sire and the dam.
Peculiarity of form and constitution will also be inherited. This is a most important but neglected consideration; for, however desirable or even perfect may have been the conformation of the sire, every good point may be nentralized or lost by the defective structure of the mare. The essential points should be good in both parents, or some minor defect in either be met, and got rid of, by excellence in that particular point in the other. The unskilful or carcless breeder too often so badly pairs the animals, that the good points of each are almost lost: the defects of both increased, and the produce is far inferior to both sire and dam.

Mr. Baker, of Reigate, places this in a striking point of view. He speaks of his own experience : "A foal had apparently clear and good eyes, but the first day had not passed, befure it was evident that it was totally blind. It had gutta serena.

"Inquiry was then made about the sire, for the mare had good eyes. His were, on tho slightest inspection, evidently bad, and not one of his colts had escaped the direful effects of his im. perfect visien.

"A mare had been the subject of farcical enlargements, and not being capable of performing mnch work, a foal was procured from her. She survived; but the foal soon after birtl evinced symptoms of farey, and dicd. 
"A mare was lame from navicular disease. A foal was breil from her that at five years conld scarcely go across the country, and was sold for a few pounds. The mare was a rank jib in single harness ; the foal was as bad."

It is useless to multiply these examples. They occur in the experience of every one, and yet they are strangely disregarded.

The nare is sometimes put to the horse at too early an age; or, what is of more frequent occurrence, the mare is incapacitated for work by old age. The owner is unwilling to destroy her, and he determines that she shall bear a foal, and thus remunerate him for her keep. What is the consequence? The foal exhibits an unkiudliness of growth,-a correspouding weakness,--and there is searcely an organ that possesses its natural and proper strength.

Of late years, these principles liave been much lost sight of in the breeding of hurses for general use ; and the following is the explanation of it. There are nearly as good stallions as there used to be. Few but well-formed and valuable horses will be selected and used as stallions. They are always the very prime of the breed; but the mares are not what they used to be. Poverty has inducerl many of the breeders to part with the mares from which they used to raise their stock, and which were worth their weight in gold; and the jade on which the farmer now rides to market, or which he uses in bis farm, costs him but little money, and is only retained because he cannot get much money for her. It has likewise become the fashion for gentlemen to ride mares, almost as frequently as geldings; and thus the better kind are taken from the breeding service, until old age or injury renders them worth little for it. An intelligent veterinary surgeon, $\mathrm{Mr}$. Castley, has placed this in a very strong light.**

It should be impressed on the-minds of breeders, that peculiarity of form and constitutiou are iuherited from both parents, - that the excellence of the mare is a point of quite as much importance as that of the horse,- and that, out of a sorry mare, let the horse be as perfect as he may, a good foal will rarely be produced. All this is recognised

" "Any one," says he, "who during the last twenty or five-andtwenty yeurs, has bud frequent opportunities of visiting some of oor great horse fairs in the north of Eagland, must be struck with the sad falling-off there is everywhere to be remarked in the quality of the one-halr and three-part bred horses exbibited for sale. The farmers, when taxed with this, eomplain that breeding horses does not suffieiently repay them; and yet we tind larre sums of money alwuys given at fairs for any horses that are really good, but bir ones are not at any time likely to pay for rearing, and less now than ever, on accomt of the advaneed rate of land, and the increased expense of production. The truth is, that farmers do not, now-adays, breed horses so generally good as they werl to do, aud this is uwing to the inferior quality of the mares which they now commonly empliny in brceding. T'hey have, to a gieat digree, bcen sempted w) part with thir best niares, and this breed from the refose. The steck consegucotly deterionates, and they are disappointed. upon the turf, though porerly or carelessness have made the general lireeder veglect or forget it.

That the constitution and endurance of the horse are inherited, no sjorting man ever duubted. The qualities of the sire or the dam descend from generation to generation, and tbe excellencies or defects of certain horses are often traced, and justly so, to some peculiarity in a firdistant ancestor.

It may, perhaps, be justly affirmed, that there is more difficulty in selecting a good mare to lireed from than a good horse, because she should possess somewhat opposite qualities. Her carcase should be long, in order to give room for the growth of the fotus; and yet with this there should be compactness of form and shortness of leg. What can they expect whose practice it is to purchase wornout, spavined, foundered mares, about whom they famey there have been some good points, and send them far into the country to breed from, and, with all their variety of shape, to be covered by the same horse? In a lottery like this there may be now and then a prize, but there must be many blanks. If horse-breeders, possessed of good judgment. would pay the same attention to breed and shape as Mr. Bakewell did with his sheep, they would probably attain their wishes in an equil degree, and greatly to their advantage, whether for the collar or the road, for racing or for hunting.

As to the shape of the stallion, little satisfactory can be said. It must depend on that of the mare, and the kind of horse wished to be bred: but if there is one point absolutely essential, it is "compactness"-as nuch goodness and strength as possible condensed into a little space.

Next to compractness, the inclination of the shoulder will be reginded. A buge stallion, with upright shoulders, never got a capital hunter or hackney. From him the breeder can obtain nothing but a cart or dray horse, and that, perhaps, spoiled by the opposite form of the mare. On the other hand, an upright shoulder is desirable, if not absolutely necessary, when a mere slow draught-horse is required.

On the subject of lreeding in and in, that is,

"The great demand for mares has also contributed to gat the best muterial for breeding out of the farmer's hands. Thirty yars ago few gentlemen would be seen riding a mare-it was ontavionable. There was, eonsequently, but little demand for her, and she was left for the nost part in the farmers' hauds, who were then to lie seen rding to market, monnted on the finest mares, and from among which they stlected the best for the porpose of breading. Like will produec like, and the stock wonld seldom disappoint them. "Then there is the demand for the foreign market. Within the last twrnty years, a great number of our finest three-parts-lned mares have been exported to various portions of the Continent, and particularly to Wance and Germany. They never find their way back again. The money brought into ont cauntry ly thir export is a mere tritle $\rightarrow$ drip in the ocean $\rightarrow$ while we are doing ourselves inealculable muschief by allowing some of our best nuteriuls to pass ont of our hiuls tor ever," - I"eterinarian, III., p. 371. 
persevering in the same breed, and selecting the best on either side, much has leen said. 'The system of crossing requires more judgment and experience than breeders usually possess. The bad qualities of the cross are too soon engrafted on the original stock, and, once engrafted there, are not, for many generations, eradicated. The good qualities of both are occasionally neutralized to a most mortifying degree. On the other hand, it is the fact, however some may deny it, that strict confinement to one breed, however valuable or perfect, produces gradual deterioration. Crossing should be attempted with great caution. The valuable points of the old breed should be re. tained, but varied or improved by the introduction of some new and valuable quality, with reference to beauty, streugth, or speed. This is the secret of the turf. The pure south-eastern blood is never left, but the stock is often changed with manifest advantage.

A mare is capable of breeding at three or four years old. Some have injudiciously commenced at two years, before her form or her strength is sufficieutly developed, and with the development of which this early breeding will materially interfere. If a mare does little more than farm-work, she may contiuue to be lred from uutil she is nearly twenty ; but if she has been hardly worked, and bears the marks of it, let her have been what she will in her youth, she will deceive the expectations of the breeder in her old age.

From the time of covering, to within a few days of the expected period of foaling, the cart mare may be kept at moderate labour, not only without injury, but with decided advantage. It will then be prudent to release her from work, and keep her near home, and under the frequent inspection of some careful person.

When nearly half the time of pregnancy has elapsed, the mare should have a little better food. She should be allowed one or two feeds of corn in the day. This is about the period when they are accustomed to slink their foals, or when abortion occurs: the eye of the owner should, therefore, be frequently upon them. Good feeding and moderate exercise will be the best preventives of this mishap. The mare that has once aborted is liable to a repetition of the accideut, and therefore should never be suffered to be with other mares between the fourth and fifth months; for such is the power of imagination or of sympathy in the mare, that if one suffers abortion, others in the same pasture will too often share the same fate. Farmers wash, and paint, and tar their stables, to prevent some supposed infection; the infection lies in the imagination.

The thorough-bred mare - the stock being intended for sporting purposes-should be kept quiet and apart from other horses, after the first four or five months. When the period of parturition is drawing near, she should be watched, and shut up, during the uight in a safe yard or loose box.

If the mare, whether of the pure or common breed, be thus taken care of, and be in good health while in foal, little danger will attend the act of parturition. If there is false presentation of the foetus, or difficulty in producing it, it will be better to have recourse to a well-informed practitioner, than to injure the mother by the violent and injurious attempts that are often made to relieve her.

The parturition being over, the mare should be turned into some well-sheltered pasture, with a hovel or shed to run into when she pleases; and as, supposing that she has foaled in April,* the grass is scanty, slie should have a couple of feeds of corn daily. The breeder may depend upon it, that nothing is gained by starving the mother and stinting the foal at this time. It is the most important period of the life of the horse; and if, from false economy, his growth is arrested, his puny form and waut of endurance will ever afterwards testify the error that has been com. mitterl. The corn should be given in a trough on the ground, that the foal may partake of it with the muther. When the new grass is plentiful, the quantity of corn may be gradually diminished.

The mare will usu:tly be found again at heat at or before the expiration of a month from the time of foaling, when, if she is principally kept for breeding purposes, she may be put again to the horse. At the same time, also, if she is used for agricultural purposes, she may go again to work. The foal is at first shut in the stable during the hours of work; but as soon as it acquires sufticieut strength to toddle after the mare, and especially when she is at slow work, it will be better for the foal and the dam that they should be together. The work will contribute to the health of the mother; the foal will more frequently draw the milk, and thrive better, and will be hardy and tractable, anci gradually familiarised with the oljects among which it is afterwards to live. While the mother, however, is thus worked, she and the foal should be well fed; and two feeds of corn, at least, should be added to the green food which they get when turned out after their work, and at night.

In five or six months, according to the growth of the foal, it may be weaned. It should then be housed for three weeks or a month, or turned into some distant rick-yard. There can be no better place for the foal than the latter, as affording, and that without trouble, both food and

* By the present rules of the jockes-club the agre of turf horses is reckoned from the $\mathbf{l}$ st of $\mathrm{J}$ anuary, but this has not by any common consent extended to the half-breds. The lst of $\mathbf{M}$ ty is nearcst to the general time of foaling, and the age of the caralry howes is datcd from that period. 
shelter. The mother should be put to harder work, and have drier meat. One or two urineballs, or a physic-ball, will be useful if the milk should be troublesome, or she should pine after her foal.

There is no primciple of greater importance than the liberal feeding of the foal during the whole of his growth, and at this time in particular. Bruised oats and bran should form a considerable part of his daily provender. The farmer may be assured that the money is well laid out which is expended on the liberal nourishment of the growing colt: yet while he is well fed, he should not be rendered delicate by excess of care.

A racing colt is often stabled; but one that is destined to be a hunter, a hackney, or an agricultural horse, should have a square rick, under the leeward side of which he may shelter himself; or a hovel, into which he may rum at night, and out of the rain. "Too often, however, the foal, after weaning, is left to struggle on as he can, and becomes poor and dispirited. He is to be seen shrinking under a hedge, cold and almost shivering, his head hanging down, and rheum distilling from his eyes. If he is made to move, he listlessly drags his limbs along, evidently weak, and generally in pain. He is a sad specimen of joverty and of misery. This is the first scene of cruelty to the horse of inferior lreed, and destined for inferior purpose."*

The process of breaking-in should commence from the very period of weaning. The foal should be daily handled, partially dressed, accustomed to the halter when led abont, and even tied up. The tractability, and gool temper, and value of the horse, depend a great deal more upon this than breeters are aware.

Everything should be done, as much as pos. sible, by the man who feeds the colt, and whose management of him should be always kind and gentle. There is no fault for which a breekter should so invariably discharge his servant as cruelty, or even harshness, towards the rising stock; for the principle on which their after usefulness is founded, is early attachment to, and confidence in man, and obedience, implicit obedience, resulting prineipally from this.

After the second winter the work of breakingin may commence in good earnest. The colt may be bitted, and a bit selected that will not hurt his molitl, and much smaller than those in common use. With this he may be suffered to amuse liinself, and to play, and to champ it for an bow', on a few successive dass.

Having become a little tractable, portions of the harness may be put upon him, concluding with the blind winkers; aud, a few days after-

* Fonatt on Humunity to Animals, p. 115 wards, he may go into the team. It would be better if there could be one horse before, aud one behind him, beside the shaft horse. 'There should at first be the mere empty waggon. Nothing should be done to him, except that he should have an occasional pat or kind word. The other horses will keep him moving, and in his place; and no great time will pass, sometimes not even the first day, before he will begin to pull with the rest. The load may then be gradually increased.

The agricultural horse is sometimes wanted to ride as well as to draw. Let his first lesson be given when he is in the team. Let his feeder, if possible, be first put upon him. He will be too much hampered by his harness, and by the other horses, to make much resistance; and, in the majority of cases, will quietly and at once submit. We neet not to repeat, that no whip or spur should be used in giving the first lessons in riding.

When he lhegins a little to understand his business, backing-the most difficult part of his work-may be taught him; first to back well without anything behind him, and then with a light eart, and afterwarts with some serious loadalways taking the greatest care not seriously to hurt his mouth. If the first lesson causes much soreness of the gums, the colt will not readily submit to a second. If he has bcen previously rendered tractable by kind usage, time and paticnce will do everything that can be wished. Some carters are in the habit of blinding the colt when teaching him to back. 'This may be necessary with a restive and olstinate one, but should be used only as a last resort.

'The colt having been thus partially broken-in, the necessity of implicit obedience must be tanght him, and that not by severity, but by firmmess and steadiness. The voice will go a great way, but the whip or the spur is sonetimes indispensable-not so severely applied as to excite the animal to resistance, but to convince him that we have the power to enforce submission. Few-it may almost be said, no-horses, are naturally vicious, 1t is cruel usage which has first provoked resistance. That resistance has been followed by greater severity, and the stubbornness of the animal has increased. Open warfare has ensued, in which the man has seldom gained advantage, and the borse has been frequently rendered unserviceable. Correction may, or must be used, to enforce implicit obedience after the education has proceeded to a certain extent, but the early lessons should be ineulcated with kindness alone. Young colts are sometimes very perverse. Many days will occasionally pass before they will permit the bridle to be put on, or the saddle to be worn ; and one act of harshuess will double or treble this time: patience and kindness, however, will always prevail. On some morning, when he is in a 
better humour than usual, the bridle may be put on, and the saddle may be worn; and, this compliance being followed by lindness and soothing on the part of the breaker, and no inconvenience or pain being sullered by the animal, all resistance will be at an end.

The same principles will apply to the breaking-in of the horse for the road or the chase. The handling, and some portion of instruction, should commence from the time of weaning. The future tractability of the horse will much depend on this. At two years and a half, or three years, the regular process of breaking-in should commence. If it is delayed until the animal is four years old, his strength and obstinacy will be more difficult to overcome. The plan usually pursued by the breaker camot perhaps be much improved, except that there should be much more kindness and patience, and far less harshness and cruelty, than these persons are accustomed to exhibit, and a great deal more attention to the form and natural action of the horse. A healstall is put on the colt, and a cavesson (or apparatus to confine and pinch the nose) affixed to it, with long reins. He is first accustomed to the rein, then led romed a ring on soft ground, and at length mounted and taught his paces. Next to preserving the temper and docility of the horse, there is nothing of so much importance as to teach him every pace, and every part of his duty, distinctly and thoroughly. Each must constitute a separate and sometimes longcoutinued lesson, and that taught by a man who will never suffer his passion to get the better of his discretion.

After the cavesson has been attached to the headstall, and the long rein put on, the colt should be quietly led ahout by the lireaker-a steady boy following behind, by occasional threatening with the whip, but never by an actual blow, to keep him moving. When the animal follows readily and quietly, he may be taken to the ring, and walked round, right and left, in a very small circle. Care should be taken to teach him this pace thorvughly, never suffering him to break into a trot. The boy with his whip may here agin be necessary, but not a single blow should actually fahl.

Becoming tolerably perfect in the watk, he should be quickened to a trot, and kept steadily at it; the whip of the boy, if needful, urging him on, and the cavesson restraining him. These lessons should be short. The pace should be kept perfect, and distinct in each ; and docility and improvement rewarded with frequent caresses, and handfuls of coru. The length of the rein may now be gradually increased, and the pace quickened, and the time extended, until the animal becomes tractable in these his first lessous, towards the conclusion of which, erupper-straps, or something similar, may lie attached to the elothing. These, playing about the sides and flanks, accustom him to the flapping of the coat of the rider. The annoyance which they occasion will pass over in a day or two; for when the animal finds that no harm comes to him, he will cease to regard them.

Next comes the bitting. The bit should be large and smooth, and the reins buckled to a ring on either side of the pad. There are many curious and expensive machiues for this purpose, but the simple rein will be quite sufficient. It should at first be slack, and then very gradually tightened. This will prepare for the more perfect manner in which the head will be afterwards got into its proper position, when the colt is accustomed to tho saddle. Occasionally the breaker should stand in front of the colt, and take hold of each side rein near to the mouth, and press upon it, and thus begin to teach him to stop and to back on the pressure of the rein, rewarding every act of docility, and not being too eager to punish occasional carelessuess or waywardness.

The colt may now be taken into the road or street, to be gradually accustomed to the oljects amone which his services will be required. Here, from fear or plarfulness, a considerable degree of starting and shying may be exhibited. As little notice as possible should be takien of it. The same or a similar object should he soon passed agrain, lut at a greater distance. If the colt still shies, let the distance be farther increased, until he takes no notice of the object. Then he may be gradually brought nearer to it, and this will be usually effected without the slightest difficulty; whereas, had there been an attempt to force him close to it in the first instance, the remembrance of the contest would have been associated with every appearance of the olject, and the habit of shying would have been established.

Hitherto, with a cool and patient breaker, the whip may hive been shown, but will scarcely hase been used ; the colt must now, however, be accustomed to this necessary instrument of authority. Let the breaker walk by the side of the animal. and throw his riglit arm over his back, holding the reins in his left, occasionally quickening his pace, and at the moment of doing this, tapping the horse with the whip in his right hand, and at first very gently. The tap of the whip and the quickening of the pace will soon become associated in the mind of the animal. If necessary, these reminders may gradually fall a little heavier, and the feeling of pain be the monitor of the necessity of increased exertion. The lessons of reining in and stopping, and backing on the pressure of the bit, may continue to be practised at the same time.

He may now be tanght to bear the sadile. Some little caution will be necessary at the first putting of it on. The breaker should stand at the heal of the colt, patting him, and engaging his 
attention, while one assistant, on the off-side, gently places the saddle on the back of the animal; and another, on the near side, slowly tightens the girths. If he submits quietly to this, as he generally will when the previous process of breaking-in has been properly conducted, the ceremony of mounting may be attempted on the following, or on the third day. The breaker will need two assistants in order to accomplish this. He will remain at the head of the colt, patting and making much of him. The rider will put his foot into the stirrup, and bear a little weight upon it, while the man on the off-side presses equally on the other stirrup-leather; and, according to the docility of the animal, he will gradually increase the weight, until he balances himself on the stirrup. If the colt is uneasy or fearful, he should be spoken to kindly and patted, or a mouthful of corn be given to him; bnt if he offers serious resistance, the lessons must terminate for that day. He may probably be in better humonr on the morrow.

When the rider has balanced himself for a minute or two, he may gently throw his leg over, and quietly seat himself in the saddle. The breaker will then Jead the animal round the ring, the rider sitting perfectly still. After a few minutes he will take the reins, and handle them as gently as possible, and guide the horse by the pressure of them; patting him frequently, and especially when he thinks of dismounting,-and, after having dismounted, offering him a little corn or green meat. The use of the rein in checking him, and of the pressure of the leg and the touch of the heel in quickening his pace, will soon be taught, and his education will be nearly completed.

The horse having thus far submitted himself to the breaker, these pattings and rewards must be gradually diminished, and implicit obedience mildly but firmly enforced. Severity will not often be necessary. In the great majority of cases it will be altogether nncalled for: but shonld the animal, in a moment of waywardness, dispute the command of the breaker, he must at once be tanght that he is the slave of man, and that we have the power, by other means than those of kinduess, to bend him to our will. The education of the horse should he that of a child. Pleasure is, as much as possible, associated with the early lessons ; but firmness, or, if need be, coercion, must establish the habit of obedience. Tyranny and cruelty will, more speedily in the horse than even in the child, provoke the wish to disobey; and, on every practicable occasion, the resistance to command. The restive and vicious horse is, in ninety-nine cases ont of a hundred, made so by ill-usage, and not by nature. None but those who will take the trouble to try the experiment, are aware how absolute a command the due admixture of firmness and kindness will soon give ns over any horse.

\section{CASTHATION}

The period at which this operation may be best performed depends much on the breed and form of the colt, and the purpose for which he is destined. For the common agricultural horse, the age of four or five months will be the nost proper time, or, at least before he is weaned. Few horves are lost when cut at that age. Care, however, should be taken that the weather is not too hot, nor the flies too numerous. We enter our decided protest, however, against the recommendation of valuable but incautious agricultural writers, that "colts should be cut in the months of June or July, when files pester the horses, and cause them to be continually moving about, and thereby prevent swelling." One moment's reflection will convince the reader that nothing can be more likely to produce intlammation, and consequent swelling and danger, than the torture of the flies hovering romd and stinging the sore part.

If the horse is designed either for the carriage or for heavy draught, the farmer should not think of castrating him until he is at least a twelve month old; and, even then, the colt should be carefully examined. If he is thin and spare about the neck and shoulders, and low in the withers, he will materially improve by remaining uncut another six months; but if his fore-quarters are fairly developed at the age of a twelve-month, the operation should not be delayed, lest he become heavy and gross before, and perhaps has begun too decidedly to have a will of his own. No specific age, then, can be fixed; but the castration shonld be performed rather late in the spring or early in the autumn, when the air is temperate, and particularly when the weather is dry. No preparation is necessary for the sucking colt, but it may be prudent to bleed and to plysic one of more advanced age. In the majority of cases, no after-treatment will be necessary, except that the animal should be sheltered from intense heat, and more particularly from wet. In temperate weather he will do much better running in the field than nursed in a close and hot stable. The moderate exercise that he will take in grazing will be preferable to perfect inaction. A large and well-ventikated box, however, may be permitted.

The manner in which the operation is performed will he properly left to the veterinary surgeon. The haste, carelessuess, and brutality, of the common gelder should no longer be permitted; but the veterinary surgeon should be able and willing to discharge every portion of his duty. The old method of opening the scrotum on either side, and cutting off the testicles, and preventing hremorrhage by a temporary compression of the vessels while they are seared with a hot iron must not,perhaps, le abandoned; but there is no necessity for that extra pain, and that appearance, at least, of bru- 
tality, which occur when the spermatic cord (the blood-ressels and the nerve) is as tiglitly compressed between two pieces of wood as in a powerful vice, and left there until either the testicle drops off, or is removed on the following day by the operator.

To the practice of some farmers, of twitching their colts at an early period, sometimes even so early as a month, there is stronger oljection. When the operation of twitching is performed, a small cord is drawn as tightly as possible round the bag, between the testicle and the belly. The circulation is thus stopped, and, in a ferv days, the testicles and the bag drop off; lut not until the animal has sadly suffered. It is occasionally necessary to tighten the cord on the second or third day, and inflammation and death have frequently ensued.

Another mode of castration has been lately introduced, which bids fair to supersede every other: it is called the operation by Torsion. An incision is made into the scrotum, as in the other modes of operation, and the vas deferens is exposed and divided. The artery is then seized by a pair of forceps contrived for the purpose, and twisted six or seven times round. It retracts as soon as the hold on it is quitted, the coils are not untwisted, and all bleeding has ceased. The testicle is removed, and there is no sloughing or danger. The most painful part of the operation-the application of the firing iron or the clams-is aroided, and the wound readily beals.

\section{CHAPTER XVI.}

THE FORE LEGS.

WE arrive now at those parts of the frame which are most essentially connected with the action and value of the horse, and oftenest, and most annoyingly, the suljiects of disease. The extremities contain the whole apparatus of voluntary motion, with which the action, and speed, and strength of the horse are most eoncerned.

We commence with the upper portion. of which the fore extremity, the shoulder, is seen at $G$, page 263.

THE SHOULDER.

The scamila or shondder-blade, situnted forward on the side of the chest, is a bone of a somewhat triangular shape, with its apex or narrowest point downward, and its broar and thin expansion upward. The point of the shoulder lies opposite to the first and second ribs; the linder expansion of the base reaches as far back as the seventh rib; it therefore extends obliquely along the chest. It is divided, externally, into two mequal portions by a rislge or spine running through almost the whole of its extent, and designed, as wil] be presently seen, for the attachment of important muscles. The liroad or upper part having no muscles of any consequence attached to it, is terminated by cartilage.

The shoulder-blade is united to the chest by musele alone. There is one large muscle, with very remarkable tendinous fibres and of immense strength (the serratus major, greater saw-shaped muscle). attached to the chest, and to the extensive smooth internal surface of the shoulder-blade, and by which, assisted, or rather strengthened, by the muscles of the breast, the weight of the body is supported, and the sbock of the widest leap, or the most rapid motion, sustained. Ilaul there been a bony union between the shoulder and the body, the vital parts contained in the chest could not have endured the dreadful shock which they would occasionally have experienced ; nor could any bone have long remained whole if exposed to such violence. The muscles within the shoulder-blade act as powerful and safe springs. They yield, as far as necessary, to the force impressed upon them. By their gradual yielding they destroy the violence of the slock, and then, by their elastic power, immediately regain their former situation.

\section{SPRAIN OF THE SHOULDER.}

These muscles are occasionally injured by some unexpected shock. Although in not more than one case in twenty is the farrier right when he talks of his shoulder-lameness, yet it cannot be denicd, that the muscles of the sloulder are occasionally sprained. 'This is effected oftener by a slip or side-fall, than by fair, although violent exertion. It is of considerable importance to be able to distinguish this shoulder-lameness from injuries of other parts of the fore extremity. There is not much tenderness, or heat, or swelling. It is a sprain of muscles deeply seated, and where these symptoms of injury are not immediately evident. If, on standing before the horse, and looking at the size of the two shoulders, or rather their points, one should appear evidently larger than the other, this must not be considered as indicative of sprain of the muscles of the shoulder. It probably arises from bruise of the point of the sloulder, which a slight examination will determine.

The symptoms, however, of shoulder-lameness can scarcely be mistaken; and, when we relate them, the farmer will recollect that they very 
seldom occurred when the village smith pointed to the shoulder as the seat of disease, and punished the animal to no purpose. In sprain of the shoulder the horse evidently suffers extreme pain while moving, and, the muscle underneath being inflamed and tender, he will extend it as little as possible. He will drag his toe along the ground. It is in the lifting of the foot that the shoulder is principally moved. If the foot is lifted high, let the horse be ever so lame, the shoulder is little, if at all, affected. In sprain of the back sinews, it is only when the horse is in motion that the injured parts are put to most pain; the pain is greatest here when the weight rests on the limb in shoulder-lameness, and there is a peculiar quickness in catching up the limb the moment the weight is thrown on it. This is particularly evident when the horse is going down hill, and the injured limb bears an additional portion of the weight. In the stable, too, when, in other cases, the horse points or projects one foot before the other, that foot is usually flat on the ground. In shoulder-lameness, the toe alone rests on the ground. The circumstance which most of all characterises this affection is, that when the foot is lifted and then brought considerably forward, the horse will express very great paiu, which he will not do if the lameness is in the foot or the leg. This point has been longer dwelt upon, in order that the reader may be enabled to put to the test tho many cases of shoulder-lameness, which exist only in the imagination of the groom or the farrier.

In sprain of the internal muscles of the shoulder, few local measures can be adopted. The horse should be bled from the vein on the inside of the arm (the plate vein), because the blood is then abstracted more immediately from the inflamed part. A dose of physic should be given, and fomentations applied, and principally on the inside of the arm, close to the chest, and the horse should be kept as quiet as possible. The injury is too deeply seated for external stimulants to have very great effect, yet a blister will properly be resorted to, if the lameness is not speedily removed. The swimming of the horse is an inluman practice: it tortures the animal, and increases the iuflammation. The pegging of the shoulder (puncturing the skin, and blowing into the cellular structure beneath until it is considerably puffed up) is another relic of ignorance and barbarity.

\section{SLANTING DIRECTION OF THE SHOULDER.}

The lessening or breaking of the shock, from the weight being thrown violently on the fore legs, is effected in another way. It will be observed, that (see G and $J$, p. 263 ) the shoulder-blade and the lower bone of the shoulder are not connected together in a straight line, but form a very considerable angle with each other. This will be more evident from the following cut, which represents the fore and hind extremities in the situations which they occupy in the horse.

This angular coustruction of the limbs reminds us of the similar arrangement of the springs of a carriage, and the ease of motion, and almost perfect freedom from jolting, which are thereby perfect free
obtained.

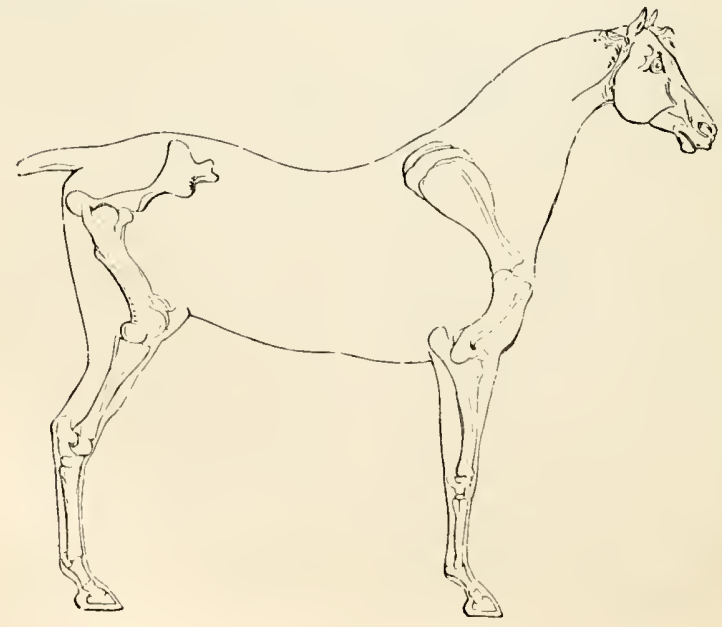


It must not perhaps be said, that the form of just in proportion as the point of the shoulder the spring was borrowed from this construction is bronght forwarl and elevated, will be the forof the limbs of the horse, but the effect of the ward action and elevation of the limb, or the carriagc-spring beautifully illustrates the connex- space passed over at every effort. ion of the different bones in the extremities of this quadrinped.

The obliquity or slanting direction of the shoulder effects other very nseful purposes. That the stride in the gallop, or the space passed over in the trot, may be extensive, it is necessary that the fore part of the animal should be considerably elevated. The shoulder, by means of the muscles which extend from it to the inferior part of the limb, is the grand agent in effecting this. Had the bones of the shoulder been placed more upright than we see them, they could not then have been of the length which they now are,-their connexion with the chest could not have been so secure,-and their movements upon each other would have been comparatively restricted. The slightest inspection of this cut, or of that at page 263 , will show that,
The slanting shoulder accomplishes a most useful olject. The inuseles extending from the shoulder-blade to the lower bone of the shoulder are the powers by which motion is given to the whole of the limb. The extent and energy of that motion depend much on the force exerted or the strength of the muscle, but there are circumstances in the relative situations of the different bones which have far greater influence.

Let it be supposed that, by means of a lever, some one is endeavouring to raise a certain weight.

$A$ is a lever, resting or turning on a pivot $\mathrm{B}$; $\mathrm{C}$ is the weight to be raised; and $\mathrm{D}$ is the power, or the situation at which the power is applied. If the strength is applied in a direction perpendicular to the lever, as represented by the line $\mathrm{E}$, the

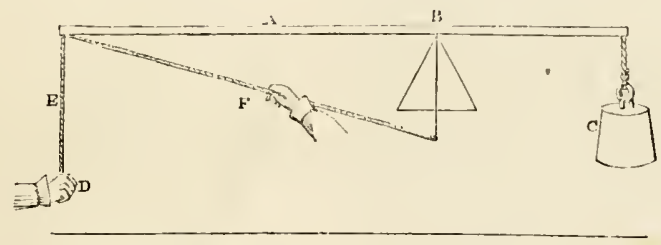

power which must be exerted can easily be calculated.

In proportion as the distance of the power from the pivot or centre of motion exceeds that of the weight from the same place, so will be the advantage gained. The power here is twice as far from the centre as the weight is, and therefore advantage is gained in the proportion of two to one: or if the weight is equal to $200 \mathrm{lbs}$., a force of 100 ibs. will balance it. If the direction in which the power is applieil is altered, and it is in that of the line F, will 1001hs. effect the purnose? No; nothing like it. How, then, is the necessary power to lie calculated? The calculation of the force which must be exerted in a direction intermediate between the directions of the line $\mathrm{E}$, and of the lever A B, involves questions of geometry, somewhat foreign to the object of these pages. But though the exact estimation of the power to be exerted at intermediate positions is a question of some difficulty, a very little consideration will serve to show that the forre to be applied, increases with, and in a greater degree than, the angle between the directions of $\mathrm{E}$ and $\mathrm{F}$. For suppose the direction of $F$ to coincide with that of $A B$, then no force exerted, however great, would sup-. port $\mathrm{C}$, the whole effect being to move the lever in the direction of its length.

Let the shoulder of the horse be considered. The point of the shoulder-the shoulder-joint-is the pivot or centre of motion; the leg attached to the bone of the arm is the weight; the shoulderblade being more fixed, is the part whence the power emanates, and the muscles extending from the one to the other are the lines in which that power is exerted. These lines approach much more nearly to a perpendicular in the oblique than in the upright shoulder (see cut). In the upright one, the shoulder-blade and the bone of the arm are almost in a straight line, and the real action and power of the muscle are most strangely diminished. In this point of view the oblique shoulder is most important. It not only gives extensive action, but facility of action. The power of the muscles is more than doubled by being exerted in a line approaching so much nearer to a perpendicular.

There is yet another advantage of the oblique shoulder. The point of the shoulder is projected forward; and therefore the pillars which support the fore-part of the horse are likewise placed proportionably forward, and they have less weight to 
carry. They are exposed to less concussion, and especially concussion in rapid action. The horse is also much safer; for having less weight situated before the pillars of support, he is not so likely to have the centre of gravity thrown before and beyond them by an accidental trip; or, in other words, he is not so likely to fall; and he rides more pleasantly, for there is far less weight bearing on the hand of the rider, and annoying and tiring him. It likewise unfortunately happens that nature, as it were to supply the deficiency of action and of power in an upright shoulder, has accumulated on it more muscle, and therefore the upright shoulder is proverbially thick and cloddy ; and the muscles of the breast which were designed to strengthen the attachment of the shoulders to the chest, and to bind them together, must, when the point of the shoulder lies backward, and under the horse, be proportionably thickened and strengthened, and the horse is thus still more heavy before, more unpleasant, and more unsafe to ride.

Then, ought every horse to have an oblique shoulder? No! The question has relation to those horses that are designed to ride pleasantly, or from which extensive and rapid action is required. In them it has been said that an oblique shoulder is indispensable: but there are others which are seldom ridden; whose pace is slow and who have nothing to do but to throw as much weight as possible into the collar. To them an upright shoulder is an advantage, because its additional thickness gives them additional weight to throw into the collar, which the power of their hinder quarters is fully sufficient to accomplish; and because the upright position of the shoulder gives that direction to the collar which enables the horse to act upon every part of it, and that inclination of the traces which will enable his weight or power to be most adrantageously employed.

An improved lireed of our heavy draughthorses has of late yeals been attempted, and with much success. Sufticient uprightness of shoulder is retained for the purposes of draught, while a slight degree of obliquity has materially quickened the pace and improved the appearance.

Above its junction with the lumerus, or lower division of the limb, the shoulder-blade forms what is called the point of the shoulder. There is a round blunted projection best seen in the cut (p. 418). The neck of the shoulder-blade there forms a shallow cavity, into which the head of the next bone is received.

The cavity is shallow because extensive motion is required, and because both of the bones being so moveable, and the motion of the one connected so much with that of the other, dislocation was less likely to occur. A capsular ligament, or one extending round the heads of both bones, confines them securely together.

This joint is rarely or never dislocated; and, should it suffer dislocation, the muscles of the slroulder-blade and the lower bone of the shoulder are so strong, that the reduction of it would be impossible. The point of the shoulder, however, projecting considerably, is much exposed to injury from accident or violence. Even turning in a narrow stall has inflicted a serious bruise. Fomentations of warm water will usually remove the tenderness and lameness, but should they fail, blood should be taken from the plate vein, or, in very obstinate cases a blister should be resorted to.

A description of the principal muscles of the shoulder-blade, their situation, attachments, and use, may not be uninteresting to the lover of the horse, and may guide his judgment as to the capability and proper form of that noble animal.

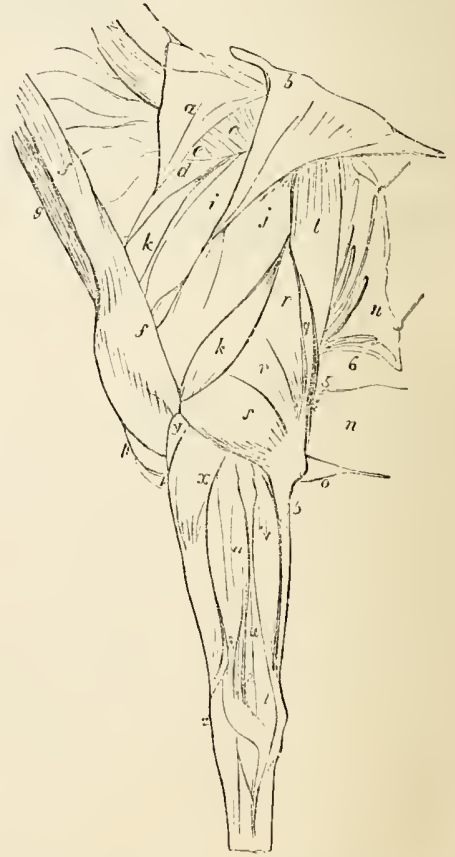

CET OF MUSCLES ON THE OUTSIDE OF THE SHOULDER,

$a$ and $b$, in the above cut, represent a portion of the Trapesius muscle attached to the longer 
bones of the withers broadly and strongly and to the ligament and fasciæ of the neck (a portion of which is seen at $b$ ), narrowing lelow, terminating almost in a point, and inserted into a tubercle on the spine or ridge of the shoulder-blade. It occupies the space between the withers and the upper part of the shoulder-blade, and is large and strong in proportion to the height of the withers, and the slanting of the shoulder. Its nse is evidently to elevate and support the scapula-to raise it, and likewise to draw it backward; therefore, constitnting one of the most important muscles connected with the action of the horse, and illustrating the advantage of high withers and a slanting shoulder. A portion of it is represented as turned back, in order to show other muscles beneath. A moment's inspection will convince the reader that although a low forehand and thick shoulder are very properly objected to, yet still some fulness and fleshiness are necessary, ever about the withers; otherwise, althongh there may be height of withers, and obliquity of shonlder, to give extensive action, there will not he sufficient muscular power to work the machine with either quickness or continuance.

At $c$ is a portion of the levator humeri, (the raiser of the shoulder), descending from the tubercle of the head (see cut, page 263), and from the base of the temporal bone, and attaching itself to the first four bones of the neck, and to the ligagament of the neck ; inserting itself into the covering of the muscles of the shoulder, and those about the point of the shoulder, and at length terminatiug in a ridge on the body of the humerus, arising from the greater tubercle. It is a muscle of immense power and great utility, raising and drawing forward the shoulder and the arm, or, when these are fixed, turning the head and neck if one only acts, and depressing them if the muscles on both sides act at the same time.

At $d$ is a portion of the serratus magnus muscle, between the shoulder and side of the chest, and constituting the bulk of the lower part of the neck. It is deeply seated, arising from the fourth, fifth, sixth, and seventh bones of the neck anteriorly, and attached posteriorly to the eight first ribs. All its fibres tend towards and are inserted into the inner surface of the shoulder, and by means of them the shoulder is attached to the chest, and the immense weight of the body supported. The use of this muscle in obviating concussion, has already been spoken of.

When the horse is standing, this muscle occasionally discharges another important function. The shoulders and legs are then rendered fixed points by the weight of the body, and this muscle exerts all its power in dilating the cavity of the chest, and thus materially assists in the act of breathing. Therefore, as was stated when that disense was treated of, a horse labouring under inflammation of the lungs will obstinately stand night and day, in order that he may obtain the assistauce of this muscle in respiration, which is become laborious and painful; and for the same reason it is that we regard his lying down as one of the most favourable symptoms, because it sliows us that the breathing is so much relieved as not to ueed the assistance of this muscle.

At $e$ is a small portion of the splenius muscle, which was spoken of when the neck was described, p. $33 \%$.

$f$ represents a muscle sometimes described as a portion of the lavator humeri, or elevator of the shoulder, arising from the nipple-shaped process or tubercle of the temporal bone, running down the somewhat lateral but fore part of the neck, inserted into the upper and middle part of the lower bone of the shoulder, and thence continued down to the arm. Its office is to bend the head : or, the head and neck being fixed, to elevate and bring forward the arm. It is in powerful action when the horse is rumuing at his speed with the head projected.

At $g$ is a portion of the sterno maxillaris, or muscle common to the fore part of the chest and the lower jaw, and described at p. 337.

$h$ designates the principal portion of this muscle extending from the slioulder to the hnmerus, and emplored in drawing this bone towards the shonlder-blade, and bending the whole of the limb. Exceedingly powerful action is required from this muscle, therefore it is very tendinous, and inserted in such a direction as to act with great mechanical advantage, and that advantage increased in proportion to the slanting position of the shoulder.

The muscle $i$, antea spinatus, is situated on the onter and anterior part of the shoulder, below and behind the muscle next mentioned; and its office is to extend the humerus on the scapula. It is also attached to the greater tubercle of the humerus, and to a bony ridge extending from it to the capsular-ligament of the shoulder-joint. Its action is to assist in the flexion of the humerus, and to give it a motion outwards.

The muscle $j$, postea spinatus, belind the spine or ridge, occupies that space of the shoulder, and is inserted into the outer and upper head of the bone. It draws this bone outward and upward.

At $k$, is a muscle common to the breast and the shoulder-blade, and called the pectoralis parrus. It arises from the breast-bone, and reaches to the corering of the shoulder-joint, and the muscles of the shoulder. Its action, in common with that of a larger muscle, seen at $m$, the great pectoral, is to draw the head of the shonlder backward, and also the lower part of the shoulderblade, aud to give the latter a more upright position. 
At $q$ is the tendon of a very important muscle, / site direction to the shoulder-blade. At the upper the extensor longus of the arm, reaching from the upper angle aud the posterior border of the shoulder-blade to the point of the elbow and the inside of the arm, and which will be presently described. At $r$ and $s$ are the three divisions of another muscleconcernerl in the same office, arising from the shoulder-blade and the lower bone of the shoulder, and likewise attached to the point of the elbow by a very strong tendon.

This cut represents the muscles on the inside of the shoulder and fore-arm. $a$ is a very prominent one. It is called the pectoralis transversus (the muscle crossing the breast). It arises from the first four bones of the sternum, and runs across to the inner part of the arm; it is also attached to the inforior part of the body of the humerus, and to the fascia covering the arm, and reaching a considerable way down the arm. The use of this muscle is obvious and important. It binds the arm to the side of the horse; it keeps the legs straight hefore the horse when he is at speed, that the weight of the body may be received on them in a direction most easy and safe to the horse and to the rider, and most advantageous for the full play of all the muscles concerned in progression. Considering the nnevenness of surface over which a horse often passes, and the rapid turnings which are sometimes necessary, these muscles have enough to do; and when the animal is pushed beyond his strength, and these muscles are wearied, and the fore-legs spread ont, and the horse is "all abroad," the confused and unpleasant mauner of going, and the sudden falling off in speed, are well known to every rider. Mr. Percivall very properly observes, that this muscle has probably more to do in enabling the arm to support weight than to give it motion.

$$
\begin{aligned}
& \text { THE HCMERUS, OR LOWER BONE OF THE } \\
& \text { SHOULDER. }
\end{aligned}
$$

Forming a joint with the shoulder-blade at the pint of the shoulder is the humerus. It is a short strong bone, slinting hackward in an oppo- part it has a large round head, received into the shallow cavity of the shoulder-blade, or, as Mr. Percivall has graphically described it, "it is the segment of a globe, smooth and polished, evidently for the purpose of playing like a spherical hinge within the cup-like concavity occupying the place of the apex of the scapula. There are no two bones in the skeleton whose articular connexion is of a nature to admit more varied and extensive motion than exists between the scapula and the humerus. If we attempt to lift a horse's fore-leg, we camnot merely bring it forward and carry it backward, but we can also to a considerable extent make it perform a sort of rotary motion, in consequence of the mobility existing in this joint between the socket of the scapula and the head of the humerus."* It has several protuberances for the insertion of muscles, and is terminated below by two condyles or heads, which in front receive the principal bone of the arm between them as in a groove, thus adding to the security and strength of the joint, and limiting the action of this joint, and of the limb below to mere bending and extension, without any side motion. Farther behind these heads receive the elbow deep between them, in order to give more exteusive action to the arm. In a well-formed horse this hone can scarcely be too short, in orler that the fore-legs may be as forward as possible, for reasons already stated, and because, when the lower bone of the shoulder is long, the shoulder must be too upright. Dislocation can scarcely occur in either of the attachments of the bone, and fracture of it is almost impossible. The lower bone of the shoulder and the shoulder-blade are by horsemen confounded together, and included under the appellation of the shoulder, and in compliance whth general usage we have described thcm as combining to form the shoulder.

Among the muscles arising from the hnmerus are too short and very strong ones, seen at $r$ and $s$, page 420 , the first proceeding from the upper part of this bone to the elbow, and the second from the internal part, and likewise going to the elbow, and both of them being powerful agents in extending the leg.

In front, at $y$, is one of the muscles of the humerus, the external one employed in bending the arm, arising from the inner and back part of the neck and body of the hnmerus, turning obliquely round that bone, and inserted into the inner and upper part of the bone of the arm.

\section{THE ARM.}

The arm, extending from the elbow to the knee (see $\mathrm{K}$ and L, p. 263 and also cut. p 420), consists, in the young liorse, of two distinct bones.

\footnotetext{
- Veterinarian, vol. xv., p. 307.
} 
The long and front bone, called the radius, is nearly straight, receiving into its upper end the lower heads of the humerus; and the lower end corresponding with the upper layer of the bones of the knee. The short and hinder bone is called the ulna. It has a very long and powerful projection, received letween the lieads of the humerus, and called the elbow; it then stretches down, narrowing by degrees (see L, p. 263, and the cut, p. 420) to below the middle of the front bone, where it terminates in a point. The two bones are united together by cartilage and ligament; but these are by degrees absorbed and changed to bone, and before the horse becomes old the whole of the arm consists of one bone only.

It will be perceived that, from the slanting direction of the humerus, the weight of the horse, and the violence of the concussion, will be shared between the radius and the ulna, and therefore less liable to injure either. The circumstance, also, of so much weight and jar being coumunicated to them, will account for the extensive and peculiarly strong union between these bones in the young horse; the speedy inflammation of the uniting substance and absorption of it, and the substitution of bone, and complete bony union between the radius and ulna in the old horse. The immense muscles that are attached to the point of the elbow likewise render it necessary that the union between these bones should be very strong.

The arm is a most important part of the horse, as will be seen when we deseribe the muscles that belong to it. The museles $q, r$, and $s$, proceeding from the shoulder-blade and the humerus, and inserted into the elbow, have been already spoken of. They are the grand agents in extending the arm; and in proportion to the power which they exert, will be the quickness and the length of the stride. The strength of the horse, so far as his fore-limbs are concerned, principally resides here. Then there will naturally be a large and muscular arns, and such a formation of the limb, and particularly of the elbow, as will enable these muscles to act with most advantage.

The principle of the lever (referred to at $p$. 419 ) is here beautifully applicable. The elbow. joint is the centre of motion; the whole of the lower part of the leg is the weight to be raised; and the power by which it is to be raised in one act of progression, the extending of the limb, is the muscles inserted into the elbow. In proportion as the weight is more distant than the power from the centre of motion, as it is in the construction of this limb, so will be the greater degree of energy requisite to be exerted. Supposing that the weight, taking the knee to he the centre of it, is eighteen inches from the elbow. joint-that the limb weighs 60 lbs., and that the elvow projects two inches from the joint-then an energy equal to nine times the weight, or jathib., will be needed to nove and extend the limb. because the weight is nine times farther from the centre of motion than the power is. If in another horse the point of the elbow projects three incbes from the joint, the weight of the leg remaining the same, only six times the force, or $3601 \mathrm{bs} .$, will be required, making a difference in, or saving of, muscular action, equal to $180 \mathrm{lbs}$. in each extension of the arm. If a few pounds in the weight of the rider tell so much for or against the horse in a long race, this saving of power must make an almost incalculable difference; and, therefore, judges of the horse rightly attach so much importance to the depth of tlie elbow, or the projection of the point of the elbow from the joint.

When deseribing the proper obliqui $y$ of the shoulder, it was stated that the power was exerted with most advantage in a line perpendiculir to the arm of the lever, and that the slightest deviation from that line was manifestly disadvantageous. If the reader will examine the cut, he will per ceive that muscles from the shoulder and the bone of the arm take a direction much nearer to a perpendicular line in the long than in the short elbow, and therefore act with proportionably greater advantage; and if this advantage from the direction in which the power is applied to that which we gain from the increased length of the bone is considered, it will be plain that the addition of one-third to the length or projection of the elbow would be attended by a saving of one half in the expenditure of muscular power. There is, however, a limit to this. In proportion as the elbow is lengthened, it must move over a greater space in order to give the requisite extension to the limb; and consequently the muscles which act upon it must be lengthened, otherwise, al though the action might be easy it would be confined. There must be harmony of proportion in the different parts of the limb, but a deep elbow, within a certain range, is always connected witl increased power of action.

The elbow is sometimes fractured. If the animal is placed in the hands of a skilful veterinarian, although the chances of cure are certainly against the horse, yet the owner needs not to despair. The treatment of fracture of the elbowjoint will be considered in its proper place.

Enlargements sometimes appear aliont the elbow, either the consequence of a violent blow, or from the calkins of the shoes injuring this part when the horse sleeps with his legs donbled under him. If a seton is passed through the tnmour, it will sometimes rapidly diminish, and even disappear; but if it is of considerable magnitude, the skin should be opened along the middle of the swelling, and the tumour dissected out.

The elhow-joint is sometimes punctured, either 
accidentally, or through the brutality of the groom or carter. The swelling is often rapid and extensive, and fatal inflammation may ensue. Rest, and the closure of the wound, are the most imIortant considerations.

There are other muscles of the fore-arm employed in extending the limb. At $x$, page 420 , is the principal one, called the extensor metacarpi. It is attached superiorly to the outer and fore parts of the external condyle of the humerns, and also to the capsular ligament, and inferiorly to the antero-superior part of the great metacarpal bone. Its superior attachments are principally feshy, with a few tendinous fibres interposed. These diminish towards the centre, but a little lower down is a tendon, round at its origin. but gradually growing flat and expanding in breadth towards its termination. Its office is to extend the leg.

The next muscle in situation and importance is seen at $w$, and called the extensor pedis. It rises from the fore part of the external conilyle of the humerus, and pursues its course down the leg, and expanding after it has passed the fetlock, it serves the purjose of a capsular ligament, covering and adhering to the pastem joints. Its office is to extend the foot and pasterns, and, at the same time, to assist in the extension of the knee.

At $u$, page 120 , is the tendon of another extensor muscle, and at $z$ a curions ublique one, passing over the tendon of $x$, confining it in its situation, and likewise itself assisting in extending or straightening the leg.

The muscles employed in bending the leg are both numerous and powerful. Two of the superficial ones are given in the cut, page 422 . 'The first is at $t$, page 420 ; it is also seen at $b$, page 420. It is ealled the flexor medius metacarpi, because its office is to bend the leg. The other is seen at $v$, page 420 . It is called the flexor metacarpi extermus, and is also designed to flex the leg.

The internal flexor is seen at $e$. Its office is also to bend the leg.

A portion of one of the most powerful of the flexor muscles, and porterful indeed they must be, is delineated at $c$, page 420 . It is the flexor brachii. It rises flom the extremity of the ridge of the shoulder-blade in the form of a large and round tendon, which runs between two prominences in the upper part of the front of the lower bone of the shonlder, and in as perfect a groove or pulley as art ever contrived. This groove is lined with smooth cartilage; and between it and the tendon there is a secretion of vily fluid, so that the tendon may play freely in the pulley without friction. Having escoped from this pulley, and passed the head of the lower bone of the shoulder, the cord swells out into a round fleshy body, still containing many tendinous fibres. Deeply seated, it contributes materially to the bulk of the front of the arm, and is inserted into the head and neck of the bone of the arm, and likewise into the capsular ligament of the ellow joint. It is the muscle by which, almost alone, the whole of the leg below the arm is bent, and carried forward and upward.

It acts at great disadvantage. It is inserted into the very head of the bone of the arm, and expanded even upon the joint. Then the power is applied almost close to the centre of motion, while the weight to be raised is far distant from it. The power is thirty times nearer the centre of motion than is the weight; and, calculating. as before, the weight of the arm and the rest of the limb at $60 l b s .$, it must act with a force of thirty times sixty, or 1800 lbs. In addition to this, the line of the direction of the force strangely deviates from a perpendicular. The direction of the muscle is nearly the same as that of the limb, and the mechanical disadvantage is almost incalculably great. If it is calculated at only ten times more, this muscle, and its feeble coadjutors, act with a force of ten times 1800 , or $18,0001 \mathrm{lss}$.

Why this almost incredible expenditure of muscular power? That the beauty of the limb might be preserved, and the joint be compact. If the tendon had been inserted half-way down the arm, the elbow-joint would have offered a very unsightly appearance.

Beauty of form, however, is the least result of this conformation. Extensive and rapid motion are among the excellences of the horse. $\mathrm{He}$ is valuable in proportion as he bas them combined with stoutness; and ly this conformation of the limb coukl he alone olitain them. Therefore the tendon is at first unusually strong; it plays through the natural but perfect pulley of the bone of the arm without friction; the body of the musele is mixed with tendinous fibres, and the insertion into the fore-arm is very extensive, lest the application of such immense force should tear it from its adhesions. There is sufticient strength in the apparatus; the power may be safely applied at this mechanical disadvantage; and it is applied close to the joint to give an extent and rapidity of motion which could not otherwise have been obtained, and without which the horse would have been comparatively useless.

At the back of the arm are other flexor muscles of great power, to bend the lower portions of the limb. Two of them have been described belonging to the arm and the leg, and some very peculiar ones acting on the feet must not be omitted. Only a small portion of one of them can be seen in our cut, p. 420 , at 1 .

The first is the fexor pedis perforatus. It is 
deeply scated in the posterior part of the arm, where, with the perforans, it forms a thick fleshy mass, the tendons issuing from which are adapted to the convexity and concavity of each other. As it descends along the bone of the arn, it becomes tendinous; and, approaching the knee, it is bound dawn by arches or bands of ligament, that it may not start in sudden and riolent action. Proceeding from the knee, it midens, and partly wraps round the tendon of the perforating muscle, and they run down together in contact, yet not adhering; freely playing over each other, and a mucous fluid obviating all friction. Both of them are enclosed in a sheath of dense cellular substance, attached to them by numerous fibrils; and they are likewise supported by various ligamentous expansions.

Near the fetlock the tendon still further expands, and forms a complete ring round the tendon of the perforating muscle. This is seen at $\mathrm{J}, \mathrm{p}$. 299. The use of this will be best explained when the fetlock is treated of.

The perforated tendon soon afterwards divides, and is inserted into the smaller and larger pastern bones, and serves to flex or bend the fetlock and joints, as it had previously assisted in the flexion of the knee.

The flexor perforans muscle has nearly the same origin as the perforatus; but it continues muscular farther down the arm than it, and lies before it. At the knee its tendon passes, like the perforatus, under strong ligamentary arches, which confine it in its situation. It then becomes round, and is partly enveloped in the perforatus, and at the fetlock is entirely surrounded by it. It emerges from the perforatus when that tendon divides, and continues its progress alone after the other has inserted itself into the pasterns, and, passing over the navicular bone, is broadly implanted into the posterior cavity of the foot.

It is sufficiently plain that the arm should be large and muscular, otherwise it could not discharge all these duties. Horsemen differ on a variety of other points, but here they are agreed. A full and swelling fore-arm is the characteristic of every thorough-bred horse. Whatever other good points the animal may possess, if the arm is narrow in front and near the shoulder, flat on the side, and altogether deficient in muscular appearance, that horse is radically defective. He can neither raise his knee for rapid action, nor throw his legs sufficiently forward.

The arm should likewise be long. In proportion to the length of the muscle is the degree of contraction of which it is capable; and in proportion also to the degree of contraction will be the extent of motion in the limb beneath. A racer, with a short arm, would be sadly deficient in stride; a hunter, with the same defect, would not he able to double his legs well under him in the leap.
There is, however, a medium in this, and the advantige of length in the arm will depend on the use to which the horse is applierl. 'T'he lady's horse, the cavalry horse, every horse in which prancing action is esteemed a beauty, and in which utility is, to a certain degree, sacrificed to appearance, must not be too long in the arm. If he is long there, he will be proportionably short in the leg; and although this is an undoulited excellence, whether speed or continuance is regarded, the short leg will not give the grand and imposing action which fashion may require. In addition to this, a horse with short legs may not have quite so easy action as auother whose length is in the shank rather than in the arm.

\section{THE KNEE}

The Knee (M, p. 263, and eut, p. 418), answering to the human wrist, constitutes the joint or joints between the arm and the shank or leg: and is far more complicated than any joint that his been yet considered. Beside the lower heads of the bone of the arm, and the upper heads of the three bones of the leg, there are no less than six other bones interposed, arranged in two rows, three in each row, and the seventh placed behind.

What was the intention of this complicated structure. A joint between the elbow and the fetlock was absolutely necessary to the action of the horse. An inflexible pillar of that length could scarcely have been lifted from the ground, much less far enough for rapid or safe motion. It was likewise necessary, that the interposing joint should be so constituted as to preserve this part of the limb in a straight direction, and possess sufficient strength to resist all common work and accidents. Being in a straight direction, the shock or jar between the ends of the bones of the arm and the leg would be dreadful, and would speedily inflict irreparable injury. The heads of all bones are covered with elastic cartilage, in order to protect them from injury by concussion; but this would be altogether insufficient here. Six distinct bones are therefore placed here, each covered above and below by a thick coating of cartilage, counected together by strong ligaments, but separated by interposed fluids aud membranes. The concussion is thus spread over the whole of them-slared by the whole of them; and, by the peculiarity of their connexion, rendered harmless.

These six distinct bones, united to each other by numerous and powerful ligaments, will also afford a far stronger joint than the apposition of any two kones, however perfect and strong might be the capsular ligament, or by whatever other ligaments it might be strengthened. In addition to the comnexion between the individual bones, there is a perfect capsular ligament here, extending from the bone of the arm to those of the leg; and 
the result of the whole is, that the hardest work and the severest accidents produce little deformity, and no dislocation in the knee; nor do the shocks and jars of many a year cause inflammation or disease. It is an undeniable fact, that such is the perfect construction of this joint, and to so great a degree does it lessen concussion, that the injuries resulting from hard work are, almost withont an exception, found below the knee, which seems to escape the injuries of the hock. There is a remarkable difference in the effects of work on the knee and the hock. The knee is subject to enormous concussion in its strict sense. The hock to a somewhat different work. The knee altogether escapes lony enlargements and inflammations of the ligaments, like spavins; and, what is more remarkable, it also escapes the damages to which the anterior fetlock is liable from precisely the same concussion as the knee.

The seventh bone, the trapezium, so called from its quadrangular figure, is placed (see M, p. 263) behind the others, and does not bear the slightest portion of the weight. It, however, is exceedingly useful. Two of the fiexor muscles, already described, proceed from the bone of the arm, and are inserted into it; and being thus thrown off the limb, have a less oblique direction given to them, and, therefore, according to the principle of the lever, act with considerably more power. It is also useful in another way. As the tendons of the various nuuscles descend the limbs, they are tied down, as we have described, by strong ligamentous bands: this is particularly the case in the neighbourbood of the joints. The use of it is evident. The extensor tendons, which lie principally on the front of the leg, are prevented from starting and strengthened and assisted in their action; but the flexor tendons which are at the back would be liable to friction, and their motion impeded, if they were bound down too tightly. This projecting bone prevents the annular or ring-like ligament from pressing too closely on the main flexor tendons of the foot; and, while it leaves them room to play, leaves room likewise for a little bag filled with mucus to surround them, which mucus oozing slowly out, supplies the course of the tendons with a fluid that prevents much injurious friction.

The knee should be broad. It should present a very considerable width, compared with the arm above, or the shank below. In proportion to the breadth of the linee is the space for the attachment of muscles, and for the accumulation of ligamentous expansions and bands. In propor$t$ ' on to the breadth of the knee there will be more strength : and likewise the direction of some muscles will be less oblique, and the course of others will be more removed from the centre of motion, in either of which cases much power will be gained.

\section{BROKEN KNEES.}

The treatment of broken knees is a sulject of considerable importance, for many horses are sadly blemished, and others are destroyed, by wounds in the knee-joint. The horse, when falling, naturally throws his knees forward; they receive all his weight, and are sometimes very extensively lacerated. The first thing to be done is, by very careful washing with warm water, to cleanse the wound from all gravel and dirt. It must then be ascertained whether the joint is penetrated. The grating of the probe on one of the bones of the knee, or the depth to which the probe enters the wound, will too plainly indicate that the joint has been opened. Shonld any doubt exist, a linseed-meal ponltice must be applied. This will at least act as a fomentation to the round, and will prevent or abate inflammation; and when, twelve hours afterwards, it is taken off. the symovia or joint-oil, in the form of a glairy, rellowish, transparent fluid, will be seen, if the capsular ligament has been penetrated. Should doubt remain after the first poultice, a second ought to be applied.

It having been ascertained that the interior of the joint is not injured, attention must be paid to the wound that is actually made. The horse should wear a cradle to prevent his getting at the wound. A stimulating application-the common black-oil of the farrier is as good as any-should be lightly applied every day until healthy pus is produced on the wonnd, and then a little friar's balsam will probably effect a cure.

The opening of the joint, however, being ascertained, the first and immediate care is to close the orifice; for the fluid which separated and lubricated the bones of the knee being suffered to escape, they will be bronght into contact with and will rub apon each other; the delicate membrane with which they are covered will be highly inflamed; the constitution will be speedily affected, and a degree of fever will ensue that will destroy the horse; while, in the mean time, of all the tortures that can be inficted on the poor animal, none can equal that which accompanies inflammation of the membranes lining the joints.

The manner of closing the orifice must be left to the judgment of the veterinary surgeon, who alone is capable of properly treating such a case. It may be effected by a compress enclosing the whole of the wound, and not to be removed for many days; or it may be attempted by the old and generally successful method of applying the hot iron over the wound, and particularly over the spot where the ligament appears to be lacerated. A poultice may then be placed on the part, and the case treated as a common wound. The surgeon will find no difficulty in determining whether the sharp edge of the common firing-iron slonld be 
usel, as would be the case if the laceration is considerable, or whether the budding-iron sbould be resorted to. After the use of the cautery, the applicatiou of a blister may, in some cases, be ser. viceable. Should the joint-oil continue to flow, the iron may be applied a second, or even a third time. By its application, so much swelling is produced on the immediate puncture, and in the neighbouring parts, as mechanically to close and plug un the orifice.

If, however, the opening into the joint is extensive, and the joint-oil continues to flow, and the horse is evidently suffering much pain, humanity will dictate that he should be destroyed. The case is hopeless. A high degree of fever will ere long carry him off, or the inflammation will cause a deposit of matter in the cavity of the joint that will produce incurable lameness.

The pain caused by the iron is doubtless great; it is, however, necessary: but let no reader of "The Horse" permit the torturing experiments of the farrier to be tried, who will frequently inject stimulating fluids, and even oil of vitriol, into one of the most seusible and irritable cavities in the whole frame.

A person well acquainted with the anatomy of the part will judge of the probability of a favourable result, not merely by the extent, but by the situation of the wound. If it is low down, and opposite to the bottom row of the bones of the kuee, a small opening into the joint will be easily closed. A larger one needs not to cause despair, because there is little motion between the lower row and the bones of the leg. If it is high up, there is more danger, because there is more motion. If it is situated opposite to the mion of the two rows, the result is most to be dreaded, because between these is the principal motion of the joint, and that motion will not only disunite and irritate the external wound, but cunse dreadful friction between the bones brought into actual contact with each other, through the loss of the joint-oil.

Among the various methods of treating opened knee-joint, where the lesion is very considerable, is oue introduced by Mr. Turner, of Croydon, which must not be passed over in silence. The wound having been cleansed, a paste is prepared composed of wheaten flour and table-beer, which are stirred together and boiled for five minutes, or until they become of the cousistence commonly used by paper-hangers. This is spread on the wound, and round the joint, and four inches above and below it. Pledgets of tow are passed over this and confined in their places by means of a stocking, and over the whole is another layer, and another stocking or bandage. 'This is not removed until the joiut has closed, and the synovia ceases to flow. On the second or third day the bandage will become dry and hard, and cause considerable pain. It must not be meddlet with lefure or behind, but four longitudinal incisions may be made through the bandages on earh side, which will sufficiently liberate the joint and reusove the pain.*

When the knee has been mucl lacerated, although the wound may be healed, some blemish will remain. The extent of this blemish will depend on that of the original wuund, and more especially on the nature of the treatment that has been adopted. Every caustic application will destroy a portion of the skin, and leave a certain mark. Should the blemish be cousiderable, a mild blister may be applied over the part. after the wound has healed. It will stimulate the liair to grow more rapidly and thickly round the scar, and particularly liair of the natural colour; aud, by contracting the skin, it will lessen the scar itself. Many persons have great faith in ointments thit are said to promote the growth of the hair. If they have this property, it must be from their stimulating the slin in which the roots of the hair are imbedded. These ointments usually contain a small portion of blistering matter, in the form of turpentine, or the Spanish-fly. The common application of gunpowder and lard may, by blackening the part, conceal the blemish, lut can have no possible effect in quickening the growth of the hair.

In examining a horse for purchase, the knees should be very strictly scrutinised. A small blemish on them should not induce us at once to coudemn the animal for a bad rider, for the merest accident may throw the safest horse. A broken knee, however, is a suspicious circumstance, and calls for the most careful olservation of the make and action of the horse. If it is accompanied by a thick and upright shoulder, and legs far under the horse, and low slovenly action, he is unwise who does not take the hint. This faulty conformation has produced its natural consequence. But if the shoulder is oblique, and the pastem of the proper length and inclination, and the fore-arm strong, the good judge will not reject the animal because he may have been accidentally thrown.

THE I.EG.

The part of the limb between the linee and the fetlock consists of three bones-a large one before. called the cannon or stank, and two sualler or splint bones belind (see N, p. 263). The shaulibone is rounded in front, and flattened, or even concave behind. It is the straightest of the long bones, as well as the most superficially situated, for in some parts it is covered only by the slin. The upper head is flat, with slight ilepressions corresponding with the lower row of the bones of the knee. The lower head is differently and

* A full acconnt of this interesting operation may be found in the Veterin trian for 1829 . 
cnîiously formed. It resembles a double pulley. There are three elevations; the principal one in the centre, and another on each side. Between them are two slight grooves, and these so precisely correspond with the deep depressions and slight prominences in the upper head of the larger pastem, and are so enclosed and guarded by the elevated edges of that bone, that when the shank-bone and pastern are fitted to each other, they form a perfect linge. They admit of the bending and extension of the limb, but of no lateral or side motion. This is a circumstance of very great importance in a joint so situated, and having the whole weight of the horse thrown upon it.

The snaller bones are placed behind the larger ones on either side. A slight projection of the head of each can alone be seen in front. The heads of these bones are enlarged, and receive part of the weight conveyed by the lower row of the bones of the knee. They are united to the larger bone by the same kind of substance which is found in the colt between the bone of the elbow and the main bone of the arm; and which is designed, by its great elasticity, to lessen the concussion or jar when the weight of the animal is thrown on them. They reach from one-lalf to two-thirds of the length of the shank-bone, and, through their whole extent, are united to it by this substance; but, as in the elbow, from the animal being worked too soon, or too violently, inflammation ensues - bony matter is deposited in the room of the ligamentous, and a bony union takes place instead of the natural one. There is no doubt that the ease of motion is somewhat lessened by this substitution of bone, but other elastic principles are probably called into more powerful action, and the value of the horse is not perceptibly impaired, although it is laard to say what secret injury may be done to the neighbouring joints, and the cause of which, the lameness not appearing until a distant period, is not suspected.

In this process, however, mischief does often immediately extend to the neighbouring parts. The disposition to deposit bone reaches beyond the circumscribed space between the larger and smallex bones of the leg, and a tumour, first callons, and afterwards bony, is found, with part of its base resting on the line of union between these bones. This is called a

SPLINT.

The splint is invariably found on the ontside of the small bones and generally on the inside of the leg (c, p. 436). Why it should appear on the outside of the small bones it is difficult to explain, except that the space between these bones is occupied by an important mechanism, which will be presently described; and, as in the case of abscess, a natural tendency was given to them to determine outward, that vital parts might not be injured. The cause of their almost exclusive appearance on the inside of the leg admits of easier explanation. The inner splint-bone is placed nearer the centre of the weight of the body than the other, and, from the nature of its connexion with the bones of the knee, actually receives more of the weight than does the outer bone, and therefore is more liable to injury, and inflammation, and this consequent deposit of bony matter. The inner bone receives the whole of the weight transmitted to the small bone of the knee. It is the only support of that bone. A portion only of one of the bones rests on the outer split-bone, and the weight is shared between it and the shank. In addition to this, there is the absurd practice of many smiths of raising the outer heel of the shoe to an extravagant degree, which throws still more of the weight of the horse on the inner splint-bone. Bony tumours occasionally appear on other parts of the shank-bone, being the consequence of violent blows or other external injuries, and are commonly called splints.

When the splint of either sort is forming, the horse is frequently lame, for the periosteum or membrane covering the bone is painfully stretched ; but when this membrane has accommodated itself to the tumour that extended it, the lameness subsides, and altogether disaypears, unless the splint be in a situation in which it interferes witl the action of some tendon or ligament, or in the immediate neighbonrhood of a joint. Pressing upon a ligament or tendon, it may cause inflammation of those substances; or, being close to a joint, it may interfere with its action. Splints, then, do not neressarily cause unsoundness, and may not lessen in the slightest degree the action or value of the horse. All depends on their situation.

The treatment of splints, if it is worth while to meddle with them, is exceedingly simple. The hair should beclosely shaved off round the tumour; a little strong mercurial ointment rubbed in for two days; and this followed by an active blister. If the splint is of recent formation, it will generally yield to this, or to a second blister. Should it however resist these applications, it can rarely be advisable to cauterize the part, anless the tunour materially interferes with the action of the suspensory ligament, or the flexor tendon; for it not unfrequently happens, that, although the splint may have apparently resisted this treatment, it will afterwards, and at no great distance of time, begin rapidly to lessen, and quite disappear. There is also a natural process by which the greater part of splints disappear when the horse grows old.

The hydriodate of potash made into an ointment with lard, and a small quantity of mercurial ointment being added, will frequently cause the disappearance of a splint of either sort 
As for the old remedies, many of them liutal enough-bruising the splint with a hammer, boring it with a gimlet, chipping it off with a mallet, sawing it off, slitting down the skin and periosteum over it, sweating it down with hotoils, and passing setons over it-the voice of humanity, and the progress of science, will consign them to speedy oblivion.

Professor Serell has introduced a new treatment of sjlints, which is certainly ingenious, and generally successful. He removes any inflammation about the part by the use of poultices or fomen. tations, and then, the horse being cast, the operation is commenced by pinching up the skin, immediately above the bony enlargement, with the finger and thumb of the left hand, and with the knife, or lancet, or scissors, making an orifice sufficient to introduce a probe-pointed bistoury, with the edge on the convex side. This is passed under the skin along the whole length of the ossification beneath, cutting through the thickened periosteum down to the bone; and this being effectually completed by drawing the knife backwards and forwards several times, a small tape or seton is inserted, and if the tumour is of long standing, kept in during a few days. The operation is attended with very slight pain to the animal. Perhaps slight inflammation may appear, which subsides in a few days if fomentation is used. The inflammation being removed. the enlargement considerably subsides, and in many cases becomes quite absorbed.*

The inside of the leg, immediately under the knee, and extending to the head of the inner splint bone, is sulject to injury from what is termed the speedy cut. A horse with high action, and in the fast trot, violently strikes this part, either with his hoof or the edge of the shoe. Sometimes bony enlargement is the result, at others great heat and tendemess; and the pain from the blow seems occasionally to be so great that the horse drops as if he were shot. The only remedy is to take care that no part of the shoe projects beyond the foot; and to let the inner side of the shoe-except the country is very deep, or the horse used for hunting - have but one nail, and that near the toe. This part of the hoof, being unfettered with nails, will expand when it comes in contact with the ground, and contract when in air and relieved from the pressure of the weight of the body; and, althongh this contraction is to no great extent, it will be sufficient to carry the foot harmlessly by the leg. Care should likewise be taken that the shoe is of equal thickness at the heel and the toe, and that the bearing is equal on both sides.

Immediately under the linee is one of those ligamentous rings by which the tendons are so usefully bound down and secured; but if the hinder

- Vide Veterinarian, vol, riii. p. 501. bone of the knee, the trapezium, described at p. 426 , is not sufficiently prominent, this ring will confine the llexor tendons of the foot too tightly, and the leg will be very deficient in depth under the knee. This is called being tied in below the knee $(b$, p. 436). Every horseman recognises it as a most serious defect. It is scarcely compatible with speed, and most assuredly not with continuance. Such a horse cannot be ridden far and fast without serious sprain of the back sinews. The reason is plain. The pressure of the ring will produce a degree of friction inconsistent with the free action of the tendons ; more force must, therefore, be exerted in every act of progression ; and, although the muscles are powerful, and sufficiently so for every ordinary purpose, the repetition of this extra exertion will tire and strain them.

A more serious evil, however, remains to be stated. When the back sinews, or tendons, are thus tied down, they are placed in a more oblique direction, and in which the power of the muscles is exerted with greater disadvantage. A greater degree of exertion is required, and fatigue and sprain will not unfrequently result. There are few more serious defects than this tying-in of the tendons immediately below the knee. The fore-leg may be narrow in front, but it must be deep at the side, in order to renter the horse valuable; for then only will the tendous have free action, and the muscular force be exerted in the most advantageous direction. There are few good race-horses whose legs are not deep below the knee. If there are exceptions, it is because their exertion, although violent, is but of short continuance. The race is decided in a few minutes, and, during that short period, the spirit and energy of the animal may successfully struggle with the disadvantages of form : but where great and long-continued exertion is required, as in the hunter or the backney, no strength can long contend with a palpably disadvantageous misapplication of muscular power.

As they descend the back part of the leg, the tendons of the perforated and perforating flexor muscles should be far and distinctly apart from the shank-bone. There should be space free from thickening for the finger and thumb on either side to be introduced between them and the bone, and that extending from the knee to the fetlock. In a perfect leg, and towards its lower part, there should be three distmet and perfect projections visible to the eye, as well as perceptible by the finger-the sides of the shank-bone being the most forward of the three; next, the suspensory ligament; and, hindermost of all, the flexor tendons. When these are not to be distinctly seen or felt, or there is considerable thickening alout them and between them ( $d$, p. 436), and the leg is round instead of flat and deep, there has been what is commonly, but improperly, called 
SPRAIN OF THE BACK-SINEWS.

These tendons are enclosed in a sheath of dense cellular substance, in order to confine them in their situation, and to defend them from injury. Between the tendon and the sheath there is a mucous fluid to prevent friction; but when the horse has been over-worked, or put to sudden and violent exertion, the tendon presses upon the delicate membrane lining the sheath, and inflammation is produced. A different fluid is then thrown out, which coagulates, and adhesions are formed between the tendon and the sheath, and the motion of the limb is more difficult and painful. At other times, from violent or long contimued exertion, some of the fibres which confine the tendons are ruptured. A slight injury of this nature is called a sprain of the back-sinews or tendons; and, when it is more serious, the horse is said to have broken dou'n. It should be remembered, however, that the tendon can never be sprained, because it is inelastic and incapable of extension; and the tendon, or its sheath, are scarcely ever ruptured, even in what is called breaking down. The first iujury is confined to inflammation of the sheath, or rupture of a few of the attaching fibres. This inflammation, however, is often very great, the pain intense, and the lameness excessive. The anguish expressed at every bending of the limb, and the local swelling and heat, will clearly indicate the seat of injury.

In every serious affection of this liud, care should be taken that the local inflammation does not produce general disturbance of the system; and, therefore, the horse should be bled and physicked. The bleeding may be at the toe, by which an important local, as well as general, effect will be produced. The vessels of the heart will be relieved, while fever will be prevented. Let not the bleeding be performed in the farrier's usual way of first paring down the sole, and then taking out a piece of it at the toe of the frog; in which case a wound is made often difficult to heal, and through which fungous granulations from the sensible parts beneath will obstinately spring: but, after the sole has been well thimned, let a groove be cut with the rounded head of a small drawing-knife, at the junction of the sole and the crust (see $z$ in the next cut, p. 432). The large vein at the toe will thus be opened, or the groove may be widened backward until it is found. When the blood begins to appear, the vein may be more freely opened by a small lancet thrust horizontally under the sole, and almost any quantity of blood may be easily procured. The immersion of the foot in warm water will cause the blood to flow more rapidly. A sufficient quantity having been withdrawn, a bit of tow should be placed in the groore, and a patten shoe tacked on, by which the heels may be raised from the ground, and much tension removed from the sinews. The bleeding will thus be immediately stopped, and the wound will readily heal.

As a local application, no hot farrier's oil should come near the part, but the leg should be well fomented with warm water two or three times in the day, and half an hour at each time. Between the fomentations, the leg should be enclosed in a poultice of linseed-meal. Any herb that pleases the owner may lie added to the fo. mentation, or vinegar or Goulard's extract to the poultice; for the beneficial effect of both depends simply on the warmth of the water and the moisture of the poultice. All stimulating applications will infallibly aggravate the mischief.

The horse beginning to put his foot better to the ground, and to bear pressure on the part, and the heat having disappeared, the ohject to be accomplished is changed. Recurrence of the inflammation must be prevented, the enlargement must le got rid of, and the parts must be strengthened. The two latter purposes cannot be better effected than by using an elastic bandage-one of thin flannel will be the best. This will sustain and support the limb, while by few means are the alsorbents sooner induced to take up the effused coagulable matter of which the swelling is composed, than by moderate pressure. If the bandage is kept wet with vinegar - to each pint of which a quarter of a pint of spirit of wine has been added -the skin will be slightly stimulated and contracted, and the cold produced ly the constant evaporation will tend to subdue the remaining and deep-sented inflammation. This bandage should be daily tightened in proportion as the parts are capable of learing increased pressure, and the treatment should be persisted in for a fortnight. If, at the expiration of that period, there is no swelling, tendemess, or heat, the horse may gradually, and very cautiously, be put to his usual work.

Should there, however, remain the slightest lameness or considerable enlargement, the leg must be blistered, and, indeed, it would seldom be had practice to blister after every case of severe sprain; for the inflammation may lie deep in the slieath of the tendons, and the part once sprained way long remain weak, and subject to renewed injury, not only from unusual, bat even ordinary exertion. If a blister is resorted to, time should be given for it to produce its gradual and full effeet, and the horse should be afterwards turned out for one or two montls. We must here be permitted to repeat that a blister should never be used while any heat or tendemess remains about the part, otherwise the slightest injury may be, and often is, converted into incurable lamcness.

Very severe sprains, or, much oftener, sprains 
badly treated, may require the application of the cautery. If from long-continued inflammation the structure of the part is materially altered-if the swelling is becoming callous, or the skin is thickened and prevents the free motion of the limb, no stimulus short of the heated iron will be sufficient to rouse the absorbents to remove the injurious deposit. The principal use of firing is to rouse the absorbents to such increased action that they shall take up and remove the diseased thickness of the skin, and likewise the unnatural deposit in the cellular substance beneath. The firiug should be applied in straight lines, because the skin, contracting by the application of the cautery, and gradually regaining its elastic nature, will thus form the best bandage over the weakened part. It should likewise be as deep as it can be applied without penetrating the skin. Here, even more particularly than in the blister, time should be given for the full action of the firing. This removal of diseased matter is a work of slow progress. Many weeks pass away before it is perfectly accomplished; and, after firing, the horse should have at least a six months', and it would be better if he could be given a twelve months' run at grass. When the animal has been set to work in a few weeks, and the enlargement remains, or lameness returns, the fault is to be attributed to the impatience of the owner, and not to the want of power in the operation or skill in the operator.

Farriers are apt to blister immediately after firing. A blister may be useful six weeks or two months after firing, if lameness remains ; but can never be wanted immediately after the severe operation of the cautery. If the iron has been skilfully applied, subsequent blistering inflicts on the animal, already sufficiently tortured, much unnecessary and useless pain, and should never be resorted to by him who possesses the slightest feeling of humanity.

In examining a horse for purchase, the closest attention should be paid to the appearance of these flexor tendons. If there is any thickness of cellular substance around them, that horse has been sprained violently. or the sprain has not been properly treated. This thickening will probably fetter the motion of the tendon, and dispose the part to the recurrence of inflammation and lameness. Such a horse, although at the time perfectly free from lameness, should be regarded with suspicion, and cannot fairly be considered as sound. He is only patched up for a while, and will probably fail at the close of the first day's hard work.

\section{WIND GALIS}

In the neighbourhood of the fetlock there are occasionally found considerable enlargements, oftener on the hind-leg than the fore-one, which are denominated wind-galls ( $e$, p. 436.) Between the tendons and other parts, and wherever the tendons are exposed to pressure or friction, and particularly about their extremities, little bags or sacs are placed, containing and suffering to ooze slowly from them a mucous fluid to lubricate the parts. From undue pressure, and that most frequently caused by violent action and straining of the tendons, or, often, from some predisposition about the horse, these little sacs are injured. They take on infiammatiou, and sometimes become large and indurated. There are few liorses perfectly free from them. When they first appear, and until the inflammation subsides, they may be accompanied by some degree of lameness; but otherwise, except when they attain a great size, they do notinterfere with the action of the animal, or cause any considerable unsoundness. The farriers used to suppose that they contained wind-hence their name, wind-galls; and hence the practice of opening them, by which dreadful inflammation was often produced, and many a valuable horse destroyed. It is not uncommon for wind-galls entirely to disappear in aged horses.

A slight wind-gall will scarcely be subjected to treatment; but if these tumours are numerous and large, and seem to impede the motion of the limb, they may be attacked first by bandage. The roller should be of flannel, and soft pads should be placed on each of the enlargements, and bound down tightly upon them. The bandage should also be wetted with the lotion recommended for sprain of the hack-sinews. The wind-gall will often diminish or disappear by this treatment, but will too frequently return when the horse is again hardly worked. A blister is a more effectual, but too often temporary remedy. Wind-galls will return with the renewal of work. Firing is still more certain, if the tumours are sufficiently large and amoying to justify our haring recourse to measures so severe; for it will not only effect the immediate absorption of the fluid, and the reduction of the swelling, but, by contracting the skin, will act as a permanent bandage, and therefore prevent the reappearance of the tumour. The iodine and mercurial ointments have occasionally been used with advantage in the proportion of three parts of the former to two of the latter. 
THE PASTERNS.

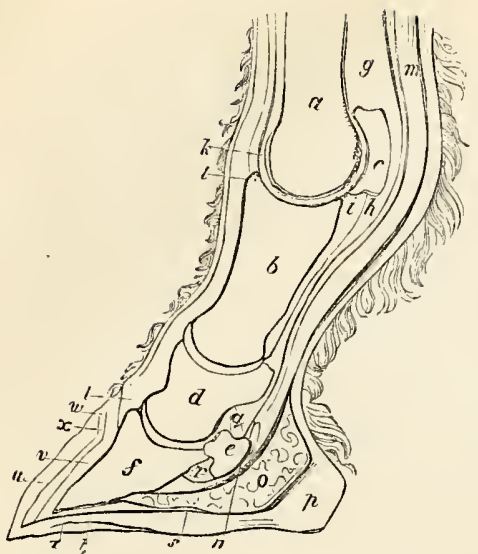

a The shank-ione.

$b$ The upper and larger pastera-bone.

c The sessamoid-bone.

$d$ The lower or smaller pastern-bone.

$e$ The navicular or shuttle-bone.

The coffin-hone, or bone of the foot.

$g$ The suspensory ligament, inserted jnta the sessamoid bone.

h A continuation of the suspensory ligament, inserted in to the smaller pastern booe.

$i$ The small inelastic ligament, tying down the sessamoid bone to the larger pastern-bone.

$k$ A long ligament reacbing from the pastcrn bone to the knee.

$l$ The extensor tendon inserted into butl the pasterus and the coffin-bone.

$m$ The tendon of the perforating flesor inserted into the eoffinbone, after having passed over the naviculur bne.

$n$ The seat of the navicolir joint lameness.

- The inner or sensible frog.

$p$ The cleft of the borny frog

$q$ A liganent uniting the navicular bone to the smaller pastern.

$r$ A ligament nuiting the navicular bone to the coffin-bone.

s The sensible sole, between the coffin-bone and the horny sole.

The horny sole.

$u$ The crust or wall of the foot.

v The sensible lamine to which the crust is attached.

$w$ The coronary ring of the erust.

$x$ The covering of the coronary ligament from which the crust is secreted.

I Place of bleeding at the toe,

At the back of the shank just below the knee, and in the space between the two splint-bones, is found an important ligament, admirably adapted to obviate eoncussion. It originates from the head of the shank-bone, and also from the heads of the splint-bones; then, deseending down the leg, it fills the groove between the splint-bones, bnt is not attached to either of them. A little lower down it expands on either side, and, approaching the pasterns, bifurcates, and the branches are in serted into two little bones found at the baek of the upper pastern, one on each side, ealled the sessamoid bones. (See page 345 , and in this cut, which represents the pastern and foot, sawn through the centre.) The bones form a lind of joint both with the lower head of the shank-bone and the upper pastern-bone, to both of which they are united by ligaments ( $i$ and $g$ ), but much more closely tied to the pastern than to the shank. The flexor tendons pass down between them through a large mucous bag to relieve them from the friction to which, in so confined a situation, they would be exposed. The suspensory ligament is continued orer the sessamoids, and afterwards obliquely forward over the pastern to unite with the long extensor tendon, and downward to the perforated tendon, which it surrounds and fixes in its place, and also to the smaller pastern-bone.

It will he easy to perceive, from this deseription of the situation of the suspensory ligament, why splints placed backward on the leg are more likely to produce lameness than those whieh are found on the side of it. They may interfere with the motion of this ligament, or, if they are large, may bruise and wound it.

The principal action of these ligaments is with the sessamoid bones, which they seem to suspend in their places, and they are therefore called the suspensory ligaments. The pasterns (see preceding cut) are united to the shank in an oblique direetion, differing in degree in the different breeds of horses, and in each adapted to the purpose for which that breed was designed. The reight falls upon the pastern in the direction of the shankbone, and the pastern being set on obliquely, a portion of that weiglit must be communicated to the sessamoids. Mnch concussion is saved by the yielding of the pasterns, in consequence of their oblique direction; and the conenssion which would be produced by that portion of weight which falls on the sessamoid bones is completely destroyed, for there is no bone underneath to receive it. They are suspended by this ligament-an elastic ligament, which gradually jields to, and is lengthened by, the force impressed unon it, and in this gradual yielding and lengthening, materially lesseuing, or generally preventing, all painful or dangerous eoncussion.

If the ligament lengthens, the sessamoid bones must descend when the weight is thrown on them, and it would apnear that they do so. If the thorough-bred horse with his long pasterns is carefully observed as he stands, the tuft at the fetlock will be some inches from the turf; but when he is in rapid motion, and the weight is thrown violently on this joint, the tuft descends and sweeps the very ground. This, however, is from the combined action of the fetlock and pastern-joints, and the sessamoid-bones. The sessamoids do not actually descend; but they revolve, they partly turn over. The strong ligament by which they are attached to the pastern-bone aets as a hinge, and the projecting part of the bone to which the 
suspensory ligament is united, turns round with the pressure of the weight; so that part of the bone becomes lower. How is it raised again? This ligament, strangely constructed as a ligament, is elastic. It yields to the force impressed upon it and lengthens; but as soon as the foot is litted from the ground, and the weight no longer presses, and the force is removed, its elastic power is exerted, and it regains its former dimensions, and the sessamoid-bone springs back into its place, and by that forcible return assists in raising the limb.*

It may be supposed that ligaments of this character, and discharging such functions, will occasionally be subject to injury, and, principally, to strains. Mr. W. C. Spoonert gives a very satisfactory account of this. He says that "hunters and race-horses are considerably more liable to lesions of the suspensory ligament than any other description of horses. The character of these strains is very rarely so acute as that of the tendons. They generally come on gradually with little inHammation or lameness. Occasionally the injury is sudden and severe, but then it is rarely confined to these ligaments, for although they may be principally involved, the neighbouring parts are generally implicated. The usual symptoms are a slight enlargement and lameness at first, or there may be the former without the latter. The enlargement is commonly confined to the ligament below the place of bifurcation, and sometimes one division alone is affected. With the exception of strains of the flexor sinews, this unfits more animals for racing than any other cause-indeed horses are rarely or never fit for the turf after the suspensory ligaments have been diseased," or for hunting.

The case being evidently a lesion of the suspensory ligament, nothing short of firing will be of service.

The length and obliquity of the pastern vary in the different breeds of horses, and on it depends the elastic action of the animal, and the easiness of his paces. The pastern must be long in proportion to its obliquity, or the fetlock will be too close to the ground, and, in rapid action, come violently into contact with it. It is necessary that the fetlock should be elevated a certain distance from the ground, and this may be effected either by a

* Mr. Percivall very clearly describes this : "Furthermore, it seems to us that these elastic parts assist in the elevation of the feet from the ground in those paces in which they are called into sudden and forcible action. The suspensory ligament, by its reaction, instantaneously after its extension, aids the flexor muscles in bending the pastern joints. The astonisbing activity and expedition displayed in the movemenss of the race-horse at speed, seem to be referable, in part, to the promptitude with which the suspensory ligament can act liefure the liesor muscles are duly prepared; the latter, we shuuld say catih, as it were, and then tirect the limb first suatched lirom the ground by the powers of elasticity."-Percivall's Lectures on the Yeterinary Art, val. p. 334.

+ Mr. W. C. Spooner on the Foot and Leg of the Horse, p. 208 short and upright, or a long and slanting pasterı. In proportion as the pastern is oblique or slanting, two consequences will follow, less weight will be thrown on the pastern, and more on the sessamoid, and, in that proportion, concussion will be prevented.

Fvery advantage, however, has, to a certain extent, its corresponding disadvantage. In proportion to the obliquity or slanting of the pastern, will be the stress on the fetlock-joint, and, therefore, the liability of that joint to injury and strain ; and also the liability to sprain of the back-sinews from the increased action and play of the flexor tendons; and likewise to injuries of the pasternjoints, for the ligaments will be weak in proportion to their length. The long and slanting pastern is advantageous in the race-horse, from the springiness of action and greater extent of stride by which it is accompanied. A less degree of it is given in the hunter who is to mite continuance of exertion with ease of pace. For the hackney there should be sufficient obliquity to give pleasantness of going but not enough to endanger continuance and strength. Experience among horses will alone point out the most advantageous direction of the pastern, for the purpose required ; but the slightest observation will show the neessity of considerable variety in the structure of this part. Let the reader imagine the heavy dray-horse with his short and upright pasterns contending in the race; or the race-horse with his long and weak pasterns, endeavouring to dig his toe into the ground in order to move some heavy weight. The concussion which attends the common action of the carthorse is little, because his movements are slow, and therefore the upright and strong pastern is given to him, which he can force into the ground, and on which he can throw the whole of his im. mense weight. The oblique pastern is given to the race-horse because that alone is compatible with extent of stride and great speed. Except a horse for general purposes, and particularly for riding, is very hardly used, a little too much obliquity is a far less evil than a pastern too upright. While the jolting of the upright pastern is an insufferable nuisance to the rider, it is injurious and most unsate to the horse, and produces many diseases in the feet and legs, and particularly ringbone, ossification of the cartilages, and contracted feet.

Strains of the pastern joint are not so frequent, nor so severe as those of the fetlock, but they are not uncommon, especially in horses with pasterns naturally too upright. By careless observers they are not so readily detected as in the fetlock joint, for the increased heat round the pastern joint may be overlooked.

The treatment will not differ materially from that of the fetlock joint. 
LESIONS OF THE SUSPENSORT LIGAMENT.

The suspensory ligament is sometimes strained and even ruptured by extraordinary exertion. The sessamoids, which in their natural state are suspended by it, and from which function its name is derived, are in the latter case let down, and the fetlock almost touches the ground. This is generally mistaken for rupture of the flexor tendon; but one circumstance will sufficiently demonstrate that it is the suspensory ligament which is concerned, viz. that the horse is able to bend his foot. Rupture of this ligament is a bad, and almost desperate case. The horse is frequently lame for life, and never becomes perfectly sound. Keeping him altogether quiet, bandaging the leg, and putting on a high-heeled shoe, will afford the most pro. bable means of relief.

The common injury to this ligament is sprain, indicated by lameness, and swelling, and heat, more or less severe in proportion as the neighbouring parts are inrolved. This will sometimes yield to rest and cooling treatment; but if the case is obstinate, it will be necessary to have recourse to the actual cautery. The hunter and the race-horse are most subject to lesions of these ligaments-the hunter from leaping the fence, and the race-horse from the violent efforts which are occasionally demanded from him. In both cases, the neighbouring parts usually share in the injury, and a cure is rarely completely effected.

The means of cure are the same as in lesions of other joints, but they must be more seriously and perseveringly applied.

\section{THE FETLOCK.}

The fetlock-joint is a very complicated one, and from the stress which is laid on it, and its being the principal seat of motion below the knee, it is particularly subject to injury. There are not many cases of sprain of the back-sinew that are not accompanied by inflammation of the ligaments of this joint; and numerous supposed cases of sprain higher up are simple affections of the fetlock. It requires a great deal of care, and some experience, to distinguish the one from the other. The heat about the part, and the point at which the horse least endures the pressure of the finger, will be the principal guiles. Occasionally, by the application of cooling lotions, the inflammation may be subdued, but, at other times, the horse suffers dreadfully, and is unable to stand. A serious affection of the fetlock-joint demands treatment more prompt and severe than that of the sheaths of the tendons.

GROGGINESS

The peculiarknuckling of the fetlock-joint, and the tottering of the whole of the fore-leg, known by the name of grouginess, and which is so often seen in old and over-worked horses, is seldom an affection of either the fetlock or the pastern-joints simply. Indeed it is difficult to fix on any particular joint, unless it is that which is deep in the foot, and where the flexor tendon runs over the navicular bone. It seems oftenest to be a want of power in the ligaments of the joints generally, produced by frequent and severe sprains, or by ill-judged and cruel exertion. Professor Stewart very truly sars, that " it is common among all kinds of fast workers, and long journeys at a fast pace will make almost any horse groggy. Bad shoeing and want of stable care may help to increase, but never can alone produce grogginess. It is one of the evils of excessive work." " In the majority of cases it admits of no remedy.

\section{CUTTING.}

The inside of the fetlock is often bruised by the shoe or the hoof of the opposite foot. Many expedients used to be tried to remove this; the inside heel has been raised and lowered, and the outside raised and lowered; and sometimes one operation has succeeded, and sometimes the contrary ; aud there was no point so involved in obscurity, or so destitute of principles to guide the practitioner. The most successful remedy, and that which in the great majority of cases supersedes all others, is Mr. Turner's shoe, of equal thickness from heel to toe, and having but one nail, and that near the toe on the inside of the shoe; care being taken that the shoe shall not extend beyond the edge of the crust, and that the crust shall be rasped a little at the quarters.

There are some defects, however, in the natural form of the horse, which are the causes of cutting, and which no contrivance will remedy; as when the legs are placed too near to each other, or when the feet are turned inward or outward. A horse with these defects should be carefully examined at the inside of the fetlock, and if there are any sore or callous places from cutting, there will be sufficient reason for rejecting the animal. Some horses will cut ouly when they are fatigned or lame, and old ; many colts will cut before they arrive at their full strength.

A consideration of the pasterns will throw more light upon this and other diseases of the extremities.

The upper pastern bone $(b, p .432$, and $a$ in the first figure, and $b$ in the second in the following cuts) receives the lower pulley-like head of the slank-bone, and forms a hinge-joint admitting only of bending and extension, but not of side motion; it likenise articulates with the sessamoid-bones. Its lower head has two rounded protuberances, which are received into corresponding depressions - Stewart's Stable Econumy, p. 385. 
in the lower pastern. On either side, above the $\mid$ in front of the bones are seen in the accompanying pastern-joint, are roughened projections for the cut, in which a represents the lower part of the attachment of very strong ligaments, both the capsular ligaments, and many cross ligaments, which render the joint between the two pasterns sufficiently secure.

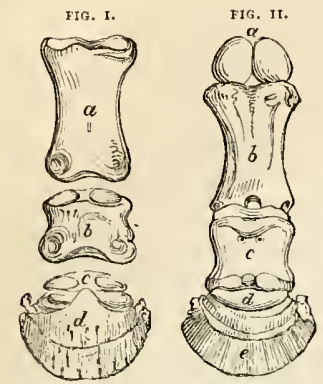

FIG. 1. $-a$ The upper pastern. $t$ The lower pastern. $c$ The navicular bone. $d$ The colfin-bone.

Fig. 2.- $a$ The sessanuid bone. $b$ The upper pastern. $c$ The lower pastern, $d$ The navicular bone. $e$ The coffin-bone, with the horny laminæ.

The lower pastern $(d, \mathrm{p}, 432$, and $b$ in the first figure, and $c$ in the second in this cut) is a short and thick bone with its larger head downward. Its upper head has two depressions to receive the protuberances on the lower head of the upper bone, bearing some resemblance to a pulley, but not so decidedly as the lower head of a shank-bone. Its lower head resembles that of the other pastern, and has also two prominences, somewhat resem. bling a pulley, by which it articulates with the coffin-bone; and a depression in front, corresponding with a projection in the coffun-bone. There are also two slight depressions behind, receiving eminences of the navicular bone. Neither of these joints admit of any lateral motion. The ligaments in of this joint, both the capsular and the cross ones,

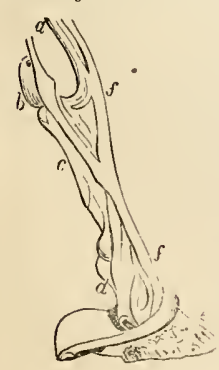
are, like those of the pastern- joint, exceedingly strong. The tendon of the extensor muscle is inserted into the fore part of the upper and lower pastern-bones as well as into the upper part of the coffin-bone $(l, p .432)$; and at the back of these bones the suspensory ligament is expanded and inserted, while a portion of it goes over the fore part of the upper pastern to reach the extensor tendon. These attachments shank-bone; $b$ the sessamoid-bones; $c$ the upper pastern; $d$ the lower pastern; and $e$ the colfin-bone; $f$ are the branches of the suspensory ligaments going to unite with the extensor tendon; $g$ the long extensor tendon; $h$ ligaments comnecting the two pastern-bones together; and $i$ the lateral cartilages of the foot.

\section{SPRAIN OF THE COFFIN-JOINT.}

The proof of this is when the lameness is sudden, and the heat and tenderness are principally felt round the coronet. Bleeding at the toe, physic, fomentation, and blisters are the nsual means adopted. This lameness is not easily removed, even by a blister: and if removed, like sprains of the fetlock and of the back sinews, it is apt to returu, and finally prodnce a great deal of disorganization and mischief in the foot. Sprain of the coffin-joint sometimes becomes a very serious affair. Not being always attended by any external swelling and heing detected only ly heat round the coronet, the seat of the lameness is often overlooked by the groom and the farrier; and the disease is suffered to become confirmed before its nature is discovered.

From violent or repeated sprains of the pastern or coffin-joints, or extension of the ligaments attached to other parts of the pastern-bones, inflammation takes place in the periosteum, and bony matter is formed, which often rapidly increases, and is recognised by the name of

\section{RING BONE.}

Ringhone is a deposit of bony matter in one of the pasterns, and usually near the joint. It rapidly spreads, and involves not only the pastern-bones, but the cartilages of the foot, and spreading around the pasterns and cartilages, thus derives its name. When the first deposit is on the lower pastern, and on hoth sides of it, and produced by violent inflammation of the ligaments of the joints, it is recognised by a slight enlargement, or bony tumour on each sile of the foot, and just alove the coronet. (See $f$ in the accompanying cnt.) Horses with short upright joints, and with small feet and high action, are oftenest, as may be supposed, the subjects of this disease, which is the consequence either of concussion or sprain of the pastern-joints. It is also more frequent in the hind foot than the fore, because from the violent action of the hind legs in propelling the horse forward, the pasterus are more subject to ligamentary injury behind than before: ret the lameness is not so great there, because the disease is confined principally to the ligaments, and the bones have not been injured by concussion; while from the position of the fore limbs, there will generally be in them injury of the hones to be 
added to that of the ligaments. In its early stage, and when recognised only by a bony enlargement on both sides of the pastern-joint, or in some few cases on one side only, the lameness is not very considerable, and it is not impossible to remove the disease by active blistering, or by the application of the cautery: but there is so much wearand tear in this part of the animal, that the iuflammation and the disposition to the formation of bone rapidly spread. The pasterns first become connected together by bone instead of ligament, and thence results what is called an anchylosed or fixed joint. From this joint the disease proceeds to the cartilages of the foot, and to the union between the lower pastern, and the coffin and navicular bones. 'The motion of these parts likewise is impeded or lost, and the whole of the foot becomes one mass of spongy bone. From a disposition to spread, and at first around the pastern-joint, which is situated just above the co. ronet, the disease has acquired the name of ringbone.

This will be

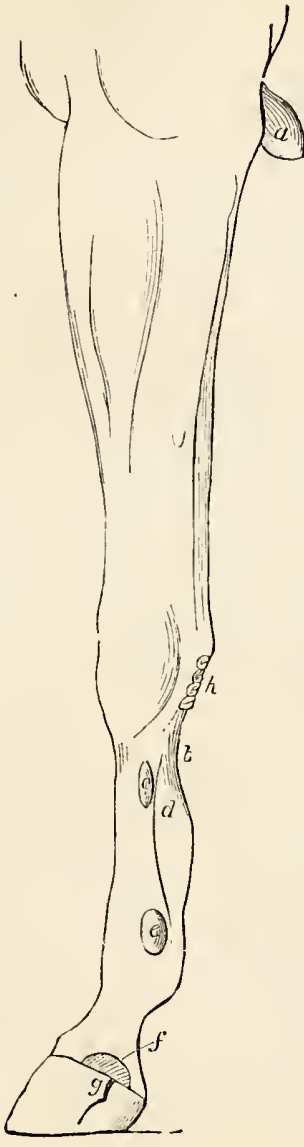

the proper place to introduce a bird's-eye view of some of the principal lamenesses to which the fore extremities of the horse are sulject.

At $a$ is a representation of the capped hock, or enlargement of the joint of the elbow.

$b$ is the tying-in of the leg below the knee.

$c$ is the most frequent situation of splint on the side of the shank-bone, and not producing lameness after its first formation, because it does not interfere with the motion of the linee, nor injure the suspensory ligament.

$d$ is the situation and appearance of the enlargement accompanying sprain of the back sinews. This, however, is an aggravated case; and the sprain may be great, and the lameness distressing, without all this swelling.

$e$ is the place of wind-gall.

$f$ gives the appearance of ringbone when it first appears on the side of the pastern, about the joint, and where there is naturally some prominence of bone.

$g$ is the situation of saud-crack in the fore-leg.

$h$ the situation of mallenders.

The fore-legs, when viewed in front, should be widest at the chest, and should gradually approach to each other as we descend towards the fetlock. The degree of width must depend on the purpose for which the horse is wanted. The legs of a heavy draught-horse can scarcely be too far apart. His rounded chest enables him to throw more weight into the collar; and not being required for speed, he wants not that occasionally increased expansion of chest which the circular form is not calculated to give. A hunter, a hackney, and a coach-horse should have sufficient expansion of the chest, or the legs sufficiently wide apart, to leave room for the play of the lungs; but depth more than roundness of chest is here required, because the deep chest admits of most expansiou when the horse, in rapid action, and the circulation proportionally quickened, needs most room to breathe: yet if the breast is too wide, there will be considerable reight thrown before, and the horse will be heavy in hand and unsafe.

Whether the legs are near to each other or wide apart, they should be straight. The elbow should not have the slightest inclination inward or outward. If it inclines towards the ribs, its action will be confined, and the leg will be thrown outward when in motion, and describe a curious and awkward curve. This will give a peculiar rolling motion, unpleasant to the rider and unsafe to the animal. The toe will likewise be turned outward, which will not only prevent the foot from coming flat on the ground in its descent, but be usually accompanied by cutting, even more certainly than when the toe turns inward. If the elbow is turned outward, the toes will necessarily be turned inward, which is a great unsightliness, and to a considerable degree injurious, for the weight cannot be perfectly distributed over the foot-the bearing cannot be true. There will also be undue pressure on the inner quarter, a tendency to unsafeness, and a disposition to splint and corn. The legs should come down perpendicularly from the elbow. If they incline backward and under the horse, there is undue stress on the extensor muscles; and, the legs being brought nearer the centre of 
gravity, too great weight is thrown forward, and the horse is liable to knuckle over and become unsafe. If the legs have a direction forward, the flexor muscles are strained, and the action of the horse is awkward and confined. The toe should be found precisely under the point of the shoulder. If it is a little more forward, the horse will probably be deficient in action; if it is more under the horse, unsafeness will be added to still greater defect in going

\section{CHAPTER XVII.}

THE HIND LEGS,

\section{THE HAUNCH.}

THE haunch (see O, p. 263, and the cut p. 418) is composed of three bones. The first is the ilinm, principally concerned in the formation of the haunch. Its extended branches behind the flanks are prominent in every horse. When they are more than usually wide, the animal is said to be ragged-hipped. A branch runs up to the spine at the commencement of the sacral vertebræ (E), and here the haunch-bones are firmly united with the hones of the spine. The ischium, or hip-bone, is behind and below the ilium. Its tuberosities or prominences are seen under the tail (cut, p. 263). The pulis unites with the two former below and behind.

From the loins to the setting on of the tail a line should be carried on almost straight, or rounded only in a slight degree. Thus the haunch-bones will be most oblique, and will produce a corresponding obliquity, or slanting direction, in the thigh-bone-a direction in which, as stated when the fore legs were described, the muscles act with most adrantage. This direction of the hannch is characteristic of the thorough-bred horse; and by the degree in which it is found, we judge to a considerable extent of the breeding of the animal. If the bones at D and E, p. 263, take a somewhat arched form, as they do in the cart-horse, it is evident that the haunch-bone $O$ would be more ppright. The thigh-bone $\mathrm{P}$ would likewise be so. The stifle $\mathrm{Q}$ would not be so far under the body, and the power of the horse would be considerably impaired. The oblique direction of the baunch and thigh bones, produced by the straightness of the lime of the spine, does not, as is commonly supposed, afford increased surface for the attachment of muscles, but places the muscles in a direction to act with great advantage. It is in the advantageous direction, quite as mich as in the bolk of the mnscle, that the strength of the horse consists.

It will be seen, from the different cuts, that the angles formed ly the fore and hind extremities have different directions. One points forward, and the other backward. The action of the fore legs thus least interferes with the chest, and that of the hind legs with the belly.

Width of haunch is a point of great consequence, for it eridently affords more room for the attachment of muscles; and eren though it should be so wide as to subject the horse to the charge of being ragged-hipped, and may somewhat offend the eye, it will not often be any detriment to action. If the loins are broad and the horse well ribbed home, the protuberances of the ilium cau scarcely be too far apart. Many a raggedhipped horse has possessed both fleetness and strength, while but few that were narrow across the haunch could boast of the latter quality.

The opening in the centre of these bones, which constitutes the passage through which the young animal is expelled from the mother, is large in the mare, and in every quadruped, because there cannot, on account of the form of the animal, be any danger of abortion from the weight of the foetus pressing ou the part.

The only portion of these bones exposed to injury or fracture are the tuberosities or prominences of the hannch. A fall or blow may chip off or disunite a portion of them, and, if so, there are $n 0$ means of forcibly bringing the disunited parts together again, and retaining them in their natural position. The power of nature, however, will gradually unite them, but that uniou will be attended by deformity and lameness. A charye, or very strong adhesire plaster, across the haunch, may be useful, as helping, in some slight degree, to support the parts, and hold them together.

\section{THE THIGH.}

In the lower and fore part of the hip-lones is a deep cavity or cup for the reception of the head of the thigh-bone.* Although in the movement of the hind legs there cannot be the coneussion to which the fore legs are exposed (for the weight of the bouly is never thrown violently upon them). yet in the powerful action of these limbs there is

* This, although the true thigh-bone, is so concealed hy thick muscles that its situstion and shape are not visible to the eve. It is therefore frcquently overlooked by horsemen, who call the ncxt bone, extending from the stifle to the hock, the thigh. 
much strain on the joints, and we shall, therefore, find that there are, in all of them, admirable provisions against injury. The head of the upper bone of the thigh is receired into a deep cup the acetabulum), by which it is surrounded on every side, and dislocation from which would seem almost impossible. But the bouy eup may give way? Not so ; provision is made against this. All three of the hiunch-bones unite in the formation of this cup, and the sutures by which they are held togegether are of such a nature, that, generally speaking, no shock, or exertion, or accident, can disunite them. There is even something more in order to make the attachment doubly sure. In addition to the usual capsular and other ligaments, a singularly strong one rises from the base of the cup, and is inserted into the head of the thigh-bone, seeming as if it would render separation or dislocation altogether impossible. Such, however, is the strange power of the muscles of the hind limbs, that, with all these attachments, sprain of the ligaments of the thigh, or the round bone, as horsemen call it, and even dislocation of it, are occasionally found.

The thigh-bone is both the largest and strongest in the frame. It is short and thick, and exbibits the most singular prominences, and roughnesses, and hollows, for the insertion of the immense muscles that belong to it. Four prominences, in particular, called by anatomists trochanters, two on the outside, one on the inside, and one near the head of the bone, afford attachment to several important muscles. The bead of the bone is placed at right angles with its body, by which this important advantage is gained, that the motion of the thighjoint is principally limited to the act of bending and extending, although it possesses some slight lateral, and even some rotatory action. The lower head of the thigh-bone is complicated in its form. It consists of two prominences, which are received into corresponding depressions in the next bone, and a hollow in front, in which the bone of the knee or stifle plays as over a perfect pulley.

A short description of the muscles of the hinder extremities may not be uninteresting to the horseman. The next cut will entain a few of them.

The muscles of the hinder extremity are more powerful than those of any other part of the frame, therefore an extraordinary provision is made to confine them in their respective situations, aud thus contribute to their security and strength. When the skin is stripped from any part, we do not at once arrive at the muscles, but they are thickly covered by a dense, strong, tendinous coat, intended to confine them to their places. This membrine, called the faseia, is of extraordinary strength in the hind quarter, and reaches over the whole of the hannch and thigh, and only ceases to be found at the hock where there are no muscles to be protected. If the power of the muscles is suffcient to dislocate or fracture the thigh-bone, they need the support and confinement of this tendinous coat. When this tendinous band is dissected off, another is found beneath, which is represented at $a$, raised and turned lack, larger than the former, thicker and more muscular. It proceeds from the haunch-bones to the stifle, upon the fore and outer part of the haunch and thigh, and is intended to tighten and strengthen the other.

Under the part of this flat and binding muscle, which is represeuted in our cut as raised from its

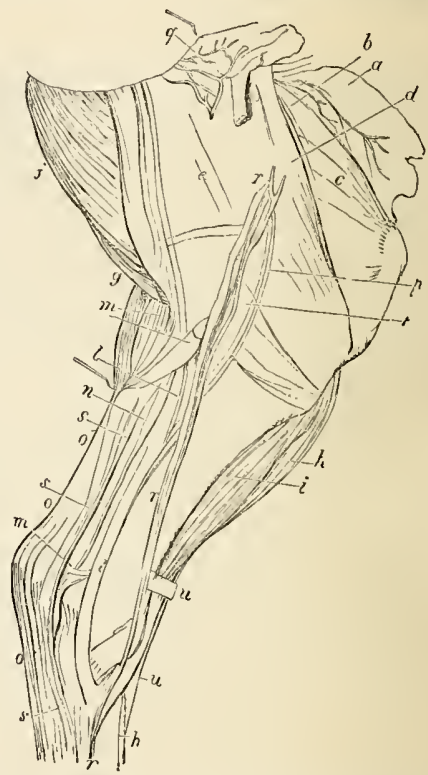

natural situation, is a large round one proceeding from the ilium, not far from the cup which receives the upper bone of the thigh, and running straight down this bone, and thence its name rectus. It is inserted into the bone of the stifle. An inspection of the cut, p. 263, will show that it is so situated as to be enabled to exert its great power in the most advantageous way. It is a very prominent muscle, and possesses immense strength. It terminates in a tendon, which is short and very strong, and which is, before its insertion into the patella, united with the prolongation of the tendinous substance at $q$, in the cut, p. 439 , and also with the tendon of the muscle at $i$, in that cut, and at $c$, in the following cut, and which is properly 
called rustus, from its great bulk. Some have divided this into two muscles: the external and internal. The external arising from the outer surface of the upper hone of the thigh ; the internal from the inner surface; and they are inserted into the upper part of the bone of the stifle, both on the inner and outer side. These muscles act at considerable mechanical disadvantage. They form a very slight angle, not at all approaching to a right angle; but they are muscles of immense size, and occupy all the fore part of the thigh from the stifle upwards. They are powerful extensors of the thigh, and of the hinder leg generally ; for they are all inserted into the bone of the knee, and that is connected by strong tendons with the bone of the true leg.

On the inside of the thigh are several other large fleshy muscles, which will be easily recog. nised on the thigh of the living horse. First is a long, narrow, prominent musele, the sartorius, $d$, arising partly from the lumbar vertebrie, and extending down the thigh-assisting in binding the leg, and turning it inward-giving it a rotatory motion, and also aiding in many of the natural actions of the horse.

Next comes a broad, thin musele, the gracilis, $e$, occupying the greater portion of the surface of the inner part of the thigh, and particularly the prominent part of it. It arises from the lower portion of the haunch-bone, and, in its passage downward uniting with the last muscle, is inserted with it into the inner and upper part of the tibia. It acts with great mechanical disadvantage, but its power is equal to the task. It bends the leg and rotates it inward.

Still, on the inside of the thigh, and forming the posterior edge of the thigh inwards, and contributing much to its bulk, is another important muscle, the pectineus. Part of it acts with very great mechanical advantage, and powerfully flexes the thigh on the pelvis, and lifts and bends the leg. It is one of the most effectual of the extensor muscles. Considering the weight of limb which it has to raise and flex, it had need to possess great power.

We now turn to some of the muscles that are evident to the eye on the outside of the thigh.

First is the glutceus externus, situated in the middle of the external part of the haunch. It is of a triangular figure, attached to the anterosuperior and to the inferior spines of the ilinm, and is inserted into the smaller outer prominence of the upper bone of the thigh. Next is the great glutans muscle, arising from the spinous and transverse processes of several of the bones of the loins, and from the sacrum, and from the different edges of the ilium, and inserted into the great protuberance of the upper bone of the thigh (p. 263), behind and a little above the joint that unites the thigh to the haunch-bone. It is seen at $c$, in this cut. It constitutes the upper and outer part of the

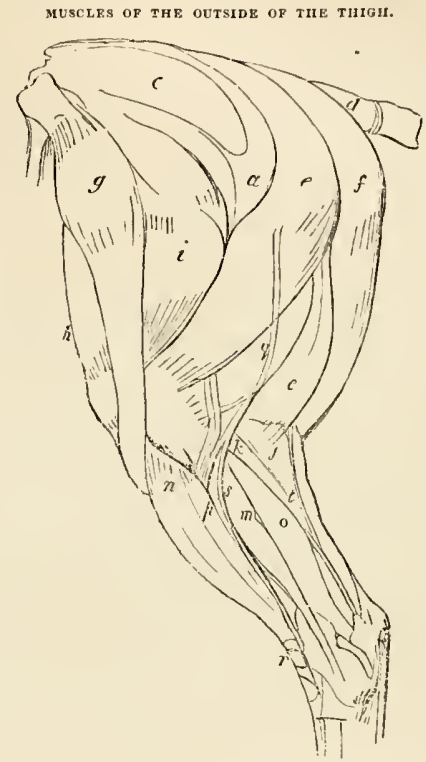

haunch, and gives that fulness and roundness to it which good judges so much admire in the quarters of the horse. It is one of the main instruments in progression. When the thigh has been brought forward under the body by the muscles already described, the plain action of these glutæi muscles is to extend the haunch, and force or project the body onward. To effect this they must be very powerful, and therefore they are so large, and rise from such an extensive surface. They ought, also, to act at great mechanical advantage, and so, in one sense, they do. Springing from the loins and the ilimm and the sacrum, they act almost in a right, or perpendicular line; in that line in which we have seen that the greatest power is gained.

There is another and smaller glutaus muscle under that which has been last described, arising likewise from the back of the ilium, inserted into the same protuberance of the thigh-bone, and assisting in the same office. It is not visible in the cut.

These museles, as Mr. Percivall well explains it, are extensors either of the femoris upon the pelvis, or the pelvis and loins upon the hind quarter. When the limb has been carried in advance under the body by the muscles of the anterior 
femoral region, and the toe firmly set domn upon the ground, the glutei, by extending the hannch, will carry the trunk forward; thus becoming potent agents in progression, and the maximus being the most powerful of them.

In the acts both of rearing and kicking these muscles are thrown into violent and forcible contraction. In the former action the limbs become the fixed points and the trunk the reight moved, and vice versa in the latter.;

There are also several other muscles proceeding from different parts of the haunch-bones, aud inserted about the heads of the upper thigh-bone, and performing the same work; but there are two muscles to which we must particularly refer. The first occupies the outer part of the quarter behind, and is beautifully dereloped in the bloodhorse; it is found at e, p. 439. It arises high up from the bones of the spine, from others at the root of the tail, from the protuberances of the ischium (vide cut, p. 263), and from other bones of the pelvis. It in fact consists of two muscles, but is usually described as one muscle with two heads biceps femoris, the tro-headed muscle of the thigh. It is situated on the postero-external side of the haunch and thigh, where, being superficial, it is well marked in the living animal. The two divisions of it have an opposite action. The anterior or superior one assists the rasti in ex-

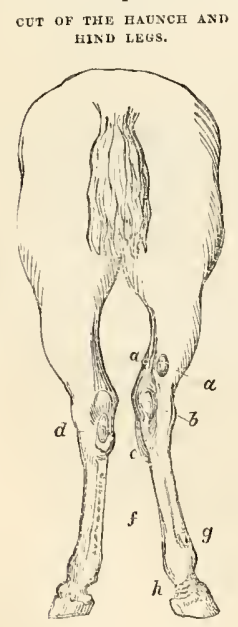
tending the thighthe posterior one flexes it. They both, however, co-operate in abducting the limb, and also in rotating it forward, the hock, at the same time, turning outwards.

Those muscles alone have beeu se. lected which are particularly prominent in the thorongh-bred horse, and are the source of his strength and speed. The annexed cut, containing one excellence above and many defeets below, will not be unacceptable here:-

The Os Femoris, or Thigh Bone (see $P_{s}$ p. 263), is long and eylindrical, taking an oblique direction from above, downwards; and from

* Percivall's Anatomy, p. 148. behind, forwards. At its upper extremities, and projecting from the boly, is a thick flattened neck, terminating in a large smooth hemispherical head, adapted to a hollow, or acetabulum, in the superior point of the haunch.

This bone is commonly called the Round Bone. It has, in some rare instances, been dislocated and fractured. It is much oftener sprained, but not so frequently as the groom or farrier imagines. There is nothing peculiar in the lameness to detect injury of this part, except that the horse will drag his leg after him. Injury of the round bone will be principally discovered by heat and tenderness in the situation of the joint.

A part so deeply situated is treated with diffienlty. Fomentations should first be used to abate the inflammation, and, after that, an active blister should be applied. Straius of this joint are not always immediately relieved, and the muscles of the limb in some cases waste considerably: it therefore may be necessary to repeat the blister, while absolute rest should accompany every stage of the treatment. It may even be requisite to fire the part,-or, as a last resort, a charge may be placed over the joint, and the horse turned out for two or three months.

Proceeding from the body of the bone is a large irregular projection, rising from a kind of pyramidal eminence (see p. 263), and into which are implanted various powerful muscles.

\section{THE STIFLE.}

The inferior extremity presents a pulley-like articulatory surface in front, over which plays the patella, and two condyles, rouuded and smooth, presenting inferiorly and posteriorly, and which are receired into slight depressions on the upper surface of the lower bone; while in frout is a curious groove, orer which plays a small inregular bone, the patella, or stitle bone. The whole is commonly called the stiffe joint. The patella $(Q$, p. 263) answers to the kneepan in the human sulject. Some of the tendons of the strongest muscles of the upper boue of the thigh are inserted into it, and continued from it over the lower bone. This important joint is hereliy much strengthened; for the proper ligaments between the upper and lower boues, and these additional tendlons and ligaments from the patella, must form altogether a very powerful union. The patella liliemise answers another and even more important purpose. The tendous of some strong muscles are inserted into it. When these muscles are not in action, the patella lies in the groove which nature lias contrived for it; but when they begin to coutract, it starts from its partial hiding-place, becomes prominent from the joint, and alters the line of direction in which the muscles act. It increases the angle, and thus 
very materially increases the power of the muscles.

The lower bone of the thigh is double. The larger portion, in front, extending from the stifle to the hock, is called the Tibia. The smaller bone, or fibula, behind (see $\mathrm{R}, \mathrm{p}, 263$ ), reaches not more than a third of the way down. It is united to the shank bone, like the splint bone, by a cartilaginous substance, which is soon changed into a bony one. Of the use of these little bones wo caunot speak.

The lower bone of the thigh forms an angle with the upper one, being the reverse of that which exists between the upper bone and the pelvis. The object of this is twofold,-to obviate concussion, and to give a direction to the muscles favourable to their powerful action; and in proportion to the acuteness of the angle, or the degree in which the stifle is brought under the horse, will these purposes be accomplished. There is much difference in this in different horses, and the constriction of this part of the frame is a matter worthy of more regard than is generally paid to it.

This part of the thigh shonld likewise be long. In proportion to the length of the muscle is the degree of contraction of which it is capable; and also in proportion to the contraction of the muscle is the extent of motion in the limb: but it is still more necessary that this part of the thigh should have considerable muscle, in order that strength may be added to such extent or compass of motion. Much endurance would not be expected from a horse with a thin arm. A horse with thin and lanky thighs will not possess the strength which considerable exertion would sometimes require. In the cuts, p. 438 and 439 , the principal muscles of this part of the thigh are delineated. They are usually somewhat prominent, and may readily be traced in the living animal: a very brief notice of them may not be uninteresting.

The continuation from $g, p .439$, is the tendinous expansion given to bind and strengthen these muscles.

$n$ is a very important muscle. It is the principal extensor muscle of the hind leg (extensor pedis, extensor of the foot). It commences by a small flat tendon, common to it, and the flexor metatarsi. Passing over the tibia it becomes fleshy: but a little above the hock it changes to a flat tendon, and pursues its conrse in front of the hock in anion with the tendon of the peronæus. On the fetlock joint they disunite. It now begins to expand, and is finally inserted into the upper part of the coffin-bone, or bone of the foot, after having given rarious fibres to both the pasterus. The course of the corresponding tendon in the hind leg is given in the cut, p. 439 , fig. $l$. It helps to flex the hock-joint, but is principally con- cerned in the extension of the foot, and also the pastern and fetlock joints.

At $m$, p. 439 , is another of the extensor muscles, called the peronaus, from a name given to the fibula. It arises from the whole course of the fibula, and also becomes tendinous before it reaches the hock. Abont half way down the shank it is found in the same sheath with the principal extensor muscle, and is inserted with it into the coffin-bone. Its office is to co-operate with the extensor pedis in raising the foot from the ground, and bringing it forward under the body.

At $o$ is the flexor pedis, one of the principal flexor muscles of the foot, arising from the upper part of the tibia. As it approaches the hock it is distinguished by its large round terıdon, which is seen to enter into a groove at the back of the hock. Its tendon passes down the back of the leg like that of a similar muscle in the fore leg. It is the perforating flexor muscle of the hind leg, and assists in flexing the pasteru and fetlock. $k$ is a very slender muscle, arising from the head of the fibula, and proceeding over the external part of the thigh, and, just above the hock, its tendon unites with that of the perforating muscle.

$j$ is a very powerful muscle, springing from the head of the upper bone of the thigh, and, midway down the lower bone of it, ending in a flat tendon, which is inserted into the point of the hock. Its use is to extend the hock. It is evidently most advantageously situated for powerful action; for it acts almost at right angles, and its effect is increased in proportion to the projection of the point of the hock.

We will now turn to the inner side. See cut, p. 438 .

$m$ gives a portion of the muscle which has been just described.

$n$ is an inside view of the perforating flexor muscle of the foot.

$l$ is the peronæus.

$o$ is the flexor perforatus muscle, having its origin from near the lower head of the upper bone of the thigh-becoming tendinons as it passes down the thigh-expanding over and surrounding the point of the hock, and assisting in extending it. After this the tendon pursues its course domn the posterior part of the leg, in a manner so much resembling that of similar tendons in the fore leg, that it will be sufficient to refer to a deseription of the perforated and perforating flexor tendons at p. 425 .

At $e$ is a continuation of the gracilis muscle, p. 438 , orer the stifle.

At $h$ is the extensor pedis already described, p. 439 , with its tendon.

At $i$ is a muscle used to bend the hock, the 
fexor metatarsi, or bender of the leg; arising from the external conclyle of the os femoris, and inserted into the large and small metatarsal bones. It is a muscle of considerable power, although disadvantageously situated, both as to its direction and its being inserted so near to the joint. It flexes the hock, the joint turning somewhat inwards.

At $k$ is a short muscle extending from the upper to the lower thigh-bones (the popliteus), bending the stifle and tnrning the limb inward.

These cuts represent the situation of some of the principal blood-vessels and nerves of the hind extremities.

In the crit of the inside of the thigh, p. 438, $p$ represents the course of the principal artery; at $q$ are blood-vessels belonging to the groin; at $r$ is the large cutanenus vcin, or the rein immediately under the skin. The principal nerves on the fore part of the inside of the thigh pursue their course at $t$, in the direction of the subcutaneous vein ; and those of the posterior part are seen at $s$, while at $u$ are those important ligamentous bands at the bending of the hock which confine the tendons.

In the cut of the outside of the thigh, p. 439 , $p$ will give the course of the anterior arteries and veins; $q$ that of the principal nerves, and coming into sight below; and $r$ the bands described in the former plate.

Also, in the cut of the ontside of the shoulder and arm, p. 420, the figures 1, 2, and 3 , designate the places of the principal artery, nerve, and vein of the leg; 4 gives the subcutaneous vein ruming within the arm; and 5 the subcutaneous vein of the side of the chest.

In the cut of the inside of the arm, p. 422, the lines above represent, in the order from the front, the principal nerves, arteries, and veins of the shoulder and arm; and, on the muscles, $k$ represents the principal subcutaneous vein of the inside of the arm, and $i$ the artery by which it is accompanied.

The stifle joint is not often subject to sprain. The heat and tenderness will guide to the seat of iujury. Occasioually, dislocation of the patella has occurred, and the horse drags the injured limb after him, or rests it on the fetlock; the aid of a veterinary surgeon is here requisite. The muscles of the inside of the thigh have sometimes been sprained. This may be detected by diffused heat, or heat on the inside of the thigh above the stifle. Rest, fomentations, l) leeding, and plysic, will be the proper means of cure.

\section{THOROVGH-PIN.}

Mention has been made of uind-galls and their treatment. A similar enlargement is found above the hock, hetween the tendons of the flexor of the foot and the extensor of the hock. As from its situation it must necessarily project on both sides of the hock, in the form of a round swelling, it is called a thorough-yin, $a, \mathrm{p}, 440$. It is an indication of considerable work, but is rarely attended by lameness. The mode of treatment must resemble that for wind-galls. Although thoroughpin cannot, perhaps, be pronounced to be unsomdness, it behores the buyer to examine well a horse that is disfigured by it, and to ascertain whether undue work may not have injured him in other respects.

\section{THE HOCK.}

This is a most important joint, occasionally the evident, and mnch oftener the unsuspected seat of lameness, and the proper formation of which is essentially comerted with the value of the horse. It answers to the ankle in the human being.

The inferior head of the tibia is formed into two deep grooves, with three sharpened ridges, one separating the grooves, and the other two constitnting the sides of them. It is seeu at $a$ in the following cnt. It rests upon a singularly-shaped bone, $b$, the astragalus, which has two cincular risings or projections, and, with a depression between them, answering exactly to the irregularities of the tibia. These are received and morticed into each other. At the posterior part its convex surface is received into a concavity near the base of another bone, and with which it is united by very strong ligaments. This bone, $c$, is called the os calcis, or bone of the heel, and it prjoects npwards, flattened at its sides, and receives, strongly implanted into it, the tendons of powerful muscles. These bones rest on two others, the os cuboides, $d$ (cube-formed), behind, and the larger cuneiform or wedge-shaped bone $e$, in front. The larger wedge-shaped hone is supported by two smaller ones, $f$, and these two smaller ones and the cuboides by the upper heads of the shank-bone $g$, and the splint-bones $h$. The cuboides is placed on the exterual splint-bone, and the cannon-bone, or principal bone of the leg; the small wedgebone is principally evident on the inner splint. bone, not seen in the cut; and the middle wedgebone on the shank-bone only, $g$. These bones are all connected together by very strong ligaments, which prevent dislocation, but allow a slight degree of motion between them, and the surfaces which are opposed to each other are thickly covered by elastic cartilage.

Considering the situation and action of this joint, the weight and stress thrown upon it must be exceedingly great, and it is necessarily liable to much injury in rapid and powerful motion. What are the provisions to prevent injury? The grooved or pulley-like heads of the tibia and the astragalus, received deeply into one another, and coufined by powerfnl ligaments, admitting freely of hinge like 
action, but of no side motion, to which the joint / dislocation. When, howeror, the work which this would otherwise be exposed in rapid movement, or CUT ов тHЕ носк.

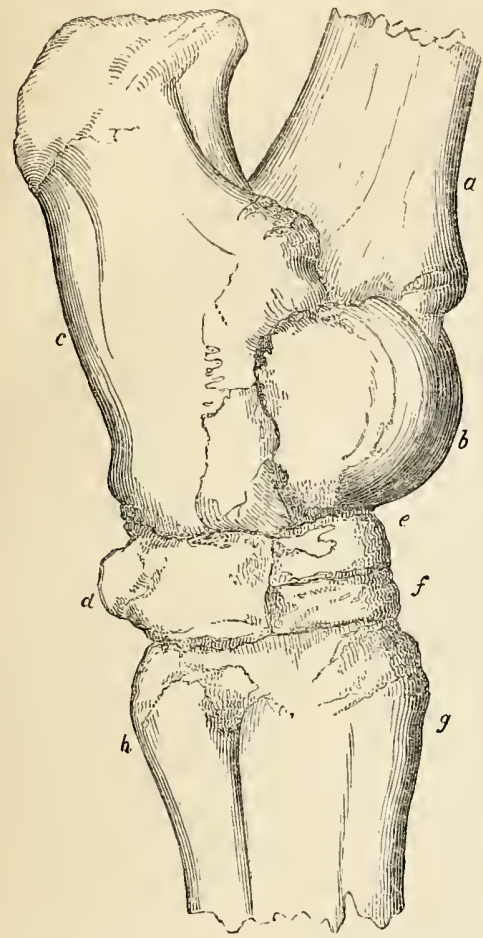

on an uneven surface. A slight inspection of the cut will show that the stress or weight thrown by the tibia $a$ on the astragalus $b$, does not descend perpendicularly, but in a slanting direction. By this much concussion is avoided, or more readily diffused among the different bones; and, the joint consisting of six bones, each of them covered with elastic cartilage, and each admitting of a certain degree of motion, the diminished concussion is diffused among them all, and thereby neutralised and rendered comparatively harmless. Each of these bones is covered not only by cartilage, but by a membraue secreting synovia; so that, in fact, these bones are formed into so many distinct joints, separated from each other, and therely guarded from injury, yet united by various ligaments-possessing altogether sufficient motion, yet bound together so strongly as to defy joint has to perform, and the thoughtlessness ani cruelty with which that work is often exacted, are considered, it will not excite any surprise if this necessarily complicated mechanism is sometimes deranged. The hock, from its complicated structure and its work, is the principal seat of lameness behind.

ENLARGEMENT OF THE HOCK,

First, there is inflammation, or sprain of the hock-joint generally, arising from sudden violent concussion, by some check at speed, or overweight, and atteuded with enlargement of the whole joint, and great tenderness and lameness. This, however, like other diffused inflaumations, is not so untractable as an intense one of a more circumscribed nature, and by rest and fomentation, or, perchance, firing, the limb recorers its action, and the horse becomes fit for ordinary work.

The swelling, however, does not always subside. Enlargement, spread over the whole of the hockjoint, remains. A horse with an enlarged lock must always be regarded with suspicion. In truth, he is unsound. The parts, altered in structure, must be to a certain degree weakened. The animal may discharge his usual work during a long period, without return of lameness; bit if one of those emergencies should occur when all his energies require to be exerted, the disorganised and wealsened part will fail. The purchase, therefore, of a horse with enlarged hock will depend ou cireumstances. If he has other excellences, he will not be uniformly rejected; for he may be ridden or driven moderately for many a year without inconvenience, yet one extra lard day's mork may lame him for ever.

\section{CURB.}

There are often injuries of particular parts of the hock-joint. Curb is an affection of this kind, It is an enlargement at the back of the hock, three or four inches below its point. It is represented at $d, p .440$, and it is either a strain of the ring-like ligament which binds the tendons in their place, or of the sheath of the teudons; oftener, however, of the ligament than of the sheath. Any sudden action of the limb of more than usnal riolence may produce it, and therefore horses are found to "throw ont curlos" after a hardly-contestel race, an extriordinary leap, a serere gallop over heavy ground, or a sudden check in the gallop. Young horses are particularly liable to it, and horses that are corr-hocked (vide cut, p. 440), -whose hocks and legs resemble those of the cow, the hocks being tumed inward, and the legs forming a considerable angle outwards. This is intelligilule enough; for in hocks so formed, the ammlar liganient must be continually on the stretch, in order to coufiue the tendon. 
Curbs are generally accompanied by considerable lameness at their first appearance, but the swelling is not always great. They are best detected by observing the leg sideway.

The first olject in attempting the cure is to abate inflammation, and this will be most readily accomplished by cold evaporating lotions frequently applied to the part. Equal portions of spirit of wine, water, and vinegar, will afford an excellent application. It will be almost impossible to keep a bandage on. If the heat and laneness are considerable, it will be prudent to give a dose of physic, and to bleed from the subeutaneous vein, whose course is represented at $r$, page 438 ; and whether the injury is of the annular ligament, or the sheath of the tendon, more active means will be necessary to perfect the cure. Either a liquid blister should be rubbed on the part, consisting of a vinous or turpentine tineture of cantharides, and this daily applied until some considerable swelling takes place; or, what is the preferable plan, the hair should be cut off, and the part blistered as soon as the heat has been subilued. The blister should be repeated until the swelling has disappeared, and the horse goes sound. In severe cases it may be necessary to fire; but a fair trial, however, should be given to milder measures. If the iron is used, it should be applied in straight lines.

There are few lamenesses in which absolute and long-continued rest is more requisite. It leaves the parts materially weakened, and, if the horse is soon put to work again, the lameness will frequently return. No horse that has had curbs should be put even to ordinary work in less than a month after the apparent cure, and, even then, he slould very gradually resume his former habits.

A horse with a curb is manifestly unsound. A horse with the restige of curb should be regarded with much snspicion, or generally condemned as unsound.

Curb is also an hereditary complaint, and therefore a horse that has once suffered from it should always be regarded with suspicion, especially if either of the parents has exhibited it.

\section{BOG SPAVIN.}

The hock is plentifully furnished with reservoirs of mneus to lubricate the different portions of this complicated joint. Some of these are found on the inside of the joint, which could not be represented in the eut, page 443 . From overexertion of the joint they become inflamed, and considerably enlarged. They are wind-galls of the hock. The subcutaneous vein passes orer the inside of the hock, and over some of these enlarged mucous reservoirs, and is compressed between them and the external integument, - the course of the blood is partially arrested, and a portion of the vein below the impediment, and between it and the next valve, is distended, and causes the soft tumour on the inside of the hock, called Bog or Blood spavin.

This is a very serions disease, attended with no great, but often permanent lameness, and too apt to return when the enlargement has subsided under medical treatment. It must be considered as decided unsoundness. In a horse for slow draught it is scarcely worth while even to attack it. And in one destined to more rapid action, the probability of a relapse should not be forgotten, when the chances of success and the expenses of treatment are calculated.

The cause of the disease-the enlarged mucous capsule-lies deep, and is with difficulty operated upon. Uniform pressure would sometimes cause the ausorption of the fluid contained in cysts or bags like these, but, in a joint of such extensive motion as the hock, it is difficult, or almost impossible, to confine the pressure on the precise spot at which it is required. Could it be made to bear on the enlarged bag, it would likewise press on the vein, and to a greater degree hinder the passage of the blood, and increase the dilatation below the obstruction. The old and absurd method of passing a ligature above and below the enlarged portion of the vein, and then dissecting out the tumour, is not, in the advanced stage of veterinary science, practised by any surgeon who regards his reputation. The ouly method of relief which holds out any promise even of temporary success is exciting considerable inflammation on the skin, and thus rousing the deeper seated absorbents to carry away the fluid effused in the enlarged bag. For this purpose, blisters or firing may be tried; but in the majority of cases the disease will bid defiance to all appliances, or will return and baffle our hopes when we had seemed to be accomplishing our object.

A horse with bog sparin will do for ordinary work. He may draw in a cart, or trot fairly in a lighter carriage, with little detriment to his utility ; but he will never do for hard or rapid work.

\section{BONE SPAVIN.}

A still more formidable disease ranks under the name of Spavin, and is an affection of the bones of the hock-joint. It has been stated that the bones of the leg, the shank-bone $g$, page 443 , and the two small splint-bones behind, $h$, support the lower layer of the bones of the hock. The cube-bone, $d$, rests principally on the shank-bone, and in a slight degree on the outer splint-bone. The middle wedge-bone, $f$, rests entirely upon the slrank-bone, and the smaller wedge-bone presses (not seen in the cut) in a very slight degree on the shank-bone, but principally or almost entirely on the inner splint-bone. Then the sphint-bones sus- 
tain a very unequal degree of concussion and weight. Not only is the inner one placed more under the body and nearer the centre of gravity, but it has almost the whole of the weight and concussion communicated to the smaller cuneiform bone carried on to it. It is not, therefore, to be wondered at that, in the violent action of this joint in galloping, leaping, heavy draught, and especially in young horses, and before the limbs have become properly knit, the inner splint-bone, or its ligaments, or the substance which connects it with the shank-bone, should suffer material injury.

The smith increases the tendency to this by his injudicious management of the feet. It is a common notion that cutting, and wounds in the feet-from one foot treading on the other-are prevented by putting on a shoe with a calkin on the outer heel, that is, the extremity of the heel being considerably raised from the ground. It is not unnsual to see whole teams of horses with the outer heel of the hind foot considerably raised above the other. This unequal bearing, or distribution of the weight, cannot fail of being injurious. It places an unequal strain on the ligaments of the joints, and particularly of the hock-joint, and increases the tendency to sparin.

The weight and concussion thus throm on the inner splint-bone produce inflammation of the cartilaginons substance that unites it to the shankbome. In consequence of it, the cartilage is absorbed, and bone deposited ; the union between the splint-bone and the shank becomes bony, instead of cartilaginous; the degree of elastic action between them is destroyed, and there is formed a splint of the hind leg. This is uniform] on the inside of the hind leg, because the greatest weight and concussion are thromn on the inner splint-bones. As in the fore leg, the disposition to form bony matter baving commenced, and the cause which produced it continuing to act, bone continues to be deposited, and it generally appears in the form of a tumour, where the head of the splint-bone is united with the shank, and in front of that union. It is seen at $c$, page 410 . This is called Bone Spavin. Inflammation of the ligaments of any of the small bones of the hock, proceeding to bony tnmour, would equally class under the name of spavin; but, commonly, the disease commences on the precise spot that has been described.

While spavin is forming there is alwars lameness, and that frequently to a very great degree: but when the membrave of the bone has accomo. dated itself to the tumour that extended it, the lameness subsides or disappears, or depends upon the degree in which the bony deposit interferes with the motion of the joint. It is well known to horsemen, that many a hunter, with spavin that would cause his rejection by a veterinary surgeon, stands his work without lameness. The explanation is this: there is no reason why an old lony tumour on the outside of any of the bones of the hock, free from counexion with the next bone, and from any tendon, should be at all injurious; as, for instance, one immediately under $e$ or $f$, p. 443 : but from the complicated nature of the hock, it is difficult, if not impossible, to be quite sure of the place, or extent, from inspection, of the tumour, and, besides, the disposition to throw out bone covered by the tumour, may continue and extend to the joint. The surgeon, therefore, cannot be perfectly safe in pronouncing a bone spavin to be of no consequence. Horses with exceedingly large spavins are often seen that are only slightly lame, or that merely have a stiffness in their gait at first starting, but which gradually goes off after a little motion; while otlers, with the bony tumour comparatively small, have the lameness so great as to destroy the usefulness of the horse. There is always this peculiarity in the lameness of spavin, that it abates, and sometimes disappears, on exercise ; and, therefore, a horse with regard to which there is any suspicion of this affection shonld be examined when first $\dot{m}$ the morning it is taken from the stable.

If the sparin continues to increase, the bony deposit first spreads over the lower wedge-bones $f$, p. 443 , for these are nearest to its original seat. They are capable of slight motion, and share in every action of the joint, but their principal design is to obviate concussion. The chief motion of the joint, and that compared with which the motion of the other bones is scarcely to be regarded, is confined to the tibia $a$, and the astragalus $b$, and therefore stiffiness rather than lameness may accompany spavin, even when it is beginning to affect the small bones of the joint. Hence, too, is the advantage of these bones having each its separate ligaments and membranes, and constituting so many distinct joints, since injury may happen to some of them, without the effect being propagated to the rest. When the bony deposit continues to enlarge, and takes in the second layer of bonesthe larger wedge-bones $e$-and eren spreads to the cuboid bones on the other side, the lameness may not be rery great, because these are joints, or parts of the joint, in which the motion is small: but when it extends to the union of the tibia $a$, and the astragalus $b$-when the joint, in which is the chief motion of the hock, is attacked-the lameness is indeed formidable, and the horse becomes nearly quite useless.

Sparined horses are generally capable of slow mork. They are equal to the greater part of the work of the farm, and therefore they should not be always rejected by the small farmer, as ther may generally be procured at little price. These 
horses are not only capable of agricultural work, but they generally improve under it. The lameness in some degree abates, and even the bony tumour to a certain degree diminishes. There is sufficient moderate motion and friction of the limb to rouse the absorbents to action, and cause them to take up a portion of the bony matter thrown out, but not enough to renew or prolong inflammation. It cannot be said that the plough affords a cure for spavin, but the spavined horse often materially improves while working at it.

For fast work, and for work that must be regularly performed, spavined horses are not well calculated; for this lameness behind produces great difficulty in rising, and the consciousness that he will not be able to rise without painful effort occasionally prevents the horse from lying down at all; and the animal that cannot rest well, cannot long travel far or fast.

The treatment of spavin is simple enongh, but far from being always effectual. The owner of the horse- will neither consult his own interest nor the dictates of humanity, if he suffers the chisel and mallet, or the gimlet, or the pointed iron, or arsenic, to be used; ret measures of considerable severity must be resorted to, Repeated blisters will usually cause either the absorption of the bony deposit, or the abatement or removal of the inflammation of the ligaments, or, as a last resource, the heated iron may be applied.

The account of the diseases of the hock is not yet completed. It is well known that the horse is frequently subject to lameness belind, when no ostensible cause for it can be found, and there is no exterual heat or enlargement to indicate its seat. Farriers and grooms pronounce these to be affections of the stifle, or round bone; or, if the gait of the horse and peculiar stiffness of motion point out the hock as the affected part, yet the joint may be of its natural size, and neither heat nor tenderness can be discorered. The groom has his own method of unravelling the mystery. He says that it is the beginning of spavin ; but months and years pass away, and the spavin does not appear, and the horse is at length destroyed as incurably lame.

Horsemen are indelted to Mr. W. J. Goodwin, V.S. to Her Majesty, for the discovery of the seat of frequent lameness behind. The ent, p. 443, represents the two layers of small bones within the hock-the larger wedge-like bone $e$, above; and the middle $f$, and the smaller one below, and it will be seen that almost the whole of the weight of the horse, communicated by the tibia $a$, is thrown upon these bones. The cube-bone $d$ does little more than support the point of the hock $c$. It is then ensy to imagine that, in the concussion of hard work or rapid travelling, these bones, or the delicate and sensible membranes in which they are wrapped, may be severely injured. Repeated dissections of horses that have been incurably lame behind, without anything external, during life, to point out the place or cause of lameness, have shown that inflammation of the membranes lining these joints, and secreting the fluid that lubricates them, has taken place.*

Mr. Goodwin narrates a very interesting case in corroboration of this account of hock lameness. The author of this work had the honour of being present when the examination took place. "The patient was a hamess horse of unusual perfection, both in shape and action, and was a great favourite with an illustrious personage. He suddenly became lame behind on the off leg, but withont the least accident or alteration of structure to accoumt for it. He was turned out for a short time, and the lameness disappeared. He was then incautiously made to perform his usual work, until perfectly incapacitated for it by returning and aggravated lameness. Suspecting the seat of lameness to be in the hock, although the joint was perfectly unaltered in form, he was, three months after the commencement of the lameness, blistered and fired, and placed either in a loose place or paddock, as circumstances seemed to require. Not the least amendment took place at the end of six months, even in his quiescent state, and, after twelve months from the time of lis being given up for treatment, he was destroyed, lis case being naturally considered a hopeless one. Ulceration of the synovial membrane was found, taling its origin between the two cuneiform bones. These boncs had become carious, and the disease had gradually extended itself to other parts of the joint. Mr. Goodwin had no doubt that if the animal had been suffered to work on for any greater lengtll of time, necrosis, or anchylosis of every bone concerned in the hock, would have been the result."-(Veterinarian, iii. 158.)

Much more depends, than they who are not well accustomed to horses imagine, on the length of the os calcis, or projection of the hock. In proportion to the length of this bone will two purposes Le effected. The line of direction will be more advantageous, for it will be nearer to a perpendicular, and the arm of the lever to which the power is applied will be lengthened, and thus mechanical advantage will be gained to an almost incredible extent. The slightest lengthening of the point of the hock will wonderfully tell in the course of a day's work, and therefore it is that the

* These opinions of the seat and nalure of obscure hock-laneness are now maintained by the majority of veterinary surgeons, although some of them differ a little with regard to the artioulation that is generally affeeted, and the manner in which the depressions or exeavations on the surface of these bones is effeeted. In the tenth volume of the "Veterinarian," are some valuable observations on this subject by Professor Dick, and Messrs. Pritchard and Spooner. 
character of the os calcis is of such immense importance.

The point of the hock is sometimes swelled. A soft fluctuating tnmour appears on it. This is an enlargement of one of the mucous bags of which mention has been made, and that surrounds the insertion of the tendous into the point of the hock. It is termed

\section{CAPPED HOCK.}

It is seldom accompanied by lameness, and yet it is a somewhat serious business, for it is usually produced by blows and mostly by the injuries which the horse inflicts upon limself in the act of kicking: therefore it is that a horse with a capped hock is very properly regarded with a suspicious eye. The whole of the hock should le carefully examined, in order to discover whether there are other marks of violence, and the previous listory of the animal should be carefully inquired into. Does he kick in harness or in the stall, or has he been lying on a thiu bed, or on no bed at all; and thus may the hock have been bruised, and the swelling produced?

It is exceedingly difficult to apply a bandage over a capped hock; and puncturing the tumour, or passing a seton through it, would be a most injudicious practice. Blisters, or iodine, repeated as often as may be necessary, are the best means to be employed. Occasionally the tumour will spontaneously disajpear; but at other times it will attain a large size, or assume a callous structure, that will bid defiance to all the means that can be employed.

MALLENDERS AN1 SALLENDERS.

On the inside of the hock, or a little below it, as well as at the bend of the knee $(h$, p. 436$)$, there is occasionally a scurfy eruption, called mal. lenders in the fore leg, and sallenders in the hind leg. They seldom produce lameness; but if no means are taken to get rid of them, a discharge proceeds from them which it is afterwards difficult to stop. They usually indicate bad stable management.

A diuretic ball should be occasionally given, and an ointment of sugar-of-lead and tar, with treble the quantity of lard, rubbed over the part. Should this fail, a weak mercurial ointment may be used. Iodime has here also been useful.

The line of direction of the legs beneath the hocks, should not be disregarded. The leg should descend perpendicularly to the fetlock. The weight and stress will thus be equally diffused, not only over the whole of the hock, but also the pasterns and the foot. Some horses have their hocks closer than usual to each other. The legs take a divergent direction outward, and the toes also are turned outward. 'These horses are said to be Cat or Cow hocked. They are generally supposed to possess considerable speed. Perhaps they do so ; and it is thus accounted for. The cow-hocked horse has his legs not only turned more outward, but bent more under lim, and this increases the distance between the point of the hock and the tendons of the perforating muscle: see $b$, in the cut, page 440. . It increases the space which is usually occupied by thorough-pin, see $a$, in the same page. Then the point of the hock, moved by the action of the mus. cles, is enabled to describe a greater portion of a circle; and in proportion to the increased space passed over by the point of the hock, will the space traversed by the limb be increased, and so the stride of the horse may be lengthened, and, thus far, his speed may be increased. But this advantage is more thau counterbalanced by many evils. This increased contraction of the muscles is an expenditure of animal porrer; and, as already stated, the weight and the concussion beiug so unequally distributed by this formation of the limbs, some part must be over-strained and overworked, and injury must ensue. On this account it is that the cow-hocked horse is more subject than others to thorough-pin and sparin; and is so disposed to curbs, that these hocks are denominated by horsemen curby hocks. The mischief extends even farther than this. Such a horse is peculiarly liable to windgall, sprain of the fetlock, cutting, and knuckling.

A slight inclination to this form in a strong powerful horse may not be very objectionable, but a horse decidedly cor-hocked should never be selected.

\section{SWELLED LEGS.}

The fore legs, but oftener the himd ones, and especially in coarse horses, are sometimes subject to considerable enlargement. Occasioually, when the horse does not seem to labour under any other disease, aud sometimes from an apparent shifting of disease from other parts, the hind legs suddenly swell to an enormous degree from the lock and almost from the stifle to the fetlock, attended by a greater or less degree of heat, and tenderness of the skin, and sometimes excessive and very peculiar lameness. The pulse likewise becomes quick and hard, and the horse evidently labours under considerable fever. It is acute inflammation of the cellular substance of the legs, and that most sudden in its attacks, and most violent in its degree, and therefore attended by the effusion of a considerable quantity of fluid into the cellular membrane. It occurs in young horses, and in those which are over-fed and little exercised. $F_{0}$ mentation, diuretics, or purgatives, or, if there is much fever, a moderate bleeding will often relieve the distension almost as suddenly as it appeared.

The kind of swelled legs most frequently occur- 
ing and most troublesome is of a different nature, or rather it is most various in its kind and causes, and consequences and mode of treatment. Sometimes the legs are filled, but there is little lameness or inconvenience. At other times the limbs are strangely gorged, and with a great degree of stiffness and pain. Occasionally the horse is apparently well at night, but, on the following morning, one or both of the legs are tremendously swollen; and on its being tonched, the horse catches it up suddenly, and nearly falls as he does so. Many horses, in seemingly perfect health, if suffered to remain several days without exercise, will have swelled legs. If the case is neglected, abscesses appear in various parts of the legs; the heels are attacked by grease, and, if proper measures are not adopted, the horse has an enlarged leg for life.

The cure, when the case has not been too long neglected, is sufficiently plain. Physic or diuretics, or both, must be had recourse to. Mild cases will generally yield to their influence; but, if the animal has been neglected, the treatment must be decisive. If the horse is in high condition these should be preceded or accompanied by bleeding; but if there are any symptoms of debility, bleeding would only increase the want of tone in the vessels.

Horses taken from grass and brought into close stables very speedily have swelled legs, because the difference of food and increase of nutriment rapidly increase the quantity of the circulating fluid, while the want of exercise takes away the means by which it might be got rid of. The remedy here is sufficiently plain. Swelled legs, however, may proceed from general debility. They may be the consequence of starvation, or disense that has cousiderably weakened the animal; and these parts, being farthest from the centre of circulation, are the first to show the loss of power by the accumulation of fluid in them. Here the means of cure would be to increase the general strength, with which the extremities would sympathise. Mild diureties and tonies would therefore be evidently indicated.

Horses in the spring and fall are subject to swelled legs. The powers of the constitution are principally employed in providing a new coat for the animal, and the extremities have not their share of vital influence. Mingled cordials and diuretics are indicated here-the diuretic to lessen the quantity of the circulating fluid, and the cordial to invigorate the frame.

Swelled legs are often teasing in horses that are in tolerable or good health; but where the work is somewhat irregular, the cure consists in giving more equable exercise, walking the horse out daily when the usual work is not required, and using plenty of friction in the form of hand-rubbing. Bandages have a greater and more durable effect, for nothing tends more to support the capillary ressels, and rouse the action of the absorbents, than moderate pressure. Hay-bands will form a good bandage for the agricultural horse, and their effect will probably be increased by previously dipping them in water.

\section{GREASE.}

The physic, or the diuretic ball, may occasionally be used, but very sparingly; and only when they are absolutely required. In the hands of the owner of the horse, or of the veterinary surge on, they may be employed with benefit; but in those of the carter or the groom they will do far more harm than good. The frequent and undue stimulus of the urinary organs by the diuretic ball, will be too often followed by speedy and incurable debility. If the swelling bids defiance to exercise and friction and bandage, the aid of the diuretic may be resorted to, but never until these have failed, unless there is an evident tendency to humour or grease.

Swelled legs, although distinct from grease, is a disease that is apt to degenerate into it. Grease is a specific inflammation of the skin of the heels, sometimes of the fore-feet, but oftener of the hinder ones. It is not a contagious disease, as some have asserted, althongh when it once appears in a stable it frequently attacks almost every horse in it. Bad staule management is the true cause of it.

There is a peculiarity about the skin of the heel of the horse. In its healtlyy state there is a secretion of greasy matter from it, in order to prevent excoriation and chapning, and the skin is soft and pliable. Too often, however, from bad management, the secretion of this greasy matter is stopped, and the skin of the heel becomes red, and dry, and scurfy. The joint still continuing to be extended and flexed, cracks of the skin begin to appear, and these, if neglected, rapidly extend, and the heel becomes a mass of soreness, ulceration, and fungus.

The distance of the heel from the centre of circulation, and the position of the hind limbs, render the return of blood slow and difficult. There is also more variation of temperature here than in any other part of the frame. As the horse stands in the closed stable, the heat of this part is too often increased by its being embedded in straw. When the stable door is open the heels are nearest to it, and receive first, and most powerfully, the coll current of air. When he is taken from his stable to work the heels are frequently covered with mire and wet, and they are oftenest and most intensely chilled by the long and slow process of evaporation which is taking place from them. No one, then, can wonder at the frequency with which the heels are attacked by inflammation, and the difficulty there is in subduing it.

Much error has prevailed, and it has led to considerable bad practice, from the notion of 
humours flying about the horse, and which, it is said, must have vent somewhere, and attack the heels as the weakest part of the frame. Thence arise the physicking, and the long conrse of diuretics, which truly weaken the amimal, and often do irreparable mischief.

Grease is a local complaint. It is produced priucipally by causes that act locally, and it is most successfully treated by local applications. Diuretics and purgatives may be useful in abating inflammation; but the grand olject is to get rid of the inflammatory action which exists in the skin of the heel, and to heal the wounds, and remedy the mischief which it has occasioned.

The first appearance of grease is usually a dry and scurfy state of the skin of the heel, with redness, heat, and itchiness. The heel should be well but gently washed with soap and water, and as much of the scurf detached as is easily removable. An ointment, composed of one part plum. diacet. and seven of adeps suillæ, will usually supple, and cool, and heal the part.

When cracks appear, the mode of treatment will depend on their extent and depth. If they are but slight, a lotion, composed plumbi sulph. 3 ij. et aluminis 3 iij., dissolved in a piut of water, will often speedily dry them up, and close them. There is sometimes considerable caprice in the application of this lotion, which has induced Professor Morton to have recourse to alumen et terebinthinus rulgaris one part each, and adeps suillæ three parts, made into an ointment.

If the cracks are deep, with an ichorous discharge and considerable lameness, it will be necessary to poultice the heel. A poultice of linseed meal will be generally effective, unless the discharge is thin and offensive, when an ounce of finely powdered charcoal should be mixed with the linseed meal; or a poultice of carrots, boiled soft and mashed. The efficacy of a carrot-poultice is seldom sufficiently appreciated in cases like this.

When the inflammation and pain have evidently subsided, and the sores discharge good matter, the calamine ointment may be applied with advantage; and the cure will generally be quickened if a very diluted vitriolic or alum solution is applied.

The best medicine will consist of mild aloetic balls; gentle diuretics being giren towards the close of the treatment.

After the chaps or cracks hare healed, the legs will sometimes continue gorged and swelled. A flannel bandage, evenly applied over the whole of the swelled part, will be very serviceable; or, should the season admit of it, a run at grass, particularly spring grass, should be allowed. A blister is inadmissible, from the danger of bringing back the inflammation of the skin, and the discharge from it; but the actual cautery, special care being taken not to penetrate the skin, may occasionally be resorted to.

In some cases the cracks are not confined to the centre of the heels, but spread over them, and extend on the fetlock, and even up the leg, while the legs are exceedingly swelled, and there is a watery discharge from the cracks, and an apparent oozing through the skin at other places. 'The legs are exceedingly tender and sometimes hot, and there is an appearance which the farrier thinks very decisive as to the state of the disease, and which the better informed man should not overlook-the heels smoke-the skin is so hot, that the watery fluid partly evaporates as it runs from the cracks or oozes through the skin.

There will be great danger in suddenly stopping this discharge. Inflammation of a more important part has rapidly succeeded to the injudicious attempt. The local application should be directed to the abatement of the inflammation. The poultices just referred to should be diligently used night and day, and especially the carrot-poultice ; and when the heat, and tenderness, and stiffness of motion have diminished, astringent lotions may be applied-either the alum lotion, or a strong decoction of oak-bark, changed, or used alternately, but not mixed. The cracks should likewise be dressed with the ointment above-mentioned; and, the moment the horse can bear it, a flannel bandage shonld be put on, reaching from the coronet to three or four inches above the swelling.

The medicine should be confined to mild diuretics, mixed with one-third part of cordial mash; or, if the horse is gross, and the inflammation luns high, a dose of physic may be given. If the horse is strong, and full of tlesh, physic should always precede and sometimes supersede the diuretics. In cases of much debility, diuretics, with aromatics or tonics, will be preferable

The feeding shonld likewise vary with the case, bnt with these rules, which admit of no exception, that green meat should be given, and more especially carrots, when they are not too expensire, and mashes, if the horse will eat them, and never the full allowance of corn.

Walking exercise should he resorted to as soon as the horse is able to bear it, and this by degrees may be increased to a gentle trot.

From bad stable management at first, and neglect during the disease, a ret worse kind of grease occasionally appears. The ulceration extends over the skin of the heel and the fetlock, and a fungus springs from the surface of both, highly sensible, bleeding at the slightest touch, and interspersed with scabs. By degrees, portions of the fungus begin to be covered with a horny substance protruding in the form of knobs, and collected together in bunches. These are known by the name of grapes. A fotid and very peculiar 
exudation proceeds from nearly the whole of the unnatural substance. The horse evidently suffers much, and is gradually worn down by the discharge. The assistance of a veterinary surgeon is here indispensable.

Some horses are more subject to grease than others, particularly draught horses, both heavy and light, but particularly the former, and if they have no degree of blood in them. It was the experience of this which partly contributed to the gradual change of coach and other draught horses to those of a lighter breed. In the great majority of cases, grease arises from mismanagement and neglect.

Everything that has a tendency to excite inflammation in the skin of the heel is a cause of grease. Therefore want of exercise is a frequent source of this disease. The fluid which accumulates about the extremities and is unable to return, is a source of irritation by its continued pressure. When high feeding is added to irregular or deficient exercise, the disease is evidently still more likely to be produced. Want of cleanliness in the stable is a fruitful sonrce of grease. When the heels are imbedded in filth, they are weakened by the constant moisture surrounding them-irritated by the acrimony of the dung and the urine, and little prepared to endure the cold evaporation to which they are exposed when the horse is taken out of the stable. The absurd practice of washing the feet and legs of horses when they come from their work, and either carelessly sponging them down afterwards, or leaving them to dry as they may, is, however, the most common origin of grease.

When the horse is warmed by his work, and the heels share in the warmth, the momentary cold of washing may not be injurions, if the animal is immediately rubbed dry; yet even this would be better avoided: but to wash out the heels, and then leave them partially dry or perfectly wet, and suffering from the extreme cold that is produced by evaporation from a moist and wet surface, is the most absurd, dangerous, and injurious practice that can be imagined. It is worse when the post-horse or the plough-horse is plunged up to his belly in the river or pond, immediately after his work. The owner is little aware how many cases of inflammation of the lungs, and borrels, and feet, and heels follow. It would, therefore, be an excellent rule never to wash the heels of these horses. After they have been suffered to stand for twenty minutes in the stable, during which time the horse-keeper or the carter may be employed in taking care of the harness, or carriage, or beginning to dress the horse, the greater part of the dirt which had collected about the heels may be got rid of with a dry brush ; and the rest will disappear a quarter of an hour afterwards under the operation of a second brushing. The trouble will not be great, and the heels will not be chilled and subject to inflammation.

There has been some dispute as to the propriety of cutting the hair from the heels.* Custom has very properly retained the hair on our farm-horses. Nature would not have given it had it not been useful. It guards the heel from being injured by the inequalities of the ploughed field; it prevents the dirt, in which the heels are constantly enveloped, from reaching and caking on, and irritating the skin; it linders the usual moisture which is mixed with the clay and mould from reaching the skin, and, it preserves an equal temperature in the parts. If the liair is suffered to remain on the heels of the farm-horses, there is greater necessity for brushing and hand-rubbing the heels, and never washing them.

Fashion and utility have removed the hair from the heels of our hackney and carriage horses. When the horse is carefully tended after his work is over, and his legs quickly and completely dried, the less hair he has about them the better, for then both the skin and the hair can be made perfectly dry before evaporation begins, or proceeds so far as to deprive the legs of their heat. Grease is the child of negligence and mismanagement. It is driven from our cavalry, and it will be the fault of the gentleman and the farmer if it is not speedily banished from every stable.

* Professor Stewart has the following observations:- " During two very wet winters I have had opportunity of observing the results of trimming and no trimming, among upwards of 500 horses. More tban 300 of these have been enployed in coaching and posting, or work of a similar kind, and about 150 are carthotses. Grease, and other skin diseases of the heels have becs of most frequent occurence where the horses are both trimmed and washed; they have beea common where the horses were trimmed but not washed, and there bave been very few cases where washing or trimming were forbidden or seglected."-Stable Economy, p. 116 . 


\title{
CHAPTER XVIII.
}

\author{
THE FOOT.
}

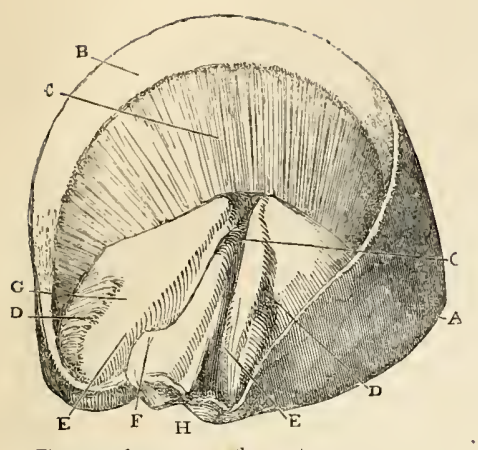

A The external crust seen at the quarter.

B The coronary ring.

c The little horny plates lining the crust.

D The same continued over the hars.

E B 'The two concave surfaces of the inside of the horny frog.

F That which externally is the cleft of the frog.

II The bars.
The rounded part of the beels, belonging to the frog.

This smaller cut exhibits, in as satisfactory a manner, the mechanism and structure of the base of the foot.

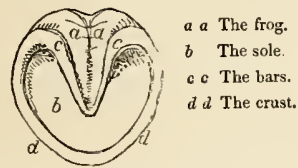

The foot is composed of the horny box that covers the extremities of the horse, and the contents of that box. The hoof or box is composed of the crust or wall, the coronary ring and band, the bars, the horny laminæ, the sole, and the horny frog.

\section{THE CRUST OR WALL OF THE HOOF.}

The crust or wall, is that portion which is seen when the foct is placed on the ground, and reaches from the termination of the hair to the ground. It is deepest in front, where it is called the toe, measuring there about three inches and a half in depth (see cut, p. 452 ), shallower at the sides, which are denominated the quarters, and of least extent behind, where it is seldom more than au inch and a half in height, and is termed the heel. The crust in the healthy foot presents a flat and narrow surface to the ground, ascending obliquely backwards, and possessing different degrees of obliquity in different horses. In a sound hoof the proper degree of obliquity is calculated at forty-five degrees, or the fourth part of a semicircle, at the front of the foot. When the obliquity is greater than this, it indicates undue flatness of the sole, and the crust is said to have "fallen in." If the obliquity is very much increased the sole projects, and is said to be pumiced or convex.

If the foot is more upright, or forms a greater angle than forty-five degrees, it indicates much contraction, and a sole too concave; and this difference of obliquity is often so great, that the convexity or concavity of the sole may be affirmed without the trouble of raising the foot for the purpose of examination.

It is of some importance to observe whether the depth of the crust appears rapidly or slowly to decrease from the front to the heel. If the decrease is little, and even at the heel the crust is higl and deep, this indicates a foot liable to contraction, sand-crack, thrush, and inflammation. The pasterns are upright, the paces of that horse are not pleasant. On the other hand, if the crust rapidly diminishes in depth, and the heels are low, this is accompanied by too great slanting of the pastern, and disposition to sprain in the back sinew. The foot, generally, is liable to be weak and flat, and bruised, and there is more tendency to the fre quent, but obscure lameness, of which there will presently be occasion to treat-the navicular-joint disease.

The crust is composed of numerous horny fibres, connected together by an elastic membranous sub. stance, and extending from the coronet to the base of the hoof. It differs materially in its texture, its elasticity, its growth, and its occasional fragility, according to the state in which it is kept, and the circumstances that are acting upon it.

The exterior wall of the hoof should be smooth and level. Protuberances or rings round the crust indicate that the horse has had inflammation in the feet, and that to such a degree, as to produce an unequal growth of horn, and probably to leave some injurious consequences in the internal part of the foot. If there is a depression or hollow in the front of the foot, it betrays a sinking of the coffin-bone, and a flat or pumiced sole. If there is a hollow at the quarters, it is the worst symptom of bad contraction.

The thicliness of the crust, in the front of the foot, is rather more than half an inch; it becomes gradually thinner towards the quarter's and heels, but this often varies to a considerable extent. In some hoofs, it is not more than half the above thick 
ness. If, however, there is not, in the majority of horses, more than half an inch for nail-hold at the toe, and not so much at the quarters, it will not appear surprising that these horses are occasionally wounded in shoeing, and especially as some of them are very unmanageable while undergoing this process.

Whilst the crust becomes thinner towards hoth quarters, it is more so at the inner quarter than at the outer, because more weight is thrown upon it than upon the outer. Ii is more under the horse. It is under the inner splint-bone, on which so much more of the weight rests than on the outer; and, being thimner, it is able to expand more. Its elasticity is called more into play, and concussion and injury are avoided. When the expansion of the quarters is prevented by their being nailed to an unbending shoe, the inner quarter suffers most. Corns are oftenest found there; contraction begins there; sand-crack is seated there. Nature meant that this should be the most yielding part, in order to obviate concussion, because on it the weight is principally thrown, and therefore when its power of yielding is taken away, it must be the first to suffer.

A careful observer will likewise perceive that the inner quarter is higher than the outer. While it is thin to yield to the shock, its increased surface gives it sufficient strength.

On account of its thinnesss, and the additional weight which it bears, the inner heel wears away quicker than the outer; a circumstance that should never be forgotten by the smith. His object is to give a plane and level bearing to the whole of the crust. To accomplish this, it will be often scarcely necessary to remove anything from the inner heel, for this has already been done by the wear of the foot. If he forgets this, as he too often seems to do, and cuts away with his knife or his buttress an equal portion ali round, he leaves the inner and weaker quarter lower than the outer; he throws an uneven bearing upon it; and produces corns and sandcracks and splints, which a little care and common sense might have avoided.

\section{THE CORONARY RING,}

The crust does not vary much in thickness (see A, page 451 , aud $b$, in the accompanying cut), until near the top, at the coronet, or union of the horn

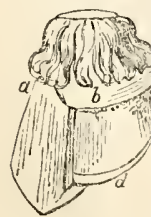

of the foot with the skin of the pasterns, where ( $w$, page 432$)$ it rapidly gets thin. It is in a manner scooped and hollowed out. It likewise changes its colour and consistence, and seems almost like a continuation of the skin, but easily separable from it by maceration or disease. This thin part is called the coronary ring, $x$, p. 432. It ex- tends round the upper portion of the hoofs, and receives, within it, or covers, a thickened and bulbous prolongation of the skin, called the coronary ligament (see $b$, in the accompanying cut). This prolongation of the skin-it is nothing more-is thickly supplied with blood-vessels. It is almost a mesh of blood-vessels connected together by fibrous texture, and many of them are employed in secreting or forming the crust or wall of the foot. Nature has enabled the sensible laminæ of the coffin-bone, $c$, which will be presently described, to secrete a certain quantity of horn, in order to afford an immediate defence for itself when the crust is wounded or taken amay. Of this there is proof when in sand-crack or quittor it is necessary to remove a portion of the crust. A pellicle of horn, or of firm bard substance resembling it, soon covers the wound; but the crust is prineipally formed from this coronary ligament. Hence it is, that in sand-crack, quittor, and other diseases in which strips of the crust are destroyed, it is so long in being renewed, or growing down. It must proceed from the coronary ligament, and so gradually creep down the foot with the natural growth or lengthening of the horn, of which, as in the human nail, a supply is slowly given to answer to the wear and tear of the part.

Below the coronary ligament is a thin strip of horny matter, which has been traced to the frog, and has been supposed by some to be connected with the support or action of that body, but which is evidently intended to add to the security of the part on which it is found, and to bind together those various substances which are collected at the coronet. It resembles, more than anything else, the strip of skin that surrounds the root of the buman nail, and which is placed there to strengthen the union of the nail with the substance from which it proceeds

\section{THE BARS.}

At the back part of the foot the wall of the hoof, instead of continning round and forming a circle, is suddenly bent in as in the small cut, in page 451 , where $d$ represents the base of the crust, and $e$ its inflection or bending at the heel. The bars are, in fact, a continuation of the crust, forming an acute angle, and meeting at a point at the toe of the frog-see $a, b$, and $c$, in the smaller cuts -and the inside of the hars, like the minside of the crust-see the first and larger cut-presents a continuance of the horny leaves, showing that it is a part of the same substance, and helping to discharge the same office.

It needs only the slightest consideration of the cut, or of the vatural boof, to show the importance of the bars. The arch which these form on either side between the frog and the quarters, is admirably contrived both to admit of and to limit to its proper 
extent the expansion of the foot. When the foot is placed on the ground, and the weight of the animal is thromn on the leaves of which mention has just been made, these arches will shorten and widen, in order to admit of the expansion of the quarters - the bow returning to its natural curve, and porrerfully assisting tlse foot in regaining its usual form. It can also be conceived that these bars must form a powerful protection against the contraction, or viring in, of the quarters. A moment's inspectiou of the cut (see $g$, p. 45l) will show that, if the bars are taken away, there will be mothing to resist the contraction or falling in of the quarters when the foot is exposed to any disease or bad management that would induce it to contract. One moment's observation of them will also render evident the security which they afford to the frog $(f)$, and the effectual protection which they give to the lateral portions of the foot.

Then appears the necessity of passing lightly over them, and leaving prominent, when the foot is pared for shoeing, that which so many smiths cut perfectly away. They imagine that it gives a more open appearance to the foot of the horse. Horses shod for the purpose of sale have usually the bars removed with this view; and the smiths in the neighbourhood of the metropolis and large towus, shoeing for dealers, toc often habitually pursue, with regard to all their cnstomers, the injurious practice of removing the bars. The horny frog, deprived of its guard, will speedily contract, and become elevated and thrushy; and the whole of the heel, having lost the power of resilience, or reaction, which the curve between the bar $c$ and the crust $d$ gave it (vide P. 451 , cut), will speedily fall in.

\section{THE HORNY LAMINE.}

The inside of the crist is covered by thin horuy leaves ( $c$, p. 451), extending all rouud it, and reaching from the coronary ring to the toe. They are about 500 in number, broadest at their base, and terminating in the most delicate expansion of horn. They not a little resemble the inuer surface of a mushroom. In front they run in a directiou from the coronet to the toe, and towards the quarters they are more slanting from behind forwards. They correspoud, as will be presently shown, with similar cartilaginous and fleshy leaves on the surface of the coffiu-bone, and form a beanful elastic body, by which the whole weight of the hor'se is supported.

\section{TIIE SOLE}

Is under and occupies the greater portion of the concave and elastic surfice of the foot (see $b, \mathrm{p}$. 451 ), extending from the erust to the bars and frog. It is not so thick as the crust, because, notwithstanding its siturtion, it does not support so much weight as the crust; and becanse it was intended to expand, in order to prevent concussion, when, hy the descent of the bone of the foot, the weight was thrown upon it. It is not so brittle as the crust, aud it is more elastic tham it. It is thickest at the toe (see $t, p .432$ ), because the first ant principal stress is thrown on that part. The coffinbone $f$ is driven forward and downward in that direction. It is likewise thicker where it unites with the crust than it is towards the centre, for a similar and evideut reason, because there the weight is first and principally thrown.

In a state of nature it is, to a certain degree, hollow. The reason of this is plain. It is intended to descend or yield with the weight of the horse, and by that gradual descent or yielding most materially lessen the shock which would result from the sudden action of the weight of the animal in rapid aud violent exercise; and this descent can only be given by a hollow sole. A flat sole, already pressing upon the ground, could not be lrought lower; nor could the functions of the frog be then discharged; nor would the foot have so secure a hold. Then if the sole is naturally hollow, and hollow because it must descend, the smith should not interfere with this important actiou. When the foot will bear it, he must pare out sufficient of the horn to preserve the proper concarity; also a small portion at the toe and near the crust, and cutting deeper towards the centre. He must put ou a shoe which shall not prevent the descent of the sole, and which not only shall not press upon it, bnt shall leave sufficient room between it and the sole to admit of this descent. If the sole is pressed upon by the coffin-bone duriug the lengthening of the elastic laminx, and the shoe will not permit its descent, the sensible part between the coffin-bone and the horn will necessarily be bruised, and inflammation and lameness will ensue. It is from this cause, that if a stone insinuates itself between the shoe and the sole, it produces so much lameness. Of the too great coucavity of the sole, or the want of concavity in it, we shall treat when we arrive at diseases of the foot.

\section{THE FROG.}

In the space between the bars, and accurately filling it, is the Frog. It is a triangular portion of horn, projecting from the sole, aluost on a level with the crust, and covering and defending a soft and elastic substance called the sensible frog. It is wide at the heels, and there extending beyond a portion of the crust; narrowing rapidly when it hegins to be confined between the bars, and terminating in a point at somewhat more than linlf the distance from the heel to the toe. It consists of two rounded or projecting surfaces, with is fissmre or cleft between them reaching half way dom the frog, and the two portions again uniting to form the point or toe of the frog. 
The frog is firmly united to the sole, but it is perfectly distinct from it. It is of a different nature, being softer. and far more elastic; and it is secreted from a different surface, for it is thrown out from the substance which it covers. It very much resembles a wedge with the sharp point forwards; and it is placed towards the back part of the foot. The foot is seldom put flush and flat upon the ground, but in a direction downwards, yet somewhat forwaris; then the frog evidently gives safety to the tread of the aumal, for it oceasionally ploughs itself into the ground, and prevents the horse from slipping. This is of considerable consequence, when some of the paces of the horse are recollected, in which his heels evidently come first to the ground, and in which the danger from shipping would be very great. Rieference needs only be made to the gallop as illustrative of this.

The frog being placed at, and filling the linder part of the foot, discharges a portion of the duty sustained by the crust; for it supports the weight of the animal. It assists, likewise, and that to a material degree, in the expansion of the foot. It is formed internally of two prominences on the sides (see $a, p .372$ ), and a cleft in the centre, presenting two conearities with a sharp projection in the middle, and a gralually romded one on each side. It is also composed of a substance peculiarly flexible and elastic. What can be so well adapted for the expansion of the foot when a portion of the weight of the body is thrown on it? How easily will these irregular surfaces yield and spread ont, and how readily return again to their natural state? In this view, therefore, the horny frog is a powerful agent in opening the foot; and the diminution of the substance of the frog, and its elevation above the ground, are both the canse and the consequence of contraction-the cause, as being able no longer powerfully to act in expanding the heels, and the consequence, as obeying a law of nature, by which that which no longer discharges its natural function is gradually removed. It is, however, the cover and defence of the internal and sensible frog, which will be presently treated of ; enough, hotverer, has been said to show the absurdity of the common practice of unspringly cutting it away. In order to discharge, in any degree, some of the offices which we have assigned to it, and fully to discharge even one of them, it must come in occasional contact with the ground. In the unshod horse it is constantly so: but the additional support given by the shoes, and more especially the hard roads orer which the horse is now compelled to travel, render this complete exposure of the frog to the groumi, not only umecessnry, but injurious. Being of so much softer consistence than the rest of the foot, it would be speedily worn awny: occasional pressure, however, or contact with the ground, it must bave.
The rough and detached parts should be cut of at each shoeing, and the substance of the frog itself, so as to bring it just above or within the level of the shoe. It will then, in the descent of the sole, when the weight of the horse is thrown upon it in the putting down of the foot, descend likewise, and pressing upon the gromid, do its duty : while it will be defended from the wear, and bruise, and injury that it would receive if it came upon the ground with the first and full shock of the weight. This will be the proper guide to the smith in shoeing, and to the proprietor in the clirection which be gives. The latter should often look to this, for it is a point of very great moment. A few smiths carry the notion of frog pressure to an absurd extent, and leave the frog beyond the level of the sole,- a practice which is dangerous in the horse of slow draught, and destructive to the hackney or the hunter; but the majority of them err in a contrary way, and, cutting off too much of the frog, lift it above the ground, and destroy its principal use. It should be left just above, or within the level of the shoe.

\section{THE COFFIẌ-BONE.}

The interior part of the foot must now be considered. The lower pastern, a small portion of which (see $d$, p. 432) is contained in the horny box, has been already described, p. 435.-Beneath it, and altogether inclosed in the hoof, is the coffin-bone, or proper bone of the foot (see $f, \mathrm{p}$. 432 , and $d$, fig. $1, p .435$ ). It is fitted to, and fills the fore part of the hoof, occupying about half of it. It is of a liglit and spongy strueture (see $t$, fig. 1, p. 435), and filled with numerous minute foramina. Through these pass the blood-ressels and nerves of the foot, which are necessarily numerous, considering the important and various secretions there carrying on, and the circulation through the foot, which could not pussibly be kept up if these ressels did not run throngli the substance of the bone. Considering the manner in which this bone is inclosed in the horny box, and yet the important surfaces around and below it that are to be nomished with blood, the circulation which is thus carried on within the very body of the bone is one of the most beautiful provisions of nature that is to be found in the whole frame. No inconvenience can arise from occasional or constant pressure, but the bone allows free passage to the blood, and protects it from every possible obstruction.

The fore part of the coffin-bone is not only thus perforated, but it is curiously roughened for the attachment of the numerous minnte laminie about to be described. On its upper surface it presents a concavity for the head of the lower pasteru, p. 435. In front, immediately above $d$, is a striking prominence, into which is inserted the 
extensor tendon of the foot. At the back, e, p. 43:2, it is sloped for articulation with the navicular hone, and more underneath, is a depression for the reception of the perforating flexor tendon $m$, continued down the leg. passing over the navicular bone at $n$, and at length inserted into this bone. On either sidc, as seen p. 435 , are projections called the wings or heels of the coffin-bone, and at the bottom it is hollowed to answer to the convexity of the interual part of the sole.

That which deserves most attention in the coffin-bone is the production of the numerous laminæ round its front and sides. They are prolongations of the thick and elastic membrane covering it, and consist of cartilaginous, fleslyy plates, proceeding from it, ruuning down the coffin-bone, and corresponding with and received between the horny leaves that line the inside of the hoof-bone-each horny plate heing received between tivo sensitive plates, and vice versin. These laminie are exceedingly sensitive and vascular, and elastic, and, as first simply and beautifully explained by Mr. Percivall, their elasticity is not inherent in the laminæ, but in the sulistance which comnects these laminæ with the coffin-bone, and which, while it contains highly elastic properties, affords a convenient bed for the numerous vessels that secrete the lamine. While the animal is at rest, the whole weight of the horse is supported by them, and not by the sole. This extraordinary fact has been put to the test of experiment. The sole, bars, and frog were removed from the foot of a horse, and yet as he stoor, the coffin-bone did not protrude, or in the slightest degree descend; lut when the rapidity with which the foot descends is added to the weight of the horse, these little leaves, horny and fleshy, gradually lengthen, and suffer the bones to press upon the sole. The sole then descends, and in descending, expands; and so, by an admirable mechanism, the violent shock which would be produced by the pressure of such a weight as that of the horse, and the velocity with which it descends, is lessened or destroyed, and the complicated apparatus of the foot remains uninjured. When the foot is again lifterl, and the weight which pressed upon it is removed, the principle of elasticity is called into exercise, and by it the sole resumes its concavity, and the horny frog its folded state; - the quarter's return to their former situntion, - the leaves regain their former length, and exerything is prepared for a repetition of action.

\section{THE SEXSIRLE SOLE.}

Betreen the coflin-bone and the horny sole is situated the sensible sole, p. 432 , formed above of a substance of a ligamentous or tendinous nature, and below of a cuticular or skin-like substance plentifully supplied with blood-ressels. It was phend betreen the coffin-lrone and the sole, by its yielding structure to assist in preventing concus. sion, and also to form a supply of liorn for the sole. It extenls beyoud the colin-bone, but not at all under the frog. Leaving a space for the frog, it proceeds over the bars, and there is covered by some lamine, to unite with those that have been described, p. 451 , as found in the bars. It is here likewise thicker, and more elastic, and by its elasticity is evidently assisting in obviating concussion. It is supplied with nerrous filures, and is lighly sensible, as the slightost experience in horses will erince. The lameness which ensues from the pressure of a stone of of the shoe on the sole is consed by inflammation of the sensible sole. Corns result from bruise and inflimmation of the seusible sole, between the crust and the bar.

\section{TIIE SENSIBLE FROG.}

The coffin-bone does not occuly more than onehalf of the hoof. The posterior part is filled ly a soft mass, partly ligamentous, and partly tendinous $(0, p, 432)$. Its shape below corresponds with the cavities of the horny frog; in front it is attached to the inferior part of the coffin-bone; and farther back, it adheres to the lower part of the cartilages of the heels, where they liegin to form the rounded protuberances that constitute the heel of the foot. It occupies the whole of the hack part of the foot above the lorny frog and between the cartilages. Tumning immediately above the frog, and along the greater part of it, we find the perforans flexor tenton, which passes orer the navicular bone, e, p. 432, and is inserted into the heel of the coffin-bone.

\section{THE NAYICULAR BOXE}

Is placed behind and beneath the lower pastembone, and behind and above the heel of the coffinbone, $e, p .432$, so that it forms a joint with both bones, and answers a very important office in strengthening the union between these parts, in receiving a portion of the weight which is thrown on the lower pastern, and in enabling the flexor tendon to act with more advantage. Supposing that this tendon were inserted into the coffin bone withont the intervention of the navicular bone, it mould act at great mechanical disadrantage in bending the pastern, for it is inserted near the end of the coffin-bone, and the weight, concentrated about the middle of the bone, is far off, and requires a great nower to raise it; but when the naricular bone is interposed, the centre of motions becomes the posterior elge of that bone, where it is in contact with the tendon, and then it will be seen that the distance of the power from the centre of motion is nearly or quite the same as the weight, and very great expenditure of muscular power wal 
be saved. In the one case, the power must be at least double the weight, in the other they will be nearly equal; and also the angle at which the tendon is inserted, is considerably more advantageous. Perhaps this is the principal use of the navicular bone; yet at the same time we are aware of the benefit which accrues (see p. 432) from a portion of the weight being taken from the coffinbone, and thrown on the navicular bone, and from it on the tendon, and the tendon resting on the elastic frog underneath. The navicular bone is sometimes, but inaccurately, said to descend with the motion of the foot. It does not do that. It cannot; for it is connected both with the pastern and coffin-bones by inelastic ligaments. When, however, the horny bulb, with its tuft of hair, at the back of an oblique fetlock, descends in the rapid gallop, and almost touches the ground, the navicular bone, being as it werea part of the pastern, must descend with it. With this exception, both in the extending and the bending of the pastern, the navieular bone turns or rolls upon the other bones rather than descends or ascends, and with this remarkable advantage, that when the pastern is extended (see p. 432 ), the navicular bone is plated in that situation which enables the flexor tendon to act with greatest alvantage in again bending the foot.

\section{THE CARTILAGES OF THE FOOT.}

There is a groore extending along the upper part of the coffin-bone and on either side, except at the protuberance which receives the extensor tendon $e$, p. 432 , occupied by cartilage, which, like the crust, is convex outwards and concave inwards. It extends to the very posterior part of the foot, rising about the quarters half an inch or more above the hoof, and diminishing in height forward and backward. These cartilages occupy a greater portion of the foot than does the cottin-bone, as will be seen in the lowest cut, p. 435 , where they are represented as extending far behind the coffinbone. They are held in their situation not merely by this groove, but by other comexious with the coffin-bone, the navicular bone, and the flexor tendon, and are thus perfectly secured.

Below are other carilages connected with the mider edges of the former, and on either side of the frog.

Between these cartilages is the sensible frog, filling up the whole of the space, and answering several important purposes, being an elastic hed on which the navicular bone and the tendon (see p. 432) can play with security, and without concussion or shock, by which all concussion communicated to the cartilages of the foot are destroyed - by which these cartilages are kept asunder, and the expansion of the upper part of the foot preserved. As the descent of the sole increases the width of the lower part of the foot, so the elevation of the frog, a portion of it being pressed upward and outward by the action of the navicular bone and tendon, causes the expansion of its upper part. Precisely as the strong nusscle peculiar to quadrupeds at the back of the eye (see p. 277), being forcibly contracted, presses upon the fatty matter in which the eye is imbedded, which may be displaced, lut cannot be squeezed into less compass, and which, being forced towards the inner corner of the eye, drives before it that important and beautiful mechanism the haw, so the elastic and yielding substance the frog, being pressed upon by the navicular bone and the tendon, and the pastem, and refusing to be coudensed into less compass, forces itself out on either side of them, and expands the lateral cartilnges, which again, by their inherent elasticity, recur to their former situation, when the frog no longer presses them outward. It appears, that by a different mechanism, but both equally admirable, and referable to the same principle, viz., that of elasticity, the expansion of the upper and lower portions of the hoof are effected, the one by the descent of the sole, the other by the compression and rising of the frog.

It is this expansion upward, which contributes principally to the preservation of the usefulness of the horse, when our destructive methods of shoeing are so calculated to destroy the expansion beneath. In draught horses, from the long-continued as well as violent pressure on the frog, and from the frog on the cartilage, inflammation is accasionally produced, which terminates in the cartiluges being clianged into bony matter.

\section{CHAPTER XIX.}

\section{THE DISEASES OF THE FOOT.}

OF these there is a long list. That will not be wondered at by those who have duly considered the complicated structure of the foot, the duty it has to perform, and the injuries to which it is exposed. It will be proper to commence with that which is the cause of many other diseases of the foot, and connected with almost all.

INFLAMMATION OF THE FOOT, OR ACUTE FOUNDER,

The sensible laminie, or fleshy plates on the 
front and sides of the coflin-hone, being replete with blood-vessels, are, like every other vaseular part, liable to inflammation, from its usual causes, and particularly from the violence with which, in rapid and long-continued action, these parts are strained and bruised. When in a severely contested race they have been stretched to their utmost, while, at the fullest stride of the horse, his weight has been thrown on them with destructive force; or, when the feet have been lattered and bruised in a hard day's journey, it will be no wonder if inflummation of the over-worked parts should ensue, and the occurrence of it may probably be produced and the disease aggravated by the too prevalent absurd mode of treating the animal. If a horse that has been ridden or driven hard is suffered to stand in the cold, or if his feet are washed and not speedily dried, he is very likely to have "fever in the feet." There is no more fruitful source of inflammation in the human being, or the brute, than these sudden changes of temperature. This has been explained as it regards grease, but it bears more immediately on the point now under consideration. The danger is not confined to change from heat to cold. Sudilen transition from cold to heat is as injurious, and therefore it is that so many horses, after having been ridden far in frost and snow, and placed immediately in a hot stable, and littered up to the knees, are attacked by this complaint. The feet and the lungs are the organs oftenest attacked, beculse they have previously suffered most by our mismanagement, and are most disposed to take on disease, and that which wonld cause slight inflammation of other parts, or trifling general derangement, will produce all its mischief on these organs; therefore it is that horses, the crust or lamina of whose feet are warped or obliquely placed, are most subject to it.

Sometimes there is a sudden change of inflammation from one organ to another. A horse may have laboured for several dars under evident inflammation of the lungs; all at once that will subside, and the disease will appear in the feet, or inflammation of the feet may follow similar affections in the bowels or the eyes. In cases of severe inflammation of the lungs, it may not be bad practice to remore the slioes and poultice the feet.

To the attentive ouserver the symptoms are clearly marked, and set there is no disease so often overluoked by the groom and the carter, and even by the veterinary sulgeon. The disease may assume an arute or a chronic form. The earliest symptoms of fever in the feet are fidgetiness, frequent shifting of the fore-legs, but no pawing, much less any attempts to reach the belly with the hiud-feet. The pulse is quickened, the flanks heaving, the nostrils red, and the horse, by his anxious countenance, and possibly moaning, indi- cating great pain. Presently he looks about his litter, as if preparing to lie dowu, lut he does not do so immediately; he continues to shift his weight from foot to foot: he is africil to draw his feet sufficiently under him for the purpose of lying down: but at length he drops. The circumstance of his lying down at an early period of the disease will sufficiently distinguish inflammation of the feet from that of the lungs, in which the horse ohstinately persists in standing until he drops from mere exhaustion. His quietness when down will distinguish it from colic or inflammation of the bowels, in both of which the loorse is up and down, and frequently rolling and kicking when down. When the grievance is in the feet, the horse experiences so much relief, from getting rid of the weight painfully distending the inflamed and higbly sensible laminie, that he is glad to lie as long as he can. He will likewise, as elearly as in inflammation of the lungs or bowels, point out the seat of disease by looking at the part. His muzzle will often rest on the feet or the affected foot. He must be inattentive who is not aware of what all this indicates.

If the feet are now examined, they will be found evidently hot. The patient will express pain if they are slightly rapped with a hammer, and the artery at the pastem will throb violently. No great time will now pass, if the disease is suffere 1 to pursue its course, before he will be perfectly unable to rise; or, if he is forced to get up, and one foot is lifted, he will stand with difficulty on the other, or perhaps drop at once from intensity of pain.

The treatment will resemble that of other inflammations, with such differences as the situation of the disease may suggest. Bleeding is indispensable; and that to its fullest extent. If the disease is confined to the fore-feet, four quarts of blood should be taken as soon as possible from the toe of each at the situation pointed out, fig. $z, 1$. 432 , and in the manner alrendy described; care being takeu to open the artery as well as the vein. The feet may likewise be put into warm water, to quicken the flow of the blood, and increase the quantity abstracted. Poultices of linseed meal, made very soft, should corer the whole of the foot and pastern, and be frequently renewed, which will promote exaporation from the neighbouring parts, and possibly tlirongh the pores of the hoof, and, hy softening and rendering supple the hoof, will relieve its painful pressure on the swelled and tender parts heneath. More fully to accomplish this last mupose, the shoe should be remored, the sole parred as thin as possible, and the crust, and particularly the quarters, well rasped. All this must be done gently, and with a great deal of patience, for the poor animal can scarcely bear his feet to be meddled with. There used to be occa- 
sional doukt as to the administration of physic, from fear of metastasis of intlammation, which has sometimes occurred, and been generally fatal. When, however, there is so much danger of losing the patient from the original attack, we must ruu the risk of the other. Sedative and cooling medicines should be diligently administered, consisting of digitalis, nitre, and emetic tartar.

If no amendment is observed, three quarts of blood should betaken from each foot on the following day. In extreme cases, a third bleeding of two quarts may be justifiable, and, instead of the ponltice, cloths kept wet with water in which nitre has been dissolved immediately before, and in the proportion of an ounce of nitre to a pound of water, may be wrapped round the feet. Abont the third day a blister may be tried, taking in the whole of the pastern and the coronet; lut a cradle must previously be put on the neck of the horse, and the feet must be corered after the blister, or they will probally be sadly blemished. The horse shonld be kept on mash diet, unless green ment can lie procured for him; and even that should not be given too liberally, nor should he, in the slightest degree, be coaxed to eat. When he appears to be recovering, his getting on his fect should not be hurried. It should be left perfeotly to his own discretion; nor should even walking exercise be permitted nntil he stands firm on his feet. When that is the case, and the season will permit, two months' run at grass will be very serviceable.

It is not always, however, or often, that infiammation of the feet is thus easily subdued; and, if it is subdued, it sometimes leaves after it some fearful consequences. The loss of the hoof is not an unfrequent one. Abont six or seven dass from the first attack, a slight separation will begin to appear between the coronet and the hoof. This should be carefully attended to, for' the sepa. rated horn will never again unite with the parts beneath, but the dismnion will extend, and the hoof will be lost. It is true that a new hoof will be formed, but it will be smaller in size and weaker than the first, and will rarely stand hard work. When this separation is observed, it will be a matter of calculation with the proprietor of the horse whether he will suffer the medical treatment to proceed.

\section{CHRONIC LAMINITIS.}

This is a species of founder, insidious in its attack, and destructive to the horse. It is a milder form of the preceding disease. There is lameness, but it is not so severe as in the former case. The horse stands as usnal. The crust is warm, and that warmth is constant, but it is not often prolably greater than in a state of health. The surest symptom is the actiou of the animal.
It is diametrically opposite to that in the navicular disease. The horse throws as much of his weight as he can, on the posterior parts of his feet.

The treatment should he similar to that recommended for the acute disease-blood-letting, cataplasms, fomentations, and blisters, and the last much sooner and much more frequently than iu the former disease.

\section{PUMTCED FEET}

The sensible and horny little plates which were elongated and partially separated during the intensity of the inflammation of founder, will not. always perfectly unite again, or will have lost much of their elasticity, and the coffin-bone, no longer fully supported by them, presses upon the sole, and the sole becomes Hattened, or convex, from this unnatural weight, and the horse acquires a pumiced foot. This will also happen when the animal is used too soon after an attack of inflam. mation of the feet, and before the lamina have regained sufficient strength to supjort the weight of the horse, or to contract again by their elastic power when they have yielded to the weight. When the coffin-bone is thus thrown on the sole, and renders it pumiced, the crust at the front of the hoof will "fall in," leaving a kind of hollow about the middle of it.

Pumiced feet, especially in horses with large, wide feet, are frequently produced without this acute inflammation. Undue work, and especially much hattering of the feet on the pavement, will extend and sprain these laminæ so much, that they will not have the power to contract, and thus the coffin-bone will be thrown lackward on the sole. A very important law of nature will unfortunately soon be actire here. When pressure is applied to any part, the ahsorbents become husy in removing it; so, when the coffin-bone begins to press upon the sole, the sole becomes thin from the increased wear and tear to which it is subjected by contact with the ground, and also because these ahsorbents are rapilly taking it away.

This is one of the diseases of the feet for which there is no cure. No skill is competent to effect a reunion between the separated fleshy and horny laminæ, or to restore to them the strength and elasticity of which they have been deprived, or to take up that hard horny substance which speedily fills the space between the crust and the receding coffin-bone. Some efforts have been made to palliate the disease, but they lave been only to a slight degree snccessful. If horses, on the first appearance of flat feet, were tumed out in a dry place, or put into a box for two or tliree months, sufficient stress would not be thrown on the lamine to increase the evil, and time might be given for the growth of horn enongh in the sole to support the coffin-lone; yet it is much to be 
doubted whether these horses wotll ever be useful, even for ordinary purposes. The slorest work required of them would drive the coffin-bone on the sole, and the projection would gradually reappear, for no power and no length of time can again unite the separated leaves of the coffin-bone and the hoof. All that can be clone in the way of palliation is by shoeing. Nothing must press on the projecting and pumiced part. If the projection is not considerable, a thick bar shoe is the best thing that ean be applied; but should the sole have much descended, a shoe with a very wide web, bevelled off so as not to press on the part, may be used. These means of relief, howerer, are only temporary, the disease will proceed; and at no great distance of time, the horse will be useless.

The occasional removal of the shoe, and compelling the horse to stand for awhile on the crust and laminx, has been resorted to. The bar shoe and the leathern sole, and occasional dressing with tar ointment have had their advocates, and it is sufliciently plain that the pumiced foot should have plenty of cover.

A somewhat similar affection, known by the name of a "Seedy Toe," is thus described by Mr. W. C. Spooner :- “ It can scaucely be called a disease, but it is rather a natural defect, which may be considerably increased by labour and bad shoeing. It arises from too great dryness of the horn, which renders it brittle, and causes its fibres to separate. There is a want of that tough elastic material which comnects the longitudinal fibres together, and produces that strong bond of union between them and the horny lamina and the sole. There is a hollow space within the foot, which sometimes extends aprard aud arouud, so as to admit a large probe. Neither the bone nor the laminæ, however, are exposed, but are still protected by the internal portion of the crust. The osly thing to be done is to anoint the foot occasionally, particularly the affected part, with tar and grease. A blister may also be applied to excite the development of a new growth of horn, that which is become dry and brittle being occasionally cut away."*

\section{CONTRACTION.}

The cut, p. 451, will give a fair idea of the young healthy foot, approaching nearly to a circle, and of which the quarters form the widest part, and the inner quarter (this is the near foot) rather wiler than the outer. This shipe is not long preserved in many horses, but the foot increases in length, and narrows in the quarters, and particularly at the heel, and the frog is diminished in width, and the sole becomes more concare, and the heels higher, and lameness, or at least a shortened and feeling action, ensues.

* Spooner on the Foot of the Horse.
It must be premised that there is a grent leal more horror of contracted lieels than there is oceasion for. Many persons reject a lurse at once if the quarters are wiring in; but the fact is, that although this is an unnatural form of the hoof, it is slow of growth, and nature kindly makes that prosision for the slowly altered form of the hoof which she does in similar cases-she accommodates the parts to the change of form. As the hoof draws in, the parts beneath, and particularly the coffin-bone, and especially the heels of thit bone, diminish; or, after all, it is more a change of form than of capacity. As the foot lengthens in proportion as it narrows, so does the colfin-bone, and it is as perfectly adjusted as before to the box in which it is placed. Its laminze are in as intimate and perfect union with those of the crust as before the boof had begun to ehange. On this account it is that many horses, with rery contracted feet, are perfectly sound, and no horse should bo rejected merely because he lus contraction. He should undoubtedly be examined more carefully, and with considerable suspicion; but if he has good action, aud is otherwise unexceptionable, there is no reason that the purchase should not be male. A horse with contracted feet, if he goes sound, is better than another with open but weak heels.

The opinion is perfectly erroneous that contraction is the necessary consequence of shoeing. There can be no doubt that an inflexible iron ring being nailed to the foot prevents, to a very consideralile degree, the descent of the sole and the expansion of the heels below; and it is likewise probable, that when the expansion of the heels is prevented thes often begin to contract. But here agtin nature, eut off from one resource, finds others. If one of the jugalar veins is lost, the blood pursues its course by other chamels, and the borse does not appear to suffer in the slightest degree. Thus also if the expansion of the heels below is diminished, that of the cartilages above is made more use of. If the coffin-bone has not so much descent downward, it probably acquires one lackward, and the functions of the foot are usefully if not perfectly performed. The plain proof of this is, that although there are many horses that are injured or ruined by bad shoeing, there are others, and they are a numerous cliss, who suffer not at all from good shoeing, and scareely even from bad. Except it be from accident, how seldom is the farmer's hor'se lame? and it might even be further asked, how seldom is his foot much contracted? Some gentlemen who are careful of their horses have driven them twenty years, and principally over the rough parement of towns, without a day's lameness. Shoeing may be a necessary evil, but it is not the evil which some speculative persons have supposed it to be ; and the undoubted fact is, 
that when the horse is put to real had work, and when the injury produced by shoeing in destroying the expansibility of the foot would most of all show itself, the foot lasts a great deal Jonger than the leg; nay, horsemen tell us that one pair of good feet is worth two pairs of legs.

Having thus premised that contraction is not inevitably accompanied by lameness, and that shoeing, with all its evils, does not necessarily injure the foot, those cases of contraction, too numerous, which are the consequence of our stable management, and which do cripple and ruin the lorse, may be considered. There is nothing in the appearance of the feet which would enable us to decide when contraction is or is not destructive to the usefulness of the animal; his manner of going, and his capability for work, must be our guides. Lameness usually accompanies the beginning of contraction; it is the invariable attendant on rapid contraction, but it does not always exist when the wiring in is slow or of long standing.

A very excellent writer, particularly when treating of the foot of the horse, Mr. Blaine, has given us a long and correct list of the causes of injurious contraction, and most of them are, fortunately, under the control of the owner of the animal. He places at the head of them, neglect of paring. The hoof is continually growing, the crust is lengthening, and the sole is thickening. This is a provision for the wear and tear of the foot in an unshod state; lut when it is protected by a shoe, and none of the horn can be worn away by coming in contact with the ground, and the growth of horn continues, the hoof grows high, and the sole gets thick, and, in consequence of this, the descent of the sole and the expansion of the heels are prevented, and contraction is the result. The smitl might lessen, if not prevent the evil, hy carefully thinning the sole and lowering the lieels at each shoeing; but the first of these is a matter of considerable labour, and the second could not be done effectually without being accompanied by the first, and therefore they are both neglected. The prejudice of many owners of horses assists in increasing the evil; they imagine that a great deal of mischief is done by cutting avay the foot. Nischief may be the result of injudicious cutting, when the bars are destroyed and the frog is elevated from the ground; but more evil results from the unyielding thickness of horn impairing the elastic and expansive principle of the foot. If gentlemen would occasionally stand by, and see that the sole is properly thimmed, and the heels lowered, they would be amply repaid in the comfort and usefulness of the horse.

Ill-judged economy is another source of this disease. If the shoes of one smith will, with ordinary Work, last a little more than three weeks, while another contrives to make lis last six weeks, he is supposed to be the better workman and the more honest man, and he gets the greater part of the custom. His shoe is suffered to remain on during the whole time, to the manifest injury of the feet, and that injury is materially increased by the greater thickness and weight of these shoes, and the tightness with which they are fastened on, the nails being necessarily placed nearer to the quarters, and possibly an additional nail or two used in the fasteming, and these also applied at the quarters. There is no rule which admits of so little exception, as that, once in about every three weeks, the growth of horn which the natural wear of the foot cannot get rid of, should be pared away-the toe should be slortened in most feet-the sole should be thinned, and the heels lowered. Every one who has carefully observed the shape of the horse's foot, must have seen that in proportion to its height or neglected growth, it contracts and closes round the coronet. A low-heeled horse might lave other serious defects, of which it will be our duty to speak, but he has seldom a contracted foot.

Another source of contraction is the want of natural moisture. The unshot colt has seldom contracted feet, nor does the horse at grass acquire them, because the hoof is kept cool and damp by occasional rain, and by the regular dew. It is thus rendered supple, and its elasticity is preserved, and the expansive power of the foot is uninjured. The hoof of the stabled horse sometimes has not one drop of moisture on it for several days. The effect of this, in the contraction of the horn, is sufficiently erident. Hence the propriety of stopping the feet where there is the least tendency to contraction. The intelligent and careful groom will not omit it a single night. Cow-dung, with a small portion of clay to give it consistence, is a common and very good stopping. A better one is a piece of thick felt cut to the shape of the sole and soaked in water. The common stopping of tar and grease is peculiarly aljectionalie, for it closes the pores of the feet, and ultimately increases the dryness and brittleness which it was designed to remedy.

The usuak management of the farmer's horse that is often turned out after his daily task is exacted, or whose work is generally performed where the feet are exposed to moisture, is an excellent preventive against contraction.

Some persons have complained mucl of the influence of litter. If the horse stands many hours in the day with his feet imbedded in straw, it is supposed that the hoof must be unnaturally heated; and it is said that the horn will contract under the influence of heat. It is seldom, however, that the foot is so surrounded by the litter that its heat will be sufficiently increased to produce this effect. It will be difficult to produce the case in which contraction, or thrush, or tendermess, have been produced by the horse standing on dry litter. There 
are thousands of horses that stand upon straw twenty hours ont of the twenty-four, without receiving the slightest injury l'rom it. The author of this work is not one of those who would, during the day, remove all litter from under the lorse. It gives a naked and uncomfortable appearance to the stable. There is a considerable difference in our own feelings whether we staud for an hour or two on the hard stones, or a soft carpet, and especially whether we beat our feet upon the one or the other. Humanity and a proper care of the foot of the horse shoukl induce the orner to keep some litter under the animal during the day ; but his feet need not sink so deeply in it that their temperature becomes much affected. If the straw is suffered to remain until it is wet, hot, and rotten, the effluvia proceeding from it may produce cough, or inflammation of the eyes, or thrushes in the feet; but a light bed of straw, with tolerable attention to cleanliness, can never do harm. "There are horses," says Professor Stewart, "that, in the habit of pawing and stamping, slip alsout and sometimes lame themselves on the bare stones; many disposed to lie down during the day, will not, or ought not, to do it, with a slight portion of litter uuder them. It is a frequent observation with regard to road horses, and many others, that the more a horse lies the better he works. Lame or tender-footed horses cannot lie too much, and a great deal of standing ruins the best legs and feet. Some hor'ses, indeed, do not need this day-bedding, but many are the better for it, and none are the worse."*

Thrushes are much oftener the consequence than the cause of contraction. The homy frog, yielding to the pressure of the contracted quarters, is diminished in size, and the lower portion of the fleshy frog becomes imprisoned, irritated, and inflamed, and pus or matter is discliarged at the cleft; yet there are many heels in the last stage of contraction that are not thrusly. On the other hand, thrush never long existed, accompanied by much discharge, without producing a disposition to contraction; therefore, thrush may be considered as both the cause and conseqnence of contraction.

The removal of the bars takes away a main impediment to contraction. Their use in assisting the expansion of the foot has been already stated, and should a disposition to contraction be produced ly any other cause, the eutting away of the bars would hasten and aggravate the evil; but the loss of the bar would not of itself produce contraction.

The contraction, however, that is comnected with permanent lameness, alihough increased by the circumstances which we have mentioned, usually derives its origin from a different source, and from one that acts violently and suddeuly. Inflammation of the little plates covering the coffin-bone is the most usual cause ; and a degree of inflammation

* Stcwart's Stable Economy, p. 139. not suffreiently intense to be characteristil as acute founder, but quickly leading to sad results, inay and does spring from causes almost unsuspected. There is one fiact to which we have alluderl, and that cannot be doubter, that contriotion is excecd. ingly rare in the agricultural horse, but frequently occurs in the stable of the gentleman aud the coach-proprietor. It is rare where the lorse is seemingly neglected and badly shod; and frequent where every care is taken of the animal, and the shoes are unexceptionable and skilfully applied. Something may depend upon the breed. Blood horses are particularly liable to contraction. Not only is the foot naturally small, but it is disposed to become narrower at the heels. On the other hand, the broad, flat foot of the cart-borse is subject to diseases enough, but contractiou is seldom one of the number. $†$ In horses of equal blood not a little seems to depend upon the colour, and the dark chesuut is proverbially prone to contraction.

Whatever is the canse of that rapid contraction or narrowing of the beels which is accompanied by severe lameness, the symptoms may be easily distinguished. While standing in the stable the horse will point with, or place forward, the contracted foot, or, if both feet are affected, he will alteruately place one before the other. When he is taken ont of the stable, he will not, perhaps, exhibit the decided lameness which characterises spraiu of the Alexor tendon, or some diseases of the fuot; but his step nill be peculiarly short and quick, and the feet will be placed gently and tenderly on the ground, or searcely lifted from it in the walk or the trot. It wonld seem as if the slightest irregularity of surface would throw the animal down, and so it threatens to do, for he is constantly tripping and stumbling. If the fore feet are carefully observed, one or both of tbem will lie narrowed across the quarters and torarls the heels. In a few cases the whole of the foot appears to be contracted anc shrunk; but in the majority of instauces, while the heels are narower, the foot is louger. The contraction appears sometimes in loth heels: at other times in the imner heel only ; or, if both are affected, the inner one is rived in the most, either from the coronet to the base of the foot, or only or principally at the coronet-oftener near the base of the footbut in mast cases the hollow being greatest about

+ A valued correspondent suggests, that the difference between these two kinds of horses may perhaps throw some light on the subjert. The long-rontinuted and heavy pressurc on the frog in the cart-house proluces ossification of the eartilages from which the blood-hor'se is free. In the guichness of the action of the blondhorsc, the cxpansion of the frog is not suficiently continued to produce this cflect; lout the concussion is severe, and the frog and he shorter lamina towards the heel are the first to suffer, and contrac tion ensues. We do not find contraction in the himl fect, where there is lattle contraction, nor ossification, beeause the pressure is chjefly on the toe. Quick dratight horses hare it both ways, but chietly in contraction.

The reater will form his own opinion on this subject. 
mid-way between the coronet and the bottom of the foot. This irregularity of contraction, and uncertainty as to the place of it, prove that it is some internal disorganization, the seat of which varies with the portion of the attachment betreen the hoof and the foot that was principally strained or injured. In every recent case the contracted part will be hotter than the rest of the foot, and the sole will, in the majority of cases, be unnaturally eollcave.

Of the treatment of contraction attended with lameness, little can be said that will be satisfactory. Numberless have been the mechanical contrivauces to oppose the progress of contraction, or to force back the foot to its original shape, and many of them have enjoyed considerable but short-lived reputation. A clip was placed at the inside of each heel, which, resting on the bars, was intended to afford an insurmountable obstacle to the further wiring in of the foot, while the heels of the shoe were bevelled outward in order to give the foot a tendency to expand. The foot, however, contiumed to contraet, until the clip was imbedded in the horn, and worse lameness was produced.

A shoe jointed at the toe, and with a screw adapted to the heels, was contrived, by which, when softened by poulticing, or immersion in warm water, the quarters were to be irresistibly widenerl. They were widened by the daily and cautious use of the serew until the foot seemed to assume its natural form, and the inventor began to exult in having diseovered a cure for contraction: but, no sooner was the common shoe again applied, and the horse had returned to his work, than the heels began to narrow, and the foot became as contracted as ever. Common sense would have foretold that such must have been the result of this expansive process; for the heels could have been only thus forced asunder at the expense of partial or total separation from the interior portions of the foot with which they were in contact.

The contracted heel can rarely or never permanently expand, for this plain reason, that although we may liave power over the crust, we cannot renew the lamine, or restore the portion of the frog that has been absorbed.

If the action of the horse is not materially impaired, it is better to let the contraction alone, be it as great as it will. If the contraction has evidently produced considerable lameness, the owner of the horse will have to calculate between his value if cured, the expense of the cure, and the probability of failure.

The medical treatment should alone be undertaken by a skilful reterinary surgeon, and it will principally consist in abating any inflammation that may exist, by local bleeding and physic, paring the sole to the utmost extent that it will bear; rasping the quarters as deeply as can be, without their being too much weakened, or the coronary ring (see- $b$, p. 432) insured; rasping deeply likewise at the toe, and perhaps scoring at the toe. The horse is afterwards made to stand during the day in wet clay, placed in one of the stalls. He is at night moved into anotber stall, and his feet bound up thickly in wet cloths; $o r^{\circ}$ he is turned out into wet pasturage, with tips, or, if possible; without them, and his feet are frequently pared out, and the quarters lightly rasped. In five or six months the horn will generally have grown down, when he may be taken up, and shod with shoes unattached by nails on the inner side of the foot, and put to gentle work. The foot will be found very considerably eularged, and the owner will, perhaps, think that the cure is accomplished. The horse may, possibly, for a time stand very gentle work, and the imer side of the foot being left at liberty, its natural expansire process may be resumed: the intemal part of the foot, however, has not been healthily filled up with the espansion of the crust. If that expansion has been effected forward on the quarters, the crust will no longer be in contact with the lengthened and narrowed heels of the coffin-bone. There will not be the natural adhesion and strength, and a very slight cause, or even the very habit of contraction, will, in spite of all care and the fieedom of the immer quarter, in very many instances, cause the foot to wire in again as badly as before.

\section{THE NAIICELAR-JOINT DISEASE.}

Many horses with well-formed and open feet become sadly and permanently lame, and veterinary surgeons have been puzzled to discover the cause. The farrier lias had his convenient explanation "the shoulder;" but the scientific practitioner may not have been able to diseover an ostensible cause of lameness in the whole limb. There is no one accustomed to horses who does not recollect an instance of this.

By reference to the cut, e, p. 432 , it will be seen that, behind and heneath the lower pasternbone, and behind and above the heel of the coffinbone, is a small bone called the navicular or shutlle bone. It is so placed as to strengthen the union between the lower pastern and the coffin-bone, and to enable the flexor tendon, which passes over it in order to be inserted into the bottom of the coffin-bone, to act with more advantage. It forms a kind of joint with that tendon. There is a great deal of weight thrown on the navicular-bone, and from the vavicular-bone on the tendon; and there is a great deal of motion or play between them in the bending and extension of the pasterns. It is very easy to conceive that, from sudden concussion, or from rapid and overstrained motion, and that, perhaps, after the animal has been sometime at rest, and the parts have not adanted themselves for motion, there 
may be too much play between the bone and the tendon-the delicate membrane which covers the bone, or the cartilage of the bone, may be bruised, and inflamed, and lestroyed; that all the painful eflects of an inflamed and open joint may ensue, and the horse be irrecoverably lame. Numerous dissections hare shown that this joint, formed by the tendon and the bone, has been the frequent, and the almost invariable, seat of these obseme lamenesses. The membrine covering the cartilage of the bone has been found in an ulcerated state; the cartilage itself has been ulcerated and eaten away; the bone has become carions or decayed, and bony adhesions have taken place between the navicular and the pastern and the coffin-lones, and this part of the foot has often become completely disorganised and useless. This joint is probably the seat of lameness, not only in well-formed and perfect feet, but in those which become lame after contraction; for in proportion as the inner frog is compressed by the contraction of the beels, and is absorbed by that pressure, and the sole is become concare, and the horny frog, and the coffin-bone too, thereby elevated, there will be less room for the action of this joint, and more danger of the tendon and the delicate mem. brane of the navicular-bone being crushed between that bone and the horny frog.

Stable management has little to do with the production of this disease, any farther than if a horse stands idle in the stable several days, and the structure of the foot, and all the apparatus connected with motion, become unused to exer. tion, and indisposed for it, and be is then suddenly and violently exercised, this membrane is very liable to be bruised and injured. This, amongst other evils, will be lessened by a loose box, in which a horse will always take some exercise.*

The cure of navicular disease is difficult and nncertain. The first and all-important point is the removal of the inflammation in this very susceptible membrame. Local bleeding, poulticing, and plysic will be our principal resources. If there is contraction, this must, if possible, be renoved by the means already pointed out. If

* To Mr. James Turner the veterinary profession is indebted for a knowledge of the seat and curse ol this lameacss. In the year 1816 he first alluded to it, and the trutl and importanee of his discovery is now universally allowed.

According to Mr. Turner, contraction of the hoof is more or less apparent in the majority of horses that have been accustomed to be shou. This is often leag hefore they have attained the highest value for work, and not unfiequently before they are five years old. This contraction is not, however, necessarily con. nected with lanieness-a large proportion of horses in the very mirlst of labour are perfectly free from lameness.

The next deviation from nature is the passive state to which the fuot is suboilted at leust twenty-two or twenty.three hours out of the twenty-four, and sometimes for several cunsecntive days. Let this be compared with the few hours during which the fet of a horse at pasture are in a griescent state, and there will he no cause of surj rise in the chiuge of forn and position, arul cha- there is no contraction, it will nevertheless be jrudent to get rid of all surrounding pressure, and to unfetter, as much as possible, the inside heel of the coffin-bone, by paring the sole and rasping the quarter's, and using the shoe without nails on the imner quarter, and applying cold poultices to the cormet and the whole of the foot. This is a case, however, which must be turned over to the veterinary surgeon, for he alone, from his knowledge of the anatomy of the foot, and the precise seat of the disease, is competent to treat it. If attacked on its earliest appearance, and before ulceration of the membrane of the jom thas taken place, it may be radically cured: but ulceration of the menbrane will be with difficulty healed, and caries of the bone will for ever remain.

Blistering the coronet will often assist in promoting a cure by diverting the inflammation to another part, and it will materially quicken the growth of the holn. A seton passed through the frog by a skilful operator, and approaching as nearly as possible to the seat of disease, has been serviceable.

In cases of old contraction, attended by a short and feeling step, neurotomy, or the excision of a portion of the nerve (for an explanation of the nature and eflects of which see p. 299), may be resorted to with decided advantage. Not only will the lameness be remored, but, by the foot Leing again brought fully and firmly upon the ground, the inner side of the shoe heing unfettered by nails, a portion of the contraction may be removed by the sole being allowed to descend and the foot to expand at each contact with the ground.

Even when the navicular-joint is particularly suspected, if there is no apparent inflammation (and that would be readily detected by the heat of the foot), neurotomy may lie practised with the bope of alleviating the sufferings of the animal, and thus removing a portion of the lameness; bit if the lameness is extreme, either with or without contraction, and especially if there is heat about the foot, the operation is dangerous. There is, probably, ulceration of the membrane-possibly, decay of the lone; and the additional friction to which the parts would be subjected, by the freer

racter, and the state of contraction- which takes place in the foot deprived of its natural pressure and motion.

The first consequence of contraction is the gradual displacement of the navicular and colfin bones. They ascend within the hoof. An unnatural arch is formed by the ascent of the frog, and the delicate synovial nembrane lining the joint is erushed and liruised bo the very material which nature has bestoried as a defence. This bruise of the synovial membrane lining the joint is the veritable sonrce of this complaint, the actuul cause of the Fhole not consisting in the rear and tear of the part, but having its origin in rest. It is engendered in the stable, bui it becomes permanently established by sudden violtace ont of it. Geucral eantraction of the fort of the horse may take place to a great crtent with comparative impunity, but it is a partial contruction or pressute which is the root of the eril.-Turner on the Faticulur Discuse, Telerinarian, vol. ii., p. 53. 
action of the horse, the sense of pain being removesl, would cause that ulecration or decay to proceed more rapidly until the foot would be completely disorganised, or the tendon would be gradually morn through by rubbing against the ronghened surface of the bone.

\section{SAND-CRACK.}

This, as its name imports, is a crack or division of the hoof from above downward, and into which sand and dirt are too apt to insinuate themselves. It is so called, because it most frequently occurs in sandy districts, the loeat of the sand applied to the feet giving them a disposition to crack. It occurs both in the fore and the hind feet. In the fore feet it is nsually found in the inner quarter (see $g, p .436$ ), but occasionally in the outer quarter, becanse there is the principal stress or effort towards expansion in the foot, and the immer quarter is weaker than the outer. In the linil feet the erack is almost invariably found in the front, because in the digging of the toe into the ground in the act of drawing, the principal stress is in front.

This is a most serions defect. It indicates a brittleness of the crust, sometimes natural, but oftener the consequence of mismanagement or disease, which, in spite of every meaus adopted, will frobably be the source of fiture annoyance. On a loof that has once been thus divided no dependence can be placed, unless, by great care, the natural suppleness of the horn has been restored and is retained.

Sand-crack may lıappen in an instant from a false step or over-exertion, and therefore a horse, although he may spring a sand-crack within an lour after the purchase, cannot be returned on that account.

It is always necessary to examine the inner quarter of the foot at the time of purchase, for it has more than once occurred that, by low dealers, and particularly at fairs, a sancl-crack has heen neatly covered with pitch, and then, the whole of the hoof having been oiled, the injury was so adroitly concealed that an incautious person might be easily deceived.

The crack sometimes does not penetrate through the horn. It then causes no lameness; nevertheless, it must not be neglected. It shows that there is brittleness, which should induce the purchaser to pause; and, if proper means are not taken, it will generally soon penetrate to the quick. It should be pared or rasped fairly out; and if the paring or rasping has been deep, the foot should be strengthened by a coating of pitch, with coarse tape boumd over it, and a second coating of pitch corering this. Every crack should be pared or rasped to ascertain its depth. If it penetrates through the crust, even although no lameness exists, a firing-iron, red-hot, should be passed somewhat deeply above and below it, in order to prevent its lengthening-the edges should be thinned to remove any painful or injurious pressure, and the foot shonll be bound up in the manner directed, care being taken that the shoe does not press upon the crust immediately under the sand-crack.

If the crack has penetrated through the crust, and lameness has ensued, the case is more serious. it must be carefully examined, in order to ascer. tain that no dirt or sand has got into it; the edges must be more considerably thinned, and if any fungus is beginning to protrude through the crack, and is imprisoned there, it must he destroyed by the application of the butyr (chloride) of antimony. This is preferable to the cantery, because the edges of the horn will not be thickened or rough. ened, and thus become a source of after-irritation. The iron must then be run deeply across, abore, and below the crack, as in the other case; a pleiget of dry tow being placed in the crack, in and over it, and the whole bound down as tightly as possible. On the third day the part should be examined, and the canstic again applied if necessary: but if the crack is dry, and defended by a hard horny crust, the sooner the pitch plaster is put on the better.

The most serious case is, when, from tread or neglect, the coronet is divided. The growtl of horn proceeds from the coronary ligament, and unless this ligament is sound the loorn will grow down dismitel. The method to be here adopted is to run the back of the firing-iron over the coronet where it is divided. Some inflammation will ensue; and when the scab proluced by the cautery peels off, as it will in a few days, the division will be obliterated, and sound and united hom will grow down. When there is sufficient horn above the crack, a horizontal line should be drawn with a firing-iron between the sound born and the crack. The connexion between the sound part and the crack will thus be prevented, and the new horn will gradually and safely descend, but the borse should not be used until sufficient horn has grown down fairly to isolate the crack. In this case, as in almost every one of sand-crack, the horse should be kept as quiet as possible. It is not in the power of the surgeon to effect a perfect cure, if the owner will continue to use the animal. When the hom is divided at the coronet, it will be five or six months hefore it will grow fairly down, and not before that, should the animal be used even for ordinary work. When, however, the horn lias grom an inch from the coronet, the horse may be turned out-the foot being well defended by the pitch plaster, and that renewed as often as it lecomes loose-a bar-shoe being worn, cliambered so as not to press upon the hoof imme- 
diately under the crack, and that shoe being taken off, the sole pared out, and any bulbous projection of new horn being removed once in every three weeks.

To remedy the undue brittleness of the hoof, there is no better application than that recommended in page 457 , the sole being covered at the same time with the common cow-dung or felt stopping.

\section{TREAD AND OVER-REACH.}

Under these terms are comprised bruises and wound of the coronet, inflicted by the other feet.

A Tread is said to have talien place when the inside of the coronet of one hind foot is struck by the calkin of the shoe of the other, and a bruised or contused wound is inflicted. The coronary ring is highly vascular externally, and within it is cartilaginous; the blow, therefore, often produces much pain and hemorrhage, and contusion and destruction of the parts. The womld may appear to be simple, but it is often of a sadly complicated nature, and much time and care will need to be expended in repairing the mischief. Mr. Percivall very accurately states that " the wound has, in the first place, to cast off' a slough, consisting of the bruised, separated, and dendened parts; then the chasm thereby exposed has to granulate; and finally, the sore has to eicatrize and form new horm." *ै

A tread, or wound of the coronet, must nerer be neglected, lest gravel should insinuate itself into the wound, and form deep ulcerations, called sinuses or pipes, and which constitute quittor. Although some mildly stimulating escharotic may be occasionally required, the caustic, too frequently used by farriers, should be carefully avoided, not only lest quittor should be formel, but lest the coronary ligament should be so injured as to be afterwards ineapable of secreting perfect horn. When properly treated, a tread is seldom productive of much injury. If the dirt is well washed out of it, and a pledget of tow, dipped in Friar's balsam, bound over the wound, it will, in the majority of cases, speedily heal. Should the bruise be extensive or the wound deep, a poultice may be applied for one or two days, and then the Friar's bnlsam, or digestive ointment. Sometimes a soft tumour will form on the part, which will be quickly brought to suppuration by a poultice; and when the matter has run out, the ulcer will heal by the application of the Friar's balsam, or a meak solution of blue vitriol.

An Over-reach is a tread upon the heel of the coronet of the fore foot by the shoe of the corresponding hind foot, and either inflicted by the toe or by the inner edge of the inside of the shoe.
The preventive treatment is the bevelling, or rounding off, of the inside edge or rim of the hind shoes. The cure is, the cutting anray of the loose parts, the application of Friar's balsam, and prosection from the dirt.

There is a singular species of over-reaching, termed Forging or Clicking. The horse, in the act of trotting, strikes the toes of the hind shoes against the fore ones. The noise of the clicking is unpleasant, and the trick or habit is not altogether free from danger. It is most frequent in young horses, and is attributable to too great activity or length of stride in the hind legs. The rider may do something by keeping the head of the horse well up; but the smith can effect more by making the hind shoes of elicking horses short in the toe, and having the web broad. When they are too long, they are apt to be torn off-rihen too narrow, the hind foot may bruise the sole of the fore one, or may be locked fast between the branches of the fore shoe.

\section{FALSE OUARTER.}

If the coromary ligament, by which the horn of the crust is secreted, is divided by some cut or bruise, or eaten through by any caustic, there will occasionally be a division in the horn as it groms down, eitlier in the form of a permanent sandcrack, or one portion of the horn overlapping the other. It occasionally follows neglected sandcrack, or it may le the consequence of quittor. This is exteriorly an evident fissure in the hom, and extending from the coronet to the sole, but not always penetrating to the lamine. It is a very serious defect, and exceedingly difficult to remedy; for occasionally, if the horse is over-weighted or hurried on his journey, the fissure will open and bleed, and very serious inconvenience and lameness may ensue. Grit and dirt may insimate itself into the aperture, and penetrate to the sensible laminæ. Inflammation will almost of necessity be produced; and much mischief mill be effected. While the energies of the animal are not severely taxed, he may not experience much inconvenience or pain; but the slightest exertion will cause the fissure to expand, and painful lameness to follow.

This is not only a very serious defect, but one exceedingly difficult to remedy. The coronary ligament must be restored to its perfect state, or at least to the discharge of its perfect function Nuch danger would attend the application of the caustic in order to effect this. A blister is rarely sufficiently active: lut the application, not too severely, of a heated flat or rounded iron to the coronet, at the injured part, affords the best chance of success-the edges of the horn on either side of the crack being thinned, the hoof supported, 
and the separated parts held together by a firm encasement of pitch, as described when speaking of the treatment of sand-crack. The coronet must be examined at least once in every fortnight, in order to ascertain whether the desired union has taken place; and, as a palliatice during the treatment of the case, or if the treatment should be unsuccessful, a bar-shoe may be used, and care taken that there be no bearing at or immediately under the separation of the horn. This will be best effected, when the crust is thick and the quarters strong, by paring off a little of the bottom of the crust at the part, so that it shall not touch the shoe; but if the foot is weak, an indentation or hollow should be made in the shoe. Strain or concussion on the immediate part will thus be aroided, and, in sudden;or violent exertion, the crack will not be so likely to extend npward to the curonet, when whole and sound horn has begun to be formed there.*

Iu some cases false quarter assumes a less serions character. The horn grows down whole, but the ligament is mialle to secrete that which is perfectly healthy, and, therefore, a narrow.slip of horn of a different and lighter colour is produced. This is sometimes the best result that cau be procured when the surgeon has been able to obliterate the absolute crack or separation. It is, however, to be regarded as a defect, not sufficient to condemu the horse, but indicating that he has bad sand-crack, anil that a disposition to sand-crack may possibly remain. There will also, in the generality of cases, be some degree of tenderness in that quarter, which may produce sligbt lameness when unusual exertion is required from the horse, or the shoe is suffered long to press on the part.

\section{QUTTTOR.}

This has been described as being the result of neglected or bad tread or over-reach; but it may be the consequence of any wonnd in the foot, and in any part of the foot. In the natural process of ulceration, matter is thrown out from the wound. It precedes the actual healing of the part. The matter which is secreted in wonnds of the foot is usually pent up there, and, increasing in quantity, and urging its way in every direction, it forces the little tleshy plates of the coflin-bone, from the horny ones of the crinst, or the horny sole from the fleshy sole, or even eats deeply into the internal parts of the foot. These pipes or simases ran in every direction, and constitute the essence of quittor.

* James Clirk, whose works have not heen ralued as they deserve, expresses in few words the real state of the case, and the course that should be pursued:-

"We may so far palliate the complaint as to render the horse something useful by using a shoe of such a construction as will support the limb without resting or pressing too much upon the wethicned quarter." A proper stopping should also cover tle sole, on which some eoarse tow may be pliced, and a piece of leather over that; the whole being corifined by a broad web-shoe.
If it arises from a wound at the bottom of the foot, the purulent matter which is rapidly formed is pent up there, and the nail of the shoe or the stub remains in the wound, or the small aperture which was made is immediately closed again. This matter, however, continues to be secreted, and separates. the horny sole from the Heshy one to a considerable extent, and at length forces its way upwards, and appears at the coronet, and usually at the quarter, and there slowly oozes out, while the aperture and the quantity discharged are so small that the inexperienced would have no suspicion of the extent of the mischief within, and the difficulty of repairing it. The opening may scarcely admit a probe into it, yet over the greater part of the quarter and the sole the horu may have separated from the foot, and the matter. may have penetrated under the cartilages and ligaments, and into the coffin-joint. Not only so, but two mischievous results may have been produced,- - the pressure of the matter wherever it has gone has formed.ulcerations that are indisposed to heal, and that require the application of strong and painful stimulants to indace them to heal; and, worse than this, the horn, once separated from the sensible parts beneath, will never again unite with them. Quittor may occur in both the fore and the hind feet.

It will be sufficiently plain that the aid of a skilful practitioner is here requisite, and also the full exercise of patience in the proprietor of the horse. It may ve necessary to remove much of the horuy sole, which will be speedily reproducerl when the fleshy surface beneath can be lrought to a healthy condition; but if much of the horn at the quarters must be taken away, five or six months may probably elapse before it will be sufficiently gromn down again to reuder the horse useful.

Measures of considerable sererity are indispensable. The application of some caustic will alone produce a healthy action on the ulcerated surfaces; but on the ground of interest and of humanity we protest against that brutal practice, or at least the extent to which it is carrien, that is pursued by many ignorant smiths, of coring out, or deeply destroying the liealthy as well as the diseased parts - and parts which no process will again restore. The unhealthy surface must be removed; but the cartilages and ligaments, and even portions of the bone, need not to be sacrificed.

The experienced veterinary surgeon will alone be able to counsel the proprietor of the horse when, in cases of confirmed quittor, there is reasonable hope of permanent cure. A knowledge of the anatomy of the foot is necessary to enable him to decide what parts, inclispensable to the action of the animal, may bave been irreparably injured or destroyed, or to save these parts from the destructive effect of torturing canstics. When any portion of the bone can be felt ly the probe the chances of 
success are diminished, and the omner and the operator should pause. When the joints are ex. posed, the case is hopeless, although, in a great many instances, the bones and the joints are ex. posed hy the remedy and not by the disease. One bint may not be necessary to the practitioner, but it may guide the determination and hopes of the owner: if, when a probe is introduced into the fis. tulous orifice on the coronet, the direction of the sinuses or pipes is backward, there is much probability that a perfect cure may be effected; but if the direction of the simuses is forward, the cure is at best doubtful. In the first instance, there is veither bone nor joint to be injured; in the other, the more important parts of the foot are in danger, and the principal action and concussion are found.

Neglected bruises of the sole sometimes lay the foundation for quittor. When the foot is flat, it is very liable to be brtused if the horse is ridden fast over a rough and stony road; or, a small stone, insinuating itself between the shoe and the sole, or confined by the curvature of the shoe, will frequently lame the horse: The heat and tenderness of the part, the occasional redness of the horn, and the absence of puncture, will clearly mark the bruise. The sole must then be thimned, and particularly orer the bruised part, aud, in neglected cases, it must be pared even to the quick, in order to ascertain whether the inflammation has run on to suppuration. Bleeding at the toe will be clearly indicated; and poultices, and such other means as have either been described under" "Inflammation of the Feet," or will be pointed out under the next head. The principal causes of lruises of the foot are leaving the sole too much exposed by nieans of a narrow-mebled shoe, or the smith paring out the sole too closely, or the pressure of the shoe on the sole, or the introduction of gravel or stones between the shoe and the sole.

The anthor subjoins the mode of cure in this disease, as it has been practised by two veterinary surgeons. They are both excellent, and, so far as can well be the case, satisfactory.

Mr. Percivall snys:- "The ordinary mode of cure consists in the introduction of caustic into the sinus; and so long as the cartilage preserves its integrity - by which I mean, is free from cariesthis is perhaps the most prompt and effectual mode of proceeding. The farrier's practice is to mix about lialf a drachm of corrosive sublimate in porwder with twice or thrice the quantity of flour, and make them into a paste with water. This he takes up by little at a time with the point of his probe, and works it about in the sinus until the paste appears rising in the orifice above. After this is done he commonly has the horse walked about for an hour or two, or even sent to slow work again, which prodnces a still more effectual solution of the caustic, at the same time that it tends greatly to its uniform and thorough diffusion into every re. cess and winding of the sinus. The consequence of this sharp caustic dressing is a general slough from the sinus. Every part of its interior surface is destroyed, and the dead particles become agglutinated, and cast off along with the discharges in the form of a dark firm curdled mass, which the farrier calls the core; and so it commonly proves, for granulations follow close behind it, and fill up the sinus." "*it

The other mode of treatment, is that of Mr. Newpor't, a surgeon of long standing:- "After the shoe has been removed, thin the sole until it will yield to the pressure of the thumb; then cut the under parts of the wall in an oblique direction from the heel to the anterior part, immediately under the seat of complaint, and only as for as it extends, and rasp the side of the wall thin enough to give way to the pressure of the orer-distended parts, and put on a bar-shoe mther elevated from the frog. Ascertain with a probe the direction of the sinuses, and introduce into them a saturated solution of sulphluate of zine, by means of a small syringe, Place over this dressing the common cataplasm, or the turpentine ointment, and renew the application every twenty-four hours. I have frequently found three or four such applications complete a cure. I should recommend that when the probe is introduced, in order to ascertain the progress of cure, that it be gently and carefully used, otherwise it may break down the new-formed lymph. I have found the solution very valuable, where the synovial fluid has escaped, but not to be used if the inflammation of the parts is great." +

PRTCK OR WOUND IN THE SOLE OR CRUST.

This is the most frequent cause of quittor. It is evident that the sole is very liable to be wounded by nails, pieces of glass, or even sharp flints. Every part of the foot is sulject to injuries of this description. The usual place at which these wounds are found is in the hollow between the bars and the frog, or in the frog itself. In the fore feet the injury will be generally recognised on the inner quarter, and on the hind feet near the toe. In fact these are the thimest parts of the fore and hind feet. Nuch more frequently the lamine are wounded by the nail in shoeing; or if the nail does not penetrate through the internal surface of the crust, it is driven so close to it that it presses upon the flesly parts beneath, and causes irritation and inflammation, and at length ulceration. When a horse becomes suddenly lame, after the legs have been carefully examined, and no cause of lameness appears in them, the shoe should be taken off. In many cases the offending substance will be immediately detected, or the additional heat felt in some

* Percivall's Hippopathology, vol. i., p. 218.

+ The Veterinarian, rol. i., 1., 329. 
part of the foot will point out the seat of injury; or, if the crust is rapped with the hammer all round, the flinching of the horse will discover it ; or pressure with the pincers will render it evident.

When the shoe is removed for this examination the smith should never be permitted to wrench it off, but each nail should be drawn separately, and examined as it is drawn, when some moisture appearing upon it will not unfrequently reveal the spot at which matter has been thrown out.

Sudden lameness occurring within two or three days after the horse has been shod, will lead to the suspicion that the smith has been in fault; yet no one who considers the thinness of the crust, and the difficulty of shoeing many feet, will blame him for sometimes pricking the animal. His fault will consist in concealing or denying that of which he will almost always be aware at the time of shoeing, from the flinching of the horse, or the dead sound, or the peeuliar resistance that may be noticed in the driving of the nail. We would plead the cause of the honest portion of an humble class of men, who discharge this mechanical part of their business with a skill and good fortune scarcely credible: bat we resign those to the reproaches and the punishment of the owner of the horse who too often, and with bad policy, deny that which accident, or possibly momentary carelessness, might have occasioned, and the neglect of which is franght with danger, although the mischief resulting from it might at the time have been easily remedied.

When the seat of misehief is ascertained, the sole should be thimned round it, and at the nailhole, or the puneture, it should be pared to the quick. The escape of some matter will now probably tell the nature of the injury, and remove its consequences. If it be puncture of the sole effected by some mail, or any similar body, picked up on the road, all that mill be necessary is a little to enlarge the opening, and then to place on it a pledget of tow dipped in Friar's balsam, and over that a little common stopping. If there is much heat and lameness, a joultice should be applied.

The part of the sole that is wounded and the depth of the wound should be taken into consideration. It will be seen, by reference to the cut in p. 432 , that a deep puncture towards the back part of the sole, and penetrating even into the sensible frog, may not be productive of serious consequence. There is no great motion in the part, and there are no tendous or bones in danger. A puncture near the toe may not be followed by much injury. There is little motion in that part of the foot, and the internal sole covering the coffin-boue will soon heal. A puncture, however, about the centre of the sole may wound the flexor tendon where it is inserted into the coffin-bone, or ming eren penetrate the joint which unites the na- vicular bone with the coffin-hone, or pierce through the tendon into the joint which it forms with the navicular bone, and a degree of iuflammation may ensue, that, if neglected, may be fatal. Many horses have been lost by the smallest puncture of the sole in these dangerous points. All the anatomical skill of the veterinarian should be called into requisition, when he is examining the most trifling wound of the foot.

If the foot has lieen wounded by the wrong direction of a nail in shoeing, and the sole is wellpared out over the part on the first appearance of lameness, little more will be necessary to be done. The opening should be somewhat enlarged, the Friar's balsam applied, and the shoe tacked on with or without a poultice, according to the degree of lameness or heat, and on the following day all will often be well. It may, however, be pruclent to keep the foot stopped for a few days. If the accident has been neglected, and matter begins to be formed, and to be pent up and to press on the neighbouring parts, and the horse evidently suffers extreme pain, and is sometimes scarcely able to put his foot to the gronud, and much matter is poured out when the opening is enlarged, further precautions must be adopted. The fact must be recollected that the living and dead horn will never unite, and every portion of the horny sole that has separated from the fleshy sole above must be removed. The separation must be followcel as far as it reaches. Nuch of the success of the treatment depends on this. No small strip or edge of separated horn must be suffered to press ulon any part of the wound. The exposed fleshy sole must then be touched, but not too severely, with the butyr (chloride) of antimony, some soft and dry tow being spread on the part, the foot stopped, and a poultice placed over all if the inflammation seems to require it. On the following day a thin pellicle of horn will frequently be found over a part or the whole of the wound. 'This shonld be, yet very lightly, again touched with the canstic; but if there is an appearance of fungus spronting from the exposed surface, the application of the butyr must be more serere, the tow being again placed over it, so as to afford considerable yet uniform pressure. Many days do not often elapse before the new horn covers the whole of the wound. In these extensive openings the Friar's balsam will not always be successful, but the cure must be effected by the judicious and never-too-severe use of the caustic. Bleeding at the toe, aud physic, will be resorted to as useful auxiliaries when much inflammation arises.

In searching the foot in order to ascertain the existence of prick, there is often something very censuralle in the carelessness with which the hom is cut away between the lottom of the crust and the sole, so as to leave little or no hold for the 
nails, although some months must elapse before the horn will grow down sufficiently far for the shoe to be securely fastened.

When a free opening has been made below, and matter has not broken ont at the coronet, it will rarely be necessary to remove any portion of the horn at the quarters, although we may be able to ascertain by the use of the probe that the separation of the crust extends for a considerable space above the sole.

CORNS.

In the angle between the bars (c, p. 452) and the quarters, the horn of the sole has sometimes a red appearance, and is more spongy and softer than at any other part. The horse flinches when this portion of the horn is pressed upon, and occasional or permanent lameness is prodnced. This disease of the foot is termed Corns; bearing this resemblance to the corn of the human being, that it is produced by pressure and is a cause of lameness. When corns are neglected, so much inflammation is produced in that part of the sensible sole, that suppuration follows, and to that, quittor succeeds, and the matter either undermines the horny sole, or is discharged at the coronet.

The pressure hereby produced manifests itself in varions ways. When the foot becomes contracted, the part of the sole enclosed between the external crust that is wiring in, and the bars that are opposing that contraction (see cut, p. 452 ), is placed in a kind of vice, and becomes inflamed; hence it is rare to see a contracted foot withont corns. When the shoe is suffered to remain on too long, it becomes imbedded in the heel of the foot; the external crust grows down on the outside of it, and the bearing is thrown on this angular portion of the sole. No part of the sole can bear continued pressure, and inflammation and corns are the result. From the length of wear the shoe sometimes becomes loosened at the heels, and gravel insinuates itself between the shoe and the crust, and accumulates in this angle, and sometimes seriously wonnds it.

The bars are too frequently cut away, and then the heel of the shoe must be bevelled inward, in order to answer to this absurd and injurious shaping of the foot. By this slanting direction of the heel of the shoe inward, an unnatural disposition to contractiou is given, and the sole must sulfer in two ways -in being pressed upon by the shoe, and squeezed between the outer crust and the external portion of the bar. The shoe is often made unnecessarily narrow at the heels, by which this angle, seemingly less disposed to bear pressure than any other part of the foot, is exposed to accidental bruises. If, in the paring out of the foot, the smith should leave the bars prominent, he too frequently neglects to pare awry the horn in the angle between the bars and the external crust; or if he cuts away the bars, he scarcely tonches the horn at this point ; and thus, before the horse has been shod a fortnight, the shoe rests on this angle and prorlnces corrs. The use of a shoe for the fore feet, thickened at the heels, is, and especially in weak feet, a source of corns, from the undue bearing there is on the heels, and the concnssion to which they are snbject.

The unshod colt rarely has corns. The heels have their natural power of expansion, and the sensible sole at this part can scarcely be imprisoned. while the projection of the heel of the crust and the har is a sufficient defence from extemal injury. Corns seem to be the almost inevitable consequence of shoeing, which, by limiting, or in a manner destroying, the expansibility of the foot, must. when the sole attempts to descend, or the coftinbone has a backward and downward direction (see cnt, p. 432 ), imprison and injure this portion of the sole. This evil consequence is increased when the shoe is badly formed, or kept on too lonir or when the paring is omitted or injndicionsly extended to the bar's. By this unnatural pressure of the sole, blood is thrown out, and enters into the pores of the soft and diseased horn which is then secreted; therefore the existence and the extent of the corn is judged of by the colour and softness of the horn at this place.

Corns are most frequent and serious in horses with thin horn and flat soles, and low weak heels. They do not often occur in the outside heel. It is of a stronger construction than the inside one. The method adopted by shoeing-smiths to ascertain the existence of corn by the pain evinces when they pinch the bar and crust with their irons, is very fallacions. If the horn is uaturally thin, the horse will slıriuk nuder no great pressnre althongh he has nocom, and occasionally the bars are so strong as not to give way under any pressure.

The cure of old corns is difficult; for as all shoeing has some tendency to produce pressure here, the habit of throwing ont this diseased horn is difficult to get rid of when once contracted; recent corns, however, will yield to good shoeing.

The first thing to be done is well to pare ont the augle between the crnst and the bars. Two objects are answered by this: the extent of the disease will be ascertained, and one canse of it removed. A very small drawing linife must be nsed for this purpose. The corn must be pared ont to the very bottom, takiug care not to wound the sole. It may then be discovered whether there is any eflusion of blood or matter underneath. If this is suspected, an opening must be made through the horn, the matter evacuated, the separated horn taken away, the course and extent of the sinuses explored, and the treatment recommended for quittor adopted. Should there II II 
be no collection of fluid, the butyr of antimony should be applied over the whole extent of the corn, after the horn has been thinned as closely as possible. The object of this is to stimulate the sole to throw out more healthy horn. In bad cases a bar-shoe may be put on, so chambered, that there shall be no pressure on the diseased part. This may be worn for one or two shoeings, but not constantly, for there are few frogs that would hear the constant pressure of the bar-shoe: and the want of pressure ou the heel, generally occasioned by their use, would prodnce a softened and bulbous state of the heels, that would of itself be an inevitable source of lameriess.

Mr. Turner is in the habit of using a shoe that promises to lessen to a very material degree the sufferings of the horse. The ground surface of the shoe is so bevelled off, that it does not come into contact with the ground, and thus much concussion is saved to the horse. A slight space, however, should be left between the heel of the foot, and that of the shoe; and which cannot be better occupied than by the leather sole, preventing the insinuation of foreign bodies, and yet preserving the heel from concussion.

In unusually troublesome cases of corns, recourse should be had to the bar-shoe.

Mr. Spooner, of Southampton, very properly states, that the corns occasionally fester, and the purulent matter which is secreted, having no dependent orifice, ascends, torturing the animal to a dreadful extent, and breaks out at the coronet. These cases are very troublesome. Sinuses are formed, and the evil may end in quittor. A large and free dependent orifice must then be made, and poultice applied; to which should succeed a solution of sulphate of zinc, with the application of the compound tar ointment.

The cause of corn is a most important subject of inquiry, and which a careful examination of the foot and the shoe will easily discover. The cause being ascertained, the effect may, to a great extent be afterwards removed. Turning out to grass, after the horn is a little grown, first with a bar. shoe, and afterwards with the shoe fettered on one side, or with tips, will often be serviceable. A horse that has once had corns to any considerable extent should, at every shoeing, have the seat of corn well pared ont, and the lutyr of antimony applied. The seated shoe (hereafter to be described) should be used, wirh a web sufficiently thick to cover the place of corn, and extending as far back as it can be made to do without injury to the frog.

Low weak heels shonld be rarely touched with the knife, or anything more be done to them, than lighitly to rasp them, in order to give them a level surface. The inner heel should he particularly spared. Corns are seldom found in the hiud feet, because the heols are stronger, and the feet are not exposed to so much concussion; and when they are found there, they are rarely or never productive of lameness. There is nothing perhaps in which the improvemeut in the veterinary art has relieved the horse from so much suffering as shoeing. Where corns now exist of any consequence, they are a disgrace to the smith, the groom, and even to the owner.

\section{THRUSH.}

This is a discharge of offensive matter from the cleft of the frog. It is inflammation of the lower surface of the sensible frog, and during which pus is secreted together with, or instead of horn. When the frog is in its sound state the cleft sinks but a little way into it; but when it becomes contracted or otherwise diseased, it extends in length, and penetrates even to the sensible horn within, and through this unnaturally deepened fissure the thrushy discharge proceeds. A plethoric state of the body may be a predisposing cause of thrush, but the immediate and grand cause is moisture. This should never be forgotten, for it will lead a great way towards the proper treatment of the disease. If the feet are habitully covered with any moist application-his standing so much on his own dung is a fair example-thrush will inevitably appear. It is cansed by anything that iuterferes with the healthy structure and action of the frog. We find it in the hinder feet oftener and worse than in the fore, because in our stable management the hinder feet are too much exposed to the pernicious effects of the dung and the urine, moistening, or as it were macerating, and at the same time irritating them. The distance of the hinder feet from the centre of the circulation would also, as in a case of grease, more expose them to accumulations of fluid and discharges of this lind. In the fore feet, thrushes are usually connected with contraction. We have stated that they are both the cause and the effect of contraction. The pressure on the frog from the wiring in of the heels will produce pain and inflammation; and the inflammation, by the increased heat and suspended function of the part, nill dispose to contraction. Horses of all ages, and in almost all sitnations, are sulject to thrush. The unshod colt is frequently thus diseased

Thrushes are not always accompanied by lameness. In a great many cases the appearance of the foot is scarcely, or not at all altered, and the disease can only be detected by close examination, or the peculiar sinell of the discharge. The frog may not appear to be rendered in the slightest degree tender by it, and therefore the horse may not be considered by many as unsound. Every disease, however, should be considered as legal unsoundness, and especialiy a disease which, although not attended with present detriment, 
must not be neglected, for it will eventually injure and lame the horse. All other things being right, a horse should not be rejected because he has a slight thrush, for if the shape of the hoof is not altered, experience tells that the thrush is easily removed; but if this is not soon done, the shape of the foot and the action of the horse will be altered, and manifest uusoundness will result.

The progress of a neglected thrush, although sometimes slow, is sure. The frog begins to contract in size-it beconves rough, ragged, lrittle, tender-the discharge is more copious and more offensive-the horu gradually disappears-a mass of harlened mucus usurps its place-this easily peals off, aud the seusible frog remains exposed the lorse cannot bear it to be tonched-fungous gramulations spring from it-they spread aroundthe sole becomes uuder-ruu, aud canker steals over the greater part of the foot.

There are few errors more common or more dangerous than this, that the existence of thrush is a matter of little consequence, or even, as some suppose, a beuefit to the horse-a discharge for superabundant humours-and that it should not be dried up too quickly, and in some cases not diied up at all. If a youmg colt, fat and full of blood, has a had thrush, with much discharge, it will be prudent to accompany the attempt at cure by a dose of phrsic or a course of diuretics. A few diuretics may not be injurions when we are endeavouring to dry up thrush in older loorses: but the disease can scarcely be attacked too soon, or subdued too rapidly, and especially when it steels on so insidiously, and has such fatal cuusequences in its train. If the heels once begin to contract through the baneful effect of thrush, it will, with dilliculty, or not at all, be afterwards removed.

There are many recipes to stop a ruming thrush. Aluost every application of an astringent, but not of too caustic nature, will have the effect. The common Egyptiacum (vinegar boiled with honey and verdigrease) is a good liniment; but the most effectual and the safest-drying up the discharge speedily, but not suddenly-is a paste composed of blue vitriol, tar, and lard, in proportions according to the virulence of the caulier. A pledget of tow covered with it should be introduced as deeply as possible, yet withont force, into the cleft of the frog every night, and removed in the morning before the horse goes to work. Attention sliould at the same time, as in other diseases of the foot, be paid to the apparent cause of the complaint, and that cause should be carefully ubriated or removed. Before the application of the paste, the frog should be examined, and every loose part of the hom or hardened discharge removed; and if much of the frog is then exposed, a larger and wider piece of tow covered with the paste may be placed uver it, in addition to the pledget introduced into the cleft of the frog. It will be necessary to preserve the frog moist while the cure is in progress, and this may be done by filling the feet with tow covered by common stopping, or using the felt pad, likewise covered with it. 'Turning out would be prejudicial rather than of benefit to thrushy feet, except the dressing is continued, and the feet defended from moisture.

\section{CANKER}

Is a separatiou of the horn from the sensible part of the foot, and the sprouting of fungous matter instead of it, occupying a purtion or even the whole of the sole and frog. It is the occasional consequence of bruise, puncture, corn, quittor, and thrush, and is exceedingly difficult to cure. It is more freifuently the consequence of neglected thrush than of auy other disease of the foot, or rather it is thrush involving the frog, the bars, and tlje sole, and making the foot in one mass of rauk putrefaction.

It is oftenest found in, and is almost peculiar to the lieary breed of cart horses, and partly resulting from constitutional predisposition. Horses with white legs and thick skins, and much hair upon their legs, - the rery character of many dray horses, - are subject to canker, especially if they have had an attack of grease, or their heels are habitually thick and greasy. The disposition to canker is certainly hereditars. The dray horse likewise has this disadvantage, that in order to give him font-hold, it is sonetimes necessary to raise the heels of the hinder feet so high, that all pres. sure on the frog is taken away; its functions are destroyed, and it is rendered liable to disease. Canker, however, arises mostly from the peculiar injurr to which the feet of these horses are sulject from the enormous shoes with which they are covered-the bulk of the nails with which these shues are fastened to the foot, the strain of the foot iu the violent although short exertiou of moving he:try weights; but, most of all, neglect of the feet and the filthiness of the stable in these establishments.

Although canker is a disease most difficult to remove, it is easily prerented. Attention to the punctures to which these lieary horses, with their clubbed feet and brittle hoofs, are more than any others subject iu sloeing, and to the bruises and treads on the coronet, to whicli from their arkwardness and meight they are so liable, and the greasy heels which a very slight degree of negligence will produce in them, and the stopping of the thrushes, which are so apt in them to rum on to the separation of the horn frum the sensible frog, will most materially lesseu the number of cankered feet. Where this disease often vccurs, the omier of the team may be well assured that there is gross mismanagement either in himself or his horsolicerer, 
or the smith, or the surgeon, and it will rarely be a difficult matter to detect the precise nature of that mismanagement.

The cure of canker is the business of the rete. rinary surgeon, and a most painful and tedious business it is. The principles on which he proceeds are, first of all, to remore the extraneous fungous growth, and for this purpose he will need the aid of the knife and the caustic, or the cautery, for he should cut away every portion of horn which is in the slightest degree separated from the sensible parts beneath. He will have to discourage the growth of fresh fungus, and to bring the foot into that state in which it will again secrete healthy horn. Here he will remember that he has to do with the surface of the foot ; that this is a disease of the surface only, and that there will be no necessity for those deeply-corroding and torturing causties which penetrate to the very lone. A slight and daily application of the chloride of antimony, and that not where the new horn is forming, but on the surface which continues to be diseased, and accompanied by as firm but equal pressure as can be made - the careful avoidance of the slightest degree of moisture - the horse being exereised or worked in the mill, or wherever the foot will not be exposed to wet, and that exercise adopted as early as possible, and even from the beginning if the malady is confined to the sole and frog-these means will succeed if the disease is capable of cure. Humanity, perhaps, will dictate that, considering the long process of cure in a cankered foot, and the daily torture of the caustic, and the suffering which would otherwise result from so large or exposed a surface, the nerves of the leg should be dirided in order to take away the sense of pain; but then, especial care must be taken that the horse is placed in such a situation, and exposed to such work, that, being insensible to pain, he may not injuriously batter and bruise the diseased parts.

Medicine is not of much avail in the cure of canker. It is a mere local disease; or the only cause of fear is, that so great a determination of blood to the extremities having existed during the long progress of cure, it may in some degree continue, and produce injury in another form. Grease has occasionally followed canker. They have been known to alternate. It may, therefore, be prudent, when the cure of a cankered foot is nearly eflected, to subject the horse to a course of alteratives or diuretics.

\section{OSSIFTCATION OF THE CARTILAGES.}

Mention has been made of the side cartilages of the foot, occupying (see cut, page 435) a considerable portion of the external sile and back part of the foot. They are designed to preserve the expmsion of the upper part of the foot, and especially when that of the lower part is limiteil or destrojed by caceless shoeing. These cartilages are subject to inflammation, and the result of that inflammation is, that the cartilages are absorbed, and bone substituted in their stead. This ossification of the cartilages frequently accompanies ring. bone, but it may exist without any affeetion of the pastern joint. It is oftenest found in horses of heavy dranght. It arises not so much from con. cussion, as from sprain, for the pace of the horse is slow. The cause, indeed, is not well understood, but of the effect there are too numerous instances. Very few heavy draught horses arrive at old age without this change of structure; and particularly if they are much emplosed in the paved streets. The change commences sometimes at the anterior part of the cartilage, but much oftener at the posterior and inferior part. "From the combined operation of great reight and high action, the feet, and particularly the heels, come with great force on the ground. The cartilages, being imbedded in the beels of the feet, are, therefore, the parts that receive the greatest degree of concussion, the consequence of which is that subacute inflammation is set up, and the secreting vessels deposit ossific instead of eartilaginous matter, in the room of that which is absorbed in the usual process of nature."*

No evident inflammation of the foot, or great, or perhaps even perceptible lameness, accompanies this change; a mere slight degree of stiffness may have been observed, which, in a horse of more rapid pace, would have been lameness. Even when the change is completed, there is not in many cases anything more than a slight increase of stiffness, little or not at all interfering with the usefulness of the horse. When this altered structure appears in the lighter horse, the lameness is more decided, and means should be taken to arrest the progress of the change. These are blisters or tiring; but, after the parts have become bony, no operation will restore the cartilage. Some benefit, however, will be derived from the use of leather soles. Adrautage has resulted from bar-shoes in conjunction with leather.

Connected with ringbone the lameness may be very great. This has been spoken of in page 436 .

WEAKX̃ESS OF THE FOOT.

This is more accurately a bad formation, than a disease; often, indeed, the result of disease, but in many instances the natural construction of the foot. The term weak foot is familiar to every horseman, and the consequence is too severely felt by all who have to do with horses. In the slanting of the crust from the coronet to the toe, a less angle is almost invarially former, amounting probably to not more than forty instead of forty-five degrees; and, after the horse has been worked for one or two years the line is not straight, but a little * W. C. Spooner on the Fout of the Horse, p. 249. 
indented or hollow, midway between the coronet and the toe. This has been described as the accompaniment of pumiced feet, but it is often seeu in weak feet, that, although they might become pumiced by sererity of work, do not otherwise have the sole convex. The crust is not only less oblique than it ought to be, but it has not the smooth, even appearance of the good foot. The surface is sometimes irregularly roughened, but it is much oftener roughened in circles or rings. The form of the crust likerrise presents too much the appearance of a cone; the bottom of the foot is unnaturally wide in proportion to the coronet; and the whole of the foot is generally, but not always, larger than it should be.

When the foot is lifted, it will often present a round and circular appearance, with a fulness of frog, that would mislead the inexperienced, and indeed be considered as almost the perfection of structure ; but, being examined more closely, many glaring defects will be seen. The sole is tlat, and the smith finds that it will bear little or uo paring. The bars are small in size. 'l'ley are not cut away by the smith, hut they can be scarcely said to have any existence. The heels are low, so low that the very coronet seems almost to touch the ground; and the crust, if examined, appears scarcely thick enough to bolil the nails.

Horses with these feet can never stand much work. They will be subject to corns, to bruises of the sole, to convexity of the sole, to puuctures in nailing, to breaking away of the crust, to inflammation of the foot, and to sprain and injury of the pastern, and the fetlock, and the flexor tendon.

These feet admit of little improvement. Shoeing as seldom as may be, and with a light yct wide concave web; little or no paring at the time of sloeing, and as little violent work as passible, and especially on rough roads, may protract for a long period the evil day, but he who buys a horse with these fect will sooner or later have cause to repent his bargain.

\section{CHAPTER XX.}

\section{FRACTURES.}

Accidents of this description are not of frequent occurrence, but when' they do happen it is not always that the mischief can be repaired; occasionally, however, and wuch more frequently than is generally imagined, the life of a valuable animal might be saved if the orver, or the veterinary surgeon, would take a little trouble, and the patient is fairly tractable, and that, in the majority of cases, he will soon become. The number of raluable animals is far too great that are destroyed under a confused notion of the difficulties of controlling the patient, or the incurable character of the accident. Messrs. Blaine and Percivall have given a valuable recoril of the usual cases and treatment of fracture which occur in the practice of the English veterinary surgeon, and the splendid work of Hurtrel d'Arboral contains a record of all that has been attempted or effected on the Continent. The anthor of this volume must confine himself to a rapid surrey of that which they have described, adding a few cases that have been brought under his own observation, or communicated to him by others.

With the exception of accidents that occur in casting the animal for certain operations, and his struggles during the operation, the causes of Fracture are usually blows, kicks, or falls, and the lesion may be considered as simple, confined to one bone, and not protruding through the skin -or compound, the bone or bones protruding through the skin-or complicated, where the bone is broken or splintered in more than one direction.
The duty of the veterinary surgeon resolves itself into the replacing of the displaced bones in their natural position, the keeping of them in that position, the healing of the integument, and the taling of such measures as will prevent any untoward circumstances from afterwards occurring.

In the greater number of cases of fracture ti will be necessary to place the horse under considerable restraint, and even to suspend or sling him.

The cut in the nest page contains a riew of the suspensory apparatus used by Mr. Percirall. A broad piece of sail-cloth, furnished with two breechings, and two breast-girths, is placed under the animal's belly, and, by means of ropes and pulleys attached to a cross beam abore, he is elevated or lowered as circumstances may require. It will seldom be necessary to lift the patient quite off the ground, and the horse will be quietest, and most at his ease, when his feet are suffered just to touch it. The head is confined by two collar ropes, and the head-stall well padded. Many horses may plunge about and be difficult to manage at first, but, generally speaking, it is not long ere they become perfectly passive.

The use of the different buckles and straps which are attached to the sail-cloth will be evident on inspection. If the horse exhibits more than usual uneasiness, other ropes may be attached to the colvers of the sail-cloth. This will afford considerahle relief to the patient, as well as add to the security of the bandages 


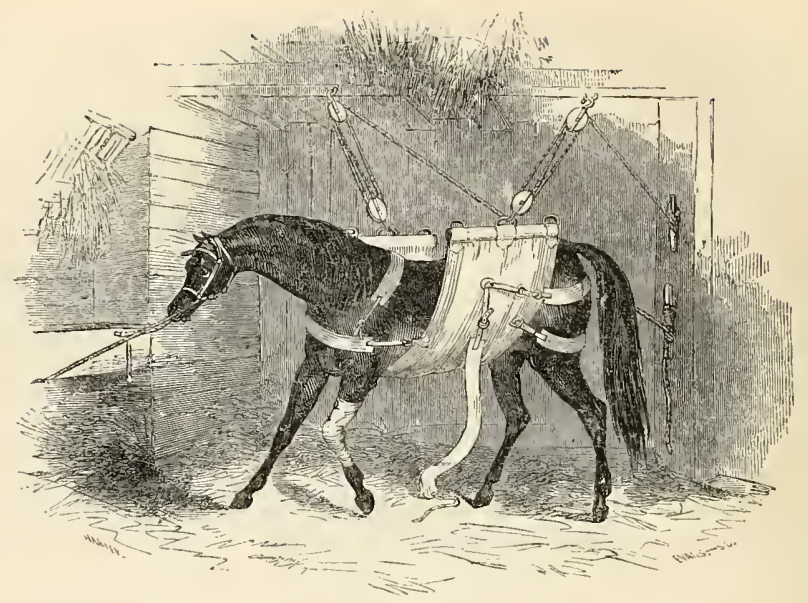

In many cases the fracture, although a simple one, may be visible on the slightest inspection; in others, there may be merely a suspicion of its existence. Here will be exhibited the skill and the humanity of the educated surgeon, or the recklessness and brutality of the empiric. The former will carefully place his patient in the position at once the least painful to the sufferer, and the most commodious for himself. $\mathrm{He}$ will proceed with geutleness, patience, and management-no rough handling or motion of the parts, inflicting torture on the animal, and adding to the injury already received. It is interesting to observe how soon the horse compreheuds all this, aud submits to the uecessary inspection; and how complete and satisfactory the examination terminates under the superintendence of the humane aud cautious practitioner, while the brute in luman shape fails in comprehending the real state of the case.

Heat, swelling, tenderness, fearfulness of the slightest motion, crepitus, and especially change of the natural position of the limb, are the most frequent indications of fracture.

The probability of reuniou of the parts denends upon the depth of the wound convected with the fracture - the contusion of the soft parts in the immediate neighbourhood of it-the blood-vessels, arterial or renous, that have been wounded-the propinquity of some large joint to which the in. flammatiou may be communicated-dislocation of the extremities of the fractured joint-injuries of the periosteum - the existence of sinuses, caries, or necrosis, or the fracture being compound, or broken into numerous spiculæ or splinters.

In a horse thiat is full of flesh, the cure of frac-

ture is difficult; likewise in an old or rrom-out horse-or when the part is inaccessible to the band or to instrumeuts-or when separation has taken place between the parts that were begimning to unite- $\mathrm{Or}$ where the surrounding tissues have been or are losing their vitality-or when the patient is alrealy afflicted with any old or permanent disease.

It may be useful briefly to review the various seats of fracture.

\section{FRACTURE OF THE SKULL.}

The skull of the horse is so securely defended by the yielding resistance of the temporal muscle, that fracture rarely occurs excent at the occipital ridge; and should a depression of bone be there effected, it will produce complete coma, and bid defiance to all surgical skill. Fracture of the skull is generally accompanied by stupidity, convulsive motions of the head or limbs, laborious breathing, and a staggering walk. The eves are almost or quite closed, the head is carried low, and the lower lip hangs down. Blows on the crauium, which the brutality of man too often inflicts, as well as many accidents, are very serious matters, and require considerable atteutiou, for, although it may lave been ascertained that the cranium is uninjured, there may be considerable concussion of the brain.

It having been known that a horse had received a violent blow on the head, the strictest examiuation of the part should take place. An artillery horse broke loose from his groom, and, after galloping about, dashed in to his owu stall with such force as sadly to cut his face under the forelock. The farrier on duty sewed up the wound, proper 
dressings were applied, and in a little more than a fortnight the wound was healed and the horse dismissed, apiarently well. Four days afterwards the patient moved stiffly; the jaws could not be separated more than a couple of inches, and there was evident locked jaw. The horse was cast, and the place where the wound had been was most carefully examined. On cutting to the bottom of it, a fracture was discovered, and a piece of bone threefourths of an inch long was found on the centre of the parietal suture. This was removed-the would was properly dressed, and a strong aloetic drink was given with great difficulty. The aloetic drink was repeated-the bowels liecame loosened - the tetanic symptoms diminished, and in less than three weeks the horse was perfectly cured.*

This is a very interesting case. There was some carelessuess iu entrusting the treatment of the wound to the farrier: but the surgeon afterwards repaired the error as well as he conld, and no one was better pleased than he was at the result. A violent blow heing receired on the forehead, the part should alway's be most carefully examined.

Hurtrel DArboval relates three cases of fracture of the skull. One occurred in a mare that ran violently against a carriage. The skull was depressed, aud a portion of bone was removed, but it was four months ere complete reunion of the edges was effected. Another horse received a violent kick on the forehead. The union of the depressed bones was effected after the external wound was healed, but there was always a depression, an inch in length. An aged mare met with the same accident. A depression here remained as large as a finger.

\section{FRACTURE OF THE ARCH OF THE ORBIT OF THE EYE.}

A very interesting account of this, followed by perfect cure, is related at p. 284 .

FRACTURE OF THE NASAL BONES

This will sometimes occur from falling, or be produced by a kick from another horse, or the brutality of the attendant or the rider. We have seen a passionate man strike a horse about the head with a heavy hunting-whip. The danger of punishment of this kind is obviuus ; and so would be the propriety of using the whip for another purpose. A fracture of this kind is generally accompanied by a lacera. tion of the membrane of the nose, and considerable limorrhage, which, however, may generally be arrested by the application of cold water. The fractured portion of bone is usually depressed, and, the space for breathing being diminished, difficulty of respiration occurs. The author had a case of fracture of both nasal bones. He was enabled to elevate the depressed parts, but the inflam-

\footnotetext{
- Veterinarian, vol. vii., p. 142.
}

mation and swelling were so great, that the numal was threatenel with suffocation. The operation of tracheotomy was resolted to, and the animal did well.

If there is fracture of the nusal bones with de. pressiou, and only a little way from the central arch and the section between the nostrils, a slightly curved steel rod may be cautiously introduced into the passage, and the depressed portions carefully raised. If this cannot be effected, the trephine must be applied a little above or below the fracture, and the elevator or steel rod be introduced through the aperture. If the fracture is in any other part of the bone, it will be impossible to reach it with the elevator, for the turbinated hones are in the way. The trephine must then be resorted to in the first instance. The wound, if there is any, must be covered, and a compress kept on it.

A writer in a French journal relates a case in which a horse was violently kicked, and there was a cuntused wound with depression of bone. The trephine was applied. Fifteen splinters were extracted, and the case terminated well. It nevertheless too often happens that, in the injuries of the nasal membrane, the inflammation will obstinately continue in despite of all that the surgeon can $d$, and the natural termination of every injury of the membrane of the nose, and, in fact, of every chronic disease of the frame, will appearglanders.

If, however, glanders do not appear, some portion of bone may remain depressed, or the membraue may be thickened by inflammation. The nasal passage will then be obstructed, and a difficulty of breatling, resembling roaring, will ensue.

\section{THE SUPERIOR MAXILLARY OF UPPER JAW-BONE}

Will occasioully be fractured. Mr. Cartwright had a case in which it was fractured by a kick at the situation where it unites with the lachrymal and malar bones. He applied the trephine, and remored many small pieces of bone. The wound was then corered by adhesice plaster, and in a month the parts were healed.

Mr. Claywortl speaks of a mare who, being ridden almost at speed, fell and fractmed the upper jaw, three inches above the corner incisors. The front teeth and jaw were turned like a hook completely within the lower ones. She was cast, a balling iron put into her mouth, and the surgeon, exerting considerable force, pulled the teeth outward into their former and proper situation. She was then tied up so that she could not rub her muzzle against anything, and was well fed with lean-meal, and linseed tea. Nuch inflammation ensued, but it gradually subsided, and, at the expiration of the sixth week, the mouth was quite liealed, and scarcely a vestige of the fracture remained.

A very extraordinary and almost incredible ac- 
count of a fracture of the superior maxillary bone is given in the records of the Royal and Central Society of Agriculture in France. A horse was kicked by a companion. There was fracture of the upper part of the superior maxillary and zygomatic bones, and the eye was almost forced out of the socket. Few men would have dared to undertake a fracture like this, but M. Revel shrank not from his duty. He removed several small splinters of bone-replaced the larger bones-retumed the eye to its socket-confined the parts by means of sufficient sutures-slung the horse, and rendered it impossible for the animal to rub his bead against anything. In six weeks the cure was complete.

\section{THE MAXIILARY BONE OR IOWER JAW}

Is more subject to fracture, and particnlarly in its branches between the tushes and the lower teeth, and at the symplyysis between the two branches of the jaw. Its position, its length and the small quantity of muscle that covers it, expecially anteriorly, are among the canses of its fracture; and the same circumstances combine to render a reumion of the divided parts more easy to be accomplished. Mr. Blaine relates that in a fracture of the lower jaw he succeeded by making a strong leather frame that exactly encused the whole jaw. The author of this volume has effected the same object by similar means.

M. H. Boulay attended a horse, fracture of whose lower maxillary had taken place at the neck of that bone, between the tushes and the corner incisor teeth. The whole of the interior part of the maxillary bone in which the incisor teeth were planted was completely detached from the other portion of the bone, and the parts were merely held together by the membrane of the moth.

The horse was cast-the corner tooth on the left side extracted-the wound thoroughly cleansedthe fractured bones brought into contact-some holes were drilled between the tushes and the second incisor teeth, ahove and below, through which some pieces of brass wire were passed, and thus the jaws were apparently fixed immoveably together. The neek of the maxillary bone was surroumded by a sufficient compress of tow; and a ligature tied around it, with its bearing place on the tushes, and all motion thus prevented.

The horse was naturally an untractable animal, and in his efforts to open his jaws the wires yielded to his repeated struggles, and were to a certain degree separated. The bandage of tow was, however, tightened, and was sufficient to retain the fractured eilges in apposition.

The mouth now began to exhale an infections and gangrenous odour; the animal was dispiritel, and would not take any food; gangrene was evidently approarhing, and Mr. Boulay determined to ampitate the inferior fortion of the maxillary bone, the union of which seemed to be impossible. The sphacelated portion of the maxillary was entirely removed; every fragment of bone that had an oblique direction was sawn away, and the rough and umeven portions which the saw conld not reach were rasped off.

Before night, the horse had recovered his natural spirits, and was searching for something to eat. On the following day a few oats were given to him, and he ate them with so much appetite and ease, that no one looking at him would think that he had been deprived of his lower incisor teeth. On the following day some hay was given to him, which he ate without difficulty, and in a fortnight was dismissed, the wounds being nearly healed.*

In the majority of these cases of simple fracture a cure might be effected, or should, at least, be attempted, by means of well-adapted bandages around the mnzzle, confined by straps. It will always be prudent to call in veterinary aid, and it is absolutely necessary in case of compound frac ture of the lower jaw.

\section{FRACTURE OF THE SPINE.}

This accident, fortunately for the horse, is not of frequent occurrence, but it has been uniformly fatal. It sometimes happens in the act of falling, as in leaping a wide ditch; but it oftener occurs while a horse is struggling during a painful operation. It is generally sufficiently evident while the horse is on the ground. Either a snap is heard, indicative of the fracture, or the struggles of the hint-limbs suddenly and altogether cease. In a fer cases the animal has been able to get up and walk to his stable; in others, the existence of the fracture has not been apparent for several hours: showing that the vertebræ, although fractured, may remain in their place for a certain period of time. The bone that is broken is usually one of the posterior dorsal or anterior lumbar vertebræ. There is no satisfactory case upon record of reunion of the fractured parts.

In the human being, the depressed portion of the spinal arch and of the fractured vertebræ have been removed by a dextrous operation, and sensibility and the power of voluntary motion have, in cases few and far between, been restored; but in the horse this has rarely or never been effected. We should consider him a bold operator, but we should not very much dishike him, who made one trial, at least, how far surgical skill might be available here.

Mr. W. C. Spooner relates an interesting case, and many such have probably occurred. A horse had been clipped about three weeks, and was afterwards galloped sharply on rough ground, and pulled up suddenly and repeatedly for the purpose

* Rec. c'e Méd, Vét., Nov, 1838. 
of sweating him. After that he did not go so well as before, and would not canter readily, although he had previously been much used to that pace. Two days hefore he was destroyed, the groom was riding him at a slow pace, when he suddenly gave way behind and was carried home, and could not afterwards stand. He had, doubtless, fractured the spine slightly when pulled up suddenly, but without displacing the bones. $*$

M. Dupuy was consulted respecting a mare apparently palsied. She had an uncertain and staggering walk, accompanied by evident pain. After various means of relief had in vain been tried during five-and-twenty days, she was destroyed. A fracture of the last dorsal vertebra was discovered. It had never been quite complete, and ossific union was beginning to take place.

\section{FRACTURE OF THE RIBS.}

These fractures are not always easily recognised. Those that are covered by the scapula may exist for a long time without being detected, and those that are situated posteriorly are so thickly covered by muscles as to reuder the detection of the injury almost impossible. A man was trying to catch a mare in a field. She leaped at the gate, but failing to clear it, she fell on her back on the opposite side. She lay there a short time, and then got up, and trotted to the stable. She was saddled, and her master, a heavy man, cantered her more than three miles. She then became unusually dull and sluggish, and was left on the road. She was bled; and on the following morniug an attempt was made to lead her home. She was not, however, able to travel more than a mile. On the following morning she was evidently in great pain, and a veterinary surgeon discovering a slight depression of the spinous processes of the eleventh and trelfth dorsal vertebræ, and detecting a certain crepitus, ordered her to be destroyed. On post mortem examination, the twelfth dorsal vertebra was found fractured, and the eleventh. twelfth, and thirteenth rilss on the near side were all fractured about two inches from their articulation with the vertebre.t

Hurtrel D'Arboval says that " the two ribs belind the elbow are the most subject to fracture, and the false ribs, from the rielding motion which they passess, are least liable." The ordinary causes of fracture are kicks and blows, or falls on the chest, and especially in leaping. The fractures are generally about their middle, and, in the true ribs, commonly oblique. They are occasionally broken into splinters, and if those splinters are directed inward, they may seriously wound the pleura or lungs. In order most certainly to detect the situation and extent of these fractures, it may

* Veterinarian, vol. xi., p. 207.

+ Veterinarien, vol, iii., p. 681 . be necessary to trace the rib through its whole extent, and should there be any irregularity, to press firmly upon it above and below in order to ascertain the nature and extent of the injury.

If fracture is letected, it is not often that much essential good can be done. If there is little or no displacement, a broad roller slould be tightly drawn round the chest, in order to prevent as much as possible the motion of the rils in the act of breathing, and to throw the labour on the diaphragm and the abdominal muscles until the fractured parts are united. If the fractured parts protrude outwards, a firm compress must be placed upon them. If they are depressed, it will always be adrisable to place a firm bandage over the seat of fracture, although, perhaps, there may be scarcely the possibility of elevating them to any considerable degree. Should much irritation be the consequence of the nature or direction of the fracture, proper meaus must be adopted to allay the consti. tutional disturbance that may be produced. General or local bleedings will be most serviceable.+

\section{FRACTURE OF THE PELVIS.}

This is not of frequent occurrence, on account of the thickness of the soft parts which surround the pelvis, and protect it from injury, but it is of a most serious character when it does take place, on account of the violeuce which must have been necessary to produce it. The usual canses are falls from a considerable height, or heavy blows on the pelvis. The injury may have reference to the internal or external portion of the pelvis. In the first case, the dauger may not be discovererl until irreparable mischief is produced. When it is chiefly external, the altered appearance of the hip speaks for itself. It is rarely in our power to afford auy assistance in cases like this, except when there are fractured portions of the bone that may be partially or entirely removed, or the projecting spine of the ilium is onls partially fractured.

II. Levrat gives an interesting account of a case of fracture of the right side of the pelvis, near the acetabulum, in leaping a wide ditch when hmnting. "The lameness which it occasioned," says he, "was such that the toe of the foot mas scarcely permitted to touch the ground while the motion was at all rapid. When the motion was slow the foot was placed flat on the ground, but with great difficulty moved forward. On applying my right hand to the fractured part, which did not exhibit any heat, and seizing with my left hand the point of the thigh, I felt a morement of the ischium, which easily euabled me to judge of the fracture

$¥$ Cases of anctiylosis of the vertebre of the horse are 100 frequent, from the heary weights and studen and violent concussion which are too frequently thrown on these parts. Complete auchylosis of all the dorsal and lumbar vertebrae have been jroduced, exiendiug even to the haunch.-Suudifort's Mus, Inat, vol. ui., p. 38 to 44 , and iii., p. 243. 
and its seat, and to discover that none of the fractured parts were displaced. I ordered her to be kept quiet for three weeks, aud then permitted to wander about the stable. At the end of two months she was mounted aud exercised at a foot pace, aud in another month she was enabled to sustain the longest day's work without lameness. In the following year she was placed in the stud of the Baron de Stael, where she produced some good foals.*

The annals of the school at Alfort contain the case of an old mare with fracture of the pelvis and of the left ischium, and in whom union of the bones was effected so promptly, that on the thirtieth day very little lameness remained, and she shortly returned to her asual work. She soon afterwards died from some other cause, and the state of the osseous parts was thoroughly examined. These cases, however, stand almost alone, and post mortem examination discovers fractures of the ischium and the pelvis, and each bone divided into many pieces, so that it is impossible for the hind quarters of the auimal to be supported-also fractures of the external angle of the ilium, which rarely is again consolidated, aud roughness of the bony fragments, which produce sad laceration of the soft parts. Fracture of the ischium presents almost insuper. able difficulties-that of the ilium is uniformly fatal. +

FRACTERE OF THE TAIL.

This accident is not of frequent occurrence, except from accidental entanglement, or the application of brute force. The fracture is easily recognised, frequently by the eye aud always by the fingers. If the tail is not amputated, a cord passed over a pnlley, and with a small weight attached to it, will bring the separated bones again into apposition, and in about a month the natural cartilage of the part will be sufficiently re-instated.

\section{FRACTURES OF THE IIMBS.}

These, fortunately, are of rare occurrence in the horse, for although their divided edges might be easily brought again into appositiou, it wonld be almost impossible to retain them in it, for the slightest motion would displace them. A rapid survey of each may not, however, be altogether useless.

\section{FRACTURE OF THE SHOULDER.}

The author is not aware of the successful treatment of this accident by any English veterinary surgeon. Mr. Fuller attempted it, but from the difficulty of keeping the divided edges of the bone in apposition with each other, and the natural untractableness of the animal, and symptoms of teta-

\footnotetext{
* Rec. de Mèd. Vèt., Nov. I\$31, and Veterinarian, vol, vi., p. 390 .

+ Dict. Vét. Mar. Hurtrel D'Arboval, vol, ii, p. 586.
}

nus beginning to appear, the patient was destroyed. The fracture was a little above the neck of the scapula, and the muscles were dreadfully lacerated. ${ }^{+}$

It is not at all times easy to discover the existence and precise situation of fracture of the liumerus. The lameness is very great-the animal will not bear at all upon the broken limb-he will drag it along the ground-he will move slowly and with difficnlty, and his progression will consist of a succession of short leaps. The lifting of the foot will give very great pain. If he is roughly handled, he will sometimes rear, or throw himself suddenly down. By careful application of the hand a crepitns will more or less distinctly be heard. The chances are always materially against the union of a fracture of the humerus. The patient must be kept constantly suspended, and splints and bandages carefully applied. M. Delaguette attended au entire draught-horse, whose humerus had been fractured by the kick of a mare. The fracture extended longitudinally through two-thirds of the length of the bone, and the parts were separated from each other. They were brought again into apposition, and kept so by means of pitch plasters and splints. The horse was put into slings; the pavement of the stable was taken up; a bollow dug nnder the fractured limb, and this depression filled with straw, in order to afford a soft support to the foot. He was bled, gruel alone given as food, and injections daily administered.

On the 25th-day the rollers were removed and replaced. On the 40th day he began to rest on the fractured limb. On the 60 h day the bandages were removed-the fracture had been well consolidated, and the horse rested his weight upon it. It is reluctantly added that he was afterwards destroyed, on acconnt of some disease of the loins.|I

\section{FRACTURE OF THE ARM.}

This accideut is not of unfrequent occurrence. It commonly takes an oblique direction, and is usually first discovered by the displacement of the limb. Mr. Gloag, of the 10th Hussars, gives an interesting accouut of a case that occurred in his practice. "An entire black cart-horse was grazing in a field, into which some mares were accidentally turned. One of them kicked him severely a little above the kuee. He, however, contrived to get home, and, being carefully examined, there was found a simple fracture of the radins, about an iuch and a half above the knee. The ends of the fractured bone could be heard distinetly gratiug against each other, both in advancing the leg and turning it sideway from the body. He was immediately placed in a sling not completely elevated from the

\footnotetext{
\$ Veterinarian, vol, viii,, p. 143.

"I Journal Pratique, Dec. 1834.
} 
ground, but in which he could occasionally relieve himself by standing. The leg was well bathed with warm water, and the ends of the bone bronght as true to their position as possible. Some thin slips of green wood were then immersed in boiling water until they would readily bend to the shape of the knee, and they were tied round the joint, reaching about nine inches above and six below the knee, the euds of them being tied round with tow.

"A fortnight afterwarls he became very troullesome, knocking his foot on the ground, and when, at the expiration of the sixth week, he was taken from the slings, there was a considerable bony deposit above the knee. This, however, gradually subsided as the horse regained his strength, and, with the exception of tuming the leg a little outwards, he is as useful as ever for common purposes."

\section{FRACTURE OF THE ELBOW.}

This is far more exposed to danger than the two last bones, and is oftener fractured. The fracture is generally an oblique one, and about twothirds from the summit of the limb. It is immediately detected by the altered action, and different appearance of the limb. It is not so difficult of reduction as either the humerus or the scapula, when the fracture is towards the middle of the bone. A great quantity of tow saturated with pitch must be placed around the elbow, and confined with firm adhesive plasters, the ground being hollowed away in the front of the injured leg, so that no pressure shall be made by that foot.

\section{FRACTURE OF THE FEMUR.}

Considering the masses of muscle that surround this bone, and the immense weight which it supports, it would naturally be deemed impossible to reduce a real fracture of the femur. If the divided bones are ever united, it is a consequence of the simple repose of the parts, and their tendency to unite. Professor Dick, however, relates a very singular and interesting account of the cure of fracture of the femur. He was requested to attend a bay mare that had met with an accident in leaping a sunken fence. He found a wound in the stifle of the hind leg, running tranvsersely across the anterior of the articulation, about an inch and a half in length, and in it was a portion of bone that had been fractured, and that had escaped from its situation torards the inside of the stifle, where it was held by a portion of ligament. The isolated nature of the fractured portion, the difficulty, or rather impossibility of replacing it in its situation, and the few ressels which the convecting medium possessed, renderer it impossible that union would be effected; he therefore determined to remove it.

$$
\text { * Veterinarias, vol. iv., p. } 422 .
$$

Having enlarged the wound, and divided the portion of capsular ligament which retained it in its plice, he extracted the lone, and found it to be the upper part of the immer anterior conayle of the femur, measuring three inches in length, one inch and a half in breadth, and about an inch in thickness, and being in shape nearly similar to the longitudinal section of a hen's egg.

After the removal of the bone the animal seemed very much relieved; the wound was firmly sewed up, alhesive strapping applied over it, and the part kept wet with cold water.

Two dars afterwards considerable swelling had taken place; she seemed to suffer much, and there was some oozing from the wound. Fomentations were again applied, and she was slung.

She now began rapidly to improve, and, although one of the largest articulations in the body had been laid open, and a part of the articular portion of the bone removed, the wound healed so rapidly that in three weeks she walked with little lameness to a loose box. At the expiration of another three weeks the Professor again risited her. On being led out she trotted several times along the stalile yard, apparently sound, with the exception of moving the limb in a slight degree wider than usual, and so completely was the part recovered that, had it not been for a small scar that remained, a stranger could not have known that such an accident had taken place. +

\section{FRACTURE OF THE PATELLA.}

This does occasionally, though rery seldom occur. It is usually the consequence of violent kicks, or blows, and if this singular bone is once disunited, no power can bring the divided portions of the bone together again.

\section{FRACTURE OF THE TIBIA.}

This affection is of more frequent occurrence, and of more serious consequence than we were accustomed to imagine it to be. Mr. Trump, twelve years ago, first called the attention of the profession to some singular circumstances comnected with the tibia. A large draught horse belonging to the Dorlais Iron Company, at Merthyr Tydvil, came in from his labour very lame in the near hind leg, but with no visible sign of any severe injury being receired. The foot was searched, but nothing farther was done. He stood in the stable sereral days, and then was turned into a field, and was discovered one morning with the limb dependent, and a fraction of the tibia just abore the hock.

Fourteen or sixteen months after that, another horse came home from a jonney of seven miles, lame, with a slight mark on the inside of the thigh-a mere scratch, and very little tumefac-

$$
\text { + Veterinarian, vol. ii., p. } 110 .
$$


tion. There was nothing to account for such severe lameness : but, a few mornings afterwards, the tibia was seen to be fractured. The front of the bone was splintered as from a blow.

Two months after that, another horse had been observed to be lame seven or eight days. A slight seratch was observed on the inside of the thigh, with a little swelling, and increased heat and tenderness just above the hock. Mr. Trump had examined the foot during the time that the horse stood in the stable, not being satisfied that the apparently slight injury on the thigh could account for the lameness. He was turned to grass, and three days afterwards the tibia was found broken at the part mentioned, and evidently from a blow. Were there not positive proof of the circumstance, it would have been deemed impossible that a fracture, and of such a bone, could have existed so long without detection.*

Mr. J. S. Mayer gives an interesting account of the successful treatment of a case of fracture of the tibia, The simplicity of the process will, we trust, encourage many another veterinary surgeon to follow his example.

"A borse receired a blow on the tibia of the near leg, but little notice was taken of it for two or three days. When, however, we were called in to examine him, we found the tibia to be obliquely fractured about midway between the hock and the stifle, and a small wound existing on the inside of the leg. It was set in the following manner: - The leg from the stifle down to the hock was well covered with an adhesive compound; it was then wrapped round with fine tow, upon which another layer of the same adhesive mixture was laid, the whole being well splinted and bandaged up, so as to render what was a slightly compound fracture a simple one. The local inflammation and sympathetic fever that supervened were kept down by antiphlogistic measures. At the end of sir weeks the bandages and splints were removed, and readjusted in a similar way as before, and at the termination of three months from the time of the accident he was discharged, cured, the splints leeing wholly taken off, and merely an adhesive stay kept on the leg. The horse is now at work and quite sonud, there being merely a little thickening, where the callns is formed."

\section{FRACTURE OF THE HOCK.}

This is not of frequent occurrence, but very difficult to treat, from the almost impossibility of finding means to retain the bone in its situation. A case, however, somewhat simple in its nature occurred in the practice of $\mathrm{Mr}$. Cartwright. A

* Veferimarian, vol, iii., p. 394.

+ The Trunsactions of the Vet. Med. Association. Some other cases of the suecessful treatment of fractures are related in this work. colt, leaping at some rails, got lis leg between them, and, unable to extricate himself, hung over on the other side. After being liberated it appeared on examination, that there was a simple horizontal fracture of the whole of the os calcis about the middle. A splint was contrived so as to reach from the middle of the tibia to that of the cannon bone, and this was applied to the front of the leg, keeping the hock from its usual motion, and relaxing the muscles inserted into the os calcis. Underneath this splint a charge was applied about the part, in order to form a level surface for the splint to rest upon. The whole was bound together by proper adhesive bandages, and he was ordered to be kept quiet in the stable, but not to be slung. In about two months the hock was fired and became perfectly sound.†

FRACTURE OF THE CANNON OR SHANK BONE.

This is of more frequent occurrence than that of any other bone, on accoint of the length of the leg, and the danger to which it is exposed. There is rarely any difficulty in detecting its situation, but there is sometimes a great deal in bringing the divided edges of the bone again into apposition. A kind of mindlass, or a power equal to it, is occasionally necessary to produce sufficient extension in order to effect the desired purpose: but the divided edges being brought into apposition are retained there by the force of the muscles above. Splints reaching from the foot to above the knee should then be applied. The horse should be racked up during a fortnight, after which, if the case is going on well, the animal may often be turned out.

In cases of compound fracture the wounds should be carefully attended to: but $\mathrm{Mr}$. Percivall kays that be knows one or two old practitioners, who are in the habit of treating these cases in a very summary and generally successful manner. They employ such common support, with splints and tow and bandages, as the case seems to require, and then the animal with his leg bound up is turned out, if the season permits; otherwise he is placed in a yard or box, where there is not mnch straw to incommode his movements. The animal will take care not to impose too much weight on his fractured limb ; and, provided the parts are well secured, nature will generally perform the rest.\|

FRACTURE OF THE SESSAMOID BONES.

There are but two instances of this on record. The first is related by Mr. Fuller of March. He was galloping steadily and not rapidly a horse of his own, when the animal suddenly fell as if he had been shot. He was broken down in both

\$ Veterinarian, rol. iii,, p. 69.

|| Percivall's Hippopathology, vol.i, p. 269. 
fore legs. The owner very humanely ordered him to be immediately destroyed. Both the perforans and perforatus tendons of the near fore leg were completely ruptured, just where they pass over the sessamoid bone, which was fractured in a transverse direction. The sessamoid bone of the off leg was fractured in the same direction, but the tendous were entire.*

The second case is one described by Mr. Harris of Preston. A strong conch-like animal was galloped rapilly. He had not got more than a hundred yards before he suddenly fell, and it was with great difficulty that he could be led home, a distance of about two miles. There was soon considerable swelling in the off fore leg-great pain on the animal's attempting to walk, and his fetlock nearly touched the ground. Some slight crepitus could be detected, but the exact seat of it could not be ascertained. Mr. Harris considered the case as hopeless, but the owner would have some means tried to save the animal. He was accordingly bled and physicked, and cold lotions and bandages were applied to the foot. Two days afterwards some bony spiculæ began to protrude throngh the skin, and, the case being now perfectly hopeless, the animal was destroyed. The inner sessamoid bone was shivered to atoms. $f$

FRACTURE OF THE UPPER PASTERN.

Thick and strong, and movable as this bone seems to be, it is occasionally fractured. This has been the consequence of a violent effort by the horse to save himself from falling, when he has stumbled,-it has happened when he has been incautiously permitted to run down a steep descentand has occurred when a horse has been travelling on the best road, and at no great pace.

The existence of fracture in this bone is, generally speaking, easily detected. The injured foot is as lightly as possible permitted to come in contact with the ground. As little weight as may be is thrown on it, or, if the animal is compelled to use it, the fetlock is bent down nearly to the ground, and the toe is turned upward. If the foot is rotated, a crepitus is generally heard.

'l'his, however, is not always the case. M. Levrat was requested to examine a horse that had suddenly become lame. The near hind leg was retracted, and the foot was kept from touching the ground. He carefully examined the foot, and discovered that much pain was expressed when the pasteru was handled. He suspected fracture of the bone, but he could not detect it. He bled the animal, ordered cooling applications to the part, and gave a dose of physic. Three days afterwards be again saw his patient, and readily detected a

* Veterinarian, vol. iii., p. 393.

+ Eutcrinartan, vol, v., p. 375 . fracture, taking a direction obliquely across the pastern. ${ }_{+}^{+}$

'The probability of suceess in the treatment of this fracture, depends on its lueing a simple or compound one. If it runs laterally across the bone, it may be readily and successfully treated if it extends to the joints above and below, it will probably terminate in anchylosis, and if the bone is shivered, as it too frequently is, into various parts, there would scarcely seem the possibility of a successful treatment of the case. The instances, however, are numerous in which the case terminates successfully. Hurtre] D'Arboval recommends that a bandage steeped in some adhesive matter should be applied from the coronet to the middle of the leg. On this some wet pasteboard is to be moulded, enveloped afterwards in a linen bandage. A small splint is now to be applied before and behind and on each side, and the hollow places are filled with tow, in order to give them an equal bearing. If this does not appear to be sufficiently secure, other splints, thicker and broader, are placed over those extending to the knee or the hock.

The case related by M. Lerrat was treated in this way. It will be comparatively seldom that it will be necessary to suspend the patient. The animal, under the treatment of M. Levrat, kept his foot in the air for nearly three weeks. At the end of that period he now and then tried to rest his toe on the litter. Six weeks after the accident, he began to throw some weiglit on the foot; and a few days afterwards he was able to go to a pond, about fifty paces from his stable, and where, of his own accord, he took a foot-bath for nearly an hour at a time. At the expiration of another month he was mounted, and went very well at a walking pace; he was, however, still lame when he was trotted.

Another horse, treated by the same surgeon, was soon able to rest on the bad leg, in order to change his position-he was allowed three weeks after that, and then commenced his former daily work-the drawing of a heavy cart. He limped a little when he was trotted; but did as much slow work as he was ever accustomed to do.

\section{FRACTURE OF THE LOWER PASTERN.}

Although this bone is much shorter than the upper pastern, there are sereral instances of fracture of it. The fractures of this bone are commonly longitudinal, and often present a lesion of continuity extending from the larger pastern to the coffinbone. It is frequently splintered, the splinters taking this longitudinal direction. Hurtre] $\mathrm{D}^{\circ} \mathrm{A}$ :boral relates three cases of this, and in one of them the bone was splintered into four pieces. In several instances, lowever, this bone has been separated

₹ Rer. de Mél. Vèt., Nov, 1831 
into eight or ten distinct pieces. When the fracture of the bone is neither compound nor complicated, it may be perfectly reduced hy proper bandaging, and, in fact, there have been cases, in which umion has taken place with slight assistance from art beyond the application of a few bandages.

M. Gazot relates a very satisfactory termination of fracture of this bone in a carriage-horse. The animal fell, and was totally unable to rise again. He was placed on some hurdles, and drawn home. A veterinary surgeon being consulted, recognised fracture of the lower pastern in both feet, and advised that the animal should be destroyed. It was a favourite horse, between five and six years old, and the owner determined to give it a chance of recovery.

M. Gazot was consulted. He plainly recognised a transverse fracture in the lower pastern of the right leg, and a longitudinal one in the left pastern. They were both of them simple fractures. The horse was manageable and seemed to comprehend the whole affair. He had plenty of good litter under him, which was changed twice in the day. The first olyject that was attempted to be accomplished was the healing of the excoriations that had taken place in drawing him home, and abating the inflammation that was appearing about the pasterns.

At the termination of the first week all these were healed, the horse fed well, and was perfectly quiet, except that when he was tired of lying on one side he contrived to get on bis knees and then to raise himself on his haunches, and, having voided his urine and his dung, he turned himself upon the other side, without the bandages round his pasterns being in the slightest degree interfered with.

At the expiration of the second week he seemerl to wish to get up. The groom had orders to assist him, and a sling was passed under him. Some oats were placed in the manger, and he seemed to enjoy the change for a little while. Soon afterwards he began to be imeasy, and a copious perspiration appeared on every part. He was immediately lowered, when, with evident delight, he stretched out his head and his legs, and lay almost without motion during several hours. On the following day be was again placed in the sling, and again lowered as soon as he appeared to be fatigued.

At the expiration of a month from the time of the accident he could get up without assistauce, and would continue standing two or three hours, when he lay down again, but with a degree of precantion that was truly admirable. The bandages around the pasterns had been continued until this period, and had been kept wet with a spirituous embrocation. The horse was encouraged to walk a little, some corn being offered to him in a sieve. $\mathrm{He}$ was sadly lame, and the lameness was cousi- derally greater in the left than in the right foot. A calculous enlargement could also be felt in the direction of the fracture on each pastern; but it was greatest in the left fetlock, and there was reason to fear the existence of ancholysis between the pastern bones of the left leg. That foot was surromded with emollient cataplasms, and, two days afterwards, was pared out, and the cautery applied over both pasterns, the spirituous embrocation being continued.

A fortnight afterwards the effect of the cautery was very satisfactory. The action of the part was "more free, and there was no longer any fear of auchylosis. It was however deemed prudent to apply the cautery over the right pastern. Walking exercise was now recommended, and in the course of another month the limmeness was much diminished. It was most on the left side, which, however, had resumed its former degree of inclination.

At the expiration of four months the borse was sent to work. His master, however, doubting the stability of the cure, sold bim, for which he ought to have had his own legs broken, and he fell into lad hands. He was worked hardly and halfstarved; nevertheless, the calculus continued to diminish, and the lameness altogether disappeared. $\mathrm{He}$ soon, however, passed into better bands. He was bought by a farmer at Chalons, in whose service he long remained, in good condition, and totally free from lameness. His last owner gave him the name of Old Broken Leg.*

\section{FRACTURE OF THE COFFIX BONT.}

This is an accident of very rare occurrence, and difficult to distinguish from other causes of lameness. The animal halts very considerably-the foot is hot and tender-the pain seems to be exceedingly great, and none of the ordinary causes of lameness are perceiver. According to Hurtrel D'Arboval, it is not so serious an accident as has been represented. The fractured portions cannot be displaced, and in a rascular bone like this, the uuion of the divided parts will be readily effected.

Mr. Percivall very properly remarks, that, "buried as the coffin and navieular bones are within the hoof, and out of the way of all external injury as well as of muscular force, fracture of them cimnot proceed from ordinary causes. It is, perhaps, thus prodnced:-in the healthy foot, in consequence of the elasticity of their connections, these bones yield or spring under the impression the $y$ receive from the bones above, and thus are enabled to bear great weights, and sustain riolent shocks without injury; but, disease in the foot is often found to destroy this elasticity, by changing the cartilage into bone, which cannot receive the

* Recueil de Mèd. Vét. 1834, p. 7. No apology is offered for the intrnduction of cases like this. The cause of science and of humanity is equally served. 
same weight and concussion without risk of fracture. Horses that have undergone the operation of neurotomy more frequently meet with this accident than others, because they batter their senseless feet with a force which, under similar circum: stances, pain would forbid the others from doing."*

FRACTURE OF THE NAVICULAR BONE

has been sufficiently considered under the article “Navicular Joint Disease," p. 462.
Mr. Mayer sums up his account of the treatment of fractures in a way that reflects much credit on him and the profession of which lie is a member. "Let your remedies," says he, " be governed by those principles of science, those dictates of humanity, and that sound discretion, which, while they raise the moral and intellectual superiority of man, distinguish the master of his profession from the bungling empiric." $\dagger$

\section{CHAPTER XXI.}

\section{ON SHOEING.}

THE period when the shoe began to be nailed to the foot of the horse is uncertain. William the Norman introduced it into our country.

We have seen, in the progress of our inquiry, that, while it affords to the foot of the horse that defence which seems now to be necessary against the destructive effects of our artificial and flinty roads, it has entailed on the animal some evils. It has limited or destrosed the beautiful expansibility of the lower part of the foot-it has led to contraction, although that contraction has not always been accompanied by lameness-in the most careful fixing of the best shoe, and in the careless manufacture and setting on of the bad one, irreparable injury has occasionally been done to the horse.

We will first attend to the preparation of the foot for the shoe, for more than is generally imagined, of its comfurt to the horse and its safety to the rider, depends ou this. If the master would occasionally accompany the horse to the forge, more expense to himself and punishment to the horse would be spared than, perhaps, he would think possible, provided he will take the pains to understand the matter himself, otherwise he had better not interfere.

The old shoe must be first taken off. We hive something to observe even here. The shoe was retained on the foot by the ends of the nails lieng twisted off, turned down, and clenched. T'hese clenches should he first raised, which the smith seldum takes the trouble thoronghly to do; but after looking carefully round the crust and loosening one or two of the clenches, he takes hold first of one heel of the shoe, and then of the other, and by a violent wrench separates them from the foot: then, by means of a third wrench, applied to the middle of the shoe, he tears it off. By these means he must enlarge every nail-hole, and weaken the future and steady hold of the shoe,

* Percivall's Hippopalhology, rol. i., p. 272. and sometimes tear off portions of the crust, and otherwise injure the foot. The horse generally shows by his flinching that he suffers from the violence with which this preliminary operation too often is performed. The clenches should always be raised or filed off; and, where the foot is tender, or the horse is to be examined for lameness, each nail should be partly punched out. According to the common system of procedure, many a stub is left in the crust, the source of future annoyance.

The shoe having been removed, the smith proceeds to rasp the edges of the crust. Let not the stander-by object to the apparent violence which he uses, or fear that the foot will suffer. It is the only means that he has to detect whether any stuls remain in the nail-holes; and it is the most courenient method of removing that portion of the erust into which dirt and gravel have insinuated themselves.

Next comes the important process of paring out, with regard to which it is almost impossible to lay down any specific rules. This, howerer, is undoulited, that far more injury has been done by the neglect of paring, than by carrying it to too great an extent. The act of paring is a work of much more labour than the proprietor of the horse often imagines. The surith, except he is overlooked, will frequently give himself as little trouble about it as he can; and that portion of horn which, in the unshod foot, would be worn away by contact with the ground is suffered to accumulate month after month, until the elasticity of the sole is destroyed, and it can no longer descend, and its other fuuctions are imjeded, and foundation is laid for corn, and contraction, and navicular disease, and inflammation. That portion of horn should be left on the foot, which will defend the internal parts from being bruised, and ret suffer the external sole to descend. How is this to be ascer- 
tained? The strong pressure of the thumb of the smith will be the best guide. The buttress, that most destructive of all instruments, being, except on very particular occasions, banished from every respectable forge, the smith sets to work with his drawing-knife, and removes the growth of horn, until the sole will yield, although in the slightest possible degree, to the strong pressure of his thumb. The proper thickness of horn will then remain.

If the foot has been previously neglected, and the horn is become very hard, the owner must not olject if the smith resorts to some other means to soften it a little, and takes one of his flat irons, and having heated it, draws it over the sole, and keeps it, a little while, in contact with the foot. When the sole is really thick, this rude and apparently barbarous method can do no harm, but it should never be permitted with the sole that is regularly pared out.

The quantity of horn to be removed in order to leave the proper degree of thickness will vary with different feet. From the strong foot a great deal must be taken. From the concave foot the horn may be removed until the sole will yield to a moderate pressure. From the flat foot little needs to be pared; while the pumiced foot should be deprived of nothing but the ragged parts.

The paring being nearly completed, the knife and the rasp of the smith must be a little watched, or he will reduce the crust to a level with the sole, and thus endanger the bruising of it by its pres. sure on the edge of the seating. The crust should be reduced to a perfect level, all round, but left a little higher than the sole.

The heels will require considerable attention. From the stress which is thrown on the inner heel, and from the weakness of the quarter there, the horm usually wears away considerably faster than it would on the outer one, and if an equal portion of horn were pared from it, it would be left lower than the outer heel. The smith should, therefore, accommodate his paring to the comparative wear of the heels, and be exceedingly careful to leave them precisely level.

If the reader will recollect what has been said of the intention and action of the bars, lie will readily perceive that the smith should be checked in his almost universal fondness for opening the heels, or, more truly, removing that which is the main impediment to contraction. The portion of the heels between the inflexion of the bar and the frog should scarcely be touched-at least the ragged and detached parts alone should be cut away. The foot may not look so fair and open, lut it will last longer without contraction.

The bar, likewise, should be left fully prominent, not only at its first inflexion, but as it runs down the side of the frog. The heel of the shoe is designed to rest partly on the heel of the foot and partly on the bar, for reasons that have been already stated. If the bar is reak, the growth of it should be encouraged; and it should be scarcely touched when the horse is shod, unless it has attained a level with the crust. The reader will recollect the observation which has been already made, that the destruction of the bars not only leads to contraction by removing the grand impediment to it, but by adding a still more powerful cause in the slanting direction which is given to the bearing at the heels, when the bar does not contribute to the support of the weight.

It will also be apparent that the horn between the crust and the bar should be carefully pared out. Every horseman has observed the relief which is given to the animal lame with corns when this angle is rell thinned. This relief, however, is often but temporary; for when the horn grows again, and the shoe presses upon it, the torture of the horse is renewed.

The degree of paring to which the frog must be subjected will depend on its prominence, and on the shape of the foot. The principle has already been stated, that it must be left so far projecting and prominent, that it shall he just within and abore the lower surface of the shoe; it will then descend with the sole sufficiently to discharge the functions that have been attributed to it. If it is lower, it will be bruised and injured; if it is higher, it cannot come in contact with the ground, and thus be enabled to do its duty. The ragged parts must be removed, and especially those occasioned by thrush, but the degree of paring must depend entirely on the principle just stated.

It appears, then, that the office of the smith requires some skill and judgment in order to be properly discharged; and the proprietor of horses will find it his interest occasionally to visit the forge, and complain of the careless, or idle, or obstinate fellow, while he rewards by some trifling gratuity the expert and diligent workman. $\mathrm{He}$ should likerrise rememler that a great deal more depends on the paring out of the foot than on the construction of the shoe; that few shoes, except they press upon the sole or are made outrageously had, will lame the horse; but that he may be very easily lamed from ignorant and improper paring out of the foot.

\section{THE PUTTING ON OF THE SHOE.}

The foot being thus prepared, the smith looks about for a shoe. He should select one that as nearly as possible fits the foot, or may be easily altered to the foot. He will sometimes, and especially if he is an idle and reckless fellow, care little ahout this, for he can easily alter the foot to the shoe. The toe-knife is a very coprenient 
instrument for him, and plenty of horn can be struck off with it. or remored by the rasp, in order to make the foot as small as the shoe; while he cares little, although by this destructive methord the crust is materially thinned where it should receive the nail, anl the danger of puncture and of pressure upon the sole is increased; and a foot so artiticially diminished in size will soon grow over the shoc, to the hazard of considerable or permanent lameness.

While the horse is travelling, dirt and gravel are apt to insinuate themselves between the web of the shoe and the sole. If the shoe were that, they would be permanently retained there, and would liuise the sole, and be productive of injury but when the shoe is properly hevelled off, it is scarcely possible for them to remain. They must be shaken out almost every time that the foot comes in contact with the ground.

The web of the shoe is likewise of that thickness that when the foot is properly pared, the prominent part of the frog shall lie just within and above its ground surface, so that in the descent of the sole the frog shall come sufficiently on the ground to enable it to act as a redge and to expand the quarters, while it is defencled from the wear and injury it would receive if it came on the ground witl the first and full shock of the weight.

The nail-holes are, on the ground side, placed as near the outer edge of the shoe as they can safely be, and bronglit ont near the inner erlge of the seating. The nails thus take a direction inward, resembling that of the crust itself, and lave firmer hold, while the strain upon them in the common shoe is altogether prevented, and the reight of the horse being thrown on a flat surface, contraction is not so likely to be produced.

The smith sometimes objects to the use of this shoe on account of its not being so easily formed as one composed of a bar of iron, either ilat or a little hevelled. It likenise occupies more time in the forging; but these ohjections would ranish when the owner of the horse declared that he wonld have him shod elserhere, or when he con sented-as, in justice, he should-to pay somewhat more for a shoe that required better workmanship, and longer time in the construction.

It is expedient not only that the foot and ground surfice of the shoe should be most accurately level, but that the crust should be exactly smoothed and fitted to the shoe. Much skill and time are necessary to do this perfectly with the drawing-knife. The swith has adopted a method of more quickly aud more accurately adapting the shoe to the foot. He pares the crust as level as he can, and then he brings the shoe to a heat somewhat below a red heat, and applies it to the foot, and detects any little elerations t.y the deeper vor. II. colour of the bnrned horn. This practice has been much inveigled against; but it is the abuse, and not the use of the thing which is to be conlemned. If the shoe is not too hot, nor held too long on the foot, an accuracy of adjustment is thus obtained which the knife would be long in producing, or would not produce at all. If, however, the shoe is made to burn its way to its sent, with little or no previous preparation of the foot, the heat must be injurious both to the sensible and insensible parts of the foot.

The heels of the shoe should be examined as to their proper width. Whatever is the custom of shoeing the horses of dealers, and the too prevalent practice in the metropolis of giving the foot an open appearance, althongh the posterior part of it is thereby exposed to injury, nothing is more certain than that, in the horse destined for roadwork, the heels, and particnlarly the seat of corn, can scarcely be too well covered. Part of the shoe projecting externally can be of no possible good, but will prove an occasional source of mischief, and especially in a heavy country. A sloe, the web of which projects inward as far as it can without tonching the frog, affords protcction to the angle between the bars and the crust.

Of the manner of attaching the shoe to the foot the orner can scarcely be a competent judge; he can only take care that the shoe itself shall not be lieavier than the rork requires-that, for work a little hard the shoe shall still be light, with a bit of steel welled into the toe-that the nails shall be as small, and as few, and as far from the heels as may be consistent with the security of the sloe; and that, for light work at least, the shoe shall not be driven on so closely and firmly as is often done, nor the points of the nails be lronght out so high up as is generally practised.

\section{CALKINS.}

There are fer cases in which the use of calkins (a turning up or eleration of the heel) can be adinissible in the fore-feet, except in flosty weather, when it may in some degree prevent unpleasant or dangerous slipping. If, however, calkins are used, they should be placed on both sides. If the outer heel only is raised with the calkin, as is too often the case, the weight cannot be thrown evenly on the foot, and undue straining and injury of some part of the foot or of the leg must be the necessary consequence. Few things deserve more the attention of the horseman than this most absurd and injurious of all the practices of the forge. One quarter of an hour's walking, with one side of the shoe or boot raised consideribly above the other, will painfully convince us oî what the horse must suffer from this too common method of shoeing. It cannot be excused even in the linuting shoe. If the horse is ridden far to cover, or galloped orer much hard 
and flinty ground, he will inevitably suffer from this unequal distribution of the weight. If the calkin is put on the outer heel, in order to prevent the borse from slipping, eitler the horn of that beel should be lowered to a corresponding degree, or the other heel of the shoe should be raised to the same level by a gradual thickening. Of the ose of calkins in the hinder foot we shall presently speak.

CLIPS.

These are portions of the upper edge of the shoe, hammered out, and turned up so as to embrace the lower part of the crust, and which is usually pared out a little, in order to receive the clip. They are very useful, as more securely attaching the shoe to the foot, and relieving the crust from that stress upon the vails which wonkd otherwise be injurious. A clip at the toe is almost necessary in every draught-horse, and absolutely so in the horse of heavy dranght, in order to prevent the shoe from being loosened or torn off by the pressure which is thrown upon the toe in the act of drawing. The elip on the outside of each shoe, at the beginuing of the quarters, will give security to it. Clips are likewise necessary on the shoes of all heavy horses, and of all others who are disposed to stamp, or violently paw with their feet, and thus incur the danger of displacing the shoe; but they are evils, inasmuch as they press upon the crust as it grows down, and they should only be used when circumstances absolutely require them. In the bunter's shoe they are not required at the sides. One at the toe is sufficient.

THE HINDER SHOE.

In forming the hinder shoes it should be remembered that the hind limbs are the principal instruments in progression, and thut in every act of progression, except the walk, the toe is the point on which the whole frame of the animal turns, and from which it is propelled. This part, then, should be strengthened as much as possible; and, therefore, the hinder shoes are made broader at the toe than the fore ones. Another good effect is produced by this, that, the linder foot leing shortened, there is less danger of orer-reaching or forging, and especially if the shoe is wider on the foot surface than on the ground one. The shoe is thus made to slone inward, and is a little within the toe of the crust.

The shape of the hinder foot is somewhat different from that of the fore foot. It is straighter in the quarters, and the shoe must have the same form. For carriage and draught horses generall ${ }_{5}$, calkins may be put on the heels, because the animal will be thus enabled to dig his toe more firmly into the ground, and uroe limself forward, and throw his weight into the collar "ith greater advantage; but the calkins must not be too high, and they must be of an equal height on each heel, otherwise, as has been stated with regard to the fore feet, the weight will not be fairly distributed over the foot, and some part of the foot or the leg will materially suffer. The nails in the hinder shoe may be placed nearer to the heel than in the fore shoe, because, from the comparatively little weight and concussion thrown on the hinder feet, there is not so much danger of contraction.

\section{DIFFEPENT KINDS OF SHOES.}

The shoe must vary in substance and weight with the kind of foot, and the nature of the work. A weak foot should never wear a heavy shoe, nor any foot a shoe that will last longer than a month. Here, perhaps, ne may be permitted to caution the horse-proprietor against having his cattle shod by contract, unless he binds down his farrier or veterinary surgeon to remove the shoes once at least in every month; for if the contractor, by a heary shoe, and a little steel, can cause five or six weeks to intervene between the shoeings, he will do so, although the feet of the horse must necessarily suffer. The shoe should never be heavier than the work requires, for an ounce or two in the weight of the shoe will sadly tell at the end of a hard day's work. This is acknowledged in the hunting shoe, which is narrower and lighter than that of the hackney, although the foot of the hackney is smaller than that of the bunter. It is more decidedly acknowledged in the racer, who wears a shoe only sufficiently thick to prevent it from bending when it is used.

\section{THE CONCAVE-SEATED SHOE.}

The proper form and construction of the shoe is a subject deserving of very serious inquiry, for it is most important to ascertain, if possible, the lind of shoe that will do the least mischief to the feet. A cut is subjoined of that which is useful and valuable for general purposes. It is employed in many of our best forges, and promises gradually to supersede the flat and the simple concave shoe, although it must, in many respects, yield to the unilateral shoe.

It presents a perfectly flat surface to the ground, in order to give as many points of bearing as possible, except that, on the outer edge, there is a groove or fuller, in which the nail-holes are pnnched, so that, sinking into the fuller, their heads project lut a little way, and are soon worn down level with the shoe. The ground surface of the common shoe used in the country is somewhat convex, and the imer rim of the shoe comes first on the ground: the consequence of this is, that the weight, iustead of being borne fitirly on the crust, is supported by the mils and clenches, which must be injurious to the foot, and often chip and break it. 


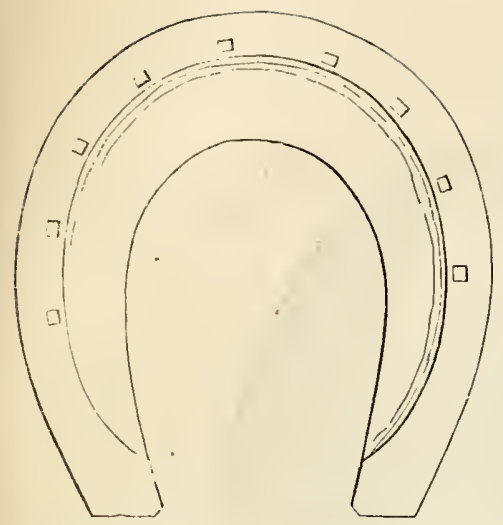

The web of this shoe is of the same thickness throughout, from the toe to the heel; and it is sufficiently wide to guard the sole from bruises, and, as much so as the frog will permit, to cover the seat of corn.

On the foot side it is seated. The outer part of it is accurately fiat, and of the width of the crust, and designed to support the crust, for by it the whole weight of the horse is sustained.

Towards the beel this flattened part is wider and occupies the whole breadth of the web, in order to support the heel of the crust and its reflected part-the bar: thus, while it defends the horn included within this angle from injury, it gives that equal pressure upon the bar and the crust, which is the best preventive against corns, and a powerful obstacle to contraction.

It is fastened to the foot by nine nails-five on the outside, and four on the inner side of the shoe ; those on the outside extending a little farther down towards the heel, because the outside heel is thicker and stronger, and there is more nail-hold; the last nail on the inner quarter being farther from the heel on account of the weakmess of that quarter. For feet not too large, and where moderate work only is required from the horse, four nails on the outside, and three on the inside, will be sufficient; and the last nail being far from the heels, will allow more expansion there.

The inside part of the web is bevelled off, or rendered concave, that it may not press upon the sole. Notwithstanding our iron fetter, the sole does, althongh to a very inconsiderable extent, descend when the foot of the horse is put on the ground. It is unable to bear constant or even occasional pressure, and if it came in contact with the shoe, the sensible sole letreen it and the coftin-bone would be bruised, and lameness would ensue. Many of our lorses, from too early and undue work, have the natural concave sole flattened, and the disposition to descend and the degree of descent are thereby increased. The concave shoe prevents, even in this case, the possibility of much injury, because the sole can never descend in the degree in which the shoe is or may be bevelled. A shoe bevelled still farther is necessary to protect the projecting or pumiced foot.

\section{THE UNILATRRAL, OR ONE SIDE NAILED SIOE.}

For a material improrement in the art of slove ing, we are indebted to Mr. Turner of Regent Street. What was the state of the foot of the horse a few years ago? An unyielding iron hoof was attached to it by four nails in each quarter, and the consequence was, that in nine cases out of ten the foot underwent a very considerable alteration in its form and in its usefulness. Before it had attained its full development-before the animal was five years old, there was, in a great many cases, an evident contraction of the hoof. There was an alteration in the manner of going. The step was shortened, the sole was hollowed, the frog was diseased, the general elasticity of the foot was destroyed-there mas a disorgauization of the whole horny cavity, and the value of the horse was materially diminished. What was the grand cause of this? It was the restraint of the shoe. The firm attachment of it to the foot by nails in each quarter, and the consequent strain to which the quarters and every part of the foot were exposed, produced a necessary tendency to contraction, from which sprang almost all the maladies to which the foot of the horse is sulject.

The unilateral shoe has this great advantage: it is identified with the grand principle of the expansibility of the horse's foot, and of remoring $0 r^{\circ}$ preventing the worst ailments to which the foot of the lorse is liable. It can be truly stated of this shoe, that while it affords to the whole organ an iron defence equal to the common shoe, it permits, what the common shoe never did or can do, the perfect liberty of the foot.

IVe are enabled to present our readers with the last improvement of the unilateral shoe.

The following cut gives a view of the onter side of the off or right unilateral shoe. The respective situations of the fire nails will be observed; the distance of the last from the heel, and the proper situations at which they emerge from the crust. The two clips will likewise be seen-one in the front of the foot, and the other on the side between the last and second nail.

The second cut gives a view of the inner side of the unilateral shoe. The tro nails near the toz are in the situation in which MIr. Turner directs that they shonld be placed, and behind them is no 
other attachment, between the shoe and the crust. The portion of the crust which is rasped off from the imer surface of the shoe is now, we believe, not often removed from the side of the foot; it has an unpleasant appearance, and the rasping is somewhat unnecessary. The heel of this shoe exhilits the method which Mr. Turner has adopted, and with considerable success, for the cure of corns; he cuts away a portion of the ground surface at the heel, and all injurious compression or concussion are rendered in a manner impossible.

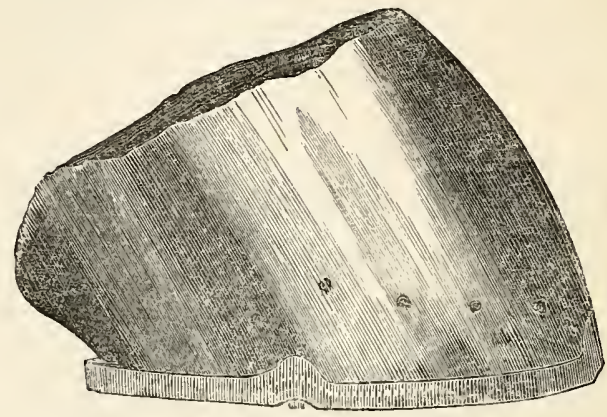

There can be no doubt that this one-sided nail. ing has been exceedingly useful. It has, in many a case that threatened a serious termination, restored the elasticity of the foot, and enabled it to discharge its natural functions. It has also restored to the foot, even in bad cases, a great deal of its natural formation, and enabled the horse to discharge his duty with more ease and pleasure to himself, and greater security to his rider.
It is difficult to tell what was the character of " the old English shoe." It certainly was larger than there was any occasion for it to be, and nearly covered the lower surface of the foot. The nailholes were also far more numerous than they are at present. The ground side was usually somewhat convex, "The effect of this," says Mr. IV. C. Spooner, "was to place the foot in a kind of hollow dish, which effectually prevented its proper

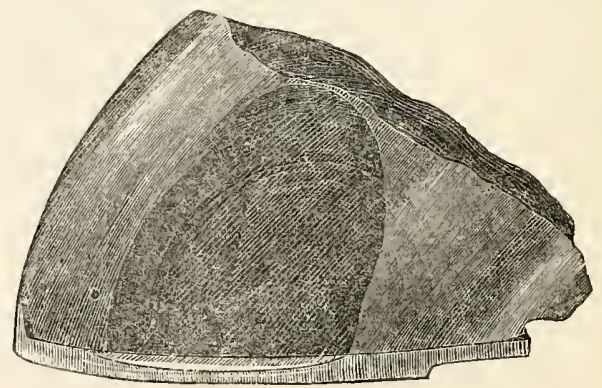

expansion, the crust resting on a mere ledge/ surface flat, and to take care that it did not press instead of a flat surfice; ant on the ground side, from the imer rim coming to the orvumil first, the weight was almost supporten by the nuils and clinches, which were plices, four or five on eich side, at some distance from the toe, and approaching nearly to the hecls. " "\%"

It was an improvement to make the ground p. 113 .

* A Treatise on the Foot of the Horse, by Mr. W. C. Sprooner, on the sole. At length, however, came the concave-seated shoe of Osmer, which was advocated by Mr. Clark, of Edinburgh, improved by Mr. Moorcroft, and ultimately became very generally and isefully adopted.

\section{THE HUNTING SHOE.}

The humter's shoe is different from that com. monly used, in form as well as in weight. It is 
not so much bevelled off as the common concaveseated shoe. Sufficient space alone is left for the introduction of a picker between the shoe and the sole, otherwise, in going over heavy ground, the clay would iusinuate itself, and by its tenucity loosen, and even tear off the shoe. The heels likewise are somewhat shorter, that they may not be torn off by the toe of the hind-feet when gallopIng fast, and the onter heel is frequently but injudiciously turned up to prevent slipping. If calkins are necessary, both heels should have an equal bearing.

\section{THE BAR-SHOE.}

A bar-shoe is often exceedingly useful. It is the continuation of the common shoe round the heels, and by means of it the pressure may be taken off from some tender part of the foot, and thrown on another which is better able to bear it, or more widely and equally diffused over the whole foot. It is principally resorted to in cases of corn, the seat of which it perfectly covers-in pmiced feet, the soles of which may be thus elevated above the ground an 7 secured from pressure-in sandcrack, when the pressure may be removed from the fissure, and thrown on either side of it, and in thrushes, when the frog is tender, or is become cankered, and requires to be frequentily dressed. and the dressing can by this means alone be retained. In these cases the bar-shoe is an excelleut contrivance, if worn only for one or two shoeings. or as long as the disease requires it to be worn, but it must be left off as soon as it can be dispensed with. If it is nsed for the protection of a diseased foot, however it may be chambered and laid off the frog, it will soon become flattened npon it; or if the pressure of it is thromu on the frog, in order to relieve the sand-crack or the corn, that frog must be very strong and healthy which can long bear the great and continued pressure. More mischief is often produced in the frog than previously existed in the part that was relieved. It will be plain that in the use of the bar-shoe for corn or sand-crack, the crust and the frog should be precisely on a level : the bar also should be the widest part of the shoe, in order to afforil as extended bearing as possible on the frog, and therefore less likely to be injurious. Bar-shoes are evideutly not safe in frosty weather. They are never safe when much speed is required from the horse, and they are apt to be wrenched off in a heavy, clayey country.

\section{TIPS.}

Tips are short shoes, reaching only half round the foot, and worn while the horse is at grass, in order to prevent the crust being torn by the occasional hardness of the ground, or the pawing of the animal. The quarters at the same time being free, the foot disposed to contract has a charice of expanding and regaining its natural shape.

\section{THE EXPANDING SHOE.}

Our subject would not be complete if we did not describe the supposed expanding shoe, although it is now almost entirely ont of use. It is either seated or concave like the common shoe, with a joint at the toe, by which the natural expansion of the foot is said to be permitted, and the injurious consequences of shoeing prevented. There is, however, this radical defect in the jointed shoe, that the nails occupy the same situation as in the common shoe, and prevent, as they do, the gradual expansion of the sides and quarters, and allow only of a hinge-like motion at the toe. It is a most imperfect accommodation of the expansion of the foot to the action of its internal parts, and even this accommodation is afforded in the slightest possible degree, if it is affurded at all. Either the nails fix the sides and quarters as in the common shoe, and then the joint at the toe is useless; or, if that joint merely opens like a hinge, the nailholes near the toe cau no longer correspond with those in the quarters, which are unequally expand ing at every point. There will be more stress on the crust at these holes, which will not only enlarge them and destroy the fixed attachinent of the shoe to the hoof, but often tear away portions of the crust. This shoe, in order to answer the iutended purpose, should consist of many joints, rumning aloug the sides and quarters, which would make it too complicated and expensive and frail for general use.

While the shoe is to be attached to the foot by uails, Te must be content with the concave-seated or unilateral one, taking care to place the $\mathrm{n}$ illholes as far from the heels, and particularly from the inner heel, as the state of the foot and the nature of the work will admit; and where the country is not too heavy nor the work too severe, omitting all but two on the inner side of the foot.

\section{FELT OR LEATHER SOLES.}

When the foot is bruised or inflamed the concussion or shock produced by the hard contact of the elastic iron with the ground gives the animal much pain, and aggravates the injury or disease. A strip of felt or leather is, therefore, sometimes placed between the seating of the shoe and tho erust, which, from its want of elasticity, deadens or materially lessens the vibration or shock, and the horse treads more freely and is eridently relieved. This is a grod contrivance while the inflammation or tenderness of the foot continnes, but a very bad practice if constantly adopted. The nails cannot be driven so surely or securels when this substance is interposed betreen tlie shoe and the foot. The contraction and swelling of the felt 
or leather from the effect of moisture or diyness will soon render the attachment of the shoe less firm-there will be too much play upon the nailsthe nail-holes will enlarge, and the crust will be broken away.

After wounds or extensive bruises of the sole, or where the sole is thin and flat and tender, it is sometimes covered with a piece of leather, fitted to the sole, and nailed on with the shoe. This may be allowed as a temporary defence of the foot; but there is the same oljection to its permanent use from the insecurity of fastening, and the strain on the crust, and the frequent chipping of it. There are also these additional inconveniences, that if the hollow between the sole and the leather is filled with stopping and tow, it is exceedingly difficult to introduce them so esenly and accurately as not to produce partial or injurious pressure. A few days work will almost invariably so derange the padding, as to cause unequal pressure. The long contact of the sole with storping of almost every kind will produce, not a healthy, elastic horn, but that of a scaly, spungy nature-and if the hollow is not thus filled, gravel and dirt will insinuate themselves, and eat into and injure the foot.

The general habit of stopping the feet requires some consideration. It is a very good or a very bad practice, according to circumstances. When the sole is flat and thin it should be omitted, except on the evening before shoeing, and then the application of a little moisture may render the jaring of the foot safer and more easy. If it were oftever used it would soften the foot, and not only increase the tendency to descent, bnt the occasional occurrence of lameness from pebbles or irregularities of the road.

Professor Stewart gives a raluable account of the proper application of stopping. "Farm horses seldom require any stopping. Their feet receive sufficient moisture in the fields, or, if they do not get much, they not do need much. Cart-horses used in the town should be stopped every Saturday night, until Monday moming. Fast going horses should be stopped once a week, or oftener during winter, and every second night in the hot weeks of summer. Groggy horses, and all those with high heels, concave shoes, or hot and tender feet, or an exuberance of horn, require stopping almost every night. When neglected, especially in dry weather, the sole becomes hard and rigid, and the horse goes lame, or becomes lame if he were not so before." $*$

One of tiro substances, or a mixture of both, is generally used for stopping the feet-clay and cow-dung. The clay used alone is too hard, and dries too rapidly. Many horses have been lamed by it. If it is used in the stable, it should always be removed before the horse goes to work. It may, * Sten art's Stable Econony, p. 127. perhaps, be applied to the feet of heavy draughthorses, for it will work out before much mischief is done.

Cow-dung is softer than the clay, and it has this good property, that it rarely or never becomes too hard or dry. For ordiuary work, a mixture of equal parts of clay and cow-dung will be the best application ; either of them, however, must be applied with a great deal of caution, where there is any disposition to thrush. Tow used alone, or with a small quantity of tar, will of ten be serviceable.

In the better kind of stables a felt pad is frequently used. It was first introduced by Veterinary Surgeon-General Cherry. It keeps the foot cool and moist, and is very useful, when the sole has a tendency to become flat. For the concare sole, tow would be preferable.

The shoe is sometimes displaced when the horse is going at an oldinary pace, and more frequently during hunting; and no person who is a sportsman needs to be told in what a vexatious predicament every one feels himself who happens to lose a shoe in the middle of a chase, or just as the hounds are getting clear away with their fox over the open country.

Mr. Percival has invented a sandal which occupies a very small space in the pocket, can be buckled on the foot in less than two minutes, and will serve as a perfect substitute for the lost one, on the road, or in the field; or may be used for the race-horse when travelling from one course to auother; or may be truly serviceable in cases of diseased feet that may require at the same time exercise and daily dressing. The cut on the following page is a short sketch of the horse sandal.

From an inspection of this cut it will be seen, that the shoe, or iron part of the sandal, consists of three principal parts, to which the others are appendages; which are, the tip, so called from its resemblance to the horse-shoe of that name; the middle bar, the broad part proceeding backward from the tip; and the side bars, or branches of the middle har, extending to the heels of the hoof. The appendages are, the toe-elasp, the part projecting from the frout of the tip, and which moves by a hinge upon the toe-clip, which toe-clasp is furnished with two iron loops. The heel-elips are two clips at the heels of the side bars which correspond to the toe-clip; the latter embracing the toe of the crust, while the former embrace its heels. Through the heel-clips run the rings, which move and act like a hinge, and are double, for the purpose of admitting both the straps. In the plate, the right ring only is represented; the left being omitted, the better to show the heelclip. The straps, which are composed of web, consist of a hoof-strap and a heel and coronet-strap.

The hoof-strap is fumished with a buckle, whose oflice it is to bind the shoe to the hoof; for 
which purpose it is passed through the lower rings and both loops of the shoe, and is made to encircle the hoof twice.
The heel and coronet-strap is furnished with two pads and two sliding loops; one, a moveable pad, reposes on the heel, to defend that part from

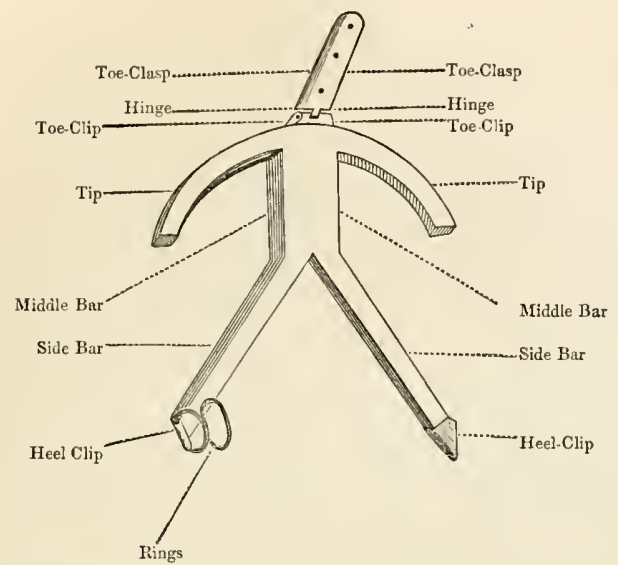

the pressure and friction of the strap; the other, a pad attached to the strap near the buckle, affords a similar defence to the coronet, in front. The heel-strap runs through the upper rings, crosses the heel, and encircles the coronet, and its office is to keep the heels of the shoe closely applied to the hoof, and to prevent them from sliding forward.

In the application of the sandal the foot is taken up with one hand, and the shoe slipped upon it with the other. With the same hand the shoe is retained in its place, while the foot is gradually let down to rest on the ground. As soon as this is done, the straps are drawn as tight as possible and buckled.

The following cut presents an accurate delineation of the sandal, when properly fastened on the foot.

Horses occasionally fall from bad riding, or bad shoeing, or over-reaching, or an awkward way of setting on the saddle. The head, the neck, the kuees, the back, or the legs, will oftenest snffer. It is often difficult to get the animal on his legs again, especially if he is old, or exhausted, or injured by the fall. The principal object is, to support the head, and to render it a fixed point from which the muscles may act in supporting the body.

If the horse is in harness, it is seldom that he can rise until he is freed from the shafts and traces. The first thing is to secure the head, and to keep it down, that he may not beat hinself against the ground. Next, the parts of the harness connected with the carriage must be unbuckled-the carriage must then be backed a little way, so that he may have room to rise. If necessary, the traces must be taken off; and after the horse gets $u p$ he mnst be steadied a little, until he collects himself.

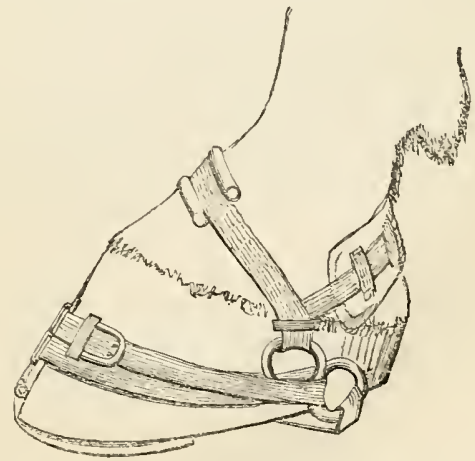




\section{CHAPTER XXII.}

OPERATIONS.

These belong more to the veterinary surgeon than to the proprietor of the horse, but a short account of the manner of conducting the principal ones shoulil not be omitted.

It is frequently necessary to bind the human patient, and in no painful or dangerous operation should this be omitted. It is more necessiry to lind the horse, who is not under the control of reason, and whose struggles may not only be injurious to himself but dangerous to the operator.

The trevis is a machine indispensable in every continental forge; even the quietest horses are there put into it to be shud.

The side-line is a very simple and useful method of confining the harse, and placing him in sufficient suljection for the operations of docking, nicking, and slight firing. The long line of the hobbles, or a common cart-rope with a noose at the end, is fastened on the pastern of the hind-leg that is not to he operated ou. The rope attached to it is then brought over the neck and round the withers, and there tied to the portion that comes from the leg. The leg may thus be drawn so far forward that, while the horse evidently cannot kick with that leg, he is disarmed of the other; for he would not have sufficient support under lim if he attempted to raise it: neither can he easily use his fore-legs, or, if he attempts it, one of them may be lifted up, and then lie becomes nearly powerless. If necessary, the aid of the twitch or the barnacles may be resorted to.

For every miuor operation, and even for many that are of more importance, this mode of restraint is sufficient, especially if the operator lias active and determined assistants; and we confess that we are no friends to the casting of horses, if it can possibly be prevented. When both legs are included in the hobble or rope-as in another way of using the sicle-line-the horse may appear to be more secure; but there is greater danger of his falling in his violent struggles during the operation.

For castrating and severe firing the animal must be thrown. The safety of the horse and of the operator will require the use of the improred hobbles, by which any leg may be released from confinement, and returned to it at pleasure; and, when the operation is euded, the whole of the legs may be set at liberty at once without danger. The method of putting the legs as closely together as possible before the pull-the necessity of the assistants all pulling together-and the porer which one man standing at the head and firmly holding the snafle-bridle, and another at the haunch pushing the horse when he is beginning to fall, have in bringing him on the proper side, and on the very spot on which he is intended to lie. need not to be described. It will generally be foum most convenient to tlurow the patients on the off side, turning them over when it is required. 'This, however, is a method of securing the horse to which we repeat that we are not partial, and to which we should not resort except necessity compelled; for in the act of falling, and in the struggles after falling, many accidents have occurred both to the horse and the surgeon.*

Among the minor methods of restraint, but sufficient for many purposes, are the tritch and the barnacles. The former consists of a noose passed through a hole at the end of a strong stick, and in which the muzzle is inclosed. The stick being turned round, the muzzle is securely retained, while the horse suffers considerable pain from the pressure-sufticiently great, indeed, to render him comparatively inattentive to that which is produced by the operation; at the same time he is afraid to struggle, for every motion increases the agony caused by the twitch, or the assistant has power to increase it by giving an additional turn to the stick.

The degree of pain produced by the application of the twitch should never be forgotten or unnecessarily increased. In no case should it be resorted to when milder measures would have the desired effect. Grooms and horsekeepers are too much in the habit of having recourse to it, when they liave a somewhat troullesome horse to manage. The degree of useless torture which is thus inflicted in large establishments is dreadful; and the temper of many a horse is too frequently completely spoiled.

The barnacles are the handles of the pincers placed over and inclosing the muzzle, and which, being compressed by the assistant, gire pain almost equal to that of the twitch. These may appear to be barbarous modes of enforcing submission, but they are absolutely indispensable. In a few instances the blindfolding of the horse terrifies him into submission: but this is not to be depended upon. The twitch should be resorted to when the least resistance is offered; and when that, as it occasionally does, renders the horse more violent, recourse must be had to the side-line or the hobbles.

* The safest and best hobbles are those invented by Mr. Gloag and improved by $\mathrm{Mr}$. Daws, as represented in the Veterinarian, vol. x., p. 108, and vol. xi., p. 163. The thumh-serew (6g. 3) should, however, be inverted. 
In the painful examination of the fore-leg or foot while on the around, the other foot should be held up by an assistant; or, if lis ail is required in an operation, the knee may be fully bent, and the pastern tiel up to the arm. When the hindleg is to be examined in the same way, the fore-leg on that side should be held or fastened up.

\section{RLEEDING.}

The operation of bleeding has been already described (p. 362), but we would remind our readers of the necessity, in every case of acute inflammation, of making a large orifice, and abstracting the blood as rapidly as possible, for the constitution will thus be the more speedily and beneficially affected; and also of the propriety of never determining to take a precise quantity of blood, but of keeping the finger ou the artery until the pulse begins to faulter, or the strong beating of fever becomes softer, or the animal is faint, or the oppressed pulse of inflammation of the lungs is rouncler and fuller.

In cases of inflammation, and in the hands of a skilful practitioner, bleeding is the sheet-anchor of the veterinarian; yet few things are more to be reprobated than the indiscrimate bleeding of the groom or the farrier.

The change which takes place in the blood after it is drawn from the vein is diligently noticed by many practitioners, and is certainly deserving of some attention. The blood coagulates soon after it is taken from the vein. The coagulable part is composed of two substances: that which gives colour to the blood, and that in which the red particles float. These, by degrees, separate from each other, and the red particles sink to the bottom. If the coagulation takes place slowly, the red particles have more time to sink through the fluid, and there appears on the top a thick, yellowish, adhesive substance, called the buffy coat. The slowness of the coagulatiou and the thickness of buffy coat are indicative of inflammation, and of the degree of inflammation.

In a healthy state of the system, the coagnlation is more rapid, the red particles have not time to fall through, and the buffy coat is thin. These appearances are worth observing; but much more dependence is to be placed on the character and change of the pulse, and the symptoms generally. When the horse is exhausted and the system nearly broken up, the bluod will sometimes not coagulate but be of one uniform black colour and loose texture. When the blood runs down the side of the vessel in which it is received, the coagulation will be very imperfect. When it is drawn in a full stream, it coagulates slowly, and when procured from a smaller orifice, the coagulation is more rapid. Every circumstance affecting the coagulation and appearance of the blood, the pulse, and the general symptoms, should be most attentively regarded.

A great deal of mystery is associated with bleeding in the management of the racer and the hunter. The habour of the turf and the field having ceased, there is frequently some difficulty in preventing a plethoric state of the constitutiona tendency to inflammatory complaints. If the horse is rapilly accumulating flesh, it may be prudent to abstract blood, dependent in quantity on the age and constitution of the animal. Attention to this may prevent many a linrse from going wrong; but the custom that once prevailed of bleeding every lorse a fortnight or more after the racing or hunting season had passed, is decidedly objectionable.

As preparatory to work, bleeding is far from being so much employed as it used to be. As a universal practice, when the horse is first taken from grass, it now scarcely exists. It would not always be objected to, if the horse was fat and full of flesh, but, otherwise, it is a custom more honoured in the breach than the observance. It certainly produces very considerable effect. More rapidly than any species of diet-more rapidly than any sweating or purging, it reduces the condition of the horse, but, we have often thought, at the expense of those essentials to life and health that cannot be easily replaced.

\section{BLISTERING.}

We have spoken of the effect of Blisters, when treating of the various diseases to which they are applicable. The principle on which they act is, that no two intense inflammations can exist in neighbouring parts, or perhaps in the system, at the same time. Hence we apply some stimulating acrimonious substance to the skin, in order to excite external inflammation, and thus lessen or remove that which exists in some deeper seated and, generally, not far distant part. Hence, also, we blister the sides in inflammation of the lings-the aldomen in that of the bowels-the legs in that of the cellular substance surrounding the sheaths of the tendons, or the sheaths themselves, and the coronet or the heel in inflammation of the navicular joint.

Blisters have likewise the property of increasing the activity of the neighbouring ressels: thus we blister to bring the tumour of strangles more speedily to a head-to rouse the absorbents generally to more energetic action, and cause the disappearance of tumours, and even callous and bony substances.

The judgment of the practitioner will decide whether the desired effect will be best produced by a sudden and violent action, or by the continuauce of one of a milder character. Inflammation should be met by active blisters; old enlargements 
and swellings will be most certainly removed by milder stimulants-by the process which farriers call sweating doun.

There are few more active or effectual blisters than the Spanish fly, mixed with the proportions of lard and resin that will be hereafter stated. The best liquid or sweating blister is an infusion of the fly in spirit of turpentine, and that lowered with neat's-foot oil according to the degree of activity required.

In preparing the horse for blistering, the hair should be clipped or shaved as closely as possible, and the ointment thoroughly rubbed in. Much fault is often found with the ointment if the blister does not rise, but the failure is generally to be attributed to the idleness of the operator.

The heal of the horse slould be tied up during the first two days; except that, when the sides are blistered, the body-cloths may be so contrived as to prevent the animal from nibbling and blemishing the part, or blistering his muzzle. At the expiration of twenty-four hours, a little olive or neat'sfoot oil should be applied over the blister, which will considerably lessen the pain and supple the part, and prevent cracks in the skin that may be difficult to heal. The oil should be applied morning and night, until the scabs peel off. When they legin to loosen, a lather of soap and water applied with a sponge may hasten their remoral, but no violence must be used.

Every particle of litter should he carefully remored from the stall, for the sharp ends of the straw coming in contact with a part rendered so tender and irritable by the blister, will cause a very great annoyance to the animal. After the second day the horse may be suffered to lie down; but the possibility of blemishing himself should be prevented by a cradle or woorlen necklace, consisting of round strips of wood, strung together, reaching from the lower jaw to the chest, and preventing him from sufficiently turuing or bending his hearl, to get at the blistered part.

A blister thus treated will rarely produce the slightest blemish. Then the scabs are all remover, the blister may be repeated, if the case should aprear to require it, or the horse mily be turned out.

In inflammations which threaten life, a blister can scarcely be too active or extensive. In inflammation of the lungs it should reach over the whole of the sides, and the greater part of the brisket, for, should a portion of the thy be absorbed, and produce stranifury (inflammation, or spasmodic affection of the neck of the bladder), even this new irritation may assist in subduing the first and more dangerous one. In blistering, however, for injuries or diseases of the legs or feet, some caution is necessaxy. When speaking of the treatment of sprain of the back sinews, 1.431 , it was stated that " a blister should never be used while any heat or tendermess remained about the part," for we should then add to the superficial inflammation instead of abating the deeper-seated one, and enlargements of the limb and extensive ulcerations might follow, which would render the horse perfectly unserviceable. Wheu there is a tendency to grease, a blister is a dangerous thing, and has often agravated the disease. In winter, the inflammation of the skin produced by blistering is apt to degenerate into grease; therefore, if it should be necessary to blister the horse during that season, great care must be taken that he is not exposed to cold, and, particularly, that a current of cold air does not come upon the legs.

The inhuman practice of blistering all round at the same time, and perhaps high on the legs, cannot be too strongly reprobated. Many a valuable horse has been lost through the excessive general irritation which this has produced, or its violent effect on the urinary organs, and that has heen particularly the case, when corrosive sublimate has entered into the composition of the blister.

If strangury should appear, the horse should be plentifully supplied with linseed tea, which is thus best prepared-a gallon of boiling water is thrown on half a pound of linseed; the infusion suffered to stand until nearly cold, and the clean mucilaginous fluid then poured off. Three quarters of a pound of Epsom salts should also be given, dissolved in a quart of water, and, after that, a ball every six hours, containing opium, and camphor, with linseed-meal and treacle.

Half a pound or a pound of good mustard powder, made into a paste with boiling water, and applied hot, will often prodnce as good a blister as cantharicles. It is a preferable one, when, as in inflammation of the kidneys, the effect of cantharides on the urinary organs is feared. Hartshorn is not so effectual. Tincture of croton makes an active liquid blister, and so do some of the preparatious of iodine.

\section{FIRING.}

Whatever seeming cruelty may attend this operation, it is in many cases indispensable. The principle on which we have recourse to it is similar to that which justifies the use of a blister-by producing superficial inflammation we mas be enabled to get rid of a deeper-seated one, or we may excite the absorbents to remove an unnatural bony or other tumour. It raises more intense external inflammation than we can produce by any other means. It may be truly said to be the most powerful agent that we have at our disposal. Humanity, howerer, will dictate, that on account of the inflammation which it excites, and the pain it inflicts, it should only he had recourse to when milder 
means have failed, except in those cascs in which experieuce has taught us that milder means rarely succeed.

The part which is to be submitted to the operation should be shaved, or the hair cut from it as closely as possible with the trimming scissors. This is necessary in order to bring the iron into immediate contact with the skin, and likewise to prevent the smoke that will arise from the burned hair obscuring the view of the operator. 'The horse must then be thrown. This is absolutely necessary for the safety both of the operator and the animal. The side-line may be apjlied in a shorter time, and so many hands may be not wanted to cast the horse; but no person can fire accurately, or with the certainty of not penetrating the skin, except the animal is effectually secured by the hobbles. Although accidents have occurred in the act of casting, yet many more have resulted to the operator, the assistants, or the horse, in a protracted operation, when the side-line only has heen nsed.

The details of the operation belong to the veterinary surgeon. The grand points to be attended to are to luave the elge of the iron round and smooth-the iron itself at, or rather below, a red heat-to pass it more or less rapidly over the skin, and with slighter or greater pressure according to the degree of heat-to burn into the skin until the line produced by the iron is of a brown colour, rather light than dark, and, by all means, in common cases, to avoid penetrating the skin. Leaving out of the question the additional cruelty of deep firing, when not absolutely required, we may depend on it that if the skin is burned through, inflammation, and ulceration, and sloughing will ensue, that will be with much difficulty combated-that will unavoidably leave unnecessary b]emish, and that has destroyed many valuable horses. It may happen, nerertheless, that by a sudden plunge of the animal the skin will be unavoidably cut through. The act of firing requires much skill and tact, and the practitioner cannot be always on his guard against the struggles of the tortured beast. It will, also, and not unfrequently, occur that the skin, partially divided, will separate in two or three days after the operation. This must not be attributed to any neglect or unskilfulness of the surgeon, and the ulceration thus produced will be slight and easily treated, compared with that caused by actually burning through the skin.

A very considerable change has taken place in the breed of many of the varieties of the horse, and the labour exacted from him. As illustrations of this we refer to the altered character and pace of the modern hunter and the additional increase of speed required from the coach and the post horse ; the exertion being limited only by the degree to which every muscle and every nerve can be ex. tended, while the calculation between the utmost exaction of cruelty and the expenditure of vital power, is reduced to the merest fraction. The consequence of this is, that the horse is suljected to severer injuries than he used to be, and severer measures are and must be employed to remedy the evil. Hence the horrible applications of the actual cautery to the horse that have dis. graced the present day. Lesions-gashes have been made on either side of the tendon of the leg, which it took no fewer than seven months to heal. Was there nothing short of this lengthened torture that could have been done to relieve the victim? Could be not have been more lightly fired for the road or for the pur. poses of breeding? Was there no pasture on which he had earned a right to graze?-or could he not have been destroyed? These sad lesions will occasionally come before the practitioner and the owner. It will be for the first to adrocate that which, on a careful view of the case, mercy prompts; and the latter, except there is a reasonable prospect of ultimate enjoyment, as well as usefulness, should nerer urge a continuation of suffering.

Supposing, however, that prospect to exist, the surgeon must discharge his duty. These gashes, after a while, begin to close, and then commences the beautiful process of granulation. Little portions of the integument form on the centre of the wound. and the sides of the wound creep closer together, and the skin steals over the surface, until the chasm is perfectly closed. In order to insure the continuance of this, a ridge of contracted integument as hard as any cartilage, but without its elasticity, runs frou one end of the lesion to the other, tighter, and harder, and more effectual erery week, and month, and year, and lasting during the life of the animal. Therefore, the veterinary surgeon is not to be too severely censured, if, after lue consideration, he is induced to undertake one of these fearful operations: but let him do it as seldom as he can, and only when every circunstance promises a favomable result.

Some practitioners blister immediately after firing. As a general usage it is highly to be reprobated. It is wanton and useless cruelty. It may be required in bony tumours of considerable extent, and long standing, and interfering materially with the action of the neighbouring joint. Spavin accompanied by much lameness, and ring-bone spreading round the coronet and inrolving the side cartilages or the pastern joint, may justify it. 'The inflammation is rendered more intense, and of considerably longer duration. In old affections of the round bone it may be admitted, but no excuse can be made for it in slighter cases of sprain or weakness, or staleness.

On the day after the operation, it will be 
prudent gently to rub some neat's-foot oil, or lard over the wound. This will soften the skin, and render it less likely to separate or ulcerate. A bandage would add to the irritation of the part. Any cracks of the slin, or ulcerations that may ensue, must be treated with the calamine ointment.

It will be evident that there is an advantage derived from firing to which a blister can have no preteusion. The skin, partially destroyed by the iron, is reinstated and healed, not merely by the formation of some new matter filling up the vacuity, but by the gradual drawing together and closing of the separated edges. The skin, therefore, is lessened in surface. It is tightened over the part, and it acts, as just described, as a salutary and permanent bandage. Of the effect of pressure in removing eulargements of every lind, as well as giving strength to the part to which it is applied, we have repentedly spoken; and it is far from being the least valuable effect of the operation of firing, that by contracting the skin, it affords a salutary, equable, and permanent pres. sure. It was on this principle, but the practice cannot be defended, that colts which were not very strong on the legs, used to be fired round the fetlock, and along the back sinew, or over the hock, in order to brace and strengthen the parts. It is on the same principle that a racer or hunter, that has become stale and stiff, is sometimes fired and turned out. For whatever reason the horse is fired, he should, if practicable, be turned ont, or soiled in a loose box, for three or four months at least. The full effect intended to result from the external irritation is not soon produced, and the benefit derived from pressure proceeds still more slowly. In the thickenel and tender state of the skin, and the substance beneath, a retum to hard work, for some weeks after firing, would be likely to excite new inflammation, and cause even worse mischief than that which before existed.

Some reeks pass before the tumified parts begin to contract, and they only, who have had experience in these cases, can imagine how long, with gentle voluntary exercise, the process of absorption is carried on. He who rould expect that much good should accrue from the operation of firing, must be content to give up his horse for three or four months; but if he will use him sooner, and a worse lameness should follow, let him blame his own impatience, and not the inefficiency of the means, or the want of skill in the surgeon.

The firing in every case should be either in longitudinal or parallel lines. On the back sinews, the fetlock, and the coronet, this is peculiarly requisite, for thus only will the skin contract so as to form the greatest and most equable pressure.
Some practitioners may pride themselves on the accuracy of their diamonds, lozenges, and feathers, but plain straight lines, about half an inch from each other, will constitute the most advantageous mode of firing. The destroying of deeply-seated inflammation, by the exciting of violent inflammation on the skin, is as well obtained; and common sense will determine, that in no way can the pressure which results from the contraction of the skin be so advantageously employed-to which may be added, that it often leaves not the slightest blemish.

\section{SETONS}

Are pieces of tape or cord, passed, by means of an instrument resembling a large needle, either through abscesses, or the hase of ulcers with deep sinuses, or between the skin and the muscular or other substances beneath. They are retained there by the ends being tied together, or by a knot at each end. The tape is mored in the wound twice or thrice in the day, and occasionally wetted with spirit of turpentine, or some acrid fluid, in order to increase the inflammation which it produces, or the discharge which is intended to be established.

In auscesses, such as occur in the withers or the poll, and when passed from the summit to the very bottom of the swelling, setons are highly useful, by discharging the purulent fluid and suffering any fresh quantity of it that may be secreted to how out; and by the degree of inflammation which they excite on the interior of the tumour, stimulating it to throw out healthy granulations which gradually occupy and fill the hollow. In deep fistulous wounds they are indispensalile, for except some channel is marle through which the matter may flow from the bottom of the wound, it will coutinue to penetrate deeper into the part, and the healing process will never be accomplished. On these accounts, a seton passed through the base of the ulcer in poll-evil and fistulous withers is of so much benefit.

Setons are sometines useful by promoting a discharge in the neighlourhood of an inflamed part, and thus diverting and carrying away a portion of the fluids which distend or overload the vessels of that part; thus a seton is placed with considerable advantage in the cheek, when the eyes are much inflamed. We confess, however, that we prefer a rowel under the jaw.

With this view, and to excite a new and different inflammation in the neighbourhood of a part already inflamed, and especially so deeply seated and so difficult to be reached as the navicular joint, a seton has occasionally been used with manifest benefit, but we must peremptorily olject to the indiscriminate use of the frog-seton for almost every disease of the fiog or the foot.

In inflammations of extensive organs setons 
afford only feeble aid. Their action is too circumscribed. In intlammation of the chest or the intestines, a rowel is preferable to a seton; and a blister is far better than either of them.

On the principle of exciting the absorbents to action, for the removal of tumours, as spavin or splent, a blister is quicker in its action, and far more effectual than any seton. Firing is still more useful.

\section{DOCKING.}

The shortening of the tail of the horse is an operation which fashion and the convenience of the rider require to be performed on most of these animals. The length of the dock, or stump, is a matter of mere caprice. To the close-cropped tail of the waggon-horse, however, we decidedly olject, from its perfect ugliness, and because the animal is deprived of every defence against a thousand torturers. The supposition that the blood which would have gone to the nourishment of the tail causes greater development and strength in the quarters, is too absurd to deserve serious refutation. It is the rump of the animal being wholly uncovered, and not partly hidden by the intervention of the tail, that gives a false appearance of increased bulk,

The operation is simple. That joint is searched for which is the nearest to the desired length of tail. 'The hair is then turned up, and tierl round with tape for an inch or two above this joint; and that which lies inmediately upon the joint is cut off. The horse is fettered with the side-line, and then the veterinary surgeon with his docking. machine, or the farmer with his earving-knife and mallet, cuts throngh the tail at one stroke. Considerable bleeding ensues, and frightens the timid and the ignorant; but if the blowd were suffered to flow on until it ceased of its own accord, the colt, and especially if he were very young, would rarely be serjously injured. As, however, the bleeding rould occasionally continue for some hours, and a great quantity of llood might be lost, and the animal might be somewhat wealicned, it is usual to stop the hæmorrhage by the application of a red-hot irou to the stump. A large hole is made in the centre of the iron, that the bone may not be seared, which would exfoliate if it were burned with any severity, or drop off at the joint above, and thus shorten the dock. The iron rests on the muscular parts round the bone, and is brought into contact with the bleeding vessels, and very sneedily stops the hremorrhage. Care should be taken that the iron is not too hot - and that it is not held too long or too forcibly on the part, for many more horses would be destroyed by severe application of the cautery, than by the bleeding being left to its own course.

Powdered resin sprinkled on the stump, or indeed any other application, is worse than useless. It causes unnecessary irritution, and sometimes extensive ulceration; but if the simple iron is moderately applied, the horse nuy go to work immediately after the operation, and no dressing will be afterwards required. If a slight bleeding should occur after the cautery, it is much better to let it alone than to run the risk of inflammation or locked-jaw by re-applying the iron with greater severity.

Some farmers dock their colts a few days after they are dropped. This is a commendable custom on the score of humanity. No colt was ever lost by it: and neither the growth of the hair, nor the beauty of the tail, is in the least impaired.

\section{NICKING.}

T'his barbarous operation was once sanctioned by fashion, and the breeder and the dealer even low are sometimes tempted to inflict the torture of it in order to obtain a ready sale for their colts. It is not, however, practised to the extent that it used to be, nor attended by so many circumstances of eruelty.

We must liere introduce a small portion of the anatomy of the horse, which we had reserved for this place. The ejghteen dorsal vertebræ or bones of the back (see $d$, p. 34t), and the five lumbar vertebrie or bones of the loins $(f, p .314)$, have already been described. The continuation of the spine consists of the sacrum, composed of fire bones $(h, p .34-k)$, which, althongh separate in the colt, are in the full-grown horse united into one mass. The bones of the ilium, the upper and side portion of the haunch, articulate strongly with the sacrum, forming a bony union rather than a joint. The spinal marrow and the blood-vessels here generally begin to diminish, and numerous branches of nerves are given ont, which, joined by some from the rertebræ of the loins, form the nerrous apparatus of the hind-legs.

The bones of the tail $(i$, p. 34.4$)$ are a contimuation of those of the sacrum. They are fifteen in number, gradually diminishing in size, and losing altogether the character of the spinal vertebræ. Prolongations of the spinal marrow run through the whole of them, and likewise some arterial res. sels, which are a continnation of those which supply the sacrum. Much attention is paid by persons who are acquainted with the true form of the horse to this continuation of the sacral and tail-bones. From the loins to the setting on of the tail the line should be nearly straight, or inclining only a slight degree downward. There is not a surer test of the breed of the horse than this straight line from the loins to the tail; nor, as was shown when the muscles of the quarters were described, is there any circumstance so much connected with the mechanical advantage with which these muscles act. 
The tail seems to lie designeil to perfect the beauty of the lorse's form. There are three sets of nuscles belonging to the tail: the erector corcygis, situated on the superior and lateral part of it, and by the action of which $(d, p .439)$ the tail may be both elevated and drawn on one sidethe depressor coccygis, on the inferior and lateral part of it, by the action of which the tail may be both lowered and drawn on one.side-and the curvator coccygis, by the action of which the tail may be curred or flexed on either sile. The depressor and lateral muscles are more powerful that the erector ones, and when the horse is undisturhed, the tail is bent down close on the buttocks; but when he is excited, and particularly when he is at speed, the erector muscles are called into action, the tail is elevated, and there is an appearance of energy and spirit which adds materially to his beauty. To perpetuate this, the operation of nicking was contrived. The depressor muscles and part of the lateral ones are cut through, and the erector muscles, left without any antagonists, lieep the tail in a position more or less erect, according to the whim of the operator or the depth to which the incisions have been carried.

The operation is thus performed:-The sideline is put on the horse, or some persons deem it more prudent to cast him, and that precaution we should be disposed to recommend; the hair at the end of the tail is securely tied together, for the purpose of afterwards attaching a weight to it; the operator then grasps the tail in his hand, and, lifting it up, feels for the centre of one of the bones-the prominences at the extremities will guide him-from two to four inches from the root of the tail, according to the size of the horse; he then, with a sharp knife, divides the muscles deeply from the edge of the tail on one side to the centre, and, continuing the incision across the bone of the tail, he makes it as deep on the other side. One continued incision, steadily yet rapidly made, will accomplish all this. If it is a bloodhorse that is operated on, this will be sufficient. For a hunter, two incisions are usually made, the second being about two inches below the first, and likewise as nearly as possible in the centre of one of the bones.

On a hackney, or cocktail, a third incision is made; for fashion has decided that his tail shall be still more elevated and curved. Two incisions only are made in the tail of a mare, and the second not very deep.

When the second incision is made, some fibres of the muscles between the first and second will project into the wound, and must be removed by a pair of curved scissors. The same must be done with the projecting portions from letween the secont and third incisions. The wounds should then be carefully examined, in order to ascertain that the muscles have been equally divided on each side, otherwise the tail will be carried awry. 'This being done, pledgets of tow must be introduced deeply into each incision, and confined, but not too tightly, by a bandage. A very profuse bleeding will alone justify any tightness of bandage, and the ill consequences that have resulted from nicking are mainly attributable to the unnecessary force that, is used in confining these pledgets. Even if the bleeding, immediately after the operation, should have heen very great, the roller must be loosened in two or three hours, otherwise swelling and inflammation, and even death, may possihly ensue. Twenty-four hours after the operation, the bandage must be quite removed; and then, all that is necessary, so far as the healing of the incisions is concerned, is to keep them' clean.

If, however, the tail were suffered to hang down, the divided edges of the muscles would again come in contact with each other, and close; the natural depression of the tail would remain; and the animal would have been punished for no purpose. The wounds must remain open, and that can only be accomplished by forcibly keeping the tail curved back during two or three weeks. For this purpose a cord, one or two feet in length, is affixed to the end of the hair, which terninates in another divided cord, each division going over a pulley on either side of the back of the stall. A weight is hung at either extremity sufficient to keep the incisions properly open, and regulated by the degree in which this is wished to be accomplished. The animal will thus be retained in an uneasy position, although, after the first two or three days, probably not one of acute pain. It is barbarous to incrense this uneasiness or pain by affixing too great a weight to the cords; for it should be remembered that the proper elevated curve is given to the tail, not by the weight keeping it in a certain position for a considerable time, but by the depth of the first incisions, and the degree in which the wounds are kept open. By every ounce of weight beyond that which is necessary to keep the incisions apart, unnecessary suffering is inflicted. Some practitioners use only one pulley; others do not use any, but put on a light girth, and tie a cord from the end of the tail to the girth, bending it over the back. The double pulley, however, is the least painful to the horse, and more perfectly secures the proper elevation and straight direction of the tail.

The dock should not, for the first three or four days, be brought higher than the back. Dangerous initation and inflammation would pro bably be produced. It may, after that, be gradually raised to an elevation of forty-five degrees. The horse should be taken out of the pulleys, and 
gently exercised once or twice every day ; but the pulleys cannot finally be dispensed witl until a fortnight after the wounds have healed, because the process of contraction, or the approach of the divided parts, goes on for some time after the skin is perfect over the incisions, and the tail would thus sink below the desired elevation.

If the tail has not been unnecessarily extended by enormous weights, no bad consequences will usually follow; but if considerable intlammation slould ensue, the tail must be taken from the pulley and diligeutly fomented with simple warm water, and a dose of physic given. Locked-jaw has, in some rare instances, followed, under which the horse generally perishes. 'The best means of eure in the early state of this disease is to amputate the tail at the joint above the highest incision. In order to prevent the hair from coming off, it should be unplaited and combed out every fourth or fifth day.

\section{CIIAPTER XXIII.}

\section{THE VICES AND DISAGREEABLE OR DANGEROUS HABITS OF THE HORSE.}

THE horse has many excellent qualities, but he has likewise defects, and these occasionally amounting to vices. Some of them may be attributed to natural temper, for the human being searcely discovers more peculiarities of habit and disposition than does the horse. The majority of them, however, as perhaps in the human being, are cunsequences of a faulty education. Their early instructor has beeu ignorant and brutal, and they have become obstimate and vicious.

\section{RESTIVENESS.}

At the head of the vices of the horse is Restiveness, the most aunoying and the most daugerous of all. It is the produce of bad temper and worse education; aud, like all other halits founded on uature and stamped by education, it is iuveterate. Whether it appears in the form of kicking, or rearing, or plunging, or bolting, or in any way that threateus danger to the rider or the horse, it rarely admits of eure. A determined rider may to a certain extent subjugate the animal; or the horse may have his favourites, or form his attachments, and with some particular person he nay be comparatively or perfectly manageable; but others cannot long depend upon him, and even his master is not always sure of him. It is a rule, that admits of very few exceptions, that he noither displays his misdom nor consults his safety, who attempts to eonquer a restive horse.

An excellent veteriuary surgeon, and a man of great experience in horses, Mr. Castley, truly said, in "The Veterinarian,"- " From whatever eause the vicious liabits of horses may originate, whether from some mismanagement or from natural baclness of temper, or from what is called in Yorkshire a mistetch, whenever these animals aequire one of them, and it becomes in some degree confirmed, they very seldom, if ever, altogether forget it. In refereuce to driving it is so true. that it may be taken as a kind of aphorism, that if a horse kieks once in harness, no matter from what cause, he will be liable to kick ever afterwards. A good coachmau may drive him, it is true, and may make bim go, but he eannot make him forget his rice; and so it is in riding. You may conquer a restive horse-you may make him go quiet for months, nay, almost for years together ; lut I affirm that, uiler other circumstances, and at some future opportunity, he will be sure to return to his old tricks."

Mr. Castley gives two singular and conclusive instances of the truth of this doctrine. "When a very young man," says he, "I remember purcliasing a horse at a fair in the north of England, that was offered rery cheap on account of his being unmanageable. It was said that nobody could ride him. We found that the animal objected to have anything placed upon his back, and that, when made to move forward with nothing more than a saddle on, he instantly threw himself domn on his side with great violence, and would then endeavour to roll upon his back.

"There was at that time in Yorkshire, a famous colt-breaker, known by the name of Jumper, who was almost as celebrated in that country for taming vicious horses into submission, as the famed Whisperer was in Ireland. We put this animal into Jumper's hands, who took him away, and in about ten days brought him home agaiu, certainly not looking worse in condition, but perfectly subdued and alwost as obedient as a dog; for he would lie down at this man's bidding, and only rise again at his command, and cary double or anything. I took to riding him myself, and may say, that I was vever better carried for six or eiglit months, during which time he did not show the least vice whatever. I then sold him to a Lineolnshire farmer, who said that he would give him a summer's rum at grass, and show him as a very fine horse at the great Horncastle fair.

"Happening to meet this gentleman un the 
following year, I naturally enongh inquired after my old friend. 'Ob,' said he, 'that was a bad business - the horse turned out a sad rebel. The first time we attempted to mount him, after getting him up from grass, he in an instant threw the man down with the greatest riolence, pitching him several yards over his head; and after that he threw every one that attempted to get on his back. If he could not throw his rider, he would throw himself doun. We could do nothing with him, and I was obliged at last to sell him to go in a stage-coach.'"

In the next story, Jumper's counterpart and superior, the Irish Whisperer, is brought on the the stage, and, although he performed wonders, he could not radically cure a restive horse. "At the Spring Meeting of 1801, Mr. Whalley's King Pippin was brought on the Curragh of Kildare to run. He was a horse of the most extraordinary savage and vicions disposition. His particnlar propensity was that of flying at and vorrying any person who eame within his reach, and if he had an opportunity, he would get his head round, seize lis rider by the leg with his teeth, and drag him down from his back. For this reason he was always ridden with what is called a sword; which is a strong flat stick, having one end attached to the cheek of the bridle, and the other to the girth of the saddle, a contrivance to prevent a horse of this kind from getting at his rider.

"King Pippin had long been difficult to manage and dangerons to go near to, but on the occasion in question he could not be got ont to run at all. Nobody could put the bridle upon his head. It being Faster Monday, and consequently a great loliday, there was a large concourse of people assembled at the Curragh, consisting principally of the neighbouring peasantry; and one countryman, more fearless than the rest of the lookers-on, forgetting, or perhays never dreaming that the better part of courage is discretion, volunteered his services to bridle the horse. No snoner had lie committed himself in this operation, than Ting Pippin seized him somewhere about the shoulders or chest, and, says Mr. Watts (Mr. Castley's informant?, 'I know of nothing I can compare it to, so much as a dog shaking a rat.' Fortunately for the poor fellow, his body was very thickly covered with elothes, for on such oecasions an Irishman of this class is fond of displaying his wardrobe, and if $h c$ has three coats at all in the uorld, he is sure to put them all on.

"This circumstance, in all probability, saved the individual who had so gallantly volunteered the forlorn hope. His person was so deeply enveloped in extra-teguments, that the horse never got fairly hold of his skin, and I nnderstand that he escaped with but little injury, beside the sadly rent and totally ruined state of his holiday toggery.
"The Whisperer was sent for, who, having arrived, was shut up with the horse all night, and in the morning he exhibited this hitherto ferocious animal, foliowing him about the course like a dog -lying down at his command-suffering his mouth to be opened, and any person's hand to be introduced into it-in short, as quiet almost as a sheep.

"He came out the same meeting, and won his race, and his docility continued satisfactory for' a considerable time; but at the end of about three years his vice returned, and then he is said to have lilled a man, for which he was destroyed."

It may not be uninteresting, in this connexion, to give some account of this tamer of quadruped vice. However strange and magical his power may seem to be, there is no doubt of the truth of the account that is given of lim. The Rev. Mr. Townsend, in his Statistical Survey of Cork, first introduced him to the notice of the pullic generally, although his fame had long spread over that part of Irelaud. We, however, give the following extract from "Croker's Fairy Legends and Traditions of Ireland," Part II., p. 200, for his performances seem the work of some elfin sprite, rather than of a rude and ignorant horse-breaker.

"He was an awkward, ignorant rustic of the lowest class, of the name of Sullivan, but better known ly the appellation of the Whisperer. His occupation was horse-breaking. The nickuame he acquired from the vulgar notion of his being alile to communicate to the animal what he wished by means of a whisper; and the singularity of his method seemed in some degree to justify the supposition. In his own neighbourhood the votoriety of the fact made it seem less remarkable, but $f$ doubt if any instance of similar suljugating talent is to be found on recorl. As far as the sphere of his control extended, the boast of reni, ridi, vici, was more justly claimed by Sullivan than even by Casar himself.

"How his art was acquired, and in what it consisted, is likely to be for ever unknown, as he has lately (about 1810) left the world without divulging it. His son, who follows the same trade, possesses but a small portion of the art, having either never learned the true secret, or being incapable of putting it into practice. The wonder of his skill consisted in the celerity of the operation, which was performed in prixacy, without any apparent means of coercion. Every description of horse, or even mule, whether previously broken or unhandled, whatever their peculiar habits or vices might have been, submitted without show of resistance to the magical influence of his art, and in the short space of half an hour became gentle and tractable. This effect, though instantaneously produced, was generally durable. Though more submissive to lim than to others, the animals seemed to have acquired a docility unknown before. 
"When sent for to tame a vieious beast, for which he was either paid according to the distance, or generally two or three guineas, he directed the stable, in which he and the object of the experiment were, to be shut, with orders not to open the door until a signal was given. After a tête-ü-tctte of about half an hour, during which little or no bustle was heard, the sigual was made, and, upon opening the door, the horse appeared lying duwn, and the man by his side, playing with him like a child with a puppy dog. From that time he was found perfectly willing to submit to any discipline-however repugnant to his nature before." "I once," continues Mr. Croker, "saw his skill tried on a lorse, which could never before be brought to stand for a smith to shoe him. The day after Sullivan's half hour's lecture, I went, not without some incredulity, to the smith's shop, with many other curious spectators, where we were eye-witnesses of the complete success of his art. This, too, had been a troop horse, and it was supposed, not without reason, that after regimental discipline had failed, no other would be found availing. I observed that the animal appeared terrified whenever Sullivan either spoke to or looked at him; how that extraordinary ascendancy conld have been obtained, is difficult to conjecture.

"In common cases this mysterious preparation was unnecessary. He seemed to possess an instinctive power of inspiring awe, the result, perhaps, of natural intrepidity, in which, I believe, a great part of his art consisted; though the circumstance of the tête-à-téte shows that, on particular oceasions, something more must have been added to it. A faculty like this would, in some hands, have made a fortune, and I understand that great offers were made to him, for the exercise of his art abroad. But hunting was his passion. He lived at home in the style most agreeable to his disposition, and nothing could induce him to quit Duhallow and the fox-hounds."

Mr. Castley witnessed the total failure of the younger Sullivan. He says, "we have in the regiment a remakably nice horse, called Lancer, that has always been very difficult to shoe, lut seren or eight years ago, when we first got him, he was downright vicious in that respect. When the regiment was stationed at Cork, the farrier. major sought out the present Sullivan, the son of the celebrated Whisperer, and brought him up to the barracks in order to try his hand upon Lancer, and make him more peaceable to shoe; but I must say this person did not appear to possess any particular controlling power over the animal more than any other man. Lancer seemed to pay no attention whatever to his charm, and at last fairly beat him out of the forge. Time, however, and a long persererance in kind and gentle treatment, have effected what force

vot. I. could not. to shoe."*

The horse is now pretty reasonable

- An account, bearing considerable zesemblance to the feats of the English horse-tamer, has been lately lajd before the public.

Mr. Catlin has published an account, the veracity of which is unimpeached, of his travels among the Noth American Iodians. He thus describes the manoer in which the Indian tames the wild horse. "He toils his lasso on his arm, and gallops fearlessly into the herd of wild horses. He soon gets it over the neck of one of the number, when he instantly dismonnts, leaving his ow a horse, and runs as fast as he can, letting the lasso pass ont grauinally and carefully throngh his hands, until the horse falls for wast of breath, and lies helpless on the ground. The Iodian advances slowly towards the horse's head, keeping the lasso tight upon his neck, until he fasteus a pair of hobbles on the aumnal's two fore feet, and also loosens the lasso, giving the horse a chance to breathe, and passing a noose round the under jaw, by which he gets great power over the affighted animal, that is reariag and plunging when it gets lieath, and by which, as he advances, hand over hand, towards the horse's nose, he is able to hold it down, and prevent it from throwing itself over oa its back. By this means he gradually advances, until he is able to place his hand on the auimal's nose and over its eyes, and, at length, to breathe into its nostrils, when jt soon becomes docile and ennquered; so that he has little elge to do than to remove the hobbles from its feet, and lead or rude it to the camp. The animal is so completely conquered, that it subuits quietly ever after, and is led or rode away with very little difficulty."

Mr. Ellis, B.A., of Trinity College, Cambridge, happened to read this account, and he felt a natural desire to ascertain how far this mode of horse-taming might be employed among British horses. He soun had the opportunity of putting the veracity of the story to the test. His brother-in law had a filly, not yet a year old, that had bece removed from her dam three months before, and since thit time had not bcen taken out of the stable. A great amatenr in everything relating to horses was present, and at his reunest it was determined that the experimeat of the efficacy of breathing into the nostrils should be imnediately put to the test. The filly was brought from the stable, the amateur leading licr by the halter. She was quite wild, and bolted, and dragged the amateur a considerable distance. He bad beeo using a shor halter ; he chnnged it for a longer one, and was thea able to lead the little scared thing to the front of the house. The experiment was tried under manifest disadvantage, for the filly was in the open air, several strangers were about her, and buth the owotr and the amateur were rather seeking amusement from the failure than knowledge from the success of their experiment.

The filly was restive and frighteaed, and with great difficulty the amateur nanaged to cover ber eyes. At length be succeeded, and blew into the nostrils. No particular effect seemed to follow. He then breathed into her nostrils, und the moment he did so, the filly, who had very much resisted having her eyes blindfolded, and had been rery restive, stood perfectly still and 1remhled. From thit time she became rery tractable. Another gentleman also breathed into her nostrils, and she evidently enjoged it, and kept putting up her nose to receive the breath.

On the following morning she was led out again. She was perfectly tractuble, and it seemed tn be almost impossible to frighten her.

A circumstance which, in a great measure, corroborated the possibility of easily taming the most ferocions horses, oceurred on the next day. A maa, on a neighbouring farm, was alteanting to break-in a very restive colt, who foiled him in evers possible way. After several manceuvres the amateur succeeded in breathing into one of the nostrils, and from that noment all became easy. The horse was completely subdued. He suffered himself to be led gnietly away with a loose halter, and was perfectly at command. He was led through a field in wheh were four horses that bad been his enmpanions. They all surrounded him; he took no notice of them, out quielly followtd his new master. A surcirgle was buckled on him, and then a saddle, and he was finally fited with a bridle. The whole esperimeat occupied about an hour, and not in a single instance did he rebel.

On the next day, however, the brcaker, a severe and obstinate fellow, took him in hand, and, according to his ustal custom, began to beat him most cruelly. The horse broke from him. and became as unmanageable as ever. The spirit of the animal had bec'n subdued but not broken. 


\section{BACKING OR GIBBING.}

One of the first kinds of restiveness, taking them in alphabetical order, is backing or gibbing. These are so closely allied that we hardly know how to separate them. Some horses have the habit of backing at first starting, and that more fiom playfulness than desire of mischief. A mo. derate application of the whip will usually be effectual. Others, even after starting, exhibit considerable obstinacy and viciousness. This is fre. quently the effect of bad breaking. Either the shoulder of the horse had been wrung when he was first put to the collar, or he had been foolishly accustomed to be started in the break up-hill, and, therefore, all his work coming upon him at once, he gradually acquired this dangerous habit.

A hasty and passionate breaker will often make a really good tempered young horse an inveterate gibler. Every young horse is at first shy of the collar. If he is too quickly forced to throw his weight into it, he will possibly take a dislike to it, that will occasionally show itself in the form of gibling as long as he lives. The judicious horse-breaker will resort to no severity, even if the colt should go out several times without even touching collar. The example of his companion will ultimately induce him to take to it voluntarily and effectually.

A large and heavy stone should be put behind the wheel before starting, when the horse, finding it more difficult to back than to go forward, will gradually forget this unpleasant trick. It will likewise be of advantage, as often as it can be managed, so to start that the horse shall have to lack up-hill. The difficulty of accomplishing this will soon make him readily go forward. A little coaxing, or leading, or moderate flagellation, will assist in accomplishing the cure.

When, however, a horse, thinking that he has had enough of work, or has been improperly checked or corrected, or beginning to feel the painful pressure of the collar, swerves, and gibs, and backs, it is a more serious matter. Persuasion should first be tried; and, afterwards, reasonable coercion, but no cruelty: for the brutality which is often exercised in attempting to compel a gibbing horse to throw himself habitually into the collar, never set accomplished the purpose. The horse may, perhaps, be whipped into motion : but if he has once begun to gib, he will have recourse to it again whenever any circumstance displenses or anmoys him, aud the habit will be so rapidly and completely formed, that he will become insensible to all screrity.

It is useless and dingerous to contend with a horse determined to back, unless there is plenty of room, and, by tight reining, the driver can make him back in the precise direction be wishes, and especially up-hill. Such a horse should be immediately sold, or turned over to some other work. In a stage-coach as a wheeler, and particularly as the near-wheeler; or, in the middle of a team at agricultural work, he may be serviceable. It will be useless for him to attempt to gib there, for he will be dragged along by his companions whether he will or not; and, finding the inutility of resistance, he will soon be induced to work as well as any horse in the team. The reformation will last while he is thus employed, but, like restiveness generally, it will be delusire when the horse returns to his former occupation. The disposition to annoy wrill very soon follow the power to do it. Some instances of complete reformation may have occurred, but they are rare.

When a horse, not often accustomed to gib, betrays a reluctance to work, or a determination not to work, common sense and humanity will demand that some consideration should be taken before measures of severity are resorted to. The horse may be taxed beyond his power. He soon discovers whether this is the case, and by refusing to proceed, tells his driver that it is so. The utmost cruelty will not induce many horses to make the slightest effort, when they are conscious that their strength is inadequate to the task. Sometimes the withers are wrung, and the shoulders sadly galled, and the pain, which is intense on level ground and with fair draught, becomes insupportable when he tugs up a steep acclivity. T'hese things should the examined into, and, if possible, rectified; for, under such circumstances, cruelty may produce obstinacy and vice, but not willing obedience.

They who are accnstomed to horses know what seemingly trivial circumstances occasionally produce this vice. A horse, whose shoulders are raw, or have frequently been so, will not start with a cold collar. When the collar has acquired the warmth of the parts on which it presses, the animal will go without reluctance. Some determined gilbers have been reformed by constantly wearing a false collar, or strip of cloth round the shoulders, so that the coldness of the usual collar should never be felt; and others bave been cured of gib. ling by keeping the collar on night and day, for the animal is not able to lie down completely at full length, which the tired horse is always glad to do. When a horse gibs, not at starting, but while doing his work, it has sometimes been useful to line the collar with cloth instead of leather; the perspiration is readily absorbed, the substance which presses on the shoullers is softer, and it may be far more accurately eased off at a tender place.

BITING

This is either the consequence of natural ferocity, or a habit acquired from the foolish and teasing 
play of grooms and stable-boys. When a horse is tickled and pinched by thoughtless and mischievous youths, he will first pretend to bite his tormentors; by degrees he will proceed farther, and actually bite them, and, very soon after that, he will be the first to challenge to the combat, and, without provocation, seize some orportumity to gripe the incantions tormentor. At length, as the love of mischief is a propensity too easily acquired, this war, half playful and half in earnest, becomes habitual to him, and degenerates into absolute viciousness.

It is not possible to enter the stall of some horses without danger. The animal gives no warning of his intention; he is seemingly quiet and harmless: but if the incautious by-stander comes fairly within his reach, lie darts upon him, and seldom fails to do some mischief. A stallion addicted to biting is a most formidable creature. He lifts the intruder-he sliakes him-he attacks him with his feet-he tramples upon him, and there are many instances in which he effects irreparable mischief. A resolute groom may escape. When he bas once got firm hold of the head of the horse, he may back him, or muzzle him, or harness him ; but he must be always on his guard, or in a moment of carelessness he may be seriously injured.

It is seldom that anything can be done in the way of cure. Kindness will aggravate the evil, and no degree of severity will correct it. "I have seen," says Professor Stewart, "biters punished until they trembled in every joint, and were ready to drop, but have never in any case known them cured by this treatment, or by any other. The lash is forgotten in an hour, and the horse is as ready and determined to repeat the offence as before. He appears unable to resist the temptation, and in its worst form biting is a species of insanity."*

Prevention, however, is in the power of every proprietor of liorses. While he insists on gentle and humane treatment of his cattle, he shouid systematically forbid this horse-play. It is that which can never be considered as operating as a reward, and thereby rendering the horse tractable; nor does it increase the affection of the animal for his groom, because he is annoyed and irritated by being thus incessantly teased.

\section{GETTING THE CHEEK OF THE BIT INTO THE MOUTH.}

Some horses that are disposed to be mischievous try to do this, and are very expert at it. They soon find what advantage it gives them over their driver, who by this manourre loses almost all command. Harsh treatment is here completely out of the question. All that can be done is, by some mechanical contrivance, to render the thing difficult or impossible, and this may be managed by fastening a romd piece of leather on the inside of the cheek of the bit.

* Stewart's Stabie Economy, p. 160.
KICRING.

This, as a vice, is another consequence of the culpable habit of grooms and stable-boys of teasing the horse. That which is at first an indication of annoyance at the pinching and tickling of the groom, and withont any design to injure, gradually becomes the expression of anger, and the effort to do mischief. The horse likewise too soon recognises the least appearance of timidity, and takes advantage of the discovery. There is no cure for this vice; and he cannot be justified who keeps a kicking horse in his stable.

Some horses acquire, from mere irritability and fidgetiness, a habit of kicking at the stall or the bail, and particularly at night. The neighbouring hor'ses are disturbed, and the kicker gets swelled hocks, or some more serious injury. This is also a habit very difficult to correct if suffered to become established. Mares are far more subject to it than horses.

Before the habit is inveterately established, a thorn bush or a piece of furze fastened against the partition or post will sometimes effect a cure. When the horse finds that he is pretty severely pricked he will not loug continue to punish himself. In confirmed cases it may be necessary to have recourse to the log, lut the legs are often not a little lruised by it. A rather long and heavy piece of wood attached to a chain has been buckled above the hock, so as to reach abont half way domn the leg. When the horse attempts to kick violently, his leg will receive a severe blow : this, and the repetition of it, may, after a time, teach him to be quiet.

A much more serious vice is kicking in harness. From the least annoyance about the rump or quarters, some horses will kick at a most violent rate, and destroy the bottom of the chaise, and endanger the limbs of the driver. Those that are fidgety in the stable are most apt to do this. If the reins should perchance get under the tail, the violence of the licker will often be most ontrageous ; and while the animal presses down his tail so tightly that it is almost impossible to extricate the reins, he continues to plunge until he has demolished everything behind him.

This is a rice standing foremost in point of danger, and which no treatment will always conquer. It will be altogether in vain to try coercion. If the shafts are very strong and without flaw, or if they are plated with iron underneath, and a stout kicking-stran resorted to which will barely allow the horse the proper use of his hind limbs in progression, but not permit him to raise them sufficiently for the purpose of kicking, he may be prevented from doing mischief; or if he is harnessed to a heavy cart, and thus confined, his efforts to lash out will be restrained: but it is frequently a 
very unpleasant thing to witness these attempts, though ineffectual, to demolish the vehicle, for the shafts or the kicking-strap may possibly break, and extreme danger may ensue. A horse that has once begun to kick, whatever may have been the original cause of it, can never be depended upon again, and he will be very unwise who ventures behind him. The man, however, who must come within reach of a kicker should come as close to him as possible. The blow may thus become a push, and seldom is injurious.

\section{UNSTEADINESS WIILE BEING MOUNTED.}

When this merely amounts to eagerness to start -very umpleasant, indeed, at times, for many a rider has been throrn from his seat before he was fairly fixed iu it-it may be remedied by an active and good horseman. We have known many in. stances in which, while the elderly, and inactive, and fearful man has been making more than one ineffectual attempt to vault into the saddle, the horse has been dancing about to his annoyance and danger; but the animal had no sooner been transferred to the management of a yourger and more agile rider than lie became perfectly sublued. Sererity will here, more decidedly than in any other case, do harm. The rider should be fearless -he should carelessly and confidently approach the horse, mount at the first effort, and then restrain him for a while; patting him, and not suffering him to proceed until he becomes perfectly quiet. Horses of this kind should not be too lighly fed, and should have sufficient daily exereise.

When the difficulty of mounting arises, not from eagerness to start, but nnwillingness to be ridken, the somer that horse is disposed of the better. He may be conquered by a skilful and determined lorseman; lut even he will not succeed without frequent and dangerous contests that will mar all the pleasure of the ride.

\section{FEARIXG}

This sometimes results from playfulness, carried, incleed, to an unpleasant aud dangerous extent; but it is oftener a desperate and occasionally successful effort to unhorse the ricler, and consequently a vice. The horse that has twice decidedly and dangerously reared, sliould never be trusted again, miless, indeed, it was the fault of the rider, who had been using a deep curb and a sharp bit. Some of the best horses will contend against these, and then rearing may be immediately and permanently cured by using a snaffle-bridle alone.

The horse-breaker's remedy, that of pulling the horse backward on a soft piece of ground, should he practised by reckless and brutal fellows alone. Many horses have beeu injured in the spine, and others have broken their necks, by being thus suddenly pulled over; while even the fellow, who fears no danger, is not always able to extricate himself from the falling horse. If rearing proceeds from vice, and is unprovoked by the bruising and laceration of the mouth, it fully partakes of the inveteracy which attends the other divisions of restiveness.

\section{RUNNING AWAY}

Some headstrong horses will occasionally endeavour to bolt with the best rider. Others with their wonted sagacity endeavour thus to dislodge the timid or unskilful one. Some are hard to hold, or bolt only during the excitement of the chase; others will run away, prompted by a vicious propensity alone. There is no certain cure here. The method which affords any probability of suc. cess, is to ride such a horse with a strong curb and sharp bit; to haye him always firmly in haud; and, if he will run away, and the place will admit of it, to give him (sparing neither curb, whip, nor spur) a great deal more rumning than he likes.

\section{TIClOUS TO CLEAN.}

It would scarcely be credited to what an extent this exists in some horses that are otherwise perfectly quiet. It is only at great hazard that they can le cleaned at all. The origin of this is probably some maltreatment. There is, however, a great difference in the sensibility of the skin in different horses. Some seem as if they could scarcely be made to feel the whip, while others camnot bear a fly to alight on them without an expression of annoyance. Iu young horses the skin is peculiarly delicate. If they have been curried with a broken comb, or hardly rubbed with an uneven lirusl, the recollection of the torture they have felt makes them impatient, and even vicious, during every succeeding operation of the kind. Many grooms, likewise, seem to delight in producing these exbibitions of unetsiness and vice; although, when ther are carried a little too far, and at the hazard of the limbs of the groom, the animals that have been almost tutored into these expressions of irritation are brutally kicked and punished.

'This, however, is a vice that may be conquered. If the horse is dressed with a lighter hand, and wisped rather thau brushed, and the places where the skin is most sensitive are aroided as much as thorough cleanliness will allow, he will graduilly lose the recollection of former ill-treatment, and become tractalle and quiet.

\section{Viclous TO SHOE.}

The correction of this is more peculiarly the business of the smith; yet the master should diligently concern himself with it, for it is oftener the consequence of injudicious or bad usage than of natural vice. It may be expected that there will le some difficulty in slioeing a horse for the first 
few times. It is an operation that gives lim a little uneasiness. The man to whom he is most accustomed should go with him to the forge; and if another and steady horse is shor before him; he may be induced more readily to submit. It cannot be denied that, after the habit of resisting this necessary operation is formed, force may sometimes be necessary to reduce our rebellious servant to obedience; but we unhesitatingly affirm that the majority of horses vicious to shoe are rendered so by harsh usage, and by the pain of correction being added to the uneasiness of shoeing. It should be a rule in every forge that no smith should be permitted to strike a horse, much less to twitch or to gag him, without the master-farrier's order; and that a young horse should never be twitched or struck. There are few horses that may not be gradually rendered manageable for this purpose by milduess and firmmess in the operator. They will soon understand that no harm is meant, and they will not forget their usual habit of obedience; but if the rememberance of corporal pumishment is comnected with shoeing, they will always be fidgety, and occasionally dangerous.

This is a very serious vice, for it not only exposes the animial to occasional severe injury from his own struggles, but also from the correction of the irritated smith, whose limbs and whose life being in jeopardy, may be forgiven if he is sometimes a little too hard-handed. Such a horse is very liable, and without any fault of the smith, to be pricked and lamed in shoeing; and if the habit should be confirmed, and should increase, and it at length becounes uecessary to cast him, or to put him in the trevis, the owner may be assured that many years will not pass ere some formidable or fatal accident will take place. If, therefore, mild treatment will not correct this vice, the horse camnot be too soon got rid of.

Horses have nany unpleasant labits in the stable and on the road, which cannot be said to amount to vice, but wlich materially lessen their value.

SWALLOWING WITHOUT GRINDING.

Some greedy horses habitually swallow their corn without properly grinding it, and the power of digestion not being adequate to the dissolving of the husk, no nutriment is extracted, and the oats are voided whole. This is particularly the case when horses of unequal appetite feed from the same manger. The greedy one, in his eagerness to get more than his share, bolts a portion of his corn whole. If the farmer, without considerable inconvenience, could contrive that every horse shall have his separate division of the manger, the one of smaller appetite and slower feed would have the opportunity of grinding at his leisure, without the fear of the greater share being stoleu by his neighbour.
Some horses, however, are naturally greedy feeders, and will not, even when alone, allow themselves time to chew or grind their com. In consequence of this they carry but little flesh, and are not equal to severe work. If the rack was supplied with hay when the corn was put into the manger, they will continue to eat on, and their stomachs will become disteuded with half-chewed and indigestible food. In consequence of this they will be incapable of considerable exertion for a long time after feeding, and, occasionally, dangerous sympitoms of staggers will occur.

The remedy is, not to let such horses fast too long. The nose-bag should be the companion of every considerable journey. The food should likewise be of such a nature that it cannot be rapidly bolted. Chaff should be plentifully mixed with the corn, and, in some cases, and especially in horses of slow work, it should, with the corn, constitute the whole of the food. This will be treated on more at large under the article "Feeding."

In every case of this kind the teetl should be carefully examined. Some of them may be unduly lengthened, particularly the first of the grinders: or they may be ragged at the edges, and may abrade and wound the cheek. In the first case the horse camnot properly masticate his food; in the latter he will not; for these animals, as too often happens in sore throat, would rather starve than put themselves to much pain.

\section{CRIB-BITING.}

This is a very unpleasant habit, and a consilerable defect, although not so serious a one as some have represented. The horse lays hold of the manger with lis teetl, violently extends his neck, and then, after some convulsive action of the throat, a slight grunting is heard, accompanied by a sucking or drawing in of air. It is not an effort at simple eructation, arising from indigestion. It is the iuhalation of air. It is that which takes place with all kiuds of diet, and when the stomach is empty as well as when it is full.

The effects of crib-liting are plain enough. The teeth are injuxed and worn away, and that, in an old horse, to a very serious degree. A considerable quantity of corn is often lost, for the lorse will frequently crib with his mouth full of it, and the greater part will fall over the edge of the manger. Much saliva escapes while the manger is thus forcibly held, the loss of which must be of serious detriment in impairing the digestion. The crib-biting horse is notoriously more sulject to colic than other horses, and to a species difticult of treatment and frequently dangerous. Although many a crib-hiter is stout and strong, and capable of all ordinary work, these horses do not generally carry so much flesh as others, and have not their endurance. On these accounts 
crib-biting has very properly been decided to be unsoundness. We must not look to the state of the disease at the time of purchase. The question is, does it exist at all? A case was tried before Lord Tenterden, and thus decided: "a horse with erib-biting is unsound."

It is one of those tricks which are exceedingly eontagious. Every companion of a crib-biter in the same stables is likely to acquire the habit, and it is the most inveterate of all habits. The edge of the manger will in vain be lined with iron, or with sheep-skin, or with sheep-skin covered with tar or aloes, or any other unpleasant substance. In defiance of the annoyance which these may occasion, the horse will persist in the attack on his manger. A strap buckled tightly round the neck, by compressing the windpipe, is the best means of preventing the possibility of this trick; but the strap must be constantly worn, and its pressure is too apt to produce a worse affection, viz. an irritation in the windpipe, which terminates in roaring.

Some have recommended turning out for five or six months; but this has never succeeded except with a young horse, and then rarely. The old crib-biter will employ the gate for the same purpose as the edge of his manger, and we have often seen him galloping across a field for the mere object of having a gripe at a rail. Medicine will be altogether thrown away in this case.

The only remedy is a muzzle, with bars across the bottom; sufficiently wide to enable the animal to piek up his eorn, and to pull his hay, but not to grasp the edge of the manger. If this is worn for a considerable period, the horse may be tired of attempting that which he cannot accomplish, and for a while forget the habit, but, in a majority of cases, the desire of crib-biting will return with the power of gratifying it.

The canses of crib-biting are various, and some of them beyond the control of the proprietor of the horse. It is often the result of imitation; but it is more frequently the consequence of idleness. The ligh-fed and spirited horse must be in mis. chief if he is not usefully employed. Sometimes, but we believe not often, it is produced by partial starvation, whether in a bad straw-yard, or from umpalatable food. An occasional cause of cribbiting is the frequent custom of grooms, even when the weather is not severe, of dressiug them in the stable. The horse either catches at the edge of the manger, or at that of the partition on each side, if he has been turued, and thus he forms the habit of laying hold of these substances on every occasion.

\section{WIND-SUEKING.}

This bears a close analogy to crib-biting. It arises from the same causes; the same purpose is accomplished; and the same results follow. The horse stands with his neck beut; his head drawn iuward; his lips alternately a little opened and then closed, and a noise is heard as if he were sucking. If we may judge from the same comparative want of condition and the flatulence which we have described under the last head, either some portion of wind enters the stomach, or there is an injurious loss of saliva. This diminishes the value of the horse almost as much as crib-biting; it is as contagious, and it is as inveterate. The only remedies, and they will seldom avail, are tying the head up, except when the horse is feeding, or putting on a muzzle with shark spikes towards the neck, and which will prick him whenever he attempts to rein his head in for the purpose of wind-sucking.

\section{CUTTING.}

Of this habit mention has been made at $p$. 434 ; and we would advise the owner of a cutting horse, without trying any previous experiments of raising or lowering the heels, to put on the cuttiug foot a shoe of even thickness from heel to toe, not projecting in the slightest degree beyond the crust, and the crust itself being rasperl a little at the quarters. The shoe should be fastened as usual on the outside, but with only one nail on the inside, and that almost close to the toe. The principle ou which this shoe acts has been explained at p. 487 .

\section{NOT LYING DOWN.}

It not uncommonly happens that a horse will seldom or never lie down in the stable. He sometimes continues in apparent good health, and feeds and works well; but generally his legs swell, or he becomes fatigued sooner than another horse. If it is impossible to let him loose in the stable, or to put him into a spare box, we know not what is to be done. No means, gentle or eruel, will force him to lie down. The secret is that he is tied up, and either has never dared to lie down through fear of the confinement of the halter, or he has been cast in the night, and severely injured. If he can be suffered to range the stable, or have a comfortable box, in which be may be loose, he will usually lie down the first night. Some few horses, however, will lie down in the stable, and not in a loose box. A fresh, well-made bed, will generally tempt the tired horse to refresh himself with sleep.

\section{OVER-REACH.}

This unpleasant roise, known also by the term "clicking," arises from the toe of the hind foot knocking against the shoe of the fore foot. In the trot, one fore leg and the opposite hind leg are first lifted from the ground and moved forward, the other fore leg and the opposite hind leg remaining 
fixod; but, to keep the centre of gravity within the base, and is the stride, or space passed over by these legs, is often greater than the distance between the fore and hind feet, it is necessary that the fore feet should be alternately moved out of the way for the hind ones to descend. Then, as occasionally happens with horses not perfectly broken, and that bave not been taught their paces, and especially if they have high hinder quarters and low fore ones, if the fore feet are not raised in time the hind feet will strike them. The fore foot will generally be caught when it has just begun to be raised, and the toe of the hind foot will meet the middle of the bottom of the fore foot. It is an unpleasant noise, and not altogether free from danger ; for it may so happen that a horse, the action of whose feet generally so much interferes with cach other, may advance the hind foot a litile more rapidly, or raise the fore one a little more slowly, so that the blow may fall on the heel of the shoe, and loosen or displace it; or the two shoes may be locked together, and the animal may be thrown; or the contusion may be received even higher, and on the tendons of the leg, and considerable swelling and lameness may follow.

If the animal is young, the action of the horse may be materially inproved; otherwise nothing can be done, except to keep the toe of the hind foot as short and as round as it can safely be, and to bevil off and ronnd the toe of the shoe, like that which has been worn by a stumbler for a fortnight, and, perhaps, a little to lower the heel of the fore foot.

A blow received on the heel of the fore foot in this manner has not unfrequently, and especially if neglected, been followed by quittor."

The heel most frequently suffers in over-reaching, although the pastern is sometimes injured. It nsually or almost always occurs in fast paces on deep ground. The injury is inflicted by the edge of the inner part of the shoe. The remedy is the cutting aray the edge of the shoe. An account of the most successful treatment of over-reach has been given in p. 465 .

\section{PAWIXG.}

Some hot and irritable horses are restless even in the stable, and paw frequently and violently. Their litter is destroyed, the floor of the stable

* Mr. Simpson relates an interesting though unfortunate case of this interference after the operation of nemrotomy :-

"Aa old but spleadid horse had been sadly lame in the of fore foot during some moaths. Maay plans of treatment were adopted, wilhout the desired effect; and at length it was determined to have recourse to aeurotomy. A portion of the metacarpal nerve was excised oo hoth sides, just above the fetlock. Three weeks afterwards, the hurse being quite free from lameness, be was pat into barness, and driven about twelve miles. He appeared to go very well, hut, on arriviag at his journey's eod, it was found that the off hiad foot was covered with blond, and the heels of the neurotomised foot were dreadfully bruised and cut, from repeated blows from the corresponding foot behind. In order to remaly broken up, the shoes worn out, the feet bruised, and the legs sometimes sprained. If this habit does not exist to any great extent, yet the stuble never looks well. Shackles are the only remedy, with a chain sufficiently long to enable the horse to slift his posture, or move in his stall; but these must be taken off at night, otherwise the animal will seldom lie down. Except, lrowever, the horse possesses peculiar value, it will be better to dispose of him at once, than to sulumit to the danger and inconvenience that he may occasion.

\section{QUIDDING}

A horse will sometimes partly chew his hay, and suffer it to drop from his mouth. If this does not proceed from irregular teeth, which it will be the business of the veterinary surgeon to rasp down, it will be found to be connected with sore throat, and then the horse will exhibit some other symptom of indisposition, and particularly, the swallowing of water will be accompanied by a peculiar gulping effort. In this case the disease (catarrh, with sore throat) must be attacked, and the quidding will cease.

\section{ROLLIKG.}

This is a very pleasant and perfectly safe amusement for a horse at grass, but cannot be indulged in the stable without the chance of his being dangerously entangled with the collar rein; and being cast. Yet, although the horse is cast, and bruised, and half-strangled, he will roll again on the following night, and continute to do so as long as he lives. The only remedy is not a very pleasant one to the horse, nor alwrays quite safe; yet it must be had recourse to if the habit of rolling is inveterate. "The horse," says Mr. Castley, "shonld be tied with length enough of collar to lie down, but not to allow of his head resting on the ground; because, in order to roll over, a horse is obliged to place his head quite down upon the ground."

\section{SHTING}

We have briefly treated of the cause of this vice at page 282 , and observed that while it is often the result of cowardice, or playfulness, or want of work, it is at other times the consequence of a defect of sight. It has been remarked, and

this, the toe of the hind foot was ordered to be shortened as much as possible.

"Four days afterwards be was driven again with the same con. tusions, but did not appear to fet] the slightest pain, either when the blows were ioflisted or when he was examined again some days afterwards.

"There was not the same activity in this foot that there had been betore the operation, and it conld not ret out of the way of the hind foot, a circumstance that would hardly have been expected, for it is the general belief that, although sensation is destroyed in the font, the locomotive puwers of the leg are unimpaired. This deserves future inquily."-The Teterinarian, vol. viii., p. 242 . 
we believe very truly, that shying is oftener a vice of half or quarter-bred horses, than of those who have in them more of the genuine racing blood.

In the treatment of shying, it is of great importance to distinguish between that which is the consequence of defective sight, and what results from fear, or newness of objects, or mere affectation or skittishness. For the first, the nature of which we have explained at page 282 , every allowance must be made, and care must be taken that the fear of correction is not associated with the imagined existence of some terrifying object. The severe use of the whip and the spur cannot do good here, and are likely to aggravate the vice tenfold. A word half encouraging and half scolding, with a gentle pressure of the heel, or a slight touch of the spur, will tell the horse that there was nothing to fear, and will give him confidence in his rider on a future occasion. It should be remembered, however, that although a horse that shies from defective sight may be taught considerable reliance on his rider, he can never have the cause of the habit removed. We may artificially strengthen the human sight, but that of the horse must be left to itself.

The shying from skittishness or affectation is quite a different affair, and must be conquered: kut how? Severity is altogether out of place. If he is forced into contact with the object by dint of correction, the dread of punishment will afterwards be associated with that object, and, on the next occasion, his startings will be more frequeut and more dangerous. The way to cure him is to go on, turning as litt3e as possible out of the road, giving a hassh word or two, and a gentle touch with the spur, and thes taking no more notice of the matter. After a few times, whatever may bave been the object which he chose to select as the pretended cause of affright, he will pass it almost without notice.

In page 41 . ander the head "breaking-in," we described how the colt may be cured of the hahit of shring from fear or newness of objects; and, if he then is accosstomed as much as possible to the objects among which his services will be required, he will not possess this annoying vice when he grows to maturer age.

$\mathrm{Mr}$, John Lawrence, in his last work on the horse, says, "These animals generally fix on some particular shying butt: for example, I recollect having, at different periods, three hacks, all very powerful; the one made choice of a wind-mill for the object or butt, the other a tilted waggon, and the last a pig led in a string. It so happened, however, that I rode the two former when amiss from a violent cold, and they then paid no more attention to either wind-mills or tilted waggons than to any other objects, convincing me that their shying when in health and spirits was pure affectation; an affectation, however, which may be speedily united with obstinacy and vice. Let it be treated with marked displeasure, mingled with gentle, but decided firmness, and the habit will be of short endurance."

It is now generally admitted by all riding. masters and colt-breakers, that a great deal more is to be effected by lenient than by harsh treatment. Rewards are found to operate more beneficially than punislments; and therefore the most scientific and practised riding-masters adopt methods based upon the former. The writer of the present work remembers a very remarkable instance of the efficacy of this plan, or rather of its vast and decided superiority over violence of the worst description. A vicious thorough-bred horse had baffled the efforts of every one into whose hands he had been put in order to be rendered tractable: at length a foreigner of considerable repute among the equestrians of the "school," took him to make trial of ; and in the course of a twelvemonth had rendered him so quiet that not only could any person ride him with the utmost safety; but, at the same time, he was so docile and tractable that he could be induced, by certain signs, to lie down and permit his rider to mount before he arose again.

The same forbearance and humanity have been practised with the same beneficial results upon shy horses. With all such persons as are best able to give counsel in cases of shyness, the language is now-a-days, "let the horse alone""take no notice of his shyness"- " work him mell and accustom him to the objects be dislikes, and in time he will of himself leave off his trick of shying."

This is good advice; but, let it not be misinterpreted. Let it not be understood to mean that the animal is to receive any encouragement to shy ; for by no other expression can be characterised that erroneous and foolish practice of patting the horse,

* "We will suppose a case-a very common one, an everyday one. A man is riding a young horse upon the high road in the country, and meets a stage-vuach. What with the noise, the bustle, the imprsing appearance altogether, and the slashing of the roachman's whip, the animal at its approach erects his bead and crest, pricks his ears, looks affrighted, and no sooner comes alongside of the machine than be suddenly starts out of the road. His rider, annoyed by this, instantly commenees a round of castigation with whip, spur, and curb, in which he persists nntil the horse, as as well as himself, has lost his temper; and then one whips, spurs, and pulls, and the other jumps, plunges, frets, and throws up his head, until hoth, pretty well exhausted by the conflict, grow tranquil again and proceed on their journey, though not for some time afterwards in their former mutual confidence and satisfaction, Should they in their road, ur even on a distant day, (meet with another coach, what is the consequence? The horse is not only more alarmed than before, but now, the moment he has started, bcing conscious of his fault and expecting ehastisement, he jumps about in fearful agitation, making plunges to strike into a gallop, and attempting to run away. So that by this correction, instead of rendering his horse tranquil during the passage of a coach, the rider adds to the evil of shying that of subsequently plungiug, and perhaps running away."-The Veterinarian, vol. i., p. 96. 
or " making much of him," either just before or during the time he evinces slyness. The former is bad, becuuse it draws the attention of the animal to the object he dreads; the latter is worse, because it fills hin with the impression either that the object itself is really terrific, or that he has acted right in shying at it, and ought to do so again.

Whether we are approaching the frightful ob. ject, or the horse is actually shying, "we should let him alone"- "we should take no notice whatever of him"-neither letting him perceive that we are aware that we are advancing towards anything he dislikes; nor do more witl lnim, while in the act of shying, than is necessary for due restraint with a steady hand upon the rein. We may depeud upou it, that battling on our part will only serve to augment affight and arouse resistance on his, and that the most judicious course we can pursue is to persevere in mild forbearant usage.

Shying on coming out of the stable is a habit that can rarely or never be cured. It proceeds from the remembrance of some ill-usage or hurt which the animal has received in the act of proceeding from the stable, such as striking his lead against a low doorway, or entangling the harness. Coercion will but associate greater fear and more determined resistance with the old recollection. Mr. Castley gives an interesting anecdote, which tends to prove that while severity will be worse than useless, even kind treatment will not always break a confirmed habit. "I remember a very fine grey mare that had got iuto this habit, and never could be persuaded to go through a doorway without taking an immense jump. To avoid this, the servants used to back her in and out of the stable; but the mare hapnening to meet with a severe injury of the spine, was no longer able to back; and then I have seen the poor creature, when brouglt to the door, endeavouring to balance herself, with a staggering motion, upon her halfparalysed hind extremities, as if making preparation and summoning up resolution for some great effort; and then, when urged, she would plunge headlong forward with such violence of exertion, as often to lose her feet, and tumble down, altogether most pitiable to be seen. This I merely mention," he continues, "as one proof how inveterate the habits of horses are. They are evils, let it always be remembered, more easy to prevent than to cure."

When the cure, howerer, is early attempted, it may be so far overcome that it will be unattended with danger or difficulty. The horse should be bridled when led out or in. He should be held short and tight by the liead, that he may feel he has not liberty to make a leap, and this of itself is often sufficient to restrain him. Punishment or a threat of punishment will be highly improper. It is only timid or high-spirited horses that aequire this habit, and rough usage invariably increases their agitation and terror. Some may be led out quite at leisure when blindfolded; others when they have the harness bridle on; some will best take their own way; and a few may be ridden through the doorway that cannot be led. I3y quietness and kindness, however, the horse will be most easily and quickly subdued.

\section{SLIPPING THE COLLAR.}

This is a trick at which many horses are so clever that scarcely a niglit passes without their getting loose. It is a very serious habit, for it enables the horse sometimes to gorge himself with food, to the imminent danger of staggers; or it exposes him, as he wanders about, to be kicked and injured by the other horses, while his restless. ness will often keep the whole team awake. If the web of the halter, being first accurately fitted to his neck, is suffered to slip only one way, or a strap is attached to the halter and buckled round the neck, but not sufficiently tight to be of serious inconvenience, the power of slipping the collar will be taken away.

\section{TRIPPING.}

He nutst be a skilful practitioner or a mere pretender who promises to remedy this habit. If it arises from a heary forehand, and the fore legs being too much under the horse, no one can alter the natural frame of the auimal: if it proceeds from tenderness of the foot, grogginess, or old lameness, these ailments are seldom cured. Also, if it is to be traced to labitual carelessness and idleness, no whipping will rouse the drone. A known stumbler should never be ridden, or driven by any one who values his safety or his life. A tight hand or a strong bearing-rein are precautious that should not be neglected, although they are generally of little avail ; for the inveterate stumbler will rarely be able to save himself, and this tight rein may sooner and farther precipitate the rider. If, after a trip, the horse suddenly starts forward, and endeavours to break into a sharp trot or canter, the rider or driver may be assured that others before him have fruitlessly endeavoured to remedy the nuisance.

If the stumbler has the foot kept as short and the toe pared as close as safety will permit, and the shoe is rounded at the toe, or has that shape given to it which it naturally acquires in a fortnight from the peculiar action of such a horse, the animal may not stumble quite so much; or if the disease which produced the habit can be alleviated, some trifling good may be done; but in almost every case a stumbler should be got rid of, or put to slow and heary rork. If the latter alteruative is adopted, 
he may trip as much as he pleases, for the weiglt name which is given to this peculiar and incessant of the load and the motion of the other horses will and unpleasant action. It indicates an impatient, keep him upon his legs.

\section{WEAVING.}

This consists in a motion of the head, neck, and body, from side to side, like the shuttle of a weaver passing through the web, and hence the irritable temper, and a dislike to the confinement of the stable. A horse that is thus incessantly on the fret will seldom carry flesh, or be safe to ride or drive. There is no cure for it, but the close tying up of the animal, or at least allowing him but one loose rein, except at feeding-time.

\section{CHAPTER XXIV.}

\section{THE GENERAL MANAGEMENT OF THE HORSE.}

THIs is a most important part of our subject, even as it regards the farmer, although there are comparatively few glaring errors in the treatment of the agricultural horse : lut it comes more especially home to the gentleman, who is too often and too implicitly under the guidance of an idle, and ignorant, and designing groom.

We will arrange the most important points of general management under the following heads :

AIR.

The breathing of pure air is necessary to the existence and the health of man and beast. It is comparatively lately that this has been admitted even in the management of our best stalles. They have been close and hot and foul, instead of airy and cool and wholesome. The effect of several horses being shut up in the same stable is completely to empoison the air ; and yet, even in the present day, there are too many who carefully close every aperture by which a breath of fresh air can by possibility gain admission. In effecting this, even the key-hole and the threshold are not forgotten. What, of necessity, must be the consequence of this? Why! if one thought is bestowed on the new and dangerous character that the air is assuming, it will be too evident that sore throat, and swelled legs, and bad eyes, and inflamed lungs, and mange, and grease, and glanders, will scarcely ever be long out of that stable.

Let this be considered in another point of view. The horse stands twenty or two-and-twenty hours in this unnatural vapour bath, and then he is suddenly stripped of all his clothing, he is led into the open air, and there he is kept a couple of hours or more in a temperature fifteen or twenty degrees below that of the stable. Putting the inhumanity of this out of the question, must not the animal thus unnaturally and absurdly treated be subjected to rheumatism, catarrh, and various other complaints? Does he not often stand, hour after hour, in the road or the street, while his owner is warming himself within, and this perhaps after every pore has been opened by a brushing gallop, and his susceptibility to the painful and the injurious influence of cold has been excited to the utmost?

It is not so generally known, as it ought to be, that the return to a hot stable is quite as dangerous as the change from a heated atmosphere to a cold and biting air. Many a horse that has travelled without harm over a bleak country has been suddenly seized with inflammation and fever when he has, immediately at the end of his journey, been surmonded with heated and foul air. It is the sulden cliange of temperature, whether from heat to cold, or from cold to heat, that does the mischief, and yearly destroys thousands of horses.

Mr. Clark of Edinburgh was the first who adrocated the use of well ventilated stables. After hin Professor Coleman established them in the quarters of the cavalry troops; and there cannot be a donbt that he saved the Government many thousand pounds every year. His system of ventilation, however, like many other salutary innovations, was at first strongly resisted. Much evil was predicted; but, after a time, diseases that used to dismount whole troops almost entirely disappeared from the army.

The stable should be as large, compared with the number of horses that it is destined to contain, as circumstances will allow. A stable for six horses should not be less than forty feet in length, and thirteen or fourteen feet wide. If there is no loft above, the inside of the roof should always be plastered, in order to prevent direct currents of air and occasional droppings from broken tiles. The heated and foul air should escape, and cool and pure air be admitted, by elevation of the central tiles ; or by large tubes carried through the roof, with caps a little above them, to prevent the beating in of the rain; or by gratings placed high up in the walls. These latter apertures should be as far above the horses as they can conveniently be placed, by which means all injurious draught will be prevented.

If there is a loft above the stable, the ceiling should be plastered, in order to prevent the foul air from penetrating to the hay above, and injuring 
both its taste and its wholesomeness; and no openings should be allowed above the racks, though which the hay may be thrown into them; for they will permit the foul air to ascend to the provender, and also in the act of filling the rack, and while the horse is eagerly gazing upward for his food, a grass seed may fall into the eye, and produce considerable inflammation. At other times, when the careless groom has left open the trap-door, a stream of cold air beats down on the head of the horse.

The stable with a loft over it should never be less than twelve feet high, and proper ventilation should be secured either by tubes carried through the loft to the roof, or by gratings close to the ceiling. These gratings or openings should be enlarged or contracted by means of a covering or shutter, so that during spring, summer, and antumn, the stable may possess nearly the same temperature with the open air, and in winter a temperature of not more than ten degrees above that of the external atmosphere.

A hot stable has, in the mind of the groom, been loug connected with a glossy coat. The latter, it is thought, cannot be obtained without the former.

'To this we should reply that, in winter, a thin, glossy coat is not desirable. Nature gives to every animal a warmer clothing when the cold weather approaches. The horse-the agricultural horse especially-acquires a thicker and a lengthened coat, in order to defend him from the surrounding cold. Man puts on an additional and a warmer covering, and his comfort is increased and his health preserved by it. He who knows anything of the farmer's horse, or cares about his enjoyment, will not object to a coat a little longer and a little roughened when the wintzy wind blows bleak. The coat, however, needs not to be so loug as to be unsightly; and warm clothing, even in a conl stable, will, with plenty of honest grooming, keep the hair sufficiently smooth and glossy to satisfy the most fastidious. The over-heated air of a close stable sares much of this grooming, and therefore the idle attendant unscrupulously sacrifices the health and safety of the horse. When we have presently to treat of the hair and skin of the horse, this will be placed in a somewhat different point of view.

If the stable is close, the air will not only be hot, but foul. The breathing of every animal contaminates it; and when, in the course of the night, with every aperture stopped, it passes again and again through the lungs, the blood cannot undergo its proper and healthy change; digestion will not be so perfectly performed, and all the functions of life are injured. Let the orner of a raluable horse think of his passing twenty or twenty-two out of the twenty-four hours in this debilitating atmesphere! Nature does wonders in enabling every aninal to accommodate itself to the situation in which it is placed, and the horse that lives in the stable-oven suffers less from it than would scarcely be conceived possible; but he does not, and cannot, possess the power and the hardihood which he would acquire under other circum. stances.

The air of the improperly close and heated stable is still farther contaminated by the urine and dung, which rapidly ferment there, and give out stimulating and unwholesome vapours. When a person first enters an ill-managed stable, and especially early in the morning, he is annoyed, not only by the heat of the confined air, but by a pungent smell, resembling hartshorn; and can he be surprised at the inflammation of the ejes, and the cluronic cough, and the disease of the lungs, by which the animal, who bas been all night shut up in this vitiated atmosphere, is often attacked; or if glanders and farcy should occasionally break out in such stables? It has been ascertained by chemical experiment that the urine of the horse contains in it an exceedingly large quantity of hartshorn; and not only so, but that, influenced by the heat of a crowded stable, and possibly by other decompositions that are going forward at the same time, this ammoniacal vapour begins to be rapidly given out almost immediately after the urine is voided.

When disease begins to appear among the in. habitants of these ill-ventilated places, is it wonderful that it should rapidly spread among them, and that the plague-spot should be, as it were, placed on the door of such a stable? When distemper appears in spring or in autumn, it is in very many cases to be traced to sucli a pest-house. It is peculiarly fatal there. The horses belonging to a small establishment, and rationally treated, have it comparatively seldom, or have it lightly; but among the inmates of a crowded stable it is sure to display itself, and there it is most fatal. The experience of every veterinary surgeon, and of every large proprietor of horses, will conoborate this statement. Agriculturists should bring to their stables the common sense which directs them in the usual concerns of life, and should begin, when their pleasures and their property are so much at stake, to assume that authority and to enforce that obedience, to the lack of which is to be attributed the greater part of bad stable-management and horse-disease. Of nothing are we more certain than that the majority of the maladies of the horse, and those of the forst and most fatal character, are directly or indirectly to be attributed to a deficient supply of air, cruel exaction of work, and insufficient or bad fare. Each of these evils is to be dreaded-each is, in a manner, watching for its prey; and when they are combined, more 
than half of the inmates of the stable are often swept away.

Every stable should possess within itself a certain degree of ventilation. The cost of this would be trifling, and its saving in the preserration of valuable animals may be immense. The apertures need not be large, and the whole may be so contrived that no direct current of air shall fall on the horse.

A gentleman's stable should never be without a thermometer. The temperature should seldom exceed $70^{\circ}$ degrees in the summer, or sink below $40^{\circ}$ or $50^{\circ}$ in the winter.

\section{LITTER.}

Having spoken of the vapour of hartshorn, which is so rapidly and so plentifully given out from the urine of a horse in a heited stable, we next take into consideration the sulyject of litter. The first caution is frequently to remove it. The early extrication of gas shows the rapid putrefaction of the urine; and the consequence of which will be the rapid putrefaction of the litter that has been moistened by it. Everything hastening to decomposition should be carefully remored where life and health are to be preserved. The litter that has been much wetted or at all softened by the urine, and is beginning to decay, should be swept away every morning; the greater part of the remainder may then be piled under the manger; a little being left to prevent the painful and injurious pressure of the feet on the hard parement during the day. The soiled and macerated portion of that which was left should be removed at night. In the hetter kind of stables, however, the stalls should be completely emptied every morning.

No heap of fermenting dung should be suffered to remain during the diny in the corner or in any part of the stable. With regard to this the directions of the master should be peremptory.

The stable should be so contrived that the urine shall quickly rui off, and the offensive and injurious vapour from the decomposing fluid and the litter will thus be materially lessened; if, however, the urine is carried away by means of a gutter running along the stable, the floor of the stalls must slant towards that gutter, and the declivity must not be so great as to strain the back sinews. and become an occasional, although unsuspected, cause of lameness. Mr. R. Lawrence trell observes, that, "if the reader will stand for a fer minutes with his toes higher than his heels, the pain he will feel in the calves of his legs will soon convince him of the trutl of this remark. Hence, when a horse is not eating, he always endeavours to find his level, either by standing across the stall or else as far back as his halter will permit, so that his lind-legs may meet the ascent of the other side of the channel."
This inclination of the stall is also a frequent cause of contraction of the heels of the foot, by throwing too great a proportion of the weight upon the toe and removing that pressure on the heels which tends most to keep them open. Care, thereforc, must be taken that the slanting of the floor of the stalls shall be no more than is sufficient to drain off the urine with tolerable rapidity. Stalls of this kind certainly do best for mares; but for horses we much prefer those with a grating in the centre, and a slight inclination of the floor on every side towards the middle. A short branch may communicate with a larger drain, by means of which the urine may be carried off to a reservoir outside the stable. Traps are now contrived, and may be procured at little expense, by means of which neither any offensive smell nor current of air cam pass through the grating.

The farmer should not lose any of the urine. It is from the dung of the horse that he derives a principal and the most valuable part of his manure. It is that which earliest takes on the process of putrefaction, and forms one of the strongest and most durable dressings. That which is most of all concemed with the rapidity and the perfection of the decomposition is the urine.

Humanity and interest, as well as the appearance of the stable, should induce the proprietor of the horse to place a moderate quantity of litter under him during the day. The farmer who wants to convert every otherwise useless substance into manure, will have additional reason for adopting this practice: especially as he does not confine himself to that to which in towns and in gentlemen's stables custom seems to have limited the bed of the horse. Pea and bean haum, and potatotops, and heath, occupy in the stable of the farmer, during a part of the year, the place of wheaten and oaten straw. It should, however, be remembered, that these sulstances are disposed more easily to ferment and putrefy than straw, and therefore should be more carefully examined and oftener removed. It is the faulty custom of some farmers to let the bed accumulate until it reaclies almost to the horse's belly, and the bottom of it is a mass of dung. If there were not often many a hole and cranny through which the wind can enter and disperse the foul air, the health of the animal would materially suffer.

\section{ITGHT.}

This neglected branch of stable-management is of far more consequence than is generally imagined; and it is particularly neglected by those for whom these treatises are principally designed. The farmer's stable is frequently destitute of any glazed window, and has only a shutter, which is raised in warm weather, and closed when the weather becomes cold. When the horse is in the 
staole only during a few hours in the day, this is not of so much consequence, nor of so much, probably, with regard to horses of slow work; but to carriige-horses and lackneys, so far, at least, as the eyes are concerned, a dark stable is little less injurious than a foul and heated oue. In order to illustrite this, reference may be made to the unpleasant feeliug, and the utter impossibility of seeing distinctly, when a man suddeuly emerges from a dark place into the full blaze of day. The scnsation of mingled pain and girldiness is not soon forgotten; and some minutes pass before the eye can accommodate itself to the increased light. If this were to happen every day, or several times in the day, the sight would be irreparably injured, or possibly blindness would ensue. Can we wonder, then, that the lorse, taken from a dark stable into a glare of light, feeling, probably, as we should do under similar circumstances, and unable for a considerable time to see anything around him distinetly, should lecome a starter, or that the frequently repeated violent effect of sudden light should induce inflammation of the eye so inteuse as to terminate in blindness? There is, iudeed, no doubt that lorses kept in dark stables are frequently notorious starters, and that abominable luabit has been properly traced to this cause.

Farmers know, and should profit by the knowledge, that the darkness of the stable is not unfrequently a cover for great uncleanliness. A glazed window, with leaden divisions between the small panes, would not cost much, and would admit a degree of light somewhat more approaching to that of day, and at the same time would render the concealment of gross inattention and want of cleanliness impossible.

If plenty of light is admitted, the walls of the stable, and especially that portion of them which is before the horse's head, must not be of too glaring a colour. The constant reflection from a white wall, and especially if the sun shines into the stable, will be as injurious to the eje as the sudlen clianges from darkness to light. The perpetual slight excess of stimulus will do as much mischief as the occasional but more violent one when the animal is taken from a kind of twilight to the blaze of dar. The colour of the stalle, therefore, should depend on the quantity of light. Where much cau be almitted, the walls slould be of a grey hue. Where darkness would otherwise prevail, freyuent whitewashiug may in some degree dissipate the gloom.

For anotler reason it will be evident that the stalile should not possess too glaring a light : it is the resting-place of the horse. The work of the farmer's horse, indeed, is confined principally to the day. The hour of exertion having passed, the animal returus to his stable to feed and to repose, and the latter is as necessary as the former, in order to prepare him for renewed work. Something approaching to the dimness of twilight is requisite to induce the animal to compose himself to sleep. This lialf-light more pitrticularly suits lorses of heavy work, and who draw almost as much by the weight of carcass which they can throw into the collar, as by the degree of muscular energy of which they are capable. In the quietness of a dimly-lighted stable they obtain repose, and accumulate flesh and fat. Dealers are perfectly aware of this. They have their darkened stables, in which the young horse, with little or no exercise, and fed upon mashes and ground corn, is male up for sale. The round and plump appearance, however, which may delude the unwary, soon vanishes with altered treatmeut, and the animal is found to be unfit for hard work, and predisposed to many an inflammatory disease. The circumstances, then, under which a stable somewhat dalkened may be allowed, will be easily determined by the owner of the horse; but, as a general rule, dark stables are unfriendly to cleanliuess, and the frequent cause of the vice of starting, and of the most serious diseases of the eyes.

\section{GROONING.}

Of this much need not be said to the agriculturist, since custom, and, apparently without ill effect, has allotted so little of the comb and brush to the farmer's horse. 'The animal that is worked all day, and turned out at night, requires little more to be done to him than to have the dirt bruslied off his limbs. Pegular grooming, by rendering his skin more sensible to the alteration of temperature, and the inclemency of the reather, would be prejudicial. The horse that is altogether turued out needs no grooming. The dandriff or scurf which accumulates at the roots of the hair, is a provision of nature to defend him from the wind and the cold.

It is to tlie stabled horse, highly fed, and little or irregularly worked, that grooming is of so much consequence. Good rubbing with the brush or the curry-comb opens the pores of the skin, circulates the blood to the extremities of the boly, produces free and healthy perspiration, and stands in the room of exercise. No horse will carry a tine coat without either uunatural heat or dressing. They both effect the same purpose; they both increase the insensible perspiration: but the first does it at the expense of health and streugth, while the second, at the same time that it produces a glow on the skin, and a determiuation of blood to it, rouses all the energies of the frame. It would be well for the proprietor of the horse if he were to insistand to see that his orders are really obeyed-that the fine eoat in which he and his groom so much delight, is produced by honest rubbing, and not by a heated stable and thick clothing, and most of all, not by stimulating or injurious spices. The horse 
should be regularly dressed every day, in acldition to the grooming that is necessary after work.

When the weather will permit the horse to be taken out, he should never be groomed in the stable, unless he is an animal of peculiar value, or placed for a time under peculiar circumstances. Without dwelling on the want of cleanliness, when the scurf and dust that are brushed from the horse lodge in his manger, and mingle with his food, experience teaches, that if the cold is not too great, the animal is bracel and invigorated to a degree that cannot be attained in the stable, from being dressed in the open air. There is no necessity, however, for half the punishment which many a groom inflicts upon the horse in the act of dressing ; and particularly on one whose skin is thin and sensible. The curry-comb should at all times be lightly applied. With many horses its use may be almost dispensed with; and even the brush needs not to be so hard, nor the points of the bristles so irregular as they often are. A soft brush, with a little more weight of the hand, will be equally effectual, and a great deal more pleasant to the horse. A hair-cloth, while it will seldom irritate and tease, will be almost sufficient with horses that have a thin skin, and that have not been neglected. After all, it is no slight task to dress a horse as it ought to be done. It occupies no little time, and demands considerable patience, as well as dexterity. It will be readily ascertained whether a horse has been well dressed by rubbing him with one of the fingers. A greasy stain will detect the idleness of the groom. When, howerer, the horse is changing his coat, both the curry-comb and the brush should be used as lightly as possible.

Whoever would be convinced of the benefit of friction to the horse's skin, and to the horse generally, needs only to observe the effects produced by well hand-rubbing the legs of a tired horse. While every enlargement subsides, and the painful stiffness disappears, and the legs attain their natural warmth, and become fine, the animal is evidently and rapidly reviving; he attacks his food with appetite, and then quietly lies down to rest.

\section{EXERCISE.}

Our observations on this important branch of stable-management must have only a slight reference to the agricultural horse. His work is usually regular and not exhausting. $\mathrm{He}$ is neither predisposed to disease by idleness, nor worn out by excessive exertion. He, like his master, has enough to do to keep, him in health, and not enough to distress or injure him: on the contrary, the regularity of his work prolongs life to an extent rarely witnessed in the stable of the gentleman. Our remarks on exercise, then, must have a general bearing, or have principal reference to those persons who are in the middle stations of life, and who contrive to keep a horse for business or pleasure, but cannot afford to maintain a servant for the express purpose of looking after it. The first rule we would lay down is, that every horse should have daily exercise. The animal that, with the usual stable feeding, stands idle for three or four days, as is the case in many establishments, must suffer. $\mathrm{He}$ is predisposed to fever, or to grease, or, most of all, to diseases of the foot; and if, after three or four days of inactivity, he is ridden far and fast, he is almost sure to have inflammation of the lungs or of the feet.

A gentleman or tradesman's horse suffers a great deal more from idleness than he does from work. A stable-fed horse should have two hours' exercise every day, if he is to be kept free from disease. Nothing of extraordinary or even of ordinary labour can be effected on the road or in the field without sufficient and regular exercise. It is this alone which can give energy to the system, or develop the powers of any animal.

How then is this exercise to be given? As much as possible by, or under the superintendence of the owner. The exercise given by the groom is rarely to be depended upon. It is inefficient or it is extreme. It is in many cases both irregular and injurious. It is dependent upon the caprice of him who is performing a task, and who will render that task subservient to his own pleasure or purpose.

In training the hunter and the race-horse, regular exercise is the most important of all considerations, however it may be forgotten in the usual management of the stable. The exercised horse will discharge his task, and sometimes a severe one, with ease and pleasure; while the idle and neglected one will be fatigued ere half his labour is accomplished, and, if he is pushed a little too far, dangerous inflammation will ensue. How often, nevertheless, does it happen, that the horse which has stood inactive in the stable three or four days, is ridden or driven thirty or forty miles in the comse of a single day! This rest is often purposely given to prepare for extra exertion ;to lay in a stock of strength for the performance of the task required of him: and then the owner is surprised and dissatisfied if the animal is fairly knocked ap, or possibly becomes seriously ill. Nothing is so common and so preposterous, as for a person to buy a horse from a dealer's stable, where he has been idly fattening for sale for many a day, and immediately to give him a long run after the hounds, and then to complain bitterly, and think that he has been imposed upon, if the animal is exhausted before the end of the chase, or is compelled to be led home suffering from violent inflammation. Regular and gradually increasing exercise would have made the same horse appear a treasure to his owner. 
Exercise should be somewhat proportioned to the age of the horse. A young horse requires more than an old one. Nature has given to young animals of evcry kind a disposition to activity; but the exercise must not be violent. A great deal depends upon the manner in which it is given. To preserve the temper, and to promote bealth, it should be moderate, at least at the beginning and the termination. The rapid trot, or even the gallop, may be resorted to in the middle of the exercise, but the lorse should be brought in cool. If the owner would seldom intrust his horse to boys, and would insist on the exercise being taken within sight, or in the neighbourhood of his residence, many an accident and irreparable injury wonld be avoided. It should be the owner's pleasure, and it is lis interest, personally to attend to all these things. He manages every other part of his concerns, and he may depend on it that he suffers when he neglects, or is in a manner excluded from, his stables.

FOOD.

The system of manger-feeding is becoming general among farmers. There are few horses that do not habitually waste a portion of their hay; and by some the greater part is pulled down and trampled under foot, in order first to cull the sweetest and best locks, and which could not be done while the hay was enclosed in the rack. A good feeder will afterwards pick up much of that which was thrown down; but some of it must be soiled and rendered disgusting, and, in many cases, one-third of this division of their food is wasted. Some of the oats and beans are imperfectly chewed by all horses, and scarcely at all by hungry and greedy ones. The appearance of the dung will sufficiently evince this

The olservation of this induced the adoption of manger-feeding, or of mixing a portion of chaff with the corn and beans. By this means the animal is compelled to chew his food ; he cannot, to any great degree, waste the straw or hay: the chaff is too hard and too sharp to be swallowed without considerable mastication, and, while he is forced to grind that down, the oats and beans are ground with it, and yield more nourishment; the stomach is more slowly filled, and therefore acts better on its contents, and is not so likely to be overloaded; and the increased quantity of salira thrown out in the lengthened maceratiou of the food, softens it, and makes it more fit for digestion.

Professor. Stewart very properly remarks that " many horses swallow their corn in great haste, and when much is eaten that habit is exceedingly dangerous. The stomach is filled-it is overloaded before it has time to make preparation for acting on its contents-the food ferments, and painful or dangerous colic ensues. By adding chaff to his com, the horse must take more time to eat it, and time is given for the commenecment of digestion, lefore fermentation can occur. In this way chaff is very useful, especially after long fasts." *

If, when considerable provender was wasted, the horse maintained his condition, and was able to do his work, it was evident that much might be saved to the farmer, when he adopted a system by which the horse ate all that was set lefore him; and by degrees it was found out, that even food somewhat less nutritious, but a great deal clieaper, and which the horse either would not eat, or would not properly grind down in its natural state, might be added, while the animal would be in quite as good plight, and always ready for work.

Chaff may lie composed of equal quantities of clover or meadow hay, and wheaten, oaten, or barley straw, cut into pieces of a quarter or half an inch in length, and mingled well together; the allowance of oats or beans is afterwards added, and mixed with the chaff. Many farmers very properly bruise the oats or beans. The whole oat is apt to slip out of the chaff and be lost; but when it is bruised, and especially if the chaff is a little wetted, it will not readily separate; or, should a portion of it escape the grinders, it wi!l be partly prepared for digestion by the act of bruising. The prejudice against bruising the oats is, so far as the farmer's horse, and the waggon horse, and every horse of slow dranght, are concerned, altogether unfounded. The quantity of straw in the chaff will always counteract any supposed purgative quality in the bruised oats. Horses of quicker dranght, except they are naturally disposed to scour, will thrive better with bruised than with whole oats; for a greater quantity of nutriment will be extracted from the food, and it will always be easy to apportion the quantity of straw or beans to the effect of the mixture on the bowels of the horse. The priucipal alteration that should be made in the horse of harder and more rapid work, such as the post-horse, and the stage-coach horse, is to increase the quantity of hay, and diminish that of straw. Two trusses of hay may be cut with one of straw.

Some gentlemen, in defiance of the prejudice and opposition of the coachman or the groom, have introduced this mode of feeding into the stables of their carriage horses and hackneys, and with manifest advantage. There has been no loss of condition or power, and considerable saving of provender. This system is not, however, calculated for the hunter or the race-horse. Their food must lie in smaller bulk, in order that the action of the lungs may not be impeded by the distension of the stomach; yet many hunters have gone well

* Stewart's Stable Economy, p. 225. 
over the field who have been manger-fed, the proportion of corn, however, being materially increased.

For the agricultural and cart horse, eight pounds of oats and two of beans should be added to every twenty pounds of chaff. Thirty-four or thirty-six pounds of the mixture will be sufficient for any moderate-sized horse, with fair, or even hard work. The dray and waggon horse may require forty pounds. Hay in the rack at night is, in this case, supposed to be omitted together. The rack, however, may remain, as occasionally useful for the sick horse, or to contain tares or other green meat.

Horses are very fond of this provender. The majority of them, after having been accustomed to it, will leave the best oats given to them alone, for the sake of the mingled chaff and corn. We would, however, caution the farmer not to set apart too much damaged hay for the manufacture of the chaff. The horse may be thus induced to eat that which he would otherwise refuse; but if the nourishing property of the hay has been impaired, or it has acquired au injurious principle, the animal will either lose condition, or become diseased. Much more injury is done by eating damaged hay or musty oats than is generally imagined. There will be sufficient saving in the diminished cost of the provender by the introduction of the straw, and the improved condition of the horse, without poisoning him with the refuse of the farm. For old horses, and for those with defective teeth, chaff is peculiarly useful, and for them the grain should be broken down as well as the forder.

While the mixture of chaff with the corn prevents it from being too rapidly devoured and a portion of it swallowed whole, and therefore the stomach is not too loaded with that ou which, as containing the most nutriment, its chief digestive power should be exerted, yet, on the whole, a great deal of time is gained by this mode of feeding, and more is left for rest. When a horse comes in wearied at the close of the day, it occupies, after he has eaten his corn, two or three hours to clear his rack. On the system of manger-feeding, the chaff being already cut into small pieces, and the beans and oats bruised, he is able fully to satisfy his appetite in an hour and a half. 'Two additional hours are therefore devoted to rest. 'I'his is a circumstance deserving of much consideration even in the farmer's stable, and of immense consequence to the postmaster, the stage-coach proprietor, and the owner of every hard-worked horse.

Manger food will he the usual support of the farmer's horse during the winter, and while at constant or occasional hard work: but from the middle of April to the end of July, he may be fed with this mixture in the day and turned out at night, or he may remain out during every restday. A team in constant employ should not, however, be suffered to be out at night after the end of July.

The farmer should take care that the pasture is thick and good; and that the distance from the yard is not too great, or the fields too large, otherwise a very considerable portion of time will be occupied in catching the horses in the morning. He will likewise have to take into consideration the sale he would have for his hay, and the necessity for sweet and untrodden pasture for his cattle. On the whole, however, turning out in this way, when circumstances will admit of it, will be found to be more beneficial for the horse, and cheaper than soiling in the yard.*

The horse of the inferior farmer is sometimes fed on hay or grass alone, and the animal, although he rarely gets a feed of corn, maintains himself in tolerable condition, and does the work that is required of him: but hay and grass alone, however good in quality, or in whatever quantity allowed, will not support a horse under hard work.

Other sulstances containing a larger proportion of nutriment in a smaller compass, have been added. They shall be briefly enumerated, and an estimate formed of their comparative value.

In almost every part of Great Britain, oats have been selected as that portion of the food which is to afford the principal nourishment. They contain seven hundred and forty-three parts out of a thousand of nutritive matter. They should be about or somewhat less than a year old, heavy, dry, and sweet. New oats will weigh ten or fifteen per cent. more than old ones; but the difference consists principally in watery matter, which is gradually evaporated. New oats are not so readily

* Professir Stewart thus sums ap the comparatire ailvantage of chaff and racked feeding :-

"Where the stablemen are careful, waste of fodder is diminished, but not prevented, by feeding from the manger.

"Where the racks are gnod, careful stublemen may prevent nearly all waste of fudder withont ontting it.

"An acourate distribution of the fodder is not a very important olject.

"No horse seems to like his corm the better for being uningled with chaff.

"Aming half-starved horses chaff-cutting promotes the consumpition of damaged fodder.

"Full-fed horses, rather than eat the mixture of sound with unsound, will reject the whole, or eat less than their work demands.

"Chaff is more easily eaten than hay. This is an advantage to old horses and others working all duy - a disadvantage when the horses stand long in the stable.

"Chaff insures complete matication and delibcratc digestion of the corn. It is of considerable, and of most importance in this respect. All the fodder needs not to be mingled with the corn, one pound of chaff being sufficient to secure the mastioation and slow ingestion of four pounds of torn.

"The cost of cutting all the fodder, especially for heavy horses, is repaid only when hay is dear, and wasted in large quautities

"Among bard-womking horses bad food should never be cut." -Stevart's Slable Eiconomy, p. 225. 
ground down lyy the teeth as old ones. They form a more glutinous miss, difficult to digest, and, when eaten in considerable quantities, are apt to occasion colic and even staggers. If they are to be used before they are from three to five months old, they would he materially improved by a little kiln-drying. There is no fear for the liorses from simple drying, if the corn was good when it was put in the kill. The old oat forms, when chewed, a smooth and uniform mass, which readily dissolves in the stomach, and yields the nourishmeut which it contains. Perhaps some chemical change may have been slowly effected in the old oat, disposiug it to be more readily assimilated. Oats should be plump, bright in colour, and free from unpleasant smell or taste. The musty smell of wetted or damaged corn is produced by a fungus which grows upon the seed, and which has an imjurious effect on the nrinary organs, and often on the intestines, producing profuse staling, inflammation of the kilueys, colic, and inflummation of the bowels.

This musty smell is removed by kiln-drying the oat; but care is here requisite that too great a degree of heat is not employed. It should be sufficient to destroy the fungus without injuring the life of the seed. MIany persons, but without just cause, have considerable fear of the kiln-burnt oat. It is said to produce inflammation of the bladder, and of the eyes, and mangy affections of the skin. The fact is, that many of the kiln-dried oats that are given to horses were damaged before they were dived, and thus beame unhealthy. A considerable improvement would be effected, by cutting the unthreshed oat-straw into chaff, and the expense of threshing would be savel. Oat-straw is better thin that of barler, but does not contain so much nutriment as that of wheat.

When the horse is fed on hay and oats, the quantity of the oats must vary with his size and the work to be performed. In winter, four feeds, or from ten to fourteen pounds of oats in the day, will be a fair allowance for a horse of fifteen hands one or two inches high, and that lias moderate work. In summer, half the quantity, with green food, will be sufficient. Those who work on the farm have from ten to fourteen pounds, and the hunter from twelve to sixteen. There are no efficient and safe substitutes for good oats; but, on the contrary, we are much inclined to believe that they possess an invigorating property which is not found in other food.

Oatmeal will form a poultice more stimulating than oue composed of linseed meal aloue-or they may be mingled in different proportions as circumstances require. In the form of gruel it constitutes one of the most important articles of diet for the sick horse-not, indeed, forced upon him, bat a pail containing it being slung in his box, vist I. and of which he will soon begin in dlink when water is denied. Few groons wake gosd gruel; it is either not boiled long enough, or a sufficient quantity of oatmeal has not heen used. The proportions should be, a pound of treal thrown ints a gallon of water, anl kejt constantly stirred until it boils, an 1 five minutes afterwards.

White-water, made by stirring a pint of oatmeal in a pail of water, the chill being taken from it, is an excellent beverage for the thirsty and tired horse.

Barley is a common food of the horse on varions parts of the Continent, aud, until the introduction of the oat, seems to have constituted almost his only food. It is more nutritions than oats, containing nine hundred and twenty parts of nutritive matter in every thousand. There seems, however, to be something necessary besides a great proportion of nutritive matter, in order to render any substance wholesome, strengthening, or futtening; therefore it is that, in many horses that are hardly worked, and, indeed, in horses generally, barley does not agree with them so well as oats. They are occasionally subject to intlammatoiy complaints, and particularly to surfeit and mange.

When barley is given, the quantity should not exceed a peck daily. It should alwars be bruised, and the chaff should consist of equal quantities of hay and barley-straw, and not cut too slort. If the farmer has a quantity of spotted or unsaleable barley that he wishes thus to get rid of, he must very gradually accustom his horses to it, or he will probably produce serions illness among them. For horses that are recovering from illness, barler, in the form of malt, is often serviceable, as tempting the appetite and recruiting the strength. It is best given in mashes-water, considerably below the boiling heat, being poured upon it, and the vessel or pail kept covered for half an hour.

Grains fresh from the mash-tub, either alone, or mixed with oats or chaff, or both, my be occasionally given to horses of slow dianght; they woukl, however, afford very insufficient nourishment for horses of quicker or harder work.

Wheat is, in Great Britain, more rarely given than barley. It contains nine hundred and fiftyfire parts of nutritive matter. When furmers have a damaged or unmarketable sample of wheat, they sometimes give it to their horses, and, being at first used in small quantities, they become ac customed to it, and thrive and work well : it must, however, always be bruised and given in chaft. Whent contains a greater portion of gluten, or sticky athesive matter, than any other kind of griain. It is difficult of digestion. and apt to cake and form obstructions in the bowels. This will oftener be the case if the lorse is suffered to drints much water soon after feeding upon wheat.

Fermentation, colic, and death, are occasionally I. I 
the consequence of eating any great quantity of wheat. A horsethat is fed on wheat should have very little hay. The proportion should not be more than one truss of hay to two of straw. Wheaten flower, boiled in water to the thickness of starch, is given with good effect in over-purging, and especially if combined with chalk and opium.

Bran, or the ground husk of the wheat, used to be frequently given to sick horses on account of the supposed advantage derived from its relaxing the bowels. There is no doubt that it does operate gently on the intestinal canal, and assists in quickening the passage of its contents, when it is occasionally given; but it must not be a constant, or even frequent food. Mr. Ernes attended three mills at which many horses were kept, and there were always two or three eases of indigestion from the accumulation of brand or pollard in the large intestines. Bran may, however, be useful as an occasional aperient in the for'm of a mash, liut never shonld become a regular article of food.

Beans. - These form a striking illustration of the principle, that the nourishing or strengthening effects of the different articles of food depend more on some peculiar property which they possess, or some combination which they form, than on the actual quantity of nutritive matter. Beans contain but fire lundred anl seventy parts of nutritive matter, yet they add materially to the vigour of the horse. There are many horses that will not stand hard work without beans being mingled with their food, and these not horses whose tendency to purge it may be necessary to restrain by the as. tringency of the bean. 'There is no traveller' who is not aware of the difference in the spirit and continuance of his horse whether he allows or denies him beans on his joumey. They afford not merely a temporary stimulus, but they may be daily used without losing their power, or producing exhanstion. They are indispensable to the hardworked coach-horse. Washy horses could never get through their work without them; and old horses would often sink under the task imposed upon them. They should not be given to the horses whole or split, but crushed. This will make a material difference in the quantity of nutriment that will be extracted. They are sometimes given to turf horses, but only as an occasional stimulant. Two pounds of beans mar, with advantige, he mixed with the chaff of the agricultural horse, during the wiuter. In summer the quantity of beans should be lessened, or they should be alto. gether discontimued. Beans are generally given whole. This is very absurd; for the roung horse, whose teeth are strong, seldinm requires them; while the old horse, to whom they are in a momner necessary, is scarcely able to masticate them, swallows many of them whole which he is unable to break, and drops much corn from his mouth in the ineffectual attempt to crush them Beans should not be merely split, but cruslied; they will even then give sufficient employment to the grinders of the animal. Some postmasters use chaff with beans instead of oats. With hardly. worked horses they may possibly be allowed ; but, in general cases, beans, without oats, would be too binding and stimulating, and would produce costiveness, and probably megrims or staggers.

Beans should be at least a twelvemonth old before they are given to the horse, and they should be carefulity preserved from damp and mouldiness, which at least disgust the horse if they do no other harm, and harbour an insect that destroys the inner part of the bean.

The straw of the bean is nutritive and wholesome, and is usually given to the horses. Its nutritive properties are supposed to be little inferior to those of oats. The small and plump bean is generally the best.

Peas are occasionally given. They appear to be in a slight degree more nourishing than beans, and not so heating. They contain five hundred and seventy-four parts of nutritive matter. For horses of slow work they may be used; but the quantity of chaff should be increased, and a few oats added. They have not been found to answer with horses of quick draught. It is essential that they should be crushed; otherwise, on account of their globular form, they are apt to escape from the teeth, and many are swallowed whole. Exposed to warnth and moisture in the stomach, they swcll considerably, and may painfully and injurionsly distend it. The peas that are giren to horses should be sound, and at least a twclvemouth old.

In some northern counties pea-meal is frequently used, not only as an excellent food for the horse, but as a remedy for diabetes.

Linsced is sometimes given to sick horsesraw, ground, and boiled. It is supposed to be useful in cases of catarill.*

Herbage, green and dry, constitutes a principal part of the food of the horse. There are few things with regard to which the furmer is so careless as the mixture of grasses on both his upland and meadow pasture. Hence we find, in the same field, the ray-grass, coming to perfection only in a loamy soil, not fit to cut until the middle or latter

* " Mr. Black, veterioury surgeon of the 14 th Dragoons, says that sugar was tried as an anti-le of foul during the Peniostriar War. Teahorses were selccted, each of which got 8 lbs. a day at fonr rations. They took it very readily, and their coats becane fine, smooth, and glussy. They got no corn, and only $7 \mathrm{lhs}$. of hay, instead of the ordinary allowance, whirh is $12 \mathrm{lhs}$. The sngar stemed to sniply the place of the corn so well, that it mouli have been probibly given abroad: but pence came, and the cirrumstances that rendercd the use af sugar for corn desirable ceased, and the horse's returned to their untal diet. That the sngar might not he appropiated to uther purposes it was slightly scented with assafretida, which rid not produce any apparent effect upon them." 
part of July, and yielding little aftermath; the meadow for-tail, best cultivated in a clayey soil, fit for the scythe in the beginning of June, and yielding a plentiful aftermath; the glancous fescncgrass, ready at the middle of Jume, and rapidly deteriorating in value as its seeds ripen; and the fertile meadow-grass, increasing in ralue until the end of July. These are circumstances the importance of which will, at no distant period, be recognised. In the mean time, Siuctair's account of the different grasses, or the condensation of the mast important part of his work in Sir Humphry Davy's Agricultural Chemistry, or Low's Elements of Practical Agriculture, are well deserving of the diligent perusal of the farmer.

Hay is most in perfection when it is about a twelvemonth old. The horse perhaps would prefer it earlier, but it is neither so wholesome, nor so nutritive, and often has a purgative quality. When it is about a year old, it retains or should retain somewhat of its green colour, its agreeable smell, and its pleasant taste. It has undergone the show process of fermentation, by which the sugar which it contains is dereloped, and its nutritive quality is fully exercised. Old hay becomes dry and tasteless, and innutritive and unwholesome. After the grass is cut, and the hay stacked, a slight degree of fermentation takes place in it. This is necessary for the development of the saccharine principle; but occasionally it proceeds too far and the hay becomes mow-burnt, in which state it is injurious, or even poisonous. The horse soon shows the effect which it has upon him. He has diabetes to a considerable degree-he becomes hide-bound-his strength is wasted-his thirst is excessire, and he is almost wortbless.

Where the system of manger-feediug is not adopted, or where hay is still allowed at night, and chaff and corn in the dar, there is no error into which the farmer is so apt to fall as to give an undue quantity of hay, and that generally of the worst kind. If the manger system is good, there can be no necessity for hay, or only for a small quantity of it; but if the rack is over-loaded, the greedy horse will be eating all night, instead of taking his rest-when the time for the morning feed arrives, his stomach will be already filled, and he will be less capable of work from the want of sleep, and from the long-continued distension of the stomach rendering it impossible for the food to be properly digested.

It is a good practice to sprinkle the hay with water in which salt has been dissolved. It is evidently more palatable to the animal, who will leave the best unsalted hay for that of an inferior quality that has been moistened with brine; and there can be no doubt that the salt very materially assists the process of digestion. The preferable way of salting the hay is to sprinkle it over the different layers as the rick is formed From its attrantion for wate:, it would combine with that excess of moisture which, in wet scasons, is the cause of too rapid and violent fermentation, and of the hay becoming morr-burnt, or the rick catcling fire, and it would become more incorporated with the hay. The only objection to its being thus used is, that the colour of the hay is not so bright; but this will be of little consequence for home con sumption.

Of the value of Tares, as forming a portion of the late spring and summer food of the stabled and agricultural horse, there can be no doubt. They are cut after the pods are formed, but a con siderable time before the seeds are ripe. They supply a larger quantity of food for a limited time than almost any other forage-crop. The ricia sativa is the most profitable variety of the tare. It is very nutritive, and acts as a gentle aperient. When surfeit-lumps appear on the skin, and the horse begins to rub himself against the divisions of the stall, and the legs swell, and the heels threaten to crack, a few tares, cut up with the chaff, or given instead of a portion of the hay, will afford considerable relief. Ten or twelve pounds may be allowed daily, and half that weight of hay subtracted. It is an erroneous notion, that, given in moderate quautities, they either roughen the coat or lessen the capability for hard work.

Rye Grass affords a valuable article of food, but is inferior to the tare. It is not so uutritive. It is apt to scour, and, occasionally, and late in the spring, it has appeared to be injurious to the horse.

Clover, for soiling the horse, is inferior to the tare and the rye grass, but, nevertheless, is useful when they canuot be obtained. Clover hay is, perhaps, preferable to meadow hay for chaff. It will sometimes tempt the sick horse, and may be given with advautage to those of slow and heary work; but custom seems properly to have forbidden it to the hunter and the hackney.

Lucern, where it can be obtained, is preferable even to tares, and Sain-foin is superior to lucern. Although they coutain but a small quautity of nutritive matter, it is easily digested, and perfectly assimilated. They speedily put both muscle and fat on the horse that is worn down by labour, and they are almost a specific for hide-bound. Some farmers have thought so highly of lucern as to sub stitute it for oats. This may be allowable for the agricultural horse of slow and not severe work, but he from whom speedier action is sometimes required, and the horse of all work, must have a proportion of hard meat within him.

The Swedish Turnip is an article of food the value of which has not been sufficiently appreciated, and particularly for agricultural horses, Although it is far from containing the quantity of 
nutritive matter which has been supposed, that whieh it has seems to be capable of easy and complete digestion. It should be sliced with chopped straw, aud without hay. It quickly fattens the horse, and produces a smooth glossy ccat and a loose slin. It will be good practice to give it once in the day, and that at night when the work is done.

Carrots.-The virtues of this root are not sufficiently known, whether as contributing to the strength and endurance of the sonnd horse, or the rapid recovery of the sick one. T'o the healthy horse they should be given sliced in his chaff. Half a bushel will be a fair daily allowance. There is little provender of which the horse is fonder. The following account of the value of the carrot is not exaggerated. "This root is held in much esteem. There is none better, nor perhaps so good. When first given it is slightly diuretic and laxative; but as the horse becomes aecnstomed to it these effects cease to be prodnced. They also improve the state of the skin. They form a gead substitute for grass, and an excellent alterative for horses out of coudition. To sick and idle horses they render corn umecessary. They are beneficial in all chronic diseases convected with breathing, and have a marked influence upon chronic caugh and broken wind. They are serviceable in diseases of the skin, and in combination with oats they restore a worn horse much sooner than oats alone."**

Potatoes have been given, and with advantage, in their raw state, sliced with the chaff; lont, where it has been convenient to boil or steam t'rem, the benefit has been far mare evident. Purging has them rarely ensued. Scme have given boiled potatoes alone, and horses, instead of rejecting them, have soon preferred them even to the oat; but it is better to mix them with the usual manger fced, in the proportion of one pound of polatoes to two and a half ponnds of the other ingredients. The use of the potato must depend on its cheapness, and the facility for boiling it. Half a dozen horses would soon repay the expeuse of a steaming boiler in the saving of provender, without taking into the account their improved condition and capability for work.t A horse fed on potatoes should have lis quantity of water materially curtailed.

Furze has sometimes been given during the winter months. There is considerable troulle attending the preparation af it, although its plentifulness and little value for other purposes would, on a large farm, well repay that trouble. The

* Stewart's Stable Economy, p. 183.

+ Prufessor Low silys that 15 lbs. of potatoes yield as much nourivimẻnt as four pounds and a half of oats. Von Thaver as. stits that three bushels are equal to $112 \mathrm{lbs}$. of hay; and Curwen, who tried potatops extensively in the fecding of burses, says that an acre goes as fur us futur acres of his. furze is cut down at about three or four years' growth; the green branches of that and the preceding year are bruised in a mill, and then given to the horses in the state in which they come from the mill, or cnt up with the chaff. Horses are very fond of it. If twenty pounds of the furze are given, five pounds of straw, the beans, and three pounds of the aats, may be withdrawn.

It may not be uninteresting to conclude this catalogne of the different articles of horse-food with a list of the quantities of nutritive matter contained in each of them; for although these quantities cannot be considered as expressing the actual value of each, because other circumstances besides the simple quantity of nutriment seem to influence their effect in supporting the strength and condition of the horse, yet many a useful lint may be derived when the farmer looks orer the praduce of his soil, and inquires what other grasses or vegetables might suit his land. The list is partly taken from Sir IIumphry Davy's Agricultural Clemistry :-1000 parts of wheat contain 955 parts of nutritive matter; barley, 920 ; oats, 743 ; peas, 574 ; beans, 570 ; potatoes, 230 ; red heet, 148 ; parsuips, 99 ; earrots, 98. Of the grasses, 1000 parts of the meadow eat's-tail contain, at the time of seeding, 98 parts of nutritive matter; narron-leared meadow grass in seed, and sweet-scented soft grass in flower, 95 ; narrow-leavel and flat-stalked meadow grass in flower, fertile mealow grass in seed, and tall fescue in tlower, 13 ; fertile meadow grass, meadow fescue, reed-like fescue, and creeping soft grass in flower, 78; sweet-scented soft grass in flower, and the aftermath, $i \gamma$; fiorin, cut in the winter, 76 ; tall fescne, in the aftermath, and meadow soft grass in flower, 74 ; cabhrage, 73 ; crested dog's-tril and lume when flowering, 71; yellow oat, in flawer, 66 ; Swedish turnips, 61 ; narrow-leaved meadow grass, creeping beet, romdheaded cocksfoot, and spiked fescue, 59 ; roughish and fertile meadow grass, flowering, 56; forin, in summer, 54 ; coummon tumips, 42 ; suin-foin, and broad-leaved and long-rooted clover, 39; white clover, 32 ; and lncern, 23.

The times of feeding should be as equally di vided as convenience will perruit; and when it is likely that the horse will be kept longer than nsual from home, the nose-bag should invariably be taken. The small stomach of the horse is emptied in a few hours; and if he is suffered to remain hungry much beyond his accustomed time, he will afterwarls devour his food so voraciously as to distend the stomach and endanger an attack of staggers. When this disease appears in the farmer's stable, he may attribute it to various causes; the true one, in the majority of instances, is irregularity in feeding. If the reader will turn back to p. 286, he will be eanvinced that this 
deserves more serious attention than is generally given to it.

When extra work is required from the animal, the system of management is of en injudicious, for a double feed is put before him, and as soon as he has swallowed it he is started. It would be firr better to give him a double feed on the previous evening, which would be digested before he is wanted, and then he might set out in the morning after a very small portion of corn has been given to him, or perhajs only a little hay. One of the most successful methods of enabling a horse to get well through a long journey is to give lim only a little at a time while on the road, and at uight to indulge him with a double feed of corn and a full allowance of beans.

Water.-This is a part of stable management little regarded by the farmer. He lets his horses loose morning and night, and they go to the nearest pond or brook and drink their fill, and no harm results, for they obtain that kind of water which nature designed them to have, in a manner prepared for them by some unknown influence of the atmosphere, as well as by the deposition of many saline admixtures. The difference between hard and soft water is known to every one. In hard water soap will curdle, vegetables will not boil scft, and the saccharine matter of the malt cannot be fully obtained in the process of brewing. There is nothing in which the different effect of hard and soft water is so evident as in the stomach and digestive organs of the horse. Hard water, drain fresh from the well, will assuredly make the coat of a horse unaccustomed to it stare, and it will not unfrequently gripe and otherwise injure him. Instinct or experience has made eren the horse himself conscious of this, for he will never drink hard water if he has access to soft, and he will leave the most transparent and pure water of the well for a river, although the stream may be turbid, and even for the maddiest pool.* He is injured, howerer, not so much by the hardness of the well-water as by its coldness - particularly by its coldness in summer, and when it is many degrees below the temperature of the atmosphere. The water in the brook and the pond being warmed by long exposure to the air, as well as having liecome soft, the horse driuks freely of it without danger.

If the horse were watered three times a day, and especially in summer, he would often be saved from the sad torture of thirst, and from many a disease. Whoever has observed the eagerness with which the over-worked horse, hot and ti:ed, plunges his muzzle into the pail, and the

- Some triners hare so much fear of hard or strange water, that they cirly with them to the different courses the water thut the aniinal ha: been accustomel to drink, and that which they know agrees with it difficulty of stopping him until he has drained the last drop, may form some idea of what he had previously sufferel, and will not wonder at the violent spasm;, and inllanmation, and sudden death, that often result.

There is a prejudice in the minds of many persons against the horse being fairly supplied with water. They think that it injures his wind, and disables hiin for quick and hard work. If h9 is galloped, as he too often is, immediately after drinking, his wind may be irreparably injured; but if he were oftener snffered to satiate his thirst at the intervals of rest, he would he happier : nd better. It is a fact unsuspected by those who have not carefully observed the horse, that if he has frequent access to water he will not drink so mnch in the course of the day, as another will do, who, to cool his parched mouth, swallows as fiast as he can, and knows not when to stop.

On a journey, a horse should be liberally sup. plied with water. When he is a little cooled, two or three quarts may be given to lim, and after that, his feed. Before he has finished his corn two or three quarts more may be offered. $\mathrm{He}$ will take no harm if this is repeated three or four timos during a long and hot day.

It is a judicious rule with travellers, that when a horse begins to refuse his food, he should be pushed no farther that day. It may, however, be worth while to try whether this does not proceed from thirst, as much as from exhanstion, for in many instances his appetite and his spirits will return soon after he has partaken of the refreshing draught.

\section{MANAGEMENT OF THE FEET.}

This is the only division of stable management that remaius to be considered, and one sadly neglected by the carter and groom. The feet should be carefully examined every morning, for the shoes may be loose and the horse would have been stopped in the middle of his work; or the clenches may be raised, and endanger the wounding of his legs; or the shoe may begin to press upon the sole or the heel, and bruises of the sole, or corn, may be the result; and the horse having stood so long in the stable, every little increase of heat in the foot, or lameness, will be more readily detected, and serious disease may often be prevented.

When the horse comes in at night, and after the harness has been taken off and stowed away. the heels should be well brushed out. Ifandrnbbing will be preferahle to washing, especially in the agricultural horse, whose heels, covered witl long hair, can scarcely be dried again. If the dirt is suffered to accumulate in that long hair, the heels will become sore, and grease will follow; and if the heels are washed, and par- 
ticularly during the winter, grease will result from the coldness occasioned by the slow evaporation of the moisture. The feet should be stopped-even the feet of the farmer's horse, if he remains in the stable. Very little clay should be used in the stopping, for it will get hard and press upon the sole. Cow-dung is the best stopping to preserve the feet cool and elastic; but, before the stopping is applied, the picker should be run round the whole of the foot, between the shoe and the sole, in order to detect any stone that may have iusinnated itself there, or a wound on any other part of the sole. For the hackney and hunter, stopping is indispensable. After several days' hard work it will afford very great relief to take the shoes off, having put plenty of litter under the horse, or to turn him, if possible, into a loose-box; and the shoes of every horse, whether hardly worked or not, should be removed or changed once in every three weeks.

\section{CHAPTER XXY.}

\section{THE SKIN AND ITS DISEASES.}

THE skin of the horse resembles in construction that of other animals. It consists of three layers, materially differing in their structure and office. Extcrnally is the euticle,- the epidermis or scarfskin-composed of innumerable thin transparent scales, and extending over the whole animal. If the scarf-skin is examined by means of a microscope, the existence of seales like those of a fish is readily detected. In the action of a blister they are raised from the skin beneath in the form of pellucid bladders, and in some diseases, as in mange, they are thrown off in hard, dry, white scales, numerous layers of which are placed one above another. In every part of the body the scarf-skin is permeated by innumerable pores, some of which permit the passage of the hairthrough others, the perspirable matter finds a passage-others are perforated by tubes through which varions unctuous secretions make their escape, while, through a fourth variety, numerons fluids and gases are inhaled. It is destitute of nerves and blood-vessels, and its principal nse seems to be to protect the cutis from injury, and to restrain and moderate its occasional morlid sensibility.

There is at all times a singular change taking place in this outer covering of the animal. There is a constant alteration and renewal of every part of it, but it adheres to the true skin through the medium of the pores, and also numerons little eminences, or projections, which seem to be prolongations of the nerves of the skin. The enticle is in itself insensible; but one of its most important functions is to protect and defend the parts beneath, which are so often exposed to the effects of a morbid sensibility.

Beneath the cuticle is a thin soft substance, through which the pores and eminences of the true skin pass. It is termerl the rete mucosum, from its web-like structure, and its soft mucons consistence. Its office is to cover the minute vessels and nerres in their way from the cutis to the enticle. It is also connected with the colour of the skin. In horses with white hair, the rete mucosum is white; it is brown in those of a bromn colour-black in the black, and in patches of different colours with those the hue of whose integument varies. Like the cuticle, it is reproduced after abrasion, or other injury.

The cutis, or true skin, lies beneath the rete mucosum. It is decidedly of a filbrous texture, elastic, but with difficulty lacerated-exceedingly vascular, and highly sensitive. It is the substance which is converted into leather when remored from the body, and binds together the different parts of the frame. In some places it does this literally, and clings so closely to the substance beneath that it scarcely admits of any motion. this is the case about the foreliead and the back, while upon the face, the sides, and flanks, it hangs in loosened folls. In the parts connected with progression it is folded into varions duplicatures, that the action of the auimal may admit of the least possible obstruction. The entis is thinnest, and most elastic, on those parts that are least covered with hair, or where the hair is altogether deficient, as the lips, the muzzle, and the inside of the flanks.

Whatever is the colour of the rete mucosum, the true skin is of a pale white; in fact, the cutis has no connection with the colour of the hair. Of its general character, Mr. Percirall gives a very accurate description :- " It appears to consist of a dense substratum of cellular tissue, with which are interwoven fibres of a ligamentous nature, in such a manner that inuumerable areolæ, like the meshes of a net, are formed in it. These areolæ open, throngh correspondent pores in the cuticle, upon the external surface, and are for the purpose of transmitting thither blood-vessels and absorbents, giving passage to the hair, and lodging the various secretory organs of the skin."*

\footnotetext{
- Percival's Anatomy of the Horse, p. 400
} 
Over a great part of the frame lies a singular muscle peculiar to quadrupeds, and more extensive and powerful in the thin-skinned an 1 thin-hairen animals, than in those with thicker hides. It reaches from the poll over the whole of the carcase, and down to the arm before, and the stille behind. 13y its contraction the skin is puckered in every direction; and if it acts strongly and rapialy, the horse is not only enabled to shake off any insect or fly that may amnoy him, hut sometimes to displace a great part of his harmess, and to render it difficult for the most expert rider to keep his seat. This muscle also assists the skin in bracing that part of the frame which it covers, and, perhaps, gives additionai streugth to the muscles beneath. It is called the paniculus carnosus, or fleshy panicle or covering.

The slin answers the double purpose of protection and strength. Where it is necessary that the parts should be bound and knit together, it arlheres so tightly that we can scarcely raise it. Thus the bones of the knees and the pasterns and the tendons of the legs, on which so much stress is frequently thrown, are securely tied down and kept in their places. It is in order to take additioual alvantage of this binding and strengthening power that we fire the legs of overworked horses, in whom the sinews have begum to start, and the ligaments of the joints to swell, or he displaced. The skin is tight along the muscles of the back and loins, and down the yet more powerful muscles of the quarters; but in other places it is loosely attached, that it may not interfere with the motious of the animal. About the brisket, and within the arms and at the flanks, it hangs even in folds.

Of its strength we have abundant proof, both in the living and lead animal. Its fibres are interlaced in a most curious and intricate manner, so as, when living, to be scarcely lacerable, and couverted into leather after death.

It is, while the animal is alive, one of the most elastic bodies with which we are acquainted. It not only perfectly adapts itself to the slow growth or decrease of the body, and appears equally to fit, whether the horse is in the plumpest condition or reduced to a skeleton; but, when a portion of it is distended to an extraordinary degree, in the most powerful action of the muscles, it, in a moment, again contracts to its usual dimensious.

It is principally indebted for this elasticity to almost inummerible minute glands which pour out an oily fluid that softens and supples it. When the horse is in heatth, and every organ discharges its proper functions, a certain quantity of this unctuons matter is spread over the smface of the skin, and is contained in all the pores that penetrate its substance, and the skin becomes pliable, casily raised from the texture benenth, and presenting that peculiar yielling suftness and elasticity which experience has proved to be the hest proofs of the condition, or, in other worts, the general health of the animal. Then, tro, from the oiliness and softness of the skin, the hair lies in its natural and proper lirection, and is smooth and glossy. When the system is thanged, and especially the digestive system, and the vessels concerned in the nourishment of the animal feebly act, those of the skin evidently sympathize. This oily secretion is no more thrown out; the skin loses its pliancy; it seems to cling to the animal, and we have that peculiar appearance which we call hide-bound. This, however, requires attentive consideration.

We observe a lorse in the summer. We find him with a thin smooth glossy coat, and his extremities clean and free almost from a single rough or misplaced hair. We meet with lim again towards the winter, when the thermometer has fallen almost or quite to the freezing point, and we scarcely recognise him in his thick, rough, coarse, colourless coat. and his legs enveloped in long shaggy hair. The liealth of the horse is, to a certain degree, deranged. $\mathrm{He}$ is dull, languid, easily fatigued. He will break into a sweat with the shightest exertion, and it is almost impossible thoroughly to dry him. He may perhaps feed as well as usual, although that will not generally be the case, but he is not equal to the demands which we are compelled to make npon him.

This process goes on for an uncertain time, depending on the constitution of the animal, nutil nature has efferter a change, and then he once more rallies: but a great alteration lias taken place in him-the hair has lost its soft and glossy character, and is become diy and staring. The skin ceases to secrete that peculiar unctuous matter which kept it soft and tlexible, and becomes dry and scaly; and the exhalents on the surface, hasing become relaxel, are frequently pouring out a profuse perspiration, wilhout any apparent adequate cause for it.

So passes the approach to winter, and the owner complains sadly of the appearance of his steed, and, according to the old custom, gives him plenty of cordial balls, - prerhips too many of them,- - on the whole not being unserviceable at this critical period, yet not productive of a great deal of good. At length the aninal rallies of himself, and although not so strong and full of spirits as he ought to be, is hardier and more lively than he was, and able to struggle with the cold of the coming winter.*

What a desideratum in the management of the horse would be a course of treatment that

* Mr. E. Gabriel, V. S., on the Treatment of the Horse in Autumm.-Velerinarian, rol., xili, p. 627. 
would render all this unnecessary? This desideratum has been found-a free escape of perspiration, a moist and softened state of the skin, an evident inclease of health and capability of enduring fatigue, and working on shorter supply of food than lie could licfore. This is said to be performed by the clipping and singeing systems.

Mr. Thomas Turner, who was almost one of the earliest advocates of these systems, states that during the months of Octoler and November an inordinate growth of hair is observed over the whole surface of the body, and in many horses as early as the beginning of September, and almost invariably prevails, more or less, in every horse that is not thorough-bred. The debilitating effects thereby induced are profuse perspiration on the least possible exertion-depression of the animal spirits, and temporary loss of appetite. The im. mediate removal of all the superfluous hair by close clipping, instantly proves so powerful a tonic to the animal, that he unhesitatingly affirms it to he inferior to none at present known in our pharmacopœia. Mr. Turner adds,- " Now, signal as the success of clipping has been, I do entertain a hope, and am of opinion that, in the majority of instances, it may be superseded by singeing under certain modifications." *

We may not, perhaps, be able satisfactorily to explain the apparently magical effects of clipping and singeing on the general constitution, and particularly the wind of the horse, or the respiratory functions generally, but there is no doubt of their existence. An increased tone is given to the system generally; and probably, in some way not yet sufficiently developed, the increased current of the electric fluid may bave much to do with it.

Mr. Snewing gives an interesting account of the effect of clipping on two horses in his establishment. He had a cob, with a fixed catarrh of several months' standing. It did not interfere with the animal's general health, but was a source of consideralile amnoyance. At length the owner determined to sell him; but first he had him clipped. After a few days his attention was drawn to the circumstance, that either the horse's cough

* Veterinarian, vol. xiv., p. I8.

In justice, however, to an excellent sportsman, Nimrod, we must quote another opinion, and with that the sobject shill be left to the consideration of nur readers. "On the subject of clipning, I cannot agree with MIr. Gibriel as to the call for it, much less admit its almost unirersal adoption. I wonld clip road-coach horses, and at hunter that had been sommered entirely at grass, despairing of condition on any other terms. It is a mere substitute for good grooming. As for its almost universal adoption, such is far from buini the case. I did not see three clipped horses last year (1840), at Melun, in the Qnord stables, not one, nor in Mr. Foljambe's. Singed ones I did see to a certain extent; but a hard-riding Meltonian told me that he would lave no more spirits of wine charged in his groom's bouk. 'A mere substitute,' said he, 'in my stahle for the olri furthoncd elbow grease: In my ofinion, the harse is not yet foalcd which cannot be got into perfect condition without tisis outrage on nature."-The V'terinarian, vol. xiv., p. 35 . must have left him, or, from repeatedly hearing it, he had ceased to regard it. He watched the animal, and, truly enough, he found that the cough had entirely disappeared. He rode him through the winter and the following summer, and there was no return of it.

The other instance was in a mare which he had after this one was sold. In the months of August, September, and October, 1841, she was continually the subject of intermittent cough. He had her clipped, and in a few days sle ceased to congh, and has not been heard to cough from that time.

\section{HIDE-EOCND.}

This is not so much a diminution of the cellular or fatty substance between the skin and the muscles beneath, as it is an alteration in the skin itself. It is a hardness and unyieldingness of the skin from the want of the oily matter on its surface and in its substance. It is the difference that is presented to the feeling by well curried and supple leather, and that which has become, dry and unyielding.

The surface of the skin becoming dry and hard the scales of the cuticle are no longer penetrated by the hair, but, separating themselves in every direction, give that peculiar roughness to the coat which accompanies want of condition. It betokens impaired function of the vessels everywhere, and particularly those of the stomach and borrels. Hide-bound is not so much a disease as a symptom of disease, and particularly of the digestive organs; and our remedies must be applied not so much to the skin-although we have, in friction and in warmth, most valuable agents in producing a healthy condition of the integuments-as to the cause of the hide-bound, and the state of the constitution generally. Every disease that can affect the general system may produce this derangement of the functions of the skin. Glanders, when become constitutional, is strongly indicated by the unthrifty appearance of the coat. Chronic, cough, grease, farcy, and founder, are accompauied by hide-bound; and diet too sparing, and not adequate to the work exacted, is an unfailing source of it. If the cause is removed, the effect will cease.

Should the cause be obscure, as it frequently is - should the horse wear an unthrifty coat, and his hide cling to his ribs, without any apparent disease, we shall generally be warranted in tracing it to sympathy with the actual, although not demonstrable, suspension of some important secretion or function, either of the alimentary canal, or the respiratory functions. A few mashes, and a mild dose of physic, are first indicated, and, simple as they appear to be, they often have a very beneficial effect. The regular action of the bowels being reestablished, that of all the organs of the frame will 
speedily follow. If the horse cannot be spared for physic, alteratives may be administered. There is no better alterative for hide-bound and an unthrifty cont, than that which is in common use, levigated antimony, nitre, and sulphur. The peculiar effect of the antimony and sulphur, and electric influence on the skin, with that of the sulphur on the bowels, and of the nitre on the urinary organs, will be here advantageously combined.

Should the horse not feed well, and there is no indication of fever, a slight tonic may be added, as gentian, or ginger; but in the majority of cases attended by loss of condition, and an unthrifty coat, and hide-bound, tonies and aromatics should be carefully avoided.

The cause of the impaired action of the ressels being removed, the powers of nature will generally be, sufficient, and had better be left to themselves. There are not any more dangerous mediciues in common use in the stable, and especially in cases like these, than tonics and cordials. They often arouse to fatal action a tendency to fever that would otherwise have slept, or they produce a state of excitement nenr akin to fever and apt to degenerate into it. By the stimulus of a cordial the secretions may be suddenly roused, and among them, this unctuous secretion from the pores of the skin, so necessary to apparent condition; but the effect soon passes over, and a repetition of the stimulus is necessary-the labit is soon formed-the dose must be gradually increased, and in the mean time the animal is kept in a state of dangerous excitement, by which the powers of nature must be eventually impaired.

Friction may be employed with advantage in the removal of hide-bound. It has repeatedly been shown that this is one of the most efficacious instruments we can use to call into exercise the suspended energies either of the absorbent or secreting ressels. Warmth may likewise be had recourse to - not warmth of stable, which has been shown to be so injurious, but warmth arising from exercise, and the salutary, although inexplicable, intluence of clipping and singeing. Before this can be fully considered, the hair by which the skin is covered must be described.

The base of the bulb whence the hair proceeds being beneath the true skin, it is easy to perceive that the hair will grow again, although the cuticle may have been destroyed. A good blister, although it mas remove the cuticle, and seemingly for a while the hair with it, leaves no lasting trace. Even firing, lightly and skilfully performed, and not penetrating through the skin, leaves not much blemish; but when, in broken knees, the true skin is cut through, or destroyed, there will always remain a spot clevoid of hair. The method of hastening and perfectiug the re-production of the hair has been described in p. 428 .
PORLS OF TIL SKIN.

Besides the openings al rearly mentioned through which proceeds the unctuous fluid that supplies and softens the skin, there are others more numerous, by means of which a vast quantity of aqueous fluid escapes, and perspiration is carried on. As in the humau being, this actually exists in a state of health and quietness, although imperceptible; but when the animal is excited by exercise, or labours under some stages of disease, it becomes risible, aud appears in the form of drops.

This process of perspiration is not, lowever, so far under the control of medicine as in the human being.

We are not aware of any drugs that will certainly produce it. Warm clothing seems occasionally to effect it, but this is more in appearance than reality. The insensible perspiration cannot escape through the mass of clothing, and assumes a visible form. This, perhaps, is the case when sheep-skins are applied over the back and loins in "locked jaw." They produce a good effect, acting as a warm poultice over the part, and so contributing to relax the muscular spasms. There are, however, a few medicines, as antimony and sulphur, that have an evident and very considerable effect on the skin in opening its pores and exciting its vessels to action.

Of the existence of absorbent vessels on the skin, or those which take up some fluid or substance, and couvey it into the circulation, we have satisfactory proof. A horse is even more easily salivated than the human being. Salivation has been produced by rubbing a splint with mercurial ointment, previous to blistering; and a very few drachms rubbed on the inside of the thighs will probably produce a greater effect than the practitioner desires.

From some parts of the skin there are peculiar secretions, as that of grease in the heel, and mallenders in the knee.

\section{MOUT.TING}

Twice in the sear the hair of the body of the horse is changed. The short, fine coat of summer would afford little protection against the winter, and that of the winter would be oppressive to the animal, if it appeared during the summer. The hair of the mane and tail remains. The bulbous root of the hair does not die, but the pulpy matter seems to be removed from the root of the hair, which, thus deprived of its nourishment, perishes and drops off, and a new hair springs at its side from the same bulb. The hair which is produced in the autumn, is evidently different from that which grows in the spring; it is coarser, thicker, and not so glossy as the other. As moulting is a process extendiug over the whole of the skiu, and requiring a very considerable expenditure of vital 
power, the health of the animal is generally affected at these times. That energy and nervous and vital influence, which should support the whole of the frame, is to a great degree determined to the skin, and the animal is languid, and unequal to much hard work. He perspires greatly with the least unusual exertion, and if he is pressed beyond his strength becomes seriously ill.

The treatment which the groom in this case adopts is most absurd and dangerous. The horse, from the deranged distribution of vital power, is disposed to fever, or he labours under a slight degree of ferer, sufficiently indicated by the increased quickness of pulse, redness of nose, and heat of mouth. The lassitude and want of appetite which are the accompaniments of this febrile state, are mistaken for debility; and cordials of various kinds, some of them exceedingly stimulating, are unsparingly administered. At length, with regard to the hunter, the racer, and even in the hackney and the carriage horse, the scissors or the lamp are introduced, and a new method is established of guarding against this periodical debility, setting at defiance the occasional exposure to cold, and establishing a degree of health and strength previously unknown. Friction may be allowed, to assist the falling off of the old hair, and to loosen the cuticle for the appearance of the new hair, but it is somewhat more gently applied than it used to be. The currycomb is in a great measure banished, and even the lirush is not applied too hard or too long. The old hair is not forced off before the young hair is ready to take its place.

Nature adapts the coat to the climate and to the season. The Sheltie bas one as long and thick as that of a bear; and, as the summer is short and cold in those northern islands, the coat is rongh and shaggy during the whole of the year. In the southern parts of our country the short and light and glossy coat of summer gradually vields to the close and heavy, and warm clothing of winter. In the deserts of Arabia, where the winter is rarely cold, the coat remains short and glossy throught the year. These are wise and kind provisions of nature, and excite our admiration.

\section{COLOUR.}

The colour of the hair admits of every variety, and each colour becomes in turn fashionable. Like that of the skin, it is influenced by, or depends on, the mucuous mesh-work under the cuticle. There are comparatively few perfectly white horses now remaining. The snow-white palfrey, with its round carcase, and barb head, originally from Spain, or perhaps from Barbary, and rarely exceeding the size of a Galloway, is nearly extinct. Some however yet remain in the possession of the Duke of Montrose. They are of good constitution and pleasant in their paces. The majority of white horses are those that have become so. Light-grey colts begin to grow white before they are five years old, especially if they have not much dark mixture about the joints.

Grey horses are of different shades, from the lightest silver to a dark iron-grey. The silvergrey reminds the observer of the palfrey, improved by an admixture of Arab blood. He does not often exceed fourteen hands and a half in height, and is round carcassed-thin-legged-with oblique pasterns, calculated for a light carriage, or for a lady's riding-seldom subject to disease-but not very fleet, or capable of hard work.

The iron-grey is usually a larger horse; higher in the withers, deeper and thinner in the carcase, more angular in all his proportions, and in many cases a little too long in the legs. Some of these greys make good hackneys and hunters, and especially the Irish horses; but they are principally used for the carriage. They have more endurance than the flatness of their chest would promise; but their principal defect is their feet, which are liable to contraction, and yet that contraction not so often accompanied by lameness as in many other borses.

The dappled grey is generally a handsomer and a better horse. All the angular points of the iron-grey are filled np, and with that which not only adds to symmetry, but to use. Whether as a hackney, or, the larger variety, a carriage horse, there are few better, especially since his form has heen so materially improred, and so much of his heaviness got rid of by the free use of foreign blood. There are not, however, so many dappled greys as there used to be, since the lays have been bred with so much care. The dappled grey, if dark at first, generally retains his colour to old age.

Some of the greys approach to a nutmeg, or even bay colour. Mlany of these are handsome, and most of them are liardy.

The roans, of every variety of colour and form, are composed of white mixed with bay, or red, or black. In some it seens to be a natural mixture of the colours; in others it appears as if one colour was powitered or sprinkled over another. They are pretty horses for ladies or light carriages, and many of them easy in their paces, but they do not usually display much blood, nor are they celehrated for eulurance. If they should have white fore legs, with wlite hoofs, they are too often tender-footed, or become so with even a little hard work.

The strawberry loorse is a mixture of sorrel with white; usually handsome and pleasant, but more celelorated for these qualities than for strength and endurance. 
The pied horse is one that has distinct spots or patches of different colours, but generally of white with some other colour. They are not liked as hackneys, on account of their peculiarity of colour, nor in teams of horses; but they look well when tolerably matched in a phaeton or light carriage. Their value must depend on their breed. Of themselves they have no peculiar character, except that a white leg and foot is as suspicious in them as it is in the roan.

The dun, of the Galloway size, and with considerable blood, is often attached to the curricle or the phaeton. 'The larger variety is a true farmer's or miller's horse, with no great speed or extraordiuary strength, yet a good-tempered, good-feeding, good-constitutioned, useful horse enough. Varieties of the dun, sliaded with a darker colour, or dappled, and with some lireeding, and not standing too high, are beautiful animals, and much sought after for light carringes.

The crenm-colour, of Hanoverian extrartion, with its white iris and red pupil, is approprinted to royal use. Attached to the state-carriage of the monarch, he is a superb animal. His lulky, yet perfectly-formed hody, his swelling crest, and his proud and lofty action, as if conscious of his office, qualify lim for the service that is exacted from him, but we have little experience how far he would suit other purposes.

Of the chesnuts there are three rarieties-the pale red or the sorrel, usually with some white, either on the face or the legs-generally lightly made, yet some of them bulky enough for the heaviest loads. Their colour is generally objectionable, and they are supposed to be somewhat deficient in endurance.

The light chesunt, with less red and a little more bay or brown, is considered a preferable animal, especially if he has little or no white about him; yet even he, althongh pleasant to ride, is sometimes irritable, and generally weak. We must except one variety, the Suffolk punch; a heavy horse, and adapted for slow work, but perfect of his kind-rrhom no labour can daunt, no fatigue orercome. This is a breed now, unfortunately, nearly extinct. The present variety, however crossed, is not equal to the old Suffolk.

The dark chesnut is as different a horse from the hackney-like chesnut as can he well imagined: round in the carcase, powerful in the quarters, but rather fine in the legs, possessed of great endurance, and with a constitution that rarely knows an ailment, except that the feet are small and disposed to contraction, and the horse is occasionally of a hot and unmanageable temper.

Of the bays, there are many varieties, and they include the very best of our horses of every description. The bright yellow bay, althongh very beau tiful, and especially if his mane and tail are black, is the least valuable-the lightness of his colour seems to give him some tenderness of constitution. The pure bay, with no white about him, and black from the knees and hocks to the feet, is the most desirable of all. He has generally a good constitution, and good feet; and, if his confurmation is not faulty, will turn out a valuable horse for almost every purpose.

The bay-brown has not always so much show and action, but, generally, more strength and endurance, and usefulness. He has greater substance than the lighter bay, and more depth of leg: and, if he had the same degree of breeding, he would be as handsome, and more valnable.

When, however, we arrive at the browns, it is necessary to examine the degree of breeding. This colour is not so fashionable, and therefore these horses have been considerably neglected. There are many good ones, and those that are good are valuable; others, probably, are only a half or a quarter bred, and therefore, comparativel $y$ coarse, yet useful for the saddle and for harness-for slow work, and, occasionally, for that which is more rapid.

The black brown is generally more neglected, so far as its breed is concerned, and should be more carefully examined. It is valuable if it retains the goodness of constitution of the brown and baybrown.

Of the black, greater eare has been taken. The heavy black of Lincolnshire and the midland counties is a noble animal, and would be almost beyond price if he could be rendered more active. "The next in size constitute the majority of our waggonhorses, and perhaps our best; and, on a smaller breed, and to the improvement of which much attention has been devoted, many of our cavalry are mounted. A few black thorough-bred horses and black hunters are occasionally seen, but the improvement of lorses of this colour has not been studied, except for the purposes that have been mentioned. Their peculiar high action, while not objectionable for draught, and desirable for the parade, would be unbearable in the roadster. Black horses have been said to be more sulject to vice, disease, and blindness, than those of any other colour. This charge is not true to its full extent; but there certainly are a great many worthless black horses in every part of the country.

After all, there is an old saying, that a good horse cannot be of a bad colour; and that it is far more necessary to attend to the conformation and points of the animal than to his colour. The foregoing observations, however, although they admit of many exceptions, may be useful in guiding to the judicious purchase of the horse.

\section{SURFEIT.}

Large pimples or eruptions often appear suddenly on the skin of the horse, and especially in 
the spring of the year. Occasionally they disappear as quickly as they came. Sometimes they seem to be attended with great itching, but, at other times, the annoyance is comparatively little. Wheu these eruptions have remained a few days, the cuticle frequently peels off, and a small scaly spot-rarely a sore-is left. This is called a surfeit, from its resemblance to some eruptions on the skin of the humau being when indigestible or unwholesome food has been taken. The surfeit is, in some cases, confined to the neck; but it oftener spreads over the sides, back, loins, and quarters. The cause is enveloped in some obscurity. The disease most frequently appears when the skin is irritable during or after the process of moulting, or when it sympathises with any disorder of the stomach. It has been known to follow the eating of poisonous herbs or mow-burnt hay, but, much oftener, it is to be traced to exposure to cold when the skin was previously irritable and the horse heated by exercise. It has also been attributed to the immoderate drinking of cold water wheu the animal was hot. It is obstruction of some of the pores of the skin and swelling of the surrounding substance, either from primary affection of the skin, or a plethoric state of the system, or sympathy with the digestive organs.

The state of the patient will sufficiently guide the surgeon as to the course he should pursue. If there is simple eruption, without any marked inflammatory action, alteratives should be resorted to, and particularly those recommended for hidebound in p. 524. They should be given on several successive nights. The night is better than the morning, becanse the warmth of the stable will cause the antimony and sulphur to act more powerfully on the skin. The horse should be warmly clothed - half an hour's walking exercise should be given, an additional rug being thrown over himsuch green meat as can be procured should be used in moderate quantities, and the chill should be taken from the water.

Should the eruption continue or assume a more virulent character, bleeding and aloetic physic must be had recourse to. but neither should be carried to auy extreme. The physic haring set, the alteratives should again be had recourse to, and attention should be paid to the comfort and diet of the horse.

If the eruptiou, after several of these alternate appearances aud disappearances, should remain, and the cuticle and the hair begin extensively to peel off, a worse affection is to be feared, for surfeit is too apt to precede, or degenerate into, mange. This disorder, therefore, must next be considered.

\section{MIANGE}

Is a pimpled or vesicular eruption. After a while the vesicles break, or the cuticle and the hair fall off, and there is, as in obstinate surfeit, a bare spot covered with scurf-some fluid oozing from the skin beneath, and this changing to a scab, which likewise soou peels off, and leaves a wider spot. This process is attended by considerable itching and tenderness, and thickening of the skin, which soon becomes more or less folded, or pucliered. The mange generally first appears on the neck at the root of the mane, and its existence may be suspected even before the blotches appear, and when there is only considerable itchiness of the part, by the ease with which the short hair at the root of the mane is plucked out. From the neck it spreads upward to the head, or downward to the withers and back, and occasionally extends over the whole carcase of the horse.

One cause of it, although an unfrequent one, has been stated to be neglected or inveterate surfeit. Several instances are on record in which poverty of condition, and general neglect of cleanliness, preceded or produced the most violeut mange. A remark of Mr. Blaine is rery important:"Among the truly healthy, so far as my experience goes, it never arises spontaneously, but it does readily from a spontaneous origin among the unhealthy." The most common cause is contagion. Anidst the whole list of diseases to which the horse is exposed, there is not one more highly contagious than mange. If it once gets into a stable, it spreads through it, for the slightest contact seems to be sufficient for the communication of this noisome complaint.

If the same biush or currycomb is used on all the horses, the propagation of mange is assured; and horses feeding in the same pasture with a mangy one rarely escape, from the propensity they have to nibble one another. Mange in cattle has been propagated to the horse, and from the horse to cattle. There are also some well-authenticated instances of the same disease being communicated from the dog to the horse, but not from the horse to the dog.

Mange has been said to originate in want of cleanliness in the management of the stable. The comfort and the health of the horse demand the strictest cleanliness. The eyes and the lungs frequently suffer from the noxious fumes of the purrifying dung and urine; but, in defiance of commou prejudice, there is no authentic instance of mange being the result. It may, however, proceed from poverty. When the animal is half starred, and the functions of digestiou and the porrer of the constitution are weakened, the skin soon sympathises, and mange is occasionally produced instead of surfeit and hide-bound. Every farmer has proof enough of this being the case. If a horse is turned on a common where there is scarcely sufficient herbage to satisfy lis appetite, or if he is placed in one of those straw-yards that 
are under the management of mercenary and unfeeling men, and are the very abodes of nisery, the animal comes up a skeleton, and he comes up mangy too. Poverty and starvation are fruitful sources of mange, but it does not appear that filth has much to do with it, although poverty and filth generally go hand in hand.

The propriety of bleeding in cases of mange depends on the condition of the patient. If mange is the result of poverty, and the animal is much debilitated, bleeding will increase the evil, and will probably deprive the constitution of the power of rallying. Physic, however, is indispeusable in every case. It is the first step in the progress towards cure. A mercurial ball will be preferable to a common aloetic one, as more certain and effectual in its operation, and the mercury probably baring some influence in mitigating the disease. In this, however, mange in the horse resembles itch in the human being-medicine alone will never effect a cure. There must be some local application. There is this additional similarity - that which is most effectual in curing the itch in the human being must form the basis of every local application for the cure of mange in the horse. Sulphur is indispensable in every unguent for mange. It is the sheet-anchor of the veterinary surgeon. In an early and not very acute state of mange, equal portions of sulphur, turpentine, and train-oil, gently but well rubbed on the part, will be applied with advantage. Farriers are fond of the black sulphur, but that which consists of earthy matter, with the mere dregs of various substances, cannot be so effectual as the pure sublimed sulphur. A tolerably good stout brush, or even a currycomb, lightly applied, should be used, in order to remove the dandriff or scurf, wherever there is any appearance of mange. After that, the horse should be washed with strong soap and water as far as the disense has extended; and, when be has been thoroughly dried, the ointment should be well rubbed in with the naked hand, or with a piece of flannel. More good will be done by a little of the ointment being well rubbed in, than by a great deal being merely smeared over the part. The rubbing should be daily repeated.

The sulphur seems to have a direct influence on the disease-the turpentine has an indireet one, by exciting some irritation on the skiu of a different nature from that produced by the mange, and under the influence of which the irritation of mange will be diminished, and the disease more easily combated. During the application of the ointment, and as soon as the physic has set, an alterative ball or powder, similar to those recommended for the other affections of the skin, should be daily given. If, after some day's have passed, no progress should appear to have been made, lialf a pound of sulphur should be well mixed with a pint of oil of tar, or, if that is not to be oltained, a pint of Barbadoes tar, and the affected parts rubbed as before. On every fift ointment should be washed off with warm soap and water. The progress towards cure will thus be ascertained, and the skin will be cleansed, and its pores opened for the more effectual application of the ointment.

The horse should be well supplied with nourishing, but not stimulating food. As much green meat as he will eat should be given to him, or, what is far better, he should be tumed out, if the weather is not too cold. It may be useful to add, that, after the horse has been once well dressed with either of these liniments, the danger of contagion ceases. It is necessary, however, to be assured that every mangy place has been anointed. It will be prudent to give two or three dressings after the horse bas been apparently cured, and to continue the alteratives for ten days or a fortnight.

The cure being completed, the clotbing of the horse should be well soaked in water, to which a fortieth part of the saturated solution of the chloride of lime has heen added; after which it should be washed with soap and water, and again washed and soaked in a solution of the chloride of lime. Every part of the harmess should nndergo a similar purification. The currycomb may be scoured, but the brush should be burned. The rack, and manger, and partitions, and every part of the stable which the horse conld possibly lave touched, should be well washed with a hair-broom-a pint of the cbloride of lime being added to three gallous of mater. All the wood-work should then he scoured with soap and water, after which a second washing with the chloride of lime will render all secure. Some farmers have pulled down their stables, when they have been thoronghly infected with mange. This is being mnecessarily cautious. The efficacy of the chloride of lime was not then known; but if that is carefully and sufficiently applied to every part of the stable and its furniture, there camnot afterwards be danger.

Every case of itchiness of the skin should be regarded with suspiciou. When a horse is seeu to rub the root of his tail, or his liend. or neck, against the manger, the parts shou d be carefully examined. Some of the hair may have been rubbed or torn off, but if the roots remain firmly adlierent, and there is only redness and not scurfiness of the skin, it probably is not mange, but only inflammation of the skin, from too great fulness of blood. $A$ little blood should be abstracted-a purgative administered-and the alteratives given. The mange ointment cannot do harm, and may possibly prevent this heat of the skin from degenerating into mange, or arrest the 
progress of mange if it has commenced. If a / be seared with a rel-hot iron. Unless these prescurfiness of skin should appear on any of the cautions are used, the warts will speedily sprout points that are pressed upon by the collar or har- again.

ness, the veterinary surgeon will do right to guard against danger by alterative medicine and the use of the ointment.

\section{WARTS.}

These are tumours of variable size, arising from the cuticle, and afterwards connected with the true skin by means of the vessels which supply the growth of the tumours. They are found on the eyelids, the muzzle, the ears, the belly, the neck, the penis, and the prepuce. There are some caustics available, but frequently they must be removed by an operation. If the root is very small, it may be snipped asunder, close to the skin, with a pair of scissors, and touched with the lunar caustic. If the pedicle or stem is somewhat larger, a ligature of waxed silk should be passed firmly round it, and tightened every day. The source of nutriment being thus removed, the tumour will, in a short time, die and drop off. If the warts are large, or in considerable clusters, it will be necessary to cast the horse, in order to cut them off close to the skin: the root should then

\section{VERMIN}

Both the biped and the quadruped are suliject to the visitation of insects, that fasten on the skin, and are a constant nuisance from the itchiness which they occasion. If the horse, after being turned out for the winter, is taken $u p$ in the spring, long and rough in his coat, and poor in condition, and with evident hide-bound, he will almost invariably be afflicted with vermin.

In our present imperfect acquaintance with natural history, it is difficult to account for the appearance of certain insects, and of those alone on the integument of one animal, while others of an altogether different character are found on its neighbour. Each one has a tormentor peculiar to itself.

The vermin of the horse is destroyed by an infusion of tobaceo, or a solution of corrosive sublimate, the latter requiring the greatest cantion. The skin being once cleansed of them, an attention to cleanliness will prevent their reappearance.

\section{CHAPTER XXY.}

\section{ON SOUNDNESS, AND THE PURCHASE AND SALE OF HORSES.}

THERE are few sources of greater annoyance both to the purchaser and the seller of the horse than disputes with regard to the soundness of the animal. Although, in deseribing the various parts of the horse, we have glanced at the comnection of certain natural conformations, and some alterations of structure, and accidents, and diseases, with the question of soundıess or unsoundness, it may not be uninteresting to these for whom our work is designed, if we now bring into one point of view the substance of that which has been scattcred over many pages.

That horse is sound in whom there is no disease, and no. alteration of structure that impairs, or is likely to impair, his natural usefulness. The horse is unsound that labours under disease, or has some alteration of structure which does interfere, or is likely to interfere, with his natural usefulness. ${ }^{2}$ The term "natural usefulness" must be borne in mind. One horse may possess great speed, but is

\footnotetext{
* Since the publication of our first edition, this definition or rule as to soundriess or unsounduess has received very high judicial sanction, Coales v. Stephens, 2 Moody aud Robinson, 157; Scholeficld v. Robb, id. 210 . We shull adhere to it as our test of soundness or unsoundness throughout this chayter, not forgetting what is said in the following extruct from a note to one of these eases. "A; it may now be considered as settled luw, that the
}

soon knocked up; another will work all day, bnt cannot be got beyond a snail's space: a third with a heavy forehand is liable to stumble, and is continually putting to hazard the neck of his rider; another, with an irritable constitution and a loose washy form, loses his appetite and begins to scour if a little extra work is exacted from him. The term unsoundness must not not be applied to either of these; it would be opening far too widely a door to disjutation and endless wrangling. The buyer can discern, or ought to know, whether the form of the horse is that which will render him likely to suit lis purpose, and he should try him sufficiently to ascertain his natural strength, endurance, and manner of going. Unsomdness, we repeat, has reference only to disease, or to that alteration of structure which is connected with, or will produce disease, and lessen the usefulness of the animnl.

These prineiples will be best illustrated by a

breurh of a warranty of soundness does not entitle the purchaser to return the horse, but unly to recover the ditference of value of the lorse with or without the particular nnsoundness, the question of temporary maladies, producing no permanent deteribration of the animal, w ould, generally speaking, only involve a right to damages merely nominal," 
brief consideration of the usually supposed appearances or causes of nnsoundness.

Broken knees certainly do not constitute nnsoundness, after the wounds are healed, unless they interfere with the action of the joint; for the horse may have fallen from inere aceident, or through the fault of the rider, without the slightest damage more than the blemish. No person, however, would buy a horse with broken knees, until he hai thoroughly tried him, and satisfied himself as to his form and action.

Capped hocks may be produced by lying on an unevenly paved stable, with a scanty supply of litter, or by kicking generally, in neither of which cases would they constitute unsoundness, although in the latter they would be an indication of vice; but, in the majority of instances, they are the consequence of sprain, or of latent injury of the hock, and accompanied by enlargement of it, and would constitute unsounduess. A special warranty should always be taken against capped hocks.

Contraction is a considerable deviation from the natural form of the foot, lut not necessarily constituting unsoundness. It requires, however, a most careful examination on the part of the purchaser or veterinary surgeon, in order to ascertain that there is no heat about the quarter, or ossification of the cartilage-that the frog, although diminished in size, is not diseased - that the horse does not step short and go as if the foot were tender, and that there is not the slightest trace of lameness. Unless these circumstances, or some of them, are detected, a horse must not be pronounced to be unsound because his feet are contracted ; for many horses with strangely contracted feet do not suffer at all in their action. A special warranty, however, should be required where the feet are at all contracted.

Corns manifestly constitute unsounduess. The portion of the foot in which bad corns are situated will not bear the ordinary pressure of the shoe; and accidental additional pressure from the growing down of the born, or the introduction of dirt or gravel, will cause serious lameness. They render it necessary to wear a thick and heavy shoe, or a bar shoe, in order to protect the weakened and diseased part; and they are very seldom radically cured. There may be, however, and frequently is, a difference of opinion as to the actual existence or character of the corn. A veterinary surgeon may consider it so slight and insignificant as not apparently to injure the horse, and he pronounces the animal to be sound; but he shonld be cautious, for there are-corns of every shade and degree, from the slightest degree to the most serious evil. They may be so slight and manageable as, though ranging under the class of morbid alteration of structure, yet not to diminish the natural usefulness of the horse in any degree. Slight corns will dis- appear on the horse being shod with ordinary skill and care, even without any alteration in the shoe.

Covan.-This is a disease, and consequently unsounlness. IIowever slight may be its degree, and of whatever short standing it may be, although it may sometimes scarcely seem to interfere with the usefulness of the loorse, yet a change of stabling, or slight exposure to wet and cold, or the least over-exertion, may, at other times, canse it to degenerate into many dangerous complaints. A horse, therefore, should never be purchased with a cough upon him, without a special warranty; or if -the cough not being observed-he is purchased mider a general warranty, that warranty is thereby broken. It is not law, that a horse may be returned on breach of the warranty. The seller is not bound to take him back, nnless he has contracted so to do; but he is liable in damages. Lord Ellenborough has completely decided this matter. "I have always held," said he, "that a warrinty of soundness is broken, if the animal, at the time of sale, had any infirmity upon him that rendered him less fit for present service. It is not necessary that the disorder shonld be permanent or incurable. While he has a cough, he is nnsound, althongh that may either be temporary or prove mortal." **

Poaring, Wheezing, Whistuing, High-blowiNG and Gruntisg, being the result of alteration of structure, or disease in some of the air-passages, and interfering with the perfect freedom of breathing, especially when the horse is put on his speed, without doubt constitute unsoundness. There are decisions to the contrary, which are now universally admitted to be erroneous. BRoKen wIND is still more decidedly unsoundness.

Crib-Biting.-Although some learned judges

* In deciding nn another case, the same judge said, "I have always held it that a cough is a breach of the warranty. On that understanding I have always acted, and think it quite clear." It was argued on the other band that two-thirds of the horses in Lozdon had coughs, yet still the judge maintinined that the cough was a breach of warranty. When it was farther argued that the horse had been hunted the day after the purchase, and the cough might have been inereased by this, the reply was singular, but decisive. "There is oo proof that he would have got well if he had not been huoted." This doctrine is confirmed by Parke, $\mathrm{B}$., in the first case cited in p. 485 .

In p. 254, it is very properly stated that roaring is msoundness, because it impairs the function of respirtion. This was not always, however, the law of the bench. Lord Elienborough, qnoting from Sir James Mansfield, says, "It has been held by very high authority that roaring is not necessarily unsoundness, and I entirely concnr in that opinion. If the horse emits a loud nnise, which is offensive to the ear, merely from a bad habit which he has coutracted, or from any cause tbat does not interfere with his general health, or muscular powers, he is still to be considered a sound horse. On the other hand, if the roaring proceeds from any disense or organic infirmity, which renders him incapable of performing the nsual functions of a horse, then it does constitute unsoundness. The plaintiff has not done enough in showing that this horse wus a roarer. To prove a breach of the warranty he must go on to show that the roaring was symptomatic of disease." These extructs are taken from a singular work, not alwass correct, yet from which much amuscment, and instruntion too, mav be derived- "The Artventures of a Gentleman in Search of a Horse, by Caveat Emptor." 
have asserted that erib-biting is simply a trick or bad habit, it must be regarded as unsoundness. This umuatural sucking in of the air must to a certain degree injure digestion. It must dispose to colic, and so interfere with the strength, and uscfuluess, and health of the horse. Some cribbiters are good goers, but they probably would have possessed more endurance had they not acquired this habit; and it is a fact well established, that as soon as a horse becomes a crib-biter, he, in in nine cases ont of ten, loses condition. $\mathrm{He}$ is not to the experienced eye the horse be was before. It may not lead on to strongly-marked disease, or it may rarely do so to any considerable degree; but a horse that is morbidly deficient in condition, must, to that extent, have his capability for extraordinary work diminished, and so be bronght within our definition of unsoundness. In its very early stage it may be a mere trick-confirmed, it must have produced morbid deterioration. The wear of the front teeth, and the occasional brealiug of them, make a horse old before his time, and sometimes render it difficult or almost impossible for him to graze, when the state of the animal or the convenience of the owner requires that he should be turned out.

Curb constitutes unsounduess while it lasts, and perhaps while the swelling remains, although the inflammation may have subsided; for a horse that has once thrown out a curb is, for a while at least, very liable to do so again, to get lame in the same place on the slightest extra exertion; or, at all events, he would there first fail on extraordinary exertion. A horse, however, is not returnable, although he should spring a curb five minutes after the purchase; for it is dome in a moment, and does not necessarily indicate any previous unsoundness or weakness of the part.

Cutrting, as rendering a horse liable to serious injury of the legs, and indicating that he is either weak, or has an ankwardness of gait inconsistent with safety, prodıces, rather than is, unsoundness. Many horses go lame for a considerable period after cutting themselves severely ; and others have dropped from the sudden agony, and endangered themselves and their riders. As some doubt, however, exists on this subject, and as it is a very material oljection to a horse, cutting, when evident, should have its serious consequences provided against by a special warranty.

Enlarged Glands.-The enlargement of the glands under the jaw has not been so much considered as it ought to have been in our estimtae of the soundness of the horse. Simple catarrh will occasionally, and severe affection of the chest will generally, be accompanied by swelling of these glands, which does not subside for a considerable time after the cold or fever has apparontly been cured. To slight enlargements of the glands under the jaw much attention need not be paid ; but if they are of considerable size, and especially if they are tender, and the glands at the root of the ear partake of the enlargement, and the membrane of the nose is redder than it should be, we should hesitate in pronouncing that horse to be sound. We must consider the swelling as a symptom of disease.

ENLARged Hock.-A horse with eularged bock is unsound, the structure of this complicated joint being so materially affected that, although the horse may appear for a considerable time to be capable of ordinary work, he will occasionally fail even in that, and a few days' hard work will always lame him.

ThE Eres. - That inflammation of the eye of the horse which usually terminates in blindness of one or both eyes, has the peculiar character of receding or disappearing for a time, once or twice, or thrice, before it fully runs its course. The eye, after an attack of inflammation, regains so nearly its former natural brilliancy that a person even well acquainted with horses will not always recognise the traces of former disease. After a time, however, the inflammation returns, and the result is inevitable. A horse that has had one attack of this complaint, is long afterwards sound, however perfect the eye may seem to be, because he carries about with him a disease that will probably again break out, and eventually destroy the sight. Whether, therefore, he may be rejected or not, depends on the possibility of proving an attack of inllammation of the eje, prior to the purchase. Next to direct evidence of this are appearances about the ere, of which the reterinary surgeon at least ought not to be ignorant. Allusion las been made to them in p. 240 . They consist chiefly of a puckeriug of the lids towards the inner corner of one or both eyes-a difference in the size of the eyes, although perhaps only a slight one, and not discorered except it be looked for-a gloominess of the eye-a dullness of the iris-a little dullness of the transparent part of the eje generally-a minute, faint, dusky spot, dcep in the eye, and generally with little radiations of white lines proceeding from it. If these symptoms, or the majority of them, existed at the time of purchase, the auimal hat assuredly been diseased before, and was unsound. Starting has been considered as an equivocal proof. It is usually an indication of defective sight, lut it is occasionally a trick. Connected, however, with the appearances just described, it is a very strong corroborative proof.

LAMENEs, from whatever cause arising, is unsoundness. However tempority it nay be, or however obscure, there must be disense which lessens the utility of the horse, and renders him unsound for the time. So says common seuse, 
but there are contradictory decisions on the case. "A horse labouring under a temporary injury or hurt, which is capable of being speedily cured or removed, is not, according to Chief Justice Eyre, an unsound horse; and where a warranty is made that such a horse is sound, it is male without any view to such an injury; nor is a horse so circumstanced within the meaning of the warranty. To vitiate the warranty, the injury the horse had sustained, or tlie malady mder which he laboured, ought to he of a permanent nature, and not such as may arise from a temporary injury or accident. "*

Ou the contrary, Lord Ellenborougl say"s : "I have always held, and now bold, that a warranty of soundness is broken, if the animal at the time of sale las any infirmity upon him which renders him less fit for present service. It is not necessary that the disorder should be permanent or incurable. While a horse bas a cough he is unsound, although it may either be temporary or may prove mortal. The liorse in question having been lame at the time of sale, when he was warranted to be sound, his condition subsequently is no defence to the action." + The decisions of Mr. Baron Parke, already referred to, confirm this doctriue.

Nedrotomy. - A question has arisen how far a horse that has nndergone the operation of the division of the nerve of the leg (see p. 298), and has recovered from the lameness with which be was before affected, and stands his work well, may be considered to be sound. Chief Justice Best held such a horse to be unsound, and in our opinion there camnot be a doubt about the matter. The operation of neurotomy does not remove the disease cuusing the lameness, but only the sensation of pain. A borse on whom this operation has been performed may be improved by it, may cease to be lame, may go well for many years; but there is no certainty of this, and he is unsomnd, within our definition, unless nature gave the nerve for no useful purpose.

Ossification of the Latigal Cartilages constitutes unsoundness, as interfering with the natural expansion of the foot, and, in horses of quick work. almost invarialily producing lameness.

Pumced Foot.- When the umion between the horny and seusible laminx, or little plates of the foot (see p. 458), is reakened, and the coffin-bone is let down, and presses upon the sole, and the sole yields to this umnatural weight, and becomes rounded, and is brought in contact with the ground, and is bruised and injured, that horse must be unsomnd, and unsound for ever, because there are no means by which we can raise the cotlin-bone ayain into its place.

QuidDing.--If the mastication of the food gives pain to the animal, iu consequence of sore-

\footnotetext{
* 2 Espiz. Rep. 673 Garment v. Barrs

+4 Cumpbell, 251 , Elton v. Broyden.
}

ness of the mouth or throat, he will drop it before it is perfectly chewed. 'This, as an indication of disease, constitutes unsomdness. Quidding sometimes arises from irregularity in the teeth, which wound the cheek with their sharp edges; or a protruling tooth renders it impossible for the horse to close lis jaws so as to chew his food thoroughly. Quidding is unsounduess for tle time; but the unsoundness will cease when the teeth are properly filed, or the soreness or other cause of this imperfect chewing removed

Quitron is manifestly unsoundness.

Ring-Bone. - Although when the bony tumour is small, and on one side only, there is little or 110 lameness, and there are a few instances in which a borse with ring-bone has worked for many years without its retum, jet from the action of the foot, and the stress upon the part, the inflammation and the formation of bone may acquire a tendency to spread so rapidly, that we must pronounce the slightest enlargement of the pasterns, or around the coronet, to be a cause of unsoundness.

SANDCRACK is manifestly unsoundness. It may, however, occur without the slightest warning, and no horse can be rejected on account of a sandcrack that has sprung after purchase Its usual cause is too great brittleness of the crust of the hoof; but there is no infallible method of detecting this, or the degree in which it must exist in order to constitute unsoundness. When the born round the bottom of the foot has chipped off so much that only a skilful smith can fasten the shoe with out pricking the horse, or even when there is a teudeney in the horn to chip and break in a much less degree than this, the horse is musound, for this brittleness of the crust is a disease of the part, or it is such an altered structure of it as to interfere materially with the usefulness of the animal.

Spavin.-Bone spavin, comprehending in its largest sense every bony tumour on the liock, is not necessarily unsounduess. If the tumour affects in the slightest degree the action of the horse, it is unsoundness; even if it does not, it is seldom safe to pronounce it otherwise than unsoundness. But it may possibly be (like splint in the foreleg) so situated as to have no tendency to affect the action. A reterinary surgeon consulted on the purchase will not always reject a horse because of such a tumour. His evidence on a question of soundness will depend on the facts. The situation and history of the tumour may be such as to enable him to give a decisive opinion in a horse going sound, but not often.

Bog or Blood Spavin is unsounduess, because, although it may not be productive of lameness at slow work, the rupid and powerful action of the hock in quicker motion will produce permanent 
yet perhaps not considerable lameness, which can scarcely ever be with certainty removed.

Splixt.-It depends entirely on the situation of the bony tumour on the shank bone, whether it is to be considered as unsomindess. If it is not in the neighbourhood of any joint, so as to interfere with its action, and if it does not press npon any ligament or tendon, it may be no cause of unsoundness, although it is often very unsightly. In many cases it may not lessen the capalility and value of the animal. This has been treated on at considerable length in $\mathrm{p} .428$.

Stringhalt.- This siugular and very unpleasant action of the hind leg is decidedly an unsoundness. It is an irregular communication of nervous energy to some muscle of the thigh, observable when the horse first comes from the stable, and gradually ceasing on exercise. It has usually been accompanied by a more than commou degree of strength and endurance. It must, however, be traced to some morbid alteration of structure or function; and it rarely or never fails to deteriorate and gradually wear out the animal.

'Thickening of the B.tck Sinews,-Sufficient atteution is not always paid to the fineness of the legs of the horse. If the flexor tendons have been sprained, so as to produce considerable thickening of the cellular substance in which their sheaths are enveloped, they will long afterwards, or perhaps always, be liable to sprain, from causes by which they would otherwise be scarcely affected. The continuance of any considerable thickness around the sheaths of the tendons indicates previous and violent spraiu. 'This very thickening will fetter the action of the tendons, and, after much quick work, will occasionally renew the inflammation and the lameness; therefore, such a horse cannot be sound. It requires, however, a hittle discrimination to distinguish this from the gumminess or rouudness of leg, peculiar to some breeds. There should be an evident difference between the injured leg and the other.

Thorodghpis, except it is of great size, is rarely productive of lameness, and therefore cannot be termed unsounduess; but as it is the consequence of hard work, and now and then does produce lameness, the hock should be most carefully examined, and there should be a special warranty against it.

Thrush.-There are various cases on record of actions on account of thrushes in horses, and the decisions have been much at variance, or perfectly contradictory. Thrush has not veen always cunsidered by legal men as unsoundness. We, however, decidedly so consider it; as being a disease interfering, and likely to interfere with the usefulness of the horse, Thrush is inflamma. tion of the Jower surface of the inner or sensible frog-aud the secretion or throwing out of pus- almost invariably accompanied by a slight degree of tenderness of the frog itself, or of the heel a little above it, and, if neglected, leading to diminution of the substance of the frog, and separation of the horn from the parts beneath, and underrunning, and the production of fungus and canker, and, ultimate]y, a diseased state of the foot, destructive of the present, and dangerous to the future usefulness of the horse.

WiNDGALLS. - There are few horses perfectly free from windgalls, but they do not interfere with the action of the fetlock, or cause lameness, except when they are numerous or large. They constitute unsoundness only when they cause lameness, or are so large and numerous as to render it likely that they will cause it.

In the purchase of a lorse the buyer usually receives, embodied in the receipt, what is termed a warranty. It should be thus expressed :-

"Received of A. B. forty pounds for a grey mare, warranted only five years old, sound, free from vice, and quiet to ride asu drive.

" \pm 40 .

"C. D."

A receipt, incluting merely the word "warranted," extends only to souuduess,_- warranted sound" goes no farther; the age, freedom from vice, and quietness to rile and drive, should be especially named. This warranty comprises every cause of unsoundness that can be detected, or that lurks in the constitution at the time of sale, and to every ricious habit that the animal has hitherto shown. To establish a breach of the warranty, and to be enabled to tender a return of the horse and recover the difference of price, the purchaser must prove that it was unsound or viciously disposed at the time of sale. In case of cough, the horse must have been heard to cough immediately after the purchase, or as be was led home, or as soon as he had entered the stable of the purchaser. Coughing, even on the following morning, will not be sufficient; for it is possible that he might have caught cold by cbauge of stabling. If he is lame, it must be proved to arise from a cause that existed before the animal was in the purchaser's possession. No price will imply a warranty, or be equivalent to one ; there must be an express warranty. A fraud must be proved in the seller, in order that the buyer may be enabled to return the horse or maintain an action for the price. The warranty should be given at the time of sale. A warranty, or a promise to warrant the horse, given at any period antecedent to the sale, is invalid; for horseflesh is a very perishable commodity, and the constitution and usefulness of the animal may undergo a considerable change in the space of a few days. A warranty after the sale is invalid, for it is giveu without any legal consideration. In order to complete the purchase, there must be a transfer of the 
auimal, or a memorandum of agreement, or the payment of eamest money. The least sum will suffice for earnest. No verbal promise to buy or sell is binding without one of these. The moment either of these is effected, the legal transfer of property or delivery is made, and whatever may happen to the horse, the seller retains, or is entitled to the money. If the purchaser exercises any act of ownership, by using the animal without leave of the vendor, or by having any operation performed, or any medicines given to him, he makes him his own. The warranty of a servant is considered to be binding on the master.*

If the horse should be afterwards discovered to have been unsound at the time of warranty, the buyer may tender a return of it, and, if it be not taken back, may bring his action for the price; but the seller is not bound to rescind the contract, unless he has agreed so to do.

Although there is no legal compnlsion to give immediate notice to the seller of the discovered unsounduess, it will be better for it to be done. The animal should then be tendered at the house or stable of the vendor. If he refuses to receive him, the animal may be sent to a livery stable and sold; and an action for the difference in price may be brought. The keep, however, can be recovered only for the time that necessarily interrened between the tender and the determination of the action. It is not legally necessary to tender a return of the horse as soon as the unsoundness is discovered. The animal may be kept for a reasonable time afterwards, and even proper medical means used to remove the unsoundness; but courtesy, and indeed justice, will require that the rotice should be given soon as possible. Although it is stated, on the authority of Lord Loughborough, that "no length of time elapsed after the sale will alter the uature of a contract originally false," yet it seems to have been once thought it was necessary to the action to give notice of the unsoundness in a reasonable time. The cause of action is certainly complete on breach of the warranty. It used to be supposed that the buyer had no right to have the horse medically treated, and that he would waive the warranty by doing so. The question, however, would be, has he injured or diminished the value of the horse by this treatmeut? It will generally be prudent for him to refrain from all medical treatment, because the means adopted, however skilfully employed, may have an unfortunate effect, or may be misrepresented by ignorant or interested observers.

The purchaser possibly may like the horse, notwithstanding his diseovered defect, and he may

- The weight of authority decides that the master is bound by the act of the servant. Lord Kenyon, however, had some duubt o.. tiv sutiject. retain, and bring his action for the depreciation in value on account of the nnsoundness. Few, how. ever, will do this, because his retaining the horse will cause a suspicion that the defect was of 110 great consequence, and will give rise to much eavil about the quantum of damages, and after all, very slight damages will probably be obtained. "I take it to be clear law," says Lord Eldon, "that if a person purchases a horse that is Farranted, and it afterwards turns out that the horse was unsound at the time of the warrauty, the buyer, may, if he pleases, keep the horse, and bring an action on the warranty; in which he will have a right to recover the difference between the value of a sound horse, and one with such defects as existed at the time of warranty; or he may return the horse, and bring an action to recorer the full money paid : but in the latter case, the seller has a right to expect that the horse shall be returned to him in the same state he was wheu sold, and not by any means diminished in value : for if a person keeps a warranted article for any leugth of time after discovering its defects, and when he returns it, it is in a worse state than it would have been if returmed immediately after such discovery, I think the party can have no defence to an action for the price of the article on the ground of non-compliance with the wirranty, but must be left to his action on the warranty to recover the difference in the value of the article warranted, and its value when sold." +

Where there is 110 warranty, an action may be brought on the ground of fraud ; but this is very difficult to be maintained, and not often hazarded. It will be necessary to prove that the dealer knew the defect, and that the purchaser was imposed npon by his false representation, or other fraudulent means. If the defect was evideut to every eye, the purchaser has no remedy, he shoull have taken more care; lut if a warranty was given, that extends to all unsoundness, palpable or concealed. Although a person shonld ignorautly or carelessly buy a blind horse, warranted sound, he may reject it; the warranty is his guard, and prevents him from so closely examining the horse as he otherwise would hare done; but if he buys a blind horse, thinking him to be sound, and without a warranty, he has no remedy. Every one ought to exercise common circumspection and common sense.

A man should have a more perfect knowledge of horses than falls to the lot of most, and a perfect knowledge of the vendor too, who ventures to buy a horse without a warranty.

If a person buys a horse warranted sound, and discovering no defect in him, and, relying on the warranty, re-sells them, and the unsoundness is discorered by the second purchaser, and the + Curlis v. Hunnay, 3 Esp. 83. 
horse returned to the first purchaser, or an action commenced against him, he has his claim on the first seller, and may demand of him not only the price of the horse, or the difference in value, but every expense that may have been incurred.

Absolute exchanges, of one horse for another, or a sum of money being paid in addition ly one of the parties, stand on the same ground as simple sales. If there is a warranty on either side, and that is broken, an action may be maintained: if there be no warranty, deceit must be proved.

The trial of horses on sale often leads to disputes. The law is perfectly clear, but the application of it, as in other matters connected with horse-flesh, attended with glorious uncertainty. The intended purchaser is only liable for damage done to the horse through his own misconduct. The seller may put what restriction he chooses on the trial, and takes the risk of all accidents in the fair use of the horse within such restrictions.

If a horse from a dealer's stable is galloped far and fast, it is probable that he will soon show distress; and if he is puslied farther, inflammation and death may eusue. The dealer rarely gets recompensed for this; nor ought he, as he linows the unfituess of his horse, and may thauk himself for permitting such a trial; and if it should occur soon after the sale, he runs the risk of having the horse returned, or of an action for its price.

In this, too, he is not much to be pitied. The mischievous and fraudulent practice of dealers, especially in London, of givińg their horses, by over-feeding, a false appearance of muscular substance, leads to the ruin of many a valuable animal. It would be a useful lesson to have to contest in an action or two the question whether a horse overloaded with fat can be otherwise than in a state of disease, and consequently unsound.

It is proper, however, to put a limit to what has been too frequently asserted from the bench, that a horse warranted sound must be taken as fit for immediate use, and capable of being inmediately put to any fair work the owver chooses. A hunter honestly warranted sound is certainly warranted to be in immediate condition to follow the hounds. The mysteries of condition, as has been shown in a former part of the work, are not sufficiently unravelled.

In London, and in most great towns, there are repositories for the periodical sale of horses by auction. They are of great convenience to the seller, who can at once get rid of a horse with which he wishes to part, without waiting month after month before he obtains a purchaser, and he is relieved from the nuisance or fear of having the animal returned on account of breach of the warranty, because in these places only two days are allowed for the trial, and if the horse is not returned within that period, he cammot be afterwards returned. They are also convenient to the purchaser, who can thus in a large town soon find a horse that will suit him, and which, from this restriction as to returning the animal, he will obtain twenty or thirty per cent. below the dealers' prices. Although an auction may seem to offer a fair and open competition, there is no place at which it is more necessary for a person not much accustomed to horses to take with him an experienced friend, and, when there, to depend on his own judgment, or that of his friend, heedless of the observations or manœurres of the by-standers, the exaggerated commendation of some horses, and the thousand faults found with others. There are always numerous groujs of low dealers, copers, and channters, whose business it is to delude and deceive.

One of the regulations of the Bazaar in King Street was exceedingly fair, both with regard to the previous omner and the purchaser, viz.-

"When a horse, having been warranted sound, shall be returned within the prescribed period, on account of unsoundness, a certificate from a veterinary surgeon, particularly describing the 11 soundness, must accompany the lorse so returned; wher, if it be agreed to by the veterinary surgeon of the establishment, the amount received for the horse shall be immediately paid lack; but if the veterinary surgeon of the establishment slould not confirm the certificate, then, in order to avoid further dispute, one of the veterinary surgeons of the college shall be called in, and his decision shall be final, and the expense of such umpire shall be borne by the party in error."

\section{CHAPTER XXVII.}

\section{A LIST OF THE MEDICINES OSED IN THE TREAMMENT OF THE DISEASES OF THE HORSE.}

$\mathrm{HE}_{\mathrm{E}}$ will rarely consult his own interest, who, not $/$ of the horse nearly resemble each other. They baving had the advantage of a veterinary educafion, undertakes the treatment of any of the serious diseases of his horses. Many of the maladies are continually varying their character, and re quire, in their different stages, a very different treatment, and in the plainest case not only the 
characteristic symptoms of disense are olscure, but even the indications of returning healtl, or increasing danger, are often scarcely ascertainable, consequently the sick horse, as well as the humill being, neerls the care of one whom study and experience have qualified for the task. A list of the drugs generally employed, with a slight account of their history, adulteritions, and medicinal effects, will be interesting to the horse-proprietor as well as to the reterinary surgeon; and may occasionally be useful when professional aid cannot be obtained.

Frequent reference will be made to Professor Morton's most valuable Mauual of Pharmacy. This work will be found to be a treasure to every veteriuary surgeon. Mr. W. C. Spooner's Materia Medica, in his recent compendium of White's account of the horse, will occasionally be laid under contribution.

ACACia Gumm.-Many varieties of gum arabic are procured from Egypt, Arabia, and the East Indies. It is an exudation from the trunk and branches of various trees. It is employed in the form of a mncilage, made by dissolving it in water, in the proportion of one part of the gum to three or four of water. Various insoluble powders may be thus suspended, or oils rendered miscible or emulsions formed. Emulsions composed of gum arabic are supposed to be nseful in urinary affections.

Acidum Aceticum, Acetic Acid, Vinegar.Vinegar is a very useful application for sprains and brnises. Equal parts of boiling water and cold vinegar will form a good fomentation. Extract of lead, or bay salt, may be added with some advantage. As an internal remedy, vinegar is rarely given, nor has it, except in large doses, any considerable medicinal power. The veterinarian and the horse-owner should manufacture their own vinegar. That which they buy frequently contains sulphnric acid and pungent spices, and irritates the intlamed part to which it is applied.

Acidum Arseniosum, Arsenic.-Were it not that some practitioners continue to use it as a tonic, in doses of from ten to twenty grains daily, and others employ it to core out old ulcers, we would not include it in our list, for we have little faith in it. There are better and safer tonics, and far better and safer causties. The method of detecting the presence of arsenic, in cases of poisoning, has been described at page 394 .

Acidum Muriaticum, or Hydrochloric Acid : SpIrit of SALT.-This acid is formed by distilling corrosive sublimate with antimony. The butter-like matter which is produced (whence the common name, Butyr of Antimony) has a strong aftinity for water, which it attracts from the atmosphere, and thus becomes converted into a thuid. The less water it is suffered to attract to itself the more powerful it remains, and therefore it shonld be kept in stoppered bottles. The proof of its goodness is its weight. It is decidedly the best liqnid caustic we have. It is most managealle, and its effect can most readily be ascertained. As soon as it touches any muscular or living part, a change of colour is perceived, and the effeet of the canstic can be fairly judged of by the degree of change. For corns, canker, indisposition in the sole to secrete good horn, wounds in the foot not attended by healthy action, and for every case where the superficial application of a caustic is needed, this acid is univalled.

Acidua Nitricusi, Nithic Acid, AquaFoutis.-This is a valuable external application. It is both a caustic and an antiseptic. It destroys fungous excrescences. A pledget of tar should be dipped in the acid, and then firmly pressed on the cankerous surface. Every part with which the acil has come into contact will be deadened and slough off, and healthy grannlations will spring up.

Acidun Hydrocianicum, Prussic Acid.This, in a concentrated state, is truly a deadly poison; a few drops of it will kill a large animal. In a dilnted form, it is a powerful sedative. In doses of six drops, largely diluted, it abates both pulmonary and gastric irritation. It may be worth trying in the form of enema in cases of Tetanus. It may also be given by the mouth in the same disease. Nothing is more likely to tranquillize the general excitement of the nervous system. The author of this work was the first person who applied the hydrocyanic acid for the purpose of allaying irritation of the skin in dogs. It seldom fails of producing the desired effect, and it has had a similar good effect in subdring itchiness and mange in the horse.

Acinum Sulphuricum, Sulpuntc Acid.When mixed with tar in the proportion of an ounce to the pound, it is a good application for thrush and canker: a smaller quantity mixed with olive oil makes a good stimulating liniment. If too much snlphuric acid is added, either by mistake or wilfully, it inflames and corrodes the stomach and bowels. The proper antidotes in this case are magnesia, or the carbonate of soda or potash, with soft soap. The acid might possibly be neutralizer by this combination.

ADEPS, Hog's LARD, very properly forms the basis of most of our ointments. It is tasteless, inodorous, and free from every stimulating quality. That cannot be said of all the ingredients used in the composition of onr unguents.

Alcohol, Rectified Spirit.-This is necessarily used in many of onr tinctures and other preparations, and is sometimes given to the horse in almost a pure state. Some horses that are compelled to travel far and quickly, show evident 
fatigue before they arrive at the end of their journey. A cordial or carminative tincture, to the extent of three or four ounces, largely diluted, may occasionally be given, and they rally, and cheerfully pursue their course to the end. The groom or the stableman gives the gin or whiskey of the country, in preference to any other stimulant. In cases of thorough fatigue the Daffy's Elixir may be administered, and probably reudered more stimulant by the addition of pepper. Mr. Bracy Clark recommends four ounces of the tincture of allspice in cases of gripes. On the other hand, some veterinary surgeons have preferred simple hot water, or the infusion of several of our medicinal herbs, as peppermint, rosemary, \&c. We should be loath, except on extraordinary occasions, to advocate the use of any spirituous drink.

Alozs.-Tbere are two kinds used in horse practice, the Barbadoes and the Cape. The Socotrine, preferred by the human surgeon, are very uncertain in their effect on the horse, and are seldom to be met with pure. Of the Barbadoes and the Cape, the first are much to be preferred. They are obtained principally from the island of Barbadoes, and are the juice of the large leaves of the aloe, boiled to a considerable thickness, and then poured into gourds in which they gradually harden. The true Cape are the extract of a species of aloes chiefly cultivated at the Cape of Good Hope. The Barbadoes aloes are black, with a shade of brown, of an unctuous feeling, with a stronger smell, broken with difficulty, and the fracture dull. The Cape are darker coloured, stronger smelling, very brittle, and the fracture jerfectly glossy. Every veterinary surgeon who nses much aloes should buy them in the mass, and powder them at home, and then, by attending to this account of the difference of the two, he can scarcely be imposed upon. It is, however, the fact, that these are mostly adulterated, by their being melted together. Aloes purchased in powder are too often sadly adulterated.

The Cape aloes may be powdered at all times, and the Barbadoes in frosty weather, when enough should be prepared, to be kept in closed lottles, for the year's consumption. They may also be powdered when they have been taken from the gourd, and exposed to a gentle heat for two or three hours before they are put into the mortar. In the proportion of fifteen ounces of the powder mixed with one ounce of powdered ginger, and beaten up with eight ounces of palm oil, and afterwards divided into the proper doses, it will form a purging mass more effectual, and much less likely to gripe, than any that can be procured by melting the drug. If the physic is given in the shape of a ball it more readily dissolves in the stomach, and more certainly and safely acts on the bowels when mingled with some oily matter, like that just recommended, than when combined with syrup or honey, which are apt to ferment, and be themselves the cause of gripes. It is also worse than useless to add any diuretic to the mass, as soap or carbonate of soda. The action of these on one set of organs will weaken that of the aloes on another. A plysic mass should never be kept more than two or three months, for, after that time, it rapidly loses its purgative property.

Directions for physicking will be found at p. 403. We will only add that, as a promoter of condition, the dose should always be mild. A few fluid stools will be sufficient for every good purpose. Violent disease will alone justify violent purging.

The Barbadoes aloes have a greater purgative power than the Cape, exclusive of griping less and being safer. In addition to this, the action of the bowels is kept up longer by the Barbadoes aloes than by the Cape. If the horse is well mashed, and carefully exercised, and will drink plenty of warm water, the Cape may be ventured on, or at least mixed with equal quantities of the Barbadoes; but if there is any neglect of preparation for physic, or during the usual operation of the phrsic, the Cape are not always to be depended upon. The combination of alkaline compounds with aloes alters the results of the medicine. Their action is quickened, but their purgative properties are impaired, and they cease to operate specifically on the larger intestines. Such is the opinion of Professor Morton, and undoubtedly the latter would be an advantage gained. The activity of the aloes may be occasionally increased by a few drops of the croton oil. Mashes are useful helps when physic is administered.

Some persons are fond of what are called halfdoses of physic. Three or four drachms are given on one day, and three or four on the following; and perhaps, if the medicine has not operated, as in this divided state it will not always, two or three additional drachms are given on the third day. The consequence is, that the bowels having been rendered irritable by the former doses, the horse is orer-purged, and inflammation and death occasionally ensue. In physicking a horse, whatever is to be done should he done at once. Whatever quantity is intended to be given should be given in one dose.

The system of giving small doses of aloes as alteratives is not good. These repeated minute doses lodging in some of the folds of the intestines, and at length uniting, often produce more effect than is desirable. It is never safe to ride a horse far or fast, with even a small dose of aloes within him.

Most of all objectionable is the custom of giving small doses of aloes as a nauseant, in inflammation of the lungs. There is so much 
sympathy between the contents of the chest and the belly in the horse, and inflammation of one part is so likely to be transferred to another, that it is treading on very daugerous ground, when with much inflammation of the lungs, that is given which will stimulate and may inflame the intestines.

Aloes are most cominonly, because most easily, administered in the form of ball, but in a state of solution their effect is more speedy, effectual, and safe.

Aloes are useful in the form of tincture. Eight ouuces of powdered aloes, and one ounce of powdered myrrh, may be put into two quarts of rectified spirit, diluted with an equal quantity of water. The mixture should be daily well shaken for a fortnight, and then suffered to stand, in order that the undissolved portion may fall to the bottom. This will constitute a very excellent application for wounds, whethor recent or of long standing and inlisposed to heal. It is not only a gentle stim. ulant, but it forms a thin crust over the wound, and shields it from the action of the air.

The principal adulteration of aloes is by means of resin, and the alteration of colour is concealed by the addition of charcoal or lamp-black. This adulteration is easily enough detected by dissolving the aloes in hot water. All aloes contaiu some resinous matter, which the water will not dissolve and which has very slight purgative effect. The excess of this resin at the bottom of the solution will mark the degree of adulteration.

Alteratives are a class of medicines the nature and effect of which are often much misunderstood, and liable to considerable abuse. It is a very convenient name in order to excuse that propensity to dose the horse with medicines, which is the disgrace of the groom, and the bane of the stable.

By alteratives we understand those drugs which effect some slow change in the diseased action of certain parts without interfering with the food or work; but by common consent the term seems to be confined to mediciues for the diseases of the circulation, or of the digestive organs, or of the skiu. If a horse is lieavy and incapable of work from too good keep, or if he is off his food from some temporary indigestion-or if he has mange or grease, or cracked heels, or swelled legs, a few alteratives are prescribed, and the complaint is expected to be gradually and imperceptibly removed. For all skin affections there is no better alterative than that so often recommended in this treatise, consisting of black antimony, nitre, and sulphur. If there is any tendency to grease, some resin may be applied to each ball. If the complaint is accompanied by weakness, a little gentian aud giuger may be further added but; we enter our protest against the ignorant use of mercury in any form, or any of the mineral acids, or mineral tonics, or heating spices, as alteratives. We indeed should be pleased if we could banish the term alterative from common usage. The mode of proceeding which reason and science would dictate is to ascertain the nature and degree of the diseise, and then the medicine which is calculated to restore the healtliy action of the part, or of the frame generally.

Alum is occasionally used internally in cases of super-purgation in the form of alum-whey, two drachms of the powder being added to a pint of hot milk; but there are much better astringents, although this may sometimes succeed when others fail. If alum is added to a vegetable astringent, as oak-bark, the power of both is diminished. Its principal use is external. A solution of two draclums to a pint of water forms alone, or with the addition of a small quantity of white ritrol, a very useful wash for cracked heels, and for grease geuerally; and also for those forms of swelled legs attended with exudation of moisture through the skin. Some add the Goulard lotion, forgetting the chemical decomposition that takes place; the result of which is, that the alumine, possessing little astringency, is detached, and two salts, with no astringency at all, the sulphrate of lead and the sulphate of potash, are formed.

The Burnt Alum is inferior to the common alum for the purposes mentioned, and we have better stimulants, or causties, to apply to wounds.

Ampovia is, to the annoyance of the horse, and the injury of his eyes and his lungs, plentifully extricated from the putrifying dung and urine of the stable, but when combined with water in the common form of hartshorn, it is seldom used in veterinary practice. It has been given, and with decided benefit, and when other things have failed, in flatulent colic ; and is best administered in the form of the aromatic spirit of ammonia, and in doses of one or two ounces, in warm water.

Chloride of Amsonia, or sal ammoniac, is scarcely deserving of a place in our list. It is not now used internally; and as an astringent embrocation, it must yield to several that are more ef fectual, and less likely to blemish.

Axisi Semixa, Anise-seed.-This seed is here mentioned principally as a record of old times, when it was one of the sheet-auchors of the farrier. It is not yet quite discarded from his shop as a stimulant, a carminative, and a cordial.

Anodynes.- Of these there is but one in horse practice: Opium is the only drug that will lull pain. It may be given as an anodyue, but it will also be an astringent in doses of one, two, or three drachms.

Antimons.-There are several valuable preparations of this metal.

The Black Sesqui-Sulphuret of Antmont, a compound of sulphur and antimony, is a good 
alterative. It is given with more sulphur and with nitre, in varying doses, according to the disease, and the slow or rapid effect intended to be produced. It should never be bought in powder, whatever trouble there may be in levigating it, for it is often grossly adulterated with lead, manganese, forge-dust, and arsenic. The adulteration may be detected by plaeing a little of the powder on a red-hot iron plate. The pure sulphuret will evaporate without the slightest residue-so will the arsenic : but there will be an evident smell of garlic. A portion of the lead and the manganese will be left behind.

Antimonit Potassio Tartras, Emetic Tartar. -The tartrate of potash and antimony, or a combination of super-tartrate of potash and oxide of antimony, is a very useful nauseant, and has considerable effect on the skin. It is particularly valuable in inflammation of the lungs, and in every catarrhal affection. It is given in doses of from one drachm to a drachm and a half, and combined with nitre and digitalis. It is also beneficial in the expulsion of worms. It should be given in doses of two drachms, and with some mechanical vermifuge, as tin filings, or ground glass, and administered on an empty stomach, and for several successive days. Although it may sometimes fail to expel the worms, it will materially improve the condition of the horse, and produce sleckness of the coat. To a slight degree the emetic tartar is decomposed by the action of light, and should be liept in a jar, or green bottle. It is sometimes adulterated with arsenic, which is detected by the garlic smell when it is placed on hot iron, and also ly its not giving a beautiful gold-colowed precipitate when sulphuret of ammonia is added to a solution of it. It has also been externally applied in chest affections, in combination with lard, and in quantities of from one drachm to two drachms of the autimony, to an ounce of the lard; but, except in extreme cases, recourse should not be had to it, on account of the extensive sloughing which it sometimes produces.

Pulvis Antimonir Compositus, The Compound Powder of Antrimony.-Commonly known by the name of James's Pouder. It is employed as a sulorific in fever, either alone or in combination with mercurials. The dose is from one to two diachms. The late Mr. Bloxam used to trust to it alone in the treatment of Epidemic Catarrh in the horse. It is, however, decidedly inferior to Emetic Tartar. It is often adulterated with chalk and lurnt bones, and other white powders, and that to so shameful a degree, that little dependence can le placed on the antimonial powder usually sold by druggists. The muriatic or sulphuric acids will detect reost of these adulterations

ANTI-SPASMODICS. - Of these our list is scanty, for the lorse is subject only to a few spasmodic diseases, and there are ferrer medicines which have an anti-spasmodic effect. Opium stands tirst for its general power, and that exerted particularly in locked jaw. Oil of turpentine is almost a specific for spasm of the bowels. Camphor, assafoetida, and various other medicines, used on the human sulject, have a very doubtful effect on the horse, or may be considered as almost inert.

Argextum, Silver.-One combination only of this metal is used, and that as a mauageable and excellent caustic, viz., the Lunar Caustic. It is far preferable to the bot iron, or to any acid, for the destruction of the part if a horse sbould have been bitten by a rabid $\log$; and it stands next to the butyr of antimony for the removal of fungus generally. It has not yet been administered internally to the horse.

Arsexicum, Arsenic.- This drug used to be employed as a tonic, in order to core out old ulcers; but it is now seldom employed, for there are better and safer tonics, and far better and safer caustics. The method of detecting the presence of arsenic in cases of poisoning has been described at p. 394.

BALLs. - The usual and the most convenient mode of administering veterinary medicines is in the form of balls, compounded with oil, and not with honey or syrup, on account of their longer keeping soft and more easily dissolving in the stomach. Balls should never weigh more than an ounce and a half, otherwise they will be so large as not to pass without difficulty down the gullet. They should not be more than an inch in diameter and three inches in length. The mode of delivering balls is not difficult to acquire; but the balling-iron, while it often wounds and permanently injures the bars, occasions the hurse to struggle more than he otherwise would against the administration of the medicine. The horse should be backed in the stall; the tongue sliould be drawn gently out with the left hand on the off side of the mouth, and there fixed, not by continuing to pull at it, but by pressing the fingers against the side of the lower jaw. The ball, being now taken between the tips of the fingers of the right hand, is passed rapidly up the mouth, as near to the palate as possible, until it reaches the root of the tongue. It is then delivered with a slight jerk, and the hand being immediately withdrawn and the tongue liberated, the ball is forced through the pharynx into the cesophagus. Its passage should be watched down the left side of the throat; and if the passage of it is not seen going down, a slight tap or blow under the chin will generally cause the horse to swallow it, or a few gulps of water will convey it ínto the stomach. Very few balls should be kept ready made, for they may become so hard as to be incapable of passing down the gullet, or dissolving in the stomach, and the life of the horse may be endangered or lost. 
This is peculiarly liable to be the case if the ball is too large, or wrapped in thick paper.

Bark, Plinvian. - A concentrated preparation of this is entitled the Sulphate of Quisine. The simple bark is now seldom used. If it has any good effect, it is in dialsetes. The quinine, however, is strongly recommended by Professor Morton, as singularly efficacious in the prostration of strength which is often the consequence of influenzia.

BAsilicon is a valuable digestive ointment, composed of resin, bees'-wax, and olive-oil. If it is needed as a stimulant, a little turpentine and verdigris may be added.

Beliadonxe Extractum, Extract of Deadly Nightshade. - The inspissated juice is principally used as a narcotic and sedative, and indicated where there is undue action of the nervous and rascular systems, as in tetanus, carditis, and nerrous affections generally. Externally, it is beneficially applied to the eye.

Birsters are applications to the skin which separate the cuticle in the form of vesicles containing a serous fluicl. They excite increased action in the ressels of the skin by means of which this fluid is thrown out. The part or neighbouring parts are somewhat relieved by the discharge, but more by the inflammation and pain that are produced, and lessen that previonsiy existing in some contiguous part. On this principle we account for the decided relief often obtained by blisters in inflammation of the lungs, and their efficacy in abating deeply-seated disease, as that of the tendons, ligaments, or joints; and also the vecessity of previously removing, in these latter cases, the superficial inflammation caused by them, in order that one of a different kind may be excited, and to which the deeply-seated inflammation of the part will be more likely to yield. The blisters used in horse-practice are composed of cantharides or the oil of turpentine, to which some have added a tincture of the croton-nut.

For some important remarks on the composition, application, and management of the blister, see p. 493.

Bole Armeniax is an argillaceous earth combined with iron, and is supposed to possess some astringent property. The propriety of its being administered inwardly is doubtful ; for it may remain in the intestiual caual, and become the uncleus of a calculus. On account of its supposed astringency, it is employed exterually to give consistence to ointments for grease. Eren the bole Armenian has not escaped the process of adulteration, and is largely mixed with inferior earths. The fraud may be suspected, but not satisfactorily detected, by the colour of the porder, which slould be a bright red.

Catamine.- See Zinc.
Calomer.-Sce Mercury.

Campron is the produce of one of the laurus species, a native of Japan, and too often imitated by passing a stream of chlorine through oil of turpentine. Accorling to Professor Morton, it is a narcotic. It diminishes the frequency of the pulse, and softens its tone. When long exhilited, it acts on the kidneys. Externally applied, it is said to be a discutient and an anolyne for chronic sprains, bruises, and tumours. The camphor ball is a favourite one with the groom, and occasionally administered by the veteriuary surgeon. Mr. WV. C. Spooner uses it, mixed with opium, in cases of locked jaw, and in doses of from one to two drachms. In the form of camphorated oil, it pro. motes the absorption of fluids thrown out beneath the skin, the removal of old callus, and the suppling of joints stiff from labour. Combined with oil of turpentine it is more effective, but in this combination it occasionally blemishes.

Cantharides are the basis of the most approved and useful veterinary blisters. The cantharis is a fly, the native of Italy and the south of France. It is destroyed by sulphur; dried and powdered, and mixed with palm oil and resin in the proportions directed at p. 392. Its action is intense, and yet superficial; it plentifully raises the cuticle, yet rarely injures the true skin, and therefore seldom blemislues. The application of other acrid substances is occasionally followed by deeply-seated ulcerations; but a blister composed of the Spanish fly alone, while it does its duty, leaves, after a few weeks have passed, scarcely a trace behind.

The art of blistering consists in cutting, or rather shaving, the hair perfectly close; then well rubling in the ointment, for at least ten minutes; and, afterwarls, and what is of the greatest cousequeuce of all, plastering a little more of the ointment lightly over the part, and leaving it. As soon as the resicles have perfectly risen, which will be in tweuty or twenty-four hours, the torture of the animal way be somewhat relieved by the application of olive or neat's-foot oil, or any emollient ointment.

When too exteusive a blister has been em. ployed, or, from the intensity of the original inHammation, the blister has not risen, (for no two inteuse inflammations can exist in neighbouring parts at the same lime,) strangury - great difficulty in passiug urine, and even suppression of it, has occurred. The careful washing off of the blister, and the administration of plenty of warm water, with opium, and bleeding if the symptoms run high, will generally remove this unpleasant effect. An infusion of two onnces of the flies in a pint of oil of turpentine, for several days, is occasionally used as a liquid blister; and, when sufficiently lowered with common oil, it is called a sueating 
oil, for it maintains a certain degree of irritation and inflammation on the skin, yet not sufficient to blister, and thus gradually abates or removes some old or deep inflammation, or canse of lameness.

Of late cantharides have come into more general use. They were recommended by $\mathrm{Mr}$. Vines, in combination with vegetable bitters, as a stimulating tonic, in cases of debility. He next applied them for the cure of Glanders, and with considerable success. The Veterinary public is much indebted to Mr. Vines, for the steadiness with which he has followed up the employment of the Spanish fly. The dose is from five to eight grains given daily, but withheld for a day or two when diuresis supervenes.

Capsici Bacca, Capsicun Berries. -They are valuable as stimulants affecting the system generally, yet not too much accelerating the pulse. Their beneficial effect in cases of cold, has seldom been properly estimated. The dose is from a scruple to half a drachm.

Carui Semina, Caraway Seeds. These and ginger, aloue or combiued, are the best stimulauts used in horse-practice.

Cascarille Cortex, Cascarilla Bark.Tonic as well as aromatic. It must not, however, be used with the sulphates of iron or zinc.

Castor Oil, Oleum Ricini.-An expensive medicine. It must be giren in large doses, and even then it is nncertain in its effects. Mild as is its operation in most animals, it sometimes gripes and even endangers the horse.

Catechu, Japan Earth, yet, no earth, but extracted from the wood of one of the acacia trees, is a rery useful astringent. It is given in superpurgation, in doses of one or two drachms, with opium, as a yet more powerîul astringeut ; chalk, to neutralize any acid in the stomach or bowels; and pordered gum, to sheath the over-irritated mucous coat of the intestines. It is not often adulterated in our country, but grossly so abroad, fine sand and aluminous earth being mixed with the extract. It is seldom given with any alkali, yet the prescription just recommended contains chalk: but, although the chalk, as an alkali, may weaken the astringency of the catechn, it probably neutralizes some acid in the stomach or bowels, that would have diminished the power of the catechu to a greater degree. It must not be given in conjunction with any metallic salt, for the tanuin or gallic acid, on which its power chiefly or entirely depends, has an affinity for all metals, and will unite with them, and form a gallate of them, possessing little astringent energy. Common ink is the uuion of this tannin principle with iron.

A tincture of catechu is sometimes made by macerating three ounces of the powder in a quart of spirit for a fortnight. It is an excellent appli- cation for wounds; and, with the aloes, constitutes all that we want of a balsamic nature for the purpose of hastening the healing process of wounds.

Caustics are substances that burn or destroy the parts to which they are applied. First among them stands the red-hot iron, or actual cautery, and then pure alkalies, potash, and soda, and the sulphuric and nitrous acids. Milder caustics are found in the sulplate of copper, red precipitate, burnt alum, and vedigris. They are principally used to destroy fungous excrescences, or stimulate indolent tumours, or remove portions of cellular substance, or muscle infected by any poison.

Creta Preparata, ChilK, is principally used in combination with catechu and opium in cases of super-purgation. All adventitious matters are removed by washing, and the prepared or levigated chalk remains in the form of an impalpable powder. It is usually atministered in doses of two or three ounces. It is externally applied over ulcers that discharge a thin and ichorous matter.

Chamomile, Antuemis. - The powder of the flower is a useful vegetable tonic, and the mildest in our list. It is given in doses of one or two drachms, and is exhibited in the early stage of convalescence in order to ascertain whether the febrile stage of the disease is passed, and to prepare the way for a more powerful tonic, the gentian. If no acceleration of pulse, or heat of mouth, or indication of return of ferer, accompanies the cautious use of the chamomile, the gentian, with carbonate of iron, may be safely ventured upon; but if the gentian had been first used, and a little too soon, there might have been considerable, and perhaps dangerous return of fever.

Chancoal is occasionally used as an antiseptic, being made into a poultice with linseed meal, and applied to foul and offensive ulcers, and to cracked heels. It removes the fotid and unwholesome smell that occasionally proceeds from them.

CHARges are thick adhesive plasters spread over parts that lave been strained or weakened, and, being applied to the skin, adhere for a considerable time. The following mixture makes a good charge:-Burgundy or common pitch, five ounces; tar, six ounces ; yellow wax, one ounce, melted together, aud when they are becoming cool, half a drachm of powdered cantharides well stirred in. This must be partially melted afresh when applied, and spread on the part with a large spatula, as hot as can be done without giving the animal too much pain. Flocks of tow should be scattered over it while it is warm, and thus a thick and adhesive covering will be formed that cannot be separated from the skin for many months. It is used for old sprains of the loins, and also strains of the back sinews. The charge acts in three ways-by the slight stimulant power which it possesses it gradually removes all deep- 
seated inflammation; by its stimulus and its pressure it promotes the absorption of any callus or thickening beneatl, and, acting as a constant bandage, it gives tone and strength to the part.

Clysters.-These are useful and too often neglected means of hastening the evacuation of the bowels when the disease requires their speedy action. The old ox-bladder and wooden pipe may still he employed, and a considerable quantity of fluid thrown into the intestine; but the patent stomach and clyster pump of $\mathrm{Mr}$. Reid is far preferable, as enabling the practitioner to inject a greater quantity of fluid, and in a less time.

Two ounces of soft or yellow soap, dissolved in a gallon of warm water, will form a useful aperient clyster. It will detach or dissolve many irritating substances that may have adhered to the mucous coat of the bowels. For a more active aperient, half a pound of Epsom salts, or even of common salt, may be dissolved in the same quantity of water. A stronger injection, but not to be ased if much purgative medicine has beeu previously given, may be composed of an ounce of Barbadoes aloes, dissolved in two or three quarts of warm water. If nothing else can be procured, warm water may be employed; it will act as a fomentation to the inflamed and irritable surface of the bowels, and will have no inconsiderable effect even as an aperient.

In cases of over-purging or inflammation of the bowels, the injection must be of a soothing nature. It may consist of gruel alone, or, if the purging is cousiderable, and difficult to stop, the gruel must be thicker, and four ounces of prepared or powdered chalk well mixed with or suspended in it, with two scruples or a drachm of porrdered opium.

No oil should enter into the composition of a clyster, except that linseed oil may be used for the expulsion of the ascarides, or needle-worms.

In epidemic catarrh, when the horse sometimes obstinately refuses to eat or to drink, his strength may be supported by nourishing clysters; but they should consist of thick gruel only, and not more than a quart should be administered at once. A greater quantity would be ejected soon after the pipe is withdrawn. Strong broths, and more particularly ale and wine, are dangerous ingredients. They may rapidly aggravate the fever, and should never be adninistered, except under the superinteudence, or by the direction, of a reterinary surgeon.

The principal art of administering a elyster consists in not frightening the horse. The pipe, well oiled, should be very gently introduced, and the fluid not too lastily thrown into the intestine; its heat being as nearly as possible that of the intestiue, or about $96^{\circ}$ of Fahrenheit's thermometer.
Collyria, Lotions for the Exes.-These have been sufficiently described when iuflammation of the eyes was treated of.

Copaiba, Barsam of Capivi.-The resin is obtained from a tree growing in South America and the Wiest India Islands. It is expensive, much adulterated, and seldom used; for its properties differ but little from those of common diuretics.

Copper.-There are two combinations of this metal used in veterinary practice : the rerdigris or subacetate, and the blue vitriol or sulphate.

Verdigris or Subacetate of Copper is the common rust of that metal produced by subjecting it to the action of acetic acid. It is given internally by some practitioners, in doses of two or three drachms daily, as a tonic, and particularly for the cure of farcy. It is, however, an uncertain and dangerous medicine. The corrosive sublimate, with regetable tonics, as recommended at p. 320 , is preferable. Verdigris is, however, usefully applied externally as a mild caustic. Either alone, in the form of fine powder, or mixed with an equal quantity of the sugar (superacetate) of lead, it eats down proud flesh, or stimulates old ulcers to healthy action. When boiled with honey and vinegar, it constitutes the farriers' Egyptiacum, certainly of benefit in cankered or ulcerated mouth, and no bad application for thrushes; but yielding, as it regards both, to better remedies, that are mentioned under the proper heads. Some practitioners use alum and oil of vitriol in making their Egyptiacum, forgetting the strange decomposition which is produced.

Blue Vitriol or Sulphate of Copper is the union of sulphuric acid and copper. It is a farourite tonic with many practitioners, and has been vaunted as a specific for glanders; while others, and we think properly, have no very good opinion of it in either respect. As a cure for glanders, its reputation has nearly nassed away. As a tonic, when the horse is slowly recorering from severe illness, it is daugerous, and its internal use should be confined to cases of long-continued discharge from the nostril, when catarrh or ferer have ceased. It may then be given with benefit in doses of from one to two drachms twice in the day, and always combined with gentian and ginger. It is principally valuable as an external application, dissolved in water in the proportion of two drachus to a pint, and acting as a gentle stimulant. If an ounce is dissolved in the same quautity of water, it becomes a mild caustic. In the former proportion it rouses old ulcers to a healthy action, and disposes eren recent wounds to heal more quickly than they otherwise would do ; and in the latter it removes fungous granulations or proud flesh. The blue vitriol is sometimes reduced to powder and sprinkled upon the 
wound for this purpose : it is also a good application for canker in the foot.

Cordials are useful or injurious according to the judgment with which they are given. When a horse comes lome thoroughly exhausted, and refuses his food, a cordial may be beneficial. It may rouse the stomach and the system generally, and may prevent cold and fever; but it is poison to the animal when administered after the cold is actually caught and fever begins to appear. More to be reprobated is the practice of giving frequent cordials, that by their stimulus on the stomach (the skin sympathising so much with that viseus) a fine coat may be produced. The artificial excitement of the cordial soon becomes as zecessary to enable the horse to do even common work, ns is the excitement of the dram to sustain the animal spirits of the drunkard.

In order the recal the appetite of the lorse slowly recovering from illness, a cordial may sometimes be allowed; or to old horses that have been worked hard and used to these excitements when young; or to draught horses, that have exhibited slight symptoms of staggers when their lahour has been unusually protracted and their stomachs left too long empty; or mixed with diuretic medicine, to fine the legs of the overworked and debilitated animal; bnt in no other case should they obtain a place in the stable, or be used at the discretion of the carter or the groom.

Corrosive Sublimate.-See Mercury.

Creasote has very lately been introdnced into veterinary practice, and is much valued on account of its antiseptic properties. It is obtained by the destructive distillation of rarious substances, as pyroligneous acid, tar, wood smoke, \&c. Pure creasote is colourless and transparent; its odour is that of smoked meat, and its taste is caustic and buruing. It coagnlates the albumen of the blood, and hence has heen lately employed in stopping hrmorrhages. It acts very powerfully on the general system, and quickly destroys small animals. Professor Morton gives a very interesting and faitliful account of it. It is, according to him, both a stimulant and a tonic. In an undiluted state it acts as a caustic. When diluted it is a general excitant and an antiseptic. In the form of a lotion, a liniment, or an ointment, it lias been useful in farey and glanders, also in foot-rot, canker, and thrusli,-—mange, caries, excessive suppuration, and the repression of fungous granulations. As a caustic, it acts as a powerful stimulant, and it is an antiseptic.

Croton Tiglin Semina, Croton Seeds.-The croton-nut has not been long introduced into veterinary practice, althongh it has been used from time immemorial by the inlabitants of India as a powerful purgative. An oil has been extracted from it, and used by the surgeon; the meal is adopted by the veterinarian. It is given in doses from a scruple to half a drachm, aud from its acrid uature, in the form of a ball, with an ounce of linseed meal. When it does operate, the effect is generally observed in six or eight hours, the stools leing profuse and watery, and the patient frequeutly griped. On account of its speedy operation, it may be given in locked jaw and staggers; and also in dropsy of the chest or belly, from the watery and profuse stools which it produces; but it is often uncertain in its operation, and its griping, and the debility which it occasions, are serions objections to it as commou plysic. When placed on the tongue of the horse in quantities varying from treuty to forty drops, it produces purging, but the membrane of the mouth frequently becomes violeutly inflamed. This likenise happens, but not to so great a degree, when it is given in the form of a drink, or in a mash.

Desiulcents are substances that have the power of diminishing the effect of acrimonious or stimulating substances. The first, by some oily or mucilaginous substance, sheaths the sensible parts. The other dilutes the stimulus, and diminishes its power. It will rarely be difficult to determive which effect should be produced, and the means by which it is to be effected.

Diaphoretics are medicines that increase the sensible and insensible perspiration of the animal. As it regards the horse, they are neither many nor powerful. Antimony in its various forms, and snlphur, have some effect in opening the pores of the skin, and exciting its vessels to action, and especially when assisted by warmth of stable or clothing, and therefore is useful in those diseases in which it is desirable that some portion of the blood should be diverted from the overloaded, and inflamed, and vital organs of the chest, to the skin or the extremities. The only diaphoretics, however, on which much confidence can be placed, and especially to produce condition, are warn clothing and grood grooming.

Digestives are applications to recent or old wounds, as mild stimulints, in order to produce a healthy appearance and action in them, and to cause them more speedily to heal. A weak solution of blue vitriol is an excellent digestive; so is the tincture of aloes, and the tincture of myrrh. The best digestive ointment is one composed of three parts of calamine ointment (Turner's cerate) and one of common turpentine.

Digitalis. - The leaves of the common foxglove, gathered about the flowering time, dried carefully in a dark place, and powdered, and kept in a close black bottle, form one of the most valuable medicines in veterinary practice. It is a direct and powerful sedative, diminishing the frequency of the pulse, and the general irritability of the system, and acting also as a mild diuretic; 
it is therefore useful in every inflammatory and febrile complaint, and particularly in inflammation of the chest. It is usually given in combination with emetic tartar and nitre. The average dose is one drachm of digitalis, one and a half of emetic tartar, and three of nitre, repeated twice or thrice in the day.

Digitalis seems to have an immediate effect on the heart, lessening the number of its pulsations; but effecting this in a singular manner-not by causing the heart to beat more slowly, but producing certain intermissions or pauses in its action. When these become marked-when at every sixth or seventh beat, the pulsations are suspended while two or three can be slowly comited, this is preeisely the effect that is intended to be produced, and, however ill the horse may appear to be, or however alarming this intermittent pulse may seem to the standers-by, from that moment the animal will frequently begin to amend. The dose must then be diminished one-half, and, in a few days, it may be omitted altogether: but the emetic tartar and the nitre should be continued during some days after the practitioner lias deemed it prudent to try the effect of mild vegetable tonics.

There is no danger in the intermittent pulse thus produced; but there is much when the digitalis fails to produce any effect on the circulation. The disease is then too powerful to be arrested by medicine. Digitalis requires watching; but the only consequence to be apprebended from an over-dose is, that the patient may be reduced a little too low, and his convalescence retarded for a day or two.

In the form of infusion or tincture, digitalis is very useful in inflammation of the eyes. It is almost equal in its sedative influence to opium, and it may with great advantage be alternated with it, when opium begins to lose its power. The infusion is made by pouring a quart of boiling water on an ounce of the powder. When it is become cold, a portion of the liquid may be introduced into the eye. One or two drops of the tincture may be introduced with good effect. This may be obtained by macerating three ounces of the digitalis in a quart of spirit.

The infusion has been serviceable in mange; but there are better applications.

DiURetics constitute a useful but much abused class of medicines. They stimulate the kidneys to secrete more than the usual quantity of urine, or to separate a greater than ordinary proportion of the watery parts of the blood. The deficiency of water in the blood, thus occasioned, must be speedily supplied or the healthy circulation cannot be carried on, and it is geverally supplied by the absorbents taking up the watery fluid in some part of the frame, and carrying it into the circulation. Hence the evident use of diuretics in dropsical affections, in swelled legs, and also in inflammation and fever, by lessening the quantity of the circulating fluid, and, consequently, that which is sent to the inflamed parts.

All this is effected by the kidneys being stimulated to increased action; but if this stimulus is too often or too violently applied, the energy of the kidney may be impaired, or inflammation may be produced. That inflammation may be of an acute character, and destroy the patient; or, although not intense in its nature, it may by frequent repetition assume a chronic form, and more slowly, but as surely, do irreparable mischief. Hence the necessity of attention to that portion of the food which may have a diuretic power. Mowburnt hay and foxy oats are the unsuspected canses of many a disease in the horse, at first obscure, but ultimately referable to injury or inflammation of the urinary organs. Hence, too, the impropriety of suffering medicines of a diuretic nature to be at the command of the ignorant carter or groom. In swelled legs, cracks, grease, or accumulation of fluid in any part, and in those superficial eruptions and inflammations which are said to be produced by humonrs floating in the blood, diuretics are evidently beneficial; but they should be as mild as rossible, and not oftener given or continued longer than the case requires. For some cautions as to the administration of diuretics, the reader is referred to p. 409 . The expensive Castile soap, and eamphor, so often resorted to, are not needed, for the common liquid turpentine is quite sufficient in all ordinary cases, and nitre and digitalis may be added if fever is suspected.

Drinks.-Many practitioners and horse-proprietors have a great objection to the administration of medicines in the form of drinks. A drink is not so portable as a ball, it is more troublesome to give, and a portion of it is usually wasted. If the drink contains any acid substance, it is apt to excoriate the mouth, or to irritate the throat already sore from disease, or the unpleasant taste of the drug may unnecessarily nauseate the horse. There are some medicines, however, which must be given in the form of drink, as in colic; and the time, perhaps, is not distant when purgatives will be thus administered, as more speedy, and safer in their operation. In eases of much debility and eutire loss of appetite, all medicine should be given in solution, for the stomach may not lave sufficient power to dissolve the paper in which the ball is wrapped, or the substance of the ball.

An ox's horn, the larger end being cut slantingly, is the usual and best instrument for administering drinks. The noose of a lalter is introduced into the mouth, and then, by means of a stable fork, the head is elevated by an assistant consider. ably higher than for the delivery of a ball. The 

surgeon stands on a pail or stable basket, on the
off-side of the horse, and draws out the tongue with the left hand; he then with the right hand introduces the horn gently into the mouth, and over the tongue, and by a dexterous turn of the horn empties the whole of the drink-not more than about six ounces-into the back part of the mouth. The horn is now quickly withdrawn, and the tongue loosened, and the greater portion of the fluid will be swallowed. A portion of it, however, will often be obstinately held in the mouth for a long time, and the head must be kept up until the whole is got rid of, which a quick, but not violent slap on the muzzle will generally compel the horse to do. The art of giving a drink consists in not putting too much into the horn at once; introducing the horn far enough into the mouth, and quickly turn. ing and withdrawing it, without bruising or wounding the mouth, the tongue being loosened at the same moment. A bottle is a disgraceful and dangerous instrument to use, except it be a flat pint bottle, with a long and thick neck.

Frrrum, Iros.-Of this metal there are two preparations adopted by veterinarians. The rust, or Carbonate, is a mild and useful tonic in doses of from two to four drachms. The Sulphate (green vitriol or coppenas) is more powerful. It should never be given in the early stages of recovery, and always with caution. The dose should be the same as that of the carbonate. The sulphate has lately been recommended for the cure of that deceitful stage or form of glanders, in which there is nothing to characterise the disease but a very slight discharge from the nostrils. It is to be dissolved in the common drink of the horse. It is worth a trial, but too sanguine expectations must not be encouraged of the power of any drug over this intractable malady. The iron should be given in combination with gentian and ginger, but never with any alkali or nitre, or soap, or catechu, or astringent vegetable.

FEVER.-For the nature and treatment of the fever, both pure and symptomatic, reference may be made to p. 361 .

Forge water used to be a favourite tonic with farriers, and also a lotion for canker and ulcers in the mouth. It owes its power, if there be any, to the iron with which it is impregnated.

Fomentations open the pores of the skin and promote perspiration in the part, and so abate the local swelling, and relieve pain and lessen inflammation. They are often used, and with more benefit when the inflammation is somewhat deeply seated, than when it is superficial. The effect depends upon the warmth of the water, and not on any herb that may have been boiled in it. They are best applied by means of flannel, frequently dipped in the hot water, or on which the water is poured, and the heat should be as great as the hand will bear. The benefit that might be derived from them is much impaired by the absurd method in which the fomentations are conducted. They are rarely continued long enough, and when they are removed, the part is left wet and uncovered, and the coldness of evaporation succeeds to the heat of fomentation. The perspiration is thus suddenly checked; the animal suffers considerable pain, and more harm is done by the extreme change of temperature than if the fomentation had not been attempted.

Gentian stands at the head of the vegetable tonics, and is a stomachic as well as a tonic. It is equally useful in chronic debility, and in that which is consequent on severe and protracted illness. It is generally united with chamomile, ginger, and, when the patient will bear it, carbunate of iron. Four drachms of gentian, two of chamomile, one of carbonate of iron, and one of ginger, will make an excellent tonic ball. An infusion of gentian is one of the best applications to putrid ulcers.

GINGER is as valuable as a cordial, as gentian is as a tonic. It is the basis of the cordial ball, and it is indispensable in the tonic ball. Although it is difficult to powder, the veterinary practitioner should always purchase it in its solid form. If the root is large, heavy, and not worm-eaten, the black ginger is as good as the white, and considerably cheaper. The powder is adulterated with beanmeal and the sawdust of boxwood, and rendered warm and pungent by means of capsicum.

Helleborus Albus, Whtte Hellebore.This is a drastic cathartic, and should be used with great caution. It is a powerful nauseant, and lowers both the force and frequency of the pulse, and is therefore given with good effect in various inflammations, and particularly that of the lungs. In the hospital of the veterinary surgeon, or in the stable of the gentleman who will superiutend the giving and the operation of every medicine, it may be used with safety; but with him who has to trust to others, and who does not see the horse more than once in twelve or twenty-four hours, it is a dangerous drug. If it is pushed a little too far, trembling and giddiness and purging follow, and the horse is sometimes lost. The hanging of the head, and the frothing of the mouth, and, more particularly, the sinking of the pulse, will give waruing of danger; but the medical attendant may not have the opportunity of observing this, and when he does observe it, it may be too late. Its dose varies from a scruple to half a drachm. In doses of a drachm it could not be given with safety; and yet, such is the different effect of medicines given in different doses, that in the quantity of an ounce it is said to be a diuretic and a tonic, and exhibited with advantage in chronic and oustinate grease. 
Hellemonus Nioer, Bifack Heleebore.This is used mostly as a local application, and as such it is a very powerful stimulant. Mr. E. Stanley, of Banbury, frequently resorts to it in fistulons affections of the poll and withers, and with considerable success. The alscess having formed, and exit being given to the imprisoned fluid, it is allowed to discharge itself, for two or three days, being dressed with an ordinary digestive ointment. When the pus assumes a laudable character, he introduces a few portions of the fibrous part of the root, passing them down to the bottom of the sinns, and letting them remain for a fortnight or more; in the mean time, merely keeping the surrounding parts clean. On examination it will be found that the healing process has commenced.

Professor Morton adds, that an ointment, formed of the powder of either the black or white Hellebore, in the proportion of one part of the powder to eight of lard, will be found exceedingly active for the dressing of rowels and setons.*

HemLock is used by some practitioners, instead of digitalis or bellebore, in affections of the chest, whether acute or chronic ; but it is inferior to both. The dose of the powder of the dried leaves is about a drachm.

Hydrargraum. - This metal is found native in many countries in the form of minute globules. It also occurs in masses, and in different varieties of crystallization. It has the singular property of being liquid in the natural temperature of our earth. It freezes, or assumes a singnlar species of crystallization, at $39^{\circ}$ below 0 of $\mathrm{Fah}$, and at $660^{\circ}$ above 0 of Fah. it boils, and rapidly eraporates. In its metallic state it appears to have no action on the animal system, but its componnds are mustly powerful excitants, and some of them are active canstics.

The Common Mercurial Ointment may be used for ring-worm, and that species of acarus which seems to be the sonrce, or the precursor, of mange. The componnd mercurial ointment is also useful in the destruction of the same insect. For most eruptions connected with or simulating mange, the author of this work has been accustomed to apply the following ointment with considerable success:-

$$
\begin{aligned}
& \text { Sublimed sulphur . . . . . } 1 \mathrm{lb} \text {. } \\
& \text { Common turpentine . . . . } 4 \text { oz. } \\
& \text { Mercurial ointment . . . } 2 \mathrm{oz} \text {. }^{\circ} \\
& \text { Linseed oil . . . . . . } 1 \text { pint. }
\end{aligned}
$$

The Mercurial Ointment is prepared by rubbing quicksilver with lard, in tlre proportion of one part af mercury to three of lard, until no globules appear. The practitioner should, if possilule, prepare it himself, for he can seldom get it pure or of the proper strength from the druggist.
It is employed with considerahle advantage in preparing splents, spavins, or other bony or callous tumours, for blistering or firing. One or two drachms, according to the nature and size of the swelling, may be daily well rubbed in; but it should be watched, for it sometimes salivates the horse very speedily. The tumours more readily disperse, at the application of a stronger stimnlant, when they have been thus prepared. Mercurial ointment in a weaker state is sometimes necessary for the cure of mallenders and sallenders; and in very obstinate cases of mange, one-eighth part of mercurial ointment may be added to the ointment recommended at p. 525 .

Calomel, the submuriate or protochloride of mercury, may be given, combined with aloes, in mange, surfeit, or worms. It is also useful in some cases of chronic cough, in farcy, and in jaundice. Alone it has little purgative effect on the horse, but it assists the action of other aperients. It is given in doses from a scruple to a drachm. As soon as the gums become red, or the animal begins to quid or drop his hay, it must be discontinued. Calomel has lately gained much repute in arresting the progress of epidemic catarrh in the horse. Mr. Percisall has succeeded in this attempt to a very considerable extent. In fact, the influence of calomel in veterinary practice seems to have been far too mnch undervalued. $t$

Corrosire Sublimate, the oxymuriate or bichloride of mercury, combined with chlorine in a double proportion, is a useful tonic in farcy. It should be given in doses of ten grains daily, and gradually increased to a scruple, until the horse is purged, or the mouth becomes sore, when it may be omitted for a few days, and resumed. Some have recommended it as a diuretic, bnt it is too daugerous a medicine for this purpose. It is used externally in solution; in substance in quittor, as a stimulant to foul ulcers; and in the proportion of five grains to an ounce of rectified spirit in obstinate mange, or to destroy vermin on the skin. It is, however, too uncertain and too dangerons a medicine for the horse-proprietor to venture on its use.

Ethiop's Mineral, the black sulphuret of mercury, is not often used in horse practice, but it is a good alterative for obstinate snrfeit or foulness of the skin, in doses of three drachms daily. Four drachms of cream of tartar may be advantageously added to each dose.

Infusions.--The active matter of some regetable substances is partly or entirely extracted by water. Dried vegetables yield their properties more readily and perfectly than when in their green state. Boiling water is poured on the substance to be infused, and which should have been 
previously pounded or powdered, and the vessel then covered and placed near a fire. In five or six hours the transparent part may be poured off, and is ready for use. In a few days, however, all infusions become thick, and lose their virtue, from the decomposition of the vegetable matter.

The infusion of chamomile is advantageously used instead of water in compounding a mild tonic drench. The infusion of catechu is useful in astringent mixtures; that of linseed is nsed instead of common water in catarrh and cold; and the infusion of tobacco in some injections.

IoDrNe.-This substance has not been long introduced into reterinary practice. The first object which it seemed to accomplish, was the reduction of the enlarged glands that frequently remain after catarrh, but it soon appeared that it could reduce almost every species of tumour. Much concerned in the first introduction of iodine iuto veterinary practice, the writer of the present work bears willing testimony to the zeal aud success of others, in establishing the claims of this most valuable medicine. Professor Morton has devoted much time and labour to the different combinations of iodine, and they are described at length in his usefu] "Nanual of Pharmacy." $\mathrm{He}$ gives the formula of the composition of a liniment, an ointment, and a tincture of iodine, adapted to different species and stages of lisease. He next describes the preparatiou of the iodide of potassium - the combination of iodine and potash, - and theu the improvement on that under the name of the diniodide of copper-the union of two parts of the iodide of potassium with four of the sulphate of copper.

The action of this compound is an admirable tonic and a stimulant to the absorbent system, if comlined with regetable tonies, and, occasionally, small doses of cantharides. Professor Spooner and Mr. Daws applied this compound, and with marked success, to the alleviation of farcy, nasal gleet, and glanders. It is pleasing to witness these trinmphs over disease, a little while ago so unexpected, and now so assured.

JUNIPER, OIL OF.-This essential oil is retained because it has some diuretic property, as well as being a pleasant aromatic. It frequently enters iuto the composition of the diuretic ball.

Lead, Plumbum.-The Carbonate of Lead lias a deleterious effect on the biped and the quadruped in the neighbourhood of lead works. They are subject to violent griping pains, and to coustipation that can with great difficulty, or not at all, be overcome. Something of the same kind is occasionally observed in the cider counties, and the "painter"s colic" is a circumstance of too frequient occurrence-the occasional dreadful pains, and the ravenous appetite extending to everything that comes in the way of the animal. Active purgatives followed by opium are the most effectual remedies.

The Acetate of Lead, Plumbi Acetas.-Sugar of Lead is seldom giren exterually to the horse, but is used as a collyrium for inflammation of the eyes.

The Liquor Plumbi Subacetatis, or Goulard's Extract, or, as it used to be termed at the Veterinary College, the Aqua Vegeto, is a better collyrium, and advantageously used in external and superficial inflammation, and particularly the inflammation that remains after the application of a blister.

LIME was formerly sprinkled over cankered feet, and greasy heels, but there are less painful caustics, and more effectual absorbents of moisture. Lime-water is rarely used, but the Chloride of Lime is exceedingly valuable. Diluted with twenty times its quantity of water, it helps to form the poultice applied to every part from which there is the slightest offensive discharge. The fotid smell of fistulons withers, poll-evil, canker, and ill-conditioned wounds, is immediately remored, and the ulcers are more disposed to heal. When mangy horses are dismissed as cured, a washing with the diluted chloride will remove any infection that may lurk about them, or which they may carry from the place in which they have been confined. One pint of the chloride mixed with three gallons of water, and brushed over the walls and manger and rack of the foulest stable, will completely remove all infection. Professor MLorton, very properly, says that the common practice of merely whitewashing the walls serves only to cover the infectious matter, and perhaps to preserve it for an indefinite length of time, so that when the lime scales off, disease may be again engendered by the exposed virus. The horse furniture worn by a glandered or, mangy animal will be effectually purified by the chloride. Internally administered, it seems to have little or no power.

Lininexts are oily applications of the consistence of a thick fluid, and designed either to soothe an inflamed surface, or, by gently stimulating the skin, to remove deeper-seated pain or inflammation. As an emollient liniment, one composed of half an ounce of extract of lead and four ounces of olive oil will be useful. For sprains, old swellings, or rheumatism, two ounces of hartshorn, the same quantity of camphorated spirit, an ounce of oil of turpentine, and half an ounce of landanum may be mixed together; or an ounce of camphor may be dissolved in four ounces of sweet oil, to which an ounce of oil of turpentine may be afterwards added. A little powdered cantharides, or tincture of cantharides, or mustard powcler, will render either of these more powerful, or convert it into a liquid blister. 
Lisseed.-An infusion of linseed is often used instend of water, for the drink of the horse with sore-throat or catarrh, or disease of the urinary orgaus, or of the howels. A pail containing it should be slung in the stable or loose box. Thin gruel, however, is preferalle; it is as bland and sonthing, and it is more nutritious. Liuseed meal forms the best poultice for almost every purpose.

Magnesia.-The sulphate of magnesia, or Epsom Satis, should be used only in promoting the purgative effect of clysters, or, in repeated doses of six or eight ounces, geutly to open the bowels at the commencement of fever. Some doubt, however, attends the latter practice; for the dose must occasionally be thrice repeated before it will act, and then, although safer than aloes, it may produce too much irritation in the intestinal canal, especially if the fever is the precursor of inflammation of the lungs.

Mashes constitute a very importaut part of horse-provender, whether in sickuess or healtl. A mash given occasionally to a horse that is other. wise fed on dry meat prevents him from becoming dangerously costive. To the over-worked and tired horse nothing is so refreshing as a warm mash with his usual allowance of corn in it. The art of getting a horse into apparent condition for sale, or giving him a round and plump appearance, consists prineipally in the frequent repetition of mashes, and from their easiness of digestion and the mild nutriment which they afford, as well as their laxative effect, they form the principal diet of the sick horse.

They are made by pouring boiling water on bran, and stirring it well, and then covering it over until it is sufficiently cool for the horse to eat. If in the heat of summer a cold mash is preferred, it should, nevertheless, be made with hot water, and then suffered to remain until it is cold. This is not always sufficiently attended to by the groom, who is not aware that the efficacy of the mash depends principally on the change which is effected in the bran and the other ingredients by the boiling water rendering them more easy of digestion, as well as more aperient. If the horse refuses the mash, a few outs may be spriukled over it, in order to tempt him to eat it; but if it is previously designed that corn shonld be given iu the mash, it should be scalded with the bran, in order to soften it and renler it more digestible. Bran mashes are very useful preparatives for physic, and they are necessary during the operation of the physic. They very soou become sour, and the manger of the horse of whose diet they form a principal part should be daily and carefully cleaned out.

When horses are weakly and much reduced, malt mashes will often be very palatable to them and very nutritive: but the water that is poured on a malt mash should he considerably below the boiling heat, otherwise the malt will be set, or clogged together. If the owner was aware of the value of a malt mash, it would be oftener given when the horse is rapidly getting weaker from protracted disease, or when he is begiuning to recover from a disease by which he has been much reduced. The only exception to their use is in cases of chest affection, in which they must not be given too early. In grease, and in mange accom. panied by much emaciation, malt mashes will be peculiarly useful, especially if they constitute a principal portion of the food.

Mustard, Sinapis.-This will be found occasionally useful, if, in inflammation of the chest or bowels, it is well rubbed on the chest or the abdomen. The external swelling and irritation which it excites may, to a greater or less degree, abate the inflammation within.

Mrrre may be used in the form of tincture or it may be united to the tincture of alues as a stimulating and digestive application to wounds. Diluted with an equal quantity of water, it is a good application for canker in the mouth, but as an internal medicine it seems to be inert, although some practitioners advocate its use, combined with opium, in cases of chronic cough.

Nitrous Ether, Spirt of, is a very useful medicine in the advanced stages of fever, for while it, to a certain degree, rouses the exhausted powers of the animal, and may be denominated a stimulant, it never brings back the dangerous febrile action which was subsiding. It is given in doses of three or four dracbms.

Olive $\mathrm{O}_{1 \mathrm{~L}}$ is an emollient and demulcent. Its laxative effect is very inconsiderable and uncertain in the horse.

Opiux.-However underrated by some, there is not a more valuable drug on our list. It does not often act as a narcotic, except in considerable doses; but it is a powerful antispasmodic, sedative, and astringent. As an antispasmodic, it enters into the cholic drink, and it is the sheet. anchor of the veterinarian in the treatment of tetanus or locked jaw. As a sedative, it relaxes that universal spasm of the muscular system which is the characteristic of tetauus; and, perhaps, it is only as a sedative that it has such admirable effect as an astringent, for when the irritation around the mouths of the vessels of the intestines and kidness is allajed by the opium, the undue purging and profuse staling will necessarily be arrested.

Opinm should, however, be given with caution. It is its secondary effect that is sedative, and, if giren in cases of fever, its primary effect in increasing the excitation of the frime may be very $\mathrm{conl}^{-}$ siderable, and highly injurions. In the early and voL. I. 
acute stage of fever, it would be bad practice to give it in the smallest quantity; but when the fever has passed, or is passing, there is nothing which so rapidly subdues the irritability that accompanies extreme weakness. It becomes an excellent tonic, because it is a sedative.

If the blue or green vitriol, or cantharides, bave been pushed too far, opium, sooner than any other rrug, quiets the disorder they liave occasioned. It is given in doses of one or two drachms, in the form of a ball. Other medicines are nsually combined with it, according to the circumstances of the case.

Externally, it is useful in ophthalmia. In the form of decoction of the poppy-head, it may constitute the basis of an anodyne poultice; but it must not be given in union with any alkali, with the exception of chalk, in over-purging; nor with the superacetate of lead, by which its powers are materially impaired; nor with sulphate of zinc, or copper, or iron.

From its high price it is much adulterated, and it is not always met with in a state of purity. The best tests are its smell, its taste, its toughness and pliancy, its fawn or brown colour, and its weight, for it is the heaviest of all the vegetable extracts, except gum arabic ; yet its weight is often fraudulently increased by stones and bits of lead dexterously concealed in it. The English opium is almost as good as the Turkish, and frequently sold for it; but is distinguishable by its blickness and softness.

PALM OII, when genuine, is the very best sub. stance that can be used for making masses and balls. It has a pleasant smell, and it never becomes rancid.

Pлтсн is used to give adhesiveness and firmness to charges and plasters. The common pitch is quite as good as the more expensive Burgundy pitch. The best plister for sandcrack consists of one pound of pitcli and an ounce of yellow bees'wax melted together.

Prysic.- The cases which require physic, the composition of the most effectual and safest physicball, and the mode of treatment under physic, have been already described.

Potash.-Two compounds of potash are used in veterinary practice. The Nitrate of Potash (Nitre) is a valuable cooling medicine and a mild diuretic, and, therefore, it should enter into the composition of every fever-ball. Its dose is from two to fonr drachms. Grooms often dissolve it in the water. There are two oljections to this : either the horse is nanseated and will not drink so much water as he ought: or the salt taste of the water causes considerable thirst, and disinclination to solid food. Nitre, while dissuiving, materially lowers the temperature of water, and furnishes a very eold and useful lotion for sprain of the back sinews, and other local inflammations. The lotion should be used as soon as the salt is dissolved, for it quickly becomes as warm as the surrounding air. The Bitartrate of Potash (Cream of Tartar) is a mild diuretic, and, combined with Æthiop's mineral, is used as an alterative in obstinate mange or grease. The objection, bowever, to its use in such an animal as the horse, is the little power which it seems to exercise.

Poultices.-Few horsemen are aware of the value of these simple applications in abating inflammation, relieving pain, cleansing wounds, and disposing them to heal. They are applications of the best kind continued much longer than a simple fomentation ean be. In all inflammations of the foot they are very beneficial, by softening the horn hardened by the heat of the foot and contracted and pressing on the internal and highly sensible parts. The moisture and warnth are the useful qualities of the poultice; and that poultice is the hest for general purposes in which moisture and warmth are longest retained. Perspiration is most abundantly promoted in the part, the pores are opened, swellings are relieved, and discharges of a healthy nature procured from wounds.

Linseed meal forms the best general poultice, because it longest retains the moisture. Bran, although frequently used for poultices, is oljectionable, because it so soon becomes dry. To abate considerable inflammation, and especially in a wounded part, Goulard may be added, or the linseed meal may be marle into a paste with a decoction of poppyheads. To promote a liealthy discharge from an old or foul ulcer; or separation of the dead from the living parts, in the process of what is called coring out; or to hasten the ripening of a tumour that must be opened; or to cleanse it when it is opened,-two ounces of common turpentine may be added to a pound of linseed meal : but nothing can be so absurd, or is so injurious, as the addition of turpentine to a poultice that is designed to be an emollient. The drawing poultices and stoppings of farriers are often highly injurious, instead of abating inflammation.

If the ulcer smells offensively, two ounces of powdered charcoal may be added to the linseed meal, or the poultice may be made of water, to which a solution of the chloride of lime has been added in the proportion of lialf an ounce to a pound. As an emollient poultice for greuse and cracked heels, and especially if accompanied by much unpleasant smell, there is nothing preferable to a poultice of mashed carrots with chercoal. For old grease some shight stimulant must be added, as a tle yeast or the grounds of table-beer.

There are two errors in the application of a poultice, and particularly as it regards the legs. It is often put on too tight, by means of which the return of the blood from the foot is prevented, and 
the diseasc is increased instead of lessened; or it is too hot, and numecessary pain is given, and the inflammation aggravated.

Puwders. - Some horses are very difficult to ball or drench, and the violent struggle that would accompany the attempt to conquer them may heighten the fever or inflammation. To such horses powders must be given in mashes. Emetic tartar and digitalis may be generally used in eases of inflammation or fever; or emetic tartar for worms ; or ealomel or even the farina of the croton nut for physic: but powders are too often an exeuse for the laziness or awkwariness of the carter or groom. The horse frequently refuses them, especially if his appetite has otherwise begun to fail : the powder and the mash are wasted, and the animal is unnecessarily nauseated. All medicine should be given in the form of ball or drink.

R.sкING. - This consists in introducing the hand into the rectum of the horse, and diawing out any hardened dung that may be there. It may be necessary in costiveness or fcrer, if a clyster pipe camnot be obtained; but an injection will better effect the purpose, and with less inconvenience to the animal. The introduction of the hand into the rectum is, however, useful to ascertain the existence of stone in the bladder, or the degree of distension of the bladder in suppression of urine, for the bladder will be easily felt below the intestine, and, at the same time, by the heat of the intestine, the degree of inflammation iu it or in the bladder may be detected.

Resis.-The rellow resin is that which remains after the distillation of oil of turpentine. It is used exterually to give consistence to ointments, and to render them slightly stimulant. Internally it is a nseful diuretic, and is given in doses of five or six drachms made into a ball with soft soap. The common liquid turpentine is, however, preferable.

RoweLs.-The mamner of rowelling has been already described. As exciting inflammation on the surface, and so lessening that which had previously existed in a neighbouring but deeperseated part, they are decidedly inferior to blisters, for they do not act so quickly or so extensively; therefore they should not be used in acute inflanmation of the lungs or bowels, or any vital part. When the inflammation, however, although not intense, has long continued, lowels will be serviceable by producing an irritation and discharge that can be better kept up than by a blister. As promoting a permanent, although not very considerable discharge, and some inflammation, rowels in the thighs are useful in swelled legs, and obstinate grease. If fluid is thrown out under the skin in any other part, the rowel acts as a permanent drain. Whien sprain of the joint or the muscles of the shoulders is suspected, a rowel in the chest will be serviceable. The wound caused by a rowel will readily heal, and with little blemish, unless the useless leather of the farrier has been inserted.

Secale condutu, the Firgot of Rye.-This is well known to be an excitant in assisting parturition in cattle, sheep, and dogs. It has been used with success in the mare by Mr. Richardson, of Lincoln. It should only be applied in difficult cases, and the dose should be two drachms, combined with some carminative, and given every hour.

SEDATIVEs are medicines that subdue irritation, repress spasmodic action, or deaden pain. We will not inquire whether they act first as stimulants. if they do, their effect is exceedingly transient, and. is quickly followed by depression and diminished action. Digitalis, hellebore, opium, turpentine, are medicines of this kind. Their effect in ditferent diseases or stages of disease, and the circum stances which indicate the nse of any one of them in preference to the rest, are considered under their respective titles.

SoDd.-The Carbonate of Soda is a nseful antacid, and probably a diuretic, but it is not much used in veterinary practice. The Chloride of Soda is uot so efficacious for the removal of umpleasant smells and all infection as the chloride of lime; but it is exceedingly useful in changing malignant and corroding and destructive sores into the state of simple ulcers, and in nleers that are not malignant it much hastens the cure. Poll-evil and fistulous withers are much benefited by it, and all farcy ulcers. It is used in the proportion of one part of the solution to twentyfour of water.

Sodi Chloridus, Common Salt, is very extensively employed in veterinary practice. It forms an efficacious aperient clyster, and a solution of it has been given as an aperient drink. Sprinkled over the hay, or in a masl, it is very palatable to sick horses; and in that languor and disinclination to food which remain after severe illness, few things will so soon recall the appetite as a divink composed of six or eight ounces of salt in solution. To horses in health it is more useful than is generally imagined, as promoting the digestion of the food, and, consequently condition. Externally applied, there are few better lotions for inflamed eyes than a solution of half a drachm of salt in four ounces of water. In the proportion of an ounce of salt to the same quantity of water, it is a good embrocation for sore shoulders and backs : and if it does not always disperse warbles and tumours, it takes away much of the tenderness of the skin.

Son 玉 Sulpus. - Sulphate of Suda.-Glauber's Salt.-This meclicine is seldom nsed in the treatment of the horse. It appears to have some diuretic property.

So.r is supposcd to possess a diuretic quality, $x \times 2$ 
and therefore enters into the composition of some diuretic masses. See Resin. By many practitioners it is made an ingredient in the physicball, but uselessly or even injuriously so; for if the aloes are finely powdered and mixed with palm oil, they will dissolve readily enough in the bowels without the aid of the soap, while the action of the soap on the kidneys will impair the purgative effect of the aloes.

STARCH may be substituted with advantage for gruel in obstinate cases of purging, both as a elyster, and to support the strength of the animal.

Stoppings constitute an important, but too often neglected part of stable management. If a horse is irregularly or seldom worked, his feet are deprived of moisture; they become hard and unyielding and brittle, and disposed to corn and contraction and founder. The very dung of a neglected and filthy stable would be preferable to habitual standing on the cleanest litter without stopping. In wouuds, and bruises, and corns, noisture is even more necessary, in order to supple the horn, and relieve its pressure on the tender parts beneath. As a common stopping, nothing is better than cow-dung with a fourth part of clay well beaten into it, and confined with splents from the binding or larger twigs of the broom. In cases of wounds a little tar may be added; but tar, as a common stopping, is too stimulating and drying. Pads made of thick felt have lately been contrived, which are fitted to the sole, and, swelling on being wetted, are sufficiently confined by the shoe. Having been well saturated with water, they will continue moist during the night. They are very useful in gentlemen's stables: but the cow-dung and clay are sufficient for the farmer.

Strichnia.-This drug has frequently been employed with decided advantage in cases of paralysis in the log; and lately, and with decided advantage, it has been administered to the horse. The dose is from one to three grains, given twice in the day.

Sulphur is the basis of the most effectual applications for mange. It is an excellent alterative, combined usually with antimony and nitre, and particularly for mange, surfeit, grease, hide-bound, or want of condition ; and it is a useful ingredient in the cough and fever ball. When given alone, it seems to have little effect, except as a laxative in doses of six or eight ounces; but there are ninch better aperients. The black sulphur consists principally of the dross after the pure sulphur has been separated.

TAR melted with an equal quantity of grease forms the usual stopping of the farrier. It is a warm, or slightly stimulant and therefore useful, dressing for bruised or wounded feet; but its principal virtue seens to consist in preventing the penetration of dirt and water to the rounded part. As a common stopping it has been considered objectionable. From its warm and drying properties it is the usual and proper basis for thrush ointments ; and from its adhesiveness, and slightly stimulating power, it often forms an ingredient in applications for mange. Some practitioners give it, and advantageously, with the usual congh medicine, and in doses of two or three drachms for chronic cough. The common tar is as effectual as the Barbadoes for every veterinary pnrpose. The oil, or spirit (rectified oil) of tar is sometimes used alone for the cure of mange, but it is not to be depended upon. The spirit of tar, mixed with double the quantity of fish oil, is, from its peculiar penetrating property, one of the best applications for hard and brittle feet. It should be well rubbed with a brush, every night, both on the crust and sole.

Triscrures.-The medicinal properties of many substances are extracted by spirit of wine, lut in such small quantities as to be scarcely available for internal use in veterinary practice. So much alves or opium must be given in order to produce effect on the horse, that the quantity of spirit necessary to dissolve it would be injurious or might be fatal. As applications to wounds or infiamed surfaces, the tinctures of aloes, digitalis, myrrh, and opium, are highly useful.

Toвacco, in the bands of the skilful veterinarian, may be advantageously employed in cases of extreme costiveness, or dangerous cholic; but should never be permitted to be used as an external application for the cure of mange, or an internal medicine to prumote a fine coat.

Tosics are valuable medicines when judiciously employed; but, like cordials, they have been fatally abused. Many a horse recoveriug from severe disease has been destroyed by their too early, or too free use. The vetcrinary surgeon occasionally administers them injuriously, in his anxiety to gratify the impatience of his employer. The mild vegetable tonics, chamomile, gentian, and ginger, and, perhaps, the carbonate of iron, may sometimes be given with benefit, and may hasten the perfect recovery of the patient; but there are few principles more truly founded on reason and experience, than, that disease once removed, the powers of nature are sufficient to re-establish health. Against the more powerful mineral tonics, except for the particular purposes that have been pointed out under the proper heads, the horse proprietor and the veterinarian should be on his guard.

Turpentine.-The common liquid turpentine has been deseribed as one of the best diuretics, in doses of half an ounce, and made into a ball witl linseed meal and powdered ginger. It is added to the calamine or any other mild ointment in order to render it stimulating and digestive, and, from its 
adhesiveness and slight stimulating power, it is an ingredient in mange ointments. The oil of turpentine is an excellent antispasmodic. For the removal of cholic it stands untivalled. Forming a tincture with cantharides, it is the basis of the sweating blister for old strains and swellings. As a blister it is far inferior to the common ointment. As a stimulant frequently applied it must be sufficiently lowered, or it may blemish.

WAx.-The yellow wax is used in charges and some plasters to render them less brittle.

Zinc.-The impure carbonate of zine, under the name of Calamine Powder, is used in the preparation of a valualle healing ointment, called 'Tumer's Cerate. Five parts of lard aud one of resin are melted together, and when these begin to get cool, two parts of the calamine, reduced to an impalpable powder, are stirred in. If the wound is not healthy, a small quantity of common turpentine may be added. This salve justly de- serves the name which it has gained, "The Healing Ointment." 'The culamine is sometimes sprinkled with alvantage on cracked heels and superficial sores.

The sulphate of zinc, White Vitriol, in the proportion of three grains to an ounce of water, is an excellent application in ophthalmia, when the inflammatory stage is passing over; and quittor is most successfully treated by a saturated solution of white vitriol being injected into the sinuses. A solution of white vitriol of less strength forms a wash for grease that is occasionally useful, when the alum or blne vitriol does not appear to succeed.

Zingrberis Radix.-Ginger Root.-This is an admirable stimulant and carminative. It is useful in loss of appetite and flatulent cholic, while it rouses the intestinal canal to its proper action. The cordial mass resorted to by the hest surgeons consists of equal parts of ginger and gentian beaten into a mass with treacle.

\section{ON DRAUGHT.}

THE iuvestigation of the sulject of draught by animal power, to which this treatise is devoted, and which will form an appropriate supplement to an account of the Horse,-has frequently occupied the attention of theoretical and practical men ; so much so, that our object will be to collect what has been said and done, and, by arranging it methodically, to show in what manner the information may be applied and rendered nseful, rather than to attempt to produce anything absolutely new upon the subject. Notwithstanding, however, all that has been written, if we open my of the authors who have treated the subject, in the hope of obtaining direct practical information, we shall be much disappointed.

It might have been expected that the particular result of every method known and in use for the convevance of a load from one spot to another, by animal power, whether by sledges, by wheelcarriages, or by water, as in canals, being so coustantly and necessarily a matter of practical experiment, would have been accurately known and recorded; - but the contrary is too much the case.

The theoretical investigations have been made with too little reference to what really takes place in practice; and the practical portion of the subject has not generally been treated in that useful and comprehensive manner which it deserves and demands.

In fact, there is hardly a question in practical mechanics on which, though much has been written, opinions are apparently less fixed; or on which the information we do possess is in a less defined and available state.
Oue great object of research has been the average force of traction or power of the horse.

If we consult the most approved authors and experimentalists, Desaguilliers, Smeaton, \&c., we find this power variously stated as equal to $80 \mathrm{lbs}$., 100 lbs., 150 lbs., and even 200 lbs. : we are therefore left almost as iguorant as before; but the knowledge of this average power is fortunately of little importance in practice. It is the knowledge of the best application, and of the effect, of that power which alone is useful: and these are governed by circumstances so varving and dissimilar, such as the form and state of the road, the structure of the carriage, the size and friction of the wheels, \&c., \&c., that scarcely any two cases of draught would, as regards the effect of the power of the horse, present the same results.

'The difference of opinion here manifest is still greater when existing on a purely practical question.

In the inquiries instituted by a committee of the House of Commons in 1806 and 1808 , on the subject of roads and carriages, two well-informed practical men, Mr. Russell of Exeter, and Mr. Deacon of Islington, the most extensive carriers in Fugland, were examined upon an important question, viz., the advantage or disadvantage of a par ticular form of wheel. It was stated by one that, having given the wheels in question a twelve months' trial, he found that they tended to injure the road and increase the draught in the proportion of four to five; while it was stated by the other, who had also made the experiment on a large scale, that he found they materially assisted 
in keeping the roals in repair, and diminished the draught in the proportion of five to four.

Amidst snch conflicting and eontradictory opinions it would appear difficult to come to any useful conclusion, and we might naturally be disposed to adopt a very common practice, that of taking an average result.

A little consideration, however, will show that these apparent discrepancies and contradictions arise, in great measmre, from attempting to generalise and apply to practice the results of experiments made in, and therefore applicable only to, particular cases.

- The results of experiments thus made at various times and places, and without that identity of condition and eircumstance so necessary when standard rules are to be deduced from them, have, nevertheless been used for that purpose : and this circumstance, combined with the variety of distinct points to be considered before we can estimate accurately what even constitutes draught, will perhaps account for the disagreement among the practical and scientific authorities alluded to.

We must therefore examine severally all these puints; and then, by considering their relative bearing upon each other, we may hope to reconcile the different opinions advanced, without which re cannot collect from them any information which will lead us to a practical and beneficial result.

We shall proceed to divide the subject under separate and distinct heads, and under each head to examine the methods or means now in use, or which have been proposed, and endeavour to estimate their comparative advantages by availing ourselves of what is already written and known upon each.

It will be necessary first, however, to explain and define clearly some terms which will occur frequently in the course of this paper, and especially the word "draught," which is itself the title of the treatise.

This word is used in such a very general and vague sense, that it would be difficult, if not impossible, to give an explanation which should apply equally to all its different meanings.

In the expression " dranght by animal power," it would seem to mean the action itself of drawing; while, on the other hand, it is freqnently used to signify the amount of power employed, as well as the degree of resistance-as when we say the draught of a horse, or the draught of a carriage. "Draught power" is also an expression used. We shall, however, confine our use of the word to the two meanings-draught, the action of dragging; and draught, the amount of resistance to the power employed to drag any given weight.

"Force of traction," is another expression requiring explanation; but here we must enter into more detail, and give a practical illustration of our meaning.
A force is most conveniently measured by the reight which it would be capable of raising ; lut it is not therefore necessarily applied vertically, in which direction weight or gravity acts.

If a weight of $100 \mathrm{lbs}$. be suspended to a rope, it is clearly exerting upon this rope a force of 100 lbs.; but if the rope be passed over a pulley void of friction, and continued horizontally, or in any other lirection, and then attached to some fixed point, the weight still acts upon all parts of this rope, and consequently npon the point to which it is fixed, with a force equal to $100 \mathrm{lbs}$. : and so inversely, if a horse be pulling at a rope with a force which, if the rope were passed over a pulley, wonld raise $100 \mathrm{lbs}$., the force of traction of the horse is in this case $100 \mathrm{lbs}$. Spring steel-yards being now commonly in use, we may be permitted to refer to them as affording another clear exemplification of our meaning. In pulling at a steelyard of this description, if the same force be ex+ erted, whether horizontally or vertically, the index will, of conrse, show the same amount; and, consequently, if the strength of the horse be measured by attaching the traces to one of these steel-yards, the number of pounds indicated on the dial will bo the exact measure of the strain the horse exerts, and the amount of strain is called his "force of traction."

Haring fixed as nearly as possible the meaning of these terms, which will frequently oceur in the course of our progress, we shall proceed to the division of the suljeet.

It is evident that there are three distinet agents and points of consideration in the operation of dranght, which are quite independent of each other. They are-first, the moving power and the mode of applying it; secondly, the velicle for conveying the weight to be moved ; thirdly, the canal, road, or railway, or what may le generally termed the channel of conveyance.

All these individually influence the amount of draught, and require separate consideration; but the mode of combining these different agents has also a material effect upon the result,-consequently, they must be considered in relation to each other; and to obtain the maximum useful effect, with the greatest economy, in the employment of any given power, it is evidently necessary that these different agents should not only each le the best adapted to its purpose, and perfect to the greatest possible degree, but also that they should all be comlined to the greatest advantage.

We shall proceed, then, to examine the different agents now employed, the modes of applying them, and the proportionate effects produced.

And, first, with regard to the species of moring power:-this may be of two kinds, animal and mechanical.

By "animal power" we mean the direct applica- 
tion of the strength of any animal to dragging or pulling, as in the simple case of a horse dragging a cart. By " mechanical," the application of any power through the intervention of machinery : the source of power in this latter case may still, however, be auimal power, or a purely mechanical agent, as a steam-engine.

The latter is the only species of mecbanical power which it has been attempted, with any prospect of suceess, to apply practically to locomotion; and thercfore that alone we propose to compare with the animal power.

Now, although these two powers, viz., simple animal power and the steam-engine, may in most instances be applied so as to produce the same effect, and may therefore, to a superficial observer, appear similar; yet there do exist such essential differences in the mode of action, or the means by which the effect is produced, that there are many cases in which the one may be used, wherein the other may be totally inapplicable.

In this treatise, draught by animal porrer is the principal object of consideration; but as great efforts have been made for many years, and are still now perseveringly made, to supersede animal power entirely by mechanical-to dismiss our old servant the horse, and supply his place by the steam-engine - it may be as well, in justice to the former, to say a few words in his defence, and to take a brief view of the distinguisling featnres of the two agents.

To enter into all their respective merits, and to weigh their comparative advantages in all circumstances, would involve us in many questions foreign to that under our immediate consideration, and would embrace suljects which may supply matter well worthy of our future attention. It is sufficient for our present purpose to show that there still exist great oljections to the universal application of machinery to draught, - objections which do not equally apply to the use of animal power; that there are mauy advantages in the latter, which are not yet obtained by the former; and that animal power continues, for all the ordinary purposes of traffic upon common roads, to be the most simple in its application, and certain in its effect.

We shall confine ourselves partienlarly to the consideration of that part of the question which relates to the slow transport of heavy goods, as being the most important branch of the subject, especially for agricultural purposes. Economy is, of course, the grand desideratum in the consideration of this question; consequently, the comparative expense of the two powers, supposing them for the moment equally convenient and applicable, will first demand our attention.

A difficulty arises here, however, from the want of a certain measure of comparison. The power of a one-liorse engine is by no means exactly the same thing as that of a horse. As wo have before stated, the mode of applying them being different, the variations in the results aro different, and consequently the effects do not bear a constant proportion to each other, in different circumstances: we must therefore be careful not to fall into the mistake which we have ourselves pointed out as a very common source of error, viz,, the drawing general conclusions from data obtained in a particular case. We shall take the power of the horse, and that of the steam-engine as ascertained practically on railways, where the effect of each is less influenced by accidental circumstances, and consequently can be better ascertained than on a road. We shall confine our calculations of expense to this particular case, and then endeavour to discover how far the samo results are to be expected, or what modifications are likely to take place, and what alterations are to be made in the results under different circumstances. As regards the first, viz., the comparative cost of animal and mechanical power on a railway, we cannot do better than quote the mords of the late MIr. Tredgold upon this sulject, and we accordingly extract the following passage from his work upon Railways :-

"The relative expense of different moring powers for railways is an interesting inquiry, and the same materials being necessary to estimato the absolute expense for any time or place, it is desirable to give some particulars to aid the researches of those who wish to make such comparative estimates. The amuual expense of a horse depends on-

"1. The interest of purchase-money.

" 2 . Decrease of value.

"3. Hazard of loss.

"4. Value of food.

“ 5 . Harness, shoeing, and farriery.

" 6 . Rent of stabling.

“7. Expense of attendance.

"According to the average duration of a horse in a state fit for labour, of the description required on a railway, the first three items may be estimated at one-fourth of the purchase-money; the food, hamess, shoeing, sc., included in the 4t.lt, 5 th, and 6th, will most likely not exceed $\$ 10$ per annum, nor yet be much short of that amount ; and supposing one man to attend to two horses, this would add $£ 1512 s$. if the man's mages were 2s. per diay; and, at this rate, the labour of a horse, of the value of $£ 20$, would cost $£ 60$ 12s. per year ; or, since there are 312 working dars in the year, the daily expense would be $3 s .10 \frac{1}{2} l$., or 186 farthings. But the power of a horse is about 125 llss. when travelling at the rate of three miles per hour, and the day's work eighteen miles. 
"The amnual expense of a high-pressure lcco motive engine, or steam carriage, consists of-

"1. The interest of the first cost.

“2. Decrease of value.

"3. Hazard of accidents.

" 4 . Value of coals and water.

" 5 . Renewals and repairs.

"6. Expense of attendance.

"It is difficult to procure these particulars from the experience of those who employ engines; we will therefore annex, by way of example, such sums as we think likely to cover the expense. The first cost of the engine and its carriage may be stated at $\$ 50$ per horse power, and its decrease of value and hazard will render its annual expense about one-fifth of its first cost, or $\$ 10$ per annum per horse power. The expense of fuel and water per day will be not less than one bushel and a half of coals per horse power, and fonrteen cubic feet of water; and, taking the coals at $6 d$. per bushel, and the water and loading with fuel at $3 d$., the annual expense will be $£ 1512 s$, t the renewals and repairs, at 20 per cent. on the first cost, will be $£ 10$, which is as little as can be expected to cover them. Attendance, suppose one man and one boy for each six-horse engine, at $6 s$. per day, or 1s. per day for each horse-power, or £15 12s. per annum; therefore the total anunal expense of one horse-porrer would be $£ 514 \mathrm{~s}$., or 158 farthings per day." - This power is equal to a force of traction of $166^{2} \mathrm{lbs}$. for the same number of miles per day as the horse; but from this gross amount of power we must deduct that necessary to move the engine with its supply of coals: this will reduce it at least to $155 \mathrm{lbs}$; consequently, in the one case we have a force of traction of $125 \mathrm{lbs}$, at an expense of 186 farthings, and, in the other, a force of 155 lbs. at an expense of 158 farthings; and reducing them both to one standard quantity of work done, we find the expense of the horse is $\frac{186}{123}=1.488$, and of the locomotive engine, 1.019 , or abont as 147 is to 100 . In this case, therefore, there appears to be a decided economy in the use of the steam-engine, and accordingly its application has become very general, and is becoming more so every day.

Let us now examine what alterations are requisite, before we can apply these calculations to the case of dranght upon common roads. Sup. posing both species of power equally convenient and applicable, and confining our observations merely to the amount of power and proportionate expense.

The force of traction of the horse, and the yearly cost, will remain so nearly the same, that for our present purpose we may consider them quite unaltered. Not exactly so with the locomotive engine.

All the parts of the machine must be made mucll stronger and heavier, and consequently more expensive, for road-work than for a railway, and, therefore, the first cost will be greater-the wear and tear will also he greater, and as the work will be more variable, the consumption of fuel will be increased as well as the price, which, generally speaking, will be much less on a line of railway, than it can possibly be elsewhere.

Still all these circumstances will not influence the result so much as the increased effect of the weight of the engine. On a railway, with the carriage as now constructed, the force of traction is not much more than $\frac{1}{50}$ or $\frac{1}{200}$ of the weight mored; consequently, the power necessary to move the engine itself is not very considerable. On a road, however, this proportion is materially altered; here the average force required to more a well-constructed carriage cannot be estimated in practice, at less, even when the roads are in good repair, than $\frac{1}{25}$; the engine, according to the construction of the best locomotive engines now in use, will weigh, with its carriagc and fuel, at least one-half ton, or $1120 \mathrm{lbs}$. per horse power, and $\frac{1}{25}$ of 1120 is nearly 45 lls., which we have to deduct from the gross power of the engine, and which leaves only $121 \frac{2}{3} \mathrm{lbs}$. as the available power. The proportional expense of the horse and the steam-engine is now therefore about as 115 to 100 , and this without taking into account the causes of increased expenditure a]ready alluded to as regards the prime cost, the repairs, and the consumption of fuel. From these calculations it would appear, that even if mechanical power was found as convenient and applicalle in practice as horse power, still no great economy can be expected from the employment, upon common roads, of small locomotive engines, such as the best of those now in use, and known to the public, unless it is in cases where other means may fail to produce some particular effect which may be required ; if, for instance, a considerable velocity is necessary, the power of a horse is very nearly exhausted in moving his own body, anil then there can be no doubt that a mechanical agent, in which power may always be exchanged for a proportional velocity, will have some advantages on a very good road, which in fact approaches very nearly to a railway. But in every case in which velocity is not a principal olject, as in the one now under consideration, and where consequently, little momentum is acquired, and frequent though slight obstructions ocenr, as on an ordinary road, an animal appears to possess decided advantages. He adapts himself admirably to the work, increasing or diminishing his efforts according to the variations of the draught, resting himself, as it were, and acquiring vigour where his utmost strength is not called for, and thus becomes enabled to make exertions far beyond his 
average strength where any impediment or obstruction is to be overcome. Indeed, he appears rather to increase the average effect of his pouters by these alternations of exertion and comparative relaxation; and when it is considered that the draught will, in an ordinary road, frequently vary in the proportion of six or eight to one, and that these changes may succeed eacb other suddenly, the importance of such an accommodating faculty will be immediately appreciated.

By mechanical power, such as a steam-engine affords, these advantages are not easily obtained. Without great weight or rapid motion no momentum can be acquired; and unless when the carriage is in very rapid motion, a very small obstruction will check, and perhaps totally stop the machine. For instance, supposing the carriage to be advancing steadily under the effect of a foree of traction of $500 \mathrm{lbs}$., and that a stone or rut suddenly causes a resistance, which it would require 800 or $1000 \mathrm{lbs}$. to overcome, a case by no means rare even on tolerable roads; if the impetus or momentum of the mass be not sufficient to carry it over this obstruction, the machine must stop until some increased power be given to it.

It is also to be remembered, that what we are accustomed, in practice, to consider as the average power of a horse, is the average excess remaining over and above that necessary to carly his own body; and that in all ordinary cases he is able to nzaintain and continue nearly the same exertions, although the comparative dranght of the carriage he considerably increased. Thus, if the road be slightly muddy or sandy, or newly gravelled, the dranght, as we shall see more accuritely laid down when we come to the subject of wheeled carriages, will be double and even treble what it is on the same road when freed from dust or dirt; but the average power of the horse remains nearly the same, and, practically speaking, equal in both circumstances; that is to say, that the poner necessary to move the weight of the horse's body, which forms no inconsiderable portion of his whole power, is not materially increased by a state of road which will even treble the dranght of the carriage; consequently, the excess, or available portion of his power, remains unimpaired, and the full benefit of it, as well as of any increased exertions of the animal, is felt and is applied solely to dragging the load.

Not so with a locomotive steam-engine, becanse, beyond the power necessary to perform the work of dragging the load, a large additional power must be provided to move the engine itself. In other words, if an engine of ten-horse power be capable of dragging a certain load, the weight of this engine forming a portion of the load to be moved, a corresponding portion of the power is unprofitably absorbed in moving it, and the excess, or remaining power, is alone available for useful purposes, and can alone be compared to the animal or horse power. Now, if the draught is augmented, as we have just supposed, by any sand, dirt, or roughness of the road, or any other impediment, the force required to move the useless weight (of the engine) is proportionally increased; it may even, as we have stated, be doubled or trebled; and the whole power of the engine remaining the same, the surplus or remaining portion is considerably diminished, and that at the very moment when, as before stated, it produces only one-half or one-third the effect.

Moreover, if at any part of the road a power equal to twenty hor'ses is required, the engine, as regards its construction, must be a 20 -horse engine. It is erroneous to suppose that a steam engine, because it is a high-pressure engine, can therefore, as occasion requires, be worked for any length of time beyond its nominal power, by merely raising the steam. Every part of a machine is calculated and arranged for a certain pressure and corresponding power, and that is the real power of it. It is optional to work at or below that power, but, if below, it will be to a disadvantage, as the bulk and weight of the machine will be as great as if it were always worked to its full extent, and both have to be carried over all those parts of the road where a far less power would be sufficient. The velocity of the carriage might indeed be increased, while travelling on the good and level portion of the road; but these alternations in the speed and power cammot be ef fected without a considerable degree of complexity, weight, and expense in the machinery; and, as we are confiniug ourselves to the consideration of the case where relocity is not required, and might even be an inconvenience, the excess of power will be wasted.

These oljections to the use of mechanical power, in certain cases, are pointed out, not as being insurmountable obstacles to the use of machinery, but as serious difficulties which, in practice, have not yet been overcome. In fact, there is not at present any practical substitute for horse power on common roads, and, as far as the public is concerned, nothing has yet been done. We, therefore, must consider them as oljjections re. maining to be overcome; and we are compelled to draw the conclusion, that, at the present moment, animal power (always confining ourselves to the question of the economical transport of heary goods upon common roads) is superior to any mechanical agent, and that beasts of draught, and particularly the horse, although the most ancient, still remain the most advantageous source of power.

Long experience has pointed out varions modes of applying animal potrer; but it is frequently illdirected, owing to the want of an adequate know 
ledge of the mechanical structure of the auimal, and the manner in which he exerts his strength.

In the most powerful steam-engiue, if too great a resistance be applied, or, practically sjeaking, if we attempt to make it do more work than it is calculated for, there is an immediate loss of power, in consequence of the diminution of velocity cansed thereby; and if we continue to oppose a still greater resistance, we reach the point at which it is unable to overcome it, and it ceases to produce any effect. Again, a very small obstacle may be so applied as greatly to impede an engine of considerable power, or even to stop it altogether. The power of an engine is limited, and resistance must always be proportioned to it; and there is a proportion beyond which it is useless to go, and less than which would not absorb the whole force.

An animal is but a beautiful piece of machinery, and although perfect in its construction, and wonderfully accommodating in its movements, it still, like the engine, has a limited power, and has its pecnliar modes of action, its strong and its feeble parts; and we must well consider its structure, to be able to apply the resistance in that degree, and in that manner, which shall enable it to jroduce the greatest effect. The consideration of the comparative effects of the exertions of a man and a horse, will at once exemplify this, and lead us more clearly to the knowledge of the peculiar qualities or faculties of the horse.

If a liorse be made to carry a heavy weight rapidly up a steep ascent, or if a man be employed to drag slowly a heavy carriage along a rough road, the strength of both will be soon exhansted, and little effect produced; but if a mau be made to carry a weight up a ladder, and if a horse draw a heary carriage along a road, they will each produce a cousiderable effect : yet, in the former case, the horse and the man are as strong as in the latter, but their power is not properly applied, and is consequently wasted.

These different results are easily explained, by considering the mechanical structure of the two bodies, aud the mode in which their muscular strength is exerted.

The action of pulling is effected in either case by throwing the body forward beyond the feet, which form the fulcrum, and allowing the weight of the body, in its tendency to descend, to act against the resistance applied horizontally, and drag it forward; as the resistance yields, the feet are carried forward; and the action renewed, or rather continued.

Let A ( fig. I) be the centre of gravity, or the point in which the whole of the weight of the body

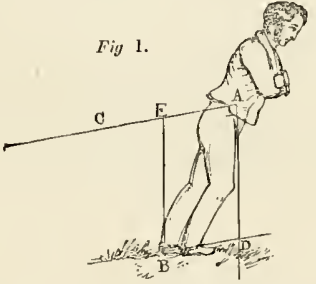

may be supposed to be accumulated, and $B$ the fulcrum, or point of resistance; $\mathrm{AC}$ the direction of the power to be overcome.

If the legs are intlexible, the body, acting by its gravity, tends in its descent to describe a circle around the point $B$, lut is opposed by the resistance $\mathrm{AC}$; and it is demonstrable, by the law of the resolution of forces, that if $\mathrm{BD}$ be drawn parallel to $\mathrm{AC}$, the lengtles of the lines $\mathrm{AD}, \mathrm{AB}$, and DB represent respectively the proportions between the weight of the body, the strain upon the point of support, and the effect produced ; that is, if $\mathrm{AD}$ be taken as the measure of the weight of the body, then $A B$ is the measure of the strain upori the legs, and $\mathrm{BD}$ or $\mathrm{AE}$ the power pulling in the direction of $\mathrm{AC}$.

Consequently, the effect increases with the

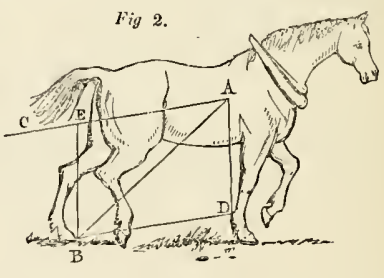

weight of the body and the distance which it is thrown beyond the feet, and is limited only by the capability of resistance at $B$, or the muscular strength of the legs. This is evidently the case in practice; for even if the body were brought nearly horizontal, when its weight would act to the greatest advantage, still, if the leg's are incapable of resisting the strain, they would yield, and no effect be produced. In a man, this muscular strength of the limbs is very great, and he can lift or carry immense weights, and ascend easily, even loaled, a ladder; but he is not well adapted to the purpose of dragging: as his own weight is small proprortionably to his strength, and the centre of gravity is low, and by the construction of his body cannot be thrown far beyond the fulcrum at his feet; consequently, however capable his 
legs may be of resisting a great strain, AE remains small, and his muscular force is not advantageously brought into action.

A horse, on the contrary, by the formation of the body, can relieve his weight partly from his fore-legs; and, extending his hind-legs as in fig. 2 , throw the centre of gravity a considerable distance in front of his feet $\mathrm{B}$. AE is here proportionably much greater than in the former case, and the whole of his force is, therefore, adrantageously employed. He is, in fact, by his mechanical construction, a beast of draught.

The same train of reasoning which has here pointed out the species of work peeuliarly adapted to the different structures of the man and of the horse, if continued further, will now serve to show the circumstances in which the power of the latter is best applied, and the greatest effect produced.

We shall here consider both the quality and the degree of the dranght.

And first, it is to be observed, that, although the weight of the animal's body is the immediate cause in the action of pulling, yet, as before stated, it is by the action of the muscles in adrancing the legs and raising the body, that this cause is constantly reuewed, and the effort continued. The manner and the order of succession in which a horse thus lifts and adrances lis legs may, of course, influence the movement of his body, and ought therefore to be examined into: accordingly, we fiud that many writers upon draught have touched upon this part of the suliject, but they appear to have contented themselves with inrenting in their closet the manner in which they conceived a horse must have moved his legs, rather than to have taken the trouble to go out of doors to see what really did take place, and, consequently, many have arrived at erroneons conclusions. The ancient sculptors, who generally studied nature so faithfully, either neglected this point, or otherwise our modern horses, by constant artificial training, have altered their step : for we find in the celebrated frieze from the Parthenon at Athens, a portion of which, now in England, is more commonly known under the name of the Elgin marbles, the only horses which are represented trotting, lave both their legs on the same side of the body raised at once, the other two being firm upon the ground-a position which horses of the present day never assume while trotting.

In the case of these relievos, it is true that there are only four horses, out of more than two hundred, which are in the action of trotting, all the others being represented in a canter or gallop; and only two of these four are entirely in the foregroumd, and distinct from the other figures. It would not be safe, therefore, to draw too general a conclusion from this example alone; but we have another decided proof of the remark we have made, in the case of the four horses of the church of St. Marc at Venice.

Whether this was then the mode of trotting or not, it is certain that it is never seen to occur in nature in the present day; and indeed it appears quite inconsistent with the necessary balancing of the body, and was, therefore, more probably an error of the artist.

It perhaps may have been found difficult or troublesome to watch the movement of a horse's legs; but a very little practice will euable anybody to verify what we are about to state: by keeping near the side of a horse that is walking, it will be easily seen that, immediately after the raising of either of the hind-legs from the ground, the foreleg of the corresponding side is also raised, so that the latter leaves the ground just before the former touches it. If the fore-legs be then watched, it will be seen that, immediately after the movement of either of these, the hind-leg upon the opposite side is put in action, so that the order of succession appears to be in walking, as numbered in $f i g .3$.

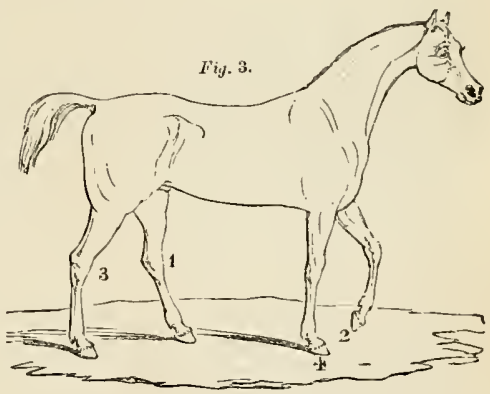

If the horse be now examined from a short distance, it will be seen that, when he is walking freely, the successive movements of the legs are at equal intervals of time, and that the muscular force of one limb only is brought juto action at the same moment. But if a horse which is dragging a load with some considerable exertion be watched, it will be seen that he then acts longer upon his legs, and allows a less interval of time for raising and adrancing them; and at the same time, the regularity of the movement is generally destroyed; the limbs on the same side generally being moved more simultaneously, or at nearer intervals of time, than those at the opposite coruers : thus, the miscular forces of two limbs are always acting together; the morement of the whole body is less continued and uniform than in the former case, lut each impulse is more powerful, and a resistance, which would be too great for the muscles of 
one leg, is overcome by the united exertion of tro. We shall point out, hereafter, the necessity of attending to this in the application of this power to draught.

In trotting, the action is of course quicker, and a less resistance will, as might be expected, cause the horse to move his legs at two intervals instead of at four equal intervals of time: indeed, a horse accustomed to go in harness generally acquires the habit of that action. There is this striking difference between trotting and walking: in walking, we bave seen that the interval between the movement of the legs on the same side was less than the other interval of time: in trotting, on the contrary, the legs situated diagonally, or at opposite corners, move almost simultaneously. Owing to the velocity aud the momentum which the body acquires in consequence of that velocity, in trotting fast, the successive impulses are less distinctly perceptible, and the movement more continued and uniform than in a slow trot, or in walking.

In galloping, the movement is totally different: the fore-legs are thrown forward nearly simultaneousiy, and the hind-legs brought up quickly, and nearly together; it is, in fact, a succession of leaps, by far the greatest interval of time elapsing while the legs are extended after the leap is taken: this is the position, therefore, which catches the eye, and which must be represented in a drawing to produce the effect of a horse in a gallop, although it is the moment when the animal is making no exertion.

The canter is to the gallop very much what the walk is to the trot, though probalily a more artificial pace. The exertion is much less, the spring less distant, and the feet come to the ground in more regular succession: it is a pice of eitse, quite inconsistent with any exertion of draught.

The consequence of these peculiar movernents in the limbs of the animal is, that a succession of impulses is conveyed to the body; and when the movement is slow, and the body of the horse does not acquire any considerable impetus or momertum, the resistance should be such as to receive each of these impulses, and leave the horse nnrestrained in the intervals.

It must, therefore, be a rigid resistance, roid of elasticity.

It must not, however, be a constant, unremitted resistance.

For it is a well-known fact, that, however powerful may be the muscles of a limb, they must not be kept constantly on the stretch. Thus we feel even more fatigue by standing than by walking, because one particular set of muscles is then kept constantly exerted. It is evident, therefore, that the resistance or draught must not be perfectiy constant, but should afford frequent opportunities of relaxing the efforts. Neither must it be a yielding resistance, as in that case the animal could not make any great exertion; for if he applied too much porver, he would be liable to fall forward; and should he at any time fall short of the necessary exertion, he would be drawn back by the strain, and it would require a considerable effort to restore the motion.

If a horse be made to drag a rope passing over a pulley and descending into a well with a certain weight, say of $200 \mathrm{lbs}$. attached to it, it is obvious that he could not make an effort greater than 200 lbs. without instantly considerably increasing his relocity, which would be a waste of power ; nor must he for an instant relax his efforts, or fall below that mark, for he would then be unable even to resist the pull, and would be overcome by the weight. Such an extreme case as this, of course, is not likely to occur often in practice, but the disad rantage of the principle is obvious.

An arrangement of this sort is, indeed, sometimes made use of, for raising the earth from excavations, or the materials of a building; but the exertion is continued only for a few seconds, or for a distance of not more than ten or tweuty yards: if prolonged, the inconvenience would be seriously felt, as it is, to a certain degree, in towing canal boats; the length and curve of the rope give an elasticity to the straiu, and the necessity of keeping the rope out of the water, or from dragging along the towing-path, compels the animal to keep up a constant, unremitted pull, and that, too, in an oblique direction, so as to throw him into an unfavouralle position. We accordingly find that, in these circumstances, the average work of a horse is equivalent only to about four-fifths of that given by Smeaton, Desaguilliers, and others, who extimated the power of the horse from the work done in a horse-mill, where the resistance is inelastic, aud all circunstances favourable, with the exception of the circular path.

The disidrantage of this kind of resistance is well known to carmen, though of course without consideration of the reason. A horse is said to pnll better when he is close to his work, that is to say, when he is attached at once to the body to be moved, because every exertion be makes is then communicated at once to the mass; but the leader of a team, unless he keeps the traces constantly ou the stretch, may frequently waste a poweiful effort without producing much effect upon the carriage.

Another inconvenience resulting from harnessing horses in a team, or ore before the other, is, that the leader, by tightening the traces, is continually relieving the strain from the body horse, and reciprocally the body horse from the leader; so that these horses labour under all the disadvantages of a long, elastic, and constantly yielding connexion with the load, which is not 
only fatigning to them, lont, in cases where the re sistance is variable, prevents the full and united effect of their exertions being properly communicated to the carriage. For, if a slight obstacle, as a rut or stone in a road, checks the progress of the velicle, the shaft-horse can immediately throw his whole weight into the collar, and the united effect of his strength and impetus is conveyed unimpaired to the vehicle, and forces it over the obstacle! but if any elasticity is interposed between the power and the resistance, as in the case of the traces of the leader of a team, the whole, or the greater part of the effect of impetus is lost, and that force which; if concentrated in one effort, would effect the object, being lengthened into a continued and comparatively feeble pull, is insufficient.

If we wish to destroy the impetus of a body moving with violence, we receive it with a yielding resistance ; the action of catcling a cricketball exemplifies this perfectly; and therefore, if the full effect of momentum is wanted, all elasticity in the direction of the movement shonld be avoided.

We have entered rather fully into the consider. ation of this particular point, becanse the principle is not only applicable to the mode of communicating the immediate action of the moving power, but will be found also of considerabie importance when we arrive at the subject of wheel-carriages.

A consideration of these various points brings us to this conclusion, that the draught ought neither to be constantly uniform nor without remission, nor jet yielding or elastic; sudden shocks or violent changes in the relocity must also evidently be disadrantageous, as tending to distress and injure the animal,

Having determined upon the necessary quality of the resistance, we will proceed to examine into the quantity or the degree of resistance or dranght, and the speed best adapted to the exertion of the animal. The useful effect of a horse, or the work done, must evidently depend upon three things, viz. the rate at which he is made to travel, the power of traction he can exert, and the number of hours he can continue to work daily at that speed; and where there is no fixed condition mhich determines any one of these, such as a particular load to be moved, or a certain velocity which it is desirable to attain, or a limited time to perform the work in, then the object must be to search for those proportions of the three by which, at the end of the day, the greatest quantity of work shall have been produced.

With respect to the first two, viz., the speed and power exerted, it will be obvious, that where a horse travels unloaded, the greatest distance he can go in any given time for several days in succession without injurious fatigue, is the linit of his velocits; on the other hand, the load may be so great, that he can scarcely put it in motion-this is the limit of his power: in both cases, the useful effect is no. thing. But between these limits of velocity and power, there is a proportion which affords the maximum quantity of effect, and which, therefore, must be the most advantageous for the application of horse power.

It has been asserted by theorists, and the theory appears to be supported by experience, that the velocity corresponding to this maximum, or that at which a horse working continually a certain number of hours per day will do the most work, is equal to half the extreme or limit of velocity of the same horse working the same number of hours unloaded; and that the force of traction corresponding to this speed, is equal to half the limit of his power. For instance, if six hours be the length of a day's work decided upon, and if a horse working that time can go six miles per hour unloaded, and therefore producing no useful effect, and supposing the limit of power of the same horse be equal to $250 \mathrm{lbs}$., it is found that he will do the most work in the same number of hours when drawing a load at the rate of half six, or three miles per hour; and half of 250 , or 125 lbs. will be the strain corresponding to this speed. Our next step, then, must be to find these limits: now, the limit of velocity depends upon the length of time during which the speed is kept up; we subjoin therefore a Table deduced from experiments, and which represents the proportion of the duration of labour and maximum velocity of the average of horses accustomed to their respective velocities.

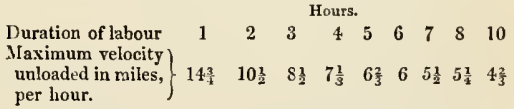

This within the range here given may be considered as very nearly the law of decrease of speed by increased duration of labour; and at the first glance we see the great advantage of reducing the speed and prolonging the exertion. There are, however, many causes to limit the duration of a day's work of a horse. Tredgold, in his work on Pailways, before quoted, says: "The time assigned for the day's work of a horse is usnally eight hours but it is certain, from experience, that some advantage is gained by shortening the hours of labour; and we have observed, that a horse is least injured by his labour, where his day's work is performed in ahout six hours; where the same quantity of labour is performed in less than six hours, the over-exertion in time shows itself in stiffened joints, while the wearying effects of long-continued action become apparent, if the duration of the day's mork be prolonged much beyond eight hours. Indeed, under the management of a 
good driver, a full day's work may be completed in the time before mentioned-six hours - with benefit to the health and vigour of the animal."

We may be permitted, however, to abandon the idea of improving the health of the auimal, or of rendering his business a pleasure to him-an attempt, the success of which is, we should think, very questionable-and content ourselves with endeavouring to check the barbarous practice of working horses to death, either by over-driving or overloading them; and we shall, as is generally the case, consult our own interests, and follow the dictates of humanity at the same time, by not injuring so useful an animal: and we thiuk experience proves there will be no danger of doing this by working eight or nine hours a-day. By referriug to the foregoing Table, we see that the maximum velocity of the average of horses corresponding to eight hours' work, is five miles and a half per hour, consequently, the rate at which be would travel when loaded, is a little more than two miles and a half per hour. There is no doubt that some horses coulil conveniently travel faster; but as the speed must generally be governed by that of other horses, the arerage is, in this case, the rate to be adopted. 'The force exerted under these circumstances depending upou the quality of the horse, it is very difficult to obtain even an approximate value of it, unless the experiment be made upon each individual horse : it is fortunately, however, of no great consequence in practice, because if we feel sure that we are employing all the pouer we can command to the greatest advantage, it is not of any very great importance that we should know the exact amount of that power.

In comparing animal horse-power with that of the steam-engine, we estimated it at about 125 lbs., but we believe that, with tolerably good horses, it may generally be taken at more than that.

We have thus far confined our attention to the cases where velocity, as well as duration of labour, was left to clioice; this is far from being always the case. In stage-coaches, or other conveyances for passengers, speed is absolutely necessary, and it ouly remains to learn how that speed can be obtained with the greatest economy. The following Table, extracted from Tredgold, will show the great reduction in the effect produced by increasing the velocity.

The first column being the velocity or rate per hour, continued for six hours per day; the second represents the force of traction of which the animal is capable; and the third, the comparative effects produced. A force of traction of $125 \mathrm{lbs}$. coutinued for six hours, at the rate of three miles per hour, being taken as the standard, and considered equal to the arbitrary number 1000 .

$\begin{array}{ccc}\text { Miles per hour. } & \text { Force of traction in lbs. } & \text { Effect produced. } \\ 2 & \mathbf{1 6 6} & 888 \\ 3 & 125 & 1000 \\ 3 \frac{1}{2} & 10.1 & 972 \\ 4 & 83 & 888 \\ 4 \frac{1}{2} & 62 \frac{1}{2} & 750 \\ 5 & 41 \frac{2}{3} & 555 \\ 5 \frac{1}{8} & 36 \frac{1}{2} & 500\end{array}$

If, however, the hours of labour le lessened, takiug the velocity corresponding to the greatest useful effect, the results will be much greater, and the velocity may be raised much higher, as will be seen in the following Table.

Here the first column is the length of day's work, the second the best velocity corresponding to that time, or half the limit of velocity shown in Table 1 , and the third column the comparative effect produced, the force of traction being in each case 1:5 lbs.

$\begin{array}{ccc}\begin{array}{c}\text { Duration of labour } \\ \text { in hours. }\end{array} & \begin{array}{c}\text { Velocity, } \\ \text { miles per hour. }\end{array} & \text { Effect produced. } \\ 2 & 5 \frac{1}{4} & 578 \\ 3 & 4 \frac{1}{4} & 709 \\ 4 & 3 \frac{3}{8} & 813 \\ 5 & 3 \frac{1}{4} & 909 \\ 6 & 3 & 1000 \\ 7 & 2 \frac{3}{4} & 1063 \\ 8 & 2 \frac{5}{8} & 1110\end{array}$

To attain higher velocity, it is necessary still further to reduce the load, and the next Table is calculated upon the supposition of the strain being only one-half the-last, viz., $62 \frac{1}{2}$ lbs.; this is about the average exertion of each horse in a four-borse heavy stage-coach.

$\begin{array}{ccc}\begin{array}{c}\text { Duration of labour, } \\ \text { hours per day. }\end{array} & \text { Velocity. } & \text { Effect produced } \\ 4 & 5 \frac{1}{2} & 613 \\ 3 & 6 \frac{2}{5} & 534 \\ 2 & 7 \frac{1}{5} & 434 \\ 1 & 11 & 307\end{array}$

In mails or light coaches, where ten, eleren, and even eleven and a half or twelve miles an hour is attained, the average strain of each horse is barely 40 lbs., and the effect produced, or value of work done, not much more than one-half the above.

It must be remembered, that these tables are all calculated upon the supposition of the road being good, and the work such as not to cause any immediate injury to the animal, and is atapted only to the average quality of horses. They are not, therefore, at ouce applicable as data for calculations in all ordinary cases, but ouly serve to show the comparative forces which may be exerted under different degrees of speed. The results or effects of this force will always be influenced by the quality of the resistance, as we have already observed, in the cases of slow travelling; but in rapid travelling the power is much more expensive, owing to the great loss which we sce by the tables is 
sustained by increased velocity; and it is, therefore, the more important to study well the means of applying the power in question.

In this rapid travelling, the bad consequences of a uniform and constant strain is still more felt by the horses, and the necessity of occasional relief is still more urgent than at low velocities. It is universally admitted by horse-proprietors and postmasters, whose interests make them peculiarly sensible on this point, that a flat piece of road is more destructive of horses than the same length of road where gentle rises and alteruate flat and swelling ground vecur; and that a long hill is easier surmounted where there are occasional short levels, and even descents, than when the whole is one unifurm ascent.

It only remains for us, before we dismiss the sulject of the moving power, to consider the particular mode of applying it, or the manner of harnessing the horses.

Under this head comes the question of the best direction of the traces, or, as it has generally but less clearly been called, the angle of inclination of the line of traction. This question appears to have been always considered one of great importance : the point has been frequently diseussed, and rarious opinions have been advanced; some having recommended it to be horizontal, others inclined; and, as they have each in their turn, in demonstrating the correctness of their own theory, proved the error of others, there can be no presumption in laying them all aside, and in taking a different, but, at the same time, a more simple and practical view of the case. By referring to a figure similar to that by which we showed the mode of action of the horse in pulling, we see that if $A D$ represent that portion of his whole weight which is relieved from his fore-legs, and $\mathrm{AE}$ the direction of the traces, then $A F$ is the measure of the horizontal pull upon the carriage. Now, AF bears a constant proportion to $A B$, which represents the strain upon the legs; and $\mathrm{AD}$ being constant, $\mathrm{AB}$, and, consequently, $\mathrm{AF}$ increase or dininish according as the angle ADB is increased or diminished - that is to say, the horizontal pull applied to the curriage is proportionate to the strain upon the legs; but they are both dependent upon the angle formed by the traces, increasing or diminishing as the latter are inclined downwards or upwards from the collar; so that whether the traces be inclined upwards, as fig. 4 , or downwards, as fig. 6 , or whether they be horizontal, as $f i g .5$, makes no difference in the manner of pulling. In the first case, a portion of the animal's weight is borne by the traces, and is transferred by them to the carriage. $\mathrm{AF}$ is here sinall, but the strain upon the legs $A B$, is also proportionably less than in the second case, where the trices are horizontal. In fig. 6, where the traces incline downwards, we see that the horizontal force $\mathrm{AE}$ is much more considerable; but, at

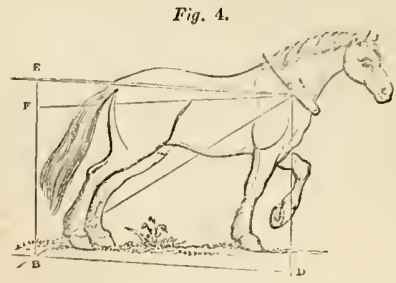

Fig. 5.

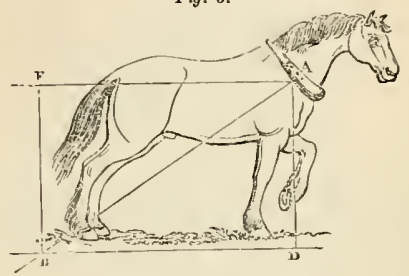

Fig. 6

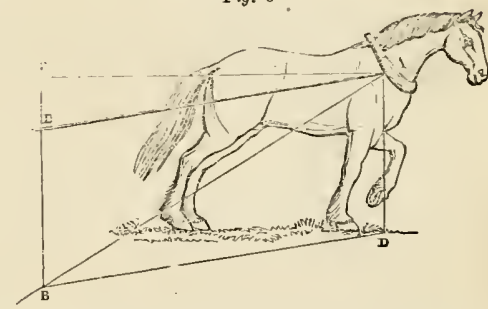

the same time, $A B$ is increased, and consequently the muscular exertion required in the legs is proportionally great: in fact, here a portion of the weight of the load is transferred to his shoulders.

The comparative advantages, therefore, of the

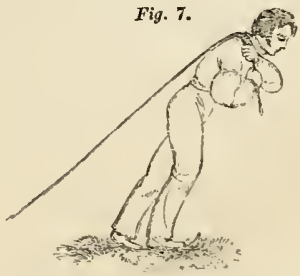

three do not follow any general rule, but depend simply upon the peculiar qualities of the particular 
animal employed, and his relative capabilities of lifting and pulling, or the proportion existing between the weight of his body and his muscular strength. To render this more clear to our own feelings, we will take the case of a man. We have already seen that an able-bodied man is more adapted for lifting than pulling; consequently, in his case it would be advantageous to throw a certain portion of the weight upon him, by making lim pull upwards, as in fig. $\tau$, or, what we are

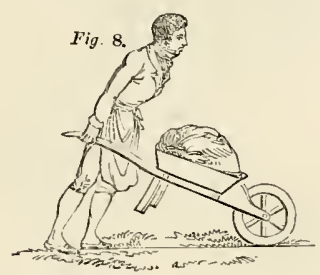

more accustomed to see, and which amounts to the same thing, applying his strength to a wheelbarrow, fig. 8, and we have freqnently seen an ordinary man wheel $800 \mathrm{lbs}$ in this manner.

If, however, we take a person unaccustomed to hard work, and consequently not so strong in the legs, although he may be unable even to lift the wheel-barrow which the other moved with ease, still he may, by pnshing horizontally, put in motion a considerable load; and lastly, in the case of an invalid who can barely earry his own weight, if he lean on the back of a garden-chair, he will not only walk himself, but push on the chair; or a child who is yet too weak to stand, can, if part of his weight be supported in a go-cart, not only move himself, but also the frame which supports him. These are very familiar and homely comparisons, but they are cases exactly similar to the three positions of the traces, and the argument will equally apply to horses as to men. It is true, we rarely use for draught a horse that cannot stand; but the case is very possible that a large heavy horse, otherwise not strong, or one which it was not desirable to fatigue, night pull better and longer, if part of the weight was borne upon the carriage, or if, in other words, the traces inclined npwards. And we know by experience, that in the case of stage-coaches, where, owing to the speed, the weight of the horse's body is already generally a burden to him, it is disadvantageous to increase that weight by inclining the traces much downwards; on the contrary, where we wish to obtain the utmost effect of a powerful horse, or of a horse that is muscular, but withont much weight forward, it is highly advantageous to augment the effect of his gravity by inclining the traces downwards even as much as $15^{\circ}$, or about 1 upon 3 ; the struin upon the traces will be then considerably increased, and the effect augmented, provided always that he is aule to exert the necessary strength in his legs. As far, therefore, as the mere force of traction is concerned, there is no par. ticular angle which will always produce the greatest effect-but it must depend upon the particular capability of the horse; and this in its turn varies, and is affected by circumstances; for the same horse that upon a level road requires no addition to his weight, might be materially assisted by a slight addition when ascending a hill, if not continued too long; and most horses would be benefited considerably by the opposite arrangement in a descent, that is, by a portion of their weight being borne up ; they should at least have no additioual load thrown on them while descending a hill.

There is also a time, when inclining the traces downwards is almost indispensable: it is when dragging a four-wheeled waggon over a rough broken road. If the front wheel, wbich is generally small, meets with an obstacle by falling into a hole, or stopping against a stone, it requires no profound reasoning to show, that a force pulling upwards in the direction A B, fig. 9, will raise the whole wheel

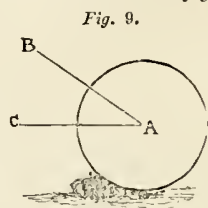
over the oustacle with much greater facility than if applied horizontally, as A C: this is the only circumstance, unconnected with the horse, that ought to gorern the direction of the traces, and the degree of the inclination here must, of course, still be proportioned to the porrer of the horse. We see therefore that, in proportion as the horse is stronger, or that we are disposed to make him exert a greater effort, the traces should be inclined downwards from the collar; with a good average horse, perhaps one-sixth or one-seventh of the distauce from the collar to the extremity ; with a horse of inferior capabilities, arising from weakness in the limbs, and not want of weight, or with an ordinary horse when travelling above six miles an hour, the traces slould be nearer the horizontal line, except when the circumstance of a rough road, before alluded to, requires some modification of this. To be able to apply these rules generally in practice, it would be necessary to have some means of altering the traces while on the road; as we have stated that they should be differently arranged according as the road is level or rough, or ascending or descending, this would not be difficult to contrive, avd has, indeed, been suggested by some writers upon this sulject; but it is probable that, except in stage-waggons, where the same carriage goes along a great extent, and consequent variety of road, it will be sufficient to adjust the traces according to the average state of the roads in the neighbourliood: and we cannot greatly err, if we bear in mind that inclining the 
traces downwards from the collar to the carriages, amonnts to the same thing as throwing part of the weight of the load on to the shatts, a thing frequently done in two-wheeled carts, and a manourre which all good earmen know how to put in fractice. The impossibitity of inclining the traces of the leaders, owing to their distance from the carriage, is an additional reason to those given before, why they (the leaders) cannot, when required, exert such an effort as the shaft horse or wheeler; and on rongh cross-roals, is a great argument in favour of harnessing horses alorenst.

Yet what can be more contrary to the rules here laid down than the injudicious moile freguently adopted in harnessing horses? IIow constantly do we see the efforts of horses paralyzed by misapplication of their respective qualities! In the annexed sketch ( $f i g .10)$, for instance, which repre-

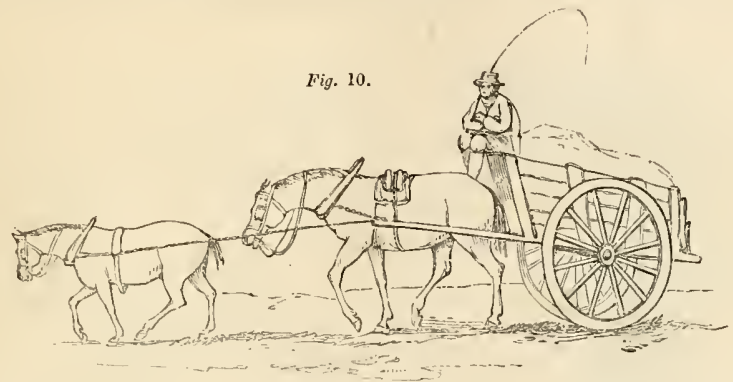

sents a very common specimen of this, the light, / description was taken from the harness in use in muscular, little horse, which is capable of consider- his own time, it is still referring to a period abont able exertion, is nearly lifted from the ground, and twenty-seven centuries back. prevented from making any exertion, liy the traces leading npwards; while the feeble old horse, scarcely capahle of carrying his own body, is nearly dragged to the ground, and compelled to employ his whole strength in carrying himself, and even part of the weight of the leader; so that the strength of the one willing and able to work is not employed, and the other is so overloaded as to be useless.

The mode of attaching the traces does not admit of much variety. The slioulders have always been made use of for this purpose.

Homer, who is supposed to have lived about 900 sears B.c., describes very minutely, in the twenty-fourth book of the Fliad, the mode of harnessing horses at the time of the siege of Troy, nearly 3000 years ago; but if we suppose that his

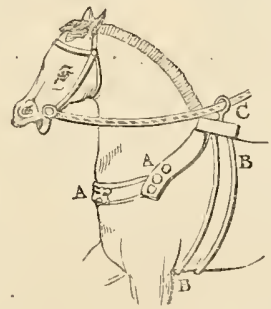

A simple strap, formed of several thicknesses of leather, so as to b3 very stiff, and fitted well to the neck and shoulders, served as a collar, as seen at $\mathrm{AA}$ (figs. 11, 12). A second strap, B B, passed round the body, and was attached to the shoulder-strap at the withers. At this point was fixed the yoke, CC, which was fixed to the pole.

A pair of horses were thns yoked together

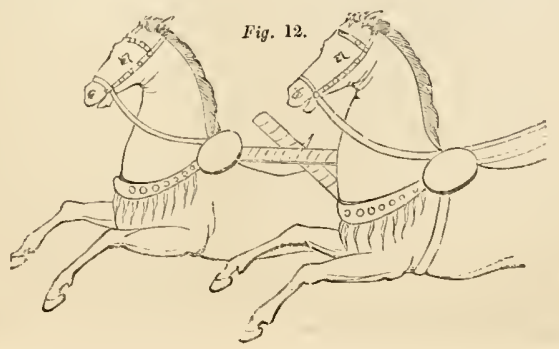


without traces or breechings, as oxen are seen borses, one on each side, each furnished with his at the present time in many parts of the country.

This was a simple arrangement, but by no means a bad one; and it would appear that they performed all the manœuvres of cavalry with chariot and horses thus harnessed. The pair yoked to the pole were called yoked horses: abreast of these was frequently placed what was called an outer horse, with a simple shoulder-strap or collar, FF, and a single trace, GG, passing inside, as in fig. 13. Sometimes there were two of those strap or collar and trace. These straps, if well fitted, were not bad; but as they must have pressed in some degree upon the throat, they could not be equal to the collar of the yoked horses, still less to the collar at present used.

In more modern times these shoulder-straps gave place to the breast-strap. A horse can no doubt exert a considerable strain against such a strap, but in action it must impede the morement of the shoulder.

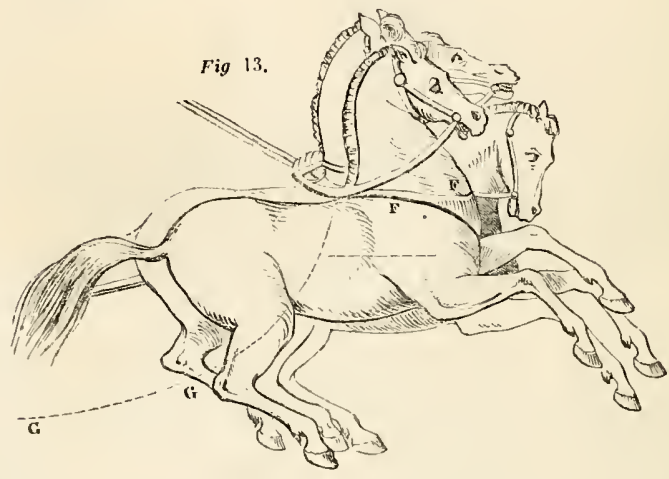

In some parts of South America the trace is fixed to the pummel of the saddle, which in its turn is well secured to the horse by saddle-girths, breast-straps, and breechings; and we are informed that horses in this manner drag very considerable loads. It resembles completely the harness of the ancients, with the addition of the breechings. It is, of course, a mere temporary arrangement, converient only as requiring no preparation. The trace is, in fact, the lasso of the rider, which is always fastened to the saddle; and when he has entangled it round the horns of a bull, or attached it to anything he may have occasion to transport, he takes one or two turns of the thong round the pummel of the saddle, and the horse will at full gallop drag the load after him. Here the load being generally upon the ground, the trace must incline considerally downwards; and this, added to the weight of the rider, will perhaps account in some degree for the extraordinary effects of a young powerful horse goaded to the utmost, and continuing the exertion only for a short time.

A gentleman who travelled some time in this part of America, and frequently witnessed the practical effects of this arrangement, has suggested the propriety of introducing it into the Artillery,

by means of which a number of horses might in an instant be attached to a gun, to extricate it from any heavy or broken ground in which it might be entangled. Certainly, the length of these traces would enable these additional horses to secure a good footing; and any number of horses might thus be made to lend their assistance in time of need. We do not pretend, however, to judge of the practical utility of this measure, but merely record the suggestion of another.

The collar now generally used is an improvement upon the ancient shoulder-strap described by Homer: and it is probably the best possible mode of attaching the traces to the horses. If the connection is made at the proper place on the collar, the latter bears flat and evenly upon the muscles which cover the collar-bone, and the shoulders of the horse are left almost as free in their action as if the collar were not there. Alout A (figs. $1415)$ is the point of the shoulder where the trace should come: and a little inclination downwards, which can easily be effected in the case of the shaft-horse by the shafts, and in the others by the belly-band, will, if necessary, prevent the collar rising up and inconveniencing the throat of the horse.

Reflecting uron the rarious circumstances 
which we have shown to occut in the application of animal power, and the rarious conclisions we have drawn while considering the best and most auvantageous application of this porver-ani we must le excised the frequent repetition of the terms, for the sake of the clearness gained br itit would appear that the resistance should be as much as possible rigiil and inelastic, so as to receive immediately, and unimpaired, the direct

Fig. 14.

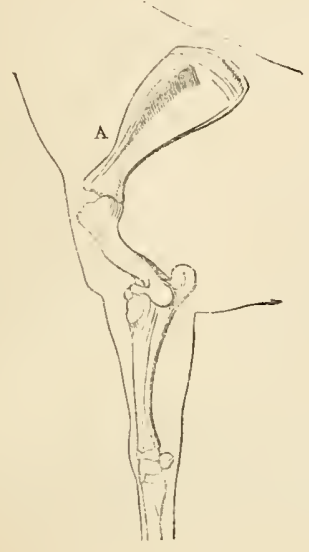

That, as regards the degree of resistance, where relncity is not required, a force of traction of from $100 \mathrm{lbs}$. to $125 \mathrm{lbs}$., or even $150 \mathrm{lbs}$., * according to the strength of the horse, continued for eight hours a dar, at about two and a half to three miles per hour, is the best proportion of quantity and duration of labour; that where six or eight miles per hour is required, the duration of the day's work should be shortened to five or sir hours, and the draught reduced to 80 lbs. or $100 \mathrm{lbs}$. At still higher velocities the dranght must not exceed 50 lbs. or 60 lbs., and the time of working two or three hours. But this speed can only be attained by the sacrifice of the horse; and consequently the question will rather be what the horse is capable of doing, than what can be clone with economy; and it becomes a matter of calculation, depending altogether upon the first cost of the horse, and the profits arising from his employment.

With respect to the mode of harnessing the

* The load which will prodnce this amount of draus ht will be determined when we consider the subject of the roul, on the quality of which it will be seen that this mainly depends. effects of the slightly irregular exertions of the animal; that this resistance should not be such as to yield dirently to a sulden impulse: that it should he so far uniform as to be free from vinlent changes or sulilen shocks, but not so constant as to allow of no remission, unr of those alternations of exertion anil comparative relaxation which we have stater to he advantageous to the perfect development of animal power.

Fig. 15.

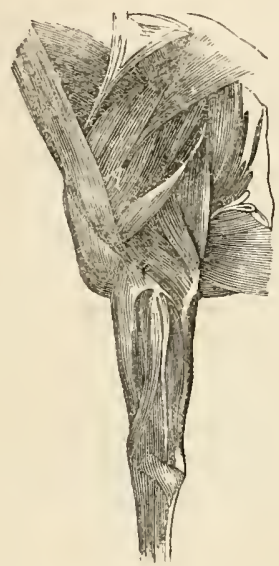

horse, it is hardly necessary to say that great care should be taken in fitting the collar, and in attaching the traces to the proper point. As to the direction of the traces, it must, as me have shown, entirely depend upon the circumstances of the case. Where the draught is heary and slow, if the road be good, the traces should be nearly horizontal, unless the journey be short, or the traffic be only in one direction, and the cart retum empty, or unless any other reason render it desirable to compe the horse to exert himself more than he would naturally do; the traces should then be inclined downward towards the carriage, with an inclination perhaps of one upon four or fire, prorided almays that the horse is camable of continuing the exertion which, by the additional load thrown upon his shoulders, he is thus called upou to make. If, in the same case of low speed, the roal be very heary, or broken and rough, the proportion of draught upon each horse must be lesseneil by diminishing the load, but the traces should lie attached still lower to the carriage, at a slope of one upon three or four, by which much greater 
power is given to the animal to drag the loal over any obstruction.

At all high velocities, the traces should generally be horizontal. The cases of rough roads or powerful horses may slightly affect this arrangement, as at low velocities, but not in so great a degree.

We will now proceed to examine the mode in which these conditions are practically to be fulfilled, and the result of the application of the principles which we have laid down, by considering the subject of the vehicles for conveying the weight to be mored.

Those in present use are boats, as canal-boats, sledges, and wheeled carriages, which last of course include every species of carriage, whcther waggon or cart, heavy or light.

Canal-boats and canals, we snspect, are gradually going out of use, and will, excepting in some peculiar cases, or umless some great improvement takes place, in time be superseded entirely by railways; but still it must be many years before this can be effected: and in the mean time, the produce of the most extensive manufactories in the world, and the supply of immense masses of people, will be transported over these beautifully smooth. level, and noiseless roads; and, even if there beds were dry, and become the course of railwars (an event which may perhaps lefall some of them). we must, out of respect for the extraordiry benefits we have derived from their assistance, and the almust incredible effect they have produced upon the commerce and riches of the country, have deroted a few lines to that part of their consideration which bears upon our subject, viz., the draught of canal-boats.

The great advantage in the transport of goods by water conreyance, is the smallness of the power required. A body floating in water is left so very free in its movements, that motion may le gradually communicated to it by any power however small, at least the limit is very far removed; but, althougl a very slow movement may thus easily be obtained, the slightest iucrease of speed causes a very great increase of resistance.

The resistance to a body moving in a lluid, arises principally from the striking of the particles of the fluid against the front of the moving body, so that if the speed of the ressel be inereased, not only does it encounter a proportionably greater number of particles, but also it is struck by each with a force proportionate to the relocity, and consequently the resistance is found to increase as the square of the relocity; thus, if the speed of the vessel be trebled, the number of particles, or the quantity of water which it meets in its progress for a certain space of time, is trebled, and the resistance of each particle leing also three times as great, owiug to the bouts strilingrg it with treble the velocity, the united effect is nine times as great; therefore, if in the first instance it required one pound to draw the ressel, it would now require nine, but nine times the weight or resistance, moved at three times the velocity, will require twenty-seren times the quantity of power in action; consequently, we see that the resistance increases as the square of the velocity, and the power required to be exerted for a given time increases as the cube of that velocity.

This law of the increase of resistance is modified however by other causes, which have been observed and deeply investigated within the last few jears; and which produce such an effect, that with boats of a peculiar form, a diminution of resistance actually occurs at a certain increased velocity, and very high rates of speed, such as even ten or twelve miles per hour, have been attained. There are also some small sources of resistance, such as the friction of the water, which do not increase in the ratio above named, but at moderate velocities the rule applies, and as yet no means have been discovered, by which, with the present dimensions of canals and their locks, larger quantities and weights can be conveyed at any but very low rates of speed. The draught of an ordinary canal-boat, at the velocity of $2 \frac{1}{2}$ miles per lour, is about $\frac{1}{900}$ of its weight, that is to say, a canal-boat, with its loal weighing 33 tons, or $73,920 \mathrm{lbs}$, is moved at the rate mentioned, by a force equivalent to $80 \mathrm{lbs}$., being $\frac{1}{926}$ part of the load. This is found by Mr. Bevan to he the result upon the Grand Junction Canal, and a force of traction of $80 \mathrm{lbs}$. is here found to be equivalent to a horse power. The average power of an orlinary lorse is certainly rather more; and in the commencement of this paper, we mentioned this as an instance of a small effect being produced, most probably owing to the peculiar application of the power. We believe it to be the case, and think it likely, that if the disadrantages before alluded to, arising from the mode of applying the power, could be removed, the effect might be raised 100 lbs., or 120 lbs. of traction, and consequently the load moved would then be 40 or 50 tons; this is an increase well worthy of consileration.

We now come to the consideration of the means of transport employed on land. 'These are sledges, rollers, and wheel carriages. The order in which they are here mentioned, is probably that in which they were invented or first employed. A sledge is certainly the rudest and most primitive form of velicle; the wheeled carritige, and even the placing the load itself upon rollers, is the effect of a much more advanced state of the mechanical arts, and is probably of much later date than the sledge.

When man first felt the necessity or the desire of transporting any article from one spot to another, he doubtless endearoured to lift or carry it: if it 
proved too heary for him to carrs. he would naturally enleavou to irag it. Here frequent experivients woulil soon show lim low much less labour was required to drag a bocty with a smooth surface in contact with the ground. than when the contrary was the case; and if the borly to be moverl did not itself present a smooth surfice on any of its sides, but was, on the contrars, rougl and angular in all directions, he would naturally be led to interpose between it and the rround some plane surface which should prevent the angles and projections of the body from entering the ground and impeding the progress; and we may presume that sledges were tbus very early brought into use, When attempting to transport still heavier masses, the accidental presence of round stones, or of a piece of timber, may have shown the advantage of interposing rolling bodies, and tlus may rollers have been invented and first brought into use.

These steps appear natural and likely to have led to these results; they are at any rate sulficient to account for the first introduction of these two means of facilitating transport, lut no steps of this kind appear capable of leading to the beautiful yet simple contrivance of a wheel.

A roller is hy no means an imperfect wheel, as it may at first appear to be: they have nothing in common but their rotatory or revolving action, but the effect of this motion is totally different in the two. In a roller, friction is avoided altogether by it; in a wheel this friction exists as completely as in a sledge, but the sliding surfaces being at the centre of the wheel, instead of on the ground, are always the same, and being under control, may be kept in that state which shall cause as little friction as possible; moreover, the friction is at a point where we have the means of overcoming it, by acting with the power of a considerable lever, as we shall hereafter show.

There is, indeed, a kind of roller which partakes somewhat of the character of the whee], but witlout possessing the advantages of it.

This species of roller might have licen an intermediate step between the two, and we shall therefore describe it, when we have dismissed the subject of sledges and rollers.

In England sledges are at the present time very little in use. In some commercial tomns the facility with which bulky and heavy articles can be placed upon them, without being raised to the height of a cart, has caused them still to be employed, but even in these cases, they are in general used only upon the pavement where the friction is not considerable, and for short distances, in which case the saving of labour, in loading and unloading, more than compensates for the increase of power absorbed by the draught. Low-whieeled trucks, however, in these cases possess, the same advantage, and have gradually been substituted for them, where this alvantage was indispensable: for agriculmml purposes they are almost becone obsolete, and for all purposes of traffic between distant points thes are quite abandoned.

It is only in the nortl of England and in some parts of Cornwall, that they are sometimes used in farms, but wherever gonl roakls exist, and mechanical arts keep pace with the improvements of the age, they have given place to wheel carriages. An examination into their nature and action will immediately account for this.

A slerge is merely a frame, generally of wood, upon which the load is placed, and resting at once upon the ground, the friction lietween the under surface of the sledge and the ground bears a considerable proportion to the loal: but if the ground be very uneven and full of holes, the sledge, by extending over a great surface, avoids the licles, and slides only upon the eninences, which being naturally the stones or the hard portions of the ground, eause less friction; on such a road, a wheel would be continually sinking into those holes, and thus oppose considerable resistance, and would also expose the load to frequent danger of upsetting.

It would appear, therefore, that over broken groumd, or even unon a very lad uneven roal, a sledge may sometimes be more advantageous than wheels, and its extreme simplicity of construction renders it very economical as regards first cost ; but the ground must indeed be very lad, or the country be rery poor and little cultivated, where the formation of roads would not amply repay themselves by allowing the use of wheels; for the power required to draw a loaded sledge will be at least four or five times greater than that required for an equally loaded cart upon a tolerably good road.

The draught of a sledge, even upon the pavement, is about one-fifth of the load, so that to draw a ton weight requires a force of traction of about four hundred rreight; upon roads the friction will be much greater: it is difficult to state its amount, as it must depend so much upon the nature of the ground, but with the load before mentioned, viz. one ton, the force of traction will probably vary from five to seven bundred weight: over a strong rocky surface the resistance of a sledge will be much the same as on pavement. Its use, therefore, must be confined to very particular cases, where the absence of roads, or the want of means, prevents the adoption of more improved velicles; and these cases are fortunately too rare in England to render it worth our while to bestow much time upon its description.

Sledges are generally formed of two longituclinal pieces of timber. four or tive feet apart, with their lower edges shod with iron; and transverse planks, holted to these, form the floor, and thes. 
are thus easily constructed. The traces should be more inclined than witl wheeled carriages, because the friction bearing a greater proportion to the load, it is more advantageous to throw a portion of that load upon the horse, and being used upou uneven ground it is more important to be able to lift the front of the sledge over obstacles.

Although in this country the use of sledges is very limited, in many parts of the world they constitute the best, and, iudeed, the only means of conveyance. U $\mathrm{U}_{\mathrm{p}}$ ice the friction is so tritling that they oppose less resistance even than wheels, for the reasons before stated, of their covering a larger surface, and thereby sliding over those asperities which would impede the progress of a wheel: upon suow the advantage is still more decided: where a wheel wonld sink a considerable depth and becoure almost immoveable, a sledge will glide upon the thin frozen crust without leaving a trace, and with an ease truly wonderful. In all cold climates they are consequently in general nse ; and the depth of winter is there the season for the transport of merehandize.

The Esquimaux with their dogs, the Laplanders with their rein-deer, and the Russians with horses, use the sledge to a great extent in the winter, over the frozen rivers or the hard snow.

In the warm climates, on the contrary, not only are they now almost unknowu, but the records which refer to periods so far removed as 3,000 years make no mention of such conveyauces.

Follers come next under consideration; they certuinly afford the means of transporting a heavy weight with less power than any other means with which we are acquainted; their motion is not necessarily attended with any frietion. A cylinder, or a sphere, can roll unon a plane without any rubbing of the surfaces whatever, and consequently without friction; and, in the same manner, a plane will roll upon this roller without friction: in practice, this is more or less the case, according to the perfection of workmanship in the formation of the rollers, and, if cylindrical, the care with which they are placed at right angles to the direction at which they are to move. There is ouly one sumce of resistance which is inseparable from the use of rollers, viz., the unevenuess of the surfaces, or the yielding of the material, which amounts to nearly the same thing.

A circle resting upon a straight line can only touch it in a single point, and the contact of a cylinter with a plane is merely a line: consequently, if the material of the roller, and the surface on which it rolled, were perfectly hard and inelastic, snch would be their contact, whatever weight might be placed upon the roller.

But in pructice no sich material can he obtained, and rollers, on the contrary, are generally made of wood, and when loaded, they inusi yield until the surface AB, fig. 16, is proportionate to the pressure. Still, if the substance were perfectly elastic ; that is to say, if it would return to its original form with the same force and
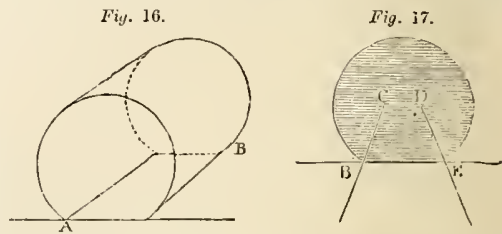

velocity which were required to distort it, this alteration would not cause any resistance; the elasticity at $\mathrm{E}$ would tend to raise the back of the roller with a force DE, fig. 17, equal to, and exactly similar, but opposite to $\mathrm{CB}$, and would consequeutly balance it.

Although perfect elasticity is unattainable, yet most hard substances possess this quality to some extent; cousequently, when the loal is not sufficient to crush the materials, the resistance is not much increased by even a consilterable yieldingprovided this yielding, as we before satid, arises from elasticity. Thus if a bladder be filled with air and used as a roller, the resistance will not be greater than if a perfect and hard cylinder were employed, although the bladder may be nearly flattened under the weight;-but the permanent compression of the loller, and the crushing of dust or other extraneous substances lying in the way, are the great imperliments to its movements; these coustitute a resistance in the direction $B C$, which is not counterbalanced by any force arising from elasticity on the opposite side. The eflect of this resistance is dependent upon the diameter of the roller, dininishing when the latter is increased, though not in so rapil a proportion.

If to a circle a horizontal force $P$ be applied

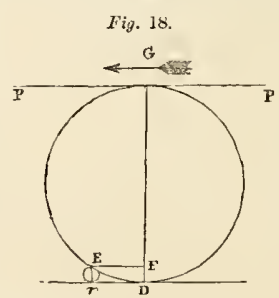
at $\mathrm{G}, \mathrm{fig} .18$; if an obstacle be placed at $\mathrm{H}$, the force $\mathrm{P}$ will tend to jush the roller over the obstacle, and will act with a lever equal to $\mathrm{GF}$, and for all small ol, stacles $G F$ may be considered equal to $G D$ the diameter. The weight upon the roller pressing it down, acts with a lever equal

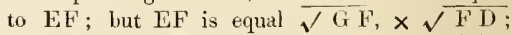
therefore $\mathrm{E} r$, which is equal to $\mathrm{F} \mathrm{D}$, rentaining constant, and the diameter being increased, $\mathrm{EF}^{\mathrm{T}}$ increases only as the square root of dimneter, and consequenty, the force necessary to ulvance the 
ruller is inversely as the square root of the diameter; that is to say, if a roller be increased four times in diameter, the resistance arising from the causes now under consideration will be reduced to $\frac{1}{\sqrt{4}}$ or $\frac{1}{2}$, and if increased nine times in dia meter, the resistance will be only equal to $\frac{1}{\sqrt{9}}$ or $\frac{1}{3}$.

This being the only source of resistance to the action of a roller, it will easily be conceived that, in practice, by laying a plank or any other plane surface upon the ground, and preparing in like manner the lower surface of the body to be moved, and interposing rollers between the two, a very great weight may be moved with comparatively small power; but, on the other hand, there is a serious practical inconvenience attending the use of the roller, which prevents its adoption except in very particular cases.

A weight moved upon rollers proceeds at twice the rate of the roller; for if C, fig. 19, be the
Fig. 19.

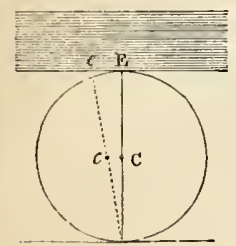
centre of the roller $\mathrm{D}$, the point of contact with the ground, and $\mathrm{E}$ that with the weight to be moved, and $\mathrm{W}$ the weight, if this weight be put in motion, the point $D$ is for an instant stationary, since it is in close contact with the ground. The diameter $\mathrm{ECD}$ moves, therefore, round the point $D$ as a centre, and, consequently, $\mathrm{E}$ being as twice as far from $\mathrm{D}$ as $\mathrm{C}$ is, describes $\mathrm{E} e$ twice as great a distance as $\mathrm{C} c$; fresh points are now brought to the summit and in contact with the ground, and again the latter is stationary, while the former moves twice the distance which the point $\mathrm{C}$ does. The summit, therefore, or tbat point which is in immediate contact with the weight, always moves with twice the velocity of the centre of the roller; but the velocity of the centre is, of course, that of the roller, and the velocity of the point $\mathrm{E}$, which is in contact with, and is moved by, the weight, is the same as that of the weight moved; therefore, as the weight is forced forward, it moves at twice the rate of the roller, it will gain upon the rollers, and others must be continually supplied in front-an inconvenience much felt in practice.

This confines the use of the roller to cases where the distance is very short, or where the weight conveyed is exceedingly great, and reduction in the resistance of more importance than the inconveuience alluded to.

The most remarkable instance of the application of rollers is the transport of the rock which now serves as the pedestal of the equestrian statue of Peter the Great at St. Petersburgh.
This rock, a single block of granite, was discovered in the centre of a bog, four miles from the waterside; it weighed, after being eut into a

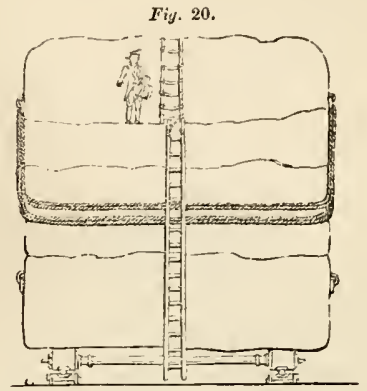

convenient shape, 1217 tons. Notwithstanding its enormous weight it was raised and turned upon its side, and placed upon a frame. A road was made across the bog, and a timber railway laid down; the whole was then left till the depth of winter, when the boggy ground was frozen, and the operations then commenced. The railway consisted of two lines of timber a a a a, (figs. 20 , 21,22 ,) furwished with hard metal grooves; similar

Fig. 21.

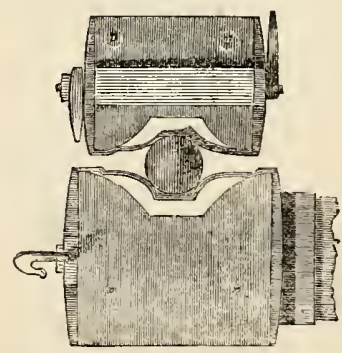

and corresponding metal grooves were fixed to the under side of the sledge, and between these grooves were placed the rollers, which were spheres of hard brass, about six inches diameter. The impossibility of confining cylindrical rollers to a perfectly parallel direction, and without which the friction would have been considerable, rendered the adoption of spherical rollers or balls runuing in a groove a matter of necessity, as otherwise the small surface upon which they can bear, and the consequent danger of crushing, or at least tlattening that surface, is a serious oljection to spheres: once placed upon the rollers, it was dritwn by. means of capstans. The resistance docs not alpear 


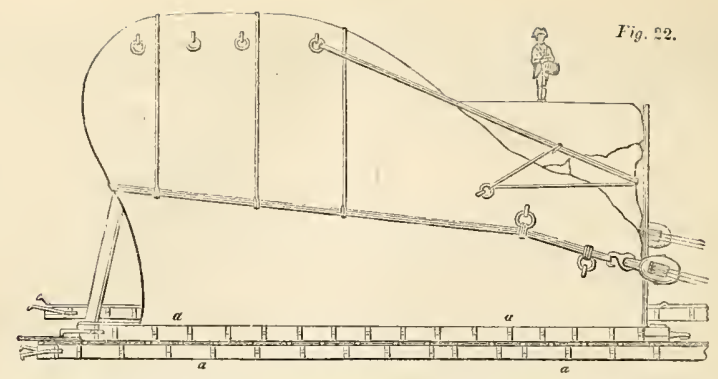

to have been great, considering the enormous weight, since sixty men at the capstans with treble purcliase blocks moved it with ease.

The transport of this enormous rock under such disadvantageous circumstances of country, over a distance of four miles, and its subsequent passage of thirteen miles by water iu a vast cassoon or vessel coustructed for the purpose, was a work surpassing anything attempted by the ancients, and, indeed, in modern times the only thing which can be compared to it is the dragging a ship of the line up a slip; the weight is in this case nearly the same as that of the rock, but the distance traversed is short, and the difficulties to be overcome much less. A plane of inclined timber is prepared and well greased; a frame of wood, technically called a cradle, is fixed under the vessel, it is floated on to the inclined plane and drawn up by the united efforts of a number of well-manned capstans, with powerful tackle: in this case no rollers are used: it is a sledge, the surface being well covered with grease to lessen the friction.

Fig. 23.

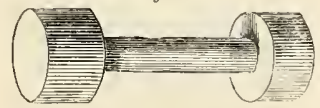

We have stated that there was a particular construction of roller which might be considered, as regards its form merely, an intermediate step

Fig. 24.

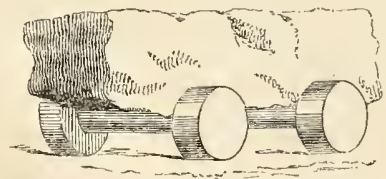

between the roller and the wheel. It consists of a roller with the diameter of the extremities increased as in $f i g, 23$; the only advantage of this roller is that the hody rests upon the sinall part of the roller, see fig. 24 , and when put in motion, will not gain so rapidly on the rollers; or in other words, the roller will move with more than half the velocity of the body. A mere inspection of fig. 25, is sufficient to show that the velocity of Fig. 25.

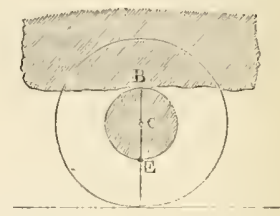

the centre, $\mathrm{C}$, will be to that of the body resting on the point $B$, as C D to B D, so that if the ends of the rollers are twice the size of the intermediate part, C D will be equal to two-thirds of $\mathrm{B} \mathrm{D}$, and the roller will move at two-thirds of the rate of the body; a less number of rollers are therefore required, and the resistance is somewhat diminished by having larger rollers in contact with the gromd.

In using a roller of this sort, the illea may have struck the workman, or it may have occurred accidentally, to confime the spindle of the roller, and compel it to move with the body; and thus a clumsy pair of wleels, fixed to a spindle, would have resulted from his experiment. Such a supposition is quite gratuitous, as we have no record of any such contrivance having existed before wheels were made: indeed it is inferior both to the roller and the wheel: the only argument in favour of such a theory is, that rollers of this sort have been employed in comparatively modern times.

At Rome, in 1588 , an obelisk, ninety feet high, of a single block of stone, weighing upwards of 160 tous, and which had originally been brought 
from Egypt, was removed from one square, in as to form an inconsidelable part of the whole which it stood, to another near the Vatican, and resistance, or dranght of the carriage. there again erected in the spot where it now is.

In dragging this through the streets of Rome, it was fixed in a strong frame of wood, which rested upon a smaller frame, which were furnished each with a pair of rollers, or spindles, of the form above referred to; they were turned by capstan bars: indeed they cannot be better descrilhed than by stating that they resembled exactly the naves of a pair of cart-wheels (all the spokes being removed), and fixed to a wooden axle. If a heavy waggon lay upon a pair of these, we can conceive that by putting bars into the mortices of the naves, we could force them round, and thus advance the waggon: but the resistance would evidently be greater than if either rollers or wheels were employed.

All the difficulties incidental to the nse of the roller appear to be surmonnted, and all objections met, by the contrivance of the wheel.

The wheel being attached to the load, or to the earriage which contains it, moves with it, is part of the machine, and consequently as we require only the number of wheels immediately necessary for the support of the load, we can afford to construct them of those dimensions and materials best suited to the purpose. By increasing their diameter, we are enabled to surmount impediments with much greater facility, as we have shown in the case of the roller; and although there is a resistance arising from friction at the axle, which does not exist in the roller, yet this may be so reduced by increasing the diameter of the wheel,
Of the first introrluction of the wheel we have no record whatever. The priuciple appears to us so simple as to lave been necessarily the result of pure invention, almost of inspiration; while, at the same time, it is so exreedingly effective and perfect, as hardly to admit of improvement.

The great antiquity of wheeled carriages or chariots precludes all hopes of discovering their origin. About fifteen hundred years before the Christian era they appear to have been in com. mon use amongst the Egrptians in their warfare. Pharaoh dispatched six hnndred chosen chariots in pursuit of the Israelites, while the rest of the army followed with all the chariots of Egspt: here, therefore, they were in general use, and serving as the cavalry of the present day. MIoreover, the oldest records, which enter into any detail of their construction, described them as in a very forward and perfect state.

At the siege of Troy, nearly three thousand rears ago, they formed, according to Homer, the cavalry of the Greeks and Trojans; and every officer or hero of good blood possessed, at least, a pair of horses and a charioteer.

These chariots being built to run over broken ground, where no roads existed, were made low and broad, and they were by no means badly contrived for the purpose for which they were in tended; the wheels were constructed with a nave and spokes, felloes and tires; and the pole $a$, appears to have been fixed on the axletree, $b$, in

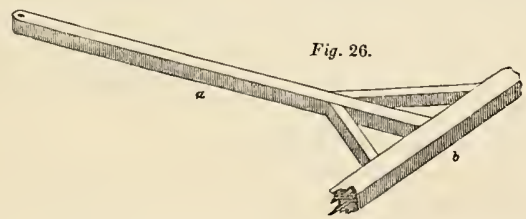

the manner shown in fig. 26. The body of the self in a "beautiful new-built travelling carriage," chariot was placed upon this frame. The team drawn by favourite horses, while the treasures, ingenerally consisted, as we have before stated, of a pair of horses, attached to the pole; six and even a greater number of horses were, however, frequently harnessed abreast, but in that case a second pole was generally affixed to the axletree, so as to lave a pair of horses attached to each pole, and the axletrees themselves were always made nearly as long as the whole width occupied by the horses.

They appear to have had light chariots for more domestic purposes, and four-wheeled carriages for conveyance of heavy goods; and certainly King Priam, when he went to the Grecian camp to ransom the body of his son Hector, travelled with some degree of comfort and luxnry : he rode himtended as a ransom, were conveyed in a fourwheeled waggon drawn by mules. All these details, as well as the mode of harnessing the horses, which operation, it must be confessed, was performed by Priam himself and his sons, are fully described in the twenty-fourth book of the Iliad.

That Homer was well acquainted with the construction of the spoked wheel running freely upon the axletree, and, perhaps, even with the mode of hanging the body of the carriage upon straps for springs, in the same manner as the public coaches are to this day in many parts of France, and, till lately, even in the neighbourhood of Paris, is 
evident from the passage in which he describes Juno's chariot. He there says, while Juno Nas putting the golden bits to the horses, Hebe fastened on the wheels to the iron axles. "These wheels had eight brazen spokes, and the felloes were of gold, and the tires of brass."-"The seat was fastened with gold and silver corls."

This, of course, gives us Homer's ideas of perfection in a chariot.

All the epithets which could convey illeas of swiftness, were applied to these chariots and to the horses, but we have no positive information as regards the real velocity with which they would travel: as roads were scarce, and probably at best merely tracks, much could not be expected from vehicles constructed under such circumstances; the wheels were small, from twenty to thirty inches diameter, and all the parts of the chariots excessively heavy, so as to resist the repeated shocks to which they were sulject.

The chariots represented npon the Frieze of the Parthenon, before alluded to, and which is probably upwards of 2200 years old, are very light in their construction, and only want springs to be called gigs.

The advancement of all the branches of the mechanical arts las necessasily introduced many improvements in the details of the construction of the wheel itself, as well as in that of the axle and the rest of the carriage, and by this means no donbt increased very greatly the use and advantage of it ; but it is a remarkable fact, that these improvements have been confined exclusively to the workmanslip and mechanical details, and that the principle has remained exactly the same, and has not even received any addition during this immense lapse of time.

Upwards of 3000 years ago, the wheels appear to have been independent of each other, and muning upon fixed axles: we cau say no more of the must improved wheel of the most finished carriage of the present day.

We are far from intending to cast any slight npou modern invention, or to compare the groaning axletrees and creaking wheels of the ancients with the noiseless Collinge's axles of the nimeteenth century; lnt truth compels us to acknowlerlye that a period of thirty centuries, more than half the time which is supposed to lave elapsed since the creation of the world, has produced no radical change nor brought into action any new principle in the use of the wheel as applied to carriages.

The particular form and construction of the wheel as well as of all the other parts of the carriage, however, admit of great variety, and the draught is materially affected by their variation. We slaall, therefore, after examining the action of wheels in general, deseribe the mode of construction now adopted, and then endeavour to point out the advantages and disadvantages of the various furms which have been giren to the different parts of it.

First let us examine the theory of it, and suppuse it acting on a level plain.

The wheel being a circle, the centre will re main always at the same height, and consequently will move parallel to the plane in a perfectly level line: if any weight be attached to or suspended from its centre, this will also move in a contimued straight line, without rising or falling, and consequently when once put in movement, there is nothing to check its jrogress (neglecting fur the moment the slight resistance of the air), and it will require no force to keep it in motion so long as the wheels continne to turn.

We have, therefure, in this case only to examine into the force necessary to turn the wheels. The wheels, if left to themselves, would roll on with perfect freedom, whatever might be their weight, or whatever weight might be attached to them, provided nothing in the mode of attaching that weight impeded their revolution ; but in practice we cammot admit of the load revolving with the wheel, and we have no means of suspending it to the wheel, excepit by means of an axle fixed to the load, and passing through the centre of the wheel. This axle presses upon the lower snrface of the hole, and consequently when the wheel revolves, causes a friction proportionate to the load upon the axle. This friction is then the only source of resistance to the motion of a wheel, under the circumstances here supposed; and it is the action of this friction, the degree in which this affects the draught, and by what means this effect is increased and diminished, that we are now alout to consider.

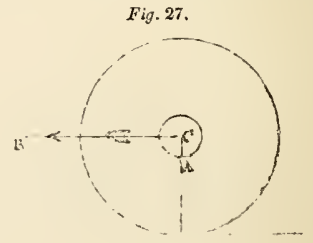

Let $\mathrm{C}, \mathrm{fig}, 27$, be the centre of a wheel, of which $C D$ is the radius, and $C A$ that of the axle passing through the wheel, and which being fixed to the load does not revolve with the wheel.

If a force $\mathrm{C} \mathrm{B}$ be applied to the centre of the wheel, tendiug to advance it in the direction $B$, the point $\mathrm{D}$ being in contact with the ground, the wheel is compelled to turn or roll, and the force $\mathrm{C} \mathrm{B}$, in tuning the wheel, acts with a leverage equal to C D, but the friction between the axle and the wheel is at the point $A$, and in prevent- 
ing the turning of the wheel it acts only at the extremity of the lever $\mathrm{CA}$; consequently if $\mathrm{CD}$ be ten times as great as $\mathrm{CA}$, the forec $\mathrm{C} \mathrm{B}$ need only be equal to one-tenth of the amount of the friction, aud as a general rule, the radius of the axle and the friction remaining the same, the force necessary to overcome the resistance arising from this friction will be intersely as the ralius or the diameter of the wheel, or, in other words, the draught will, in this case, diminish exactly in proportion as the diameter of the wheel is in. creased.

The exact amount of resistance occasioned by friction will depend upon the nature of the substances in contact at the axle, as well as upon the proportionate dimensions of the wheel aud axle

The friction between polished surfaces bears a certain proportion to the pressure; if the pressure is doubled, the friction will, within certain limits, he also doulled; but the proportion between the friction and the pressure is only constant so long as the same sulstances are employed: it varies very much with different substances. Thus with solt wood sliding upon soft wood, the friction amounts to one-fourth or one-third of the pressure; while between hard lorass and iron, the surfaces smouth and oiled, the resistance may be as low as $1-30 t h$ of the pressure. The relative advantages, therefore, of different materials, as applied to the axle and box of a wheel, is a point of much consequence.

Mletals, generaliy spealing, are the best adapted for this purpose. Oring to their hardness, the friction between them is small, and they will bear without injury a greater pressme, proportionably to the surface; and, from their strength, the axle may be of much smaller dimensions than if male of "wood; and we have proved that a reduction in the diameter of the axle causes a proportionate reduction in the resistance caused by friction. In consequeuce of these advautages, iron or steel axles, working in iron boxes, are now almost miversally alopted. The friction in this case, when the parts are in proper order, greased, and the pressure upon them not excessive, amomts to about one-eighth, or, at the nust, one-fifth of the pressure or weight; suppose it one-sixth, and if the diameter of the wheel is to that of the axle as 18 or 20 to 1 , which is about the proportion in a large two-wheeled cart, the whole resistance arising from friction at the axle will be equal to ${ }_{b}^{t}$ of $\frac{1}{15}$, or of $\frac{1}{20}$, which is equal to $\frac{1}{105}$ and $\frac{1}{120}$ respectively. So that to move one tou would not, in the latier case, require a force of traction greater than $1 \leqslant \frac{1}{2}$ lbs,; and having overcome this resistance, the force of traction required remains nearly the same at all velocities; that is to say, friction is not materially affected by velocity, therefore the re- sistance arising from it is not sensibly gugmented ly a cunsiderable increase in the speed. In practice, however, the friction at the asle is far from being the greatest impediurent to the motion of a carriage. We have hitherto, for the purpose of considering friction alowe, supposed the surface ujou which the wheel moved as perfectly hard, smooth, level, and plane; we need hardly say that such can never be the case in a road. The friction, howerer, remains, practically speaking, the same, and the laws which govern the amount and the effects of it remain unaltered; and we have only to ascertain what is the additional resistance arising from other sources, to obtain the whole draught of the carriage. We lave already stated, when pointing out the difference between the roller and the wheel, that the morement of the latter was attended with two sources of resistance, riz., friction at the centre, which we have consilered, and another, which is common buth to the wheel and the roller, arising from impediments in the road, or the yielding of the materials.

The laws which affect the amount of this latter are, of course, the same in a wheel as in a roller.

We have found that the power required to overcome it is inversely as the square root of the diameter: therefore, by increasing the diameter of the wheel, the effect of friction, which is inversely as the diameter, diminishes much more rapidly than that caused by impediments in the roads; and on ordinary roads, with conmon carts, the amount of the latter is about three times as great as that of the former, and when the roads are at all injured lyy weather or by neglect, or if they are naturally lieary or sandy, it bears a much greater proportion. A light four-wheeled cart, weighing, with its load, $1000 \mathrm{lbs.}, *$ was repeatedly drawn upon different sorts of roads; the average of a number of experiments gave the following results:

\begin{tabular}{|c|c|}
\hline Description of Road. & $\begin{array}{l}\text { Force of Traction required } \\
\text { to mure the Curriage. }\end{array}$ \\
\hline umpilie roal, - hard, dry & . . . $30 \frac{1}{3} \mathrm{lbs}$. \\
\hline Ditto dirty : & 39 \\
\hline (l, conjpict loam . & - 53 \\
\hline dinitry by-roatl . . . & . 106 \\
\hline urmpilie roat-new gravelled & . 143 \\
\hline se, saudy road . . . . & . . 204 \\
\hline
\end{tabular}

The friction at the axles, which were of wood, was, of course, nearly constant, and probably absorted at least $\frac{1}{60}$ of the weight, or $1: 2 \frac{1}{2}$ llis. of the forte of traction, leaving, therefore, for the resistance caused by the road in the difierent cases, as muder-

* The experiunent was unt marle with a lond of exactly 1000 lbs., bat the proportions of the results are calculated to this standind The public are indebted to Mr. Bevau for these as well as fur a great number of other highly useful and practical esperiments upon the efiects of purrer in various cases. 
Description of Road. Force of Traction required to move the Carriage, independent of the Friction at the Axles.

Turnpike-road-hard, dry, about . . . 18 lbs. Ditto dirty :. . . . $26 \frac{1}{2}$ Ditto new gravelled: . . . $130 \frac{2}{2}$

Loose, sandy road . . . . . . . . $191 \frac{1}{2}$

So that in the last case, one by no means of rare occurrence in many parts of the country, the portion of draught immediately caused by the state of the road was ten times as great as on a good turmpikeroad, and about fifteen times as great as that which arose from friction at the axles. It would be hopeless to attempt to remedy this by increasing the size of the wheel: the experiment was made with wheels of the ordinary size. To double their diameter would evidently be attended, in practice, with insurmountable difficulties; and yet, even if this were effected, it would barely reduce the total amount of the draught by one-fourth; but the form of the wheel may materially influence the state of the road: we shall, therefore, proceed to consider the various forms employed

Some years ago, when the principal turnpike roads of the kingdom were at many parts, at particular seasons of the year, in little better condition than that on which the last experiment was tried, various attempts were made to reduce the resistance, by using narrow wheels. These attempts, and the laws which it was found necessary to enact to prevent the entire destruction of the roads, led, at last, to curious results, having gradually caused the introduction of the worst-formed wheel which could probably be invented, either as regards increasiug the draught or the destruction of the roads.

To understand these alterations clearly, we must describe the principal features of the wheel now in use.

The general construction of it presents a striking instance of strength arising from the judicious union of substances of very different qualities-wood and iron.

A strong circular frame of wood, composed of different segments, called felloes, is bound together by a hoop, or several hoops of iron, called tires, which thus, at the same time that it gives great strength, protects the outer surface from wear.

The nave, a circular block of wood, is sustained in the centre of this frame by the spokes, which, instead of being in the plane of the felloes, form a cone: this is called the dishing of the wheel. The object of it is to give stiffness, to resist lateral shocks, as when the wheel slips sideways, into a rut or hole. A reference to a comparative view of the wheel, with and without dishing, will more clearly explain our meaning. Fig. 28, is a wheel with the spokes all in one plane; $f i g .29$, a wheel with a considerable degree of disling.

Here it is evident that a small pressure on the nave in fig. 28 , would have a tendency to push it through, and would meet with but little resistarice. In fig. 29 , on the contrary, this force would be opposed at once by the direction of the spokes,

Fig. 28.

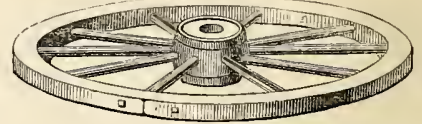

Fig. 29.

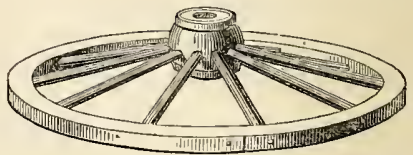

which form an arch, or dome, that cannot he flattened without bursting the fellnes or tires. The dishing, therefore, gives the wheel a very great degree of stiffness and strength, which it would not otherwise possess.

In consequence of this conical form, the necessity of keeping the lower spokes which support the

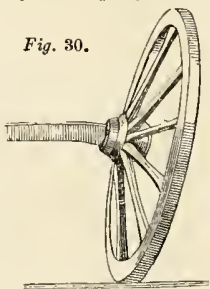
weight as vertical as possible, has required that the whole wheel should be placed ollique, and the axle bent downwards, as in fig. 30 : this, as we shall hereafter show, is attended with very serious evils. As a wheel is intended to roll upon the ground, without friction, it is natural to suppose that the outer surface of the tires should be cylindrical, as it is the only form which admits of the wheel rolling freely in a straight line; but it is nevertheless the form of this surface, its breadth, and the degree of dishing which have varied so much from the causes before mentioned, viz.. the state of the roads, and to the consideration of which we will now return.

A road, however much neglected and out of repair, will generally have, at a certain depth, a hard bottom; above this will be a coat of mud of loose stuff, more or less deep, according to the material used, and the frequency of repair or the quantity of wet to which it may be exposed. It is sinking through this, until it reaches the hard bottom, that causes the resistance to the progress of the wheel: whether the wheel be wide or narrow, it must squeeze or grind its way to the bottom of this mud; a narrow wheel evidently displaces less, and therefore offers less resistance. The great object of carriers, then, was very naturally to place as great a load as they could upon wheels which 
were as narrow as possible, consistent with the necessury strength.

It was soon perceived that the entire destruction of the roads would be the consequence of this system, which had its origin in the bad state of the roads. A cercain width of tire proportionate to the loat was therefore required by law, The endeavour to evade this law was the cause of the absurd form of whet we are about to describe and to cundemn.

In apparent obedience to the law, the felloes of

Fig. 31. the wheels were made of anexcessive breadth; but to retain the advantages of the uarrow wheel, the midlle tire was made to project so fir beyond the others (see fig. 31), that it in fact constituted the whet, the others being added merely to give a nominal, and not a real widtl. The enormous loads which it was found advantageous to place on these wheels rendered it necessary to give them a considerable degree of dishing, to resist lateral shocks, and, besides, the carriers were by this means enalled to give a great width of floor to the carriage, still keejing the vehicle in the common tracks or ruts, so that the wheels ultimately assumed the form represented, fig. 32 .

If such a machine had been constructed for the express purpose of grinding the materials of the road to powder, or of serving as a check or drag to the waggon, it might, iuleed, have been judicious, but is a wheel it wis monstrous. Yet this is the form of wheel upon which the contradictory opinions referred to in the first page of this treatise were given lefore a Committee of the House of Comuons. A carrier of Exeter was

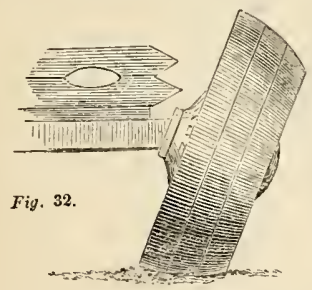

in farour of these wheels, and in support of his opinion, adopts them to this day. But a few days ago we saw one of his waggons with wheels, which, although only about twelve inches wide, were six inclies smaller at the outside than at the inside. Such a cone, if set rolling aud left to itself, would run round in a circle of little more than twenty feet diameter. What must be the grinding and the friction, then, when it is constantly compelled to go on in a straight line? yet enough has been written and silid upon this subject to convince, we should imagine, the most prejudiced of the absurdity of the system.

We shall repeat the principal arguments which were made use of at the time of the inquiry mentioned.

Mr. Cummins took great pains, by constructing models, to show that conical wheels were not adapted for rolling in a straight line, by making a small conical wheel run over longitudiual bars, as

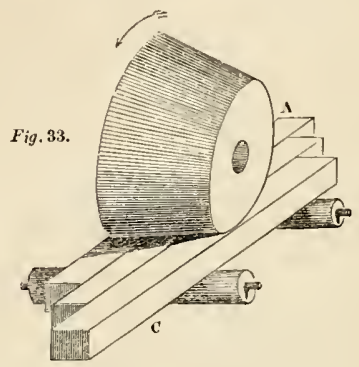

in $f i g .33$. It was seen that if the middle rart of the tire rolled upou the centre bar without moving it, the bar A was pushed backwards while the bar $\mathrm{C}$ was pushed forwards; clearly showing if, instead of slidiug bars, the wheel had moved upon a road, how much it must have ground the road, and what a small portion of the tire was truly rolling.

That such must have been the case is, indeed, easily proved without a model. We will take only three different parts of the wheel and consider them as independent hoors of different diameter; if these hoops are compelled to go the same number of revolutions, the large one will evidently gain upon the second, while the third will be left far behind. Now, if, instead of being independeut of each other, they be fixed to the same axle, and compelled to revolve together, the large one not being able to advance faster than the others, must tear up the ground. The smaller one, on the contrary, being dragged forward faster than it would naturally roll, must drag up the ground; and this is what must take place, and does, with any but a cylindrical wheel, and that to a very considerable extent.

Suplose, for instance, a conical wheel, of an average diameter of four feet six inches; that is to say, that the centre advances about fomrteen feet to every revolution of the wheel. If the inner tire be six inches larger in diameter than the outer tire, the circumference of it will be about eighteen inches greater ; therefore, at each revolu- 
tion of the wheel the inner tire would naturally advance eighteen inches more than the outer tire; hut they are compelled to go over the same distance of gromil. The one or the other, therefore, must have disturbed the ground, or, what is nearer the truth, upon every fourteen feet of road run, the former has passed over nine inches less ground than the development of its circumference, the latter nine inches more-the one pushing back the ground, the other dragging it forward, or, which would be equivalent to the dragging of the load with the wheels locked-a distance of four and a half inches mon every fourteen.

Every child knows that the front wheel of a carriage goes oftener round than the hind wheel. If, then, the front wheel were obligerl to make only one revolution to every revolution of the other, hut still impelled at the same rate, it must be partly dragged over the road. If these wheels be placed side by side, instead of one being in front of the other, the effect must be the same. Now, suppose them to he the outer and imer tire of the same wheel, the circumstances are not thereby altered: the smaller circle and the larger circle cannot hoth roll upon the ground. A conizal wheel is then constantly twisting the surface upon which it rests, and hence arises a very consicleralile resistance, as well as destruction to the roaus.

If these arguments are not sufficient to decide the point completely, let the reader bear in mind simply, that a cone, when left to itself, will always roll in a circle. The frustum of a cone, $A \dot{B}$,

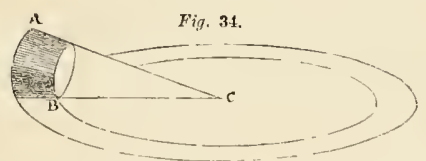

$f i g .34$, is only a portion of the entire cone, $\mathrm{ABC}$, which will roll round the point $\mathrm{C}$; if this entire cone be completely severed at the point $B$, the two parts will still continue to roll round the same point, and if the portion BC be now abstracted, the motion of the remainder will not be altered. If a wine-glass or decanter-anything which is not of the same size at the two parts which are in contact with the surface on which it rests, he rolled upon a table, those who are not already too familiar with the fact to require an illustration of it, will immediately see the truth of this statement. If, then, a wheel thus formed wonld naturally quit the straight line: when compellerl to follow it, it is chear that exactly the same effect must be produced as when a cylindrical mill-stone, as in fig. 35, which, if left to itself, would proceed in a straight line, is compelled to follow a curved line, and is constantly tristed round the centre $\mathrm{C}$, it wonld grind everytbing heneath it to

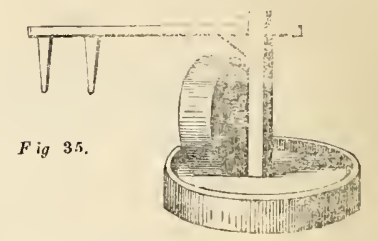

powder. Yet these travelling grindstones were in use npwards of twenty years, to the destruction of the roads, and at a great expense of power to those who have persisted in employing them.

The increased strain upon the axles, from this constant tendency of the wheel to be twisted outwards, with the consequent friction, is a source of resistance absorbed and rendered comparatively inconsiderable, by the far greater friction on the ground: but it is not the less a cause of great increase of draught, and the union of all these serious disadvantages justifies, we think, our assertion, that such a wheel is as injudicious a contrivance as could possibly be invented. We trust they will not long continue to disgrace our wheelwrights, and injure our roads.

The cylindrical form is the only one which onght to be almitted. As a wheel must, however, always be liable to sinls a little into the road, and cannot be expecterl always to hear perfectly flat upon the ground, the surfare of the tires should be

Fig. 36. slightly curved, and the edges rounded $a b$ off, as in fig. 36 . As the rounding

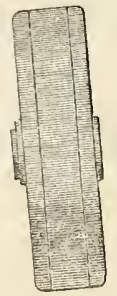

a $\quad b$ is rendered necessary by the yielding of the road, its degree must depend unon the state of the road, and the form of the wheel may approach more nearly to the true cylinder, in proportion as the roads approach nearer to perfection in point of harduess and flatness. When the roads are good, a very little dishing will he sufficient, and a slight inclination of the wheel from the vertical will make it correspond with the barrel or curve of the roasl, which is now generally very trifling.

Next to the form, the breadth of the wheel is the point reofuiring most consideration : it is one, however, which depends entirely upon the state of the road.

We have seen, that the displacement or crushing of the materials forming the upper surface of the roal is one of the principal causes of resistance. If the whole mass of the road were formed of a yielding substance, into which the wheel wonld 
sink to a depth exactly proportionate to the weight bearing upon it, it is probable that great breaitt 1 would be alvantageous, so that the wheel might form a roller, teniling to consolitate the materials rather than cause any permanent displincoment: but, in the improverl state of modem roads, it miny safely be consilered that such is ncver the case.

A road, as we have hefore stated, always consists of a hard bottom, covered with a stratum, more or less thick, of soft, yielding material. A wheel, even moderately loaked, will force its way through, and form a rut in this upper coating. The resistance will be nearly proportionate to the breadth of this rut; the depth of it will not increase in the ratio of the pressure. In considering, then, simply, the case of a single wheel or a pair of wheels forming two distinct ruts, it is evident that it should form as narrow a rut as possible, but that it should not in any degree crush or derange the core or hard hasis of the road. When a rut is thus formed, a small track or portion of the roal is for a time rendered clean and hard, and consequently capable of bearing a greater load than before, and with less injury. It is, then, highly important in a fourwheel carriage that the hind wheels should follow exactly in the track of the front wheels. If rollers were necessary for the road, as if, for instance, it was merely a bed of clay, then indeed, but only in such a case, might it be judicious to canse the wheels to run in different tracks, as has been proposerl, and wits at one time carried into effect under the encouragement of an act of Parliament. Such wheels were called straddlers: they might have been necessary tools for the preservation of such roads as then existed, but the increased dranght soon tanght the public to evade the law which encouraged them.

Mr. Deacon, one of the principal carriers in England, in an excellent practical work on wheelcarriages, published in 1810 , describing these wheels, says, "If the axle of a six-inch wheel is of that length to cause the hind wheels to make tracks five inches outside the tracks of the fore-wheels, and nine-inch wheels seven inches outside, they are then called straddlers, and are allowed to carry a greater weight than if not so. The original intent of these was most excellent; but the effect has been defeated by the carrier or other person not only making the bed or axle contrary to what was intended, but also by carrying with them a false collar, with a joint therein, to put on and take off at pleasure; so that they have no great difficulty in making the wheels straddlers a little before they come to a weighing-machine, and making them not so when they have passed the same."

On modern roads such an arrangement would hardly be beneficial, even to the road itself, and would nearly double the amount of draught.

Too great care and prccaution cannot be taken to insure the wheels running in the same track. Let it be remembered that, on a good road, the forming the rut is the camse of three fourths, and oftrner five-sixths, of the whole resistance. Narrow wheels, thcrefore, ruming in the same track, without doubt offer the least resistance, provided there is surface sufficient to bear the weight, without destruction to the foundation of the road.

Six inches in breadth of the flat or cylindrical part, $a b$, fig. 36 , independent of the rounded edges, will be quite sufficient, in a wheel of ordinary size, to bear a ton without injury to the roads, if in good condition; and according as the weight upon each wheel is more or less than this, the hreadth shonlil be proportionably increased or diminished.

The most simple innovation upon the original wooden wheel is the cast-iron nave. This wo should think nust be much less liable to wear than the wooden nave, which is literally honeycombed with the mortices for the spokes; and a wheel of this sort can be repaired by the most ordinary wheelwright, prorided he has one of the castings at hanel.

We should strongly recommend that these naves should be made with a double row of sockets for the spokes, so as to cross the dishing of them in the same manner as those of the wrought iron wheels described above; and we think they would then form a strong, durable, and economical wheel. There might be some danger from the effects of wet or damp remaining in the cast-iron sockets, and attacking the wood; but we should think a small hole bored into the socket to allow the moisture to escape, and common precaution in painting these parts, would prevent any evil consequences.

With respect to the size of wheels, we have shown that wheels of large diameter certainly offer less resistance than small ones; lut expense and weight cause a limit to this. From four feet nine inches to five feet six inches is a good size for cartwheels, and is ahout the limit where any great increase of diameter would cause more inconvenience and expense than would be compensated for by any advantage gained; and if much less in diameter than this, the draught is unnecessarily angmented.

Yet the front wheels of a waggon are always below this standard! rarely exceeding four feet, and frequently much less. This is a serious evit attending the use of four wheels; it is an arrangement originally made for the purpose of enabling the front wheels to lock under the body of the waggon, which may thus turn in a small space.

Now it rarely happens that a waggon is required to turn short round, and it cannot cause any serious inconvenience if it be rendered 'alti). gether incapalle of doing so.

In this respect a great improrement has taken 
place within a few years. In the place of those moving mountains which were formerly dragged slowly along upon immensely heavy and broad, but low, wheels, we now see, particularly on the roads leading northward from London, a great number of light, well-built waggons, with much larger wheels, especially the front wheels, which, instead of being small enough to turn under the floor of the waggon, are about four feet six inches in diameter. As those waggons are used principally on the road, and are never required to turn in a small compass, but a very small action is allowed to the fore axle. and the floor and hody of the waggon is continued from end to end of nearly the same width.

A waggon with part of the floor and body cut away, so as to form a sort of recess for the front wheels to turn into, allows of considerable movement; and by this arrangement there is nothing to prevent the front wheel being made of large diameter, as in the case just described. Our present object, however, is not to enter into a detailed description of how we should build a waggon, but simply to recommend the use of large front wheels, as tending much to diminish the dranght. An intelligent wheelwright will always know how to construet a waggon so as to admit of this.

The consideration of the subject of wheels naturally includes that of the comparative advantages of two-wheeled and fonr-wheeled carriages. Upon this point opinions differ as much as upon any; and we fear that we are not likely to do more than to arrange the different opinions given by others, without advancing any of our own. If we succeed, however, in doing this clearly we shall have done much, because we may thus enable each individual to separate those arguments which apply particularly to his own case; and combining these opinions with his own judgment, he will be more likely to arrive at a just conclusion, than if he were altogether unaided by the experience of others.

The adrocates of light two-wheeled carts assert that a horse working alone is capable of performing more work than when forming one of a team; and that in consequence of this increased effect, there is a saving of expense nearly in the proportion of three to two, or one-third.

The advocates for waggons assert, on the contra$\mathrm{ry}$, that it requires that each horse in a single-horse cart should be of a superior quality, and therefore more expensive than those of a team, where the average power only is considered; that the wear and tear, first cost, and expense of attendance of several small carts, is greater than that of a waggon carrying the same load, and that in consequence there is an economy obtained by the latter.

Numbers of facts and the results of long experience are adduced on either side, all of which convey much useful information; and the substance of the whole appears to be, that with light single. horse two-wheeled carts, good horses are able to draw greater loads, and do more work in proportion than a waggon team; that these carts are easier loaded and unloaded, do less injury to the roads, and that they do not require more borses in action than are sufficient for the work to be performed.

On the other hand, it is found that the horses must be stronger and better fed; that being en. tirely dependent on their own exertions, and doing more work, they are more fatigued and sooner knocked up; that on rough roads they are liable to be shaken and injured by the sudden move. ments and shocks of the cart, all of which are conveyed by the shafts directly to the horse; that in ascending or descending hills, the whole weight heing above the axletree, it destroys the balance, and is thrown too much upon the horse in the former case, or tends to raise him from the ground in the latter, which, even if any alteration of the balance be found advantageous, is exactly the contrary of what would be necessary.

That with a waggon-the average power of several horses is obtained-horses of inferior quality may therefore be used;-they are not so much fatigued, because ly relieving each other they can alternately exert themselves or relax. Greater loads can be carried with less attendance of drivers, and they are less liable to accidents; they are easier withdrawn from any hole, or forced over any obstruction, because only balf the load being upon each pair of wheels, the whole force of the team is applied successively to each half of the load, consequently in any bad road the power occasionally required is less, although the draught of the carriage, properly speaking, is greater than that of a two-wheeled cart. These various arguments would appear to lead to the conclusion, that upon good roads, and for short distances, with good horses, two-wheeled single-horse carts are the best; but that, with inferior roads and ordinary horses, light four-wheeled waggons, with a team of three or four horses, are the most advantageous.

Two-wheeled carts with two horses are decidedly inferior to either of these: the shaft horse suffers all the inconveniences complained of in the single-horse cart, and the leader does not produce. more effect than when in a waggon team.

It is impossible to decide generally upon the comparative merits of the different arrangements, because the result depends entirely upon the circumstances of the case.

We may, however, endeavour to unite in some degree the advantages claimed by both. The draught of a cart is less than that of a waggon for several reasons: amongst others, because the wheels are larger and the horse produces more effect, because his force is applied immediately to 
the resistance. A light waggon with large front wheels would not be much inferior in point of draught to the cart, and two horses abreast in double shafts would work with equal advantage to the single horse; while an additional horse may always be applied when an excessive load or the state of the roads should require it.

All that we have said with respect to the size and contrivance of wheels is equally applicable to Jight carriages as to heavy, and we shall now proceed to consider the different modes of placing the loads upon the wheels.

It might appear at first sight that this would not affect the amount of the draught; that provided a weight to be moved were placed upon the wheels, and the wileels put in motion, that nothing unore could be required. Upon a perfectly Jevel smooth plane, and with a constant force of traction, this woul!l, iudeed, be the case; but, in practice, the conditions are entirely altered. Impediments are continually met with, which obstruet the progress of the wheels, and the draught is constantly varied by the different inclinations of the road : it is, therefore, necessary to study the means by which impediments can be easiest overcome, and by which the resistance thus caused will affect the animal, which is the source of power, in the least disadvantageous manner.

We have already stated that impetus is necessary to overcome an obstruction, and that elasticity in the direction of the movement is destructive of the full effect of impetus.

When, therefore, the wheel of a carriage comes in contact with any impediment, it is most essential that the whole of the impetus or momentum which the carriage has already obtained, should be brought into full action, to force the wheel forward. To effect this, no elasticity should intervene between the wheel and the load, at least in the direction of the motion, that is, longitudinally; otherwise, as we instanced in the case of catching a cricket-ball, a force which would be quite irresistible if opposed by a rigid resistance, is checked with ease by a very little degree of elasticity; so with a wheel meeting a small stone, if the load were so placel, or hung upon the wheels, as to allow free or elastic action longitudinally, that is, in the direction of the movemcut, the wheel being stopped against the stone, the whole load would be gradually checked, and lirought to a full stop; whereas, if this same load had been fixed firmly to the wheel, its impetus would have carried the wheel over the stone, with very little loss of velocity.

In the first case, it would be necessary for the horses to drag the load over the stone by main force; in the latter, they would only have to make up by degrees for the loss of velocity which the mass bad sustained in passing over the stone. The total quantity of power required will indeed be the same in either case; but in the one, the horses must exert it in a single effort, while in the other, this momentary exertion is borrowed, as it were, from the impetns of the mass in motion, and being spread over a greater space of time, as far as the horses are concerned, only augments in a small degree the average resistance. It is thus that the fly-wbeel of a steam-engine in a rollingmill accumulates power, sometimes for several minutes, till it is able to roll, with apparent ease, a large mass of metal, which, without the effect of the fly.wheel, would stop the engine immediately; or, to mention a case more to the point, in the operation of scotching a wheel, a large stone, and even a brick, will render almost immoveable a waggon which, when in motion, would pass orer the same stone without any seusible alteration of speed. It is most essential, therefore, that the effect of the momentum of the load should in no way be reduced by auy longitudinal elasticity, arising either from the injudicious application of springs, or weakness in the construction of the carriage.

The action of impetus, and the effect of an injudicious mode of hanging the load, is of course more sensible at high than at low relocities,

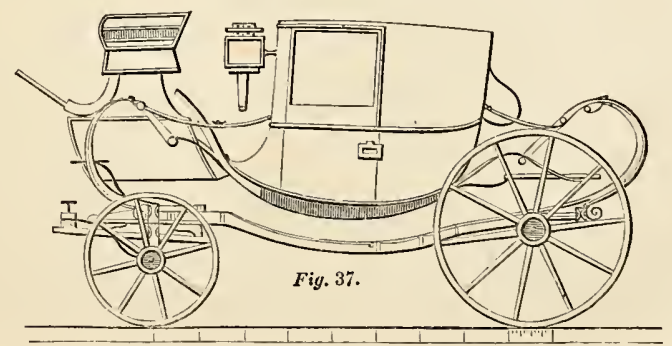


and in a carringe bung npon springs, than in a waggon without springs; but although not so sensitule to the eye, it nerertheless affects the draught materially even in the latter ease. Carriages hung upon springs, as in fig. 37, which are called $\mathrm{C}$ springs, and which admit of verr considerable longitudinal movement in the borly of the carriage, are notoriously the most heary to pull; and calriolets, which are hung in this mauner, are expressively callet, in the stable, horse-mu1derers, and require heavy powerful horses to drag them; while lighter animals are able to drag much greater weights in stanhopes and springcarts, which do not admit of this elasticity.

This is one of the reasons why the dranght of a two-wheeled cart is less than that of a waggon. In a cart, the horse pulls at once on the shafts, which are fixed immediately both to the load and to the axletree, so that not only the impetus of the load, but also of the horse, acts directly and without elasticity upon the wheel. In a waggon, owing to the smalness of the frout wheels, there is a considerable space between the fore-axle and the floor of the waggon, which is filled up with jieces of timber, called bolsters : this admits of considerable play in the parts, and exeept in new-built or very strong waggons, there is never that firm conneetion between the load and the wheels which we luave stated to be necessary. Large wheels would bring the axletrees much nearer the floors of the waggons, and, therefore, admit of a much stronger and firmer mode of attachment, which would be found to protuce a very considerable effect in diminishing the draught.

We have been very particular in confiuing our ohservations to longitudinal elasticity, or jielding in the direction in which the power is applied, and in which the progressive movement talies place; because elasticity in any other direction, instead of increasing the draught, tends very much to diminish it. Let us suppose the load placed upon perfeetly easy springs, which allow it to move freely in every direction, excejt longitudinally, when any one of the wheels comes in contact with a stone, the elasticity of the spring will allow it to rum over the stone without sensilly raising the load which is noon it; and the force which is required to pull the wheel over the stone, will be restored again by the descent of the wheel from the stone, which will tend to impel the mass forward, with exactly the same force as was required to draw it up to the top of this impediment. Without this elasticity it would be necessary to raise the whole load nith a suddeu jerk, and thus instantaneously impart rapid movement to the whole mass, which would absorb much power, and which would liy no means be returned lyy the load falling down firm the stone. We see, therefore, that the use of smings is to enable the wheels to rise and fall according to the inequalities of the ground, while the load continues one constant equable motion. The advantages of this action are very clearly pointed out in a letter addressed to the Committee on the Highways of the Kingdom, by Mr. D. Giddy, and given in the Appendix to their first Peport, printed in the year 1808; and this letter explains so clearly, and in such few viords, the whole theory of wheels, as well as springs, that we think we cannot do better than quote it at length :-

"Taking wheels completely in the abstract, they must be considered as answering two different purposes.

"First, They transfer the friction which would take place between a sliding body and the rough uneven surface over which it slides, to the smooth, oiled peripheries of the axis and box, assisted by a leverage in the proportion of the diameter of the wheel to the axis.

"Secondly, They procure mechanical advantage for overcoming obstacles, liy introducing time proportioned to the square roots of their diameters, when the obstacles, are small as compared with the wheels; and they pass over transverse ruts or hollows, small in the same comparison, with an absolute adrantage projortioned to their diameters, and a mechanical one proportionate to the square roots of these diameters.

"Consequently wheels, thus considered, cannot be too large; in practice, however, they are limited by weight, by expense, and by experience.

"With reference to the preservation of roads, wheels should be made wide, and so constructed, that the whole breadth may bear at once; and every portion in contact with the ground, should roll on without any sliding.

"It is evident, from the well-known properties of the eycloid, that the above conditions cannot all unite, unless the roads are perfectly hard, smootli, and flat; and the felloes of the wheels, with their tire, are accurate portions of a cylinder. These forms, therefore, of roads and whee]s, would seem to be asymptotes, towards which they should always approximate, lut which, in practice, they are never likely to reacli.

" Roards must have some degree of curvature to throw off water, aud the peripheries of wheels should, in their transverse section, be as nearly is possille tangents to th is curve; but since no exact form can be assigned to roals, and they are found to differ almost from mile to mile, it is presumed, that a small transverse convexity given to the peripheries of wheels, otherwise eylindrical, will sufficiently adlapt them to all roads; and that the pressure of such wheels, greatest in the middle, and gradually diminishing towards the sides, will be less likely to disarrange ordinary materials, than a pressure suddenly discontinued at the edges of wheels rerfectly fiat. 
"The spokes of a wheel should be so arranged, as to present themselves in a straight line against the greatest force they are in common cases likely to sustain. These must evidently be exerted in a direction pointer towards the carriage, from lateral percussions, and from the descent of either wheel below the level of the other ; cousequently, a certain degree of what is termed dishing, must be advantageous, by adding strength; whilst this form is esteemed useful for protecting the nave, and for obviating the ill effects of expansions and contractions.

"The line of traction is theoretically best disposed, when it lies exactly parallel to the direction of motion; and its power is diminished at any inclination of that line, in the proportion of the radius of the wheel to the cosine at the angle. When obstacles frequently occur, it had better, perhaps, receive a small inclination upward, for the purpose of acting with most advantage when these are to be overcome. But it is probable, that different animals exert their strength most alvantageously in different directions; and, therefore, practice alone con determine what precise inclination of the line is best adapted to horses, and what to oxen. These considerations are, howerer, only applicable to cattle drawing immediately at the carriage; and the convenience of their draught, as comnected with the insertion of the line of traction, which continued, ought to pass througl the aris, introduces another limit to the size of the wheels.

" Springs were in all likelihood first applied to carriages with no other view than for the accommodation of travellers: they have since been found to answer several important ends. They convert all percussions into mere increase of pressure; thus preserving both the carriage and the materials of the roads from the effect of blows; and small obstacles are surmounted when springs allow the frame and wheels freely to ascend, without sensibly moving the body of the carriage from its place.

"If the whole weight is supposed to be concentrated on springs very long, extremely flexible, and with the frame and wheels wholly devoid of inertia, this paradoxical conclusion will most certainly follow: that such a carriage may be drawn over the roughest road without any agitation, and by the smallest increase of force.

"It seems probable that springs. under some modification of form and material, may be applicable with advantage to the heaviest waggon."

And there call be no doubt, that, in the rords of the writer, the application of springs would be highly advantageous. At high velocities, as we have before said, the effect of springs is still greater. What we have instamed as regards springs, is generally well known and miderstood. All stage-coiches, and many travelling-carriages, bang upon grasshopper springs, which allow of per- pendicular withont any longitudinal actiuls. It would be much to the interests of horse-nasters if the mode of suspending post-chaises were a little more attended to. The more elasticity, or in other words, the more action, there is in grasshopper springs, the more effect it will produce in diminishing the draught: with a $\mathrm{C}$ spring a very contrary effect is produced.

A carriage hung upon $\mathrm{C}$ springs may certainly be made the most comfortable to the rider, but ail the ease that can be required, and much more than is found in the generality of post-chaises, may be obtained by rell-constructed grasshopper springs, and with cousiderable advantage to the horses.

The practice of loading coaches as high as possible to make them r'm light, as the coachmen have found by experience. is only a mode of assisting the springs. The mass being placed at a greater height above the wheels, at the extremity of a long lever, is not so easily displaced laterally by any motion of the wheels, which, therefore, rise and fall on either side as they run over the stones, acting only on the springs, wlich restore the full pressure and velocity in descending, from the oustacle which was imparted to them in ascending, and without producing any sudden concussions upon the load, which swings to and fro with long easy movements. It is possible, also, that the weight, being thus swung from side to side, may, upon good roads, diminish the draught, as it is in fact generilly running upon two of the wheels; while, in the other direction, it equally admits of the front and hind wheels successively passing over any impediments; and yet, by the mauner in which it is fixed upon the springs, it does not admit of any longitudinal elasticity.

The fact of coaches thus loaded rumning light, has been clearly proved by the failure of what were called Safety Coaches, in which the only difference consisted in placing the load very low. These coaches, although completely answering their purpose of safety, were discontinued solely, we believe, from their being found destructive of the borses.

Experiments, nevertheless, have been made to prove that this was ouly an idle prejudice of coachmen; but universally received opinions, even if leading to erroneous conchusions, generally liare some good foundation; and coachmen, althougls they may not lave been so much so at the tiwe these experiments were published (in 1817), ase certainly now rather an intelligent class of men. We should, therefore, prefer risking a theort, if a theory were necessars, in support of their prejn. dices rather than in opposition to them. The experiments alluded to were not, in our opinion, made under the circumstances which occur in prac. tice. Small models (the wheels being seven inches iir diameter) were drawn along a table acruss which 
were piacel small strips of wood, to represent the obstructions met with in a road; but these strips of wood came in contact with each pair of wheels at the same time, and never caused any lateral motion They produced, therefore, a totally different effect from that which takes place in a road, where the action rarely affects more than one wheel at a time; consequently, in the model, the wheels, in passing over an obstruction, threw the whole weight backwards in a direction exactly opposite to the movement required; while, in practice, the carriage is generally thrown sideways, which does not affect its forward motion.

The conclusions drawn from these experiments are, therefore, as might be expected, at variance with practical results, and directly contrary to the opinions of those whose daily experience onght to enalile them to judge correctly.

The effects, also, of velocity and momentum must be difficult to imitate in models.

The advantage of placing the load high will not, however, equally apply at low velocities, still less when springs are not used; it may frequently, indeed, in the latter case, produce quite a contrary effect.

In a rough road, the increased force with which the load would be thrown from side to side might prove very inconvenient, and even dangerous, and would certainly be liable to increase the resistance when the front wheels meet with any obstruction: but this, it must be particularly rememberel, is only true in the case of low velocities and carriages without springs.

We have now considered in succession the various parts of the vehicle for conveying the weight, and shown in what manner they affect the dinnght, and how they should be constructed so as to diminish as much as possible the amount of this dranght. We have endeavoured to point out the advantages and necessity of attending to the construction and size of the wheel. Thus it should be as nearly cylindricai and vertical as possible, and of as large a diameter as can conreniently be admitted. 2 !!ly, That there should be a firm, nnyielding conncction in the direction of the movement between the power employed, the weight moved, and the wheels; in other words, that the force should always act directly and without elasticity both upon the load and upon the wheels; and that the impetus or momentum of the load, when in movement, should always act in the same manner, without elasticity, in propelling the wheels; - and lastly, that it is highly advantageons to interpose as much elasticity as possible, by means of springs in a vertical direction hetween the wheels and the body, so that the ormer may rise ald fall over stones or irregularities in the road without communicating any sudden shocks to the lond: and we helieve that the proper pplication of spings in all cases, even with the heaviest loads, would be found productive of great good effect.

Attention to these points will tend to diminish considerably the amount of draught. As far as regards friction at the axles, and the resistance in passing over obstacles in the road, it will assist the favourable application of the force of traction when obtained from animal power; but that which we have shown to be the most considerable source of resistance is unfortunately least affected by any of those arrangements. We allude to the resistance arising from the yielding or crushing of the material of the road: we have seen that on a good turnpikeroad the dranght was increased in the proportion of thirty to forty, or about one-third, by the road leing slightly dirty; and that, on a heavy, sandy road, the draught was increased to 205 , or nearly seven times. Springs will not affect this; and even increasing the diameter of the wheel will be of very slight assistance; nothing but removing at once the prime source of this evil, improving the roads, can remedy this. We are thus naturally led to the third division of our subject, viz., the road or channel of conveyance. In considering this as a branch of the sulject of dranght by animal power, we shall merely point out what are the principal desiderata in the formation of a good road, and what are the evils principally to be avoided. To enter into all the details of their construction, dependent as it is on the different materials to be found in the neighbourhood, their comparative cost, the quality of the ground over which the road is made, and many other points, wonld be to enter upon a much more extensive field than is at all required for the proper consideration of the subject of draught by animal power. The requisites for a good road are all that we shall indicate.

Channel of conveyance, in a general point of view, would include canals, roads, and railways. Of the first, however, we shall say little; their construction does not materially affect the amount of draught, and we have already examined the made of applying the power, and the quantity of effect produced : we shall proceed therefore at once to the question of roads.

The inquiry into the best form and construction of wheel carriages bas tanght us, what we might indeed have foreseen, that perfection in a road would be a plain, level, hard surface: to hare learned this only would not have advanced us much, as such perfection is unattainable; lut we have learned also the comparative advantages of these different qualities of harduess, smoothness, and level. We have come to the conclusion, that slight alterations of level which shall vary the exertion required of the animal, without at any time causing excessive fatigue, are rather advantageous for the full development of bis power than otherwise: that the inconrenien $\mathrm{e}$ of romblness is 
obviated by the use of springs; and that even when the ordinary carts and waggons without springs are used, still the resistance arising from mere unevenuess of surface, when not excessive, is not nearly so great as that which is caused by the yielding of the substance of the road. Hardness, therefore, and consequently the absence of dust and dirt, which is easily crushed or displaced, is the great desideratum in roads.

To satisfy this condition, however, smoothness is to a certain degree requisite, as the prominent parts would be always subject to alrasion and destruction: fur the same reason, even if for no other, ruts and everything which can tend to form them must be avoided.

A road should, in its transverse section, be nearly flat. A great curvature or barrel, as it is termed, is useless; for the only olject can be to drain the water from it: but if there are ruts, or hollow places, no practicable curvature will effect this; and if the road is bard and smooth, a very slight inclination is sufficient. Indeed, an excess of curvature is not only useless with the present construction of carriages, but facilitates the destruction of the road; for there are few wheels perfectly cylindrical: yet these, when ruming on a barrelled (1.' curred road, can bear only upon one edge, as in fig. 38 . The conical wheels still in use, although much inclined at the axle, are never
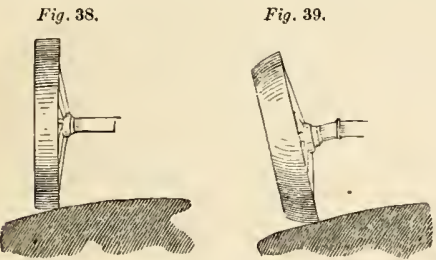

sufficiently so to bring the lower surface of the wheel even, horizontal, and therefore are constantly ruuning upon the edge, as in fig. 39, until they lave formed a rut coinciding with their own shape. In a barrelled or curved road, the mischief done will, of course, be great in proportion to this curvature. This form is, therefore, mischievous as well as useless. Six inches' rise in the centre of a road of twenty feet wide, is more than sufficient to ensure drainage, if draiuage is not effectually prevented by ruts or hollow places, and less than this will suffice where the road is good, and is kept in proper order.

The hardness of the surface, the most important feature, will of course principally depend upon the materials used, and the formation of the road, and still more upon the state of repair in which it is kept. It is easy to form a good roal when the foundation is already laid by the existance of an old one; levelling the surface,-apply. ing a covering of eight or ten inches in thickness of broken stones,-having as few round or smooth surfaces as possible, the hardest that can be obtained,-and above all things securing good drainage, both from the surface and from the bottom, is all that is required: lut constant repair and urremitting attention are necessary to keep a road thus formed in good condition.

These repairs and attention do not consist in laying on at certain intervals of time large quantities of materials, but in constantly removing the sand which is formed, and which, in wet weather, holds the water, and prevents drainage; in filling up as quickly as possible, with fresh materials, any ruts or hollows; and particularly in keeping clear all the drains, and even in scraping small drains from ruts, or such parts of the road as may con tain the water, and which it may not be possible immediately to fill up.

By atteution to these points, those who are in terested in the preservation of the roads, and the expenses attending it, will find that economy will nltimately be the result; and those who are interested in diminishing the labour and expense of draught, we shall only refer again to the table (page 576) of the resistances of a waggon upon different roads, from which they will see, that a horse upon a clean road well do one-third more than upon one slightly muddy; more than four times as much as upon new-laid gravel; and nearly seren times as much as upon a heary sandy road.

No arguments that we can put forward can at all strengthen the effect that such facts must produce; and we shall, therefore, quit the subject of roads, and conclude our observations on draught by a few words explanatory of the object of rail-roads and their effects as regards dimimishing draught.

The great desideratum in the formation of a good road is the facilitating the rolling of the wheels. We have shown that, for this purpose, a hard, smooth surface is necessary; and, as this is only required for the wheels, two longitudinal tracks, of such surface, of proper width, are sufficient for the mere passage of the carriage. If, therefore, there is a considerable traffic between two points along a line of road, without much in. terruption from crossing, all the qualities of a good road may be obtained in a very superior degree, by liaving two parallel rails, or tracks of wood or iron, raised a little above the general level of the ground. This is a rail-road. It evidently affords the means of attaining any degree of perfection in those essentials for a good road-hardness and smoothness of surface for the wheels to roll upon. It requires, however, that the carriages should be all nearly alike, as regards the width and form of the wheels; and experience has proved that such a 
road is not generally worth constructing, unless the traffic is sufficient to allow of carriages being built expressly for that or similar roads. This being the case, the form and dimensions of the rails, and the general construction of the carriages, are uncontrolled by any other consideration than that of diminishing draught.

A considerable improvement upon this point may, therefore, be expected in the railway over the common road. A railway, as now constructed, consists simply of two parallel bars of iron, haring a flat upper surface of about two and a half inches wide. With the exception of this surface, the forms adopted for the bars are various, depending principally on the mode selected for supporting them, some resting on and secured to blocks of stone, placed at intervals of about three feet-others secured in like manner to "sleepers," or beans of wood which are placed transversely, resting on the ground; while according to a third system the bars are secured along their whole length to longitudinal timbers. The wheels at the present time, generally made of wrought iron, and from three to four feet in diameter, are made slightly conical with a flange abont one inch deep on the inner side. This slight flange, and the cone of the wheel, which is also very slight, are found sufficient to keep the wheels from running off the rails, even at the highest velocities. This brief description is sufficient to give a general idea of the construction of railways, which is all that is necessary for our present purpose. It will be easily conceived that hard, cast-iron wheels, running upon smooth edges of iron in this manner, can meet with but little resistance except that arising from friction at the axle: Accordingly we find, upon a well-constructed railway in good order, that the resistance at moderate velocities does not exceed, in any sensible degree, that which must arise from this cause. It has been found that a force of traction of $1 \mathrm{lb}$. will put in motion a weight of 200,300 , and even, in some cases, $350 \mathrm{lbs}$.: so that a horse, exerting an effort of only 125 lhs., would drag on a level 12 or 14 tons. This is ten or twelve times the average effect of his work upon a good common road, and, as it arises entirely from the hardness and smoothness of the surface, we cannot conclude our observations by a more striking and unanswerable argument than this, in proof of the immense advantages and saving of expense which would result from greater attention to the state of the roads. 


\section{INDEX TO.THE OX.}

A Bon isus, the, description of, $1+4$.

Abortion, eauses of, 167 ; is a babit, 168 ; symptoms and treatment of, 168 .

Absorbent vessels of the skin, inflammation of the, 157; cases, eauses, and syimptoms of, 157 .

Adulteration of milk, 90 .

A rriculture in England, 55.

Albumen, what, 107.

Alcohol an addition, in the form of gin or brandy, to cordial draughts, 182

Alderney, breed of cattle of, 48 ; descriptinn of the, 86 .

Alderney cow little esteemed, 56 .

Alemtejo, herds of cattle of the, 18 .

Alimentary canal, mechanical obstructions of the, 15 k.

Alimentary substance, elementary constituents of, 106 ; proximate priaciples of, 106.

Alloy stock of cattle, 82 ; how founded, 83 .

A loes, seldom used as a purgative in the treatment of horned cattle, 178 ; tincture of, an excellent dressing, 183.

Aloetic purgative useful in colic, 179 .

Alteratives and specific inedicines, 179.

Alum, a powerful astringent, 182; whey, 182.

Amarosis, 158.

American bison, description of the, 10, 11 .

Ammonia, liquid, useful in hoove, 181; subcarbonate of, a stimulant, 181.

Ancient Britons, tame cattle of the, 16 .

Anglesea, a breeding district, 71 ; breed of cattle in, 71 .

Angoumois, breed of eattle of, 16 .

Angus, breed of cattle of, 78 ; ox of, 55 .

Animal food, given to cattle in some countries, 37 ; substances, elementary constituents of, 106 .

Antelope bubalus, or wild ox of the Arabs, 12.

Antimony, chloride of, a useful caustic, 183.

A ntispasmodics, 180 .

A perieots for cattle, 178 .

Apis, worship of in Eypt, 20.

A poplexy, causes of, 131 .

Applications, external, 132

Argyleshire, kyloes of, 74 .

Arrian on the ancient Indians, 21.

Arrivals at the London markets of country killed meat, 100 .

Artificial grasses, important to the cattle-keeper, 115.

As'l gayâl, or seloi, what, 5 .

Astringents, 182.

Auge, Pays d', breed of cattle of, 47 .

Aunis, breed of oxen of, 47.

Aurochs, or zubr, fine levied by the Russian government for killing the, 8 ; ferocity of the, 8 ; swif ness of the, 8 ; specitnen of the, in British Museun, 9; coluur of the, 9.

Austrian States, cattle of, 50 .

Australia, destitute of the indirrenous species of ox, 2 .

Auvergne, eattle of, 46 .

Average dead weight of eattle, 88 .

A yrshire breed of cattle, 74 ; cows, management of, 85 .

Azara on the cattle pastures of Paraguay, 24.

BACKELEY, or war-oxen, 39.

Baer, M. de, his opinion respecting the ilentity of the Caucasian and Lithuanian bisons, 10 .

Bailey, Mr., return of the sale of part of Mr. C. Collings's stock, given by, 83 .

Bakewell, Mr., breed of cattle of, 41 .
Ballymahoe; fuir of, cattle sold at the, 59 .

Bal-Siva, treatment of bulls devoted to, 22

Basse Bretagne, breed of cattle of, 47 .

Beastings, or first milk, essential to the calf, 173 .

Beechey, Capt., skulls brought to England by, described, 16 .

$B$ eef considered inferior to mutton in $m$ ist countries of

Europe, 30 ; the roast of Old England, 5 t.

Beet tribe, useful as food for cattle, 114 .

Bell, his description of the yak or bubul of Tartary, 7 ; of the urus or uhr ox, 8 .

Bells hung round the necks of cattle in Switzerland, 35.

Benzoin, compound tincture of, an excelleut dressing, 183 .

Berri, cattle of, $\$ 6$.

Berry, Rev. H., injunctions laid down by, for breeding cattle, 42 .

Bird, Mr., on the cross-breed of the zebu and gayal, 21.

Bison Americanus, 3; European, description of the, 8; odour of the, 8 ; flesh of, used as food, 10 ; hunting of the, by the American Indians, 10; ferocity of the, 11 .

Blackmsor, breed of cattle in vale of, 64

Black-water, 152.

Blain, or gloss anthrax, causes and symptoms of, 137; treatment of, 138 ; is contagious, 138.

Blisters, I83.

Bloxedge, a celehrated bull, 58 .

Bloomfield, his description of a Suffolk cheese, 81.

Boufs de nature and de haut crû, descriptions of, 16 .

Bogra el weish, Arabian wild ox, 12.

Bolingbroke, a celebrated bull, 83 .

Booth's distillery, mode of fattening oxen in, 96 .

Bornou, description of zebu of, 19.

Bos, the genus, 2; subdivided by naturalists, 2; leading characters of, 2; brachyceros, heads of, in the British Museum, 12; Caffer, or Cape buffalo, 12; longifrons, description of the skull of, 14; Pegasus, a species of buffalo, 12; primigenius, 14; Scoticus, wild oxen of England, 13.

Bovine race, fossil skulls of, in the British Museum, 14

Bourbon, breed of cattle in, 46 .

Brahmin bull used as a beast of draught and burden, 22 .

Brain, inflammation of the, symptoms of, 130; treatment of, 131.

Breeding, principle to be guided by in, 41,42 .

Breeds of cattle most valued for milking, 43.

Brindled Beauty, a valuable cow, 59.

Brown, Mr., his account of horn-cores, 14 ; on the symptoms of inflammation of the liver, 128 .

Bruce on the zebu of Abyssinia, 20.

Bruises of cattle, treatment of the, 163 .

Byron, Lord, his description of a bull-fight, 53 .

Buchanan, Dr., his description of the cry of the gayâl, 4 .

Buffalo, the semi-domesticated, 6 ; wild different opinions respecting, 6 ; superiority of, for agricultural purposes, 22 . Bull, various names for, 57 .

Bull, Galloway, 78 .

Bull-fights of Rome, 17.

Bullocks, sacred to Siva, 23 .

Burchell, MIr., his description of the sadu'e-ox, 25.

Burckhardt nu the Arab's mode of making butter, 28.

Burgogne, breed of eattle of; 47 .

Butter, little koown by the Greeks and Romans, 28 ; used in the East from the earliest ages, 28; fondness for, of the Arabs, 29.

Butyrum, a kind $o$ ? butter mentioned by Pliny, 28 . 
Cabbage, eultivation of the, as food for cattle, 112.

Cæcum, the, description of, 145.

Cæsar, his description of the uros, 9 .

Caledonian joint stock dı11ry, 94 .

Calamine ointment, useful in superficial wounds, 183.

Calf, twin female, not neeessarily barren, 40 ; experiment to prove the eontrary, 4.1 .

Calomel, useful in dysentery, 179.

Calves, instances of three and four at a birth, 41: mode of fattening in Forfarslire, 79 ; diseases and treatment of, 173.

Camarque, Pays de, breed of cattle of, 4.8 .

Campagra of Rome, bulls of the, 17 .

Canley, breed of cattle, 58 .

Cantley, Captain, remains of a species of ox found by, 16 . Cape buffalo, description of the, 12 .

Capture of bulls in the Alemtejo, 51 .

Caraway secds, useful as a cordial, 181 .

Cariarvonshire, breed of cattle in, 71.

Carob-trec, pods of, a nutricious food for eattle, 112.

Carrick, lireed of eattle of, 74 .

Carrot, the, a valuable food for cattle, 115.

Carved delineations of the zebu, 20.

Castor oil, all excellent purgative, 179 .

Cataract of the eve, 158 .

Catarrh, or hoose, nature, symptoms and treatment of, 121 , is epidemic, 122 .

Catechu, an effectual astringent, 182.

Catesby, on mixing the breed of bisons with tame cattle, 3 .

Cattle, tame, of the aneient Britons, 16; wild, of Chilhng. ham Pask, probably deseended lrom, 16 ; vast herds of in Spain and Portugal, 51; of Great Britain, division into sections of the, 56; progressive changes in the breeds of, 86 ; general roles for the treatment of, 88 .

Cattle-fairs of England, 105.

Caueasian mountains, bison of the, 10 .

Caustics, 183.

Chalets, or publie dairies of Switzerland, 49 .

Charges, or plasters, 184.

Charolais, eattle of, 46 .

Chatelherault Park, wild ox of, 13; eattle of, description of, 55 .

Cheese, made from the milk of sheep and goats, 28.

Cheshire, renowned as a dairy coonty, 60 .

Chillingham Park, wild white $\mathrm{cx}$ of, 13 ; description of wild cattle of, 13 ; instance of their tenacity of life, 18 .

Chloride of lime, a disinfectant, 181.

Cholet, breed of cattle of, 47 .

Chorea, anknown in horned cattle, 142 .

Chowries, of India, made of the tail of the yak, 7 .

Christmas, supply of beef at, 99 .

Chyle, the enmposition of, 109.

Clapperton his description of the zelun of Bornou, I9.

Cleanliness, indispensable in a dairy, 94 .

Clouted, or Devonshire, cream, 64 .

Close breeding, 43.

Clover, important as an aticle of foud for cattle, 116; various species of; 116 .

Clue, or fardel hound, 150 .

Colic, or fret, 133.

Collings, Mr. C., T'eeswater breed brought to perfeetion by, 82.

Collings, Mr. Robert, prices realised by sale of stock of, 83 . Colon, the, description of, I45.

Columbo-root, a tonie, 1st.

Columella, his description of the labouring ox, 26; of the cow, 27.

Comparative excellencies of the Galloway and Angus brecds of cattle, 78

Concrelious in the stomach, causes of, 154; treatment of, 155 .

Connaught, breed of cattle of, 72 .

Constitutional temperament of the ox, preliminary remarks relative to, 118 .
Consumption, causes and symptoms of. 125.

Contoar, or beauty of form, desirable in cattle, 41 .

Copper-mines, vicinity of, injurioos to cattle, 157 .

Cornwall, breed of cattle of, 62 .

Corrosive sublimate, solution of, a dangerous application, I 61

Cotentin, breed of eattle of, 47 .

Cottager, general roles for the, in the management of cows, 88.

Countess, a valuable cow, 83 .

Cow, deseription of the skeleton of the, 30 ; of Savoy, 48 ; of Lower Saxony, 50; of Westphalia, 50; Zetland, 51 various names for the, 57; Cheshire, 60; Devonshire, 64 ; Sussex, 68 ; Kerry, 72 ; Kyloe, 74 ; Ayrshire, 74, 75 Galloway, 78 ; Suffolk, 80 ; Yorksbire, short-horned, 84 ; Alderney, 86 .

Cow-pox, 172; different opinions respecting the origin of the, 173 ; genuine and spurious, 173 ; treatnent of the, 173.

Craven Park, wild ox of, 13 ; eattle of, 55.

Croton oil, a powerful purgative, 179 .

Cud, chewing the, 2; loss of, eause and treatment of, 150.

Cuvier, his opinion respecting the urus, 9.

Culley, Mr., his description ol the wild oxen of Chillingham, 13; on the impossibility of uniting good milkers with good feeders, 44 ; on the short-liorned lireed of eattle, 51 ; on the eomparitive merits of long and short-horned eatıle, 61 ; on the yearly produce of a Suffulk cow, 80 ; on the Holderness breed of e.ttle, 81 .

Cunniugham, Allau, on the departure of a Highland herd of cattle to the south, 102.

D, a celebrated bull, 58 .

Dairies, in Switzerlaud and Holland, 94 ; plans of, 95.

Darwin, Mr., on the exportation of the hides of the $0 \mathrm{x}, 23 ;$ on the ose of the lasso, 23; on the bulls of the Falkland Islands, 24.

Denbighshire, dairy much attended to in, 71 .

Denuriark, race of eàttle of, 50 .

Uenham, Major, on the bu!lock ased for the saddle, 25 .

Dentition of the ox, 31 .

Derbyshire cattle, original character of, 60 .

Desmarest, $\mathbf{1 1}$, on the breeds of eattle in France, 48.

Devonslsire eatile, 55 ; bull, deseription of, 63 .

Diarrhcea, enuses, symptonts, and treatment of, 136 .

Diet, mixture or alteruation of, essential to cattle, 99 .

Digestion, proetss of, 109 .

Digestive organs of the ox, description of, $1 \pm 3$.

Digitalis, usetul in reducing the action of the heart, 180 .

Dillon, Mr., his description of the Malabar batfalo, 6 .

Diseases of eattle, 118.

Dishley, or new Leicester long-horns, 41; deterioration of the, 50 .

Disinfectants, 183.

Diuretie medicines, 180 ; servieeable, 180.

Domestie zebu brecd, origin of the, 21.

Dorsetshire cheese, 64 .

Douglas, Mr. Wavid, death of, 25.

Drenchts, cordial astringent, 182 .

Dressings, 183.

Drop, see mlk-fever.

Drovers of Eingland and Scotland, and droves of cattle, 101, 103.

Dauntries, cattle-market of, 78 .

Dunlop cheese, 75 .

Duodetam, the, deseription of, 14.5 .

Dorlatin ox, the, 82 ; weight of the, 8.5 .

Dutch eattle, or Lincolns, 85 ; den variety of, introduced by $\operatorname{Sir}$ C. Buck, 85 .

Dysentery, natare of, 135 ; symptoms and treatment of, 136.

EDINBURGI, management of dairies in the neighbourhood of, 76 . 
Egypt, existence of the zehu race in, 19.

Enteritis, 132; causes and symptoms of, 132 ; treatment of, 133.

Epilepsy, 141 ; causes, symptoms, and treatment of, 142 .

Epsoin salts, a purgative, 178 .

Ergot of rye, useful in parturition, 180 .

Exeter, mixed hreeds of cattle in the vicinity of, $6 \mathbf{k}$.

Eye, diseases of the, 158 .

Eyelids, diseases of the, 158 ; causes and treatment of diseases of the, 158 .

Eyes, inflammation of the, treatment of, 158.

Falkirk tryst, description of, from Glasgow Chronicle, 105. Favourite, a noted bull, 83 .

Ferocity of the hison, 11.

Fever, simple, causes and symptoms of, 119 ; inflamm?tury, symptoms and treatment of, 120; typhus, symptoms aud treatment of, 121; milk, or puerperal, 169.

Fever-mixture, a good, for cattle, 180 .

Fibrin, what, 107.

Flatulent colic, causes, symptoms, and treatment of, 133.

Fleming, Dr., his description of a skull, 14

Flight, $\mathbf{I L}_{\mathrm{l}}$., the present proprietor of Laycock's Dairy, 90 . Flintshire, a dairy county, 71 ; breed of cattle in, 71 .

Fluid manure, wasted by English dairy farmers, 96 .

Fœtal calf; unnatural positions of the, 166; mode of extracting the, when dead, from the mother, 166.

Fætus, alteration in the position of the, $\mathrm{J} 65$; unnatural positions of the, 166 .

sljambe, a cel brated bull, 82 .

Fomentations, 184

Food, fattering of cattle dependent on the quality of the, 106.

Forfarshire, mode of fattening calves in, 79 .

Fossil skulls, 10; relics, 14 .

Foul in the foot, callses and treatment of, 159.

Fowler, Mr., breed of long-horned cattle of, 58 .

France, breeds of cattle of, 46 .

Franclie Comté, eattle of, $4 \mathrm{~S}$.

Free-martins, description of, 40.

Freyburg, breed of catt'e of, 48 .

Friar's-balsam, a dressing, 183

Friesland, cattle of, 50 .

GADFLy, the, of the ox, extract from the Pirtorial Museum of Animated Nature, descriptive of the, 162 .

Gaijal, the, 3.

Gayâl, description of the, 3.

Galloway, breed of e.ttle of, 77 .

Galloway ox, 55 .

Garget, nature, causes, and treatment of, 171

Garrick, a valuable bull, 58 .

Gascon breed of cattle, description of the, 46 .

Gelatin, what, 107.

Gelle, M., on inflammation of the mucous membrane of the stomach, 135 .

Gentian, a tonic, 181 .

George, a celebrated calf, 83 .

Gestation, period of, in the cow, 40 ; natural period of, 164 ; precautions to be taken during, 165 .

Ghee, or liquid butter of India, 29 ; mode of preparation of, 29 .

Ginger, a cordial, 181

Glamorganshire, breed of cattle of, 69 .

Gluuber's salts, an excellent purgative, 178 .

Gloucestershire, a dairy county, 65 ; breed of cattle of, 66 . Gluten, description of, 107.

Goulard Jotion, highly useful, 184.

Gour, the, 3.

Graham, Professor, on the comparative excellence of malt and barley as food for eattle, 111 .

(iray, .Ir., his description of the Bos Brachyceros, 12.

Grat liritain, horued cattle of, 54; superiority of the cattle of, 56 .
Grinders, or molar teeth, 33 .

Groningeo, cattie of, 50 .

Gruyeres, breed of cattle of, 48

Guano, analysis of, 113 ; fertilizıng power of, 11 t; introduction of, for manure, 113.

Gullet, obstruction of the, 145 ; symptoms and treatment of, 146 .

$\mathrm{Gum}$, existing in all vegetables, 107.

Gutteridge, Mr., on the success of neurotomy, 164 .

Gyall, the, 3; fine specimen of the, in the Zoological Gardens, 3 ; cross-breed of, with the common Indian bull, 4 .

II ARris, Mr., his description of the gyall, 3.

Haw, inflammation of the, 159 ; treatment of, 159 .

Ilayes, $\mathrm{Mr}$, on a case of inflammation of the brain, 132 .

Hearing, sense of, acute in the ox, 35 .

Heart, inflammation of, 126 ; causes, symptoms, and treat ment of, 126 .

Hebrides, cattle of the, 73 .

Hellebore, white, a sedative, 180 ; useful in pneumonin, 12

Hemlock, long-leaved water, deleterious to the ox, 35 .

Hepatitis, symptoms and treatment of, 127 ; cases of, 128.

Herefordshire, breed of cattle of, 65 ; essentially a breeding county, 65 .

Herefordshire cattle, 55 .

Herodotus, his description of the bull Apis, 22; on the Peonian wild oxen, 10.

Iindus, veneration for the gayâl, 4

Holland, breed of cattle of, 50 ).

Holstein, breed of cattle of, 50 .

Honiton, dairies in the vale of, 64 .

Honve, 143 ; cause, symptons, and treatment of, 147 ; chloride of lime useful in, 147; singular case of, 148 .

Horns, of the aurochs, prodigious size of, $9 ;$ of the zebu, disease in, 20; tendency to the development of the, in cattle, 20; an indication of age in the ox proved to be fallacious, 34

Hubback, a celebrated bull, 82

Hungarian breed of white cattle, 17 .

Hungary, cattle of, 49 .

Husard, M., on mixing yew-cuttings with other food, 36 .

Husbandry, oxen less available than the horse in, 45 .

Icr.L $1 \mathrm{ND}$, cattle of, 50 .

Ileun, the, description of, 145 .

Importations of cattle from abroad, 99, 100.

Insisor-teeth, 31 .

Inflammation, of the laryux, 122; of the lungs, 123; of the heart, 126; of the liver, 127; of the brain, 130; of the spleen, 130; of the peritoneum, 132; of the miscons membrane of the stomach, 135 ; of the kidneys, 137 ; of the tongue, 137; of the eyes, 158; of the haw, 159; of the substance of the udder, 171 .

Injections, aperient, 178 ; sedative, 178 .

Instruments with which the farmer should be provided, 184.

Intelligence of the ox, 39 ; anecdotes illustrative of, 39 .

Intestinal canal, description of the, 144 .

Introsusceptio, what, 134; strange remedy for, 13 t

Iodide of potassium, a convenient preparation, 179 .

Iodine, most valuable in ita uses, both internal and external, 179

Ireland, breeds of cattle of, 59 ; trade of in butter and cattle, 72 .

Isis, venerated under the form of a cow, 22

ltaly, breed of eattle of, 49 ; buffaloes of, 7 .

J AUN DicE, causes of, 128 ; treatment of, 129

Jejunum, description of the, 145 .

Jemner, Dr., discovery of cow-pox by, 172.

Jersey, breed of cattle of, 48 .

Johnson, on the droves of cattle of Russia, 19 .

Juingly Gau, the, 3. 
Jura Mountains, breed of cattle of the, 48 .

Jutland, short-horned race of cattle traced from, 50 .

KERRY breed of cattle, 72.

Kidneys, inflammation of the, 137 ; causes, symptoms, and treatment of, 137.

Kino, an astringent, 182.

Klein, Mr. Jacob, his description of the fossil skull of a bison, 15 .

Kolben, instances of the intelligence of the backeley or war oxen given by, 39 .

Kotzebue, Otho Von, on the exportation of European cattle, 25.

Kyloes, or black cattle of Scotland, 73; description of the, 73 .

La Charente, the Marais of, breed of oxen of, 47 .

Lady, a celebrated cow, 88 .

La Marche, cattle of, 46 .

Lanarkshire, celebrated for the rearing of calves, 76 ; mode of fattening calves in, 76 .

Lancashire breed of cattle, 55,57 .

Lard, an ingredient in ointments and plasters, 183, 184.

Larynx, inflammation of the, 122 ; symptoms and trealnent of, 122.

Lasso, dexterity in throwing the, 23.

Laura, a celebrated cow, 83 .

Laudanum, an antispasmodic, 181.

Laycock's Dairy, description of, 90,92 .

Lead mines, vicinity of, injurious to cattle, 156.

Lead, white, the basis of a cooling oiniment, 183 .

La Vaillant, on the courage of the backeley, or war oxen, 40.

Lice, mode of destroying in cattle, 161.

Lime, carbonate of, a most useful antacid, 182.

Iimosin, cattle of, 46 .

Lincolnshire ox, the, 85 .

Lines, descriptive of the cow, 44.

Linnæus on the loss of cattle from eating the long-leaved water-hemlock, 35 .

Linseed oil little inferior to castor oil, 179.

Lithuania, horns of aurochs of, 10.

Lithuanian aurochs, origin of the, 15 .

Liver, inflammation of the, 127.

Live-stock, increase of importation of, into England, 101.

Locked-jaw, cause, symptoms, and treatment of, 142 .

London markets, arrival at, of country-killed meat, 100.

Long-horned cattle, decline of, in various counties of England, 61.

Loo, or low (see Foul in the foot), 159.

Lord, Mr., on the treatment of preumonia, 124.

Lothians, various breeds of cattle in, 76 .

Lotions, 184.

Lncern, a valuable article of food for cattle, 115 ; management of, 115.

Lunar caustic, useful in removing warts, 183.

Lungs, inflammation of the, 123; symptems of, 123.

Lyme Hall park, wild cattle in, 61 .

Lyon, Captain, his description of bovine animals, 12.

Mackfnzie, Sir G., on Iceland cattle, 50.

Macrae, Mr., his statement respecting the gayâl, 4 .

Maine, breed of cattle of, 47 .

Major, a celebrated bull, 83 .

Malabar, description of the buffalo of, 6 .

Malt, an article of food for caltle, 110 .

Manilla buffalo, description of the, 6 .

Man, Isle of, cattle in, $\neg 1$

Mange, treatment of, 161 ; ointment for, 161

Mangold-wurzel, culture of, 114; analysis of, 117.

Mantell, Dr., description of a pair of horns in the collection if, 15 .

Manyplus, description of the, 144; retention of food in the, 150 ; causes of obscure, 150 ; cares of, 150 ; symptoms ar d treatment of, 151 .

Marsden, Mr, on tame buffaloes, 6 .
Martial on the buhalus, 9 .

Medicine, mode of administering to cattle, 144.

Medicines employed in the treatment of cattle, 177 ; with which the farmer should be provided, 184.

Mercury, sulphate of, useful in cutaneous diseases, 179 .

Merionellishire, breed of cattle in, 71 .

Mesenteric glands, enlargement of the, symptoms and treatment of, 155.

Mesentery, description of the, $\mathbf{1 4 5}$.

Metropolitan Dairy, 94.

Middle-horned stock of cattle, 62 ; description of the, 62 .

Millbank, Mr., enormous weight of an ox bred by, 82 ; or a cow bred by, 82 .

Milk, fever, 169 ; different opinions as to the canse of, 169 ; symptoms of, 169 ; treatment of, 170,171 ; substitutes for, for calves, 177 .

Milking cattle, anticipated degeneracy of, 86 .

Miscarriage, see Arbortion.

Mixture of the zebu and European race of cattle, 20.

Mode of judging of the weight of cattle, 87.

Molar teeth, 33 .

Montgomeryshire, two varieties of cattle in, 71 .

Moor-ill, see Wood-evil.

Mucous membrane of the stomach, ilflammation of the, 135 ; causes and symptons of, 135.

Mucus, what, 107.

Mundy, Mr., breed of cattle of, 59 .

Murrain, account of the, in England in the eighteenth century, 122; symptoms of, 122; absurd remedies fur, 122.

Museum of Paris, fossil skulls in the, 16.

Musk ox, description of the, 11; hunting of the, 11.

Myrrh, tincture of, a useful dressing, 183.

NANTEs, cattle of, 47 .

Navel-ill, causes and treatment of, 175 .

Neurotomy, advantages of, and mode of performing, 164 .

Niebelungen Lied, verses from the, 14.

Nitrate of potass, a good cooling lotion, 180, 184 .

Nitre, or nitrate of potass, a useful febrifuge medicine, 180 .

Nitrous ether, spirit of, 180 .

Nivernois, cattle of, 47 .

Nomadic herdsmen of Russia, 49.

Norfolk, breed of cattle of, 79 .

North America, bison of, 3 .

North Devon, cattle of, 62 .

Northumberland, Earl of, extract from the household bonk of, in the time of Henry VII1., 54.

Nostrums, the farmer and cattle-keeper to beware of, 184 .

Noxions plants, accessible to grazing cattle, 35,36 .

Nux vomica, recommended in cases of palsy, 141 .

Esophagus, description of the, 143 .

Oilcake, composition of, 112

Oily or fatty matters, 108 .

Ointments, 183.

Oleaginous purgative, an, 179.

Olive oil, an excellent purgative, 179 .

Ophthalmia, causes and treatment of, 158 ; periodical treatmểnt of, 158 .

Opium, an antispasmodic, 180.

Orkney Islands, breed of cattle of, 74 .

Osiris, venerated under the form of a bull, 22.

Ovibus Moschatus, the, or musk ox, 11.

Owen, Professor, his opinion respecting the migin of the Lithuanian aurochs, 16 ; notice of a skull found at Herne Bay, 14.

Ox, of the ruminating order of quadrupeds, 1 ; wild, different names tor the, 7; Egyptian adoration of the, 21 ; universality of, 23 ; of Aunis, 47 ; of Fontenay, 47 ; of La Charente, 47; of the Marais to the north of Luçon, 47; of Poiton, 47; Devonshire, 63; Sussex, 67; Peusbroke, 69; Galloway, 77 .

Oxen, used for the plough, $27 ;$ for treading out corn, $2 \bar{i}$; 
various breeds of, 46 ; names much nsed for the plough in Devonshire, 64.

Oxen-drivers of Africa, cruelties praotised by the, 26.

Oxmantown, Lord, eattle bred by, 59 .

PACK-OXEN of South Afrioa, 25.

Paget, Mr., breed of oattle of, 59 .

Palsy, causes and symptoms of, 140 ; ignorance as to the cause of, 141 ; absurd remedies resorted to for, 141; treatment of, 141

Pantas, see Wood-evil.

Parkinson, Mr., on the produce of a Suffulk cow, 81 ; on the mode of treating foul-in-the-foot, 160.

Parmesan, clieese of the, 49 .

Parsnips, a useful food for cattle, 117.

Parturition, 164; cases of, in which assistance is needful, 166 ; management of the cow during, 165 ; precursor sigus of, 165 ; use of ergot of rye in, 165.

Pembroke ox, description of the, 69 .

Penny Cyclopædia, directions for judging of the weight of oattle given in, 87 ; extract from, on herdsuen and drovers, 101.

Percival, Mr., on the different breeds of oxen at the Cape and in South Africa, 26.

Perkins, Mr., oattle market erected by, 104.

Phrenitis, 130 ; symptons and treatment of, 131.

Phthisis, or consumption, nature of, 125 ; is hereditary, 126 ; use of jodine in, 126.

Piteh, forms a good plaster, 184 .

Plants, whioh are cordials and stimulants, 37 ; list of, eaten by the goat, 37 ; by the hog, 37 .

Plasters, 184.

Playfair, Profes vor Lyon, on the superiority of barley to malt as food for cattle, 111.

Pleuritis, causes, symptoms, and treatment of, 125.

Pliny, on wild oxen, 9 ; his dircctions for making butyrnos, 28.

Preumonia, symptoms of, 123 ; treatment of, 124.

Pconian bonassos, mentioned by Aristotle, 9.

Poison, symptoms of, 37 ; different kinds of, 156; effect of, 156 ; treatment of cattle affectcd by, 157 .

Poitou, breed of oxen of, 47.

Pelled stock of cattle, the, 77 .

Poppy-heads, useful as a fomentation, 184.

Port Essington, wild aninals in the forests adjacent to, 25.

Portugal, herds of cattle of, 18 .

Potass, carbonate of, 182.

Pottie, Mr., on foot-root in the ox, 160.

Poultices, 183.

Preserved meat, arrival of in London from Russia, 101.

Princep, Mr., valuable breed of cattle of, 59 .

Prize oxe1, 56.

Probang, improvements in the, 146.

Prout, Dr., on the general composition of the oliyle, 109 ; on chlorine, 110.

Pulse, the, of the ox, 119.

Purgative, an active, 179.

Purgatives which may readily be made np, 179.

Puerperal fever, see Mlilk fever.

QueEN of the Scots, a celebrated heifer, 78 .

RABIEs, see Phrenitis.

Radnorshire, breed of cattle of, 70 .

Rape-cake, used as manure, 112.

Rask, Professor, on the ancient peopling of India, 21.

Read, Mr., description of probang invented by, 146 .

Rectum, description of the, 145 .

Red-water, rature, causes, and symptons of, 152; Mr. Inuate's description of, 152 ; treatment of, 153.

Religious establisliments, munificence of, 54 .

Reproduction, 40.

Resin, forms a useful plaster, $18 \%$.

Resting-grounds for cattle in the ontskirts of London, 104.
Rctionlum, deseription of the, 144 .

Rhenmatism, acute, symptoms of, 139 ; treatment of, 140 ; ehronic, treatment of, 140.

Rhodes, Messrs., dairy of, 93 .

Richardson, Dr., on the uses of the skin of the bison, 10.

Rogers, Captain, on the localitics and habits of the gour, 5 .

Romans, aimed at breeding oxen for labour, 27.

Rndge, Mr., on the profit of a Gloucestershire dairy, 67.

Rumen, description of the, 141; distension of the, wit' food, 149 ; treatment of, 149 ; case of, related by $\mathrm{Mr}$. Steel, 149.

Ruminantia, or ruminating animals, 1 ; oharaoteristics of, 1. Rumination, description of, 2 .

Russja, oattle of, 49 .

Russian goverument, penalty to, for killing European bison, 8 .

SaccharINe principle, abnndant in many vegetables, 107.

Sainfoin, a valuable food for cattle, 116 ; management of 116.

Saiutonge, breed of cattle of, 46 .

Salesnen employed in the sale of cattle, 101.

Salt, importance of, in the animal economy, 109 ; essential to the health of cattle, 92 ; cominon, an excellent purga tive and vermifuge, 178.

Salted provisions imported into the United Kingdom, 100. Searlet obnoxions to the bull, 35 .

Scotland, breeds of cattle of, 73 .

Scott, Sir W., his lines on the Argyleslire wild bull, 74 ; on Highland herdsmen, 102.

Scottish Highlands, cattle of, 55 .

Soriptural allusions to butter, 29.

Sedative and febrifuge medicines, 180 .

Seloi, or as'l gayâl, description of the, 5 .

Setons, 182

Sbakspere, a celebrated bull, 58 .

Shaw, his description of butter-making in Barbary, 29.

Shetland Islands, breed of cattle of, 74 .

Shiâl, the, 3 .

Short-horned breed of cattle, the, 81 ; improvements in the breed of, 83 .

Shropsbire, changes in catıle in, 61 .

Sight, sense of, of the ox, 35 .

Silver, nitrate of, a caustic, 183 .

Simonds, Mr., probang armed with forceps invented by, 146 ; on the symptoms of milk fever in cattle, 169.

Skeleton of the cow, description of the, 30 .

Skin, diseases of the, 161 ; causes and symptoms of, 161 .

Skulls of aurochs, 10 ; names nnder which various fossil skulls of oxen and bisons are described, 10 .

Slinking, see Abortion.

Smell, sense of, acute in the aurochs, $9 ;$ in the $o x, 35$.

Smith, Colonel, his description of a speoies of zebu, 21 .

Smithfield market, oruelties of, notorions, 34 ; reasons for and against the abolition of, 104 .

Soda, carbonate of, 182.

Soiling, or stall-feeding of cattle, 90 .

Solinus, his mention of bisons, 9 .

Somersetshire, cheeses of, 66 ; dairy farms of, 65.

South America, herds of cattle of, 3 ; descencled from the domestic oxen of the Spaniards, 3 .

Spain, herds of cattle of, 18.

Spasmodic colic, symptoms and treatment of, 134.

Spleen, inflammation of the, 130 ; causes and symptoms of, 130 .

Spooner, Mr., on the osophagean canal, 143 .

Staffordshire, original breed of eattle of, 61 .

Stall-feeding of cattle advocated, 97 ; objections to, 97.

Starcb, properties of, 108 ; convertible into sugar, 105.

Steer, or labouring ox, used for the purposes of draught, 4 .

Stimnlants, 1S3; and cordials, 181.

Strains of cattle, treatment of the, 163.

Snftolk cow, description of, $\mathrm{SO}$; duns, 80 . 
Sugar, pre-eminently nutritious, 106.

Sulphate of iron a tonic, 181.

Sulphus, 178.

Sulphuric ether, a powerful stimulant, 181.

Sultan, a valuable bull, 58 .

Sussex, cattle of, 67 ; not a dairy county, 67 .

Swiss breeds of cattle, 48 .

Sykes, Lieut.-Col., on the extensive breeding of oxen in India, 22 .

Symmetry of the bull, 43 ; of the cow, 43 ; of the ox, 43 .

Tankerville, Lord, his description of Chillingham-park rild eattle, is.

Tar, an excellent envering for broken horns, 184.

Tares, an important article of food for cattle, 117.

Tartar emetic, a most valuable medicine, 180 ; ointment of, a powerful irritant to the skin, 180 .

Tartars, the, use of the tail of the yak as a standard in battle, 7 .

Taste, sense of, in the ox, 35 .

Taunton, cattle of the vale of, 65 .

Tavernier, on the price and food of oxen used in travelling, 22.

Teats, treatment of sore, 172.

Teeswater, or Holderness breed of cattle, 81 .

Tetanus, cause, syuptoms, and treatment of, 142 ; generally fatal, 142 .

Thevenot on the use of the oxen of India for travelling, 22 .

Thibet, ox of, 7 .

Thorns, mode of extracting from the fnot, 159.

Thrush, symptoms and treatment of, I 39 .

Tobacco-water a dangerous remedy, 161 .

Tongue of the ox, description and functions of, 38 .

Tonics, 181.

Tornea, mortality among cattle in, 36 .

Touraine, cattle of, 46 .

Traill, Dr., his description of the gour, 5 .

Triptolemus, conquest of the Indians by, 21.

Trysts, or fairs, of Scotland, 105.

Turner, Mr., his description of the tame breed of buffaloes, 7.

Turnill, Captain, breed of cattle founded by, 86 .

Turnip, importance of the, as food for cattle, 113; proportions of the ingredients of, analysed, 113 ; most advantageous mode of consuming, 114 .

Turpentiue, spirit of, efficacy in bronchitis, 123; a useful medicine for calves. 175 ; a diuretic, an anti-spasmodic, and a vermifuge, 180.

Twopenny, a celebrated bull, 58 .

UDDER, inflamnation of the substance of the, see Garget.

Unguent, a useful, in mange, 183.

Urus, or uhr-ox, descriptoin of, 8,9 .

Uterus, rupture of, during parturition, 167.

Utrecht, cattle of, 50 .

VARro, his description of the ox, 26 .
Veal of the London markets, 61 .

Vegetable kingdom, elementary constituents of, 106.

Ventilation indispensable in a dairy, 94.

Verandah, useful round a dairy, 94 .

Verdigris, a caustic, 183.

Vetches, an important article of food for cattle, 117.

Virgil, his description of a heifer, 26; of the threshingfloor, 27.

Vitriol, blue, a caustic, 183 .

Von Spix on the uses of the tane cattle of Brazil, 24.

WADEN, description of the, 12.

Wagons drawn by oxen in South Africa, 26.

Wales, cattle of, 55 ; niddle-horned cattle of, 69 .

Wallachia, cattle of, 49 .

Warbles, 161 ; mode of destroying, 163 .

Warts, on the eyelids, 158 ; mode of removing, 158.

Washington, a valuable bull, 58 .

Water, good clear, essential to cattle, 118.

Wax, us: ful as an ingredient in plaster, 184.

Weaning of calves, 176 .

Weissenborn, Dr., on the strength and haunts of the aurochs, 8.

White buffalo, description of the, 12 ; cattle always much esteemed, 17 ; oxen of Poland, 17.

White, Mr., on turning out cattle in winter, $5 \mathrm{t}$; on the disorder termed mindering, 156.

Wild cattle of Europe and Western A sia, different opinions respecting the origin of, 20.

Willoughby, Sir C., introduction of short-horned cattle by, 61 .

Wine used in the treatment of cattle, 182.

Wood-evil, causes, symptoms, and treatment of, 151 .

Woods, Mr., his description of the horns of a skull, 14 .

Wool of the musk ox, uses of, 12.

Worship of the ox first taught by Triptolemus, 21 .

Wounds of cattle, 163; various kinds of, 163; treatment of, 163 .

Yak, tanie breed, description of the, 7 ; wild, description of the, 7 ; little knowu respecting the liabits of, 7 .

Yellows, or jaundice, 128.

Yew, shoots of, injurions to cattle, 36 .

Yorkshire cattle, description of, 57 .

Youat,, Mr., on the food of the lahouring ox, 44; on its activity, 45 ; on the polled cattle of Angus, 76 ; on the adulteration of milk, 90 ; his calculation as to the number of head of cattle fattened in and about London, 97; his estimate of cattle yearly brought to the London markets, 99 ; on rabies in the $0 x, 131$; on red-water, 152 ; on neurotomy, 164 .

Yvart, M., on the plants in France injurious to catle, 36.

$Z$ EBU race, peculiarities of the, 19 ; localities of the, 19 antiquity of, in India, 20 ; veneration for, 20.

Zinc, sulphate of, a useful lotion for the eye, 184. 


\section{INDEX TO THE HORSE.}

Abyssinian horse, account of the, 199.

Acetabulum, description of the, 438 .

Acetic acid, its properties, 537 .

Acini, description of, 397 .

Action of the hackney described, 248 ; high, not indispensable in the hackney, 248.

Adej's, prapcrties of, 537 .

Ethiop's inineral, an alterative, 547 .

Ethusa cynapium, poisonous, 393.

Age, natural, of the horse, 330 ; of the horse as indicated by the teeth, 325; other jndications of, 330 .

Air, a supply of pure, necessary for the health of the horse, 510.

Alcohol, its medicinal properties, 537 .

Alfred, his attention to the improvement of the horse, 225 .

Aloes, Barbadoes, far preferable to Cape, 538; description of the different kinds of, 538; principal adulterations of, 539 ; tincture of, its composition and use, 539 .

Altcratives, the best, 539 ; nature and effect of, 539 .

Alum, the use of, in restraining purging, 539; solution of. a good wash for grease, 539 ; burnt, a stimulant and caustic for wounds, 539 .

American horse, description of the, 215.

Ammonia, given in flatulent colic, 539 ; vapour of, plentifully extricated from dung and urine, most injurious to the eyes and lungs, 539

Anchylosis of bones, what, 348 .

Anderson, Dr., his accounit of the galloway, 259.

Animal poisons, an account of, 393 .

Animal power compared with tbat of the steam-engine, 554; its advantages over mechanical, except wher velocity is required, 557 .

Animals, zoological division of, 262

Anise-seed, its properties, 539 .

Anodyne, opium the only one to be depended on, 539 .

Antea spinatus muscle, description of the, 421 .

Antimonial powder, a good febrifuge, 540 .

Antimnny, black sulphuret of, method of detecting its adulterations, 539 ; used as an alterative, 540 ; tartarized, used as a nauseant, diaphoretic, and worm medicine, 540 .

Antispasmodics, nature of, 540 .

A poplexy, nature and treatment of, 285 .

Aqueous fluid, an, why placed in the labyrinth of the ear, 274 ; humour of the eye, description of the, 280 .

Arab breed, the, introduced by James I., 231 .

Arabia, not the original country of the horse, 201; few good horses there even in the seventh century, 201.

Arabian horse, history of the, 201 ; Bisbop Heber's description of, 205; comparisun between, and the barb, 203; general form of, 202 ; qualities of, 202 ; scanty nourishment of, 206 ; treatment of, 205 ; varieties of, 202.

Arabs, attachment of, to their horses, 205 ; value their mares more than their horses, 206.

A rehed form of the skull, advantage of, 270 .

Arm, description of the, 423; action of, explained on the principle of the lever, 419,423 ; extensor muscles of the, 424; flexor museles of the, 424; full and swelling, advantage of, 425; should be museular and long, 425 ; fracture of the, 478 .

Arsenic, medical use of, 540 ; treatment under poison by, 394.

Arteries, description of the, $339 ;$ of the arm, 423 ; of the face, 309 ; neck, 339 ; shoulder, 417 .

Ascaris, account of the, 405 .
Ascot course, length of the, 239.

A stragalus, account of the, 442 .

Athelstan, his attention to the improvement of the horse, 225.

Atlas, anatomy of the, 336 .

Attechi, the, an Arabian breed, 202.

Auscultation, the importance of, 365 .

Australian horse, description of the, 209.

Axle, friction of the, dependent on the material employed 584.

BACK, general description of the, 347 ; proper form of the 347 ; long and short, comparative advantages of, 348 ; anatomy of the, 347 ; museles of the, 349 .

Backing, of the colt, 502 ; a bad habit of the horse, usual origin of it, 502 .

Back sinews, sprain of the, 430 ; thickening of the, constituting unsoundness, 534 .

Balls, the manner of giving, 540 ; the manner of making, 540.

Barb, deseription of the, 199, 201,237; comparison between, and the Arabian, 203.

Barbs or paps, treatment of, 333 .

Bark, Peruvian, the properties of it, 541 .

Barley cousidered as food for the horse, 517 .

Barnacles, use of the, as a mode of restraint, 492.

Bar-shoe, description and use of, 489 .

Barrel, proper shape of the, in the hunter, 244.

Bars, description and office of the, 452 ; proper paring 0 for shoeing, 453 ; folly of cutting them away, 453 ; re. moval of, a cause of contraction, 453 ; corns, 453

Basilicon ointment, 541 .

Bay horses, description of, 527; Malton, account of him, 235.

Beans, good for hardly worked horses, and that have a tendency to purge, 518,520 ; should always be crushed, 185 .

Bearing-rein, the use and abuse of, 321 .

Beet, the nutritive matter in, 520 .

Belladonna, extract of, $54 \mathrm{l}$.

Berners, Juliana, authoress of the first book on hunting, 246

Bible, history of the horse in the, 187 .

Biceps femoris, account of the, 440 .

Bile, account of the, 397,398 .

Birman horse, account of the, 209.

Bishoping the teeth, description of, 329 .

Biting, a bad habit, and how usually acquired, 502 .

Bit, the, often 100 sharp, 322 ; the ancient, 193; sometimes got into the mouth, 503 .

Bitting of the colt, 415 .

Black horses, deseription and character of, 257,527 .

Bladder, description of the, 409 ; inflammation of, symptoms and treatment, 410 ; neck of, 410 ; stone in the, 410 .

Bleeding, best place for general, 362, 493 ; directions for, 339,362 ; from veins rather than arterjes, 339 ; comparison between the fleam and lancet, 362 ; at the toe described, 363; finger should be on the pulse during, 493 ; importance of, in inflammation, 493.

Blinòness, usual method of discovering, 2S0 ; discovered by the pupil not dilating or contracting, 280 ; of one eye, 2 so.

Blistering all round at once, barbarity and danger of, 49l, 541 ; after firing, absurdity and cruelty of, 495 .

Blisters, best composition of, 494 ; the different kinds anil uses of, 493 ; best mode of applying, 494 ; caution with 
regard to their application, 494 ; the principle of their action, 541; use of, in inflammation, 494; comparison between them and rowels and setons, 497 .

Blood, changes in during respiration, 354 ; change in after bleeding, 363 ; coagulation of, 363 ; horses, very subject to contraction, 461 .

Blood-spavin, nature and treatment of, 362 .

Bloody urine, 409 .

Bog-spavin, nature and treatment of, 362,444 .

Bole, Armenian, medical use of, 541 .

Bone spavin, nature and treatment of, 414 .

Bots in the stomach, natural history of, 391 ; not 1isually injurious, 592 .

Bournou horse, description of the, 200.

Bowels, inflammation of the, 401 .

Brain, description of the, 265,271 ; its cortical and cineritious composition, 271 ; the office of each, 271, 272; compression of the, 284 ; pressure on the, 284 ; inflainmation of the, 287 .

Bran, as food for the horse, 518.

Breaking in, cruel Arabian method of, 205; the South American method of, 213; should commence in the second winter, 414 ; description of its various stages, 414 ; necessity of gentleness and patience in, $414 ;$ of the farmer's horse, 414; of the hunter or hackncy, 415.

Breast, muscles of the, 350 .

Breathing, the mechanism of, 354 .

Breeding, 25L; as applied to the farmer's horse, 251; qualities of the mare of as much importance as those of the horse, 251,411; the peculiarity of form and constitution inherited, 411 ; in-and-in, observations on, 412.

Brewers' horses, account of them, 257 ; portrait of one, 258 ; account of their breed, 258.

Bridle, the ancient, 193.

Broken down, what, 430 .

Broken knees, treatment of, 531 ; method of judging of the danger of, 531; when healed not unsoundness, but the form and action of the horse should be carefully exansined, 531.

Broken wind, nature and treatment of, 383 ; influenced much, and often caused by the manner of feeding, 383; how distinguished from thick wind, 384 .

Pronchial tubes, description of the, 343 .

Bronchitis, nature and treatment of, 376 .

Bronchocele, account of, 369 .

Bronchotomy, the operation of, 342 .

Brood mare, description of the, 411 ; should not be too old, 412 ; treatinent of, after covering, 413 ; after foaling, 413 .

Brown horses, description of, 527 .

Bryony, dangerous, 394.

Buccinator muscle, description of the, 310 .

Bucephalus, account of, 192.

Burleigh, Lord, his opinion of hunting, 245 .

Busbequius, his interesting account of the Turkish horse, 212.

Савваgг, the nutritive matter in, 520 .

Cæcum, description of the, 396.

Calamine powder, account of, 553 .

Calculi in the intestines, 403 .

Calkins, advantages and disadvantages of, 485 ; should be placed on botb heels, 485 .

Calmuck horse, description of the, 220.

Camphor, the medical use of, 541 .

Canadian horse, description of the, 215.

Canals, advantages and disadvantages of, 568 ; smallness of power requisite for the transmission of goods by theni, 568 .

Caul-boat, calculation of the draught of, 568 ; the ease of draught of, might be increased by a different made of applying the power, 568 .

Canker of the foot, nature and treatment of, 471

Cannon, or shank-bone, description of the, 427 .
Canter, action of the horse during, 560 .

Cantharides, form the best blister, 393,541 ; given for the cure of glanders, 393,542 .

Cape of Good Hope, the horses of, 201.

Capillary vessels, the, 359 .

Capivi, balsam of, 543 .

Capped hock, nature and treatment of, 436 ; description of 436,447 ; although not always unsoondness, there should be a special warrauty against it, 531 .

Capsicum berries, their stimulating effect, $5 \mathbf{1 2}$.

Carbon of the blood got rid of in respiration, 377 .

Carbonate of iron, a mild tonic, 546

Carraways, a good aromatic, $5+2$.

Carriage-horses produced by crossing the Suffolk with a hunter, 257.

Carriages, two and four-wheeled, comparison hetween, 582 ; light, should have no longitudinal elasticity in the hang. iug or springs, 582 ; disadvantage of $\mathrm{C}$ springs $\mathrm{iu,} 582$; hung on strays or springs in the time of Homer, 565 .

Carrots, excellent effects of, in disease, 520 ; the nutritive matter in, 520 .

Carts, two-wheeled, computation of the friction of, 580 ; can perform proportionally more work than wagons, 580 ; easier loaded, and do not so much injure the roads, 580 ; require better horses and more attendants, 580 ; the horse sooner knocked up and injured by the shocks of the shafts, 580 ; on good roads, and for short distances, superior to wagons, 580 ; with two horses, disadvantage of, 580 ; have less draught than wagons, reason why, 580 .

Cartilages of the foot, description and action of the, 456 ; ossification of the, 472,533 ; a cause of unsoundness, 489.

Caruncula lacrymalis, the, 303 .

Cascarilla bark, a tonic and aromatic, 542 .

Castley, Mr., on restiveness in the horse, 499.

Castor-oil, not a purgative for the horse, 512 .

Castration, method of, 410 ; pruper period for, 410 ; the operation by torsion, 410 .

Cataract in the eye, nature of, 281 ; cannot be operated on in the horse, 281; method of exanination for, 281; the occasional appearance and disappearance of, 305 .

Catarrh, description and treatment of, $36 \mathrm{~s}$; distinguished from glanders, 314 ; distinguished from inflammation of the lungs, 364 ; epilemic, 369.

Catarrbal fever, nature and treatinent of, 369 .

Catechu, a good astringent, method of giving, and adulteratious of, 542 .

Catheter, description of ore, 410 .

Caustic, an account of the best, 542.

Cavalry horse, description of the, 202 ; anecdotes of the, 202.

Cawl, description of the, 598 .

Cercbellum, description of the, 271.

Cerebrun, description of the, 271 .

Chalk, its medicinal use in the horse, 542 .

Chaff, attention should be paid to the goodness of the ingredients, 515 ; lest conıosition of, 515 ; when given to the hard-worked horse much time is saved for repose, 516 ; quantity of, necessary for different kinds of horses, 516.

Cluamomile, a mild tonic, 542 .

Chamnel of the jaws, what, 325 .

Charcoal, useful in a poultice, and as an antiseptic, 542 .

Charges, composition and use of, 512 .

Chariots, the first account of the use of, 190 ; in Solomon's time, 190; the Grecian, 194; description of that of Priam, 573; that of Juno described, 574; on the freize of the Parthenon, description of, 574 ; used by the Egyptians 1,500 years before the Christian æera, 573 ; at the siege of Troy, 573 ; description of the ancient, 573 ; of the ancients, could not move with much velocity, 574 . Cliest, anatomy of the, 344 ; proper form of the, 345,346 ; 
the importance of depth of, 345 ; narrow and rounded, Cordials, the use and abuse of, in the horse, 544.

comparison letween, 345 ; the broad chest, 346 ; founder, Cornea, description of the, 278 ; mode of exarnining the, description of, 351 .

Chestunut liorses, varieties of, 527.

Chillaby, friendship between him and a cat, 237 .

Chirese horse, description of the, 209.

Chinked in the chine, what, 348.

Cliloride of lime, an excellent disinfectant, 548; of soda, useful in unhealthy ulcers, 551.

Chorea, 296.

Choroid coat of the eye, description and use of the, 279 .

Chyle, the formation of, 396 .

Ciliary processes of the eye, description of the, 280 .

Cineritions matter of the brain, nature and function of the, 271 .

Circassian horse, description of the, 207.

Cleveland Bay, description of the, 253 .

Clicking, cause and remedy of, 506 .

Clipping, recommendation of, 524 .

Clips, when necessary, 486.

Clover, considered as an article of foorl, 519.

Clysteri, the composition and great us fulness of, 513 directions as to the administration of, 513 .

Clydesdale horse, description of the, 257.

Coaches, calculation of the power of horses in drawing according to their speed, 562; loaded high, run lighter, especially in rapid travelling, 583 ; safety, heavy draught of, 583 .

Coach-horse, description of the, 253 ; best breed of, 253.

Coat, fine, persons much too solicitous to procure it, 513 .

Cocktail-horse, mode of docking, 498 .

Coffin-bone, description of the, 454; the lamellæ, or leaves of, 455; fracture of, 482.

Coffin-joint, sprain of, 435 .

Cold, common, description and treatment of, $36 \%$.

Colic, flatulent, account of, 400 ; spasmodic, description and treatment of, 399 .

Collar, the best niethod of attaching the traces to the horse, 367 ; proper adaptation of, to the shoulder, 563 .

Colocynth, is poisonous, 393.

Colon, description of the, 397 .

Colonel, account of his performances, 241 .

Colour, remarks on, 526 .

Colt, early treatiment of the, 413 .

Complexus major, description of the, 339 ; minor, description of the, 339 .

Concave-seated shoe, the, described and recomnended, 486 .

Conestoga horses, description of the, 216.

Conical wheels, compared with flat ones, 577 ; extreme absurdity of, 577 ; strange degree of friction and dragging with them, 577 ; afford great resistance and destroy the road, 577 ; are in fact travelling grindstones, 578 .

Conium maculatum, poisonous, 393.

Conjunctiva, description of the, 278 ; appearance of, how far a test of inflammation, 278 .

Consumption, account of, 385 .

Contraction of the foot, rature of, 459,531 ; the peculiarity of the lameness produced by, 461 ; how far connected with the navicular disease, 463 ; is not the necessary consequence of shoeing, 459 ; produced by neglect of paring, 460 ; wearing the shoes too long, 460 ; want of natural moisture, 460 ; the removal of the bars, 461; not so much produced by litter as imagined, 460 ; the cause rather than the consequence of thrush, $46 \mathrm{I}$; best mode of treating, 462 ; rarely permanently cured, 462; does not necessarily imply unsoundness, 531 ; although not necessarily unsoundness, should have a special warranty against it, 531; blood horses very subject to, $46 \mathrm{I}$.

Convexity of the eye, the proper, not sufficiently attended to, 278.

Copaiba, account of the resin, 543 .

Copper, the combinations of, used in veterinary practice, 543. Corded veins, what, 318 . 278 ; its prominence or flatness, 278 ; should be perfectly trausparent, 278 .

Corns, the nature and treatment of, 469 ; produced by cutting away the bars, 469 ; not paring out the font between the crust and bars, 469 ; pressure, 469 ; very difficult to cure, 469 ; constitute unsoundness, 531 .

Coronary ligament, description of the, 452 ; the crust principally produced from, 452 ; ring, description of the, 452 . Curonet, description of the, 452 .

Corrosive sublimate, treatment under poison by, 394; a good tonic for farcy, 394, 547.

Corsican horse, account of the, 218.

Cortical substance of the brain, description of, 272 .

Cossack horse, description of the, 220 ; beaten in a race by English blood-horses, 220.

Cough, the nature and treatment of, 381 ; constitutes nnsoundness, 531 ; the ocsasional difficulty with regard to this, 53 t.

Cow-hocks, deseription of, 447 .

Cradle, a safc restraint upon the horse when blistered, 494 .

Cramp, the nature and treatment of, 294.

Cream-coloured horses, account of, 527 ; peculiarity in their eyes, 279.

Cream of tartar, a mild diuretic, 550.

Creosote, its use in veterinary practice, 544 .

Crib-biting, description of, 505 ; causes and cure, 506; injurious to the horse, 506 ; coustitutes unsoumdness, 506,531

Cricket-ball, the action of catching a, 561 .

Cricoid cartilage of the windpipe, the, 341 .

Cromwell, Oliver, his stud of race-horses, 232.

Cropping of the ear, absurdity of, 273.

Croton, the farina of, used as plysic, 544.

Crusaders, the improvement of the horse neglected by them, 227.

Crust of the foot, description of the, 451 ; composition of the, 451 ; consisting within of numerous horny plates, 452 ; proper degree of it, slantiag, 451 ; proper thickness of the, 451 ; brittleness of, remedy for, 435 ; the cause of sanderack, 464 .

Crystalline lens, description of the, 281 .

Cuboid bones, description of the, 442.

Coneifurm bones, description of the, $270,442$.

Curbs, nature and treatment of, 443 ; hereditary, 252 ; constitute unsoundness, 532 .

Cuticle, description of the 522

Cutis, or true skin, account of the, 522 .

Cutting, cause and cure of, $43 \mathrm{t}, 506$; constitutes unsoundness, 532 ; away the foot, unfounded prejudice against, 460 .

DANDRIFF, the nature of, 522.

Darley Arabian, account of the, 234 .

Dartmoor pouies, description and anecdote of, 260.

Deacon, Mr., his opinion on the forms of wheels, 553, 579 .

Denham, Major, interesting account of the loss of bis horse, 205.

Depressar labii inferioris muscle, description of the, 310.

Desert horses, account of the, 200.

Diabetes, the nature and treatment of, 409 .

Diameter of wheels, the effect of increasing the, 582 .

Diaphoretics, their nature and effcets, 544 .

Diaphragm, description of the, $35 \mathrm{l}$; rupture of, 353 ; its connection with respiration, 353.

Digestion, the process of it deseribed, 389.

Digestives, their nature and use, 34.4 .

Digitalis, highly recommended in colds and all inflammatory complaints, 544 .

Dilator magnus lateralis muscle, description of the, 310 ; nar is lateralis muscle, description of the, 310 .

Dishing of whecls described, and effect of, 576 ; both irward and outward effect of, 570 . 
Distressed horse, treatment of the, 246.

Diuretic medicines, the use and abuse of, 545 .

Docking, method of perforning, 497.

Dogs, dauger of encouraging them abont the stable, 291.

Doncaster course, the length of, 239.

Dongola horse, description of the, $19 \mathrm{~S}$

Draught, theory of, 553 ; has not been sufficiently explained, 553,559 ; implies the moving power, the vehicle, and the road, 553 ; the moving power particularly considered, 554 ; considered in respect of the resistance, 557 ; calculation of, according to velocity and time, 557 ; much influenced by the direction of the traces, 563 ; the line of, should be parallel to the direction of motion, 563 ; in cattle, should pass through the axle of the wheels, 564 ; in bad roads may have a slight inclination pwward, 567 ; resistance of, should be as much as possible firm and inelastic, 567 ; how increased by the state of the road, 585 ; of boats, difficulty of, iucreasing rapidly with the velocity, 568 ; calculation of the power of, 568 ; of the sledge, 569 ; of the roller, 569 ; horse, the heavy, 256 ; horses, the inferior ones about the metropolis, wretched state of, 259.

Dray-horse, proper form of the, 258; the largest bred in Lincolnshire, 258; usually too large and heavy, 258 .

Drinks, how to adıninister, 545 ; comparison between them and balls, 545 .

Dropsy of the chest, 387 ; of the heart, 357 .

Drum of the ear, description and use of the, 274 .

Dun horse, account of the, 527 .

Duodenum, description of the, 296 .

Diseases of the, 296 .

Dnra mater, description of the, 271 .

Dutch horse, description of the, $22 \%$.

$E_{A R}$, description of the external parts, 273 ; internal parts, 274 ; bones of the, description and nse of, $27 \%$; labyrintlı of the, 274; indicative of the temper, 273; clipping and singeing, cruelty of, 273 ; treatment of wounds or bruises of, 306 ; cruel operations on the, 306 .

East Indian horse, description of the, 207.

Eclipse, the pedigree and history of, 236 ; account of his proportions, 237.

Edward II introdnced Lombardy horses into England, 227.

Edward III., the breed of horses much improved by, 227 ; introduced Spanish horses, 227 ; had runing horses, 228.

Egypt, account of the horses of, 188, 198.

Elasticity of the ligament of the seck, 270 .

Elaterium, poisonous, 393.

Elbow, the proper form and inclination of, 423 ; capped, 423; fracture of, 479 ; punctured, 423.

Elizabeth, Queell, the number and value of horses much diminished when sle reigned, 230 ; a staunch luntress, 245.

Emetic tartar, used as a nanseant, diaphoretic, and wormmedicine, 540 .

Enamel of the teeth, account of the, 325 .

English horse, history of the, 224; first crossed by the Romans, 224; improved by Athelstan, 225; William the Conqueror, 226; John, 227.

Ensiform cartilage, the, 345 .

Entanglement of the intestines, description of, $40 \mathrm{t}$.

Enteritis, account of, 401 .

Epidemic catarrh, nature and treatment of, 369 ; malignant, nature and treatment of, 374 .

Epiglottis, description of the, 341 .

Epilepsy, nature and treatment of, 296.

Epsom salts, used as a purgative, 549 .

Epsom course, the length of, 239

Ergot of rye, the action of, 551 .

Ethmoid bone, description of the, 270 .

Ethiopian horse, account of the, 198 .

Fuphorbium, the abominable use of it, 393 .

Ewe-neck, unsightliness and inconvenience of, 338
Exchanges of horses stand on the same ground as sales, 536 .

Exercise, directions for, 514 ; the necessity of regular, 514; want of, producing grease, 44.8 ; more injury done by the want of it than by the hardest work, 514 .

Exmoor pony, description of the, 260 .

Expansion shoe, description and use of the, 489.

Expense of horse, calculation of the annual, 555 .

Extensor pedis muscle, descriptin of the, 441 .

Eye, description of the, 274 ; fracture of the orbit of the, 284 ; healthy appearance of the, 276 ; diseases of the, 302 ; inflammation of, common, 303 ; ditto, specific, 303 ; ditto, causes, 304 ; ditto, medical treatment of, 303,305 ; ditto, untractalle nature of, $30 \%$; ditto, consequences of, 304,305 ; ditto, marks of recent, 532 ; ditto, constitutes unsoundness, 532; ditto, hereditary, 304 ; method and importance of examining it, 278,281 ; indicative of the temper, 274 ; the pit above, indicative of the age, 265 ; muscles of the, 282 .

Eyebrows, substitute for, 275 .

Eyelashes, description of, 275 ; fully of singeing them, 275 .

Eyelid, description of, 275 .

Eyelids, diseases of the, 302 .

Exostosis on the orbit of the eye, 284 .

Face, description of the, 307 ; cut of the muscles, nerves, and blood-vessels of, 309 .

Falling-in of the foot, what, 458 .

False quarter, nature and treatment of, 465 .

Farcy, a disease of the absorbents of the skin, 318 ; connected with glanders, 318 ; both grenerated and infectious, 320 ; symptoms nf, 319 ; treatment of, 320 ; luds, what, 320 ; the effect of cantharides in, 320 ; dinivdide of copper, 320 .

Farmer's horse, description of the, 251; fit for riding as well as draught, 25l ; the general management of, 251 ; no blemished or unsound mare to be used for breeding, 252.

Feeding, high, counected with grease, 450 ; regular periods of, necessity of attending to, 520 ; nauner of, has much influence in broken wind, 384 .

Feeling, of the mouth, constant, indispensable in the good rider, 248.

Feet, good, importance of, in the hunter, 245 ; the general management of, 521 ; attention to, and stopping at night, recommended, 521.

Felt soles, description and use of, 489.

Femur, fracture of the, 479 .

Fetlock, description of the, 434 .

Fever, idiopathic or pure, 361 ; symptoms of, 361 ; symptomatic, 361 .

Fibula, description of the, 441 .

Finland horse, description of the, 222 .

Firing, the principle on which resorted to, 494 ; mode of applying, 495 ; should not penetrate the skin, 495 ; absurdity and cruelty of blistering after, 495 ; horse should not be used for some months alter, 496 .

Fistula lacrymalis, 276 .

Fits, symptoms, causes, and treatment of, 296.

Flanders horse, description of the, 259 ; our heavy draught horses advantageously crossed with, 259.

Fleam and lancet, comparison between them, 362 .

Flemish horse, account of the, 224

Fleur-de-Lis, account of her performances, 242.

Flexor of the arm, description of the, 424 ; metatarsi muscle, description of the, 442 ; pedis perforatus, the perforated muscle, description of the 424,441 ; pedis perforans, the perforating muscle, description of the, 425, 429, 441.

Flying Childers, an accout of him, 234.

Foal, early treatment of, 413 ; early handling of, important, 413; importance of liberal feeding of, 414; time for weaning of, 414 .

Fomentations, theory and use of, 546

Food of the horse, observatiuns on, 515 ; a list of the usual articles of, 516 ; should be apportioned to the work, 516 . 
Foot, description of the, 451 ; the original defence of, 194 ; diseases of the, 456 ; canker, 471 ; corns, 469 ; contraction, 459 ; false quarter, 465 ; founder, acute, 456 ; chronic larninitis, 45S; inflammation, 456 ; navicular joint diseasc, 462 ; overreach, 465 ; prick, 467 ; pumiced, 458 ; quittor, 466 ; sanderack, 361 ; thrusl, 470 ; tread, 465 ; weakness, 472 ; wounds, 4.67 .

Forceps, arterial, the use of, 363 .

Forehead, 265.

Fore-legs, description of, 417 ; diseases of them, 428 ; proper position of them, 4.36 .

Forge-water occasionally used, 546.

Forrester, an example of the emulation of the horse, 240 .

Founder, acute, symptoms, canses, and treatment of, 456 ; chronic, nature and treatment of, 458 .

Foxglove, strougly reco:mmended in colds, and all fevers, 544.

Fracture of the skull, treatment of, 283 ; general observations on fractures, 473 ; of the skull, 474 ; orbit of the eye, 475 ; nasal bones, 475 ; superior maxillary, or upper jaw-bone, 475 ; inferinr ditto, 476 ; spine, 476 ; ribs, 477 ; pelvis, 477 ; tail, 478 ; limbs, 478 ; shoulder, 478 ; arm, 478 ; elbow, 478 ; femur, 479 ; patella, 479 ; tihia, 479 ; hock, 480; leg, 480; sessamoid bones, 480; pastern, 481; lower pastern, 481; coffin-bone, 482 navicular hone, 483 .

French horse, description of the, 217

Friction, comparison of, in the wheel and roller, $469 ;$ on the axle, dependent on the material employed, 575 ; is not materially increased by the velocity, 575 ; reduced as the diameter of the axle is diminished, 575 ; inversely as the diameter of the wheel, 575 .

Frog. horny, description of the, 453 ; sensible, description of the, 453, 455; ditto, action and use of the, $45 \mathrm{t}_{\text {; }}$ pressure, question of the, $45 \mathrm{f}$; proper paring of, for shoeing, 454 ; diseases of the, 454.

Frontal-bones, description of the, 265 ; sinuses, description of the, 267 ; perforated to detect glanders, 267 .

Furze, considered as an article of food, 515 .

GiLL, account of the, 398 ; bladder, the horse has none, 398.

Galloping, the action of the horse during, 560 .

Galloway, description of the, 259 ; anecdotes and performauces of the, 259 .

Gall-stones, 407 .

Gancho, the Sonth American, deseription of, 213; his methou of taking and breaking the wild horse, 213; his boots, curious manufacture of, 214 .

Gentian, the best tonic for the horse, 546 .

Gibbing, a bad habit, cause of, and means of lessening, 502 .

Gigs, formation of, 333 .

Ginger, an excellent aromatic and tonic, 516, 553.

Glanders, nature of, 312 ; symptoms, $267,312,317$; slow progress of, 313,315 ; appearances of the nose in, 267, 313, 314; detected by injecting the frontal sinuses, 267; how distinguished from catarrh, 314; ditto, from strangles, 314 ; connected with farcy, 314,315 ; treatment of, 318 ; causes, 315 ; both generated and contagious, 315,317 ; oftenest produced by improper stable management, 315,316 ; mode of communication, 316 , 317 ; prevention of, 318 ; account of its speedy appearance, 315 .

Glands, enlarged, it depends on many circurnstances whether they constitute unsoundness, 532.

Glass-eye, nature and treatment of, 306 .

Glauber's salt, its effect, 551 .

Glutri muscles, description of the, 439

Godolphin Arabian, an account of the, 237.

Goulard's extract, 548 .

Gracilis muscle, description of the, 439,441 .

Grains, occasionaliy used for horses of slow work, 517.

Grapes on the heels, treatment of, $\mathbf{4 4 9}$.
Grasses, neglect of the farmcr as to the proper mixlure of, 518.

Grasshopper springs, description of, 583; would be advantageously adopted in post-chaises, 583 .

Grease, nature and treatment of, 448 ; cause of, 448 ; generally a nere local coinplaint, 449 .

Greece, early domestication of the horse in, 192; the horse introduced therc from Egypt, 192.

Grey horses, account of the different shades of, 526 .

Grinders, construction of the, 326.

Grinding, of the food, accomplished by the mechanis'n of the joint of the lower jaw, 324 ; swallowing without, 505.

Grogginess, account of, 431 .

Grooming, as important as exercise to the horse, 513; opens the pores of the skin, and gives a fine coat, 513; directions for, 514 .

Grunter, the description of, 385; is unsound, 531.

Gullet, description of the, 390 ; foreign bodies in, 391 .

Guni-arabic, for what purpose used, 537 .

Gutta serena, nature and treatinent of, 306 .

H^вıтs, vicious or dangerous, 499.

Hackney, description of the, 248 ; its proper action, 248; anecdotes of the, 249 ; coaches, account of, 254 .

Hæinaturia, 409.

Hair, account of the, 522; question of cutting it from the heels, 450.

Hamilton, Duke of, the Clydesdale horses owe their origin to $\mathrm{him}, 257$.

Harnessing, the best modes as regards draught, 567 ; method of, in the time of Homer, 56.5.

Haunch, description of the, 437 ; wide, advantage of, 437 ; injuries of the, 437 ; joint, singular strength of it, 437 ; also of the thigh bones, advantage of the oblique direction of, 437 .

Haw, curious mechanism of the, 276; diseases of, 302 absurdity and cruelty of destroying it, 277 .

Hay, considered as food, 515,516 ; mowburut, injurious, 519 ; old preferable to new, 519.

Head, anatomy of the, 265 ; the numerous bones composing it, the reason of this, 265 ; importance of the proper setting on of, 337 ; beaut iful provision for its support, 269.

Head, Captain, lis account of the South American horse, 213.

Healing ointment, account of the, 553 .

Hearing of the horse, the, very acute, 273.

Heavy black horses, account of, 257.

Heart, description of the, 356 ; its action described, 356 inflammation of the, $240 ;$ dropsy of the, 240 .

Heber, Bishop, his account of the Arabian, 204.

Heels, question of cutting the hair from them, 450 ; low, disadvantage of, 473 ; proper paring of, for shoeing, 484 ; washing of the, producing grease, 450 .

Hellebore, white, used in inflammation of the lungs and fevers, 546 ; black, its use, 547 .

Hemlock, given in inflammation of the chest, 547

Henry VIll., tyrannical regulations concerning horses, by him, 229; the breed of the horse not materially improved by him, 229 .

Hepatic duct, the, 398 .

Hernia, the nature and treatment of, 405.

Hide-bound, the nature and treatment of, 524 .

High-blower, a description of the, 367,385 ; is unsound, 531 .

Highland pony, description of the, 261.

Hind legs, description of the, 437 .

Hind wheels sbould follow the precise track of the fore ones, 579.

Hip-joint, the great strength of the, 438 .

Hips, ragged, what, 437 .

Hissar, the East India Company's sale of horses at, 208.

Hobbles, description of the best, 492 . 
Honk, the advantage of its numerous separate bones and ligaments, 442; capped, 436, 449; cow, 419; description of the, 442 ; enlargement of the, nature of, and how affecting soundness, 443, 532; inflamnation of the small bones of, a frequent cause of lameness, 443 ; the principal seat of lameness behind, 443 ; lameness of $\mathrm{it}$, without apparent cause, 366 ; fracture of, 480.

Hog's-lard, properties of, 537.

Holstein horses, account of the, 223.

Homer, his account of the method of harnessing horses, 565.

Hoof, description of the, 451 .

Horizontal direction of the traces when proper, 567 .

Hom of the crust, secreted principally by the coronary ligament, 452; once separated from the sensible part within, will never again wite with it, 458 .

Hornet, sting of the, 593 .

Horse, the first allusion to him, 187; not known in Canaan at an early period, 187; description of, in early times, 196, 197; not the native of Arabia, 201; Arabian, 201; Armenian, 190 ; American, 215; Anstrian, 219 ; English, 224; Barb, 199 ; Birman, 209 ; Bournon, 200 ; Cappadocian, 191; first used in the cavalry service, 188; chariot races formed part of the Olympic games, 195; calculation of the annual expense of, 555 ; Chinese, 209; Circassian, 207; uncertiin whether he was first trained to draught or mounted, 190 ; coach, proper form, qualities, breed of, 253 ; the different colours of the different breeds, 526 ; Corsican, 218; Cossack, 210; Dongola, 198; Dutch, 224; when first domesticated in Egypt and Canaan, 187; not domesticated until after many other animals, 187; not found in Egypt in the very early periods, 187; East Indian, 207 ; the flesh of, eaten, 211; English, history of, 225; farmer's, 254; Finland, 222 ; Flemish, 224; fossi] remains found in every part of the world, 187; French, 217 ; general management of, 510 ; among the Greks, 189; heavy black, 257; early emploved in humting the ostrich, 188; heavy dranght, 256 ; tyrannical regulations respecting, by Henry VIII, 229 ; grey, the, of Sir Edward Antrobus, 245; hiring, early regulations of, 225, 227; Hungarian, 220; Iceland, 222; lrish, 261 ; Italian, 218; sublime description of, by Job, 188; much improved by John, 227 ; Lombardy, when first introduced into England, 227 ; market, first account of, 226 ; Mecklesburg, 223 ; Nubian, 198; Parthian, 191 ; Portuguese, 217 ; Prussian, 224 ; Russia, 220 ; Norwegian, 223 ; Pcrsian, 191, 206; the early price of, 190; knglish, not used for the plough in early times, 226 ; power, calculation of, 567 ; price of, in Solomon's time, 190 ; prices of, at different periods, 225,231 ; ridden, the first account of, 188 ; sagacity of, 250 ; can see almost in darkness, 279; Sardinian, 218; South American, 212; ditto, instinet and sagacity of, 2 13: management of, in South America, 213; Spanish, 216; Swedish, 222; Tartarian, 210; Thessalian, 193; Toorkoman, 211; Turkish, 212; wild, 210, 212 ; English improved under William the Conqueror, 226 ; zoological description of, 262 ; immense number of, in the armies of some ancient eastern monarchs, 190 ; numerous in Britain at the invasion of the Romans, 224.

Howell the Good, his laws respecting the horse, 225.

Humerus, description of the, 422 .

Hungarian horse, description of the, 220 .

Hunter, the, general account of, 243; proper degree of blood in, 243 ; form of, 244 ; spirit of, 245 ; anecdotes of, 246, 247; management of, 245; symptoms of dangerous distress in, 246 ; management of the, when distressed, 246 ; the summering of, 247 ; shoe, description of the, 488 .

Hydrocyanic acid, poisoning by it, 393 ; its necasional good service, 537 .

Hydrothorax, symptoms and treatment of, 387 .
ICELANn horse, description of the, 222.

Ileum, description of the, 396 .

Inflammation, nature of, 359 ; trcatment of, 359 ; hot or cold applications to, guide in the choice of, 360 ; importance of bleeding in, 359,493 ; when proper to physic in 360 ; of the bowels, 401; ditto, distinction betwecn it and colic, 399 ; brain, 287 ; eye, 308 ; foot, 456 ; kidneys, 408; larynx, 365; lungs, 376 ; stomach, 391 ; trachea, 366 ; veins, 339 .

Influenza, nature and treatment of, 369 .

Infusions, manner of making them, 547 .

Insanity, $30 \mathrm{l}$.

Intercostal muscles, description of the, 345 .

Intestines, description of the, 395 .

Introsusception of the intestincs, treatment of, 404 .

Invertebrated animals, what, 262 .

Iodine, usefulness of, in reducíng enlarged glands, 548 .

Iranee horse, description of the, 208.

Iris, description of the, 280 .

Irish horse, description of the, 261.

Iron, the carbonate of, a mild and useful tonic, 546 sulphate of, a stronger tonic, 516 ; ditto, recommended for the cure of glanders, 546 .

Italian horse, deseription of the, 218.

Itchiness of the skin should always be regarded with suspicion, 529 .

James I. established the first regulations for racing, 231; introduction of the Arabian blood by him, 231.

James's powder, 540.

Jaundice, symptoms and treatment of, 407.

$J_{a w}$, the lower, admirable mechanism of, 323,324 ; npper, description of, 323 .

Jejunum, description of the, 396 .

John, the breed of liorses improved by, 227.

Jointed shoe, the description and use of, 489 .

Jugnlar vein, anatomy of the, 309,339 .

Jumper, the horse-breaker, anecdotes of his power over animals, 499.

Juniper, oil of, use of, 548 .

Juno, her chariot described, 574 .

KaDisciil, an Arabian breed of horses, 202.

Kicking, a bad and inveterate habit, 503 .

Kidneys, description of the, 407 ; inflammation of, symptoms and treatment of, 408 .

King Pippin, aneedotes of him as illustrating the inveterateness of vicious habits, 500 .

Knee, an anatonical description of the, 425 ; tied in below, 429 ; broken, treatment of, 426,531 .

Kochlani, an Arabian breed of horses, 202.

Knowledge of the horse, how acquired, 264.

LABYRINTH of the ear, description and use of the, 274

Lachrymal duct, description of the, 276 ; gland, description and use of the, 276 .

Lamella or laminæ, loorny, account of the, 453, 455; fleshy, account of the, 455 ; weight of the horse supported by the, 455 .

Lameness, shoulder, method of ascertaining, 417; from whatever cause, unsoundness, 532 .

Lampas, nature and treatment of, 323 ; cruelty of burning the bars for, 323 .

Laminæ of the foot, see Lamel':

Lancet and fleam, comparison between them, 362

Lapland horse, account of the, 222.

Laryngitis, chronic and acute, $365,366$.

Larynx, description of the, 341 ; inflammation of the, 365. Lasso, description of the, 213.

Laudanum, the use of, in veterinary practice, 549 .

Lead, the compounds of, used in veterinary practice, 548 ; extract of, 548 , sugar of, use of, 548 ; white, use of, 518 .

Leather soles, description and use of, 489 . 
Leg, cut of the, 299; description of the, 427 ; fracture of the, 482 .

Legs, fore, the situation of, 4.17 ; hind, anatomical description of the, 437 ; of the hackney, should not be lifted too nigh, 248 ; swelled, 44.7.

Levator humeri muscle, description of the, 338,421 .

Lever, muscular action explained on the principle of it, 419 .

Ligament of the neck, description and elasticity of the, 269.

Light, the degree of, in the stable, 512.

Lightness in hand of essential consequence in a hunter, 243.

Limbs, fracture of the, 478 .

Lime, the chlaride of, exceedingly useful for bad smelling wounds, \&c., 548 ; the chloride of, valuable in cleansing stables from infection, 548.

Lincolnshire, the largest heavy black horses bred in, 258 .

Linaments, the composition and use of, 548 .

Linseed, an infusion of, used in catarrh, 518,549 ; meal forms the best poultice, $54.9,550$.

Lips, anatomy and uses of the, 321 ; lips, the hands of horse, 321.

Litter, the, cannot be too frequently removed, 512 ; proper substances for, 512 ; contraction not so much produced by it as some inagine, 460 .

Liver, the anatomy and use of it, 397 ; diseases of the, 406 .

Liverpool, account of the course at, 239.

Locked jaw, symptoms, cause, and treatment of, 291.

Loins, description of the, 348 .

Lombardy horse, the, when introduced into England, 227

Longissimus dorsi muscle, description of the, 349 .

Lucern, considered as an article of food, 519.

Lumbricus teres, the, 405 .

Lunar caustic, a very excellent application, 540 .

Jungs, description of the, 356 ; symptoms of inflammation of the, 377 ; causes of, 377; low distinguished from catarrl and distemper, 364. 370; treatment of, 378,380 ; importance of early bleeding in, 380 ; blisters preferable to rowels or setons in, 380 ; consequences of, $381,382,385$.

Maoness, the symptoms and treatment of, 289.

Magnesia, the sulphate of, 549 .

Mahratta horse, account of the, 208.

Mealinders, the situation of 436 ; the nature and treatment of, 447 .

M[ammalia, the, an important class of animals, 262.

Manchester, account of the course at, 239.

Mane, description and use of the, $188,339$.

Mange, deseription and treatment of, 528 ; causes of, 528 ; ointment, recipes for, 529; highly infectious, 528; method of purifying the stable after, 529 .

Manger feeding, the advantage of, 515 .

Mare, put to the horse too early, 412, 413; deterioration in, 4.12; her proper form, 412 ; breeding in and in, 412 ; time of being at heat, 413 ; time of going with foal, 413 ; best time for covering, 413 ; management of, when with foal, 413 ; management of, after foaling, 413; nore concerned than the horse in breeding, 251 ; preferable to gelding for the farmer, 251 ; selection of, for breeding, 252.

Mark of the teeth, what, 325 .

Markham's Arabian, an account of, 231.

Marsi, the sire of many of the New-foresters, 260.

Mashes, importance of their use, 549 ; best method of making them, 549 .

Masseter muscle, description of the, 309, 32 t.

Maxillary hones, anatomy of the, 322 ; fractures of, 475 , 476.

Meadow grasses, the quantity of untritive matter in, 520 .

Mechanical power, oljections to the use of, 557 .

Mecklenburg horses, account of, 223

Mledicines, a list of the most useful, 536 .

Medullary substance of the brain, its nature and function, $266,271$.
Megrims, cause, 284; symptoms, 285; treatment, 285; apt to returil, 285 .

Melt, description of the, 398

Memory of the horse, instances of, 249 :

Mercurial ointment, the use of, in vcterinary practice, 547.

Mercury, its use in epidemic eatarrh, 374.

Mcrlin, the sire of many of the Welsh ponies, 260 .

Mesentery, description of the, 396 .

Metacarpals, description of the, 427.

Midriff, description of the, 351 .

Moisture, want of, a cause of contraction, 460 .

Mojinniss horse, description of the, 208.

Moon blindness, the nature of, 303

Moulting, the process of, 525 ; the horse usually languid at the time of, 526 ; no stimulant or spices should be given, 526 ; mode of treatment under, 526 .

Mounting the colt, 416 .

Mouth of the horse, description of the bones of, 322 ; should be always felt lightly in riding, 218; importance of its sensibility, 321 .

Mowburnt hay, injurious, 519 .

Nuriatic acid, its properties, 537 .

Muscles of the back, description of the, 349 ; breast, ditto, 350 ; eye, ditto, 282 ; face, ditto, 309 ; neck, ditto, 337 ; ribs, ditto, 345 ; shoulder-blade, 417,420 ; lower bone of the shoulder, 417,422 ; the advantageous direction of, more important than their bulk, 419

Muscular action, the principle of, 423 .

Mustard, the use of, 549 .

Myrrh, the use of, for canker and wounds, 549.

NASALIS labii superioris muscle, description of the, 310

Nasal bones, fracture of, 475 ; gleet, 311 ; polypus, 310 .

Navcs, cast-iron, to whecls, advantage of, 579 ; description of the best construction of, 579 .

Navicular bone, description of the, 455 ; the action and use of it, 455 .

Navicular joint disease, nature and treatment of the, 462 ; how far connected with contraction, 463 ; the cure very uncertain, 463 ; fracture of, 483.

Neapolitan horse, description of the, 218.

Neck, anatomy and muscles of the, 337 ; description of the arteries of the, 339 : description of the veins of the, 339 ; bones of the, 336 ; proper conformation of the, 337 ; comparison between long and short, 337 ; loose, what, 337 .

Nerves, the, construction and theory of, 265 ; spinal, the compound nature of, 272 ; of the face, 309.

Neurotomy, or nerve operation, object and effect of it, 298; manner of perforning it, 299; cases in which it should or should not be performed, 299 ; a vestige of the performance of it constitutes unsoundness, $5 \dot{5} 3$.

Newcastle, the Duke of, his oppusition to the introduction of the Arabian blood, 231.

New Forcstcr, description of the, 260

Newmarket, races established at, by Charles I., 231; description of the different courses at, 239.

Nicking, the method of performing, 497 ; useless cruelty often resorted to, 498 .

Nimrod, his objection to elipping, 524 .

Nitre, a valuable cooling medicine, and mild diuretic, 550 .

Nitric acid, for what employed, 537 .

Nitrous æther, spirit of, a nild stimulant and diuretic, 549 .

Nurman lorse, description of the, 217.

Norwegian horse, description of the, 223 .

Nose, description of the bones of the, 307 ; spontaneous bleeding from, 307 ; the importance of its lining mesnbrane, 308,364 ; the nose of the lorse slit to increase his wind, 309.

Nosebag, importance of the, 520 .

Nostrils, description of the, 307 ; peculiar inflammation of the membrane of the, 267: the membrane of, important in ascertaining disease, 310,364 ; importance of an 
expanded one, 309 ; slit by some nations to increase the wind of the horse, 309 .

Nubian horse, account of the, 198.

Nutriment, the quantity of, contained in the different articles of food, 520 .

OAts, the usual food of the horse, 516,520 ; should be old, heavy, dry, and sweet, 516 ; kiln-dried, injurious to the horse, 517 ; proper quantity of, for a horse, 517.

Oatmeal, excellent for gruel, and sometimes used as a poultice, 517 .

Occipital bone, description of the, 266.

Enanthe fistulosa, poisonous, 393.

Esophagns, description of the, 389.

O'Kelly, Colone], anecdotes of him and Eclipse, 236.

Olfactory nerves, the importance of them, 308.

Olive oil, an emollient, 519.

Olymia, the races at, 195 .

Omentum, description of the, 398 .

Opacity of the eye, the nature and treatment of, 303 .

Operations, description of the most important, 492 ; the dreadful ones cansed by cruel treatment and driving, 255.

Ophthalmia, 303.

Opium, its great value in veterinary practice, 549 ; adulterations of $\mathrm{it}, 550$.

Orbicularis muscle of the eye, description of it, 282 .

Orbit of the eye, fracture of, 284 .

Os femoris, account of, 440 .

Ossification of the cartilages, cause and treatment of, 472.

Overreach, the nature and treatment of, 465,506 ; often producing sanderack or quittor, 507 .

Ozena, account of, 311 .

PAce, the effect of, in straining the horse, 255 .

Pachydermata, an order of animals, 263.

Pack-horse, description of the, 260.

Pack-wax, description of the, 269, 336.

Palate, description of the, 340 .

Palm oil, the best substance for making up balls, 550 .

Palsy, the causes and treatment of, 297.

Pancreas, description of the, 399.

Paps or barbs, 333.

Parietal boncs, description of the, 268 .

Paring out of the foot for shoeing, directions for, 483 ; negleet of, a cause nf contraction, 460 .

Parotid gland, description of the, and its diseases, 310, 332.

Parsnips, the nutritive matter in, 520 .

Partlenon, description of chariots on the frieze of it, 574

Pastern, upper, fracture of, 481 ; lower, fracture of, 481 ; description of the, 432,434 ; bones of the, 432 ; proper obliquity of the, 433 .

Patella, or stifle bone, description of the, 440 ; fracture of, 479.

Pawing, remedy for, 507 .

Payment of the smallest sum completes the purchase of a horse, 535 .

Peas sometimes used as food, but should be crushed, 518, 520.

Pectineus muscle, the, 439 .

Pectorales muscles, description of the, 350,421 .

Pelvis, fracture of the, 477 .

Pericardium, description of the, 356 .

Peronæus muscle, description of the, 441 .

Persian horse, description of the, 206; managenent of, 206.

Persian race, description of a, 207.

Perspiration, insensible, no medicines will certainly increase it, 525 .

Peter the Great, the immense block of marble constituting the pedestal of his statue, how moved, 571 .

Pharynx, anatomy of the, 335 .

Plirenitis, 287.

Phthisis pulmonalis, description of, 385 .
Physic balls, method of compounding the best, 540; should never be given in inflammation of the lungs, 355 .

Physicking, rules for, 402.

Pia mater, description of the, 271.

Pied horse, account of the, 527 .

Pigmentum nigrum, account of the, 279.

Piper, description of the, 284.

Pit of the eye, the, indicative of the age, 265.

Pitch, its use for charges and plasters, 550 .

Pithing, a humane method of destroying animals, 336.

Pleura, description of the, 354 .

Pleurisy, the nature and treatment of, 355,386 .

Pneumonis, the nature and treatment of, 377 .

Poisons, account of the most frequent, 393 ; tests of the different ones, 394 .

Pole-evil, the canse and treatment of, 336 ; importance of the free escape of the matter, 336 .

Pony, varieties of the, 259

Popliteus muscle, description of the, 412.

Porter, Sir R. Ker, his account of the Persian horse, 206.

Portuguese horse, the, 217.

Post, the first establishment of it, 254.

Post-chaises, grasshopper springs would be advantagcously adopted for, 583 .

Postea spinatus muscle, description of the, 421 .

Potash, the compound of, 550 .

Potatoes, considered as an article of food, 520 .

Poultices, their various compositions, manner of acting, and great use, 550 .

Powders, comparison between them and balls, 551 .

Power of dranght in the horse, illustrations of, 255 ; calenlation of, 555 ; compared with that of the human being, $55 \mathrm{~S}$; compared with that of a steam-engine on railways, 556 ; on conimon roads, 556 ; on bad roads, 557 ; dependent on his weight and muscular force, 557 ; how diminished when towing a boat on a canal, 560 ; greater when close to his work, 560 ; this depends on his strength, and the time he can exert it, 561 ; the diminution of, according tu his speed, table of, 562 .

Pressure nn the brain, effect of, $28 \%$.

Priam's chariot, a description of, 573 ; he harnessed his own horses, 573 .

Prices of horses at different periods, 225, 227, 228 .

Prick in the foot, treatment of, 467 ; injurions method of removing the liorn when searching for, 468 .

Prussian horse, account of the, $22 \%$.

Prussic acid, treatment of poisoling by, 393 .

Puffing the glims, a trick of fraudulent horse-dealers, 265.

Pulling, the action of, explained, 358 .

Pulse, the natural standard of the, 358 ; varieties of the, 358 ; importance of attention to the, 359 ; the most convenient place to feel it, $35 \mathrm{~S}$; the finger on the pulse during the bleeding, 359 .

Pumiced feet, description and treatment of, 458; do not admit of cure, 458 ; constitute unsoundness, 533

Pupil of the eye, description of the, 280 ; the mode of discovering blindness in it, 280.

Purchase, to complete the, there must be a memorandum, or payment of some sum, however small, 535 .

Purging, violent, treatment of, 402 .

Quarters of the horse, description of the, 439 ; importance of their muscularity and depth, 439 ; foot, deseription of, 452 ; inner, the crust thinner and weaker at, 452 ; folly of lowering the crust, 452 .

Quidding the food, cause of, 507 ; unsoundness while it lasts, 533 .

Quinine, the sulphate of, 541 .

Quittor, the nature and treatment of, 466 ; the treatment often long and difficult, exercising the patience both of the practitioner and owner, 466 ; is unsoundness, 533 .

RABIES, symptoms of, 289 . 
Race-courses, different lengths of, 239.

Races, early, mere running on train-scent, 231; frequent cruelty of, $238,24.0$; different kinds of, described, 238 ; regular, first established at Stamford, 231; regulations for, established by James I., 231; patronized by Charles I., 231 ; Persian, description of, 207 ; the great length of the old courses, 238 ; consequences of the introduction of short races, 239, 240; the different lengths that are run, 239 ; the races at Smithfield, 226.

Race-horse, his history, 233; form, 234; emulation, 340.

Racks, no openings should be allowed above them, 511.

Radius, description of the, 423 .

Ragged-hipped, what, 437 ; no impediment to action, 437 .

Railways, mechanical advantage of, 255,585 ; they immensely increase the power of the horse, 586 .

Raking, the operation of, 551 .

Rearing, a dangerous and inveterate habit, 504 .

Recti muscles of the neck, description of, 338; of the thigh, 438 .

Rectum, description of the, $396,397$.

Reins, description of the proper, 321 .

Resin, its use in veterinary practice, 551.

Resistance in draught, ohservations on, 560 .

Respiration, description of the mechanism and effect of, 353.

Respiratory nerves, the, 272.

Restiveness, a bad habit, and never cured, 499 ; anecdotes in proof of its inveterateness, 499.

Retina, description of the, 281 .

Retractor muscle of the eye, 282

Rheumatism, 297.

Rilbed home, advantage of being, 347 .

Ribs, anatomy of the, 345,346 .

Richard Cœur-de-Lion, account of his Arabian horses, 227.

Richmond, Duke of, his method of breeding good carriage horses, 257.

Riding, directions for, 248 .

Ringbone, the nature and treatment of, 435 ; constitutes unsoundness, 533 .

Roach-backed, what, 348 .

Roads, how affected by different wheels, 576 ; how influencing the proper breadth of the wheels, 576 ; the great extent to which they affect the draught, 584 ; soft and yielding, far more disadvantageous than rough ones, 584 ; slight alterations in their level advantageous, $5 \mathrm{~S} 4$; hardness the grand desideratum in, 585 ; should be nearly flat, 585 ; necessity of constant repairs and attention to them, 585; calculation of the degree by which the resistance is increased by bad ones, 575,576 .

Roan horses, account of, 526 .

Roaring, the nature of, 366,384 ; curious history of, 367 constitutes unsoundness, 531 ; from tight reining, 368 from buckling in crib-biting, 368 ; treatment of, 369 .

Rollers, calculation of the draught of, 570; how probably first invented or brouglit into use, 569 ; comparison of their power with that of wheels, 573 ; mechaoism and principle of, 570 ; particular circumstances in which their use is advantageous, 571 ; the weight moves with double the velocity of the rollers, and therefore fresb rollers must be supplied in front, 571 ; the immense block of marble at St. Petershurg, description of its being moved on them, 571 .

Rolling, danger of, and remedy for, 507 .

Roman nose in the horse, what, 307 .

Rome, the ancient races at, 197 .

Round-bone, the, can scarcely be dislocated, 440 .

Rowels, manuer of inserting, and their operation, 551 comparisons between them, blisters, and setons, 497 .

Running away, method of restraining, 504 .

Rupture, treatment of, 405 ; of the suspensory ligament, 434.

Russian horse, account of the, 220 .

Rye-grass, considered as an article of food, 519 .
SAnnLEs, the ancient, 193; the proper construction of, 350 ; points of, 350 .

Saddle-backed, what, 348 ; galls, treatment of, 350 .

Saddling of the colt, 415 .

Safety coaches, the heavy draught of, 583 .

Sagacity of the horse, 250 .

Sainfoin, used as an article of food, 519.

Sal ammoniac, the medical use of, 539 .

Saliva, its nature and use, 333.

Salivary glands, description of the, 332 .

Sallenders, nature and treatment of, 449 .

Salt, use of in veterinary practice, 551 ; value of, mingled in the food of animals, 519 .

Sandal, Mr. Percival's, 490.

Sanderack, the situation of, 436 ; the nature and treatment of, 464 ; most dangerous when proceeding from tread, 464 ; liable to returo unless the brittleness of the hoof is remedied, 464 ; constitutes unsoundness, 533 .

Sardinian horse, account of the, 218 .

Sartorius muscle, description of the, 439 .

Savin, dangerous, 394 .

Scapula, description of the, 417 .

Sclerotica, description of the, 278 .

Scouring, general treatment of, 402 .

Secale cornutum, the effect of, $55 \mathrm{I}$.

Sedatives, a list of them, and their mode of action, 551 .

Serratus major muscle, description of the, $344,417,421$.

Sessamoid bones, adnirable use of, in obviating concussion, 432 ; fracture of, 480 .

Setons, mode of introducing, 496 ; cases in which they are useful, 496; comparison between them and rowels and blisters, 497 .

Shank-bone, the, 427.

Shetland pony, description of the, 261

Shoe, the concave-seated, described, and recommended, 486 ; the manner in which the old one should be taken off, 483 ; the putting on of the shoe, 484 ; it should be fitted to the foot, and not the font to the shoe, 484 ; description of the hinder, 486 ; the unilateral, or one-side nailed shoe, 487 ; the bar-shoe, 489; the tip, 489; the hunting, 488 ; the jointed, or expansion, 489 .

Shoeing, not necessarily productive of contraction, 459 ; preparation of the foot for, 483 ; the principles of, 483.

Short-bodied horses, when valuable, 245.

Shoulder, anatomical description of the, 417 ; slaating direction of the, advantageous, 418,419; when it should be oblique, and when upright, 420 ; sprain of the, 417 ; laneness, method of ascertaining, 418 ; fracture of the, 478 . Shoulder-blade, muscles of the, 417 ; wby united to the chest by muscle alone, 417 ; lower bone of the, description of, 422 ; muscles of the, 424 .

Shying, the probable cause of, 282, 507; treatment of, 508 ; on coming out of the stable, description of, 509.

Side-line, description of the, 492

Sight, the acute sense of, in the horse, 279.

Silver, the nitrate of, an excellent caustic, 540.

Singeing, recommendation of, 524 .

Sinuses in the foot, necessity of following them as far as they reach, 468 .

Sitfasts, treatment of, 350

Skeleton of the horse, description of the, 263

Skin, anatomical description of the, 522; function and uses of it, 523 ; pores of it, 525 ; when the animal is iv health is soft and elastic, 523 .

Skull, anatomical description of the, 266; arched form of the roof, 270 ; fracture of the, 283,474 .

Smith field market, early account of, 226

Sledges, calculation of the draught of, 569 ; description of the mechanism and use of, 569 ; where more advantageous than wheels, and where very disadvantageous, 569, 570 ; calculation of the power of, 569 ; their advantage in travelling over ice and snow, 570; Esquimaux, an account of the, 570 . 
Slipping the collar, remedy for, 509 .

Smell, the sense and seat of, 308 ; very acute in the horse, 308.

Snewing, Mr., his advocacy of clipping, 524 .

Soap, its use in veterinary practice, 551.

Soda, chloride of, its nse in ulcers, 551 ; sulphate of, 551 .

Sole, the horny, description of, 453 ; descent of, 453 ; proper form of, 453 ; management of, in shoeing, 453 the sensible, 453,455 ; felt, or leather, their use, 489.

Solomon, imported horses from Egypt, 190.

Sore-tirroat, symptoms and treatment of, 365 .

Soundness, consists in there being no disease, or alteration of structure that does or is likely to impair the nsefulness of the horse, 530 ; considered with reference to the principal causes of unsoundness, 531.

South American horse, description of it, 212 ; management of it, 213.

Spanish horse, description of it, 216 .

Spasmodic colic, nature and treatment of, 399.

Spavin, blood, the nature and treatment of, 362 ; is un. soundness, 533 ; bog, cause, nature, and treatment of 362 , 444; bone, 444; wliy not always accompanied by lameness, 445 ; is unsoundness, 533.

Spavined horses, the kind of work they are capable of, 445 . Speed, of the horse, produces rapid diminution of power, 561 ; time of labour, the most advantageous proportiou of, 561,562 ; the sacrifice of the horse in endeavouring to obtain it, 562 .

Speedy-cut, account of, 429

Sphenoid bone, description of the, 270 .

Spinalis dorsi muscle, description of the, 349 .

Spine, description of the, 347 ; fracture of, 476 .

Spleen, description of the, 398 .

Splenius muscle, description of the, 337 .

Splint, nature and treatment of, 428,436 ; when const ituting nusoundness, 534 ; bones, description of the, 428 .

Sprain of the back-sinews, treatment of, 430,436 ; sometimes requires firing, 431; any remaining thickening constitutes unsoundness, 534 ; sprain of the shoulder, 417 .

Spring steel-yard, the force of traction illustrated by, 554 .

Springs to carriages, theory of their effect, $5 \mathrm{~S} 2$; with some modifications might be adapted to the heaviest wagons, 583 ; great advantages of, in rapid travelling, 583 ; grasshopper, description of, $583 ; \mathrm{C}$, disadvantages of, 583 .

Spur, the ancient, 194.

Stables, dark, an occasional cause of inflammation of the eye, 304 ; hot and foul, a frequent one of inflammation of the eye, 304; ditto, lungs, 510 ; ditto, glanders, 315 , 316 ; should be large, compared with the number of horses, 510 ; the minagement of, too much neglected by the owner of the horse, 510 ; the ceiling of, should be plastered, if there is a loft ibove, 510 ; should be so contrived that the urine will run off, 512 ; the stalls should not have too much declivity, 512 ; should be sufficiently light, yet without any glaring colour, 513 .

Staggers, stomach, symptoms, cause, and treatment of, 285 , 520 ; generally fatal, 285 ; producing blindness, 287 ; sometimes epidemic, 287 ; mad, symptoms and treatment, 287.

Staling, profuse, cause and treatment of, 409.

Stallion, description of the, proper for breeding, 412 .

Stamford, races first established at, 231 .

Starch, used in superpurgation, 552 .

Stargazer, the, 338 .

Steam-engine, comparison of the, with the exertion of animal power on railways, 556 ; common roads, 556 ; calculation of the expense, 555 ; small, has little advantage in expense over horse power, 557.

Steeple-chase, description and censure of it, 247.

Sternum, or breast-bone, description of the, 345,421 .

Stifle, description of the, 440 ; accidents and diseases of the, 442 .

Stirrup, the ancient, 194.
Stomach, description of the, 389,390 ; very small in the horse, 390 ; inflammation of the, 391 ; pump recoinmended in apoplexy, 287.

Stone in the bladder, symptoms and treatment of, 410 ; kidney, 410.

Stoppings, the best composition of, and their great use, 552

Straddlers, wheels so called, description of, 579 ; objection to them, 579 ; method of evading the law concerning, 579 .

Strain, uniform, and constant in draught, bad consequences of, 563 .

Strangles, symptoms and treatment of, 334 ; distinguished from glanders, 314 ; the importance of blistering early in, 334 .

Strangury, produced by hlistering, 494; treatment of, 494 Strawberry horse, account of the, 526 .

Stringhalt, natnre of, 294; is decidedly unsoundness, 296 534 .

Structure of the horse, importance of a knowledge of, 264 .

Strychnia, account of, 552 .

Stylo-maxillaris muscle, description of the, 309 .

Sublingual-gland, description of the, 333 .

Submaxillary glands, description of the, 333 ; artery, description of the, 310 .

Sub-scapulo hyöldeus muscle, description of the, 309

Suffolk punch, description of the, 256 ; honesty and continuance of the old breed, 256 .

Sugar of lead, use of, 548 .

Sullivan, the Irish whisperer, anecdotes of his power over the horse, 500; the younger did not iulierit the power of his father, 501 .

Sulphate of copper, use of, in veterinary practice, ${ }^{-} 513$; iron, 546 : magnesia, 549 ; zinc, 553 .

Sulphur, an excellent alterative and ingredient in all applications for mange, 552 .

Summering of the hunter, consideration $\mathrm{nf}, 247$.

Surfeit, description and treatment of, 527 ; importance of bleeding in, 528 .

Suspensory ligament, beautiful mechanism of the, 432 ; rupture of the, 431 ; snspensory muscle of the eye, description of the, 282

Swallowing without grinding, 505

Swedish horse, deseription of the, 222 .

Swelled legs, cause and treatment of, 447 ; most frequently connected with debility, 448 .

Sweetbread, description of the, 399

Sympathetic nerves, description of the, 273.

$\mathrm{T}_{\mathrm{A} I \mathrm{~L}}$, anatomy of the, 344 ; fracture of the, 478 ; docking, 497 ; nicking, 497.

Tar, its nse in veterinary practice, 552 .

Tares, a nutritive and healthy foud, 519 .

Tartar, cream of, 550 .

Tartarian horse, description of the, 210 .

'Taysee horse, description of the, 208.

Team, disadvantages of draught in, explained, 560 ; their united power not equal to the calculat in of so miny liorses, 560

Tears, the secretion and nature of the, 276 ; how conveyed to the nose, 276 ; sometines shed by the horse from pain and grief, 276 .

Teeth, description of the, as connected with age, 325 ; at birth, 325; two months, 325; twelve months, 326 ; eighteen months, 326; the front sometimes pushed out, that the next pair may sooner appear, and the horse appear to be older than he is, 327 ; three years, 327 ; three and a half years, 327 ; fuur years, 328 ; four and a half years, 328 ; five years, 328 ; six years, 328 ; seven years, 329 ; eiglit years, 329 ; change of the, 327 ; enamel of the, 325 ; irregular, inconvenience and danger of 331 ; mark of the, 325 ; frauds practised with regard to the, 328 ; diseases of the, 331 .

Temper, denoted by the eye, 274 ; by the ear, 273 . 
Temperature, sudden change of, injurious in its cffect, 510 . Temporal boncs, description of the, 268 .

Tendons of the leg, 428 .

Tetanus, symptoms, causes, and treatment of, 291.

Thessalian liorse, account of, 193.

Thick wind, nature and treatment of, 382,$381 ;$ often found in round-chested horses, 382.

Thigh and haunch bones, description of, 437 ; form of, 437 ; should be long and muscular, 437; description of the muscles of the inside of the upper bone of, 439 ; ditto, of the outside, 439 ; mechanical calculation of their power, 439.

Tliorongh-bred horses, the quality of, has not degenerated, 234.

Thorough-pin, the nature and treatment of, 4.42 ; is not unsnuudness, 534 .

Thrush, uature and treatment of, 470 ; the consequence rather than the cause of contraction, 461 ; its serinus nature and consequences not sufficiently considered, 471 ; constitutes unsoundness, 534 .

Thymus gland, the, 351 .

Thy roid cartilage of the windpipe, description of the, 341 .

Tibia, account of the, 441, 442; fracture of, 479 .

Tied in below the knee, nature and disadvantage of, 429 .

Tinctures, account of the best, 552 .

Tips, description and use of, 489.

T'obacco, when used, 552 .

Toe, bleeding at the, described, 363 .

T'ongue, anatomy of the, 331 ; diseases of, 332 ; bladders alung the under part of it, 332 .

Tonics, an account of the best, 552 ; their use and danger in veterinary practice, 552 .

Tonrkoman horse, description of, 211.

Torsion, the mode of castration by, 417 ; forceps, description of, 417.

Traces, the direction of them, very important in draught, 563 ; proper angle of the, 563 ; the proper inclination of them depending on the kind of horse and the road, 561: they should be inclined downward on rough roads, 564 ; inclined downward, the same as throwing a part of the weight on the shafts, 565 ; direction of them, rarely attended to, 565 ; the manner of affixing them in South rica, 566 .

..., windpipe, description of, 341 ; inflammation (ii).

12 ; operation of, 343.

rce of, illustrated by reference to the spring i54; the proper line of, very inportant in

le, description of the, 420 .

e, description of the, 426 .

erent rate of, at different times, 254 ; compid and slow, 562 .

and treatment of, 465 ; often producing quittor, 465 .

is comparison of moving potver in dranght, 56.

liripm an nnoying and inveterate habit, 509 .

Irmolici i the thigh, description of the, 438 .

incmearis muscle, the, 283.

Trotter, the performance of the hackney as one, 250 .

Trotting, cruel exhibitions of, 250 ; action of the horse during, 559; position of the limbs in, unfaithfully repre. sented in the Elgin marbles and the church of St. Mark, 559.

Turbinated bones, description of the, 308 .

Turkish horse, description of the, 212 .

Turner, Mr. T., on clipping, 524 .

Turnips, considered as an article of food, 520

Turpentine, the best diuretic, 54.5; a useful ingredient in mange ointments, 553 .

Tushes, description of the, 328 .

Twitch, description of the, 492 .
ULCERS in the mouth, trentment of, 331,332 .

Una, description of the, 423.

Unguiculata, a trihe of animals, 262

Ungulata, a tribe of animals, 261.

Unilateral shoe, 487 .

Unsoundness, contraction does not always cause it, 459 : being discovered, the animal should be tendered, 534; (litto, lut the tender or return not legally necessary, 535; the horse may be returned and action brought for depreciation in value, but this not advisable, 535 ; medical means may be adopted to cure the horse; they are, however, better declined, lest in an unfortunate jssue of the case they should be misrepresented, 535 .

Unsteadiness whilst mounting, remedy for, $50 \%$.

Urine, albuminous, 409 ; bloody, 409 .

Vastus muscle, description of the, 439 .

Vatican, the obelisk in the, curious method of moving it, 573.

Vehicles of drauglit, comparisnn of the best, 581 .

Veins, description of the, 362 ; of the arm, description, $8 \mathrm{c}$., 442 ; of the face, ditto, 309 ; of the neck, ditto, 339 ; if the shoulder, ditto, 418 ; inflammation of the, treatment of, 339.

Velocity, calculation of, 561 .

Vena portarum, the, 397 .

Verdigris, an uncertain medicine, when given intcrually, 543; a mild canstic, 513 .

Vermin, account of, 530 .

Vertebræ, the dorsal and lumbar, 347 .

Vertebrated animals, what, 262

Vices of horses, account of the, 499 .

Vicious to clean, a bad habit that should be conquered, 504 ; vicious to shoe, a bad habit that may also be conquered, 504 .

Vinegar, its use in veterinary practice, 537 .

Vines, Mlr., his use of the Sparish Hy in glanders, $5 \pm 2$.

Viper, account of the bite of, 393 .

Vision, theory of, 279.

Vitreous humour of the eye, account of the, 281.

Vitriol, blue, use of in veterinary practice, 543 .

WaGon horse, the, 256.

Wagons, inferior horses may be used in them compared with carts, 580 ; horses drawinr, not so fatigued as in carts, 580; require fewer drivers, and are not so liable ta accidents, 580 ; with inferior roads and ordinary hors s preferable to carts, 580 ; with large front wheels, atlvantage of, 579 ; particularly with two horses abreast, 581 ; reason why they have more draught than two-nheeled carts, 580 .

Walking, movement of the legs in, 559 ; different when drawing a load, 559 .

Wall-eyed horses, what, 280 ; whether they become bliıd, 280.

War-horse, description of the ancient, 227 .

Warbles, treatment of, 350 .

Warranty, the form of a, 534 ; breach of, how established, 534 ; no price will imply it, 534 ; when there is none, the action must he brought on gromd of frand, 534 .

W'arts, method of getting rid of, 530 .

$W$ ashing of the heels productive of grease, 450.

Washy horses, description and treatment of, 402 .

Wasps, treatment of the sting of, 393.

Water, generally given too sparingly, 521 ; management of on a journey, 521 ; the difference in effect, between hard and soft, 521 ; spring, principally injurious on account of its coldness, 521 ; stomach of the horse, the, 397.

Water farcy, nature and treatment of, 320 .

Water conveyance, smallness of power required in, 568 ; resistance to, increases with the square of the velocty; 568 ; nower to he excrted in, increases as the cule of the velucity, $\tilde{u} 68$. 
Water-dropwort, poisonous, 393 ; hemlock, poisonous, 393; parsley, poisonous, 393.

Wax, used in charges and plasters, 553.

Weakness of the foot, what, 472 .

Weaving, indicating an irritable temper, and no cure for it, 510.

Weight, calculation of the power of the horse to overcome, $255,558,560$.

Wellesley Arabian, account of the, 237.

Welsh pony, description of the, 260 .

Wheat, considered as food for the horse, 517,520 ; inconvenience and danger of it, 517 .

Wheels, the principle on which they act explained, 574; effect of increasing the diameter of the, 582 : no record of the time of their invention, 573 ; spoked, known to Homer, 573 ; little improvement of the principle of, from the earliest times, 574 ; principle of, on a level surface, 574; theory of the degree of friction attending them, 574; friction of, on the axle dependent on the material employed, 574; consideration of the various forms of, 576 ; dishing of, described, 576 ; advantages of, 576 ; conical and flat, calculation between the effects of, 577 , 585 ; obliquely placed, ill consequences of, 577 ; narrow and broad, comparison between, 576 ; conical, strange degree of friction and dragging with, 576 ; travelling grindstones, 578 ; cylindrical, the best form, 578 ; description of, and proper rounding of the edges, 578 ; but influenced by the state of the road, 578 ; hind, should follow the precise track of the fore ones, 579 ; considered as to their effect on the road, 579 ; straddlers, description of, and their effect, 579 ; proper breadth of, in proportion to the load, 579 ; with cast iron naves, 579 ; size of, 579 ; advantage of large front ones, 579; should have the spokes so arranged as to present themselves against the greatest force, 583 .
Wheezer, description of the, 384 ; is unsound, 531 .

Whipping, sound, cruelty of, 255 .

Whisperer, the, anecdotes of his power over the horse, 500.

Whistler, description of the, 384 ; is unsound, 531 .

Wlite Turk, account of the, 231 .

White lead, use of, 548 ; vitriol, its use in veterinary practice, 553.

Wild horse, description of the, $210,212$.

William the Conqueror, improvement effected in the English horse by him, 226.

Wind, broken, nature and treatment of, 383 ; galls, description and treatment of, 431, 436 ; ditto, unsoundness when they cause lameness, or are likely to do so, 534 ; thick, nature and treatment of, 382 .

Windpipe, description of the, 341 ; should be prominent and loose, 342 .

Wind, sucking, nature of, and remedy for, 506 .

Withers, description of the, 337,349 ; high, advantage of, 349 ; fistulous, treatment of, 349 .

Work of the horse should not exceed six hours per diem, 561.

Worms, different kinds, and treatment of, 405 .

Wounds in the feet, treatment of, 467.

Xenophon, lis account of the horse, 196.

YeLLows, symptoms and treatment of the, 4.07 .

Yew, the leaves of, poisonous, 393

Zive, its use in medicine, 553.

Zoological classification of the horse, 262.

Zygomatic arch, reason of the strong construction of the, 268.

Zygomaticus muscle, description of the, 310 . 





